\title{
111тh CONGREss
1stassion
}

To provide affordable, quality health care for all Americans and reduce the growth in health care spending, and for other purposes.

\section{IN THE HOUSE OF REPRESENTATIVES}

OCTOBER 29, 2009

Mr. Dingell (for himself, Mr. Rangel, Mr. Waxman, Mr. George Miller of California, Mr. Stark, Mr. Pallone, and Mr. Andrews) introduced the following bill; which was referred to the Committee on Energy and Commerce, and in addition to the Committees on Education and Labor, Ways and Means, Oversight and Government Reform, the Budget, Rules, Natural Resources, and the Judiciary, for a period to be subsequently determined by the Speaker, in each case for consideration of such provisions as fall within the jurisdiction of the committee concerned

\section{A BILL}

To provide affordable, quality health care for all Americans and reduce the growth in health care spending, and for other purposes.

1 Be it enacted by the Senate and House of Representa-

2 tives of the United States of America in Congress assembled,

3 SECTION 1. SHORT TITLE; TABLE OF DIVISIONS, TITLES,

4 AND SUBTITLES.

5 (a) Short Titue.-This Act may be cited as the 6 "Affordable Health Care for America Act". 
(b) Table of Divisions, Titles, and Sub-

2 TITLES.-This Act is divided into divisions, titles, and

3 subtitles as follows:

DIVISION A-AFFORDABLE HEALTH CARE CHOICES

TITLE I-IMMEDIATE REFORMS

TITLE II-PROTECTIONS AND STANDARDS FOR QUALIFIED HEALTH BENEFITS PLANS

Subtitle A-General Standards

Subtitle B-Standards Guaranteeing Access to Affordable Coverage

Subtitle C—Standards Guaranteeing Access to Essential Benefits

Subtitle D-Additional Consumer Protections

Subtitle E-Governance

Subtitle F-Relation to Other Requirements; Miscellaneous

TITLE III-HEALTH INSURANCE EXCHANGE AND RELATED PROVISIONS

Subtitle A-Health Insurance Exchange

Subtitle B-Public Health Insurance Option

Subtitle C-Individual Affordability Credits

TITLE IV—SHARED RESPONSIBILITY

Subtitle A-Individual Responsibility

Subtitle B-Employer Responsibility

TITLE V-AMENDMENTS TO INTERNAL REVENUE CODE OF 1986

Subtitle A—Shared Responsibility

Subtitle B-Credit for Small Business Employee Health Coverage Expenses

Subtitle C-Disclosures To Carry Out Health Insurance Exchange Subsidies

Subtitle D-Other Revenue Provisions

\section{DIVISION B-MEDICARE AND MEDICAID IMPROVEMENTS}

TITLE I-IMPROVING HEALTH CARE VALUE

Subtitle A-Provisions related to Medicare part A

Subtitle B-Provisions Related to Part B

Subtitle C-Provisions Related to Medicare Parts A and B

Subtitle D-Medicare Advantage Reforms

Subtitle E-Improvements to Medicare Part D

Subtitle F-Medicare Rural Access Protections

TITLE II-MEDICARE BENEFICIARY IMPROVEMENTS

Subtitle A-Improving and Simplifying Financial Assistance for Low Income Medicare Beneficiaries

Subtitle B-Reducing Health Disparities

Subtitle C-Miscellaneous Improvements

TITLE III-PROMOTING PRIMARY CARE, MENTAL HEALTH SERV-

ICES, AND COORDINATED CARE

TITLE IV-QUALITY

Subtitle A-Comparative Effectiveness Research

Subtitle B-Nursing Home Transparency

Subtitle C-Quality Measurements

Subtitle D-Physician Payments Sunshine Provision

Subtitle E-Public Reporting on Health Care-Associated Infections

TITLE V-MEDICARE GRADUATE MEDICAL EDUCATION

TITLE VI-PROGRAM INTEGRITY 
Subtitle A-Increased funding to fight waste, fraud, and abuse

Subtitle B-Enhanced penalties for fraud and abuse

Subtitle C-Enhanced Program and Provider Protections

Subtitle D-Access to Information Needed to Prevent Fraud, Waste, and Abuse TITLE VII-MEDICAID AND CHIP

Subtitle A-Medicaid and Health Reform

Subtitle B-Prevention

Subtitle C-Access

Subtitle D-Coverage

Subtitle E-Financing

Subtitle F-Waste, Fraud, and Abuse

Subtitle G-Puerto Rico and the Territories

Subtitle H-Miscellaneous

TITLE VIII-REVENUE-RELATED PROVISIONS

TITLE IX-MISCELLANEOUS PROVISIONS

DIVISION C-PUBLIC HEALTH AND WORKFORCE DEVELOPMENT

TITLE I-COMMUNITY HEALTH CENTERS

TITLE II-WORKFORCE

Subtitle A-Primary Care Workforce

Subtitle B-Nursing Workforce

Subtitle C-Public Health Workforce

Subtitle D-Adapting Workforce to Evolving Health System Needs

TITLE III-PREVENTION AND WELLNESS

TITLE IV—QUALITY AND SURVEILLAANCE

TITLE V-OTHER PROVISIONS

Subtitle A-Drug Discount for Rural and Other Hospitals; 340B Program Integrity

Subtitle B-Programs

Subtitle C-Food and Drug Administration

Subtitle D-Community Living Assistance Services and Supports

Subtitle E-Miscellaneous

DIVISION D-INDIAN HEALTH CARE IMPROVEMENT

TITLE I-AMENDMENTS TO INDIAN LAWS

TITLE II-IMPROVEMENT OF INDIAN HEALTH CARE PROVIDED UNDER THE SOCIAL SECURITY ACT

1 DIVISION A-AFFORDABLE HEALTH CARE CHOICES

3 SEC. 100. PURPOSE; TABLE OF CONTENTS OF DIVISION; GENERAL DEFINITIONS. 
1 Americans and reduce the growth in health care 2 spending.

(2) Building on Current system.-This di4 vision achieves this purpose by building on what 5 works in today's health care system, while repairing 6 the aspects that are broken.

(3) Insurance Reforms.-This division-

(A) enacts strong insurance market reforms; workers, employers, and the Government;

17 so that all Americans have coverage of essential 18 health benefits.

(4) Health delivery Reform.-This division institutes health delivery system reforms both to increase quality and to reduce growth in health spend22 ing so that health care becomes more affordable for 23 businesses, families, and Government.

24 (b) Table of Contents of Division.-The table 25 of contents of this division is as follows:

Sec. 100. Purpose; table of contents of division; general definitions. 


\title{
TITLE I-IMMEDIATE REFORMS
}

Sec. 101. National high-risk pool program.

Sec. 102. Ensuring value and lower premiums.

Sec. 103. Ending health insurance rescission abuse.

Sec. 104. Sunshine on price gouging by health insurance issuers.

Sec. 105. Requiring the option of extension of dependent coverage for uninsured young adults.

Sec. 106. Limitations on preexisting condition exclusions in group health plans in advance of applicability of new prohibition of preexisting condition exclusions.

Sec. 107. Prohibiting acts of domestic violence from being treated as preexisting conditions.

Sec. 108. Ending health insurance denials and delays of necessary treatment for children with deformities.

Sec. 109. Elimination of lifetime limits.

Sec. 110. Prohibition against postretirement reductions of retiree health benefits by group health plans.

Sec. 111. Reinsurance program for retirees.

Sec. 112. Wellness program grants.

Sec. 113. Extension of COBRA continuation coverage.

Sec. 114. State Health Access Program grants.

Sec. 115. Administrative simplification.

\section{TITLE II-PROTECTIONS AND STANDARDS FOR QUALIFIED HEALTH BENEFITS PLANS}

\author{
Subtitle A-General Standards
}

Sec. 201. Requirements reforming health insurance marketplace.

Sec. 202. Protecting the choice to keep current coverage.

Subtitle B-Standards Guaranteeing Access to Affordable Coverage

Sec. 211. Prohibiting preexisting condition exclusions.

Sec. 212. Guaranteed issue and renewal for insured plans and prohibiting rescissions.

Sec. 213. Insurance rating rules.

Sec. 214. Nondiscrimination in benefits; parity in mental health and substance abuse disorder benefits.

Sec. 215. Ensuring adequacy of provider networks.

Sec. 216. Requiring the option of extension of dependent coverage for uninsured young adults.

Sec. 217. Consistency of costs and coverage under qualified health benefits plans during plan year.

Subtitle C—Standards Guaranteeing Access to Essential Benefits

Sec. 221. Coverage of essential benefits package.

Sec. 222. Essential benefits package defined.

Sec. 223. Health Benefits Advisory Committee.

Sec. 224. Process for adoption of recommendations; adoption of benefit standards.

Subtitle D-Additional Consumer Protections

Sec. 231. Requiring fair marketing practices by health insurers. 
Sec. 232. Requiring fair grievance and appeals mechanisms.

Sec. 233. Requiring information transparency and plan disclosure.

Sec. 234. Application to qualified health benefits plans not offered through the Health Insurance Exchange.

Sec. 235. Timely payment of claims.

Sec. 236. Standardized rules for coordination and subrogation of benefits.

Sec. 237. Application of administrative simplification.

Sec. 238. State prohibitions on discrimination against health care providers.

Sec. 239. Protection of physician prescriber information.

Sec. 240. Dissemination of advance care planning information.

Subtitle E-Governance

Sec. 241. Health Choices Administration; Health Choices Commissioner.

Sec. 242. Duties and authority of Commissioner.

Sec. 243. Consultation and coordination.

Sec. 244. Health Insurance Ombudsman.

Subtitle F-Relation to Other Requirements; Miscellaneous

Sec. 251. Relation to other requirements.

Sec. 252. Prohibiting discrimination in health care.

Sec. 253. Whistleblower protection.

Sec. 254. Construction regarding collective bargaining.

Sec. 255. Severability.

Sec. 256. Treatment of Hawaii Prepaid Health Care Act.

Sec. 257. Actions by State attorneys general.

Sec. 258. Application of State and Federal laws regarding abortion.

Sec. 259. Nondiscrimination on abortion and respect for rights of conscience.

Sec. 260. Authority of Federal Trade Commission.

Sec. 261. Construction regarding standard of care.

Sec. 262. Restoring application of antitrust laws to health sector insurers.

Sec. 263. Study and report on methods to increase EHR use by small health care providers.

\section{TITLE III-HEALTH INSURANCE EXCHANGE AND RELATED PROVISIONS}

Subtitle A-Health Insurance Exchange

Sec. 301. Establishment of Health Insurance Exchange; outline of duties; definitions.

Sec. 302. Exchange-eligible individuals and employers.

Sec. 303. Benefits package levels.

Sec. 304. Contracts for the offering of Exchange-participating health benefits plans.

Sec. 305. Outreach and enrollment of Exchange-eligible individuals and employers in Exchange-participating health benefits plan.

Sec. 306. Other functions.

Sec. 307. Health Insurance Exchange Trust Fund.

Sec. 308. Optional operation of State-based health insurance exchanges.

Sec. 309. Interstate health insurance compacts.

Sec. 310. Health insurance cooperatives.

Sec. 311. Retention of DOD and VA authority.

Subtitle B-Public Health Insurance Option 
Sec. 321. Establishment and administration of a public health insurance option as an Exchange-qualified health benefits plan.

Sec. 322. Premiums and financing.

Sec. 323. Payment rates for items and services.

Sec. 324. Modernized payment initiatives and delivery system reform.

Sec. 325. Provider participation.

Sec. 326. Application of fraud and abuse provisions.

Sec. 327. Application of HIPAA insurance requirements.

Sec. 328. Application of health information privacy, security, and electronic transaction requirements.

Sec. 329. Enrollment in public health insurance option is voluntary.

Sec. 330. Enrollment in public health insurance option by Members of Congress.

Sec. 331. Reimbursement of Secretary of Veterans Affairs.

Subtitle C-Individual Affordability Credits

Sec. 341. Availability through Health Insurance Exchange.

Sec. 342. Affordable credit eligible individual.

Sec. 343. Affordability premium credit.

Sec. 344. Affordability cost-sharing credit.

Sec. 345. Income determinations.

Sec. 346. Special rules for application to territories.

Sec. 347. No Federal payment for undocumented aliens.

TITLE IV-SHARED RESPONSIBILITY

Subtitle A-Individual Responsibility

Sec. 401. Individual responsibility.

Subtitle B-Employer Responsibility

Part 1-Health Coverage Participation Requirements

Sec. 411. Health coverage participation requirements.

Sec. 412. Employer responsibility to contribute toward employee and dependent coverage.

Sec. 413. Employer contributions in lieu of coverage.

Sec. 414. Authority related to improper steering.

Sec. 415. Impact study on employer responsibility requirements.

Sec. 416. Study on employer hardship exemption.

\section{Part 2-Satisfaction of Health Coverage Participation REQUIREMENTS}

Sec. 421. Satisfaction of health coverage participation requirements under the Employee Retirement Income Security Act of 1974.

Sec. 422. Satisfaction of health coverage participation requirements under the Internal Revenue Code of 1986.

Sec. 423. Satisfaction of health coverage participation requirements under the Public Health Service Act.

Sec. 424. Additional rules relating to health coverage participation requirements.

TITLE V-AMENDMENTS TO INTERNAL REVENUE CODE OF 1986

Subtitle A-Provisions Relating to Health Care Reform

•HR 3962 IH 
Part 1-Shared Responsibility

SUBPART A-INDIVIDUAL RESPONSIBILITY

Sec. 501. Tax on individuals without acceptable health care coverage.

SUBPART B-EMPLOYER RESPONSIBILITY

Sec. 511. Election to satisfy health coverage participation requirements.

Sec. 512. Health care contributions of nonelecting employers.

Part 2-Credit for Small Business Employee Health Coverage EXPENSES

Sec. 521. Credit for small business employee health coverage expenses.

Part 3-Limitations on Health Care Related Expenditures

Sec. 531. Distributions for medicine qualified only if for prescribed drug or insulin.

Sec. 532. Limitation on health flexible spending arrangements under cafeteria plans.

Sec. 533. Increase in penalty for nonqualified distributions from health savings accounts.

Sec. 534. Denial of deduction for federal subsidies for prescription drug plans which have been excluded from gross income.

Part 4-Other Provisions to Carry Out Health Insurance Reform

Sec. 541. Disclosures to carry out health insurance exchange subsidies.

Sec. 542. Offering of exchange-participating health benefits plans through cafeteria plans.

Sec. 543. Exclusion from gross income of payments made under reinsurance program for retirees.

Sec. 544. CLASS program treated in same manner as long-term care insurance.

Sec. 545. Exclusion from gross income for medical care provided for Indians.

Subtitle B-Other Revenue Provisions

Part 1-General Provisions

Sec. 551. Surcharge on high income individuals.

Sec. 552. Excise tax on medical devices.

Sec. 553. Expansion of information reporting requirements.

Sec. 554. Delay in application of worldwide allocation of interest.

Part 2-Prevention of Tax Avoidance

Sec. 561. Limitation on treaty benefits for certain deductible payments.

Sec. 562. Codification of economic substance doctrine; penalties.

Sec. 563. Certain large or publicly traded persons made subject to a more likely than not standard for avoiding penalties on underpayments.

Part 3-Parity in Health Benefits

Sec. 571. Certain health related benefits applicable to spouses and dependents extended to eligible beneficiaries. 
1 (c) General Definitions.-Except as otherwise 2 provided, in this division:

(1) Acceptable coverage.-The term "ac4 ceptable coverage" has the meaning given such term $5 \quad$ in section $302(\mathrm{~d})(2)$.

6 (2) BASIC PLAN.-The term "basic plan" has 7 the meaning given such term in section 303(c).

8 (3) Commissioner.-The term "Commis9 sioner" means the Health Choices Commissioner es10 tablished under section 241.

(4) Cost-sharing.-The term "eost-sharing" 12 includes deductibles, coinsurance, copayments, and 13 similar charges, but does not include premiums, bal14 ance billing amounts for non-network providers, or 15 spending for non-covered services.

16 (5) Dependent.-The term "dependent" has 17 the meaning given such term by the Commissioner 18 and includes a spouse.

19 (6) Employment-based health plan.-The 20 term "employment-based health plan"-

(A) means a group health plan (as defined in section 733(a)(1) of the Employee Retirement Income Security Act of 1974);

25 lowing: 
(i) FEDERAL, STATE, AND TRIBAL GOVERNMENTAL PLANS.-A governmental plan (as defined in section 3(32) of the Employee Retirement Income Security Act of 1974), including a health benefits plan offered under chapter 89 of title 5, United States Code.

(ii) Church Plans.-A church plan (as defined in section 3(33) of the Employee Retirement Income Security Act of 1974); and

(C) excludes coverage described in section $302(\mathrm{~d})(2)(\mathrm{E})$ (relating to TRICARE).

(7) EnHanced PLAN.—The term "enhanced plan" has the meaning given such term in section $303(\mathrm{c})$.

(8) Essential benefits Package.-The term "essential benefits package" is defined in section $222(a)$.

(9) Exchange-Participating health BeneFITS PLAN.-The term "Exchange-participating health benefits plan" means a qualified health benefits plan that is offered through the Health Insurance Exchange and may be purchased directly from 
1 the entity offering the plan or through enrollment

2 agents and brokers.

(10) Family.-The term "family" means an

4 individual and includes the individual's dependents.

5 (11) Federal POVERTy LeVEL; FPL.-The

6 terms "Federal poverty level" and "FPL" have the

7 meaning given the term "poverty line" in section

$8673(2)$ of the Community Services Block Grant Act

9 (42 U.S.C. $9902(2)$ ), including any revision required

10 by such section.

11 (12) Health Benefits Plan.-The term

12 "health benefits plan" means health insurance cov-

13 erage and an employment-based health plan and in-

14 cludes the public health insurance option.

15 (13) Health insurance coverage.-The

16 term "health insurance coverage" has the meaning

17 given such term in section 2791 of the Public

18 Health Service Act, but does not include coverage in

19 relation to its provision of excepted benefits-

20 (A) described in paragraph (1) of sub-

21 section (c) of such section; or

22 (B) described in paragraph (2), (3), or (4)

23 of such subsection if the benefits are provided

24 under a separate policy, certificate, or contract

25 of insurance. 
(14) Health insurance issuer.-The term "health insurance issuer" has the meaning given 3 such term in section 2791(b)(2) of the Public Health $4 \quad$ Service Act.

6 term "Health Insurance Exchange" means the 7 Health Insurance Exchange established under sec8 tion 301.

(16) Indian.-The term "Indian" has the 10 meaning given such term in section 4 of the Indian 11 Health Care Improvement Act (24 U.S.C. 1603).

13 term "Indian health care provider" means a health 14 care program operated by the Indian Health Service, 15 an Indian tribe, tribal organization, or urban Indian 16 organization as such terms are defined in section 4 17 of the Indian Health Care Improvement Act (25 18 U.S.C. 1603).

19 (18) Medicaid.—The term "Medicaid" means 20 a State plan under title XIX of the Social Security 21 Act (whether or not the plan is operating under a 22 waiver under section 1115 of such Act).

23 (19) Medicaid Eligible individual.-The 24 term "Medicaid eligible individual" means an indi- 
1 vidual who is eligible for medical assistance under

$2 \quad$ Medicaid.

(20) Medicare.-The term "Medicare" means

4 the health insurance programs under title XVIII of

5 the Social Security Act.

6 (21) Plan sPonsor.-The term "plan spon7 sor" has the meaning given such term in section $83(16)(B)$ of the Employee Retirement Income Secu$9 \quad$ rity Act of 1974 .

10 (22) Plan YEAR.-The term "plan year" 11 meansplan; or

(B) with respect to a health benefits plan other than an employment-based health plan, a 12-month period as specified by the Commissioner.

20 The terms "premium plan" and "premium-plus 21 plan" have the meanings given such terms in section $22303(\mathrm{c})$.

(24) QHBP OFFERING ENTITY.-The terms 24 "QHBP offering entity" means, with respect to a 25 health benefits plan that is- 
(A) a group health plan (as defined, subject to subsection (d), in section 733(a)(1) of the Employee Retirement Income Security Act of 1974), the plan sponsor in relation to such group health plan, except that, in the case of a plan maintained jointly by 1 or more employers and 1 or more employee organizations and with respect to which an employer is the primary source of financing, such term means such employer; insurance issuer offering the coverage;

(C) the public health insurance option, the Secretary of Health and Human Services;

(D) a non-Federal governmental plan (as defined in section 2791(d) of the Public Health Service Act), the State or political subdivision of a State (or agency or instrumentality of such State or subdivision) which establishes or maintains such plan; or

(E) a Federal governmental plan (as defined in section 2791(d) of the Public Health Service Act), the appropriate Federal official. 
(25) Qualified health Benefits Plan.-

2 The term "qualified health benefits plan" means a 3 health benefits plan that-

(27) Service AREa; PRemium Rating AREa.The terms "service area" and "premium rating area" mean with respect to health insurance coverage-

(A) offered other than through the Health Insurance Exchange, such an area as established by the QHBP offering entity of such coverage in accordance with applicable State law; and

(B) offered through the Health Insurance Exchange, such an area as established by such entity in accordance with applicable State law 
and applicable rules of the Commissioner for Exchange-participating health benefits plans.

(28) State.-The term "State" means the 50

4 States and the District of Columbia and includes-

(A) for purposes of title I, Puerto Rico, the Virgin Islands, Guam, American Samoa, and the Northern Mariana Islands; and

(B) for purposes of titles II and III, as elected under and subject to section 346, Puerto Rico, the Virgin Islands, Guam, American Samoa, and the Northern Mariana Islands.

(29) State Medicaid AGEnCy.-The term

13 "State Medicaid agency" means, with respect to a 14 Medicaid plan, the single State agency responsible 15 for administering such plan under title XIX of the 16 Social Security Act. (30) Y1, Y2, ETC.—The terms "Y1", "Y2", 18 "Y3", "Y4", "Y5", and similar subsequently num19 bered terms, mean 2013 and subsequent years, re20 spectively.

\section{TITLE I-IMMEDIATE REFORMS}

22 SEC. 101. NATIONAL HIGH-RISK POOL PROGRAM.

23 (a) In GeneraL.-The Secretary of Health and 24 Human Services (in this section referred to as the "Sec25 retary") shall establish a temporary national high-risk 
1 pool program (in this section referred to as the "pro2 gram") to provide health benefits to eligible individuals 3 during the period beginning on January 1, 2010, and, sub4 ject to subsection $(\mathrm{h})(3)(\mathrm{B})$, ending on the date on which 5 the Health Insurance Exchange is established.

6 (b) Administration.-The Secretary may carry out 7 this section directly or, pursuant to agreements, grants, 8 or contracts with States, through State high-risk pool pro9 grams provided that the requirements of this section are 10 met.

11 (c) Eligibility.-For purposes of this section, the 12 term "eligible individual" means an individual-

13

14

15

16

17

18

19

20

21

22

23

24
(1) who-

(A) is not eligible for-

(i) benefits under title XVIII, XIX, or XXI of the Social Security Act; or

(ii) coverage under an employmentbased health plan (not including coverage under a COBRA continuation provision, as defined in section $107(d)(1))$; and (B) who-

(i) is an eligible individual under section 2741(b) of the Public Health Service Act; or 
(ii) is medically eligible for the program by virtue of being an individual described in subsection (d) at any time during the 6 -month period ending on the date the individual applies for high-risk pool coverage under this section;

(2) who is the spouse or dependent of an indi8 vidual who is described in paragraph (1); or

(3) who has not had health insurance coverage

10 or coverage under an employment-based health plan 11 for at least the 6-month period immediately pre12 ceding the date of the individual's application for 13 high-risk pool coverage under this section.

14 For purposes of paragraph (1)(A)(ii), a person who is in 15 a waiting period as defined in section 2701(b)(4) of the 16 Public Health Service Act shall not be considered to be 17 eligible for coverage under an employment-based health 18 plan.

19 (d) Medically Eligible Requirements.-For 20 purposes of subsection (c)(1)(B)(ii), an individual de21 scribed in this subsection is an individual-

22 (1) who, during the 6-month period ending on 23 the date the individual applies for high-risk pool cov24 erage under this section applied for individual health 25 insurance coverage and- 
11 In making a determination under paragraph (1) of wheth-

12 er an individual was offered individual coverage at a pre-

13 mium rate above the premium rate for high risk pool cov-

14 erage, the Secretary shall make adjustments to offset dif-

15 ferences in premium rating that are attributable solely to

16 differences in age rating.

17 (e) EnRoliment.-To enroll in coverage in the pro18 gram, an individual shall-

(1) submit to the Secretary an application for 20 participation in the program, at such time, in such 21 manner, and containing such information as the Sec22 retary shall require;

23 (2) attest that the individual is an eligible indi24 vidual and is a resident of one of the 50 States or 25 the District of Columbia; and 
1 (3) if the individual had other prior health in2 surance coverage or coverage under an employment3 based health plan during the previous 6 months, 4 provide information as to the nature and source of 5 such coverage and reasons for its discontinuance.

6 (f) Protection Against Dumping Risks by In7 SURERS.-

(1) In GENERAL.—The Secretary shall establish 9 criteria for determining whether health insurance 10 issuers and employment-based health plans have dis11 couraged an individual from remaining enrolled in 12 prior coverage based on that individual's health sta13 tus.

(2) SAnCtions.-An issuer or employment15 based health plan shall be responsible for reimburs16 ing the program for the medical expenses incurred 17 by the program for an individual who, based on cri18 teria established by the Secretary, the Secretary 19 finds was encouraged by the issuer to disenroll from 20 health benefits coverage prior to enrolling in the pro21 gram. The criteria shall include at least the fol22 lowing circumstances:

23 (A) In the case of prior coverage obtained 24 through an employer, the provision by the em25 ployer, group health plan, or the issuer of 
money or other financial consideration for disenrolling from the coverage.

(B) In the case of prior coverage obtained directly from an issuer or under an employment-based health plan-

(3) Construction.-Nothing in this sub24 section shall be construed as constituting exclusive 25 remedies for violations of criteria established under 
1 paragraph (1) or as preventing States from applying

2 or enforcing such paragraph or other provisions

3 under law with respect to health insurance issuers.

4 (g) Covered Benefits, Cost-sharing, Premiums, 5 and Consumer Protections.-

6 (1) Premium.-The monthly premium charged 7 to eligible individuals for coverage under the pro8 gramof the highest such premium to the lowest such premium does not exceed the ratio of 2 to 1 ;

(A) may vary by age so long as the ratio (B) shall be set at a level that does not exceed 125 percent of the prevailing standard rate for comparable coverage in the individual market; and

18 Health insurance issuers shall provide such informa19 tion as the Secretary may require to determine pre20 vailing standard rates under this paragraph. The 21 Secretary shall establish standard rates in consulta22 tion with the National Association of Insurance 23 Commissioners.

(2) Covered Benefits.—Covered benefits 25 under the program shall be determined by the Sec- 
1 retary and shall be consistent with the basic cat-

2 egories in the essential benefits package described in 3 section 222. Under such benefits package-

(3) No PREEXISTING CONDITION EXCLUSION PERIODS.-No preexisting condition exclusion period shall be imposed on coverage under the program.

(4) Appeals.-The Secretary shall establish an appeals process for individuals to appeal a determination of the Secretary-

(A) with respect to claims submitted under this section; and

(B) with respect to eligibility determinations made by the Secretary under this section. (5) State contribution, Maintenance of EFFORT.-As a condition of providing health bene- 
1 fits under this section to eligible individual residing

2 in a State-

(A) in the case of a State in which a qualified high-risk pool (as defined under section 2744(c)(2) of the Public Health Service Act) was in effect as of July 1, 2009, the Secretary shall require the State make a maintenance of effort payment each year that the high-risk pool is in effect equal to an amount not less than the amount of all sources of funding for high-risk pool coverage made by that State in the year ending July 1, 2009; and

(B) in the case of a State which required health insurance issuers to contribute to a State high-risk pool or similar arrangement for the assessment against such issuers for pool losses, the State shall maintain such a contribution arrangement among such issuers.

(6) Limiting PRogram expenditures.-The Secretary shall, with respect to the program-

(A) establish procedures to protect against fraud, waste, and abuse under the program; and

(B) provide for other program integrity methods. 
(7) Treatment as Creditable Coverage.-

2 Coverage under the program shall be treated, for 3 purposes of applying the definition of "creditable 4 coverage" under the provisions of title XXVII of the 5 Public Health Service Act, part 6 of subtitle B of 6 title I of Employee Retirement Income Security Act 7 of 1974 , and chapter 100 of the Internal Revenue 8 Code of 1986 (and any other provision of law that 9 references such provisions) in the same manner as 10 if it were coverage under a State health benefits risk 11 pool described in section 2701(c)(1)(G) of the Public 12 Health Service Act.

13 (h) Funding; Termination of Authority.-

14 (1) IN GENERAL.-There is appropriated to the 15 Secretary, out of any moneys in the Treasury not 16 otherwise appropriated, $\$ 5,000,000,000$ to pay 17 claims against (and administrative costs of) the 18 high-risk pool under this section in excess of the pre19 miums collected with respect to eligible individuals 20 enrolled in the high-risk pool. Such funds shall be 21 available without fiscal year limitation.

22 (2) Insufficient Funds. - If the Secretary es23 timates for any fiscal year that the aggregate 24 amounts available for payment of expenses of the 25 high-risk pool will be less than the amount of the ex- 
1 penses, the Secretary shall make such adjustments

2 as are necessary to eliminate such deficit, including 3 reducing benefits, increasing premiums, or estab$4 \quad$ lishing waiting lists.

22 SEC. 102. ENSURING VALUE AND LOWER PREMIUMS.

24 XXVII of the Public Health Service Act is amended by 25 inserting after section 2713 the following new section:

(3) Termination of authority.-

(A) In GENERAL.-Except as provided in subparagraph (B), coverage of eligible individuals under a high-risk pool shall terminate as of the date on which the Health Insurance Exchange is established.

(B) Transition to exchange.-The Secretary shall develop procedures to provide for the transition of eligible individuals who are enrolled in health insurance coverage offered through a high-risk pool established under this section to be enrolled in acceptable coverage. Such procedures shall ensure that there is no lapse in coverage with respect to the individual and may extend coverage offered through such a high-risk pool beyond 2012 if the Secretary determines necessary to avoid such a lapse.

(a) Group Health Insurance Coverage.-Title 
1 “SEC. 2714. ENSURING VALUE AND LOWER PREMIUMS.

2 "(a) IN GENERAL.-Each health insurance issuer

3 that offers health insurance coverage in the small or large

4 group market shall provide that for any plan year in which

5 the coverage has a medical loss ratio below a level specified

6 by the Secretary (but not less than 85 percent), the issuer

7 shall provide in a manner specified by the Secretary for

8 rebates to enrollees of the amount by which the issuer's

9 medical loss ratio is less than the level so specified.

10 “(b) Implementation.-The Secretary shall estab-

11 lish a uniform definition of medical loss ratio and method-

12 ology for determining how to calculate it based on the av-

13 erage medical loss ratio in a health insurance issuer's book

14 of business for the small and large group market. Such

15 methodology shall be designed to take into account the

16 special circumstances of smaller plans, different types of

17 plans, and newer plans. In determining the medical loss

18 ratio, the Secretary shall exclude State taxes and licensing

19 or regulatory fees. Such methodology shall be designed

20 and exceptions shall be established to ensure adequate

21 participation by health insurance issuers, competition in

22 the health insurance market, and value for consumers so

23 that their premiums are used for services.

24 “(c) SunseT.-Subsections (a) and (b) shall not 25 apply to health insurance coverage on and after the first 
1 date that health insurance coverage is offered through the

2 Health Insurance Exchange.".

3 (b) Individual Health Insurance Coverage.-

4 Such title is further amended by inserting after section

52753 the following new section:

6 "SEC. 2754. ENSURING VALUE AND LOWER PREMIUMS.

7 "The provisions of section 2714 shall apply to health

8 insurance coverage offered in the individual market in the

9 same manner as such provisions apply to health insurance

10 coverage offered in the small or large group market except

11 to the extent the Secretary determines that the application

12 of such section may destabilize the existing individual

13 market.".

14 (c) Immedate Implementation.-The amend-

15 ments made by this section shall apply in the group and

16 individual market for plan years beginning on or after

17 January 1, 2010, or as soon as practicable after such date.

18 SEC. 103. ENDING HEALTH INSURANCE RESCISSION ABUSE.

19 (a) Clarification Regarding application of

20 Guaranteed Renewability of Individual and

21 Group Health Insurance Coverage.-Sections 2712

22 and 2742 of the Public Health Service Act (42 U.S.C.

$23300 \mathrm{gg}-12,300 \mathrm{gg}-42)$ are each amended-

24 (1) in its heading, by inserting "AND CON-

25 TINUATION IN FORCE, INCLUDING PROHIBI- 
1 TION OF RESCISSION," after "GUARANTEED RE-

2 NEWABILITY"; and

(2) in subsection (a), by inserting ", including 4 without rescission," after "continue in force".

(1) Group health insurance Market.-Sec-

8 tion 2712 of such Act (42 U.S.C. 300gg-12) is

9 amended by adding at the end the following:

10 “(f) Rescission.-A health insurance issuer may re-

11 scind group health insurance coverage only upon clear and

12 convincing evidence of fraud described in subsection

13 (b)(2), under procedures that provide for independent, ex14 ternal third-party review.".

(2) Individual health MaRKET.-Section

162742 of such Act (42 U.S.C. $300 \mathrm{gg}-42$ ) is amended

17 by adding at the end the following:

18 "(f) Rescission.-A health insurance issuer may re19 scind individual health insurance coverage only upon clear 20 and convincing evidence of fraud described in subsection 21 (b) (2), under procedures that provide for independent, ex22 ternal third-party review.".

23 (3) Guidance.-The Secretary of Health and 24 Human Services, no later than 90 days after the 25 date of the enactment of this Act, shall issue guid- 
1 ance implementing the amendments made by para-

2 graphs (1) and (2), including procedures for inde-

3 pendent, external third-party review.

4 (c) OPPORTUNITY FOR INDEPENDENT, EXTERNAL

5 Third-Party Review in Certain Cases.-

6 (1) INDIVIDUAL MARKET.-Subpart 1 of part B

7 of title XXVII of such Act (42 U.S.C. 300gg-41 et

8 seq.) is amended by adding at the end the following:

9 "SEC. 2746. OPPORTUNITY FOR INDEPENDENT, EXTERNAL THIRD-PARTY REVIEW IN CASES OF RESCISSION.

12 “(a) Notice and Review Right.-If a health in-

13 surance issuer determines to rescind health insurance cov-

14 erage for an individual in the individual market, before

15 such rescission may take effect the issuer shall provide the

16 individual with notice of such proposed rescission and an

17 opportunity for a review of such determination by an inde-

18 pendent, external third-party under procedures specified

19 by the Secretary under section 2742 (f).

20 "(b) Independent Determination.-If the indi21 vidual requests such review by an independent, external 22 third-party of a rescission of health insurance coverage, 23 the coverage shall remain in effect until such third party 24 determines that the coverage may be rescinded under the 25 guidance issued by the Secretary under section 2742 (f).". 
(2) ApPlication to group health insurANCE.-Such title is further amended by adding after section 2702 the following new section:

4 "SEC. 2703. OPPORTUNITY FOR INDEPENDENT, EXTERNAL THIRD-PARTY REVIEW IN CASES OF RESCISSION.

7 "The provisions of section 2746 shall apply to group 8 health insurance coverage in the same manner as such 9 provisions apply to individual health insurance coverage, 10 except that any reference to section $2742(\mathrm{f})$ is deemed a 11 reference to section 2712 (f).".

12 (d) EFFECTIVE Date.-The amendments made by 13 this section shall take effect on the date of the enactment 14 of this Act and shall apply to rescissions occurring on and 15 after July 1, 2010, with respect to health insurance cov16 erage issued before, on, or after such date.

17 SEC. 104. SUNSHINE ON PRICE GOUGING BY HEALTH INSURANCE ISSUERS.

19 The Secretary of Health and Human Services, in con20 junction with States, shall establish a process for the an21 nual review of increases in premiums for health insurance 22 coverage. Such process shall require health insurance 23 issuers to submit a justification for any premium increases 24 prior to implementation of the increase. 
32

1 SEC. 105. REQUIRING THE OPTION OF EXTENSION OF DE“(a) In GENERAL. - A group health plan and a health

12 insurance issuer offering health insurance coverage in con-

13 nection with a group health plan that provides coverage

14 for dependent children shall make available such coverage, 15 at the option of the participant involved, for one or more 16 qualified children (as defined in subsection (b)) of the par17 ticipant.

"(b) Qualified Child Defined.-In this section,

19 the term 'qualified child' means, with respect to a partici20 pant in a group health plan or group health insurance cov21 erage, an individual who (but for age) would be treated 22 as a dependent child of the participant under such plan 23 or coverage and who-

"(1) is under 27 years of age; and

$"(2)$ is not enrolled as a participant, bene26 ficiary, or enrollee (other than under this section, 
33

1 section 2746 , or section 704 of the Employee Retire-

2 ment Income Security Act of 1974) under any

3 health insurance coverage or group health plan.

4 “(c) Premiums.-Nothing in this section shall be 5 construed as preventing a group health plan or health in6 surance issuer with respect to group health insurance cov7 erage from increasing the premiums otherwise required for 8 coverage provided under this section consistent with 9 standards established by the Secretary based upon family 10 size.".

(2) Employee Retirement income security 12 ACT OF $1974 .-$

(A) In GENERAL.-Part 7 of subtitle B of title I of the Employee Retirement Income Security Act of 1974 is amended by inserting 16 after section 703 the following new section:

17 “SEC. 704. REQUIRING THE OPTION OF EXTENSION OF DEPENDENT COVERAGE FOR UNINSURED YOUNG ADULTS.

20 “(a) In GENERAL.—A group health plan and a health 21 insurance issuer offering health insurance coverage in con22 nection with a group health plan that provides coverage 23 for dependent children shall make available such coverage, 24 at the option of the participant involved, for one or more 
1 qualified children (as defined in subsection (b)) of the par-

2 ticipant.

3 “(b) Qualified Child Defined.-In this section,

4 the term 'qualified child' means, with respect to a partici-

5 pant in a group health plan or group health insurance cov-

6 erage, an individual who (but for age) would be treated

7 as a dependent child of the participant under such plan

8 or coverage and who-

9

"(1) is under 27 years of age; and

10

"(2) is not enrolled as a participant, bene-

11 ficiary, or enrollee (other than under this section)

12 under any health insurance coverage or group health

13 plan.

14 “(c) Premiums.-Nothing in this section shall be

15 construed as preventing a group health plan or health in-

16 surance issuer with respect to group health insurance cov-

17 erage from increasing the premiums otherwise required for

18 coverage provided under this section consistent with

19 standards established by the Secretary based upon family

20 size.".

(B) Clerical amendment.-The table of contents of such Act is amended by inserting after the item relating to section 703 the following new item:

"Sec. 704. Requiring the option of extension of dependent coverage for uninsured young adults.". 
(3) IRC.-

(A) In gEneraL.- Subchapter A of chapter 100 of the Internal Revenue Code of 1986 is amended by adding at the end the following new section:

6 "SEC. 9804. REQUIRING THE OPTION OF EXTENSION OF DEPENDENT COVERAGE FOR UNINSURED YOUNG ADULTS.

“(a) In GeneraL.-A group health plan that pro-

10 vides coverage for dependent children shall make available

11 such coverage, at the option of the participant involved,

12 for one or more qualified children (as defined in subsection

13 (b)) of the participant. “(b) Qualified Child Defined.-In this section,

15 the term 'qualified child' means, with respect to a partici16 pant in a group health plan, an individual who (but for 17 age) would be treated as a dependent child of the partici18 pant under such plan and who"(2) is not enrolled as a participant, bene21 ficiary, or enrollee (other than under this section, 22 section 704 of the Employee Retirement Income Se23 curity Act of 1974 , or section 2704 or 2746 of the 24 Public Health Service Act) under any health insur25 ance coverage or group health plan. 
1 "(c) Premiums.-Nothing in this section shall be

2 construed as preventing a group health plan from increas-

3 ing the premiums otherwise required for coverage provided

4 under this section consistent with standards established

5 by the Secretary based upon family size.".

6

7

8

9

"Sec. 9804. Requiring the option of extension of dependent coverage for uninsured young adults.".

10

11 Title XXVII of the Public Health Service Act is amended

12 by inserting after section 2745 the following new section:

13 “SEC. 2746. REQUIRING THE OPTION OF EXTENSION OF DE-

17 insurance coverage offered by a health insurance issuer

18 in the individual market in the same manner as they apply

19 to health insurance coverage offered by a health insurance

20 issuer in connection with a group health plan in the small

21 or large group market.".

22 (c) EFFECTive Dates.-

(1) Group health Plans.-The amendments 
1 plans for plan years beginning on or after January

$2 \quad 1,2010$.

15 Income SeCurity ACT OF 1974.-

16 SIONS. "30-day period".

(2) Individual health insurance COVERAGE.- Section 2746 of the Public Health Service Act, as inserted by subsection (b), shall apply with respect to health insurance coverage offered, sold, issued, renewed, in effect, or operated in the individual market on or after January 1, 2010.

SEC. 106. LIMITATIONS ON PREEXISTING CONDITION EXCLUSIONS IN GROUP HEALTH PLANS IN ADVANCE OF APPLICABILITY OF NEW PROHIBITION OF PREEXISTING CONDITION EXCLU-

(a) Amendients to the Employee Retirement

(1) Reduction In LOOK-BACK PERIOD.-Section 701(a)(1) of the Employee Retirement Income Security Act of 1974 (29 U.S.C. 1181(a)(1)) is amended by striking " 6 -month period" and inserting

(2) Reduction in PERMitTed PREexisting CONDITION LIMITATION PERIOD.-Section 701(a)(2) of such Act (29 U.S.C. 1181(a)(2)) is amended by striking "12 months" and inserting "3 months", 
1 and by striking "18 months" and inserting "9

2 months".

3 (3) Sunset of INTERIM Limitation.- Section

4701 of such Act (29 U.S.C. 1181) is amended by

5 adding at the end the following new subsection:

6 “(h) Termination.-This section shall cease to

7 apply to any group health plan as of the date that such

8 plan becomes subject to the requirements of section 211

9 of the (relating to prohibiting preexisting condition exclu10 sions).".

11 (b) Amendments to the Internal Revenue 12 CODE OF 1986.-

13 (1) REDUCTION IN LOOK-BACK PERIOD.-Sec14 tion 9801(a)(1) of the Internal Revenue Code of 151986 is amended by striking "6-month period" and 16 inserting "30-day period".

17 (2) REDUCTION IN PERMITTED PREEXISTING 18 CONDITION LIMITATION PERIOD.-Section $199801(\mathrm{a})(2)$ of such Code is amended by striking "12 20 months" and inserting "3 months", and by striking 21 "18 months" and inserting "9 months".

22 (3) Sunset OF InTERIM Limitation.-Section 239801 of such Code is amended by adding at the end 24 the following new subsection: 
1 “(g) Termination.-This section shall cease to 2 apply to any group health plan as of the date that such 3 plan becomes subject to the requirements of section 211 4 of the (relating to prohibiting preexisting condition exclu5 sions).".

6 (c) Amendments to Public Health Service 7 ACT.-

8

9

10

11

12

13

14

15

16

17

18

19

20

21

22 apply to any group health plan as of the date that such

23 plan becomes subject to the requirements of section 211

24 of the (relating to prohibiting preexisting condition exclu25 sions).".

(1) Reduction in LOOK-BACK Period.-Section 2701(a)(1) of the Public Health Service Act (42 U.S.C. $300 \operatorname{gg}(\mathrm{a})(1))$ is amended by striking " 6 month period" and inserting "30-day period".

(2) Reduction in PERMitTed PREexisting CONDITION LIMITATION PERIOD.-Section 2701(a)(2) of such Act (42 U.S.C. $300 \mathrm{gg}$ (a)(2)) is amended by striking "12 months" and inserting "3 months", and by striking "18 months" and inserting "9 months".

(3) Sunset of interim Limitation.- Section 2701 of such Act (42 U.S.C. $300 \mathrm{gg}$ ) is amended by adding at the end the following new subsection:

“(h) Termination.-This section shall cease to 
(4) Miscellaneous technical amendMENT.-Section 2702(a)(2) of such Act (42 U.S.C.

3 300gg-1) is amended by striking "701" and insert4 ing " 2701 ".

5 (d) Effective Date.-

6 (1) In GENERAL.-Except as provided in para7 graph (2), the amendments made by this section 8 shall apply with respect to group health plans for 9 plan years beginning on or after January 1, 2010.

(2) Spectal RUle FOR COLlective BaR11 GaINING AGREEMENTS.-In the case of a group 12 health plan maintained pursuant to 1 or more collec13 tive bargaining agreements between employee rep14 resentatives and 1 or more employers ratified before 15 the date of the enactment of this Act, the amend16 ments made by this section shall not apply to plan 17 years beginning before the earlier of-

(A) the date on which the last of the collective bargaining agreements relating to the plan terminates (determined without regard to any extension thereof agreed to after the date of the enactment of this Act);

(B) 3 years after the date of the enactment of this Act. 
1 SEC. 107. PROHIBITING ACTS OF DOMESTIC VIOLENCE DITIONS.

4 (a) ERISA.-Section 701(d)(3) of the Employee Re5 tirement Income Security Act of 1974 (29 U.S.C. ) is 6 amended-

(1) in the heading, by inserting "OR DOMESTIC VIOLENCE" after "PREGNANCY"; and

10 "relating to pregnancy".

11 (b) PHSA.-

(1) Group MARKET.-Section 2701(d)(3) of 13 the Public Health Service Act (42 U.S.C. $14300 \operatorname{ggg}(\mathrm{d})(3))$ is amended-

(A) in the heading, by inserting "OR DOMESTIC VIOLENCE" after "PREGNANCY"; and

20 Act is amended by inserting after section 2753 the 21 following new section:

22 "SEC. 2754. PROHIBITION ON DOMESTIC VIOLENCE AS PRE-

(B) by inserting "or domestic violence" after "relating to pregnancy".

(2) Individual Market.-Title XXVII of such EXISTING CONDITION.

25 coverage in the individual market may not, on the basis 26 of domestic violence, impose any preexisting condition ex- 
1 clusion (as defined in section 2701(b)(1)(A)) with respect

2 to such coverage.".

3 (c) IRC.-Section 9801(d)(3) of the Internal Rev-

4 enue Code of 1986 is amended-

5

24 Income SECURITy ACT OF 1974.VIOLENCE" after "PREGNANCY"; and "relating to pregnancy".

(d) Effective Dates.ary 1, 2010.

(1) in the heading, by inserting "OR DOMESTIC

(2) by inserting "or domestic violence" after

(1) Except as otherwise provided in this subsection, the amendments made by this section shall apply with respect to group health plans (and health insurance issuers offering group health insurance coverage) for plan years beginning on or after Janu-

(2) The amendment made by subsection (b)(2) shall apply with respect to health insurance coverage offered, sold, issued, renewed, in effect, or operated in the individual market on or after such date.

SEC. 108. ENDING HEALTH INSURANCE DENIALS AND DELAYS OF NECESSARY TREATMENT FOR CHILDREN WITH DEFORMITIES.

(a) Amendments to the Employee Retirement 
(1) In GeneraL.—Subpart B of part 7 of subtitle B of title I of the Employee Retirement Income Security Act of 1974 is amended by adding at the

4 end the following new section:

5 “SEC. 715. STANDARDS RELATING TO BENEFITS FOR MINOR CHILD'S CONGENITAL OR DEVELOPMENTAL DEFORMITY OR DISORDER.

8 “(a) Requirements FOR Treatment FOR Chil9 DREn With Deformities.-

11 health insurance issuer offering group health insur12 ance coverage, that provides coverage for surgical 13 benefits shall provide coverage for outpatient and in14 patient diagnosis and treatment of a minor child's 15 congenital or developmental deformity, disease, or 16 injury. A minor child shall include any individual 17 who is 21 years of age or younger. “(2) Treatment defined."(A) IN GENERAL.-In this section, the term 'treatment' includes reconstructive surgical procedures (procedures that are generally performed to improve function, but may also be performed to approximate a normal appearance) that are performed on abnormal structures of the body caused by congenital defects, 
developmental abnormalities, trauma, infection, tumors, or disease, including-

"(i) procedures that do not materially affect the function of the body part being treated; and

“(ii) procedures for secondary conditions and follow-up treatment.

“(B) Exception.- Such term does not include cosmetic surgery performed to reshape normal structures of the body to improve appearance or self-esteem.

13 shall comply with the notice requirement under section 14 713(b) (other than paragraph (3)) with respect to the re15 quirements of this section.".

(A) Subsection (c) of section 731 of such Act is amended by striking "section 711" and inserting "sections 711 and 715".

(B) The table of contents in section 1 of such Act is amended by inserting after the item relating to section 714 the following new item:

"Sec. 715. Standards relating to benefits for minor child's congenital or developmental deformity or disorder.".

(b) Amendments to the Internal Revenue

24 Code of 1986.- 
(1) In GENERAL.-Subchapter B of chapter 100 of the Internal Revenue Code of 1986 is amended by adding at the end the following new section:

4 "SEC. 9814. STANDARDS RELATING TO BENEFITS FOR MINOR CHILD'S CONGENITAL OR DEVELOPMENTAL DEFORMITY OR DISORDER. “(a) Requirements for Treatment for Chil-

8 DRen With Deformities.-A group health plan that 9 provides coverage for surgical benefits shall provide cov10 erage for outpatient and inpatient diagnosis and treat11 ment of a minor child's congenital or developmental de12 formity, disease, or injury. A minor child shall include any 13 individual who is 21 years of age or younger. “(b) Treatment Defined.-

"(1) IN GENERAL.-In this section, the term 16 'treatment' includes reconstructive surgical proce17 dures (procedures that are generally performed to 18 improve function, but may also be performed to ap19 proximate a normal appearance) that are performed 20 on abnormal structures of the body caused by con21 genital defects, developmental abnormalities, trau22 ma, infection, tumors, or disease, including"(A) procedures that do not materially affect the function of the body part being treated, and 
"(B) procedures for secondary conditions and follow-up treatment.

“(2) ExceptTIOn.-Such term does not include

4 cosmetic surgery performed to reshape normal struc-

5 tures of the body to improve appearance or self-es6 teem.".

(2) Clerical amendment.-The table of sec-

8 tions for subchapter B of chapter 100 of such Code

9 is amended by adding at the end the following new 10 item:

"Sec. 9814. Standards relating to benefits for minor child's congenital or developmental deformity or disorder.".

(c) Amendments to the Public Health Service

12 ACT.-

(1) In GeneRAL.—Subpart 2 of part A of title

15 by adding at the end the following new section:

16 “SEC. 2708. STANDARDS RELATING TO BENEFITS FOR

“(a) Requirements for Treatment for Chil-

20 Dren With Deformities.-

"(1) In GENERAL.—A group health plan, and a

22 health insurance issuer offering group health insur23 ance coverage, that provides coverage for surgical 24 benefits shall provide coverage for outpatient and in- 
1 patient diagnosis and treatment of a minor child's 2 congenital or developmental deformity, disease, or 3 injury. A minor child shall include any individual 4 who is 21 years of age or younger.

\section{“(2) Treatment Defined.-}

"(A) IN GENERAL.-In this section, the term 'treatment' includes reconstructive surgical procedures (procedures that are generally performed to improve function, but may also be performed to approximate a normal appearance) that are performed on abnormal structures of the body caused by congenital defects, developmental abnormalities, trauma, infection, tumors, or disease, including-

"(i) procedures that do not materially affect the function of the body part being treated; and

“(ii) procedures for secondary conditions and follow-up treatment.

"(B) Exception.—Such term does not include cosmetic surgery performed to reshape normal structures of the body to improve appearance or self-esteem.

“(b) Notice.-A group health plan under this part 25 shall comply with the notice requirement under section 
1 715(b) of the Employee Retirement Income Security Act

2 of 1974 with respect to the requirements of this section

3 as if such section applied to such plan.’.

4 (2) Indvidual Health Insurance.-Subpart

52 of part B of title XXVII of the Public Health

6 Service Act, as amended by section 161(b), is fur-

7 ther amended by adding at the end the following

8 new section:

9 “SEC. 2755. STANDARDS RELATING TO BENEFITS FOR 10 MINOR CHILD'S CONGENITAL OR DEVELOP11 MENTAL DEFORMITY OR DISORDER.

12 "The provisions of section 2708 shall apply to health

13 insurance coverage offered by a health insurance issuer

14 in the individual market in the same manner as such pro-

15 visions apply to health insurance coverage offered by a

16 health insurance issuer in connection with a group health

17 plan in the small or large group market.".

(3) Conforming amendments.-

(A) Section 2723(c) of such Act (42 U.S.C. 300gg-23(c)) is amended by striking "section 2704" and inserting "sections 2704 and $2708 "$.

(B) Section 2762(b)(2) of such Act (42 U.S.C. 300gg-62(b)(2)) is amended by striking 
"section 2751" and inserting "sections 2751 and $2755 "$.

(d) Effective Dates.-

(1) The amendments made by this section shall apply with respect to group health plans (and health 6 insurance issuers offering group health insurance 7 coverage) for plan years beginning on or after Janu$8 \quad$ ary $1,2010$.

(2) The amendment made by subsection (c)(2)

10 shall apply with respect to health insurance coverage

11 offered, sold, issued, renewed, in effect, or operated 12 in the individual market on or after such date.

13 (e) Coordination.-Section 104(1) of the Health 14 Insurance Portability and Accountability Act of 1996 is 15 amended by striking "(and the amendments made by this 16 subtitle and section 401)" and inserting ", part 7 of sub17 title B of title I of the Employee Retirement Income Secu18 rity Act of 1974, parts A and $\mathrm{C}$ of title XXVII of the 19 Public Health Service Act, and chapter 100 of the Internal 20 Revenue Code of 1986".

21 SEC. 109. ELIMINATION OF LIFETIME LIMITS.

(a) Amendments to the Employee Retirement

23 Income Security ACT OF 1974.-

24 (1) In GENERAL._-Subpart B of part 7 of sub25 title B of title I of the Employee Retirement Income 
1 Security Act of 1974 (29 U.S.C. 1185 et seq.), as

2 amended by section 108, is amended by adding at

3 the end the following:

4 “SEC. 716. ELIMINATION OF LIFETIME AGGREGATE LIMITS.

5 “(a) In GENERAL. - A group health plan and a health

6 insurance issuer providing health insurance coverage in

7 connection with a group health plan, may not impose an

8 aggregate dollar lifetime limit with respect to benefits pay-

9 able under the plan or coverage.

10 “(b) Definition.-In this section, the term 'aggre-

11 gate dollar lifetime limit' means, with respect to benefits

12 under a group health plan or health insurance coverage

13 offered in connection with a group health plan, a dollar

14 limitation on the total amount that may be paid with re-

15 spect to such benefits under the plan or health insurance

16 coverage with respect to an individual or other coverage

17 unit on a lifetime basis.".

18 (2) Clerical amendment.-The table of con-

19 tents in section 1 of such Act, is amended by insert-

20 ing after the item relating to section 715 the fol-

21 lowing new item:

"Sec. 716. Elimination of lifetime aggregate limits.".

22 (b) Amendments to the Internal Revenue

23 Code OF 1986.-

(1) In GENERAL.-Subchapter B of chapter

25 100 of the Internal Revenue Code of 1986, as 
1 amended by section 108(b), is amended by adding at

2 the end the following new section:

3 “SEC. 9815. ELIMINATION OF LIFETIME AGGREGATE LIMITS.

5 “(a) In GENERAL. - A group health plan may not im6 pose an aggregate dollar lifetime limit with respect to ben7 efits payable under the plan.

8 "(b) Definition.- In this section, the term 'aggre9 gate dollar lifetime limit' means, with respect to benefits

10 under a group health plan a dollar limitation on the total

11 amount that may be paid with respect to such benefits

12 under the plan with respect to an individual or other cov13 erage unit on a lifetime basis.".

14

15 tions for subchapter B of chapter 100 of such Code,

16 as amended by section $108(\mathrm{~b})$, is amended by adding

17 at the end the following new item:

"Sec. 9854. Standards relating to benefits for minor child's congenital or developmental deformity or disorder.".

19 ACt Relating to the Group Market.-
(1) In generaL.- Subpart 2 of part A of title XXVII of the Public Health Service Act (42 U.S.C. 300gg-4 et seq.) as amended by section 108(c)(1), is amended by adding at the end the following: 
1 “SEC. 2709. ELIMINATION OF LIFETIME AGGREGATE LIM-

2

3 "(a) In GENERAL.—A group health plan and a health

4 insurance issuer providing health insurance coverage in

5 connection with a group health plan, may not impose an

6 aggregate dollar lifetime limit with respect to benefits pay-

7 able under the plan or coverage.

8 "(b) DEFINITIOn.- In this section, the term 'aggre-

9 gate dollar lifetime limit' means, with respect to benefits

10 under a group health plan or health insurance coverage,

11 a dollar limitation on the total amount that may be paid

12 with respect to such benefits under the plan or health in-

13 surance coverage with respect to an individual or other

14 coverage unit on a lifetime basis.".

15 (2) INDIVIDUAL MARKET.-Subpart 2 of part B

16 of title XXVII of the Public Health Service Act (42

17 U.S.C. $300 \mathrm{gg}-51$ et seq.), as amended by section

18 108(c)(2), is amended by adding at the end the fol-

19 lowing:

20 “SEC. 2756. ELIMINATION OF ANNUAL OR LIFETIME AGGRE-

\section{GATE LIMITS.}

22 "The provisions of section 2709 shall apply to health 23 insurance coverage offered by a health insurance issuer 24 in the individual market in the same manner as they apply 25 to health insurance coverage offered by a health insurance 
1 issuer in connection with a group health plan in the small

2 or large group market.".

3

4

5

6

7

8

9

10

11

17 the Employee Retirement Income Security Act of 1974, 18 as amended by sections 108 and 109, is amended by in-

19 serting after section 716 the following new section:

23 contain a provision which expressly bars the plan, or any 24 fiduciary of the plan, from reducing the benefits provided 25 under the plan to a retired participant, or beneficiary of 
1 such participant, if such reduction affects the benefits pro-

2 vided to the participant or beneficiary as of the date the 3 participant retired for purposes of the plan and such re4 duction occurs after the participant's retirement unless 5 such reduction is also made with respect to active partici6 pants. Nothing in this section shall prohibit a plan from 7 enforcing a total aggregate cap on amounts paid for re8 tiree health coverage that is part of the plan at the time 9 of retirement.

10 “(b) No Reduction.-Notwithstanding that a group

11 health plan may contain a provision reserving the general 12 power to amend or terminate the plan or a provision spe13 cifically authorizing the plan to make post-retirement re14 ductions in retiree health benefits, it shall be prohibited 15 for any group health plan, whether through amendment 16 or otherwise, to reduce the benefits provided to a retired 17 participant or the participant's beneficiary under the 18 terms of the plan if such reduction of benefits occurs after 19 the date the participant retired for purposes of the plan 20 and reduces benefits that were provided to the participant, 21 or the participant's beneficiary, as of the date the partici22 pant retired unless such reduction is also made with re23 spect to active participants.

24 "(c) Reduction Described. - For purposes of this 25 section, a reduction in benefits- 
“(1) with respect to premiums occurs under a

2 group health plan when a participant's (or bene3 ficiary's) share of the total premium (or, in the case

4 of a self-insured plan, the costs of coverage) of the

5 plan substantially increases; or

6 "(2) with respect to other cost-sharing and ben-

7 efits under a group health plan occurs when there is

8 a substantial decrease in the actuarial value of the

9 benefit package under the plan.

10 For purposes of this section, the term 'substantial' means

11 an increase in the total premium share or a decrease in

12 the actuarial value of the benefit package that is greater

13 than 5 percent."

14 (b) Conforming Amendment.-The table of con15 tents in section 1 of such Act, as amended by sections

16108 and 109, is amended by inserting after the item relat-

17 ing to section 716 the following new item:

"Sec. 717. Protection against postretirement reduction of retiree health benefits.".

18 (c) WaIVER.-An employer may, in a form and man-

19 ner which shall be prescribed by the Secretary of Labor,

20 apply for a waiver from this provision if the employer can

21 reasonably demonstrate that meeting the requirements of

22 this section would impose an undue hardship on the em-

23 ployer. 
1 (d) EFFEctive Date.-The amendments made by

2 this section shall take effect on the date of the enactment 3 of this Act.

4 SEC. 111. REINSURANCE PROGRAM FOR RETIREES.

5

6

7

8

9

10

11 bursement to assist participating employment-based

12 plans with the cost of providing health benefits to

13 retirees and to eligible spouses, surviving spouses

14 and dependents of such retirees.

(1) In GENERAL.-Not later than 90 days after the date of the enactment of this Act, the Secretary of Health and Human Services shall establish a temporary reinsurance program (in this section referred to as the "reinsurance program") to provide reim-

(2) Definitions.-For purposes of this sec16 tion: (1)

(A) The term "eligible employment-based plan" means a group health plan or employment-based health plan that-

(i) is -

(I) maintained by one or more employers (including without limitation any State or political subdivision thereof, or any agency or instrumentality of any of the foregoing), former 
employers or employee organizations or associations, or a voluntary employees' beneficiary association, or a committee or board of individuals appointed to administer such plan; or (II) a multiemployer plan (as defined in section 3(37) of the Employee Retirement Income Security Act of 1974); and

(ii) provides health benefits to retirees.

(B) The term "health benefits" means medical, surgical, hospital, prescription drug, and such other benefits as shall be determined by the Secretary, whether self-funded or delivered through the purchase of insurance or otherwise.

(C) The term "participating employmentbased plan" means an eligible employmentbased plan that is participating in the reinsurance program.

(D) The term "retiree" means, with respect to a participating employment-benefit plan, an individual who-

(i) is 55 years of age or older; 
10 the reinsurance program, an eligible employment-based

11 plan shall submit to the Secretary an application for par-

12 ticipation in the program, at such time, in such manner,

13 and containing such information as the Secretary shall re14 quire.

(ii) is not eligible for coverage under title XVIII of the Social Security Act; and (iii) is not an active employee of an employer maintaining the plan or of any employer that makes or has made substantial contributions to fund such plan.

(E) The term "Secretary" means Secretary of Health and Human Services.

(b) PARTicipation.-To be eligible to participate in 
pating employment-based plan involved within the plan year for the appropriate employment based health benefits provided to a retiree or to the spouse, surviving spouse, or dependent of a retiree. In determining the amount of any claim

(2) Program payments and Limit.-If the

20 Secretary determines that a participating employ21 ment-based plan has submitted a valid claim under 22 paragraph (1), the Secretary shall reimburse such 23 plan for 80 percent of that portion of the costs at24 tributable to such claim that exceeds $\$ 15,000$, but is 25 less than $\$ 90,000$. Such amounts shall be adjusted 
1 each year based on the percentage increase in the 2 medical care component of the Consumer Price 3 Index (rounded to the nearest multiple of $\$ 1,000$ ) 4 for the year involved.

5 (3) Use OF PAYMents.-Amounts paid to a 6 participating employment-based plan under this sub7 section shall only be used to reduce the costs of 8 health care provided by the plan by reducing pre9 mium costs for the employer or employee association 10 maintaining the plan, and reducing premium con11 tributions, deductibles, copayments, coinsurance, or 12 other out-of-pocket costs for plan participants and 13 beneficiaries. Where the benefits are provided by an 14 employer to members of a represented bargaining 15 unit, the allocation of payments among these pur16 poses shall be subject to collective bargaining. 17 Amounts paid to the plan under this subsection shall 18 not be used as general revenues by the employer or 19 employee association maintaining the plan or for any 20 other purposes. The Secretary shall develop a mech21 anism to monitor the appropriate use of such pay22 ments by such plans.

23 (4) APPEAls AND PROGRAM PROTECTIONS.24 The Secretary shall establish- 
(A) an appeals process to permit participating employment-based plans to appeal a determination of the Secretary with respect to claims submitted under this section; and

(B) procedures to protect against fraud, waste, and abuse under the program.

(5) Audits.-The Secretary shall conduct annual audits of claims data submitted by participating employment-based plans under this section to ensure that they are in compliance with the requirements of this section.

(d) Retiree Reserve Trust Fund.-

(1) Establishment.-

(A) In GENERAL.- There is established in the Treasury of the United States a trust fund to be known as the "Retiree Reserve Trust Fund" (referred to in this section as the "Trust Fund"), that shall consist of such amounts as may be appropriated or credited to the Trust Fund as provided for in this subsection to enable the Secretary to carry out the reinsurance program. Such amounts shall remain available until expended.

(B) Funding.-There are hereby appropriated to the Trust Fund, out of any moneys 
in the Treasury not otherwise appropriated, an amount requested by the Secretary as necessary to carry out this section, except that the total of all such amounts requested shall not exceed $\$ 10,000,000,000$.

(C) Appropriations from the trust

(i) IN GENERAL.-Amounts in the Trust Fund are appropriated to provide funding to carry out the reinsurance program and shall be used to carry out such program.

(ii) LIMITATION TO AVAILABLE FUNDS. - The Secretary has the authority to stop taking applications for participation in the program or take such other steps in reducing expenditures under the reinsurance program in order to ensure that expenditures under the reinsurance program do not exceed the funds available under this subsection.

\section{SEC. 112. WELLNESS PROGRAM GRANTS.}

23 (a) Allowance of Grant.-

24 (1) IN GENERAL.-For purposes of this section, 25 the Secretaries of Health and Human Services and 
63

1 Labor shall jointly award wellness grants as deter-

2 mined under this section. Wellness program grants

3 shall be awarded to small employers (as defined by

4 the Secretary) for any plan year in an amount equal

5 to 50 percent of the costs paid or incurred by such

6 employers in connection with a qualified wellness

7 program during the plan year. For purposes of the

8 preceding sentence, in the case of any qualified

9 wellness program offered as part of an employment-

10 based health plan, only costs attributable to the

11 qualified wellness program and not to the health

12 plan, or health insurance coverage offered in connec-

13 tion with such a plan, may be taken into account.

14

15

16

17

18

19

20

21

22

23

24

25
(2) Limitations.-

(A) PERIOD.-A wellness grant awarded to an employer under this section shall be for up to 3 years.

(B) AmounT.-The amount of the grant under paragraph (1) for an employer shall not exceed-

(i) the product of $\$ 150$ and the number of employees of the employer for any plan year; and

(ii) $\$ 50,000$ for the entire period of the grant. 
1 (b) Qualified Wellness Program.-For purposes 2 of this section:

(1) Qualified wellness PRogram.-The term "qualified wellness program" means a program that -

(A) includes any 3 wellness components described in subsection (c); and

(B) is to be certified jointly by the Secretary of Health and Human Services and the Secretary of Labor, in coordination with the Director of the Centers for Disease Control and Prevention, as a qualified wellness program under this section.

(2) Programs must be consistent with ReSEARCH AND BEST PRACTICES.-

(A) In GENERAL.-The Secretary of Health and Human Services and the Secretary of Labor shall not certify a program as a qualified wellness program unless the program-

(i) is consistent with evidence-based research and best practices, as identified by persons with expertise in employer health promotion and wellness programs;

(ii) includes multiple, evidence-based strategies which are based on the existing 
65

and emerging research and careful scientific reviews, including the Guide to Community Preventative Services, the Guide to Clinical Preventative Services, and the National Registry for Effective Programs, and

(iii) includes strategies which focus on prevention and support for employee populations at risk of poor health outcomes.

(B) Periodic updating and Review.The Secretaries of Health and Human Services and Labor, in consultation with other appropriate agencies shall jointly establish procedures for periodic review, evaluation, and update of the programs under this subsection.

(3) Health literacy and accessibility.The Secretaries of Health and Human Services and Labor shall jointly, as part of the certification process-

(A) ensure that employers make the programs culturally competent, physically and programmatically accessible (including for individuals with disabilities), and appropriate to the health literacy needs of the employees covered by the programs; 
(B) require a health literacy component to provide special assistance and materials to employees with low literacy skills, limited English and from underserved populations; and

(C) require the Secretaries to compile and disseminate to employer health plans information on model health literacy curricula, instructional programs, and effective intervention strategies.

(c) Wellness Program Components.-For pur-

11 poses of this section, the wellness program components de12 scribed in this subsection are the following:

(1) Health awareness Component.-A

14 health awareness component which provides for the 15 following:

(A) Health education.-The dissemination of health information which addresses the specific needs and health risks of employees.

24 An employee engagement component which provides 25 for the active engagement of employees in worksite 
1 wellness programs through worksite assessments and

2 program planning, onsite delivery, evaluation, and 3 improvement efforts.

4 (3) Behavioral Change Component.-A be5 havioral change component which encourages 6 healthy living through counseling, seminars, on-line 7 programs, self-help materials, or other programs 8 which provide technical assistance and problem solv9 ing skills. Such component may include programs re10 lating to-

(4) Supportive environment Component.-

20 A supportive environment component which includes 21 the following:

(E) nutrition;

(F) substance abuse;

(G) depression; and

(H) mental health promotion.

(A) ON-site POLICIES.-Policies and services at the worksite which promote a healthy lifestyle, including policies relating to-

(i) tobacco use at the worksite; 
68

(ii) the nutrition of food available at the worksite through cafeterias and vending options;

(iii) minimizing stress and promoting positive mental health in the workplace; and

(iv) the encouragement of physical activity before, during, and after work hours.

10 be allowed under subsection (a) unless the Secretaries of 11 Health and Human Services and Labor, in consultation 12 with other appropriate agencies, jointly certify, as a part 13 of any certification described in subsection (b), that each 14 wellness program component of the qualified wellness pro15 gram17 employer;

18 (2) shall not mandate participation by employ19 ees; and

(3) may provide a financial reward for partici21 pation of an individual in such program so long as 22 such reward is not tied to the premium or cost-shar23 ing of the individual under the health benefits plan. 24 (e) Privacy Protections._-Data gathered for pur25 poses of the employer wellness program may be used solely 
69

1 for the purposes of administering the program. The Secre-

2 taries of Health and Human Services and Labor shall de-

3 velop standards to ensure such data remain confidential

4 and are not used for purposes beyond those for admin-

5 istering the program.

6 (f) Certain Costs Not Included.-For purposes

7 of this section, costs paid or incurred by an employer for

8 food or health insurance shall not be taken into account

9 under subsection (a).

10 (g) Outreach.-The Secretaries of Health and

11 Human Services and Labor, in conjunction with other ap-

12 propriate agencies and members of the business commu-

13 nity, shall jointly institute an outreach program to inform

14 businesses about the availability of the wellness program

15 grant as well as to educate businesses on how to develop

16 programs according to recognized and promising practices

17 and on how to measure the success of implemented pro18 grams.

19 (h) EFFECTIVE DATE.-This section shall take effect 20 on July 1, 2010.

21 (i) Authorization of Appropriations.-There 22 are authorized to be appropriated such sums as are nec23 essary to carry out this section. 
1 SEC. 113. EXTENSION OF COBRA CONTINUATION COVERAGE.

3 (a) Extension of Current Periods of Continu4 ation Coverage.-

5

6 who is, under a COBRA continuation coverage pro-

7 vision, covered under COBRA continuation coverage

8 on or after the date of the enactment of this Act,

9 the required period of any such coverage which has

10 not subsequently terminated under the terms of such

11 provision for any reason other than the expiration of

12 a period of a specified number of months shall, not-

13 withstanding such provision and subject to sub-

14 section (b), extend to the earlier of the date on

15 which such individual becomes eligible for acceptable

16 coverage or the date on which such individual be-

17 comes eligible for health insurance coverage through

18 the Health Insurance Exchange (or a State-based

19 Health Insurance Exchange operating in a State or

20 group of States).

21 (2) Notice.-As soon as practicable after the

22 date of the enactment of this Act, the Secretary of

23 Labor, in consultation with the Secretary of the

24 Treasury and the Secretary of Health and Human

25 Services, shall, in consultation with administrators

26 of the group health plans (or other entities) that 
1 provide or administer the COBRA continuation cov-

2 erage involved, provide rules setting forth the form

3 and manner in which prompt notice to individuals of

4 the continued availability of COBRA continuation

5 coverage to such individuals under paragraph (1).

6 (b) Continued Effect of Other Terminating

7 Events.-Notwithstanding subsection (a), any required

8 period of COBRA continuation coverage which is extended

9 under such subsection shall terminate upon the occur-

10 rence, prior to the date of termination otherwise provided

11 in such subsection, of any terminating event specified in

12 the applicable continuation coverage provision other than

13 the expiration of a period of a specified number of months.

14 (c) Access to State Health Benefits Risk

15 Pools.-This section shall supersede any provision of the

16 law of a State or political subdivision thereof to the extent

17 that such provision has the effect of limiting or precluding

18 access by a qualified beneficiary whose COBRA continu-

19 ation coverage has been extended under this section to a

20 State health benefits risk pool recognized by the Commis-

21 sioner for purposes of this section solely by reason of the

22 extension of such coverage beyond the date on which such

23 coverage otherwise would have expired.

24 (d) Definitions.-For purposes of this section- 
21 Human Services (in this section referred to as the "Sec-

22 retary") shall provide grants to States (as defined for pur23 poses of title XIX of the Social Security Act) to establish 24 programs to expand access to affordable health care cov25 erage for the uninsured populations in that State in a 
1 manner consistent with reforms to take effect under this 2 division in $\mathrm{Y} 1$.

3 (b) Types of Programs.-The types of programs

4 for which grants are available under subsection (a) include 5 the following:

6 (1) State insurance Exchanges.-State in7 surance exchanges that develop new, less expensive, 8 portable benefit packages for small employers and 9 part-time and seasonal workers.

10 (2) Community coverage Program.-Com11 munity coverage with shared responsibility between 12 employers, governmental or nonprofit entity, and the 13 individual.

14 (3) Reinsurance Plan PROGRam.-Reinsur15 ance plans that subsidize a certain share of carrier 16 losses within a certain risk corridor health insurance 17 premium assistance.

18 (4) Transparent Marketplace Program.19 Transparent marketplace that provides an organized 20 structure for the sale of insurance products such as 21 a Web exchange or portal.

22 (5) AUtomated ENROLLMent PROGRAM.23 Statewide or automated enrollment systems for pub$24 \quad$ lic assistance programs. 
(6) Innovative strategies.-Innovative strategies to insure low-income childless adults.

(7) Purchasing Collaboratives.-Business/

4 consumer collaborative that provides direct contract

5 health care service purchasing options for group 6 plan sponsors. REGULATORY CHANGES.-In order to be awarded a

10 grant under this section for a program, a State shall 11 demonstrate that-

(A) it has achieved the key State and local statutory or regulatory changes required to begin implementing the new program within 1 year after the initiation of funding under the grant; and

23 tion.

(B) it will be able to sustain the program without Federal funding after the end of the period of the grant.

(2) Ineligibility.-A State that has already developed a comprehensive health insurance access program is not eligible for a grant under this sec-

(3) APplication REQUiRed.-No State shall receive a grant under this section unless the State 
1 has approved by the Secretary such an application, 2 in such form and manner as the Secretary specifies.

(4) Administration based on Current Pro-

4 GRAM.-The program under this section is intended

5 to build on the State Health Access Program funded

6 under the Omnibus Appropriations Act, 2009 (Pub-

7 lic Law 111-8).

8 (d) Funding Limitations.-

9 (1) IN GENERAL.-A grant under this section 10 shall-

(A) only be available for expenditures before Y1; and

(B) only be used to supplement, and not supplant, funds otherwise provided.

(2) Matching Fund Requirement.-

(A) IN GENERAL.- Subject to subparagraph (B), no grant may be awarded to a State unless the State demonstrates the seriousness of its effort by matching at least 20 percent of the grant amount through non-Federal resources, which may be a combination of State, local, private dollars from insurers, providers, and other private organizations.

(B) WAIVER.-The Secretary may waive the requirement of subparagraph (A) if the 
1 State demonstrates to the Secretary financial

2 hardship in complying with such requirement.

3 (e) STUDY.-The Secretary shall review, study, and

4 benchmark the progress and results of the programs fund5 ed under this section.

6 (f) REPORT._Each State receiving a grant under 7 this section shall submit to the Secretary a report on best 8 practices and lessons learned through the grant to inform 9 the health reform coverage expansions under this division 10 beginning in Y1.

11 (g) Funding.-There are authorized to be appro12 priated such sums as may be necessary to carry out this 13 section.

\section{SEC. 115. ADMINISTRATIVE SIMPLIFICATION.}

15 (a) Standardizing Electronic Administrative 16 Transactions.-

17 (1) In GeneraL.-Part $\mathrm{C}$ of title XI of the So18 cial Security Act (42 U.S.C. 1320d et seq.) is 19 amended by inserting after section 1173 the fol20 lowing new sections:

21 “SEC. 1173A. STANDARDIZE ELECTRONIC ADMINISTRATIVE TRANSACTIONS.

23 “(a) Standards for Financial and Administra24 TIVE TransaCtions.- 
“(1) IN GENERAL.—The Secretary shall adopt and regularly update standards consistent with the 3 goals described in paragraph (2). TIVE TRANSACTIONS.-The goals for standards

6 under paragraph (1) are that such standards shall, 7 to the extent practicable-

"(A) be unique with no conflicting or redundant standards;

"(B) be authoritative, permitting no additions or constraints for electronic transactions, including companion guides;

"(C) be comprehensive, efficient and robust, requiring minimal augmentation by paper transactions or clarification by further communications;

"(D) enable the real-time (or near realtime) determination of an individual's financial responsibility at the point of service and, to the extent possible, prior to service, including whether the individual is eligible for a specific service with a specific physician at a specific facility, on a specific date or range of dates, include utilization of a machine-readable health 
plan beneficiary identification card or similar mechanism;

"(E) enable, where feasible, near real-time adjudication of claims;

"(F) provide for timely acknowledgment, reason and remark codes) in unambiguous terms, not permit optional fields, require that data elements be either required or conditioned upon set values in other fields, and prohibit additional conditions except where required by (or to implement) State or Federal law or to protect against fraud and abuse; and

"(H) harmonize all common data elements across administrative and clinical transaction standards.

“(3) TIME FOR ADOPTION.-Not later than 2 years after the date of the enactment of this section, 22 the Secretary shall adopt standards under this sec23 tion by interim, final rule. 
“(4) REQUiREMENTS FOR SPECIFIC STANDARDS. - The standards under this section shall be

8

9

10

11

12

13

14

15

16

17

18

19

20

21

22

23

24
"(A) clarify, refine, complete, and expand,

as needed, the standards required under section 1173

"(B) require paper versions of standard-

developed, adopted, and enforced so as to-

ized transactions to comply with the same standards as to data content such that a fully compliant, equivalent electronic transaction can be populated from the data from a paper version;

"(C) enable electronic funds transfers, in order to allow automated reconciliation with the related health care payment and remittance advice;

"(D) require timely and transparent claim and denial management processes, including uniform claim edits, uniform reason and remark denial codes, tracking, adjudication, and appeal processing;

"(E) require the use of a standard electronic transaction with which health care providers may quickly and efficiently enroll with a 
health plan to conduct the other electronic transactions provided for in this part; and "(F) provide for other requirements relating to administrative simplification as identified by the Secretary, in consultation with stakeholders.

“(5) Building ON EXIsting Standards.-In adopting the standards under this section, the Secretary shall consider existing and planned standards. “(6) ImPlementation AND ENFORCEMENT.Not later than 6 months after the date of the enactment of this section, the Secretary shall submit to the appropriate committees of Congress a plan for the implementation and enforcement, by not later than 5 years after such date of enactment, of the standards under this section. Such plan shall include-

"(A) a process and timeframe with milestones for developing the complete set of standards;

“(B) a proposal for accommodating necessary changes between version changes and a process for upgrading standards as often as annually by interim, final rulemaking; 
"(C) programs to provide incentives for,

and ease the burden of, implementation for certain health care providers, with special consideration given to such providers serving rural or underserved areas and ensure coordination with standards, implementation specifications, and certification criteria being adopted under the HITECH Act;

“(D) programs to provide incentives for, and ease the burden of, health care providers who volunteer to participate in the process of setting standards for electronic transactions;

"(E) an estimate of total funds needed to ensure timely completion of the implementation plan; and

"(F) an enforcement process that includes timely investigation of complaints, random audits to ensure compliance, civil monetary and programmatic penalties for noncompliance consistent with existing laws and regulations, and a fair and reasonable appeals process building off of enforcement provisions under this part, and concurrent State enforcement jurisdiction. The Secretary may promulgate an annual audit and certification process to ensure that all health plans 
1 and clearinghouses are both syntactically and func-

2 tionally compliant with all the standard transactions

3 mandated pursuant to the administrative simplifica-

4 tion provisions of this part and the Health Insurance

$5 \quad$ Portability and Accountability Act of 1996.

6 “(b) Limitations on Use of Data.-Nothing in

7 this section shall be construed to permit the use of infor-

8 mation collected under this section in a manner that would

9 violate State or Federal law.

10 “(c) Protection of Data.-The Secretary shall en-

11 sure (through the promulgation of regulations or other-

12 wise) that all data collected pursuant to subsection (a) are

13 used and disclosed in a manner that meets the HIPAA

14 privacy and security law (as defined in section 3009(a)(2)

15 of the Public Health Service Act), including any privacy

16 or security standard adopted under section 3004 of such

17 Act.

18 “SEC. 1173B. INTERIM COMPANION GUIDES, INCLUDING OPERATING RULES.

20 "(a) In GeneraL.-The Secretary shall adopt a sin21 gle, binding, comprehensive companion guide, that in22 cludes operating rules for each X12 Version 5010 trans23 action described in section $1173(\mathrm{a})(2)$, to be effective until 24 the new version of these transactions which comply with 25 section $1173 \mathrm{~A}$ are adopted and implemented. 
1 "(b) Companion Guide and Operating Rules

2 Development.-In adopting such interim companion

3 guide and rules, the Secretary shall comply with section

4 1172, except that a nonprofit entity that meets the fol-

5 lowing criteria shall also be consulted:

6 “(1) The entity focuses its mission on adminis-

7 trative simplification.

8 “(2) The entity uses a multistakeholder process

9 that creates consensus-based companion guides, in-

10 cluding operating rules using a voting process that

11 ensures balanced representation by the critical

12 stakeholders (including health plans and health care

13 providers) so that no one group dominates the entity

14 and shall include others such as standards develop-

15 ment organizations, and relevant Federal or State

16 agencies.

17 "(3) The entity has in place a public set of 18 guiding principles that ensure the companion guide

19 and operating rules and process are open and trans20 parent.

21 "(4) The entity coordinates its activities with 22 the HIT Policy Committee, and the HIT Standards 23 Committee (established under title XXX of the Pub24 lic Health Service Act) and complements the efforts 
1 of the Office of the National Healthcare Coordinator

2 and its related health information exchange goals.

"(5) The entity incorporates the standards

4 issued under Health Insurance Portability and Ac-

5 countability Act of 1996 and this part, and in devel-

6 oping the companion guide and operating rules does

7 not change the definition, data condition or use of

8 a data element or segment in a standard, add any

9 elements or segments to the maximum defined data

10 set, use any codes or data elements that are either

11 marked 'not used' in the standard's implementation

12 specifications or are not in the standard's implemen-

13 tation specifications, or change the meaning or in-

14 tent of the standard's implementation specifications.

15 “(6) The entity uses existing market research

16 and proven best practices.

17 "(7) The entity has a set of measures that

18 allow for the evaluation of their market impact and

19 public reporting of aggregate stakeholder impact.

20 “(8) The entity supports nondiscrimination and

21 conflict of interest policies that demonstrate a com-

22 mitment to open, fair, and nondiscriminatory prac-

23 tices. 
"(9) The entity allows for public reviews and

2 comment on updates of the companion guide, includ-

3 ing the operating rules.

4 “(c) Implementation.-The Secretary shall adopt

5 a single, binding companion guide, including operating

6 rules under this section, for each transaction, to become

7 effective with the X12 Version 5010 transaction imple-

8 mentation, or as soon thereafter as feasible. The com-

9 panion guide, including operating rules for the trans-

10 actions for eligibility for health plan and health claims sta-

11 tus under this section shall be adopted not later than Oc-

12 tober 1, 2011, in a manner such that such set of rules

13 is effective beginning not later than January 1, 2013. The

14 companion guide, including operating rules for the remain-

15 der of the transactions described in section 1173(a)(2)

16 shall be adopted not later than October 1, 2012, in a man-

17 ner such that such set of rules is effective beginning not

18 later than January 1, 2014.".

(2) Definitions.-Section 1171 of such Act (42 U.S.C. $1320 \mathrm{~d}$ ) is amended-

(A) in paragraph (1), by inserting ", and associated operational guidelines and instructions, as determined appropriate by the Secretary" after "medical procedure codes"; and 
(B) by adding at the end the following new paragraph:

“(10) Operating Rules.-The term 'oper-

4 ating rules' means business rules for using and proc-

5 essing transactions, such as service level require-

6 ments, which do not impact the implementation

7 specifications or other data content requirements.".

8 (3) Conforming amendment.-Section

$91179(\mathrm{a})$ of such Act (42 U.S.C. $1320 \mathrm{~d}-8(\mathrm{a})$ ) is

10 amended, in the matter before paragraph (1) -

11 (A) by inserting "on behalf of an indi12 vidual" after "1978)"; and

13 (B) by inserting "on behalf of an indi14 vidual" after "for a financial institution" and

15 (b) Standards for Clatms Attachments and

16 Coordination of Benefits.-

17 (1) STANDARD FOR HEALTH ClatMS ATTACH18 MENTS.-Not later than 1 year after the date of the 19 enactment of this Act, the Secretary of Health and 20 Human Services shall promulgate an interim, final 21 rule to establish a standard for health claims attach22 ment transaction described in section $1173(\mathrm{a})(2)(\mathrm{B})$ 23 of the Social Security Act (42 U.S.C. 1320d$242(\mathrm{a})(2)(\mathrm{B}))$ and coordination of benefits. 
18 Not later than January 1, 2014, the Secretary of Health

19 and Human Services shall promulgate an interim final 20 rule to establish a standard for the first report of injury 21 transaction described in section $1173(\mathrm{a})(2)(\mathrm{G})$ of the So22 cial Security Act (42 U.S.C. 1320d-2(a)(2)(G)).

23 (d) Unique Health Plan Identifier.-Not later 24 October 1, 2012, the Secretary of Health and Human 25 Services shall promulgate an interim final rule to establish 
88

1 a unique health plan identifier described in section 2 1173(b) of the Social Security Act (42 U.S.C. 1320d3 2(b)) based on the input of the National Committee of 4 Vital and Health Statistics and consultation with health 5 plans, health care providers, and other interested parties. 6 (e) Expansion of Electronic Transactions in 7 Medicare.-Section 1862(a) of the Social Security Act 8 (42 U.S.C. $1395 y(a)$ ) is amended-

9 (1) in paragraph (23), by striking "or" at the 10 end;

11 (2) in paragraph (24), by striking the period 12 and inserting "; or"; and

13 (3) by inserting after paragraph (24) the fol14 lowing new paragraph:

15 "(25) subject to subsection (h), not later than 16 January 1, 2015, for which the payment is other 17 than by electronic funds transfer (EFT) so long as 18 the Secretary has adopted and implemented a stand19 ard for electronic funds transfer under section 20 1173A.".

21 (f) Expansion of Penalties.-Section 1176 of 22 such Act (42 U.S.C. 1320d-5) is amended by adding at 23 the end the following new subsection:

24 “(c) Expansion of Penalty Authority.-The 25 Secretary may, in addition to the penalties provided under 
1 subsections (a) and (b), provide for the imposition of pen-

2 alties for violations of this part that are comparable-

3

4

24 FITS Plans.-On or after the first day of Y1, a health 25 benefits plan shall not be a qualified health benefits plan 
1 under this division unless the plan meets the applicable

2 requirements of the following subtitles for the type of plan 3 and plan year involved:

4 (1) Subtitle B (relating to affordable coverage).

5 (2) Subtitle C (relating to essential benefits).

6 (3) Subtitle D (relating to consumer protec7 tion).

8 (c) Terminology.-In this division:

9 (1) EnRolliment in EMPLOYMENT-Based 10 HeAlth PLANS.-An individual shall be treated as 11 being "enrolled" in an employment-based health 12 plan if the individual is a participant or beneficiary 13 (as such terms are defined in section 3(7) and 3(8), 14 respectively, of the Employee Retirement Income Se15 curity Act of 1974) in such plan.

16 (2) INDIVIDUAL AND GROUP HEALTH INSUR17 ANCE COVERAgE.-The terms "individual health in18 surance coverage" and "group health insurance cov19 erage" mean health insurance coverage offered in 20 the individual market or large or small group mar21 ket, respectively, as defined in section 2791 of the 22 Public Health Service Act. 
1 SEC. 202. PROTECTING THE CHOICE TO KEEP CURRENT COVERAGE.

3 (a) Grandfathered Health Insurance Cov4 ERAGE DEFINED.-Subject to the succeeding provisions of 5 this section, for purposes of establishing acceptable cov6 erage under this division, the term "grandfathered health 7 insurance coverage" means individual health insurance 8 coverage that is offered and in force and effect before the 9 first day of $\mathrm{Y} 1$ if the following conditions are met:

10

11

12

\section{(1) Limitation on New EnRolliment.-}

(A) In general.-Except as provided in this paragraph, the individual health insurance issuer offering such coverage does not enroll any individual in such coverage if the first effective date of coverage is on or after the first day of Y1.

(B) Dependent COVERAge PeRMITTED.-Subparagraph (A) shall not affect the subsequent enrollment of a dependent of an individual who is covered as of such first day. (2) Limitation on Changes in terms oR CONDITIONs.-Subject to paragraph (3) and except as required by law, the issuer does not change any of its terms or conditions, including benefits and cost-sharing, from those in effect as of the day before the first day of Y1. 
2 The issuer cannot vary the percentage increase in

3 the premium for a risk group of enrollees in specific

4 grandfathered health insurance coverage without

5 changing the premium for all enrollees in the same 6 risk group at the same rate, as specified by the 7 Commissioner.

8 (b) Grace Period for Current Employment9 Based Health Plans.-

\section{(A) In GENERAL.-The Commissioner} shall establish a grace period whereby, for plan years beginning after the end of the 5-year period beginning with Y1, an employment-based health plan in operation as of the day before the first day of Y1 must meet the same requirements as apply to a qualified health benefits plan under section 201, including the essential benefit package requirement under section 221 . PLANS.- Subparagraph (A) shall not apply to an employment-based health plan in which the coverage consists only of one or more of the fol24 lowing: 
93

25 vision.
vision.

(i) Any coverage described in section 3001(a)(1)(B)(ii)(IV) of division B of the American Recovery and Reinvestment Act of 2009 (Public Law 111-5).

(ii) Excepted benefits (as defined in section 733(c) of the Employee Retirement Income Security Act of 1974), including coverage under a specified disease or illness policy described in paragraph $(3)(\mathrm{A})$ of such section.

(iii) Such other limited benefits as the Commissioner may specify.

In no case shall an employment-based health plan in which the coverage consists only of one or more of the coverage or benefits described in clauses (i) through (iii) be treated as acceptable coverage under this division.

(2) Transitional treatment as acceptABLE COVERAGE.-During the grace period specified in paragraph (1)(A), an employment-based health plan (which may be a high deducible health plan, as defined in section 223(c)(2) of the Internal Revenue Code of 1986) that is described in such paragraph shall be treated as acceptable coverage under this di- 
(1) In GENERAL.-Individual health insurance

4 coverage that is not grandfathered health insurance

5 coverage under subsection (a) may only be offered

6 on or after the first day of $\mathrm{Y} 1$ as an Exchange-par-

$7 \quad$ ticipating health benefits plan.

(2) Separate, excepted COVerage PeR-

(A) paragraph (1) shall prevent the offering of excepted benefits described in section 2791(c) of the Public Health Service Act so long as such benefits are offered outside the Health Insurance Exchange and are priced separately from health insurance coverage; and

(B) this division shall be construed-

(i) to prevent the offering of a standalone plan that offers coverage of excepted benefits described in section 2791(c)(2)(A) of the Public Health Service Act (relating to limited scope dental or vision benefits) for individuals and families from a Statelicensed dental and vision carrier; or

(ii) as applying requirements for a qualified health benefits plan to such a 

plan.

\section{Subtitle B-Standards Guaran-} 5 teeing Access to Affordable Cov6 erage

7 SEC. 211. PROHIBITING PREEXISTING CONDITION EXCLUSIONS.

9 A qualified health benefits plan may not impose any 10 preexisting condition exclusion (as defined in section 11 2701(b)(1)(A) of the Public Health Service Act) or other12 wise impose any limit or condition on the coverage under 13 the plan with respect to an individual or dependent based 14 on any of the following: health status, medical condition, 15 claims experience, receipt of health care, medical history, 16 genetic information, evidence of insurability, disability, or 17 source of injury (including conditions arising out of acts 18 of domestic violence) or any similar factors.

19 SEC. 212. GUARANTEED ISSUE AND RENEWAL FOR INSURED PLANS AND PROHIBITING RESCISSIONS.

22 The requirements of sections 2711 (other than sub23 sections (e) and (f)) and 2712 (other than paragraphs (3), 24 and (6) of subsection (b) and subsection (e)) of the Public 25 Health Service Act, relating to guaranteed availability and 
1 renewability of health insurance coverage, shall apply to

2 individuals and employers in all individual and group

3 health insurance coverage, whether offered to individuals

4 or employers through the Health Insurance Exchange,

5 through any employment-based health plan, or otherwise,

6 in the same manner as such sections apply to employers

7 and health insurance coverage offered in the small group

8 market, except that such section 2712(b)(1) shall apply

9 only if, before nonrenewal or discontinuation of coverage,

10 the issuer has provided the enrollee with notice of non-

11 payment of premiums and there is a grace period during

12 which the enrollee has an opportunity to correct such non-

13 payment. Rescissions of such coverage shall be prohibited

14 except in cases of fraud as defined in section 2712(b)(2)

15 of such Act.

16 SEC. 213. INSURANCE RATING RULES.

17 (a) In GENERAL.-The premium rate charged for a

18 qualified health benefits plan that is health insurance cov-

19 erage may not vary except as follows:

(1) Limited age variation permitted.-By

21 age (within such age categories as the Commissioner

22 shall specify) so long as the ratio of the highest such

23 premium to the lowest such premium does not ex24 ceed the ratio of 2 to 1. 
(2) BY AREA.-By premium rating area (as permitted by State insurance regulators or, in the case of Exchange-participating health benefits plans, 4 as specified by the Commissioner in consultation 5 with such regulators).

(3) By Family enrolliment.-By family en7 rollment (such as variations within categories and 8 compositions of families) so long as the ratio of the 9 premium for family enrollment (or enrollments) to 10 the premium for individual enrollment is uniform, as 11 specified under State law and consistent with rules 12 of the Commissioner.

13 (b) Actuarial Value of Optional Service Cov14 ERAGE.-

(1) In GENERAL.-The Commissioner shall esti16 mate the basic per enrollee, per month cost, deter17 mined on an average actuarial basis, for including 18 coverage under a basic plan of the services described 19 in section $222(\mathrm{~d})(4)(\mathrm{A})$.

20 (2) Considerations.-In making such esti21 mate the Commissioner-

(A) may take into account the impact on overall costs of the inclusion of such coverage, 24 but may not take into account any cost reduc25 tion estimated to result from such services, in- 
cluding prenatal care, delivery, or postnatal care;

(B) shall estimate such costs as if such coverage were included for the entire population covered; and

(C) may not estimate such a cost at less than $\$ 1$ per enrollee, per month.

(c) STUdy AND REPORTS.-

(1) Studyy. - The Commissioner, in coordina10 tion with the Secretary of Health and Human Serv11 ices and the Secretary of Labor, shall conduct a 12 study of the large-group-insured and self-insured 13 employer health care markets. Such study shall ex14 amine the following:

15 (A) The types of employers by key charac16 teristics, including size, that purchase insured 17 products versus those that self-insure.

18 (B) The similarities and differences be19 tween typical insured and self-insured health $20 \quad$ plans.

(C) The financial solvency and capital reserve levels of employers that self-insure by em23 ployer size. 
(D) The risk of self-insured employers not being able to pay obligations or otherwise becoming financially insolvent.

(E) The extent to which rating rules are likely to cause adverse selection in the large group market or to encourage small and midsize employers to self-insure.

(2) REPORTs.-Not later than 18 months after

9 the date of the enactment of this Act, the Commis10 sioner shall submit to Congress and the applicable 11 agencies a report on the study conducted under 12 paragraph (1). Such report shall include any rec13 ommendations the Commissioner deems appropriate 14 to ensure that the law does not provide incentives 15 for small and midsize employers to self-insure or cre16 ate adverse selection in the risk pools of large group 17 insurers and self-insured employers. Not later than 1818 months after the first day of Y1, the Commis19 sioner shall submit to Congress and the applicable 20 agencies an updated report on such study, including 21 updates on such recommendations. 
1 SEC. 214. NONDISCRIMINATION IN BENEFITS; PARITY IN MENTAL HEALTH AND SUBSTANCE ABUSE DISORDER BENEFITS.

5 health benefits plan shall comply with standards estab-

6 lished by the Commissioner to prohibit discrimination in

7 health benefits or benefit structures for qualifying health

8 benefits plans, building from section 702 of the Employee

9 Retirement Income Security Act of 1974, section 2702 of

10 the Public Health Service Act, and section 9802 of the

11 Internal Revenue Code of 1986.

12 (b) Parity in Mental Health and Substance

13 Abuse Disorder Benefits.-To the extent such provi-

14 sions are not superceded by or inconsistent with subtitle

$15 \mathrm{C}$, the provisions of section 2705 (other than subsections 16 (a)(1), (a)(2), and (c)) of the Public Health Service Act

17 shall apply to a qualified health benefits plan, regardless

18 of whether it is offered in the individual or group market,

19 in the same manner as such provisions apply to health

20 insurance coverage offered in the large group market.

21 SEC. 215. ENSURING ADEQUACY OF PROVIDER NETWORKS.

22 (a) In GEnERAL.-A qualified health benefits plan 23 that uses a provider network for items and services shall 24 meet such standards respecting provider networks as the 25 Commissioner may establish to assure the adequacy of 26 such networks in ensuring enrollee access to such items 
1 and services and transparency in the cost-sharing differen-

2 tials among providers participating in the network and

3 policies for accessing out-of-network providers.

4 (b) Internet ACCEss to InFormation.-A quali-

5 fied health benefits plan that uses a provider network shall

6 provide a current listing of all providers in its network

7 on its Website and such data shall be available on the

8 Health Insurance Exchange Website as a part of the basic

9 information on that plan. The Commissioner shall also es-

10 tablish an on-line system whereby an individual may select

11 by name any medical provider (as defined by the Commis-

12 sioner) and be informed of the plan or plans with which

13 that provider is contracting.

14 (c) Provider Network Defined.-In this division,

15 the term "provider network" means the providers with re-

16 spect to which covered benefits, treatments, and services

17 are available under a health benefits plan.

18 SEC. 216. REQUIRING THE OPTION OF EXTENSION OF DE-

PENDENT COVERAGE FOR UNINSURED YOUNG ADULTS.

21 (a) In GEneraL.-A qualified health benefits plan

22 shall make available, at the option of the principal enrollee

23 under the plan, coverage for one or more qualified children

24 (as defined in subsection (b)) of the enrollee. 
1 (b) Qualified Child Defined.-In this section, 2 the term "qualified child" means, with respect to a prin3 cipal enrollee in a qualified health benefits plan, an indi4 vidual who (but for age) would be treated as a dependent 5 child of the enrollee under such plan and who-

6

7

8 other than under this section.

9

10 strued as preventing a qualified health benefits plan from

11 increasing the premiums otherwise required for coverage

12 provided under this section consistent with standards es-

13 tablished by the Commissioner based upon family size

14 under section $213(\mathrm{a})(3)$.

15 SEC. 217. CONSISTENCY OF COSTS AND COVERAGE UNDER

18 In the case of health insurance coverage offered 19 under a qualified health benefits plan, if the coverage de20 creases or the cost-sharing increases, the issuer of the cov21 erage shall notify enrollees of the change at least 90 days 22 before the change takes effect (or such shorter period of 23 time in cases where the change is necessary to ensure the 24 health and safety of enrollees). 


\section{Subtitle C-Standards Guaran- 2 teeing Access to Essential Bene- 3 fits}

4 SEC. 221. COVERAGE OF ESSENTIAL BENEFITS PACKAGE.

5 (a) In GENERAL.-A qualified health benefits plan

6 shall provide coverage that at least meets the benefit

7 standards adopted under section 224 for the essential ben-

8 efits package described in section 222 for the plan year

9 involved.

10 (b) Choice of Coverage.-

11 (1) Non-EXChange-PARTICIPATING HEALTH

12 BENEFITS PLANS.-In the case of a qualified health

13 benefits plan that is not an Exchange-participating

14 health benefits plan, such plan may offer such cov-

15 erage in addition to the essential benefits package as

16 the QHBP offering entity may specify.

17 (2) Exchange-Participating health Bene-

18 FITS PLANS.-In the case of an Exchange-partici-

19 pating health benefits plan, such plan is required

20 under section 203 to provide specified levels of bene-

21 fits and, in the case of a plan offering a premium-

22 plus level of benefits, provide additional benefits.

23 (3) Continuation of offering of separate

24 EXCEPTED BENEFITS COVERAGE.-Nothing in this

25 division shall be construed as affecting the offering 
1 outside of the Health Insurance Exchange and

2 under State law of health benefits in the form of ex3 cepted benefits (described in section $4202(\mathrm{~b})(1)(\mathrm{B})(\mathrm{ii}))$ if such benefits are offered under 5 a separate policy, contract, or certificate of insur6 ance.

7 (c) Clinical Appropriateness.-Nothing in this 8 Act shall be construed to prohibit a group health plan or 9 health insurance issuer from using medical management 10 practices so long as such management practices are based 11 on valid medical evidence and are relevant to the patient 12 whose medical treatment is under review.

13 (d) Provision of Benefits.-Nothing in this divi14 sion shall be construed as prohibiting a qualified health 15 benefits plan from subcontracting with stand-alone health 16 insurance issuers or insurers for the provision of dental, 17 vision, mental health, and other benefits and services.

18 SEC. 222. ESSENTIAL BENEFITS PACKAGE DEFINED.

19 (a) IN GENERAL.-In this division, the term "essen20 tial benefits package" means health benefits coverage, 21 consistent with standards adopted under section 224, to 22 ensure the provision of quality health care and financial 23 security, that-

(1) provides payment for the items and services 25 described in subsection (b) in accordance with gen- 
1 erally accepted standards of medical or other appro-

2 priate clinical or professional practice;

3 (2) limits cost-sharing for such covered health

4 care items and services in accordance with such ben-

5 efit standards, consistent with subsection (c);

6 (3) does not impose any annual or lifetime limit

7 on the coverage of covered health care items and 8 services;

9 (4) complies with section 215(a) (relating to 10 network adequacy); and

11 (5) is equivalent in its scope of benefits, as cer12 tified by Office of the Actuary of the Centers for 13 Medicare \& Medicaid Services, to the average pre14 vailing employer-sponsored coverage in Y1.

15 In order to carry out paragraph (5), the Secretary of 16 Labor shall conduct a survey of employer-sponsored cov17 erage to determine the benefits typically covered by em18 ployers, including multiemployer plans, and provide a re19 port on such survey to the Health Benefits Advisory Com20 mittee and to the Secretary of Health and Human Serv21 ices.

22 (b) Minimum Services To Be Covered.- -Subject 23 to subsection (d), the items and services described in this 24 subsection are the following:

25 (1) Hospitalization. 
(2) Outpatient hospital and outpatient clinic services, including emergency department services.

(3) Professional services of physicians and other 4 health professionals.

(4) Such services, equipment, and supplies inci6 dent to the services of a physician's or a health pro7 fessional's delivery of care in institutional settings, 8 physician offices, patients' homes or place of resi9 dence, or other settings, as appropriate.

10 (5) Prescription drugs.

11 (6) Rehabilitative and habilitative services.

(7) Mental health and substance use disorder 13 services, including behavioral health treatments.

14 (8) Preventive services, including those services 15 recommended with a grade of $\mathrm{A}$ or $\mathrm{B}$ by the Task 16 Force on Clinical Preventive Services and those vac17 cines recommended for use by the Director of the 18 Centers for Disease Control and Prevention.

19 (9) Maternity care.

20 (10) Well-baby and well-child care and oral 21 health, vision, and hearing services, equipment, and 22 supplies for children under 21 years of age.

23 (11) Durable medical equipment, prosthetics, $24 \quad$ orthotics and related supplies. 
1 (c) Requirements Relating to Cost-Sharing

2 and Minimum Actuarial Value.-

(1) No Cost-SHARING For PREventive SERV-

4 ICES.- There shall be no cost-sharing under the es-

5 sential benefits package for-

6
(A) preventive items and services recommended with a grade of A or B by the Task Force on Clinical Preventive Services and those vaccines recommended for use by the Director of the Centers for Disease Control and Prevention; or

(B) well-baby and well-child care.

(2) Annual limitation.-

(A) Annual limitation.-The cost-sharing incurred under the essential benefits package with respect to an individual (or family) for a year does not exceed the applicable level specified in subparagraph (B).

(B) Applicable level.-The applicable level specified in this subparagraph for $\mathrm{Y} 1$ is not to exceed $\$ 5,000$ for an individual and not to exceed $\$ 10,000$ for a family. Such levels shall be increased (rounded to the nearest $\$ 100)$ for each subsequent year by the annual percentage increase in the enrollment-weighted 
average of premium increases for basic plans applicable to such year, except that Secretary shall adjust such increase to ensure that the applicable level specified in this subparagraph meets the minimum actuarial value required under paragraph (3).

(C) UsE of COPAYMENTS.-In establishing cost-sharing levels for basic, enhanced, and premium plans under this subsection, the Secretary shall, to the maximum extent possible, use only copayments and not coinsurance.

(A) IN GENERAL.—The cost-sharing under the essential benefits package shall be designed to provide a level of coverage that is designed to provide benefits that are actuarially equivalent to approximately 70 percent of the full actuarial value of the benefits provided under the reference benefits package described in subparagraph (B).

(B) Reference Benefits PACKAGE DESCRIBED._The reference benefits package described in this subparagraph is the essential benefits package if there were no cost-sharing 25 imposed. 
1 (d) Assessment and Counseling for Domestic

2 Violence.-The Secretary shall support the need for an 3 assessment and brief counseling for domestic violence as 4 part of a behavioral health assessment or primary care 5 visit and determine the appropriate coverage for such as6 sessment and counseling.

7 (e) Abortion Coverage Prohibited as Part of 8 Minimum Benefits Package.-

(1) Prohibition of Required coverage.-

10 The Health Benefits Advisory Committee may not 11 recommend under section $223(\mathrm{~b})$, and the Secretary 12 may not adopt in standards under section 224(b), 13 the services described in paragraph $(4)(\mathrm{A})$ or $(4)(\mathrm{B})$ 14 as part of the essential benefits package and the 15 Commissioner may not require such services for 16 qualified health benefits plans to participate in the 17 Health Insurance Exchange.

18 (2) Voluntary CHOICE OF COVERAGE BY 19 PLAN.-In the case of a qualified health benefits 20 plan, the plan is not required (or prohibited) under 21 this Act from providing coverage of services de22 scribed in paragraph $(4)(\mathrm{A})$ or $(4)(\mathrm{B})$ and the 23 QHBP offering entity shall determine whether such 24 coverage is provided. 
(3) Coverage under PUblic Health INSURANCE OPTION.-The public health insurance option shall provide coverage for services described in para-

4 graph (4)(B). Nothing in this Act shall be construed

5 as preventing the public health insurance option

6 from providing for or prohibiting coverage of serv7 ices described in paragraph (4)(A).

8

9

10

11

12

13

14

15

16

17

18

19
(4) Abortion services.-

(A) Abortions for which public fundING IS PROHIBITED.-The services described in this subparagraph are abortions for which the expenditure of Federal funds appropriated for the Department of Health and Human Services is not permitted, based on the law as in effect as of the date that is 6 months before the beginning of the plan year involved.

(B) Abortions for Which Public FundING Is ALLOWED.-The services described in this subparagraph are abortions for which the expenditure of Federal funds appropriated for the Department of Health and Human Services is permitted, based on the law as in effect as of the date that is 6 months before the beginning of the plan year involved. 
(f) Report Regarding Inclusion of OraL

2 Health Care in Essential Benefits Package.-Not

3 later than 1 year after the date of the enactment of this

4 Act, the Secretary of Health and Human Services shall

5 submit to Congress a report containing the results of a

6 study determining the need and cost of providing acces-

7 sible and affordable oral health care to adults as part of

8 the essential benefits package.

9 SEC. 223. HEALTH BENEFITS ADVISORY COMMITTEE.

10 (a) EstABLishMENT.-

11 (1) IN GENERAL.-There is established a pri-

12 vate-public advisory committee which shall be a

13 panel of medical and other experts to be known as

14 the Health Benefits Advisory Committee to rec-

15 ommend covered benefits and essential, enhanced, 16 and premium plans.

17 (2) ChaIR.-The Surgeon General shall be a 18 member and the chair of the Health Benefits Advi19 sory Committee.

20 (3) Membership.-The Health Benefits Advi21 sory Committee shall be composed of the following 22 members, in addition to the Surgeon General:

23 (A) Nine members who are not Federal 24 employees or officers and who are appointed by 25 the President. 
(B) Nine members who are not Federal employees or officers and who are appointed by

11 Such initial appointments shall be made not later 12 than 60 days after the date of the enactment of this 13 Act.

(4) Terms.-Each member of the Health Bene15 fits Advisory Committee shall serve a 3-year term on 16 the Committee, except that the terms of the initial 17 members shall be adjusted in order to provide for a 18 staggered term of appointment for all such mem19 bers.

(5) Participation.-The membership of the 21 Health Benefits Advisory Committee shall at least 22 reflect providers, patient representatives, employers 23 (including small employers), labor, health insurance 24 issuers, experts in health care financing and deliv25 ery, experts in oral health care, experts in racial and 
1 ethnic disparities, experts on health care needs and

2 disparities of individuals with disabilities, represent3 atives of relevant governmental agencies, and at

4 least one practicing physician or other health profes-

5 sional and an expert in child and adolescent health

6 and shall represent a balance among various sectors

7 of the health care system so that no single sector

8 unduly influences the recommendations of such

9 Committee.

10 (b) DUTIES.-

11 (1) ReCommendations on BenEFit stand12 ARDS.-The Health Benefits Advisory Committee 13 shall recommend to the Secretary of Health and 14 Human Services (in this subtitle referred to as the 15 "Secretary") benefit standards (as defined in para16 graph (5)), and periodic updates to such standards. 17 In developing such recommendations, the Committee 18 shall take into account innovation in health care and 19 consider how such standards could reduce health dis20 parities.

21 (2) Deadine.-The Health Benefits Advisory 22 Committee shall recommend initial benefit standards 23 to the Secretary not later than 1 year after the date 24 of the enactment of this Act. 
(3) State InPuT.-The Health Benefits Advi-

2 sory Committee shall examine the health coverage

3 laws and benefits of each State in developing rec-

4 ommendations under this subsection and may incor-

5 porate such coverage and benefits as the Committee

6 determines to be appropriate and consistent with

7 this Act. The Health Benefits Advisory Committee

8 shall also seek input from the States and consider

9 recommendations on how to ensure quality of health

10 coverage in all States.

11 (4) Public InPut.-The Health Benefits Advi12 sory Committee shall allow for public input as a part

13 of developing recommendations under this sub14 section.

(5) Benefit standards Defined.-In this

16 subtitle, the term "benefit standards" means stand17 ards respecting-

(A) the essential benefits package described in section 222, including categories of covered treatments, items and services within benefit classes, and cost-sharing consistent with subsection (d) of such section; and

(B) the cost-sharing levels for enhanced plans and premium plans (as provided under section 303(c)) consistent with paragraph (5). 
(6) Levels of COST-SHARING FOR ENHANCED AND PREMIUM PLANS.sharing for premium plans shall be designed so that such plans have benefits that are actuarially equivalent to approximately 95 percent of the actuarial value of the benefits provided under the reference benefits package described in section 222(c)(3)(B).

\section{(c) Operations.-}

(1) Per DIEm PAY.-Each member of the Health Benefits Advisory Committee shall receive travel expenses, including per diem in accordance with applicable provisions under subchapter I of 25 Ployees.-Members of the Health Benefits Advi- 
1 sory Committee shall not be considered employees of

2 the Federal Government solely by reason of any 3 service on the Committee, except such members shall

4 be considered to be within the meaning of section $5202($ a) of title 18, United States Code, for the pur6 poses of disclosure and management of conflicts of 7 interest.

8 (3) Application of Faca.-The Federal Advi9 sory Committee Act (5 U.S.C. App.), other than sec10 tion 14, shall apply to the Health Benefits Advisory 11 Committee.

12 (d) Publication.-The Secretary shall provide for 13 publication in the Federal Register and the posting on the 14 Internet Website of the Department of Health and Human 15 Services of all recommendations made by the Health Ben16 efits Advisory Committee under this section.

17 SEC. 224. PROCESS FOR ADOPTION OF RECOMMENDATIONS; ADOPTION OF BENEFIT STANDARDS.

(a) Process for Adoption of Recommenda-

20 TIONS.-

(1) Review of Recommended standards.-

22 Not later than 45 days after the date of receipt of 23 benefit standards recommended under section 223 24 (including such standards as modified under para25 graph (2)(B)), the Secretary shall review such 
1 standards and shall determine whether to propose

2 adoption of such standards as a package.

(2) Determination to adopt standards.-

4 If the Secretary determines-

(A) to propose adoption of benefit standards so recommended as a package, the Secretary shall, by regulation under section 553 of title 5, United States Code, propose adoption of such standards; or

(B) not to propose adoption of such standards as a package, the Secretary shall notify the Health Benefits Advisory Committee in writing of such determination and the reasons for not proposing the adoption of such recommendation and provide the Committee with a further opportunity to modify its previous recommendations and submit new recommendations to the Secretary on a timely basis.

(3) Contingency.-If, because of the application of paragraph $(2)(B)$, the Secretary would otherwise be unable to propose initial adoption of such recommended standards by the deadline specified in subsection (b)(1), the Secretary shall, by regulation under section 553 of title 5, United States Code, 
1 propose adoption of initial benefit standards by such

2 deadline.

3 (4) Publication.-The Secretary shall provide

4 for publication in the Federal Register of all deter-

5 minations made by the Secretary under this sub6 section.

7 (b) Adoption of Standards.-

8 (1) Initial standaRds.-Not later than 18 9 months after the date of the enactment of this Act, 10 the Secretary shall, through the rulemaking process 11 consistent with subsection (a), adopt an initial set of 12 benefit standards.

13 (2) PERIOdic UPDATING STANDARDS.-Under 14 subsection (a), the Secretary shall provide for the 15 periodic updating of the benefit standards previously 16 adopted under this section.

17 (3) REQUIREMEnT.-The Secretary may not 18 adopt any benefit standards for an essential benefits 19 package or for level of cost-sharing that are incon20 sistent with the requirements for such a package or 21 level under sections 222 (including subsection (d)) 22 and $223(\mathrm{~b})(5)$. 


\section{Subtitle D-Additional Consumer Protections}

3 SEC. 231. REQUIRING FAIR MARKETING PRACTICES BY HEALTH INSURERS.

5 The Commissioner shall establish uniform marketing

6 standards that all QHBP offering entities shall meet with

7 respect to qualified health benefits plans that are health 8 insurance coverage.

9 SEC. 232. REQUIRING FAIR GRIEVANCE AND APPEALS MECHANISIMS.

11 (a) IN GENERAL.—A QHBP offering entity shall pro12 vide for timely grievance and appeals mechanisms with re13 spect to qualified health benefits plans that the Commis14 sioner shall establish consistent with this section. The 15 Commissioner shall establish time limits for each of such 16 mechanisms and implement them in a manner that is pro17 tective to the needs of patients.

18 (b) Internal Clatms and Appeals Process.-

19 Under a qualified health benefits plan the QHBP offering 20 entity shall provide an internal claims and appeals process 21 that initially incorporates the claims and appeals proce22 dures (including urgent claims) set forth at section 23 2560.503-1 of title 29, Code of Federal Regulations, as 24 published on November 21, 2000 (65 Fed. Reg. 70246) 
1 and shall update such process in accordance with any

2 standards that the Commissioner may establish.

3 (c) External Review Process.-

4 (1) In gENERAL.-The Commissioner shall es-

5 tablish an external review process (including proce-

6 dures for expedited reviews of urgent claims) that

7 provides for an impartial, independent, and de novo

8 review of denied claims under this division.

9 (2) REQUIRING FAIR GRIEVANCE AND APPEALS

10 MECHANISMS.-A determination made, with respect

11 to a qualified health benefits plan offered by a

12 QHBP offering entity, under the external review

13 process established under this subsection shall be

14 binding on the plan and the entity.

15 (d) Tine Limits.-The Commissioner shall establish

16 time limits for each of these processes and implement

17 them in a manner that is protective to the patient.

18 (e) Construction.-Nothing in this section shall be 19 construed as affecting the availability of judicial review 20 under State law for adverse decisions under subsection (b)

21 or (c), subject to section 251.

22 SEC. 233. REQUIRING INFORMATION TRANSPARENCY AND 23 PLAN DISCLOSURE.

24 (a) Accurate and Timely Disclosure.- 
(1) For exchange-PARTicipating heAlth BENEFITS PLANS.-A QHBP offering entity offering

3 an Exchange-participating health benefits plan shall

4 comply with standards established by the Commis-

5 sioner for the accurate and timely disclosure to the

6 Commissioner and the public of plan documents,

7 plan terms and conditions, claims payment policies

8 and practices, periodic financial disclosure, data on

9 enrollment, data on disenrollment, data on the num-

10 ber of claims denials, data on rating practices, infor-

11 mation on cost-sharing and payments with respect to

12 any out-of-network coverage, and other information

13 as determined appropriate by the Commissioner.

14 (2) Employment-Based health Plans.-The

15 Secretary of Labor shall update and harmonize the

16 Secretary's rules concerning the accurate and timely

17 disclosure to participants by group health plans of

18 plan disclosure, plan terms and conditions, and peri-

19 odic financial disclosure with the standards estab-

20 lished by the Commissioner under paragraph (1).

(3) Use of Plain language.-

(A) In gENERAL.-The disclosures under paragraphs (1) and (2) shall be provided in 24 plain language. 
(B) Definition.-In this paragraph, the term "plain language" means language that the intended audience, including individuals with limited English proficiency, can readily understand and use because that language is concise, well-organized, and follows other best practices of plain language writing.

(C) Guidance.-The Commissioner and the Secretary of Labor shall jointly develop and issue guidance on best practices of plain lan13 tion disclosed under this subsection shall include in14 formation on enrollee and participant rights under 15 this division.

(5) Cost-Sharing Transparency.-A quali17 fied health benefits plan shall allow individuals to 18 learn the amount of cost-sharing (including 19 deductibles, copayments, and coinsurance) under the 20 individual's plan or coverage that the individual 21 would be responsible for paying with respect to the 22 furnishing of a specific item or service by a partici23 pating provider in a timely manner upon request. At 24 a minimum, this information shall be made available 
1 to such individual via an Internet Website and other

2 means for individuals without access to the Internet.

3 (b) Contracting Reimbursement.-A qualified

4 health benefits plan shall comply with standards estab-

5 lished by the Commissioner to ensure transparency to each

6 health care provider relating to reimbursement arrange-

7 ments between such plan and such provider.

8 (c) Pharmacy Benefit Managers Transparency

9 REQUiREMENTS.-

10 (1) IN GENERAL.-If a QHBP offering entity

11 contracts with a pharmacy benefit manager or other

12 entity (in this subsection referred to as a "PBM")

13 to manage prescription drug coverage or otherwise

14 control prescription drug costs under a qualified

15 health benefits plan, the PBM shall provide at least

16 annually to the Commissioner and to the QHBP of-

17 fering entity offering such plan the following infor-

18 mation, in a form and manner to be determined by

19 the Commissioner:

(A) Information on the number and total cost of prescriptions under the contract that are filled via mail order and at retail pharmacies.

(B) An estimate of aggregate average payments under the contract, per prescription 25 (weighted by prescription volume), made to mail 
order and retail pharmacies, and the average amount, per prescription, that the PBM was paid by the plan for prescriptions filled at mail order and retail pharmacists.

(C) An estimate of the aggregate average payment per prescription (weighted by prescription volume) under the contract received from pharmaceutical manufacturers, including all rebates, discounts, prices concessions, or administrative, and other payments from pharmaceutical manufacturers, and a description of the types of payments, and the amount of these payments that were shared with the plan, and a description of the percentage of prescriptions for which the PBM received such payments.

(D) Information on the overall percentage of generic drugs dispensed under the contract at retail and mail order pharmacies, and the percentage of cases in which a generic drug is dispensed when available.

(E) Information on the percentage and number of cases under the contract in which individuals were switched because of PBM policies or at the direct or indirect control of the PBM from a prescribed drug that had a lower 
cost for the QHBP offering entity to a drug that had a higher cost for the QHBP offering entity, the rationale for these switches, and a description of the PBM policies governing such switches.

(2) Confidentialitit of information.-In-

7 formation disclosed by a PBM to the Commissioner

8 or a QHBP offering entity under this subsection is

9 confidential and shall not be disclosed by the Com-

10 missioner or the QHBP offering entity in a form

11 which discloses the identity of a specific PBM or

12 prices charged by such PBM or a specific retailer,

13 manufacturer, or wholesaler, except only by the

14 Commissioner-

(A) to permit State or Federal law enforcement authorities to use the information pro17 vided for program compliance purposes and for 18 the purpose of combating waste, fraud, and 19 abuse;

(B) to permit the Comptroller General, the Medicare Payment Advisory Commission, or the Secretary of Health and Human Services to review the information provided; and 
(C) to permit the Director of the Congressional Budget Office to review the information provided.

(3) Annual Public RePort.-On an annual 5 basis, the Commissioner shall prepare a public re6 port providing industrywide aggregate or average in7 formation to be used in assessing the overall impact 8 of PBMs on prescription drug prices and spending. 9 Such report shall not disclose the identity of a spe10 cific PBM, or prices charged by such PBM, or a 11 specific retailer, manufacturer, or wholesaler, or any 12 other confidential or trade secret information.

13 (4) Penalties.-The provisions of subsection 14 (b)(3)(C) of section 1927 shall apply to a PBM that 15 fails to provide information required under sub16 section (a) or that knowingly provides false informa17 tion in the same manner as such provisions apply to 18 a manufacturer with an agreement under such sec19 tion that fails to provide information under sub20 section $(b)(3)(A)$ of such section or knowingly pro21 vides false information under such section, respec22 tively. 
1 SEC. 234. APPLICATION TO QUALIFIED HEALTH BENEFITS

4 The requirements of the previous provisions of this

5 subtitle shall apply to qualified health benefits plans that

6 are not being offered through the Health Insurance Ex-

7 change only to the extent specified by the Commissioner.

8 SEC. 235. TIMELY PAYMENT OF CLAIMS.

9 A QHBP offering entity shall comply with the re-

10 quirements of section 1857 (f) of the Social Security Act

11 with respect to a qualified health benefits plan it offers

12 in the same manner as a Medicare Advantage organization

13 is required to comply with such requirements with respect

14 to a Medicare Advantage plan it offers under part $\mathrm{C}$ of

15 Medicare.

16 SEC. 236. STANDARDIZED RULES FOR COORDINATION AND SUBROGATION OF BENEFITS.

18 The Commissioner shall establish standards for the

19 coordination and subrogation of benefits and reimburse-

20 ment of payments in cases of qualified health benefits

21 plans involving individuals and multiple plan coverage.

22 SEC. 237. APPLICATION OF ADMINISTRATIVE SIMPLIFICATION.

24 A QHBP offering entity is required to comply with 25 administrative simplification provisions under part $\mathrm{C}$ of 
1 title XI of the Social Security Act with respect to qualified

2 health benefits plans it offers.

3 SEC. 238. STATE PROHIBITIONS ON DISCRIMINATION AGAINST HEALTH CARE PROVIDERS.

5 This Act (and the amendments made by this Act)

6 shall not be construed as superseding laws, as they now

7 or hereinafter exist, of any State or jurisdiction designed

8 to prohibit a qualified health benefits plan from discrimi-

9 nating with respect to participation, reimbursement, cov-

10 ered services, indemnification, or related requirements

11 under such plan against a health care provider that is act-

12 ing within the scope of that provider's license or certifi-

13 cation under applicable State law.

14 SEC. 239. PROTECTION OF PHYSICIAN PRESCRIBER INFORMATION.

16 (a) STUDY.-The Secretary of Health and Human

17 Services shall conduct a study on the use of physician pre-

18 scriber information in sales and marketing practices of

19 pharmaceutical manufacturers.

20 (b) REPORT.-Based on the study conducted under 21 subsection (a), the Secretary shall submit to Congress a 22 report on actions needed to be taken by the Congress or 23 the Secretary to protect providers from biased marketing 24 and sales practices. 
1 SEC. 240. DISSEMINATION OF ADVANCE CARE PLANNING INFORMATION.

3 (a) In GENERAL.—The QHBP offering entity -

(1) shall provide for the dissemination of infor-

5 mation related to end-of-life planning to individuals

6 seeking enrollment in Exchange-participating health

7 benefits plans offered through the Exchange;

(2) shall present such individuals with-

(A) the option to establish advanced directives and physician's orders for life sustaining treatment according to the laws of the State in which the individual resides; and

(B) information related to other planning tools; and

(3) shall not promote suicide, assisted suicide, 16 euthanasia, or mercy killing.

17 The information presented under paragraph (2) shall not 18 presume the withdrawal of treatment and shall include 19 end-of-life planning information that includes options to 20 maintain all or most medical interventions.

21 (b) Construction.- Nothing in this section shall 22 be construed-

(1) to require an individual to complete an ad24 vanced directive or a physician's order for life sus25 taining treatment or other end-of-life planning docu26 ment; 
1 (2) to require an individual to consent to re2 strictions on the amount, duration, or scope of med3 ical benefits otherwise covered under a qualified $4 \quad$ health benefits plan; or

(3) to promote suicide, assisted suicide, eutha6 nasia, or mercy killing.

7 (c) Advanced Directive Defined.-In this sec8 tion, the term "advanced directive" includes a living will, 9 a comfort care order, or a durable power of attorney for 10 health care.

11 (d) Prohibition on the Promotion of Assisted 12 SUICIDE.-

13 (1) In GENERAL.- Subject to paragraph (3), 14 information provided to meet the requirements of 15 subsection (a)(2) shall not include advanced direc16 tives or other planning tools that list or describe as 17 an option suicide, assisted suicide, euthanasia, or 18 mercy killing, regardless of legality.

19 (2) Construction.-Nothing in paragraph (1) 20 shall be construed to apply to or affect any option 21 toment or medical care; (B) withhold or withdraw of nutrition or 25 hydration; and 
(C) provide palliative or hospice care or use an item, good, benefit, or service furnished for the purpose of alleviating pain or discomfort, even if such use may increase the risk of death, so long as such item, good, benefit, or service is not also furnished for the purpose of causing, or the purpose of assisting in causing, death, for any reason.

(3) No PREemption of state LaW.-Nothing 10 in this section shall be construed to preempt or oth11 erwise have any effect on State laws regarding ad12 vance care planning, palliative care, or end-of-life de13 cision-making.

\section{Subtitle E-Governance}

\section{SEC. 241. HEALTH CHOICES ADMINISTRATION; HEALTH} CHOICES COMMISSIONER.

17 (a) In GEnERAL.-There is hereby established, as an 18 independent agency in the executive branch of the Govern19 ment, a Health Choices Administration (in this division 20 referred to as the "Administration").

(b) Commissioner.-

(1) IN GENERAL.-The Administration shall be

23 headed by a Health Choices Commissioner (in this 24 division referred to as the "Commissioner") who 
1 shall be appointed by the President, by and with the

2 advice and consent of the Senate.

(2) Compensation; ETC.-The provisions of 4 paragraphs (2), (5), and (7) of subsection (a) (relat5 ing to compensation, terms, general powers, rule6 making, and delegation) of section 702 of the Social 7 Security Act (42 U.S.C. 902) shall apply to the 8 Commissioner and the Administration in the same 9 manner as such provisions apply to the Commis10 sioner of Social Security and the Social Security Ad11 ministration.

12 (c) Inspector GeneraL.-For provision estab13 lishing an Office of the Inspector General for the Health 14 Choices Administration, see section 1647.

15 SEC. 242. DUTIES AND AUTHORITY OF COMMISSIONER.

16 (a) Duties.-The Commissioner is responsible for 17 carrying out the following functions under this division: 18 (1) QUALIFIED PLAN STANDARDS.-The estab19 lishment of qualified health benefits plan standards 20 under this title, including the enforcement of such 21 standards in coordination with State insurance regu22 lators and the Secretaries of Labor and the Treas23 ury. 
(2) Health insurance exchange.-The es-

2 tablishment and operation of a Health Insurance

3 Exchange under subtitle A of title III.

(3) INDIVIDUAL AFFORDABILITY CREDITS.-

5 The administration of individual affordability credits

6 under subtitle $\mathrm{C}$ of title III, including determination

7 of eligibility for such credits.

8 (4) AdDitional FunCtions.-Such additional

9 functions as may be specified in this division.

10 (b) Promoting Accountability.-

11 (1) In gEneral.-The Commissioner shall un12 dertake activities in accordance with this subtitle to

13 promote accountability of QHBP offering entities in

14 meeting Federal health insurance requirements, re-

15 gardless of whether such accountability is with re16 spect to qualified health benefits plans offered 17 through the Health Insurance Exchange or outside 18 of such Exchange.

(2) Compliance examination and audits.-

(A) In GENERAL.—The Commissioner shall, in coordination with States, conduct audits of qualified health benefits plan compliance with Federal requirements. Such audits may include random compliance audits and targeted 
audits in response to complaints or other suspected noncompliance.

(B) Recoupment of costs in connecTION WITH EXAMINATION AND AUDITS.-The Commissioner is authorized to recoup from qualified health benefits plans reimbursement for the costs of such examinations and audit of such QHBP offering entities.

(c) Data Collection.-The Commissioner shall 10 collect data for purposes of carrying out the Commis11 sioner's duties, including for purposes of promoting qual12 ity and value, protecting consumers, and addressing dis13 parities in health and health care and may share such data 14 with the Secretary of Health and Human Services. (d) SAnCtions Authority.-

(1) In General.- - In the case that the Com17 missioner determines that a QHBP offering entity 18 violates a requirement of this title, the Commis19 sioner may, in coordination with State insurance 20 regulators and the Secretary of Labor, provide, in 21 addition to any other remedies authorized by law, 22 for any of the remedies described in paragraph (2). 23 (2) Remedies.-The remedies described in this 24 paragraph, with respect to a qualified health benefits 25 plan offered by a QHBP offering entity, are- 
(A) civil money penalties of not more than the amount that would be applicable under similar circumstances for similar violations under section $1857(\mathrm{~g})$ of the Social Security Act;

(B) suspension of enrollment of individuals under such plan after the date the Commissioner notifies the entity of a determination under paragraph (1) and until the Commissioner is satisfied that the basis for such determination has been corrected and is not likely to recur;

(C) in the case of an Exchange-participating health benefits plan, suspension of payment to the entity under the Health Insurance Exchange for individuals enrolled in such plan after the date the Commissioner notifies the entity of a determination under paragraph (1) and until the Secretary is satisfied that the basis for such determination has been corrected and is not likely to recur; or

(D) working with State insurance regulators to terminate plans for repeated failure by the offering entity to meet the requirements of this title. 
(e) Standard Definitions of Insurance and

2 Medical Terms.-The Commissioner shall provide for

3 the development of standards for the definitions of terms

4 used in health insurance coverage, including insurance-re-

5 lated terms.

6 (f) Efficiency in Administration.-The Commis-

7 sioner shall issue regulations for the effective and efficient

8 administration of the Health Insurance Exchange and af-

9 fordability credits under subtitle C, including, with respect

10 to the determination of eligibility for affordability credits,

11 the use of personnel who are employed in accordance with

12 the requirements of title 5, United States Code, to carry

13 out the duties of the Commissioner or, in the case of sec-

14 tions 308 and 341(b)(2), the use of State personnel who

15 are employed in accordance with standards prescribed by

16 the Office of Personnel Management pursuant to section

17208 of the Intergovernmental Personnel Act of 1970 (42

18 U.S.C. 4728).

19 SEC. 243. CONSULTATION AND COORDINATION.

20 (a) Consultation.-In carrying out the Commis-

21 sioner's duties under this division, the Commissioner, as

22 appropriate, shall consult at least with the following:

23 (1) State attorneys general and State insurance 24 regulators, including concerning the standards for 25 health insurance coverage that is a qualified health 
1 benefits plan under this title and enforcement of

2 such standards.

(2) The National Association of Insurance

4 Commissioners, including for purposes of using

5 model guidelines established by such association for 6 purposes of subtitles B and D.

7 (3) Appropriate State agencies, specifically con-

8 cerning the administration of individual affordability

9 credits under subtitle $\mathrm{C}$ of title III and the offering

10 of Exchange-participating health benefits plans, to

11 Medicaid eligible individuals under subtitle A of such 12 title.

13 (4) The Federal Trade Commission, specifically 14 concerning the development and issuance of guid15 ance, rules, or standards regarding fair marketing 16 practices under section 231 or otherwise, or any con17 sumer disclosure requirements under section 233 or 18 otherwise.

19 (5) Other appropriate Federal agencies.

20 (6) Indian tribes and tribal organizations.

21 (b) CoOrdination.-

22 (1) In GENERAL.-In carrying out the func23 tions of the Commissioner, including with respect to 24 the enforcement of the provisions of this division, 25 the Commissioner shall work in coordination with 
1 existing Federal and State entities to the maximum

2 extent feasible consistent with this division and in a

3 manner that prevents conflicts of interest in duties

$4 \quad$ and ensures effective enforcement.

5 (2) UNIFORM STANDARDS.-The Commissioner, 6 in coordination with such entities, shall seek to 7 achieve uniform standards that adequately protect 8 consumers in a manner that does not unreasonably $9 \quad$ affect employers and insurers.

10 SEC. 244. HEALTH INSURANCE OMBUDSMAN.

11 (a) In GEnERAL.-The Commissioner shall appoint 12 within the Health Choices Administration a Qualified 13 Health Benefits Plan Ombudsman who shall have exper14 tise and experience in the fields of health care and edu15 cation of (and assistance to) individuals.

16 (b) Duties.-The Qualified Health Benefits Plan 17 Ombudsman shall, in a linguistically appropriate man18 ner-

19 (1) receive complaints, grievances, and requests 20 for information submitted by individuals through 21 means such as the mail, by telephone, electronically, 22 and in person;

23 (2) provide assistance with respect to com24 plaints, grievances, and requests referred to in para25 graph (1), including- 
(A) helping individuals determine the relevant information needed to seek an appeal of a decision or determination;

(B) assistance to such individuals in choosing a qualified health benefits plan in which to enroll; problems arising from disenrollment from such a plan; and

(D) assistance to such individuals in presenting information under subtitle C (relating to affordability credits); and

14 Commissioner that describe the activities of the Om15 budsman and that include such recommendations for 16 improvement in the administration of this division as 17 the Ombudsman determines appropriate. The Om18 budsman shall not serve as an advocate for any in19 creases in payments or new coverage of services, but 20 may identify issues and problems in payment or cov21 erage policies. 


\section{Subtitle F-Relation to Other \\ 2 Requirements; Miscellaneous}

3 SEC. 251. RELATION TO OTHER REQUIREMENTS.

4 (a) Coverage Not Offered Through Ex5 Change.-

(1) In GENERAL.-In the case of health insur-

7 ance coverage not offered through the Health Insur-

8 ance Exchange (whether or not offered in connection

9 with an employment-based health plan), and in the

10 case of employment-based health plans, the require-

11 ments of this title do not supercede any require-

12 ments applicable under titles XXII and XXVII of

13 the Public Health Service Act, parts 6 and 7 of sub-

14 title B of title I of the Employee Retirement Income

15 Security Act of 1974, or State law, except insofar as

16 such requirements prevent the application of a re-

17 quirement of this division, as determined by the

18 Commissioner.

19 (2) Construction.-Nothing in paragraphs

20 (1) or (2) shall be construed as affecting the appli21 cation of section 514 of the Employee Retirement 22 Income Security Act of 1974.

23 (b) Coverage Offered Through Exchange.- 
(1) In GENERAL.-In the case of health insurance coverage offered through the Health Insurance 3 Exchange-

17 graph shall be construed as preventing the applica18 tion of rights and remedies under State laws to 19 health insurance issuers generally with respect to 20 any requirement referred to in paragraph (1)(A). 21 The previous sentence shall not be construed as pro22 viding for the applicability of rights or remedies 23 under State laws with respect to requirements appli24 cable to employers or other plan sponsors in connec25 tion with arrangements which are treated as group 
1 health plans under section 802(a)(1) of the Em-

2 ployee Retirement Income Security Act of 1974.

3 SEC. 252. PROHIBITING DISCRIMINATION IN HEALTH CARE.

4 (a) In GENERAL.-Except as otherwise explicitly per-

5 mitted by this Act and by subsequent regulations con-

6 sistent with this Act, all health care and related services

7 (including insurance coverage and public health activities)

8 covered by this Act shall be provided without regard to

9 personal characteristies extraneous to the provision of

10 high quality health care or related services.

11 (b) Implementation.-To implement the require-

12 ment set forth in subsection (a), the Secretary of Health

13 and Human Services shall, not later than 18 months after

14 the date of the enactment of this Act, promulgate such

15 regulations as are necessary or appropriate to insure that

16 all health care and related services (including insurance

17 coverage and public health activities) covered by this Act

18 are provided (whether directly or through contractual, li-

19 censing, or other arrangements) without regard to per-

20 sonal characteristics extraneous to the provision of high

21 quality health care or related services.

22 SEC. 253. WHISTLEBLOWER PROTECTION.

23 (a) Retaliation Prohibited.-No employer may

24 discharge any employee or otherwise discriminate against

25 any employee with respect to his compensation, terms, 
1 conditions, or other privileges of employment because the

2 employee (or any person acting pursuant to a request of

3 the employee)-

4 (1) provided, caused to be provided, or is about

5 to provide or cause to be provided to the employer,

6 the Federal Government, or the attorney general of

7 a State information relating to any violation of, or

8 any act or omission the employee reasonably believes

9 to be a violation of any provision of this Act or any

10 order, rule, or regulation promulgated under this

11 Act;

12 (2) testified or is about to testify in a pro-

13 ceeding concerning such violation;

14 (3) assisted or participated or is about to assist

15 or participate in such a proceeding; or

16 (4) objected to, or refused to participate in, any

17 activity, policy, practice, or assigned task that the

18 employee (or other such person) reasonably believed

19 to be in violation of any provision of this Act or any

20 order, rule, or regulation promulgated under this 21 Act.

22 (b) Enforcement ACTIOn.-An employee covered 23 by this section who alleges discrimination by an employer 24 in violation of subsection (a) may bring an action governed 25 by the rules, procedures, legal burdens of proof, and rem- 
1 edies set forth in section 40(b) of the Consumer Product

2 Safety Act (15 U.S.C. 2087(b)).

3 (c) Employer Defined.-As used in this section, 4 the term "employer" means any person (including one or 5 more individuals, partnerships, associations, corporations, 6 trusts, professional membership organization including a 7 certification, disciplinary, or other professional body, unin8 corporated organizations, nongovernmental organizations, 9 or trustees) engaged in profit or nonprofit business or in10 dustry whose activities are governed by this Act, and any

11 agent, contractor, subcontractor, grantee, or consultant of 12 such person.

13 (d) Rule of Construction.-The rule of construc14 tion set forth in section 20109(h) of title 49, United 15 States Code, shall also apply to this section.

16 SEC. 254. CONSTRUCTION REGARDING COLLECTIVE BARGAINING.

18 Nothing in this division shall be construed to alter 19 or supersede any statutory or other obligation to engage 20 in collective bargaining over the terms or conditions of em21 ployment related to health care. Any plan amendment 22 made pursuant to a collective bargaining agreement relat23 ing to the plan which amends the plan solely to conform 24 to any requirement added by this division shall not be 
1 treated as a termination of such collective bargaining

2 agreement.

3 SEC. 255. SEVERABILITY.

4 If any provision of this Act, or any application of such

5 provision to any person or circumstance, is held to be un-

6 constitutional, the remainder of the provisions of this Act

7 and the application of the provision to any other person

8 or circumstance shall not be affected.

9 SEC. 256. TREATMENT OF HAWAII PREPAID HEALTH CARE ACT.

11 (a) IN GENERAL.—Subject to this section-

12 (1) nothing in this division (or an amendment

13 made by this division) shall be construed to modify

14 or limit the application of the exemption for the Ha-

15 waii Prepaid Health Care Act (Haw. Rev. Stat. §§

16 393-1 et seq.) as provided for under section

$17514(\mathrm{~b})(5)$ of the Employee Retirement Income Secu-

18 rity Act of 1974 (29 U.S.C. 1144(b)(5)), and such

19 exemption shall also apply with respect to the provi-

20 sions of this division; and

21 (2) for purposes of this division (and the 22 amendments made by this division), coverage pro23 vided pursuant to the Hawaii Prepaid Health Care 24 Act shall be treated as a qualified health benefits 25 plan providing acceptable coverage so long as the 
1 Secretary of Labor determines that such coverage

2 for employees (taking into account the benefits and

3 the cost to employees for such benefits) is substan-

4 tially equivalent to or greater than the coverage pro-

5 vided for employees pursuant to the essential bene-

6 fits package.

7 (b) Coordination With State Law of Hawait.-

8 The Commissioner shall, based on ongoing consultation

9 with the appropriate officials of the State of Hawaii, make

10 adjustments to rules and regulations of the Commissioner

11 under this division as may be necessary, as determined

12 by the Commissioner, to most effectively coordinate the

13 provisions of this division with the provisions of the Ha-

14 waii Prepaid Health Care Act, taking into account any

15 changes made from time to time to the Hawaii Prepaid

16 Health Care Act and related laws of such State.

17 SEC. 257. ACTIONS BY STATE ATTORNEYS GENERAL.

18 Any State attorney general may bring a civil action 19 in the name of such State as parens patriae on behalf of 20 natural persons residing in such State, in any district 21 court of the United States or State court having jurisdic-

22 tion of the defendant to secure monetary or equitable relief

23 for violation of any provisions of this title or regulations 24 issued thereunder. Nothing in this section shall be con- 
1 strued as affecting the application of section 514 of the

2 Employee Retirement Income Security Act of 1974.

3 SEC. 258. APPLICATION OF STATE AND FEDERAL LAWS REGARDING ABORTION.

5 (a) No Preemption of State Laws Regarding 6 ABORTIOn.-Nothing in this Act shall be construed to

7 preempt or otherwise have any effect on State laws regard-

8 ing the prohibition of (or requirement of) coverage, fund-

9 ing, or procedural requirements on abortions, including

10 parental notification or consent for the performance of an 11 abortion on a minor.

12 (b) No Effect on Federal Laws Regarding

13 Abortion.-

(1) In GENERAL.-Nothing in this Act shall be

15 construed to have any effect on Federal laws regard16 ing-

(A) conscience protection;

(B) willingness or refusal to provide abortion; and

(C) discrimination on the basis of the willingness or refusal to provide, pay for, cover, or refer for abortion or to provide or participate in training to provide abortion.

24 (c) No Effect on Federal Civil Rights Law.25 Nothing in this section shall alter the rights and obliga- 
1 tions of employees and employers under title VII of the

2 Civil Rights Act of 1964 .

3 SEC. 259. NONDISCRIMINATION ON ABORTION AND RESPECT FOR RIGHTS OF CONSCIENCE.

5 (a) Nondiscrimination.-A Federal agency or pro6 gram, and any State or local government that receives 7 Federal financial assistance under this Act (or an amend8 ment made by this Act), may not-

(1) subject any individual or institutional health 10 care entity to discrimination; or

(2) require any health plan created or regulated 12 under this Act (or an amendment made by this Act) 13 to subject any individual or institutional health care 14 entity to discrimination,

15 on the basis that the health care entity does not provide, 16 pay for, provide coverage of, or refer for abortions.

17 (b) Definition.-In this section, the term "health 18 care entity" includes an individual physician or other 19 health care professional, a hospital, a provider-sponsored 20 organization, a health maintenance organization, a health 21 insurance plan, or any other kind of health care facility, 22 organization, or plan.

23 (c) Administration.-The Office for Civil Rights of 24 the Department of Health and Human Services is des25 ignated to receive complaints of discrimination based on 
1 this section, and coordinate the investigation of such com-

2 plaints.

3 SEC. 260. AUTHORITY OF FEDERAL TRADE COMMISSION.

4 Section 6 of the Federal Trade Commission Act (15

5 U.S.C. 46) is amended by striking "and prepare reports"

6 and all that follows and inserting the following: "and pre-

7 pare reports, and to share information under clauses (f)

8 and (k), relating to the business of insurance. Notwith-

9 standing section 4, such authority shall include the au-

10 thority to conduct studies and prepare reports, and to

11 share information under clauses (f) and (k), relating to

12 the business of insurance, without regard to whether the

13 entity or entities that is the subject of such studies, re-

14 ports, or information is a for-profit or not-for-profit enti-

15 ty.".

16 SEC. 261. CONSTRUCTION REGARDING STANDARD OF CARE.

18 (a) In GENERAL.-The development, recognition, or 19 implementation of any guideline or other standard under 20 a provision described in subsection (b) shall not be con21 strued to establish the standard of care or duty of care 22 owed by health care providers to their patients in any med23 ical malpractice action or claim (as defined in section 24 431(7) of the Health Care Quality Improvement Act of 251986 (42 U.S.C. $11151(7)$ ). 
1 (b) Provisions Described.-The provisions de-

2 scribed in this subsection are the following:

3

4

5

6

7

8

9

10

11

12 23 amended by adding at the end the following:

25 contained in this Act shall modify, impair, or supersede

(1) Section 324 (relating to modernized payment initiatives and delivery system reform under the public health option).

(2) The amendments made by section 1151 (relating to reducing potentially preventable hospital readmissions).

(3) The amendments made by section 1751 (relating to health care acquired conditions).

(4) Section 3131 of the Public Health Service Act (relating to the Task Force on Clinical Preventive Services), added by section 2301.

(5) Part D of title IX of the Public Health Service Act (relating to implementation of best practices in the delivery of health care), added by section 2401.

SEC. 262. RESTORING APPLICATION OF ANTITRUST LAWS TO HEALTH SECTOR INSURERS.

(a) Amendment to McCarran-Ferguson ACt.-

Section 3 of the Act of March 9, 1945 (15 U.S.C. 1013), commonly known as the McCarran-Ferguson Act, is

“(c)(1) Except as provided in paragraph (2), nothing 
1 the operation of any of the antitrust laws with respect to

2 price fixing, market allocation, or monopolization (or at3 tempting to monopolize) by-

4 "(A) a person engaged in the business of health

5 insurance, in connection with providing health insur6 ance; or

$7 \quad$ "(B) a person engaged in the business of med8 ical malpractice insurance, in connection with pro$9 \quad$ viding medical malpractice insurance.

10 “(2) Paragraph (1) shall not apply to-

11 “(A) collecting, compiling, classifying, or dis12 seminating historical loss data;

13 “(B) determining a loss development factor ap14 plicable to historical loss data;

15 "(C) performing actuarial services if doing so 16 does not involve a restraint of trade; or

17 "(D) information gathering and rate setting ac18 tivities of a State insurance commission or other 19 State regulatory entity with authority to set insur20 ance rates.

21 "(3) For purposes of this subsection-

22 "(A) the term 'antitrust laws' has the meaning 23 given it in subsection (a) of the first section of the 24 Clayton Act, except that such term includes section 255 of the Federal Trade Commission Act to the ex- 
1 tent that such section 5 applies to unfair methods of

2 competition;

3 "(B) the term 'historical loss data' means infor4 mation respecting claims paid, or reserves held for 5 claims reported, by any person engaged in the busi6 ness of insurance; and

$7 \quad$ “(C) the term 'loss development factor' means 8 an adjustment to be made to the aggregate of losses 9 incurred during a prior period of time that have 10 been paid, or for which claims have been received 11 and reserves are being held, in order to estimate the 12 aggregate of the losses incurred during such period 13 that will ultimately be paid.".

14 (b) Related Provision.-For purposes of section 155 of the Federal Trade Commission Act (15 U.S.C. 45) 16 to the extent such section applies to unfair methods of 17 competition, section 3(c) of the McCarran-Ferguson Act 18 shall apply with respect to the business of health insur19 ance, and with respect to the business of medical mal20 practice insurance, without regard to whether such busi21 ness is carried on for profit, notwithstanding the definition 22 of "Corporation" contained in section 4 of the Federal 23 Trade Commission Act.

24 (c) Related Preservation of Antitrust 25 Laws.-Except as provided in subsections (a) and (b), 
1 nothing in this Act, or in the amendments made by this

2 Act, shall be construed to modify, impair, or supersede

3 the operation of any of the antitrust laws. For purposes

4 of the preceding sentence, the term "antitrust laws" has

5 the meaning given it in subsection (a) of the first section

6 of the Clayton Act, except that it includes section 5 of

7 the Federal Trade Commission Act to the extent that such

8 section 5 applies to unfair methods of competition.

9 SEC. 263. STUDY AND REPORT ON METHODS TO INCREASE EHR USE BY SMALL HEALTH CARE PROVIDERS.

12 (a) STUDY.-The Secretary of Health and Human

13 Services shall conduct a study of potential methods to in-

14 crease the use of qualified electronic health records (as 15 defined in section 3000(13) of the Public Health Service

16 Act) by small health care providers. Such study shall con17 sider at least the following methods:

18 (1) Providing for higher rates of reimbursement 19 or other incentives for such health care providers to 20 use electronic health records (taking into consider21 ation initiatives by private health insurance compa22 nies and incentives provided under Medicare under 23 title XVIII of the Social Security Act, Medicaid 24 under title XIX of such Act, and other programs). 
(2) Promoting low-cost electronic health record

2 software packages that are available for use by such

3 health care providers, including software packages

4 that are available to health eare providers through

5 the Veterans Administration and other sources.

6 (3) Training and education of such health care

7 providers on the use of electronic health records.

8 (4) Providing assistance to such health care

9 providers on the implementation of electronic health 10 records.

11 (b) REPORT.-Not later than December 31, 2013, 12 the Secretary of Health and Human Services shall submit 13 to Congress a report containing the results of the study 14 conducted under subsection (a), including recommenda15 tions for legislation or administrative action to increase 16 the use of electronic health records by small health care 17 providers that include the use of both public and private 18 funding sources. 


\section{TITLE III-HEALTH INSURANCE}

2

3

4

5

6

9 the Health Choices Administration and under the direc-

10 tion of the Commissioner a Health Insurance Exchange

11 in order to facilitate access of individuals and employers,

12 through a transparent process, to a variety of choices of

13 affordable, quality health insurance coverage, including a

14 public health insurance option.

(b) Outuine of Duties of Commissioner.-In ac-

16 cordance with this subtitle and in coordination with appro-

17 priate Federal and State officials as provided under sec-

18 tion 243(b), the Commissioner shall-

(1) under section 304 establish standards for,

20 accept bids from, and negotiate and enter into con-

21 tracts with, QHBP offering entities for the offering

22 of health benefits plans through the Health Insur-

23 ance Exchange, with different levels of benefits re-

24 quired under section 303, and including with respect

25 to oversight and enforcement; 
(2) under section 305 facilitate outreach and

2 enrollment in such plans of Exchange-eligible indi-

3 viduals and employers described in section 302; and

4 (3) conduct such activities related to the Health

5 Insurance Exchange as required, including establish-

6 ment of a risk pooling mechanism under section 306

7 and consumer protections under subtitle D of title

8 II.

9 SEC. 302. EXCHANGE-ELIGIBLE INDIVIDUALS AND EMPLOY10 ERS.

11 (a) Access to Coverage.-In accordance with this

12 section, all individuals are eligible to obtain coverage

13 through enrollment in an Exchange-participating health

14 benefits plan offered through the Health Insurance Ex-

15 change unless such individuals are enrolled in another

16 qualified health benefits plan or other acceptable coverage.

17 (b) Definitions.-In this division:

18 (1) EXChange-ELIGIBLE INDIVIDUAL.-The

19 term "Exchange-eligible individual" means an indi-

20 vidual who is eligible under this section to be en-

21 rolled through the Health Insurance Exchange in an

22 Exchange-participating health benefits plan and,

23 with respect to family coverage, includes dependents

24 of such individual. 
(2) Exchange-Eligible EMPLOyer.-The term "Exchange-eligible employer" means an em3 ployer that is eligible under this section to enroll 4 through the Health Insurance Exchange employees 5 of the employer (and their dependents) in Exchange6 eligible health benefits plans.

(3) EMPLOYMENT-RELATED DEFINITIONS.-

8 The terms "employer", "employee", "full-time em9 ployee", and "part-time employee" have the mean10 ings given such terms by the Commissioner for pur11 poses of this division.

12 (c) Transition.-Individuals and employers shall 13 only be eligible to enroll or participate in the Health Insur14 ance Exchange in accordance with the following transition 15 schedule:

(1) FIRST YEAR.-In Y1 (as defined in section $17 \quad 100(\mathrm{c}))-$

(A) individuals described in subsection (d)(1), including individuals described in subsection $(d)(3)$; and

(B) smallest employers described in subsection (e)(1).

(2) SECOND YEAR.-In Y2-

(A) individuals and employers described in paragraph (1); and 
(B) smaller employers described in subsection $(\mathrm{e})(2)$.

(3) Third And subsequent YeARs.-In Y3-

(A) individuals and employers described in paragraph $(2)$; Commissioner under subsection (e)(4).

(1) InDIVIDUAL DESCRIBED.-Subject to the 12 succeeding provisions of this subsection, an indi13 vidual described in this paragraph is an individual 14 who-

(A) is not enrolled in coverage described in subparagraph (C) or (D) of paragraph (2); and

22 For purposes of subparagraph (B), in the case of an 23 individual who is self-employed, who has at least 1 24 employee, and who meets the requirements of section 
1412 , such individual shall be deemed a full-time em-

2 ployee described in such subparagraph.

(2) Acceptable coverage.-For purposes of 4 this division, the term "acceptable coverage" means 5 any of the following:

(A) Qualified health Benefits Plan COVERAGE.-Coverage under a qualified health benefits plan.

(B) Grandfathered health insurance COVERAGE; COVERAGE UNDER CURRENT GROUP HEALTH PLAN.-Coverage under a grandfathered health insurance coverage (as defined in subsection (a) of section 202) or under a current group health plan (described in subsection (b) of such section).

(C) Medicare.-Coverage under part A of title XVIII of the Social Security Act.

(D) Medicaid.-Coverage for medical assistance under title XIX of the Social Security Act, excluding such coverage that is only available because of the application of subsection (u), (z), or (aa) of section 1902 of such Act.

(E) Members OF THE ARMed FORCES AND DEPENDENTS (INCLUDING TRICARE).Coverage under chapter 55 of title 10, United 
States Code, including similar coverage furnished under section 1781 of title 38 of such Code.

(F) VA.-Coverage under the veteran's health care program under chapter 17 of title 38, United States Code.

(G) OTher COverage.-Such other health benefits coverage, such as a State health benefits risk pool, as the Commissioner, in coordination with the Secretary of the Treasury, recognizes for purposes of this paragraph.

The Commissioner shall make determinations under this paragraph in coordination with the Secretary of the Treasury.

(3) Continuing Eligibility Permitted.-

(A) In GENERAL.-Except as provided in subparagraph (B), once an individual qualifies as an Exchange-eligible individual under this subsection (including as an employee or dependent of an employee of an Exchange-eligible employer) and enrolls under an Exchange-participating health benefits plan through the Health Insurance Exchange, the individual shall continue to be treated as an Exchange-eligible individual until the individual is no longer enrolled 
with an Exchange-participating health benefits plan.

(B) Exceptions.-

(i) IN GENERAL.-Subparagraph (A) shall not apply to an individual once the

23 dividual who is eligible for child health assistance 24 under title XXI of the Social Security Act for a pe- 
1 riod during Y1 shall not be an Exchange-eligible in-

2 dividual during such period.

3 (e) EMployers.-

(1) Smallest EmPlOYeR.-Subject to para5 graph (5), smallest employers described in this para6 graph are employers with 25 or fewer employees.

(2) Smaller employers.-Subject to para8 graph (5), smaller employers described in this para9 graph are employers that are not smallest employers 10 described in paragraph (1) and have 50 or fewer em11 ployees.

13 (5), small employers described in this paragraph are 14 employers that are not described in paragraph (1) or 15 (2) and have 100 or fewer employees. (4) LARger EMPLOYERS.-

(A) IN GENERAL.-Beginning with Y3, the Commissioner may permit employers not described in paragraph (1), (2), or (3) to be Exchange-eligible employers.

(B) Phase-IN._-In applying subparagraph (A), the Commissioner may phase-in the application of such subparagraph based on the number of full-time employees of an employer and 
such other considerations as the Commissioner deems appropriate.

(5) Continuing Eligibility.-Once an em-

4 ployer is permitted to be an Exchange-eligible em-

5 ployer under this subsection and enrolls employees

6 through the Health Insurance Exchange, the em-

7 ployer shall continue to be treated as an Exchange-

8 eligible employer for each subsequent plan year re-

9 gardless of the number of employees involved unless

10 and until the employer meets the requirement of sec-

11 tion 411(a) through paragraph (1) of such section

12 by offering a group health plan and not through of-

13 fering an Exchange-participating health benefits 14 plan.

(6) EMPLOYER PARTICIPATION AND CONTRIBU16 TIONS.-

(A) SATisfaction OF EMPLOYER RESPONSIBILITY._For any year in which an employer is an Exchange-eligible employer, such employer may meet the requirements of section 412 with respect to employees of such employer by offering such employees the option of enrolling with Exchange-participating health benefits plans through the Health Insurance Exchange con- 
sistent with the provisions of subtitle B of title IV.

(B) Employee CHOICE.-Any employee offered Exchange-participating health benefits plans by the employer of such employee under subparagraph (A) may choose coverage under any such plan. That choice includes, with respect to family coverage, coverage of the dependents of such employee.

(7) Affiliated groups.-Any employer which 11 is part of a group of employers who are treated as 12 a single employer under subsection (b), (c), (m), or 13 (o) of section 414 of the Internal Revenue Code of 141986 shall be treated, for purposes of this subtitle, 15 as a single employer.

(8) Treatment of multi-employer 17 PLANS.-The plan sponsor of a group health plan 18 (as defined in section 773(a) of the Employee Re19 tirement Income Security Act of 1974) that is a 20 multi-employer plan (as defined in section 3(37) of 21 such Act) may obtain health insurance coverage with 22 respect to participants in the plan through the Ex23 change to the same extent that an employer not de24 scribed in paragraph (1) or (2) is permitted by the 25 Commissioner to obtain health insurance coverage 
1 through the Exchange as an Exchange-eligible em2 ployer.

(9) Other counting Rules.-The Commis-

4 sioner shall establish rules relating to how employees

5 are counted for purposes of carrying out this sub6 section.

7 (f) Special Situation Authority.-The Commis8 sioner shall have the authority to establish such rules as 9 may be necessary to deal with special situations with re10 gard to uninsured individuals and employers participating 11 as Exchange-eligible individuals and employers, such as 12 transition periods for individuals and employers who gain, 13 or lose, Exchange-eligible participation status, and to es14 tablish grace periods for premium payment.

15 (g) Surveys of Individuals and Employers.-

16 The Commissioner shall provide for periodic surveys of 17 Exchange-eligible individuals and employers concerning 18 satisfaction of such individuals and employers with the 19 Health Insurance Exchange and Exchange-participating 20 health benefits plans.

21 (h) Exchange Access Study.-

22 (1) In General.- The Commissioner shall con23 duct a study of access to the Health Insurance Ex24 change for individuals and for employers, including 25 individuals and employers who are not eligible and 
1 enrolled in Exchange-participating health benefits

2 plans. The goal of the study is to determine if there

3 are significant groups and types of individuals and

4 employers who are not Exchange-eligible individuals

5 or employers, but who would have improved benefits

6 and affordability if made eligible for coverage in the

$7 \quad$ Exchange.

8 (2) Items InCLUded IN STUdy.-Such study 9 also shall examine-

10 (A) the terms, conditions, and affordability 11 of group health coverage offered by employers 12 and QHBP offering entities outside of the Ex13 change compared to Exchange-participating 14 health benefits plans; and

(B) the affordability-test standard for access of certain employed individuals to coverage 19 in Y6, and thereafter, the Commissioner shall sub20 mit to Congress a report on the study conducted 21 under this subsection and shall include in such re22 port recommendations regarding changes in stand23 ards for Exchange eligibility for individuals and em24 ployers. 
1 SEC. 303. BENEFITS PACKAGE LEVELS.

2 (a) In GeneraL._-The Commissioner shall specify

3 the benefits to be made available under Exchange-partici-

4 pating health benefits plans during each plan year, con-

5 sistent with subtitle C of title II and this section.

6 (b) Limitation on Health Benefits Plans OF-

7 FERED By OFFERING ENTITIES.-The Commissioner may

8 not enter into a contract with a QHBP offering entity

9 under section 304(c) for the offering of an Exchange-par-

10 ticipating health benefits plan in a service area unless the

11 following requirements are met:

12

(1) REQUIRED OFFERING OF BASIC PLAN.-The

13 entity offers only one basic plan for such service 14 area.

15 (2) OPTIONAL OFFERING OF ENHANCED

16 PLAN. - If and only if the entity offers a basic plan

17 for such service area, the entity may offer one en-

18 hanced plan for such area.

19 (3) OPtional OFFERING OF PREMIUM PLAN.-

20 If and only if the entity offers an enhanced plan for 21 such service area, the entity may offer one premium 22 plan for such area.

23 (4) OPTIONAL OFFERING OF PREMIUM-PLUS 24 PLANS.-If and only if the entity offers a premium 25 plan for such service area, the entity may offer one 26 or more premium-plus plans for such area. 
1 All such plans may be offered under a single contract with

2 the Commissioner.

3 (c) Specification OF Benefit Levels FOR

4 Planis.-

5 (1) In GeneraL.-The Commissioner shall es-

6 tablish the following standards consistent with this

7 subsection and title II:

8

9

10

11

12

13

14

15

16

17

18

19

20

21

22

23

24
(A) Basic, Enhanced, AND PRemium PLANS.-Standards for 3 levels of Exchangeparticipating health benefits plans: basic, enhanced, and premium (in this division referred to as a "basic plan", "enhanced plan", and "premium plan", respectively).

(B) Premium-Plus Plan Benefits.Standards for additional benefits that may be offered, consistent with this subsection and subtitle $\mathrm{C}$ of title II, under a premium plan (such a plan with additional benefits referred to in this division as a "premium-plus plan") .

(2) BASIC PLAN.-

(A) In GENERAL.-A basic plan shall offer the essential benefits package required under title II for a qualified health benefits plan with an actuarial value of 70 percent of the full ac- 
tuarial value of the benefits provided under the reference benefits package.

(B) TIERED COST-SHARING FOR AFFORDABLE CREDIT ELIGIBLE INDIVIDUALS.-In the case of an affordable credit eligible individual (as defined in section 342(a)(1)) enrolled in an Exchange-participating health benefits plan, the benefits under a basic plan are modified to provide for the reduced cost-sharing for the income tier applicable to the individual under section $324(\mathrm{c})$.

(3) Enhanced Plan.-An enhanced plan shall offer, in addition to the level of benefits under the basic plan, a lower level of cost-sharing as provided under title II consistent with section 223(b)(5)(A). (4) Premium Plan.-A premium plan shall offer, in addition to the level of benefits under the basic plan, a lower level of cost-sharing as provided under title II consistent with section 223(b)(5)(B).

(5) Premium-Plus Plan.-A premium-plus plan is a premium plan that also provides additional benefits, such as adult oral health and vision care, approved by the Commissioner. The portion of the premium that is attributable to such additional benefits shall be separately specified. 
(6) Range of Permissible variation IN COST-SHARING.-CThe Commissioner shall establish a

3 permissible range of variation of cost-sharing for

4 each basic, enhanced, and premium plan, except with

5 respect to any benefit for which there is no cost-

6 sharing permitted under the essential benefits pack-

7 age. Such variation shall permit a variation of not

8 more than plus (or minus) 10 percent in cost-shar-

$9 \quad$ ing with respect to each benefit category specified

10 under section 222. Nothing in this subtitle shall be

11 construed as prohibiting tiering in cost-sharing, in-

12 cluding through preferred and participating pro-

13 viders and prescription drugs. In applying this para-

14 graph, a health benefits plan may increase the cost-

15 sharing by 10 percent within each category or tier,

16 as applicable, and may decrease or eliminate cost-

17 sharing in any category or tier as compared to the 18 essential benefits package.

19 (d) Treatment of State Benefit Mandates.-

20 Insofar as a State requires a health insurance issuer offer-

21 ing health insurance coverage to include benefits beyond

22 the essential benefits package, such requirement shall con-

23 tinue to apply to an Exchange-participating health bene-

24 fits plan, if the State has entered into an arrangement 25 satisfactory to the Commissioner to reimburse the Com- 
1 missioner for the amount of any net increase in afford-

2 ability premium credits under subtitle $\mathrm{C}$ as a result of an

3 increase in premium in basic plans as a result of applica-

4 tion of such requirement.

5 (e) Rules Regarding Coverage of and Afford6 Ability Credits for Specified Services.-

8 ERAgE Through THE HEALTh INSURANCE EX-

9 CHANGE.-The Commissioner shall assure that, of

10 the Exchange participating health benefits plan of-

11 fered in each premium rating area of the Health In12 surance Exchange-

(A) there is at least one such plan that provides coverage of services described in subparagraphs (A) and (B) of section 222(d)(4); and

(B) there is at least one such plan that does not provide coverage of services described in section $222(\mathrm{~d})(4)(\mathrm{A})$ which plan may also be one that does not provide coverage of services described in section 222(d)(4)(B).

23 health benefits plan provides coverage of services de24 scribed in section $222(\mathrm{~d})(4)(\mathrm{A})$, the plan shall pro- 
1 vide assurances satisfactory to the Commissioner

2 that-

(A) any affordability credits provided under subtitle $\mathrm{C}$ of title II are not used for purposes of paying for such services; and

(B) only premium amounts attributable to the actuarial value described in section 213(b) are used for such purpose.

SEC. 304. CONTRACTS FOR THE OFFERING OF EXCHANGEPARTICIPATING HEALTH BENEFITS PLANS.

(a) Contracting Duties.-In carrying out section 301(b)(1) and consistent with this subtitle:

(1) Offering ENTIty AND PLAN STANDARDS.-The Commissioner shall—

(A) establish standards necessary to implement the requirements of this title and title II for-

(i) QHBP offering entities for the offering of an Exchange-participating health benefits plan; and

(ii) Exchange-participating health benefits plans; and (B) certify QHBP offering entities and qualified health benefits plans as meeting such 
standards and requirements of this title and title II for purposes of this subtitle.

(2) Soliciting and Negotiating Bids; CON-

(A) Bid solicitation.-The Commis-

(C) Denial of excessive premiums.-
Commissioner shall deny excessive pre-

(C) Denial of Excessive Premiums.-
The Commissioner shall deny excessive premiums and premium increases. sioner shall solicit bids from QHBP offering entities for the offering of Exchange-participating health benefits plans. Such bids shall include justification for proposed premiums.

(B) Bid Review and negotiation.-The Commissioner shall, based upon a review of such bids including the premiums and their affordability, negotiate with such entities for the offering of such plans. (D) Contracts.-The Commissioner shall enter into contracts with such entities for the offering of such plans through the Health Insurance Exchange under terms (consistent with this title) negotiated between the Commissioner and such entities.

25 carrying out this subtitle, the Commissioner may 
1 waive such provisions of the Federal Acquisition

2 Regulation that the Commissioner determines to be

3 inconsistent with the furtherance of this subtitle,

4 other than provisions relating to confidentiality of

5 information. Competitive procedures shall be used in

6 awarding contracts under this subtitle to the extent

7 that such procedures are consistent with this sub-

8 title.

9 (b) Standards for QHBP Offering Entities To

10 Offer Exchange-Participating Health Benefits

11 Plans.-The standards established under subsection

12 (a)(1)(A) shall require that, in order for a QHBP offering

13 entity to offer an Exchange-participating health benefits

14 plan, the entity must meet the following requirements:

15 (1) LICENSED.-The entity shall be licensed to

16 offer health insurance coverage under State law for

17 each State in which it is offering such coverage.

18 (2) DATA REPORTING.-The entity shall pro-

19 vide for the reporting of such information as the

20 Commissioner may specify, including information

21 necessary to administer the risk pooling mechanism

22 described in section 306(b) and information to ad-

23 dress disparities in health and health care.

24 (3) AFFORDABILITY.-The entity shall provide 25 for affordable premiums. 
(4) Implementing AFFORDABILITy CRED-

2 ITS.-The entity shall provide for implementation of

3 the affordability credits provided for enrollees under

4 subtitle $\mathrm{C}$, including the reduction in cost-sharing

5 under section $344(\mathrm{c})$.

6 (5) EnRoLliment.-The entity shall accept all 7 enrollments under this subtitle, subject to such ex8 ceptions (such as capacity limitations) in accordance 9 with the requirements under title II for a qualified 10 health benefits plan. The entity shall notify the 11 Commissioner if the entity projects or anticipates 12 reaching such a capacity limitation that would result 13 in a limitation in enrollment.

14 (6) Risk POOLING PARTicipation.-The entity 15 shall participate in such risk pooling mechanism as 16 the Commissioner establishes under section 306(b).

17 (7) Essential community PROviders.-With 18 respect to the basic plan offered by the entity, the 19 entity shall include within the plan network those es20 sential community providers, where available, that 21 serve predominantly low-income, medically-under22 served individuals, such as health care providers de23 fined in section $340 \mathrm{~B}(\mathrm{a})(4)$ of the Public Health 24 Service Act and providers described in section $251927(\mathrm{c})(1)(\mathrm{D})(\mathrm{i})(\mathrm{IV})$ of the Social Security Act (as 
1 amended by section 221 of Public Law 111-8). The

2 Commissioner shall specify the extent to which and

3 manner in which the previous sentence shall apply in

4 the case of a basic plan with respect to which the

5 Commissioner determines provides substantially all

6 benefits through a health maintenance organization,

7 as defined in section 2791(b)(3) of the Public

8 Health Service Act. This paragraph shall not be con-

9 strued to require a basic plan to contract with a pro-

10 vider if such provider refuses to accept the generally

11 applicable payment rates of such plan.

12 (8) Culturally and Linguistically APPRO-

13 PRIATE SERVICES AND COMMUNICATIONS.-The en-

14 tity shall provide for culturally and linguistically ap-

15 propriate communication and health services.

16 (9) SPECIAL RUles With REsPeCt To INDIAN

17 ENROLLEes AND INDIAN HEALth CARE PRO18 VIDERS.-

19 (A) CHOICE OF PROviders.-The entity 20 shall-

(i) demonstrate to the satisfaction of the Commissioner that it has contracted with a sufficient number of Indian health 25 care providers to ensure timely access to covered services furnished by such pro- 
viders to individual Indians through the entity's Exchange-participating health benefits plan; and

(ii) agree to pay Indian health care providers, whether such providers are participating or nonparticipating providers with respect to the entity, for covered services provided to those enrollees who are eligible to receive services from such providers at a rate that is not less than the level and amount of payment which the entity would make for the services of a participating provider which is not an Indian health care provider.

(B) Special Rule Relating to indian HEALTH CARE PROVIDERS.-Provision of services by an Indian health care provider exclusively to Indians and their dependents shall not constitute discrimination under this Act.

(10) Program integrity standards.-The entity shall establish and operate a program to protect and promote the integrity of Exchange-participating health benefits plans it offers, in accordance with standards and functions established by the Commissioner. 
(11) Additional Requirements.-The entity

2 shall comply with other applicable requirements of

3 this title, as specified by the Commissioner, which

4 shall include standards regarding billing and collec-

5 tion practices for premiums and related grace peri-

6 ods and which may include standards to ensure that

7 the entity does not use coercive practices to force

8 providers not to contract with other entities offering

9 coverage through the Health Insurance Exchange.

$10 \quad$ (c) CONTRACTS.-

11 (1) Bid application.-To be eligible to enter

12 into a contract under this section, a QHBP offering

13 entity shall submit to the Commissioner a bid at

14 such time, in such manner, and containing such in-

15 formation as the Commissioner may require.

16 (2) TERM. - Each contract with a QHBP offer-

17 ing entity under this section shall be for a term of

18 not less than one year, but may be made automati-

19 cally renewable from term to term in the absence of

20 notice of termination by either party.

21 (3) ENForCement of NETWORK ADEQUACY.-

22 In the case of a health benefits plan of a QHBP of-

23 fering entity that uses a provider network, the con-

24 tract under this section with the entity shall provide

25 that if- 
(A) the Commissioner determines that such provider network does not meet such standards as the Commissioner shall establish under section 215; and

17 ing entities offering Exchange-participating health 18 benefits plans, including the marketing of such 19 plans. Such processes shall include the following:

(A) Grievance and Complaint mechaNIsMs.-The Commissioner shall establish, in coordination with State insurance regulators, a process under which Exchange-eligible individuals and employers may file complaints concerning violations of such standards. 
(B) ENForCEMENT.-In carrying out au-

thorities under this division relating to the Health Insurance Exchange, the Commissioner may impose one or more of the intermediate sanctions described in section $242(\mathrm{~d})$.

(C) Termination.-

(i) In general.- The Commissioner may terminate a contract with a QHBP offering entity under this section for the offering of an Exchange-participating health benefits plan if such entity fails to comply with the applicable requirements of this title. Any determination by the Commissioner to terminate a contract shall be made in accordance with formal investigation and compliance procedures established by the Commissioner under which-

(I) the Commissioner provides the entity with the reasonable opportunity to develop and implement a corrective action plan to correct the deficiencies that were the basis of the Commissioner's determination; and (II) the Commissioner provides the entity with reasonable notice and 
opportunity for hearing (including the right to appeal an initial decision) before terminating the contract.

(ii) EXCEPTION FOR IMMINENT AND SERIOUS RISK TO HEALTH.-Clause (i) shall not apply if the Commissioner determines that a delay in termination, resulting from compliance with the procedures specified in such clause prior to termination, would pose an imminent and serious risk to the health of individuals enrolled under the qualified health benefits plan of the QHBP offering entity. (D) Construction.-Nothing in this subsection shall be construed as preventing the application of other sanctions under subtitle $\mathrm{E}$ of title II with respect to an entity for a violation of such a requirement.

(5) SPECIAL RULE RELATED TO COST-SHARING AND INDIAN HEALTH CARE PROVIDERS.-The contract under this section with a QHBP offering entity for a health benefits plan shall provide that if an individual who is an Indian is enrolled in such a plan and such individual receives a covered item or service from an Indian health care provider (regardless 
1 of whether such provider is in the plan's provider

2 network), the cost-sharing for such item or service

3 shall be equal to the amount of cost-sharing that

4 would be imposed if such item or service-

5 (A) had been furnished by another pro6 vider in the plan's provider network; or

7 (B) in the case that the plan has no such 8 network, was furnished by a non-Indian pro9 vider.

10 (6) National Plan.-Nothing in this section 11 shall be construed as preventing the Commissioner 12 from entering into a contract under this subsection 13 with a QHBP offering entity for the offering of a 14 health benefits plan with the same benefits in every 15 State so long as such entity is licensed to offer such 16 plan in each State and the benefits meet the applica17 ble requirements in each such State.

18 (d) No Discrimination on the Basis of Provi19 SION OF ABORTION.-No Exchange participating health 20 benefits plan may discriminate against any individual 21 health care provider or health care facility because of its 22 willingness or unwillingness to provide, pay for, provide 23 coverage of, or refer for abortions. 
1 SEC. 305. OUTREACH AND ENROLLMENT OF EXCHANGE-ELIGIBLE INDIVIDUALS AND EMPLOYERS IN EXCHANGE-PARTICIPATING HEALTH BENEFITS PLAN.

(a) In GeneraL.-

(1) Outreach.—The Commissioner shall con7 duct outreach activities consistent with subsection 8 (c), including through use of appropriate entities as 9 described in paragraph (3) of such subsection, to in10 form and educate individuals and employers about 11 the Health Insurance Exchange and Exchange-par12 ticipating health benefits plan options. Such out13 reach shall include outreach specific to vulnerable 14 populations, such as children, individuals with dis15 abilities, individuals with mental illness, and individ16 uals with other cognitive impairments.

(2) Eligibility._-The Commissioner shall 18 make timely determinations of whether individuals 19 and employers are Exchange-eligible individuals and 20 employers (as defined in section 302).

21 (3) Enrollment.-The Commissioner shall es22 tablish and carry out an enrollment process for Ex23 change-eligible individuals and employers, including 24 at community locations, in accordance with sub25 section (b).

26 (b) Enrolliment Process.- 
(1) In GENERAL.-The Commissioner shall establish a process consistent with this title for enrollments in Exchange-participating health benefits

4 plans. Such process shall provide for enrollment

5 through means such as the mail, by telephone, elec6 tronically, and in person.

7

8

9

10

11

12
(2) Enroliment PERIOds.-

(A) Open EnRolliment PERIOD.-The Commissioner shall establish an annual open enrollment period during which an Exchange-eligible individual or employer may elect to enroll in an Exchange-participating health benefits plan for the following plan year and an enrollment period for affordability credits under subtitle C. Such periods shall be during September through November of each year, or such other time that would maximize timeliness of income verification for purposes of such subtitle. The open enrollment period shall not be less than 30 days.

(B) Spectal enrollment.-The Commissioner shall also provide for special enrollment periods to take into account special circumstances of individuals and employers, such as an individual who- 
(i) loses acceptable coverage;

(ii) experiences a change in marital or other dependent status;

(iii) moves outside the service area of the Exchange-participating health benefits plan in which the individual is enrolled; or (iv) experiences a significant change in income.

(C) Enrollment information.-The Commissioner shall provide for the broad dissemination of information to prospective enrollees on the enrollment process, including before each open enrollment period. In carrying out the previous sentence, the Commissioner may work with other appropriate entities to facilitate such provision of information.

(3) Automatic Enrollment For NON-MedICAID ELIGIBLE INDIVIDUALS.-

(A) In GENERAL.-The Commissioner shall provide for a process under which individuals who are Exchange-eligible individuals described in subparagraph (B) are automatically enrolled under an appropriate Exchange-participating health benefits plan. Such process may involve a random assignment or some other 
1 form of assignment that takes into account the health care providers used by the individual involved or such other relevant factors as the Commissioner may specify.

(B) Subsidized INDIVIduals DESCRIBED.-An individual described in this subparagraph is an Exchange-eligible individual who is either of the following:

(i) AFFordability CREDit Eligible INDIVIDUALS.—The individual—

(I) has applied for, and been determined eligible for, affordability credits under subtitle C; (II) has not opted out from receiving such affordability credit; and (III) does not otherwise enroll in another Exchange-participating health benefits plan.

(ii) INDIVIDUALS ENROLLED IN A TERMINATED PLAN.-The individual who is enrolled in an Exchange-participating health benefits plan that is terminated (during or at the end of a plan year) and who does not otherwise enroll in another 
Exchange-participating health benefits plan.

(4) Direct payment of preniums to PLANS.-Under the enrollment process, individuals

5 enrolled in an Exchange-participating health benefits

6 plan shall pay such plans directly, and not through

7 the Commissioner or the Health Insurance Ex8 change.

(c) Coverage Information and Assistance.-

11 sioner shall provide for the broad dissemination of 12 information on Exchange-participating health bene13 fits plans offered under this title. Such information 14 shall be provided in a comparative manner, and shall 15 include information on benefits, premiums, cost16 sharing, quality, provider networks, and consumer 17 satisfaction.

(2) Consumer assistance with Choice.-To 19 provide assistance to Exchange-eligible individuals 20 and employers, the Commissioner shall-

(A) provide for the operation of a toll-free telephone hotline to respond to requests for as24 sistance and maintain an Internet Web site through which individuals may obtain informa- 
tion on coverage under Exchange-participating health benefits plans and file complaints;

(B) develop and disseminate information to Exchange-eligible enrollees on their rights and responsibilities;

(3) UsE OF OTHER ENTITIES.-In carrying out

16 this subsection, the Commissioner may work with 17 other appropriate entities to facilitate the dissemina18 tion of information under this subsection and to pro19 vide assistance as described in paragraph (2).

20 (d) Coverage for Certain Newborns Under 21 MEDICAID.-

(1) IN GENERAL. - In the case of a child born 23 in the United States who at the time of birth is not 24 otherwise covered under acceptable coverage, for the 25 period of time beginning on the date of birth and 
1 ending on the date the child otherwise is covered

2 under acceptable coverage (or, if earlier, the end of

3 the month in which the 60-day period, beginning on

4 the date of birth, ends), the child shall be deemed-

5 (A) to be a Medicaid eligible individual for

6 purposes of this division and Medicaid; and

(B) to be automatically enrolled in Medicaid as a traditional Medicaid eligible individual (as defined in section 1943(c) of the Social Security Act).

(2) Extended treatment as Medicaid ELI-

12 GIBLE INDIVIDUAL.-In the case of a child described

13 in paragraph (1) who at the end of the period re-

14 ferred to in such paragraph is not otherwise covered

15 under acceptable coverage, the child shall be deemed

16 (until such time as the child obtains such coverage

17 or the State otherwise makes a determination of the 18 child's eligibility for medical assistance under its 19 Medicaid plan pursuant to section 1943(b)(1) of the 20 Social Security Act) to be a Medicaid eligible indi21 vidual described in section 1902(1)(1)(B) of such 22 Act.

23 (e) Medicaid Coverage for Medicaid Eligible 24 INDIVIDUALS.- 
(1) Medicaid enrollment obligation.-An

2 individual may apply, in the manner described in 3 section $341(b)(1)$, for a determination of whether

4 the individual is a Medicaid-eligible individual. If the 5 individual is determined to be so eligible, the Com6 missioner, through the Medicaid memorandum of 7 understanding under paragraph (2), shall provide 8 for the enrollment of the individual under the State 9 Medicaid plan in accordance with such memorandum 10 of understanding. In the case of such an enrollment, 11 the State shall provide for the same periodic redeter12 mination of eligibility under Medicaid as would oth13 erwise apply if the individual had directly applied for 14 medical assistance to the State Medicaid agency.

(2) Coordinated enrolliment with state 16 THROUGH MEMORANDUM OF UNDERSTANDING.17 The Commissioner, in consultation with the Sec18 retary of Health and Human Services, shall enter 19 into a memorandum of understanding with each 20 State with respect to coordinating enrollment of in21 dividuals in Exchange-participating health benefits 22 plans and under the State's Medicaid program con23 sistent with this section and to otherwise coordinate 24 the implementation of the provisions of this division 25 with respect to the Medicaid program. Such memo- 
1 randum shall permit the exchange of information

2 consistent with the limitations described in section $3 \quad 1902(a)(7)$ of the Social Security Act. Nothing in

4 this section shall be construed as permitting such 5 memorandum to modify or vitiate any requirement 6 of a State Medicaid plan.

7 (f) Effective Culturally and Linguistically 8 Appropritate Communication.-In carrying out this 9 section, the Commissioner shall establish effective methods 10 for communicating in plain language and a culturally and 11 linguistically appropriate manner.

12 (g) Role for Enrollment Agents and Bro13 KERS.-Nothing in this division shall be construed to af14 fect the role of enrollment agents and brokers under State 15 law, including with regard to the enrollment of individuals 16 and employers in qualified health benefits plans including 17 the public health insurance option.

18 (h) Assistance for Small Employers.-

19 (1) IN GENERAL.-The Commissioner, in con20 sultation with the Small Business Administration, 21 shall establish and carry out a program to provide 22 to small employers counseling and technical assist23 ance with respect to the provision of health insur24 ance to employees of such employers through the 25 Health Insurance Exchange. 
(2) Duties. - The program established under paragraph (1) shall include the following services:

(A) Educational activities to increase awareness of the Health Insurance Exchange and available small employer health plan options.

(B) Distribution of information to small employers with respect to the enrollment and selection process for health plans available under the Health Insurance Exchange, including standardized comparative information on the health plans available under the Health Insurance Exchange.

(C) Distribution of information to small employers with respect to available affordability credits or other financial assistance.

(D) Referrals to appropriate entities of complaints and questions relating to the Health Insurance Exchange.

(E) Enrollment and plan selection assistance for employers with respect to the Health Insurance Exchange.

(F) Responses to questions relating to the Health Insurance Exchange and the program established under paragraph (1). 
(3) Authority to PRovide services DIRECTLY OR BY CONTRACT.-The Commissioner may

3 provide services under paragraph (2) directly or by

4 contract with nonprofit entities that the Commis-

5 sioner determines capable of carrying out such serv6 ices.

(4) Small Employer Defined.-In this sub8 section, the term "small employer" means an em$9 \quad$ ployer with less than 100 employees.

10 (i) Participation of Small Employer Benefit 11 Arrangements.-

(1) In GENERAL.-The Commissioner may 13 enter into contracts with small employer benefit ar14 rangements to provide consumer information, out15 reach, and assistance in the enrollment of small em16 ployers (and their employees) who are members of 17 such an arrangement under Exchange participating 18 health benefits plans.

19 (2) SMALl EMPLOYER BENEFIT ARRANGEMENT 20 DEFINED.-In this subsection, the term "small em21 ployer benefit arrangement" means a not-for-profit 22 agricultural or other cooperative that-

23 (A) consists solely of its members and is 24 operated for the primary purpose of providing 25 affordable employee benefits to its members; 
(B) only has as members small employers in the same industry or line of business;

(C) has no member that has more than a 5 percent voting interest in the cooperative; and (D) is governed by a board of directors $6 \quad$ elected by its members.

\section{SEC. 306. OTHER FUNCTIONS.}

(a) Coordination of Affordability Credits.-

9 The Commissioner shall coordinate the distribution of af-

10 fordability premium and cost-sharing credits under sub-

11 title $\mathrm{C}$ to QHBP offering entities offering Exchange-par-

12 ticipating health benefits plans.

13 (b) Coordination of Risk Pooling.-The Com-

14 missioner shall establish a mechanism whereby there is an 15 adjustment made of the premium amounts payable among 16 QHBP offering entities offering Exchange-participating 17 health benefits plans of premiums collected for such plans 18 that takes into account (in a manner specified by the Com19 missioner) the differences in the risk characteristics of in20 dividuals and employees enrolled under the different Ex21 change-participating health benefits plans offered by such 22 entities so as to minimize the impact of adverse selection 23 of enrollees among the plans offered by such entities. For 24 purposes of the previous sentence, the Commissioner may 25 utilize data regarding enrollee demographics, inpatient 
1 and outpatient diagnoses (in a similar manner as such

2 data are used under parts $\mathrm{C}$ and $\mathrm{D}$ of title XVIII of the 3 Social Security Act), and such other information as the

4 Secretary determines may be necessary, such as the actual

5 medical costs of enrollees during the previous year.

\section{SEC. 307. HEALTH INSURANCE EXCHANGE TRUST FUND.}

7 (a) Establishment of Health Insurance Ex8 Change Trust Fund.-There is created within the 9 Treasury of the United States a trust fund to be known 10 as the "Health Insurance Exchange Trust Fund" (in this 11 section referred to as the "Trust Fund"), consisting of 12 such amounts as may be appropriated or credited to the

13 Trust Fund under this section or any other provision of 14 law.

15 (b) Payments From Trust Fund.-The Commis16 sioner shall pay from time to time from the Trust Fund 17 such amounts as the Commissioner determines are nec18 essary to make payments to operate the Health Insurance 19 Exchange, including payments under subtitle C (relating 20 to affordability credits).

21 (c) Transfers to Trust Fund.-

22 (1) Dedicated Payments.-There are hereby 23 appropriated to the Trust Fund amounts equivalent 24 to the following: 
(A) Taxes on individuals not obtainING ACCEPTABLE COVERAGE.-The amounts received in the Treasury under section 59B of the Internal Revenue Code of 1986 (relating to requirement of health insurance coverage for individuals).

(B) EMPloyment taXes ON EMPLOYERS NOT PROVIDING ACCEPTABLE COVERAGE.-The amounts received in the Treasury under sections 3111(c) and 3221(c) of the Internal Revenue Code of 1986 (relating to employers electing to not provide health benefits).

(C) Excise tax on failures to MeET CERTAIN HEALTH COVERAGE REQUIREMENTS.-The amounts received in the Treasury under section $4980 \mathrm{H}(\mathrm{b})$ (relating to excise tax with respect to failure to meet health coverage participation requirements).

(2) Appropriations to COVER GOVERnMent CONTRIBUTIONS.-There are hereby appropriated, out of any moneys in the Treasury not otherwise appropriated, to the Trust Fund, an amount equivalent to the amount of payments made from the Trust Fund under subsection (b) plus such amounts as are 
1 necessary reduced by the amounts deposited under 2 paragraph (1).

3 (d) Application of Certain Rules.-Rules simi-

4 lar to the rules of subchapter B of chapter 98 of the Inter5 nal Revenue Code of 1986 shall apply with respect to the 6 Trust Fund.

7 SEC. 308. OPTIONAL OPERATION OF STATE-BASED HEALTH INSURANCE EXCHANGES.

9 (a) IN GENERAL.-If-

10 (1) a State (or group of States, subject to the 11 approval of the Commissioner) applies to the Com12 missioner for approval of a State-based Health In13 surance Exchange to operate in the State (or group 14 of States); and

15 (2) the Commissioner approves such State16 based Health Insurance Exchange,

17 then, subject to subsections (c) and (d), the State-based 18 Health Insurance Exchange shall operate, instead of the 19 Health Insurance Exchange, with respect to such State 20 (or group of States). The Commissioner shall approve a 21 State-based Health Insurance Exchange if it meets the re22 quirements for approval under subsection (b).

23 (b) REQUiREMents For APPRoval.-

24 (1) In generaL.-The Commissioner may not 25 approve a State-based Health Insurance Exchange 
1 under this section unless the following requirements

2 are met:

(A) The State-based Health Insurance Exchange must demonstrate the capacity to and provide assurances satisfactory to the Commissioner that the State-based Health Insurance Exchange will carry out the functions specified for the Health Insurance Exchange in the State (or States) involved, including-

(i) negotiating and contracting with QHBP offering entities for the offering of

Exchange-participating health benefits plans, which satisfy the standards and requirements of this title and title II;

(ii) enrolling Exchange-eligible individuals and employers in such State in such plans;

(iii) the establishment of sufficient local offices to meet the needs of Exchange-eligible individuals and employers; (iv) administering affordability credits under subtitle B using the same methodologies (and at least the same income verification methods) as would otherwise apply under such subtitle and at a cost to 
the Federal Government which does exceed the cost to the Federal Government if this section did not apply; and

(v) enforcement activities consistent with Federal requirements.

(B) There is no more than one Health Insurance Exchange operating with respect to any one State.

(C) The State provides assurances satisfactory to the Commissioner that approval of such an Exchange will not result in any net increase in expenditures to the Federal Government.

(D) The State provides for reporting of such information as the Commissioner determines and assurances satisfactory to the Commissioner that it will vigorously enforce violations of applicable requirements.

(E) Such other requirements as the Commissioner may specify.

(2) Presumption for Certain state-operATED EXCHANGES.-

(A) In GeneraL.-In the case of a State operating an Exchange prior to January 1, 2010, that seeks to operate the State-based Health Insurance Exchange under this section, 
the Commissioner shall presume that such Exchange meets the standards under this section unless the Commissioner determines, after completion of the process established under subparagraph (B), that the Exchange does not comply with such standards.

(B) Process.-The Commissioner shall establish a process to work with a State described in subparagraph (A) to provide assistance necessary to assure that the State's Exchange comes into compliance with the standards for approval under this section.

\section{(c) Ceasing Operation.-}

(1) In GENERAL.-A State-based Health Insur-

16 volved, and only after providing timely and reason17 able notice to the Commissioner, cease operation as 18 such an Exchange, in which case the Health Insur19 ance Exchange shall operate, instead of such State20 based Health Insurance Exchange, with respect to 21 such State (or States).

(2) Termination; health insurance eX24 missioner may terminate the approval (for some or 25 all functions) of a State-based Health Insurance Ex- 
1 change under this section if the Commissioner deter-

2 mines that such Exchange no longer meets the re-

3 quirements of subsection (b) or is no longer capable

4 of carrying out such functions in accordance with

5 the requirements of this subtitle. In lieu of termi-

6 nating such approval, the Commissioner may tempo-

7 rarily assume some or all functions of the State-

8 based Health Insurance Exchange until such time as

9 the Commissioner determines the State-based

10 Health Insurance Exchange meets such require-

11 ments of subsection (b) and is capable of carrying

12 out such functions in accordance with the require-

13 ments of this subtitle.

14 (3) EFFECTIVEnEss.-The ceasing or termi15 nation of a State-based Health Insurance Exchange 16 under this subsection shall be effective in such time 17 and manner as the Commissioner shall specify.

18 (d) Retention of Authority.-

19 (1) AUTHORITy RETAINED.-Enforcement au20 thorities of the Commissioner shall be retained by 21 the Commissioner.

(2) Discretion to retain additional aU23 THORITY.-The Commissioner may specify functions 24 of the Health Insurance Exchange that- 
(A) may not be performed by a Statebased Health Insurance Exchange under this section; or

(B) may be performed by the Commissioner and by such a State-based Health Insurance Exchange.

(e) References.- - In the case of a State-based 8 Health Insurance Exchange, except as the Commissioner 9 may otherwise specify under subsection (d), any references 10 in this subtitle to the Health Insurance Exchange or to 11 the Commissioner in the area in which the State-based

12 Health Insurance Exchange operates shall be deemed a 13 reference to the State-based Health Insurance Exchange 14 and the head of such Exchange, respectively.

15 (f) Funding. - In the case of a State-based Health

16 Insurance Exchange, there shall be assistance provided for 17 the operation of such Exchange in the form of a matching 18 grant with a State share of expenditures required.

19 SEC. 309. INTERSTATE HEALTH INSURANCE COMPACTS.

(a) In General.-Effective January 1, 2015, 2 or 21 more States may form Health Care Choice Compacts (in 22 this section referred to as "compacts") to facilitate the 23 purchase of individual health insurance coverage across 24 State lines. 
1 (b) Model Guidelines.-The Secretary of Health 2 and Human Services (in this section referred to as the 3 "Secretary") shall request the National Association of In4 surance Commissioners (in this section referred to as 5 "NAIC") to develop model guidelines for the creation of 6 compacts. In developing such guidelines, the NAIC shall 7 consult with consumers, health insurance issuers, the Sec8 retary, and other interested parties. Such guidelines 9 shall-

10 (1) provide for the sale of health insurance cov11 erage to residents of all compacting States subject to 12 the laws and regulations of a primary State des13 ignated by the health insurance issuer;

14 (2) require health insurance issuers issuing 15 health insurance coverage in secondary States to 16 maintain licensure in every such State;

17 (3) preserve the authority of the State of an in18 dividual's residence to address-

19 (A) market conduct;

20 (B) unfair trade practices;

$21 \quad$ (C) network adequacy;

22 (D) consumer protection standards;

23 (E) grievance and appeals;

$24 \quad$ (F) fair claims payment requirements; and $25 \quad(G)$ prompt payment of claims; 
(4) permit State insurance commissioners and

2 other State agencies in secondary States access to

3 the records of a health insurance issuer to the same

4 extent as if the policy were written in that State;

5 and

6 (5) provide for clear and conspicuous disclosure

7 to consumers that the policy may not be subject to

8 all the laws and regulations of the State in which

9 the purchaser resides.

10 (c) REQUiRED CONSIDERATION.-If model guidelines

11 developed under subsection (b) are submitted to the Sec-

12 retary by January 1, 2013, the Secretary shall issue them

13 as regulations. If the NAIC fails to submit such model

14 guidelines by such date, the Secretary shall, no later than

15 October 1, 2013, develop and promulgate the regulations

16 implementing model guidelines described in subsection (b).

17 (d) No Requirement to Compact.-Nothing in

18 this section shall be construed to require a State to join

19 a compact.

20 (e) State Authority.-A State may not enter into 21 a compact under this subsection unless the State enacts 22 a law after the date of enactment of this Act that specifi23 cally authorizes the State to enter into such compact.

24 (f) Consumer Protections.-If a State enters into 25 a compact it must retain responsibility for the consumer 
1 protections of its residents and its residents retain the

2 right to bring a claim in a State court in the State in 3 which the resident resides.

4

5

6 the Secretary shall make awards, from amounts ap-

7 propriated under paragraph (5), to States in the

8 amount specified in paragraph (2) for the uses de-

$9 \quad$ scribed in paragraph (3).

10

11

12
(2) Amount specified.-

(A) In GENERAL.-For each fiscal year, the Secretary shall determine the total amount that the Secretary will make available for grants under this subsection.

(B) State amount.-For each State that is awarded a grant under paragraph (1), the amount of such grants shall be based on a formula established by the Secretary, not to exceed \$1 million per State, under which States shall receive an award in the amount that is based on the following two components:

(i) A minimum amount for each State.

(ii) An additional amount based on population of the State. 
(3) Use OF FUnds.-A State shall use amounts awarded under this subsection for activities

3 (including planning activities) related regulating 4 health insurance coverage sold in secondary States.

(4) Renewability of Grant.-The Secretary 6 may renew a grant award under paragraph (1) if the

7 State receiving the grant continues to be a member 8 of a compact.

(5) Authorization OF APPROPRIATIONS.-

10 There are authorized to be appropriated such sums 11 as may be necessary to carry out this subsection in 12 each of fiscal years 2015 through 2020.

\section{SEC. 310. HEALTH INSURANCE COOPERATIVES.}

14 (a) Establishment.-Not later than 6 months after 15 the date of the enactment of this Act, the Commissioner, 16 in consultation with the Secretary of the Treasury, shall 17 establish a Consumer Operated and Oriented Plan pro18 gram (in this section referred to as the "CO-OP pro19 gram") under which the Commissioner may make grants 20 and loans for the establishment and initial operation of 21 not-for-profit, member-run health insurance cooperatives 22 (in this section individually referred to as a "cooperative") 23 that provide insurance through the Health Insurance Ex24 change or a State-based Health Insurance Exchange 
1 under section 308. Nothing in this section shall be con-

2 strued as requiring a State to establish such a cooperative.

3 (b) Start-up AND SOLVEnCy Grants AND

4 LOANS.-

5 (1) IN GENERAL.-Not later than 36 months 6 after the date of the enactment of this Act, the

7 Commissioner, acting through the CO-OP program, 8 may make-

(A) loans (of such period and with such terms as the Secretary may specify) to cooperatives to assist such cooperatives with start-up costs; and

(B) grants to cooperatives to assist such cooperatives in meeting State solvency requirements in the States in which such cooperative offers or issues insurance coverage.

(2) Conditions.-A grant or loan may not be awarded under this subsection with respect to a cooperative unless the following conditions are met:

(A) The cooperative is structured as a notfor-profit, member organization under the law of each State in which such cooperative offers, intends to offer, or issues insurance coverage, with the membership of the cooperative being 
made up entirely of beneficiaries of the insurance coverage offered by such cooperative.

(B) The cooperative did not offer insurance on or before July 16, 2009, and the cooperative is not an affiliate or successor to an in-

(E) Substantially all of the activities of the cooperative consist of the issuance of qualified health benefits plans through the Health Insurance Exchange or a State-based health insurance exchange.

(F) The cooperative is licensed to offer insurance in each State in which it offers insurance.

(G) The governance of the cooperative must be subject to a majority vote of its members. 
(H) As provided in guidance issued by the Secretary of Health and Human Services, the cooperative operates with a strong consumer focus, including timeliness, responsiveness, and accountability to members.

(I) Any profits made by the cooperative are used to lower premiums, improve benefits, or to otherwise improve the quality of health care delivered to members.

(3) PRIORITY.-The Commissioner, in making 12 priority to cooperatives that-

18 this section shall be construed to prevent a coopera19 tive established in one State from integrating with a 20 cooperative established in another State the adminis21 tration, issuance of coverage, or other activities re22 lated to acting as a QHBP offering entity. Nothing 23 in this section shall be construed as preventing State 24 governments from taking actions to permit such in25 tegration. 
(5) Amortization of gRants and LOANs.-

2 The Secretary shall provide for the repayment of 3 grants or loans provided under this subsection to the

4 Treasury in an amortized manner over a 10-year pe5 riod.

6 (6) REPAyMent FOR Violations OF TERMS OF 7 PROGRAM.-If a cooperative violates the terms of the 8 CO-OP program and fails to correct the violation 9 within a reasonable period of time, as determined by 10 the Commissioner, the cooperative shall repay the 11 total amount of any loan or grant received by such 12 cooperative under this section, plus interest (at a 13 rate determined by the Secretary).

(7) Authorization of appropriations.15 There is authorized to be appropriated $16 \$ 5,000,000,000$ for the period of fiscal years 2010 17 through 2014 to provide for grants and loans under 18 this subsection.

19 (c) Definitions.-For purposes of this section:

20 (1) STATE.-The term "State" means each of 21 the 50 States and the District of Columbia.

22 (2) Menber.-The term "member", with re23 spect to a cooperative, means an individual who, 24 after the cooperative offers health insurance cov25 erage, is enrolled in such coverage. 
1 SEC. 311. RETENTION OF DOD AND VA AUTHORITY.

2 Nothing in this subtitle shall be construed as affect3 ing any authority under title 38, United States Code, or 4 chapter 55 of title 10, United States Code.

5

12 the Secretary of Health and Human Services (in this sub-

13 title referred to as the "Secretary") shall provide for the

14 offering of an Exchange-participating health benefits plan

15 (in this division referred to as the "public health insurance

16 option") that ensures choice, competition, and stability of

17 affordable, high quality coverage throughout the United

18 States in accordance with this subtitle. In designing the

19 option, the Secretary's primary responsibility is to create

20 a low-cost plan without compromising quality or access to 21 care.

22 (b) OfFERING AS AN ExChange-PARTICIPATING

\section{Health Benefits Plan.-}

(1) Exclusive to the exchange.-The pub25 lic health insurance option shall only be made avail26 able through the Health Insurance Exchange. 
(2) Ensuring a level playing Field.-Con-

2 sistent with this subtitle, the public health insurance

3 option shall comply with requirements that are ap-

4 plicable under this title to an Exchange-participating

5 health benefits plan, including requirements related

6 to benefits, benefit levels, provider networks, notices,

7 consumer protections, and cost-sharing.

8 (3) Provision of Benefit levels.-The pub-

9 lic health insurance option-

10

(A) shall offer basic, enhanced, and premium plans; and

(B) may offer premium-plus plans.

13 (c) Administrative Contracting.-The Secretary

14 may enter into contracts for the purpose of performing

15 administrative functions (including functions described in

16 subsection (a)(4) of section 1874 A of the Social Security

17 Act) with respect to the public health insurance option in

18 the same manner as the Secretary may enter into con-

19 tracts under subsection (a)(1) of such section. The Sec-

20 retary has the same authority with respect to the public

21 health insurance option as the Secretary has under sub-

22 sections (a)(1) and (b) of section 1874A of the Social Se-

23 curity Act with respect to title XVIII of such Act. Con-

24 tracts under this subsection shall not involve the transfer

25 of insurance risk to such entity. 
1 (d) Ombudsman.-The Secretary shall establish an 2 office of the ombudsman for the public health insurance 3 option which shall have duties with respect to the public 4 health insurance option similar to the duties of the Medi5 care Beneficiary Ombudsman under section 1808(c)(2) of 6 the Social Security Act.

7 (e) Data Collection.-The Secretary shall collect 8 such data as may be required to establish premiums and 9 payment rates for the public health insurance option and 10 for other purposes under this subtitle, including to im11 prove quality and to reduce racial, ethnic, and other dis12 parities in health and health care. Nothing in this subtitle 13 may be construed as authorizing the Secretary (or any em14 ployee or contractor) to create or maintain lists of non15 medical personal property.

16 (f) Treatment of Public Health Insurance Op17 TION.-With respect to the public health insurance option, 18 the Secretary shall be treated as a QHBP offering entity 19 offering an Exchange-participating health benefits plan.

20 (g) Access to Federal Courts.-The provisions 21 of Medicare (and related provisions of title II of the Social 22 Security Act) relating to access of Medicare beneficiaries 23 to Federal courts for the enforcement of rights under 24 Medicare, including with respect to amounts in con25 troversy, shall apply to the public health insurance option 
1 and individuals enrolled under such option under this title

2 in the same manner as such provisions apply to Medicare

3 and Medicare beneficiaries.

4 SEC. 322. PREMIUMS AND FINANCING.

5 (a) Establishment of Premiums.-

6 (1) In GENERAL.-The Secretary shall establish

7 geographically adjusted premium rates for the public

8 health insurance option-

9

10 costs ofpremium rules established by the Commissioner under section 213 for Exchange-participating health benefits plans; and

(A) in a manner that complies with the (B) at a level sufficient to fully finance the

(i) health benefits provided by the public health insurance option; and

(ii) administrative costs related to operating the public health insurance option.

(2) Contingency Margin.-In establishing 22 gency margin (which shall be not less than 90 days 23 of estimated claims). Before setting such appropriate 24 amount for years starting with Y3, the Secretary 
1 shall solicit a recommendation on such amount from

2 the American Academy of Actuaries.

3 (b) Account.-

4 (1) Establishment.-There is established in 5 the Treasury of the United States an Account for 6 the receipts and disbursements attributable to the 7 operation of the public health insurance option, in8 cluding the start-up funding under paragraph (2). 9 Section $1854(\mathrm{~g})$ of the Social Security Act shall 10 apply to receipts described in the previous sentence 11 in the same manner as such section applies to pay12 ments or premiums described in such section.

(2) StART-UP FUNDING.-

(A) In GENERAL.-In order to provide for the establishment of the public health insurance option, there is hereby appropriated to the Secretary, out of any funds in the Treasury not otherwise appropriated, $\$ 2,000,000,000$. In order to provide for initial claims reserves before the collection of premiums, there are hereby appropriated to the Secretary, out of any funds in the Treasury not otherwise appropriated, such sums as necessary to cover 90 days worth of claims reserves based on pro25 jected enrollment. 
(B) Amortization of START-UP FUnDING.-The Secretary shall provide for the repayment of the startup funding provided under subparagraph (A) to the Treasury in an amortized manner over the 10 -year period beginning with Y1.

(C) Limitation on Funding.-Nothing in this section shall be construed as authorizing any additional appropriations to the Account, other than such amounts as are otherwise provided with respect to other Exchange-participating health benefits plans.

(3) No BaIlouts.-In no case shall the public health insurance option receive any Federal funds for purposes of insolvency in any manner similar to the manner in which entities receive Federal funding under the Troubled Assets Relief Program of the Secretary of the Treasury.

\section{SEC. 323. PAYMENT RATES FOR ITEMS AND SERVICES.}

\section{(a) Negotiation of Payment Rates.-}

(1) In GENERAL.- The Secretary shall negotiate payment for the public health insurance option for health care providers and items and services, including prescription drugs, consistent with this section and section 324 . 
(2) Manner of negotiation.-The Secretary

2 shall negotiate such rates in a manner that results

3 in payment rates that are not lower, in the aggre-

4 gate, than rates under title XVIII of the Social Se-

5 curity Act, and not higher, in the aggregate, than

6 the average rates paid by other QHBP offering enti-

7 ties for services and health care providers.

8 (3) Innovative Payment methods.-Nothing

9 in this subsection shall be construed as preventing

10 the use of innovative payment methods such as those

11 described in section 324 in connection with the nego-

12 tiation of payment rates under this subsection.

13 (b) Establishment of a Provider Network.-

14 (1) In GENERAL.-Health care providers (in-

15 cluding physicians and hospitals) participating in

16 Medicare are participating providers in the public

17 health insurance option unless they opt out in a

18 process established by the Secretary consistent with

19 this subsection.

20 (2) REquiREMENTS FOR OPT-OUT PROCESS.21 Under the process established under paragraph $22 \quad(1)-$

23 (A) providers described in such paragraph 24 shall be provided at least a 1-year period prior 
to the first day of Y1 to opt out of participating in the public health insurance option;

(B) no provider shall be subject to a penalty for not participating in the public health insurance option;

(C) the Secretary shall include information on how providers participating in Medicare who chose to opt out of participating in the public health insurance option may opt back in; and period in which providers may decide whether to participate in the public health insurance option.

(3) Rulemaking.-Not later than 18 months 15 before the first day of Y1, the Secretary shall pro16 mulgate rules (pursuant to notice and comment) for 17 the process described in paragraph (1).

18 (c) Limitations on Review.-There shall be no ad19 ministrative or judicial review of a payment rate or meth20 odology established under this section or under section 21324.

22 SEC. 324. MODERNIZED PAYMENT INITIATIVES AND DELIVERY SYSTEM REFORM.

24 (a) In GENERAL.—For plan years beginning with Y1, 25 the Secretary may utilize innovative payment mechanisms 
1 and policies to determine payments for items and services

2 under the public health insurance option. The payment 3 mechanisms and policies under this section may include 4 patient-centered medical home and other care manage5 ment payments, accountable care organizations, value6 based purchasing, bundling of services, differential pay7 ment rates, performance or utilization based payments, 8 partial capitation, and direct contracting with providers. 9 (b) Requirements for Innovative Payments.10 The Secretary shall design and implement the payment 11 mechanisms and policies under this section in a manner 12 that-

13 (1) seeks to-

(A) improve health outcomes;

(B) reduce health disparities (including racial, ethnic, and other disparities); (C) provide efficient and affordable care; (D) address geographic variation in the provision of health services; or

(E) prevent or manage chronic illness; and (2) promotes care that is integrated, patient22 centered, quality, and efficient.

23 (c) Encouraging the Use of High Value Serv24 ICES.- To the extent allowed by the benefit standards ap25 plied to all Exchange-participating health benefits plans, 
1 the public health insurance option may modify cost-shar-

2 ing and payment rates to encourage the use of services 3 that promote health and value.

4 (d) Promotion of Delivery System Reform.-

5 The Secretary shall monitor and evaluate the progress of 6 payment and delivery system reforms under this Act and 7 shall seek to implement such reforms subject to the fol8 lowing:

(1) To the extent that the Secretary finds a 10 payment and delivery system reform successful in 11 improving quality and reducing costs, the Secretary 12 shall implement such reform on as large a geo13 graphic scale as practical and economical.

14 (2) The Secretary may delay the implementa15 tion of such a reform in geographic areas in which 16 such implementation would place the public health 17 insurance option at a competitive disadvantage.

18 (3) The Secretary may prioritize implementa19 tion of such a reform in high cost geographic areas 20 or otherwise in order to reduce total program costs 21 or to promote high value care.

22 (e) Non-uniformity Permitted.-Nothing in this 23 subtitle shall prevent the Secretary from varying payments 24 based on different payment structure models (such as ac25 countable care organizations and medical homes) under 
1 the public health insurance option for different geographic

2 areas.

3 SEC. 325. PROVIDER PARTICIPATION.

4 (a) In GENERAL.-The Secretary shall establish con-

5 ditions of participation for health care providers under the 6 public health insurance option.

(b) Licensure or Certification.-

(1) In GENERAL._Except as provided in para-

9 graph (2), the Secretary shall not allow a health

10 care provider to participate in the public health in-

11 surance option unless such provider is appropriately

12 licensed, certified, or otherwise permitted to practice

13 under State law.

(2) Spectal RUle FOR ihs Facilities AND PROVIDERS.-The requirements under paragraph (1)

16 shall not apply to-

(A) a facility that is operated by the Indian Health Service;

(B) a facility operated by an Indian Tribe or tribal organization under the Indian Self-Determination Act (Public Law 93-638); the Indian Health Service; or (D) a health care professional- 
(i) who is employed to provide health care services in a facility operated by an Indian Tribe or tribal organization under the Indian Self-Determination Act; and

(ii) who is licensed or certified in any State.

(c) Payment Terms for Providers.-

(1) Physiclans._-The Secretary shall provide for the annual participation of physicians under the public health insurance option, for which payment may be made for services furnished during the year, in one of 2 classes:

(A) Preferred Physicians.-Those physicians who agree to accept the payment under section 323 (without regard to cost-sharing) as the payment in full.

(B) PARTicipating, NON-PREFERRED PHYSICLANS._Those physicians who agree not to impose charges (in relation to the payment described in section 323 for such physicians) that exceed the sum of the in-network costsharing plus 15 percent of the total payment for each item and service. The Secretary shall reduce the payment described in section 323 for such physicians. 
(2) OTHER PROVIDERS.-The Secretary shall

2 provide for the participation (on an annual or other

3 basis specified by the Secretary) of health care pro-

4 viders (other than physicians) under the public

5 health insurance option under which payment shall

6 only be available if the provider agrees to accept the

7 payment under section 323 (without regard to cost-

8 sharing) as the payment in full.

9 (d) Exclusion of Certain Providers.-The Sec-

10 retary shall exclude from participation under the public

11 health insurance option a health care provider that is ex-

12 cluded from participation in a Federal health care pro-

13 gram (as defined in section 1128B(f) of the Social Secu-

14 rity Act).

15 SEC. 326. APPLICATION OF FRAUD AND ABUSE PROVISIONS.

17 Provisions of civil law identified by the Secretary by 18 regulation, in consultation with the Inspector General of 19 the Department of Health and Human Services, that im20 pose sanctions with respect to waste, fraud, and abuse 21 under Medicare, such as sections 3729 through 3733 of 22 title 31, United States Code (commonly known as the 23 False Claims Act), shall also apply to the public health 24 insurance option. 
1 SEC. 327. APPLICATION OF HIPAA INSURANCE REQUIRE-

MENTS.

3 The requirements of sections 2701 through 2792 of

4 the Public Health Service Act shall apply to the public

5 health insurance option in the same manner as they apply

6 to health insurance coverage offered by a health insurance

7 issuer in the individual market.

8 SEC. 328. APPLICATION OF HEALTH INFORMATION PRIVACY, SECURITY, AND ELECTRONIC TRANSACTION REQUIREMENTS.

11 Part $\mathrm{C}$ of title XI of the Social Security Act, relating

12 to standards for protections against the wrongful disclo-

13 sure of individually identifiable health information, health

14 information security, and the electronic exchange of health

15 care information, shall apply to the public health insur-

16 ance option in the same manner as such part applies to

17 other health plans (as defined in section 1171(5) of such

18 Act).

19 SEC. 329. ENROLLMENT IN PUBLIC HEALTH INSURANCE 20 OPTION IS VOLUNTARY.

21 Nothing in this division shall be construed as requir22 ing anyone to enroll in the public health insurance option.

23 Enrollment in such option is voluntary. 
1 SEC. 330. ENROLLMENT IN PUBLIC HEALTH INSURANCE

3 Notwithstanding any other provision of this Act,

4 Members of Congress may enroll in the public health in-

5 surance option.

6 SEC. 331. REIMBURSEMENT OF SECRETARY OF VETERANS

AFFAIRS.

8 The Secretary of Health and Human Services shall

9 seek to enter into a memorandum of understanding with

10 the Secretary of Veterans Affairs regarding the recovery

11 of costs related to non-service-connected care or services

12 provided by the Secretary of Veterans Affairs to an indi-

13 vidual covered under the public health insurance option

14 in a manner consistent with recovery of costs related to

15 non-service-connected care from private health insurance

16 plans.

\section{Affordability Credits}

19 SEC. 341. AVAILABILITY THROUGH HEALTH INSURANCE EXCHANGE.

21 (a) In GENERAL.—Subject to the succeeding provi22 sions of this subtitle, in the case of an affordable credit 23 eligible individual enrolled in an Exchange-participating 24 health benefits plan- 
1 (1) the individual shall be eligible for, in accord2 ance with this subtitle, affordability credits con3 sisting of-

13 fering entity that offers such plan from the Health

14 Insurance Exchange Trust Fund the aggregate 15 amount of affordability credits for all affordable 16 credit eligible individuals enrolled in such plan.

17 (b) Application.-

18 (1) IN GENERAL.-An Exchange eligible indi19 vidual may apply to the Commissioner through the 20 Health Insurance Exchange or through another enti21 ty under an arrangement made with the Commis22 sioner, in a form and manner specified by the Com23 missioner. The Commissioner through the Health 24 Insurance Exchange or through another public enti25 ty under an arrangement made with the Commis- 
1 sioner shall make a determination as to eligibility of

2 an individual for affordability credits under this sub3 title. The Commissioner shall establish a process

4 whereby, on the basis of information otherwise avail5 able, individuals may be deemed to be affordable 6 credit eligible individuals. In carrying this subtitle, 7 the Commissioner shall establish effective methods 8 that ensure that individuals with limited English 9 proficiency are able to apply for affordability credits. 10 (2) Use OF STATE MEDICAID AGENCIES.-If 11 the Commissioner determines that a State Medicaid 12 agency has the capacity to make a determination of 13 eligibility for affordability credits under this subtitle 14 and under the same standards as used by the Com15 missioner, under the Medicaid memorandum of un16 derstanding under section 305(e)(2)—

17 (A) the State Medicaid agency is author18 ized to conduct such determinations for any Ex19 change-eligible individual who requests such a 20 determination; and

(B) the Commissioner shall reimburse the State Medicaid agency for the costs of con25 TION.-In the case of an application made under 
1 paragraph (1), there shall be a determination of

2 whether the individual is a Medicaid-eligible indi-

3 vidual. If the individual is determined to be so eligi-

4 ble, the Commissioner, through the Medicaid memo-

5 randum of understanding under section $305(\mathrm{e})(2)$,

6 shall provide for the enrollment of the individual

7 under the State Medicaid plan in accordance with

8 such Medicaid memorandum of understanding. In

9 the case of such an enrollment, the State shall pro-

10 vide for the same periodic redetermination of eligi-

11 bility under Medicaid as would otherwise apply if the

12 individual had directly applied for medical assistance

13 to the State Medicaid agency.

14 (4) APPLICATION AND VERIFICATION OF RE-

15 QUIREMENT OF CITIZENSHIP OR LAWFUL PRESENCE

16 IN THE UNITED STATES.-

17 (A) Requirement.-No individual shall 18 be an affordable credit eligible individual (as 19 defined in section $342(\mathrm{a})(1))$ unless the indi20 vidual is a citizen or national of the United 21 States or is lawfully present in a State in the 22 United States (other than as a nonimmigrant 23 described in a subparagraph (excluding sub24 paragraphs $(\mathrm{K}),(\mathrm{T}),(\mathrm{U})$, and $(\mathrm{V}))$ of section 
101(a)(15) of the Immigration and Nationality Act).

(B) Declaration of Citizenship oR LAWFUL IMMIGRATION STATUS.-No individual shall be an affordable credit eligible individual unless there has been a declaration made, in a form and manner specified by the Health Choices Commissioner similar to the manner required under section $1137(d)(1)$ of the Social Security Act and under penalty of perjury, that the individual-

(i) is a citizen or national of the United States; or

(ii) is not such a citizen or national but is lawfully present in a State in the United States (other than as a nonimmigrant described in a subparagraph (excluding subparagraphs (K), (T), (U), and $(\mathrm{V})$ ) of section 101(a)(15) of the Immigration and Nationality Act). Such declaration shall be verified in accordance with subparagraph (C) or (D), as the case may be.

(C) Verification PRocess for CitiZENS.- 
(i) IN GENERAL.-In the case of an individual making the declaration described in subparagraph (B)(i), subject to clause (ii), section 1902(ee) of the Social Security Act shall apply to such declaration in the same manner as such section applies to a declaration described in paragraph (1) of such section.

(ii) Special RUles.-In applying section 1902(ee) of such Act under clause (i)-

(I) any reference in such section to a State is deemed a reference to the Commissioner (or other public entity making the eligibility determination);

(II) any reference to medical assistance or enrollment under a State plan is deemed a reference to provision of affordability credits under this subtitle;

(III) a reference to a newly enrolled individual under paragraph $(2)(A)$ of such section is deemed a reference to an individual newly in re- 
ceipt of an affordability credit under this subtitle;

(IV) approval by the Secretary shall not be required in applying paragraph (2)(B)(ii) of such section;

(V) paragraph (3) of such section shall not apply; and

(VI) before the end of $\mathrm{Y} 2$, the Health Choices Commissioner, in consultation with the Commissioner of Social Security, may extend the periods specified in paragraph (1)(B)(ii) of such section.

(D) Verification PROCEss FOR NONCITIZENS.-

(i) IN GENERAL.- In the case of an individual making the declaration described in subparagraph (B)(ii), subject to clause (ii), the verification procedures of paragraphs (2) through (5) of section $1137(d)$ of the Social Security Act shall apply to such declaration in the same manner as such procedures apply to a declaration described in paragraph (1) of such section. 
(ii) Spectal RUles.-In applying such paragraphs of section 1137 (d) of such Act under clause (i)—

(I) any reference in such paragraphs to a State is deemed a reference to the Health Choices Commissioner; and

(II) any reference to benefits under a program is deemed a reference to affordability credits under this subtitle.

(iii) Application to state-Based EXCHANGES.-In the case of the application of the verification process under this subparagraph to a State-based Health Insurance Exchange approved under section 308, section $1137(\mathrm{e})$ of such Act shall apply to the Health Choices Commissioner in relation to the State.

(E) Annual Reports.-The Health Choices Commissioner shall report to Congress annually on the number of applicants for affordability credits under this subtitle, their citizenship or immigration status, and the disposition of their applications. Such report shall be 
made publicly available and shall include information on-

(i) the number of applicants whose declaration of citizenship or immigration status, name, or social security account number was not consistent with records maintained by the Commissioner of Social Security or the Department of Homeland Security and, of such applicants, the number who contested the inconsistency and sought to document their citizenship or immigration status, name, or social security account number or to correct the information maintained in such records and, of those, the results of such contestations; and

(ii) the administrative costs of conducting the status verification under this paragraph.

(F) GAO REPORT.-Not later than the end of Y2, the Comptroller General of the United States shall submit to the Committee on Ways and Means, the Committee on Energy and Commerce, the Committee on Education and Labor, and the Committee on the Judiciary of 
the House of Representatives and the Committee on Finance, the Committee on Health, Education, Labor, and Pensions, and the Committee on the Judiciary of the Senate a report examining the effectiveness of the citizenship and immigration verification systems applied under this paragraph. Such report shall include an analysis of the following:

(i) The causes of erroneous determinations under such systems.

(ii) The effectiveness of the processes used in remedying such erroneous determinations.

(iii) The impact of such systems on individuals, health care providers, and Federal and State agencies, including the effect of erroneous determinations under such systems.

(iv) The effectiveness of such systems in preventing ineligible individuals from receiving for affordability credits.

(v) The characteristics of applicants described in subparagraph (E)(i).

(G) Prohibition of Database.-Nothing 25 in this paragraph or the amendments made by 
paragraph (6) shall be construed as authorizing the Health Choices Commissioner or the Commissioner of Social Security to establish a database of information on citizenship or immigration status.

(H) Initial Funding.-

(i) In GeneraL.—Out of any funds in the Treasury not otherwise appropriated, there is appropriated to the Commissioner of Social Security $\$ 30,000,000$, to be avail-

(5) Agreement with social security comable without fiscal year limit to carry out this paragraph and section $205(\mathrm{v})$ of the Social Security Act.

(ii) Funding Limitation.-In no case shall funds from the Social Security Administration's Limitation on Administrative Expenses be used to carry out activities related to this paragraph or section 205(v) of the Social Security Act. MISSIONER.-

(A) In General.-The Health Choices Commissioner shall enter into and maintain an agreement described in section 205(v)(2) of the 
Social Security Act with the Commissioner of Social Security.

(B) Funding.- The agreement entered into under subparagraph (A) shall, for each fiscal year (beginning with fiscal year 2013)—

(i) provide funds to the Commissioner of Social Security for the full costs of the responsibilities of the Commissioner of Social Security under paragraph (4), including-

(I) acquiring, installing, and maintaining technological equipment and systems necessary for the fulfillment of the responsibilities of the Commissioner of Social Security under paragraph (4), but only that portion of such costs that are attributable to such responsibilities; and (II) responding to individuals who contest with the Commissioner of Social Security a reported inconsistency with records maintained by the Commissioner of Social Security or the Department of Homeland Security relating to citizenship or immigration 
status, name, or social security account number under paragraph (4);

(ii) based on an estimating methodology agreed to by the Commissioner of Social Security and the Health Choices Commissioner, provide such funds, within 10 calendar days of the beginning of the fiscal year for the first quarter and in advance for all subsequent quarters in that fiscal year; and

(iii) provide for an annual accounting and reconciliation of the actual costs incurred and the funds provided under the agreement.

(C) Review of accounting.-The annual accounting and reconciliation conducted pursuant to subparagraph (B)(iii) shall be reviewed by the Inspectors General of the Social Security Administration and the Health Choices Administration, including an analysis of consistency with the requirements of paragraph (4).

(D) Contingency.-In any case in which agreement with respect to the provisions required under subparagraph (B) for any fiscal year has not been reached as of the first day 
of such fiscal year, the latest agreement with respect to such provisions shall be deemed in effect on an interim basis for such fiscal year until such time as an agreement relating to such provisions is subsequently reached. In any case in which an interim agreement applies for any fiscal year under this subparagraph, the Commissioner of Social Security shall, not later than the first day of such fiscal year, notify the appropriate Committees of the Congress of the failure to reach the agreement with respect to such provisions for such fiscal year. Until such time as the agreement with respect to such provisions has been reached for such fiscal year, the Commissioner of Social Security shall, not later than the end of each 90-day period after October 1 of such fiscal year, notify such Committees of the status of negotiations between such Commissioner and the Health Choices Commissioner in order to reach such an agreement.

(E) Application to PUblic Entities ADMINISTERING AFFORDABILITY CREDITS.-If the Health Choices Commissioner provides for the conduct of verifications under paragraph 
(4) through a public entity, the Health Choices

Commissioner shall require the public entity to enter into an agreement with the Commissioner of Social Security which provides the same terms as the agreement described in this paragraph (and section 205(v) of the Social Security Act) between the Health Choices Commissioner and the Commissioner of Social Security, except that the Health Choices Commissioner shall be responsible for providing funds for the Commissioner of Social Security in accordance with subparagraphs (B) through (D).

(6) Amendments to social security aCt.-

(A) Coordination of information BeTWEEN SOCLAL SECURITY ADMINISTRATION AND HEALTH CHOICES ADMINISTRATION.-

(i) In GenERAL.-Section 205 of the Social Security Act (42 U.S.C. 405) is amended by adding at the end the fol-

21 "Coordination of Information With Health Choices Administration

23 "(v)(1) The Health Choices Commissioner may col24 lect and use the names and social security account num25 bers of individuals as required to provide for verification 
1 of citizenship under subsection (b)(4)(C) of section 341

2 of the Affordable Health Care for America Act in connec-

3 tion with determinations of eligibility for affordability

4 credits under such section.

5 “(2)(A) The Commissioner of Social Security shall

6 enter into and maintain an agreement with the Health

7 Choices Commissioner for the purpose of establishing, in

8 compliance with the requirements of section $1902(\mathrm{ee})$ as

9 applied pursuant to section 341(b)(4)(C) of the Affordable

10 Health Care for America Act, a program for verifying in-

11 formation required to be collected by the Health Choices

12 Commissioner under such section 341(b)(4)(C).

13 "(B) The agreement entered into pursuant to sub-

14 paragraph (A) shall include such safeguards as are nec-

15 essary to ensure the maintenance of confidentiality of any

16 information disclosed for purposes of verifying information

17 described in subparagraph (A) and to provide procedures

18 for permitting the Health Choices Commissioner to use

19 the information for purposes of maintaining the records

20 of the Health Choices Administration.

21 "(C) The agreement entered into pursuant to sub22 paragraph (A) shall provide that information provided by 23 the Commissioner of Social Security to the Health Choices 24 Commissioner pursuant to the agreement shall be provided 
1 at such time, at such place, and in such manner as the

2 Commissioner of Social Security determines appropriate.

3 “(D) Information provided by the Commissioner of

4 Social Security to the Health Choices Commissioner pur-

5 suant to an agreement entered into pursuant to subpara-

6 graph (A) shall be considered as strictly confidential and

7 shall be used only for the purposes described in this para-

8 graph and for carrying out such agreement. Any officer

9 or employee or former officer or employee of the Health

10 Choices Commissioner, or any officer or employee or

11 former officer or employee of a contractor of the Health

12 Choices Commissioner, who, without the written authority

13 of the Commissioner of Social Security, publishes or com-

14 municates any information in such individual's possession

15 by reason of such employment or position as such an offi-

16 cer shall be guilty of a felony and, upon conviction thereof,

17 shall be fined or imprisoned, or both, as described in sec18 tion 208.

19 "(3) The agreement entered into under paragraph (2) 20 shall provide for funding to the Commissioner of Social 21 Security consistent with section 341(b)(5) of Affordable 22 Health Care for America Act.

23 "(4) This subsection shall apply in the case of a pub24 lic entity that conducts verifications under section 25 341(b)(4) of the Affordable Health Care for America Act 
1 and the obligations of this subsection shall apply to such

2 an entity in the same manner as such obligations apply

3 to the Health Choices Commissioner when such Commis-

4 sioner is conducting such verifications.".

5

6

7

8

9

10 verification procedures described in section 341(b)(4) of

11 the Affordable Health Care for America Act, the Health

12 Choices Commissioner may collect and use social security

13 account numbers as provided for in section 205(v)(1).".

14

(B) Improving The InTEgRITY OF DATA

15

16

17

18

19

20

21 in subsection (b) or any other use of such system, the U.S.

22 Citizenship and Immigration Services and any other agen-

23 cy charged with the management of the system shall es-

24 tablish appropriate safeguards necessary to protect and 
1 improve the integrity and accuracy of data relating to indi-

2 viduals by-

"(i) establishing a process though which such

4 individuals are provided access to, and the ability to

5 amend, correct, and update, their own personally

6 identifiable information contained within the system;

$7 \quad$ “(ii) providing a written response, without

8 undue delay, to any individual who has made such

9 a request to amend, correct, or update such individ-

10 ual's own personally identifiable information con-

11 tained within the system; and

"(iii) developing a written notice for user agen-

13 cies to provide to individuals who are denied a ben-

14 efit due to a determination of ineligibility based on

15 a final verification determination under the system.

16 "(B) The notice described in subparagraph (A)(ii)

17 shall include-

"(i) information about the reason for such no-

19 tice;

"(ii) a description of the right of the recipient

21 of the notice under subparagraph (A)(i) to contest

22 such notice;

23 "(iii) a description of the right of the recipient 24 under subparagraph (A)(i) to access and attempt to 25 amend, correct, and update the recipient's own per- 
1 sonally identifiable information contained within

2 records of the system described in paragraph (3);

3 and

4 "(iv) instructions on how to contest such notice

5 and attempt to correct records of such system relat-

6 ing to the recipient, including contact information

7 for relevant agencies.”.

8 (C) Streamlining administration OF

9 VERIFICATION PROCESS FOR UNITED STATES

10 Citizens.-Section 1902(ee)(2) of the Social

11 Security Act (42 U.S.C. 1396a(ee)(2)) is

12 amended by adding at the end the following:

13 "(D) In carrying out the verification procedures

14 under this subsection with respect to a State, if the Com-

15 missioner of Social Security determines that the records

16 maintained by such Commissioner are not consistent with

17 an individual's allegation of United States citizenship,

18 pursuant to procedures which shall be established by the

19 State in coordination with the Commissioner of Social Se-

20 curity, the Secretary of Homeland Security, and the Sec-

21 retary of Health and Human Services-

22 "(i) the Commissioner of Social Security shall

23 inform the State of the inconsistency;

24 "(ii) upon being so informed of the inconsist-

25 ency, the State shall submit the information on the 
1 individual to the Secretary of Homeland Security for

2 a determination of whether the records of the De-

3 partment of Homeland Security indicate that the in-

4 dividual is a citizen;

5 "(iii) upon making such determination, the De-

6 partment of Homeland Security shall inform the

$7 \quad$ State of such determination; and

8 "(iv) information provided by the Commissioner

9 of Social Security shall be considered as strictly con-

10 fidential and shall only be used by the State and the

11 Secretary of Homeland Security for the purposes of

12 such verification procedures.

13 "(E) Verification of status eligibility pursuant to the 14 procedures established under this subsection shall be 15 deemed a verification of status eligibility for purposes of 16 this title, title XXI, and affordability credits under section 17 341(b)(4) of the Affordable Health Care for America Act, 18 regardless of the program in which the individual is apply19 ing for benefits.".

20 (c) Use of AFFordability CREDits.-

21 (1) In GeneraL.-In Y1 and Y2 an affordable 22 credit eligible individual may use an affordability 23 credit only with respect to a basic plan.

24 (2) Flexibility IN PLAN ENROLLMENT AU25 THORIZED.-Beginning with Y3, the Commissioner 
1 shall establish a process to allow an affordability

2 premium credit under section 343 , but not the af-

3 fordability cost-sharing credit under section 344, to

4 be used for enrollees in enhanced or premium plans.

5 In the case of an affordable credit eligible individual

6 who enrolls in an enhanced or premium plan, the in-

7 dividual shall be responsible for any difference be-

8 tween the premium for such plan and the afford-

9 ability credit amount otherwise applicable if the indi-

10 vidual had enrolled in a basic plan.

11 (3) Prohibition of Use of Public Funds

12 FOR ABORTION COVERAGE.-An affordability credit

13 may not be used for payment for services described

14 in section $222(\mathrm{~d})(4)(\mathrm{A})$.

15 (d) Access to Data.-In carrying out this subtitle,

16 the Commissioner shall request from the Secretary of the

17 Treasury consistent with section 6103 of the Internal Rev-

18 enue Code of 1986 such information as may be required

19 to carry out this subtitle.

20 (e) No Cash Rebates.-In no case shall an afford-

21 able credit eligible individual receive any cash payment as

22 a result of the application of this subtitle.

23 SEC. 342. AFFORDABLE CREDIT ELIGIBLE INDIVIDUAL.

24 (a) DeFINITION.- 
(1) In GeneraL.-For purposes of this divi-

2 sion, the term "affordable credit eligible individual"

3 means, subject to subsection (b) and section 346, an

4 individual who is lawfully present in a State in the

5 United States (other than as a nonimmigrant de-

6 scribed in a subparagraph (excluding subparagraphs

$7 \quad(\mathrm{~K}),(\mathrm{T}),(\mathrm{U})$, and $(\mathrm{V}))$ of section $101(\mathrm{a})(15)$ of the

8 Immigration and Nationality Act)—

(A) who is enrolled under an Exchangeparticipating health benefits plan and is not enrolled under such plan as an employee (or dependent of an employee) through an employer qualified health benefits plan that meets the requirements of section 412;

(B) with modified adjusted gross income below 400 percent of the Federal poverty level for a family of the size involved;

(C) who is not a Medicaid eligible individual, other than an individual during a transition period under section 302(d)(3)(B)(ii); and (D) subject to paragraph (3), who is not enrolled in acceptable coverage (other than an Exchange-participating health benefits plan).

25 Commissioner may otherwise provide, members of 
1 the same family who are affordable credit eligible in-

2 dividuals shall be treated as a single affordable cred-

3 it individual eligible for the applicable credit for such

$4 \quad$ a family under this subtitle.

5 (3) SPECIAL RULE FOR INDIANs.-Subpara-

6 graph (D) of paragraph (1) shall not apply to an in-

7 dividual who has coverage that is treated as accept-

8 able coverage for purposes of section $59 \mathrm{~B}(\mathrm{~d})(2)$ of

9 the Internal Revenue Code of 1986 but is not treat-

10 ed as acceptable coverage for purposes of this divi11 sion.

12 (b) Limitations on Employee and Dependent

\section{Disqualification.-}

(1) In GENERAL.-Subject to paragraph (2), 15 the term "affordable credit eligible individual" does 16 not include a full-time employee of an employer if 17 the employer offers the employee coverage (for the 18 employee and dependents) as a full-time employee 19 under a group health plan if the coverage and em20 ployer contribution under the plan meet the require21 ments of section 412.

(2) Exceptions.-

(A) For CERTAin FAMILY CIRCUMStances.-The Commissioner shall estab25 lish such exceptions and special rules in the 
case described in paragraph (1) as may be appropriate in the case of a divorced or separated individual or such a dependent of an employee who would otherwise be an affordable credit eligible individual.

(B) For unaffordable employer cov-

17 fined in section 59B of the Internal Revenue Code 18 of 1986$)$.

(2) Study of InCOMe DisRegards.-The 20 Commissioner shall conduct a study that examines 21 the application of income disregards for purposes of 22 this subtitle. Not later than the first day of Y2, the 23 Commissioner shall submit to Congress a report on 24 such study and shall include such recommendations 25 as the Commissioner determines appropriate. 
(d) Clarification of Treatment of AfFord-

2 ABILITY CREDits.-Affordability credits under this sub-

3 title shall not be treated, for purposes of title IV of the

4 Personal Responsibility and Work Opportunity Reconcili-

5 ation Act of 1996, to be a benefit provided under section

6403 of such title.

7 SEC. 343. AFFORDABILITY PREMIUM CREDIT.

8 (a) In GENERAL.-The affordability premium credit

9 under this section for an affordable credit eligible indi-

10 vidual enrolled in an Exchange-participating health bene-

11 fits plan is in an amount equal to the amount (if any)

12 by which the reference premium amount specified in sub-

13 section (c), exceeds the affordable premium amount speci-

14 fied in subsection (b) for the individual, except that in no

15 case shall the affordable premium credit exceed the pre-

16 mium for the plan.

17 (b) Affordable Premium Amount.-

18 (1) In GENERAL.-The affordable premium

19 amount specified in this subsection for an individual

20 for the annual premium in a plan year shall be equal

21 to the product of-

(A) the premium percentage limit specified in paragraph (2) for the individual based upon the individual's modified adjusted gross income 25 for the plan year; and 
(B) the individual's modified adjusted gross income for such plan year.

(2) Premium percentage limits Based on

4 TABLE.-The Commissioner shall establish premium

5 percentage limits so that for individuals whose modi-

6 fied adjusted gross income is within an income tier

7 specified in the table in subsection (d) such percent-

8 age limits shall increase, on a sliding scale in a lin-

9 ear manner, from the initial premium percentage to

10 the final premium percentage specified in such table

11 for such income tier.

12 (c) Reference Premium Amount.-The reference 13 premium amount specified in this subsection for a plan 14 year for an individual in a premium rating area is equal 15 to the average premium for the 3 basic plans in the area 16 for the plan year with the lowest premium levels. In com17 puting such amount the Commissioner may exclude plans 18 with extremely limited enrollments.

19 (d) Table of Premium Percentage Limits, Ac20 tuarial Value Percentages, and Out-of-Pocket 21 Limits for Y1 Based on Income Tier.-

(1) In gEneraL.-For purposes of this sub23 title, subject to paragraph (3) and section 346, the 24 table specified in this subsection is as follows: 
In the case of modified adjusted gross income (expressed as a percent of FPL) within the following income tier:

$\begin{array}{cccc}\begin{array}{c}\text { The initial } \\ \text { premium } \\ \text { percentage } \\ \text { is- }\end{array} & \begin{array}{c}\text { The final } \\ \text { premium } \\ \text { percentage } \\ \text { is- }\end{array} & \begin{array}{c}\text { The actu- } \\ \text { arial value } \\ \text { percentage } \\ \text { is- }\end{array} & \begin{array}{c}\text { The out-of- } \\ \text { pocket limit } \\ \text { for Y1 is- }\end{array} \\ 1.5 \% & 3.0 \% & 97 \% & \$ 500 \\ 3.0 \% & 5.5 \% & 93 \% & \$ 1,000 \\ 5.5 \% & 8.0 \% & 85 \% & \$ 2,000 \\ 8.0 \% & 10.0 \% & 78 \% & \$ 4,000 \\ 10.0 \% & 11.0 \% & 72 \% & \$ 4,500 \\ 11.0 \% & 12.0 \% & 70 \% & \$ 5,000\end{array}$

$133 \%$ through $150 \%$

$150 \%$ through $200 \%$

$200 \%$ through $250 \%$

$250 \%$ through $300 \%$

$300 \%$ through $350 \%$

$350 \%$ through $400 \%$

(2) Spectal RUles.-For purposes of applying the table under paragraph (1):

(A) For lowest level OF INCOMe.-In the case of an individual with income that does not exceed 133 percent of FPL, the individual shall be considered to have income that is 133 percent of FPL. VALUE PERCENTAGE AT TIER TRANSITION POINTS.-If two actuarial value percentages may be determined with respect to an individual, the actuarial value percentage shall be the higher of such percentages. 
1 enrollee shares of premiums over time, for each in-

2 come tier identified in the table in paragraph (1).

3 SEC. 344. AFFORDABILITY COST-SHARING CREDIT.

4 (a) In GENERAL.-The affordability cost-sharing

5 credit under this section for an affordable credit eligible

6 individual enrolled in an Exchange-participating health

7 benefits plan is in the form of the cost-sharing reduction

8 described in subsection (b) provided under this section for

9 the income tier in which the individual is classified based

10 on the individual's modified adjusted gross income.

11 (b) Cost-sharing Reductions.-The Commis-

12 sioner shall specify a reduction in cost-sharing amounts

13 and the annual limitation on cost-sharing specified in sec-

14 tion 222(c)(2)(B) under a basic plan for each income tier

15 specified in the table under section $343(\mathrm{~d})$, with respect

16 to a year, in a manner so that, as estimated by the Com17 missioner-

18 (1) the actuarial value of the coverage with 19 such reduced cost-sharing amounts (and the reduced 20 annual cost-sharing limit) is equal to the actuarial 21 value percentage (specified in the table under section $22343(d)$ for the income tier involved) of the full actu23 arial value if there were no cost-sharing imposed $24 \quad$ under the plan; and 
(2) the annual limitation on cost-sharing speci-

2 fied in section $222(\mathrm{c})(2)(\mathrm{B})$ is reduced to a level

3 that does not exceed the maximum out-of-pocket

$4 \quad$ limit specified in subsection (c).

5 (c) Maximum Out-of-pocket Linit.-

6 (1) In GENERAL.—Subject to paragraph (2), 7 the maximum out-of-pocket limit specified in this 8 subsection for an individual within an income tier(A) for individual coverage-

(i) for $\mathrm{Y} 1$ is the out-of-pocket limit for $\mathrm{Y} 1$ specified in subsection (c) in the table under section $343(\mathrm{~d})$ for the income tier involved; or

(ii) for a subsequent year is such outof-pocket limit for the previous year under this subparagraph increased (rounded to the nearest $\$ 10$ ) for each subsequent year by the percentage increase in the enrollment-weighted average of premium increases for basic plans applicable to such year; or

(B) for family coverage is twice the maximum out-of-pocket limit under subparagraph (A) for the year involved. 
(2) Adjustrment.-The Commissioner shall ad-

2 just the maximum out-of-pocket limits under para-

3 graph (1) to ensure that such limits meet the actu-

4 arial value percentage specified in the table under

5 section $343(\mathrm{~d})$ for the income tier involved.

6 (d) Determination and Payment of Cost-shar-

7 ING AFFordability CREdiT.- In the case of an afford-

8 able credit eligible individual in a tier enrolled in an Ex-

9 change-participating health benefits plan offered by a

10 QHBP offering entity, the Commissioner shall provide for

11 payment to the offering entity of an amount equivalent

12 to the increased actuarial value of the benefits under the

13 plan provided under section 303(c)(2)(B) resulting from

14 the reduction in cost-sharing described in subsections (b)

15 and (c).

16 SEC. 345. INCOME DETERMINATIONS.

17 (a) In GENERAL.-In applying this subtitle for an 18 affordability credit for an individual for a plan year, the 19 individual's income shall be the income (as defined in sec20 tion $342(\mathrm{c})$ ) for the individual for the most recent taxable 21 year (as determined in accordance with rules of the Com22 missioner). The Federal poverty level applied shall be such 23 level in effect as of the date of the application.

24 (b) Program Integrity; Income Verification 25 Procedures.- 
(1) Program integrity.-The Commissioner shall take such steps as may be appropriate to en3 sure the accuracy of determinations and redeter4 minations under this subtitle.

(2) InCOMe VERIFICATION.-

(A) In genERAL.-Upon an initial application of an individual for an affordability credit under this subtitle (or in applying section $342(b))$ or upon an application for a change in the affordability credit based upon a significant change in modified adjusted gross income described in subsection $(\mathrm{c})(1)-$

(i) the Commissioner shall request from the Secretary of the Treasury the disclosure to the Commissioner of such information as may be permitted to verify the information contained in such application; and

(ii) the Commissioner shall use the information so disclosed to verify such information.

(B) Alternative Procedures.-The Commissioner shall establish procedures for the verification of income for purposes of this sub- 
title if no income tax return is available for the most recent completed tax year.

(c) Spectal Rules.-

(1) Changes in income as a Percent of

5 FPL.- In the case that an individual's income (ex-

6 pressed as a percentage of the Federal poverty level

7 for a family of the size involved) for a plan year is

8 expected (in a manner specified by the Commis-

9 sioner) to be significantly different from the income

10 (as so expressed) used under subsection (a), the

11 Commissioner shall establish rules requiring an indi-

12 vidual to report, consistent with the mechanism es-

13 tablished under paragraph (2), significant changes

14 in such income (including a significant change in

15 family composition) to the Commissioner and requir-

16 ing the substitution of such income for the income 17 otherwise applicable.

18 (2) Reporting of Significant Changes in

19 INCOME.-The Commissioner shall establish rules

20 under which an individual determined to be an af-

21 fordable credit eligible individual would be required

22 to inform the Commissioner when there is a signifi-

23 cant change in the modified adjusted gross income

24 of the individual (expressed as a percentage of the

25 FPL for a family of the size involved) and of the in- 
1 formation regarding such change. Such mechanism

2 shall provide for guidelines that specify the cir-

3 cumstances that qualify as a significant change, the

4 verifiable information required to document such a

5 change, and the process for submission of such in-

6 formation. If the Commissioner receives new infor-

7 mation from an individual regarding the modified

8 adjusted gross income of the individual, the Commis-

9 sioner shall provide for a redetermination of the in-

10 dividual's eligibility to be an affordable credit eligible

11 individual.

12 (3) Transition FOR CHIP.-In the case of a

13 child described in section 302(d)(2), the Commis-

14 sioner shall establish rules under which the modified

15 adjusted gross income of the child is deemed to be

16 no greater than the family income of the child as

17 most recently determined before Y1 by the State

18 under title XXI of the Social Security Act.

19 (4) STUdy OF GEOGRAPHIC VARIATION IN AP20 PLICATION OF FPL.-

(A) In GENERAL.-The Secretary of 22 Health and Human Services shall conduct a 23 study to examine the feasibility and implication 24 of adjusting the application of the Federal pov25 erty level under this subtitle for different geo- 
graphic areas so as to reflect the variations in cost-of-living among different areas within the United States. If the Secretary determines that an adjustment is feasible, the study should include a methodology to make such an adjustment. Not later than the first day of Y1, the Secretary shall submit to Congress a report on such study and shall include such recommendations as the Secretary determines appropriate.

(i) IN GENERAL.-The Secretary shall ensure that the study under subparagraph (A) covers the territories of the United States and that special attention is paid to the disparity that exists among poverty levels and the cost of living in such territories and to the impact of such disparity on efforts to expand health coverage and ensure health care.

(ii) Territories DeFINED.-In this subparagraph, the term "territories of the United States" includes the Commonwealth of Puerto Rico, the United States Virgin Islands, Guam, the Northern Mar- 
iana Islands, and any other territory or possession of the United States.

(d) Penalties for Misrepresentation.-In the

4 case of an individual who intentionally misrepresents

5 modified adjusted gross income or the individual fails

6 (without regard to intent) to disclose to the Commissioner

7 a significant change in modified adjusted gross income

8 under subsection (c) in a manner that results in the indi-

9 vidual becoming an affordable credit eligible individual

10 when the individual is not or in the amount of the afford-

11 ability credit exceeding the correct amount-

12 (1) the individual is liable for repayment of the

13 amount of the improper affordability credit; and

(2) in the case of such an intentional misrepre-

15 sentation or other egregious circumstances specified

16 by the Commissioner, the Commissioner may impose

17 an additional penalty.

18 SEC. 346. SPECIAL RULES FOR APPLICATION TO TERRI-

TORIES.

20 (a) One-time Election for Treatment and Ap21 Plication OF Funding.-

(1) In GENERAL. - A territory may elect, in a 23 form and manner specified by the Commissioner in 24 consultation with the Secretary of Health and 
1 Human Services and the Secretary of the Treasury

2 and not later than October 1, 2012, either-

(A) to be treated as a State for purposes of applying this title and title II; or

(B) not to be so treated but instead, to have the dollar limitation otherwise applicable to the territory under subsections (f) and ( $\mathrm{g}$ ) of section 1108 of the Social Security Act (42 U.S.C. 1308) for a fiscal year increased by a dollar amount equivalent to the cap amount determined under subsection (c)(2) for the territory as applied by the Secretary for the fiscal year involved.

(2) Conditions for acceptance.-The Commissioner has the nonreviewable authority to accept or reject an election described in paragraph $(1)(\mathrm{A})$. Any such acceptance is-

(A) contingent upon entering into an agreement described in subsection (b) between the Commissioner and the territory and subsection (c); and

(B) subject to the approval of the Secretary of Health and Human Services and the Secretary of the Treasury and subject to such other terms and conditions as the Commis- 
1 sioner, in consultation with such Secretaries,

$2 \quad$ may specify.

(3) Default Rule.-A territory failing to

4 make such an election (or having an election under

5 paragraph (1)(A) not accepted under paragraph (2))

6 shall be treated as having made the election de-

$7 \quad$ scribed in paragraph (1)(B).

8 (b) Agreement for Substitution of Percent9 AGEs FOR AFFORDABILITy CREDITS.-

10 (1) Negotiation.-In the case of a territory 11 making an election under subsection (a)(1)(A) (in 12 this section referred to as an "electing territory"), 13 the Commissioner, in consultation with the Secre14 taries of Health and Human Services and the Treas15 ury, shall enter into negotiations with the govern16 ment of such territory so that, before Y1, there is 17 an agreement reached between the parties on the 18 percentages that shall be applied under paragraph 19 (2) for that territory. The Commissioner shall not 20 enter into such an agreement unless-

(A) payments made under this subtitle with respect to residents of the territory are consistent with the cap established under subsection (c) for such territory and with sub25 section (d); and 
(B) the requirements of paragraphs (3) and (4) are met.

(2) Application of substitute PercentAGES AND DOLLAR AMOUNTS.-In the case of an

5 electing territory, there shall be substituted in sec6 tion $342(\mathrm{a})(1)(\mathrm{B})$ and in the table in section $7341(\mathrm{~d})(1)$ for 400 percent, 133 percent, and other 8 percentages and dollar amounts specified in such 9 table, such respective percentages and dollar 10 amounts as are established under the agreement 11 under paragraph (1) consistent with the following:

(A) No income gap Between medicaid AND AFFORDABILITY CREDITS.-The substituted percentages shall be specified in a manner so as to prevent any gap in coverage for individuals between income level at which medical assistance is available through Medicaid and the income level at which affordability credits are available.

(B) Adjustment FOR OUT-OF-POCKET RESPONSIBILITY FOR PREMIUMS AND COSTSHARING IN RELATION TO INCOME.-The substituted percentages of FPL for income tiers under such table shall be specified in a manner so that- 
(i) affordable credit eligible individuals residing in the territory bear the same out-of-pocket responsibility for premiums and cost-sharing in relation to average income for residents in that territory, as

(ii) the out-of-pocket responsibility for premiums and cost-sharing for affordable credit eligible individuals residing in the 50 States or the District of Columbia in relation to average income for such residents. (3) Spectal Rules with Respect to APPliCATION OF TAX AND PENALTY PROVISIONS.-The electing territory shall enact one or more laws under which provisions similar to the following provisions apply with respect to such territory:

(A) Section $59 \mathrm{~B}$ of the Internal Revenue Code of 1986, except that any resident of the territory who is not an affordable credit eligible individual but who would be an affordable credit eligible individual if such resident were a resident of one of the 50 States (and any qualifying child residing with such individual) may be treated as covered by acceptable coverage.

(B) Section $4980 \mathrm{H}$ of the Internal Revenue Code of 1986 and section 502(c)(11) of 
the Employee Retirement Income Security Act of 1974 .

(C) Section 3121(c) of the Internal Revenue Code of 1986. AND CONSUMER PROTECTION REQUIREMENTS.-The

8 laws and regulations as may be required to apply the

9 requirements of title II with respect to health insur10 ance coverage offered in the territory. (c) Cap on Additional Expenditures.-

(1) In GEnERAL.- In entering into an agreement with an electing territory under subsection (b),

16 dents of such territory during the period beginning 17 with Y1 and ending with 2019 will not exceed the 18 cap amount specified in paragraph (2) for such ter19 ritory. The Commissioner shall adjust from time to 20 time the percentages applicable under such agree21 ment as needed in order to carry out the previous 22 sentence.

(2) Cap amount.-

(A) In gEneraL.- The cap amount speci25 fied in this paragraph- 
(i) for Puerto Rico is $\$ 3,700,000,000$ increased by the amount (if any) elected under subparagraph (C); or

(ii) for another territory is the portion of $\$ 300,000,000$ negotiated for such territory under subparagraph (B).

(B) Negotiation for Certain terRITORIES.-The Commissioner in consultation with the Secretary of Health and Human Services shall negotiate with the governments of the territories (other than Puerto Rico) to allocate the amount specified in subparagraph (A)(ii) among such territories.

(C) Optional SUPPLEMENTATion FOR PUERTO RICO.-

(i) In GeneraL.-Puerto Rico may elect, in a form and manner specified by the Secretary of Health and Human Services in consultation with the Commissioner to increase the dollar amount specified in subparagraph (A)(i) by up to $\$ 1,000,000,000$.

(ii) OfFset IN MEDICAID CAP.-If Puerto Rico makes the election described in clause (i), the Secretary shall decrease 
the dollar limitation otherwise applicable to Puerto Rico under subsections (f) and (g) of section 1108 of the Social Security Act (42 U.S.C. 1308) for a fiscal year by the additional aggregate payments the Secretary estimates will be payable under this section for the fiscal year because of such election.

(d) Limitation on Funding.-In no case shall this 10 section (including the agreement under subsection (b)) 11 permit-

(1) the obligation of funds for expenditures 13 under this subtitle for periods beginning on or after 14 January 1, 2020; or (2) any increase in the dollar limitation de16 scribed in subsection (a)(1)(B) for any portion of 17 any fiscal year occurring on or after such date.

18 SEC. 347. NO FEDERAL PAYMENT FOR UNDOCUMENTED ALIENS.

20 Nothing in this subtitle shall allow Federal payments 21 for affordability credits on behalf of individuals who are 22 not lawfully present in the United States. 
16 if such employer does all of the following: RESPONSIBILITY Subtitle A-Individual Responsibility

SEC. 401. INDIVIDUAL RESPONSIBILITY. of 1986 (as added by section 501 of this Act).

Subtitle B-Employer Responsibility

\section{REQUIREMENTS} MENTS. tion 412 .

\section{TITLE IV-SHARED}

For an individual's responsibility to obtain acceptable

coverage, see section 59B of the Internal Revenue Code

\section{PART 1-HEALTH COVERAGE PARTICIPATION}

SEC. 411. HEALTH COVERAGE PARTICIPATION REQUIRE-

An employer meets the requirements of this section

(1) Offer of COVERAGE.-The employer offers each employee individual and family coverage under a qualified health benefits plan (or under a current employment-based health plan (within the meaning of section $202(b))$ ) in accordance with sec-

(2) Contribution towards COverage.-If an employee accepts such offer of coverage, the em- 
1 ployer makes timely contributions towards such cov-

2 erage in accordance with section 412 .

(3) Contribution in lieu of COverage.-

4 Beginning with Y2, if an employee declines such

5 offer but otherwise obtains coverage in an Exchange-

6 participating health benefits plan (other than by rea-

7 son of being covered by family coverage as a spouse

8 or dependent of the primary insured), the employer

9 shall make a timely contribution to the Health In-

10 surance Exchange with respect to each such em-

11 ployee in accordance with section 413.

12 SEC. 412. EMPLOYER RESPONSIBILITY TO CONTRIBUTE TO-

WARD EMPLOYEE AND DEPENDENT COVERAGE.

15 (a) In GeneraL.-An employer meets the require-

16 ments of this section with respect to an employee if the 17 following requirements are met:

(1) Offering of COVERAGE.-The employer 19 offers the coverage described in section 411(1). In 20 the case of an Exchange-eligible employer, the em21 ployer may offer such coverage either through an 22 Exchange-participating health benefits plan or other 23 than through such a plan.

(2) Employer REquired CONTRIBUtion.25 The employer timely pays to the issuer of such cov- 
1 erage an amount not less than the employer required

2 contribution specified in subsection (b) for such cov3 erage.

(3) Provision of information.-The em5 ployer provides the Health Choices Commissioner, 6 the Secretary of Labor, the Secretary of Health and 7 Human Services, and the Secretary of the Treasury, 8 as applicable, with such information as the Commis9 sioner may require to ascertain compliance with the 10 requirements of this section, including the following:

11 (A) The name, date, and employer identi12 fication number of the employer.

13 (B) A certification as to whether the em14 ployer offers to its full-time employees (and 15 their dependents) the opportunity to enroll in a 16 qualified health benefits plan or a current em17 ployment-based health plan (within the meaning 18 of section $202(\mathrm{~b}))$.

19 (C) If the employer certifies that the em20 ployer did offer to its full-time employees (and 21 their dependents) the opportunity to so enroll22 (i) the months during the calendar 23 year for which such coverage was available; 24 and 
(ii) the monthly premium for the lowest cost option in each of the enrollment categories under each such plan offered to employees.

(D) The name, address, and TIN of each full-time employee during the calendar year and the months (if any) during which such employee (and any dependents) were covered under any such plans.

11 employer provides for autoenrollment of the em12 ployee in accordance with subsection (c).

13 This subsection shall supersede any law of a State which 14 would prevent automatic payroll deduction of employee 15 contributions to an employment-based health plan.

17 Minimum Employer Contribution.-

(1) Full-tine employees.-The minimum 19 employer contribution described in this subsection 20 for coverage of a full-time employee (and, if any, the 21 employee's spouse and qualifying children (as de22 fined in section 152(c) of the Internal Revenue Code 23 of 1986)) under a qualified health benefits plan (or 24 current employment-based health plan) is equal to- 
(A) in case of individual coverage, not less than 72.5 percent of the applicable premium

23 is not a full-time employee, the amount of the min24 imum employer contribution under this subsection 25 shall be a proportion (as determined in accordance 
1 with rules of the Health Choices Commissioner, the

2 Secretary of Labor, the Secretary of Health and

3 Human Services, and the Secretary of the Treasury,

4 as applicable) of the minimum employer contribution

5 under this subsection with respect to a full-time em-

6 ployee that reflects the proportion of-

(A) the average weekly hours of employment of the employee by the employer, to

(B) the minimum weekly hours specified by the Commissioner for an employee to be a full-time employee.

(4) Salary Reductions not treated as EM13 PLOYER CONTRIBUTIONS.-For purposes of this sec14 tion, any contribution on behalf of an employee with 15 respect to which there is a corresponding reduction 16 in the compensation of the employee shall not be 17 treated as an amount paid by the employer.

18 (c) Automatic Enrollment for Employer Spon19 sored Health Benefits.-

(1) In GENERAL.-The requirement of this sub21 section with respect to an employer and an employee 22 is that the employer automatically enroll such em23 ployee into the employment-based health benefits 24 plan for individual coverage under the plan option 25 with the lowest applicable employee premium. 
(2) Opt-ouT.-In no case may an employer 2 automatically enroll an employee in a plan under 3 paragraph (1) if such employee makes an affirmative 4 election to opt out of such plan or to elect coverage 5 under an employment-based health benefits plan of6 fered by such employer. An employer shall provide 7 an employee with a 30-day period to make such an 8 affirmative election before the employer may auto9 matically enroll the employee in such a plan. (3) Notice REQuirements.scribed in paragraph (1) who automatically enrolls an employee into a plan as described in such paragraph shall provide the employees, within a reasonable period before the beginning of each plan year (or, in the case of new employees, within a reasonable period before the end of the enrollment period for such a new employee), written notice of the employees' rights and obligations relating to the automatic enrollment requirement under such paragraph. Such notice must be comprehensive and understood by the average employee to whom the automatic enrollment requirement applies. 
(B) InClusion OF SPECIFIC INFORMATION.-The written notice under subparagraph (A) must explain an employee's right to opt out of being automatically enrolled in a plan and in the case that more than one level of benefits or employee premium level is offered by the employer involved, the notice must explain which level of benefits and employee premium level the employee will be automatically enrolled in the absence of an affirmative election by the em11 ployee.

12 SEC. 413. EMPLOYER CONTRIBUTIONS IN LIEU OF COVERAGE.

14 (a) In GeneraL.-A contribution is made in accord15 ance with this section with respect to an employee if such 16 contribution is equal to an amount equal to 8 percent of 17 the average wages paid by the employer during the period 18 of enrollment (determined by taking into account all em19 ployees of the employer and in such manner as the Com20 missioner provides, including rules providing for the ap21 propriate aggregation of related employers) but not to ex22 ceed the minimum employer contribution described in sec23 tion 412(b)(1)(A). Any such contribution- 
1 (1) shall be paid to the Health Choices Com-

2 missioner for deposit into the Health Insurance Ex-

3 change Trust Fund; and

4 (2) shall not be applied against the premium of

5 the employee under the Exchange-participating

6 health benefits plan in which the employee is en-

7 rolled.

8 (b) Spectal Rules for Small Employers.-

9 (1) IN GENERAL.-In the case of any employer

10 who is a small employer for any calendar year, sub-

11 section (a) shall be applied by substituting the appli-

12 cable percentage determined in accordance with the

13 following table for "8 percent":

\section{If the annual payroll of such employer for The applicable the preceding calendar year: \\ Does not exceed $\$ 500,000$ \\ Exceeds $\$ 500,000$, but does not exceed $\$ 585,000$ \\ Exceeds $\$ 585,000$, but does not exceed $\$ 670,000$ \\ Exceeds $\$ 670,000$, but does not exceed $\$ 750,000$ \\ percentage is: \\ 0 percent \\ 2 percent \\ 4 percent \\ 6 percent}

(2) Small Employer.-For purposes of this subsection, the term "small employer" means any

16 employer for any calendar year if the annual payroll

17 of such employer for the preceding calendar year 18 does not exceed $\$ 750,000$.

(3) Annual PaYroll.-For purposes of this 20 paragraph, the term "annual payroll" means, with 21 respect to any employer for any calendar year, the 
1 aggregate wages paid by the employer during such

2 calendar year.

3 (4) Aggregation Rules.-Related employers

4 and predecessors shall be treated as a single em-

5 ployer for purposes of this subsection.

6 SEC. 414. AUTHORITY RELATED TO IMPROPER STEERING.

7 The Health Choices Commissioner (in coordination

8 with the Secretary of Labor, the Secretary of Health and

9 Human Services, and the Secretary of the Treasury) shall

10 have authority to set standards for determining whether

11 employers or insurers are undertaking any actions to af-

12 fect the risk pool within the Health Insurance Exchange

13 by inducing individuals to decline coverage under a quali-

14 fied health benefits plan (or current employment-based

15 health plan (within the meaning of section $202(b)$ ) offered

16 by the employer and instead to enroll in an Exchange-par-

17 ticipating health benefits plan. An employer violating such

18 standards shall be treated as not meeting the require-

19 ments of this section.

20 SEC. 415. IMPACT STUDY ON EMPLOYER RESPONSIBILITY REQUIREMENTS.

22 (a) In GENERAL.- The Secretary of Labor shall con-

23 duct a study to examine the effect of the exemptions under 24 section 512(a) and coverage thresholds under this division 25 (in this section referred to collectively as "employer re- 
1 sponsibility requirements)on employment-based health

2 plan sponsorship, generally and within specific industries, 3 and the effect of such requirements and thresholds on em4 ployers, employment-based health plans, and employees in 5 each industry.

6 (b) ANnuAL ReporT.-The Secretary of Labor an7 nually shall submit to Congress a report on findings on 8 how employer responsibility requirements have impacted 9 and are likely to impact employers, plans, and employees 10 during the previous year and projected trends.

11 (c) Legislative Recommendations.-No later 12 than January 1, 2012 and on an annual basis thereafter, 13 the Secretary of Labor shall submit legislative rec14 ommendations to Congress to modify the employer respon15 sibility requirements if the Secretary determines that the 16 requirements are detrimentally affecting or will detrimen17 tally affect employer plan sponsorship or otherwise cre18 ating inequities among employers, health plans, and em19 ployees. The Secretary may also submit such recommenda20 tions as the Secretary determines necessary to improve 21 and strengthen employment-based health plan sponsor22 ship, employer responsibility, and related proposals that 23 would enhance the delivery of health care benefits between 24 employers and employees. 
1 SEC. 416. STUDY ON EMPLOYER HARDSHIP EXEMPTION.

2 (a) In GENERAL.-The Secretary of Labor together

3 with the Secretary of Treasury, the Secretary of Health

4 and Human Services, and the Commissioner, shall conduct

5 a study to examine the impact of the employer responsi-

6 bility requirements described in section 415(a) and make

7 a recommendation to Congress about whether an employer

8 hardship exemption would be appropriate.

9 (b) ITEMS INCLUDED IN STUDY.-Within such study

10 the Secretaries and Commissioner shall examine cases

11 where such employer responsibility requirements may pose

12 a particular hardship, and specifically look at employers

13 by industry, profit margin, length of time in business, and

14 size. In this examination, the economic conditions shall be

15 considered, including the rate of increase in business costs,

16 the availability of short-term credit lines, and abilities to

17 restructure debt. In addition, the study shall examine the

18 impact an employer hardship waiver could have on employ-

19 ees.

20 (c) REPORT.-Not later than January 1, 2012, the

21 Secretaries and Commissioner shall report to Congress on

22 their findings and make a recommendation regarding the

23 need or lack of need for a partial or complete employer

24 hardship waiver. The Secretaries and Commissioner may

25 also submit recommendations about the criteria Congress

26 should include when developing eligibility requirements for 
1 the employer hardship waiver and what safeguards are

2 necessary to protect the employees of that employer.

3 PART 2-SATISFACTION OF HEALTH COVERAGE PARTICIPATION REQUIREMENTS

5 SEC. 421. SATISFACTION OF HEALTH COVERAGE PARTICIPATION REQUIREMENTS UNDER THE EMPLOYEE RETIREMENT INCOME SECURITY ACT OF 1974.

(a) In General.-Subtitle B of title I of the Em-

10 ployee Retirement Income Security Act of 1974 is amend-

11 ed by adding at the end the following new part: PARTICIPATION REQUIREMENTS “SEC. 801. ELECTION OF EMPLOYER TO BE SUBJECT TO NATIONAL HEALTH COVERAGE PARTICIPATION REQUIREMENTS.

17 “(a) In GENERAL.-An employer may make an elec18 tion with the Secretary to be subject to the health coverage 19 participation requirements.

20 “(b) Time and Manner.-An election under sub21 section (a) may be made at such time and in such form 22 and manner as the Secretary may prescribe. 
1 "SEC. 802. TREATMENT OF COVERAGE RESULTING FROM ELECTION.

3 “(a) In GenERAL.-If an employer makes an election 4 to the Secretary under section 801"(1) such election shall be treated as the estab-

6 lishment and maintenance of a group health plan (as 7 defined in section $733(\mathrm{a})$ ) for purposes of this title, 8 subject to section 251 of the ; and

$9 \quad$ "(2) the health coverage participation require10 ments shall be deemed to be included as terms and 11 conditions of such plan.

12 “(b) Periodic Investigations To Discover Non13 COMPLince.-The Secretary shall regularly audit a rep14 resentative sampling of employers and group health plans 15 and conduct investigations and other activities under sec16 tion 504 with respect to such sampling of plans so as to 17 discover noncompliance with the health coverage participa18 tion requirements in connection with such plans. The Sec19 retary shall communicate findings of noncompliance made 20 by the Secretary under this subsection to the Secretary 21 of the Treasury and the Health Choices Commissioner. 22 The Secretary shall take such timely enforcement action 23 as appropriate to achieve compliance.

24 "(c) Recondkeeping.-To facilitate the audits de25 scribed in subsection (b), the Secretary shall promulgate 26 recordkeeping requirements for employers to account for 
1 both employees of the employer and individuals whom the

2 employer has not treated as employees of the employer but

3 with whom the employer, in the course of its trade or busi-

4 ness, has engaged for the performance of labor or services.

5 The scope and content of such recordkeeping requirements

6 shall be determined by the Secretary and shall be designed

7 to ensure that employees who are not properly treated as

8 such may be identified and properly treated.

9 "SEC. 803. HEALTH COVERAGE PARTICIPATION REQUIREMENTS.

11 "For purposes of this part, the term 'health coverage

12 participation requirements' means the requirements of

13 part 1 of subtitle $B$ of title IV of division $A$ of (as in effect

14 on the date of the enactment of such Act).

15 “SEC. 804. RULES FOR APPLYING REQUIREMENTS.

16 "(a) Affiliated Groups.-In the case of any em-

17 ployer which is part of a group of employers who are treat-

18 ed as a single employer under subsection (b), (c), (m), or

19 (o) of section 414 of the Internal Revenue Code of 1986 ,

20 the election under section 801 shall be made by such em-

21 ployer as the Secretary may provide. Any such election,

22 once made, shall apply to all members of such group.

23 “(b) Separate Elections.-Under regulations pre24 scribed by the Secretary, separate elections may be made 25 under section 801 with respect to- 
4 "SEC. 805. TERMINATION OF ELECTION IN CASES OF SUB-

6 "The Secretary may terminate the election of any em-

7 ployer under section 801 if the Secretary (in coordination

8 with the Health Choices Commissioner) determines that

9 such employer is in substantial noncompliance with the

10 health coverage participation requirements and shall refer

11 any such determination to the Secretary of the Treasury

12 as appropriate.

\section{3 “SEC. 806. REGULATIONS.}

14 "The Secretary may promulgate such regulations as 15 may be necessary or appropriate to carry out the provi-

16 sions of this part, in accordance with section 424(a) of 17 the . The Secretary may promulgate any interim final 18 rules as the Secretary determines are appropriate to carry 19 out this part.".

20 (b) Enforcement of Health Coverage Partici21 Pation Requirements.-Section 502 of such Act (29 22 U.S.C. 1132) is amended-

23 (1) in subsection (a)(6), by striking "para24 graph" and all that follows through "subsection (c)" 
1 and inserting "paragraph (2), (4), (5), (6), (7), (8),

2 (9), (10), or (11) of subsection (c)"; and

3 (2) in subsection (c), by redesignating the sec4 ond paragraph (10) as paragraph (12) and by in5 serting after the first paragraph (10) the following 6 new paragraph:

QUIREMENTS.-

"(A) Civil Penalties.-In the case of any employer who fails (during any period with respect to which an election under section 801 (a) is in effect) to satisfy the health coverage participation requirements with respect to any employee, the Secretary may assess a civil penalty against the employer of $\$ 100$ for each day in the period beginning on the date such failure first occurs and ending on the date such failure is corrected.

"(B) Health coverage participation REQUIREMENTS.-For purposes of this paragraph, the term 'health coverage participation requirements' has the meaning provided in section 803.

“(C) Limitations on amount of PEN- 
“(i) Penalty not to aPPly where

FAILURE NOT DISCOVERED EXERCISING

REASONABLE DILIGENCE.-No penalty

shall be assessed under subparagraph (A)

with respect to any failure during any period for which it is established to the satisfaction of the Secretary that the employer did not know, or exercising reasonable diligence would not have known, that such failure existed.

“(ii) Penalty nOt TO APPly TO FAILURES CORRECTED WITHIN 30 DAYS.No penalty shall be assessed under subparagraph (A) with respect to any failure if-

"(I) such failure was due to reasonable cause and not to willful neglect, and

"(II) such failure is corrected during the 30-day period beginning on the 1st date that the employer knew, or exercising reasonable diligence would have known, that such failure existed. 
“(iii) Overall Limitation FOR UN-

INTENTIONAL FAILURES.-In the case of failures which are due to reasonable cause and not to willful neglect, the penalty assessed under subparagraph (A) for failures during any 1-year period shall not exceed the amount equal to the lesser of-

"(I) 10 percent of the aggregate amount paid or incurred by the employer (or predecessor employer) during the preceding 1-year period for group health plans, or

$$
\text { "(II) } \$ 500,000 \text {. }
$$

"(D) Advance notification OF FAILURE PRIOR TO ASSESSMENT.-Before a reasonable time prior to the assessment of any penalty under this paragraph with respect to any failure by an employer, the Secretary shall inform the employer in writing of such failure and shall provide the employer information regarding efforts and procedures which may be undertaken by the employer to correct such failure.

"(E) CoOrdination with EXCise TaX.Under regulations prescribed in accordance with section 424 of the, the Secretary and the 
Secretary of the Treasury shall coordinate the assessment of penalties under this section in connection with failures to satisfy health coverage participation requirements with the imposition of excise taxes on such failures under section $4980 \mathrm{H}(\mathrm{b})$ of the Internal Revenue Code of 1986 so as to avoid duplication of penalties with respect to such failures. “(F) Deposit of Penalty Collected.Any amount of penalty collected under this paragraph shall be deposited as miscellaneous receipts in the Treasury of the United States.". (c) Clerical Amendments.-The table of contents

14 in section 1 of such Act is amended by inserting after the

15 item relating to section 734 the following new items:

"Part 8-National Health Coverage Participation Requirements

"Sec. 801. Election of employer to be subject to national health coverage participation requirements.

"Sec. 802. Treatment of coverage resulting from election.

"Sec. 803. Health coverage participation requirements.

"Sec. 804. Rules for applying requirements.

"Sec. 805. Termination of election in cases of substantial noncompliance.

"Sec. 806. Regulations.".

16 (d) EFfective Date.-The amendments made by

17 this section shall apply to periods beginning after Decem-

18 ber 31, 2012. 
288

1 SEC. 422. SATISFACTION OF HEALTH COVERAGE PARTICINAL REVENUE CODE OF 1986.

4 (a) Failure To Elect, or Substantially Com5 ply With, Health Coverage Participation Re6 QUIREMENTS.-For employment tax on employers who fail 7 to elect, or substantially comply with, the health coverage

8 participation requirements described in part 1 , see section $93111(\mathrm{c})$ of the Internal Revenue Code of 1986 (as added 10 by section 512 of this Act).

11 (b) Other Failures.-For excise tax on other fail12 ures of electing employers to comply with such require13 ments, see section $4980 \mathrm{H}$ of the Internal Revenue Code 14 of 1986 (as added by section 511 of this Act).

15 SEC. 423. SATISFACTION OF HEALTH COVERAGE PARTICIPATION REQUIREMENTS UNDER THE PUBLIC HEALTH SERVICE ACT.

18 (a) In General.-Part $\mathrm{C}$ of title XXVII of the Pub19 lic Health Service Act is amended by adding at the end 20 the following new section:

21 "SEC. 2793. NATIONAL HEALTH COVERAGE PARTICIPATION REQUIREMENTS.

23 “(a) Election of Employer To Be Subject to 24 National Health Coverage Participation Require25 MENTS.- 
“(1) In GENERAL.—An employer may make an

2 election with the Secretary to be subject to the

3 health coverage participation requirements.

“(2) Time and ManneR.-An election under

5 paragraph (1) may be made at such time and in

6 such form and manner as the Secretary may pre-

7 scribe.

8 “(b) Treatment of Coverage Resulting From

9 Election.-

10

“(1) In GENERAL.-If an employer makes an

11 election to the Secretary under subsection (a)-

"(A) such election shall be treated as the establishment and maintenance of a group health plan for purposes of this title, subject to section 251 of the Affordable Health Care for America Act; and

"(B) the health coverage participation requirements shall be deemed to be included as terms and conditions of such plan.

22 TION REQUIREMENTS.-The Secretary shall regu23 larly audit a representative sampling of employers 24 and conduct investigations and other activities with 25 respect to such sampling of employers so as to dis- 
1 cover noncompliance with the health coverage par-

2 ticipation requirements in connection with such em-

3 ployers (during any period with respect to which an

4 election under subsection (a) is in effect). The Sec-

5 retary shall communicate findings of noncompliance

6 made by the Secretary under this subsection to the

7 Secretary of the Treasury and the Health Choices

8 Commissioner. The Secretary shall take such timely

9 enforcement action as appropriate to achieve compli-

10 ance.

11 "(3) RECORDKEePing.-To facilitate the audits

12 described in subsection (b), the Secretary shall pro-

13 mulgate recordkeeping requirements for employers

14 to account for both employees of the employer and

15 individuals whom the employer has not treated as

16 employees of the employer but with whom the em-

17 ployer, in the course of its trade or business, has en-

18 gaged for the performance of labor or services. The

19 scope and content of such recordkeeping require-

20 ments shall be determined by the Secretary and

21 shall be designed to ensure that employees who are

22 not properly treated as such may be identified and

23 properly treated.

24 “(c) Health Coverage Participation Require-

25 MENTS.-For purposes of this section, the term 'health 
1 coverage participation requirements' means the require-

2 ments of part 1 of subtitle $\mathrm{B}$ of title IV of division $\mathrm{A}$ of

3 the (as in effect on the date of the enactment of this sec4 tion).

5 “(d) Separate Elections.-Under regulations pre6 scribed by the Secretary, separate elections may be made 7 under subsection (a) with respect to full-time employees 8 and employees who are not full-time employees.

9 “(e) Termination of Election in Cases of Sub10 stantial Noncompliance.-The Secretary may termi11 nate the election of any employer under subsection (a) if 12 the Secretary (in coordination with the Health Choices 13 Commissioner) determines that such employer is in sub14 stantial noncompliance with the health coverage participa15 tion requirements and shall refer any such determination 16 to the Secretary of the Treasury as appropriate.

17 “(f) Enforcement of Health Coverage Par18 TICIPATION REQUIREMENTS."(1) Civil Penalties. - In the case of any em20 ployer who fails (during any period with respect to 21 which the election under subsection (a) is in effect) 22 to satisfy the health coverage participation require23 ments with respect to any employee, the Secretary 24 may assess a civil penalty against the employer of $25 \$ 100$ for each day in the period beginning on the 
1 date such failure first occurs and ending on the date

2 such failure is corrected.

“(2) Limitations on amount of Penalty.“(A) Penalty nOt to aPply where FAILURE NOT DISCOVERED EXERCISING REASONABLE DILIGENCE.-No penalty shall be assessed under paragraph (1) with respect to any failure during any period for which it is established to the satisfaction of the Secretary that the employer did not know, or exercising reasonable diligence would not have known, that such failure existed.

"(B) Penalty nOt TO APPly TO FAILURES CORRECTED WITHIN 30 DAYS.-No penalty shall be assessed under paragraph (1) with respect to any failure if-

"(i) such failure was due to reasonable cause and not to willful neglect, and "(ii) such failure is corrected during the 30-day period beginning on the 1st date that the employer knew, or exercising reasonable diligence would have known, that such failure existed.

"(C) Overall Limitation for UnintenTIONAL FAILURES.-In the case of failures 
which are due to reasonable cause and not to willful neglect, the penalty assessed under paragraph (1) for failures during any 1-year period shall not exceed the amount equal to the lesser of-

"(i) 10 percent of the aggregate

13 PRIOR TO ASSESSMENT.-Before a reasonable time 14 prior to the assessment of any penalty under para15 graph (1) with respect to any failure by an em16 ployer, the Secretary shall inform the employer in 17 writing of such failure and shall provide the em18 ployer information regarding efforts and procedures 19 which may be undertaken by the employer to correct 20 such failure.

22 The Secretary may bring a civil action in any Dis23 trict Court of the United States to collect any civil 24 penalty under this subsection. 
2 Under regulations prescribed in accordance with sec-

3 tion 424 of the , the Secretary and the Secretary of

4 the Treasury shall coordinate the assessment of pen-

5 alties under paragraph (1) in connection with fail-

6 ures to satisfy health coverage participation require-

7 ments with the imposition of excise taxes on such

8 failures under section $4980 \mathrm{H}(\mathrm{b})$ of the Internal Rev-

9 enue Code of 1986 so as to avoid duplication of pen-

10 alties with respect to such failures.

11 “(6) Deposit OF PENALTY COLLECTED.-Any

12 amount of penalty collected under this subsection

13 shall be deposited as miscellaneous receipts in the

14 Treasury of the United States.

15 “(g) Regulations.-The Secretary may promulgate

16 such regulations as may be necessary or appropriate to

17 carry out the provisions of this section, in accordance with

18 section $424($ a) of the . The Secretary may promulgate any

19 interim final rules as the Secretary determines are appro-

20 priate to carry out this section.'.

21 (b) EFFECTIVE DATE.-The amendments made by 22 subsection (a) shall apply to periods beginning after De23 cember 31, 2012. 
1 SEC. 424. ADDITIONAL RULES RELATING TO HEALTH COV-

(a) Assuring Coordination.-The officers con-

4 sisting of the Secretary of Labor, the Secretary of the

5 Treasury, the Secretary of Health and Human Services,

6 and the Health Choices Commissioner shall ensure,

7 through the execution of an interagency memorandum of

8 understanding among such officers, that-

9 (1) regulations, rulings, and interpretations

10 issued by such officers relating to the same matter

11 over which two or more of such officers have respon-

12 sibility under subpart B of part 8 of subtitle B of

13 title I of the Employee Retirement Income Security

14 Act of 1974 , section $4980 \mathrm{H}$ of the Internal Revenue

15 Code of 1986, and section 2793 of the Public Health

16 Service Act are administered so as to have the same

17 effect at all times; and

18 (2) coordination of policies relating to enforcing

19 the same requirements through such officers in

20 order to have a coordinated enforcement strategy

21 that avoids duplication of enforcement efforts and 22 assigns priorities in enforcement.

23 (b) Multiemployer Plans.-In the case of a group 24 health plan that is a multiemployer plan (as defined in 25 section $3(37)$ of the Employee Retirement Income Secu26 rity Act of 1974), the regulations prescribed in accordance 
1 with subsection (a) by the officers referred to in subsection

2 (a) shall provide for the application of the health coverage

3 participation requirements to the plan sponsor and con-

4 tributing employers of such plan. For purposes of this di-

5 vision, contributions made pursuant to a collective bar-

6 gaining agreement or other agreement to such a group

7 health plan shall be treated as amounts paid by the em-

8 ployer.

9 TITLE V-AMENDMENTS TO IN-

10 TERNAL REVENUE CODE OF

$11 \mathbf{1 9 8 6}$

12 Subtitle A-Provisions Relating to

Health Care Reform

PART 1-SHARED RESPONSIBILITY

Subpart A-Individual Responsibility

16 SEC. 501. TAX ON INDIVIDUALS WITHOUT ACCEPTABLE

HEALTH CARE COVERAGE.

18 (a) In GENERAL.-Subchapter A of chapter 1 of the

19 Internal Revenue Code of 1986 is amended by adding at

20 the end the following new part:

21 "PART VIII-HEALTH CARE RELATED TAXES

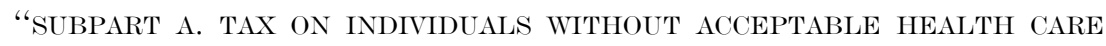
COVERAGE.

22 "Subpart A-Tax on Individuals Without Acceptable 23 Health Care Coverage

"Sec. 59B. Tax on individuals without acceptable health care coverage. 
1 "SEC. 59B. TAX ON INDIVIDUALS WITHOUT ACCEPTABLE

3 "(a) Tax Imposed.-In the case of any individual

4 who does not meet the requirements of subsection (d) at

5 any time during the taxable year, there is hereby imposed

6 a tax equal to 2.5 percent of the excess of-

“(1) the taxpayer's modified adjusted gross in-

8 come for the taxable year, over

"(2) the amount of gross income specified in

10 section $6012(\mathrm{a})(1)$ with respect to the taxpayer.

“(b) Limitations.-

“(1) Tax limited to average Premium.-

"(A) In GENERAL.-The tax imposed under subsection (a) with respect to any taxpayer for any taxable year shall not exceed the applicable national average premium for such taxable year.

“(B) Applicable national average PREMIUM.-

"(i) IN GENERAL.-For purposes of subparagraph (A), the 'applicable national average premium' means, with respect to any taxable year, the average premium (as determined by the Secretary, in coordination with the Health Choices Commissioner) for self-only coverage under a basic 
plan which is offered in a Health Insurance Exchange for the calendar year in which such taxable year begins.

"(ii) Failure to PRovide Coverage

FOR MORE THAN ONE INDIVIDUAL.-In the

13 The tax imposed under subsection (a) with respect 14 to any taxpayer for any taxable year shall not exceed 15 the amount which bears the same ratio to the 16 amount of tax so imposed (determined without re17 gard to this paragraph and after application of para18 graph (1)) as-

"(A) the aggregate periods during such "(B) the entire taxable year.

24 "(c) EXCEPTIONS.- 
“(1) DEPENDEnTs.-Subsection (a) shall not

2 apply to any individual for any taxable year if a de-

3 duction is allowable under section 151 with respect

4 to such individual to another taxpayer for any tax-

5 able year beginning in the same calendar year as

6 such taxable year.

“(2) NonRESIDENT ALIENS.-Subsection (a)

8 shall not apply to any individual who is a non-

9 resident alien.

10 "(3) INDIVIDUALS RESIDING OUTSIDE UNITED

11 states.-Any qualified individual (as defined in

12 section $911(\mathrm{~d})$ ) (and any qualifying child residing

13 with such individual) shall be treated for purposes of

14 this section as covered by acceptable coverage during

15 the period described in subparagraph (A) or (B) of

16 section $911(\mathrm{~d})(1)$, whichever is applicable.

17 “(4) INDIVIDUALS RESIDING IN POSSESSIONS

18 OF THE UNITED STATES.-Any individual who is a

19 bona fide resident of any possession of the United

20 States (as determined under section 937(a)) for any

21 taxable year (and any qualifying child residing with

22 such individual) shall be treated for purposes of this

23 section as covered by acceptable coverage during

24 such taxable year.

25 “(5) Religious CONSCIENCE EXEMPTION.- 
"(A) IN GENERAL.—Subsection (a) shall

not apply to any individual (and any qualifying

child residing with such individual) for any pe-

riod if such individual has in effect an exemption which certifies that such individual is a member of a recognized religious sect or division thereof described in section 1402(g)(1) and an adherent of established tenets or teachings of such sect or division as described in such section.

"(B) Exemption.-An application for the exemption described in subparagraph (A) shall be filed with the Secretary at such time and in such form and manner as the Secretary may prescribe. The Secretary may treat an application for exemption under section $1402(\mathrm{~g})(1)$ as an application for exemption under this section, or may otherwise coordinate applications under such sections, as the Secretary determines appropriate. Any such exemption granted by the Secretary shall be effective for such period as the Secretary determines appropriate.

25 subsection are met with respect to any individual for 
1 any period if such individual (and each qualifying 2 child of such individual) is covered by acceptable 3 coverage at all times during such period.

“(2) Acceptable COverage.-For purposes

5 of this section, the term 'acceptable coverage' means 6 any of the following:

“(A) Qualified health Benefits Plan COVERAGE.-Coverage under a qualified health benefits plan (as defined in section 100(c) of the ).

“(B) GrandFATHERED HEALTH INSURANCE COVERAGE; COVERAGE UNDER GRANDFATHERED EMPLOYMENT-BASED HEALTH PLAN.—Coverage under a grandfathered health insurance coverage (as defined in subsection (a) of section 202 of the ) or under a current employment-based health plan (within the meaning of subsection (b) of such section).

"(C) Medicare.-Coverage under part A of title XVIII of the Social Security Act.

"(D) Medicaid.-Coverage for medical assistance under title XIX of the Social Security Act.

“(E) Members of the ARMed fORCES AND DEPENDENTS (INCLUDING TRICARE).- 
Coverage under chapter 55 of title 10 , United States Code, including similar coverage furnished under section 1781 of title 38 of such Code.

"(F) VA.-Coverage under the veteran's health care program under chapter 17 of title 38, United States Code.

“(G) Members OF Indan TRIBes.Health care services made available through the Indian Health Service, a tribal organization (as defined in section 4 of the Indian Health Care Improvement Act), or an urban Indian organization (as defined in such section) to members of an Indian tribe (as defined in such section). “(H) OTHER COVERAGE.-Such other health benefits coverage as the Secretary, in coordination with the Health Choices Commissioner, recognizes for purposes of this subsection.

“(e) Other Definitions and Special Rules.“(1) Qualifying Child.-For purposes of this section, the term 'qualifying child' has the meaning given such term by section $152(\mathrm{c})$. With respect to any period during which health coverage for a child must be provided by an individual pursuant to a 
1 child support order, such child shall be treated as a 2 qualifying child of such individual (and not as a 3 qualifying child of any other individual).

4 “(2) BASIC PLAN.-For purposes of this sec5 tion, the term 'basic plan' has the meaning given 6 such term under section $100(\mathrm{c})$ of the .

“(3) Health insurance exchange.-For 8 purposes of this section, the term 'Health Insurance 9 Exchange' has the meaning given such term under 10 section $100(\mathrm{c})$ of the , including any State-based 11 health insurance exchange approved for operation 12 under section 308 of such Act.

13 "(4) Family coverage.-For purposes of this 14 section, the term 'family coverage' means any cov15 erage other than self-only coverage.

16 “(5) Modified ADJUsted Gross incone.17 For purposes of this section, the term "modified ad18 justed gross income' means adjusted gross income 19 increased by-

"(A) any amount excluded from gross income under section 911, and 24 which is exempt from tax. 
“(6) Not treated as tax IMposed by this

2 CHAPTER FOR CERTAIN PURPOSES.-The tax im-

3 posed under this section shall not be treated as tax

4 imposed by this chapter for purposes of determining

5 the amount of any credit under this chapter or for 6 purposes of section 55 .

7 “(f) Regulations.-The Secretary shall prescribe 8 such regulations or other guidance as may be necessary 9 or appropriate to carry out the purposes of this section, 10 including regulations or other guidance (developed in co11 ordination with the Health Choices Commissioner) which 12 provide-

13 "(1) exemption from the tax imposed under 14 subsection (a) in cases of de minimis lapses of ac15 ceptable coverage, and

16 "(2) a waiver of the application of subsection 17 (a) in cases of hardship, including a process for ap18 plying for such a waiver.".

19 (b) InFormation REPORTING.-

20 (1) IN GENERAL.-Subpart B of part III of 21 subchapter A of chapter 61 of such Code is amended 22 by inserting after section $6050 \mathrm{~W}$ the following new 23 section: 
1 “SEC. 6050X. RETURNS RELATING TO HEALTH INSURANCE

3 “(a) REQUIREMEnT of Reporting.-Every person

4 who provides acceptable coverage (as defined in section 5 59B(d)) to any individual during any calendar year shall, 6 at such time as the Secretary may prescribe, make the 7 return described in subsection (b) with respect to such in8 dividual.

9 "(b) Form AND MANner OF Returns.-A return 10 is described in this subsection if such return-

11 "(1) is in such form as the Secretary may pre12 scribe, and "(2) contains"(A) the name, address, and TIN of the primary insured and the name of each other individual obtaining coverage under the policy, "(B) the period for which each such individual was provided with the coverage referred to in subsection (a), and "(C) such other information as the Secretary may require.

22 "(c) Statements TO Be Furnished TO Individ23 uals With Respect to Whom Information Is Re24 QUIRED.-Every person required to make a return under 25 subsection (a) shall furnish to each primary insured whose 
1 name is required to be set forth in such return a written

2 statement showing-

"(1) the name and address of the person re-

4 quired to make such return and the phone number

5 of the information contact for such person, and

6 "(2) the information required to be shown on

7 the return with respect to such individual.

8 The written statement required under the preceding sen-

9 tence shall be furnished on or before January 31 of the

10 year following the calendar year for which the return

11 under subsection (a) is required to be made.

12 “(d) Coverage Provided By Governmental

13 Units.-In the case of coverage provided by any govern-

14 mental unit or any agency or instrumentality thereof, the

15 officer or employee who enters into the agreement to pro-

16 vide such coverage (or the person appropriately designated

17 for purposes of this section) shall make the returns and 18 statements required by this section.".

(2) Penalty for failure to file.-

(A) ReTuRn.-Subparagraph (B) of section $6724(\mathrm{~d})(1)$ of such Code is amended by striking "or" at the end of clause (xxii), by striking "and" at the end of clause (xxiii) and inserting "or", and by adding at the end the following new clause: 
"(xxiv) section $6050 \mathrm{X}$ (relating to returns relating to health insurance coverage), and'.

(B) Statement.-Paragraph (2) of section 6724(d) of such Code is amended by striking "or" at the end of subparagraph (EE), by striking the period at the end of subparagraph (FF) and inserting ", or", and by inserting after subparagraph (FF) the following new subparagraph:

"(GG) section 6050X (relating to returns relating to health insurance coverage).'.

14 tion 6012 of such Code is amended by inserting after 15 paragraph (9) the following new paragraph:

17 applies and who fails to meet the requirements of 18 section $59 \mathrm{~B}(\mathrm{~d})$ with respect to such individual or 19 any qualifying child (as defined in section $152(\mathrm{c})$ ) of 20 such individual.".

21 (d) Clerical Amendments.-

22 (1) The table of parts for subchapter A of chap23 ter 1 of the Internal Revenue Code of 1986 is 24 amended by adding at the end the following new 25 item: 
(2) The table of sections for subpart B of part

2 III of subchapter $\mathrm{A}$ of chapter 61 is amended by

3 adding at the end the following new item:

"Sec. 6050X. Returns relating to health insurance coverage.".

4 (e) Section 15 Not to ApPly.-The amendment

5 made by subsection (a) shall not be treated as a change

6 in a rate of tax for purposes of section 15 of the Internal

7 Revenue Code of 1986.

8 (f) Effective Date.-

9 (1) IN GENERAL.-The amendments made by 10 this section shall apply to taxable years beginning 11 after December 31, 2012.

12 (2) RETURNs.-The amendments made by sub13 section (b) shall apply to calendar years beginning $14 \quad$ after December 31, 2012.

15 Subpart B-Employer Responsibility

16 SEC. 511. ELECTION TO SATISFY HEALTH COVERAGE PARTICIPATION REQUIREMENTS.

18 (a) In GeneraL.-Chapter 43 of the Internal Rev19 enue Code of 1986 is amended by adding at the end the 20 following new section:

21 "SEC. 4980H. ELECTION WITH RESPECT TO HEALTH COVERAGE PARTICIPATION REQUIREMENTS.

23 “(a) Election of Employer Responsibility to 24 Provide Health Coverage.- 
“(1) IN GENERAL.—Subsection (b) shall apply

2 to any employer with respect to whom an election

3 under paragraph (2) is in effect.

“(2) Tine and Manner.-An employer may

5 make an election under this paragraph at such time

6 and in such form and manner as the Secretary may

7 prescribe.

“(3) Affiliated Groups.-In the case of any

9 employer which is part of a group of employers who

10 are treated as a single employer under subsection

11 (b), (c), (m), or (o) of section 414, the election

12 under paragraph (2) shall be made by such person

13 as the Secretary may provide. Any such election, 14 once made, shall apply to all members of such 15 group.

16 “(4) SEPARATE ELECTIONS.-Under regula17 tions prescribed by the Secretary, separate elections 18 may be made under paragraph (2) with respect to-

23 substantial noncompliance.-The Secretary 24 may terminate the election of any employer under 25 paragraph (2) if the Secretary (in coordination with 
1 the Health Choices Commissioner) determines that

2 such employer is in substantial noncompliance with

3 the health coverage participation requirements.

4 “(b) Excise Tax With Respect to Failure to

5 Meet Health Coverage Participation Require6 MENTS.-

7

8 who fails (during any period with respect to which

9 the election under subsection (a) is in effect) to sat-

10 isfy the health coverage participation requirements

11 with respect to any employee to whom such election

12 applies, there is hereby imposed on each such failure

13 with respect to each such employee a tax of $\$ 100$ for

14 each day in the period beginning on the date such

15 failure first occurs and ending on the date such fail-

16 ure is corrected.
“(2) Limitations on amount of TAX.-

“(A) TAX NOT TO APPLY WHERE FAILURE NOT DISCOVERED EXERCISING REASONABLE DILIGENCE.-No tax shall be imposed by paragraph (1) on any failure during any period for which it is established to the satisfaction of the Secretary that the employer neither knew, nor exercising reasonable diligence would have known, that such failure existed. 
"(B) TAX NOT TO APPLY TO FAILURES CORRECTED WITHIN 30 DAYS.-No tax shall be imposed by paragraph (1) on any failure if-

"(i) such failure was due to reasonable cause and not to willful neglect, and "(ii) such failure is corrected during the 30-day period beginning on the 1st date that the employer knew, or exercising reasonable diligence would have known, that such failure existed.

“(C) Overall himitation for UnintenTIONAL FAILURES.-In the case of failures which are due to reasonable cause and not to willful neglect, the tax imposed by subsection (a) for failures during the taxable year of the employer shall not exceed the amount equal to the lesser of-

"(i) 10 percent of the aggregate amount paid or incurred by the employer (or predecessor employer) during the preceding taxable year for employment-based health plans, or

$$
\text { “(ii) } \$ 500,000 \text {. }
$$

"(D) Coordination with other enFORCEMENT PROVISIONS.-The tax imposed 
under paragraph (1) with respect to any failure shall be reduced (but not below zero) by the amount of any civil penalty collected under section 502(c)(11) of the Employee Retirement Income Security Act of 1974 or section 2793(g) of the Public Health Service Act with respect to such failure.

“(c) Health Coverage Participation Require-

9 MENTS.-For purposes of this section, the term 'health 10 coverage participation requirements' means the require-

11 ments of part I of subtitle B of title IV of the (as in effect 12 on the date of the enactment of this section).".

13 (b) Clerical Amendment.-The table of sections 14 for chapter 43 of such Code is amended by adding at the 15 end the following new item:

"Sec. 4980H. Election with respect to health coverage participation requirements.".

16 (c) EFFEctive Date.-The amendments made by

17 this section shall apply to periods beginning after Decem-

18 ber 31, 2012.

19 SEC. 512. HEALTH CARE CONTRIBUTIONS OF NONELECTING EMPLOYERS.

21 (a) In GENERAL.-Section 3111 of the Internal Rev22 enue Code of 1986 is amended by redesignating subsection 23 (c) as subsection (d) and by inserting after subsection (b) 24 the following new subsection: 
1 “(c) Employers Electing Not to Provide

2 Health Benefits.-

"(1) In GENERAL.- In addition to other taxes,

4 there is hereby imposed on every nonelecting em-

5 ployer an excise tax, with respect to having individ-

6 uals in his employ, equal to 8 percent of the wages

7 (as defined in section 3121(a)) paid by him with re-

8 spect to employment (as defined in section 3121(b)).

9 “(2) SPEcial RUles FOR SMALL EMPlOY-

10 ERS.-

11

12

13

14

15

16

"If the annual payroll of such employer for The applicable the preceding calendar year:

Does not exceed $\$ 500,000$

Exceeds $\$ 500,000$, but does not exceed $\$ 585,000$

Exceeds $\$ 585,000$, but does not exceed $\$ 670,000$

Exceeds $\$ 670,000$, but does not exceed $\$ 750,000$ percentage is:

0 percent

2 percent

6 percent
4 percent

“(B) Small Employer.-For purposes of this paragraph, the term 'small employer' means any employer for any calendar year if the annual payroll of such employer for the preceding calendar year does not exceed $\$ 750,000$. 
"(C) Annual Payroll.-For purposes of this paragraph, the term 'annual payroll' means, with respect to any employer for any calendar year, the aggregate wages (as defined in section 3121(a)) paid by him with respect to employment (as defined in section 3121(b)) during such calendar year.

“(3) Nonelecting EMPloyer.-For purposes of paragraph (1), the term 'nonelecting employer' means any employer for any period with respect to which such employer does not have an election under section $4980 \mathrm{H}(\mathrm{a})$ in effect.

“(4) Speclal RUle FOR Separate EleCTIONS.-In the case of an employer who makes a separate election described in section $4980 \mathrm{H}(\mathrm{a})(4)$ for any period, paragraph (1) shall be applied for such period by taking into account only the wages paid to employees who are not subject to such election.

“(5) Aggregation; PRedecessors.-For purposes of this subsection-

"(A) all persons treated as a single employer under subsection (b), (c), (m), or (o) of section 414 shall be treated as 1 employer, and 
"(B) any reference to any person shall be treated as including a reference to any predecessor of such person.".

4 (b) Definitions.-Section 3121 of such Code is 5 amended by adding at the end the following new sub6 section:

7 “(aa) Special Rules fOR Tax on Employers 8 Electing Not to Provide Health Benefits.-For 9 purposes of section $3111(\mathrm{c})$ -

10 “(1) Paragraphs (1), (5), and (19) of sub11 section (b) shall not apply.

12 “(2) Paragraph (7) of subsection (b) shall apply 13 by treating all services as not covered by the retire14 ment systems referred to in subparagraphs (C) and $15 \quad(\mathrm{~F})$ thereof.

16 "(3) Subsection (e) shall not apply and the 17 term 'State' shall include the District of Columbia.'. 18 (c) Conforming Amendment.-Subsection (d) of 19 section 3111 of such Code, as redesignated by this section, 20 is amended by striking "this section" and inserting "sub21 sections (a) and (b)". (d) Application to Railroads.-

(1) In general.-Wection 3221 of such Code 24 is amended by redesignating subsection (c) as sub- 
1 section (d) and by inserting after subsection (b) the

2 following new subsection:

3 “(c) Employers Electing Not to Provide

4 Health Benefits.-

5 "(1) IN GENERAL.-In addition to other taxes, 6 there is hereby imposed on every nonelecting em-

7 ployer an excise tax, with respect to having individ-

8 uals in his employ, equal to 8 percent of the com-

9 pensation paid during any calendar year by such em-

10 ployer for services rendered to such employer.

11 “(2) EXCEPTION FOR SMALL EMPLOYERS.-

12 Rules similar to the rules of section $3111(\mathrm{c})(2)$ shall

13 apply for purposes of this subsection.

14 “(3) Nonelecting EMPloyer.-For purposes

15 of paragraph (1), the term 'nonelecting employer'

16 means any employer for any period with respect to

17 which such employer does not have an election under 18 section $4980 \mathrm{H}(\mathrm{a})$ in effect.

19 “(4) SPECIAL RUle FOR SEPARATE ELEC20 TIONS.-In the case of an employer who makes a 21 separate election described in section $4980 \mathrm{H}(\mathrm{a})(4)$ 22 for any period, subsection (a) shall be applied for 23 such period by taking into account only the com24 pensation paid to employees who are not subject to 25 such election.". 
(2) Definitions.-Subsection (e) of section 3231 of such Code is amended by adding at the end

3 the following new paragraph:

“(13) SPEClal RUles FOR TAX ON EMPloyers

ELECTING NOT TO PROVIDE HEALTH BENEFITS.-

$6 \quad$ For purposes of section 3221(c)—

"(A) Paragraph (1) shall be applied without regard to the third sentence thereof.

“(B) Paragraph (2) shall not apply.”.

11 of section 3221 of such Code, as redesignated by

12 this section, is amended by striking "subsections (a)

13 and (b), see section 3231(e)(2)" and inserting "this

14 section, see paragraphs (2) and (13)(B) of section 15 3231(e)".

16 (e) EfFective Date.-The amendments made by 17 this section shall apply to periods beginning after Decem18 ber 31, 2012.

PART 2-CREDIT FOR SMALL BUSINESS

20 EMPLOYEE HEALTH COVERAGE EXPENSES

21 SEC. 521. CREDIT FOR SMALL BUSINESS EMPLOYEE HEALTH COVERAGE EXPENSES.

23 (a) In GeneraL.-Subpart D of part IV of sub24 chapter A of chapter 1 of the Internal Revenue Code of 
11986 (relating to business-related credits) is amended by

2 adding at the end the following new section:

3 "SEC. 45R. SMALL BUSINESS EMPLOYEE HEALTH COVERAGE CREDIT.

5 “(a) In GENERAL.-For purposes of section 38, in

6 the case of a qualified small employer, the small business

7 employee health coverage credit determined under this sec-

8 tion for the taxable year is an amount equal to the applica-

9 ble percentage of the qualified employee health coverage

10 expenses of such employer for such taxable year.

11 “(b) Applicable Percentage.-

12 "(1) In GeneraL.-For purposes of this sec-

13 tion, the applicable percentage is 50 percent.

14 “(2) Phaseout Based ON average COM-

15 PENSATION of EMPloyees.-In the case of an em-

16 ployer whose average annual employee compensation

17 for the taxable year exceeds $\$ 20,000$, the percentage

18 specified in paragraph (1) shall be reduced by a

19 number of percentage points which bears the same

20 ratio to 50 as such excess bears to $\$ 20,000$.

21 "(c) Limitations.-

22 “(1) Phaseout based on employer size.-

23 In the case of an employer who employs more than

2410 qualified employees during the taxable year, the 25 credit determined under subsection (a) shall be re- 
1 duced by an amount which bears the same ratio to

2 the amount of such credit (determined without re-

3 gard to this paragraph and after the application of

4 the other provisions of this section) as-

5

6

7

8

9

10

11

12

13

14

15

16

17 paid by the employer to such employee during such

18 taxable year exceeds $\$ 80,000$.

"(A) the excess of-

"(i) the number of qualified employees employed by the employer during the taxable year, over

"(ii) 10 , bears to

"(B) 15 .

“(2) Credit not allowed with Respect to CERTAIN HIGHLY COMPENSATED EMPLOYEES.-No credit shall be determined under subsection (a) with respect to qualified employee health coverage expenses paid or incurred with respect to any employee for any taxable year if the aggregate compensation “(3) Credit allowed FOR ONly 2 Taxable YEARS.-No credit shall be determined under subsection (a) with respect to any employer for any taxable year unless the employer elects to have this section apply for such taxable year. An employer may elect the application of this section with respect to not more than 2 taxable years. 
1 “(d) Qualified Employee Health Coverage Ex-

2 PENSES.-For purposes of this section-

"(1) In GENERAL.-The term 'qualified em-

4 ployee health coverage expenses' means, with respect

5 to any employer for any taxable year, the aggregate

6 amount paid or incurred by such employer during

7 such taxable year for coverage of any qualified em-

8 ployee of the employer (including any family cov-

9 erage which covers such employee) under qualified

10 health coverage.

“(2) Qualified health COVERage.-The

12 term 'qualified health coverage' means acceptable

13 coverage (as defined in section $59 \mathrm{~B}(\mathrm{~d})$ ) which-

"(A) is provided pursuant to an election under section $4980 \mathrm{H}(\mathrm{a})$, and

"(B) satisfies the requirements referred to in section $4980 \mathrm{H}(\mathrm{c})$. 
"(A) the number of qualified employees employed by such employer during the taxable year does not exceed 25, and

"(B) the average annual employee compensation of such employer for such taxable year does not exceed the sum of the dollar amounts in effect under subsection (b)(2).

“(2) Qualified employee.-The term 'quali9 fied employee' means any employee of an employer 10 for any taxable year of the employer if such em11 ployee received at least $\$ 5,000$ of compensation from 12 such employer for services performed in the trade or 13 business of such employer during such taxable year. “(3) Average annual employee compensa15 TION.-The term 'average annual employee com16 pensation' means, with respect to any employer for 17 any taxable year, the average amount of compensa18 tion paid by such employer to qualified employees of 19 such employer during such taxable year.

“(4) Compensation.—The term 'compensa21 tion' has the meaning given such term in section $22408(\mathrm{p})(6)(\mathrm{A})$.

23 “(5) Family COVERage.-The term 'family 24 coverage' means any coverage other than self-only 25 coverage. 
1 “(f) Special Rules.-For purposes of this sec2 tion-

4 SELF-EMPLOYED.-In the case of a partnership (or 5 a trade or business carried on by an individual) 6 which has one or more qualified employees (deter7 mined without regard to this paragraph) with re8 spect to whom the election under section $4980 \mathrm{H}(\mathrm{a})$ 9 applies, each partner (or, in the case of a trade or 10 business carried on by an individual, such indi11 vidual) shall be treated as an employee. “(2) Aggregation Rule.-All persons treated 13 as a single employer under subsection (b), (c), (m), 14 or (o) of section 414 shall be treated as 1 employer. “(3) Predecessons.-Any reference in this 16 section to an employer shall include a reference to 17 any predecessor of such employer.

18 “(4) Denial of Double Benefit.-Any de19 duction otherwise allowable with respect to amounts 20 paid or incurred for health insurance coverage to 21 which subsection (a) applies shall be reduced by the 22 amount of the credit determined under this section. 23 "(5) Inflation ADJustment.-In the case of 24 any taxable year beginning after 2013, each of the 
1 dollar amounts in subsections (b)(2), (c)(2), and

2 (e)(2) shall be increased by an amount equal to-

"(A) such dollar amount, multiplied by

"(B) the cost of living adjustment determined under section 1(f)(3) for the calendar year in which the taxable year begins determined by substituting 'calendar year 2012' for 'calendar year 1992' in subparagraph thereof.

10 If any increase determined under this paragraph is 11 not a multiple of $\$ 50$, such increase shall be rounded 12 to the next lowest multiple of $\$ 50 . "$.

13 (b) Credit to Be Part of General Business 14 CrediT.-Subsection (b) of section 38 of such Code (re15 lating to general business credit) is amended by striking 16 "plus" at the end of paragraph (34), by striking the period 17 at the end of paragraph (35) and inserting ", plus" , and 18 by adding at the end the following new paragraph: "(36) in the case of a qualified small employer 20 (as defined in section $45 \mathrm{R}(\mathrm{e})$ ), the small business 21 employee health coverage credit determined under 22 section $45 \mathrm{R}(\mathrm{a}) . ”$

23 (c) Clerical Amendment.-The table of sections 24 for subpart D of part IV of subchapter A of chapter 1 
1 of such Code is amended by inserting after the item relat-

2 ing to section $45 \mathrm{Q}$ the following new item:

"Sec. 45R. Small business employee health coverage credit.".

3 (d) Effective Date.-The amendments made by

4 this section shall apply to taxable years beginning after

5 December 31, 2012.

6

7

8 SEC. 531. DISTRIBUTIONS FOR MEDICINE QUALIFIED ONLY IF FOR PRESCRIBED DRUG OR INSULIN.

11 of the Internal Revenue Code of 1986 is amended by add-

12 ing at the end the following: "Such term shall include an

13 amount paid for medicine or a drug only if such medicine

14 or drug is a prescribed drug or is insulin.".

15 (b) ARCHER MSAS.-Subparagraph (A) of section $16220(d)(2)$ of such Code is amended by adding at the end

17 the following: "Such term shall include an amount paid 18 for medicine or a drug only if such medicine or drug is 19 a prescribed drug or is insulin.".

20 (c) Health Flexible Spending Arrangements 21 and Health Reimbursement Arrangements.-Sec22 tion 106 of such Code is amended by adding at the end 23 the following new subsection:

24 “(f) Reimbursements for Medicine Restricted 25 to Prescribed Drugs and Insulin.-For purposes of •HR 3962 IH 
1 this section and section 105, reimbursement for expenses

2 incurred for a medicine or a drug shall be treated as a

3 reimbursement for medical expenses only if such medicine

4 or drug is a prescribed drug or is insulin.".

5 (d) EfFective Dates.-The amendment made by 6 this section shall apply to expenses incurred after Decem7 ber 31, 2010.

8 SEC. 532. LIMITATION ON HEALTH FLEXIBLE SPENDING ARRANGEMENTS UNDER CAFETERIA PLANS.

10 (a) In GENERAL.-Section 125 of the Internal Rev-

11 enue Code of 1986 is amended-

12 (1) by redesignating subsections (i) and (j) as

13 subsections (j) and (k), respectively, and

14 (2) by inserting after subsection (h) the fol-

15 lowing new subsection:

16 “(i) Limitation on Health Flexible Spending 17 Arrangements.-

"(1) IN GENERAL.-For purposes of this sec19 tion, if a benefit is provided under a cafeteria plan 20 through employer contributions to a health flexible 21 spending arrangement, such benefit shall not be 22 treated as a qualified benefit unless the cafeteria 23 plan provides that an employee may not elect for 24 any taxable year to have salary reduction contribu25 tions in excess of $\$ 2,500$ made to such arrangement. 

any taxable year beginning after 2013, the dollar amount in paragraph (1) shall be increased by an 4 amount equal to-

"(A) such dollar amount, multiplied by

"(B) the cost of living adjustment determined under section 1(f)(3) for the calendar year in which the taxable year begins determined by substituting 'calendar year 2012' for 'calendar year 1992' in subparagraph (B) thereof.

12 If any increase determined under this paragraph is 13 not a multiple of $\$ 50$, such increase shall be rounded 14 to the next lowest multiple of $\$ 50 . "$.

15 (b) EFFECTIVE Date.-The amendments made by 16 this section shall apply to taxable years beginning after 17 December 31, 2012.

18 SEC. 533. INCREASE IN PENALTY FOR NONQUALIFIED DISTRIBUTIONS FROM HEALTH SAVINGS ACCOUNTS.

(a) In GeneraL.-Subparagraph (A) of section 22 223(f)(4) of the Internal Revenue Code of 1986 is amend23 ed by striking "10 percent" and inserting "20 percent". 
1 (b) EFFective Date.-The amendment made by

2 this section shall apply to taxable years beginning after

3 December 31, 2010.

4 SEC. 534. DENIAL OF DEDUCTION FOR FEDERAL SUBSIDIES

5 FOR PRESCRIPTION DRUG PLANS WHICH

6 HAVE BEEN EXCLUDED FROM GROSS INCOME.

8 (a) In GENERAL.-Section 139A of the Internal Rev-

9 enue Code of 1986 is amended by striking the second sen10 tence.

11 (b) EFFEctive Date.-The amendment made by 12 this section shall apply to taxable years beginning after 13 December 31, 2010.

14 PART 4-OTHER PROVISIONS TO CARRY OUT HEALTH INSURANCE REFORM

16 SEC. 541. DISCLOSURES TO CARRY OUT HEALTH INSURANCE EXCHANGE SUBSIDIES.

18 (a) IN GENERAL._Subsection (l) of section 6103 of 19 the Internal Revenue Code of 1986 is amended by adding 20 at the end the following new paragraph: “(21) Disclosure OF RETURN INFORMation 22 TO CARRY OUT HEALTH INSURANCE EXCHANGE SUB23 SIDIES.-

“(A) In GENERAL.—The Secretary, upon 25 written request from the Health Choices Com- 
missioner or the head of a State-based health insurance exchange approved for operation under section 308 of the, shall disclose to officers and employees of the Health Choices Administration or such State-based health insurance exchange, as the case may be, return information of any taxpayer whose income is relevant in determining any affordability credit described in subtitle $\mathrm{C}$ of title III of the. Such return information shall be limited to-

“(i) taxpayer identity information with respect to such taxpayer,

"(ii) the filing status of such tax-

"(iii) the modified adjusted gross income of such taxpayer (as defined in section 59B(e)(5)),

"(iv) the number of dependents of the taxpayer, "(v) such other information as is prescribed by the Secretary by regulation as might indicate whether the taxpayer is eligible for such affordability credits (and the amount thereof), and 
"(vi) the taxable year with respect to

18 To Disclosures.-Paragraph (4) of section 6103(p) of 19 such Code is amended-

which the preceding information relates or, if applicable, the fact that such information is not available.

“(B) Restriction on use OF Disclosed INFORMATION.-Return information disclosed under subparagraph (A) may be used by officers and employees of the Health Choices Administration or such State-based health insurance exchange, as the case may be, only for the purposes of, and to the extent necessary in, establishing and verifying the appropriate amount of any affordability credit described in subtitle $\mathrm{C}$ of title III of the and providing for the repayment of any such credit which was in excess of such appropriate amount.".

\section{(b) Procedures and Recordkeeping Related}

(1) by inserting ", or any entity described in subsection (1)(21)," after "or (20)" in the matter preceding subparagraph (A),

(2) by inserting " or any entity described in subsection (1)(21)," after "or (o)(1)(A)," in subparagraph (F)(ii), and 
(3) by inserting "or any entity described in subsection (l)(21)," after “or (20)," both places it ap-

3 pears in the matter after subparagraph $(\mathrm{F})$.

5 Paragraph (2) of section 7213(a) of such Code is amended 6 by striking "or (20)" and inserting "(20), or (21)".

7 SEC. 542. OFFERING OF EXCHANGE-PARTICIPATING HEALTH BENEFITS PLANS THROUGH CAFETERIA PLANS.

10 (a) In GENERAL.-Subsection (f) of section 125 of

11 the Internal Revenue Code of 1986 is amended by adding 12 at the end the following new paragraph:

"(3) Certain EXChange-PARTicipating HEALTH BENEFITS PLANS NOT QUALIFIED.benefit' shall not include any exchange-participating health benefits plan (as defined in section $101(\mathrm{c})$ of the ).

"(B) EXCEPTION FOR EXCHANGE-ELIGIBLE EMPLOYERS.-Subparagraph (A) shall not apply with respect to any employee if such employee's employer is an exchange-eligible employer (as defined in section 302 of the ).".

(b) Conforming Amendments.-Subsection (f) of 25 section 125 of such Code is amended- 
(1) by striking "For purposes of this section,

2 the term" and inserting "For purposes of this sec-

3 tion-

4 “(1) In GeneraL.-The term”, and

(2) by striking "Such term shall not include"

6 and inserting the following:

“(2) Long-TERM CARE Insurance NOT QUALI-

8 FIED.-The term 'qualified benefit' shall not in9 clude".

10 (c) EfFective Date.-The amendments made by 11 this section shall apply to taxable years beginning after 12 December 31, 2012.

13 SEC. 543. EXCLUSION FROM GROSS INCOME OF PAYMENTS MADE UNDER REINSURANCE PROGRAM FOR RETIREES.

16 (a) In GENERAL.-Section $139 \mathrm{~A}$ of the Internal Rev17 enue Code of 1986 is amended-

(1) by striking "Gross income" and inserting 19 the following:

20 “(a) Federal Subsidies for Prescription Drug 21 Plans.-Gross income", and (2) by adding at the end the following new sub23 section:

24 “(b) Federal Reinsurance Program for Retir25 EES.-A rule similar to the rule of subsection (a) shall 
1 apply with respect to payments made under section 111

2 of the Affordable Health Care for America Act.'.

3 (b) Conforming Amendment.-The heading of sec-

4 tion $139 \mathrm{~A}$ of such Code (and the item relating to such

5 section in the table of sections for part III of subchapter

6 B of chapter 1 of such Code) is amended by inserting

7 “AND RETIREE HEALTH PLANS” after "PRESCRIP-

8 TION DRUG PLANS".

9 (c) EFFECTIVE Date.-The amendments made by

10 this section shall apply to taxable years ending after the

11 date of the enactment of this Act.

12 SEC. 544. CLASS PROGRAM TREATED IN SAME MANNER AS

14 (a) In GENERAL.-Subsection (f) of section 7702B

15 of the Internal Revenue Code of 1986 is amended-

(1) by striking "State long-term care plan" in

17 paragraph (1)(A) and inserting "government long18 term care plan",

19 (2) by redesignating paragraph (2) as para20 graph (3), and

21 (3) by inserting after paragraph (2) the fol22 lowing new paragraph:

23 “(2) GOVERnMENT LONG-TERM CARE PLAN.24 For purposes of this subsection, the term 'govern25 ment long-term care plan' means- 
"(A) the CLASS program established under title XXXII of the Public Health Service Act, and “(B) any State long-term care plan.”.

(1) Paragraph (3) of section $7702 \mathrm{~B}(\mathrm{f})$ of such

7 Code, as redesignated by subsection (a), is amended

8 by striking "paragraph (1)" and inserting "this sub9 section".

10 (2) Subsection (f) of section $7702(B)$ of such 11 Code is amended by striking "StTate-MaInTAINED" 12 in the heading thereof and inserting "Govern13 MENT".

14 (c) EfFective Date.-The amendments made by 15 this section shall apply to taxable years ending after De16 cember 31, 2010.

17 SEC. 545. EXCLUSION FROM GROSS INCOME FOR MEDICAL CARE PROVIDED FOR INDIANS.

19 (a) In GeneraL.-Part III of subchapter B of chap20 ter 1 of the Internal Revenue Code of 1986 (relating to 21 items specifically excluded from gross income) is amended 22 by inserting after section 139C the following new section: 23 “SEC. 139D. MEDICAL CARE PROVIDED FOR INDIANS. 24 "(a) In GeneraL.—Gross income does not include- 
“(1) health services or benefits provided or pur-

2 chased by the Indian Health Service, either directly

3 or indirectly, through a grant to or a contract or

4 compact with an Indian tribe or tribal organization

5 or through programs of third parties funded by the

6 Indian Health Service,

“(2) medical care provided by an Indian tribe

8 or tribal organization to a member of an Indian

9 tribe (including for this purpose, to the member's

10 spouse or dependents) through any one of the fol-

11 lowing: provided or purchased medical care services;

12 accident or health insurance (or an arrangement

13 having the effect of accident or health insurance); or

14 amounts paid, directly or indirectly, to reimburse the

15 member for expenses incurred for medical care,

16 "(3) the value of accident or health plan cov-

17 erage provided by an Indian tribe or tribal organiza-

18 tion for medical care to a member of an Indian tribe

19 (including for this purpose, coverage that extends to

20 such member's spouse or dependents) under an acci-

21 dent or health plan (or through an arrangement hav-

22 ing the effect of accident or health insurance), and

23 “(4) any other medical care provided by an In-

24 dian tribe that supplements, replaces, or substitutes 
1 for the programs and services provided by the Fed-

2 eral Government to Indian tribes or Indians.

3 "(b) Definitions.-For purposes of this section-

4 "(1) In GENERAL.-The terms 'accident or

5 health insurance' and 'accident or health plan' have

6 the same meaning as when used in sections 104 and $7 \quad 106$.

8 “(2) MEDiCAL CARE.-The term 'medical care'

9 has the meaning given such term in section 213 .

10 “(3) Dependent.—The term 'dependent' has

11 the meaning given such term in section 152 , deter-

12 mined without regard to subsections (b)(1), (b)(2),

13 and $(\mathrm{d})(\mathrm{1})(\mathrm{B})$.

14 “(4) INDIAN TRIBE.-The term 'Indian tribe' 15 means any Indian tribe, band, nation, pueblo, or 16 other organized group or community, including any 17 Alaska Native village, or regional or village corpora18 tion, as defined in, or established pursuant to, the 19 Alaska Native Claims Settlement Act (43 U.S.C. 201601 et seq.), which is recognized as eligible for the 21 special programs and services provided by the 22 United States to Indians because of their status as 23 Indians.

24 “(5) Tribal organization.-The term 'tribal 25 organization' has the meaning given such term in 
1 section $4(\mathrm{l})$ of the Indian Self-Determination and

2 Education Assistance Act (25 U.S.C. 450b(1)).”.

3 (b) Clerical Amendment.-The table of sections

4 for such part III is amended by inserting after the item

5 relating to section $139 \mathrm{C}$ the following new item:

"Sec. 139D. Medical care provided for Indians.".

6 (c) EFFECTIVE DATE.-The amendments made by

7 this section shall apply to health benefits and coverage

8 provided after the date of enactment of this Act.

9 (d) No INFERENCE.-Nothing in the amendments

10 made by this section shall be construed to create an infer-

11 ence with respect to the exclusion from gross income of-

12 (1) benefits provided by Indian tribes that are

13 not within the scope of this section, and

14 (2) health benefits or coverage provided by In-

15 dian tribes prior to the effective date of this section.

16 Subtitle B-Other Revenue

Provisions

PART 1-GENERAL PROVISIONS

19 SEC. 551. SURCHARGE ON HIGH INCOME INDIVIDUALS.

20 (a) In GENERAL.-Part VIII of subchapter A of

21 chapter 1 of the Internal Revenue Code of 1986, as added

22 by this title, is amended by adding at the end the following

23 new subpart:

24 "Subpart B-Surcharge on High Income Individuals

"Sec. 59C. Surcharge on high ineome individuals. 
1 “SEC. 59C. SURCHARGE ON HIGH INCOME INDIVIDUALS.

2 "(a) General Rule.-In the case of a taxpayer

3 other than a corporation, there is hereby imposed (in addi-

4 tion to any other tax imposed by this subtitle) a tax equal

5 to 5.4 percent of so much of the modified adjusted gross

6 income of the taxpayer as exceeds $\$ 1,000,000$.

7 “(b) Taxpayers Not Making a Joint Return.-

8 In the case of any taxpayer other than a taxpayer making

9 a joint return under section 6013 or a surviving spouse

10 (as defined in section 2(a)), subsection (a) shall be applied

11 by substituting ' $\$ 500,000$ ' for ' $\$ 1,000,000$ '.

12 “(c) Modified Adjusted Gross Income.-For

13 purposes of this section, the term 'modified adjusted gross

14 income' means adjusted gross income reduced by any de-

15 duction (not taken into account in determining adjusted

16 gross income) allowed for investment interest (as defined

17 in section $163(\mathrm{~d})$ ). In the case of an estate or trust, ad-

18 justed gross income shall be determined as provided in sec-

19 tion $67(\mathrm{e})$.

$20 \quad$ “(d) Spectal Rules.-

21 "(1) Nonresident ALIEn.-In the case of a 22 nonresident alien individual, only amounts taken 23 into account in connection with the tax imposed 24 under section 871(b) shall be taken into account 25 under this section. 
"(2) Citizens AND RESIDENTS LIVING

17 posed under this section shall not be treated as tax

18 imposed by this chapter for purposes of determining 19 the amount of any credit under this chapter or for 20 purposes of section 55.".

21 (b) Clerical Amendment.-The table of subparts 22 for part VIII of subchapter A of chapter 1 of such Code, 23 as added by this title, is amended by inserting after the 24 item relating to subpart A the following new item: 
1 (c) SEction 15 Not to APPLy.-The amendment 2 made by subsection (a) shall not be treated as a change 3 in a rate of tax for purposes of section 15 of the Internal

4 Revenue Code of 1986.

5 (d) EFFective Date.-The amendments made by 6 this section shall apply to taxable years beginning after

7 December 31, 2010.

8 SEC. 552. EXCISE TAX ON MEDICAL DEVICES.

9 (a) In GeneraL.-Chapter 31 of the Internal Rev10 enue Code of 1986 is amended by adding at the end the 11 following new subchapter: “Subchapter D-Medical Devices

"Sec. 4061. Medical devices.

13 “SEC. 4061. MEDICAL DEVICES.

14 "(a) In GeneraL.-There is hereby imposed on the

15 first taxable sale of any medical device a tax equal to 2.5 16 percent of the price for which so sold.

17 “(b) Finst Taxable Sale.-For purposes of this 18 section-

“(1) In GENERAL.-The term 'first taxable 20 sale' means the first sale, for a purpose other than 21 for resale, after production, manufacture, or impor22 tation. 

LISHMENTS._-Such term shall not include the sale

3 of any medical device if-

"(A) such sale is made at a retail establishment on terms which are available to the general public, and

"(B) such medical device is of a type (and purchased in a quantity) which is purchased by the general public.

11 similar to the rules of sections 4221 (other than

12 paragraphs (3), (4), (5), and (6) of subsection (a)

13 thereof) and 4222 shall apply for purposes of this

14 section. To the extent provided by the Secretary, 15 section 4222 may be extended to, and made applica16 ble with respect to, the exemption provided by para17 graph (2). “(4) Sales to Patients not treated as RE19 SALES.-If a medical device is sold for use in con20 nection with providing any health care service to an 21 individual, such sale shall not be treated as being for 22 the purpose of resale (even if such device is sold to 23 such individual).

24 “(c) Other Definitions and Special Rules.25 For purposes of this section- 
“(1) Medical Device.-The term 'medical de-

2 vice' means any device (as defined in section 201(h)

3 of the Federal Food, Drug, and Cosmetic Act) in-

4 tended for humans.

“(2) Lease TReated as SAle.-Rules similar

6 to the rules of section 4217 shall apply.

"(3) Use treated as sale.-

“(A) In generaL.- - If any person uses a medical device before the first taxable sale of such device, then such person shall be liable for tax under such subsection in the same manner as if such use were the first taxable sale of such 13 device.

“(B) Exceptions.-The preceding sentence shall not apply to-

"(i) use of a medical device as material in the manufacture or production of, or as a component part of, another medical device to be manufactured or produced by such person, or

"(ii) use of a medical device after a sale described in subsection (b)(2). 
"(A) IN GENERAL.-Rules similar to the rules of subsections (a), (c), and (d) of section 4216 shall apply for purposes of this section.

"(B) Constructive sale Price.-If-

"(i) a medical device is sold (otherwise than through an arm's length transaction) at less than the fair market price, or "(ii) a person is liable for tax for a use described in paragraph (3), the tax under this section shall be computed on the price for which such or similar devices are sold in the ordinary course of trade as determined by the Secretary.

“(5) Resales pursuant to Certain CONTRACT ARRANGEMENTS.-

"(A) In GENERAL.-In the case of a specified contract sale of a medical device, the seller referred to in subparagraph (B)(i) shall be entitled to recover from the producer, manufacturer, or importer referred to in subparagraph (B)(ii) the amount of the tax paid by such seller under this section with respect to such sale. "(B) SPECIFIED CONTRACT SALE.-For purposes of this paragraph, the term 'specified contract sale' means, with respect to any med- 
ical device, the first taxable sale of such device if-

"(i) the seller is not the producer, manufacturer, or importer of such device, "(ii) the price at which such device is so sold is determined in accordance with a contract between the producer, manufacturer, or importer of such device and the person to whom such device is so sold. "(C) SPECIAL RULes RElated TO CREDITS AND REFUNDS.-In the case of any credit or refund under section 6416 of the tax imposed under this section on a specified contract sale of a medical device-

"(i) such credit or refund shall be allowed or made only if the seller has filed with the Secretary the written consent of the producer, manufacturer, or importer referred to in subparagraph (B)(ii) to the allowance of such credit or the making of such refund, and

"(ii) the amount of tax taken into account under subparagraph (A) shall be reduced by the amount of such credit or refund.". 
(b) Conforming Amendments.-

(1) Paragraph (2) of section 6416(b) of such

3 Code is amended-

(A) by inserting "or 4061" after "under section 4051", and

(B) by adding at the end the following: "In the case of the tax imposed by section 4061, subparagraphs (B), (C), (D), and (E) shall not apply.".

(2) The table of subchapters for chapter 31 of 11 such Code is amended by adding at the end the fol12 lowing new item:

“SUbChapter D. MEdical Denices.".

13 (c) Effective Date.-The amendments made by 14 this section shall apply to sales (and leases and uses treat15 ed as sales) after December 31, 2012.

16 SEC. 553. EXPANSION OF INFORMATION REPORTING REQUIREMENTS.

18 (a) In GeneraL.- Section 6041 of the Internal Rev-

19 enue Code of 1986 is amended by adding at the end the 20 following new subsections:

21 “(h) ApPlication to CORPORATions.-Notwith22 standing any regulation prescribed by the Secretary before 23 the date of the enactment of this subsection, for purposes 24 of this section the term 'person' includes any corporation 
1 that is not an organization exempt from tax under section $2501(\mathrm{a})$.

3 “(i) Regulations.-The Secretary may prescribe 4 such regulations and other guidance as may be appro5 priate or necessary to carry out the purposes of this sec6 tion, including rules to prevent duplicative reporting of 7 transactions.".

8 (b) Payments for Property and Other Gross

9 Procends.-Subsection (a) of section 6041 of the Inter10 nal Revenue Code of 1986 is amended-

11 (1) by inserting "amounts in consideration for 12 property," after "wages,",

13 (2) by inserting "gross proceeds," after "emolu14 ments, or other", and

15 (3) by inserting "gross proceeds," after "setting 16 forth the amount of such".

17 (c) EfFective Date.-The amendments made by 18 this section shall apply to payments made after December $1931,2011$.

20 SEC. 554. DELAY IN APPLICATION OF WORLDWIDE ALLOCA21 TION OF INTEREST.

22 (a) In General.-Paragraphs (5)(D) and (6) of sec23 tion 864(f) of the Internal Revenue Code of 1986 are each 24 amended by striking "December 31, 2010" and inserting 25 "December 31, 2019". 
1 (b) Transition.-Subsection (f) of section 864 of

2 such Code is amended by striking paragraph (7).

6 (a) In GENERAL.-Section 894 of the Internal Rev-

7 enue Code of 1986 (relating to income affected by treaty)

8 is amended by adding at the end the following new sub9 section:

13 ible related-party payment, any withholding tax im14 posed under chapter 3 (and any tax imposed under 15 subpart $\mathrm{A}$ or $\mathrm{B}$ of this part) with respect to such 16 payment may not be reduced under any treaty of the 17 United States unless any such withholding tax would 18 be reduced under a treaty of the United States if 19 such payment were made directly to the foreign par20 ent corporation.

“(2) Deductible RELATED-PARTy PAY22 MENT.-For purposes of this subsection, the term 23 'deductible related-party payment' means any pay24 ment made, directly or indirectly, by any person to 25 any other person if the payment is allowable as a de- 
1 duction under this chapter and both persons are

2 members of the same foreign controlled group of en3 tities.

“(3) Foreign CONTROLled Group OF ENTI5 TIES.-For purposes of this subsection-

6 “(A) IN GENERAL.-The term 'foreign $7 \quad$ controlled group of entities' means a controlled 8 group of entities the common parent of which 9 is a foreign corporation.

"(B) Controlled group of entities.The term 'controlled group of entities' means a controlled group of corporations as defined in section 1563(a)(1), except that-

“(i) 'more than 50 percent' shall be substituted for 'at least 80 percent' each place it appears therein, and

"(ii) the determination shall be made without regard to subsections (a)(4) and (b)(2) of section 1563 .

A partnership or any other entity (other than a corporation) shall be treated as a member of a controlled group of entities if such entity is controlled (within the meaning of section $954(d)(3))$ by members of such group (includ- 
1 ing any entity treated as a member of such

2 group by reason of this sentence).

"(4) Foreign PARENT CORPORATION.-For

4 purposes of this subsection, the term 'foreign parent

5 corporation' means, with respect to any deductible

6 related-party payment, the common parent of the

7 foreign controlled group of entities referred to in

8 paragraph $(3)(\mathrm{A})$.

“(5) Regulations.-The Secretary may pre-

10 scribe such regulations or other guidance as are nec-

11 essary or appropriate to carry out the purposes of

12 this subsection, including regulations or other guid-

13 ance which provide for-

14 "(A) the treatment of two or more persons

15 as members of a foreign controlled group of en-

16 tities if such persons would be the common par-

17 ent of such group if treated as one corporation,

18 and

19 "(B) the treatment of any member of a 20 foreign controlled group of entities as the com21 mon parent of such group if such treatment is 22 appropriate taking into account the economic 23 relationships among such entities.". 
1 (b) EFFective Date.-The amendment made by 2 this section shall apply to payments made after the date 3 of the enactment of this Act.

4 SEC. 562. CODIFICATION OF ECONOMIC SUBSTANCE DOCTRINE; PENALTIES.

6 (a) In GENERAL.-Section 7701 of the Internal Rev7 enue Code of 1986 is amended by redesignating subsection 8 (o) as subsection (p) and by inserting after subsection (n) 9 the following new subsection:

10 “(o) Clarification of Economic Substance 11 Doctrine.-

13 of any transaction to which the economic substance 14 doctrine is relevant, such transaction shall be treated 15 as having economic substance only if-

"(A) the transaction changes in a mean17 ingful way (apart from Federal income tax ef18 fects) the taxpayer's economic position, and "(B) the taxpayer has a substantial purpose (apart from Federal income tax effects) for entering into such transaction. "(2) SPECLAL RULE WHERE TAXPAYER RELIES 23 ON PROFIT POTENTIAL."(A) IN GENERAL.-The potential for 25 profit of a transaction shall be taken into ac- 
count in determining whether the requirements of subparagraphs (A) and (B) of paragraph (1) are met with respect to the transaction only if the present value of the reasonably expected pre-tax profit from the transaction is substan-

“(3) State and local tax Benefits.-For

16 tax effect which is related to a Federal income tax 17 effect shall be treated in the same manner as a Fed18 eral income tax effect.

“(4) Financial accounting Benefits.-For 20 purposes of paragraph (1)(B), achieving a financial 21 accounting benefit shall not be taken into account as 22 a purpose for entering into a transaction if the ori23 gin of such financial accounting benefit is a reduc24 tion of Federal income tax. 
“(5) Definitions and speclal Rules.-For

purposes of this subsection-

"(A) Economic substance Doctrine.-

The term 'economic substance doctrine' means the common law doctrine under which tax benefits under subtitle $\mathrm{A}$ with respect to a transaction are not allowable if the transaction does not have economic substance or lacks a business purpose.

"(B) EXCEPTION FOR PERSONAL TRANSACTIONS OF INDIVIDUALS.- - In the case of an individual, paragraph (1) shall apply only to transactions entered into in connection with a trade or business or an activity engaged in for the production of income.

\section{“(C) OTHER COMMON LAW DOCTRINES} NOT AFFECTED.-Except as specifically provided in this subsection, the provisions of this subsection shall not be construed as altering or supplanting any other rule of law, and the requirements of this subsection shall be construed as being in addition to any such other rule of law.

“(D) Determination of application of DOCTRINE NOT AFFECTED.-The determination 
of whether the economic substance doctrine is relevant to a transaction (or series of transactions) shall be made in the same manner as if this subsection had never been enacted.

“(6) Regulations.-The Secretary shall pre6 scribe such regulations as may be necessary or ap7 propriate to carry out the purposes of this sub8 section.".

9 (b) Penalty for Underpayments Attributable 10 to Transactions Lacking Economic Substance.-

(1) IN GENERAL.-Subsection (b) of section 126662 of such Code is amended by inserting after 13 paragraph (5) the following new paragraph:

14 “(6) Any disallowance of claimed tax benefits 15 by reason of a transaction lacking economic sub16 stance (within the meaning of section $7701(0)$ ) or 17 failing to meet the requirements of any similar rule 18 of law.".

19 (2) INCREASED PENALTY FOR NONDISCLOSED 20 TRANSACTIONS.-Section 6662 of such Code is 21 amended by adding at the end the following new 22 subsection:

23 “(i) Increase in Penalty in Case of Nondis24 Closed Noneconomic Substance Transactions.- 
"(1) In GENERAL.- In the case of any portion

2 of an underpayment which is attributable to one or 3 more nondisclosed noneconomic substance trans4 actions, subsection (a) shall be applied with respect 5 to such portion by substituting ' 40 percent' for ' 20 6 percent'.

“(2) Nondisclosed NONECONOMIC SUB8 STANCE TRANSACTIONS.-For purposes of this sub9 section, the term 'nondisclosed noneconomic sub10 stance transaction' means any portion of a trans11 action described in subsection $(b)(6)$ with respect to 12 which the relevant facts affecting the tax treatment 13 are not adequately disclosed in the return nor in a 14 statement attached to the return.

15 “(3) SPECIAL RULE FOR AMENDED RE16 TURNS.-Except as provided in regulations, in no 17 event shall any amendment or supplement to a re18 turn of tax be taken into account for purposes of 19 this subsection if the amendment or supplement is 20 filed after the earlier of the date the taxpayer is first 21 contacted by the Secretary regarding the examina22 tion of the return or such other date as is specified 23 by the Secretary.'. 
(3) Conforming amendment.-Subparagraph (B) of section $6662 \mathrm{~A}(\mathrm{e})(2)$ of such Code is amend3 ed-

(A) by striking "section 6662(h)" and inserting "subsections (h) or (i) of section 6662", and

12 ble to Noneconomic Substance Transactions and

\section{Tax Shelters.-}

(1) Reasonable cause exception for unDERPAYMENTS.-Subsection (c) of section 6664 of such Code is amended-

(A) by redesignating paragraphs (2) and

(3) as paragraphs (3) and (4), respectively,

(B) by striking "paragraph (2)" in paragraph (4)(A), as so redesignated, and inserting "paragraph (3)", and

(C) by inserting after paragraph (1) the following new paragraph:

“(2) ExcePtion.-Paragraph (1) shall not apply to any portion of an underpayment which is 
1 attributable to one or more tax shelters (as defined

2 in section $6662(\mathrm{~d})(2)(\mathrm{C}))$ or transactions described 3 in section $6662(\mathrm{~b})(6) .$.

4 (2) Reasonable cause Exception For Re5 PORTABLE TRANSACTION UNDERSTATEMENTS.6 Subsection (d) of section 6664 of such Code is 7 amended-

8 (A) by redesignating paragraphs (2) and 9 (3) as paragraphs (3) and (4), respectively, 10 (B) by striking "paragraph $(2)(\mathrm{C})$ " in 11 paragraph (4), as so redesignated, and inserting 12 "paragraph $(3)(\mathrm{C})$ ", and

13 (C) by inserting after paragraph (1) the 14 following new paragraph:

15 “(2) ExCEPTIOn.-Paragraph (1) shall not 16 apply to any portion of a reportable transaction un17 derstatement which is attributable to one or more 18 tax shelters (as defined in section $6662(\mathrm{~d})(2)(\mathrm{C})$ ) or 19 transactions described in section $6662(b)(6) . "$.

20 (d) Application of Penalty for Erroneous 21 Cluatm for Refund or Credit to Noneconomic Sub22 stance Transactions.-Section 6676 of such Code is 23 amended by redesignating subsection (c) as subsection (d) 24 and inserting after subsection (b) the following new sub25 section: 
1 “(c) Noneconomic Substance Transactions

2 Treated as Lacking Reasonable Basis.-For pur-

3 poses of this section, any excessive amount which is attrib-

4 utable to any transaction described in section $6662(\mathrm{~b})(6)$

5 shall not be treated as having a reasonable basis.".

6 (e) EfFective Date.-

7 (1) In GENERAL.-Except as otherwise pro-

8 vided in this subsection, the amendments made by

9 this section shall apply to transactions entered into

10 after the date of the enactment of this Act.

11 (2) UNDERPAYMENTS.-The amendments made

12 by subsections (b) and (c)(1) shall apply to under-

13 payments attributable to transactions entered into

14 after the date of the enactment of this Act.

15 (3) Understatements.-The amendments

16 made by subsection (c)(2) shall apply to understate-

17 ments attributable to transactions entered into after

18 the date of the enactment of this Act.

19 (4) REFUnds AND CREDITS.-The amendment

20 made by subsection (d) shall apply to refunds and

21 credits attributable to transactions entered into after

22 the date of the enactment of this Act. 
1 SEC. 563. CERTAIN LARGE OR PUBLICLY TRADED PERSONS

MADE SUBJECT TO A MORE LIKELY THAN NOT STANDARD FOR AVOIDING PENALTIES ON UNDERPAYMENTS.

5 (a) In GeneraL.-Subsection (c) of section 6664 of 6 the Internal Revenue Code of 1986, as amended by section 7562 , is amended-

(1) by redesignating paragraphs (3) and (4) as

9 paragraphs (4) and (5), respectively,

(2) by striking "paragraph (3)" in paragraph

$11(4)(\mathrm{A})$, as so redesignated, and inserting "paragraph

12 (4)', and

13 (3) by inserting after paragraph (2) the fol14 lowing new paragraph:

“(3) SPECLAL RULE FOR CERTAIN LARGE OR PUBLICLY TRADED PERSONS.specified person, paragraph (1) shall apply to the portion of an underpayment which is attributable to any item only if such person has a reasonable belief that the tax treatment of such item by such person is more likely than not the proper tax treatment of such item.

“(B) SpecifIED PERSON.-For purposes of this paragraph, the term 'specified person' means- 
"(i) any person required to file periodic or other reports under section 13 of the Securities Exchange Act of 1934, and “(ii) any corporation with gross receipts in excess of $\$ 100,000,000$ for the taxable year involved.

All persons treated as a single employer under section 52(a) shall be treated as one person for purposes of clause (ii).”.

10 (b) Nonapplication of Substantial Authority 11 and Reasonable Basis Standards for Reducing 12 Understatements.-Paragraph (2) of section 6662(d) 13 of such Code is amended by adding at the end the fol14 lowing new subparagraph:

“(D) Reduction nOt TO APPLY TO CERTAIN LARGE OR PUBLICLY TRADED PERSONS.Subparagraph (B) shall not apply to any specified person (as defined in section $6664(\mathrm{c})(3)(\mathrm{B})) . ”$.

20 (c) EfFective Date.-

(1) In GeneraL.-Except as provided in para22 graph (2), the amendments made by this section 23 shall apply to underpayments attributable to trans24 actions entered into after the date of the enactment 25 of this Act. 
(2) Nonapplication of understatement REDUCTION.-The amendment made by subsection (b) shall apply to understatements attributable to transactions entered into after the date of the enactment of this Act.

SEC. 571. CERTAIN HEALTH RELATED BENEFITS APPLICAPART 3-PARITY IN HEALTH BENEFITS

$$
\text { BLE TO SPOUSES AND DEPENDENTS EX- }
$$
TENDED TO ELIGIBLE BENEFICIARIES.

13106 of the Internal Revenue Code of 1986 (relating 14 to contributions by employer to accident and health 15 plans), as amended by section 531, is amended by 16 adding at the end the following new subsection: “(g) Coverage Provided for Eligible Bene18 FICIARIES OF EMPLOYEES.-

“(1) IN GENERAL.-Subsection (a) shall apply 20 with respect to any eligible beneficiary of the em21 ployee.

“(2) Eligible Benefictary.-For purposes of 23 this subsection, the term 'eligible beneficiary' means 24 any individual who is eligible to receive benefits or 25 coverage under an accident or health plan.". 
(2) Exclusion of AMounts EXPENDED FOR MEDICAL CARE.-The first sentence of section 105(b) of such Code (relating to amounts expended for medical care) is amended-

(A) by striking "and his dependents" and inserting "his dependents", and

(B) by inserting before the period the following: "and any eligible beneficiary (within the meaning of section $106(\mathrm{~g}))$ with respect to the taxpayer".

(3) Payroll taxes.-

(A) Section 3121(a)(2) of such Code is amended-

(i) by striking "or any of his dependents" in the matter preceding subparagraph (A) and inserting ", any of his dependents, or any eligible beneficiary (within the meaning of section $106(\mathrm{~g})$ ) with respect to the employee",

(ii) by striking "or any of his dependents," in subparagraph (A) and inserting ", any of his dependents, or any eligible beneficiary (within the meaning of section $106(\mathrm{~g}))$ with respect to the employee,", and 
(iii) by striking "and their dependents" both places it appears and inserting “and such employees' dependents and eligible beneficiaries (within the meaning of section $\left.106\left(g^{\prime}\right)\right) "$ (B) Section 3231(e)(1) of such Code is amended-

(i) by striking "or any of his dependents" and inserting ", any of his dependents, or any eligible beneficiary (within the meaning of section $106(\mathrm{~g})$ ) with respect to the employee,", and

(ii) by striking "and their dependents" both places it appears and inserting “and such employees' dependents and eligible beneficiaries (within the meaning of section $106(\mathrm{~g})) "$.

(C) Section 3306(b)(2) of such Code is amended-

(i) by striking "or any of his dependents" in the matter preceding subparagraph (A) and inserting ", any of his dependents, or any eligible beneficiary (within the meaning of section $106(\mathrm{~g}))$ with respect to the employee,", 
(ii) by striking "or any of his dependents" in subparagraph (A) and inserting ", any of his dependents, or any eligible beneficiary (within the meaning of section $106(\mathrm{~g}))$ with respect to the employee", and (iii) by striking "and their dependents" both places it appears and inserting “and such employees' dependents and eligible beneficiaries (within the meaning of section $106(\mathrm{~g})) "$.

(D) Section 3401(a) of such Code is amended by striking "or" at the end of paragraph (22), by striking the period at the end of paragraph (23) and inserting “; or”, and by inserting after paragraph (23) the following new paragraph:

"(24) for any payment made to or for the benefit of an employee or any eligible beneficiary (within the meaning of section $106(\mathrm{~g}))$ if at the time of such payment it is reasonable to believe that the employee will be able to exclude such payment from income under section 106 or under section 105 by reference in section 105(b) to section 106(g).". 
1 (b) Expansion of Dependency for Purposes of

2 Deduction for Health Insurance Costs of Self3 EMPLOYED INDIVIDUALS.-

(1) In GENERAL.-Paragraph (1) of section $5162(\mathrm{l})$ of the Internal Revenue Code of 1986 (relat6 ing to special rules for health insurance costs of self7 employed individuals) is amended to read as follows: "(1) Allowance of Deduction.-In the case 9 of a taxpayer who is an employee within the mean10 ing of section 401(c)(1), there shall be allowed as a 11 deduction under this section an amount equal to the 12 amount paid during the taxable year for insurance 13 which constitutes medical care for-

"(A) the taxpayer,

“(B) the taxpayer's spouse,

“(C) the taxpayer's dependents, "(D) any individual who"(i) satisfies the age requirements of payer described in section $152(\mathrm{~d})(2)(\mathrm{H})$, and

"(iii) meets the requirements of section 152(d)(1)(C), and 
17 Sick and Accident Benefits Provided to Members 18 of a Voluntary Employees' Beneficlary Associa-

19 Tion And Their Dependents.-Section 501(c)(9) of 20 the Internal Revenue Code of 1986 (relating to list of ex21 empt organizations) is amended by adding at the end the 22 following new sentence: "For purposes of providing for the 23 payment of sick and accident benefits to members of such 24 an association and their dependents, the term 'dependents' 25 shall include any individual who is an eligible beneficiary 
1 (within the meaning of section $106(\mathrm{~g})$ ), as determined

2 under the terms of a medical benefit, health insurance, 3 or other program under which members and their depend4 ents are entitled to sick and accident benefits.".

5 (d) Flexible Spending Arrangements and 6 Health Reimbursement Arrangements.-The Sec7 retary of Treasury shall issue guidance of general applica-

8 bility providing that medical expenses that otherwise qual9 ify-

10 (1) for reimbursement from a flexible spending 11 arrangement under regulations in effect on the date 12 of the enactment of this Act may be reimbursed 13 from an employee's flexible spending arrangement, 14 notwithstanding the fact that such expenses are at15 tributable to any individual who is not the employ16 ee's spouse or dependent (within the meaning of sec17 tion $105(\mathrm{~b})$ of the Internal Revenue Code of 1986) 18 but is an eligible beneficiary (within the meaning of 19 section $106(\mathrm{~g})$ of such Code) under the flexible 20 spending arrangement with respect to the employee, 21 and

22 (2) for reimbursement from a health reimburse23 ment arrangement under regulations in effect on the 24 date of the enactment of this Act may be reimbursed 25 from an employee's health reimbursement arrange- 
1 ment, notwithstanding the fact that such expenses

2 are attributable to an individual who is not a spouse

3 or dependent (within the meaning of section 105(b)

4 of such Code) but is an eligible beneficiary (within

5 the meaning of section $106(\mathrm{~g})$ of such Code) under

6 the health reimbursement arrangement with respect

7 to the employee.

8 (e) EFfective Date.-The amendments made by

9 this section shall apply to taxable years beginning after

10 December 31, 2009.

\section{DIVISION B-MEDICARE AND \\ 12 MEDICAID IMPROVEMENTS \\ 13 SEC. 1001. TABLE OF CONTENTS OF DIVISION.}

14 The table of contents of this division is as follows:

Sec. 1001. Table of contents of division.

TITLE I-IMPROVING HEALTH CARE VALUE

Subtitle A-Provisions Related to Medicare Part A

PART 1-Market Basket UPDATES

Sec. 1101. Skilled nursing facility payment update.

Sec. 1102. Inpatient rehabilitation facility payment update.

Sec. 1103. Incorporating productivity improvements into market basket updates that do not already incorporate such improvements.

Part 2-Other Medicare Part a Provisions

Sec. 1111. Payments to skilled nursing facilities.

Sec. 1112. Medicare DSH report and payment adjustments in response to coverage expansion.

Sec. 1113. Extension of hospice regulation moratorium.

Sec. 1114. Permitting physician assistants to order post-hospital extended care services and to provide for recognition of attending physician assistants as attending physicians to serve hospice patients.

Subtitle B-Provisions Related to Part B

Part 1-Physiclans' Services

•HR 3962 IH 
Sec. 1121. Resource-based feedback program for physicians in Medicare.

Sec. 1122. Misvalued codes under the physician fee schedule.

Sec. 1123. Payments for efficient areas.

Sec. 1124. Modifications to the Physician Quality Reporting Initiative (PQRI).

Sec. 1125. Adjustment to Medicare payment localities.

\section{Part 2-Market Basket Updates}

Sec. 1131. Incorporating productivity improvements into market basket updates that do not already incorporate such improvements.

\section{Part 3-Other Provisions}

Sec. 1141. Rental and purchase of power-driven wheelchairs.

Sec. 1141A. Election to take ownership, or to decline ownership, of a certain item of complex durable medical equipment after the 13-month capped rental period ends.

Sec. 1142. Extension of payment rule for brachytherapy.

Sec. 1143. Home infusion therapy report to Congress.

Sec. 1144. Require ambulatory surgical centers (ASCs) to submit cost data and other data.

Sec. 1145. Treatment of certain cancer hospitals.

Sec. 1146. Payment for imaging services.

Sec. 1147. Durable medical equipment program improvements.

Sec. 1148. MedPAC study and report on bone mass measurement.

Sec. 1149. Timely access to post-mastectomy items.

Sec. 1149A. Payment for biosimilar biological products.

Sec. 1149B. Study and report on DME competitive bidding process.

Subtitle C-Provisions Related to Medicare Parts A and B

Sec. 1151. Reducing potentially preventable hospital readmissions.

Sec. 1152. Post acute care services payment reform plan and bundling pilot program.

Sec. 1153. Home health payment update for 2010.

Sec. 1154. Payment adjustments for home health care.

Sec. 1155. Incorporating productivity improvements into market basket update for home health services.

Sec. 1155A. MedPAC study on variation in home health margins.

Sec. 1155B. Permitting home health agencies to assign the most appropriate skilled service to make the initial assessment visit under a Medicare home health plan of care for rehabilitation cases.

Sec. 1156. Limitation on Medicare exceptions to the prohibition on certain physician referrals made to hospitals.

Sec. 1157. Institute of Medicine study of geographic adjustment factors under Medicare.

Sec. 1158. Revision of medicare payment systems to address geographic inequities.

Sec. 1159. Institute of Medicine study of geographic variation in health care spending and promoting high-value health care.

Sec. 1160. Implementation, and Congressional review, of proposal to revise Medicare payments to promote high value health care.

Subtitle D-Medicare Advantage Reforms

Part 1-Payment and Administration 
Sec. 1161. Phase-in of payment based on fee-for-service costs; quality bonus payments.

Sec. 1162. Authority for Secretarial coding intensity adjustment authority.

Sec. 1163. Simplification of annual beneficiary election periods.

Sec. 1164. Extension of reasonable cost contracts.

Sec. 1165. Limitation of waiver authority for employer group plans.

Sec. 1166. Improving risk adjustment for payments.

Sec. 1167. Elimination of MA Regional Plan Stabilization Fund.

Sec. 1168. Study regarding the effects of calculating Medicare Advantage payment rates on a regional average of Medicare fee for service rates.

\section{Part 2-Beneficiary Protections and Anti-Fraud}

Sec. 1171. Limitation on cost-sharing for individual health services.

Sec. 1172. Continuous open enrollment for enrollees in plans with enrollment suspension.

Sec. 1173. Information for beneficiaries on MA plan administrative costs.

Sec. 1174. Strengthening audit authority.

Sec. 1175. Authority to deny plan bids.

Sec. 1175A. State authority to enforce standardized marketing requirements.

\section{Part 3-Treatment of Speclal Needs Plans}

Sec. 1176. Limitation on enrollment outside open enrollment period of individuals into chronic care specialized MA plans for special needs individuals.

Sec. 1177. Extension of authority of special needs plans to restrict enrollment; service area moratorium for certain SNPs.

Sec. 1178. Extension of Medicare senior housing plans.

Subtitle E-Improvements to Medicare Part D

Sec. 1181. Elimination of coverage gap.

Sec. 1182. Discounts for certain part D drugs in original coverage gap.

Sec. 1183. Repeal of provision relating to submission of claims by pharmacies located in or contracting with long-term care facilities.

Sec. 1184. Including costs incurred by AIDS drug assistance programs and Indian Health Service in providing prescription drugs toward the annual out-of-pocket threshold under part D.

Sec. 1185. No mid-year formulary changes permitted.

Sec. 1186. Negotiation of lower covered part D drug prices on behalf of Medicare beneficiaries.

Sec. 1187. Accurate dispensing in long-term care facilities.

Sec. 1188. Free generic fill.

Sec. 1189. State certification prior to waiver of licensure requirements under Medicare prescription drug program.

Subtitle F-Medicare Rural Access Protections

Sec. 1191. Telehealth expansion and enhancements.

Sec. 1192. Extension of outpatient hold harmless provision.

Sec. 1193. Extension of section 508 hospital reclassifications.

Sec. 1194. Extension of geographic floor for work.

Sec. 1195. Extension of payment for technical component of certain physician pathology services.

Sec. 1196. Extension of ambulance add-ons. 
TITLE II-MEDICARE BENEFICIARY IMPROVEMENTS

Subtitle A-Improving and Simplifying Financial Assistance for Low Income Medicare Beneficiaries

Sec. 1201. Improving assets tests for Medicare Savings Program and low-income subsidy program.

Sec. 1202. Elimination of part D cost-sharing for certain non-institutionalized full-benefit dual eligible individuals.

Sec. 1203. Eliminating barriers to enrollment.

Sec. 1204. Enhanced oversight relating to reimbursements for retroactive low income subsidy enrollment.

Sec. 1205. Intelligent assignment in enrollment.

See. 1206. Special enrollment period and automatic enrollment process for certain subsidy eligible individuals.

Sec. 1207. Application of MA premiums prior to rebate and quality bonus payments in calculation of low income subsidy benchmark.

Subtitle B-Reducing Health Disparities

Sec. 1221. Ensuring effective communication in Medicare.

Sec. 1222. Demonstration to promote access for Medicare beneficiaries with limited English proficiency by providing reimbursement for culturally and linguistically appropriate services.

Sec. 1223. IOM report on impact of language access services.

Sec. 1224. Definitions.

Subtitle C-Miscellaneous Improvements

Sec. 1231. Extension of therapy caps exceptions process.

Sec. 1232. Extended months of coverage of immunosuppressive drugs for kidney transplant patients and other renal dialysis provisions.

Sec. 1233. Voluntary advance care planning consultation.

Sec. 1234. Part B special enrollment period and waiver of limited enrollment penalty for TRICARE beneficiaries.

Sec. 1235. Exception for use of more recent tax year in case of gains from sale of primary residence in computing part $\mathrm{B}$ income-related premium.

Sec. 1236. Demonstration program on use of patient decisions aids.

\section{TITLE III-PROMOTING PRIMARY CARE, MENTAL HEALTH SERVICES, AND COORDINATED CARE}

Sec. 1301. Accountable Care Organization pilot program.

Sec. 1302. Medical home pilot program.

Sec. 1303. Payment incentive for selected primary care services.

Sec. 1304. Increased reimbursement rate for certified nurse-midwives.

Sec. 1305. Coverage and waiver of cost-sharing for preventive services.

Sec. 1306. Waiver of deductible for colorectal cancer screening tests regardless of coding, subsequent diagnosis, or ancillary tissue removal.

Sec. 1307. Excluding clinical social worker services from coverage under the medicare skilled nursing facility prospective payment system and consolidated payment.

Sec. 1308. Coverage of marriage and family therapist services and mental health counselor services.

Sec. 1309. Extension of physician fee schedule mental health add-on.

Sec. 1310. Expanding access to vaccines. 
Sec. 1311. Expansion of Medicare-Covered Preventive Services at Federally Qualified Health Centers.

Sec. 1312. Independence at home demonstration program.

Sec. 1313. Recognition of certified diabetes educators as certified providers for purposes of Medicare diabetes outpatient self-management training services.

\section{TITLE IV-QUALITY}

Subtitle A—Comparative Effectiveness Research

Sec. 1401. Comparative effectiveness research.

Subtitle B-Nursing Home Transparency

Part 1-Improving Transparency of Information on Skilled Nursing Facilities, Nursing Facilities, and Other Long-term Care FaCILITIES

Sec. 1411. Required disclosure of ownership and additional disclosable parties information.

Sec. 1412. Accountability requirements.

Sec. 1413. Nursing home compare Medicare website.

Sec. 1414. Reporting of expenditures.

Sec. 1415. Standardized complaint form.

Sec. 1416. Ensuring staffing accountability.

Sec. 1417. Nationwide program for national and State background checks on direct patient access employees of long-term care facilities and providers.

\section{Part 2-Targeting Enforcement}

Sec. 1421. Civil money penalties.

Sec. 1422. National independent monitor pilot program.

Sec. 1423. Notification of facility closure.

\section{Part 3-Improving Staff Training}

Sec. 1431. Dementia and abuse prevention training.

Sec. 1432. Study and report on training required for certified nurse aides and supervisory staff.

Sec. 1433. Qualification of director of food services of a skilled nursing facility or nursing facility.

\section{Subtitle C-Quality Measurements}

Sec. 1441. Establishment of national priorities for quality improvement.

Sec. 1442. Development of new quality measures; GAO evaluation of data collection process for quality measurement.

Sec. 1443. Multi-stakeholder pre-rulemaking input into selection of quality measures.

Sec. 1444. Application of quality measures.

Sec. 1445. Consensus-based entity funding.

Subtitle D—Physician Payments Sunshine Provision 
Sec. 1451. Reports on financial relationships between manufacturers and distributors of covered drugs, devices, biologicals, or medical supplies under Medicare, Medicaid, or CHIP and physicians and other health care entities and between physicians and other health care entities.

Subtitle E-Public Reporting on Health Care-Associated Infections

Sec. 1461. Requirement for public reporting by hospitals and ambulatory surgical centers on health care-associated infections.

TITLE V-MEDICARE GRADUATE MEDICAL EDUCATION

Sec. 1501. Distribution of unused residency positions.

Sec. 1502. Increasing training in nonprovider settings.

Sec. 1503. Rules for counting resident time for didactic and scholarly activities and other activities.

Sec. 1504. Preservation of resident cap positions from closed hospitals.

Sec. 1505. Improving accountability for approved medical residency training.

\section{TITLE VI-PROGRAM INTEGRITY}

Subtitle A-Increased Funding to Fight Waste, Fraud, and Abuse

Sec. 1601. Increased funding and flexibility to fight fraud and abuse.

Subtitle B-Enhanced Penalties for Fraud and Abuse

Sec. 1611. Enhanced penalties for false statements on provider or supplier enrollment applications.

Sec. 1612. Enhanced penalties for submission of false statements material to a false claim.

Sec. 1613. Enhanced penalties for delaying inspections.

Sec. 1614. Enhanced hospice program safeguards.

Sec. 1615. Enhanced penalties for individuals excluded from program participation.

Sec. 1616. Enhanced penalties for provision of false information by Medicare Advantage and part D plans.

Sec. 1617. Enhanced penalties for Medicare Advantage and part D marketing violations.

Sec. 1618. Enhanced penalties for obstruction of program audits.

Sec. 1619. Exclusion of certain individuals and entities from participation in Medicare and State health care programs.

Sec. 1620. OIG authority to exclude from Federal health eare programs officers and owners of entities convicted of fraud.

Sec. 1621. Self-referral disclosure protocol.

Subtitle C-Enhanced Program and Provider Protections

Sec. 1631. Enhanced CMS program protection authority.

Sec. 1632. Enhanced Medicare, Medicaid, and CHIP program disclosure requirements relating to previous affiliations.

Sec. 1633. Required inclusion of payment modifier for certain evaluation and management services.

Sec. 1634. Evaluations and reports required under Medicare Integrity Program.

Sec. 1635. Require providers and suppliers to adopt programs to reduce waste, fraud, and abuse. 
Sec. 1636. Maximum period for submission of Medicare claims reduced to not more than 12 months.

Sec. 1637. Physicians who order durable medical equipment or home health services required to be Medicare enrolled physicians or eligible professionals.

Sec. 1638. Requirement for physicians to provide documentation on referrals to programs at high risk of waste and abuse.

Sec. 1639. Face-to-face encounter with patient required before eligibility certifications for home health services or durable medical equipment.

Sec. 1640. Extension of testimonial subpoena authority to program exclusion investigations.

Sec. 1641. Required repayments of Medicare and Medicaid overpayments.

Sec. 1642. Expanded application of hardship waivers for OIG exclusions to beneficiaries of any Federal health care program.

Sec. 1643. Access to certain information on renal dialysis facilities.

Sec. 1644. Billing agents, clearinghouses, or other alternate payees required to register under Medicare.

Sec. 1645. Conforming civil monetary penalties to False Claims Act amendments.

Sec. 1646. Requiring provider and supplier payments under Medicare to be made through direct deposit or electronic funds transfer (EFT) at insured depository institutions.

Sec. 1647. Inspector General for the Health Choices Administration.

Subtitle D-Access to Information Needed to Prevent Fraud, Waste, and Abuse

Sec. 1651. Access to Information Necessary to Identify Fraud, Waste, and Abuse.

Sec. 1652. Elimination of duplication between the Healthcare Integrity and Protection Data Bank and the National Practitioner Data Bank.

Sec. 1653. Compliance with HIPAA privacy and security standards.

TITLE VII-MEDICAID AND CHIP

Sec. 1. Table of contents 【Temporary】.

Subtitle A-Medicaid and Health Reform

Sec. 1701. Eligibility for individuals with income below 150 percent of the Federal poverty level.

Sec. 1702. Requirements and special rules for certain Medicaid eligible individuals.

Sec. 1703. CHIP and Medicaid maintenance of eligibility.

Sec. 1704. Reduction in Medicaid DSH.

Sec. 1705. Expanded outstationing.

\section{Subtitle B-Prevention}

Sec. 1711. Required coverage of preventive services.

Sec. 1712. Tobacco cessation.

Sec. 1713. Optional coverage of nurse home visitation services.

Sec. 1714. State eligibility option for family planning services.

Subtitle C-Access 
Sec. 1721. Payments to primary care practitioners.

Sec. 1722. Medical home pilot program.

Sec. 1723. Translation or interpretation services.

Sec. 1724. Optional coverage for freestanding birth center services.

Sec. 1725. Inclusion of public health clinies under the vaccines for children program.

Sec. 1726. Requiring coverage of services of podiatrists.

Sec. 1726A. Requiring coverage of services of optometrists.

Sec. 1727. Therapeutic foster care.

Sec. 1728. Assuring adequate payment levels for services.

Sec. 1729. Preserving Medicaid coverage for youths upon release from public institutions.

Sec. 1730. Quality measures for maternity and adult health services under Medicaid and CHIP.

Sec. 1730A. Accountable care organization pilot program.

Sec. 1730B. FQHC coverage.

\section{Subtitle D—Coverage}

Sec. 1731. Optional Medicaid coverage of low-income HIV-infected individuals.

Sec. 1732. Extending transitional Medicaid Assistance (TMA).

Sec. 1733. Requirement of 12-month continuous coverage under certain CHIP programs.

Sec. 1734. Preventing the application under CHIP of coverage waiting periods for certain children.

Sec. 1735. Adult day health care services.

Sec. 1736. Medicaid coverage for citizens of Freely Associated States.

Sec. 1737. Continuing requirement of Medicaid coverage of nonemergency transportation to medically necessary services.

Sec. 1738. State option to disregard certain income in providing continued Medicaid coverage for certain individuals with extremely high prescription costs.

Sec. 1739. Provisions relating to community living assistance services and supports (CLASS).

\section{Subtitle E-Financing}

Sec. 1741. Payments to pharmacists.

Sec. 1742. Prescription drug rebates.

Sec. 1743. Extension of prescription drug discounts to enrollees of Medicaid managed care organizations.

Sec. 1744. Payments for graduate medical education.

Sec. 1745. Nursing Facility Supplemental Payment Program.

Sec. 1746. Report on Medicaid payments.

Sec. 1747. Reviews of Medicaid.

Sec. 1748. Extension of delay in managed care organization provider tax elimination.

Sec. 1749. Extension of ARRA increase in FMAP.

Subtitle F-Waste, Fraud, and Abuse

Sec. 1751. Health care acquired conditions.

Sec. 1752. Evaluations and reports required under Medicaid Integrity Program.

Sec. 1753. Require providers and suppliers to adopt programs to reduce waste, fraud, and abuse.

Sec. 1754. Overpayments. 
Sec. 1755. Managed care organizations.

Sec. 1756. Termination of provider participation under Medicaid and CHIP if terminated under Medicare or other State plan or child health plan.

Sec. 1757. Medicaid and CHIP exclusion from participation relating to certain ownership, control, and management affiliations.

Sec. 1758. Requirement to report expanded set of data elements under MMIS to detect fraud and abuse.

Sec. 1759. Billing agents, clearinghouses, or other alternate payees required to register under Medicaid.

Sec. 1760. Denial of payments for litigation-related misconduct.

Sec. 1761. Mandatory State use of national correct coding initiative.

Subtitle G-Payments to the Territories

Sec. 1771. Payment to territories.

Subtitle H-Miscellaneous

Sec. 1781. Technical corrections.

Sec. 1782. Extension of QI program.

Sec. 1783. Assuring transparency of information.

Sec. 1784. Medicaid and CHIP Payment and Aceess Commission.

Sec. 1785. Outreach and enrollment of Medicaid and CHIP eligible individuals.

Sec. 1786. Prohibitions on Federal Medicaid and CHIP payment for undocumented aliens.

Sec. 1787. Demonstration project for stabilization of emergency medical conditions by institutions for mental diseases.

Sec. 1788. Application of Medicaid Improvement Fund.

Sec. 1789. Treatment of certain Medicaid brokers.

Sec. 1790. Rule for changes requiring State legislation.

\section{TITLE VIII-REVENUE-RELATED PROVISIONS}

Sec. 1801. Disclosures to facilitate identification of individuals likely to be ineligible for the low-ineome assistance under the Medicare prescription drug program to assist Social Security Administration's outreach to eligible individuals.

Sec. 1802. Comparative Effectiveness Research Trust Fund; financing for Trust Fund.

\section{TITLE IX-MISCELLANEOUS PROVISIONS}

Sec. 1901. Repeal of trigger provision.

Sec. 1902. Repeal of comparative cost adjustment (CCA) program.

Sec. 1903. Extension of gainsharing demonstration.

Sec. 1904. Grants to States for quality home visitation programs for families with young children and families expecting children.

Sec. 1905. Improved coordination and protection for dual eligibles.

Sec. 1906. Assessment of medicare cost-intensive diseases and conditions.

Sec. 1907. Establishment of Center for Medicare and Medicaid Innovation within CMS.

Sec. 1908. Application of emergency services laws.

Sec. 1909. Disregard under the Supplemental Security Income program of compensation for participation in clinical trials for rare diseases or conditions. 
1 TITLE I-IMPROVING HEALTH

CARE VALUE

3 Subtitle A-Provisions Related to

\section{PART 1-MARKET BASKET UPDATES}

6 SEC. 1101. SKILLED NURSING FACILITY PAYMENT UPDATE.

(a) In General.-Section 1888(e)(4)(E)(ii) of the

8 Social Security Act (42 U.S.C. 1395yy(e)(4)(E)(ii)) is

9 amended-

(1) in subclause (III), by striking "and" at the

11 end;

(2) by redesignating subclause (IV) as sub-

13 clause (VI); and

(3) by inserting after subclause (III) the fol-

15 lowing new subclauses:

16

17

18

19

20

21

22

23

24
"(IV) for each of fiscal years 2004 through 2009, the rate computed for the previous fiscal year increased by the skilled nursing facility market basket percentage change for the fiscal year involved;

"(V) for fiscal year 2010, the rate computed for the previous fiscal year; and". 
1 (b) Delayed Effective Date.-Section

2 1888(e)(4)(E)(ii)(V) of the Social Security Act, as in-

3 serted by subsection (a)(3), shall not apply to payment

4 for days before January 1, 2010.

5 SEC. 1102. INPATIENT REHABILITATION FACILITY PAY6 MENT UPDATE.

7 (a) In GeneraL.-Section 1886(j)(3)(C) of the So8 cial Security Act (42 U.S.C. $1395 w w(j)(3)(C))$ is amended 9 by striking "and 2009" and inserting "through 2010".

10 (b) Delayed Effective Date.-The amendment 11 made by subsection (a) shall not apply to payment units 12 occurring before January 1, 2010.

13 SEC. 1103. INCORPORATING PRODUCTIVITY IMPROVEMENTS INTO MARKET BASKET UPDATES THAT DO NOT ALREADY INCORPORATE SUCH IMPROVEMENTS.

17 (a) Inpatient Acute Hospitals.-Section $181886(\mathrm{~b})(3)(\mathrm{B})$ of the Social Security Act (42 U.S.C. $191395 \mathrm{ww}(\mathrm{b})(3)(\mathrm{B}))$ is amended(1) in clause (iii) -

(A) by striking “(iii) For purposes of this subparagraph," and inserting “(iii)(I) For purposes of this subparagraph, subject to the productivity adjustment described in subclause 25 (II),"; and 
(B) by adding at the end the following new subclause:

3 "(II) The productivity adjustment described in this 4 subclause, with respect to an increase or change for a fis5 cal year or year or cost reporting period, or other annual 6 period, is a productivity offset in the form of a reduction 7 in such increase or change equal to the percentage change 8 in the 10-year moving average of annual economy-wide 9 private nonfarm business multi-factor productivity (as re10 cently published in final form before the promulgation or 11 publication of such increase for the year or period in12 volved). Except as otherwise provided, any reference to the 13 increase described in this clause shall be a reference to 14 the percentage increase described in subclause (I) minus 15 the percentage change under this subclause."; 17 inserting "(but not below zero)" after "shall be re18 duced"; and

(3) in the first sentence of clause (ix)(I)-

(A) by inserting "(determined without regard to clause (iii)(II))" after "clause (i)" the second time it appears; and

(B) by inserting "(but not below zero)" after "reduced". 
1 (b) Skilled Nursing Facilities.-Section

2 1888(e)(5)(B) of such Act (42 U.S.C. 1395yy(e)(5)(B))

3 is amended by inserting "subject to the productivity ad-

4 justment described in section 1886(b)(3)(B)(iii)(II)" after

5 "as calculated by the Secretary".

6 (c) Long Term Care Hospitals.-Section

7 1886(m) of the Social Security Act (42 U.S.C.

$81395 \mathrm{ww}(\mathrm{m}))$ is amended by adding at the end the fol-

9 lowing new paragraph:

10 “(3) Productivity adjustment.-In imple-

11 menting the system described in paragraph (1) for

12 discharges occurring on or after January 1, 2010,

13 during the rate year ending in 2010 or any subse-

14 quent rate year for a hospital, to the extent that an

15 annual percentage increase factor applies to a stand-

16 ard Federal rate for such discharges for the hos-

17 pital, such factor shall be subject to the productivity

18 adjustment described in subsection

19 (b)(3)(B)(iii)(II).”.

20 (d) Inpatient Rehabilitation Facilities.-The

21 second sentence of section 1886(j)(3)(C) of the Social Se-

22 curity Act (42 U.S.C. 1395ww(j)(3)(C)) is amended by in-

23 serting "(subject to the productivity adjustment described

24 in subsection (b)(3)(B)(iii)(II))" after "appropriate per25 centage increase". 
1 (e) Psychiatric Hospitals.-Section 1886 of the

2 Social Security Act (42 U.S.C. 1395ww) is amended by 3 adding at the end the following new subsection:

4 “(o) Prospective Payment For Psychiatric

5 Hospitals.-

“(1) Reference to establishment AND IM-

7 PLEMENTATION OF System.-For provisions related

8 to the establishment and implementation of a pro-

9 spective payment system for payments under this

10 title for inpatient hospital services furnished by psy-

11 chiatric hospitals (as described in clause (i) of sub-

12 section $(d)(1)(B)$ and psychiatric units (as described

13 in the matter following clause (v) of such sub-

14 section), see section 124 of the Medicare, Medicaid,

15 and SCHIP Balanced Budget Refinement Act of

$16 \quad 1999$.

17 “(2) Productivity adjustment.-In imple18 menting the system described in paragraph (1) for 19 days occurring during the rate year ending in 2011 20 or any subsequent rate year for a psychiatric hos21 pital or unit described in such paragraph, to the ex22 tent that an annual percentage increase factor ap23 plies to a base rate for such days for the hospital 24 or unit, respectively, such factor shall be subject to 
1 the productivity adjustment described in subsection 2 (b)(3)(B)(iii)(II).”.

3 (f) Hospice Care.-Subclause (VII) of section 4 1814(i)(1)(C)(ii) of the Social Security Act (42 U.S.C. $51395 \mathrm{f}(\mathrm{i})(1)(\mathrm{C})(\mathrm{ii}))$ is amended by inserting after "the 6 market basket percentage increase" the following: "(which 7 is subject to the productivity adjustment described in sec8 tion 1886(b)(3)(B)(iii)(II))".

$9 \quad$ (g) EfFective Dates.-

10 (1) IPPS.-The amendments made by sub11 section (a) shall apply to annual increases effected 12 for fiscal years beginning with fiscal year 2010, but 13 only with respect to discharges occurring on or after 14 January 1, 2010.

15 (2) SNF AND IRF.-The amendments made by 16 subsections (b) and (d) shall apply to annual in17 creases effected for fiscal years beginning with fiscal $18 \quad$ year 2011.

19 (3) Hospice CARE.-The amendment made by 20 subsection (f) shall apply to annual increases ef21 fected for fiscal years beginning with fiscal year 222010 , but only with respect to days of care occurring 23 on or after January 1, 2010. 
1 PART 2-OTHER MEDICARE PART A PROVISIONS

2 SEC. 1111. PAYMENTS TO SKILLED NURSING FACILITIES.

(a) Change in Recalibration Factor.-

(1) Analysis.-The Secretary of Health and Human Services shall conduct, using calendar year 2006 claims data, an initial analysis comparing total payments under title XVIII of the Social Security Act for skilled nursing facility services under the RUG-53 and under the RUG-44 classification systems.

(2) Adjustment in Recalibration FaCTOR.-Based on the initial analysis under paragraph (1), the Secretary shall adjust the case mix indexes under section 1888(e)(4)(G)(i) of the Social Security Act (42 U.S.C. 1395yy(e)(4)(G)(i)) for fiscal year 2010 by the appropriate recalibration factor as proposed in the proposed rule for Medicare skilled nursing facilities issued by such Secretary on May 12, 2009 (74 Federal Register 22214 et seq.).

(b) Change in Payment for Nontherapy Ancil-

1 Lary (NTA) Services and Therapy Services.-

(1) Changes under Current SNF ClassiFICATION SYSTEM.-

(A) In GENERAL.-Subject to subparagraph (B), the Secretary of Health and Human Services shall, under the system for payment of 
skilled nursing facility services under section 1888(e) of the Social Security Act (42 U.S.C. 1395yy(e)), increase payment by 10 percent for non-therapy ancillary services (as specified by the Secretary in the notice issued on November

(C) Implementation.-Notwithstanding any other provision of law, the Secretary may implement by program instruction or otherwise the provisions of this paragraph.

(2) Changes under a future snf case miX

(B) EFFECTive DATE.-The changes in payment described in subparagraph (A) shall apply for days on or after January 1, 2010, and until the Secretary implements an alternative case mix classification system for payment of skilled nursing facility services under section 1888(e) of the Social Security Act (42 U.S.C. $1395 y y(e))$. CLASSIFICATION SYSTEM.-

(A) Analysis.-

(i) In GENERAL.-The Secretary of Health and Human Services shall analyze 
payments for non-therapy ancillary services

under a future skilled nursing facility clas-

sification system to ensure the accuracy of

payment for non-therapy ancillary services.

Such analysis shall consider use of appro-

priate predictors which may include age,

physical and mental status, ability to per-

form activities of daily living, prior nursing

home stay, diagnoses, broad RUG category, and a proxy for length of stay.

(ii) ApPlication.-Such analysis

shall be conducted in a manner such that the future skilled nursing facility classification system is implemented to apply to services furnished during a fiscal year beginning with fiscal year 2011.

(B) Consultation.-In conducting the analysis under subparagraph (A), the Secretary shall consult with interested parties, including the Medicare Payment Advisory Commission and other interested stakeholders, to identify appropriate predictors of nontherapy ancillary costs.

(C) Rulemaking.-The Secretary shall include the result of the analysis under sub- 
paragraph (A) in the fiscal year 2011 rulemaking cycle for purposes of implementation beginning for such fiscal year.

(D) Implementation.-Subject to subparagraph (E) and consistent with subparagraph (A)(ii), the Secretary shall implement changes to payments for non-therapy ancillary services (which shall include a separate rate component for non-therapy ancillary services and may include use of a model that predicts payment amounts applicable for non-therapy ancillary services) under such future skilled nursing facility services classification system as the Secretary determines appropriate based on the analysis conducted pursuant to subparagraph (A).

(E) Budget neutrality.-The Secretary shall implement changes described in subparagraph (D) in a manner such that the estimated expenditures under such future skilled nursing facility services classification system for a fiscal year beginning with fiscal year 2011 with such changes would be equal to the estimated expenditures that would otherwise occur under title XVIII of the Social Security Act under 
such future skilled nursing facility services classification system for such year without such changes.

5 tion 1888(e) of the Social Security Act (42 U.S.C.

$61395 y y(e))$ is amended by adding at the end the following

7 new paragraph:

8

9

10

11
“(13) OUTLIERS FOR NTA AND THERAPY."(A) In GENERAL.-With respect to outliers because of unusual variations in the type or amount of medically necessary care, beginning with October 1, 2010, the Secretary"(i) shall provide for an addition or adjustment to the payment amount otherwise made under this section with respect to non-therapy ancillary services in the case of such outliers; and

“(ii) may provide for such an addition or adjustment to the payment amount otherwise made under this section with respect to therapy services in the case of such outliers.

"(B) Outliers Based ON aggregate CosTs._-Outlier adjustments or additional payments described in subparagraph (A) shall be 
17 1888(e)(8) of such Act (42 U.S.C. 1395yy(e)(8)) is 18 amended-

based on aggregate costs during a stay in a skilled nursing facility and not on the number of days in such stay.

"(C) Budget Neutrality.-The Secretary shall reduce estimated payments that would otherwise be made under the prospective payment system under this subsection with respect to a fiscal year by 2 percent. The total amount of the additional payments or payment adjustments for outliers made under this paragraph with respect to a fiscal year may not exceed 2 percent of the total payments projected or estimated to be made based on the prospective payment system under this subsection for the fiscal year.'.

(1) in subparagraph (A)-

(A) by striking "and" before "adjustments"; and

(B) by inserting ", and adjustment under section 1111(b) of the Affordable Health Care for America Act" before the semicolon at the end; 
(2) in subparagraph (B), by striking "and";

(3) in subparagraph (C), by striking the period and inserting "; and"; and

(4) by adding at the end the following new sub5 paragraph:

"(D) the establishment of outliers under paragraph (13).”.

\section{SEC. 1112. MEDICARE DSH REPORT AND PAYMENT ADJUST-} MENTS IN RESPONSE TO COVERAGE EXPANSION.

\section{(a) DSH REPORT.-}

(1) In GEneraL.-Not later than January 1, 2016, the Secretary of Health and Human Services shall submit to Congress a report on Medicare DSH taking into account the impact of the health care reforms carried out under division $\mathrm{A}$ in reducing the number of uninsured individuals. The report shall include recommendations relating to the following:

(A) The appropriate amount, targeting, and distribution of Medicare DSH to compensate for higher Medicare costs associated with serving low-income beneficiaries (taking into account variations in the empirical justification for Medicare DSH attributable to hospital characteristics, including bed size), con- 
sistent with the original intent of Medicare DSH.

(B) The appropriate amount, targeting, and distribution of Medicare DSH to hospitals given their continued uncompensated care costs, 6 to the extent such costs remain.

(2) Coordination With Medicaid DSH RE-

8 PORT.- The Secretary shall coordinate the report 9 under this subsection with the report on Medicaid 10 DSH under section 1704(a).

11 (b) Payment Adjustments in Response to Cov12 ERAGE EXPANSION.-

(1) IN GENERAL.-If there is a significant de14 crease in the national rate of uninsurance as a result 15 of this Act (as determined under paragraph $(2)(\mathrm{A})$ ), 16 then the Secretary of Health and Human Services 17 shall, beginning in fiscal year 2017, implement the 18 following adjustments to Medicare DSH:

(A) In lieu of the amount of Medicare DSH payment that would otherwise be made under section 1886(d)(5)(F) of the Social Security Act, the amount of Medicare DSH payment shall be an amount based on the recommendations of the report under subsection $(\mathrm{a})(1)(\mathrm{A})$ 25 and shall take into account variations in the 
empirical justification for Medicare DSH attributable to hospital characteristics, including bed size.

(B) Subject to paragraph (3), make an additional payment to a hospital by an amount compensated care provided by the hospital based on criteria for uncompensated care as determined by the Secretary, which shall exclude bad debt.

(2) Significant Decrease in national Rate OF UNINSURANCE AS A RESUlt OF THIS ACT.-For purposes of this subsection-

(A) In GENERAL.-There is a "significant decrease in the national rate of uninsurance as a result of this Act" if there is a decrease in the national rate of uninsurance (as defined in subparagraph (B)) from 2012 to 2014 that exceeds 8 percentage points.

(B) National Rate OF uninsurance DEFINED.-The term "national rate of uninsurance" means, for a year, such rate for the under-65 population for the year as determined and published by the Bureau of the Cen- 
sus in its Current Population Survey in or about September of the succeeding year.

(3) UnCompensated CARE INCREASE.-

(A) Computation of Dsh savings.-For each fiscal year (beginning with fiscal year 2017), the Secretary shall estimate the aggregate reduction in the amount of Medicare DSH payment that would be expected to result from the adjustment under paragraph (1)(A).

(B) Structure OF PAyment INCREASE.-The Secretary shall compute the additional payment to a hospital as described in paragraph (1)(B) for a fiscal year in accordance with a formula established by the Secretary that provides that-

(i) the estimated aggregate amount of such increase for the fiscal year does not exceed 50 percent of the aggregate reduction in Medicare DSH estimated by the Secretary for such fiscal year; and

(ii) hospitals with higher levels of uncompensated care receive a greater increase.

25 "Medicare DSH" means adjustments in payments under 
1 section $1886(d)(5)(F)$ of the Social Security Act (42

2 U.S.C. 1395ww(d)(5)(F)) for inpatient hospital services

3 furnished by disproportionate share hospitals.

4 SEC. 1113. EXTENSION OF HOSPICE REGULATION MORATORIUM.

6 Section 4301(a) of division B of the American Recov-

7 ery and Reinvestment Act of 2009 (Public Law 111-5)

8 is amended-

9

10

11

12

13

14

(1) by striking "October 1, 2009" and inserting "October 1, 2010"; and

(2) by striking "for fiscal year 2009" and inserting "for fiscal years 2009 and 2010".

SEC. 1114. PERMITTING PHYSICIAN ASSISTANTS TO ORDER POST-HOSPITAL EXTENDED CARE SERVICES AND TO PROVIDE FOR RECOGNITION OF ATTENDING PHYSICIAN ASSISTANTS AS ATTENDING PHYSICIANS TO SERVE HOSPICE PATIENTS.

(a) Ordering Post-hospital Extended Care SERVICES.-Section 1814(a) of the Social Security Act (42 U.S.C. $1395 \mathrm{f}(\mathrm{a})$ ) is amended-

(1) in paragraph (2) in the matter preceding subparagraph (A), is amended by striking "nurse practitioner or clinical nurse specialist" and insert- 
1 ing "nurse practitioner, a clinical nurse specialist, or

2 a physician assistant".

3 (2) in the second sentence, by striking "or clin-

4 ical nurse specialist" and inserting "clinical nurse

5 specialist, or physician assistant".

6 (b) Recognition of Attending Physician As-

7 sistants as Attending Physiclans to Serve Hospice

8 Patientis.-

9

10

11

12

13

14

15

16

17

18

19

20

21

22

23

24
(1) In GENERAL.- Section 1861(dd)(3)(B) of such Act (42 U.S.C. $1395 x(\mathrm{dd})(3)(\mathrm{B}))$ is amended-

(A) by striking "or nurse" and inserting “, the nurse"; and

(B) by inserting "or the physician assistant (as defined in such subsection)," after "subsection (aa)(5)),".

(2) Conforming amendment.-Section 1814(a)(7)(A)(i)(I) of such Act (42 U.S.C. $1395 \mathrm{f}(\mathrm{a})(7)(\mathrm{A})(\mathrm{i})(\mathrm{I}))$ is amended by inserting "or a physician assistant" after "a nurse practitioner".

(3) Construction.-Nothing in the amendments made by this subsection shall be construed as changing the requirements of section $1842(b)(6)(C)$ of the Social Security Act (42 U.S.C. $1395 \mathrm{u}(\mathrm{b})(6)(\mathrm{C}))$ with respect to payment for serv- 
1 ices of physician assistants under part B of title

2 XVIII of such Act.

3 (c) EFFECTIVE Date.-The amendments made by

4 this section shall apply to items and services furnished on

5 or after January 1, 2010.

6 Subtitle B-Provisions Related to

PART 1-PHYSICIANS' SERVICES

9 SEC. 1121. RESOURCE-BASED FEEDBACK PROGRAM FOR

11 Section 1848(n) of the Social Security Act (42 U.S.C.

$121395 \mathrm{w}-4(\mathrm{n}))$ is amended by adding at the end the fol-

13 lowing new paragraph:

14

15

16

17
“(9) Feedback implementation Plan.-

“(A) Timeline For Feedback PRoGRAM.-

"(i) Evaluation.-During 2011 the Secretary shall conduct the evaluation specified in subparagraph (E)(i).

“(ii) ExPANSION.-The Secretary shall expand the Program under this subsection as specified in subparagraph (E)(ii).

“(B) Establishment of nature OF REPORTS.- 
"(i) IN GENERAL.-The Secretary

shall develop and specify the nature of the reports that will be disseminated under this subsection, based on results and findings from the Program under this subsection as in existence before the date of the enactment of this paragraph. Such reports may be based on a per capita basis, an episode basis that combines separate but clinically related physicians' services and other items and services furnished or ordered by a physician into an episode of care, as appropriate, or both.

“(ii) TImeline FOR DevelopMENT.-The nature of the reports described in clause (i) shall be developed by not later than January 1, 2012.

“(iii) Public availability.-The Secretary shall make the details of the nature of the reports developed under clause (i) available to the public.

"(C) Analysis of DaTa.-The Secretary shall, for purposes of preparing reports under this subsection, establish methodologies as appropriate such as to- 
"(i) attribute items and services, in

whole or in part, to physicians;

“(ii) identify appropriate physicians for purposes of comparison under subparagraph (B)(i); and

"(iii) aggregate items and services attributed to a physician under clause (i) into a composite measure per individual. "(D) Feedback Program.-The Secretary shall engage in efforts to disseminate reports under this subsection. In disseminating such reports, the Secretary shall consider the following:

"(i) Direct meetings between contracted physicians, facilitated by the Secretary, to discuss the contents of reports under this subsection, including any reasons for divergence from local or national averages.

"(ii) Contract with local, non-profit entities engaged in quality improvement efforts at the community level. Such entities shall use the reports under this subsection, or such equivalent tool as specified by the Secretary. Any exchange of data under this 
paragraph shall be protected by appropriate privacy safeguards.

"(iii) Mailings or other methods of communication that facilitate large-scale dissemination.

"(iv) Other methods specified by the Secretary. "(E) Evaluation and expansion.“(i) Evaluation.-The Secretary shall evaluate the methods specified in subparagraph (D) with regard to their efficacy in changing practice patterns to improve quality and decrease costs.

"(ii) ExPANsION.-Taking into account the cost of each method specified in subparagraph (D), the Secretary shall develop a plan to disseminate reports under this subsection in a significant manner in the regions and cities of the country with the highest utilization of services under this title. To the extent practicable, reports under this subsection shall be disseminated to increasing numbers of physicians each year, such that during 2014 and subsequent years, reports are disseminated at 
least to physicians with utilization rates among the highest 5 percent of the nation, subject the authority to focus under paragraph (4).

"(F) Administration.-

“(i) Chapter 35 of title 44, United States Code shall not apply to this paragraph.

“(ii) Notwithstanding any other provision of law, the Secretary may implement the provisions of this paragraph by program instruction or otherwise.".

\section{SEC. 1122. MISVALUED CODES UNDER THE PHYSICIAN FEE} SCHEDULE.

(a) In General.-Section 1848(c)(2) of the Social

16 Security Act (42 U.S.C. $1395 \mathrm{w}-4(\mathrm{c})(2)$ ) is amended by 17 adding at the end the following new subparagraphs: “(K) Potentially misvalued codes."(i) In GENERAL.-The Secretary shall-

“(I) periodically identify services as being potentially misvalued using criteria specified in clause (ii); and

"(II) review and make appropriate adjustments to the relative val- 
ues established under this paragraph for services identified as being potentially misvalued under subclause (I).

“(ii) IDENTIFICATION OF POTENTIALLy Misvalued CODES.-For purposes of identifying potentially misvalued services pursuant to clause (i)(I), the Secretary shall examine (as the Secretary determines to be appropriate) codes (and families of codes as appropriate) for which there has been the fastest growth; codes (and families of codes as appropriate) that have experienced substantial changes in practice expenses; codes for new technologies or services within an appropriate period (such as three years) after the relative values are initially established for such codes; multiple codes that are frequently billed in conjunction with furnishing a single service; codes with low relative values, particularly those that are often billed multiple times for a single treatment; codes which have not been subject to review since the implementation of the RBRVS (the socalled 'Harvard-valued codes'); and such 
other codes determined to be appropriate by the Secretary.

“(iii) Review And ADJustments.-

"(I) The Secretary may use existing processes to receive recommendations on the review and appropriate adjustment of potentially misvalued services described clause (i)(II).

“(II) The Secretary may conduct surveys, other data collection activities, studies, or other analyses as the Secretary determines to be appropriate to facilitate the review and appropriate adjustment described in clause (i)(II).

“(III) The Secretary may use analytic contractors to identify and analyze services identified under clause (i)(I), conduct surveys or collect data, and make recommendations on the review and appropriate adjustment of services described in clause (i)(II). 
"(IV) The Secretary may coordi-

nate the review and appropriate adjustment described in clause (i)(II) with the periodic review described in subparagraph (B).

"(V) As part of the review and adjustment described in clause (i)(II), including with respect to codes with low relative values described in clause (ii), the Secretary may make appropriate coding revisions (including ation of coding changes) which may include consolidation of individual services into bundled codes for payment under the fee schedule under subsection (b).

"(VI) The provisions of subparagraph (B)(ii)(II) shall apply to adjustments to relative value units made pursuant to this subparagraph in the same manner as such provisions apply to adjustments under subparagraph (B)(ii)(II). 
“(L) Validating Relative Value

“(i) IN GENERAL.-The Secretary shall establish a process to validate relative value units under the fee schedule under subsection (b).

"(ii) COMPOnents AND Elements OF WORK.-The process described in clause (i) may include validation of work elements (such as time, mental effort and professional judgment, technical skill and physical effort, and stress due to risk) involved with furnishing a service and may include validation of the pre, post, and intra-service components of work.

"(iii) ScOpe OF CODES.-The validation of work relative value units shall include a sampling of codes for services that is the same as the codes listed under subparagraph (K)(ii)

“(iv) Methods.—The Secretary may conduct the validation under this subparagraph using methods described in subclauses (I) through (V) of subparagraph 
(K)(iii) as the Secretary determines to be

appropriate.

“(v) Adjustments.-The Secretary

shall make appropriate adjustments to the work relative value units under the fee schedule under subsection (b). The provisions of subparagraph (B)(ii)(II) shall apply to adjustments to relative value units made pursuant to this subparagraph in the same manner as such provisions apply to adjustments under subparagraph (B)(ii)(II).'. the provisions of subparagraphs (K) and (L) of $161848(c)(2)$ of the Social Security Act, as added by 17 subsection (a), in addition to funds otherwise avail18 able, out of any funds in the Treasury not otherwise 19 appropriated, there are appropriated to the Sec20 retary of Health and Human Services for the Center 21 for Medicare \& Medicaid Services Program Manage22 ment Account $\$ 20,000,000$ for fiscal year 2010 and 23 each subsequent fiscal year. Amounts appropriated 24 under this paragraph for a fiscal year shall be avail25 able until expended. 
22 SEC. 1123. PAYMENTS FOR EFFICIENT AREAS.

23 Section 1833 of the Social Security Act (42 U.S.C.

24 1395l) is amended by adding at the end the following new 25 subsection:

(A) Chapter 35 of title 44, United States Code and the provisions of the Federal Advisory Committee Act (5 U.S.C. App.) shall not apply to this section or the amendment made by this section.

(B) Notwithstanding any other provision of law, the Secretary may implement subparagraphs (K) and (L) of 1848(c)(2) of the Social Security Act, as added by subsection (a), by program instruction or otherwise.

(C) Section $4505(\mathrm{~d})$ of the Balanced Budget Act of 1997 is repealed.

(D) Except for provisions related to confidentiality of information, the provisions of the Federal Acquisition Regulation shall not apply to this section or the amendment made by this section.

(3) Focusing CMs Resources on POTEnTially Overvalued CODES.-Section 1868(a) of the Social Security Act (42 1395ee(a)) is repealed. 
1 “( 1 (x) Incentive Payments For Efficient

2 AREas.-

4 nished under the physician fee schedule under sec-

5 tion 1848 on or after January 1, 2011, and before

6 January 1, 2013, by a supplier that is paid under

7 such fee schedule in an efficient area (as identified

8 under paragraph (2)), in addition to the amount of

9 payment that would otherwise be made for such

10 services under this part, there also shall be paid (on

11 a monthly or quarterly basis) an amount equal to 5

12 percent of the payment amount for the services

13 under this part.
"(2) Identification OF EFFICIENT AREas."(A) In GENERAL.—Based upon available data, the Secretary shall identify those counties or equivalent areas in the United States in the lowest fifth percentile of utilization based on per capita spending under this part and part A for services provided in the most recent year for which data are available as of the date of the enactment of this subsection, as standardized to eliminate the effect of geographic adjustments in payment rates. 
"(B) IDENTIFICATION OF COUNTIES WHERE SERVICE IS FURNISHED..-For purposes of paying the additional amount specified in paragraph (1), if the Secretary uses the 5digit postal ZIP Code where the service is furnished, the dominant county of the postal ZIP Code (as determined by the United States Postal Service, or otherwise) shall be used to determine whether the postal ZIP Code is in a county described in subparagraph (A).

“(C) Limitation ON Review.-There shall be no administrative or judicial review under section 1869,1878 , or otherwise, respecting-

"(i) the identification of a county or other area under subparagraph $(\mathrm{A})$; or "(ii) the assignment of a postal ZIP Code to a county or other area under subparagraph (B).

“(D) Publication of list of counties; POSTING ON WEBSITE.-With respect to a year for which a county or area is identified under this paragraph, the Secretary shall identify such counties or areas as part of the proposed and final rule to implement the physician fee 
schedule under section 1848 for the applicable year. The Secretary shall post the list of counties identified under this paragraph on the Internet website of the Centers for Medicare \& Medicaid Services.".

6 SEC. 1124. MODIFICATIONS TO THE PHYSICIAN QUALITY REPORTING INITIATIVE (PQRI).

(a) Feedback.-Section 1848(m)(5) of the Social 9 Security Act (42 U.S.C. $1395 \mathrm{w}-4(\mathrm{~m})(5)$ ) is amended by 10 adding at the end the following new subparagraph: provide timely feedback to eligible professionals on the performance of the eligible professional with respect to satisfactorily submitting data on quality measures under this subsection.".

(2) by adding at the end the following new sub21 paragraph: (b) ApPeals.- - Such section is further amended-

“(I) INFORMAL APPEALS PROCESS.-By not later than January 1, 2011, the Secretary shall establish and have in place an informal process for eligible professionals to seek a re- 
1 view of the determination that an eligible pro-

2 fessional did not satisfactorily submit data on 3 quality measures under this subsection.".

4 (c) Integration of Physician Quality Report5 ING AND EHR ReporTing.-Section 1848(m) of such 6 Act is amended by adding at the end the following new 7 paragraph:

“(7) INTEgRation OF PHYSICLAN QUALitTy RE9 PORTING AND EHR REPORTING.-Not later than 10 January 1, 2012, the Secretary shall develop a plan 11 to integrate clinical reporting on quality measures 12 under this subsection with reporting requirements 13 under subsection (o) relating to the meaningful use 14 of electronic health records. Such integration shall 15 consist of the following:

16 "(A) The development of measures, the re17 porting of which would both demonstrate-

"(i) meaningful use of an electronic health record for purposes of subsection (o); and

"(ii) clinical quality of care furnished to an individual. "(B) The collection of health data to identify deficiencies in the quality and coordination 
of care for individuals eligible for benefits under this part.

"(C) Such other activities as specified by the Secretary.".

$61848(\mathrm{~m})(1)$ of such Act (42 U.S.C. $1395 \mathrm{w}-4(\mathrm{~m})(1)$ ) is

7 amended-

(1) in subparagraph (A), by striking "2010" and inserting "2012”; and

(2) in subparagraph (B)(ii), by striking "2009

11 and 2010" and inserting "for each of the years 2009 12 through 2012”.

13 SEC. 1125. ADJUSTMENT TO MEDICARE PAYMENT LOCALITIES.

(a) In General.-Section 1848(e) of the Social Se-

16 curity Act (42 U.S.C.1395w-4(e)) is amended by adding. 17 at the end the following new paragraph: SCHEDULE AREAS IN CALIFORNIA.and notwithstanding the previous provisions of this subsection, for services furnished on or after January 1, 2011, the Secretary shall revise the fee schedule 
areas used for payment under this section applicable to the State of California using the Metropolitan Statistical Area (MSA) iterative Geographic Adjustment Factor methodology as follows:

"(I) The Secretary shall configure the physician fee schedule areas using the Metropolitan Statistical Areas (each in this paragraph referred to as an 'MSA'), as defined by the Director of the Office of Management and Budget and published in the Federal Register, using the most recent available decennial population data as of the date of the enactment of the Affordable Health Care for America Act, as the basis for the fee schedule areas.

"(II) For purposes of this clause, the Secretary shall treat all areas not included in an MSA as a single rest of the State MSA.

“(III) The Secretary shall list all MSAs within the State by Geographic Adjustment Factor described in para- 
graph (2) (in this paragraph referred to as a 'GAF') in descending order.

"(IV) In the first iteration, the Secretary shall compare the GAF of the highest cost MSA in the State to the weighted-average GAF of all the remaining MSAs in the State (including the rest of State MSA described in subclause (II)). If the ratio of the GAF of the highest cost MSA to the weighted-average of the GAF of remaining lower cost MSAs is 1.05 or greater, the highest cost MSA shall be a separate fee schedule area.

"(V) In the next iteration, the Secretary shall compare the GAF of the MSA with the second-highest GAF to the weighted-average GAF of the all the remaining MSAs (excluding MSAs that become separate fee schedule areas). If the ratio of the secondhighest MSA's GAF to the weightedaverage of the remaining lower cost MSAs is 1.05 or greater, the secondhighest MSA shall be a separate fee 
schedule area. "(VI) The iterative process shall continue until the ratio of the GAF of the MSA with highest remaining GAF to the weighted-average of the remaining MSAs with lower GAFS is less than 1.05, and the remaining group of MSAs with lower GAFS shall be treated as a single fee schedule area.

"(VI) For purposes of the iterative process described in this clause, if two MSAs have identical GAFs, they shall be combined.

“(ii) Transition.-For services furnished on or after January 1, 2011, and before January 1, 2016, in the State of California, after calculating the work, practice expense, and malpractice geographic indices that would otherwise be determined under clauses (i), (ii), and (iii) of paragraph (1)(A) for a fee schedule area determined under clause (i), if the index for a county within a fee schedule area is less than the index in effect for such county on December 31, 2010, the Secretary shall in- 
stead apply the index in effect for such county on such date.

"(B) Subsequent Revisions.-After the transition described in subparagraph (A)(ii), not less than every 3 years the Secretary shall review and update the fee schedule areas using the methodology described in subparagraph (A)(i) and any updated MSAs as defined by the Director of the Office of Management and Budget and published in the Federal Register. The Secretary shall review and make any changes pursuant to such reviews concurrent with the application of the periodic review of the adjustment factors required under paragraph (1)(C) for California.

"(C) References TO FeE SChedule AREAS.-Effective for services furnished on or after January 1, 2011, for the State of California, any reference in this section to a fee schedule area shall be deemed a reference to an MSA in the State (including the single rest of state MSA described in subparagraph (A)(i)(II)).".

(b) Conforming Amendment to Definition of 25 Fee Schedule Area.-Section 1848(j)(2) of the Social 
1 Security Act (42 U.S.C. $1395 \mathrm{w}(\mathrm{j})(2)$ ) is amended by strik-

2 ing "The term" and inserting "Except as provided in sub3 section $(\mathrm{e})(6)(\mathrm{C})$, the term".

\section{PART 2-MARKET BASKET UPDATES}

SEC. 1131. INCORPORATING PRODUCTIVITY IMPROVEMENTS INTO MARKET BASKET UPDATES THAT DO NOT ALREADY INCORPORATE SUCH IMPROVEMENTS.

(a) Outpatient Hospitals.-

10

(1) IN GENERAL.-Section 1833(t)(3)(C)(iv) of the Social Security Act (42 U.S.C. $1395 \mathrm{l}(\mathrm{t})(3)(\mathrm{C})(\mathrm{iv}))$ is amended-

(i) by inserting "(which is subject to the productivity adjustment described in subclause (II) of such section)" after "1886(b)(3)(B)(iii)"; and

(ii) by inserting "(but not below 0)" after "reduced"; and (B) in the second sentence, by inserting the productivity adjustment described in section 1886(b)(3)(B)(iii)(II)". 
(2) EFFECTIVE DATE.-The amendments made

2 by this subsection shall apply to increase factors for 3 services furnished in years beginning with 2010 .

4 (b) Ambulance Services.-Section 1834(l)(3)(B) 5 of such Act (42 U.S.C. $1395 \mathrm{~m}(\mathrm{l})(3)(\mathrm{B}))$ ) is amended by 6 inserting before the period at the end the following: "and, 7 in the case of years beginning with 2010, subject to the 8 productivity adjustment described in section 9 1886(b)(3)(B)(iii)(II)".

10 (c) Ambulatory Surgical Center Services.11 Section 1833(i)(2)(D) of such Act (42 U.S.C. $121395 \mathrm{l}(\mathrm{i})(2)(\mathrm{D}))$ is amended-

13 (1) by redesignating clause (v) as clause (vi); 14 and

15 (2) by inserting after clause (iv) the following 16 new clause:

17 “(v) In implementing the system described in clause 18 (i), for services furnished during 2010 or any subsequent 19 year, to the extent that an annual percentage change fac20 tor applies, such factor shall be subject to the productivity 21 adjustment described in section 1886(b)(3)(B)(iii)(II).”.

22 (d) Laboratory Services.-Section 1833(h)(2)(A) 23 of such Act (42 U.S.C. 1395l(h)(2)(A)) is amended- 
(1) in clause (i), by striking "for each of the 2 years 2009 through 2013" and inserting "for $32009 " ;$ and (2) clause (ii)-

(A) by striking "and" at the end of subsubclause: "(V) the annual adjustment in the fee schedules

12 determined under clause (i) for years beginning with 132010 shall be subject to the productivity adjustment 14 described in section 1886(b)(3)(B)(iii)(II).”.

15 (e) Certain Durable Medical Equipment.-Sec16 tion 1834(a)(14) of such Act (42 U.S.C. 1395m(a)(14)) 17 is amended-

18 (1) in subparagraph (K), by inserting before 19 the semicolon at the end the following: ", subject to 20 the productivity adjustment described in section $21 \quad 1886(\mathrm{~b})(3)(\mathrm{B})(\mathrm{iii})(\mathrm{II}) "$;

22 (2) in subparagraph (L)(i), by inserting after 23 "June 2013," the following: "subject to the produc24 tivity adjustment described in section $25 \quad 1886(\mathrm{~b})(3)(\mathrm{B})(\mathrm{iii})(\mathrm{II})$, , ; 
(3) in subparagraph (L)(ii), by inserting after "June 2013" the following: ", subject to the productivity adjustment described in section 1886(b)(3)(B)(iii)(II)"; and

(4) in subparagraph (M), by inserting before 6 the period at the end the following: ", subject to the productivity adjustment described in section 1886(b)(3)(B)(iii)(II)".

\section{PART 3-OTHER PROVISIONS}

10 SEC. 1141. RENTAL AND PURCHASE OF POWER-DRIVEN WHEELCHAIRS.

(a) In General.-Section 1834(a)(7)(A)(iii) of the

13 Social Security Act (42 U.S.C. $1395 \mathrm{~m}(\mathrm{a})(7)(\mathrm{A})(\mathrm{iii})$ ) is 14 amended-

(1) in the heading, by inserting "CERTAIN COM16 PLEX REHABILITATIVE" after "OPTION FOR"; and (2) by striking "power-driven wheelchair" and 18 inserting "complex rehabilitative power-driven wheel19 chair recognized by the Secretary as classified within 20 group 3 or higher".

21 (b) EFFective Date.-The amendments made by 22 subsection (a) shall take effect on January 1, 2011, and 23 shall apply to power-driven wheelchairs furnished on or 24 after such date. Such amendments shall not apply to con25 tracts entered into under section 1847 of the Social Secu- 
1 rity Act (42 U.S.C. 1395w-3) pursuant to a bid submitted

2 under such section before October 1, 2010, under sub-

3 section (a)(1)(B)(i)(I) of such section.

4 SEC. 1141A. ELECTION TO TAKE OWNERSHIP, OR TO DECLINE OWNERSHIP, OF A CERTAIN ITEM OF COMPLEX DURABLE MEDICAL EQUIPMENT AFTER THE 13-MONTH CAPPED RENTAL PERIOD ENDS.

(a) In GeneraL.—Section 1834(a)(7)(A) of the So10 cial Security Act (42 U.S.C. $1395 \mathrm{~m}(\mathrm{a})(7)(\mathrm{A})$ ) is amend11 ed-

(1) in clause (ii)—

(A) by striking "RENTAL.—On" and inserting "RENTAL.-

“(I) In GEneraL.-Except as provided in subclause (II), on"; and (B) by adding at the end the following new subclause:

“(II) OPTION TO ACCEPT OR REJECT TRANSFER OF TITLE TO GROUP 3 SUPPORT SURFACE.-

“(aa) In GENERAL.-During the 10th continuous month during which payment is made for the rental of a Group 3 Support 
Surface under clause (i), the supplier of such item shall offer the individual the option to accept or reject transfer of title to a Group 3 Support Surface after the 13th continuous month during which payment is made for the rental of the Group 3 Support Surface under clause (i). Such title shall be transferred to the individual only if the individual notifies the supplier not later than 1 month after the supplier makes such offer that the individual agrees to accept transfer of the title to the Group 3 Support Surface. Unless the individual accepts transfer of title to the Group 3 Support Surface in the manner set forth in this subclause, the individual shall be deemed to have rejected transfer of title. If the individual agrees to accept the transfer of the title to the Group 3 Support Surface, the supplier shall trans- 
fer such title to the individual on the first day that begins after the 13th continuous month during which payment is made for the rental of the Group 3 Support Surface under clause (i).

"(bb) SPecial RULE.-If, on the effective date of this subclause, an individual's rental period for a Group 3 Support Surface has exceeded 10 continuous months, but the first day that begins after the 13th continuous month during which payment is made for the rental under clause (i) has not been reached, the supplier shall, within 1 month following such effective date, offer the individual the option to accept or reject transfer of title to a Group 3 Support Surface. Such title shall be transferred to the individual only if the individual notifies the supplier not later than 1 month after the supplier 
makes such offer that the individual agrees to accept transfer of title to the Group 3 Support Surface. Unless the individual accepts transfer of title to the Group 3 Support Surface in the manner set forth in this subclause, the individual shall be deemed to have rejected transfer of title. If the individual agrees to accept the transfer of the title to the Group 3 Support Surface, the supplier shall transfer such title to the individual on the first day that begins after the 13th continuous month during which payment is made for the rental of the Group 3 Support Surface under clause (i) unless that day has passed, in which case the supplier shall transfer such title to the individual not later than 1 month after notification that the individual accepts transfer of title. 
"(сc) Treatment OF sub-

SEQUENT RESUPPLY WITHIN PE-

RIOD OF REASONABLE USEFUL

LIFETIME OF GROUP 3 SUPPORT

SURFACE IN CASE OF NEED.-If

an individual rejects transfer of

title to a Group 3 Support Sur-

face under this subclause and the

individual requires such Support

Surface at any subsequent time during the period of the reason-

able useful lifetime of such equipment (as defined by the Secretary) beginning with the first month for which payment is made for the rental of such equipment under clause (i), the supplier shall supply the equipment without charge to the individual or the program under this title during the remainder of such period, other than payment for maintenance and servicing during such period which would otherwise have been paid if the 
individual had accepted title to such equipment. The previous sentence shall not affect the payment of amounts under this part for such equipment after the end of such period of the reasonable useful lifetime of the equipment. “(dd) Payments.-Mainte-

nance and servicing payments

shall be made in accordance with clause (iv), in the case of a supplier that transfers title to the Group 3 Support Surface under this subclause, after such transfer and, in the case of an individual who rejects transfer of title under this subclause, after the end of the period of medical need during which payment is made under clause (i)."; and

(2) in clause (iv), by inserting "or, in the case 22 of an individual who rejects transfer of title to a 23 Group 3 Support Surface under clause (ii), after the 24 end of the period of medical need during which pay- 
1 ment is made under clause (i)," after "under clause 2 (ii)".

3 (b) EfFective Date.-The amendments made by 4 this section shall apply with respect to durable medical 5 equipment not later than January 1, 2011.

6 SEC. 1142. EXTENSION OF PAYMENT RULE FOR BRACHYTHERAPY.

8 Section $1833(\mathrm{t})(16)(\mathrm{C})$ of the Social Security Act (42 9 U.S.C. $1395 \mathrm{l}(\mathrm{t})(16)(\mathrm{C}))$, as amended by section 142 of the

10 Medicare Improvements for Patients and Providers Act of

112008 (Public Law 110-275), is amended by striking, the

12 first place it appears, "January 1, 2010" and inserting 13 “January 1, 2012".

14 SEC. 1143. HOME INFUSION THERAPY REPORT TO CONGRESS.

16 Not later than July 1, 2011, the Medicare Payment 17 Advisory Commission shall submit to Congress a report 18 on the following:

(1) The scope of coverage for home infusion 20 therapy in the fee-for-service Medicare program 21 under title XVIII of the Social Security Act, Medi22 care Advantage under part $\mathrm{C}$ of such title, the vet23 eran's health care program under chapter 17 of title 2438 , United States Code, and among private payers, 25 including an analysis of the scope of services pro- 
1 vided by home infusion therapy providers to their

2 patients in such programs.

3 (2) The benefits and costs of providing such

4 coverage under the Medicare program, including a

5 calculation of the potential savings achieved through

6 avoided or shortened hospital and nursing home

7 stays as a result of Medicare coverage of home infu-

8 sion therapy.

9 (3) An assessment of sources of data on the

10 costs of home infusion therapy that might be used

11 to construct payment mechanisms in the Medicare 12 program.

13 (4) Recommendations, if any, on the structure 14 of a payment system under the Medicare program 15 for home infusion therapy, including an analysis of 16 the payment methodologies used under Medicare Ad17 vantage plans and private health plans for the provi18 sion of home infusion therapy and their applicability 19 to the Medicare program.

20 SEC. 1144. REQUIRE AMBULATORY SURGICAL CENTERS 21 (ASCS) TO SUBMIT COST DATA AND OTHER DATA.

23 (a) Cost Reporting.- 
(1) IN GENERAL.-Section 1833(i) of the Social

2 Security Act (42 U.S.C. 1395l(i)) is amended by

3 adding at the end the following new paragraph:

4 “(8) The Secretary shall require, as a condition of

5 the agreement described in section 1832(a)(2)(F)(i), the

6 submission of such cost report as the Secretary may speci-

7 fy, taking into account the requirements for such reports

8 under section 1815 in the case of a hospital.".

9

(2) Development of cost Report.-Not

10 later than 3 years after the date of the enactment

11 of this Act, the Secretary of Health and Human

12 Services shall develop a cost report form for use

13 under section 1833(i)(8) of the Social Security Act,

14 as added by paragraph (1).

15 (3) Audit Requirement.-The Secretary shall

16 provide for periodic auditing of cost reports sub-

17 mitted under section 1833(i)(8) of the Social Secu-

18 rity Act, as added by paragraph (1).

19 (4) EFFECTIVE DATE.-The amendment made

20 by paragraph (1) shall apply to agreements applica-

21 ble to cost reporting periods beginning 18 months

22 after the date the Secretary develops the cost report

23 form under paragraph (2).

24 (b) Additional Data on Quality.- 
(1) In GENERAL.—Section 1833(i)(7) of such Act (42 U.S.C. 1395l(i)(7)) is amended-

(A) in subparagraph (B), by inserting "subject to subparagraph (C)," after "may otherwise provide,"; and

(B) by adding at the end the following new subparagraph:

8 "(C) Under subparagraph (B) the Secretary shall re9 quire the reporting of such additional data relating to 10 quality of services furnished in an ambulatory surgical fa11 cility, including data on health care associated infections, 12 as the Secretary may specify.".

(2) Effective Date.-The amendment made

14 by paragraph (1) shall to reporting for years begin15 ning with 2012.

16 SEC. 1145. TREATMENT OF CERTAIN CANCER HOSPITALS.

17 Section 1833(t) of the Social Security Act (42 U.S.C. $181395 \mathrm{l}(\mathrm{t}))$ is amended by adding at the end the following 19 new paragraph:

“(18) Authorization OF ADJustment FOR CANCER HOSPITALS.a study to determine if, under the system under this subsection, costs incurred by hospitals described in section 1886(d)(1)(B)(v) with respect 
to ambulatory payment classification groups exceed those costs incurred by other hospitals furnishing services under this subsection (as determined appropriate by the Secretary). Insofar as the Secretary determines under subparagraph (A) that costs incurred by hospitals described in section $1886(\mathrm{~d})(1)(\mathrm{B})(\mathrm{v})$ exceed those costs incurred by other hospitals furnishing services under this subsection, the Secretary shall provide for an appropriate adjustment under paragraph $(2)(\mathrm{E})$ to reflect those higher costs effective for services furnished on or after January 1, 2011.”.

\section{SEC. 1146. PAYMENT FOR IMAGING SERVICES.}

(a) Adjustment in Practice Expense to Re17 Flect a Presumed Level of Utilization.-Section 181848 of the Social Security Act (42 U.S.C. 1395w-4) is 19 amended-

(1) in subsection (b)(4)-

(A) in subparagraph (B), by striking "subparagraph (A)" and inserting "this paragraph"; and subparagraph: 
TO REFLECT A PRESUMED LEVEL OF UTILIZATION._Consistent with the methodology for computing the number of practice expense relative value units under subsection $(\mathrm{c})(2)(\mathrm{C})(\mathrm{ii})$ with respect to advanced diagnostic imaging services (as defined in section 1834(e)(1)(B)) furnished on or after January 1, 2011, the Secretary shall adjust such number of units so it reflects a presumed rate of utilization of imaging equipment of 75 percent.'”; and (2) in subsection $(\mathrm{c})(2)(\mathrm{B})(\mathrm{v}))$, by adding at the end the following new subclause:

"(III) Change IN PRESUMED UTILIZATION LEVEL OF CERTAIN ADVANCED DLAGNOSTIC IMAGING SERVICES._Effective for fee schedules established beginning with 2011, reduced expenditures attributable to the presumed utilization of 75 percent under subsection (b)(4)(C) instead of a presumed utilization of imaging equipment of 50 percent.". 25 COUnt" on Single-session Imaging to Consecutive 
1 Body ParTs.-Section 1848 of such Act (42 U.S.C.

2 1395w-4) is further amended-

3
(1) in subsection (b)(4), by adding at the end the following new subparagraph:

“(D) Adjustment in technical COMpoNENT DISCOUNT ON SINGLE-SESSION IMAGING INVOLVING CONSECUTIVE BODY PARTS.-For services furnished on or after January 1, 2011, the Secretary shall increase the reduction in expenditures attributable to the multiple procedure payment reduction applicable to the technical component for imaging under the final rule published by the Secretary in the Federal Register on November 21, 2005 (part 405 of title 42, Code of Federal Regulations) from 25 percent to 50 percent."; and

(2) in subsection $(\mathrm{c})(2)(\mathrm{B})(\mathrm{v})$, by adding at the end the following new subclause:

"(III) AdDITIONAL REDUCED PAYMENT FOR MULTIPLE IMAGING PROCEDURES.-Effective for fee schedules established beginning with 2011, reduced expenditures attributable to the increase in the multiple procedure payment reduction from 25 
percent to 50 percent as described in subsection (b)(4)(D).”.

3 SEC. 1147. DURABLE MEDICAL EQUIPMENT PROGRAM IMPROVEMENTS.

6 tion 1834(a)(16) of the Social Security Act (42 U.S.C.

$71395 \mathrm{~m}(\mathrm{a})(16))$ is amended by adding at the end the fol-

8 lowing sentence: "The requirement for a surety bond de-

9 scribed in subparagraph (B) shall not apply in the case

10 of a pharmacy or supplier that exclusively furnishes eye-

11 glasses or contact lenses described in section 1861(s)(8)

12 if the pharmacy or supply has been enrolled under section

$131866(\mathrm{j})$ as a supplier of durable medical equipment, pros-

14 theties, orthoties, and supplies and has been issued (which

15 may include renewal of) a supplier number (as described

16 in the first sentence of this paragraph) for at least 5 years,

17 and if a final adverse action (as defined in section 18424.57 (a) of title 42, Code of Federal Regulations) has

19 never been imposed for such pharmacy or supplier.".

(b) Ensuring Supply of Oxygen Equipment .-

(1) In GENERAL.-Section 1834(a)(5)(F) of the

22 Social Security Act (42 U.S.C. $1395 \mathrm{~m}(\mathrm{a})(5)(\mathrm{F}))$ is 23 amended- 
(A) in clause (ii), by striking "After the"

and inserting "Except as provided in clause

(iii), after the"; and

(B) by adding at the end the following new

clause:

(2) EFfective DATE.-The amendments made 25 by paragraph (1) shall take effect as of the date of 
1 the enactment of this Act and shall apply to the fur-

2 nishing of equipment to individuals for whom the

3 27th month of a continuous period of use of oxygen

4 equipment described in section $1834(\mathrm{a})(5)(\mathrm{F})$ of the

5 Social Security Act occurs on or after July 1, 2010.

6 (c) Treatment of Current accreditation Ap-

7 Plications.-Section 1834(a)(20)(F) of such Act (42

8 U.S.C. $1395 \mathrm{~m}(\mathrm{a})(20)(\mathrm{F}))$ is amended-

$9 \quad$ (1) in clause (i)-

10 (A) by striking "clause (ii)" and inserting

11 "clauses (ii) and (iii)"; and

12

(B) by striking "and" at the end;

(2) by striking the period at the end of clause

14 (ii)(II) and by inserting a semicolon;

15 (3) by inserting after clause (ii) the following 16 new clauses:

"(iii) the requirement for accredita-

tion described in clause (i) shall not apply for purposes of supplying diabetic testing supplies, canes, and crutches in the case of

a pharmacy that is enrolled under section $1866(\mathrm{j})$ as a supplier of durable medical equipment, prosthetics, orthotics, and sup- 
"(iv) a supplier that has submitted an

15 in Case of Supplier Bankruptcy for Certain Indi-

16 VIDUALS.-Section 1834(a)(5)(F) of such Act (42 U.S.C.

$171395 \mathrm{~m}(\mathrm{a})(5)(\mathrm{F}))$, as amended by subsection (b), is further 18 amended by adding at the end the following new clause:

application for accreditation before August 1, 2009, shall retain the supplier's provider or supplier number until an independent accreditation organization determines if such supplier complies with requirements under this paragraph.”; and

(4) by adding at the end the following new sentence: "Nothing in clauses (iii) and (iv) shall be construed as affecting the application of an accreditation requirement for suppliers to qualify for bidding in a competitive acquisition area under section 1847,’.

(d) Restoring 36-month Oxygen Rental Period "(iv) EXCEPTION FOR BANKRUPTCY.-If a supplier who furnishes oxygen and oxygen equipment to an individual is declared bankrupt and its assets are liquidated and at the time of such declaration and liquidation more than 24 months of rental payments have been made, such in- 
dividual may begin a new 36 -month rental period under this subparagraph with another supplier of oxygen.".

4 SEC. 1148. MEDPAC STUDY AND REPORT ON BONE MASS

6 (a) In General.-The Medicare Payment Advisory

7 Commission shall conduct a study regarding bone mass

8 measurement, including computed tomography, duel-en-

9 ergy x-ray absorptriometry, and vertebral fracture assess-

10 ment. The study shall focus on the following:

11 (1) An assessment of the adequacy of Medicare 12 payment rates for such services, taking into account 13 costs of acquiring the necessary equipment, profes14 sional work time, and practice expense costs.

15 (2) The impact of Medicare payment changes 16 since 2006 on beneficiary access to bone mass meas17 urement benefits in general and in rural and minor18 ity communities specifically.

19 (3) A review of the clinically appropriate and 20 recommended use among Medicare beneficiaries and 21 how usage rates among such beneficiaries compares 22 to such recommendations.

23 (4) In conjunction with the findings under (3), 24 recommendations, if necessary, regarding methods 
1 for reaching appropriate use of bone mass measure-

2 ment studies among Medicare beneficiaries.

3 (b) REPORT.-The Commission shall submit a report

4 to the Congress, not later than 9 months after the date

5 of the enactment of this Act, containing a description of

6 the results of the study conducted under subsection (a)

7 and the conclusions and recommendations, if any, regard-

8 ing each of the issues described in paragraphs (1), (2) (3)

9 and (4) of such subsection.

10 SEC. 1149. TIMELY ACCESS TO POST-MASTECTOMY ITEMS.

11 (a) In GenERAL.-Section 1834(h)(1) of the Social

12 Security Act (42 U.S.C. 1395m) is amended-

13 (1) by redesignating subparagraph (H) as sub-

14 paragraph (I); and

15 (2) by inserting after subparagraph $(G)$ the fol-

16 lowing new subparagraph:

“(H) Speclal Payment RUle FOR POSTMASTECTOMY EXTERNAL BREAST PROSTHESIS GARMENTS.-Payment for post-mastectomy external breast prosthesis garments shall be made regardless of whether such items are supplied to the beneficiary prior to or after the mastectomy procedure or other breast cancer surgical procedure. The Secretary shall develop policies to ensure appropriate beneficiary access and utiliza- 
1 tion safeguards for such items supplied to a 2 beneficiary prior to the mastectomy or other $3 \quad$ breast cancer surgical procedure."

4 (b) EfFective Date.-This amendment shall apply 5 not later than January 1, 2011.

6 SEC. 1149A. PAYMENT FOR BIOSIMILAR BIOLOGICAL PRODUCTS.

8 (a) In General.-Section 1847A of the Social Secu9 rity Act (42 U.S.C. $1395 \mathrm{w}-3 \mathrm{a}$ ) is amended(1) in subsection (b)(1)period at the end and inserting "; or"; and

(C) by adding at the end the following new subparagraph:

"(C) in the case of one or more interchangeable biological products (as defined in subsection $(c)(6)(\mathrm{I}))$ and their reference biological product (as defined in subsection $(\mathrm{c})(6)(\mathrm{J})$ ), which shall be included in the same billing and 25 payment code, the sum of-

"(i) the average sales price as determined using the methodology described in paragraph (6) applied to such interchange- 
able and reference products for all National Drug Codes assigned to such products in the same manner as such paragraph (6) is applied to multiple source drugs; and "(ii) 6 percent of the amount determined under clause (i);

"(D) in the case of a biosimilar biological product (as defined in subsection $(\mathrm{c})(6)(\mathrm{H}))$, the sum of-

"(i) the average sales price as determined using the methodology described in paragraph (4) applied to such biosimilar biological product for all National Drug Codes assigned to such product in the same manner as such paragraph (4) is applied to a single source drug; and "(ii) 6 percent of the amount determined under paragraph (4) or the amount determined under subparagraph (C)(ii), as the case may be, for the reference biological product (as defined in subsection (c) $(6)(\mathrm{J}))$; or

"(E) in the case of a reference biological product for both an interchangeable biological 
product and a biosimilar product, the amount determined in subparagraph (C)."; and

(2) in subsection (c)(6)-

(A) by amending subparagraph (D)(i) to read as follows:

"(i) a biological, including a reference

"(I) a biosimilar biological product; but excluding-

"(II) an interchangeable biological product;

"(III) a reference biological product for an interchangeable biological product; and

"(IV) a reference biological product for both an interchangeable biological product and a biosimilar product; or"; and

(B) by adding at the end the following new subparagraphs:

“(H) Biosimilar BiOLOGICAL PRODUCT.The term 'biosimilar biological product' means a biological product licensed as a biosimilar bio- 
15 subsection (a) shall apply to payments for biosimilar bio-

16 logical products, interchangeable biological products, and

17 reference biological products beginning with the first day

18 of the second calendar quarter after the date of the enact19 ment of this Act.

20 SEC. 1149B. STUDY AND REPORT ON DME COMPETITIVE 21

23 States shall conduct a study to evaluate the potential es24 tablishment of a program under Medicare under title 25 XVIII of the Social Security Act to acquire durable med- 
1 ical equipment and supplies through a competitive bidding

2 process among manufacturers of such equipment and sup3 plies. Such study shall address the following:

4 (1) Identification of types of durable medical 5 equipment and supplies that would be appropriate 6 for bidding under such a program.

(2) Recommendations on how to structure such 8 an acquisition program in order to promote fiscal re9 sponsibility while also ensuring beneficiary access to 10 high quality equipment and supplies.

11 (3) Recommendations on how such a program 12 could be phased-in and on what geographic level 13 would bidding be most appropriate.

14 (4) In addition to price, recommendations on 15 criteria that could be factored into the bidding proc16 ess.

17 (5) Recommendations on how suppliers could be 18 compensated for furnishing and servicing equipment 19 and supplies acquired under such a program.

20 (6) Comparison of such a program to the cur21 rent competitive bidding program under Medicare 22 for durable medical equipment, as well as any other 23 similar Federal acquisition programs, such as the 24 General Services Administration's vehicle purchasing 25 program. 
(7) Any other consideration relevant to the ac-

2 quisition, supply, and service of durable medical

3 equipment and supplies that is deemed appropriate

$4 \quad$ by the Comptroller General.

5 (b) REPORT.-Not later than 12 months after the 6 date of the enactment of this Act, the Comptroller General

7 of the United States shall submit to Congress a report 8 on the findings of the study under subsection (a).

9 Subtitle C-Provisions Related to

11 SEC. 1151. REDUCING POTENTIALLY PREVENTABLE HOSPITAL READMISSIONS.

13 (a) Hospital. -

14 (1) In GENERAL.-Section 1886 of the Social 15 Security Act (42 U.S.C. 1395ww), as amended by 16 section $1103(\mathrm{a})$, is amended by adding at the end 17 the following new subsection:

18 “(p) Adjustment to Hospital Payments for 19 Excess Readmissions.-

20 "(1) In GENERAL.-With respect to payment 21 for discharges from an applicable hospital (as de22 fined in paragraph (5)(C)) occurring during a fiscal 23 year beginning on or after October 1, 2011, in order 24 to account for excess readmissions in the hospital, 25 the Secretary shall reduce the payments that would 
1 otherwise be made to such hospital under subsection

2 (d) (or section 1814(b)(3), as the case may be) for 3 such a discharge by an amount equal to the product 4 of-

"(A) the base operating DRG payment amount (as defined in paragraph (2)) for the discharge; and

"(B) the adjustment factor (described in paragraph $(3)(\mathrm{A}))$ for the hospital for the fiscal year.

“(2) BASE OPERATING DRG PAYMENT AMOUNT.-

"(A) In GENERAL.-Except as provided in subparagraph (B), for purposes of this subsection, the term 'base operating DRG payment amount' means, with respect to a hospital for a fiscal year, the payment amount that would otherwise be made under subsection (d) for a discharge if this subsection did not apply, reduced by any portion of such amount that is attributable to payments under subparagraphs (B) and (F) of paragraph (5).

"(B) Adjustments.-For purposes of subparagraph (A), in the case of a hospital that is paid under section 1814(b)(3), the term 'base 
operating DRG payment amount' means the payment amount under such section.

"(3) Adjustment FACTOR.-

"(A) IN GENERAL.-For purposes of para-

graph (1), the adjustment factor under this paragraph for an applicable hospital for a fiscal year is equal to the greater of-

"(i) the ratio described in subparagraph (B) for the hospital for the applicable period (as defined in paragraph (5)(D)) for such fiscal year; or

"(ii) the floor adjustment factor specified in subparagraph (C).

"(B) RATIO._-The ratio described in this subparagraph for a hospital for an applicable period is equal to 1 minus the ratio of-

"(i) the aggregate payments for ex-

cess readmissions (as defined in paragraph $(4)(\mathrm{A}))$ with respect to an applicable hospital for the applicable period; and

"(ii) the aggregate payments for all discharges (as defined in paragraph 24 (4)(B)) with respect to such applicable hospital for such applicable period. 
"(C) FloOR ADJUSTMENT FACTOR.-For purposes of subparagraph (A), the floor adjustment factor specified in this subparagraph for-

"(i) fiscal year 2012 is 0.99 ;

"(ii) fiscal year 2013 is 0.98 ;

"(iii) fiscal year 2014 is 0.97 ; or

"(iv) a subsequent fiscal year is 0.95 .

“(4) Aggregate payments, excess ReadmisSION RATIO DEFINED.-For purposes of this subsection:

"(A) Aggregate Payments For excess READMISSIONS.- The term 'aggregate payments for excess readmissions' means, for a hospital for a fiscal year, the sum, for applicable conditions (as defined in paragraph $(5)(\mathrm{A})$ ), of the product, for each applicable condition, of-

"(i) the base operating DRG payment amount for such hospital for such fiscal year for such condition;

"(ii) the number of admissions for such condition for such hospital for such fiscal year; and

"(iii) the excess readmissions ratio (as defined in subparagraph (C)) for such hos- 
pital for the applicable period for such fiscal year minus 1 .

"(B) Aggregate Payments For all DisCHARGES.- The term 'aggregate payments for all discharges' means, for a hospital for a fiscal

"(I) the risk adjusted readmissions based on actual readmissions, as determined consistent with a readmission measure methodology that has been endorsed under paragraph (5)(A)(ii)(I), for an applicable hospital for such condition with respect to the applicable period; to

"(II) the risk adjusted expected readmissions (as determined con- 
sistent with such a methodology) for such hospital for such condition with respect to such applicable period. “(ii) Exclusion OF CERTain READMISsIONs.-For purposes of clause (i), with respect to a hospital, excess readmissions shall not include readmissions for an applicable condition for which there are fewer than a minimum number (as determined by the Secretary) of discharges for such applicable condition for the applicable period and such hospital.

“(iii) Adjustment.-In order to promote a reduction over time in the overall rate of readmissions for applicable conditions, the Secretary may provide, beginning with discharges for fiscal year 2014, for the determination of the excess readmissions ratio under subparagraph (C) to be based on a ranking of hospitals by readmission ratios (from lower to higher readmission ratios) normalized to a benchmark that is lower than the 50th percentile. "(5) Definitions.-For purposes of this sub25 section: 
"(A) Applicable CONDition.-The term 'applicable condition' means, subject to subparagraph (B), a condition or procedure selected by the Secretary among conditions and procedures for which-

"(i) readmissions (as defined in subparagraph (E)) that represent conditions or procedures that are high volume or high expenditures under this title (or other criteria specified by the Secretary); and "(ii) measures of such readmissions"(I) have been endorsed by the entity with a contract under section $1890(\mathrm{a}) ;$ and

"(II) such endorsed measures have appropriate exclusions for readmissions that are unrelated to the prior discharge (such as a planned readmission or transfer to another applicable hospital).

"(B) ExPANSION OF APPLICABLE CONDITIONS._Beginning with fiscal year 2013, the Secretary shall expand the applicable conditions beyond the 3 conditions for which measures have been endorsed as described in subpara- 
graph (A)(ii)(I) as of the date of the enactment of this subsection to the additional 4 conditions that have been so identified by the Medicare Payment Advisory Commission in its report to Congress in June 2007 and to other conditions

and procedures which may include an all-condition measure of readmissions, as determined appropriate by the Secretary. In expanding such applicable conditions, the Secretary shall seek the endorsement described in subparagraph (A)(ii)(I) but may apply such measures without such an endorsement.

"(C) Applicable hospital.- The term 'applicable hospital' means a subsection (d) hospital or a hospital that is paid under section 1814(b)(3).

"(D) APPlicable PERIOD.-The term 'applicable period' means, with respect to a fiscal year, such period as the Secretary shall specify for purposes of determining excess readmissions.

"(E) Readmission.-The term 'readmission' means, in the case of an individual who is discharged from an applicable hospital, the admission of the individual to the same or another 
applicable hospital within a time period specified by the Secretary from the date of such discharge. Insofar as the discharge relates to an applicable condition for which there is an endorsed measure described in subparagraph (A)(ii)(I), such time period (such as 30 days) shall be consistent with the time period specified for such measure.

“(6) Limitations on REVIEW.-There shall be no administrative or judicial review under section 1869 , section 1878 , or otherwise of-

"(A) the determination of base operating DRG payment amounts;

"(B) the methodology for determining the adjustment factor under paragraph (3), including excess readmissions ratio under paragraph (4)(C), aggregate payments for excess readmissions under paragraph (4)(A), and aggregate payments for all discharges under paragraph (4)(B), and applicable periods and applicable conditions under paragraph (5);

"(C) the measures of readmissions as described in paragraph (5)(A)(ii); and

"(D) the determination of a targeted hospital under paragraph (8)(B)(i), the increase in 
payment under paragraph (8)(B)(ii), the aggregate cap under paragraph (8)(C)(i), the hospital-specific limit under paragraph (8)(C)(ii), and the form of payment made by the Secretary under paragraph (8)(D).

“(7) Monitoring inappropriate Changes in ADMISSIONS PRACTICES.-The Secretary shall mon-

8 itor the activities of applicable hospitals to determine

9 if such hospitals have taken steps to avoid patients

10 at risk in order to reduce the likelihood of increasing

11 readmissions for applicable conditions or taken other

12 inappropriate steps involving readmissions or trans-

13 fers. If the Secretary determines that such a hos-

14 pital has taken such a step, after notice to the hos-

15 pital and opportunity for the hospital to undertake

16 action to alleviate such steps, the Secretary may im17 pose an appropriate sanction. viding funds to applicable hospitals to take steps described in subparagraph (E) to address factors that may impact readmissions of individuals who are discharged from such a hospital, for fiscal years beginning on or after Oc25 
ment adjustment for a hospital described in subparagraph (B), with respect to each such fiscal year, by a percent estimated by the Secretary to be consistent with subparagraph (C). The Secretary shall provide priority to hospitals

"(i) had (or, in the case of an 1814(b)(3) hospital, otherwise would have had) a disproportionate patient percentage (as defined in section 1886(d)(5)(F)) of at least 30 percent, using the latest available data as estimated by the Secretary; and "(ii) provides assurances satisfactory to the Secretary that the increase in payment under this paragraph shall be used for purposes described in subparagraph $(\mathrm{E})$.

"(C) CAPS.-

“(i) Aggregate CaP.—The aggregate amount of the payment adjustment under 
this paragraph for a fiscal year shall not exceed 5 percent of the estimated difference in the spending that would occur for such fiscal year with and without application of the adjustment factor described in paragraph (3) and applied pursuant to paragraph (1).

“(ii) Hospital-SPECIFIC LIMIT.-The aggregate amount of the payment adjustment for a hospital under this paragraph shall not exceed the estimated difference in spending that would occur for such fiscal year for such hospital with and without application of the adjustment factor described in paragraph (3) and applied pursuant to paragraph (1).

“(D) Form of PAYMent.-The Secretary may make the additional payments under this paragraph on a lump sum basis, a periodic basis, a claim by claim basis, or otherwise.

"(E) Use of additional Payment."(i) IN GENERAL.-Funding under this paragraph shall be used by targeted hospitals for activities designed to address the patient noncompliance issues that re- 
sult in higher than normal readmission rates, including transitional care services described in clause (ii) and any or all of the other activities described in clause (iii). “(ii) Transitional Care SERVICES.-The transitional care services described in this clause are transitional care services furnished by a qualified transitional care provider, such as a nurse or other health professional, who meets relevant experience and training requirements as specified by the Secretary that support a beneficiary under this section beginning on the date of an individual's admission to a hospital for inpatient hospital services and ending at the latest on the last day of the 90-day period beginning on the date of the individual's discharge from the applicable hospital. The Secretary shall determine and update services to be included in transitional care services under this clause as appropriate, based on evidence of their effectiveness in reducing hospital readmissions and improving health outcomes. Such services shall include the following: 
"(I) Conduct of an assessment

prior to discharge, which assessment may include an assessment of the individual's physical and mental condition, cognitive and functional capacities, medication regimen and adherence, social and environmental needs, and primary caregiver needs and resources.

“(II) Development of a evidence-

based plan of transitional care for the individual developed after consultation with the individual and the individual's primary caregiver and other health team members, as appropriate. Such plan shall include a list of current therapies prescribed, treatment goals and may include other items or elements as determined by the Secretary, such as identifying list of potential health risks and future services for both the individual and any primary caregiver. 
"(iii) OTHER ACTIVITIES.-The other

activities described in this clause are the

following:

“(I) Providing other care coordi-

nation services not described under clause (ii).

"(II) Hiring translators and interpreters.

“(III) Increasing services offered by discharge planners.

"(IV) Ensuring that individuals receive a summary of care and medication orders upon discharge.

“(V) Developing a quality improvement plan to assess and remedy preventable readmission rates.

“(VI) Assigning appropriate follow-up care for discharged individuals. "(VII) Doing other activities as determined appropriate by the Secretary.

"(F) GAO REPORT ON USE OF FUNDS.Not later than 3 years after the date on which funds are first made available under this paragraph, the Comptroller General of the United 
States shall submit to Congress a report on the use of such funds. Such report shall consider information on the effective uses of such funds, how the uses of such funds affected hospital readmission rates (including at 6 months postdischarge), health outcomes and quality, reductions in expenditures under this title and the experiences of beneficiaries, primary caregivers, and providers, as well as any appropriate recommendations.".

12 PITALS.-Section 1814(l) of the Social Security Act (42

13 U.S.C. $1395 \mathrm{f}(\mathrm{l}))$ is amended-

(1) in paragraph (5)-

(A) by striking "and" at the end of subparagraph $(\mathrm{C})$;

(B) by striking the period at the end of subparagraph (D) and inserting "; and";

(C) by inserting at the end the following new subparagraph:

"(E) the methodology for determining the ad-

22 justment factor under paragraph (5), including the 23 determination of aggregate payments for actual and 24 expected readmissions, applicable periods, applicable 25 conditions and measures of readmissions."; and 
(D) by redesignating such paragraph as

5 “(5) The adjustment factor described in section $61886(p)(3)$ shall apply to payments with respect to a crit-

7 ical access hospital with respect to a cost reporting period

8 beginning in fiscal year 2012 and each subsequent fiscal

9 year (after application of paragraph (4) of this subsection)

10 in a manner similar to the manner in which such section

11 applies with respect to a fiscal year to an applicable hos-

12 pital as described in section 1886(p)(2).".

13 (c) Post Acute Care Providers.-

(1) INTERIM POLICY.-

(A) In GENERAL.-With respect to a readmission to an applicable hospital or a critical access hospital (as described in section 1814(l) of the Social Security Act) from a post acute care provider (as defined in paragraph (3)) and such a readmission is not governed by section 412.531 of title 42, Code of Federal Regulations, if the claim submitted by such a postacute care provider under title XVIII of the Social Security Act indicates that the individual 
acute care provider or admitted from home and under the care of a home health agency within 30 days of an initial discharge from an applicable hospital or critical access hospital, the payment under such title on such claim shall be the

(B) Applicable Percent defined.-For purposes of subparagraph (A), the applicable percent is-

(i) for fiscal or rate year 2012 is 0.996

(ii) for fiscal or rate year 2013 is $0.993 ;$ and applicable percent specified in subparagraph (B) of the payment that would otherwise be made under the respective payment system under such title for such post-acute care provider if this subsection did not apply. In applying the previous sentence, the Secretary shall exclude a period of 1 day from the date the individual is first admitted to or under the care of the post-acute care provider.$$
\text { (i) for fiscal or rate year } 2012 \text { is }
$$

0

(iii) for fiscal or rate year 2014 is 0.99 .

(C) EFfective DATE.-Subparagraph (1) shall apply to discharges or services furnished 
(as the case may be with respect to the applicable post acute care provider) on or after the first day of the fiscal year or rate year, beginning on or after October 1, 2011, with respect to the applicable post acute care provider.

(2) Development and application of PeRFORMANCE MEASURES.-

(A) In GENERAL.-The Secretary of Health and Human Services shall develop appropriate measures of readmission rates for post acute care providers. The Secretary shall seek endorsement of such measures by the entity with a contract under section 1890(a) of the Social Security Act but may adopt and apply such measures under this paragraph without such an endorsement. The Secretary shall expand such measures in a manner similar to the manner in which applicable conditions are expanded under paragraph (5)(B) of section 1886(p) of the Social Security Act, as added by subsection (a).

(B) Implementation.-The Secretary shall apply, on or after October 1, 2014, with respect to post acute care providers, policies similar to the policies applied with respect to 
applicable hospitals and critical access hospitals under the amendments made by subsection (a). The provisions of paragraph (1) shall apply with respect to any period on or after October 1, 2014, and before such application date described in the previous sentence in the same manner as such provisions apply with respect to fiscal or rate year 2014.

(C) Monitoring And Penalties.-The provisions of paragraph (7) of such section 1886(p) shall apply to providers under this paragraph in the same manner as they apply to hospitals under such section.

(3) Definitions.-For purposes of this subsection:

(A) Post acute Care PRovider.-The term "post acute care provider" means-

(i) a skilled nursing facility (as defined in section 1819(a) of the Social Security Act);

(ii) an inpatient rehabilitation facility (described in section 1886(h)(1)(A) of such Act);

(iii) a home health agency (as defined in section 1861(o) of such Act); and 
(iv) a long term care hospital (as defined in section 1861(ecc) of such Act).

(B) OTHer terms .-The terms "applicable condition", "applicable hospital", and "readmission" have the meanings given such terms in section 1886(p)(5) of the Social Security Act, as added by subsection (a)(1).

(d) Physicians.-

(1) STudy.-The Secretary of Health and

10 Human Services shall conduct a study to determine 11 how the readmissions policy described in the pre12 vious subsections could be applied to physicians.

(2) Considerations.-In conducting the study, the Secretary shall consider approaches such 15 as-

(A) creating a new code (or codes) and payment amount (or amounts) under the fee schedule in section 1848 of the Social Security Act (in a budget neutral manner) for services

(B) developing measures of rates of read25 
(C) applying a payment reduction for physicians who treat the patient during the initial admission that results in a readmission; and (D) methods for attributing payments or payment reductions to the appropriate physician or physicians.

(3) REPORT.-The Secretary shall issue a pub8 lic report on such study not later than the date that 9 is one year after the date of the enactment of this 10 Act.

11 (e) Funding.-For purposes of carrying out the pro12 visions of this section, in addition to funds otherwise avail13 able, out of any funds in the Treasury not otherwise ap14 propriated, there are appropriated to the Secretary of 15 Health and Human Services for the Center for Medicare 16 \& Medicaid Services Program Management Account $17 \$ 25,000,000$ for each fiscal year beginning with 2010 . 18 Amounts appropriated under this subsection for a fiscal 19 year shall be available until expended.

20 SEC. 1152. POST ACUTE CARE SERVICES PAYMENT REFORM PLAN AND BUNDLING PILOT PROGRAM.

24 Human Services (in this section referred to as the 25 "Secretary") shall develop a detailed plan to reform 
1 payment for post acute care (PAC) services under

2 the Medicare program under title XVIII of the So3 cial Security Act (in this section referred to as the

4 "Medicare program)". The goals of such payment 5 reform are to-

6 (A) improve the coordination, quality, and efficiency of such services; and (B) improve outcomes for individuals such as reducing the need for readmission to hospitals from providers of such services.

12 plan described in paragraph (1) shall include de13 tailed specifications for a bundled payment for post 14 acute services (in this section referred to as the 15 "post acute care bundle"), and may include other 16 approaches determined appropriate by the Secretary. 17 (3) Post ACUTE SERVICES.-For purposes of 18 this section, the term "post acute services" means 19 services for which payment may be made under the 20 Medicare program that are furnished by skilled 21 nursing facilities, inpatient rehabilitation facilities, 22 long term care hospitals, hospital based outpatient 23 rehabilitation facilities and home health agencies to 24 an individual after discharge of such individual from 
1 a hospital, and such other services determined ap2 propriate by the Secretary.

3 (b) Details.-The plan described in subsection 4 (a)(1) shall include consideration of the following issues:

5 (1) The nature of payments under a post acute 6 care bundle, including the type of provider or entity 7 to whom payment should be made, the scope of ac8 tivities and services included in the bundle, whether 9 payment for physicians' services should be included 10 in the bundle, and the period covered by the bundle.

11 (2) Whether the payment should be consoli12 dated with the payment under the inpatient prospec13 tive system under section 1886 of the Social Secu14 rity Act (in this section referred to as MS-DRGs) 15 or a separate payment should be established for such 16 bundle, and if a separate payment is established, 17 whether it should be made only upon use of post 18 acute care services or for every discharge.

19 (3) Whether the bundle should be applied 20 across all categories of providers of inpatient serv21 ices (including critical access hospitals) and post 22 acute care services or whether it should be limited 23 to certain categories of providers, services, or dis24 charges, such as high volume or high cost MS25 DRGs. 
(4) The extent to which payment rates could be 2 established to achieve offsets for efficiencies that 3 could be expected to be achieved with a bundle pay4 ment, whether such rates should be established on a 5 national basis or for different geographic areas, 6 should vary according to discharge, case mix, 7 outliers, and geographic differences in wages or 8 other appropriate adjustments, and how to update 9 such rates.

10 (5) The nature of protections needed for indi11 viduals under a system of bundled payments to en12 sure that individuals receive quality care, are fur13 nished the level and amount of services needed as 14 determined by an appropriate assessment instru15 ment, are offered choice of provider, and the extent 16 to which transitional care services would improve 17 quality of care for individuals and the functioning of 18 a bundled post-acute system.

19 (6) The nature of relationships that may be re20 quired between hospitals and providers of post acute 21 care services to facilitate bundled payments, includ22 ing the application of gainsharing, anti-referral, 23 anti-kickback, and anti-trust laws.

24 (7) Quality measures that would be appropriate 25 for reporting by hospitals and post acute providers 
1 (such as measures that assess changes in functional

2 status and quality measures appropriate for each

3 type of post acute services provider including how

4 the reporting of such quality measures could be co-

5 ordinated with other reporting of such quality meas-

6 ures by such providers otherwise required).

7 (8) How cost-sharing for a post acute care bun-

8 dle should be treated relative to current rules for

9 cost-sharing for inpatient hospital, home health,

10 skilled nursing facility, and other services.

11 (9) How other programmatic issues should be

12 treated in a post acute care bundle, including rules

13 specific to various types of post-acute providers such

14 as the post-acute transfer policy, three-day hospital

15 stay to qualify for services furnished by skilled nurs-

16 ing facilities, and the coordination of payments and

17 care under the Medicare program and the Medicaid 18 program.

19 (10) Such other issues as the Secretary deems 20 appropriate.

21 (c) Consultations and Analysis.-

22 (1) Consultation with stakeholders.-In

23 developing the plan under subsection (a)(1), the Sec-

24 retary shall consult with relevant stakeholders and

25 shall consider experience with such research studies 
1 and demonstrations that the Secretary determines

2 appropriate.

(2) Analysis and data collection.-In de-

$4 \quad$ veloping such plan, the Secretary shallmitted on claims) and collect such data as the Secretary determines are appropriate to develop such plan required in this section; and section (b) and other issues that the Secretary determines appropriate;

(B) analyze the impacts (including geographic impacts) of post acute service reform approaches, including bundling of such services on individuals, hospitals, post acute care providers, and physicians;

(C) use existing data (such as data sub(D) if patient functional status measures are appropriate for the analysis, to the extent practical, build upon the CARE tool being developed pursuant to section 5008 of the Deficit Reduction Act of 2005 .

24 the provisions of this section, in addition to funds 25 otherwise available, out of any funds in the Treasury 
1 not otherwise appropriated, there are appropriated

2 to the Secretary for the Center for Medicare \& Med-

3 icaid Services Program Management Account

$4 \$ 15,000,000$ for each of the fiscal years 2010

5 through 2012. Amounts appropriated under this

6 paragraph for a fiscal year shall be available until

7 expended.

8 (2) Expedited data COLLECTION.-Chapter

935 of title 44, United States Code shall not apply to

10 this section.

11 (e) Public Reports.-

12 (1) INTERIM REPORTS.-The Secretary shall 13 issue interim public reports on a periodic basis on 14 the plan described in subsection (a)(1), the issues 15 described in subsection (b), and impact analyses as 16 the Secretary determines appropriate.

17 (2) Final Report.-Not later than the date 18 that is 3 years after the date of the enactment of 19 this Act, the Secretary shall issue a final public re20 port on such plan, including analysis of issues de21 scribed in subsection (b) and impact analyses.

22 (f) Conversion of Acute Care Episode Dem23 onstration to Pilot Program and Expansion to In24 Clude Post Acute Services.- 
(1) In GeneraL.-Part E of title XVIII of the

2 Social Security Act is amended by inserting after

3 section $1866 \mathrm{C}$ the following new section:

4 "CONVERSION OF ACUTE CARE EPISODE DEMONSTRATION

5 TO PILOT PROGRAM AND EXPANSION TO INCLUDE

6 POST ACUTE SERVICES

7 "Sec. 1866D. (a) Conversion And Expansion.-

8 “(1) In GENERAL.-By not later than January

9 1, 2011, the Secretary shall, for the purpose of pro-

10 moting the use of bundled payments to promote effi-

11 cient, coordinated, and high quality delivery of

12 care-

13 "(A) convert the acute care episode dem14 onstration program conducted under section $15 \quad$ 1866C to a pilot program; and

16 "(B) subject to subsection (c), expand such 17 program as so converted to include post acute 18 services and such other services the Secretary 19 determines to be appropriate, which may in$20 \quad$ clude transitional services. “(2) Bundled Payment struCtures."(A) IN GENERAL.-In carrying out paragraph (1), the Secretary may apply bundled payments with respect to“(i) hospitals and physicians; 
“(ii) hospitals and post-acute care

providers;

“(iii) hospitals, physicians, and postacute care providers; or "(iv) combinations of post-acute providers. "(B) Further application.“(i) In GENERAL.-In carrying out paragraph (1), the Secretary shall apply bundled payments in a manner so as to include collaborative care networks and continuing care hospitals.

"(ii) Collaborative Care NetTwORK DEFINED.-For purposes of this subparagraph, the term 'collaborative care network' means a consortium of health care providers that provides a comprehensive range of coordinated and integrated health care services to low-income patient populations (including the uninsured) which may include coordinated and comprehensive care by safety net providers to reduce any unnecessary use of items and services furnished in emergency departments, manage chronic conditions, improve quality and 
20 for the number of acute and post-acute bundling test sites 21 under the pilot program to ensure that over time the pilot 22 program is of sufficient size and scope to-

efficiency of care, increase preventive services, and promote adherence to post-acute and follow-up care plans.

“(iii) Continuing Care hospital DEFINED.-For purposes of this subparagraph, the term 'continuing care hospital' means an entity that has demonstrated the ability to meet patient care and patient safety standards and that provides under common management the medical and rehabilitation services provided in inpatient rehabilitation hospitals and units (as defined in section 1886(d)(1)(B)(ii)), longterm care hospitals (as defined in section 1886(d)(1)(B)(iv)(I)), and skilled nursing facilities (as defined in section 1819(a)) that are located in a hospital described in section $1886(d)$.

"(b) SCOPE.-The Secretary shall set specific goals "(1) test the approaches under the pilot program in a variety of settings, including urban, rural, and underserved areas; 
"(2) include geographic areas and additional

2 conditions that account for significant program

3 spending, as defined by the Secretary; and

"(3) subject to subsection (d), disseminate the

5 pilot program rapidly on a national basis.

6 To the extent that the Secretary finds inpatient and post

7 acute care bundling to be successful in improving quality

8 and reducing costs, the Secretary shall implement such

9 mechanisms and reforms under the pilot program on as

10 large a geographic scale as practical and economical, con-

11 sistent with subsection (e). Nothing in this subsection

12 shall be construed as limiting the number of hospital and

13 physician groups or the number of hospital and post-acute

14 provider groups that may participate in the pilot program.

15 “(c) Limitation.-The Secretary shall only expand

16 the pilot program under subsection (a) if the Secretary

17 finds that-

"(1) the demonstration program under section

$19 \quad 1866 \mathrm{C}$ and pilot program under this section main-

20 tain or increase the quality of care received by indi-

21 viduals enrolled under this title; and

22 "(2) such demonstration program and pilot pro-

23 gram reduce program expenditures and, based on

24 the certification under subsection (d), that the ex-

25 pansion of such pilot program would result in esti- 
1 mated spending that would be less than what spend-

2 ing would otherwise be in the absence of this section.

3 “(d) Certification.-For purposes of subsection

4 (c), the Chief Actuary of the Centers for Medicare \& Med-

5 icaid Services shall certify whether expansion of the pilot

6 program under this section would result in estimated

7 spending that would be less than what spending would

8 otherwise be in the absence of this section.

9 “(e) Voluntary Participation.-Nothing in this

10 paragraph shall be construed as requiring the participa-

11 tion of an entity in the pilot program under this section.

12 “(f) Evaluation on Cost and Quality of

13 CARE.-The Secretary shall conduct an evaluation of the

14 pilot program under subsection (a) to study the effect of

15 such program on costs and quality of care. The findings

16 of such evaluation shall be included in the final report re-

17 quired under section 1152(e)(2) of the Affordable Health

18 Care for America Act.

19 “(g) Study of Additional Bunding and Epi20 sode-based Payment for Physiclans' Services.-

“(1) In GENERAL.—The Secretary shall provide

22 for a study of and development of a plan for testing

23 additional ways to increase bundling of payments for

24 physicians in connection with an episode of care,

25 such as in connection with outpatient hospital serv- 
1 ices or services rendered in physicians' offices, other

2 than those provided under the pilot program.

“(2) Application.-The Secretary may imple-

4 ment such a plan through a demonstration pro-

5 gram.”.

(2) Conforming Amendment.-Section

$7 \quad 1866 \mathrm{C}(\mathrm{b})$ of the Social Security Act (42 U.S.C.

8 1395cc-3(b)) is amended by striking "The Sec-

9 retary" and inserting "Subject to section 1866D, the

10 Secretary".

11 SEC. 1153. HOME HEALTH PAYMENT UPDATE FOR 2010.

12 Section 1895(b)(3)(B)(ii) of the Social Security Act

13 (42 U.S.C. $1395 \mathrm{fff}(\mathrm{b})(3)(\mathrm{B})(\mathrm{ii})$ ) is amended-

(1) in subclause (IV), by striking "and";

15

(2) by redesignating subclause (V) as subclause

16 (VII); and

17 (3) by inserting after subclause (IV) the fol18 lowing new subclauses:

“(V) 2007, 2008, and 2009, subject to clause (v), the home health market basket percentage increase; 
1 SEC. 1154. PAYMENT ADJUSTMENTS FOR HOME HEALTH CARE.

3 (a) Acceleration of Adjustment for Case Mix 4 Changes.-Section 1895(b)(3)(B) of the Social Security 5 Act (42 U.S.C. $1395 \mathrm{fff}(\mathrm{b})(3)(\mathrm{B}))$ is amended-

(1) in clause (iv), by striking "Insofar as" and 7 inserting "Subject to clause (vi), insofar as"; and CHANGES FOR 2011.-

"(I) IN GENERAL.—With respect to the case mix adjustments established in section $484.220(\mathrm{a})$ of title 42, Code of Federal Regulations, the Secretary shall apply, in 2010, the adjustment established in paragraph (3) of such section for 2011, in addition to applying the adjustment established in paragraph (2) for 2010 .

“(II) Construction.-Nothing in this clause shall be construed as limiting the amount of adjustment for case mix for 2010 or 2011 if more recent data indicate an appropriate adjustment that is greater than the 
amount established in the section described in subclause (I).".

(b) Rebasing Home Health Prospective Pay4 ment Amount.-Section 1895(b)(3)(A) of the Social Se5 curity Act (42 U.S.C. $1395 \mathrm{fff}(\mathrm{b})(3)(\mathrm{A})$ ) is amended-

(1) in clause (i)-

(A) in subclause (III), by inserting "and before 2011" after "after the period described in subclause (II)"; and

(B) by inserting after subclause (III) the following new subclauses:

"(IV) Subject to clause (iii)(I), for 2011, such amount (or amounts) shall be adjusted by a uniform percentage determined to be appropriate by the Secretary based on analysis of factors such as changes in the average number and types of visits in an episode, the change in intensity of visits in an episode, growth in cost per episode, and other factors that the Secretary considers to be relevant.

"(V) Subject to clause (iii)(II), for a year after 2011, such a amount (or amounts) shall be equal to the 
amount (or amounts) determined under this clause for the previous year, updated under subparagraph (B)."; and

(2) by adding at the end the following new clause:

"(iii) SPEClAL RULE IN CASE OF INABILITY TO EFFECT TIMELY REBASING."(I) APPLICATION OF PROXY AMOUNT FOR 2011.-If the Secretary is not able to compute the amount (or amounts) under clause (i)(IV) so as to permit, on a timely basis, the application of such clause for 2011, the Secretary shall substitute for such amount (or amounts) 95 percent of the amount (or amounts) that would otherwise be specified under clause (i)(III) if it applied for 2011.

"(II) Adjustment FOR SUBsEQUENT YEARS BASED ON DATA.- If the Secretary applies subclause (I), the Secretary before July 1, 2011, shall compare the amount (or amounts) applied under such sub- 
15 SEC. 1155. INCORPORATING PRODUCTIVITY IMPROVE-

19 cial Security Act (42 U.S.C. $1395 \mathrm{fff}(\mathrm{b})(3)(\mathrm{B})$ ) is amend20 ed-

clause with the amount (or amounts) that should have been applied under clause (i)(IV). The Secretary shall decrease or increase the prospective payment amount (or amounts) under clause (i)(V) for 2012 (or, at the Secretary's discretion, over a period of several years beginning with 2012) by the amount (if any) by which the amount (or amounts) applied under subclause (I) is greater or less, respectively, than the amount (or amounts) that should have been applied under clause (i)(IV).”.

\section{MENTS INTO MARKET BASKET UPDATE FOR} HOME HEALTH SERVICES.

(a) In General.-Section 1895(b)(3)(B) of the So-

(1) in clause (iii), by inserting "(including being subject to the productivity adjustment described in section 1886(b)(3)(B)(iii)(II))" after "in the same manner"; and 
(2) in clause (v)(I), by inserting "(but not

2 below 0$)$ " after "reduced".

3 (b) EFFEctive Date.-The amendments made by 4 subsection (a) shall apply to home health market basket 5 percentage increases for years beginning with 2011.

6 SEC. 1155A. MEDPAC STUDY ON VARIATION IN HOME HEALTH MARGINS.

8 (a) In General.-The Medicare Payment Advisory 9 Commission shall conduct a study regarding variation in 10 performance of home health agencies in an effort to ex11 plain variation in Medicare margins for such agencies. 12 Such study shall include an examination of at least the 13 following issues:

(1) The demographic characteristics of individ15 uals served and the geographic distribution associ16 ated with transportation costs.

17 (2) The characteristics of such agencies, such 18 as whether such agencies operate 24 hours each day, 19 provide charity care, or are part of an integrated 20 health system.

21 (3) The socio-economic status of individuals 22 served, such as the proportion of such individuals 23 who are dually eligible for Medicare and Medicaid 24 benefits. 
(4) The presence of severe and or chronic dis-

2 ease or disability in individuals served, as evidenced

3 by multiple discontinuous home health episodes with

$4 \quad$ a high number of visits per episode.

5 (5) The differences in services provided, such as

6 therapy and non-therapy services.

7 (b) REPORT.-Not later than June 1, 2011, the Com-

8 mission shall submit a report to the Congress on the re-

9 sults of the study conducted under subsection (a) and shall

10 include in the report the Commission's conclusions and

11 recommendations, if appropriate, regarding each of the

12 issues described in paragraphs (1), (2) and (3) of such

13 subsection.

14 SEC. 1155B. PERMitTING HOME HEALTH AGENCIES TO AS-

SIGN THE MOST APPROPRIATE SKILLED SERVICE TO MAKE THE INITIAL ASSESSMENT VISIT UNDER A MEDICARE HOME HEALTH PLAN OF CARE FOR REHABILITATION CASES.

(a) In GENERAL.-Notwithstanding section $20484.55(a)(2)$ of title 42 of the Code of Federal Regula21 tions or any other provision of law, a home health agency 22 may determine the most appropriate skilled therapist to 23 make the initial assessment visit for an individual who is 24 referred (and may be eligible) for home health services 25 under title XVIII of the Social Security Act but who does 
1 not require skilled nursing care as long as the skilled serv-

2 ice (for which that therapist is qualified to provide the

3 service) is included as part of the plan of care for home

4 health services for such individual.

5 (b) Rule of Construction.-Nothing in sub6 section (a) shall be construed to provide for initial eligi-

7 bility for coverage of home health services under title 8 XVIII of the Social Security Act on the basis of a need

9 for occupational therapy.

10 SEC. 1156. LIMITATION ON MEDICARE EXCEPTIONS TO THE PROHIBITION ON CERTAIN PHYSICIAN REFERRALS MADE TO HOSPITALS.

13 (a) In General.-Section 1877 of the Social Secu14 rity Act (42 U.S.C. 1395nn) is amended-

(1) in subsection $(d)(2)-$

(A) in subparagraph (A), by striking "and" at the end;

(B) in subparagraph (B), by striking the period at the end and inserting "; and"; and

(C) by adding at the end the following new subparagraph:

"(C) in the case where the entity is a hospital, the hospital meets the requirements of paragraph (3)(D).";

(2) in subsection $(d)(3)-$ 
(A) in subparagraph (B), by striking "and" at the end;

(B) in subparagraph (C), by striking the period at the end and inserting "; and"; and

(C) by adding at the end the following new

(3) by amending subsection (f) to read as fol-

10 lows:

\section{“(f) Reporting AND Disclosure Require-}

12 MENTS.-

"(1) IN GENERAL._Each entity providing cov-

14 ered items or services for which payment may be

15 made under this title shall provide the Secretary

16 with the information concerning the entity's owner-

17 ship, investment, and compensation arrangements, 18 including-

"(A) the covered items and services provided by the entity, and

"(B) the names and unique physician identification numbers of all physicians with an ownership or investment interest (as described 25 in subsection $(\mathrm{a})(2)(\mathrm{A}))$, or with a compensation arrangement (as described in subsection 
(a) (2)(B)), in the entity, or whose immediate relatives have such an ownership or investment interest or who have such a compensation relationship with the entity.

5 Such information shall be provided in such form, 6 manner, and at such times as the Secretary shall 7 specify. The requirement of this subsection shall not 8 apply to designated health services provided outside 9 the United States or to entities which the Secretary 10 determines provide services for which payment may 11 be made under this title very infrequently. “(2) Requirements FOR hospitals WITH 13 PHYSICIAN OWNERSHIP OR INVESTMENT.-In the 14 case of a hospital that meets the requirements de15 scribed in subsection (i)(1), the hospital shall"(A) submit to the Secretary an initial report, and periodic updates at a frequency determined by the Secretary, containing a detailed description of the identity of each physician owner and physician investor and any other owners or investors of the hospital;

"(B) require that any referring physician owner or investor discloses to the individual being referred, by a time that permits the indi25 
the receipt of services, as determined by the Secretary, the ownership or investment interest, as applicable, of such referring physician in the hospital; and

"(C) disclose the fact that the hospital is partially or wholly owned by one or more physicians or has one or more physician investors"(i) on any public website for the hospital; and "(ii) in any public advertising for the hospital.

The information to be reported or disclosed under this paragraph shall be provided in such form, manner, and at such times as the Secretary shall specify. The requirements of this paragraph shall not apply to designated health services furnished outside the United States or to entities which the Secretary determines provide services for which payment may be made under this title very infrequently.

“(3) Publication of information.-The Secretary shall publish, and periodically update, the information submitted by hospitals under paragraph (2)(A) on the public Internet website of the Centers for Medicare \& Medicaid Services.”; 
(4) by amending subsection $(\mathrm{g})(5)$ to read as

2 follows:

“(5) FAilure to REPORT OR Disclose INFORMATION.-

"(A) Reporting.-Any person who is required, but fails, to meet a reporting requirement of paragraphs (1) and (2)(A) of subsection (f) is subject to a civil money penalty of not more than $\$ 10,000$ for each day for which reporting is required to have been made.

"(B) Disclosure.-Any physician who is required, but fails, to meet a disclosure requirement of subsection (f)(2)(B) or a hospital that is required, but fails, to meet a disclosure requirement of subsection (f)(2)(C) is subject to a civil money penalty of not more than $\$ 10,000$ for each case in which disclosure is required to have been made.

"(C) Application.-The provisions of section 1128A (other than the first sentence of subsection (a) and other than subsection (b)) shall apply to a civil money penalty under subparagraphs (A) and (B) in the same manner as such provisions apply to a penalty or proceeding under section 1128A(a)."; and 
(5) by adding at the end the following new sub-

2 section:

3 “(i) Requirements to Qualify for Rural Pro4 VIDER AND Hospital OwNership Exceptions TO 5 Self-referral Prohibition.-

“(1) Requirements DESCRIBED.-For purposes of subsection $(d)(3)(D)$, the requirements described in this paragraph are as follows:

"(A) Provider agrenment.-The hospital had-

"(i) physician ownership or investment on January 1, 2009; and "(ii) a provider agreement under section 1866 in effect on such date.

“(B) Prohibition on physician ownerSHIP OR INVESTMENT.-The percentage of the total value of the ownership or investment interests held in the hospital, or in an entity whose assets include the hospital, by physician owners or investors in the aggregate does not exceed such percentage as of the date of enactment of this subsection.

“(C) Prohibition on expansion of FaCILITY CAPACITY.-Except as provided in paragraph (2), the number of operating rooms, pro- 
cedure rooms, or beds of the hospital at any time on or after the date of the enactment of this subsection are no greater than the number of operating rooms, procedure rooms, or beds, respectively, as of such date.

"(D) ENsuring BONA FIDE OWNERSHIP AND INVESTMENT.-

"(i) Any ownership or investment interests that the hospital offers to a physician are not offered on more favorable terms than the terms offered to a person who is not in a position to refer patients or otherwise generate business for the hospital.

"(ii) The hospital (or any investors in the hospital) does not directly or indirectly provide loans or financing for any physician owner or investor in the hospital.

"(iii) The hospital (or any investors in the hospital) does not directly or indirectly guarantee a loan, make a payment toward a loan, or otherwise subsidize a loan, for any physician owner or investor or group of physician owners or investors that is re- 
lated to acquiring any ownership or investment interest in the hospital.

"(iv) Ownership or investment returns are distributed to each owner or investor in the hospital in an amount that is directly proportional to the ownership or investment interest of such owner or investor in the hospital.

"(v) The investment interest of the owner or investor is directly proportional to the owner's or investor's capital contributions made at the time the ownership or investment interest is obtained.

"(vi) Physician owners and investors do not receive, directly or indirectly, any guaranteed receipt of or right to purchase other business interests related to the hospital, including the purchase or lease of any property under the control of other owners or investors in the hospital or located near the premises of the hospital.

"(vii) The hospital does not offer a physician owner or investor the opportunity to purchase or lease any property under the control of the hospital or any 
other owner or investor in the hospital on more favorable terms than the terms offered to a person that is not a physician owner or investor.

"(viii) The hospital does not condition any physician ownership or investment interests either directly or indirectly on the physician owner or investor making or influencing referrals to the hospital or otherwise generating business for the hospital. "(E) Patient safety.-In the case of a hospital that does not offer emergency services, the hospital has the capacity to-

"(i) provide assessment and initial treatment for medical emergencies; and "(ii) if the hospital lacks additional capabilities required to treat the emergency involved, refer and transfer the patient with the medical emergency to a hospital with the required capability.

“(F) Limitation ON APPLication TO CERTAIN CONVERTED FACILITIES.-The hospital was not converted from an ambulatory surgical center to a hospital on or after the date of enactment of this subsection. 
“(2) EXCEPTION TO PROHIBITION ON EXPAN-

"(A) Process.-

“(i) Establishment.-The Secretary shall establish and implement a process under which a hospital may apply for an exception from the requirement under paragraph $(1)(\mathrm{C})$.

“(ii) OppoRtunity FOR COMMUNiTy INPUT.-The process under clause (i) shall provide persons and entities in the community in which the hospital applying for an exception is located with the opportunity to provide input with respect to the application.

"(iii) TIming FOR ImplementaTION.-The Secretary shall implement the process under clause (i) on the date that is one month after the promulgation of regulations described in clause (iv).

"(iv) Regulations.-Not later than the first day of the month beginning 18 months after the date of the enactment of this subsection, the Secretary shall promulgate regulations to carry out the process 
under clause (i). The Secretary may issue such regulations as interim final regulations.

"(B) Frequency.-The process described in subparagraph (A) shall permit a hospital to apply for an exception up to once every 2 years. “(C) Permitted increase.-

“(i) IN GENERAL.-Subject to clause (ii) and subparagraph (D), a hospital granted an exception under the process described in subparagraph (A) may increase the number of operating rooms, procedure rooms, or beds of the hospital above the baseline number of operating rooms, procedure rooms, or beds, respectively, of the hospital (or, if the hospital has been granted a previous exception under this paragraph, above the number of operating rooms, procedure rooms, or beds, respectively, of the hospital after the application of the most recent increase under such an exception).

“(ii) 100 PERCENT INCREASE LIMITATION.-The Secretary shall not permit an increase in the number of operating rooms, 
procedure rooms, or beds of a hospital under clause (i) to the extent such increase would result in the number of operating rooms, procedure rooms, or beds of the hospital exceeding 200 percent of the baseline number of operating rooms, procedure rooms, or beds of the hospital.

“(iii) BASELINE NUMBER OF OPERATING ROOMS, PROCEDURE ROOMS, OR BEDS.-In this paragraph, the term 'baseline number of operating rooms, procedure rooms, or beds' means the number of operating rooms, procedure rooms, or beds of a hospital as of the date of enactment of this subsection.

"(D) INCREASE LIMITED TO FACILITIES ON THE MaIN CAMPUS OF THE hospital.Any increase in the number of operating rooms, procedure rooms, or beds of a hospital pursuant to this paragraph may only occur in facilities on the main campus of the hospital.

“(E) CONDitions FOR APPROVAL OF AN INCREASE IN FACILITY CAPACITY.-The Secretary may grant an exception under the proc- 
ess described in subparagraph (A) only to a

"(i) that is located in a county in which the percentage increase in the population during the most recent 5-year period for which data are available is estimated to be at least 150 percent of the percentage increase in the population growth of the State in which the hospital is located during that period, as estimated by Bureau of the Census and available to the Secretary; "(ii) whose annual percent of total inpatient admissions that represent inpatient admissions under the program under title $\mathrm{XIX}$ is estimated to be equal to or greater than the average percent with respect to such admissions for all hospitals located in the county in which the hospital is located; "(iii) that does not discriminate against beneficiaries of Federal health care programs and does not permit physicians practicing at the hospital to discriminate against such beneficiaries;

"(iv) that is located in a State in which the average bed capacity in the 
State is estimated to be less than the national average bed capacity;

"(v) that has an average bed occupancy rate that is estimated to be greater than the average bed occupancy rate in the State in which the hospital is located; and "(vi) that meets other conditions as determined by the Secretary.

"(F) Procedure Rooms.-In this subsection, the term 'procedure rooms' includes rooms in which catheterizations, angiographies, angiograms, and endoscopies are furnished, but such term shall not include emergency rooms or departments (except for rooms in which catheterizations, angiographies, angiograms, and endoscopies are furnished).

"(G) Publication OF Final DECISIONs.-Not later than 120 days after receiving a complete application under this paragraph, the Secretary shall publish on the public Internet website of the Centers for Medicare \& Medicaid Services the final decision with respect to such application.

“(H) Limitation ON REview.-There shall be no administrative or judicial review 
under section 1869 , section 1878 , or otherwise of the exception process under this paragraph, including the establishment of such process, and any determination made under such process.

“(3) Physiclan OWNer OR Investor DEFINED.-For purposes of this subsection and sub8 section $(\mathrm{f})(2)$, the term 'physician owner or investor' 9 means a physician (or an immediate family member 10 of such physician) with a direct or an indirect own11 ership or investment interest in the hospital.

“(4) Patient SAFETy REQUIREMEnt.-In the 13 case of a hospital to which the requirements of para14 graph (1) apply, insofar as the hospital admits a pa15 tient and does not have any physician available on 16 the premises 24 hours per day, 7 days per week, be17 fore admitting the patient-

"(A) the hospital shall disclose such fact to the patient; and

"(B) following such disclosure, the hospital shall receive from the patient a signed acknowledgment that the patient understands such fact. 25 retary from terminating a hospital's provider agree- 
1 ment if the hospital is not in compliance with regu-

2 lations pursuant to section 1866.”.

3 (b) Verifying Compliance.-The Secretary of

4 Health and Human Services shall establish policies and 5 procedures to verify compliance with the requirements de6 scribed in subsections (i)(1) and (i)(4) of section 1877 of

7 the Social Security Act, as added by subsection (a)(5).

8 The Secretary may use unannounced site reviews of hos9 pitals and audits to verify compliance with such require10 ments.

11 (c) Implementation.-

12 (1) Funding.-For purposes of carrying out 13 the amendments made by subsection (a) and the 14 provisions of subsection (b), in addition to funds 15 otherwise available, out of any funds in the Treasury 16 not otherwise appropriated there are appropriated to 17 the Secretary of Health and Human Services for the 18 Centers for Medicare \& Medicaid Services Program 19 Management Account \$5,000,000 for each fiscal 20 year beginning with fiscal year 2010. Amounts ap21 propriated under this paragraph for a fiscal year 22 shall be available until expended.

23 (2) Administration.-Chapter 35 of title 44, 24 United States Code, shall not apply to the amend- 
1 ments made by subsection (a) and the provisions of 2 subsection (b).

3 SEC. 1157. INSTITUTE OF MEDICINE STUDY OF GEOGRAPHIC ADJUSTMENT FACTORS UNDER MEDICARE.

6 (a) In GeneraL.-The Secretary of Health and 7 Human Services shall enter into a contract with the Insti8 tute of Medicine of the National Academy of Science to 9 conduct a comprehensive empirical study, and provide rec10 ommendations as appropriate, on the accuracy of the geo11 graphic adjustment factors established under sections 12 1848(e) and 1886(d)(3)(E) of the Social Security Act (42 13 U.S.C. $1395 \mathrm{w}-4(\mathrm{e}), 1395 \mathrm{ww}(\mathrm{d})(3)(\mathrm{E}))$.

14 (b) MatTers Included._-Such study shall include 15 an evaluation and assessment of the following with respect 16 to such adjustment factors:

17 (1) Empirical validity of the adjustment factors.

18 (2) Methodology used to determine the adjust19 ment factors.

20 (3) Measures used for the adjustment factors, 21 taking into account-

(A) timeliness of data and frequency of revisions to such data;

(B) sources of data and the degree to which such data are representative of costs; and 
(C) operational costs of providers who participate in Medicare.

3 (c) Evaluation.- Such study shall, within the con4 text of the United States health care marketplace, evalu5 ate and consider the following:

6 (1) The effect of the adjustment factors on the 7 level and distribution of the health care workforce 8 and resources, including-

9 (A) recruitment and retention that takes 10 into account workforce mobility between urban 11 and rural areas;

12 (B) ability of hospitals and other facilities 13 to maintain an adequate and skilled workforce; 14 and

(C) patient access to providers and needed 16 medical technologies.

17 (2) The effect of the adjustment factors on pop18 ulation health and quality of care.

19 (3) The effect of the adjustment factors on the 20 ability of providers to furnish efficient, high value 21 care.

22 (d) REPORT.-The contract under subsection (a) 23 shall provide for the Institute of Medicine to submit, not 24 later than 1 year after the date of the enactment of this 25 Act, to the Secretary and the Congress a report containing 
1 results and recommendations of the study conducted

2 under this section.

3 (e) Funding.-There are authorized to be appro4 priated to carry out this section such sums as may be nec5 essary.

6 SEC. 1158. REVISION OF MEDICARE PAYMENT SYSTEMS TO ADDRESS GEOGRAPHIC INEQUITIES.

8 (a) Revision of Medicare Payment Systems.9 Taking into account the recommendations described in the 10 report under section 1157, and notwithstanding the geo11 graphic adjustments that would otherwise apply under sec12 tion $1848(\mathrm{e})$ and section $1886(\mathrm{~d})(3)(\mathrm{E})$ of the Social Se13 curity Act (42 U.S.C. 1395w-4(e), 1395ww(d)(3)(E)), the

14 Secretary of Health and Human Services shall include in 15 proposed rules applicable to the rulemaking cycle for pay16 ment systems for physicians' services and inpatient hos17 pital services under sections 1848 and section $1886(d)$ of 18 such Act, respectively, proposals (as the Secretary deter19 mines to be appropriate) to revise the geographic adjust20 ment factors used in such systems. Such proposals' rules 21 shall be contained in the next rulemaking cycle following 22 the submission to the Secretary of the report described 23 in section 1157.

24 (b) Payment Adjustments.- 
(1) Funding For Improvements.-For years

2 before 2014, the Secretary shall ensure that the ad-

3 ditional expenditures resulting from the implementa-

4 tion of the provisions of this section, as estimated by

5 the Secretary, do not exceed $\$ 8,000,000,000$, and do

6 not exceed half of such amount in any payment year.

7 (2) HOLD HARMLEss. - In carrying out this

8 subsection-

9

10

11

12

13

14

15

16

17

18

19

20

21

22

23

24

25
(A) for payment years before 2014, the Secretary shall not reduce the geographic adjustment below the factor that applied for such payment system in the payment year before such changes; and

(B) for payment years beginning with 2014, the Secretary shall implement the geographic adjustment in a manner that does not result in any net change in aggregate expenditures under title XVIII of the Social Security Act from the amount of such expenditures that the Secretary estimates would have occurred if no geographic adjustment had occurred under this section.

(c) Medicare Improvement Fund.-

(1) Amounts in the Medicare Improvement Fund under section 1898 of the Social Security Act, 
1 as amended by paragraph (2), shall be available to 2 the Secretary to make changes to the geographic ad3 justments factors as described in subsections (a) and

4 (b) with respect to services furnished before January 5 1, 2014. No more than one-half of such amounts 6 shall be available with respect to services furnished 7 in any one payment year.

8 (2) Section 1898(b) of the Social Security Act 9 (42 U.S.C. $1395 \mathrm{iii}(\mathrm{b}))$ is amended-

10 (A) by amending paragraph (1)(A) to read 11 as follows:

"(A) the period beginning with fiscal year 2011 and ending with fiscal year 2019, $\$ 8,000,000,000 ;$ and"; and

(B) by adding at the end the following new paragraph:

18 fiscal year 2014 or a subsequent fiscal year specified 19 by the Secretary, the amount available to the fund 20 under subsection (a) shall be increased by the Sec21 retary's estimate of the amount (based on data on 22 actual expenditures) by which-

"(A) the additional expenditures resulting 24 from the implementation of subsection (a) of 25 section 1158 of the Affordable Health Care for 
America Act for the period before fiscal year 2014 , is less than

"(B) the maximum amount of funds available under subsection (a) of such section for funding for such expenditures.".

6 SEC. 1159. INSTITUTE OF MEDICINE STUDY OF GEOGRAPHIC VARIATION IN HEALTH CARE SPENDING AND PROMOTING HIGH-VALUE HEALTH CARE.

10 (a) In GeneraL.-The Secretary of Health and

11 Human Services (in this section and the succeeding sec12 tion referred to as the "Secretary") shall enter into an 13 agreement with the Institute of Medicine of the National 14 Academies (referred to in this section as the "Institute") 15 to conduct a study on geographic variation and growth 16 in volume and intensity of services in per capita health 17 care spending among the Medicare, Medicaid, privately in18 sured and uninsured populations. Such study may draw 19 on recent relevant reports of the Institute and shall in20 clude each of the following:

(1) An evaluation of the extent and range of 22 such variation using various units of geographic 23 measurement, including micro areas within larger 24 areas. 
1 (2) An evaluation of the extent to which geo2 graphic variation can be attributed to differences in 3 input prices; health status; practice patterns; access 4 to medical services; supply of medical services; socio5 economic factors, including race, ethnicity, gender, 6 age, income and educational status; and provider $7 \quad$ and payer organizational models.

8 (3) An evaluation of the extent to which vari9 ations in spending are correlated with patient access 10 to care, insurance status, distribution of health care 11 resources, health care outcomes, and consensus12 based measures of health care quality.

13 (4) An evaluation of the extent to which vari14 ation can be attributed to physician and practitioner 15 discretion in making treatment decisions, and the 16 degree to which discretionary treatment decisions 17 are made that could be characterized as different 18 from the best available medical evidence.

19 (5) An evaluation of the extent to which vari20 ation can be attributed to patient preferences and 21 patient compliance with treatment protocols.

22 (6) An assessment of the degree to which vari23 ation cannot be explained by empirical evidence.

24 (7) For Medicare beneficiaries, An evaluation of 25 the extent to which variations in spending are cor- 
1 related with insurance status prior to enrollment in

2 the Medicare program under title XVIII of the So-

3 cial Security Act, and institutionalization status;

4 whether beneficiaries are dually eligible for the

5 Medicare program and Medicaid under title XIX of

6 such Act; and whether beneficiaries are enrolled in

7 fee-for-service Medicare or Medicare Advantage.

8 (8) An evaluation of such other factors as the

$9 \quad$ Institute deems appropriate.

10 The Institute shall conduct public hearings and provide

11 an opportunity for comments prior to completion of the

12 reports under subsection (e).

13 (b) Recommendations.-Taking into account the

14 findings under subsection (a) and the changes to the pay-

15 ment systems made by this Act, the Institute shall rec-

16 ommend changes to payment for items and services under

17 parts $\mathrm{A}$ and $\mathrm{B}$ of title XVIII of the Social Security Act,

18 for addressing variation in Medicare per capita spending

19 for items and services (not including add-ons for graduate

20 medical education, disproportionate share payments, and

21 health information technology, as specified in sections

$221886(\mathrm{~d})(5)(\mathrm{F}), \quad 1886(\mathrm{~d})(5)(\mathrm{B}), \quad 1886(\mathrm{~h}), \quad 1848(\mathrm{o})$, and

23 1886(n), respectively, of such Act) by promoting high-

24 value care (as defined in subsection (f)), with particular

25 attention to high-volume, high-cost conditions. In making 
1 such recommendations, the Institute shall consider each 2 of the following:

(1) Measurement and reporting on quality and 4 population health.

(2) Reducing fragmented and duplicative care.

6 (3) Promoting the practice of evidence-based 7 medicine.

8 (4) Empowering patients to make value-based 9 care decisions.

10 (5) Leveraging the use of health information 11 technology.

12 (6) The role of financial and other incentives 13 affecting provision of care.

$14 \quad$ (7) Variation in input costs.

15 (8) The characteristies of the patient popu16 lation, including socio-economic factors (including 17 race, ethnicity, gender, age, income and educational 18 status), and whether the beneficiaries are dually eli19 gible for the Medicare program under title XVIII of 20 the Social Security Act and Medicaid under title 21 XIX of such Act.

22 (9) Other topies the Institute deems appro23 priate.

24 In making such recommendations, the Institute shall con25 sider an appropriate phase-in that takes into account the 
1 impact of payment changes on providers and facilities and

2 preserves access to care for Medicare beneficiaries.

3 (c) SPECIFIC Considerations.-In making the rec4 ommendations under subsection (b), the Institute shall 5 specifically address whether payment systems under title 6 XVIII of the Social Security Act for physicians and hos7 pitals should be further modified to incentivize high-value 8 care. In so doing, the Institute shall consider the adoption 9 of a value index based on a composite of appropriate meas10 ures of quality and cost that would adjust provider pay11 ments on a regional or provider-level basis. If the Institute 12 finds that application of such a value index would signifi13 cantly incentivize providers to furnish high-value care, it 14 shall make specific recommendations on how such an 15 index would be designed and implemented. In so doing, 16 it should identify specific measures of quality and cost ap17 propriate for use in such an index, and include a thorough 18 analysis (including on a geographic basis) of how pay19 ments and spending under such title would be affected by 20 such an index.

21 (d) Additional Considerations.-The Institute 22 shall consider the experience of governmental and commu23 nity-based programs that promote high-value care.

24 (e) REPORTS.- 
(1) Not later than April 15, 2011, the Institute

2 shall submit to the Secretary and each House of

3 Congress a report containing findings and rec-

4 ommendations of the study conducted under this

5 section.

6 (2) Following submission of the report under

7 paragraph (1), the Institute shall use the data col-

8 lected and analyzed in this section to issue a subse-

9 quent report, or series of reports, on how best to ad-

10 dress geographic variation or efforts to promote

11 high-value care for items and services reimbursed by

12 private insurance or other programs. Such reports

13 shall include a comparison to the Institute's findings

14 and recommendations regarding the Medicare pro-

15 gram. Such reports, and any recommendations,

16 would not be subject to the procedures outlined in 17 section 1160 .

18 (f) High-value Care Defined.-For purposes of 19 this section, the term "high-value care" means the effi20 cient delivery of high quality, evidence-based, patient-cen21 tered care.

22 (g) Appropriations.-There is appropriated from 23 amounts in the general fund of the Treasury not otherwise 24 appropriated $\$ 10,000,000$ to carry out this section. Such 25 sums are authorized to remain available until expended. 
1 SEC. 1160. IMPLEMENTATION, AND CONGRESSIONAL REVIEW, OF PROPOSAL TO REVISE MEDICARE PAYMENTS TO PROMOTE HIGH VALUE HEALTH CARE.

(a) Preparation And Submission of Implemen-

6 TAtion Plans.-

(1) Final implementation Plan.-Not later

8 than 240 days after the date of receipt by the Sec-

9 retary and each House of Congress of the report

10 under section $1159(\mathrm{e})(1)$, the Secretary shall submit

11 to each House of Congress a final implementation

12 plan describing proposed changes to payment for

13 items and services under parts $\mathrm{A}$ and $\mathrm{B}$ of title

14 XVIII of the Social Security Act (which may include

15 payment for inpatient and outpatient hospital serv-

16 ices for services furnished in PPS and PPS-exempt

17 hospitals, physicians' services, dialysis facility serv-

18 ices, skilled nursing facility services, home health

19 services, hospice care, clinical laboratory services,

20 durable medical equipment, and other items and

21 services, but which shall exclude add-on payments

22 for graduate medical education, disproportionate

23 share payments, and health information technology, 24 as specified in sections $1886(\mathrm{~d})(5)(\mathrm{F})$, $251886(\mathrm{~d})(5)(\mathrm{B}), 1886(\mathrm{~h}), 1848(\mathrm{o})$, and $1886(\mathrm{n})$, re26 spectively, of the Social Security Act) taking into 
1 consideration, as appropriate, the recommendations

2 of the report submitted under section 1159(e)(1)

3 and the changes to the payment systems made by

4 this Act. To the extent such implementation plan re-

5 quires a substantial change to the payment system,

6 it shall include a transition phase-in that takes into

7 consideration possible disruption to provider partici-

8 pation in the Medicare program under title XVIII of

9 the Social Security Act and preserves access to care

10 for Medicare beneficiaries.

11 (2) Preliminary implementation Plan.-

12 Not later than 90 days after the date the Institute

13 of Medicine submits to each House of Congress the

14 report under section 1159(e)(1), the Secretary shall

15 submit to each House of Congress a preliminary

16 version of the implementation plan provided for

17 under paragraph (1)(A).

18 (3) No INCREASE IN BUdGET EXPENDI-

19 TURES.-The Secretary shall include with the sub-

20 mission of the final implementation plan under para-

21 graph (1) a certification by the Chief Actuary of the

22 Centers for Medicare \& Medicaid Services that over

23 the initial 10-year period in which the plan is imple-

24 mented, the aggregate level of net expenditures

25 under the Medicare program under title XVIII of 
1 the Social Security Act will not exceed the aggregate

2 level of such expenditures that would have occurred

3 if the plan were not implemented.

4 (4) WAIVERS REQUIRED.-To the extent the

5 final implementation plan under paragraph (1) pro-

6 poses changes that are not otherwise permitted

7 under title XVIII of the Social Security Act, the

8 Secretary shall specify in the plan the specific waiv-

9 ers required under such title to implement such

10 changes. Except as provided in subsection (c), the

11 Secretary is authorized to waive the requirements so

12 specified in order to implement such changes.

13 (5) Assessment OF IMPACT.-In addition,

14 both the preliminary and final implementation plans

15 under this subsection shall include a detailed assess-

16 ment of the effects of the proposed payment changes

17 by provider or supplier type and State relative to the 18 payments that would otherwise apply.

19 (b) Review by MedPAC and GAO.-Not later than 2045 days after the date the preliminary implementation 21 plan is received by each House of Congress under sub22 section (a)(2), the Medicare Payment Advisory Committee 23 and the Comptroller General of the United States shall 24 each evaluate such plan and submit to each House of Con25 gress a report containing its analysis and recommenda- 
1 tions regarding implementation of the plan, including an

2 analysis of the effects of the proposed changes in the plan

3 on payments and projected spending.

4 (c) Implementation.-

5 (1) In GenERAL.-The Secretary shall include,

6 in applicable proposed rules for the next rulemaking

7 cycle beginning after the Congressional action dead-

8 line, appropriate proposals to revise payments under

9 title XVIII of the Social Security Act in accordance

10 with the final implementation plan submitted under

11 subsection (a)(1), and the waivers specified in sub-

12 section (a)(4) to the extent required to carry out

13 such plan are effective, unless a joint resolution (de-

14 scribed in subsection $(\mathrm{d})(5)(\mathrm{A}))$ with respect to such

15 plan is enacted by not later than such deadline. If

16 such a joint resolution is enacted, the Secretary is

17 not authorized to implement such plan and the waiv-

18 er authority provided under subsection (a)(4) shall

19 no longer be effective.

20 (2) Congressional aCtion deadine.-For

21 purposes of this section, the term "Congressional ac-

22 tion deadline" means, with respect to a final imple-

23 mentation plan under subsection (a)(1), May 31,

242012 , or, if later, the date that is 145 days after the 
1 date of receipt of such plan by each House of Con-

2 gress under subsection (a).

3 (d) Congressional Procedures.-

4 (1) Introduction.-On the day on which the 5 final implementation plan is received by the House 6 of Representatives and the Senate under subsection 7 (a), a joint resolution specified in paragraph (5)(A) 8 shall be introduced in the House of Representatives 9 by the majority leader and minority leader of the 10 House of Representatives and in the Senate by the 11 majority leader and minority leader of the Senate. If 12 either House is not in session on the day on which 13 such a plan is received, the joint resolution with re14 spect to such plan shall be introduced in that House, 15 as provided in the preceding sentence, on the first 16 day thereafter on which that House is in session.

17 (2) Consideration in the house of ReP18 RESENTATIVES.-

(A) Reporting and Discharge.-Any committee of the House of Representatives to which a joint resolution introduced under paragraph (1) is referred shall report such joint resolution to the House not later than 50 legislative days after the applicable date of introduc25 tion of the joint resolution. If a committee fails 
to report such joint resolution within that period, a motion to discharge the committee from further consideration of the joint resolution shall be in order. Such a motion shall be in order only at a time designated by the Speaker in the legislative schedule within two legislative days after the day on which the proponent announces an intention to offer the motion. Notice may not be given on an anticipatory basis. Such a motion shall not be in order after the last committee authorized to consider the joint resolution reports it to the House or after the House has disposed of a motion to discharge the joint resolution. The previous question shall be considered as ordered on the motion to its adoption without intervening motion except 20 minutes of debate equally divided and controlled by the proponent and an opponent. A motion to reconsider the vote by which the motion is disposed of shall not be in order.

(B) Proceeding to consideration.After each committee authorized to consider a joint resolution reports such joint resolution to the House of Representatives or has been discharged from its consideration, a motion to pro- 
ceed to consider such joint resolution shall be in order. Such a motion shall be in order only at a time designated by the Speaker in the legislative schedule within two legislative days after the day on which the proponent announces an intention to offer the motion. Notice may not be given on an anticipatory basis. Such a motion shall not be in order after the House of Representatives has disposed of a motion to proceed on the joint resolution. The previous question shall be considered as ordered on the motion to its adoption without intervening motion. A motion to reconsider the vote by which the motion is disposed of shall not be in order.

(C) Consideration.-The joint resolution shall be considered in the House and shall be considered as read. All points of order against a joint resolution and against its consideration are waived. The previous question shall be considered as ordered on the joint resolution to its passage without intervening motion except two hours of debate equally divided and controlled by the proponent and an opponent. A motion to reconsider the vote on passage of a joint resolution shall not be in order. 
(3) Consideration in the senate.-

(A) Reporting and Discharge.-Any committee of the Senate to which a joint resolution introduced under paragraph (1) is referred shall report such joint resolution to the Senate within 50 legislative days. If a committee fails to report such joint resolution at the close of the 15th legislative day after its receipt by the Senate, such committee shall be automatically discharged from further consideration of such joint resolution and such joint resolution or joint resolutions shall be placed on the calendar. A vote on final passage of such joint resolution shall be taken in the Senate on or before the close of the second legislative day after such joint resolution is reported by the committee or committees of the Senate to which it was referred, or after such committee or committees have been discharged from further consideration of such joint resolution.

(B) Proceeding to consideration.-A motion in the Senate to proceed to the consideration of a joint resolution shall be privileged and not debatable. An amendment to such a motion shall not be in order, nor shall it be in 
order to move to reconsider the vote by which such a motion is agreed to or disagreed to.

\section{(C) Consideration.-}

(i) Debate in the Senate on a joint resolution, and all debatable motions and appeals in connection therewith, shall be limited to not more than 20 hours. The time shall be equally divided between, and controlled by, the majority leader and the minority leader or their designees.

(ii) Debate in the Senate on any debatable motion or appeal in connection with a joint resolution shall be limited to not more than 1 hour, to be equally divided between, and controlled by, the mover and the manager of the resolution, except that in the event the manager of the joint resolution is in favor of any such motion or appeal, the time in opposition thereto shall be controlled by the minority leader or a designee. Such leaders, or either of them, may, from time under their control on the passage of a joint resolution, allot additional time to any Senator 
during the consideration of any debatable motion or appeal.

(iii) A motion in the Senate to further limit debate is not debatable. A motion to recommit a joint resolution is not in order.

(4) Rules Relating to senate and house

(A) Coordination with aCtion BY OTHER HOUSE.-If, before the passage by one House of a joint resolution of that House, that

(i) The joint resolution of the other House shall not be referred to a committee. House receives from the other House a joint resolution, then the following procedures shall apply:

(ii) With respect to the joint resolution of the House receiving the resolution, the procedure in that House shall be the same as if no such joint resolution had been received from the other House; but the vote on passage shall be on the joint resolution of the other House.

(B) Treatment of companion measURES.-If, following passage of a joint resolu- 
tion in the Senate, the Senate then receives the companion measure from the House of Representatives, the companion measure shall not be debatable.

(C) Rules of house of RepresentaTIVES AND SENATE.-This paragraph and the preceding paragraphs are enacted by Congress-

(i) as an exercise of the rulemaking power of the Senate and House of Representatives, respectively, and as such it is deemed a part of the rules of each House, respectively, but applicable only with respect to the procedure to be followed in that House in the case of a joint resolution, and it supersedes other rules only to the extent that it is inconsistent with such rules; and

(ii) with full recognition of the constitutional right of either House to change the rules (so far as relating to the procedure of that House) at any time, in the same manner, and to the same extent as in the case of any other rule of that House. (5) Definitions.-In this section: 
(A) JOINT RESOLUTION.-The term "joint resolution" means only a joint resolution-

(i) which does not have a preamble;

(ii) the title of which is as follows: "Joint resolution disapproving a Medicare final implementation plan of the Secretary of Health and Human Services submitted under section 1160(a) of the Affordable Health Care for America Act"; and

(iii) the sole matter after the resolving clause of which is as follows: "That the Congress disapproves the final implementation plan of the Secretary of Health and Human Services transmitted to the Congress on-.", the blank space being filled with the appropriate date.

(B) Legislative DaY.-The term "legislative day" means any calendar day excluding any day on which that House was not in session.

(6) Budgetary treatment.-For the purposes of consideration of a joint resolution, the Chairmen of the House of Representatives and Senate Committees on the Budget shall exclude from the evaluation of the budgetary effects of the meas- 
1 ure, any such effects that are directly attributable to

2 disapproving a Medicare final implementation plan

3 of the Secretary submitted under subsection (a).

4 Subtitle D-Medicare Advantage Reforms

6 PART 1-PAYMENT AND ADMINISTRATION

7 SEC. 1161. PHASE-IN OF PAYMENT BASED ON FEE-FORSERVICE COSTS; QUALITY BONUS PAYMENTS.

(a) Phase-in of Payment Based on Fee-For-

10 SERvice Costs.- Section 1853 of the Social Security Act

11 (42 U.S.C. $1395 \mathrm{w}-23$ ) is amended-

(1) in subsection $(\mathrm{j})(1)(\mathrm{A})-$

(A) by striking "beginning with 2007" and inserting "for 2007, 2008, 2009, and 2010"; and

(B) by inserting after "(k)(1)" the following: ", or, beginning with 2011, 1/12 of the blended benchmark amount determined under subsection (n)(1)"; and

(2) by adding at the end the following new sub-

21 section: 
“(1) IN GENERAL.-For purposes of subsection (j), subject to paragraphs (3) and (4), the term

3 'blended benchmark amount' means for an area-

"(A) for 2011 the sum of"(i) $2 / 3$ of the applicable amount (as

23 indirect costs of medical education from capitation 24 rates described in subsection $(\mathrm{k})(4)$. 
“(3) FeE-For-SERvice PAYMent FloOR.-In

2 no case shall the blended benchmark amount for an

3 area and year be less than the amount specified in

4 paragraph (2).

“(4) Exception For PACE Plans.-This sub-

6 section shall not apply to payments to a PACE pro-

7 gram under section 1894.".

8 (b) Quality Bonus Payments.-Section 1853 of

9 the Social Security Act (42 U.S.C. 1395w-23), as amend-

10 ed by subsection (a), is amended-

11 (1) in subsection (j), by inserting "subject to

12 subsection (o)," after "For purposes of this part,";

13 and

14 (2) by adding at the end the following new sub15 section:

16 “(o) Quality Based Payment Adjustment.-

17 "(1) IN GENERAL.-In the case of a qualifying 18 plan in a qualifying county with respect to a year 19 beginning with 2011, the blended benchmark 20 amount under subsection (n)(1) shall be increased-

"(A) for 2011, by 1.5 percent;

"(B) for 2012, by 3.0 percent; and

"(C) for a subsequent year, by 5.0 percent.

25 COUNTY DEFINED.-For purposes of this subsection: 

fying plan' means, for a year and subject to paragraph (4), a plan that, in a preceding year specified by the Secretary, had a quality ranking (based on the quality ranking system established by the Centers for Medicare \& Medicaid Services for Medicare Advantage plans) of 4 stars or higher.

"(B) Qualifying COUNTY.-The term 'qualifying county' means, for a year, a countythird of counties in the amount specified in subsection $(n)(2)$ for a year specified by the Secretary; and

"(ii) for which, as of June of a year specified by the Secretary, of the Medicare Advantage eligible individuals residing in the county at least 20 percent of such individuals were enrolled in Medicare Advantage plans.

“(3) Determinations of quality.-

“(A) Quality Performance.-The Secretary shall provide for the computation of a 
quality performance score for each Medicare Advantage plan to be applied for each year.

"(B) Computation of score.“(i) Quality Performance sore.For years before a year specified by the Secretary, the quality performance score for a Medicare Advantage plan shall be computed based on a blend (as designated by the Secretary) of the plan's performance on-

“(I) HEDIS effectiveness of care quality measures;

"(II) CAHPS quality measures; and

"(III) such other measures of clinical quality as the Secretary may specify.

Such measures shall be risk-adjusted as the Secretary deems appropriate.

“(ii) Establishment of OUTCOMEBASED MEASURES.-By not later than for a year specified by the Secretary, the Secretary shall implement reporting requirements for quality under this section on measures selected under clause (iii) that 
reflect the outcomes of care experienced by individuals enrolled in Medicare Advantage plans (in addition to measures described in clause (i)). Such measures may include-

"(I) measures of rates of admission and readmission to a hospital;

"(II) measures of prevention quality, such as those established by the Agency for Healthcare Research and Quality (that include hospital admission rates for specified conditions); "(III) measures of patient mortality and morbidity following surgery; "(IV) measures of health functioning (such as limitations on activities of daily living) and survival for patients with chronic diseases;

"(V) measures of patient safety; and

"(VI) other measure of outcomes and patient quality of life as determined by the Secretary.

Such measures shall be risk-adjusted as the Secretary deems appropriate. In determining the quality measures to be used 
under this clause, the Secretary shall take into consideration the recommendations of the Medicare Payment Advisory Commission in its report to Congress under section 168 of the Medicare Improvements for Patients and Providers Act of 2008 (Public Law 110-275) and shall provide preference to measures collected on and comparable to measures used in measuring quality under parts $\mathrm{A}$ and $\mathrm{B}$.

“(iii) Rules FOR SELECTION OF MEASURES.-The Secretary shall select measures for purposes of clause (ii) consistent with the following:

“(I) The Secretary shall provide preference to clinical quality measures that have been endorsed by the entity with a contract with the Secretary under section 1890(a).

“(II) Prior to any measure being selected under this clause, the Secretary shall publish in the Federal Register such measure and provide for a period of public comment on such measure. 


\section{7}

"(iv) Transitional USE OF BLEND.—For payments for years specified by the Secretary, the Secretary may compute the quality performance score for a Medicare Advantage plan based on a blend of the measures specified in clause (i) and the measures described in clause (ii) and selected under clause (iii).

“(v) Use OF QUALity OUTCOMES MEASURES.-For payments beginning with a year specified by the Secretary (beginning after the years specified for section (iv)), the preponderance of measures used under this paragraph shall be quality outcomes measures described in clause (ii) and selected under clause (iii).

“(C) Reporting of DATA.-Each Medicare Advantage organization shall provide for the reporting to the Secretary of quality performance data described in this paragraph (in order to determine a quality performance score under this paragraph) in such time and manner as the Secretary shall specify.

“(4) Notification.-The Secretary, in the annual announcement required under subsection 
1 (b)(1)(B) in 2010 and each succeeding year, shall 2 notify the Medicare Advantage organization that is 3 offering a qualifying plan in a qualifying county of 4 such identification for the year. The Secretary shall 5 provide for publication on the website for the Medi6 care program of the information described in the 7 previous sentence.

“(5) Authority TO DISQUALIFY DEFICIENT 9 PLANs. - The Secretary may determine that a Medi10 care Advantage plan is not a qualifying plan if the 11 Secretary has identified deficiencies in the plan's 12 compliance with rules for Medicare Advantage plans 13 under this part.".

14 SEC. 1162. AUTHORITY FOR SECRETARIAL CODING INTENSITY ADJUSTMENT AUTHORITY.

16 Section 1853(a)(1)(C)(ii) of the Social Security Act 17 (42 U.S.C. 1395w-23(a)(1)(C)(ii) is amended-

18 (1) in the matter before subclause (I), by strik19 ing "through 2010" and inserting "and each subse20 quent year"; and

(2) in subclause (II)-

(A) by inserting "periodically" before "conduct an analysis";

25 "are incorporated"; and 
(C) by striking "only for 2008, 2009, and 2010" and inserting "for 2008 and subsequent years".

4 SEC. 1163. SIMPLIFICATION OF ANNUAL BENEFICIARY ELECTION PERIODS.

6 (a) 2 Week Processing Period for Annual En7 Rollment Period (AEP)._-Paragraph (3)(B) of section 8 1851(e) of the Social Security Act (42 U.S.C. 1395w9 21(e)) is amended-

10 (1) by striking "and" at the end of clause (iii);

11 (2) in clause (iv)-

(A) by striking "and succeeding years" and inserting “, 2008, 2009, and 2010”; and (B) by striking the period at the end and inserting "; and"; and ceeding years, the period beginning on November 1 and ending on December 15 of the year before such year.".

22 (b) Elimination of 3-month Additional Open 23 Enrollment Period (OEP).-Effective for plan years 24 beginning with 2011, paragraph (2) of such section is 25 amended by striking subparagraph (C). 
1 SEC. 1164. EXTENSION OF REASONABLE COST CONTRACTS.

2 Section $1876(\mathrm{~h})(5)(\mathrm{C})$ of the Social Security Act (42

3 U.S.C. $1395 \mathrm{~mm}(\mathrm{~h})(5)(\mathrm{C}))$ is amended-

4 (1) in clause (ii), by striking "January 1,

52010 " and inserting "January 1, 2012'; and

6 (2) in clause (iii), by striking "the service area

7 for the year" and inserting "the portion of the

8 plan's service area for the year that is within the

9 service area of a reasonable cost reimbursement con-

10 tract".

11 SEC. 1165. LIMITATION OF WAIVER AUTHORITY FOR EM-

PLOYER GROUP PLANS.

13 (a) IN GENERAL. - The first sentence of each of para-

14 graphs (1) and (2) of section 1857(i) of the Social Secu-

15 rity Act (42 U.S.C. $1395 \mathrm{w}-27(\mathrm{i})$ ) is amended by inserting

16 before the period at the end the following: ", but only if

1790 percent of the Medicare Advantage eligible individuals

18 enrolled under such plan reside in a county in which the

19 MA organization offers an MA local plan".

20 (b) EFFECTIVE DATE.-The amendment made by

21 subsection (a) shall apply for plan years beginning on or

22 after January 1, 2011, and shall not apply to plans which

23 were in effect as of December 31, 2010.

24 SEC. 1166. IMPROVING RISK ADJUSTMENT FOR PAYMENTS.

25 (a) REPort To Congress.-Not later than 1 year

26 after the date of the enactment of this Act, the Secretary 
1 of Health and Human Services shall submit to Congress

2 a report that evaluates the adequacy of the risk adjust3 ment system under section 1853(a)(1)(C) of the Social Se4 curity Act (42 U.S.C. 1395-23(a)(1)(C)) in predicting

5 costs for beneficiaries with chronic or co-morbid condi6 tions, beneficiaries dually-eligible for Medicare and Med7 icaid, and non-Medicaid eligible low-income beneficiaries; 8 and the need and feasibility of including further grada9 tions of diseases or conditions and multiple years of bene10 ficiary data.

11 (b) Improvements to Risk Adjustment.-Not

12 later than January 1, 2012, the Secretary shall implement

13 necessary improvements to the risk adjustment system

14 under section 1853(a)(1)(C) of the Social Security Act (42

15 U.S.C. 1395-23(a)(1)(C)), taking into account the evalua-

16 tion under subsection (a).

17 SEC. 1167. ELIMINATION OF MA REGIONAL PLAN STABILIZATION FUND.

19 (a) In GenerAL.-Section 1858 of the Social Secu20 rity Act (42 U.S.C. 1395w-27a) is amended by striking 21 subsection (e).

22 (b) Transition.-Any amount contained in the MA 23 Regional Plan Stabilization Fund as of the date of the 24 enactment of this Act shall be transferred to the Federal 25 Supplementary Medical Insurance Trust Fund. 
1 SEC. 1168. STUDY REGARDING THE EFFECTS OF CALCU-

LATING MEDICARE ADVANTAGE PAYMENT RATES ON A REGIONAL AVERAGE OF MEDICARE FEE FOR SERVICE RATES.

5 (a) In GeneraL._-The Administrator of the Centers 6 for Medicare and Medicaid Services shall conduct a study 7 to determine the potential effects of calculating Medicare 8 Advantage payment rates on a more aggregated geo9 graphic basis (such as metropolitan statistical areas or 10 other regional delineations) rather than using county 11 boundaries. In conducting such study, the Administrator

12 shall consider the effect of such alternative geographic 13 basis on the following:

14 (1) The quality of care received by Medicare $15 \quad$ Advantage enrollees.

16 (2) The networks of Medicare Advantage plans, 17 including any implications for providers contracting 18 with Medicare Advantage plans.

19 (3) The predictability of benchmark amounts 20 for Medicare advantage plans.

21 (b) Consultations.-In conducting the study, the 22 Administrator shall consult with the following:

(1) Experts in health care financing.

(2) Representatives of foundations and other 25 nonprofit entities that have conducted or supported 26 research on Medicare financing issues. 
1 (3) Representatives from Medicare Advantage

2 plans.

3 (4) Such other entities or people as determined

4 by the Secretary.

5 (c) REPORT.-Not later than one year after the date 6 of the enactment of this Act, the Administrator shall 7 transmit a report to the Congress on the study conducted 8 under this section. The report shall contain a detailed 9 statement of findings and conclusions of the study, to10 gether with its recommendations for such legislation and 11 administrative actions as the Administrator considers ap12 propriate.

\section{PART 2-BENEFICIARY PROTECTIONS AND ANTI-} FRAUD

15 SEC. 1171. LIMITATION ON COST-SHARING FOR INDIVIDUAL HEALTH SERVICES.

17 (a) In GeneraL.-Section 1852(a)(1) of the Social 18 Security Act (42 U.S.C. 1395w-22(a)(1)) is amended-

(1) in subparagraph (A), by inserting before the 20 period at the end the following: "with cost-sharing 21 that is no greater (and may be less) than the cost22 sharing that would otherwise be imposed under such 23 program option"; 
(2) in subparagraph (B)(i), by striking "or an

2 actuarially equivalent level of cost-sharing as deter-

3 mined in this part"; and

(3) by amending clause (ii) of subparagraph

5 (B) to read as follows:

“(ii) Permitting use of Flat COPAYMENT OR PER DIEM RATE.-Nothing in clause (i) shall be construed as prohibiting a Medicare Advantage plan from using a flat copayment or per diem rate, in lieu of the cost-sharing that would be imposed under part $\mathrm{A}$ or $\mathrm{B}$, so long as the amount of the cost-sharing imposed does not exceed the amount of the cost-sharing that would be imposed under the respective part if the individual were not enrolled in a plan under this part.".

(b) Limitation for Dual Eligibles and Quali-

19 Fied Medicare Beneficiaries.-Section 1852(a)(7) of 20 such Act is amended to read as follows:

“(7) Limitation on COST-Sharing FOR DUAL 22 ELIGIBLES AND QUALIFIED MedicARe Bene23 FICIARIES.-In the case of a individual who is a full24 benefit dual eligible individual (as defined in section $251935(\mathrm{c})(6))$ or a qualified medicare beneficiary (as 
1 defined in section $1905(\mathrm{p})(1)$ ) who is enrolled in a

2 Medicare Advantage plan, the plan may not impose

3 cost-sharing that exceeds the amount of cost-sharing

4 that would be permitted with respect to the indi-

5 vidual under this title and title XIX if the individual

6 were not enrolled with such plan.".

7 (c) Effective Dates.-

8 (1) The amendments made by subsection (a)

9 shall apply to plan years beginning on or after Janu-

$10 \quad$ ary $1,2011$.

11 (2) The amendments made by subsection (b)

12 shall apply to plan years beginning on or after Janu13 ary $1,2011$.

14 SEC. 1172. CONTINUOUS OPEN ENROLLMENT FOR ENROLLEES IN PLANS WITH ENROLLMENT SUSPENSION.

17 Section 1851(e)(4) of the Social Security Act (42 18 U.S.C. $1395 \mathrm{w}(\mathrm{e})(4))$ is amended-

19 (1) in subparagraph (C), by striking at the end 20 "or";

(2) in subparagraph (D)-

(A) by inserting ", taking into account the 23 health or well-being of the individual" before 24 the period; and 
(B) by redesignating such subparagraph as subparagraph (E); and

(3) by inserting after subparagraph (C) the fol-

4 lowing new subparagraph:

"(D) the individual is enrolled in an MA plan and enrollment in the plan is suspended under paragraph (2)(B) or $(3)(\mathrm{C})$ of section $1857(\mathrm{~g})$ because of a failure of the plan to meet applicable requirements; or'.

10 SEC. 1173. INFORMATION FOR BENEFICIARIES ON MA PLAN ADMINISTRATIVE COSTS.

(a) Disclosure of Medical Loss Ratios and

13 Other Expense Data.-Bection 1851 of the Social Se14 curity Act (42 U.S.C. 1395 w-21), as previously amended 15 by this subtitle, is amended by adding at the end the fol16 lowing new subsection:

17 “(p) Publication of Medical Loss Ratios and 18 Other Cost-RELated Information.-

"(1) In GENERAL.-The Secretary shall pub20 lish, not later than November 1 of each year (begin21 ning with 2011), for each MA plan contract, the 22 medical loss ratio of the plan in the previous year. “(2) Submission of DATA.“(A) IN GENERAL.—Each MA organization 25 shall submit to the Secretary, in a form and 
manner specified by the Secretary, data necessary for the Secretary to publish the medical loss ratio on a timely basis.

"(B) DATA FOR 2010 AND 2011.-The data submitted under subparagraph (A) for 2010 and for 2011 shall be consistent in content with the data reported as part of the MA plan bid in June 2009 for 2010.

“(C) Use of standardized Elements AND DEFINITIONS.-The data to be submitted under subparagraph (A) relating to medical loss ratio for a year, beginning with 2012, shall be submitted based on the standardized elements and definitions developed under paragraph (3). “(3) Development of DATA Reporting STANDARDS.-

"(A) IN GENERAL.—The Secretary shall develop and implement standardized data elements and definitions for reporting under this subsection, for contract years beginning with 2012, of data necessary for the calculation of the medical loss ratio for MA plans. Not later than December 31, 2010, the Secretary shall publish a report describing the elements and definitions so developed. 
$1727(\mathrm{e}))$ is amended by adding at the end the following new 18 paragraph:

“(4) Requirement FOR MINIMUM MediCAL 20 LOSS RATIO.- - If the Secretary determines for a con21 tract year (beginning with 2014) that an MA plan 22 has failed to have a medical loss ratio (as defined in 23 section $1851(\mathrm{p})(4))$ of at least .85-

“(B) Consultation.-The Secretary shall consult with the Health Choices Commissioner, representatives of MA organizations, experts on health plan accounting systems, and representatives of the National Association of Insurance Commissioners, in the development of such data elements and definitions.

“(4) Medical loss ratio to be Defined.For purposes of this part, the term 'medical loss ratio' has the meaning given such term by the Secretary, taking into account the meaning given such term by the Health Choices Commissioner under section 116 of the Affordable Health Care for America Act.".

(b) Minimum Medical Loss Ratio.- Section 857 (e) of the Social Security Act (42 U.S.C. 1395w- 
to give enrollees a rebate (in the second succeeding contract year) of premiums under this part (or part B or part D, if applicable) by such amount as would provide for a benefits ratio of at least .85 ;

"(B) for 3 consecutive contract years, the Secretary shall not permit the enrollment of new enrollees under the plan for coverage during the second succeeding contract year; and "(C) the Secretary shall terminate the plan contract if the plan fails to have such a medical loss ratio for 5 consecutive contract years.".

\section{SEC. 1174. STRENGTHENING AUDIT AUTHORITY.}

(a) For Part C Payments Risk Adjustment.-

15 Section $1857(d)(1)$ of the Social Security Act (42 U.S.C.

$161395 \mathrm{w}-27(\mathrm{~d})(1))$ is amended by inserting after "section 17 1858(c))" the following: ", and data submitted with re18 spect to risk adjustment under section 1853(a)(3)".

19 (b) Enforcement of Audits AND Defi20 CIENCIES.-

(1) In GEneraL.-Section 1857(e) of such Act, 22 as amended by section 1173, is amended by adding 23 at the end the following new paragraph: 
"(A) InFORMATION IN CONTRACT.-The

18 this section shall take effect on the date of the enactment

19 of this Act and shall apply to audits and activities con20 ducted for contract years beginning on or after January $211,2011$.

\section{SEC. 1175. AUTHORITY TO DENY PLAN BIDS.}

23 (a) In GenERAL.-Section 1854(a)(5) of the Social 24 Security Act (42 U.S.C. 1395w-24(a)(5)) is amended by 25 adding at the end the following new subparagraph: 
"(C) REJECTION OF BIDS.-Nothing in this section shall be construed as requiring the Secretary to accept any or every bid by an MA organization under this subsection.".

5 (b) Application Under Part D.-Section 1860D6 11(d) of such Act (42 U.S.C. 1395w-111(d)) is amended

7 by adding at the end the following new paragraph:

“(3) REjection OF BIDS.-Paragraph (5)(C)

9 of section 1854(a) shall apply with respect to bids

10 under this section in the same manner as it applies 11 to bids by an MA organization under such section.".

12 (c) EFFEctive Date.-The amendments made by 13 this section shall apply to bids for contract years begin14 ning on or after January 1, 2011.

15 SEC. 1175A. STATE AUTHORITY TO ENFORCE STANDARDIZED MARKETING REQUIREMENTS.

17 Section $1856(b)(3)$ of the Social Security Act (42 18 U.S.C. $1395 \mathrm{w}-26(\mathrm{~b})(3))$ is amended-

(1) by striking "The standards" and inserting

20 "(A) IN GENERAL.-The standards" with appro21 priate indentation that is the same as for the sub22 paragraph (B) added by paragraph (2); and

23 (2) by adding at the end the following new sub24 paragraph: 
"(B) ENFORCEMENT OF FEDERAL STAND-

\section{ARDS PERMITTED.-}

"(i) IN GENERAL.-Subject to the subsequent provision of this subparagraph, nothing in this title shall be construed to prohibit a State from conducting a market conduct examination or from imposing civil monetary penalties, in accordance with laws and procedures of the State, against Medicare Advantage organizations, PDP sponsors, or agents or brokers of such organizations or sponsors for violations of the marketing requirements under subsections (h)(4), (h)(6), and (j) of section 1851 and section $1857(\mathrm{~g})(1)(\mathrm{E})$.

“(ii) Additional Remedies ResultING FROM FEDERAL-STATE COOPERATION.-

"(I) State ReCommendATION.-A State may recommend to the Secretary the imposition of an intermediate sanction not described in clause (i) (such as those available under section $1857(\mathrm{~g}))$ against a Medicare Advantage organization, 
PDP sponsor, or agent or broker of such an organization or sponsor for a violation described in such clause.

"(II) Response TO RECOMMENDATION.-Not later than 30 days after receipt of a recommendation under subclause (I) from a State, with respect to a violation described in clause (i), the Secretary shall respond in writing to the State indicating the progress of any investigation involving such violation, whether the Secretary intends to pursue the recommendation from the State, and in the case the Secretary does not intend to pursue such recommendation, the reason for such decision.

“(iii) NON-DUplication OF PENALTIES.-In the case that an action has been initiated against a Medicare Advantage organization, PDP sponsor, or agent or broker of such an organization or sponsor for a violation of a marketing requirement under subsection (h)(4), (h)(6), or (j) of section 1851 or section $1857(\mathrm{~g})(1)(\mathrm{E})$ - 
"(I) in the case such action has been initiated by the Secretary, no State may bring an action under such applicable subsection or section against such organization, sponsor, agent, or broker with respect to such violation during the pendency period of the action initiated by the Secretary and, if a penalty is imposed pursuant to such action, after such period; and

"(II) in the case such action has been initiated by a State, the Secretary may not bring an action under such applicable subsection or section against such organization, sponsor, agent, or broker with respect to such violation during the pendency period of the action initiated by the Secretary and, if a penalty is imposed pursuant to such action, after such period.

Nothing in this clause shall be construed as limiting the ability of the Secretary to impose any sanction other than a civil 
monetary penalty under section 1857

against a Medicare Advantage organization, PDP sponsor, or agent or broker of such an organization or sponsor for a violation described in clause (i). this subparagraph shall be construed as affecting any State authority to regulate brokers described in this paragraph or any other conduct of a Medicare Advantage organization or PDP sponsor.".

\section{PART 3-TREATMENT OF SPECIAL NEEDS PLANS}

13 SEC. 1176. LIMITATION ON ENROLLMENT OUTSIDE OPEN ENROLLMENT PERIOD OF INDIVIDUALS INTO CHRONIC CARE SPECIALIZED MA PLANS FOR SPECIAL NEEDS INDIVIDUALS.

17 Section $1859(\mathrm{f})(4)$ of the Social Security Act (42 18 U.S.C. $1395 \mathrm{w}-28(\mathrm{f})(4))$ is amended by adding at the end 19 the following new subparagraph:

"(C) The plan does not enroll an individual on or after January 1, 2011, other than-

“(i) during an annual, coordinated open enrollment period; or "(ii) during a special election period consisting of the period for which the indi- 
20 Security Act (42 U.S.C. 1395w-28(f)(1)) is amended by 21 striking "January 1, 2011" and inserting "January 1, 222013 (or January 1, 2016, in the case of a plan described 23 in section 1177(b)(1) of the Affordable Health Care for 24 America Act)". 
(1) Plans Described.-For purposes of Sec-

2 tion $1859(f)(1)$ of the Social Security Act (42

3 U.S.C. $1395 \mathrm{w}-28(\mathrm{f})(1)$ ), a plan described in this

4 paragraph is a Medicare Advantage dual eligible spe-

5 cial needs plan that-

6 (A) whose sponsoring Medicare Advantage organization, as of the date enactment of the contract with a State Medicaid Agency that participated in the "Demonstrations Serving Those Dually-Eligible for Medicare and Medicaid" under the Medicare program; and

(B) that has been approved by the Centers for Medicare \& Medicaid Services as a dual eligible special needs plan and that offers integrated Medicare and Medicaid services under a contract with the State Medicaid agency.

(2) Analysis; REPORT.-

(A) Analysis.-The Secretary of Health and Human Services shall provide, through a contract with an independent health services evaluation organization, for an analysis of the plans described in paragraph (1) with regard to the impact of such plans on cost, quality of care, patient satisfaction, and other subjects 
specified by the Secretary. Such report also will identify statutory changes needed to simplify access to needed services, improve coordination of benefits and services and ensure protection for dual eligibles as appropriate.

(B) ReporT.-Not later than December 31, 2011, the Secretary shall submit to the Congress a report on the analysis under subparagraph (A) and shall include in such report such recommendations with regard to the treatment of such plans as the Secretary deems appropriate.

13 (c) Extension of Service Area Moratorium for 14 Certain SNPs.-Section 164(c)(2) of the Medicare Im15 provements for Patients and Providers Act of 2008 is 16 amended by striking "December 31, 2010" and inserting. 17 "December 31, 2012".

18 SEC. 1178. EXTENSION OF MEDICARE SENIOR HOUSING PLANS.

20 Section 1859 of the Social Security Act (42 U.S.C. 21 1395w-28) is amended by adding at the end the following 22 new subsection:

23 "(g) Special Rules for Senior Housing Facil24 ITy Plans.- 
“(1) IN GENERAL.-Notwithstanding any other 2 provision of this part, in the case of a Medicare Ad3 vantage senior housing facility plan described in 4 paragraph (2) and for periods before January 1, 5 2013-

"(A) the service area of such plan may be limited to a senior housing facility in a geographic area;

"(B) the service area of such plan may not be expanded; and

"(C) additional senior housing facilities may not be serviced by such plan.

“(2) Medicare advantage senior housing FACILITY PLAN DESCRIBED.-For purposes of this subsection, a Medicare Advantage senior housing facility plan is a Medicare Advantage plan that-

"(A)(i) restricts enrollment of individuals under this part to individuals who reside in a continuing care retirement community (as defined in section 1852(l)(4)(B));

“(ii) provides primary care services onsite and has a ratio of accessible providers to beneficiaries that the Secretary determines is adequate, taking into consideration the number of residents onsite, the health needs of those resi- 
dents, and the accessibility of providers offsite;

and

“(iii) provides transportation services for beneficiaries to providers outside of the facility; and

"(B) is offered by a Medicare Advantage organization that has offered at least 1 plan described in subparagraph (A) for at least 1 year prior to January 1, 2010, under a demonstration project established by the Secretary.".

\section{SEC. 1181. ELIMINATION OF COVERAGE GAP.}

(a) Immediate Reduction in Coverage Gap in

15 2010.- Section 1860D-2(b) of the Social Security Act 16 (42 U.S.C. $1395 \mathrm{w}-102(\mathrm{~b})$ ) is amended-

(1) in paragraph (3)(A), by striking "paragraph

20 paragraph:

“(7) InCREase in INItTal COVERAGE Limit IN ning during 2010, the initial coverage limit de- 
scribed in paragraph (3)(B) otherwise applica-

ble shall be increased by $\$ 500$.

“(B) Application.-In applying subpara-

"(i) except as otherwise provided in

this subparagraph, there shall be no change in the premiums, bids, or any other parameters under this part or part $\mathrm{C}$;

"(ii) costs that would be treated as incurred costs for purposes of applying paragraph (4) but for the application of subparagraph (A) shall continue to be treated as incurred costs;

"(iii) the Secretary shall establish procedures, which may include a reconciliation process, to fully reimburse PDP sponsors with respect to prescription drug plans and MA organizations with respect to MA-PD plans for the reduction in beneficiary cost sharing associated with the application of subparagraph (A);

"(iv) the Secretary shall develop an estimate of the additional increased costs attributable to the application of this paragraph for increased drug utilization and fi- 
17 2011.-Section 1860D-2(b) of such Act (42 U.S.C.

18 1395w-102(b)) as amended by subsection (a), is further 19 amended-

nancing and administrative costs and shall use such estimate to adjust payments to PDP sponsors with respect to prescription drug plans under this part and MA organizations with respect to MA-PD plans under part $\mathrm{C}$; and "(v) the Secretary shall establish procedures for retroactive reimbursement of part D eligible individuals who are covered under such a plan for costs which are incurred before the date of initial implementation of subparagraph (A) and which would be reimbursed under such a plan if such implementation occurred as of January 1, 2010.'”.

(b) Additional Closure in Gap Beginning IN 
(3) by adding at the end the following new

2 paragraph:

“(8) Phased-in Elimination of Coverage

"(A) In GeneraL.-For each year beginning with 2011, the Secretary shall consistent with this paragraph progressively increase the initial coverage limit (described in subsection (b)(3)) and decrease the annual out-of-pocket threshold from the amounts otherwise computed until, beginning in 2019 , there is a continuation of coverage from the initial coverage limit for expenditures incurred through the total amount of expenditures at which benefits are available under paragraph (4).

"(B) INCREASE IN INITLAL COVERAGE

“(i) In GENERAL.—For a year beginning with 2011, subject to clause (ii), the initial coverage limit otherwise computed without regard to this paragraph shall be increased by the cumulative ICL phase-in percentage (as defined in clause (iii) for the year) times the out-of-pocket gap 
amount (as defined in subparagraph (D))

for the year.

“(ii) MaintenanCE OF 2010 Initial

COVERAGE LIMIT LEVEL.-If for a year the

initial coverage limit otherwise computed

under this paragraph would be less than the initial coverage limit applied during 2010, taking into account paragraph (7), the initial coverage limit for that year shall be such initial coverage limit as so applied during 2010.

\section{"(iii) Cumulative Phase-IN PER-} CENTAGE.-

"(I) IN GENERAL._For purposes of this paragraph, subject to subclause (II), the term 'cumulative ICL phase-in percentage' means for a year the sum of the annual ICL phase-in percentage (as defined in clause (iv)) for the year and the annual ICL phase-in percentages for each previous year beginning with 2011.

"(II) LIMITATION.-If the sum of the cumulative ICL phase-in percentage and the cumulative OPT 
phase-in percentage (as defined in subparagraph (C)(iii)) for a year would otherwise exceed 100 percent, each such percentage shall be reduced in a proportional amount so the sum does not exceed 100 percent. "(iv) ANNUAL ICL PHASE-IN PERCENTAGE.-For purposes of this paragraph, the term 'annual ICL phase-in percentage' means-

“(I) for 2011, 8.25 percent;

“(II) for 2012, 2013, and 2014, 4.5 percent;

“(III) for 2015 and 2016, 6 percent;

“(IV) for 2017, 7.5 percent;

"(V) for 2018, 8 percent; and

"(VI) for 2019, 8 percent, or such other percent as may be necessary to provide for a full continuation of coverage as described in subparagraph $(\mathrm{A})$ in that year.

“(C) DECREASE IN ANNUAL OUT-OF-POCKET THRESHOLD.- 
“(i) In GENERAL.—For a year beginning with 2011, subject to clause (ii), the annual out-of-pocket threshold otherwise computed without regard to this paragraph shall be decreased by the cumulative OPT phase-in percentage (as defined in clause (iii) for the year) of the out-of-pocket gap amount for the year multiplied by 1.75 .

“(ii) Maintenance.-The Secretary shall adjust the annual out-of-pocket essary to ensure that the sum of the initial coverage limit described in subparagraph (A) and the out-of-pocket gap amount (defined in subparagraph (D)), as determined for the year pursuant to the provisions of this paragraph for such year, does not exceed such sum that would have applied if this paragraph did not apply.

"(iii) Cumulative OPT Phase-IN PERCENTAGE.-For purposes of this paragraph, subject to subparagraph (B)(iii)(II), the term 'cumulative OPT phase-in percentage' means for a year the sum of the annual OPT phase-in percentage (as de- 
fined in clause (iv)) for the year and the annual OPT phase-in percentages for each previous year beginning with 2011.

“(iv) AnNual OPT Phase-IN PERCENTAGE.-For purposes of this paragraph, the term 'annual OPT phase-in percentage' means-

“(I) for 2011, 0 percent;

“(II) for 2012, 2013, and 2014, 4.5 percent;

“(III) for 2015 and 2016, 6 percent;

“(IV) for 2017, 7.5 percent; and “(V) for 2018 and 2019, 8 percent.

"(D) OUT-OF-POCKET GAP AMOUNT.-For purposes of this paragraph, the term 'out-ofpocket gap amount' means for a year the amount by which-

"(i) the annual out-of-pocket threshold specified in paragraph (4)(B) for the year (as determined as if this paragraph did not apply), exceeds

"(ii) the sum of- 
"(I) the annual deductible under

14 Drug Rebates for Rebate Eligible Individuals.-

16 cial Security Act (42 U.S.C. 1395w-102) is amend17 ed-

24 Rebate Eligible Individuals.-
(A) in subsection (e)(1), in the matter before subparagraph (A), by inserting "and subsection (f)" after "this subsection"; and (B) by adding at the end the following new subsection:

(1) REQUIREMENT.- 
“(A) IN GENERAL.-For plan years beginning on or after January 1, 2011, in this part, the term 'covered part D drug' does not include any drug or biological product that is manufactured by a manufacturer that has not entered into and have in effect a rebate agreement described in paragraph (2).

"(B) 2010 PLAN YEAR REQUIREMENT.Any drug or biological product manufactured by a manufacturer that declines to enter into a rebate agreement described in paragraph (2) for the period beginning on January 1, 2010, and ending on December 31, 2010, shall not be included as a "covered part D drug " for the subsequent plan year.

17 ment under this subsection shall require the manu18 facturer to provide to the Secretary a rebate for 19 each rebate period (as defined in paragraph (6)(B)) 20 ending after December 31, 2009, in the amount 21 specified in paragraph (3) for any covered part D 22 drug of the manufacturer dispensed after December 23 31, 2009, to any rebate eligible individual (as de24 fined in paragraph (6)(A)) for which payment was 25 made by a PDP sponsor under part D or a MA or- 
1 ganization under part $\mathrm{C}$ for such period, including

2 payments passed through the low-income and rein3 surance subsidies under sections 1860D-14 and

4 1860D-15(b), respectively. Such rebate shall be paid

5 by the manufacturer to the Secretary not later than 630 days after the date of receipt of the information 7 described in section $1860 \mathrm{D}-12(\mathrm{~b})(7)$, including as 8 such section is applied under section 1857(f)(3), or 930 days after the receipt of information under sub10 paragraph (D) of paragraph (3), as determined by 11 the Secretary. Insofar as not inconsistent with this 12 subsection, the Secretary shall establish terms and 13 conditions of such agreement relating to compliance, 14 penalties, and program evaluations, investigations, 15 and audits that are similar to the terms and condi16 tions for rebate agreements under paragraphs (3) 17 and (4) of section 1927(b).

18 “(3) REBATE FOR REBATE ELIGIBLE MEDICARE 19 DRUG PLAN ENROLLEES.-

20 "(A) IN GENERAL. - The amount of the re21 bate specified under this paragraph for a manu22 facturer for a rebate period, with respect to 23 each dosage form and strength of any covered 24 part D drug provided by such manufacturer 
and dispensed to a rebate eligible individual, shall be equal to the product of-

"(i) the total number of units of such

dosage form and strength of the drug so

provided and dispensed for which payment

or a MA organization under part $\mathrm{C}$ for the rebate period, including payments passed through the low-income and reinsurance subsidies under sections 1860D-14 and 1860D-15(b), respectively; and "(ii) the amount (if any) by which"(I) the Medicaid rebate amount (as defined in subparagraph (B)) for such form, strength, and period, exceeds

"(II) the average Medicare drug program rebate eligible rebate amount (as defined in subparagraph (C)) for such form, strength, and period.

"(B) Medicaid Rebate amount.-For purposes of this paragraph, the term 'Medicaid rebate amount' means, with respect to each dosage form and strength of a covered part D 
drug provided by the manufacturer for a rebate period-

"(i) in the case of a single source drug or an innovator multiple source drug, the amount specified in paragraph (1)(A)(ii) of section 1927(c) plus the amount, if any, specified in paragraph (2)(A)(ii) of such section, for such form, strength, and period; or "(ii) in the case of any other covered outpatient drug, the amount specified in paragraph (3)(A)(i) of such section for such form, strength, and period.

"(C) Average medicare drug Program REBATE ELIGIBLE REBATE AMOUNT.-For purposes of this subsection, the term 'average Medicare drug program rebate eligible rebate amount' means, with respect to each dosage form and strength of a covered part D drug provided by a manufacturer for a rebate period, the sum, for all PDP sponsors under part D and MA organizations administering a MA-PD plan under part C, of-

"(i) the product, for each such sponsor or organization, of- 
"(I) the sum of all rebates, discounts, or other price concessions (not taking into account any rebate provided under paragraph (2) for such dosage form and strength of the drug dispensed, calculated on a per-unit basis, but only to the extent that any such rebate, discount, or other price concession applies equally to drugs dispensed to rebate eligible Medicare drug plan enrollees and drugs dispensed to PDP and MA-PD enrollees who are not rebate eligible individuals; and

"(II) the number of the units of such dosage and strength of the drug dispensed during the rebate period to rebate eligible individuals enrolled in the prescription drug plans administered by the PDP sponsor or the MAPD plans administered by the MA organization; divided by

"(ii) the total number of units of such dosage and strength of the drug dispensed during the rebate period to rebate eligible 
individuals enrolled in all prescription drug plans administered by PDP sponsors and all MA-PD plans administered by MA organizations.

“(D) Use of Estimates.-The Secretary may establish a methodology for estimating the

23 to rebate agreements under this subsection in the 24 same manner as such paragraph applies to a rebate 25 agreement under such section. 
“(5) OTHER TERMS AND CONDITIONS.-The

2 Secretary shall establish other terms and conditions

3 of the rebate agreement under this subsection, in-

4 cluding terms and conditions related to compliance,

$5 \quad$ that are consistent with this subsection.

6 “(6) Definitions.-In this subsection and sec-

7 tion $1860 \mathrm{D}-12(\mathrm{~b})(7)$ :

8

9

10

11

12

13

14

15

16

17

18

19

20

21

22

23

24

“(A) Rebate eligible individual.-The term 'rebate eligible individual'-

“(i) means a full-benefit dual eligible individual (as defined in section 1935(c)(6)); and “(ii) includes, for drugs dispensed after December 31, 2014, a subsidy eligible individual (as defined in section 1860D-14(a)(3)(A)).

"(B) Rebate PERIOD.-The term 'rebate period' has the meaning given such term in section $1927(\mathrm{k})(8)$.

“(7) WaIVER.—Chapter 35 of title 44, United States Code, shall not apply to the requirements under this subsection for the period beginning on January 1, 2010, and ending on December 31, 2010.". 
(2) Reporting Requirement For the DETERMINATION AND PAYMENT OF REBATES BY MANUFACTURES RELATED TO REBATE FOR REBATE ELIGIBLE MEDICARE DRUG PLAN ENROLLEES.-

(A) REQUiREMENTS FOR PDP SPONSORS.-Section 1860D-12(b) of the Social Security Act (42 U.S.C. 1395w-112(b)) is amended by adding at the end the following new paragraph:

“(7) Reporting ReQUiRement FOR The DETERMINATION AND PAYMENT OF REBATES BY MANUFACTURERS RELATED TO REBATE FOR REBATE ELIGIBLE MEDICARE DRUG PLAN ENROLLEES.-

"(A) IN GENERAL.-For purposes of the rebate under section 1860D-2(f) for contract years beginning on or after January 1, 2011, each contract entered into with a PDP sponsor under this part with respect to a prescription drug plan shall require that the sponsor comply with subparagraphs (B) and (C).

“(B) Report FORM AND CONTENTS.-Not later than a date specified by the Secretary, a PDP sponsor of a prescription drug plan under this part shall report to each manufacturer- 
"(i) information (by National Drug Code number) on the total number of units of each dosage, form, and strength of each drug of such manufacturer dispensed to rebate eligible Medicare drug plan enrollees under any prescription drug plan operated by the PDP sponsor during the rebate period;

"(ii) information on the price discounts, price concessions, and rebates for such drugs for such form, strength, and period;

"(iii) information on the extent to which such price discounts, price concessions, and rebates apply equally to rebate eligible Medicare drug plan enrollees and PDP enrollees who are not rebate eligible Medicare drug plan enrollees; and "(iv) any additional information that the Secretary determines is necessary to enable the Secretary to calculate the average Medicare drug program rebate eligible rebate amount (as defined in paragraph (3)(C) of such section), and to determine the amount of the rebate required under 
this section, for such form, strength, and period.

Such report shall be in a form consistent with a standard reporting format established by the Secretary.

"(C) SubMission to SECRETARY.-Each PDP sponsor shall promptly transmit a copy of the information reported under subparagraph (B) to the Secretary for the purpose of audit oversight and evaluation.

"(D) CONFIDENTIALity OF INFORMATION.-The provisions of subparagraph (D) of section $1927(b)(3)$, relating to confidentiality of information, shall apply to information reported by PDP sponsors under this paragraph in the same manner that such provisions apply to information disclosed by manufacturers or wholesalers under such section, except-

"(i) that any reference to "this section' in clause (i) of such subparagraph shall be treated as being a reference to this section;

"(ii) the reference to the Director of the Congressional Budget Office in clause (iii) of such subparagraph shall be treated 
as including a reference to the Medicare

"(iii) clause (iv) of such subparagraph

shall not apply.

"(E) Oversight.-Information reported

under this paragraph may be used by the Inspector General of the Department of Health and Human Services for the statutorily authorized purposes of audit, investigation, and evaluations.

“(F) Penalties fOR Failure to ProVIDE TIMELY INFORMATION AND PROVISION OF FALSE INFORMATION.-In the case of a PDP

"(i) that fails to provide information required under subparagraph (B) on a sponsortimely basis, the sponsor is subject to a civil money penalty in the amount of $\$ 10,000$ for each day in which such information has not been provided; or

"(ii) that knowingly (as defined in section $1128 \mathrm{~A}(\mathrm{i})$ ) provides false information under such subparagraph, the sponsor is subject to a civil money penalty in an 
amount not to exceed $\$ 100,000$ for each item of false information.

Such civil money penalties are in addition to other penalties as may be prescribed by law. The provisions of section 1128A (other than subsections (a) and (b)) shall apply to a civil money penalty under this subparagraph in the same manner as such provisions apply to a penalty or proceeding under section 1128 A(a).”.

(B) Application to ma organizaTIONS.-Section 1857(f)(3) of the Social Security Act (42 U.S.C. 1395w-27(f)(3)) is amended by adding at the end the following:

“(D) Reporting Requirement Related TO REBATE FOR REBATE ELIGIBLE MEDICARE DRUG Plan ENROLLEES.-Section 1860D12(b)(7).”.

(3) Deposit of Rebates into medicare PRe19 SCRIPTION DRUG ACCOUNT.-Section 1860D-16(c) 20 of such Act (42 U.S.C. 1395w-116(c)) is amended 21 by adding at the end the following new paragraph: “(6) Rebate For Rebate eligible medicare 23 DRUg PLAN EnRolleEs.-Amounts paid under a re24 bate agreement under section 1860D-2(f) shall be 25 deposited into the Account and shall be used to pay 
1 for all or part of the gradual elimination of the cov-

2 erage gap under section 1860D-2(b)(7).".

3 SEC. 1182. DISCOUNTS FOR CERTAIN PART D DRUGS IN ORIGINAL COVERAGE GAP.

5 Section 1860D-2 of the Social Security Act (42 6 U.S.C. 1395w-102), as amended by section 1181, is 7 amended-

(1) in subsection (b)(4)(C)(ii), by inserting $9 \quad$ "subject to subsection (g)(2)(C)," after "(ii)";

10 (2) in subsection (e)(1), in the matter before 11 subparagraph (A), by striking "subsection (f)" and 12 inserting "subsections (f) and (g)" after "this sub13 section"; and

(3) by adding at the end the following new sub15 section:

16 “(g) Requirement for Manufacturer Discount 17 Agreement for Certain Qualifying Drugs.-

"(1) In GENERAL.-In this part, the term 'cov-

19 ered part D drug' does not include any drug or bio20 logical product that is manufactured by a manufac21 turer that has not entered into and have in effect for 22 all qualifying drugs (as defined in paragraph (5)(A)) 23 a discount agreement described in paragraph (2). 


\section{“(A) Periodic Discounts.-A discount} agreement under this paragraph shall require the manufacturer involved to provide, to each PDP sponsor with respect to a prescription drug plan or each MA organization with respect to each MA-PD plan, a discount in an amount specified in paragraph (3) for qualifying drugs (as defined in paragraph $(5)(\mathrm{A})$ ) of the manufacturer dispensed to a qualifying enrollee after January 1, 2010, insofar as the individual is in the original gap in coverage (as defined in paragraph $(5)(\mathrm{E}))$.

"(B) Discount AgReement.-Insofar as not inconsistent with this subsection, the Secretary shall establish terms and conditions of such agreement, including terms and conditions relating to compliance, similar to the terms and conditions for rebate agreements under paragraphs (2), (3), and (4) of section 1927(b), except that-

"(i) discounts shall be applied under this subsection to prescription drug plans and MA-PD plans instead of State plans under title XIX; 
“(ii) PDP sponsors and MA organizations shall be responsible, instead of States, for provision of necessary utilization information to drug manufacturers; and

"(iii) sponsors and MA organizations shall be responsible for reporting information on drug-component negotiated price.

"(C) Counting Discount toward true OUT-OF-POCKET COSTS._-Under the discount agreement, in applying subsection (b)(4), with regard to subparagraph (C)(i) of such subsection, if a qualified enrollee purchases the qualified drug insofar as the enrollee is in an actual gap of coverage (as defined in paragraph $(5)(\mathrm{D}))$, the amount of the discount under the agreement shall be treated and counted as costs incurred by the plan enrollee.

"(3) Discount AMOUnt.-The amount of the 20 discount specified in this paragraph for a discount 21 period for a plan is equal to 50 percent of the 22 amount of the drug-component negotiated price (as 23 defined in paragraph $(5)(\mathrm{C})$ ) for qualifying drugs for 24 the period involved. 
"(4) AdDitional TERMs.-In the case of a dis-

2 count provided under this subsection with respect to

3 a prescription drug plan offered by a PDP sponsor

4 or an MA-PD plan offered by an MA organization,

5 if a qualified enrollee purchases the qualified drug-

6 "(A) insofar as the enrollee is in an actual

7 gap of coverage (as defined in paragraph

8 (5)(D)), the sponsor or plan shall provide the

9 discount to the enrollee at the time the enrollee

10 pays for the drug; and

11 "(B) insofar as the enrollee is in the por-

12 tion of the original gap in coverage (as defined

13 in paragraph $(5)(\mathrm{E}))$ that is not in the actual

14 gap in coverage, the discount shall not be ap-

15 plied against the negotiated price (as defined in

16 subsection $(\mathrm{d})(1)(\mathrm{B}))$ for the purpose of calcu-

$17 \quad$ lating the beneficiary payment.

18 “(5) DEFINITIONs.-In this subsection:

19 "(A) QUALIFYING DRUG.-The term

20 'qualifying drug' means, with respect to a pre-

21 scription drug plan or MA-PD plan, a drug or

22 biological product that-

23 "(i)(I) is a drug produced or distrib-

24 uted under an original new drug applica-

25 tion approved by the Food and Drug Ad- 
ministration, including a drug product marketed by any cross-licensed producers or distributors operating under the new drug application;

"(II) is a drug that was originally marketed under an original new drug application approved by the Food and Drug Administration; or

"(III) is a biological product as approved under Section 351(a) of the Public Health Services Act;

"(ii) is covered under the formulary of the plan or is treated as covered under the formulary of the plan as a result of a coverage determination or appeal under subsection $(\mathrm{g})$ or $(\mathrm{h})$ of section 1860D-4; and "(iii) is dispensed to an individual who is in the original gap in coverage. "(B) Qualifying EnRollee.-The term 'qualifying enrollee' means an individual enrolled in a prescription drug plan or MA-PD plan other than such an individual who is a subsidy-eligible individual (as defined in section 1860D-14(a)(3)). 
“(C) Drug-COMPONENT NEgOtLated PRICE.-The term 'drug-component negotiated price' means, with respect to a qualifying drug, the negotiated price (as defined in section 423.100 of title 42, Code of Federal Regulations, as in effect on the date of enactment of this subsection), as determined without regard to any dispensing fee, of the drug under the prescription drug plan or MA-PD plan involved.

"(D) ACtual gap in COVERage.-The term 'actual gap in coverage' means the gap in prescription drug coverage that occurs between the initial coverage limit (as modified under paragraph (7) and subparagraph (B) of paragraph (8) of subsection (b)) and the annual out-of-pocket threshold (as modified under subparagraph (C) of such subsection).

"(E) Original gaP in COVERage.-The term 'original in gap coverage' means the gap in prescription drug coverage that would occur between the initial coverage limit (described in subsection (b)(3)) and the out-of-pocket threshold (as defined in subsection (b)(4)(B)) if subsections (b)(7) and (b)(8) did not apply. 
"(6) SPectal RUle FOR 2010.-For the period

2 beginning January 1, 2010, and ending December

3 31, 2010, the Secretary may-

"(A) enter into agreements with manufacturers to directly receive the discount amount described in paragraph (3);

"(B) collect the necessary information from prescription drug plans and MA-PD plans to calculate the discount amount described in such paragraph; and

"(C) provide the discount described in such paragraph to beneficiaries as close as practicable after the point of sale. “(7) WAIVER.-Chapter 35 of title 44, United 15 States Code, shall not apply to the requirements 16 under this subsection for the period beginning on 17 January 1, 2010, and ending on December 31, 18 2010.".

19 SEC. 1183. REPEAL OF PROVISION RELATING TO SUBMISSION OF CLAIMS BY PHARMACIES LOCATED IN OR CONTRACTING WITH LONG-TERM CARE FACILITIES.

23 (a) Part D Submission.-Section 1860D-12(b) of 24 the Social Security Act (42 U.S.C. 1395w-112(b)), as 25 amended by section 172(a)(1) of Public Law 110-275, is 
1 amended by striking paragraph (5) and redesignating

2 paragraph (6) and paragraph (7), as added by section

3 1181(c)(2)(A), as paragraph (5) and paragraph (6), re-

4 spectively.

5 (b) Submission to MA-PD Plans.- Section

$61857(f)(3)$ of the Social Security Act (42 U.S.C. 1395w-

7 27(f)(3)), as added by section 171(b) of Public Law 110-

8275 and amended by section 172(a)(2) of such Public Law

9 and section 1181 of this Act, is amended by striking sub-

10 paragraph (B) and redesignating subparagraphs (C) and

11 (D) as subparagraphs (B) and (C) respectively.

12 (c) EfFective Date.-The amendments made by

13 this section shall apply for contract years beginning with

142010.

15 SEC. 1184. INCLUDING COSTS INCURRED BY AIDS DRUG AS-

SISTANCE PROGRAMS AND INDIAN HEALTH SERVICE IN PROVIDING PRESCRIPTION DRUGS TOWARD THE ANNUAL OUT-OF-POCKET THRESHOLD UNDER PART D.

(a) In GeneraL.-Section 1860D-2(b)(4)(C) of the

21 Social Security Act (42 U.S.C. 1395w-102(b)(4)(C)) is 22 amended-

(1) in clause (i), by striking "and" at the end; 
(A) by striking "such costs shall be treated as incurred only if" and inserting "and subject to clause (iii), such costs shall be treated as incurred only if"';

(B) by striking ", under section 1860D14, or under a State Pharmaceutical Assistance Program"; and

(C) by striking the period at the end and inserting "; and"; and

(3) by inserting after clause (ii) the following new clause:

"(iii) such costs shall be treated as incurred and shall not be considered to be reimbursed under clause (ii) if such costs are borne or paid-

"(I) under section 1860D-14;

“(II) under a State Pharmaceutical Assistance Program;

"(III) by the Indian Health Service, an Indian tribe or tribal organization, or an urban Indian organization (as defined in section 4 of the Indian Health Care Improvement Act); or "(IV) under an AIDS Drug Assistance Program under part B of 
3 (b) EFFECTive Date.-The amendments made by 4 subsection (a) shall apply to costs incurred on or after 5 January 1, 2011.

6 SEC. 1185. NO MID-YEAR FORMULARY CHANGES PERMITTED.

8 (a) In GENERAL.-Section 1860D-4(b)(3)(E) of the 9 Social Security Act (42 U.S.C. 1395w-104(b)(3)(E)) is 10 amended-

(1) in the heading, by inserting "; CERTAIN 12 FORMULARY CHANGES ONLY BEFORE INITLATING 13 MARKETING FOR A PLAN YEAR" after "STATUS OF 14 DRUG';

(2) by striking "Any removal" and inserting 16 "(i) NOTICE.-Any removal" with the same indenta17 tion as the clause added by paragraph (2); (3) by adding at the end the following new 19 clause:

"(ii) Certain Changes in ForMULARY ONLY BEFORE INITIATING MARKETING FOR A PLAN YEAR.-Any removal of a covered part D drug from a formulary used by a PDP sponsor of a prescription 25 drug plan (or MA organization of a MA- 
PD plan) or any other material change to the formulary so as to reduce the coverage (or increase the cost-sharing) of the drug under the plan for a plan year shall take effect by a date specified by the Secretary but no later than the start of plan marketing activities for the plan year. In addition to any exceptions to the previous sentence specified by the Secretary, the previous sentence shall not apply in the case that a drug is removed from the formulary of a plan because of a recall or withdrawal of the drug issued by the Food and Drug Administration, because the drug is replaced with a generic drug that is a therapeutic equivalent, or because of utilization management applied to-

"(I) a drug whose labeling includes a boxed warning required by the Food and Drug Administration under section 201.57(c)(1) of title 21, Code of Federal Regulations (or a successor regulation); or

“(II) a drug required under subsection (c)(2) of section 505-1 of the 
Federal Food, Drug, and Cosmetic Act to have a Risk Evaluation and Management Strategy that includes elements under subsection (f) of such section.".

6 (b) EFFective Date.-The amendments made by 7 subsection (a) shall apply to contract years beginning on 8 or after January 1, 2011.

9 SEC. 1186. NEGOTIATION OF LOWER COVERED PART D DRUG PRICES ON BEHALF OF MEDICARE BENEFICIARIES.

12 (a) Negotiation by Secretary.-Section 1860D1311 of the Social Security Act (42 U.S.C. 1395w-111) is 14 amended by striking subsection (i) (relating to noninter15 ference) and inserting the following: “(i) Negotiation of Lower Drug Prices.“(1) IN GENERAL.-Notwithstanding any other 18 provision of law, the Secretary shall negotiate with 19 pharmaceutical manufacturers the prices (including 20 discounts, rebates, and other price concessions) that 21 may be charged to PDP sponsors and MA organiza22 tions for covered part D drugs for part D eligible in23 dividuals who are enrolled under a prescription drug 24 plan or under an MA-PD plan. 
583

“(2) No Change IN RUles FOR

FORMULARIES.-

"(A) IN GENERAL.—Nothing in paragraph

(1) shall be construed to authorize the Secretary to establish or require a particular formulary.

"(B) Construction.-Subparagraph (A) shall not be construed as affecting the Secretary's authority to ensure appropriate and adequate access to covered part D drugs under prescription drug plans and under MA-PD plans, including compliance of such plans with formulary requirements under section 1860D$4(b)(3)$.

"(3) Construction.-Nothing in this subsection shall be construed as preventing the sponsor of a prescription drug plan, or an organization offering an MA-PD plan, from obtaining a discount or reduction of the price for a covered part D drug below the price negotiated under paragraph (1).

“(4) Annual Reports to COngress.-Not later than June 1, 2011, and annually thereafter, the Secretary shall submit to the Committees on Ways and Means, Energy and Commerce, and Oversight and Government Reform of the House of Rep- 
1 resentatives and the Committee on Finance of the

2 Senate a report on negotiations conducted by the

3 Secretary to achieve lower prices for Medicare bene-

4 ficiaries, and the prices and price discounts achieved

5 by the Secretary as a result of such negotiations.".

6 (b) EFFEctive Date.-The amendment made by

7 subsection (a) shall take effect on the date of the enact-

8 ment of this Act and shall first apply to negotiations and

9 prices for plan years beginning on January 1, 2011.

10 SEC. 1187. ACCURATE DISPENSING IN LONG-TERM CARE

12 Section $1860 D-4(c)$ of the Social Security Act (42

13 U.S.C. $1395 \mathrm{w}-104(\mathrm{c})$ ) is amended by adding at the end

14 the following new paragraph:

“(3) Reduction of wasteful dispensing."(A) In GENERAL.—For plan years beginning on or after January 1, 2012, a PDP sponsor offering a prescription drug plan and MA organization offering a MA-PD plan under part $\mathrm{C}$ shall have in place the utilization management techniques established under subparagraph (B).

“(B) Requirements.-The Secretary shall establish utilization management techniques, such as daily, weekly, or automated 
1 dose dispensing, to apply to PDP sponsors and

2 MA organizations to reduce the quantities of 3 covered part D drugs dispensed to enrollees 4 who are residing in long-term care facilities in order to reduce waste associated with unused medications.

"(C) Consultation.-In establishing the requirements under subparagraph $(\mathrm{A})$, the Secretary shall consult with the Administrator of

10 the Environmental Protection Agency, Adminis11 trator of the Food and Drug Administration, 12 Administrator of the Drug Enforcement Admin13 istration, State Boards of Pharmacy, pharmacy 14 and physician organizations, and other appro15 priate stakeholders to study and determine ad16 ditional methods for prescription drug plans to 17 reduce waste associated with unused prescrip18 tion drugs.".

\section{SEC. 1188. FREE GENERIC FILL.}

(a) In GeneraL.-Section 1128A(i)(6) of the Social 21 Security Act (42 U.S.C. 1320a-7a(i)(6)) is amended-

23 and all that follows and inserting "of 1996;"; 
(2) in the first subparagraph (D), by striking

2 "promulgated" and all that follows and inserting 3 "promulgated;";

4 (3) by redesignating the second subparagraph

5 (D) as a subparagraph (E) and by striking the pe6 riod at the end of such subparagraph and inserting 7 "; and"; and

8 (4) by adding at the end the following new sub9 paragraph:

10 "(F) with regard to a prescription drug 11 plan offered by a PDP sponsor or an MA-PD 12 plan offered by an MA organization, a reduc13 tion in or waiver of the copayment amount 14 under the plan given to an individual to induce 15 the individual to switch to a generic, bioequiva16 lent drug, or biosimilar.".

17 (b) EFFective Date.-The amendments made by 18 this subsection shall take effect on the date of the enact19 ment of this Act and shall first apply with respect to remu20 neration offered, paid, solicited, or received on or after 21 January 1, 2011. 
SEC. 1189. STATE CERTIFICATION PRIOR TO WAIVER OF LI-

(a) In General.-Section 1860D-12(c) of the So-

5 cial Security Act (42 U.S.C. $1395 \mathrm{w}-112(\mathrm{c})$ ) is amended-

(1) in paragraph (1)(A), by striking "In the case" and inserting "Subject to paragraph (5), in

8 the case"; and

(2) by adding at the end the following new paragraph:

“(5) State CerTification REQUiRed.-

"(A) In GEneraL.—Except as provided in section 1860D-21(f)(4), the Secretary may only grant a waiver under paragraph $(1)(\mathrm{A})$ if the

Secretary has received a certification from the State insurance commissioner that the prescription drug plan has a substantially complete application pending in the State.

“(B) Revocation of WaIVER UPON FindING OF FRAUD AND ABUSE.-The Secretary shall revoke a waiver granted under paragraph (1)(A) if the State insurance commissioner submits a certification to the Secretary that the recipient of such a waiver-

"(i) has committed fraud or abuse with respect to such waiver; 
"(ii) has failed to make a good faith

ments; or

"(iii) was determined ineligible for licensure by the State.".

6 (b) Exception FOR PACE Programs.-Section 7 1860D-21(f) of such Act (42 U.S.C. $1395 \mathrm{w}-131(\mathrm{f})$ ) is 8 amended-

9

10

11

17 of licensure under certain circumstances) shall apply 18 without regard to paragraph (5) of such section in 19 the case of a PACE program that elects to provide 20 qualified prescription drug coverage to a part D eli21 gible individual who is enrolled under such pro22 gram.".

23 (b) EFFEctive Date.-The amendments made by 24 this section shall apply with respect to plan years begin25 ning on or after January 1, 2010. 


\section{Subtitle F-Medicare Rural Access Protections}

3 SEC. 1191. TELEHEALTH EXPANSION AND ENHANCEMENTS.

(a) Additional Telehealth Site.-

(1) In generaL.-Paragraph (4)(C)(ii) of sec-

$7 \quad 1395 \mathrm{~m}(\mathrm{~m}))$ is amended by adding at the end the fol-

8 lowing new subclause:

(2) Effective Date.-The amendment made

11 by paragraph (1) shall apply to services furnished on 12 or after January 1, 2011.

13 (b) Telehealth Advisory Committee.-

(1) Establishment.-Section 1868 of the Social Security Act (42 U.S.C. 1395ee) is amended-

(A) in the heading, by adding at the end the following: "TELEHEALTH ADVISORY COMMITTEE"; and

(B) by adding at the end the following new subsection: “(c) Telehealth Advisory Committee.“(1) In GENERAL.—The Secretary shall appoint a Telehealth Advisory Committee (in this subsection referred to as the 'Advisory Committee') to make recommendations to the Secretary on policies of the 
1 Centers for Medicare \& Medicaid Services regarding

2 telehealth services as established under section

$3 \quad 1834(\mathrm{~m})$, including the appropriate addition or dele-

4 tion of services (and HCPCS codes) to those speci-

5 fied in paragraphs $(4)(\mathrm{F})(\mathrm{i})$ and $(4)(\mathrm{F})(\mathrm{ii})$ of such

6 section and for authorized payment under paragraph

$7 \quad$ (1) of such section.

8

9

10

11

12

13

14

15

16

17

18

19

20

21

22

23

24
“(2) Membership; Terms.-

"(A) Membership.-

“(i) IN GENERAL.-The Advisory Committee shall be composed of 9 members, to be appointed by the Secretary, of whom-

"(I) 5 shall be practicing physicians;

"(II) 2 shall be practicing nonphysician health care practitioners; and

"(III) 2 shall be administrators of telehealth programs.

“(ii) REQUIREMENTS FOR APPOINTING MEMBERS.-In appointing members of the Advisory Committee, the Secretary shall- 
"(I) ensure that each member has prior experience with the practice of telemedicine or telehealth;

"(II) give preference to individuals who are currently providing telemedicine or telehealth services or who are involved in telemedicine or telehealth programs;

"(III) ensure that the membership of the Advisory Committee represents a balance of specialties and geographic regions; and

"(IV) take into account the recommendations of stakeholders.

"(B) Terms.- The members of the Advisory Committee shall serve for such term as the Secretary may specify.

"(C) Conflicts of interest.-An advisory committee member may not participate with respect to a particular matter considered in an advisory committee meeting if such member (or an immediate family member of such member) has a financial interest that could be affected by the advice given to the Secretary with respect to such matter. 
“(3) Meetings.—The Advisory Committee

2 shall meet twice each calendar year and at such

3 other times as the Secretary may provide.

4 “(4) Permanent Committee.-Section 14 of

5 the Federal Advisory Committee Act (5 U.S.C.

6 App.) shall not apply to the Advisory Committee."

(2) Following Recommendations.-Section

$8 \quad 1834(\mathrm{~m})(4)(\mathrm{F})$ of such Act $(42 \quad$ U.S.C.

$9 \quad 1395 \mathrm{~m}(\mathrm{~m})(4)(\mathrm{F}))$ is amended by adding at the end

10 the following new clause:

11

12

13

14

15

16

17

18

19

20

21

22

23

24 “(iii) Recommendations OF THE TELEHEALTH ADVISORY COMMITTEE.-In making determinations under clauses (i) and (ii), the Secretary shall take into account the recommendations of the Telehealth Advisory Committee (established under section 1868(c)) when adding or deleting services (and HCPCS codes) and in establishing policies of the Centers for Medicare \& Medicaid Services regarding the delivery of telehealth services. If the Secretary does not implement such a recommendation, the Secretary shall publish in the Federal Register a statement re- 
garding the reason such recommendation was not implemented."

(3) Waiver of administrative Limita-

4 TION.-The Secretary of Health and Human Serv-

5 ices shall establish the Telehealth Advisory Com-

6 mittee under the amendment made by paragraph (1)

7 notwithstanding any limitation that may apply to

8 the number of advisory committees that may be es-

9 tablished (within the Department of Health and

10 Human Services or otherwise).

11 (c) Hospital Credentialing of Telemedicine

12 Physicians and Practitioners.-

13 (1) In generaL.- - Not later than 60 days after

14 the date of the enactment of this Act, the Secretary

15 of Health and Human Services shall issue guidance

16 for hospitals (as defined in paragraph (4)) to sim-

17 plify requirements regarding compiling practitioner

18 credentials for the purpose of rendering a medical

19 staff privileging decision (under bylaws of the type

20 described in section 1861(e)(3) of the Social Secu-

21 rity Act) for physicians and practitioners (as defined

22 in paragraph (4)) delivering telehealth services that

23 are furnished via a telecommunications system. 
(A) IN GENERAL.-Such guidance shall permit a hospital to accept credentialing packunder Medicare with regard to physicians and practitioners who seek medical staff privileges in the hospital to provide telehealth services via a telecommunications system from a site other than the hospital where the patient is located. (B) Construction.-Nothing in this subsection shall be construed to require a hospital to accept the credentialing package compiled by another facility.

(C) No OVERsight REQUIRED.-If a hospital does accept the credentialing materials prepared by another hospital, the hospital shall not be required to exercise oversight over the other hospital's process for compiling and verifying credentials.

(D) PRivileging._- This paragraph shall only apply to credentialing and does not relieve a hospital from any applicable privileging requirements. 
(3) Construction.-This subsection shall not

2 be construed as limiting the ability of the Secretary

3 to issue additional guidance regarding the require-

4 ments for the compilation of credentials for physi-

5 cians and practitioners not described in paragraph $6 \quad(1)$.

(4) Definitions.-In this subsection:

(A) The term "hospital" has the meaning given such term in subsection (e) of section 1861 of the Social Security Act (42 U.S.C. 1395x) and includes a critical access hospital (as defined in subsection $(\mathrm{mm})(1)$ of such section).

(B) The term "physician" has the meaning given such term in subsection $(r)$ of such section.

(C) The term "practitioner" means a practitioner described in section 1842(b)(18)(C) of the Social Security Act (42 U.S.C. $1395 \mathrm{u}(\mathrm{b})(18)(\mathrm{C}))$.

21 SEC. 1192. EXTENSION OF OUTPATIENT HOLD HARMLESS PROVISION.

23 Section 1833(t)(7)(D)(i) of the Social Security Act 24 (42 U.S.C. 1395l(t)(7)(D)(i)) is amended-

25 (1) in subclause (II)- 
(A) in the first sentence, by striking '“2010" and inserting "2012"; and

(B) in the second sentence, by striking "or 2009” and inserting “, 2009, 2010, or 2011”; and

(2) in subclause (III), by striking "January 1, 2010" and inserting "January 1, 2012".

8 SEC. 1193. EXTENSION OF SECTION 508 HOSPITAL RECLASSIFICATIONS.

10 (a) In GenERAL.-Subsection (a) of section 106 of 11 division B of the Tax Relief and Health Care Act of 2006 12 (42 U.S.C. 1395 note), as amended by section 117 of the 13 Medicare, Medicaid, and SCHIP Extension Act of 2007 14 (Public Law 110-173) and section 124 of the Medicare 15 Improvements for Patients and Providers Act of 2008 16 (Public Law 110-275), is amended by striking "Sep17 tember 30, 2009" and inserting "September 30, 2011". 18 (b) Use of Particular Wage Index for Fiscal 19 YEAR 2010.-For purposes of implementation of the 20 amendment made by subsection (a) for fiscal year 2010, 21 the Secretary shall use the hospital wage index that was 22 promulgated by the Secretary in the Federal Register on 23 August 27, 2009 (74 Fed. Reg. 43754), and any subse24 quent corrections. 
1 SEC. 1194. EXTENSION OF GEOGRAPHIC FLOOR FOR WORK.

2 Section 1848(e)(1)(E) of the Social Security Act (42

3 U.S.C. 1395w-4(e)(1)(E)) is amended by striking "before

4 January 1, 2010" and inserting "before January 1, $52012 \%$.

6 SEC. 1195. EXTENSION OF PAYMENT FOR TECHNICAL COMPONENT OF CERTAIN PHYSICIAN PATHOLOGY SERVICES.

9 Section $542(\mathrm{c})$ of the Medicare, Medicaid, and

10 SCHIP Benefits Improvement and Protection Act of 2000

11 (as enacted into law by section 1(a)(6) of Public Law 106-

12 554), as amended by section 732 of the Medicare Prescrip-

13 tion Drug, Improvement, and Modernization Act of 2003

14 (42 U.S.C. 1395w-4 note), section 104 of division B of

15 the Tax Relief and Health Care Act of 2006 (42 U.S.C.

16 1395w-4 note), section 104 of the Medicare, Medicaid,

17 and SCHIP Extension Act of 2007 (Public Law 110-

18 173), and section 136 of the Medicare Improvements for

19 Patients and Providers Act of 1008 (Public Law 110-

20 275), is amended by striking "and 2009" and inserting 21 '2009, 2010, and 2011".

22 SEC. 1196. EXTENSION OF AMBULANCE ADD-ONS.

23 (a) IN GENERAL.-Section 1834(1)(13) of the Social 24 Security Act (42 U.S.C. 1395m(l)(13)) is amended-

25 (1) in subparagraph $(\mathrm{A})-$ 
(A) in the matter preceding clause (i), by striking "before January 1, 2010" and inserting "before January 1, 2012"; and

(B) in each of clauses (i) and (ii), by striking "before January 1, 2010" and inserting "before January 1, 2012".

(b) Air Ambulance Improvements.-Section

8 146(b)(1) of the Medicare Improvements for Patients and

9 Providers Act of 2008 (Public Law 110-275) is amended

10 by striking "ending on December 31, 2009" and inserting 11 "ending on December 31, 2011".

\section{BENEFICIARY IMPROVEMENTS}

14 Subtitle A-Improving and Simplifying Financial Assistance for Low Income Medicare Beneficiaries

18 SEC. 1201. IMPROVING ASSETS TESTS FOR MEDICARE SAVINGS PROGRAM AND LOW-INCOME SUBSIDY PROGRAM.

(a) Application of Highest level Permitted

22 Under Lis to All Subsidy Eligible Individuals.-

(1) In GENERAL.-Section 1860D-14(a)(1) of 24 the Social Security Act (42 U.S.C. 1395w$25114(\mathrm{a})(1))$ is amended in the matter before subpara- 
1 graph (A), by inserting "(or, beginning with 2012,

2 paragraph $(3)(\mathrm{E}))$ " after "paragraph (3)(D)".

(2) Annual increase in Lis Resource TEST.-Section 1860D-14(a)(3)(E)(i) of such Act (42 U.S.C. $1395 \mathrm{w}-114(\mathrm{a})(3)(\mathrm{E})(\mathrm{i})$ ) is amended-

(A) by striking "and" at the end of subclause (I);

(B) in subclause (II), by inserting "(before 2012)" after "subsequent year";

(C) by striking the period at the end of subclause (II) and inserting a semicolon;

(D) by inserting after subclause (II) the following new subclauses:

“(III) for 2012, $\$ 17,000$ (or $\$ 34,000$ in the case of the combined value of the individual's assets or resources and the assets or resources of the individual's spouse); and "(IV) for a subsequent year, the dollar amounts specified in this subclause (or subclause (III)) for the previous year increased by the annual percentage increase in the consumer price index (all items; U.S. city aver- 
age) as of September of such previous year."; and

(E) in the last sentence, by inserting "or (IV)" after "subclause (II)". such Act (42 U.S.C. $1396 \mathrm{~d}(\mathrm{p})(1)(\mathrm{C})$ ) is amended-

(A) by striking "effective beginning with January 1, 2010" and inserting "effective for the period beginning with January 1, 2010, and ending with December 31, 2011"; and

(B) by inserting before the period at the end the following: "or, effective beginning with January 1, 2012, whose resources (as so determined) do not exceed the maximum resource level applied for the year under subparagraph (E) of section 1860D-14(a)(3) (determined without regard to the life insurance policy exclusion provided under subparagraph (G) of such section) applicable to an individual or to the individual and the individual's spouse (as the case may be)".

24 subsection (a) shall apply to eligibility determinations for 
1 income-related subsidies and medicare cost-sharing fur-

2 nished for periods beginning on or after January 1, 2012.

3 SEC. 1202. ELIMINATION OF PART D COST-SHARING FOR

6 (a) In GENERAL.-Section 1860D-14(a)(1)(D)(i) of

7 the Social Security Act (42 U.S.C. 1395w-

8 114(a)(1)(D)(i)) is amended-

(1) by striking "INstitutionalized INDIVID-

10 UAls.-In" and inserting "Elimination of COST-

11 SHARING FOR CERTAIN FULL-BENEFIT DUAL ELIGI-

12 BLE INDIVIDUALS.-

(2) by adding at the end the following new sub-

16 clause: UALS.-In the case of an individual who is a full-benefit dual eligible individual and with respect to whom there has been a determination that but for the provision of home and community based care (whether under section 1915,1932 , or under a waiver under section 1115) the individual would re- 
quire the level of care provided in a hospital or a nursing facility or inter-

mediate care facility for the mentally retarded the cost of which could be reimbursed under the State plan under title XIX, the elimination of any beneficiary coinsurance described in section 1860D-2(b)(2) (for all amounts through the total amount of expenditures at which benefits are available under section 1860D-2(b)(4)).".

12 (b) EfFective Date.-The amendments made by 13 subsection (a) shall apply to drugs dispensed on or after 14 January 1, 2011.

15 SEC. 1203. ELIMINATING BARRIERS TO ENROLLMENT.

17 Resources Under the Low-Income Subsidy Pro18 GRAM.-

(1) In GENERAL.-Clause (iii) of section 20 1860D-14(a)(3)(E) of the Social Security Act (42 21 U.S.C. $1395 \mathrm{w}-114(\mathrm{a})(3)(\mathrm{E}))$ is amended to read as 22 follows: RESOURCES.-For purposes of applying 25 this section- 
"(I) an individual shall be permitted to apply on the basis of selfcertification of income and resources; and

"(II) matters attested to in the application shall be subject to appropriate methods of verification without the need of the individual to provide additional documentation, except in extraordinary situations as determined by the Commissioner.".

(2) EfFective Date.-The amendment made 13 by paragraph (1) shall apply beginning January 1, 142010.

15 (b) Disclosures to Facilitate Identification 16 of Individuals Likely to Be Ineligible for the 17 Low-Income Assistance Under the Medicare Pre18 scription Drug Program to Assist Social Security 19 Administration's Outreach to Eligible Individ20 UALS.-For provision authorizing disclosure of return in21 formation to facilitate identification of individuals likely 22 to be ineligible for low-income subsidies under Medicare 23 prescription drug program, see section 1801. 
1 SEC. 1204. ENHANCED OVERSIGHT RELATING TO REIMCOME SUBSIDY ENROLLMENT.

4 (a) IN GENERAL. - In the case of a retroactive LIS

5 enrollment beneficiary who is enrolled under a prescription

6 drug plan under part D of title XVIII of the Social Secu-

7 rity Act (or an MA-PD plan under part C of such title),

8 the beneficiary (or any eligible third party) is entitled to

9 reimbursement by the plan for covered drug costs incurred

10 by the beneficiary during the retroactive coverage period

11 of the beneficiary in accordance with subsection (b) and

12 in the case of such a beneficiary described in subsection

$13(\mathrm{c})(4)(\mathrm{A})(\mathrm{i})$, such reimbursement shall be made automati-

14 cally by the plan upon receipt of appropriate notice the

15 beneficiary is eligible for assistance described in such sub-

16 section $(\mathrm{c})(4)(\mathrm{A})(\mathrm{i})$ without further information required

17 to be filed with the plan by the beneficiary.

18 (b) Administrative Requirements Relating to

19 REIMBURSEMENTS.-

20 (1) LINE-ITEM DESCRIPTION.-Each reimburse21 ment made by a prescription drug plan or MA-PD 22 plan under subsection (a) shall include a line-item 23 description of the items for which the reimbursement 24 is made.

(2) Timing of Reimbursements.-A prescrip26 tion drug plan or MA-PD plan must make a reim- 
1 bursement under subsection (a) to a retroactive LIS

2 enrollment beneficiary, with respect to a claim, not

3 later than 45 days after-

(A) in the case of a beneficiary described in subsection (c)(4)(A)(i), the date on which the plan receives notice from the Secretary that the beneficiary is eligible for assistance described in such subsection; or

(B) in the case of a beneficiary described in subsection (c)(4)(A)(ii), the date on which the beneficiary files the claim with the plan.

(3) Reporting Requirement.-For each month beginning with January 2011, each prescription drug plan and each MA-PD plan shall report to the Secretary the following:

(A) The number of claims the plan has readjudicated during the month due to a beneficiary becoming retroactively eligible for subsidies available under section $1860 \mathrm{D}-14$ of the Social Security Act.

(B) The total value of the readjudicated claim amount for the month.

(C) The Medicare Health Insurance Claims Number of beneficiaries for whom claims were readjudicated. 
(D) For the claims described in subparagraphs (A) and (B), an attestation to the Administrator of the Centers for Medicare \& Medicaid Services of the total amount of reimbursement the plan has provided to beneficiaries for premiums and cost-sharing that the beneficiary overpaid for which the plan received payment from the Centers for Medicare \& Medicaid Services.

(c) Definitions.-For purposes of this section:

(1) Covered Drug costs.-The term "cov12 ered drug costs" means, with respect to a retroactive 13 LIS enrollment beneficiary enrolled under a pre14 scription drug plan under part D of title XVIII of 15 the Social Security Act (or an MA-PD plan under 16 part $\mathrm{C}$ of such title), the amount by which-

17 (A) the costs incurred by such beneficiary during the retroactive coverage period of the beneficiary for covered part D drugs, premiums, and cost-sharing under such title; exceeds

(B) such costs that would have been incurred by such beneficiary during such period if the beneficiary had been both enrolled in the plan and recognized by such plan as qualified 25 
under section 1860D-14 of the Social Security Act to which the individual is entitled.

(2) Eligible Third PARTy.-The term "eligi-

4 ble third party" means, with respect to a retroactive

5 LIS enrollment beneficiary, an organization or other 6 third party that is owed payment on behalf of such 7 beneficiary for covered drug costs incurred by such 8 beneficiary during the retroactive coverage period of 9 such beneficiary.

(3) Retroactive coverage PERIod.-The 11 term "retroactive coverage period" means-

(A) with respect to a retroactive LIS enrollment beneficiary described in paragraph (4)(A)(i), the period-

(i) beginning on the effective date of the assistance described in such paragraph for which the individual is eligible; and

(ii) ending on the date the plan effectuates the status of such individual as so eligible; and

(B) with respect to a retroactive LIS enrollment beneficiary described in paragraph (4)(A)(ii), the period-

(i) beginning on the date the individual is both entitled to benefits under 
part A, or enrolled under part B, of title XVIII of the Social Security Act and eligi-

ble for medical assistance under a State plan under title XIX of such Act; and

(ii) ending on the date the plan effec-

(4) Retroactive Lis EnRollminent Bene-

(A) IN GENERAL.-The term "retroactive LIS enrollment beneficiary" means an individual who-

(i) is enrolled in a prescription drug plan under part D of title XVIII of the Social Security Act (or an MA-PD plan under part $\mathrm{C}$ of such title) and subsequently becomes eligible as a full-benefit dual eligible individual (as defined in section $1935(c)(6)$ of such Act), an individual receiving a low-income subsidy under section 1860D-14 of such Act, an individual receiving assistance under the Medicare Savings Program implemented under clauses (i), (iii), and (iv) of section 
1902(a)(10)(E) of such Act, or an individual receiving assistance under the supplemental security income program under section 1611 of such Act; or

(ii) subject to subparagraph (B)(i), is

a full-benefit dual eligible individual (as defined in section 1935(c)(6) of such Act) who is automatically enrolled in such a plan under section 1860D-1(b)(1)(C) of such Act.

(B) EXCEPTION FOR BENEFICIARIES ENROLLED IN RFP PLAN.-

(i) In GENERAL.- In no case shall an individual described in subparagraph (A)(ii) include an individual who is enrolled, pursuant to a RFP contract described in clause (ii), in a prescription drug plan offered by the sponsor of such plan awarded such contract.

(ii) RFP CONTRACT DESCRIBED.The RFP contract described in this section is a contract entered into between the Secretary and a sponsor of a prescription drug plan pursuant to the Centers for Medicare \& Medicaid Services' request for proposals 
issued on February 17, 2009, relating to Medicare part D retroactive coverage for certain low income beneficiaries, or a similar subsequent request for proposals.

5 SEC. 1205. INTELLIGENT ASSIGNMENT IN ENROLLMENT.

6 (a) In GenERAL.-Section 1860D-1(b)(1)(C) of the 7 Social Security Act (42 U.S.C. 1395w-101(b)(1)(C)) is 8 amended by adding after "PDP region" the following: "or

9 through use of an intelligent assignment process that is 10 designed to maximize the access of such individual to nec11 essary prescription drugs while minimizing costs to such 12 individual and to the program under this part to the great13 est extent possible. In the case the Secretary enrolls such 14 individuals through use of an intelligent assignment proc15 ess, such process shall take into account the extent to 16 which prescription drugs necessary for the individual are 17 covered in the case of a PDP sponsor of a prescription 18 drug plan that uses a formulary, the use of prior author19 ization or other restrictions on access to coverage of such 20 prescription drugs by such a sponsor, and the overall qual21 ity of a prescription drug plan as measured by quality rat22 ings established by the Secretary"

23 (b) EFFEctive Date.-The amendment made by 24 subsection (a) shall take effect for contract years begin25 ning with 2012. 
1 SEC. 1206. SPECIAL ENROLLMENT PERIOD AND AUTOMATIC

(a) Special Enrolliment Period.-Section

5 1860D-1(b)(3)(D) of the Social Security Act (42 U.S.C.

$61395 \mathrm{w}-101(\mathrm{~b})(3)(\mathrm{D}))$ is amended to read as follows:

7

“(D) Subsidy Eligible INDividuals.In the case of an individual (as determined by the Secretary) who is determined under subparagraph (B) of section 1860D-14(a)(3) to be a subsidy eligible individual.".

(b) Automatic Enrollment.-Section 1860D1(b)(1) of the Social Security Act (42 U.S.C. 1395w101(b)(1)) is amended by adding at the end the following new subparagraph:

"(D) SPeclal RUle FOR SUbsidy ELIGIBLE INDIVIDUALS.-The process established under subparagraph (A) shall include, in the case of an individual described in section 1860D-1(b)(3)(D) who fails to enroll in a prescription drug plan or an MA-PD plan during the special enrollment established under such section applicable to such individual, the application of the assignment process described in subparagraph (C) to such individual in the same manner as such assignment process ap- 
plies to a part D eligible individual described in such subparagraph (C). Nothing in the previous sentence shall prevent an individual described in such sentence from declining enrollment in a plan determined appropriate by the Secretary (or in the program under this part) or from changing such enrollment.".

8 (c) EfFective Date.-The amendments made by 9 this section shall apply to subsidy determinations made 10 for months beginning with January 2011.

11 SEC. 1207. APPLICATION OF MA PREMIUMS PRIOR TO REBATE AND QUALITY BONUS PAYMENTS IN CALCULATION OF LOW INCOME SUBSIDY BENCHMARK.

(a) In GeneraL.—Section 1860D-14(b)(2)(B)(iii)

16 of the Social Security Act (42 U.S.C. 1395w17 114(b)(2)(B)(iii)) is amended by inserting before the pe18 riod the following: "before the application of the monthly 19 rebate computed under section $1854(\mathrm{~b})(1)(\mathrm{C})(\mathrm{i})$ for that 20 plan and year involved and, in the case of a qualifying 21 plan in a qualifying county, before the application of the 22 increase under section 1853(o) for that plan and year in23 volved". 
1 (b) EFFECTive Date.-The amendment made by 2 subsection (a) shall apply to subsidy determinations made 3 for months beginning with January 2011.

\section{Subtitle B-Reducing Health} Disparities

6 SEC. 1221. ENSURING EFFECTIVE COMMUNICATION IN MEDICARE.

8 (a) Ensuring Effective Communication by the

9 Centers for Medicare \& Medicaid Services.-

(1) Study on MEdicare PAYMents FOR LAN11 GUAGE SERvices.-The Secretary of Health and 12 Human Services shall conduct a study that examines 13 the extent to which Medicare service providers uti14 lize, offer, or make available language services for 15 beneficiaries who are limited English proficient and 16 ways that Medicare should develop payment systems 17 for language services.

(2) Analyses.-The study shall include an analysis of each of the following:

(A) How to develop and structure appropriate payment systems for language services for all Medicare service providers.

(B) The feasibility of adopting a payment methodology for on-site interpreters, including 25 interpreters who work as independent contrac- 
tors and interpreters who work for agencies that provide on-site interpretation, pursuant to which such interpreters could directly bill Medicare for services provided in support of physician office services for an LEP Medicare patient.

(C) The feasibility of Medicare contracting directly with agencies that provide off-site interpretation including telephonic and video interpretation pursuant to which such contractors could directly bill Medicare for the services provided in support of physician office services for an LEP Medicare patient.

(D) The feasibility of modifying the existing Medicare resource-based relative value scale (RBRVS) by using adjustments (such as multipliers or add-ons) when a patient is LEP.

(E) How each of options described in a previous paragraph would be funded and how such funding would affect physician payments, a physician's practice, and beneficiary costsharing.

(F) The extent to which providers under parts A and B of title XVIII of the Social Security Act, MA organizations offering Medicare 
Advantage plans under part $\mathrm{C}$ of such title and PDP sponsors of a prescription drug plan under part D of such title utilize, offer, or make available language services for beneficiaries with limited English proficiency.

$(G)$ The nature and type of language services provided by States under title XIX of the Social Security Act and the extent to which such services could be utilized by beneficiaries and providers under title XVIII of such Act.

(H) The extent to which interpreters and translators providing services to Medicare beneficiaries under title XVIII of such Act are trained or accredited.

(3) Variation in payment system DESCRIBED.-The payment systems described in paragraph (2)(A) may allow variations based upon types of service providers, available delivery methods, and costs for providing language services including such factors as-

(A) the type of language services provided (such as provision of health care or health care related services directly in a non-English language by a bilingual provider or use of an interpreter); 
(B) type of interpretation services provided (such as in-person, telephonic, video interpretation);

(5) EXEMPTION FROM PAPERWORK REDUCTION ACT.-Chapter 35 of title 44, United States Code (commonly known as the "Paperwork Reduction Act" ), shall not apply for purposes of carrying out this subsection.

(6) Authorization of appropriations.The Secretary shall provide for the transfer, from the Federal Supplementary Medical Insurance Trust 
1 Fund under section 1841 of the Social Security Act

2 (42 U.S.C. 1395t) of $\$ 2,000,000$ for purposes of

3 earrying out this subsection.

4 (b) Health Plans.-Section 1857(g)(1) of the So5 cial Security Act (42 U.S.C. $1395 \mathrm{w}-27(\mathrm{~g})(1)$ ) is amend6 ed-

(1) by striking "or" at the end of subparagraph $8 \quad(\mathrm{~F})$;

(2) by adding "or" at the end of subparagraph

$10 \quad(\mathrm{G})$; and

11 (3) by inserting after subparagraph $(G)$ the fol12 lowing new subparagraph:

“(H) fails substantially to provide language services to limited English proficient beneficiaries enrolled in the plan that are required under law;".

17 SEC. 1222. DEMONSTRATION TO PROMOTE ACCESS FOR MEDICARE BENEFICIARIES WITH LIMITED ENGLISH PROFICIENCY BY PROVIDING REIMBURSEMENT FOR CULTURALLY AND LINGUISTICALLY APPROPRIATE SERVICES.

22 (a) In GeneraL.-Not later than 6 months after the 23 date of the completion of the study described in section 24 1221(a) of this Act, the Secretary, acting through the 25 Centers for Medicare \& Medicaid Services and the Center 
1 for Medicare and Medicaid Innovation established under

2 section 1115 A of the Social Security Act (as added by sec-

3 tion 1907) and consistent with the applicable provisions

4 of such section, shall carry out a demonstration program

5 under which the Secretary shall award not fewer than 24

6 3-year grants to eligible Medicare service providers (as de-

7 scribed in subsection $(b)(1))$ to improve effective commu-

8 nication between such providers and Medicare bene-

9 ficiaries who are living in communities where racial and

10 ethnic minorities, including populations that face language

11 barriers, are underserved with respect to such services. In

12 designing and carrying out the demonstration the Sec-

13 retary shall take into consideration the results of the study

14 conducted under section 1221(a) of this Act and adjust,

15 as appropriate, the distribution of grants so as to better

16 target Medicare beneficiaries who are in the greatest need

17 of language services. The Secretary shall not authorize a

18 grant larger than $\$ 500,000$ over three years for any grant-

19 ee.

20 (b) Eligibility; Priority.-

21 (1) Eligibility.-To be eligible to receive a 22 grant under subsection (a) an entity shall-

23 (A) be-

24 (i) a provider of services under part $\mathrm{A}$

25 of title XVIII of the Social Security Act; 
(ii) a service provider under part $B$ of such title;

(iii) a part $\mathrm{C}$ organization offering a

Medicare part $\mathrm{C}$ plan under part $\mathrm{C}$ of such title; or

(iv) a PDP sponsor of a prescription drug plan under part $\mathrm{D}$ of such title; and (B) prepare and submit to the Secretary an application, at such time, in such manner, and accompanied by such additional information as the Secretary may require.

(2) PRIORITY.-

(A) Distribution.-To the extent feasible, in awarding grants under this section, the Secretary shall award-

(i) at least 6 grants to providers of services described in paragraph (1)(A)(i);

(ii) at least 6 grants to service providers described in paragraph (1)(A)(ii);

(iii) at least 6 grants to organizations described in paragraph (1)(A)(iii); and (iv) at least 6 grants to sponsors described in paragraph (1)(A)(iv).

(B) For COMmunity oRganizations.The Secretary shall give priority to applicants 
that have developed partnerships with community organizations or with agencies with experience in language access.

(C) Variation in grantees.-The Secretary shall also ensure that the grantees under this section represent, among other factors-

(i) different types of language services provided and of service providers and organizations under parts A through $\mathrm{D}$ of title XVIII of the Social Security Act;

(ii) variations in languages needed and their frequency of use;

(iii) urban and rural settings;

(iv) at least two geographic regions, as defined by the Secretary; and

(v) at least two large metropolitan statistical areas with diverse populations.

18 (c) UsE OF Funds.-

(1) In GENERAL.-A grantee shall use grant 20 funds received under this section to pay for the pro21 vision of competent language services to Medicare 22 beneficiaries who are limited English proficient. 23 Competent interpreter services may be provided 24 through on-site interpretation, telephonic interpreta25 tion, or video interpretation or direct provision of 
1 health eare or health care related services by a bilin-

2 gual health care provider. A grantee may use bilin3 gual providers, staff, or contract interpreters. A

4 grantee may use grant funds to pay for competent 5 translation services. A grantee may use up to 10 6 percent of the grant funds to pay for administrative 7 costs associated with the provision of competent lan8 guage services and for reporting required under sub9 section (e).

10 (2) Organizations.-Grantees that are part C 11 organizations or PDP sponsors must ensure that 12 their network providers receive at least 50 percent of 13 the grant funds to pay for the provision of com14 petent language services to Medicare beneficiaries 15 who are limited English proficient, including physi16 cians and pharmacies.

17 (3) Determination of PAYMents For lan18 GUAGE SERVICES.-Payments to grantees shall be 19 calculated based on the estimated numbers of lim20 ited English proficient Medicare beneficiaries in a 21 grantee's service area utilizing-

22 (A) data on the numbers of limited 23 English proficient individuals who speak 24 English less than "very well" from the most re25 cently available data from the Bureau of the 
Census or other State-based study the Secretary determines likely to yield accurate data regarding the number of such individuals served by the grantee; or

(B) the grantee's own data if the grantee routinely collects data on Medicare beneficiaries' primary language in a manner determined by the Secretary to yield accurate data and such data shows greater numbers of limited English proficient individuals than the data listed in subparagraph $(\mathrm{A})$.

\section{(4) Limitations.-}

(A) Reporting.-Payments shall only be provided under this section to grantees that report their costs of providing language services as required under subsection (e) and may be modified annually at the discretion of the Secretary. If a grantee fails to provide the reports under such section for the first year of a grant, the Secretary may terminate the grant and solicit applications from new grantees to participate in the subsequent two years of the demonstration program.

(B) Type OF SERVICES.- 
(i) IN GENERAL.-Subject to clause (ii), payments shall be provided under this section only to grantees that utilize competent bilingual staff or competent interpreter or translation services which-

(I) if the grantee operates in a State that has statewide health care interpreter standards, meet the State standards currently in effect; or

(II) if the grantee operates in a State that does not have statewide health care interpreter standards, utilizes competent interpreters who follow the National Council on Interpreting in Health Care's Code of Ethics and Standards of Practice.

(ii) ExEMPTIOns.-The requirements of clause (i) shall not apply-

(I) in the case of a Medicare beneficiary who is limited English proficient (who has been informed in the beneficiary's primary language of the availability of free interpreter and translation services) and who requests the use of family, friends, or other 
persons untrained in interpretation or translation and the grantee documents the request in the beneficiary's record; and

(II) in the case of a medical emergency where the delay directly associated with obtaining a competent interpreter or translation services would jeopardize the health of the patient.

Nothing in clause (ii)(II) shall be construed to exempt emergency rooms or similar entities that regularly provide health care services in medical emergencies from having in place systems to provide competent interpreter and translation services without undue delay.

(d) Assurances.-Grantees under this section 20 (1) ensure that appropriate clinical and support 21 staff receive ongoing education and training in lin22 guistically appropriate service delivery;

23 (2) ensure the linguistic competence of bilingual 24 providers; 
1 (3) offer and provide appropriate language serv2 ices at no additional charge to each patient with lim3 ited English proficiency at all points of contact, in 4 a timely manner during all hours of operation;

(4) notify Medicare beneficiaries of their right 6 to receive language services in their primary lan7 guage;

8 (5) post signage in the languages of the com9 monly encountered group or groups present in the 10 service area of the organization; and (6) ensure that-

(A) primary language data are collected for recipients of language services and are consistent with standards developed under section 1709 (b)(3)(B)(iv) of the Public Health Service Act, as added by section 2402 of this Act, to the extent such standards are available upon the initiation of the demonstration; and

(B) consistent with the privacy protections provided under the regulations promulgated pursuant to section 264(c) of the Health Insurance Portability and Accountability Act of 1996 (42 U.S.C. 1320d-2 note), if the recipient of language services is a minor or is incapacitated, 
1 the primary language of the parent or legal

2 guardian is collected and utilized.

3 (e) Reporting Requirements.-Grantees under

4 this section shall provide the Secretary with reports at the

5 conclusion of the each year of a grant under this section.

6 Each report shall include at least the following informa-

7 tion:

8 (1) The number of Medicare beneficiaries to

9 whom language services are provided.

10 (2) The languages of those Medicare bene-

11 ficiaries.

12 (3) The types of language services provided

13 (such as provision of services directly in non-English

14 language by a bilingual health care provider or use

15 of an interpreter).

16 (4) Type of interpretation (such as in-person, 17 telephonic, or video interpretation).

18 (5) The methods of providing language services 19 (such as staff or contract with external independent 20 contractors or agencies).

21 (6) The length of time for each interpretation 22 encounter.

23 (7) The costs of providing language services 24 (which may be actual or estimated, as determined by 25 the Secretary). 
1 (8) An account of the training or accreditation

2 of bilingual staff, interpreters, or translators pro-

3 viding services under this demonstration.

4 (f) No Cost Sharing.-_Limited English proficient

5 Medicare beneficiaries shall not have to pay cost-sharing 6 or co-pays for language services provided through this

7 demonstration program.

8 (g) Evaluation and Report.-The Secretary shall 9 conduct an evaluation of the demonstration program

10 under this section and shall submit to the appropriate 11 committees of Congress a report not later than 1 year 12 after the completion of the program. The report shall in13 clude the following:

14 (1) An analysis of the patient outcomes and 15 costs of furnishing eare to the limited English pro16 ficient Medicare beneficiaries participating in the 17 project as compared to such outcomes and costs for 18 limited English proficient Medicare beneficiaries not 19 participating.

20 (2) The effect of delivering culturally and lin21 guistically appropriate services on beneficiary aceess 22 to care, utilization of services, efficiency and cost-ef23 fectiveness of health care delivery, patient satisfac24 tion, and select health outcomes. 
1 (3) The extent to which bilingual staff, inter2 preters, and translators providing services under 3 such demonstration were trained or accredited and 4 the nature of accreditation or training needed by 5 type of provider, service, or other category as deter6 mined by the Secretary to ensure the provision of 7 high-quality interpretation, translation, or other lan8 guage services to Medicare beneficiaries if such serv9 ices are expanded pursuant to subsection (c) of sec10 tion 1907 of this Act.

11 (4) Recommendations, if any, regarding the ex12 tension of such project to the entire Medicare pro13 gram.

14 (h) Accreditation or Training for Providers 15 of Interpretation, Translation or Language 16 Services in Medicare.-

17 (1) IN GENERAL.-

(A) Designation of standards.-If the Secretary, pursuant to section 1907 (c) of this Act, expands the model initially developed through the demonstration program under this section, the Secretary shall use the results of the study under section 1221 and the dem25 onstration under this section to designate standards for training or accreditation. The 
Secretary may designate one or more training or accreditation organizations, as appropriate for the nature and type of interpretation and translation services provided to Medicare beneficiaries to ensure that payments are made only for approved services by trained or accredited language services providers.

(B) Alternatives to training or aCCREDITATION.-If the Secretary designates one or more training or accreditation organizations but determines that accreditation is not available in all languages for which payments may be initiated, the Secretary shall provide payments for and accept alternatives to training or accreditation for certain languages, including languages of lesser diffusion. The Secretary must ensure that the alternatives to training or accreditation provide, at a minimum-

(i) a determination that the interpreter is proficient and able to communicate information accurately in both English and in the language for which interpreting is needed; 
(ii) an attestation from the interpreter to comply with and adhere to the role of an interpreter as defined by the National Code of Ethies and National Standards of Practice as published by the National

(iii) an attestation to adhere to HIPAA privacy and security law, as defined in section 3009(a)(2) of the Public Health Service Act, to the same extent as the healthcare provider for whom interpreting is provided.

(C) Modifiers, ADD-ONS, AND OTHER FORMS OF PAYMENT.- If the Secretary decides that modifiers, add-ons, or other forms of payment may be made for the provision of services directly by bilingual providers, the Secretary shall designate standards to ensure the competency of such providers delivering such services in a non-English language.

(2) Consultation with stakeholders AnD CONSIDERATIONS FOR ACCREDITATION OR TRAINING.- 
(A) Consultation.-In designating accreditation or training requirements under this subsection, the Secretary shall consult with patients, providers, organizations that advocate on behalf of limited English proficient individuals, and other individuals or entities determined appropriate by the Secretary.

(B) Considerations.-In designating accreditation or training requirements under this section, the Secretary shall consider, as appropriate-

(i) standards for qualifications of health care interpreters who interpret infrequently encountered languages;

(ii) standards for qualifications of health care interpreters who interpret in languages of lesser diffusion;

(iii) standards for training of interpreters; and

(iv) standards for continuing education of interpreters.

22 (i) General Provisions.-Nothing in this section 23 shall be construed to limit otherwise existing obligations 24 of recipients of Federal financial assistance under title VI 
1 of the Civil Rights Act of 1964 (42 U.S.C. 2000(d) et

2 seq.) or any other statute.

3 (j) ApPRopriations.-There are appropriated to 4 carry out this section, in equal parts from the Federal

5 Hospital Insurance Trust Fund and the Federal Supple6 mentary Medical Insurance Trust Fund, \$16,000,000 for

7 each fiscal year of the demonstration program.

8 SEC. 1223. IOM REPORT ON IMPACT OF LANGUAGE ACCESS SERVICES.

10 (a) In GeneraL.-The Secretary of Health and

11 Human Services shall enter into an arrangement with the

12 Institute of Medicine under which the Institute will pre-

13 pare and publish, not later than 3 years after the date 14 of the enactment of this Act, a report on the impact of 15 language access services on the health and health care of 16 limited English proficient populations.

17 (b) ConTENTs._-Such report shall include-

18 (1) recommendations on the development and 19 implementation of policies and practices by health 20 care organizations and providers for limited English 21 proficient patient populations;

22 (2) a description of the effect of providing lan23 guage access services on quality of health care and 24 access to care and reduced medical error; and 
1 (3) a description of the costs associated with or 2 savings related to provision of language access serv3 ices.

\section{SEC. 1224. DEFINITIONS.}

$5 \quad$ In this subtitle:

6 (1) Bilingual.-The term "bilingual" with re7 spect to an individual means a person who has suffi8 cient degree of proficiency in two languages and can 9 ensure effective communication can occur in both 10 languages.

11 (2) Competent InTERPRETER SERVICES.-The 12 term "competent interpreter services" means a 13 trans-language rendition of a spoken message in 14 which the interpreter comprehends the source lan15 guage and can speak comprehensively in the target 16 language to convey the meaning intended in the 17 source language. The interpreter knows health and 18 health-related terminology and provides accurate in19 terpretations by choosing equivalent expressions that 20 convey the best matching and meaning to the source 21 language and captures, to the greatest possible ex22 tent, all nuances intended in the source message.

23 (3) Competent translation services.-The 24 term "competent translation services" means a 25 trans-language rendition of a written document in 
1 which the translator comprehends the source lan2 guage and can write comprehensively in the target 3 language to convey the meaning intended in the

4 source language. The translator knows health and 5 health-related terminology and provides accurate 6 translations by choosing equivalent expressions that 7 convey the best matching and meaning to the source 8 language and captures, to the greatest possible ex9 tent, all nuances intended in the source document. 10 (4) EFFective COMmunication.-The term 11 "effective communication" means an exchange of in12 formation between the provider of health care or 13 health care-related services and the limited English 14 proficient recipient of such services that enables lim15 ited English proficient individuals to access, under16 stand, and benefit from health care or health care17 related services.

18 (5) INTERPRETING/INTERPRETATION.-The 19 terms "interpreting" and "interpretation" mean the 20 transmission of a spoken message from one language 21 into another, faithfully, accurately, and objectively.

22 (6) Health CARE SERVICES.-The term 23 "health care services" means services that address 24 physical as well as mental health conditions in all 25 care settings. 
(7) Health care-Related services.-The term "health care-related services" means human or

3 social services programs or activities that provide ac4 cess, referrals or links to health care.

(8) Language access.-The term "language 6 access" means the provision of language services to 7 an LEP individual designed to enhance that individ8 ual's access to, understanding of or benefit from 9 health care or health care-related services.

(9) Language services.-The term "lan11 guage services" means provision of health care serv12 ices directly in a non-English language, interpreta13 tion, translation, and non-English signage.

14 (10) Limited English PRoficient.-The 15 term "limited English proficient" or "LEP" with re16 spect to an individual means an individual who 17 speaks a primary language other than English and 18 who cannot speak, read, write or understand the 19 English language at a level that permits the indi20 vidual to effectively communicate with clinical or 21 nonclinical staff at an entity providing health care or 22 health care related services.

23 (11) Medicare BenEFiciary.-The term 24 "Medicare beneficiary" means an individual entitled 
1 to benefits under part A of title XVIII of the Social

2 Security Act or enrolled under part B of such title.

3 (12) Medicare PRogram.-The term "Medi-

4 care program" means the programs under parts A

5 through D of title XVIII of the Social Security Act.

6 (13) SERvice PROVIDER.-The term "service

7 provider" includes all suppliers, providers of services,

8 or entities under contract to provide coverage, items

9 or services under any part of title XVIII of the So-

10 cial Security Act.

Subtitle C-Miscellaneous

13 SEC. 1231. EXTENSION OF THERAPY CAPS EXCEPTIONS PROCESS.

15 Section $1833(\mathrm{~g})(5)$ of the Social Security Act (42 16 U.S.C. $1395 \mathrm{l}(\mathrm{g})(5))$, as amended by section 141 of the 17 Medicare Improvements for Patients and Providers Act of 182008 (Public Law 110-275), is amended by striking "De19 cember 31, 2009" and inserting "December 31, 2011". 
1 SEC. 1232. EXTENDED MONTHS OF COVERAGE OF IMMUNOSUPPRESSIVE DRUGS FOR KIDNEY TRANSPLANT PATIENTS AND OTHER RENAL DIALYSIS PROVISIONS.

(a) Provision of Appropriate Coverage of Im6 munosuppressive Drugs Under the Medicare Pro7 gram for Kidney Transplant Recipients.-

(1) Continued entithement to immuno9 SUPPRESSIVE DRUGS.-

(A) Kidney transplant Recipients.Section $226 \mathrm{~A}(\mathrm{~b})(2)$ of the Social Security Act (42 U.S.C. $426-1(b)(2)$ ) is amended by inserting "(except for coverage of immunosuppressive drugs under section 1861(s)(2)(J))" before “, with the thirty-sixth month".

(B) Application.-Section 1836 of such Act (42 U.S.C. 1395o) is amended-

(i) by striking "Every individual who" and inserting “(a) In GeneraL.—Every individual who"; and

(ii) by adding at the end the following new subsection:

23 “(b) Special Rules Applicable to Indviduals 24 Only Eligible for Coverage of Immunosuppressive 25 Drugs.- 
"(1) IN GENERAL.-In the case of an individual

2 whose eligibility for benefits under this title has

3 ended on or after January 1, 2012, except for the

4 coverage of immunosuppressive drugs by reason of

5 section $226 \mathrm{~A}(\mathrm{~b})(2)$, the following rules shall apply:

6 "(A) The individual shall be deemed to be

enrolled under this part for purposes of receiving coverage of such drugs.

"(B) The individual shall be responsible for providing for payment of the portion of the premium under section 1839 which is not covered under the Medicare savings program (as defined in section $1144(\mathrm{c})(7))$ in order to receive such coverage.

"(C) The provision of such drugs shall be subject to the application of-

"(i) the deductible under section 1833(b); and

"(ii) the coinsurance amount applicable for such drugs (as determined under this part).

"(D) If the individual is an inpatient of a hospital or other entity, the individual is entitled to receive coverage of such drugs under 25 this part. 
“(2) Establishment OF PROCEDURES IN ORDER TO IMPLEMENT COVERAGE.-The Secretary 3 shall establish procedures for-

"(A) identifying individuals that are entitled to coverage of immunosuppressive drugs by reason of section $226 \mathrm{~A}(\mathrm{~b})(2)$; and

"(B) distinguishing such individuals from individuals that are enrolled under this part for the complete package of benefits under this part.'.

(C) TECHNiCAL AMENDMENT TO CORRECT DUPLICATE SUBSECTION DESIGNATION.-Subsection (c) of section $226 \mathrm{~A}$ of such Act (42 U.S.C. 426-1), as added by section 201(a)(3)(D)(ii) of the Social Security Independence and Program Improvements Act of 1994 (Public Law 103-296; 108 Stat. 1497), is redesignated as subsection (d).

(2) EXTENSION OF SECONDARY PAYER REQUIREMENTS FOR ESRD BENEFICIARIES.-Section 1862(b)(1)(C) of such Act (42 U.S.C. $1395 \mathrm{y}(\mathrm{b})(1)(\mathrm{C}))$ is amended by adding at the end 25 date of the enactment of the Affordable Health Care 
1 for America Act, this subparagraph shall be applied

$2 \quad$ without regard to any time limitation.".

3 (b) Medicare Coverage for ESRD Patients.-

4 Section 1881 of such Act is further amended-

(1) in subsection (b)(14)(B)(iii), by inserting “, 6 including oral drugs that are not the oral equivalent 7 of an intravenous drug (such as oral phosphate bind8 ers and calcimimetics)," after "other drugs and 9 biologicals";

(2) in subsection (b)(14)(E)(ii)—

11

12
(A) in the first sentence-

(i) by striking "a one-time election to be excluded from the phase-in" and inserting "an election, with respect to 2011, 2012, or 2013, to be excluded from the phase-in (or the remainder of the phasein)"; and

(ii) by adding before the period at the end the following: "for such year and for each subsequent year during the phase-in described in clause (i)"; and (B) in the second sentence-

(i) by striking "January 1, 2011" and inserting "the first date of such year"; and 
(ii) by inserting "and at a time" after "form and manner"; and

(3) in subsection $(\mathrm{h})(4)(\mathrm{E})$, by striking "lesser" 4 and inserting "greater".

5 SEC. 1233. VOLUNTARY ADVANCE CARE PLANNING CONSULTATION.

7 (a) In GENERAL._-Section 1861 of the Social Secu8 rity Act (42 U.S.C. $1395 \mathrm{x}$ ) is amended-

(1) in subsection $(\mathrm{s})(2)-$

10

(A) by striking "and" at the end of subparagraph (DD);

(B) by adding "and" at the end of subparagraph (EE); and

(C) by adding at the end the following new subparagraph: “(FF) voluntary advance care planning con17 sultation (as defined in subsection (hhh)(1));"; and (2) by adding at the end the following new sub-

19 section:

20 "Voluntary Advance Care Planning Consultation

21 "(hhh)(1) Subject to paragraphs (3) and (4), the 22 term 'voluntary advance care planning consultation' 23 means an optional consultation between the individual and 24 a practitioner described in paragraph (2) regarding ad- 
1 vance care planning. Such consultation may include the

2 following, as specified by the Secretary:

"(A) An explanation by the practitioner of ad-

4 vance care planning, including a review of key ques-

5 tions and considerations, advance directives (includ-

6 ing living wills and durable powers of attorney) and

7 their uses.

8 "(B) An explanation by the practitioner of the

9 role and responsibilities of a health care proxy and

10 of the continuum of end-of-life services and supports

11 available, including palliative care and hospice, and

12 benefits for such services and supports that are

13 available under this title.

14 "(C) An explanation by the practitioner of phy15 sician orders regarding life sustaining treatment or 16 similar orders, in States where such orders or simi17 lar orders exist.

18 "(2) A practitioner described in this paragraph is19 "(A) a physician (as defined in subsection $20 \quad(\mathrm{r})(1))$; and

21 "(B) another health care professional (as speci22 fied by the Secretary and who has the authority 23 under State law to sign orders for life sustaining 24 treatments, such as a nurse practitioner or physician 25 assistant). 
1 “(3) An individual may receive the voluntary advance

2 care planning care planning consultation provided for 3 under this subsection no more than once every 5 years

4 unless there is a significant change in the health or health5 related condition of the individual.

6 "(4) For purposes of this section, the term 'order re7 garding life sustaining treatment' means, with respect to 8 an individual, an actionable medical order relating to the 9 treatment of that individual that effectively communicates

10 the individual's preferences regarding life sustaining treat11 ment, is signed and dated by a practitioner, and is in a 12 form that permits it to be followed by health care profes13 sionals across the continuum of care.".

14 (b) Construction.-The voluntary advance care 15 planning consultation described in section 1861(hhh) of 16 the Social Security Act, as added by subsection (a), shall 17 be completely optional. Nothing in this section shall-

18 (1) require an individual to complete an ad19 vance directive, an order for life sustaining treat20 ment, or other advance care planning document;

21 (2) require an individual to consent to restric22 tions on the amount, duration, or scope of medical 23 benefits an individual is entitled to receive under 24 this title; or 
(3) encourage the promotion of suicide or as-

2 sisted suicide.

3 (c) Payment.-Section 1848(j)(3) of such Act (42 4 U.S.C. $1395 \mathrm{w}-4(\mathrm{j})(3))$ is amended by inserting "(2)(FF)," 5 after "(2)(EE),".

6 (d) Frequency Limitation.-Section 1862(a) of 7 such Act (42 U.S.C. $1395 \mathrm{y}(\mathrm{a})$ ) is amended-

8

9

10

11

12

13

14

15

16

17

18

19

20

21

22

23 this section shall apply to consultations furnished on or 24 after January 1, 2011. 
1 SEC. 1234. PART B SPECIAL ENROLLMENT PERIOD AND FOR TRICARE BENEFICIARIES.

(a) Part B Special Enrollment Period.-

(1) In GENERAL.-Section 1837 of the Social

6 Security Act (42 U.S.C. 1395p) is amended by add-

7 ing at the end the following new subsection:

8 "(l)(1) In the case of any individual who is a covered 9 beneficiary (as defined in section 1072(5) of title 10,

10 United States Code) at the time the individual is entitled

11 to hospital insurance benefits under part A under section

12226 (b) or section $226 \mathrm{~A}$ and who is eligible to enroll but

13 who has elected not to enroll (or to be deemed enrolled)

14 during the individual's initial enrollment period, there

15 shall be a special enrollment period described in paragraph 16 (2).

17 "(2) The special enrollment period described in this 18 paragraph, with respect to an individual, is the 12-month 19 period beginning on the day after the last day of the initial 20 enrollment period of the individual or, if later, the 1221 month period beginning with the month the individual is 22 notified of enrollment under this section.

23 "(3) In the case of an individual who enrolls during 24 the special enrollment period provided under paragraph 25 (1), the coverage period under this part shall begin on the 26 first day of the month in which the individual enrolls or, 
1 at the option of the individual, on the first day of the sec-

2 ond month following the last month of the individual's ini3 tial enrollment period.

4 “(4) The Secretary of Defense shall establish a meth5 od for identifying individuals described in paragraph (1) 6 and providing notice to them of their eligibility for enroll7 ment during the special enrollment period described in 8 paragraph (2).”.

9 (2) EFFECTIVE DATE.-The amendment made 10 by paragraph (1) shall apply to elections made on or 11 after the date of the enactment of this Act.

12 (b) Waiver of Increase of Premium.-

13 (1) In GENERAL.-Section 1839(b) of the So14 cial Security Act (42 U.S.C. $1395 \mathrm{r}(\mathrm{b})$ ) is amended 15 by striking "section 1837(i)(4)" and inserting "sub16 section (i)(4) or (l) of section 1837”.

17 (2) EFFECTIVE DATE.-

18 (A) IN GENERAL.-The amendment made 19 by paragraph (1) shall apply with respect to 20 elections made on or after the date of the en21 actment of this Act.

(B) Rebates for Certain Disabled AND ESRD BENEFICIARIES.-

(i) IN GENERAL.-With respect to premiums for months on or after January 
2005 and before the month of the enactment of this Act, no increase in the premium shall be effected for a month in the case of any individual who is a covered beneficiary (as defined in section 1072(5) of title 10, United States Code) at the time the individual is entitled to hospital insurance benefits under part A of title XVIII of the Social Security Act under section 226 (b) or $226 \mathrm{~A}$ of such Act, and who is eligible to enroll, but who has elected not to enroll (or to be deemed enrolled), during the individual's initial enrollment period, and who enrolls under this part within the 12-month period that begins on the first day of the month after the month of notification of entitlement under this part.

(ii) Consultation with DepartMENT OF DEFEnse.-The Secretary of Health and Human Services shall consult with the Secretary of Defense in identifying individuals described in this paragraph.

(iii) REBates.-The Secretary of Health and Human Services shall establish 
a method for providing rebates of premium increases paid for months on or after January 1, 2005, and before the month of the enactment of this Act for which a penalty was applied and collected.

6 SEC. 1235. EXCEPTION FOR USE OF MORE RECENT TAX

YEAR IN CASE OF GAINS FROM SALE OF PRIMARY RESIDENCE IN COMPUTING PART B INCOME-RELATED PREMIUM.

(a) In GeneraL.-Section 1839(i)(4)(C)(ii)(II) of

11 the Social Security Act (42 U.S.C. 1395r(i)(4)(C)(ii)(II))

12 is amended by inserting "sale of primary residence," after 13 "divorce of such individual,".

14 (b) EFFective Date.-The amendment made by 15 subsection (a) shall apply to premiums and payments for 16 years beginning with 2011.

17 SEC. 1236. DEMONSTRATION PROGRAM ON USE OF PATIENT DECISIONS AIDS.

19 (a) In GeneraL.-The Secretary of Health and 20 Human Services, acting through the Center for Medicare 21 and Medicaid Innovation established under section 1115A 22 of the Social Security Act (as added by section 1907) and 23 consistent with the applicable provisions of such section, 24 shall establish a shared decision making demonstration 25 program (in this subsection referred to as the "program") 
1 under the Medicare program using patient decision aids

2 to meet the objective of improving the understanding by

3 Medicare beneficiaries of their medical treatment options,

4 as compared to comparable Medicare beneficiaries who do

5 not participate in a shared decision making process using 6 patient decision aids.

7 (b) SITES.-

8 (1) EnRoLlment.-The Secretary shall enroll

9 in the program not more than 30 eligible providers

10 who have experience in implementing, and have in-

11 vested in the necessary infrastructure to implement,

12 shared decision making using patient decision aids.

13 (2) APPLiCATION.—An eligible provider seeking

14 to participate in the program shall submit to the

15 Secretary an application at such time and containing

16 such information as the Secretary may require.

17 (3) Preference.-In enrolling eligible pro-

18 viders in the program, the Secretary shall give pref-

19 erence to eligible providers that-

20 (A) have documented experience in using 21 patient decision aids for the conditions identi22 fied by the Secretary and in using shared deci23 sion making;

24 (B) have the necessary information tech25 nology infrastructure to collect the information 
required by the Secretary for reporting pur-

poses; and

(C) are trained in how to use patient decision aids and shared decision making.

(1) In GENERAL.-An eligible provider participating in the program shall routinely schedule Medi-

8 care beneficiaries for a counseling visit after the 9 viewing of such a patient decision aid to answer any 10 questions the beneficiary may have with respect to 11 the medical care of the condition involved and to as12 sist the beneficiary in thinking through how their 13 preferences and concerns relate to their medical 14 care.

(2) Payment FOR Follow-up COUnseling VISIT.- The Secretary shall establish procedures for

17 making payments for such counseling visits provided 18 to Medicare beneficiaries under the program. Such 19 procedures shall provide for the establishment-

(A) of a code (or codes) to represent such services; and

(B) of a single payment amount for such service that includes the professional time of the health care provider and a portion of the reasonable costs of the infrastructure of the eli- 
1 gible provider such as would be made under the

2 applicable payment systems to that provider for

3 similar covered services.

4 (d) Costs of AIDs.-An eligible provider partici5 pating in the program shall be responsible for the costs 6 of selecting, purchasing, and incorporating such patient 7 decision aids into the provider's practice, and reporting 8 data on quality and outcome measures under the program. 9 (e) Funding.-The Secretary shall provide for the 10 transfer from the Federal Supplementary Medical Insur11 ance Trust Fund established under section 1841 of the 12 Social Security Act (42 U.S.C. 1395t) of such funds as 13 are necessary for the costs of carrying out the program.

14 (f) WaIver Authority.-The Secretary may waive 15 such requirements of titles XI and XVIII of the Social 16 Security Act (42 U.S.C. 1301 et seq. and 1395 et seq.) 17 as may be necessary for the purpose of carrying out the 18 program.

19 (g) REPORT.-Not later than 12 months after the 20 date of completion of the program, the Secretary shall sub21 mit to Congress a report on such program, together with 22 recommendations for such legislation and administrative 23 action as the Secretary determines to be appropriate. The 24 final report shall include an evaluation of the impact of 25 the use of the program on health quality, utilization of 
1 health care services, and on improving the quality of life 2 of such beneficiaries.

3 (h) Definitions.-In this section:

4 (1) Eligible PROvider.-The term "eligible 5 provider" means the following:

6

7

8

9

10

11

12

13

14

15

16

17

18

19 23 patients (or, if appropriate, the family caregiver of 24 the patient) understand and communicate their be25 liefs and preferences related to their treatment op-

(A) A primary care practice.

(B) A specialty practice.

(C) A multispecialty group practice.

(D) A hospital.

(E) A rural health clinic.

(F) A Federally qualified health center (as defined in section 1861(aa)(4) of the Social Security Act (42 U.S.C. 1395x(aa)(4)).

(G) An integrated delivery system.

(H) A State cooperative entity that includes the State government and at least one other health care provider which is set up for the purpose of testing shared decision making and patient decision aids.

(2) Patient decision Aid.-The term "patient decision aid" means an educational tool (such as the Internet, a video, or a pamphlet) that helps 
1 tions, and to decide with their health care provider

2 what treatments are best for them based on their

3 treatment options, scientific evidence, circumstances,

4 beliefs, and preferences.

(3) Shared Decision making. - The term

6 "shared decision making" means a collaborative

7 process between patient and clinician that engages

8 the patient in decision making, provides patients

9 with information about trade-offs among treatment

10 options, and facilitates the incorporation of patient

11 preferences and values into the medical plan.

12 TITLE III-PROMOTING PRI13 MARY CARE, MENTAL 14 HEALTH SERVICES, AND CO15 ORDINATED CARE

16 SEC. 1301. ACCOUNTABLE CARE ORGANIZATION PILOT PROGRAM.

18 Title XVIII of the Social Security Act is amended by 19 inserting after section $1866 \mathrm{D}$, as added by section $201152(\mathrm{f})$, the following new section:

21 "ACCOUNTABLE CARE ORGANIZATION PILOT PROGRAM

22 "SEc. 1866E. (a) Establishment.-

23 "(1) In GeneraL.- The Secretary shall conduct a

24 pilot program (in this section referred to as the "pilot pro25 gram') to test different payment incentive models, includ26 ing (to the extent practicable) the specific payment incen- 
1 tive models described in subsection (c), designed to reduce

2 the growth of expenditures and improve health outcomes 3 in the provision of items and services under this title to 4 applicable beneficiaries (as defined in subsection (e)) by 5 qualifying accountable care organizations (as defined in 6 subsection (b)(1)) in order to-

7 “(A) promote accountability for a patient popu8 lation and coordinate items and services under parts $9 \quad \mathrm{~A}$ and B (and may include Part D, if the Secretary 10 determines appropriate);

11 “(B) encourage investment in infrastructure 12 and redesigned care processes for high quality and 13 efficient service delivery; and

14 "(C) reward physician practices and other phy15 sician organizational models for the provision of high 16 quality and efficient health care services.

17 “(2) ScOPE.-The Secretary shall set specific goals 18 for the number of accountable care organizations, partici19 pating practitioners, and patients served in the initial tests 20 under the pilot program to ensure that the pilot program 21 is of sufficient size and scope to-

22 "(A) test the approach involved in a variety of 23 settings, including urban, rural, and underserved 24 areas; and 
1 “(B) subject to subsection $(\mathrm{g})(1)$, disseminate 2 such approach rapidly on a national basis.

3 To the extent that the Secretary finds a qualifying ac4 countable care organization model to be successful in im5 proving quality and reducing costs, the Secretary shall 6 seek to implement such models on as large a geographic 7 scale as practical and economical.

8 “(b) Qualifying Accountable Care Organiza9 TIONS (ACOs).-

11 tion: accountable care organization' and 'qualifying ACO' mean a group of physicians or other physician organizational model (as defined in subparagraph (D)) that-

"(i) is organized at least in part for the purpose of providing physicians' services; and

"(ii) meets such criteria as the Secretary determines to be appropriate to participate in the pilot program, including the 25 criteria specified in paragraph (2). "(B) INCLUSION OF OTHER PROVIDERS OF SERVICES AND SUPPLIERS.-Nothing in this 
subsection shall be construed as preventing a qualifying ACO from including a hospital or any other provider of services or supplier furnishing items or services for which payment may be made under this title that is affiliated so that such provider or supplier participates in the pilot program and shares in any incentive payments under the pilot program.

“(C) Physiclan.-The term 'physician' includes, except as the Secretary may otherwise provide, any individual who furnishes services for which payment may be made as physicians' services under this title.

“(D) OTHER PHYSICIAN ORGANIZATIONAL MODEL.-The term 'other physician organization model' means, with respect to a qualifying ACO any model of organization under which physicians enter into agreements with other providers of services for the purposes of participation in the pilot program in order to provide high quality and efficient health care services and share in any incentive payments under such program 
"(E) OTHER SERVICES.-Nothing in this paragraph shall be construed as preventing a qualifying $\mathrm{ACO}$ from furnishing items or services, for which payment may not be made under this title, for purposes of achieving performance goals under the pilot program.

“(2) QuAlifying CRITERIA.-The following are criteria described in this paragraph for an organized group of physicians to be a qualifying ACO:

"(A) The group has a legal structure that would allow the group to receive and distribute incentive payments under this section.

"(B) The group includes a sufficient number of primary care physicians (regardless of specialty) for the applicable beneficiaries for whose care the group is accountable (as determined by the Secretary).

"(C) The group reports on quality measures in such form, manner, and frequency as specified by the Secretary (which may be for the group, for providers of services and suppliers, or both).

"(D) The group reports to the Secretary (in a form, manner and frequency as specified by the Secretary) such data as the Secretary 
determines appropriate to monitor and evaluate the pilot program.

"(E) The group provides notice to applicable beneficiaries regarding the pilot program (as determined appropriate by the Secretary).

"(F) The group contributes to a best practices network or website, that shall be maintained by the Secretary for the purpose of sharing strategies on quality improvement, care coordination, and efficiency that the groups believe are effective.

"(G) The group utilizes patient-centered processes of care, including those that emphasize patient and caregiver involvement in planning and monitoring of ongoing care management plan.

"(H) The group meets other criteria determined to be appropriate by the Secretary.

20 specific payment incentive models described in this sub21 section are the following:

“(1) Performance target model.-Under

23 the performance target model under this paragraph 24 (in this paragraph referred to as the "performance 25 target model'): 
"(A) IN GENERAL.—A qualifying ACO qualifies to receive an incentive payment if expenditures for items and services for applicable beneficiaries are less than a target spending level or a target rate of growth. The incentive payment shall be made only if savings are greater than would result from normal variation in expenditures for items and services covered under parts $\mathrm{A}$ and $\mathrm{B}$ (and may include Part D, if the Secretary determines appropriate).

"(i) IN GENERAL.-The Secretary shall establish a performance target for each qualifying ACO comprised of a base to the current year by an adjustment factor (described in clause (iii)). Such a target may be established on a per capita basis or adjusted for risk, as the Secretary determines to be appropriate. clause (i), the base amount in this subparagraph is equal to the average total payments (or allowed charges) under parts 
$\mathrm{A}$ and $\mathrm{B}$ (and may include part $\mathrm{D}$, if the Secretary determines appropriate) for applicable beneficiaries for whom the qualifying ACO furnishes items and services in a base period determined by the Secretary. Such base amount may be determined on a per capita basis or adjusted for risk.

"(iii) Adjustment FACTOR.-For purposes of clause (i), the adjustment factor in this clause may equal an annual per capita amount that reflects changes in expenditures from the period of the base amount to the current year that would represent an appropriate performance target for applicable beneficiaries (as determined by the Secretary).

"(iv) Rebasing.-Under this model the Secretary shall periodically rebase the base expenditure amount described in clause (ii).

“(C) Meeting target.-

"(i) In GENERAL.-Subject to clause (ii), a qualifying $\mathrm{ACO}$ that meets or exceeds annual quality and performance targets for a year shall receive an incentive 
payment for such year equal to a portion (as determined appropriate by the Secretary) of the amount by which payments under this title for such year are estimated to be below the performance target for such year, as determined by the Secretary. The Secretary may establish a cap on incentive payments for a year for a qualifying ACO.

“(ii) Limitation. - The Secretary shall limit incentive payments to each qualifying ACO under this paragraph as necessary to ensure that the aggregate expenditures with respect to applicable beneficiaries for such ACOs under this title (inclusive of incentive payments described in this subparagraph) do not exceed the amount that the Secretary estimates would be expended for such ACO for such beneficiaries if the pilot program under this section were not implemented.

"(D) REPORTING AND OTHER REQUIREMENTS.-In carrying out such model, the Secretary may (as the Secretary determines to be appropriate) incorporate reporting require- 
ments, incentive payments, and penalties related to the physician quality reporting initiative (PQRI), electronic prescribing, electronic health records, and other similar initiatives under section 1848, and may use alternative

criteria than would otherwise apply under such section for determining whether to make such payments. The incentive payments described in this subparagraph shall not be included in the limit described in subparagraph (C)(ii) or in the performance target model described in this paragraph.

“(2) Partial capitation model.-

"(A) IN GENERAL.—Subject to subparagraph (B), a partial capitation model described in this paragraph (in this paragraph referred to as a 'partial capitation model') is a model in which a qualifying $\mathrm{ACO}$ would be at financial risk for some, but not all, of the items and services covered under parts A and B (and may include part D, if the Secretary determines appropriate), such as at risk for some or all physicians' services or all items and services under part B. The Secretary may limit a partial capitation model to ACOs that are highly integrated 
systems of care and to ACOs capable of bearing risk, as determined to be appropriate by the Secretary.

"(B) No additional PRogram expendiTURES.-Payments to a qualifying ACO for beneficiaries for a year under the partial capitation model shall be established in a manner that does not result in spending more for such ACO for such beneficiaries than would otherwise be expended for such ACO for such beneficiaries for such year if the pilot program were not implemented, as estimated by the Secretary.

“(3) OTHER PAYMent MODELS.-

"(A) IN GENERAL.—Subject to subparagraph (B), the Secretary may develop other payment models that meet the goals of this pilot program to improve quality and efficiency. "(B) No additional PRogram expendiTURES.-Subparagraph (B) of paragraph (2) shall apply to a payment model under subparagraph (A) in a similar manner as such subparagraph (B) applies to the payment model under paragraph (2). 
"(1) In GENERAL.—The Secretary shall estab-

2 lish annual quality targets that qualifying ACOs

3 must meet to receive incentive payments, operate at

4 financial risk, or otherwise participate in alternative

5 financing models under this section. The Secretary

6 shall establish a process for developing annual tar-

7 gets based on ACO reporting of multiple quality

8 measures. In selecting measures the Secretary

9 shall-

10

"(A) for years one and two of each ACOs participation in the pilot program established by this section, require reporting of a starter set of measures focused on clinical care, care coordination and patient experience of care; and "(B) for each subsequent year, require reporting of a more comprehensive set of clinical outcomes measures, care coordination measures and patient experience of care measures.

20 sible, the Secretary shall select measures that reflect 21 national priorities for quality improvement and pa22 tient-centered care consistent with the measures de23 veloped under section $1192(\mathrm{c})(1)$.

24 “(e) Applicable Benefictaries.- 
"(1) IN GENERAL.-In this section, the term

2 'applicable beneficiary' means, with respect to a 3 qualifying $\mathrm{ACO}$, an individual who-

"(A) is enrolled under part B and entitled to benefits under part A;

17 services under this title through a qualifying ACO.

18 “(f) ImPLEMENTATION.-

"(1) STARTING DATE.-The pilot program shall 20 begin no later than January 1, 2012. An agreement 21 with a qualifying ACO under the pilot program may 22 cover a multi-year period of between 3 and 5 years. “(2) WAIVER.-The Secretary may waive such provisions of this title (including section 1877) and 
1 title XI in the manner the Secretary determines nec-

2 essary in order implement the pilot program.

“(3) Performance results Reports.-The

4 Secretary shall report performance results to quali-

5 fying $\mathrm{ACOs}$ under the pilot program at least annu6 ally.

“(4) Limitations on Review.-There shall be 8 no administrative or judicial review under section 91869 , section 1878 , or otherwise of-

"(A) the elements, parameters, scope, and 11 duration of the pilot program;

"(B) the selection of qualifying ACOs for the pilot program;

"(C) the establishment of targets, measurement of performance, determinations with respect to whether savings have been achieved and the amount of savings;

"(D) determinations regarding whether, to whom, and in what amounts incentive payments are paid; and

"(E) decisions about the extension of the program under subsection (h), expansion of the program under subsection (i) or extensions under subsections $(\mathrm{j})$ or $(\mathrm{k})$. 
“(5) Administration.—Chapter 35 of title 44,

2 United States Code shall not apply to this section.

3 “(g) Evaluation; Monitoring.-

4 "(1) IN GENERAL.-The Secretary shall evalu-

5 ate the payment incentive model for each qualifying

6 ACO under the pilot program to assess impacts on

7 beneficiaries, providers of services, suppliers and the

8 program under this title. The Secretary shall make

9 such evaluation publicly available within 60 days of

10 the date of completion of such report.

11 “(2) Monitoring.-The Inspector General of

12 the Department of Health and Human Services shall

13 provide for monitoring of the operation of ACOs

14 under the pilot program with regard to violations of

15 section 1877 (popularly known as the 'Stark law').

16 “(h) Extension of Pilot Agreement With Suc-

17 Cessful Organizations.-

18 “(1) Reports To CONGRESS.-Not later than

192 years after the date the first agreement is entered

20 into under this section, and biennially thereafter for

21 six years, the Secretary shall submit to Congress

22 and make publicly available a report on the use of

23 ACO payment models under the pilot program. Each

24 report shall address the impact of the use of those 
1 models on expenditures, access, and quality under

2 this title.

“(2) Extension.-Subject to the report pro-

4 vided under paragraph (1), with respect to a quali-

5 fying ACO, the Secretary may extend the duration

6 of the agreement for such ACO under the pilot pro-

7 gram as the Secretary determines appropriate if-

"(A) the ACO receives incentive payments

with respect to any of the first 4 years of the pilot agreement and is consistently meeting quality standards or

"(B) the ACO is consistently exceeding quality standards and is not increasing spending under the program.

“(3) Termination.-The Secretary may termi16 nate an agreement with a qualifying $\mathrm{ACO}$ under the 17 pilot program if such ACO did not receive incentive 18 payments or consistently failed to meet quality 19 standards in any of the first 3 years under the pro20 gram.

21 “(i) Expansion to Additional ACOs.-

22 “(1) Testing AND REFinement of PAYMent 23 INCENTIVE MODELS.-Subject to the evaluation de24 scribed in subsection $(\mathrm{g})$, the Secretary may enter 25 into agreements under the pilot program with addi- 
1 tional qualifying ACOs to further test and refine

2 payment incentive models with respect to qualifying 3 ACOs.

“(2) Expanding use of Successful Models

"(A) IN GENERAL.—Subject to subparagraph (B), the Secretary may issue regulations to implement, on a permanent basis, 1 or more models if, and to the extent that, such models are beneficial to the program under this title, as determined by the Secretary. of the Centers for Medicare \& Medicaid Services shall certify that 1 or more of such models described in subparagraph (A) would result in estimated spending that would be less than 17 what spending would otherwise be estimated to 18 be in the absence of such expansion.

20 Demonstration.-

“(1) Extension.-The Secretary may enter in 22 to an agreement with a qualifying ACO under the 23 demonstration under section 1866 A, subject to re24 basing and other modifications deemed appropriate 
1 by the Secretary, until the pilot program under this

2 section is operational.

3 “(2) Transition.-For purposes of extension

4 of an agreement with a qualifying ACO under sub-

5 section (h)(2), the Secretary shall treat receipt of an

6 incentive payment for a year by an organization

7 under the physician group practice demonstration

8 pursuant to section $1866 \mathrm{~A}$ as a year for which an

9 incentive payment is made under such subsection, as

10 long as such practice group practice organization

11 meets the criteria under subsection $(b)(2)$.

12 “(k) Additional Provisions.-

13 “(1) AUTHORITY FOR SEPARATE INCENTIVE

14 ARRANGEMENTS.-The Secretary may create sepa-

15 rate incentive arrangements (including using mul-

16 tiple years of data, varying thresholds, varying

17 shared savings amounts, and varying shared savings

18 limits) for different categories of qualifying ACOs to

19 reflect variation in average annual attributable ex-

20 penditures and other matters the Secretary deems

21 appropriate.

22 “(2) EnCOURAgEMENT OF PARTicipation OF

23 SMALLER ORGANIZATIONS.-In order to encourage

24 the participation of smaller accountable care organi-

25 zations under the pilot program, the Secretary may 
1 limit a qualifying ACO's exposure to high cost pa-

2 tients under the program.

“(3) Involvement IN PRIVATE PAYER AND OTHER THIRD PARTY ARRANGEMENTS.-The Sec-

5 retary may give preference to $\mathrm{ACOs}$ who are partici6 pating in similar arrangements with other payers. “(4) Antidiscrimination Limitation.-The

8 Secretary shall not enter into an agreement with an 9 entity to provide health care items or services under 10 the pilot program, or with an entity to administer 11 the program, unless such entity guarantees that it 12 will not deny, limit, or condition the coverage or pro13 vision of benefits under the program, for individuals 14 eligible to be enrolled under such program, based on 15 any health status-related factor described in section $162702(a)(1)$ of the Public Health Service Act.

17 “(5) Funding.-For purposes of administering 18 and carrying out the pilot program, other than for 19 payments for items and services furnished under this 20 title and incentive payments under subsection (c)(1), 21 in addition to funds otherwise appropriated, there 22 are appropriated to the Secretary for the Center for 23 Medicare \& Medicaid Services Program Management 24 Account $\$ 25,000,000$ for each of fiscal years 2010 25 through 2014 and $\$ 20,000,000$ for fiscal year 2015 . 
1 Amounts appropriated under this paragraph for a

2 fiscal year shall be available until expended.

“(6) No duplication in payments to PHysi-

4 CLANS In MUlTiPle PILOTS.-The Secretary shall

5 not make payments under this section to any physi-

6 cian group that is paid under section $1866 \mathrm{~F}$ (relat-

7 ing to medical homes) or section $1866 \mathrm{G}$ (relating to

8 independence at home).".

9 SEC. 1302. MEDICAL HOME PILOT PROGRAM.

10 (a) In GeneraL.-Title XVIII of the Social Security

11 Act is amended by inserting after section $1866 \mathrm{E}$, as in-

12 serted by section 1301, the following new section:

14 "Sec. 1866F. (a) Establishment and Medical

15 Home Models.-

“(1) Establishment of Pilot PRogram.-

17 The Secretary shall establish a medical home pilot

18 program (in this section referred to as the "pilot pro-

19 gram') for the purpose of evaluating the feasibility

20 and advisability of reimbursing qualified patient-cen-

21 tered medical homes for furnishing medical home

22 services (as defined under subsection (b)(1)) to

23 beneficiaries (as defined in subsection (b)(4)) and to

24 targeted high need beneficiaries (as defined in sub25 section $(c)(1)(C))$. 
"(2) ScOPE.-Subject to subsection (g), the

2 Secretary shall set specific goals for the number of 3 practices and communities, and the number of pa-

4 tients served, under the pilot program in the initial

5 tests to ensure that the pilot program is of sufficient 6 size and scope to-

"(A) test the approach involved in a variety of settings, including urban, rural, and underserved areas; and "(B) subject to subsection (e)(1), dissemi12 To the extent that the Secretary finds a medical 13 home model to be successful in improving quality 14 and reducing costs, the Secretary shall implement 15 such model on as large a geographic scale as prac16 tical and economical.

17 “(3) Models OF MEDICAL HOMES IN THE 18 PILOT PROGRAM.-The pilot program shall evaluate 19 each of the following medical home models:

“(A) INDEPENDENT PATIENT-CENTERED MEDICAL HOME MODEL.-Independent patientcentered medical home model under subsection 23 (c). 
"(B) Community-Based medical home MODEL._Community-based medical home model under subsection (d).

“(4) Participation of nurse practitioners

"(A) Nothing in this section shall be construed as preventing a nurse practitioner from leading a patient centered medical home so long as-

"(i) all the requirements of this section are met; and "(ii) the nurse practitioner is acting in a manner that is consistent with State law.

"(B) Nothing in this section shall be construed as preventing a physician assistant from participating in a patient centered medical home so long as-

"(i) all the requirements of this section are met; and

"(ii) the physician assistant is acting" in a manner that is consistent with State law.

“(b) Definitions.-For purposes of this section: 
“(1) PATIENT-CENTERED MEdicAL HOME SERVICES.-The term 'patient-centered medical

3 home services' means services that-

"(A) provide beneficiaries with direct and ongoing access to a primary care or principal care physician or nurse practitioner who accepts responsibility for providing first contact, continuous and comprehensive care to such beneficiary;

"(B) coordinate the care provided to a beneficiary by a team of individuals at the practice level across office, provider of services, and home settings led by a primary care or principal care physician or nurse practitioner, as needed and appropriate;

“(C) provide for all the patient's health care needs or take responsibility for appropriately arranging care with other qualified physicians or providers for all stages of life;

"(D) provide continuous access to care and communication with participating beneficiaries; “(E) provide support for patient self-management, proactive and regular patient monitoring, support for family caregivers, use pa- 
tient-centered processes, and coordination with community resources;

“(F) integrate readily accessible, clinically useful information on participating patients that enables the practice to treat such patients

17 care' means integrated, accessible health care that is 18 provided by a physician who is a medical specialist 19 or subspecialist that addresses the majority of the 20 personal health care needs of patients with chronic 21 conditions requiring the specialist's or subspecialist's 22 expertise, and for whom the specialist or sub23 specialist assumes care management. 
“(4) Benefictaries.-The term 'beneficiaries'

2 means, with respect to a qualifying medical home, 3 an individual who-

\section{Home Model.-}

“(A) Payment authority.-Under the independent patient-centered medical home model under this subsection, the Secretary shall make payments for medical home services furnished by an independent patient-centered medical home (as defined in subparagraph (B)) pursuant to paragraph (3) for targeted high need beneficiaries (as defined in subparagraph (C)).

“(B) INDEPENDENT PATIENT-CENTERED MEDICAL HOME DEFINED.-In this section, the 25 term 'independent patient-centered medical 
home' means a physician-directed or nursepractitioner-directed practice that is qualified under paragraph (2) as-

"(i) providing beneficiaries with patient-centered medical home services; and “(ii) meets such other requirements as the Secretary may specify. “(C) Targeted high need Beneficiary DEFINED.-For purposes of this subsection, the term 'targeted high need beneficiary' means a beneficiary who, based on a risk score as specified by the Secretary, is generally within the upper 50th percentile of Medicare beneficiaries. “(D) Benefictary election to PARTiciPATE.-The Secretary shall determine an appropriate method of ensuring that beneficiaries have agreed to participate in the pilot program. “(E) Implementation.-The pilot program under this subsection shall begin no later than 12 months after the date of the enactment of this section and shall operate for 5 years. “(2) Qualification PRocess for PatientCENTERED MEDICAL HOMES.-The Secretary shall establish a process for practices to qualify as medical homes. 
“(3) Payment.-

“(A) Establishment OF METHODOLOGY._The Secretary shall establish a methodology for the payment for medical home services furnished by independent patient-centered medical homes. Under such methodology, the Secretary shall adjust payments to medical homes based on beneficiary risk scores to ensure that higher payments are made for higher risk beneficiaries.

"(B) PER BENEFICIARY PER MONTH PAYMENTS._Under such payment methodology, the Secretary shall pay independent patient-centered medical homes a monthly fee for each targeted high need beneficiary who consents to receive medical home services through such medical home.

"(C) Prospective Payment.-The fee under subparagraph (B) shall be paid on a prospective basis.

"(D) Amount OF PAYMENT.-In determining the amount of such fee, the Secretary shall consider the following:

"(i) The clinical work and practice expenses involved in providing the medical 
home services provided by the independent patient-centered medical home (such as providing increased access, care coordination, population disease management, and teaching self-care skills for managing chronic illnesses) for which payment is not

23 in larger practices, particularly in underserved and

24 rural areas, as well as federally qualified health cen25 ters, and rural health centers. 
"(1) IN GENERAL.-

“(A) Authority for Payments.-Under the community-based medical home model under this subsection (in this section referred to as the 'CBMH model'), the Secretary shall make payments for the furnishing of medical home services by a community-based medical home (as defined in subparagraph (B)) pursuant to paragraph (5)(B) for beneficiaries. DEFINED.-In this section, the term 'community-based medical home' means a nonprofit community-based or State-based organization or a State that is certified under paragraph (2) as meeting the following requirements:

"(i) The organization provides bene-

ficiaries with medical home services. "(ii) The organization provides medical home services under the supervision of and in close collaboration with the primary care or principal care physician, nurse practitioner, or physician assistant designated by the beneficiary as his or her community-based medical home provider. 
"(iii) The organization employs com-

munity health workers, including nurses or

other non-physician practitioners, lay

health workers, or other persons as determined appropriate by the Secretary, that

“(2) QUALIFICATION PROCESS FOR COMMUNITY-BASED MEDICAL HOMES.-The Secretary shall

22 establish a process to provide for the review and 23 qualification of community-based medical homes 24 pursuant to criteria established by the Secretary. 
“(3) DuRation.-The pilot program for com-

2 munity-based medical homes under this subsection

3 shall start no later than 2 years after the date of the

4 enactment of this section. Each demonstration site

5 under the pilot program shall operate for a period

6 of up to 5 years after the initial implementation

7 phase, without regard to the receipt of a initial im-

8 plementation funding under paragraph (6).

9 “(4) Preference.-In selecting sites for the

10 CBMH model, the Secretary shall give preference to

11 applications which seek to eliminate health dispari-

12 ties, as defined in section 3171 of the Public Health

13 Service Act and may give preference to any of the

14 following:

"(A) Applications that propose to coordi16 nate health care items and services under this 17 title for chronically ill beneficiaries who rely, for 18 primary care, on small physician or nurse prac19 titioner practices, federally qualified health cen20 ters, rural health clinics, or other settings with 21 limited resources and scope of services.

"(B) Applications that include other third24 for chronically ill patients covered by such 25 third-party payors. 
684

“(C) Applications from States that propose to use the medical home model to coordinate health care services for-

"(i) individuals enrolled under this title;

“(ii) individuals enrolled under title XIX; and “(iii) full-benefit dual eligible individuals (as defined in section 1935(c)(6)), with chronic diseases across a variety of health care settings.

“(5) Payments.-

“(A) Establishment OF MethodOLOGY.-The Secretary shall establish a methodology for the payment for medical home services furnished under the CBMH model.

“(B) Per Benefictary Per month PayMENTS.-Under such payment methodology, the Secretary shall make two separate monthly payments for each beneficiary who consents to receive medical home services through such medical home, as follows:

“(i) Payment to Community-Based ORGANIZATION.-One monthly payment to 
a community-based or State-based organization or State.

“(ii) Payment to PRIMary or PRINCIPAL CARE PRACTICE.-One monthly payment to the primary or principal care practice for such beneficiary. "(C) Prospective Payment.-The payments under subparagraph (B) shall be paid on a prospective basis.

"(D) Amount of PAYment.-In deter-

"(i) The clinical work and practice expenses involved in providing the medical home services provided by the primary or principal care practice (such as providing increased access, care coordination, care planning, population disease management, and teaching self-care skills for managing chronic illnesses) for which payment is not made under this title as of the date of the enactment of this section.

“(ii) Use appropriate risk-adjustment in determining the amount of the per bene- 
ficiary per month payment under this paragraph.

"(iii) In the case of the models described in subparagraphs (B) and (C) of paragraph (4), the Secretary may determine an appropriate payment amount.

8 The Secretary may make available initial implemen9 tation funding to a non-profit community based or 10 State-based organization or a State that is partici11 pating in the pilot program under this subsection. 12 Such organization shall provide the Secretary with a 13 detailed implementation plan that includes how such 14 funds will be used. The Secretary shall select a terri15 tory of the United States as one of the locations in 16 which to implement the pilot program under this 17 subsection, unless no organization in a territory is 18 able to comply with the requirements under para$19 \operatorname{graph}(1)(\mathrm{B})$.

20 "(e) Expansion of Program.-

“(1) Evaluation OF COST AND QUALITY.22 The Secretary shall evaluate the pilot program to 23 determine- 
"(i) improvement in the quality and coordination of items and services under this title, particularly with regard to the care of complex patients;

"(ii) improvement in reducing health

disparities;

"(iii) reductions in preventable hospitalizations;

"(iv) prevention of readmissions;

"(v) reductions in emergency room visits;

"(vi) improvement in health outcomes, including patient functional status where applicable;

"(vii) improvement in patient satisfaction;

"(viii) improved efficiency of care such as reducing duplicative diagnostic tests and laboratory tests; and

"(ix) reductions in health care expenditures; and

"(B) the feasability and advisability of reimbursing medical homes for medical home services under this title on a permanent basis. 
"(2) Report.-Not later than 60 days after

2 the date of completion of the evaluation under para-

3 graph (1), the Secretary shall submit to Congress

4 and make available to the public a report on the

5 findings of the evaluation under paragraph (1) and

6 the extent to which standards for the certification of

7 medical homes need to be periodically updated.

8

9

10

11

12
"(3) Expansion of PROGRAM.-

"(A) In GENERAL.—Subject to the results of the evaluation under paragraph (1) and subparagraph (B), the Secretary may issue regulations to implement, on a permanent basis, one or more models, if, and to the extent that such model or models, are beneficial to the program under this title, including that such implementation will improve quality of care, as determined by the Secretary.

"(B) Certification requirement.-The Secretary may not issue such regulations unless the Chief Actuary of the Centers for Medicare \& Medicaid Services certifies that the expansion of the components of the pilot program described in subparagraph (A) would result in estimated spending under this title that would be no more than the level of spending that the 
Secretary estimates would otherwise be spent

under this title in the absence of such expansion.

"(C) Updated StANDARDS.-The Sec-

retary shall periodically review and update the standards for qualification as an independent patient centered medical home and as a community based medical home and shall establish a process for ensuring that medical homes meet such updated standards, as applicable

“(f) Administrative Provisions.-

“(1) No DUplication in PAYMents FOR INDIVIDUALS IN MEDICAL HOMES.-During any month, the Secretary may not make payments under this section under more than one model or through more than one medical home under any model for the furnishing of medical home services to an individual.

“(2) No EFFECT ON PAYMENT FOR Medical VISITS.-Payments made under this section are in addition to, and have no effect on the amount of, payment for medical visits made under this title

“(3) Administration.-Chapter 35 of title 44, United States Code shall not apply to this section. “(4) No Duplication in physician pilot PARTICIPATION.-The Secretary shall not make pay- 
1 ments to an independent or community based med2 ical home both under this section and section $1866 \mathrm{E}$

3 or 1866G, unless the pilot program under this sec-

4 tion has been implemented on a permanent basis

5 under subsection (e)(3).

6 “(5) WAIVER.-The Secretary may waive such

7 provisions of this title and title XI in the manner the

8 Secretary determines necessary in order to imple-

9 ment this section.

10 “(g) Funding.-

11 “(1) Operational COSTS.-For purposes of 12 administering and carrying out the pilot program 13 (including the design, implementation, technical as14 sistance for and evaluation of such program), in ad15 dition to funds otherwise available, there shall be 16 transferred from the Federal Supplementary Medical 17 Insurance Trust Fund under section 1841 to the 18 Secretary for the Centers for Medicare \& Medicaid 19 Services Program Management Account \$6,000,000 20 for each of fiscal years 2010 through 2014. 21 Amounts appropriated under this paragraph for a 22 fiscal year shall be available until expended.

23 “(2) Patient-Centered medical home 24 SERVICES.-In addition to funds otherwise available, 25 there shall be available to the Secretary for the Cen- 
1 ters for Medicare \& Medicaid Services, from the

2 Federal Supplementary Medical Insurance Trust

3 Fund under section 1841-

“(A) $\$ 200,000,000$ for each of fiscal years

2010 through 2014 for payments for medical

6 home services under subsection (c)(3); and

“(B) $\$ 125,000,000$ for each of fiscal years 2012 through 2016, for payments under subsection $(d)(5)$.

10 Amounts available under this paragraph for a fiscal

11 year shall be available until expended.

“(3) Initial IMPLEMENTATION.-In addition

13 to funds otherwise available, there shall be available

14 to the Secretary for the Centers for Medicare \&

15 Medicaid Services, from the Federal Supplementary

16 Medical Insurance Trust Fund under section 1841, $17 \$ 2,500,000$ for each of fiscal years 2010 through 182012 , under subsection (d)(6). Amounts available 19 under this paragraph for a fiscal year shall be avail20 able until expended.

21 “(h) Treatment of TrHCA Medicare Medical 22 Home Demonstration Funding.-

23 "(1) In addition to funds otherwise available for 24 payment of medical home services under subsection $25(\mathrm{c})(3)$, there shall also be available the amount pro- 
1 vided in subsection $(\mathrm{g})$ of section 204 of division B

2 of the Tax Relief and Health Care Act of 2006 (42

3 U.S.C. $1395 \mathrm{~b}-1$ note), as added by section 133 of

4 the Medicare Improvements for Patients and Pro-

5 viders Act of 2008 (Public Law 110-275).

6 “(2) Notwithstanding section $1302(\mathrm{c})$ of the Af-

7 fordable Health Care for America Act, in addition to

8 funds provided in paragraph (1) and subsection

$9 \quad(\mathrm{~g})(2)(\mathrm{A})$, the funding for medical home services

10 that would otherwise have been available if such sec-

11 tion 204 medical home demonstration had been im-

12 plemented (without regard to subsection (g) of such

13 section) shall be available to the independent pa-

14 tient-centered medical home model described in sub15 section (c).".

16 (b) EFFEcTive Date.-The amendment made by 17 this section shall apply to services furnished on or after 18 the date of the enactment of this Act.

19 (c) Conforming Repeat.-Section 204 of division 20 B of the Tax Relief and Health Care Act of 2006 (42 21 U.S.C. 1395b-1 note), as amended by section 133(a)(2) 22 of the Medicare Improvements for Patients and Providers 23 Act of 2008 (Public Law 110-275), is repealed. 
1 SEC. 1303. PAYMENT INCENTIVE FOR SELECTED PRIMARY

3 (a) In GeneraL.-Section 1833 of the Social Secu4 rity Act is amended by inserting after subsection (o) the 5 following new subsection:

6 “(p) Primary Care Payment Incentives.-

7 “(1) IN GENERAL.-In the case of primary care 8 services (as defined in paragraph (2)) furnished on 9 or after January 1, 2011, by a primary care practi10 tioner (as defined in paragraph (3)) for which 11 amounts are payable under section 1848, in addition 12 to the amount otherwise paid under this part there 13 shall also be paid to the practitioner (or to an em14 ployer or facility in the cases described in clause (A)

15 of section $1842(b)(6)$ ) (on a monthly or quarterly 16 basis) from the Federal Supplementary Medical In17 surance Trust Fund an amount equal 5 percent (or 1810 percent if the practitioner predominately fur19 nishes such services in an area that is designated 20 (under section 332(a)(1)(A) of the Public Health 21 Service Act) as a primary care health professional 22 shortage area.

“(2) Primary Care Services Defined.-In 24 this subsection, the term 'primary care services'25 "(A) mean evaluation and management 26 services, without regard to the specialty of the 
physician furnishing the services, that are procedure codes (for services covered under this title) for-

"(i) services in the category designated Evaluation and Management in the Health Care Common Procedure Coding System (established by the Secretary under section 1848(c)(5) as of December 31, 2009, and as subsequently modified by the Secretary); and

"(ii) preventive services (as defined in section 1861(iii) for which payment is made under this section; and "(B) includes services furnished by another health care professional that would be described in subparagraph (A) if furnished by a physician.

“(3) Primary CARE PRACTITIONER DEFINED.-In this subsection, the term 'primary care practitioner'-

"(A) means a physician or other health care practitioner (including a nurse practitioner) who-

"(i) specializes in family medicine, general internal medicine, general pediat- 
rics, geriatries, or obstetrics and gyne-

cology; and

"(ii) has allowed charges for primary care services that account for at least 50 percent of the physician's or practitioner's total allowed charges under section 1848, as determined by the Secretary for the most recent period for which data are available; and

"(B) includes a physician assistant who is under the supervision of a physician described in subparagraph $(\mathrm{A})$.

14 no administrative or judicial review under section 151869 , section 1878 , or otherwise, respecting"(A) any determination or designation $17 \quad$ under this subsection;

"(B) the identification of services as primary care services under this subsection; and "(C) the identification of a practitioner as a primary care practitioner under this subsection. 
TIVES.-The provisions of this subsection shall not be taken into account in applying subsections (m) and (u) and any payment under such subsections shall not be taken into account in computing payments under this subsection.

"(B) With Quality Incentives.-Payments under this subsection shall not be taken into account in determining the amounts that would otherwise be paid under this part for purposes of section $1834(\mathrm{~g})(2)(\mathrm{B}) . ’$

(1) Section $1833(\mathrm{~m})$ of such Act (42 U.S.C. $141395 \mathrm{l}(\mathrm{m}))$ is amended by redesignating paragraph 15 (4) as paragraph (5) and by inserting after para16 graph (3) the following new paragraph:

17 "(4) The provisions of this subsection shall not be 18 taken into account in applying subsections $(\mathrm{m})$ or $(\mathrm{u})$ and 19 any payment under such subsections shall not be taken 20 into account in computing payments under this sub21 section.".

(2) Section 1848(m)(5)(B) of such Act (42 23 U.S.C. $1395 \mathrm{w}-4(\mathrm{~m})(5)(\mathrm{B}))$ is amended by inserting 24 “, (p)," after “(m)". 
(3) Section 1848(o)(1)(B)(iv) of such Act (42 U.S.C. $1395 \mathrm{w}-4(\mathrm{o})(1)(\mathrm{B})(\mathrm{iv}))$ is amended by insert-

3 ing "primary care" before "health professional 4 shortage area".

5 SEC. 1304. INCREASED REIMBURSEMENT RATE FOR CERTIFIED NURSE-MIDWIVES.

7 (a) In GENERAL.-Section 1833(a)(1)(K) of the So8 cial Security Act (42 U.S.C.1395l(a)(1)(K)) is amended 9 by striking "(but in no event" and all that follows through 10 "performed by a physician)".

11 (b) EFFEctive Date.-The amendment made by 12 subsection (a) shall apply to services furnished on or after 13 January 1, 2011.

14 SEC. 1305. COVERAGE AND WAIVER OF COST-SHARING FOR 15 PREVENTIVE SERVICES.

16 (a) Medicare Covered Preventive Services De17 FINED.-Section 1861 of the Social Security Act (42 18 U.S.C. 1395x), as amended by section 1233(a)(1)(B), is 19 amended by adding at the end the following new sub20 section: "(iii)(1) Subject to the succeeding provisions of this 23 subsection, the term 'Medicare covered preventive services' 24 means the following: 
“(A) Prostate cancer screening tests (as defined

2 in subsection (oo)).

"(B) Colorectal cancer screening tests (as de4 fined in subsection (pp).

"(C) Diabetes outpatient self-management 6 training services (as defined in subsection (qq)).

"(D) Screening for glaucoma for certain indi-

8 viduals (as described in subsection $(\mathrm{s})(2)(\mathrm{U})$ ).

"(E) Medical nutrition therapy services for cer10 tain individuals (as described in subsection $11(\mathrm{~s})(2)(\mathrm{V}))$.

"(F) An initial preventive physical examination 13 (as defined in subsection (ww)).

14 "(G) Cardiovascular screening blood tests (as 15 defined in subsection $(\mathrm{xx})(1))$.

16 "(H) Diabetes screening tests (as defined in 17 subsection $(\mathrm{yy}))$.

18 "(I) Ultrasound screening for abdominal aortic 19 aneurysm for certain individuals (as described in 20 subsection $(\mathrm{s})(2)(\mathrm{AA}))$.

“(J) Federally approved and recommended vac22 cines and their administration as described in sub23 section $(\mathrm{s})(10)$.

24 "(K) Screening mammography (as defined in 25 subsection (jj)). 
$1 \quad$ “(L) Screening pap smear and screening pelvic

2 exam (as defined in subsection (nn)).

3 "(M) Bone mass measurement (as defined in 4 subsection $(\mathrm{rr})$ ).

$5 \quad$ "(N) Kidney disease education services (as de6 fined in subsection ( $(\mathrm{ggg}))$.

$7 \quad$ " $(\mathrm{O})$ Additional preventive services (as defined 8 in subsection (ddd)).

9 “(2) With respect to specific Medicare covered pre10 ventive services, the limitations and conditions described 11 in the provisions referenced in paragraph (1) with respect 12 to such services shall apply.".

13 (b) Payment and Elimination of Cost-shar14 ING.-

(1) In GenERAL.-

(A) IN GENERAL.-Section 1833(a) of the Social Security Act (42 U.S.C. 1395l(a)) is amended by adding after and below paragraph (9) the following:

20 "With respect to Medicare covered preventive services, in 21 any case in which the payment rate otherwise provided 22 under this part is computed as a percent of less than 100 23 percent of an actual charge, fee schedule rate, or other 24 rate, such percentage shall be increased to 100 percent.". 
(B) Application TO Sigmoidoscopies AND COLONOSCOPIES.- Section 1834(d) of such Act (42 U.S.C. $1395 \mathrm{~m}(\mathrm{~d})$ ) is amended-

(i) in paragraph $(2)(\mathrm{C})$, by amending clause (ii) to read as follows:

"(ii) No CoInsurance.-In the case of a beneficiary who receives services described in clause (i), there shall be no coinsurance applied."; and

(ii) in paragraph $(3)(\mathrm{C})$, by amending clause (ii) to read as follows:

"(ii) No CoInsurance.-In the case of a beneficiary who receives services described in clause (i), there shall be no coinsurance applied.’.

(2) Elimination of Coinsurance in outPATIENT HOSPITAL SETTINGS.-

(A) Exclusion From OPD FEE SCHEDULE.-Section 1833(t)(1)(B)(iv) of the Social Security Act (42 U.S.C. 1395l(t)(1)(B)(iv)) is amended by striking "screening mammography (as defined in section 1861(jj)) and diagnostic mammography" and inserting "diagnostic mammograms and Medicare covered preventive services (as defined in section 1861(iii)(1))". 
(B) Conforming Amendments.-Section 1833(a)(2) of the Social Security Act (42 U.S.C. 1395l(a)(2)) is amended-

(i) in subparagraph (F), by striking "and" after the semicolon at the end;

(ii) in subparagraph (G), by adding "and" at the end; and

(iii) by adding at the end the following new subparagraph:

"(H) with respect to additional preventive services (as defined in section 1861(ddd)) furnished by an outpatient department of a hospital, the amount determined under paragraph (1) (W);".

(3) Waiver of application of Deductible FOR ALL PREVENTIVE SERVICES.-The first sentence of section 1833(b) of the Social Security Act (42 U.S.C. $1395 \mathrm{l}(\mathrm{b})$ ) is amended-

(A) in clause (1), by striking "items and services described in section 1861(s)(10)(A)" and inserting "Medicare covered preventive services (as defined in section 1861(iii))";

(B) by inserting "and" before "(4)"; and (C) by striking clauses (5) through (8). 
(4) Application to PROVIDERs OF SERV-

2 ICES.-Section 1866(a)(2)(A)(ii) of such Act (42

3 U.S.C. 1395ec(a)(2)(A)(ii)) is amended by inserting

4 "other than for Medicare covered preventive services

5 and" after "for such items and services (".

6 (c) EFFEctive Date.-The amendments made by

7 this section shall apply to services furnished on or after

8 January 1, 2011.

9 (d) Preventive Services.-

10 (1) REPORT TO CONGRESS ON BARRIERS TO

11 PREVENTIVE SERVICES.-Not later than 12 months

12 after the date of the enactment of this Act, the Sec-

13 retary of Health and Human Services shall report to

14 Congress on barriers, if any, facing Medicare bene-

15 ficiaries in accessing the benefit to abdominal aortic

16 aneurysm screening and other preventative services

17 through the Welcome to Medicare Physical Exam.

18 (2) Abdominal AORTiC ANEURYSM SCREen AC-

19 CESS.-The Secretary shall, to the extent practical,

20 identify and implement policies promoting proper

21 use of abdominal aortic aneurysm screening among

22 Medicare beneficiaries at risk for such aneurysms. 
1 SEC. 1306. WAIVER OF DEDUCTIBLE FOR COLORECTAL

5 (a) In General.-Section 1833 of the Social Secu-

6 rity Act (42 U.S.C. 1395l(b)), as amended by section

7 1305(b), is further amended-

8 (1) in subsection (a), in the sentence added by

9 section $1305(\mathrm{~b})(1)(\mathrm{A})$, by inserting "(including serv-

10 ices described in the last sentence of section

11 1833(b))" after "preventive services"; and

12 (2) in subsection (b), by adding at the end the

13 following new sentence: "Clause (1) of the first sen-

14 tence of this subsection shall apply with respect to

15 a colorectal cancer screening test regardless of the

16 code that is billed for the establishment of a diag-

17 nosis as a result of the test, or for the removal of

18 tissue or other matter or other procedure that is fur-

19 nished in connection with, as a result of, and in the

20 same clinical encounter as, the screening test.".

21 (b) EFFECTIVE DATE.-The amendment made by 22 subsection (a) shall apply to items and services furnished 23 on or after January 1, 2011. 
1 SEC. 1307. EXCLUDING CLINICAL SOCIAL WORKER SERV-

ICES FROM COVERAGE UNDER THE MEDI-

CARE SKILLED NURSING FACILITY PROSPECTIVE PAYMENT SYSTEM AND CONSOLIDATED PAYMENT.

(a) In GENERAL.-Section 1888(e)(2)(A)(ii) of the 7 Social Security Act (42 U.S.C. 1395yy(e)(2)(A)(ii)) is 8 amended by inserting "clinical social worker services," 9 after "qualified psychologist services,".

11 1861(hh)(2) of the Social Security Act (42 U.S.C.

$121395 \mathrm{x}(\mathrm{hh})(2))$ is amended by striking "and other than

13 services furnished to an inpatient of a skilled nursing facil-

14 ity which the facility is required to provide as a require15 ment for participation".

16 (c) EFFECTIVE DATE.-The amendments made by 17 this section shall apply to items and services furnished on 18 or after October 1, 2010.

19 SEC. 1308. COVERAGE OF MARRIAGE AND FAMILY THERAPIST SERVICES AND MENTAL HEALTH COUNSELOR SERVICES.

(a) Coverage of Marriage and Family Thera-

23 PIST SERVICES.-

(1) COVERAgE OF SERVICES.-Section $251861(\mathrm{~s})(2)$ of the Social Security Act (42 U.S.C. 
$1 \quad 1395 \times(\mathrm{s})(2))$, as amended by section 1235 , is

2 amended-

17 services' means services performed by a marriage and

18 family therapist (as defined in paragraph (2)) for the diag-

19 nosis and treatment of mental illnesses, which the mar-

20 riage and family therapist is legally authorized to perform

21 under State law (or the State regulatory mechanism pro-

22 vided by State law) of the State in which such services

23 are performed, as would otherwise be covered if furnished

24 by a physician or as incident to a physician's professional 25 service, but only if no facility or other provider charges 
1 or is paid any amounts with respect to the furnishing of

2 such services.

3 “(2) The term 'marriage and family therapist' means 4 an individual who-

“(A) possesses a master's or doctoral degree

6 which qualifies for licensure or certification as a

7 marriage and family therapist pursuant to State $8 \quad$ law;

$9 \quad$ “(B) after obtaining such degree has performed

10 at least 2 years of clinical supervised experience in 11 marriage and family therapy; and

12 "(C) is licensed or certified as a marriage and 13 family therapist in the State in which marriage and 14 family therapist services are performed.".

15 (3) Provision For Payment under PART 16 B.-Section 1832(a)(2)(B) of the Social Security 17 Act (42 U.S.C. $1395 \mathrm{k}(\mathrm{a})(2)(\mathrm{B})$ ) is amended by add18 ing at the end the following new clause: "(v) marriage and family therapist services;".

(4) Amount of Payment.-

(A) IN GENERAL.-Section 1833(a)(1) of the Social Security Act (42 U.S.C. 1395l(a)(1)) is amended- 
(i) by striking "and" before "(W)";

and

(ii) by inserting before the semicolon at the end the following: ", and (X) with respect to marriage and family therapist services under section 1861(s)(2)(GG), the amounts paid shall be 80 percent of the lesser of the actual charge for the services or 75 percent of the amount determined for payment of a psychologist under clause (L)".

(B) Development of Criteria With ReSPECT TO CONSULTATION WITH A HEALTH CARE PROFESSIONAL.-The Secretary of Health and Human Services shall, taking into consideration concerns for patient confidentiality, develop criteria with respect to payment for marriage and family therapist services for which payment may be made directly to the marriage and family therapist under part B of title XVIII of the Social Security Act (42 U.S.C. 1395 j et seq.) under which such a therapist must agree to consult with a patient's attending or primary care physician or nurse practitioner in accordance with such criteria. 
(5) Exclusion of MARrLage AND FAMiLy THERAPIST SERVICES FROM SKILLED NURSING FACILITY PROSPECTIVE PAYMENT SYSTEM.-Section

4 1888(e)(2)(A)(ii) of the Social Security Act (42

$5 \quad$ U.S.C. $1395 y y(\mathrm{e})(2)(\mathrm{A})(\mathrm{ii}))$, as amended by section $61307(\mathrm{a})$, is amended by inserting "marriage and 7 family therapist services (as defined in subsection $8 \quad(j j j)(1))$, , after "clinical social worker services,".

(6) Coverage of marriage AND Family 10 THERAPIST SERVICES PROVIDED IN RURAL HEALTH 11 CLINICS AND FEDERALLY QUALIFIED HEALTH CEN12 TERs.-Section 1861(aa)(1)(B) of the Social Secu13 rity Act (42 U.S.C. $1395 x($ aa $)(1)(B))$ is amended by 14 striking "or by a clinical social worker (as defined 15 in subsection (hh)(1))," and inserting " , by a clinical 16 social worker (as defined in subsection $(\mathrm{hh})(1)$ ), or 17 by a marriage and family therapist (as defined in 18 subsection (jjj) (2)), '.

(7) InCludsion of MARrLage AND FAMily THERAPISTS AS PRACTITIONERS FOR ASSIGNMENT 21 OF CLAIMS.-Section 1842(b)(18)(C) of the Social 22 Security Act (42 U.S.C. $1395 u(b)(18)(C)$ ) is amend23 ed by adding at the end the following new clause:

24 "(vii) A marriage and family therapist (as de25 fined in section 1861(jjj)(2)).'. 
1 (b) Coverage of Mental Health Counselor

2 SERVICES.-

3

4

5

6 amended-

7

8

9

10

11

12

13

14 fined in subsection $(\mathrm{kkk})(1)) ; "$.

15

16

17

18 lowing new subsection:

19

20

"Mental Health Counselor Services “(kkk)(1) The term 'mental health counselor services'

21 means services performed by a mental health counselor (as

22 defined in paragraph (2)) for the diagnosis and treatment 23 of mental illnesses which the mental health counselor is 24 legally authorized to perform under State law (or the 25 State regulatory mechanism provided by the State law) of 
1 the State in which such services are performed, as would

2 otherwise be covered if furnished by a physician or as inci-

3 dent to a physician's professional service, but only if no

4 facility or other provider charges or is paid any amounts

5 with respect to the furnishing of such services.

6 “(2) The term 'mental health counselor' means an

7 individual who-

8

9

10 cation for the practice of mental health counseling in

11 the State in which the services are performed;

12

13 formed at least 2 years of supervised mental health

14 counselor practice; and

15

16 counselor or professional counselor by the State in

17 which the services are performed.'.
"(C) is licensed or certified as a mental health

(3) Provision for Payment under Part B.- Section 1832(a)(2)(B) of the Social Security Act (42 U.S.C. $1395 \mathrm{k}(\mathrm{a})(2)(\mathrm{B}))$, as amended by subsection (a)(3), is further amended-

(A) by striking "and" at the end of clause (iv);

(B) by adding "and" at the end of clause (v); and 
(C) by adding at the end the following new

clause:

“(vi) mental health counselor services;".

(4) Amount of Payment.-

(A) IN GENERAL.-Section 1833(a)(1) of the Social Security Act (42 U.S.C. 1395l(a)(1)), as amended by subsection (a), is further amended-

(i) by striking "and" before "(X)"; and

(ii) by inserting before the semicolon at the end the following: ", and (Y), with respect to mental health counselor services under section $1861(\mathrm{~s})(2)(\mathrm{HH})$, the amounts paid shall be 80 percent of the lesser of the actual charge for the services or 75 percent of the amount determined for payment of a psychologist under clause (L)" .

(B) Development of CRiteria with RESPECT TO CONSULTATION WITH A PHYSICIAN.The Secretary of Health and Human Services shall, taking into consideration concerns for patient confidentiality, develop criteria with re- 
spect to payment for mental health counselor services for which payment may be made directly to the mental health counselor under part B of title XVIII of the Social Security Act (42 U.S.C. 1395j et seq.) under which such a counselor must agree to consult with a patient's attending or primary care physician in accordance with such criteria.

(5) Exclusion of mental health coun10 SELOR SERVICES FROM SKILLED NURSING FACILITY 11 PRospective PAYMENT SYSTEM.-Section $121888(\mathrm{e})(2)(\mathrm{A})(\mathrm{ii})$ of the Social Security Act (42 13 U.S.C. 1395yy(e)(2)(A)(ii)), as amended by section $14 \quad 1307$ (a) and subsection (a), is amended by inserting 15 "mental health counselor services (as defined in sec16 tion 1861(kkk)(1))," after "marriage and family 17 therapist services (as defined in subsection $18 \quad(j \mathrm{jjj})(1)), "$.

(6) Coverage of mental health coun20 SELOR SERVICES PROVIDED IN RURAL HEALTH 21 Clinics and federally QUaLified health CEN22 TERS.-Section 1861(aa)(1)(B) of the Social Secu23 rity Act (42 U.S.C. 1395x(aa)(1)(B)), as amended 24 by subsection (a), is amended by striking "or by a 25 marriage and family therapist (as defined in sub- 
1 section (j.jj)(2))," and inserting "by a marriage and

2 family therapist (as defined in subsection (j.jj)(2)), 3 or a mental health counselor (as defined in sub4 section $(k k k)(2))$,".

(7) Inclusion of mental health COUN6 SELORS AS PRACTITIONERS FOR ASSIGNMENT OF 7 Clatms.-Section 1842(b)(18)(C) of the Social Se8 curity Act (42 U.S.C. $1395 \mathrm{u}(\mathrm{b})(18)(\mathrm{C})$ ), as amended 9 by subsection (a)(7), is amended by adding at the 10 end the following new clause:

11 "(viii) A mental health counselor (as defined in 12 section $1861(\mathrm{kkk})(2)) . ”$.

13 (c) EFfective Date.-The amendments made by 14 this section shall apply to items and services furnished on 15 or after January 1, 2011.

16 SEC. 1309. EXTENSION OF PHYSICIAN FEE SCHEDULE MENTAL HEALTH ADD-ON.

18 Section 138(a)(1) of the Medicare Improvements for 19 Patients and Providers Act of 2008 (Public Law 110-275) 20 is amended by striking "December $31,2009 "$ and insert21 ing "December 31, 2011".

22 SEC. 1310. EXPANDING ACCESS TO VACCINES.

23 (a) In GeneraL.-Paragraph (10) of section 24 1861(s) of the Social Security Act (42 U.S.C. 1395w(s)) 25 is amended to read as follows: 
“(10) federally approved and recommended vac-

2 cines (as defined in subsection (lll)) and their re3 spective administration;".

4 (b) Federally Approved and Recommended

5 Vaccines Defined.-Section 1861 of such Act is further 6 amended by adding at the end the following new sub7 section:

8 "Federally Approved and Recommended Vaccines

9 “(Ill) The term 'federally approved and recommended 10 vaccine' means a vaccine that-

11 "(1) is licensed under section 351 of the Public 12 Health Service Act, approved under the Federal 13 Food, Drug, and Cosmetic Act, or authorized for 14 emergency use under section 564 of the Federal, 15 Food, Drug, and Cosmetic Act; and

16 "(2) is recommended by the Director of the 17 Centers for Disease Control and Prevention.".

18 (c) Conforming Amendments.-

19 (1) Section 1833 of such Act (42 U.S.C. 1395l) 20 is amended, in each of subsections (a)(1)(B), $21 \quad(\mathrm{a})(2)(\mathrm{G}), \quad$ and $\quad(\mathrm{a})(3)(\mathrm{A}), \quad$ by $\quad$ striking 22 “1861(s)(10)(A)" and inserting "1861(s)(10)" each 23 place it appears.

24 (2) Section 1842(o)(1)(A)(iv) of such Act (42 25 U.S.C. $1395 \mathrm{u}(\mathrm{o})(1)(\mathrm{A})(\mathrm{iv}))$ is amended- 
(A) by striking "subparagraph (A) or (B)

of"; and

(B) by inserting before the period the following: "and before January 1, 2011, and influenza vaccines furnished on or after January 1, $2011 ”$.

(3) Section $1847 \mathrm{~A}(\mathrm{c})(6)$ of such Act (42 U.S.C. $1395 \mathrm{w}-3 \mathrm{a}(\mathrm{c})(6))$ is amended-

(A) in subparagraph (D)(i), by inserting “, including a vaccine furnished on or after January 1, 2010"; and

(B) by the following new paragraph:

"(H) Implementation.-Chapter 35 of title 44, United States Code shall not apply to manufacturer provision of information pursuant to section $1927(\mathrm{~b})(3)(\mathrm{A})(\mathrm{iii})$ or subsection (f)(2) for purposes of implementation of this section.".

(4) Section 1860D-2(e)(1) of such Act (42 U.S.C. 1395w-102(e)(1)) is amended by striking "such term includes a vaccine" and all that follows through "its administration) and".

(5) Section 1861(ww)(2)(A) of such Act (42 U.S.C. $1395 \mathrm{x}(\mathrm{ww})(2)(\mathrm{A}))$ ) is amended by striking "Pneumococcal, influenza, and hepatitis $\mathrm{B}$ vaccine 
1 and administration" and inserting "federally ap-

2 proved or authorized vaccines (as defined in sub3 section (lll)) and their respective administration".

4 (6) Section 1927(b)(3)(A)(iii) of such Act (42

5 U.S.C. $1396 \mathrm{r}-8(\mathrm{~b})(3)(\mathrm{A})(\mathrm{iii}))$ is amended, in the 6 matter following subclause (III), by inserting 7 “(A)(iv) (including influenza vaccines furnished on 8 or after January 1, 2011)," after “described in sub9 paragraph".

10 (7) Section $1847 \mathrm{~A}(\mathrm{f})$ of such Act (42 U.S.C. $11 \quad 1395 \mathrm{w}-3 \mathrm{a}(\mathrm{f}))$ is amended-

(A) by striking "For" and inserting "(1) IN GENERAL.-For';

(B) by indenting paragraph (1), as redesignated in subparagraph (A), 2 ems to the left; and-

(C) by adding at the end the following new paragraph:

21 biological described in subparagraphs (A)(iv), (C), 22 (D), (E), or (G) of section 1842(o)(1) that does not 23 have a rebate agreement under section 1927(a), no 24 payment may be made under this part for such drug 25 or biological if such manufacturer does not submit 
1 the information described in section $21927(\mathrm{~b})(3)(\mathrm{A})(\mathrm{iii})$ in the same manner as if the 3 manufacturer had such a rebate agreement in effect. 4 Subparagraphs (C) and (D) of section 1927(b)(3)

5 shall apply to information reported pursuant to the 6 previous sentence in the same manner as such sub7 paragraphs apply with respect to information re8 ported pursuant to such section.".".

9 (d) EfFective Dates.-The amendments made-

10 (1) by this section (other than by subsection 11 (c)(6)) shall apply to vaccines administered on or 12 after January 1, 2011; and

13 (2) by subsection (c)(6) shall apply to calendar 14 quarters beginning on or after January 1, 2010.

15 SEC. 1311. EXPANSION OF MEDICARE-COVERED PREVENTIVE SERVICES AT FEDERALLY QUALIFIED HEALTH CENTERS.

18 (a) In GeneraL.-Section 1861(aa)(3)(A) of the So19 cial Security Act (42 U.S.C. 1395w (aa)(3)(A)) is amend20 ed to read as follows: paragraphs (A) through (C) of paragraph (1) and services described in section 1861(iii); 24 and". 
1 (b) EfFective Date.-The amendment made by

2 subsection (a) shall apply not later than January 1, 2011.

3 SEC. 1312. INDEPENDENCE AT HOME DEMONSTRATION PROGRAM.

5 Title XVIII of the Social Security Act is amended by 6 inserting after section $1866 \mathrm{~F}$, as inserted by section 1302 ,

7 the following new section:

"INDEPENDENCE AT HOME MEDICAL PRACTICE

DEMONSTRATION PROGRAM

10 "SEc. 1866G. (a) Establishment.-

11 "(1) In GENERAL.-The Secretary shall con12 duct a demonstration program (in this section re13 ferred to as the 'demonstration program') to test a 14 payment incentive and service delivery model that 15 utilizes physician and nurse practitioner directed 16 home-based primary care teams designed to reduce 17 expenditures and improve health outcomes in the 18 provision of items and services under this title to ap19 plicable beneficiaries (as defined in subsection (d)). 20 “(2) REQUIREMENT.-The demonstration pro21 gram shall test whether a model described in para22 graph (1), which is accountable for providing com23 prehensive, coordinated, continuous, and accessible 24 care to high-need populations at home and coordi25 nating health care across all treatment settings, re26 sults in- 
“(A) reducing preventable hospitalizations;

“(B) preventing hospital readmissions;

"(C) reducing emergency room visits;

"(D) improving health outcomes commensurate with the beneficiaries' stage of chronic illness;

"(E) improving the efficiency of care, such as by reducing duplicative diagnostic and laboratory tests;

"(F) reducing the cost of health care services covered under this title; and

"(G) achieving beneficiary and family caregiver satisfaction.

“(b) Independence at Home Medical PracTICE.-

“(1) Independence at home MedicaL PRACTICE DEFINED.-In this section:

"(A) In GENERAL.-The term 'independence at home medical practice' means a legal entity that-

"(i) is comprised of an individual physician or nurse practitioner or group of physicians and nurse practitioners that provides care as part of a team that includes physicians, nurses, physician assist- 
ants, pharmacists, and other health and social services staff as appropriate who have experience providing home-based primary care to applicable beneficiaries, make in-home visits, and are available 24 hours per day, 7 days per week to carry out plans of care that are tailored to the individual beneficiary's chronic conditions and designed to achieve the results in subsection (a);

"(ii) is organized at least in part for the purpose of providing physicians' services;

"(iii) has documented experience in providing home-based primary care services to high cost chronically ill beneficiaries, as determined appropriate by the Secretary;

"(iv) includes at least 200 applicable beneficiaries as defined in subsection (d);

"(v) has entered into an agreement with the Secretary;

"(vi) uses electronic health information systems, remote monitoring, and mobile diagnostic technology; and 
"(vii) meets such other criteria as the

Secretary determines to be appropriate to participate in the demonstration program. “(B) Physiclan.-The term 'physician' includes, except as the Secretary may otherwise provide, any individual who furnishes services for which payment may be made as physicians' services and has the medical training or experience to fulfill the physician's role described in subparagraph (A)(i).

“(2) Participation of nurse PRactitioners AND PHYSICIAN ASSISTANTS.-Nothing in this section shall be construed to prevent a nurse practitioner or physician assistant from participating in, or leading, a home-based primary care team as part of an independence at home medical practice if"(A) all the requirements of this section are met;

"(B) the nurse practitioner or physician assistant, as the case may be, is acting consistent with State law; and

"(C) the nurse practitioner or physician assistant has the medical training or experience to fulfill the nurse practitioner or physician assistant role described in paragraph (1)(A)(i). 

TIONERS.-Nothing in this subsection shall be construed as preventing an independence at home med-

4 ical practice from including a provider of services or 5 a participating practitioner described in section $61842(b)(18)(C)$ that is affiliated with the practice 7 under an arrangement structured so that such pro8 vider of services or practitioner participates in the 9 demonstration program and shares in any savings 10 under the demonstration program. “(4) Quality and PERFormance STAND12 ARDS.home medical practice participating in the demonstration program shall report on quality measures (in such form, manner, and frequency as specified by the Secretary, which may be for the group, for providers of services and suppliers, or both) and report to the Secretary (in a form, manner, and frequency as specified by the Secretary) such data as the Secretary determines appropriate to monitor and evaluate the demonstration program.

“(B) Development OF Quality PeRFORMANCE STANDARDS.-The Secretary shall 
1 develop quality performance standards for independence at home medical practices participating in the demonstration program. “(c) Shared Savings Payment Methodology.“(1) Establishment of TARget sPending

6 LEVEL.-The Secretary shall establish annual target 7 spending levels for items and services covered under 8 parts $\mathrm{A}$ and $\mathrm{B}$ furnished to applicable beneficiaries 9 by qualifying independence at home medical prac10 tices under this section. The Secretary may set an 11 aggregate target spending level for all qualifying 12 practices, or may set different target spending levels 13 for groups of practices or a single practice. Such 14 target spending levels may be determined on a per 15 capita basis and shall take into account normal vari16 ation in expenditures for items and services covered 17 under parts A and B furnished to such beneficiaries. 18 The target shall also be adjusted for the size of the 19 practice, number of practices included in the target 20 spending level, characteristics of applicable bene21 ficiaries and such other factors as the Secretary de22 termines appropriate. The Secretary may periodi23 cally adjust or rebase the target spending level $24 \quad$ under this paragraph.

25 “(2) Shared savings amounts.- 
“(A) IN GENERAL.—Subject to subparagraph (B), qualifying independence at home medical practices are eligible to receive an incentive payment under this section if aggregate expenditures for a year for applicable beneficiaries are less than the target spending level for qualifying independence at home medical practices for such year. An incentive payment for such year shall be equal to a portion (as determined by the Secretary) of the amount by which total payments for applicable beneficiaries under parts A and B for such year are estimated to be less than 5 percent less than the target spending level for such year, as determined by the Secretary.

"(B) Apportionment of savings.-The Secretary shall designate how, and to what extent, an incentive payment under this section is to be apportioned among qualifying independence at home medical practices, taking into account the size of the practice, characteristics of the individuals enrolled in each practice, performance on quality performance measures, and such other factors as the Secretary determines appropriate. 
2 The Secretary shall limit incentive payments to each 3 qualifying independence at home medical practice 4 under this paragraph, with respect to a year, as nec-

5 essary to ensure that the aggregate expenditures for 6 items and services under parts A and B with respect 7 to applicable beneficiaries for such independence at 8 home medical practice (inclusive of shared savings 9 payments) do not exceed the amount that the Sec10 retary estimates would be expended for such items 11 and services for such beneficiaries during such year 12 (taking into account normal variation in expendi13 tures and other factors the Secretary deems appro14 priate) if the demonstration program under this sec15 tion were not implemented, minus 5 percent.

16 “(d) Applicable Benefictaries.-

17 “(1) Definition.-In this section, the term 18 'applicable beneficiary' means, with respect to a 19 qualifying independence at home medical practice, 20 an individual who the practice has determined-

"(A) is entitled to benefits under part A and enrolled for benefits under part B; "(B) is not enrolled in a Medicare Advantage plan under part $\mathrm{C}$ or a PACE program $25 \quad$ under section 1894 ; 
"(C) has 2 or more chronic illnesses, such as congestive heart failure, diabetes, other dementias designated by the Secretary, chronic obstructive pulmonary disease, ischemic heart disease, stroke, Alzheimer's Disease and neurodegenerative diseases, and other diseases and conditions designated by the Secretary which result in high costs under this title;

"(D) within the past 12 months has had a nonelective hospital admission;

"(E) within the past 12 months has received acute or subacute rehabilitation services; "(F) has 2 or more functional dependencies requiring the assistance of another person (such as bathing, dressing, toileting, walking, or feeding); and "(G) meets such other criteria as the Secretary determines appropriate. “(2) Patient Election TO PARTicipate.20 The Secretary shall determine an appropriate meth21 od of ensuring that applicable beneficiaries have 22 agreed to enroll in an independence at home medical 23 practice under the demonstration program. Enroll24 ment in the demonstration program shall be vol25 untary. 

Nothing in this section shall be construed as encour-

3 aging physicians or nurse practitioners to limit ap-

4 plicable beneficiary access to services covered under

5 this title and applicable beneficiaries shall not be re-

6 quired to relinquish access to any benefit under this

7 title as a condition of receiving services from an

8 independence at home medical practice.

9 “(e) ImPLEMENTATION.-

10 “(1) StaRTing Date.-The demonstration pro11 gram shall begin not later than January 1, 2012. An 12 agreement with an independence at home medical 13 practice under the demonstration program may 14 cover not more than a 3-year period.

15 “(2) No PHYSICIAN DUPLICATION IN DEM16 ONSTRATION PARTICIPATION.-The Secretary shall 17 not pay an independence at home medical practice 18 under this section that participates in section $1866 \mathrm{D}$ 19 or section 1866E.

20 “(3) NO BENEFICLARY DUPLICATION IN DEM21 ONSTRATION PARTICIPATION.-The Secretary shall 22 ensure that no applicable beneficiary enrolled in an 23 independence at home medical practice under this 24 section is participating in the programs under sec25 tion $1866 \mathrm{D}$ or section $1866 \mathrm{E}$. 
“(4) Preference.-In approving an independ-

ence at home medical practice, the Secretary shall give preference to practices that are-

"(A) located in high-cost areas of the country;

"(B) have experience in furnishing health care services to applicable beneficiaries in the home; and

"(C) use electronic medical records, health information technology, and individualized plans of care.

“(5) Number of PRACTICES.-

“(A) IN GENERAL.-Subject to subparagraph (B), the Secretary shall enter into agreements with as many independence at home medial practices as practicable and consistent with this subsection to test the potential of the independence at home medical practice model under this section in order to achieve the results described in subsection (a) across practices serving varying numbers of applicable beneficiaries. “(B) Limitation.-In selecting qualified independence at home medial practices to participate under the demonstration program, the Secretary shall limit the number of applicable 
1 beneficiaries that may participate in the demonstration program to 10,000 .

“(6) WAIVER.—The Secretary may waive such

4 provisions of this title and title XI as the Secretary

5 determines necessary in order to implement the dem6 onstration program.

"(7) Administration.-Chapter 35 of title 44,

8 United States Code, shall not apply to this section.

9 “(f) Evaluation and Monitoring.-

10 "(1) In GENERAL.—The Secretary shall evalu-

11 ate each independence at home medical practice

12 under the demonstration program to assess whether

13 the practice achieved the results described in sub-

14 section (a).

15

“(2) Following APPLiCABLe BENE-

16 FICIARIES.-The Secretary may monitor data on ex-

17 penditures and quality of services under this title

18 after an applicable beneficiary discontinues receiving

19 services under this title through a qualifying inde-

20 pendence at home medical practice.

21 "(g) REports to Congress.-The Secretary shall 22 conduct an independent evaluation of the demonstration 23 program and submit to Congress a final report, including 24 best practices under the demonstration program. Such re25 port shall include an analysis of the demonstration pro- 
1 gram on coordination of care, expenditures under this

2 title, applicable beneficiary access to services, and the

3 quality of health care services provided to applicable bene-

4 ficiaries.

5 “(h) Funding.-For purposes of administering and 6 carrying out the demonstration program, other than for

7 payments for items and services furnished under this title 8 and shared savings under subsection (c), in addition to

9 funds otherwise appropriated, there shall be transferred

10 to the Secretary for the Center for Medicare \& Medicaid

11 Services Program Management Account from the Federal

12 Hospital Insurance Trust Fund under section 1817 and

13 the Federal Supplementary Medical Insurance Trust

14 Fund under section $1841 \$ 5,000,000$ for each of fiscal

15 years 2010 through 2015. Amounts transferred under this

16 subsection for a fiscal year shall be available until ex17 pended.

18 “(i) Antidiscrimination Limitation.-The Sec19 retary shall not enter into an agreement with an entity 20 to provide health care items or services under the dem21 onstration program unless such entity guarantees that for 22 individuals eligible to be enrolled in such program, the en23 tity will not deny, limit, or condition the coverage or provi24 sion of benefits to which the individual would have other- 
1 wise been entitled to on the basis of health status if not

2 included in this program.

3 “(j) Termination.-The Secretary may terminate

4 an agreement with an independence at home medical prac-

5 tice if such practice does not receive incentive payments

6 under subsection (c)(2) or consistently fails to meet qual-

7 ity standards.".

8 SEC. 1313. RECOGNITION OF CERTIFIED DIABETES EDUCATORS AS CERTIFIED PROVIDERS FOR PURPOSES OF MEDICARE DIABETES OUTPATIENT SELF-MANAGEMENT TRAINING SERVICES.

12 (a) In General.-Section 1861(qq) of the Social Se13 curity Act (42 U.S.C. $1395 \mathrm{x}(\mathrm{qq})$ ) is amended-

(1) in paragraph (1), by inserting "or by a cer15 tified diabetes educator (as defined in paragraph 16 (3))" after "paragraph (2)(B)"; and

17 (2) by adding at the end the following new 18 paragraphs:

"(3) For purposes of paragraph (1), the term 20 'certified diabetes educator' means an individual 21 whoin which the services are performed as a health care professional; 
"(B) specializes in teaching individuals with diabetes to develop the necessary skills and knowledge to manage the individual's diabetic condition; and

"(C) is certified as a diabetes educator by a recognized certifying body (as defined in paragraph (4)).

“(4)(A) For purposes of paragraph $(3)(C)$, the term 'recognized certifying body' means-

"(i) the National Certification Board for Diabetes Educators, or

“(ii) a certifying body for diabetes educators, which is recognized by the Secretary as authorized to grant certification of diabetes educators for purposes of this subsection pursuant to standards established by the Secretary, if the Secretary determines such Board or body, respectively, meets the requirement of subparagraph (B).

21 betes Educators or a certifying body for diabetes 22 educators meets the requirement of this subpara23 graph, with respect to the certification of an indi24 vidual, if the Board or body, respectively, is incor25 porated and registered to do business in the United 
1 States and requires as a condition of such certifi-

2 cation each of the following:

17 agement training services furnished on or after the first 18 day of the first calendar year that is at least 6 months 19 after the date of the enactment of this Act.

25 is amended by adding at the end the following new part:

"(i) The individual has a qualifying credential in a specified health care profession.

"(ii) The individual has professional practice experience in diabetes self-management training that includes a minimum number of hours and years of experience in such training.

"(iii) The individual has successfully completed a national certification examination offered by such entity.

"(iv) The individual periodically renews certification status following initial certification.".

(b) Effective Date.-The amendments made by TITLE IV-QUALITY Subtitle A-Comparative Effectiveness Research SEC. 1401. COMPARATIVE EFFECTIVENESS RESEARCH.

(a) In General._-Title XI of the Social Security Act 
"Part D—Comparative Effectiveness Research

"COMPARATIVE EFFECTIVENESS RESEARCH

4 tiveness Research Established.-

“(1) In GENERAL.-The Secretary shall estab-

6 lish within the Agency for Healthcare Research and

7 Quality a Center for Comparative Effectiveness Re-

8 search (in this section referred to as the 'Center') to

9 conduct, support, and synthesize research (including

10 research conducted or supported under section 1013

11 of the Medicare Prescription Drug, Improvement,

12 and Modernization Act of 2003) with respect to the

13 outcomes, effectiveness, and appropriateness of

14 health care services and procedures in order to iden-

15 tify the manner in which diseases, disorders, and

16 other health conditions can most effectively and ap-

17 propriately be prevented, diagnosed, treated, and 18 managed clinically.

"(A) conduct, support, and synthesize research relevant to the comparative effectiveness of the full spectrum of health care items, serv23 ices and systems, including pharmaceuticals, 24 medical devices, medical and surgical proce25 dures, and other medical interventions; 
"(B) conduct and support systematic reviews of clinical research, including original research conducted subsequent to the date of the enactment of this section;

"(C) continuously develop rigorous scientific methodologies for conducting comparative effectiveness studies, and use such methodologies appropriately;

"(D) submit to the Comparative Effectiveness Research Commission, the Secretary, and Congress appropriate relevant reports described in subsection $(d)(2)$;

"(E) not later than one year after the date of the enactment of this section, enter into an arrangement under which the Institute of Medicine of the National Academy of Sciences shall conduct an evaluation and report on standards of evidence for highly credible research; "(F) encourage, as appropriate, the development and use of clinical registries and the development of clinical effectiveness research data networks from electronic health records, post marketing drug and medical device surveillance efforts, and other forms of electronic health data; and 
"(G) appoint clinical perspective advisory panels for research priorities under this section, which shall consult with patients and other stakeholders and advise the Center on research questions, methods, and evidence gaps in terms of clinical outcomes for the specific research inquiry to be examined with respect to such priority to ensure that the information produced from such research is clinically relevant to decisions made by clinicians and patients at the point of care. “(3) Powers.-

"(A) Obtaining official Data.-The Center may secure directly from any department or agency of the United States information necessary to enable it to carry out this section. Upon request of the Center, the head of such department or agency shall furnish that information to the Center on an agreed upon schedule.

"(B) Data collection.-In order to carry out its functions, the Center shall"(i) utilize existing information, both published and unpublished, where possible, collected and assessed either by its own 
staff or under other arrangements made in

accordance with this section;

"(ii) carry out, or award grants or

contracts for, original research and experimentation, where existing information is inadequate; and

"(iii) adopt procedures allowing any interested party to submit information for the use by the Center in making reports and recommendations.

In carrying out clause (ii), the Center may award grants or contracts (or provide for intergovernmental transfers, as applicable) to private entities and governmental agencies with experience in conducting comparative effectiveness research, such as the National Institutes of Health and other relevant Federal health agencies.

"(C) Access of gao to information.The Comptroller General shall have unrestricted access to all deliberations, records, and nonproprietary data of the Center and Commission under subsection (b), immediately upon request. “(D) Periodic AUdiT.- The Center and Commission under subsection (b) shall be sub- 
1 ject to periodic audit by the Comptroller Gen-

2 eral.

3 “(b) Comparative Effectiveness Research

4 Commission.-

"(1) IN GENERAL.-There is established an

6 independent Comparative Effectiveness Research

7 Commission (in this section referred to as the 'Com-

8 mission') to advise the Center and evaluate the ac-

9 tivities carried out by the Center under subsection

10 (a) to ensure such activities result in highly credible

11 research and information resulting from such re12 search.

“(2) Duties.-The Commission shall"(A)(i) recommend to the Center national priorities for research described in subsection

(a) which shall take into account-

“(I) disease incidence, prevalence, and

burden in the United States;

"(II) evidence gaps in terms of clinical

outcomes;

“(III) variations in practice, delivery, and outcomes by geography, treatment site, provider type, disability, variation in 25 age group (including children, adolescents, adults, and seniors), racial and ethnic 
background, gender, genetic and molecular subtypes, and other appropriate populations or subpopulations; and "(IV) the potential for new evidence concerning certain categories, health care services, or treatments to improve patient health and well-being, and the quality of care; and

"(ii) in making such recommendations consult with a broad array of public and private stakeholders, including patients and health care providers and payers;

"(B) monitor the appropriateness of use of the CERTF described in subsection (g) with respect to the timely production of comparative effectiveness research recommended to be a national priority under subparagraph (A);

“(C) identify highly credible research methods and standards of evidence for such research to be considered by the Center;

"(D) review the methodologies developed by the center under subsection (a)(2)(C); "(E) support forums to increase stakeholder awareness and permit stakeholder feedback on the efforts of the Center to advance 
methods and standards that promote highly credible research;

"(F) make recommendations to the Center for policies that would allow for public access of data produced under this section, in accordance

with appropriate privacy and proprietary practices, while ensuring that the information produced through such data is timely and credible;

"(G) make recommendations to the Center for the priority for periodic reviews of previous comparative effectiveness research and studies conducted by the Center under subsection (a); "(H) at least annually review the processes of the Center and make reports to Congress and the President regarding research conducted, supported, or synthesized by the Center to confirm that the information produced by such research is objective, credible, consistent with standards of evidence developed under this section, and developed through a transparent process that includes consultations with appropriate stakeholders;

"(I) make recommendations to the Center for the broad dissemination, consistent with subsection (e), of the findings of research con- 
ducted and supported under this section that enables clinicians, patients, consumers, and payers to make more informed health care decisions that improve quality and value; and

“(J) at least twice each year, hold a public meeting with an opportunity for stakeholder input.

8 The reports under subparagraph $(\mathrm{H})$ shall not be 9 submitted to the Office of Management and Budget 10 or to any other Federal agency or executive depart11 ment for any purpose prior to transmittal to Con12 gress and the President. Such reports shall be pub13 lished on the public internet website of the Commis14 sion after the date of such transmittal.

"(3) Composition of commission.-

"(A) IN GENERAL.-The members of the Commission shall consist ofHealthcare Research and Quality or their designee;

"(ii) the Chief Medical Officer of the Centers for Medicare \& Medicaid Services or their designee;

"(iii) the Director of the National Institutes of Health or their designee; and 
"(iv) 16 additional members who shall represent broad constituencies of stakeholders including clinicians, patients, researchers, third-party payers, and consumers of Federal and State beneficiary programs.

Of such members, at least 10 shall be practicing physicians, health care practitioners, consumers, or patients.

"(B) Qualifications.-

“(i) Diverse REPRESENTATION OF PERSPECTIVES.-The members of the Commission shall represent a broad range of perspectives and shall collectively have experience in the following areas:

“(I) Epidemiology.

"(II) Health services research.

"(III) Bioethics.

“(IV) Decision sciences.

"(V) Health disparities.

"(VI) Health economies.

“(ii) Diverse RePRESEntation OF HEALTH CARE COMMUNITY.-At least one member shall represent each of the following health care communities: 
“(I) Patients.

"(II) Health care consumers.

“(III) Practicing Physicians, in-

cluding surgeons.

"(IV) Other health care practitioners engaged in clinical care.

“(V) Organizations with proven expertise in racial and ethnic minority health research.

“(VI) Employers.

"(VII) Public payers.

“(VIII) Insurance plans.

"(IX) Clinical researchers who conduct research on behalf of pharmaceutical or device manufacturers.

"(C) Limitation.-No more than 3 of the Members of the Commission may be representatives of pharmaceutical or device manufacturers and such representatives shall be clinical researchers described under subparagraph (B) (ii)(IX).

“(4) Appointment.-The Comptroller General shall appoint the members of the Commission. “(5) Chairman; vice chairman.-The Comptroller General shall designate a member of the 
1 Commission, at the time of appointment of the mem-

2 ber, as Chairman and a member as Vice Chairman

3 for that term of appointment, except that in the case

4 of vacancy of the Chairmanship or Vice Chairman-

5 ship, the Comptroller General may designate another

6 member for the remainder of that member's term.

7 The Chairman shall serve as an ex officio member

8 of the National Advisory Council of the Agency for

9 Health Care Research and Quality under section

$10931(\mathrm{c})(3)(\mathrm{B})$ of the Public Health Service Act.

11

12

13

14

15

16

17

18

23 business of the Commission (including travel time), 24 a member of the Commission shall be entitled to 25 compensation at the per diem equivalent of the rate 
1 provided for level IV of the Executive Schedule

2 under section 5315 of title 5, United States Code;

3 and while so serving away from home and the mem-

4 ber's regular place of business, a member may be al-

5 lowed travel expenses, as authorized by the Director 6 of the Commission.

“(8) DIRECTOR AND STAFF; EXPERTS AND

8 CONSUltants. - Subject to such review as the

9 Comptroller General deems necessary to assure the

10 efficient administration of the Commission, the Com-

11 mission may-

12 "(A) appoint and set the compensation for

13 an Executive Director (subject to the approval

14 of the Comptroller General) and such other per-

15 sonnel as Federal employees under section 2105

16 of title 5, United States Code, as may be nec-

17 essary to carry out its duties (without regard to

18 the provisions of title 5, United States Code,

19 governing appointments in the competitive serv-

20 ice);

"(B) seek such assistance and support as 22 may be required in the performance of its du23 ties from appropriate Federal departments and 24 agencies; 
"(C) enter into contracts or make other arrangements, as may be necessary for the conduct of the work of the Commission (without regard to section 3709 of the Revised Statutes (41 U.S.C. 5));

"(D) make advance, progress, and other payments which relate to the work of the Commission;

"(E) provide transportation and subsistence for persons serving without compensation; and

"(F) prescribe such rules and regulations as it deems necessary with respect to the internal organization and operation of the Commission.

17 mission may secure directly from any department or 18 agency of the United States information necessary 19 to enable the Commission to carry out this section. 20 Upon request of the Chairman of the Commission, 21 the head of such department or agency shall furnish 22 the information to the Commission on an agreed 23 upon schedule. "(10) Availability of Reports.-The Com25 mission shall transmit to the Secretary a copy of 
1 each report submitted under this subsection and

2 shall make such reports available to the public.

"(11) Coordination.-To enhance effective-

4 ness and coordination, the Secretary is encouraged,

5 to the greatest extent possible, to seek coordination

6 between the Commission and the National Advisory

7 Council of the Agency for Healthcare Research and

8 Quality.

9

10

11

12

13

14

15

16

17

18

19

20

21

22

23

24

25
"(12) CONFlicts of interest.-

"(A) IN GENERAL.-In appointing the members of the Commission or a clinical perspective advisory panel described in subsection (a) $(2)(G)$, the Comptroller General or the Secretary, respectively, shall take into consideration any financial interest (as defined in subparagraph (D)), consistent with this paragraph, and develop a plan for managing any identified conflicts.

"(B) Evaluation and Criteria.-When considering an appointment to the Commission or a clinical perspective advisory panel described subsection (a)(2)(G), the Comptroller General or the Secretary, respectively, shall review the expertise of the individual and the financial disclosure report filed by the individual 
pursuant to the Ethics in Government Act of 1978 for each individual under consideration for the appointment, so as to reduce the likelihood that an appointed individual will later require a written determination as referred to in

section 208(b)(1) of title 18, United States Code, a written certification as referred to in section 208(b)(3) of title 18, United States Code, or a waiver as referred to in subparagraph (D)(iii) for service on the Commission at a meeting of the Commission.

“(C) Disclosures; PRohibitions ON PARTICIPATION; WAIVERS.-

“(i) Disclosure OF Financial INTEREST.-Prior to a meeting of the Commission or a clinical perspective advisory panel described in subsection (a)(2)(G) regarding a 'particular matter' (as that term is used in section 208 of title 18, United States Code), each member of the Commission or the clinical perspective advisory panel who is a full-time Government employee or special Government employee shall disclose to the Comptroller General or Secretary, respectively, financial interests 
in accordance with requiring a waiver under section 208(b) of title 18, United States Code, or other interests as deemed relevant by the Secretary.

"(ii) Prohibitions ON PARTICIPATION.-Except as provided under clause (iii), a member of the Commission or a clinical perspective advisory panel described in subsection $(a)(2)(G)$ may not participate with respect to a particular matter considered in meeting of the Commission or the clinical perspective advisory panel if such member has a financial interest that could be affected by the advice given to the Secretary with respect to such matter, excluding interests exempted in regulations issued by the Director of the Office of Government Ethics as too remote or inconsequential to affect the integrity of the services of the Government officers or employees to which such regulations apply. "(iii) WAIVER.-If the Comptroller General or Secretary, as applicable, determines it necessary to afford the Commission or a clinical perspective advisory panel 
described in subsection (a)(2)(G) essential expertise, the Comptroller General or Secretary, respectively, may grant a waiver of the prohibition in clause (ii) to permit a member described in such subparagraph to-

“(I) participate as a non-voting member with respect to a particular matter considered in a meeting of the Commission or a clinical perspective advisory panel, respectively; or "(II) participate as a voting member with respect to a particular matter considered in a meeting of the Commission.

“(iv) Limitation ON WAIVERS AND OTHER EXCEPTIONS.-

“(I) Determination of AllowABLE EXCEPTIONS FOR THE COMMISSION.-The number of waivers granted to members of the Commission cannot exceed one-half of the total number of members for the Commission. 

ADVISORY PANELS.-No voting member of any clinical perspective advisory panel shall be in receipt of a waiver. No more than two nonvoting members of any clinical perspective advisory panel shall receive a waiver.

"(D) Financial interest Defined.For purposes of this paragraph, the term 'financial interest' means a financial interest under section 208(a) of title 18, United States Code.

“(13) Application OF FacA.-The Federal 15 Advisory Committee Act (other than section 14 of 16 such Act) shall apply to the Commission to the ex17 tent that the provisions of such Act do not conflict 18 with the requirements of this subsection.

19 “(c) Research Requirements.-Any research con20 ducted, supported, or synthesized under this section shall 21 meet the following requirements:

“(1) Ensuring TRANSPARENCY, CREDIBILITy, 23 AND ACCESS.da by the Center shall be informed by the na- 
tional priorities for research recommended under subsection $(\mathrm{b})(2)(\mathrm{A})$.

"(B) The establishment of the agenda and conduct of the research shall be insulated from inappropriate political or stakeholder influence. "(C) Methods of conducting such research shall be scientifically based.

“(D) Consistent with applicable law, all aspects of the prioritization of research, conduct of the research, and development of conclusions based on the research shall be transparent to all stakeholders.

"(E) Consistent with applicable law, the process and methods for conducting such research shall be publicly documented and available to all stakeholders.

"(F) Throughout the process of such research, the Center shall provide opportunities for all stakeholders involved to review and provide public comment on the methods and findings of such research.

"(G) Such research shall consider advice given to the Center by the clinical perspective advisory panel for the particular national research priority. 


\section{“(2) STAKEHOLDER INPUT.-}

"(A) IN GENERAL._The Commission shall consult with patients, health care providers, health care consumer representatives, and other appropriate stakeholders with an interest in the research through a transparent process recommended by the Commission.

"(B) SPECIFIC AREAS OF CONSUlTATION.-Consultation shall include where deemed appropriate by the Commission-

“(i) recommending research priorities and questions;

"(ii) recommending research methodologies; and

"(iii) advising on and assisting with efforts to disseminate research findings.

"(C) Ombudsman.-The Secretary shall designate a patient ombudsman. The ombudsman shall-

"(i) serve as an available point of contact for any patients with an interest in proposed comparative effectiveness studies by the Center; and

"(ii) ensure that any comments from patients regarding proposed comparative 
effectiveness studies are reviewed by the Center.

“(3) Taking into aCcount potential DiFFERENCES.-Research shall-

"(A) be designed, as appropriate, to take into account the potential for differences in the effectiveness of health care items, services, and systems used with various subpopulations such as racial and ethnic minorities, women, different age groups (including children, adolescents, adults, and seniors), individuals with disabilities, and individuals with different comorbidities and genetic and molecular subtypes; and-

"(B) seek, as feasible and appropriate, to include members of such subpopulations as subjects in the research.

\section{NESS INFORMATION.-}

"(1) In GeneRAL.-Not later than 90 days

21 after receipt by the Center or Commission, as appli22 cable, of a relevant report described in paragraph

23 (2) made by the Center, Commission, or clinical per24 spective advisory panel under this section, appro25 priate information contained in such report shall be 
1 posted on the official public Internet site of the Cen-

2 ter and of the Commission, as applicable.

“(2) Relevant Reports Described.-For

4 purposes of this section, a relevant report is each of

5 the following submitted by the Center or a grantee

6 or contractor of the Center:

"(A) Any interim or progress reports as

deemed appropriate by the Secretary.

“(B) Stakeholder comments. vide for the dissemination of appropriate findings

15 produced by research supported, conducted, or syn16 thesized under this section to health care providers, 17 patients, vendors of health information technology 18 focused on clinical decision support, relevant expert 19 organizations (as defined in subsection (i)(3)(A)), 20 and Federal and private health plans, and other rel21 evant stakeholders. In disseminating such findings 22 the Center shall-

"(A) convey findings of research so that they are comprehensible and useful to patients 25 and providers in making health care decisions; 
"(B) discuss findings and other considerations specific to certain sub-populations, risk factors, and comorbidities as appropriate;

"(C) include considerations such as limitations of research and what further research may be needed, as appropriate;

"(D) not include any data that the dissemination of which would violate the privacy of research participants or violate any confidentiality agreements made with respect to the use of data under this section; and

"(E) assist the users of health information technology focused on clinical decision support to promote the timely incorporation of such findings into clinical practices and promote the ease of use of such incorporation.

“(2) Dissemination PRotocols and strateGIES.-The Center shall develop protocols and strategies for the appropriate dissemination of research findings in order to ensure effective communication of findings and the use and incorporation of such findings into relevant activities for the purpose of informing higher quality and more effective and efficient decisions regarding medical items and services. In developing and adopting such protocols and strat- 
1 egies, the Center shall consult with stakeholders con-

2 cerning the types of dissemination that will be most

3 useful to the end users of information and may pro-

4 vide for the utilization of multiple formats for con-

5 veying findings to different audiences, including dis-

6 semination to individuals with limited English pro-

7 ficiency.

8 “(f) Reports to CONGREss.-

9 “(1) Annual REPORTs.-Beginning not later

10 than one year after the date of the enactment of this

11 section, the Director of the Agency of Healthcare

12 Research and Quality shall submit to Congress an

13 annual report on the activities of the Center, as well

14 as the research, conducted under this section. Each

15 such report shall include a discussion of the Center's

16 compliance with subsection $(\mathrm{c})(3)(\mathrm{B})$, including any

17 reasons for lack of compliance with such subsection.

18 “(2) ReCOMmendation FOR FAIR SHARE PER

19 CAPITA AMOUNT FOR ALL-PAYER FINANCING.-Be-

20 ginning not later than December 31, 2011, the Sec-

21 retary shall submit to Congress an annual rec-

22 ommendation for a fair share per capita amount de-

23 scribed in subsection (c)(1) of section 9511 of the

24 Internal Revenue Code of 1986 for purposes of

25 funding the CERTF under such section. 
“(3) Analysis AND REVIEW.-Not later than

2 December 31, 2013, the Secretary, in consultation

3 with the Commission, shall submit to Congress a re-

4 port on all activities conducted or supported under

5 this section as of such date. Such report shall in-

6 clude an evaluation of the overall costs of such ac-

7 tivities and an analysis of the backlog of any re-

8 search proposals approved by the Center but not

9 funded.

10 "(g) Funding of Comparative Effectiveness

11 ResearCH.-For fiscal year 2010 and each subsequent

12 fiscal year, amounts in the Comparative Effectiveness Re-

13 search Trust Fund (referred to in this section as the

14 'CERTF') under section 9511 of the Internal Revenue

15 Code of 1986 shall be available in accordance with such

16 section, without the need for further appropriations and

17 without fiscal year limitation, to carry out this section.

18 “(h) Construction.-

19 "(1) Coverage.-Nothing in this section shall

20 be construed-

"(A) to permit the Center or Commission to mandate coverage, reimbursement, or other policies for any public or private payer; or

"(B) as preventing the Secretary from cov25 ering the routine costs of clinical care received 
1 by an individual entitled to, or enrolled for, benefits under title XVIII, XIX, or XXI in the case where such individual is participating in a clinical trial and such costs would otherwise be covered under such title with respect to the bene6 ficiary. "(2) Reports AND FIndings.-None of the re8 ports submitted under this section or research find9 ings disseminated by the Center or Commission shall 10 be construed as mandates, for payment, coverage, or 11 treatment.

“(3) Protecting the Physiclan-Patient Re13 LATIONSHIP. - Nothing in this section shall be con14 strued to authorize any Federal officer or employee 15 to exercise any supervision or control over the prac16 tice of medicine.

17 “(i) Consultation With Relevant Expert OR18 ganizations.-

“(1) Consultation PRior to initiation of 20 RESEARCH.-Prior to recommending priorities or 21 initiating research described in this section, the 22 Commission or the Center shall consult with the rel23 evant expert organizations responsible for standards 24 and protocols of clinical excellence. Such consulta- 
1 tion shall be consistent with the processes estab-

2 lished under subsection (c)(2).

“(2) Consultation in dissemination OF RE-

4 SEARCH.-Any dissemination of research from the

5 Commission or the Center and findings made by the

6 Commission or the Center shall be consistent with

7 processes established under subsection (e) and

8 shall-

9 “(A) be based upon evidence-based medi-

$10 \quad$ cine; and

11 "(B) take into consideration standards and

12 protocols of clinical excellence developed by rel-

13 evant expert organizations.

14 “(3) Definitions.-For purposes of this sub15 section:

16 “(A) RELEVANT EXPERT ORGANIZA17 TIONs.-The term 'relevant expert organization' 18 means an organization with expertise in the rig19 orous application of evidence-based scientific 20 methods for the design of clinical studies, the 21 interpretation of clinical data, and the develop22 ment of national clinical practice guidelines, in23 cluding a voluntary health organization, clinical 24 specialty, or other professional organization 25 that represents physicians based on the field of 
medicine in which each such physician practices or is board certified.

"(B) Standards AND PROTOCOLS OF CLINICAL EXCELLENCE.-The term 'standards and protocols of clinical excellence' means clinical or practice guidelines that consist of a set of directions or principles that is based on evidence and is designed to assist a health care practitioner with decisions about appropriate diagnostic, therapeutic, or other clinical procedures for specific clinical circumstances.

13 TION CARE.-Nothing in this section shall be construed 14 to make more stringent or otherwise change the standards 15 or requirements for coverage of items and services under 16 this Act.".

17 (b) Comparative Effectiveness Research 18 Trust Fund; Financing for the Trust Fund.-For 19 the provision establishing a Comparative Effectiveness Re20 search Trust Fund and financing such Trust Fund, see 21 section 1802. 
Transparency

3 PART 1-IMPROVING TRANSPARENCY OF INFORMATION ON SKILLED NURSING FACILITIES, NURSING FACILITIES, AND OTHER LONGTERM CARE FACILITIES

SEC. 1411. REQUIRED DISCLOSURE OF OWNERSHIP AND ADDITIONAL DISCLOSABLE PARTIES INFORMATION.

11 rity Act (42 U.S.C. 1320a-3) is amended by adding at

12 the end the following new subsection:

“(c) Required Disclosure of Ownership AND

14 additional Disclosable Parties Information.“(1) Disclosure. - A facility (as defined in 16 paragraph $(6)(\mathrm{B}))$ shall have the information de17 scribed in paragraph (3) available"(A) during the period beginning on the date of the enactment of this subsection and ending on the date such information is made available to the public under section 1411(b) of the Affordable Health Care for America Act, for submission to the Secretary, the Inspector General of the Department of Health and Human Services, the State in which the facility 
is located, and the State long-term care ombudsman in the case where the Secretary, the Inspector General, the State, or the State longterm care ombudsman requests such information; and

"(B) beginning on the effective date of the final regulations promulgated under paragraph (4)(A), for reporting such information in accordance with such final regulations.

Nothing in subparagraph (A) shall be construed as authorizing a facility to dispose of or delete information described in such subparagraph after the effective date of the final regulations promulgated under paragraph (4)(A).

“(2) Public availability of information.During the period described in paragraph $(1)(\mathrm{A})$, a facility shall-

"(A) make the information described in paragraph (3) available to the public upon request and update such information as may be necessary to reflect changes in such information; and

"(B) post a notice of the availability of such information in the lobby of the facility in a prominent manner. 
"(A) IN GENERAL.-The following information is described in this paragraph:

"(i) The information described in subsections (a) and (b), subject to subparagraph (C).

"(ii) The identity of and information

on-

"(I) each member of the govthe name, title, and period of service of each such member;

"(II) each person or entity who is an officer, director, member, partner, trustee, or managing employee of the facility, including the name, title, and date of start of service of each such person or entity; and

"(III) each person or entity who is an additional disclosable party of the facility.

"(iii) A description of the organizational structure and the relationship of each person and entity described in sub- 
clauses (II) and (III) of clause (ii) to the facility and to one another.

“(B) Special Rule where information IS ALREADY REPORTED OR SUBMITTED.-To the extent that information reported by a facil-

ity to the Internal Revenue Service on Form 990, information submitted by a facility to the Securities and Exchange Commission, or information otherwise submitted to the Secretary or any other Federal agency contains the information described in clauses (i), (ii), or (iii) of subparagraph (A), the Secretary may allow, to the extent practicable, such Form or such information to meet the requirements of paragraph (1) and to be submitted in a manner specified by the Secretary.

"(C) Spectal RUle.-In applying subparagraph $(\mathrm{A})(\mathrm{i})$ -

"(i) with respect to subsections (a) and (b), 'ownership or control interest' shall include direct or indirect interests, including such interests in intermediate entities; and

"(ii) subsection (a)(3)(A)(ii) shall include the owner of a whole or part interest 
in any mortgage, deed of trust, note, or other obligation secured, in whole or in part, by the entity or any of the property or assets thereof, if the interest is equal to or exceeds 5 percent of the total property or assets of the entirety.

“(4) Reporting.-

"(A) In GENERAL.-Not later than the date that is 2 years after the date of the enactment of this subsection, the Secretary shall promulgate regulations requiring a facility to report the information described in paragraph (3) to the Secretary in a standardized format, and such other regulations as are necessary to carry out this subsection. Such regulations shall specify the frequency of reporting, as determined by the Secretary. Such final regulations shall also require-

"(i) the reporting of such information on or after the first day of the first calendar quarter beginning after the date that is 90 days after the date on which such final regulations are published in the Federal Register; and- 
"(ii) the certification, as a condition

of participation under the program under title XVIII or XIX, that such information is accurate and current.

"(B) GuIDANCE.-The Secretary shall proQUIREMENTS.-Nothing in this subsection shall re-

11 duce, diminish, or alter any reporting requirement 12 for a facility that is in effect as of the date of the 13 enactment of this subsection.

“(6) Definitions.-In this subsection: The term 'additional disclosable party' means, with respect to a facility, any person or entity who, through ownership interest, partnership interest, contract, or otherwiseoperational, financial, administrative, or managerial control or direction over the facility or a part thereof, or provides policies or procedures for any of the operations of 
the facility, or provides financial or cash management services to the facility;

“(ii) leases or subleases real property to the facility, or owns a whole or part interest equal to or exceeding 5 percent of the total value of such real property;

"(iii) lends funds or provides a financial guarantee to the facility in an amount which is equal to or exceeds $\$ 50,000$; or "(iv) provides management or administrative services, clinical consulting services, or accounting or financial services to the facility.

"(B) Facility.-The term 'facility' means a disclosing entity which is-

"(i) a skilled nursing facility (as defined in section 1819(a)); or “(ii) a nursing facility (as defined in section 1919(a)).

"(C) Managing employee.-The term 'managing employee' means, with respect to a facility, an individual (including a general manager, business manager, administrator, director, or consultant) who directly or indirectly man- 
ages, advises, or supervises any element of the practices, finances, or operations of the facility.

"(D) Organizational structure.-The term 'organizational structure' means, in the case of-

"(i) a corporation, the officers, directors, and shareholders of the corporation who have an ownership interest in the corporation which is equal to or exceeds 5 percent;

"(ii) a limited liability company, the members and managers of the limited liability company (including, as applicable, what percentage each member and manager has of the ownership interest in the limited liability company);

“(iii) a general partnership, the partners of the general partnership; "(iv) a limited partnership, the general partners and any limited partners of the limited partnership who have an ownership interest in the limited partnership which is equal to or exceeds 10 percent; "(v) a trust, the trustees of the trust; 
"(vi) an individual, contact information for the individual; and

"(vii) any other person or entity, such information as the Secretary determines appropriate.".

6 (b) Public Availability of Information.-Not 7 later than the date that is 1 year after the date on which 8 the final regulations promulgated under section $91124(\mathrm{c})(4)(\mathrm{A})$ of the Social Security Act, as added by sub10 section (a), are published in the Federal Register, the in11 formation reported in accordance with such final regula12 tions shall be made available to the public in accordance 13 with procedures established by the Secretary of Health 14 and Human Services.

(a) Conforming Amendments.-

(1) Skilled Nursing Facilities.-Section $171819(\mathrm{~d})(1)$ of the Social Security Act (42 U.S.C. $18 \quad 1395 \mathrm{i}-3(\mathrm{~d})(1))$ is amended by striking subparagraph 19 (B) and redesignating subparagraph (C) as subpara$20 \operatorname{graph}(\mathrm{B})$.

(2) Nursing Facilities.-Section 1919(d)(1)

22 of the Social Security Act (42 U.S.C. 1396r(d)(1))

23 is amended by striking subparagraph (B) and redes24 ignating subparagraph (C) as subparagraph (B). 
1 SEC. 1412. ACCOUNTABILITY REQUIREMENTS.

(a) Effective Compliance and Ethics Pro3 GRAMS.-

(1) Skilled NURSing FACILITIES.-Section 1819(d)(1) of the Social Security Act (42 U.S.C. 1395i-3(d)(1)), as amended by section 1411(c)(1), is amended by adding at the end the following new subparagraph:

"(C) Compliance AND Ethics PROGRAMS.-

“(i) REQuirement.-On or after the first day of the first calendar quarter beginning after the date that is 1 year after the date on which regulations developed under clause (ii) are published in the Federal Register, a skilled nursing facility shall, with respect to the entity that operates or controls the facility (in this subparagraph referred to as the 'operating organization' or 'organization'), have in operation a compliance and ethics program that is effective in preventing and detecting criminal, civil, and administrative violations under this Act and in promoting quality of care consistent with such regulations. 
“(ii) DEVELOPMENT OF REGUla-

TIONS.-

“(I) In GENERAL.-Not later than the date that is 2 years after the date of the enactment of this subparagraph, the Secretary, in consultation with the Inspector General of the Department of Health and Human Services, shall promulgate regulations for an effective compliance and ethics program for operating organizations, which may include a model compliance program.

"(II) DEsign OF REGULATIONS.-Such regulations with respect to specific elements or formality of a program may vary with the size of the organization, such that larger organizations should have a more formal and rigorous program and include established written policies defining the standards and procedures to be followed by its employees. Such requirements shall specifically apply to the 
corporate level management of multiunit nursing home chains.

"(III) Evaluation._-Not later than 3 years after the date on which compliance and ethics programs established under this subparagraph are in operation pursuant to clause (i), the Secretary shall complete an evaluation of such programs. Such evaluation shall determine if such programs led to changes in deficiency citations, changes in quality performance, or changes in other metrics of resident quality of care. The Secretary shall submit to Congress a report on such evaluation and shall include in such report such recommendations regarding changes in the requirements for such programs as the Secretary determines appropriate.

“(iii) REQUiREMENTS FOR COMPLIANCE AND ETHICS PROGRAMS.-In this subparagraph, the term 'compliance and ethics program' means, with respect to a 
skilled nursing facility, a program of the operating organization that-

"(I) has been reasonably designed, implemented, and enforced so that it generally will be effective in preventing and detecting criminal, civil, and administrative violations under this Act and in promoting quality of care; and

"(II) includes at least the required components specified in clause (iv).

"(iv) REQUIRED COMPONENTS OF PROGRAM.-The required components of a compliance and ethics program of an organization are the following:

"(I) The organization must have established compliance standards and procedures to be followed by its employees, contractors, and other agents that are reasonably capable of reducing the prospect of criminal, civil, and administrative violations under this Act. 
"(II) Specific individuals within

high-level personnel of the organiza-

tion must have been assigned overall

responsibility to oversee compliance

with such standards and procedures

and have sufficient resources and au-

thority to assure such compliance.

“(III) The organization must

have used due care not to delegate

substantial discretionary authority to

individuals whom the organization

knew, or should have known through

the exercise of due diligence, had a propensity to engage in criminal, civil, and administrative violations under this Act.

"(IV) The organization must have taken steps to communicate effectively its standards and procedures to all employees and other agents, such as by requiring participation in training programs or by disseminating publications that explain in a practical manner what is required. 
"(V) The organization must have

taken reasonable steps to achieve compliance with its standards, such as by utilizing monitoring and auditing systems reasonably designed to detect criminal, civil, and administrative violations under this Act by its employees and other agents and by having in place and publicizing a reporting system whereby employees and other agents could report violations by others within the organization without fear of retribution.

"(VI) The standards must have been consistently enforced through appropriate disciplinary mechanisms, including, as appropriate, discipline of individuals responsible for the failure to detect an offense.

"(VII) After an offense has been detected, the organization must have taken all reasonable steps to respond appropriately to the offense and to prevent further similar offenses, including repayment of any funds to 
which it was not entitled and any nec-

essary modification to its program to

prevent and detect criminal, civil, and

administrative violations under this

Act.

(2) Nursing Facilities.-Section 1919(d)(1)

17 of the Social Security Act (42 U.S.C. 1396r(d)(1)), 18 as amended by section 1411(c)(2), is amended by 19 adding at the end the following new subparagraph:

"(C) Complinee and ethics PRo-

"(i) Requirement.-On or after the first day of the first calendar quarter beginning after the date that is 1 year after the date on which regulations developed 
under clause (ii) are published in the Federal Register, a skilled nursing facility shall, with respect to the entity that operates or controls the facility (in this subparagraph referred to as the 'operating organization' or 'organization'), have in operation a compliance and ethics program that is effective in preventing and detecting criminal, civil, and administrative violations under this Act and in promoting quality of care consistent with such regulations.

\section{“(iii) Development OF REgula-} TIONS.- -

"(I) In GENERAL.-Not later than the date that is 2 years after the date of the enactment of this subparagraph, the Secretary, in consultation with the Inspector General of the Department of Health and Human Services, shall promulgate regulations for an effective compliance and ethics program for operating organizations, which may include a model compliance program. 
“(II) Design OF Regula-

TIONS.-Such regulations with respect to specific elements or formality of a program may vary with the size of the organization, such that larger organizations should have a more formal and rigorous program and include established written policies defining the standards and procedures to be followed by its employees. Such requirements shall specifically apply to the corporate level management of multiunit nursing home chains.

“(III) Evaluation.-Not later than 3 years after the date on which compliance and ethics programs established under this subparagraph are in operation pursuant to clause (i), the Secretary shall complete an evaluation of such programs. Such evaluation shall determine if such programs led to changes in deficiency citations, changes in quality performance, or changes in other metries of resident quality of care. The Secretary shall 
submit to Congress a report on such evaluation and shall include in such report such recommendations regarding changes in the requirements for such programs as the Secretary determines appropriate.

“(v) REQUIREMENTS FOR COMPLIANCE AND ETHICS PROGRAMS.-In this subparagraph, the term 'compliance and ethics program' means, with respect to a nursing facility, a program of the operating organization that-

"(I) has been reasonably designed, implemented, and enforced so that it generally will be effective in preventing and detecting criminal, civil, and administrative violations under this Act and in promoting quality of care; and

"(II) includes at least the required components specified in clause (iv).

“(vi) REQUIRED COMPONENTS OF PROGRAM.-The required components of a 
compliance and ethies program of an organization are the following:

"(I) The organization must have established compliance standards and procedures to be followed by its employees and other agents that are reasonably capable of reducing the prospect of criminal, civil, and administrative violations under this Act.

"(II) Specific individuals within high-level personnel of the organization must have been assigned overall responsibility to oversee compliance with such standards and procedures and has sufficient resources and authority to assure such compliance.

"(III) The organization must have used due care not to delegate substantial discretionary authority to individuals whom the organization knew, or should have known through the exercise of due diligence, had a propensity to engage in criminal, civil, and administrative violations under this Act. 
"(IV) The organization must

have taken steps to communicate ef-

fectively its standards and procedures to all employees and other agents, such as by requiring participation in training programs or by disseminating publications that explain in a practical manner what is required.

“(V) The organization must have taken reasonable steps to achieve compliance with its standards, such as by

utilizing monitoring and auditing systems reasonably designed to detect criminal, civil, and administrative violations under this Act by its employees and other agents and by having in place and publicizing a reporting system whereby employees and other agents could report violations by others within the organization without fear of retribution.

"(VI) The standards must have been consistently enforced through appropriate disciplinary mechanisms, including, as appropriate, discipline of 
individuals responsible for the failure

to detect an offense.

"(VII) After an offense has been

detected, the organization must have

taken all reasonable steps to respond appropriately to the offense and to prevent further similar offenses, including repayment of any funds to which it was not entitled and any necessary modification to its program to prevent and detect criminal, civil, and administrative violations under this

"(VIII) The organization must periodically undertake reassessment of its compliance program to identify changes necessary to reflect changes within the organization and its facilities.

"(vii) CoOrdination.-The provisions of this subparagraph shall apply with respect to a nursing facility in lieu of section 1902(a)(77).”. 
(1) Skilled Nursing Facilities.-Section 1819(b)(1)(B) of the Social Security Act (42 U.S.C. $1396 \mathrm{r}(\mathrm{b})(1)(\mathrm{B}))$ is amended-

(A) by striking "ASSURANCE" and inserting "ASsURANCE AND QUALitT assurance AND PERFORMANCE IMPROVEMENT PROGRAM"; (B) by designating the matter beginning with "A skilled nursing facility" as a clause (i) with the heading "IN GENERAL._-" and the appropriate indentation;

(C) in clause (i) (as so designated by subparagraph (B)), by redesignating clauses (i) and (ii) as subclauses (I) and (II), respectively; and

(D) by adding at the end the following new clause:

“(ii) Quality assurance AND PERFORMANCE IMPROVEMENT PROGRAM.-

“(I) IN GENERAL.-Not later than December 31, 2011, the Secretary shall establish and implement a quality assurance and performance improvement program (in this clause referred to as the 'QAPI program') for skilled nursing facilities, including 
multi-unit chains of such facilities.

Under the QAPI program, the Sec-

retary shall establish standards relat-

ing to such facilities and provide tech-

nical assistance to such facilities on

the development of best practices in order to meet such standards. Not

later than 1 year after the date on

which the regulations are promulgated

under subclause (II), a skilled nursing

facility must submit to the Secretary

a plan for the facility to meet such

standards and implement such best

practices, including how to coordinate

the implementation of such plan with

quality assessment and assurance activities conducted under clause (i).

“(II) Regulations.-The Secretary shall promulgate regulations to carry out this clause.". 
(A) by striking "ASSURANCE" and inserting "ASSURANCE AND QUALITY ASSURANCE AND PERFORMANCE IMPROVEMENT PROGRAM";

(B) by designating the matter beginning with "A nursing facility" as a clause (i) with the heading "IN GENERAL._-" and the appropriate indentation; and

(C) by adding at the end the following new clause:

“(ii) Quality assurance AND PERFORMANCE IMPROVEMENT PROGRAM.-

“(I) In GENERAL.-Not later than December 31, 2011, the Secretary shall establish and implement a quality assurance and performance improvement program (in this clause referred to as the 'QAPI program') for nursing facilities, including multiunit chains of such facilities. Under the QAPI program, the Secretary shall establish standards relating to such facilities and provide technical assistance to such facilities on the development of best practices in order to meet such standards. Not later than 1 
year after the date on which the regulations are promulgated under subclause (II), a nursing facility must submit to the Secretary a plan for the facility to meet such standards and implement such best practices, including how to coordinate the implementation of such plan with quality assessment and assurance activities conducted under clause (i).

"(II) Regulations.-The Secretary shall promulgate regulations to carry out this clause.".

(3) Proposal to Revise quality assurance 15 AND PERFORMANCE IMPROVEMENT PROGRAMS.16 The Secretary shall implement policies that modify 17 and strengthen quality assurance and performance 18 improvement programs in skilled nursing facilities 19 and nursing facilities on a periodic basis, as deter20 mined by the Secretary.

(4) Facility Plan.-Not later than 1 year 22 after the date on which the regulations are promul23 gated under subclause (II) of clause (ii) of sections $241819(\mathrm{~b})(\mathrm{1})(\mathrm{B})$ and $1919(\mathrm{~b})(1)(\mathrm{B})$ of the Social Se25 curity Act, as added by paragraphs (1) and (2), a 
1 skilled nursing facility and a nursing facility must

2 submit to the Secretary a plan for the facility to

3 meet the standards under such regulations and im-

4 plement such best practices, including how to coordi-

5 nate the implementation of such plan with quality

6 assessment and assurance activities conducted under

$7 \quad$ clause (i) of such sections.

8 (c) GAO Study on Nursing Facility Under9 Capitalization.-

10 (1) In GENERAL.-The Comptroller General of 11 the United States shall conduct a study that exam12 ines the following:

(A) The extent to which corporations that own or operate large numbers of nursing facilities, taking into account ownership type (including private equity and control interests), are undercapitalizing such facilities.

(B) The effects of such undercapitalization on quality of care, including staffing and food costs, at such facilities.

(C) Options to address such undercapitalization, such as requirements relating to surety bonds, liability insurance, or minimum capitalization. 
(2) REPORT.-Not later than 18 months after

2 the date of the enactment of this Act, the Comp-

3 troller General shall submit to Congress a report on

$4 \quad$ the study conducted under paragraph (1).

5 (3) Nursing Facility.-In this subsection, the 6 term "nursing facility" includes a skilled nursing fa7 cility.

8 SEC. 1413. NURSING HOME COMPARE MEDICARE WEBSITE.

(a) Skilled Nursing Facilities.-

(1) In GENERAL.-Section 1819 of the Social

11 Security Act (42 U.S.C. 1395i-3) is amendedfollowing new subsection: section (j); and

(A) by redesignating subsection (i) as sub(B) by inserting after subsection (h) the “(i) Nurs

“(i) Nursing Home Compare Website.“(1) InClusion OF ADDitional INFORMATION.ensure that the Department of Health and Human Services includes, as part of the information provided for comparison of nursing homes on the official Internet website of the Federal Government for Medicare beneficiaries 25 (commonly referred to as the 'Nursing Home 
Compare' Medicare website) (or a successor website), the following information in a manner that is prominent, easily accessible, readily understandable to consumers of long-term care services, and searchable:

"(i) Information that is reported to the Secretary under section 1124(c)(4).

"(ii) Information on the 'Special Focus Facility program' (or a successor program) established by the Centers for Medicare and Medicaid Services, according to procedures established by the Secretary. Such procedures shall provide for the inclusion of information with respect to, and the names and locations of, those facilities that, since the previous quarter-

"(I) were newly enrolled in the program;

"(II) are enrolled in the program and have failed to significantly improve;

"(III) are enrolled in the program and have significantly improved; "(IV) have graduated from the program; and 
"(V) have closed voluntarily or no longer participate under this title. "(iii) Staffing data for each facility (including resident census data and data on the hours of care provided per resident per day) based on data submitted under subsection $(b)(8)(C)$, including information on staffing turnover and tenure, in a format that is clearly understandable to consumers of long-term care services and allows such consumers to compare differences in staffing between facilities and State and national averages for the facilities. Such format shall include-

"(I) concise explanations of how to interpret the data (such as a plain English explanation of data reflecting 'nursing home staff hours per resident day');

"(II) differences in types of staff (such as training associated with different categories of staff);

"(III) the relationship between nurse staffing levels and quality of care; and 
"(IV) an explanation that appro-

priate staffing levels vary based on patient case mix.

"(iv) Links to State internet websites

with information regarding State survey and certification programs, links to Form 2567 State inspection reports (or a successor form) on such websites, information to guide consumers in how to interpret and understand such reports, and the facility plan of correction or other response to such report.

"(v) The standardized complaint form developed under subsection (f)(8), including explanatory material on what complaint forms are, how they are used, and how to file a complaint with the State survey and certification program and the State long-term care ombudsman program. "(vi) Summary information on the number, type, severity, and outcome of substantiated complaints.

"(vii) The number of adjudicated instances of criminal violations by employees of a nursing facility- 
"(I) that were committed inside the facility;

"(II) with respect to such instances of violations or crimes committed inside of the facility that were the violations or crimes of abuse, neglect, and exploitation, criminal sexual abuse, or other violations or crimes that resulted in serious bodily injury; and

"(viii) The number of civil monetary penalties levied against the facility, employees, contractors, and other agents.

"(ix) Any other information that the Secretary determines appropriate.

The facility shall not make available under clause (iv) identifying information on complainants or residents.

"(B) Deadline For PRovision OF INFORMATION.-

“(i) In GEneraL.-Except as provided in clause (ii), the Secretary shall ensure that the information described in subparagraph (A) is included on such website (or a successor website) not later than 1 
year after the date of the enactment of this subsection.

“(ii) Exception.-The Secretary shall ensure that the information described in subparagraph (A)(i) and (A)(iii) is included on such website (or a successor website) not later than 1 year after the dates on which the data are submitted to the Secretary pursuant to section 1124(c)(4) and subsection (b)(8)(C), respectively.

\section{“(2) REVIEW AND MODIFICATION OF} WEBSITE.-

"(A) IN GENERAL.-The Secretary shall establish a process-

"(i) to review the accuracy, clarity of presentation, timeliness, and comprehensiveness of information reported on such website as of the day before the date of the enactment of this subsection; and "(ii) not later than 1 year after the date of the enactment of this subsection, to modify or revamp such website in accordance with the review conducted under clause (i). 
"(B) Consultation.-In conducting the review under subparagraph $(\mathrm{A})(\mathrm{i})$, the Secretary shall consult with-

“(i) State long-term care ombudsman

programs;

“(ii) consumer advocacy groups;

“(iii) provider stakeholder groups; and "(iv) any other representatives of programs or groups the Secretary determines appropriate.".

(2) Timeliness of submission of survey AND CERTIFICATION INFORMATION.-

(A) IN GENERAL.-Section 1819(g)(5) of the Social Security Act (42 U.S.C. 1395i$3(\mathrm{~g})(5))$ is amended by adding at the end the following new subparagraph:

"(E) Submission OF Survey AND CerTIFICATION INFORMATION TO THE SECRETARY.-In order to improve the timeliness of information made available to the public under subparagraph (A) and provided on the Nursing Home Compare Medicare website under subsection (i), each State shall submit information respecting any survey or certification recommendation made respecting a skilled nursing 
facility (including any enforcement actions taken by the State or any Federal enforcement action recommended by the State) to the Secretary not later than the date on which the State sends such information to the facility. The Secretary shall use the information submitted under the preceding sentence to update the information provided on the Nursing Home Compare Medicare website as expeditiously as practicable but not less frequently than quarterly.".

(B) EFFECTIVE DATE.-The amendment made by this paragraph shall take effect 1 year after the date of the enactment of this Act.

(3) Special focus facility Program.-Section 1819(f) of such Act is amended by adding at the end the following new paragraph:

“(8) Spectal focus facility Program."(A) IN GENERAL.-The Secretary shall conduct a special focus facility program for enforcement of requirements for skilled nursing facilities that the Secretary has identified as having a poor compliance history or that substantially failed to meet applicable requirements of this Act 
“(B) Periodic surveys.-Under such program the Secretary shall conduct surveys of each facility in the program not less than once every 6 months.".

(b) Nursing Facilities.-

(1) In General.-Section 1919 of the Social Security Act (42 U.S.C. 1396r) is amended-

(A) by redesignating subsection (i) as subsection (j); and

(B) by inserting after subsection (h) the following new subsection:

“(i) Nursing Home Compare Website.“(1) INCLUSION OF ADDITIONAL INFORMATION.-

“(A) IN GENERAL.-The Secretary shall ensure that the Department of Health and Human Services includes, as part of the information provided for comparison of nursing homes on the official internet website of the Federal Government for Medicare beneficiaries (commonly referred to as the 'Nursing Home Compare' Medicare website) (or a successor website), the following information in a manner that is prominent, easily accessible, readily un- 
derstandable to consumers of long-term care services, and searchable:

"(i) Information that is reported to the Secretary under section 1124(c)(4)

"(ii) Information on the 'Special Focus Facility program' (or a successor program) established by the Centers for Medicare \& Medicaid Services, according to procedures established by the Secretary. Such procedures shall provide for the inclusion of information with respect to, and the names and locations of, those facilities that, since the previous quarter-

"(I) were newly enrolled in the program;

"(II) are enrolled in the program and have failed to significantly improve;

"(III) are enrolled in the program and have significantly improved;

"(IV) have graduated from the program; and

"(V) have closed voluntarily or no longer participate under this title. 
"(iii) Staffing data for each facility (including resident census data and data on the hours of care provided per resident per day) based on data submitted under subsection (b)(8)(C)(ii), including informaformat that is clearly understandable to consumers of long-term care services and allows such consumers to compare differences in staffing between facilities and State and national averages for the facilities. Such format shall include-

"(I) concise explanations of how to interpret the data (such as plain English explanation of data reflecting 'nursing home staff hours per resident day');

"(II) differences in types of staff (such as training associated with different categories of staff);

"(III) the relationship between nurse staffing levels and quality of care; and 
"(IV) an explanation that appropriate staffing levels vary based on patient case mix.

“(iv) Links to State internet websites

with information regarding State survey and certification programs, links to Form 2567 State inspection reports (or a successor form) on such websites, information to guide consumers in how to interpret and understand such reports, and the facility plan of correction or other response to such report.

"(v) The standardized complaint form developed under subsection (f)(10), including explanatory material on what complaint forms are, how they are used, and how to file a complaint with the State survey and certification program and the State long-term care ombudsman program. "(vi) Summary information on the number, type, severity, and outcome of substantiated complaints.

"(vii) The number of adjudicated instances of criminal violations by employees of a nursing facility- 
"(I) that were committed inside of the facility; and

"(II) with respect to such instances of violations or crimes committed inside of the facility that were the violations or crimes of abuse, neglect, and exploitation, criminal sexual abuse, or other violations or crimes that resulted in serious bodily injury. "(viii) the number of civil monetary penalties levied against the facility, employees, contractors, and other agents. "(ix) Any other information that the Secretary determines appropriate. The facility shall not make available under clause (ii) identifying information about complainants or residents.

“(B) Deadline for Provision of INForMATION.-

“(i) In GEneraL.-Except as provided in clause (ii), the Secretary shall ensure that the information described in subparagraph (A) is included on such website (or a successor website) not later than 1 
year after the date of the enactment of this subsection.

“(ii) ExceptTon.-The Secretary shall ensure that the information described in subparagraph (A)(i) and (A)(iii) is included on such website (or a successor website) not later than 1 year after the dates on which the data are submitted to the Secretary pursuant to section 1124(c)(4) and subsection (b)(8)(C), respectively.

\section{“(2) REVIEW AND MODIFICATION OF} WEBSITE.-

"(A) IN GENERAL.- The Secretary shall establish a process-

"(i) to review the accuracy, clarity of presentation, timeliness, and comprehensiveness of information reported on such website as of the day before the date of the enactment of this subsection; and "(ii) not later than 1 year after the date of the enactment of this subsection, to modify or revamp such website in accordance with the review conducted under clause (i). 
"(B) Consultation.-In conducting the review under subparagraph (A)(i), the Secretary shall consult with-

“(i) State long-term care ombudsman programs;

“(ii) consumer advocacy groups;

“(iii) provider stakeholder groups;

"(iv) skilled nursing facility employees and their representatives; and

"(v) any other representatives of programs or groups the Secretary determines appropriate.".

(2) Timeliness of submission of survey AND CERTIFICATION INFORMATION.-

(A) In GENERAL.—Section 1919(g)(5) of the Social Security Act (42 U.S.C. 1396r(g)(5)) is amended by adding at the end the following new subparagraph:

"(E) Submission OF Survey AND CERTIFICATION INFORMATION TO THE SECRETARY.- In order to improve the timeliness of information made available to the public under subparagraph (A) and provided on the Nursing Home Compare Medicare website under subsection (i), each State shall submit information 
respecting any survey or certification recommendation made respecting a nursing facility (including any enforcement actions taken by the State or any Federal enforcement action recommended by the State) to the Secretary not later than the date on which the State sends such information to the facility. The Secretary shall use the information submitted under the preceding sentence to update the information provided on the Nursing Home Compare Medicare website as expeditiously as practicable but not less frequently than quarterly.".

(B) EFfective Date.-The amendment made by this paragraph shall take effect 1 year after the date of the enactment of this Act.

(3) Special focus facility PRogram.- Section 1919 (f) of such Act is amended by adding at the end of the following new paragraph: “(10) Special focus facility PRogram."(A) In GENERAL.-The Secretary shall conduct a special focus facility program for enforcement of requirements for nursing facilities that the Secretary has identified as having a poor compliance history or that substantially 
1 failed to meet applicable requirements of this

$2 \quad$ Act

“(B) PERIOdic surveys.-Under such program the Secretary shall conduct surveys of each facility in the program not less often than once every 6 months.'.

7 (c) Availability of Reports on Surveys, Cer8 TIFICATIONS, AND COMPLAINT INVESTIGATIONS.-

(1) Skilled Nursing Facilities.-Section $101819(\mathrm{~d})(1)$ of the Social Security Act (42 U.S.C. 11 1395i-3(d)(1)), as amended by sections 1411 and 121412 , is amended by adding at the end the following 13 new subparagraph:

“(D) Availability of survey, CertifiCATION, AND COMPLAINT INVESTIGATION REPORTS.—A skilled nursing facility must—

"(i) have reports with respect to any surveys, certifications, and complaint investigations made respecting the facility during the 3 preceding years available for any individual to review upon request; and "(ii) post notice of the availability of such reports in areas of the facility that are prominent and accessible to the public. 
The facility shall not make available under clause (i) identifying information about complainants or residents.".

(2) Nursing Facilities.-Section 1919(d)(1)

5 of the Social Security Act (42 U.S.C. 1396r(d)(1)), 6 as amended by sections 1411 and 1412, is amended 7 by adding at the end the following new subpara8 graph:

“(D) Availability of survey, CertifiCATION, AND COMPLAINT INVESTIGATION REPORTS.-A nursing facility must-

“(i) have reports with respect to any surveys, certifications, and complaint investigations made respecting the facility during the 3 preceding years available for any individual to review upon request; and "(ii) post notice of the availability of such reports in areas of the facility that are prominent and accessible to the public. The facility shall not make available under clause (i) identifying information about complainants or residents.".

24 by this subsection shall take effect 1 year after the 25 date of the enactment of this Act. 
1 (d) Guidance to States on Form 2567 State In2 spection Reports and Complaint Investigation Re3 PORTS.-

(1) Guidance.-The Secretary of Health and 5 Human Services (in this subtitle referred to as the 6 "Secretary") shall provide guidance to States on 7 how States can establish electronic links to Form 82567 State inspection reports (or a successor form), 9 complaint investigation reports, and a facility's plan 10 of correction or other response to such Form 2567 11 State inspection reports (or a successor form) on the 12 Internet website of the State that provides informa13 tion on skilled nursing facilities and nursing facili14 ties and the Secretary shall, if possible, include such 15 information on Nursing Home Compare.

16 (2) REQUIREMENT.-Section 1902(a)(9) of the 17 Social Security Act (42 U.S.C. 1396a(a)(9)) is 18 amended-

19 (A) by striking "and" at the end of sub20 paragraph $(\mathrm{B})$;

21 (B) by striking the semicolon at the end of 22 subparagraph (C) and inserting “, and”; and 23 (C) by adding at the end the following new 24 subparagraph: 
"(D) that the State maintain a consumer-

oriented website providing useful information to

consumers regarding all skilled nursing facilities and all nursing facilities in the State, including for each facility, Form 2567 State in-

spection reports (or a successor form), complaint investigation reports, the facility's plan of correction, and such other information that the State or the Secretary considers useful in assisting the public to assess the quality of long term care options and the quality of care provided by individual facilities;".

(3) Definitions.-In this subsection:

(A) Nursing FACILITY.-The term "nursing facility" has the meaning given such term in section 1919(a) of the Social Security Act (42 U.S.C. $1396 \mathrm{r}(\mathrm{a})$ ).

(B) SeCRETARY.-The term "Secretary" means the Secretary of Health and Human Services.

(C) Skilled Nursing Facility.-The term "skilled nursing facility" has the meaning given such term in section 1819(a) of the Social Security Act (42 U.S.C. 1395i-3(a)). 


\section{SEC. 1414. REPORTING OF EXPENDITURES.}

2 Section 1888 of the Social Security Act (42 U.S.C.

3 1395yy) is amended by adding at the end the following 4 new subsection:

5 “(f) Reporting of Direct Care Expendi-

6 TURES.-

7

8 under this title for cost reporting periods beginning

9 on or after the date that is no more than two years

10 after the redesign of the report specified in subpara-

11 graph (2), skilled nursing facilities shall-

"(A) separately report expenditures for wages and benefits for direct care staff (breaking out (at a minimum) registered nurses, licensed professional nurses, certified nurse assistants, and other medical and therapy staff); and

"(B) take into account agency and contract staff in a manner to be determined by the Administrator.

“(2) Modification of FORM.-The Secretary, in consultation with private sector accountants experienced with skilled nursing facility cost reports, shall redesign such reports to meet the requirement of paragraph (1) not later than 2 years after the date of the enactment of this subsection. 

COUNTS.-Beginning with cost reports submitted under paragraph (1), the Secretary, working in con4 sultation with the Medicare Payment Advisory Com5 mission, the Inspector General of the Department of 6 Health and Human Services, and other expert par7 ties the Secretary determines appropriate, shall cat8 egorize the expenditures listed on cost reports, as 9 modified under paragraph (1), submitted by skilled 10 nursing facilities, regardless of any source of pay11 ment for such expenditures, for each skilled nursing 12 facility into the following functional accounts on an 13 annual basis:

"(A) Spending on direct care services (including nursing, therapy, and medical services).

"(B) Spending on indirect care (including" housekeeping and dietary services).

"(C) Capital assets (including building and land costs).

“(D) Administrative services costs.

“(4) Availability of information sub22 MITTED.-The Secretary shall establish procedures 23 to make information on expenditures submitted 24 under this subsection readily available to interested 25 parties upon request, subject to such requirements 
1 as the Secretary may specify under the procedures

2 established under this paragraph.".

3 SEC. 1415. STANDARDIZED COMPLAINT FORM.

(a) Skilled Nursing Facilities.-

(1) Development by the Secretary.-Sec-

6 tion $1819(\mathrm{f})$ of the Social Security Act (42 U.S.C.

$7 \quad 1395 \mathrm{i}-3(\mathrm{f}))$, as amended by section 1413(a)(3), is

8 amended by adding at the end the following new

9 paragraph:

10

“(9) Standardized COMPlaint Form.-The

11 Secretary shall develop a standardized complaint

12 form for use by a resident (or a person acting on the

13 resident's behalf) in filing a complaint with a State

14 survey and certification agency and a State long-

15 term care ombudsman program with respect to a

16 skilled nursing facility.".

17 (2) STATE REQUIREMENTS.-Section 1819(e)

18 of the Social Security Act (42 U.S.C. 1395i-3(e)) is

19 amended by adding at the end the following new 20 paragraph:

“(6) Complaint PRocesses and whistleBLOWER PROTECTION.-

"(A) Complaint forms.-The State must make the standardized complaint form devel- 
oped under subsection (f)(9) available upon request to-

"(i) a resident of a skilled nursing facility;

"(ii) any person acting on the resident's behalf; and

"(iii) any person who works at a skilled nursing facility or is a representative of such a worker.

“(B) Complaint resolution process.The State must establish a complaint resolution process in order to ensure that a resident, the legal representative of a resident of a skilled nursing facility, or other responsible party is not retaliated against if the resident, legal representative, or responsible party has complained, in good faith, about the quality of care or other issues relating to the skilled nursing facility, that the legal representative of a resident of a skilled nursing facility or other responsible party is not denied access to such resident or otherwise retaliated against if such representative party has complained, in good faith, about the quality of care provided by the facility or other issues relating to the facility, 
and that a person who works at a skilled nursing facility is not retaliated against if the worker has complained, in good faith, about quality of care or services or an issue relating to the quality of care or services provided at the facil-

ity, whether the resident, legal representative, other responsible party, or worker used the form developed under subsection (f)(9) or some other method for submitting the complaint. Such complaint resolution process shall include-

“(i) procedures to assure accurate tracking of complaints received, including notification to the complainant that a complaint has been received;

"(ii) procedures to determine the likely severity of a complaint and for the investigation of the complaint;

"(iii) deadlines for responding to a complaint and for notifying the complainant of the outcome of the investigation; and

"(iv) procedures to ensure that the identity of the complainant will be kept confidential. 


\section{“(C) Whistleblower PRotection.-}

“(i) Prohibition against RetaliaTION.-No person who works at a skilled nursing facility may be penalized, discriminated, or retaliated against with respect to any aspect of employment, including discharge, promotion, compensation, terms, conditions, or privileges of employment, or have a contract for services terminated, because the person (or anyone acting at the person's request) complained, in good faith, about the quality of care or services provided by a skilled nursing facility or about other issues relating to quality of care or services, whether using the form developed under subsection (f)(9) or some other method for submitting the complaint. “(ii) Retaliatory REPORTING.-A skilled nursing facility may not file a complaint or a report against a person who works (or has worked at the facility) with the appropriate State professional disciplinary agency because the person (or anyone acting at the person's request) complained in good faith, as described in clause (i). 
“(iii) RELIEF.—Any person aggrieved by a violation of clause (i) or clause (ii) may, in a civil action, obtain all appropriate relief, including reinstatement, reimbursement of lost wages, compensation, and benefits, and exemplary damages where warranted, and such other relief as the court deems appropriate, as well as costs of suit and reasonable attorney and expert witness fees.

"(iv) Rights not waivable.-The rights protected by this paragraph may not be diminished by contract or other agreement, and nothing in this paragraph shall be construed to diminish any greater or additional protection provided by Federal or State law or by contract or other agreement.

“(v) REQUIREMENT TO POST NOTICE OF EMPLOYEE RIGHTS.-Each skilled nursing facility shall post conspicuously in an appropriate location a sign (in a form specified by the Secretary) specifying the rights of persons under this paragraph and including a statement that an employee 
may file a complaint with the Secretary against a skilled nursing facility that violates the provisions of this paragraph and information with respect to the manner of filing such a complaint.

"(D) Rule of construction.-Nothing in this paragraph shall be construed as preventing a resident of a skilled nursing facility (or a person acting on the resident's behalf) from submitting a complaint in a manner or "(E) Good FaITH DEFINED.-For purposes of this paragraph, an individual shall be deemed to be acting in good faith with respect to the filing of a complaint if the individual reasonably believes-

"(i) the information reported or disclosed in the complaint is true; and "(ii) the violation of this title has occurred or may occur in relation to such information.".

24 (b) Nursing Facilities.- 
(1) Development by the secretary.-Sec-

2 tion $1919(\mathrm{f})$ of the Social Security Act (42 U.S.C.

$3 \quad 1395 \mathrm{i}-3(\mathrm{f}))$, as amended by section $1413(\mathrm{~b})$, is

4 amended by adding at the end the following new

5 paragraph:

6 “(11) STANDARDized COMPLAINT FORM.-The

7 Secretary shall develop a standardized complaint

8 form for use by a resident (or a person acting on the

9 resident's behalf) in filing a complaint with a State

10 survey and certification agency and a State long-

11 term care ombudsman program with respect to a 12 nursing facility.".

13 (2) State REQUiREMents.-Section 1919(e)

14 of the Social Security Act (42 U.S.C. 1395i-3(e)) is

15 amended by adding at the end the following new 16 paragraph:

17 “(8) Complaint PRocesses and whistle18 BLOWER PROTECTION.-

19 "(A) Complaint Forms.-The State must 20 make the standardized complaint form devel21 oped under subsection (f)(11) available upon re22 quest to-

"(i) a resident of a nursing facility;

"(ii) any person acting on the resi25 dent's behalf; and 
“(iii) any person who works at a nursing facility or a representative of such a worker.

"(B) COMplaint Resolution PRocess.-

The State must establish a complaint resolution process in order to ensure that a resident, the legal representative of a resident of a nursing facility, or other responsible party is not retaliated against if the resident, legal representative, or responsible party has complained, in good faith, about the quality of care or other issues relating to the nursing facility, that the legal representative of a resident of a nursing facility or other responsible party is not denied access to such resident or otherwise retaliated against if such representative party has complained, in good faith, about the quality of care provided by the facility or other issues relating to the facility, and that a person who works at a nursing facility is not retaliated against if the worker has complained, in good faith, about quality of care or services or an issue relating to the quality of care or services provided at the facility, whether the resident, legal representa25 tive, other responsible party, or worker used the 
1 form developed under subsection (f)(11) or some other method for submitting the complaint. Such complaint resolution process shall include-

“(i) procedures to assure accurate tracking of complaints received, including notification to the complainant that a complaint has been received;

"(ii) procedures to determine the likely severity of a complaint and for the investigation of the complaint;

"(iii) deadlines for responding to a complaint and for notifying the complainant of the outcome of the investigation; and

"(iv) procedures to ensure that the identity of the complainant will be kept confidential.

“(C) Whistleblower PRotection.-

“(i) Prohibition against retaliaTION.-No person who works at a nursing facility may be penalized, discriminated, or retaliated against with respect to any aspect of employment, including discharge, promotion, compensation, terms, condi- 
tions, or privileges of employment, or have a contract for services terminated, because the person (or anyone acting at the person's request) complained, in good faith, about the quality of care or services provided by a nursing facility or about other issues relating to quality of care or services, whether using the form developed under subsection (f)(11) or some other method for submitting the complaint.

\section{“(ii) Retaliatory Reporting.-A} nursing facility may not file a complaint or a report against a person who works (or has worked at the facility with the appropriate State professional disciplinary agency because the person (or anyone acting at the person's request) complained in good faith, as described in clause (i).

“(iii) RELIEF.-Any person aggrieved by a violation of clause (i) or clause (ii) may, in a civil action, obtain all appropriate relief, including reinstatement, reimbursement of lost wages, compensation, and benefits, and exemplary damages where warranted, and such other relief as 
the court deems appropriate, as well as costs of suit and reasonable attorney and expert witness fees.

"(iv) Rights not waIvable.-The rights protected by this paragraph may not be diminished by contract or other agreement, and nothing in this paragraph shall be construed to diminish any greater or additional protection provided by Federal or State law or by contract or other agreement.

“(v) ReQUiRement TO POST NOTICE OF EMPLOYEe RIGHTS.-Each nursing facility shall post conspicuously in an appropriate location a sign (in a form specified by the Secretary) specifying the rights of persons under this paragraph and including a statement that an employee may file a complaint with the Secretary against a nursing facility that violates the provisions of this paragraph and information with respect to the manner of filing such a complaint.

“(D) Rule of CONSTRUCTION.-Nothing. in this paragraph shall be construed as pre- 
venting a resident of a nursing facility (or a person acting on the resident's behalf) from submitting a complaint in a manner or format other than by using the standardized complaint form developed under subsection (f)(11) (including submitting a complaint orally).

"(E) GOOD FAITH DEFINED.-For purposes of this paragraph, an individual shall be deemed to be acting in good faith with respect to the filing of a complaint if the individual reasonably believes-

"(i) the information reported or disclosed in the complaint is true; and "(ii) the violation of this title has occurred or may occur in relation to such information.".

17 (c) EFFECTIVE DATE.-The amendments made by 18 this section shall take effect 1 year after the date of the 19 enactment of this Act.

20 SEC. 1416. ENSURING STAFFING ACCOUNTABILITY.

21 (a) SkIlled Nursing Facilities.-Section 22 1819(b)(8) of the Social Security Act (42 U.S.C. 1395i$233(\mathrm{~b})(8))$ is amended by adding at the end the following 24 new subparagraph: 

FORMAT.-On and after the first day of the first calendar quarter beginning after the date that is 2 years after the date of enactment of State long-term care ombudsman programs, consumer advocacy groups, provider stakeholder groups, employees and their representatives, and other parties the Secretary deems appropriate, the Secretary shall require a skilled nursing facility to electronically submit to the Secretary direct care staffing information (including information with respect to agency and contract staff) based on payroll and other verifiable and auditable data in a uniform format (according to specifications established by the Secretary in consultation with such programs, groups, and parties). Such specifications shall require that the information submitted under the preceding sentence-

"(i) specify the category of work a certified employee performs (such as whether the employee is a registered nurse, licensed practical nurse, licensed vocational 
21 Social Security Act (42 U.S.C. 1396r(b)(8)) is amended

22 by adding at the end the following new subparagraph:

nurse, certified nursing assistant, therapist, or other medical personnel);

"(ii) include resident census data and information on resident case mix; "(iii) include a regular reporting schedule; and "(iv) include information on employee turnover and tenure and on the hours of care provided by each category of certified employees referenced in clause (i) per resident per day.

Nothing in this subparagraph shall be construed as preventing the Secretary from requiring submission of such information with respect to specific categories, such as nursing staff, before other categories of certified employees. Information under this subparagraph with respect to agency and contract staff shall be kept separate from information on employee staffing.".

(b) Nursing Facilities.-Section 1919(b)(8) of the "(C) Submission OF STAFFing INFORMATION BASED ON PAYROLL DATA IN A UNIFORM FORMAT.-On and after the first day of the 
1 first calendar quarter beginning after the date that is 2 years after the date of enactment of this subparagraph, and after consulting with State long-term care ombudsman programs, consumer advocacy groups, provider stakeholder and other parties the Secretary deems appropriate, the Secretary shall require a nursing facility to electronically submit to the Secretary direct care staffing information (including information with respect to agency and contract staff) based on payroll and other verifiable and auditable data in a uniform format (according to specifications established by the Secretary in consultation with such programs, groups, and parties). Such specifications shall require that the information submitted under the preceding sentence-

"(i) specify the category of work a certified employee performs (such as whether the employee is a registered nurse, licensed practical nurse, licensed vocational nurse, certified nursing assistant, therapist, or other medical personnel); 
"(ii) include resident census data and

18 SEC. 1417. NATIONWIDE PROGRAM FOR NATIONAL AND

23 Human Services (in this section referred to as the "Sec24 retary"), shall establish a program to identify efficient, ef25 fective, and economical procedures for long term care fa- 
1 cilities or providers to conduct background checks on pro-

2 spective direct patient access employees on a nationwide 3 basis (in this subsection, such program shall be referred 4 to as the "nationwide program"). The Secretary shall 5 carry out the nationwide program under similar terms and 6 conditions as the pilot program under section 307 of the 7 Medicare Prescription Drug, Improvement, and Mod8 ernization Act of 2003 (Public Law 108-173; 117 Stat. 9 2257), including the prohibition on hiring abusive workers 10 and the authorization of the imposition of penalties by a 11 participating State under subsections (b)(3)(A) and 12 (b)(6), respectively, of such section 307. The program 13 under this subsection shall contain the following modifica14 tions to such pilot program:

(1) Agremients.-

(A) Newly participating states.-The Secretary shall enter into agreements with each State-

(i) that the Secretary has not entered into an agreement with under subsection (c)(1) of such section 307;

(ii) that agrees to conduct background checks under the nationwide program on a 24 Statewide basis; and 
(iii) that submits an application to the Secretary containing such information and at such time as the Secretary may specify. (B) Certain previously participating STATES.-The Secretary shall enter into agreements with each State-

(i) that the Secretary has entered into an agreement with under such subsection (c)(1);

(ii) that agrees to conduct background checks under the nationwide program on a Statewide basis; and

(iii) that submits an application to the Secretary containing such information and at such time as the Secretary may specify. (2) Nonapplication OF Selection CRITERIA.- The selection criteria required under subsection (c)(3)(B) of such section 307 shall not apply. (3) REQUiRED FINGERPRINT CHECK AS PART OF CRIMINAL BACKGROUND CHECK.-The procedures established under subsection (b)(1) of such section 307 shall-

(A) require that the long-term care facility or provider (or the designated agent of the long-term care facility or provider) obtain State 
and national criminal or other background checks on the prospective employee through such means as the Secretary determines appropriate that utilize a search of State-based abuse and neglect registries and databases, including the abuse and neglect registries of another

State in the case where a prospective employee previously resided in that State, State criminal history records, the records of any proceedings in the State that may contain disqualifying information about prospective employees (such as proceedings conducted by State professional licensing and disciplinary boards and State Medicaid Fraud Control Units), and Federal criminal history records, including a fingerprint check using the Integrated Automated Fingerprint Identification System of the Federal Bureau of Investigation; and

(B) require States to describe and test methods that reduce duplicative fingerprinting, including providing for the development of "rap back" capability by the State such that, if a direct patient access employee of a long-term care facility or provider is convicted of a crime following the initial criminal history background 
check conducted with respect to such employee, and the employee's fingerprints match the prints on file with the State law enforcement department, the department will immediately inform the State and the State will immediately inform the long-term care facility or provider which employs the direct patient access employee of such conviction.

(4) State RequiRements.-An agreement entered into under paragraph (1) shall require that a participating State-

(A) be responsible for monitoring compliance with the requirements of the nationwide program;

(B) have procedures in place to-

(i) conduct screening and criminal or other background checks under the nationwide program in accordance with the requirements of this section;

(ii) monitor compliance by long-term care facilities and providers with the procedures and requirements of the nationwide program;

(iii) as appropriate, provide for a provisional period of employment by a long- 
term care facility or provider of a direct patient access employee, not to exceed 60 days, pending completion of the required criminal history background check and, in the case where the employee has appealed the results of such background check, pending completion of the appeals process, during which the employee shall be subject to direct on-site supervision (in accordance with procedures established by the State to ensure that a long-term care facility or provider furnishes such direct on-site supervision);

(iv) provide an independent process by which a provisional employee or an employee may appeal or dispute the accuracy of the information obtained in a background check performed under the nationwide program, including the specification of criteria for appeals for direct patient access employees found to have disqualifying information which shall include consideration of the passage of time, extenuating circumstances, demonstration of rehabilitation, and relevancy of the particular dis- 
qualifying information with respect to the current employment of the individual;

(v) provide for the designation of a single State agency as responsible for-

(I) overseeing the coordination of any State and national criminal history background checks requested by a long-term care facility or provider (or the designated agent of the longterm care facility or provider) utilizing a search of State and Federal criminal history records, including a fingerprint check of such records;

(II) overseeing the design of appropriate privacy and security safeguards for use in the review of the results of any State or national criminal history background checks conducted regarding a prospective direct patient access employee to determine whether the employee has any conviction for a relevant crime;

(III) immediately reporting to the long-term care facility or provider that requested the criminal history 
background check the results of such review; and

(IV) in the case of an employee with a conviction for a relevant crime that is subject to reporting under section 1128E of the Social Security Act (42 U.S.C. 1320a-7e), reporting the existence of such conviction to the database established under that section;

(vi) determine which individuals are direct patient access employees (as defined in paragraph $(6)(B))$ for purposes of the nationwide program;

(vii) as appropriate, specify offenses, including convictions for violent crimes, for purposes of the nationwide program; and (viii) describe and test methods that reduce duplicative fingerprinting, including providing for the development of "rap back" capability such that, if a direct patient access employee of a long-term care facility or provider is convicted of a crime following the initial criminal history background check conducted with respect to 
such employee, and the employee's fingerprints match the prints on file with the State law enforcement department-

(I) the department will immediately inform the State agency designated under clause (v) and such agency will immediately inform the facility or provider which employs the direct patient access employee of such conviction; and

(II) the State will provide, or will require the facility to provide, to the employee a copy of the results of the criminal history background check conducted with respect to the employee at no charge in the case where the individual requests such a copy. Background checks and screenings under this subsection shall be valid for a period of no longer than 2 years, as determined by the State and approved by the Secretary.

(5) Payments.-

(A) Newly Participating states.- 
(i) IN GENERAL.-As part of the application submitted by a State under paragraph (1)(A)(iii), the State shall guarantee, with respect to the costs to be incurred by the State in carrying out the nationwide program, that the State will make available (directly or through donations from public or private entities) a particular amount of non-Federal contributions, as a condition of receiving the Federal match under clause (ii).

(ii) Federal match.-The payment amount to each State that the Secretary enters into an agreement with under paragraph (1)(A) shall be 3 times the amount that the State guarantees to make available under clause (i). Previously PARTICIPATING STATES.-

(i) In GENERAL.-As part of the application submitted by a State under paragraph (1)(B)(iii), the State shall guarantee, with respect to the costs to be incurred by the State in carrying out the nationwide program, that the State will make 
available (directly or through donations from public or private entities) a particular amount of non-Federal contributions, as a condition of receiving the Federal match under clause (ii).

(ii) Federal match.-The payment amount to each State that the Secretary enters into an agreement with under paragraph (1)(B) shall be 3 times the amount that the State guarantees to make available under clause (i).

(6) Definitions.-Under the nationwide program:

(A) LONG-TERM CARE FACILITY OR PROVIDER.-The term "long-term care facility or provider" means the following facilities or providers which receive payment for services under title XVIII or XIX of the Social Security Act:

(i) A skilled nursing facility (as defined in section 1819(a) of the Social Security Act (42 U.S.C. 1395i-3(a))).

(ii) A nursing facility (as defined in section 1919(a) of such Act (42 U.S.C. $1396 \mathrm{r}(\mathrm{a})))$.

(iii) A home health agency. 
(iv) A provider of hospice care (as defined in section 1861(dd)(1) of such Act (42 U.S.C. $1395 x(d d)(1))$ ).

(v) A long-term care hospital (as described in section 1886(d)(1)(B)(iv) of

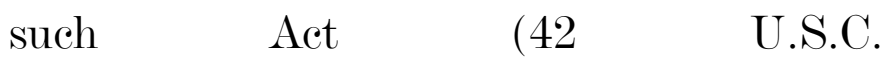
$1395 \mathrm{ww}(\mathrm{d})(1)(\mathrm{B})(\mathrm{iv})))$.

(vi) A provider of personal care services.

(vii) A provider of adult day care.

(viii) A residential care provider that arranges for, or directly provides, longterm care services, including an assisted living facility that provides a nursing home level of care conveyed by State licensure or State definition.

(ix) An intermediate care facility for the mentally retarded (as defined in section $1905(\mathrm{~d})$ of such Act (42 U.S.C. $1396 \mathrm{~d}(\mathrm{~d})))$.

(x) Any other facility or provider of long-term care services under such titles as the participating State determines appropriate. 
(B) Direct PATIENT ACCESs EMPLOYEE.-The term "direct patient access employee" means any individual who has access to a patient or resident of a long-term care facility or provider through employment or through a contract with such facility or provider and has duties that involve (or may involve) one-on-one contact with a patient or resident of the facility or provider, as determined by the State for purposes of the nationwide program. Such term does not include a volunteer unless the volunteer has duties that are equivalent to the duties of a direct patient access employee and those duties involve (or may involve) one-on-one contact with a patient or resident of the long-term care facility or provider.

(7) Evaluation and Report.-

(A) Evaluation.-The Inspector General of the Department of Health and Human Services shall conduct an evaluation of the nationwide program. Such evaluation shall include-

(i) a review of the various procedures implemented by participating States for long-term care facilities or providers, including staffing agencies, to conduct back- 
ground checks of direct patient access em-

ployees and identify the most efficient, effective, and economical procedures for conducting such background checks;

(ii) an assessment of the costs of constart-up and administrative costs);

(iii) a determination of the extent to which conducting such background checks leads to any unintended consequences, including a reduction in the available workforce for such facilities or providers;

(iv) an assessment of the impact of the program on reducing the number of incidents of neglect, abuse, and misappropriation of resident property to the extent practicable; and

(v) an evaluation of other aspects of the program, as determined appropriate by the Secretary.

(B) REPORT.-Not later than 180 days after the completion of the nationwide program, the Inspector General of the Department of Health and Human Services shall submit a re- 
port to Congress containing the results of the evaluation conducted under subparagraph (A).

(b) Funding.-

(1) Notification.-The Secretary of Health

5 and Human Services shall notify the Secretary of

6 the Treasury of the amount necessary to carry out

7 the nationwide program under this section, including

8 costs for the Department of Health and Human

9 Services to administer and evaluate the program, for

10 the period of fiscal years 2010 through 2012, except

11 that in no case shall such amount exceed $12 \$ 160,000,000$.

13 (2) Transfer OF FUnds. - Out of any funds 14 in the Treasury not otherwise appropriated, the Sec15 retary of the Treasury shall provide for the transfer 16 to the Secretary of Health and Human Services of 17 the amount specified as necessary to carry out the 18 nationwide program under paragraph (1). Such 19 amount shall remain available until expended.

20 PART 2-TARGETING ENFORCEMENT

21 SEC. 1421. CIVIL MONEY PENALTIES.

(a) Skilled Nursing Facilities.-

(1) In GENERAL.-Section 1819(h)(2)(B)(ii) of 24 the Social Security Act (42 U.S.C. 1395i$253(\mathrm{~h})(2)(\mathrm{B})(\mathrm{ii}))$ is amended to read as follows: 
“(I) Amount.-The Secretary may impose a civil money penalty in the applicable per instance or per day

"(aa) in the case where the deficiency is found to be a direct proximate cause of death of a resident of the facility, an amount not to exceed $\$ 100,000$. "(bb) in each case of a deficiency where the facility is cited for actual harm or immediate jeopardy, an amount not less than $\$ 3,050$ and not more than $\$ 25,000$; and 
"(ce) in each case of any other deficiency, an amount not less than $\$ 250$ and not to exceed $\$ 3050$.

“(III) APPLICABLE PER DAY AMOUNT.-In this clause, the term 'applicable per day amount' means"(aa) in each case of a deficiency where the facility is cited for actual harm or immediate jeopardy, an amount not less than $\$ 3,050$ and not more than $\$ 25,000$ and

"(bb) in each case of any other deficiency, an amount not less than $\$ 250$ and not to exceed $\$ 3,050$.

"(IV) REDUCTION OF CIVIL MONEY PENALTIES IN CERTAIN CIRCUMSTANCES.-BSubject to subclauses (V) and (VI), in the case where a facility self-reports and promptly corrects a deficiency for which a penalty was imposed under this clause not later than 10 calendar days after the 
date of such imposition, the Secretary may reduce the amount of the penalty imposed by not more than 50 percent. “(V) Prohibition ON ReducTION FOR CERTAIN DEFICIENCIES.-

CIENCIES.-The Secretary may not reduce under subclause (IV) the amount of a penalty if the deficiency is a repeat deficiency. “(bb) Certain OTher DEFICIENCIES.-The Secretary may not reduce under subclause (IV) the amount of a penalty if the penalty is imposed for a deficiency described in subclause (II)(aa) or (III)(aa) and the actual harm or widespread harm immediately jeopardizes the health or safety of a resident or residents of the facility, or if the penalty is imposed for a deficiency described in subclause (II)(bb). 
“(VI) LIMITATION ON AGGRE-

GATE REDUCTIONS.-The aggregate reduction in a penalty under subclause (IV) may not exceed 35 percent on the basis of self-reporting, on the basis of a waiver of an appeal (as provided for under regulations under section 488.436 of title 42 , Code of Federal Regulations), or on the basis of both.

"(VII) Collection OF CIVIL MONEY PENALTIES.-In the case of a civil money penalty imposed under this clause, the Secretary"(aa) subject to item (cc), shall, not later than 30 days after the date of imposition of the penalty, provide the opportunity for the facility to participate in an independent informal dispute resolution process, established by the State survey agency, which generates a written record prior to the collection of such penalty, but such oppor- 
tunity shall not affect the responsibility of the State survey agen-

cy for making final recommendations for such penalties;

"(bb) in the case where the of noncompliance, shall not impose a penalty for any day during the period beginning on the initial day of the imposition of the penalty and ending on the day on which the informal dispute resolution process under item (aa) is completed;

"(ce) may provide for the collection of such civil money penalty and the placement of such amounts collected in an escrow account under the direction of the Secretary on the earlier of the date on which the informal dispute resolution process under item (aa) is completed or the date that is 90 days after the 
date of the imposition of the penalty;

"(dd) may provide that such amounts collected are kept in such account pending the resolution of any subsequent appeals; "(ee) in the case where the facility successfully appeals the penalty, may provide for the return of such amounts collected (plus interest) to the facility; and "(ff) in the case where all such appeals are unsuccessful, may provide that some portion of such amounts collected may be used to support activities that benefit residents, including assistance to support and protect residents of a facility that closes (voluntarily or involuntarily) or is decertified (including offsetting costs of relocating residents to home and community-based settings or another facility), projects that support resident and family 
councils and other consumer involvement in assuring quality

care in facilities, and facility improvement initiatives approved by the Secretary (including joint

(2) Conforming amendment.-The second 24 sentence of section 1819(h)(5) of the Social Security 
1 Act (42 U.S.C. $1395 \mathrm{i}-3(\mathrm{~h})(5)$ ) is amended by insert2 ing “(ii),"after “(i),”.

3 (b) Nursing Facilities.-

(1) Penalties imposed by the state.-

5
(A) In GenERAL.-Section 1919(h)(2) of the Social Security Act (42 U.S.C. 1396r(h)(2)) is amended-

(i) in subparagraph (A)(ii), by striking the first sentence and inserting the following: "A civil money penalty in accordance with subparagraph (G)."; and

(ii) by adding at the end the following new subparagraph:

"(G) Civil Money Penalties.-

“(i) In GENERAL.-The State may impose a civil money penalty under subparagraph (A)(ii) in the applicable per instance or per day amount (as defined in subclause (II) and (III)) for each day or instance, respectively, of noncompliance (as determined appropriate by the Secretary). “(ii) ApPlicable PeR instance AMOUNT.-In this subparagraph, the term 'applicable per instance amount' means- 
"(I) in the case where the deficiency is found to be a direct proximate cause of death of a resident of the facility, an amount not to exceed $\$ 100,000$.

"(II) in each case of a deficiency where the facility is cited for actual harm or immediate jeopardy, an amount not less than $\$ 3,050$ and not more than $\$ 25,000$; and

"(III) in each case of any other deficiency, an amount not less than $\$ 250$ and not to exceed $\$ 3050$.

“(iii) APPlicable PER DAY AMOUNT.-In this subparagraph, the term 'applicable per day amount' means-

"(I) in each case of a deficiency where the facility is cited for actual harm or immediate jeopardy, an amount not less than $\$ 3,050$ and not more than $\$ 25,000$ and

"(II) in each case of any other deficiency, an amount not less than $\$ 250$ and not to exceed $\$ 3,050$. 
"(iv) ReDuCtion OF CIVIL MONEY

PENALTIES IN CERTAIN CIR-

CUMSTANCES.-Subject to clauses (v) and

(vi), in the case where a facility self-re-

ports and promptly corrects a deficiency

for which a penalty was imposed under

subparagraph (A)(ii) not later than 10 cal-

endar days after the date of such imposi-

tion, the State may reduce the amount of

the penalty imposed by not more than 50 percent.

“(v) Prohibition ON REDUCtion

FOR CERTAIN DEFICIENCIES.-

"(I) REPEAT DEFICIENCIES.-

The State may not reduce under the State had reduced a penalty imposed on the facility in the preceding year under such clause with respect to a repeat deficiency.

"(II) CERTAIN OTHER DEFICIENCIES._- The State may not reduce under clause (iv) the amount of a penalty if the penalty is imposed for a deficiency described in clause (ii)(II) or 
(iii)(I) and the actual harm or widespread harm that immediately jeopardizes the health or safety of a resident or residents of the facility, or if the penalty is imposed for a deficiency described in clause (ii)(I).

“(III) Limitation ON AGgReGATE REDUCTIONS.-The aggregate reduction in a penalty under clause (iv) may not exceed 35 percent on the basis of self-reporting, on the basis of a waiver of an appeal (as provided for under regulations under section 488.436 of title 42, Code of Federal Regulations), or on the basis of both. "(vi) Collection OF CIVIL MONey PENALTIES.-In the case of a civil money penalty imposed under subparagraph (A)(ii), the State-

"(I) subject to subclause (III), shall, not later than 30 days after the date of imposition of the penalty, provide the opportunity for the facility to participate in an independent informal dispute resolution process, established 
by the State survey agency, which generates a written record prior to the collection of such penalty, but such opportunity shall not affect the responsibility of the State survey agency for making final recommendations for such penalties;

"(II) in the case where the penalty is imposed for each day of noncompliance, shall not impose a penalty for any day during the period beginning on the initial day of the imposition of the penalty and ending on the day on which the informal dispute resolution process under subclause (I) is completed;

"(III) may provide for the collection of such civil money penalty and the placement of such amounts collected in an escrow account under the direction of the State on the earlier of the date on which the informal dispute resolution process under subclause (I) is completed or the date 
that is 90 days after the date of the imposition of the penalty;

"(IV) may provide that such amounts collected are kept in such account pending the resolution of any subsequent appeals;

"(V) in the case where the facility successfully appeals the penalty, may provide for the return of such amounts collected (plus interest) to the facility; and

"(VI) in the case where all such appeals are unsuccessful, may provide that such funds collected shall be used for the purposes described in the second sentence of subparagraph (A)(ii).".

(B) Conforming Amendment.-The second sentence of section 1919(h)(2)(A)(ii) of the Social Security Act (42 U.S.C. $1396 \mathrm{r}(\mathrm{h})(2)(\mathrm{A})(\mathrm{ii}))$ is amended by inserting before the period at the end the following: ", and some portion of such funds may be used to support activities that benefit residents, including assistance to support and protect residents of a 
facility that closes (voluntarily or involuntarily) or is decertified (including offsetting costs of relocating residents to home and communitybased settings or another facility), projects that support resident and family councils and other consumer involvement in assuring quality care in facilities, and facility improvement initiatives approved by the Secretary (including joint training of facility staff and surveyors, providing technical assistance to facilities under quality assurance programs, the appointment of temporary management, and other activities approved by the Secretary)".

(2) Penalties imposed By the SeCRETARY.-

(A) IN GENERAL.-Section 1919(h)(3)(C)(ii) of the Social Security Act (42 U.S.C. $1396 \mathrm{r}(\mathrm{h})(3)(\mathrm{C}))$ is amended to read as follows:

“(ii) AUTHORITY WITH RESPECT TO CIVIL MONEY PENALTIES.-

"(I) Amount.-Subject to subclause (II), the Secretary may impose a civil money penalty in an amount not to exceed $\$ 10,000$ for each day or 
each instance of noncompliance (as

determined appropriate by the Secretary).

"(II) ReDuction OF CIVIL MONEY PENALTIES IN CERTAIN CIRCUMSTANCES.-Subject to subclause (III), in the case where a facility selfreports and promptly corrects a deficiency for which a penalty was imposed under this clause not later than such imposition, the Secretary may reduce the amount of the penalty imposed by not more than 50 percent.

“(III) Prohibition ON ReducTION FOR REPEAT DEFICIENCIES.The Secretary may not reduce the amount of a penalty under subclause (II) if the Secretary had reduced a penalty imposed on the facility in the preceding year under such subclause with respect to a repeat deficiency.

"(IV) Collection OF CIVIL MONEY PENALTIES.-In the case of a 
civil money penalty imposed under

this clause, the Secretary-

"(aa) subject to item (bb),

shall, not later than 30 days

after the date of imposition of

the penalty, provide the oppor-

tunity for the facility to partici-

pate in an independent informal

dispute resolution process which

generates a written record prior

to the collection of such penalty;

"(bb) in the case where the penalty is imposed for each day pose a penalty for any day during the period beginning on the initial day of the imposition of the penalty and ending on the day on which the informal dispute resolution process under item (aa) is completed;

"(сc) may provide for the collection of such civil money penalty and the placement of such amounts collected in an es- 
crow account under the direction

of the Secretary on the earlier of

the date on which the informal

dispute resolution process under

item (aa) is completed or the

date that is 90 days after the

date of the imposition of the pen-

alty;

"(dd) may provide that such amounts collected are kept in such account pending the resolu-

tion of any subsequent appeals; "(ee) in the case where the facility successfully appeals the penalty, may provide for the re(plus interest) to the facility; and "(ff) in the case where all such appeals are unsuccessful, may provide that some portion of such amounts collected may be used to support activities that benefit residents, including assistance to support and protect residents of a facility that closes 


\section{8}

(voluntarily or involuntarily) or is decertified (including offsetting costs of relocating residents to home and community-based settings or another facility), projects that support resident and family councils and other consumer involvement in assuring quality care in facilities, and facility improvement initiatives approved by the Secretary (including joint training of facility staff and surveyors, technical assistance for facilities under quality assurance programs, the appointment of temporary management, and other activities approved by the Secretary).

"(V) Procedure.-The provisions of section $1128 \mathrm{~A}$ (other than subsections (a) and (b) and except to the extent that such provisions require a hearing prior to the imposition of a civil money penalty) shall apply to a civil money penalty under this clause 
in the same manner as such provisions apply to a penalty or proceeding under section $1128 \mathrm{~A}(\mathrm{a}) . ’$

(B) Conforming amendment.-Section 1919(h)(8) of the Social Security Act (42 U.S.C. $1396 \mathrm{r}(\mathrm{h})(5)(8))$ is amended by inserting "and in paragraph (3)(C)(ii)" after "paragraph (2)(A)"

(c) Effective Date.-The amendments made by

10 this section shall take effect 1 year after the date of the 11 enactment of this Act.

12 SEC. 1422. NATIONAL INDEPENDENT MONITOR PILOT PROGRAM.

(a) Establishment.-

(1) In General.-The Secretary, in consulta16 tion with the Inspector General of the Department 17 of Health and Human Services, shall establish a 18 pilot program (in this section referred to as the 19 "pilot program") to develop, test, and implement use 20 of an independent monitor to oversee interstate and 21 large intrastate chains of skilled nursing facilities 22 and nursing facilities.

23 (2) SELECTION.-The Secretary shall select 24 chains of skilled nursing facilities and nursing facili25 ties described in paragraph (1) to participate in the 
1 pilot program from among those chains that submit

2 an application to the Secretary at such time, in such

3 manner, and containing such information as the Sec-

4 retary may require.

5 (3) DURATIOn.-The Secretary shall conduct

6 the pilot program for a two-year period.

(4) Implementation.-The Secretary shall

8 implement the pilot program not later than one year

9 after the date of the enactment of this Act.

10 (b) REQUIREMENTS.-The Secretary shall evaluate

11 chains selected to participate in the pilot program based

12 on criteria selected by the Secretary, including where evi-

13 dence suggests that one or more facilities of the chain are

14 experiencing serious safety and quality of care problems.

15 Such criteria may include the evaluation of a chain that

16 includes one or more facilities participating in the "Special

17 Focus Facility" program (or a successor program) or one

18 or more facilities with a record of repeated serious safety

19 and quality of care deficiencies.

(c) Responsibilities of the Independent Mon-

21 ITOR.-An independent monitor that enters into a con-

22 tract with the Secretary to participate in the conduct of 23 such program shall-

24 (1) conduct periodic reviews and prepare root25 cause quality and deficiency analyses of a chain to 
1 assess if facilities of the chain are in compliance

2 with State and Federal laws and regulations applica-

3 ble to the facilities;

4 (2) undertake sustained oversight of the chain, 5 whether publicly or privately held, to involve the 6 owners of the chain and the principal business part7 ners of such owners in facilitating compliance by fa8 cilities of the chain with State and Federal laws and 9 regulations applicable to the facilities;

10 (3) analyze the management structure, distribu11 tion of expenditures, and nurse staffing levels of fa12 cilities of the chain in relation to resident census, 13 staff turnover rates, and tenure;

14 (4) report findings and recommendations with 15 respect to such reviews, analyses, and oversight to 16 the chain and facilities of the chain, to the Secretary 17 and to relevant States; and

18 (5) publish the results of such reviews, anal19 yses, and oversight.

20 (d) Implementation of Recommendations.-

21 (1) RECEIPT OF FINDING BY CHAIN.-Not later 22 than 10 days after receipt of a finding of an inde23 pendent monitor under subsection (c)(4), a chain 24 participating in the pilot program shall submit to 25 the independent monitor a report- 
(A) outlining corrective actions the chain will take to implement the recommendations in such report; or

(B) indicating that the chain will not implement such recommendations and why it will not do so.

(2) RECEIPT OF REPORT BY INDEPENDENT

8 MONITOR.-Not later than 10 days after the date of

9 receipt of a report submitted by a chain under para-

10 graph (1), an independent monitor shall finalize its

11 recommendations and submit a report to the chain

12 and facilities of the chain, the Secretary, and the

13 State (or States) involved, as appropriate, containing

14 such final recommendations.

15 (e) Cost of Appointment.-A chain shall be re16 sponsible for a portion of the costs associated with the 17 appointment of independent monitors under the pilot pro18 gram. The chain shall pay such portion to the Secretary 19 (in an amount and in accordance with procedures estab20 lished by the Secretary).

21 (f) WaIver Authority.-The Secretary may waive 22 such requirements of titles XVIII and XIX of the Social 23 Security Act (42 U.S.C. 1395 et seq.; 1396 et seq.) as 24 may be necessary for the purpose of carrying out the pilot 25 program. 
1 (g) Authorization of Appropriations.-There 2 are authorized to be appropriated such sums as may be 3 necessary to carry out this section.

4 (h) Definitions.-In this section:

5 (1) Facility.-The term "facility" means a 6 skilled nursing facility or a nursing facility.

(2) Nursing Facility.-The term "nursing

8 facility" has the meaning given such term in section $9 \quad 1919(a)$ of the Social Security Act (42 U.S.C. $101396 \mathrm{r}(\mathrm{a}))$.

11 (3) SECRETARY.-The term "Secretary" means 12 the Secretary of Health and Human Services, acting 13 through the Assistant Secretary for Planning and 14 Evaluation.

(4) Skilled Nursing Facility.-The term 16 "skilled nursing facility" has the meaning given such 17 term in section 1819(a) of the Social Security Act 18 (42 U.S.C. $1395(a)$ ).

19 (i) Evaluation and Report.-

20 (1) Evaluation.-The Inspector General of 21 the Department of Health and Human Services shall 22 evaluate the pilot program. Such evaluation shall23 (A) determine whether the independent 24 monitor program should be established on a 25 permanent basis; and 


\section{4}

(B) if the Inspector General determines that the independent monitor program should be established on a permanent basis, recommend appropriate procedures and mechanisms for such establishment.

(2) REPORT.-Not later than 180 days after the completion of the pilot program, the Inspector General shall submit to Congress and the Secretary a report containing the results of the evaluation conducted under paragraph (1), together with recommendations for such legislation and administrative action as the Inspector General determines appropriate.

\section{SEC. 1423. NOTIFICATION OF FACILITY CLOSURE.}

(a) Skilled Nursing Facilities.-

(1) In GENERAL.-Section 1819(c) of the Social Security Act (42 U.S.C. 1395i-3(c)) is amended by adding at the end the following new paragraph: “(7) Notification of Facility Closure."(A) In GENERAL.-Any individual who is the administrator of a skilled nursing facility must-

"(i) submit to the Secretary, the State long-term care ombudsman, residents of the facility, and the legal representatives of 
such residents or other responsible parties, written notification of an impending closure-

"(I) subject to subclause (II), not later than the date that is 60 days prior to the date of such closure; and "(II) in the case of a facility where the Secretary terminates the facility's participation under this title, not later than the date that the Secretary determines appropriate;

"(ii) ensure that the facility does not admit any new residents on or after the date on which such written notification is submitted; and

"(iii) include in the notice a plan for the transfer and adequate relocation of the residents of the facility by a specified date prior to closure that has been approved by the State, including assurances that the residents will be transferred to the most appropriate facility or other setting in terms of quality, services, and location, taking into consideration the needs and best interests of each resident. 


\section{"(B) Relocation.-}

“(i) IN GENERAL.-The State shall ensure that, before a facility closes, all residents of the facility have been successfully relocated to another facility or an alternative home and community-based setting.

“(ii) Continuation of payments UNTIL RESIDENTS RELOCATED.-The Secretary may, as the Secretary determines appropriate, continue to make payments under this title with respect to residents of a facility that has submitted a notification under subparagraph (A) during the period beginning on the date such notification is submitted and ending on the date on which the resident is successfully relocated.".

(2) Conforming amendments.-Section 1819(h)(4) of the Social Security Act (42 U.S.C. $1395 \mathrm{i}-3(\mathrm{~h})(4))$ is amended-

(A) in the first sentence, by striking "the Secretary shall terminate" and inserting "the Secretary, subject to subsection (c)(7), shall terminate"; and 
(B) in the second sentence, by striking "subsection (c)(2)" and inserting "paragraphs (2) and (7) of subsection (c)".

(1) In GENERAL.-Section 1919(c) of the So6 cial Security Act (42 U.S.C. 1396r(c)) is amended 7 by adding at the end the following new paragraph: “(9) Notification of Facility closure."(A) In generaL.-Any individual who is an administrator of a nursing facility must"(i) submit to the Secretary, the State

"(I) subject to subclause (II), not later than the date that is 60 days prior to the date of such closure; and "(II) in the case of a facility where the Secretary terminates the facility's participation under this title, not later than the date that the Secretary determines appropriate; 
"(ii) ensure that the facility does not

admit any new residents on or after the date on which such written notification is submitted; and

"(iii) include in the notice a plan for the transfer and adequate relocation of the residents of the facility by a specified date prior to closure that has been approved by the State, including assurances that the residents will be transferred to the most appropriate facility or other setting in terms of quality, services, and location, taking into consideration the needs and best interests of each resident.

"(B) Relocation.-

"(i) In GENERAL.-The State shall ensure that, before a facility closes, all residents of the facility have been successfully relocated to another facility or an alternative home and community-based setting.

“(ii) Continuation of payments UNTIL RESIDENTS RELOCATED.-The Secretary may, as the Secretary determines appropriate, continue to make payments 
under this title with respect to residents of a facility that has submitted a notification under subparagraph (A) during the period beginning on the date such notification is submitted and ending on the date on which the resident is successfully relocated.".

(c) Effective Date.-The amendments made by 8 this section shall take effect 1 year after the date of the 9 enactment of this Act.

\section{PART 3-IMPROVING STAFF TRAINING}

11 SEC. 1431. DEMENTIA AND ABUSE PREVENTION TRAINING.

$131819(\mathrm{f})(2)(\mathrm{A})(\mathrm{i})(\mathrm{I})$ of the Social Security Act (42 U.S.C.

14 1395i-3(f)(2)(A)(i)(I)) is amended by inserting "(includ-

15 ing, in the case of initial training and, if the Secretary

16 determines appropriate, in the case of ongoing training,

17 dementia management training and resident abuse preven18 tion training)" after "curriculum".

Nursing

Facilitites.-Section

$201919(\mathrm{f})(2)(\mathrm{A})(\mathrm{i})(\mathrm{I})$ of the Social Security Act (42 U.S.C.

21 1396r(f)(2)(A)(i)(I)) is amended by inserting "(including,

22 in the case of initial training and, if the Secretary deter-

23 mines appropriate, in the case of ongoing training, demen-

24 tia management training and resident abuse prevention 25 training)" after "curriculum". 
1 (c) EFFective Date.-The amendments made by 2 this section shall take effect 1 year after the date of the 3 enactment of this Act.

4 SEC. 1432. STUDY AND REPORT ON TRAINING REQUIRED FOR CERTIFIED NURSE AIDES AND SUPERVISORY STAFF.

(a) STUDY.-

(1) In GEnERAL.—The Secretary shall conduct a study on the content of training for certified nurse

11 ties and nursing facilities. The study shall include an 12 analysis of the following:

(A) Whether the number of initial training hours for certified nurse aides required under sections $1819(\mathrm{f})(2)(\mathrm{A})(\mathrm{i})(\mathrm{II}) \quad$ and 1919(f)(2)(A)(i)(II) of the Social Security Act $(42$ U.S.C. 1395i-3(f)(2)(A)(i)(II); $1396 \mathrm{r}(\mathrm{f})(2)(\mathrm{A})(\mathrm{i})(\mathrm{II}))$ should be increased from 75 and, if so, what the required number of initial training hours should be, including any recommendations for the content of such training (including training related to dementia).

(B) Whether requirements for ongoing training under such sections $1819(\mathrm{f})(2)(\mathrm{A})(\mathrm{i})(\mathrm{II}) \quad$ and $\quad 1919(\mathrm{f})(2)(\mathrm{A})(\mathrm{i})(\mathrm{II})$ 
1 should be increased from 12 hours per year, in-

2 cluding any recommendations for the content of 3 such training.

4 (2) Consultation.-In conducting the anal5 ysis under paragraph $(1)(\mathrm{A})$, the Secretary shall 6 consult with States that, as of the date of the enact7 ment of this Act, require more than 75 hours of 8 training for certified nurse aides.

9 (3) Definitions.-In this section:

10 (A) Nursing Facility.-The term "nurs11 ing facility" has the meaning given such term 12 in section 1919(a) of the Social Security Act 13 (42 U.S.C. $1396 \mathrm{r}(\mathrm{a}))$.

14 (B) SEcretary.-The term "Secretary" 15 means the Secretary of Health and Human 16 Services, acting through the Assistant Secretary 17 for Planning and Evaluation.

18 (C) Skilled NURsing Facility.-The 19 term "skilled nursing facility" has the meaning 20 given such term in section 1819 (a) of the Social 21 Security Act (42 U.S.C. 1395(a)).

22 (b) REPORT.-Not later than 2 years after the date 23 of the enactment of this Act, the Secretary shall submit 24 to Congress a report containing the results of the study 25 conducted under subsection (a), together with rec- 
1 ommendations for such legislation and administrative ac-

2 tion as the Secretary determines appropriate.

3 SEC. 1433. QUALIFICATION OF DIRECTOR OF FOOD SERVICES OF A SKILLED NURSING FACILITY OR NURSING FACILITY.

6 (a) MeDICARE.-Section $1819(\mathrm{~b})(4)(\mathrm{A})$ of the Social

7 Security Act (42 U.S.C. 1395i-3(b)(4)(A)) is amended by 8 adding at the end the following: "With respect to meeting 9 the staffing requirement imposed by the Secretary to carry 10 out clause (iv), the full-time director of food services of 11 the facility, if not a qualified dietitian (as defined in sec12 tion 483.35(a)(2) of title 42, Code of Federal Regulations, 13 as in effect as of the date of the enactment of this sen14 tence), shall be a Certified Dietary Manager meeting the 15 requirements of the Certifying Board for Dietary Man16 agers, or a Dietetic Technician, Registered meeting the 17 requirements of the Commission on Dietetic Registration 18 or have equivalent military, academic, or other qualifica19 tions (as specified by the Secretary).".

20 (b) MEDiCAID.- Section 1919(b)(4)(A) of the Social 21 Security Act (42 U.S.C. $1396 \mathrm{r}(\mathrm{b})(4)(\mathrm{A})$ ) is amended by 22 adding at the end the following: "With respect to meeting 23 the staffing requirement imposed by the Secretary to carry 24 out clause (iv), the full-time director of food services of 25 the facility, if not a qualified dietitian (as defined in sec- 
1 tion 483.35(a)(2) of title 42, Code of Federal Regulations,

2 as in effect as of the date of the enactment of this sen-

3 tence), shall be a Certified Dietary Manager meeting the

4 requirements of the Certifying Board for Dietary Man-

5 agers, or a Dietetic Technician, Registered meeting the

6 requirements of the Commission on Dietetic Registration

7 or have equivalent military, academic, or other qualifica-

8 tions (as specified by the Secretary).".

9 (c) EFFECTIVE Date.-The amendments made by

10 this section shall take effect on the date that is 180 days

11 after the date of enactment of this Act.

\section{Subtitle C-Quality Measurements}

13 SEC. 1441. ESTABLISHMENT OF NATIONAL PRIORITIES FOR QUALITY IMPROVEMENT.

15 Title XI of the Social Security Act, as amended by

16 section 1401(a), is further amended by adding at the end 17 the following new part:

"Part E-Quality Improvement PERFORMANCE IMPROVEMENT "Sec. 1191. (a) Establishment of National Pri-

22 ORITIEs By the SECRETARY.-The Secretary shall estab23 lish and periodically update, not less frequently than tri24 ennially, national priorities for performance improvement. 
1 “(b) Recommendations for National Prior2 ITIES.-In establishing and updating national priorities 3 under subsection (a), the Secretary shall solicit and con4 sider recommendations from multiple outside stake5 holders.

6 “(c) Considerations in Setting National Pri-

7 ORITIES.-With respect to such priorities, the Secretary

8 shall ensure that priority is given to areas in the delivery 9 of health care services in the United States that-

10 "(1) contribute to a large burden of disease, in11 cluding those that address the health care provided 12 to patients with prevalent, high-cost chronic dis13 eases;

14 "(2) have the greatest potential to decrease 15 morbidity and mortality in this country, including 16 those that are designed to eliminate harm to pa17 tients;

18 "(3) have the greatest potential for improving 19 the performance, affordability, and patient20 centeredness of health care, including those due to 21 variations in care;

22 “(4) address health disparities across groups 23 and areas; and 
"(5) have the potential for rapid improvement

2 due to existing evidence, standards of care or other

3 reasons.

4 “(d) Definitions.-In this part:

“(1) Consensus-Based Entity.-The term

6 'consensus-based entity' means an entity with a con-

$7 \quad$ tract with the Secretary under section 1890 .

8 “(2) Quality measure.-The term 'quality

9 measure' means a national consensus standard for

10 measuring the performance and improvement of pop-

11 ulation health, or of institutional providers of serv-

12 ices, physicians, and other health care practitioners

13 in the delivery of health care services.

14 “(e) Funding.-

15 “(1) In GENERAL.—The Secretary shall provide

16 for the transfer, from the Federal Hospital Insur-

17 ance Trust Fund under section 1817 and the Fed-

18 eral Supplementary Medical Insurance Trust Fund

19 under section 1841 (in such proportion as the Sec-

20 retary determines appropriate), of $\$ 2,000,000$, for

21 the activities under this section for each of the fiscal

22 years 2010 through 2014.

23 “(2) AUthorization OF APPROPRIATIONs.-

24 For purposes of carrying out the provisions of this 25 section, in addition to funds otherwise available, out 
1 of any funds in the Treasury not otherwise appro-

2 priated, there are appropriated to the Secretary of

3 Health and Human Services $\$ 2,000,000$ for each of

4 the fiscal years 2010 through 2014.".

5 SEC. 1442. DEVELOPMENT OF NEW QUALITY MEASURES;

6 GAO EVALUATION OF DATA COLLECTION PROCESS FOR QUALITY MEASUREMENT.

8 Part E of title XI of the Social Security Act, as added

9 by section 1441, is amended by adding at the end the fol-

10 lowing new sections:

11 “SEC. 1192. DEVELOPMENT OF NEW QUALITY MEASURES.

12 “(a) Agreements With Qualified Entities.-

13 "(1) In GeneraL.-The Secretary shall enter

14 into agreements with qualified entities to develop

15 quality measures for the delivery of health care serv-

16 ices in the United States.

17 “(2) FORM OF AGREEMENTS.-The Secretary

18 may carry out paragraph (1) by contract, grant, or

19 otherwise.

20 “(3) RECOMMENDATIONS OF CONSENSUS21 BASED ENTITY.-In carrying out this section, the 22 Secretary shall-

23 “(A) seek public input; and 
"(B) take into consideration recommendations of the consensus-based entity with a contract with the Secretary under section 1890(a).

4 “(b) Determination of Areas Where Quality

5 Measures Are Required.-Consistent with the na6 tional priorities established under this part and with the 7 programs administered by the Centers for Medicare \& 8 Medicaid Services and in consultation with other relevant 9 Federal agencies, the Secretary shall determine areas in 10 which quality measures for assessing health care services 11 in the United States are needed. “(c) Development of Quality Measures.“(1) Patient-Centered and POPUlationBASED MEASURES.-In entering into agreements 15 under subsection (a), the Secretary shall give pri16 ority to the development of quality measures that 17 allow the assessment ofment, and functional status of patients;

"(B) the continuity and coordination of care and care transitions for patients across providers and health care settings, including end of life care;

"(C) patient experience and patient engagement; 
"(D) the safety, effectiveness, and timeliness of care;

"(E) health disparities including those associated with individual race, ethnicity, age, gender, place of residence or language; and "(F) the efficiency and resource use in the provision of care.

"(2) UsE OF FUNDS.-An entity that enters into an agreement under subsection (a) shall develop quality measures that-

"(A) to the extent feasible, have the ability to be collected through the use of health information technologies supporting better delivery of health care services; and

"(B) are available free of charge to users for the use of such measures.

“(3) Availability of Measures. - The Secretary shall make quality measures developed under this section available to the public.

“(4) Testing OF PROposed Measures.-The Secretary may use amounts made available under subsection (f) to fund the testing of proposed quality measures by qualified entities. Testing funded under this paragraph shall include testing of the feasibility and usability of proposed measures. 
2 The Secretary may use amounts made available 3 under subsection (f) to fund the updating (and test4 ing, if applicable) by consensus-based entities of 5 quality measures that have been previously endorsed 6 by such an entity as new evidence is developed, in 7 a manner consistent with section $1890(b)(3)$.

8 “(d) Qualified Entities.-Before entering into 9 agreements with a qualified entity, the Secretary shall en10 sure that the entity is a public, private, or academic insti11 tution with technical expertise in the area of health quality 12 measurement.

13 “(e) Application For Grant.-A grant may be 14 made under this section only if an application for the 15 grant is submitted to the Secretary and the application 16 is in such form, is made in such manner, and contains 17 such agreements, assurances, and information as the Sec18 retary determines to be necessary to carry out this section. 19 “(f) Funding.-

20 "(1) In GENERAL.—The Secretary shall provide 21 for the transfer, from the Federal Hospital Insur22 ance Trust Fund under section 1817 and the Fed23 eral Supplementary Medical Insurance Trust Fund 24 under section 1841 (in such proportion as the Sec25 retary determines appropriate), of $\$ 25,000,000$, to 
1 the Secretary for purposes of carrying out this sec-

2 tion for each of the fiscal years 2010 through 2014.

“(2) Authorization of appropriations.-

$4 \quad$ For purposes of carrying out the provisions of this

5 section, in addition to funds otherwise available, out

6 of any funds in the Treasury not otherwise appro-

7 priated, there are appropriated to the Secretary of

8 Health and Human Services $\$ 25,000,000$ for each

9 of the fiscal years 2010 through 2014.

10 “SEC. 1193. GAO EVALUATION OF DATA COLLECTION PROCESS FOR QUALITY MEASUREMENT.

12 “(a) GAO Evaluations.-The Comptroller General

13 of the United States shall conduct periodic evaluations of

14 the implementation of the data collection processes for 15 quality measures used by the Secretary.

16 “(b) Considerations.-In carrying out the evalua17 tion under subsection (a), the Comptroller General shall 18 determine-

"(1) whether the system for the collection of 20 data for quality measures provides for validation of 21 data as relevant and scientifically credible;

22 "(2) whether data collection efforts under the 23 system use the most efficient and cost-effective 24 means in a manner that minimizes administrative 25 burden on persons required to collect data and that 
1 adequately protects the privacy of patients' personal

2 health information and provides data security;

"(3) whether standards under the system pro-

4 vide for an appropriate opportunity for physicians

5 and other clinicians and institutional providers of

6 services to review and correct findings; and

7 "(4) the extent to which quality measures are

8 consistent with section 1192(c)(1) or result in direct

9 or indirect costs to users of such measures.

10 “(c) REPORT.-The Comptroller General shall sub-

11 mit reports to Congress and to the Secretary containing

12 a description of the findings and conclusions of the results

13 of each such evaluation.".

14 SEC. 1443. MULTI-STAKEHOLDER PRE-RULEMAKING INPUT INTO SELECTION OF QUALITY MEASURES.

16 Section 1808 of the Social Security Act (42 U.S.C.

17 1395b-9) is amended by adding at the end the following 18 new subsection:

19 “(d) Multi-stakeholder Pre-Rulemaking InPut

20 Into Selection of Quality Measures.-

"(1) List of Measures.-Not later than De-

22 cember 1 before each year (beginning with 2011),

23 the Secretary shall make public a list of measures

24 being considered for selection for quality measure-

25 ment by the Secretary in rulemaking with respect to 
1 payment systems under this title beginning in the

2 payment year beginning in such year and for pay-

3 ment systems beginning in the calendar year fol-

$4 \quad$ lowing such year, as the case may be.

$5 \quad$ “(2) Consultation on selection OF EN-

6 DORSED QUALITY MEASURES.-A consensus-based

7 entity that has entered into a contract under section

81890 shall, as part of such contract, convene multi-

9 stakeholder groups to provide recommendations on

10 the selection of individual or composite quality meas-

11 ures, for use in reporting performance information

12 to the public or for use in public health care pro-

13 grams.

14 “(3) Multi-STAKeholder INPUT.-Not later

15 than February 1 of each year (beginning with

16 2011), the consensus-based entity described in para-

17 graph (2) shall transmit to the Secretary the rec-

18 ommendations of multi-stakeholder groups provided

19 under paragraph (2). Such recommendations shall

20 be included in the transmissions the consensus-based

21 entity makes to the Secretary under the contract

22 provided for under section 1890.

23 “(4) REQUIREMENT FOR TRANSPARENCY IN

24 PROCESS.- 
"(A) IN GENERAL. - In convening multi-

stakeholder groups under paragraph (2) with respect to the selection of quality measures, the consensus-based entity described in such paragraph shall provide for an open and transparent

“(5) USE OF INPUT.—The respective proposed

16 rule shall contain a summary of the recommenda17 tions made by the multi-stakeholder groups under 18 paragraph (2), as well as other comments received 19 regarding the proposed measures, and the extent to 20 which such proposed rule follows such recommenda21 tions and the rationale for not following such rec22 ommendations.

“(6) MulTi-Stakeholder GROUPs.-For pur24 poses of this subsection, the term 'multi-stakeholder 25 groups' means, with respect to a quality measure, a 
1 voluntary collaborative of organizations representing

2 persons interested in or affected by the use of such

3 quality measure, such as the following:

“(A) Hospitals and other institutional pro-

5 viders.

"(B) Physicians.

"(C) Health care quality alliances.

“(D) Nurses and other health care practitioners.

“(E) Health plans.

"(F) Patient advocates and consumer groups.

"(G) Employers.

"(H) Public and private purchasers of health care items and services.

"(I) Labor organizations.

“(J) Relevant departments or agencies of the United States.

"(K) Biopharmaceutical companies and manufacturers of medical devices.

"(L) Licensing, credentialing, and accrediting bodies.

“(7) Funding.-

"(A) IN GENERAL.-The Secretary shall provide for the transfer, from the Federal Hos- 
pital Insurance Trust Fund under section 1817

and the Federal Supplementary Medical Insurance Trust Fund under section 1841 (in such proportion as the Secretary determines appropriate), of $\$ 1,000,000$, to the Secretary for purposes of carrying out this subsection for each of the fiscal years 2010 through 2014 .

"(B) AUthorization OF APPROPRIATIONS.-For purposes of carrying out the provisions of this subsection, in addition to funds otherwise available, out of any funds in the Treasury not otherwise appropriated, there are appropriated to the Secretary of Health and Human Services $\$ 1,000,000$ for each of the fiscal years 2010 through 2014.”.

\section{SEC. 1444. APPLICATION OF QUALITY MEASURES.}

17 (a) Inpatient Hospital Services.-Bection 18 1886(b)(3)(B) of such Act (42 U.S.C. $1395 w w(b)(3)(B))$

19 is amended by adding at the end the following new clause: 20 “(x)(I) Subject to subclause (II), for purposes of re21 porting data on quality measures for inpatient hospital 22 services furnished during fiscal year 2012 and each subse23 quent fiscal year, the quality measures specified under 24 clause (viii) shall be measures selected by the Secretary 
1 from measures that have been endorsed by the entity with

2 a contract with the Secretary under section 1890(a).

3 "(II) In the case of a specified area or medical topic

4 determined appropriate by the Secretary for which a fea-

5 sible and practical quality measure has not been endorsed

6 by the entity with a contract under section 1890(a), the

7 Secretary may specify a measure that is not so endorsed

8 as long as due consideration is given to measures that

9 have been endorsed or adopted by a consensus organiza-

10 tion identified by the Secretary. The Secretary shall sub-

11 mit such a non-endorsed measure to the entity for consid-

12 eration for endorsement. If the entity considers but does

13 not endorse such a measure and if the Secretary does not

14 phase-out use of such measure, the Secretary shall include

15 the rationale for continued use of such a measure in rule-

16 making.".

17 (b) Outpatient Hospital Services.--Section

$181833(\mathrm{t})(17)$ of such Act (42 U.S.C. 1395l(t)(17)) is

19 amended by adding at the end the following new subpara20 graph:

“(F) UsE OF ENDORSED QUALITY MEASURES.-The provisions of clause $(\mathrm{x})$ of section 1886(b)(3)(C) shall apply to quality measures for covered OPD services under this paragraph 
quality measures for inpatient hospital services.".

7 measure to the entity for consideration for endorsement.

8 If the entity considers but does not endorse such a meas-

9 ure and if the Secretary does not phase-out use of such

10 measure, the Secretary shall include the rationale for con-

11 tinued use of such a measure in rulemaking.".

12 (d) Renal Dialysis Services.-Section

13 1881(h)(2)(B)(ii) of such Act (42 U.S.C.

$141395 \operatorname{rr}(\mathrm{h})(2)(\mathrm{B})(\mathrm{ii}))$ is amended by adding at the end the

15 following: "The Secretary shall submit such a non-en-

16 dorsed measure to the entity for consideration for endorse-

17 ment. If the entity considers but does not endorse such

18 a measure and if the Secretary does not phase-out use

19 of such measure, the Secretary shall include the rationale

20 for continued use of such a measure in rulemaking.".

21 (e) Endorsement OF Standards.-Section

$221890(b)(2)$ of the Social Security Act (42 U.S.C.

23 1395aaa(b)(2)) is amended by adding after and below sub24 paragraph (B) the following: 
1 "If the entity does not endorse a measure, such enti-

2 ty shall explain the reasons and provide suggestions 3 about changes to such measure that might make it 4 a potentially endorsable measure.".

5 (f) Effective Date.-Except as otherwise pro6 vided, the amendments made by this section shall apply 7 to quality measures applied for payment years beginning 8 with 2012 or fiscal year 2012, as the case may be.

9 SEC. 1445. CONSENSUS-BASED ENTITY FUNDING.

10 Section 1890 (d) of the Social Security Act (42 U.S.C. 11 1395aaa(d)) is amended by striking "for each of fiscal 12 years 2009 through 2012" and inserting "for fiscal year 132009 , and $\$ 12,000,000$ for each of the fiscal years 2010 14 through 2012" 
1 Subtitle D-Physician Payments Sunshine Provision

3 SEC. 1451. REPORTS ON FINANCIAL RELATIONSHIPS BETWEEN MANUFACTURERS AND DISTRIBUTORS OF COVERED DRUGS, DEVICES, BIOLOGICALS, OR MEDICAL SUPPLIES UNDER MEDICARE, MEDICAID, OR CHIP AND PHYSICIANS AND OTHER HEALTH CARE ENTITIES AND BETWEEN PHYSICIANS AND OTHER HEALTH CARE ENTITIES.

(a) In General.-Part A of title XI of the Social

12 Security Act (42 U.S.C. 1301 et seq.), as amended by sec13 tion 1631(a), is further amended by inserting after section 14 1128G the following new section:

15 “SEC. 1128H. FINANCIAL REPORTS ON PHYSICIANS' FINANCIAL RELATIONSHIPS WITH MANUFACTURERS AND DISTRIBUTORS OF COVERED DRUGS, DEVICES, BIOLOGICALS, OR MEDICAL SUPPLIES UNDER MEDICARE, MEDICAID, OR CHIP AND WITH ENTITIES THAT BILL FOR SERVICES UNDER MEDICARE.

“(a) Reporting of Payments or Other Trans23 Fers of Value.- 
1 nually thereafter, each applicable manufacturer or

2 distributor that provides a payment or other transfer

3 of value to a covered recipient, or to an entity or in-

4 dividual at the request of or designated on behalf of

5 a covered recipient, shall submit to the Secretary, in

6 such electronic form as the Secretary shall require,

7 the following information with respect to the pre-

8 ceding calendar year:

9 “(A) With respect to the covered recipient, 10 the recipient's name, business address, physi11 cian specialty, and national provider identifier.

12 "(B) With respect to the payment or other 13 transfer of value, other than a drug sample-

"(i) its value and date;

"(ii) the name of the related drug, device, or supply, if available, to the level of specificity available; and

"(iii) a description of its form, indicated (as appropriate for all that apply) as-

"(I) cash or a cash equivalent;

"(II) in-kind items or services; any other ownership interest, divi- 
dend, profit, or other return on invest-

ment; or

“(IV) any other form (as defined by the Secretary).

"(C) With respect to a drug sample, the name, number, date, and dosage units of the sample.

“(2) AgGregate REPORTing.-Information submitted by an applicable manufacturer or dis10 tributor under paragraph (1) shall include the ag11 gregate amount of all payments or other transfers of 12 value provided by the manufacturer or distributor to 13 covered recipients (and to entities or individuals at 14 the request of or designated on behalf of a covered 15 recipient) during the year involved, including all pay16 ments and transfers of value regardless of whether 17 such payments or transfer of value were individually 18 disclosed.

"(3) SPECIAL RULE FOR CERTAIN PAYMENTS 20 OR OTHER TRANSFERS OF VALUE.-In the case 21 where an applicable manufacturer or distributor pro22 vides a payment or other transfer of value to an en23 tity or individual at the request of or designated on 24 behalf of a covered recipient, the manufacturer or 25 distributor shall disclose that payment or other 
1 transfer of value under the name of the covered re-

2 cipient.

“(4) Delayed Reporting FOR PAYMents

4 MADE PURSUANT TO PRODUCT DEVELOPMENT

5 AGREEMENTS. - In the case of a payment or other

6 transfer of value made to a covered recipient by an

7 applicable manufacturer or distributor pursuant to a

8 product development agreement for services fur-

9 nished in connection with the development of a new

10 drug, device, biological, or medical supply, the appli-

11 cable manufacturer or distributor may report the

12 value and recipient of such payment or other trans-

13 fer of value in the first reporting period under this

14 subsection in the next reporting deadline after the

15 earlier of the following:

16 "(A) The date of the approval or clearance

17 of the covered drug, device, biological, or med-

18 ical supply by the Food and Drug Administra19 tion.

"(B) Two calendar years after the date such payment or other transfer of value was made.

“(5) Delayed Reporting For Payments 24 Made PURsuant to Clinical investigations.-In 25 the case of a payment or other transfer of value 
1 made to a covered recipient by an applicable manu-

2 facturer or distributor in connection with a clinical

3 investigation regarding a new drug, device, biologi-

4 cal, or medical supply, the applicable manufacturer

5 or distributor may report as required under this sec-

6 tion in the next reporting period under this sub-

7 section after the earlier of the following:

8 "(A) The date that the clinical investiga-

9 tion is registered on the website maintained by

10 the National Institutes of Health pursuant to

11 section 671 of the Food and Drug Administra-

12 tion Amendments Act of 2007.

13 "(B) Two calendar years after the date

14 such payment or other transfer of value was 15 made.

16 "(6) Confidentiality.-Information de-

17 scribed in paragraph (4) or (5) shall be considered

18 confidential and shall not be subject to disclosure

19 under section 552 of title 5, United States Code, or

20 any other similar Federal, State, or local law, until

21 or after the date on which the information is made

22 available to the public under such paragraph.

23 “(7) Physicians in SElf-Insured health

24 PLANs.-Nothing in this subsection shall be con25 strued to require the disclosure of a payment or 
1 other transfer of value to a physician by a self-in-

2 sured health plan.

3 “(b) Reporting of Ownership Interest by Phy4 SICIANS.-

6 BILL MEDICARE.-Not later than March 31 of each

7 year (beginning with 2011), each hospital or other

8 health care entity (not including a Medicare Advan-

9 tage organization) that bills the Secretary under

10 part A or part B of title XVIII for services shall re-

11 port on the ownership shares (other than ownership

12 shares described in section $1877(\mathrm{c})$ ) of each physi-

13 cian who, directly or indirectly, owns an interest in

14 the entity.

“(2) Additional Physician OWNership.-

16 Not later than March 31 of each year (beginning

17 with 2011), in addition to the requirement under 18 subsection (a)(1), any applicable manufacturer, ap-

19 plicable group purchasing organization, or applicable 20 distributor shall submit to the Secretary, in such 21 electronic form as the Secretary shall require, the 22 following information regarding any ownership or in23 vestment interest (other than an ownership or in24 vestment interest in a publicly traded security and 25 mutual fund, as described in section 1877(c)) held 
1 by a physician (or an immediate family member of 2 such physician (as defined for purposes of section $31877(\mathrm{a})))$ in the applicable manufacturer, applicable 4 group purchasing organization or applicable dis5 tributor during the preceding year:

6 "(A) The dollar amount invested by each physician holding such an ownership or investment interest.

"(B) The value and terms of each such ownership or investment interest.

“(C) Any payment or other transfer of value provided to a physician holding such an ownership or investment interest (or to an entity or individual at the request of or designated on behalf of a physician holding such an ownership or investment interest), including the information described in clauses (i) through (iii) of paragraph $(\mathrm{a})(1)(\mathrm{B})$, and information described in subsection (f)(8)(A) and (f)(8)(B).

"(D) Any other information regarding the ownership or investment interest the Secretary determines appropriate.

“(3) Definitions.-In this subsection: 
“(A) Physiclan.-The term 'physician' includes a physician's immediate family members (as defined for purposes of section 1877(a)).

“(B) Applicable group purchasing OR-

13 COLOGY services.-The Comptroller General of the

14 United States shall conduct a study to evaluate the 15 extent of use of physician self-referral arrangements 16 and the effects of such arrangements on the cost of 17 providing advanced diagnostic imaging and radiation 18 oncology services to Medicare beneficiaries under 19 title XVIII. The study shall be completed and sub20 mitted to Congress not later than July 1, 2011.

21 “(c) Public Availability.-

23 lish procedures to ensure that, not later than Sep24 tember 30, 2011, and on June 30 of each year be25 ginning thereafter, the information submitted under 
1 subsections (a) and (b), other than information re2 gard drug samples, with respect to the preceding 3 calendar year is made available through an Internet 4 website that-

"(A) is searchable and is in a format that 6 is clear and understandable;

"(B) contains information that is presented by the name of the applicable manufacturer or distributor, the name of the covered recipient, the business address of the covered recipient, the specialty (if applicable) of the covered recipient, the value of the payment or other transfer of value, the date on which the payment or other transfer of value was provided to the covered recipient, the form of the payment or other transfer of value, indicated (as appropriate) under subsection (a)(1)(B)(ii), the nature of the payment or other transfer of value, indicated (as appropriate) under subsection (a)(1)(B)(iii), and the name of the covered drug, device, biological, or medical supply, as applicable;

"(C) contains information that is able to be easily aggregated and downloaded; 
“(D) contains a description of any enforcement actions taken to carry out this section, including any penalties imposed under subsection (d), during the preceding year;

"(E) contains background information on industry-physician relationships;

"(F) in the case of information submitted with respect to a payment or other transfer of value described in subsection (a)(5), lists such information separately from the other information submitted under subsection (a) and designates such separately listed information as funding for clinical research;

"(G) contains any other information the Secretary determines would be helpful to the average consumer; and

"(H) provides the covered recipient an opportunity to submit corrections to the information made available to the public with respect to the covered recipient.

"(2) Accuracy of Reporting.-The accuracy of the information that is submitted under subsections (a) and (b) and made available under paragraph (1) shall be the responsibility of the reporting entity reporting under subsection (a) or (b), as ap- 
1 plicable. The Secretary shall establish procedures to

2 ensure that the covered recipient is provided with an 3 opportunity to submit corrections to the applicable 4 reporting entity with regard to information made 5 public with respect to the covered recipient and, 6 under such procedures, the corrections shall be 7 transmitted to the Secretary. "(3) SPeclal RUle FOR DRUg Samples.-In9 formation relating to drug samples provided under 10 subsection (a) shall not be made available to the 11 public by the Secretary but may be made available 12 outside the Department of Health and Human Serv13 ices by the Secretary for research or legitimate busi14 ness purposes pursuant to data use agreements. “(4) Special Rule For national Provider 16 IDENTIFIERS.-Information relating to national pro17 vider identifiers provided under subsection (a) shall 18 not be made available to the public by the Secretary 19 but may be made available outside the Department 20 of Health and Human Services by the Secretary for 21 research or legitimate business purposes pursuant to 22 data use agreements.

23 “(d) Penalties for Noncompliance.24 "(1) FAILURe to Report.- 
“(A) IN GENERAL.—Subject to subparagraph (B), except as provided in paragraph (2), any reporting entity that fails to submit information required under subsection (a) or (b), as applicable, in a timely manner in accordance

with regulations promulgated to carry out such applicable subsection shall be subject to a civil money penalty of not less than $\$ 1,000$, but not more than $\$ 10,000$, for each payment or other transfer of value or ownership or investment interest not reported as required under such subsection. Such penalty shall be imposed and collected in the same manner as civil money penalties under subsection (a) of section 1128A are imposed and collected under that section.

"(B) Limitation.-The total amount of civil money penalties imposed under subparagraph (A), with respect to each annual submission of information under subsection (a) by a reporting entity, shall not exceed $\$ 150,000$.

“(2) KNOWIng FAILURE TO REPORT.“(A) IN GENERAL.—Subject to subparagraph (B), any reporting entity that knowingly fails to submit information required under subsection (a) or (b), as applicable, in a timely 
manner in accordance with regulations promulgated to carry out such applicable subsection, shall be subject to a civil money penalty of not less than $\$ 10,000$, but not more than $\$ 100,000$, for each payment or other transfer of value or ownership or investment interest not

"(3) UsE OF Funds.-Funds collected by the money penalty under this subsection shall be used to carry out this section.

“(4) Enforcement Through state attorNEYS GENERAL.-The attorney general of a State, 
1 after providing notice to the Secretary of an intent

2 to proceed under this paragraph in a specific case

3 and providing the Secretary with an opportunity to

4 bring an action under this subsection and the Sec-

5 retary declining such opportunity, may proceed

6 under this subsection against an applicable manufac-

$7 \quad$ turer or distributor in the State.

8 “(e) Annual Report to Congress.-Not later

9 than April 1 of each year beginning with 2011, the Sec-

10 retary shall submit to Congress a report that includes the

11 following:

"(1) The information submitted under this sec-

13 tion during the preceding year, aggregated for each

14 applicable reporting entity that submitted such in15 formation during such year.

16 “(2) A description of any enforcement actions 17 taken to carry out this section, including any pen18 alties imposed under subsection (d), during the pre19 ceding year.

20 “(f) DeFinitions.-In this section:

“(1) APPlicable Distributor.-The term 22 'applicable distributor' means-

"(A) any entity, other than an applicable group purchasing organization, that buys and 25 resells, or receives a commission or other simi- 
lar form of payment, from another seller, for selling or arranging for the sale of a covered drug, device, biological, or medical supply; or

“(B) any entity under common ownership with such an entity described in subparagraph (A) and which provides assistance or support to such entity so described with respect to the production, preparation, propagation, compounding, conversion, processing, marketing, or distribution of a covered drug, device, biological, or medical supply.

Such term does not include a wholesale pharmaceutical distributor.

“(2) Applicable manufacturer.-The term 'applicable manufacturer' means any entity which is engaged in the production, preparation, propagation, compounding, conversion, processing, marketing, or manufacturer-direct distribution of a covered drug, device, biological, or medical supply (or any entity under common ownership with such entity and which provides assistance or support to such entity with respect to the production, preparation, propagation, compounding, conversion, processing, marketing, or distribution or a covered drug, device, biological, or medical supply). For purposes of this section only, 
1 such term does not include a retail pharmacy li2 censed under State law.

“(3) Clinical investigation.-The term

4 'clinical investigation' means any experiment involv5 ing one or more human subjects, or materials de6 rived from human subjects, in which a drug or de-

7 vice is administered, dispensed, or used.

“(4) Covered Drug, Device, Biological, or 9 MEDICAL SUPPLY.-The term 'covered' means, with 10 respect to a drug, device, biological, or medical sup11 ply, such a drug, device, biological, or medical supply 12 for which payment is available under title XVIII or 13 a State plan under title XIX or XXI (or a waiver 14 of such a plan).

“(5) Covered RECIPIENT.-The term 'covered 16 recipient' means the following:

“(B) A physician group practice.

"(C) Any other prescriber of a covered drug, device, biological, or medical supply.

“(D) A pharmacy or pharmacist.

"(E) A health insurance issuer, group health plan, or other entity offering a health benefits plan, including any employee of such 25 an issuer, plan, or entity. 
905

"(F) A pharmacy benefit manager, including any employee of such a manager.

"(G) A hospital.

"(H) A medical school.

"(I) A sponsor of a continuing medical education program.

“(J) A patient advocacy or disease specific group.

"(K) A organization of health care professionals.

"(L) A biomedical researcher.

“(M) A group purchasing organization.

"(6) Employee.-The term 'employee' has the meaning given such term in section 1877(h)(2).

“(7) Knowingly.-The term 'knowingly' has the meaning given such term in section 3729(b) of title 31, United States Code.

“(8) Payment oR OTHeR TRAnsfer OF VALUE.-

"(A) In GENERAL.-The term 'payment or other transfer of value' means a transfer of anything of value for or of any of the following:

"(i) Gift, food, or entertainment.

“(ii) Travel or trip.

"(iii) Honoraria. 
906

“(iv) Research funding or grant.

“(v) Education or conference funding.

"(vi) Consulting fees.

"(vii) Ownership or investment interest and royalties or license fee.

"(B) InCLusions.-Subject to subparagraph $(\mathrm{C})$, the term "payment or other transfer of value' includes any compensation, gift, honorarium, speaking fee, consulting fee, travel, services, dividend, profit distribution, stock or stock option grant, or any ownership or investment interest held by a physician in a manufacturer (excluding a dividend or other profit distribution from, or ownership or investment interest in, a publicly traded security or mutual fund (as described in section 1877(c))).

"(C) Exclusions.-The term 'payment or other transfer of value' does not include the following:

“(i) Any payment or other transfer of value provided by an applicable manufacturer or distributor to a covered recipient where the amount transferred to, requested by, or designated on behalf of the covered recipient does not exceed $\$ 5$. 
“(ii) The loan of a covered device for

a short-term trial period, not to exceed 90 days, to permit evaluation of the covered device by the covered recipient.

"(iii) Items or services provided under a contractual warranty, including the replacement of a covered device, where the terms of the warranty are set forth in the purchase or lease agreement for the covered device.

"(iv) A transfer of anything of value to a covered recipient when the covered recipient is a patient and not acting in the professional capacity of a covered recipient.

“(v) In-kind items used for the provision of charity care.

"(vi) A dividend or other profit distribution from, or ownership or investment interest in, a publicly traded security and mutual fund (as described in section $1877(\mathrm{c}))$.

“(vii) Compensation paid by an applicable manufacturer or distributor to a covered recipient who is directly employed by 
and works solely for such manufacturer or distributor.

"(viii) Payments made to a covered recipient by an applicable manufacturer or by a health plan affiliated with an applicable manufacturer for medical care provided to employees of such manufacturer or their dependents.

“(ix) Any discount (including a rebate).

“(x) Any payment or other transfer of value that is made to a covered recipient indirectly through an entity other than the applicable manufacturer in connection with an activity or service-

"(I) in which the applicable manufacturer is unaware of the identity of the covered recipient and is not using such activity or service to market its product to the covered recipient; and "(II) that is not designed to market or promote the product to the covered recipient.

"(xi) In the case of an applicable manufacturer who offers a self-insured 
plan, payments for the provision of health care to employees under the plan.

“(9) Physician.-The term 'physician' has the

4 meaning given that term in section 1861(r). For

5 purposes of this section, such term does not include

6 a physician who is an employee of the applicable

7 manufacturer that is required to submit information

8 under subsection (a).

9 “(10) Reporting Entity.-The term 'report10 ing entity' means-

11 "(A) with respect to the reporting require12 ment under subsection (a), an applicable manu-

13 facturer or distributor of a covered drug, device, 14 biological, or medical supply required to report 15 under such subsection; and

16 "(B) with respect to the reporting require17 ment under subsection (b), a hospital, other 18 health care entity, applicable manufacturer, ap19 plicable distributor, or applicable group pur20 chasing organization required to report physi21 cian ownership under such subsection.

22 “(g) Annual Reports to States.-Not later than 23 April 1 of each year beginning with 2011, the Secretary 24 shall submit to States a report that includes a summary 25 of the information submitted under subsections (a), (b), 
1 and (e) during the preceding year with respect to covered

2 recipients or other hospitals and entities in the State.

3 “(h) Relation to State Laws.-

4 “(1) IN GENERAL.-Effective on January 1,

52011 , subject to paragraph (2), the provisions of

6 this section shall preempt any law or regulation of

7 a State or of a political subdivision of a State that

8 requires an applicable manufacturer and applicable

9 distributor (as such terms are defined in subsection

10 (f)) to disclose or report, in any format, the type of

11 information (described in subsection (a)) regarding a

12 payment or other transfer of value provided by the

13 manufacturer to a covered recipient (as so defined).

14 “(2) No PREEMPTION OF ADDITIONAL RE-

15 QUIREMENTS.-Paragraph (1) shall not preempt any

16 statute or regulation of a State or political subdivi-

17 sion of a State that requires any of the following:

18 "(A) The disclosure or reporting of infor-

19 mation not of the type required to be disclosed

20 or reported under this section.

21 "(B) The disclosure or reporting, in any

22 format, of information described in subsection

23 (f)(8)(C), except in the case of information de-

24 scribed in clause (i) of subsection (f)(8)(C). 
18 Closure of Financial Relationship Report

19 (DFRR).- The Secretary of Health and Human Services 20 shall submit to Congress a report on the full results of 21 the Disclosure of Physician Financial Relationships sur22 veys required pursuant to section 5006 of the Deficit Re23 duction Act of 2005. Such report shall be submitted to 24 Congress not later than the date that is 6 months after 25 the date such surveys are collected and shall be made pub- 
1 licly available on an Internet website of the Department 2 of Health and Human Services.

3 (c) GAO REPORT.-Not later than December 31, 4 2012, the Comptroller General of the United States shall 5 submit to Congress a report on section $1128 \mathrm{H}$ of the So6 cial Security Act, as added by subsection (a). Such report 7 shall address the extent to which important transfers of 8 value are being adequately reported under such section 9 (including unreported transfers required by such section 10 as well as transfers not required to be reported by such 11 section), the impact on States of the federal preemption 12 provision under subsection (h) of such section, whether 13 changes have occurred in the pattern of payments as a 14 result of efforts to evade reporting requirements, a de15 scription of the financial relationships subject to delayed 16 reporting under subsection (a) of such section, and any 17 recommended improvements to the collection or the anal18 ysis of data reported under such section. 


\section{Subtitle E-Public Reporting on 2 Health Care-Associated Infections}

3 SEC. 1461. REQUIREMENT FOR PUBLIC REPORTING BY HOSPITALS AND AMBULATORY SURGICAL CENTERS ON HEALTH CARE-ASSOCIATED INFECTIONS.

8 is amended by inserting after section 1138 the following 9 section:

10 “SEC. 1138A. REQUIREMENT FOR PUBLIC REPORTING BY HOSPITALS AND AMBULATORY SURGICAL CENTERS ON HEALTH CARE-ASSOCIATED INFECTIONS.

(a) In GeneRAL.-Title XI of the Social Security Act

17 bulatory surgical center meeting the requirements of

18 titles XVIII or XIX may participate in the programs

19 established under such titles only if, in accordance

20 with this section, the hospital or center reports such

21 information on health care-associated infections that

22 develop in the hospital or center (and such demo-

23 graphic information associated with such infections)

24 as the Secretary specifies. 
"(2) Reporting PRotocols.- Such informa-

2 tion shall be reported in accordance with reporting 3 protocols established by the Secretary through the

4 Director of the Centers for Disease Control and Pre5 vention (in this section referred to as the 'CDC') 6 and to the National Healthcare Safety Network of 7 the CDC or under such another reporting system of 8 such Centers as determined appropriate by the Sec9 retary in consultation with such Director.

10 “(3) Coordination with Hit.-The Sec11 retary, through the Director of the CDC and the Of12 fice of the National Coordinator for Health Informa13 tion Technology, shall ensure that the transmission 14 of information under this subsection is coordinated 15 with systems established under the HITECH Act, 16 where appropriate.

17 “(4) Procedures to Ensure the validity 18 OF INFORMATION.-The Secretary shall establish 19 procedures regarding the validity of the information 20 submitted under this subsection in order to ensure 21 that such information is appropriately compared 22 across hospitals and centers. Such procedures shall 23 address failures to report as well as errors in report24 ing. 
2 after the date of enactment of this section, the Sec-

3 retary, through the Director of CDC, shall promul-

4 gate regulations to carry out this section.

5 “(b) Public Posting of Information.-The Sec6 retary shall promptly post, on the official public Internet 7 site of the Department of Health and Human Services, 8 the information reported under subsection (a). Such infor9 mation shall be set forth in a manner that allows for the 10 comparison of information on health care-associated infec11 tions-

12 "(1) among hospitals and ambulatory surgical 13 centers; and “(2) by demographic information.

15 “(c) Annual Report to Congress.—On an annual

16 basis the Secretary shall submit to the Congress a report 17 that summarizes each of the following:

18 “(1) The number and types of health care-asso19 ciated infections reported under subsection (a) in 20 hospitals and ambulatory surgical centers during 21 such year.

"(2) Factors that contribute to the occurrence

23 of such infections, including health care worker im24 munization rates. 
"(3) Based on the most recent information

2 available to the Secretary on the composition of the

3 professional staff of hospitals and ambulatory sur-

4 gical centers, the number of certified infection con-

5 trol professionals on the staff of hospitals and ambu-

$6 \quad$ latory surgical centers.

7 “(4) The total increases or decreases in health

8 care costs that resulted from increases or decreases

9 in the rates of occurrence of each such type of infec-

10 tion during such year.

11 "(5) Recommendations, in coordination with the

12 Center for Quality Improvement established under

13 section 931 of the Public Health Service Act, for

14 best practices to eliminate the rates of occurrence of

15 each such type of infection in hospitals and ambula-

16 tory surgical centers.

17 “(d) Non-PREemption of State Laws.-Nothing

18 in this section shall be construed as preempting or other-

19 wise affecting any provision of State law relating to the

20 disclosure of information on health care-associated infec-

21 tions or patient safety procedures for a hospital or ambu-

22 latory surgical center.

23 “(e) Health Care-associated Infection.-For 24 purposes of this section: 
"(1) IN GENERAL.—The term 'health care-asso-

2 ciated infection' means an infection that develops in

3 a patient who has received care in any institutional

4 setting where health care is delivered and is related

5 to receiving health care.

6 “(2) Related to Receiving health CARE.-

7 The term 'related to receiving health care', with re-

8 spect to an infection, means that the infection was

9 not incubating or present at the time health care

10 was provided.

11 “(f) Application to Critical access Hos-

12 PITALS.-For purposes of this section, the term 'hospital'

13 includes a critical access hospital, as defined in section 14 1861(mm)(1).”.

15 (b) EFFEctive Date.-With respect to section 161138 A of the Social Security Act (as inserted by sub17 section (a) of this section), the requirement under such 18 section that hospitals and ambulatory surgical centers 19 submit reports takes effect on such date (not later than 202 years after the date of the enactment of this Act) as 21 the Secretary of Health and Human Services shall specify.

22 In order to meet such deadline, the Secretary may imple23 ment such section through guidance or other instructions. 24 (c) GAO REPORT.-Not later than 18 months after 25 the date of the enactment of this Act, the Comptroller 
1 General of the United States shall submit to Congress a

2 report on the program established under section 1138A

3 of the Social Security Act, as inserted by subsection (a).

4 Such report shall include an analysis of the appropriate-

5 ness of the types of information required for submission,

6 compliance with reporting requirements, the success of the

7 validity procedures established, and any conflict or overlap

8 between the reporting required under such section and any

9 other reporting systems mandated by either the States or

10 the Federal Government.

11 (d) Report on Additional Data.-Not later than

1218 months after the date of the enactment of this Act,

13 the Secretary of Health and Human Services shall submit

14 to the Congress a report on the appropriateness of expand-

15 ing the requirements under such section to include addi-

16 tional information (such as health care worker immuniza-

17 tion rates), in order to improve health care quality and 18 patient safety.

19 TITLE V-MEDICARE GRADUATE MEDICAL EDUCATION

21 SEC. 1501. DISTRIBUTION OF UNUSED RESIDENCY POSITIONS.

23 (a) In General.- Section 1886(h) of the Social Se24 curity Act (42 U.S.C. $1395 \mathrm{ww}(\mathrm{h})$ ) is amended- 
(1) in paragraph $(4)(\mathrm{F})(\mathrm{i})$, by striking "paragraph (7)" and inserting "paragraphs (7) and (8)";

(2) in paragraph $(4)(\mathrm{H})(\mathrm{i})$, by striking "paragraph (7)" and inserting "paragraphs (7) and (8)";

(3) in paragraph $(7)(\mathrm{E})$, by inserting "and 6 paragraph (8)" after "this paragraph"; and

(4) by adding at the end the following new 8 paragraph:

“(8) Additional Redistribution of unused RESIDENCY POSITIONS.-

“(A) Reductions in limit based on unUSED POSITIONS.-

“(i) Programs subJect To ReducTION.-If a hospital's reference resident level (specified in clause (ii)) is less than the otherwise applicable resident limit (as defined in subparagraph (C)(ii)), effective for portions of cost reporting periods occurring on or after July 1, 2011, the otherwise applicable resident limit shall be reduced by 90 percent of the difference between such otherwise applicable resident limit and such reference resident level. 
"(I) In GeneraL.-Except as

otherwise provided in a subsequent subclause, the reference resident level specified in this clause for a hospital is the highest resident level for any of the 3 most recent cost reporting periods (ending before the date of the enactment of this paragraph) of the hospital for which a cost report has been settled (or, if not, submitted (subject to audit)), as determined by the Secretary.

"(II) UsE OF MOST RECENT ACCOUNTING PERIOD TO RECOGNIZE EXPANSION OF EXISTING PROGRAMS.-If a hospital submits a timely request to increase its resident level due to an expansion, or planned expansion, of an existing residency training program that is not reflected on the most recent settled or submitted cost report, after audit and subject to the discretion of the Secretary, subject to subclause (IV), the reference resident level for such hospital is the resident 
level that includes the additional residents attributable to such expansion or establishment, as determined by the Secretary. The Secretary is authorized to determine an alternative reference resident level for a hospital that submitted to the Secretary a timely request, before the start of the 2009-2010 academic year, for an increase in its reference resident level due to a planned expansion.

“(III) SPECIAL PROVIDER AGREEMENT.-In the case of a hospital described in paragraph $(4)(H)(v)$, the reference resident level specified in this clause is the limitation applicable under subclause (I) of such paragraph.

"(IV) Previous RedistribuTION.-The reference resident level specified in this clause for a hospital shall be increased to the extent required to take into account an increase in resident positions made available to the hospital under para- 
graph $(7)(B)$ that are not otherwise taken into account under a previous subclause.

“(iii) Affiliation.-The provisions of clause (i) shall be applied to hospitals which are members of the same affiliated group (as defined by the Secretary under paragraph $(4)(\mathrm{H})(\mathrm{ii}))$ and to the extent the hospitals can demonstrate that they are filling any additional resident slots allocated to other hospitals through an affiliation agreement, the Secretary shall adjust the determination of available slots accordingly, or which the Secretary otherwise has permitted the resident positions (under section 402 of the Social Security Amendments of 1967) to be aggregated for purposes of applying the resident position limitations under this subsection.

“(B) Redistribution.-

“(i) In GENERAL.-The Secretary shall increase the otherwise applicable resident limit for each qualifying hospital that submits an application under this subparagraph by such number as the Secretary 
may approve for portions of cost reporting periods occurring on or after July 1, 2011. The estimated aggregate number of increases in the otherwise applicable resident limit under this subparagraph may not exceed the Secretary's estimate of the aggregate reduction in such limits attributable to subparagraph (A).

“(ii) Requirements FOR QUALIFYING HOSPITALS.-A hospital is not a qualifying hospital for purposes of this paragraph unless the following requirements are met:

“(I) Maintenance OF PRImary CARE RESIDENT LEVEL.-The hospital maintains the number of primary care residents at a level that is not less than the base level of primary care residents increased by the number of additional primary care resident positions provided to the hospital under this subparagraph. For purposes of this subparagraph, the 'base level of primary care residents' for a hospital is the level of such residents 
as of a base period (specified by the Secretary), determined without regard to whether such positions were in excess of the otherwise applicable resident limit for such period but taking into account the application of subclauses (II) and (III) of subparagraph (A)(ii).

“(II) Dedicated assignment OF ADDITIONAL RESIDENT POSITIONS TO PRIMARY CARE.-The hospital assigns all such additional resident positions for primary care residents.

"(III) ACCREDITATION.-The hospital's residency programs in primary care are fully accredited or, in the case of a residency training program not in operation as of the base year, the hospital is actively applying for such accreditation for the program for such additional resident positions (as determined by the Secretary).

“(iii) CONSIDERATIONS IN REDISTRIBUTION.-In determining for which qualifying hospitals the increase in the oth- 
erwise applicable resident limit is provided under this subparagraph, the Secretary shall take into account the demonstrated likelihood of the hospital filling the positions within the first 3 cost reporting periods beginning on or after July 1, 2011, made available under this subparagraph, as determined by the Secretary.

"(iv) Priority FOR CERTAIN hosPITALS.-In determining for which qualifying hospitals the increase in the otherwise applicable resident limit is provided under this subparagraph, the Secretary shall distribute the increase to qualifying hospitals based on the following criteria:

"(I) The Secretary shall give preference to hospitals that had a reduction in resident training positions under subparagraph (A).

"(II) The Secretary shall give preference to hospitals with 3-year primary care residency training programs, such as family practice and general internal medicine. 
"(III) The Secretary shall give

preference to hospitals insofar as they have in effect formal arrangements (as determined by the Secretary) that place greater emphasis upon training in Federally qualified health centers, rural health clinies, and other nonprovider settings, and to hospitals that receive additional payments under subsection $(\mathrm{d})(5)(\mathrm{F})$ and emphasize training in an outpatient department.

"(IV) The Secretary shall give preference to hospitals with a number of positions (as of July 1, 2009) in excess of the otherwise applicable resident limit for such period.

"(V) The Secretary shall give preference to hospitals that place greater emphasis upon training in a health professional shortage area (designated under section 332 of the Public Health Service Act) or a health professional needs area (designated under section 2211 of such Act). 
"(VI) The Secretary shall give preference to hospitals in States that have low resident-to-population ratios (including a greater preference for those States with lower resident-topopulation ratios).

“(v) Limitation.-In no case shall more than 20 full-time equivalent additional residency positions be made available under this subparagraph with respect to any hospital.

"(vi) Application OF PER RESIDENT AMOUNTS FOR PRIMARY CARE.-With respect to additional residency positions in a hospital attributable to the increase provided under this subparagraph, the approved FTE resident amounts are deemed to be equal to the hospital per resident amounts for primary care and nonprimary care computed under paragraph (2)(D) for that hospital.

“(vii) Distribution.—The Secretary shall distribute the increase in resident training positions to qualifying hospitals 
under this subparagraph not later than July 1, 2011.

“(C) Resident Level AND LIMIT DEFINED.-In this paragraph:

“(i) The term 'resident level' has the meaning given such term in paragraph $(7)(\mathrm{C})(\mathrm{i})$.

"(ii) The term 'otherwise applicable resident limit' means, with respect to a hospital, the limit otherwise applicable under subparagraphs (F)(i) and (H) of paragraph (4) on the resident level for the hospital determined without regard to this paragraph but taking into account paragraph (7)(A).

"(D) Maintenance OF PRIMary CARE RESIDENT LEVEL.-In carrying out this paragraph, the Secretary shall require hospitals that receive additional resident positions under subparagraph $(\mathrm{B})$ -

"(i) to maintain records, and periodically report to the Secretary, on the number of primary care residents in its residency training programs; and 
"(ii) as a condition of payment for a cost reporting period under this subsection for such positions, to maintain the level of such positions at not less than the sum of-

"(I) the base level of primary care resident positions (as determined under subparagraph (B)(ii)(I)) before receiving such additional positions; and tional positions."

13 (b) IME.-

(1) IN GENERAL.-Section 1886(d)(5)(B)(v) of 15 the Social Security Act (42 U.S.C. $161395 \mathrm{ww}(\mathrm{d})(5)(\mathrm{B})(\mathrm{v}))$, in the third sentence, is 17 amended-

(A) by striking "subsection (h)(7)" and inserting "subsections $(\mathrm{h})(7)$ and $(\mathrm{h})(8)$ "; and (B) by striking "it applies" and inserting" "they apply".

25 the following clause: 
1 “(x) For discharges occurring on or after July 1, 2 2011, insofar as an additional payment amount under this 3 subparagraph is attributable to resident positions distrib4 uted to a hospital under subsection $(\mathrm{h})(8)(\mathrm{B})$, the indirect

5 teaching adjustment factor shall be computed in the same 6 manner as provided under clause (ii) with respect to such 7 resident positions.".

8 (c) Conforming Amendment.-Section 422(b)(2) 9 of the Medicare Prescription Drug, Improvement, and 10 Modernization Act of 2003 (Public Law 108-173) is 11 amended by striking "section 1886(h)(7)" and all that fol12 lows and inserting "paragraphs (7) and (8) of subsection 13 (h) of section 1886 of the Social Security Act.".

14 SEC. 1502. INCREASING TRAINING IN NONPROVIDER SETTINGS.

16 (a) DIRECT GME.-Section 1886(h)(4)(E) of the So17 cial Security Act (42 U.S.C. $1395 \mathrm{ww}(\mathrm{h})$ ) is amended18 (1) by designating the first sentence as a clause 19 (i) with the heading "IN GENERAL._-" and appro20 priate indentation;

21 (2) by striking "shall be counted and that all 22 the time" and inserting "shall be counted and 23 that- 
"(I) effective for cost reporting periods beginning before July 1, 2009, all the time";

(3) in subclause (I), as inserted by paragraph

(A) by inserting after subclause (I), as so inserted, the following:

"(II) effective for cost reporting periods beginning on or after July 1, 2009, all the time so spent by a resi-

dent shall be counted towards the determination of full-time equivalency, without regard to the setting in which the activities are performed, if the hospital incurs the costs of the stipends and fringe benefits of the resident during the time the resident spends in that setting.

Any hospital claiming under this subparagraph for time spent in a nonprovider setting shall maintain and make available to the Secretary records regarding the amount of such time and such amount in comparison with amounts of such time in 
such base year as the Secretary shall specify.".

(b) IME.-Section 1886(d)(5)(B)(iv) of the Social

4 Security Act (42 U.S.C. $1395 \mathrm{ww}(\mathrm{d})(5)(\mathrm{B})(\mathrm{iv}))$ is amend5 ed-

7 curring on or after October 1, 1997" and inserting

8 "(iv)(I) Effective for discharges occurring on or

9 after October 1, 1997, and before July 1, 2009";

10 and

11 (2) by inserting after subclause (I), as inserted

12 by paragraph (1), the following new subclause:

"(II) Effective for discharges occurring on or 14 after July 1, 2009, all the time spent by an intern 15 or resident in patient care activities at an entity in 16 a nonprovider setting shall be counted towards the 17 determination of full-time equivalency if the hospital 18 incurs the costs of the stipends and fringe benefits 19 of the intern or resident during the time the intern 20 or resident spends in that setting.".

21 (c) OIG Study on Impact on Training.- The In22 spector General of the Department of Health and Human 23 Services shall analyze the data collected by the Secretary 24 of Health and Human Services from the records made 25 available to the Secretary under section 1886(h)(4)(E) of 
1 the Social Security Act, as amended by subsection (a), in 2 order to assess the extent to which there is an increase 3 in time spent by medical residents in training in nonpro4 vider settings as a result of the amendments made by this 5 section. Not later than 4 years after the date of the enact6 ment of this Act, the Inspector General shall submit a re7 port to Congress on such analysis and assessment.

8 (d) Demonstration Project For Approved 9 Teaching Health Centers.-

10 (1) In GENERAL.-The Secretary of Health and 11 Human Services shall conduct a demonstration 12 project under which an approved teaching health 13 center (as defined in paragraph (3)) would be eligi14 ble for payment under subsections (h) and (k) of 15 section 1886 of the Social Security Act (42 U.S.C. $161395 \mathrm{ww})$ of amounts for its own direct costs of 17 graduate medical education activities for primary 18 care residents, as well as for the direct costs of grad19 uate medical education activities of its contracting 20 hospital for such residents, in a manner similar to 21 the manner in which such payments would be made 22 to a hospital if the hospital were to operate such a 23 program.

(2) Conditions.-Under the demonstration 25 project- 
(A) an approved teaching health center shall contract with an accredited teaching hospital to carry out the inpatient responsibilities of the primary care residency program of the hospital involved and is responsible for payment to the hospital for the hospital's costs of the salary and fringe benefits for residents in the program;

(B) the number of primary care residents of the center shall not count against the contracting hospital's resident limit; and

17 teaching health center" means a nonprovider setting, 18 such as a Federally qualified health center or rural 19 health clinic (as defined in section 1861(aa) of the 20 Social Security Act), that develops and operates an 21 accredited primary care residency program for which 22 funding would be available if it were operated by a 23 hospital. 
1 SEC. 1503. RULES FOR COUNTING RESIDENT TIME FOR DI-

4 (a) DIRECT GME.-Section 1886(h) of the Social Se5 curity Act (42 U.S.C. $1395 \mathrm{ww}(\mathrm{h})$ ) is amended-

(1) in paragraph $(4)(\mathrm{E})$, as amended by section $7 \quad 1502(\mathrm{a})-$ clause:

(A) in clause (i), by striking "Such rules" and inserting "Subject to clause (ii), such rules"; and

(B) by adding at the end the following new “(ii) Treatment of CERTAin NONPROVIDER AND DIDACTIC ACTIVITIES.Such rules shall provide that all time spent by an intern or resident in an approved medical residency training program in a nonprovider setting that is primarily engaged in furnishing patient care (as defined in paragraph $(5)(\mathrm{K}))$ in nonpatient care activities, such as didactic conferences and seminars, but not including research not associated with the treatment or diagnosis of a particular patient, as such time and activities are defined by the Secretary, 
shall be counted toward the determination

of full-time equivalency.";

(2) in paragraph (4), by adding at the end the

4 following new subparagraph:

“(I) Treatment of Certain time In aPPROVED MEDICAL RESIDENCY TRAINING PROGRAMING.- - In determining the hospital's number of full-time equivalent residents for purposes of this subsection, all the time that is spent by an intern or resident in an approved medical residency training program on vacation, sick leave, or other approved leave, as such time is defined by the Secretary, and that does not prolong the total time the resident is participating in the approved program beyond the normal duration of the program shall be counted toward the determination of full-time equivalency."; and

(3) in paragraph (5), by adding at the end the following new subparagraph:

"(K) NONPROVIDER SETTING THAT IS PRIMARILY ENGAGED IN FURNISHING PATIENT CARE.-The term 'nonprovider setting that is primarily engaged in furnishing patient care' means a nonprovider setting in which the pri- 
mary activity is the care and treatment of patients, as defined by the Secretary.".

4 of such Act (42 U.S.C. 1395ww(d)(5)(B)), as amended by 5 section 1501(b), is amended by adding at the end the fol6 lowing new clause:

7 “(xi)(I) The provisions of subparagraph (I) of sub8 section (h)(4) shall apply under this subparagraph in the 9 same manner as they apply under such subsection.

10 “(II) In determining the hospital's number of full11 time equivalent residents for purposes of this subpara12 graph, all the time spent by an intern or resident in an 13 approved medical residency training program in non14 patient care activities, such as didactic conferences and 15 seminars, as such time and activities are defined by the 16 Secretary, that occurs in the hospital shall be counted to17 ward the determination of full-time equivalency if the hos18 pital"(aa) is recognized as a subsection (d) hospital; "(bb) is recognized as a subsection (d) Puerto 21 Rico hospital; "(cc) is reimbursed under a reimbursement sys23 tem authorized under section 1814(b)(3); or "(dd) is a provider-based hospital outpatient de25 partment. 
1 “(III) In determining the hospital's number of full-

2 time equivalent residents for purposes of this subpara-

3 graph, all the time spent by an intern or resident in an

4 approved medical residency training program in research

5 activities that are not associated with the treatment or di-

6 agnosis of a particular patient, as such time and activities

7 are defined by the Secretary, shall not be counted toward

8 the determination of full-time equivalency.".

9 (c) Effective Dates; Application.-

10 (1) In GEneraL.-Except as otherwise pro-

11 vided, the Secretary of Health and Human Services

12 shall implement the amendments made by this sec-

13 tion in a manner so as to apply to cost reporting pe-

14 riods beginning on or after January 1, 1983.

15 (2) DIRECT GME.-Section 1886(h)(4)(E)(ii) of

16 the Social Security Act, as added by subsection

17 (a)(1)(B), shall apply to cost reporting periods be18 ginning on or after July 1, 2008.

19 (3) IME.-Section 1886(d)(5)(B)(x)(III) of the

20 Social Security Act, as added by subsection (b), shall

21 apply to cost reporting periods beginning on or after

22 October 1, 2001. Such section, as so added, shall

23 not give rise to any inference on how the law in ef24 fect prior to such date should be interpreted. 
(4) Application.-The amendments made by

2 this section shall not be applied in a manner that re-

3 quires reopening of any settled hospital cost reports

4 as to which there is not a jurisdictionally proper ap-

5 peal pending as of the date of the enactment of this

6 Act on the issue of payment for indirect costs of

7 medical education under section $1886(\mathrm{~d})(5)(\mathrm{B})$ of

8 the Social Security Act or for direct graduate med-

9 ical education costs under section 1886(h) of such

10 Act.

11 SEC. 1504. PRESERVATION OF RESIDENT CAP POSITIONS

\section{FROM CLOSED HOSPITALS.}

13 (a) DIRECT GME.-Section 1886(h)(4)(H) of the So-

14 cial Security Act (42 U.S.C. Section 1395ww(h)(4)(H))

15 is amended by adding at the end the following new clause:

“(vi) REDISTRIBUTION OF RESIDENCY SLOTS AFTER A HOSPITAL CLOSES.-

"(I) IN GENERAL.-The Sec-

retary shall, by regulation, establish a process consistent with subclauses (II) and (III) under which, in the case where a hospital (other than a hospital described in clause (v)) with an approved medical residency program 25 in a State closes on or after the date 
that is 2 years before the date of the

enactment of this clause, the Secretary shall increase the otherwise applicable resident limit under this paragraph for other hospitals in the State in accordance with this clause.

“(II) Process for hospitals IN CERTAIN AREAS.-In determining for which hospitals the increase in the otherwise applicable resident limit described in subclause (I) is provided, the Secretary shall establish a process to provide for such increase to one or more hospitals located in the State. Such process shall take into consideration the recommendations submitted to the Secretary by the senior health official (as designated by the chief executive officer of such State) if such recommendations are submitted not later than 180 days after the date of the hospital closure involved (or, in the case of a hospital that closed after the date that is 2 years before the date of the enactment of this clause, 
180 days after such date of enact-

ment).

“(III) Limitation.-The estimated aggregate number of increases in the otherwise applicable resident limits for hospitals under this clause shall be equal to the estimated number of resident positions in the approved medical residency programs that closed on or after the date described in subclause (I).".

13 MENTS.-The amendments made by this section shall not 14 effect any temporary adjustment to a hospital's FTE cap 15 under section 413.79(h) of title 42, Code of Federal Regu16 lations (as in effect on the date of enactment of this Act) 17 and shall not affect the application of section $181886(\mathrm{~h})(4)(\mathrm{H})(\mathrm{v})$ of the Social Security Act.

(c) Conforming Amendments.-

(1) Section 422(b)(2) of the Medicare Prescrip21 tion Drug, Improvement, and Modernization Act of 222003 (Public Law 108-173), as amended by section $231501(\mathrm{c})$, is amended by striking "(7) and" and in24 serting “(4)(H)(vi), (7), and”. 
(2) Section $1886(\mathrm{~h})(7)(\mathrm{E})$ of the Social Security Act (42 U.S.C. 1395ww(h)(7)(E)) is amended by inserting "or under paragraph $(4)(\mathrm{H})(\mathrm{vi})$ " after

4 "under this paragraph".

5 SEC. 1505. IMPROVING ACCOUNTABILITY FOR APPROVED MEDICAL RESIDENCY TRAINING.

(a) Specification of Gonls for Approved Med-

8 ical Residency Training Programs.-Section

$91886(\mathrm{~h})(1)$ of the Social Security Act (42 U.S.C.

$101395 \mathrm{ww}(\mathrm{h})(1))$ is amended-

11 (1) by designating the matter beginning with

12 "Notwithstanding" as a subparagraph (A) with the

13 heading "IN GENERAL._." and with appropriate in-

14 dentation; and

(2) by adding at the end the following new sub-

16 paragraph:

"(B) GoAls AND ACCOUNTABILITY FOR APPROVED MEDICAL RESIDENCY TRAINING PROGRAMS.-The goals of medical residency training programs are to foster a physician workforce so that physicians are trained to be able to do the following:

“(i) Work effectively in various health care delivery settings, such as nonprovider 25 settings. 
“(ii) Coordinate patient care within

and across settings relevant to their specialties.

"(iii) Understand the relevant cost and value of various diagnostic and treat-

ment options.

"(iv) Work in inter-professional teams and multi-disciplinary team-based models in provider and nonprovider settings to enhance safety and improve quality of patient care.

"(v) Be knowledgeable in methods of identifying systematic errors in health care delivery and in implementing systematic solutions in case of such errors, including experience and participation in continuous quality improvement projects to improve health outcomes of the population the physicians serve.

“(vi) Be meaningful EHR users (as determined under section 1848(o)(2)) in the delivery of care and in improving the quality of the health of the community and the individuals that the hospital serves." 
1 (b) GaO Study on Evaluation of Training Pro-

2 GRAMS.-

3

4 the United States shall conduct a study to evaluate

5 the extent to which medical residency training pro6 grams-
(1) In general.-The Comptroller General of 
Medical Education and the American Osteopathic Association and effectiveness of those processes in accrediting medical residency programs that meet the goals referred to in paragraph (1)(A).

6 TITLE VI-PROGRAM INTEGRITY

7 Subtitle A-Increased Funding to

8 Fight Waste, Fraud, and Abuse

9 SEC. 1601. INCREASED FUNDING AND FLEXIBILITY TO FIGHT FRAUD AND ABUSE.

(a) In GeneraL.—Section 1817(k) of the Social Se-

12 curity Act (42 U.S.C. $1395 \mathrm{i}(\mathrm{k})$ ) is amended-

(1) by adding at the end the following new 14 paragraph:

“(7) Additional Funding.-In addition to the

16 funds otherwise appropriated to the Account from

17 the Trust Fund under paragraphs (3) and (4) and

18 for purposes described in paragraphs (3)(C) and

$19(4)(\mathrm{A})$, there are hereby appropriated an additional $20 \$ 100,000,000$ to such Account from such Trust 21 Fund for each fiscal year beginning with 2011. The 22 funds appropriated under this paragraph shall be al23 located in the same proportion as the total funding 24 appropriated with respect to paragraphs (3)(A) and 25 (4)(A) was allocated with respect to fiscal year 
12010 , and shall be available without further appro-

2 priation until expended.”.

(2) in paragraph $(4)(\mathrm{A})-$

(A) by inserting "for activities described in paragraph (3)(C) and" after "necessary"; and

(B) by inserting "until expended" after "appropriation".

(b) Flexibility in Pursuing Fraud and

9 Abuse.-Section 1893(a) of the Social Security Act (42

10 U.S.C. $1395 \mathrm{ddd}(\mathrm{a}))$ is amended by inserting “, or other11 wise," after "entities".

\section{Subtitle B-Enhanced Penalties for Fraud and Abuse}

SEC. 1611. ENHANCED PENALTIES FOR FALSE STATEMENTS APPLICATIONS.

17 (a) In GeneraL.-Section 1128A(a) of the Social 18 Security Act (42 U.S.C. 1320a-7a(a)) is amended-

(1) in paragraph (1)(D), by striking all that fol20 lows "in which the person was excluded" and insert21 ing "under Federal law from the Federal health care 22 program under which the claim was made, or";

(2) by striking "or" at the end of paragraph $24 \quad(6)$; 
(3) in paragraph (7), by inserting at the end

2 "or";

3 (4) by inserting after paragraph (7) the fol4 lowing new paragraph:

5 “(8) knowingly makes or causes to be made any 6 false statement, omission, or misrepresentation of a 7 material fact in any application, agreement, bid, or 8 contract to participate or enroll as a provider of 9 services or supplier under a Federal health care pro10 gram, including managed care organizations under 11 title XIX, Medicare Advantage organizations under 12 part $\mathrm{C}$ of title XVIII, prescription drug plan spon13 sors under part D of title XVIII, and entities that 14 apply to participate as providers of services or sup15 pliers in such managed care organizations and such 16 plans;";

17 (5) in the matter following paragraph (8), as 18 inserted by paragraph (4), by striking "or in cases 19 under paragraph (7), \$50,000 for each such act)" 20 and inserting "in cases under paragraph (7), $21 \$ 50,000$ for each such act, or in cases under para22 graph (8), $\$ 50,000$ for each false statement, omis23 sion, or misrepresentation of a material fact)"; and 24 (6) in the second sentence, by striking "for a 25 lawful purpose)" and inserting "for a lawful pur- 
1 pose, or in cases under paragraph (8), an assess-

2 ment of not more than 3 times the amount claimed

3 as the result of the false statement, omission, or

4 misrepresentation of material fact claimed by a pro-

5 vider of services or supplier whose application to

6 participate contained such false statement, omission,

7 or misrepresentation)".

8 (b) EfFective Date.-The amendments made by

9 subsection (a) shall apply to acts committed on or after

10 January 1, 2010.

11 SEC. 1612. ENHANCED PENALTIES FOR SUBMISSION OF

FALSE STATEMENTS MATERIAL TO A FALSE

CLAIM.

14 (a) In GeneraL.-Section $1128 \mathrm{~A}$ (a) of the Social

15 Security Act (42 U.S.C. 1320a-7a(a)), as amended by sec-

16 tion 1611, is further amended-

17 (1) in paragraph (7), by striking "or" at the

18 end;

19 (2) in paragraph (8), by inserting "or" at the

20 end; and

21 (3) by inserting after paragraph (8), the fol-

22 lowing new paragraph:

23 “(9) knowingly makes, uses, or causes to be 24 made or used, a false record or statement material 25 to a false or fraudulent claim for payment for items 
1 and services furnished under a Federal health care

2 program;"; and

(4) in the matter following paragraph (9), as

$4 \quad$ inserted by paragraph (3) -

(A) by striking "or in cases under paragraph (8)" and inserting "in cases under paragraph (8)"; and

(B) by striking "a material fact)" and inserting "a material fact, in cases under paragraph (9), $\$ 50,000$ for each false record or statement)".

12 (b) EfFective Date.-The amendments made by 13 subsection (a) shall apply to acts committed on or after 14 January 1, 2010.

15 SEC. 1613. ENHANCED PENALTIES FOR DELAYING INSPECTIONS.

17 (a) In GeneraL.-Section 1128A(a) of the Social 18 Security Act (42 U.S.C. 1320a-7a(a)), as amended by sec19 tions 1611 and 1612, is further amended-

(1) in paragraph (8), by striking "or" at the 21 end;

23 end;

(3) by inserting after paragraph (9) the fol25 lowing new paragraph: 
“(10) fails to grant timely access, upon reason-

2 able request (as defined by the Secretary in regula-

3 tions), to the Inspector General of the Department

4 of Health and Human Services, for the purpose of

5 audits, investigations, evaluations, or other statutory

6 functions of the Inspector General of the Depart-

7 ment of Health and Human Services;"; and

8 (4) in the matter following paragraph (10), as

$9 \quad$ inserted by paragraph (3), by inserting “, or in cases

10 under paragraph (10), $\$ 15,000$ for each day of the

11 failure described in such paragraph" after "false 12 record or statement".

13 (b) Ensuring Timely Inspections Relating to

14 Contracts With MA Organizations.-Section

$151857(\mathrm{~d})(2)$ of such Act (42 U.S.C. $1395 \mathrm{w}-27(\mathrm{~d})(2))$ is

16 amended-

17 (1) in subparagraph (A), by inserting "timely" 18 before "inspect"; and

19 (2) in subparagraph (B), by inserting "timely" 20 before "audit and inspect".

21 (c) EFFective Date.-The amendments made by 22 subsection (a) shall apply to violations committed on or 23 after January 1, 2010. 
1 SEC. 1614. ENHANCED HOSPICE PROGRAM SAFEGUARDS.

3 Security Act is amended by inserting after section 1819

4 the following new section:

5 "SEC. 1819A. ASSURING QUALITY OF CARE IN HOSPICE

\section{CARE.}

7 “(a) In General.-If the Secretary determines on

8 the basis of a survey or otherwise, that a hospice program

9 that is certified for participation under this title has dem-

10 onstrated a substandard quality of care and failed to meet

11 such other requirements as the Secretary may find nec-

12 essary in the interest of the health and safety of the indi-

13 viduals who are provided care and services by the agency

14 or organization involved and determines-

"(1) that the deficiencies involved immediately

16 jeopardize the health and safety of the individuals to

17 whom the program furnishes items and services, the

18 Secretary shall take immediate action to remove the

19 jeopardy and correct the deficiencies through the

20 remedy specified in subsection $(b)(2)(A)(i i i)$ or ter-

21 minate the certification of the program, and may

22 provide, in addition, for 1 or more of the other rem-

23 edies described in subsection $(b)(2)(A)$; or

"(2) that the deficiencies involved do not imme-

25 diately jeopardize the health and safety of the indi- 
1 viduals to whom the program furnishes items and

2 services, the Secretary may-

17 compliance with such requirements. “(b) INTERMEDIATE SANCTIONS.later than July 1, 2012-
"(A) impose intermediate sanctions developed pursuant to subsection (b), in lieu of terminating the certification of the program; and "(B) if, after such a period of intermediate sanctions, the program is still not in compliance with such requirements, the Secretary shall terminate the certification of the program.

If the Secretary determines that a hospice program that is certified for participation under this title is in compliance with such requirements but, as of a previous period, was not in compliance with such requirements, the Secretary may provide for a civil money penalty under subsection $(b)(2)(A)(i)$ for the days in which it finds that the program was not in “(1) Development and implementation.The Secretary shall develop and implement, by not

"(A) a range of intermediate sanctions to apply to hospice programs under the conditions described in subsection (a), and 
“(B) appropriate procedures for appealing. determinations relating to the imposition of such sanctions.

"(2) Specified sanctions.-

"(A) IN GENERAL.-The intermediate sanctions developed under paragraph (1) may include-

"(i) civil money penalties in an amount not to exceed $\$ 10,000$ for each day of noncompliance or, in the case of a per instance penalty applied by the Secretary, not to exceed $\$ 25,000$, "(ii) denial of all or part of the payments to which a hospice program would otherwise be entitled under this title with respect to items and services furnished by a hospice program on or after the date on which the Secretary determines that intermediate sanctions should be imposed pursuant to subsection (a)(2),

"(iii) the appointment of temporary management to oversee the operation of the hospice program and to protect and assure the health and safety of the individ- 
uals under the care of the program while improvements are made,

"(iv) corrective action plans, and

“(v) in-service training for staff.

The provisions of section 1128A (other than subsections (a) and (b)) shall apply to a civil

money penalty under clause (i) in the same manner as such provisions apply to a penalty or proceeding under section $1128 \mathrm{~A}(\mathrm{a})$. The temporary management under clause (iii) shall not be terminated until the Secretary has determined that the program has the management capability to ensure continued compliance with all requirements referred to in that clause.

"(B) Clarification.-The sanctions specified in subparagraph (A) are in addition to sanctions otherwise available under State or Federal law and shall not be construed as limiting other remedies, including any remedy available to an individual at common law.

“(C) Commencement of Payment.-A denial of payment under subparagraph (A)(ii) shall terminate when the Secretary determines that the hospice program no longer demonstrates a substandard quality of care and 
meets such other requirements as the Secretary may find necessary in the interest of the health and safety of the individuals who are provided care and services by the agency or organization involved.

“(3) SEcretarial authority.-The Secretary

$7 \quad$ shall develop and implement, by not later than July

8 1, 2011, specific procedures with respect to the con-

9 ditions under which each of the intermediate sanc-

10 tions developed under paragraph (1) is to be applied,

11 including the amount of any fines and the severity

12 of each of these sanctions. Such procedures shall be

13 designed so as to minimize the time between identi-

14 fication of deficiencies and imposition of these sanc-

15 tions and shall provide for the imposition of incre-

16 mentally more severe fines for repeated or uncor17 rected deficiencies.".

18 (b) Application to Medicaid.-Section 1905(o) of 19 the Social Security Act (42 U.S.C. 1396d(o)) is amended 20 by adding at the end the following new paragraph:

21 "(4) The provisions of section 1819A shall apply to 22 a hospice program providing hospice care under this title 23 in the same manner as such provisions apply to a hospice 24 program providing hospice care under title XVIII.". 
1 (c) Application to CHIP.-Title XXI of the Social

2 Security Act is amended by adding at the end the fol-

3 lowing new section:

4 "SEC. 2114. ASSURING QUALITY OF CARE IN HOSPICE CARE.

5 "The provisions of section 1819 A shall apply to a

6 hospice program providing hospice care under this title in

7 the same manner such provisions apply to a hospice pro-

8 gram providing hospice care under title XVIII.".

9 SEC. 1615. ENHANCED PENALTIES FOR INDIVIDUALS EXCLUDED FROM PROGRAM PARTICIPATION.

11 (a) In GeneraL.-Section 1128A(a) of the Social

12 Security Act (42 U.S.C. 1320a-7a(a)), as amended by the

13 previous sections, is further amended-

(1) by striking "or" at the end of paragraph $(9)$;

(2) by inserting "or" at the end of paragraph $17 \quad(10)$;

18 (3) by inserting after paragraph (10) the fol19 lowing new paragraph:

20 "(11) orders or prescribes an item or service, 21 including without limitation home health care, diag22 nostic and clinical lab tests, prescription drugs, du23 rable medical equipment, ambulance services, phys24 ical or occupational therapy, or any other item or 25 service, during a period when the person has been 
1 excluded from participation in a Federal health care

2 program, and the person knows or should know that

3 a claim for such item or service will be presented to

$4 \quad$ such a program;"; and

5 (4) in the matter following paragraph (11), as

6 inserted by paragraph (2), by striking “ $\$ 15,000$ for

7 each day of the failure described in such paragraph"

8 and inserting " $\$ 15,000$ for each day of the failure

9 described in such paragraph, or in cases under para-

10 graph (11), $\$ 50,000$ for each order or prescription

11 for an item or service by an excluded individual".

12 (b) EFFective Date.-The amendments made by

13 subsection (a) shall apply to violations committed on or

14 after January 1, 2010.

15 SEC. 1616. ENHANCED PENALTIES FOR PROVISION OF FALSE INFORMATION BY MEDICARE ADVANTAGE AND PART D PLANS.

18 (a) In GENERAL.-Section $1857(\mathrm{~g})(2)(\mathrm{A})$ of the So-

19 cial Security Act (42 U.S.C. $1395 \mathrm{w}-27(\mathrm{~g})(2)(\mathrm{A})$ ) is

20 amended by inserting "except with respect to a determina-

21 tion under subparagraph (E), an assessment of not more

22 than 3 times the amount claimed by such plan or plan

23 sponsor based upon the misrepresentation or falsified in-

24 formation involved," after "for each such determination,". 
1 (b) EFFective Date.-The amendment made by 2 subsection (a) shall apply to violations committed on or 3 after January 1, 2010.

4 SEC. 1617. ENHANCED PENALTIES FOR MEDICARE ADVANTAGE AND PART D MARKETING VIOLATIONS.

6 (a) In GeneraL.-Section 1857(g)(1) of the Social 7 Security Act (42 U.S.C. $1395 \mathrm{w}-27(\mathrm{~g})(1)$ ), as amended 8 by section $1221(\mathrm{~b})$, is amended-

(1) in subparagraph (G), by striking "or" at 10 the end;

11 (2) by inserting after subparagraph (H) the fol12 lowing new subparagraphs:

"(I) except as provided under subparagraph (C) or (D) of section 1860D-1(b)(1), enrolls an individual in any plan under this part without the prior consent of the individual or the designee of the individual;

“(J) transfers an individual enrolled under this part from one plan to another without the prior consent of the individual or the designee of the individual or solely for the purpose of earning a commission;

"(K) fails to comply with marketing restrictions described in subsections (h) and (j) of 
section 1851 or applicable implementing regulations or guidance; or

"(L) employs or contracts with any individual or entity who engages in the conduct described in subparagraphs (A) through (K) of this paragraph;"; and

(3) by adding at the end the following new sentence: "The Secretary may provide, in addition to any other remedies authorized by law, for any of the

11 determines that any employee or agent of such orga12 nization, or any provider or supplier who contracts 13 with such organization, has engaged in any conduct 14 described in subparagraphs (A) through (L) of this 15 paragraph.'”

16 (b) EFFECTIVE DATE.-The amendments made by 17 subsection (a) shall apply to violations committed on or 18 after January 1, 2010.

19 SEC. 1618. ENHANCED PENALTIES FOR OBSTRUCTION OF 20 PROGRAM AUDITS.

(a) In GenERAL.-Section 1128(b)(2) of the Social

22 Security Act (42 U.S.C. 1320a-7(b)(2)) is amended-

(1) in the heading, by inserting "OR AUDIT" 24 after "INVESTIGATION"; and 
(2) by striking "investigation into" and all that

2 follows through the period and inserting "investiga3 tion or audit related to-"

"(i) any offense described in paragraph (1) or in subsection (a); or or indirectly, from any Federal health care program (as defined in section 1128B(f)).”.

10 (b) EfFective Date.-The amendments made by 11 subsection (a) shall apply to violations committed on or 12 after January 1, 2010.

13 SEC. 1619. EXCLUSION OF CERTAIN INDIVIDUALS AND ENTITIES FROM PARTICIPATION IN MEDICARE AND STATE HEALTH CARE PROGRAMS.

(a) In General.-Section 1128(c) of the Social Se-

17 curity Act, as previously amended by this division, is fur18 ther amended-

(1) in the heading, by striking "AND PERIOD" and inserting "PERIOD, AND EFFECT"; and

(2) by adding at the end the following new 22 paragraph:

23 “(4)(A) For purposes of this Act, subject to subpara24 graph (C), the effect of exclusion is that no payment may 25 be made by any Federal health care program (as defined 
1 in section $1128 \mathrm{~B}(\mathrm{f}))$ with respect to any item or service

2 furnished-

3

4

5

6

7

8

9

10 and $1128 \mathrm{~B}$, subject to subparagraph (C), an item or serv-

11 ice has been furnished by an individual or entity if the

12 individual or entity directly or indirectly provided, ordered,

13 manufactured, distributed, prescribed, or otherwise sup-

14 plied the item or service regardless of how the item or

15 service was paid for by a Federal health care program or

16 to whom such payment was made.

17 “(C)(i) Payment may be made under a Federal

18 health care program for emergency items or services (not

19 including items or services furnished in an emergency

20 room of a hospital) furnished by an excluded individual

21 or entity, or at the medical direction or on the prescription

22 of an excluded physician or other authorized individual

23 during the period of such individual's exclusion.

24 "(ii) In the case that an individual eligible for bene25 fits under title XVIII or XIX submits a claim for payment 
1 for items or services furnished by an excluded individual

2 or entity, and such individual eligible for such benefits did

3 not know or have reason to know that such excluded indi-

4 vidual or entity was so excluded, then, notwithstanding

5 such exclusion, payment shall be made for such items or

6 services. In such case the Secretary shall notify such indi-

7 vidual eligible for such benefits of the exclusion of the indi-

8 vidual or entity furnishing the items or services. Payment

9 shall not be made for items or services furnished by an

10 excluded individual or entity to an individual eligible for

11 such benefits after a reasonable time (as determined by

12 the Secretary in regulations) after the Secretary has noti-

13 fied the individual eligible for such benefits of the exclu-

14 sion of the individual or entity furnishing the items or 15 services.

16 "(iii) In the case that a claim for payment for items 17 or services furnished by an excluded individual or entity 18 is submitted by an individual or entity other than an indi19 vidual eligible for benefits under title XVIII or XIX or 20 the excluded individual or entity, and the Secretary deter21 mines that the individual or entity that submitted the 22 claim took reasonable steps to learn of the exclusion and 23 reasonably relied upon inaccurate or misleading informa24 tion from the relevant Federal health care program or its 25 contractor, the Secretary may waive repayment of the 
1 amount paid in violation of the exclusion to the individual

2 or entity that submitted the claim for the items or services

3 furnished by the excluded individual or entity. If a Federal

4 health care program contractor provided inaccurate or

5 misleading information that resulted in the waiver of an

6 overpayment under this clause, the Secretary shall take

7 appropriate action to recover the improperly paid amount

8 from the contractor.'.

9 SEC. 1620. OIG AUTHORITY TO EXCLUDE FROM FEDERAL

12 Section 1128(b)(15)(A) of the Social Security Act

13 (42 U.S.C. 1320a-7(b)(15)(A)) is amended-

(1) in clause (i)-

(A) by striking "has" and inserting "had"; and

(B) by striking "sanctioned entity and who knows or should know (as defined in section 1128A(i)(6)) of" and inserting "sanctioned entity at the time of, and who knew or should have known (as defined in section 1128A(i)(6)) of," ; and

(2) in clause (ii)—

(A) by striking "is an officer" and inserting "was an officer"; and 
(B) by inserting before the period the following: "at the time of the action constituting the basis for the conviction or exclusion described in subparagraph (B)".

\section{SEC. 1621. SELF-REFERRAL DISCLOSURE PROTOCOL.}

6 (a) Development of Self-Referral Disclosure

\section{PROTOCOL.-}

(1) In GenERAL._-The Secretary of Health and

9 Human Services, in cooperation with the Inspector

10 General of the Department of Health and Human

11 Services, shall establish, not later than 6 months

12 after the date of the enactment of this Act, a pro-

13 tocol to enable health care providers of services and

14 suppliers to disclose an actual or potential violation

15 of section 1877 of the Social Security Act (42

16 U.S.C. 1395nn) pursuant to a self-referral disclosure

17 protocol (in this section referred to as an "SRDP").

18 The SRDP shall include direction to health care pro-

19 viders of services and suppliers on-

20 (A) a specific person, official, or office to

21 whom such disclosures shall be made; and

22 (B) instruction on the implication of the 23 SRDP on corporate integrity agreements and 24 corporate compliance agreements. 
(2) Publication on internet website of

2 SRDP INFORMATION.-The Secretary shall post in-

3 formation on the public Internet website of the Cen-

4 ters for Medicare \& Medicaid Services to inform rel-

5 evant stakeholders of how to disclose actual or po-

6 tential violations pursuant to an SRDP.

7 (3) RELATION TO ADVISORY OPINIONS.-The

8 SRDP shall be separate from the advisory opinion

9 process set forth in regulations implementing section

$101877(\mathrm{~g})$ of the Social Security Act.

11 (b) Reduction in Amounts Owed.-The Secretary

12 is authorized to reduce the amount due and owing for all

13 violations under section 1877 of the Social Security Act

14 to an amount less than that specified in subsection (g)

15 of such section. In establishing such amount for a viola-

16 tion, the Secretary may consider the following factors:

17 (1) The nature and extent of the improper or 18 illegal practice.

19 (2) The timeliness of such self-disclosure.

20 (3) The cooperation in providing additional in21 formation related to the disclosure.

22 (4) Such other factors as the Secretary con23 siders appropriate.

24 (c) REPORT.-Not later than 18 months after the 25 date on which the SRDP protocol is established under sub- 
1 section (a)(1), the Secretary shall submit to Congress a

2 report on the implementation of this section. Such report 3 shall include-

4 (1) the number of health care providers of serv5 ices and suppliers making disclosures pursuant to an 6 SRDP;

(2) the amounts collected pursuant to the $8 \quad$ SRDP;

9 (3) the types of violations reported under the 10 SRDP; and

11 (4) such other information as may be necessary 12 to evaluate the impact of this section.

13 (d) Relation to Other law and Regulation.14 Nothing in this section shall affect the application of sec15 tion $1128 \mathrm{G}(\mathrm{c})$ of the Social Security Act, as added by sec16 tion 1641, except, in the case of a health care provider 17 of services or supplier who is a person (as defined in para18 graph (4) of such section $1128 \mathrm{G}(\mathrm{c})$ ) who discloses an over19 payment (as defined in such paragraph) to the Secretary 20 of Health and Human Services pursuant to a SRDP es21 tablished under this section, the 60-day period described 22 in paragraph (2) of such section $1128 \mathrm{G}(\mathrm{c})$ shall be ex23 tended with respect to the return of an overpayment to 24 the extent necessary for the Secretary to determine pursu25 ant to the SRDP the amount due and owing. 


\section{Subtitle C-Enhanced Program} and Provider Protections

3 SEC. 1631. ENHANCED CMS PROGRAM PROTECTION AUTHORITY.

(a) In General.- Title XI of the Social Security Act

6 (42 U.S.C. 1301 et seq.) is amended by inserting after 7 section $1128 \mathrm{~F}$ the following new section:

8 “SEC. 1128G. ENHANCED PROGRAM AND PROVIDER PROTECTIONS IN THE MEDICARE, MEDICAID, AND CHIP PROGRAMS.

12 Oversight Periods, and Enrolliment Moratoria.-

“(1) IN GENERAL.—For periods beginning after

14 January 1, 2011, in the case that the Secretary de-

15 termines there is a significant risk of fraudulent ac-

16 tivity (as determined by the Secretary based on rel-

17 evant complaints, reports, referrals by law enforce-

18 ment or other sources, data analysis, trending infor-

19 mation, or claims submissions by providers of serv-

20 ices and suppliers) with respect to a category of pro-

21 vider of services or supplier of items or services, in-

22 cluding a category within a geographic area, under

23 title XVIII, XIX, or XXI, the Secretary may impose

24 any of the following requirements with respect to a

25 provider of services or a supplier (whether such pro- 
1 vider or supplier is initially enrolling in the program

2 or is renewing such enrollment):

“(A) Screening under paragraph (2).

"(B) Enhanced oversight periods under paragraph (3).

“(C) Enrollment moratoria under paragraph (4).

8 In applying this subsection for purposes of title XIX 9 and XXI the Secretary may require a State to carry 10 out the provisions of this subsection as a require11 ment of the State plan under title XIX or the child 12 health plan under title XXI. Actions taken and de13 terminations made under this subsection shall not be 14 subject to review by a judicial tribunal.

“(2) Screening.-For purposes of paragraph

16 (1), the Secretary shall establish procedures under 17 which screening is conducted with respect to pro18 viders of services and suppliers described in such 19 paragraph. Such screening may include-

"(A) licensing board checks;

"(B) screening against the list of individuals and entities excluded from the program under title XVIII, XIX, or XXI;

"(C) the excluded provider list system;

"(D) background checks; and 
“(E) unannounced pre-enrollment or other site visits.

“(3) Enhanced OVersight PERIOd.-For

4 purposes of paragraph (1), the Secretary shall estab-

5 lish procedures to provide for a period of not less

6 than 30 days and not more than 365 days during

7 which providers of services and suppliers described

8 in such paragraph, as the Secretary determines ap-

9 propriate, would be subject to enhanced oversight,

10 such as required or unannounced (or required and

11 unannounced) site visits or inspections, prepayment

12 review, enhanced review of claims, and such other

13 actions as specified by the Secretary, under the pro-

14 grams under titles XVIII, XIX, and XXI. Under

15 such procedures, the Secretary may extend such pe-

16 riod for more than 365 days if the Secretary deter-

17 mines that after the initial period such additional

18 period of oversight is necessary.

19 “(4) Moratorium ON ENROLLment OF PRO-

20 VIDERS AND SUPPLIERS.-For purposes of para-

21 graph (1), the Secretary, based upon a finding of a

22 risk of serious ongoing fraud within a program

23 under title XVIII, XIX, or XXI, may impose a mor-

24 atorium on the enrollment of providers of services

25 and suppliers within a category of providers of serv- 
1 ices and suppliers (including a category within a spe-

2 cific geographic area) under such title. Such a mora3 torium may only be imposed if the Secretary makes

4 a determination that the moratorium would not ad5 versely impact access of individuals to care under 6 such program. “(5) Clarification.-Nothing in this sub8 section shall be interpreted to preclude or limit the 9 ability of a State to engage in provider screening or 10 enhanced provider oversight activities beyond those 11 required by the Secretary.".

12 (b) Conforming Amendments.-

13 (1) MedicaID.-Section 1902(a) of the Social 14 Security Act (42 U.S.C. 42 U.S.C. 1396a(a)) is 15 amended-

(A) in paragraph (23), by inserting before 17 the semicolon at the end the following: "or by 18 a person to whom or entity to which a morato19 rium under section $1128 \mathrm{G}(\mathrm{a})(4)$ is applied dur20 ing the period of such moratorium"; (B) in paragraph (72); by striking at the end "and";

(C) in paragraph (73), by striking the period at the end and inserting "; and"; and 
(D) by adding after paragraph (73) the following new paragraph:

4 determination made by the Secretary under sub5 section (a) of section 1128G (relating to a signifi6 cant risk of fraudulent activity with respect to a cat7 egory of provider or supplier described in such sub8 section (a) through use of the appropriate proce9 dures described in such subsection (a)), and that the 10 State will carry out any activities as required by the 11 Secretary for purposes of such subsection (a).”.

13 U.S.C. 1397bb) is amended by adding at the end the 14 following new subsection:

15 “(d) Program Integrity.-A State child health 16 plan shall include a description of the procedures to be 17 used by the State-

"(1) to enforce any determination made by the 19 Secretary under subsection (a) of section 1128G (re20 lating to a significant risk of fraudulent activity with 21 respect to a category of provider or supplier de22 scribed in such subsection through use of the appro23 priate procedures described in such subsection); and “(2) to carry out any activities as required by 25 the Secretary for purposes of such subsection.". 
(3) Medicare.-Section 1866(j) of such Act (42 U.S.C. $1395 \mathrm{cc}(\mathrm{j})$ ) is amended by adding at the end the following new paragraph:

“(3) Program integrity.-The provisions of 5 section $1128 \mathrm{G}$ (a) apply to enrollments and renewals 6 of enrollments of providers of services and suppliers $7 \quad$ under this title.".

8 SEC. 1632. ENHANCED MEDICARE, MEDICAID, AND CHIP PROGRAM DISCLOSURE REQUIREMENTS RELATING TO PREVIOUS AFFILIATIONS.

11 (a) In GeneraL.-Section 1128G of the Social Secu12 rity Act, as inserted by section 1631, is amended by add13 ing at the end the following new subsection: “(b) Enhanced Program Disclosure Require15 MENTS.-

“(1) Disclosure.-A provider of services or 17 supplier who submits on or after July 1, 2011, an 18 application for enrollment and renewing enrollment 19 in a program under title XVIII, XIX, or XXI shall 20 disclose (in a form and manner determined by the 21 Secretary) any current affiliation or affiliation with22 in the previous 10-year period with a provider of 23 services or supplier that has uncollected debt or with 24 a person or entity that has been suspended or ex- 
1 cluded under such program, subject to a payment 2 suspension, or has had its billing privileges revoked.

3 “(2) Enhanced safeguards.-If the Sec-

4 retary determines that such previous affiliation of 5 such provider or supplier poses a risk of fraud, 6 waste, or abuse, the Secretary may apply such en7 hanced safeguards as the Secretary determines nec8 essary to reduce such risk associated with such pro9 vider or supplier enrolling or participating in the 10 program under title XVIII, XIX, or XXI. Such safe11 guards may include enhanced oversight, such as en12 hanced screening of claims, required or unannounced 13 (or required and unannounced) site visits or inspec14 tions, additional information reporting requirements, 15 and conditioning such enrollment on the provision of 16 a surety bond.

17 “(3) AUTHORITY TO DENY PARTICIPATION.-If 18 the Secretary determines that there has been at 19 least one such affiliation and that such affiliation or 20 affiliations, as applicable, of such provider or sup21 plier poses a serious risk of fraud, waste, or abuse, 22 the Secretary may deny the application of such pro23 vider or supplier.".

24 (b) Conforming Amendments.- 
(1) MedicAID.-Paragraph (74) of section 1902(a) of such Act (42 U.S.C. 1396a(a)), as added

3 by section $1631(\mathrm{~b})(1)$, is amended-

(A) by inserting "or subsection (b) of such section (relating to disclosure requirements)"

before ", and that the State"; and

(B) by inserting before the period the following: "and apply any enhanced safeguards, with respect to a provider or supplier described in such subsection (b), as the Secretary determines necessary under such subsection (b)'”.

(2) CHIP.-Subsection (d) of section 2102 of such Act (42 U.S.C. 1397bb), as added by section $1631(\mathrm{~b})(2)$, is amended-

(A) in paragraph (1), by striking at the end "and";

(B) in paragraph (2) by striking the period at the end and inserting "; and" " and

(C) by adding at the end the following new paragraph:

“(3) to enforce any determination made by the Secretary under subsection (b) of section 1128G (relating to disclosure requirements) and to apply any enhanced safeguards, with respect to a provider or 
1 supplier described in such subsection, as the Sec-

2 retary determines necessary under such subsection.”.

3 SEC. 1633. REQUIRED INCLUSION OF PAYMENT MODIFIER FOR CERTAIN EVALUATION AND MANAGEMENT SERVICES.

6 Section 1848 of the Social Security Act (42 U.S.C.

7 1395w-4), as amended by section 4101 of the HITECH

8 Act (Public Law 111-5), is amended by adding at the end

9 the following new subsection:

10 “(p) Payment Modifier for Certain Evalua-

11 tion and Management Services.-The Secretary shall

12 establish a payment modifier under the fee schedule under

13 this section for evaluation and management services (as

14 specified in section 1842(b)(16)(B)(ii)) that result in the

15 ordering of additional services (such as lab tests), the pre-

16 scription of drugs, the furnishing or ordering of durable

17 medical equipment in order to enable better monitoring

18 of claims for payment for such additional services under

19 this title, or the ordering, furnishing, or prescribing of

20 other items and services determined by the Secretary to

21 pose a high risk of waste, fraud, and abuse. The Secretary

22 may require providers of services or suppliers to report

23 such modifier in claims submitted for payment.". 
1 SEC. 1634. EVALUATIONS AND REPORTS REQUIRED UNDER

3 (a) In General.-Section $1893(\mathrm{c})$ of the Social Se4 curity Act (42 U.S.C. $1395 \mathrm{ddd}(\mathrm{c})$ ) is amended-

(1) in paragraph (3), by striking at the end 6 "and";

(2) by redesignating paragraph (4) as para$8 \quad$ graph (5); and

(3) by inserting after paragraph (3) the fol-

10 lowing new paragraph:

11 "(4) for the contract year beginning in 2011

12 and each subsequent contract year, the entity pro-

13 vides assurances to the satisfaction of the Secretary

14 that the entity will conduct periodic evaluations of

15 the effectiveness of the activities carried out by such

16 entity under the Program and will submit to the

17 Secretary an annual report on such activities; and".

18 (b) Reference to Medicaid Integrity Pro-

19 GRAM.-For a similar provision with respect to the Med-

20 icaid Integrity Program, see section 1752.

21 SEC. 1635. REQUIRE PROVIDERS AND SUPPLIERS TO 22 ADOPT PROGRAMS TO REDUCE WASTE, FRAUD, AND ABUSE.

24 (a) In General.-Section 1866(j) of the Social Se25 curity Act (42 U.S.C. 42 U.S.C. $1395 \operatorname{cc}(j)$ ), as amended 
1 by section 1631(d)(3), is further amended by adding at

2 the end the following new paragraph:

“(4) Compliance PRograms FOR PRoviders

“(A) In GENERAL.-The Secretary may not enroll (or renew the enrollment of) a provider of services or a supplier (other than a physician or a skilled nursing facility) under this title if such provider of services or supplier fails to, subject to subparagraph (E), establish a compliance program that contains the core elements established under subparagraph (B) and certify in a manner determined by the Secretary, that the provider or suppler has established such a program.

“(B) Establishment OF CORE EleMENTS.-The Secretary, in consultation with the Inspector General of the Department of Health and Human Services, shall establish core elements for a compliance program under subparagraph (A). Such elements may include written policies, procedures, and standards of conduct, a designated compliance officer and a compliance committee; effective training and education pertaining to fraud, waste, and abuse 
for the organization's employees, and contractors; a confidential or anonymous mechanism, such as a hotline, to receive compliance questions and reports of fraud, waste, or abuse; disciplinary guidelines for enforcement of standards; internal monitoring and auditing procedures, including monitoring and auditing of contractors; procedures for ensuring prompt responses to detected offenses and development of corrective action initiatives, including responses to potential offenses; and procedures to return all identified overpayments to the programs under this title, title XIX, and title XXI. "(C) Timeline FOR implementation.The Secretary shall determine a timeline for the establishment of the core elements under subparagraph (B) and the date on which a provider of services and suppliers (other than physicians and skilled nursing facilities) shall be required to have established such a program for purposes of this subsection.

"(D) PILOT PRogram.-The Secretary may conduct a pilot program on the application of this subsection with respect to a category of providers of services or suppliers (other than 
1 physicians and skilled nursing facilities) that

19 SION.-For a similar provision with respect to the Med20 icaid program under title XIX of the Social Security Act, 21 see section 1753. 
1 SEC. 1636. MAXIMUM PERIOD FOR SUBMISSION OF MEDI-

4 (a) PuRPose.-In general, the 36-month period cur5 rently allowed for claims filing under parts A, B, C, and, 6 D of title XVIII of the Social Security Act presents oppor7 tunities for fraud schemes in which processing patterns 8 of the Centers for Medicare \& Medicaid Services can be 9 observed and exploited. Narrowing the window for claims

10 processing will not overburden providers and will reduce 11 fraud and abuse.

12 (b) Reducing Maximum Period For Submis13 SION.-

(1) PART A.-Section 1814(a) of the Social Se15 curity Act (42 U.S.C. $1395 \mathrm{f}(\mathrm{a}))$ is amendedof 3 calendar years" and all that follows and inserting "period of 1 calendar year from which such services are furnished; and'; and

(B) by adding at the end the following new sentence: "In applying paragraph (1), the Secretary may specify exceptions to the 1 calendar year period specified in such paragraph.'.

(2) PART B.-Section 1835(a) of such Act (42 U.S.C. $1395 n($ a)) is amended- 
(A) in paragraph (1), by striking "period of 3 calendar years" and all that follows and inserting "period of 1 calendar year from which such services are furnished; and"; and

17 that, with respect to items and services furnished by 18 such provider to an enrollee of such organization, 19 written request, signed by such enrollee, except in 20 cases in which the Secretary finds it impracticable 21 for the enrollee to do so, is filed for payment for 22 such items and services in such form, in such man23 ner, and by such person or persons as the Secretary 24 may by regulation prescribe, no later than the close 25 of the 1 calendar year period after such items and 
1 services are furnished. In applying the previous sen-

2 tence, the Secretary may specify exceptions to the 1

3 calendar year period specified.".

4 (c) EFFEctive Date.-The amendments made by 5 subsection (b) shall be effective for items and services fur6 nished on or after January 1, 2011.

7 SEC. 1637. PHYSICIANS WHO ORDER DURABLE MEDICAL EQUIPMENT OR HOME HEALTH SERVICES REQUIRED TO BE MEDICARE ENROLLED PHYSICIANS OR ELIGIBLE PROFESSIONALS.

11 (a) DME.-Section 1834(a)(11)(B) of the Social Se12 curity Act (42 U.S.C. $1395 \mathrm{~m}(\mathrm{a})(11)(\mathrm{B})$ ) is amended by 13 striking "physician" and inserting "physician enrolled 14 under section 1866(j) or other professional, as determined 15 by the Secretary".

16 (b) Home Health Services.-

17 (1) PART A.-Section 1814(a)(2) of such Act 18 (42 U.S.C. 1395(a)(2)) is amended in the matter 19 preceding subparagraph (A) by inserting "in the 20 case of services described in subparagraph (C), a 21 physician enrolled under section 1866(j) or other 22 professional, as determined by the Secretary," before 23 "or, in the case of services".

24 (2) PART B.-Section 1835(a)(2) of such Act 25 (42 U.S.C. $1395 n(a)(2)$ ) is amended in the matter 
1 preceding subparagraph (A) by inserting ", or in the

2 case of services described in subparagraph (A), a

3 physician enrolled under section $1866(\mathrm{j})$ or other

4 professional, as determined by the Secretary," after

5 "a physician".

6 (c) Discretion to Expand Application.-The

7 Secretary may extend the requirement applied by the

8 amendments made by subsections (a) and (b) to durable

9 medical equipment and home health services (relating to

10 requiring certifications and written orders to be made by

11 enrolled physicians and health professions) to other cat-

12 egories of items or services under this title, including cov-

13 ered part D drugs as defined in section 1860D-2(e), if

14 the Secretary determines that such application would help

15 to reduce the risk of waste, fraud, and abuse with respect

16 to such other categories under title XVIII of the Social

17 Security Act.

18 (d) EFFECTIVE Date.-The amendments made by 19 this section shall apply to written orders and certifications 20 made on or after July 1, 2010. 
984

1 SEC. 1638. REQUIREMENT FOR PHYSICIANS TO PROVIDE DOCUMENTATION ON REFERRALS TO PROGRAMS AT HIGH RISK OF WASTE AND ABUSE.

(a) Physicians AND Other SupPliERs.-Section

5 1842(h) of the Social Security Act is further amended by

6 adding at the end the following new paragraph

7 “(9) The Secretary may disenroll, for a period of not

8 more than one year for each act, a physician or supplier

9 under section $1866(\mathrm{j})$ if such physician or supplier fails

10 to maintain and, upon request of the Secretary, provide

11 access to documentation relating to written orders or re-

12 quests for payment for durable medical equipment, certifi-

13 cations for home health services, or referrals for other

14 items or services written or ordered by such physician or

15 supplier under this title, as specified by the Secretary.".

16 (b) Providers of SERVICEs.-Section 1866(a)(1)

17 of such Act (42 U.S.C. 1395cc), is amended-

(1) in subparagraph (U), by striking at the end

19 "and";

20 (2) in subparagraph (V), by striking the period 21 at the end and adding "; and"; and

22 (3) by adding at the end the following new sub23 paragraph:

"(W) maintain and, upon request of the Secretary, provide access to documentation relating to written orders or requests for payment 
1 for durable medical equipment, certifications for

2 home health services, or referrals for other

3 items or services written or ordered by the pro-

4 vider under this title, as specified by the Sec-

5 retary.".

6 (c) OIG Permissive Exclusion Authority.-Sec-

7 tion 1128(b)(11) of the Social Security Act (42 U.S.C.

8 1320a-7(b)(11)) is amended by inserting “, ordering, re-

9 ferring for furnishing, or certifying the need for" after

10 "furnishing".

11 (d) EFFEctive Date.-The amendments made by 12 this section shall apply to orders, certifications, and refer13 rals made on or after January 1, 2010.

14 SEC. 1639. FACE-TO-FACE ENCOUNTER WITH PATIENT REQUIRED BEFORE ELIGIBILITY CERTIFICATIONS FOR HOME HEALTH SERVICES OR DURABLE MEDICAL EQUIPMENT.

(a) Condition of Payment for Home Health

19 SERVICES.-

(1) PART A.-Section 1814(a)(2)(C) of such Act is amended-

(A) by striking "and such services" and inserting "such services"; and

(B) by inserting after "care of a physician" the following: ", and, in the case of a cer- 
tification or recertification made by a physician after January 1, 2010, prior to making such certification the physician must document that

the physician has had a face-to-face encounter (including through use of telehealth and other than with respect to encounters that are incident to services involved) with the individual during the 6-month period preceding such certification, or other reasonable timeframe as determined by the Secretary".

(2) PART B.-Section 1835(a)(2)(A) of the Social Security Act is amended-

(A) by striking "and" before "(iii)"; and

(B) by inserting after "care of a physician" the following: ", and (iv) in the case of a certification or recertification after January 1, 2010, prior to making such certification the physician must document that the physician has had a face-to-face encounter (including through use of telehealth and other than with respect to encounters that are incident to services involved) with the individual during the 6 -month period preceding such certification or recertification, or other reasonable timeframe as determined by the Secretary". 
1 (b) Condition of Payment for Durable Med2 ICAL EQUiPMENT.-Section 1834(a)(11)(B) of the Social 3 Security Act (42 U.S.C. 1395m(a)(11)(B)) is amended by 4 adding before the period at the end the following: "and 5 shall require that any written order required for payment 6 under this subsection be written only pursuant to the eligi7 ble health care professional authorized to make such writ8 ten order documenting that such professional has had a 9 face-to-face encounter (including through use of telehealth 10 and other than with respect to encounters that are inci11 dent to services involved) with the individual involved dur12 ing the 6-month period preceding such written order, or 13 other reasonable timeframe as determined by the Sec14 retary".

15 (c) Application to Other Areas Under Medi16 CARE.-The Secretary may apply a face-to-face encounter 17 requirement similar to the requirement described in the 18 amendments made by subsections (a) and (b) to other 19 items and services for which payment is provided under 20 title XVIII of the Social Security Act based upon a finding 21 that such a decision would reduce the risk of waste, fraud, 22 or abuse.

23 (d) Application to Medicaid and CHIP.-The 24 face-to-face encounter requirements described in the 25 amendments made by subsections (a) and (b) and any ex- 
988

1 panded application of similar requirements pursuant to

2 subsection (c) shall apply with respect to a certification

3 or recertification for home health services under title XIX

4 or XXI of the Social Security Act, a written order for du-

5 rable medical equipment under such title, and any other

6 applicable item or service identified pursuant to subsection

7 (c) for which payment is made under such title, respec-

8 tively, in the same manner and to the same extent as such

9 requirements apply in the case of such a certification or

10 recertification, written order, or other applicable item or

11 service so identified, respectively, under title XVIII of such

12 Act.

13 SEC. 1640. EXTENSION OF TESTIMONIAL SUBPOENA AUTHORITY TO PROGRAM EXCLUSION INVESTIGATIONS.

16 (a) In GENERAL.-Section 1128(f) of the Social Se17 curity Act (42 U.S.C. 1320a-7(f)) is amended by adding 18 at the end the following new paragraph:

19 "(4) The provisions of subsections (d) and (e) of sec20 tion 205 shall apply with respect to this section to the 21 same extent as they are applicable with respect to title 22 II. The Secretary may delegate the authority granted by 23 section 205(d) (as made applicable to this section) to the 24 Inspector General of the Department of Health and 25 Human Services or the Administrator of the Centers for 
1 Medicare \& Medicaid Services for purposes of any inves-

2 tigation under this section.".

3 (b) EFFECTIVE Date.-The amendment made by 4 subsection (a) shall apply to investigations beginning on 5 or after January 1, 2010.

6 SEC. 1641. REQUIRED REPAYMENTS OF MEDICARE AND MEDICAID OVERPAYMENTS.

8 Section $1128 \mathrm{G}$ of the Social Security Act, as inserted 9 by section 1631 and amended by section 1632, is further 10 amended by adding at the end the following new sub11 section:

12 “(c) REPORTS ON AND REPAYMENT OF OVERPAY13 ments Identified Through Internal Audits and 14 Reviews.-

“(1) REPORTing AND RETURNing OVERPAY16 MENTS. - If a person knows of an overpayment, the 17 person must-

"(A) report and return the overpayment to the Secretary, the State, an intermediary, a carrier, or a contractor, as appropriate, at the correct address, and

"(B) notify the Secretary, the State, intermediary, carrier, or contractor to whom the 25 overpayment was returned in writing of the reason for the overpayment. 
"(2) Trming.-Subject to section 1620(d) of

2 the Affordable Health Care for America Act, an

3 overpayment must be reported and returned under

4 paragraph (1)(A) by not later than the date that is

560 days after the date the person knows of the over6 payment.

7 Any known overpayment retained later than the ap-

8 plicable date specified in this paragraph creates an

9 obligation as defined in section $3729(b)(3)$ of title

1031 of the United States Code.

11 “(3) Clarification.-Repayment of any over-

12 payments (or refunding by withholding of future

13 payments) by a provider of services or supplier does

14 not otherwise limit the provider or supplier's poten-

15 tial liability for administrative obligations such as

16 applicable interests, fines, and penalties or civil or

17 criminal sanctions involving the same claim if it is

18 determined later that the reason for the overpay-

19 ment was related to fraud or other intentional con-

20 duct by the provider or supplier or the employees or

21 agents of such provider or supplier.

22 “(4) Definitions.-In this subsection:

23 “(A) Knows.-The term 'knows' has the 24 meaning given the terms 'knowing' and 'know- 
ingly' in section $3729(\mathrm{~b})$ of title 31 of the United States Code.

“(B) Overpayment.-The term "overpayment" means any funds that a person receives or retains under title XVIII, XIX, or XXI to which the person, after applicable reconciliation (pursuant to the applicable existing process under the respective title), is not entitled under such title.

“(C) Person.-The term 'person' means a provider of services, supplier, Medicaid managed care organization (as defined in section 1903(m)(1)(A)), Medicare Advantage organization (as defined in section 1859(a)(1)), or PDP sponsor (as defined in section 1860D41(a)(13)), but excluding a beneficiary.".

17 SEC. 1642. EXPANDED APPLICATION OF HARDSHIP WAIVERS FOR OIG EXCLUSIONS TO BENEFICIARIES OF ANY FEDERAL HEALTH CARE PROGRAM.

21 Section 1128(c)(3)(B) of the Social Security Act (42 22 U.S.C. 1320a-7(c)(3)(B)) is amended by striking "indi23 viduals entitled to benefits under part A of title XVIII 24 or enrolled under part B of such title, or both" and insert- 
1 ing "beneficiaries (as defined in section 1128A(i)(5)) of

2 that program".

3 SEC. 1643. ACCESS TO CERTAIN INFORMATION ON RENAL DIALYSIS FACILITIES.

5 Section $1881($ b) of the Social Security Act (42 U.S.C.

$61395 \mathrm{rr}(\mathrm{b}))$ is amended by adding at the end the following

7 new paragraph:

8 “(15) For purposes of evaluating or auditing pay-

9 ments made to renal dialysis facilities for items and serv-

10 ices under this section under paragraph (1), each such

11 renal dialysis facility, upon the request of the Secretary,

12 shall provide to the Secretary access to information relat-

13 ing to any ownership or compensation arrangement be-

14 tween such facility and the medical director of such facility

15 or between such facility and any physician.".

16 SEC. 1644. BILLING AGENTS, CLEARINGHOUSES, OR OTHER ISTER UNDER MEDICARE.

19 (a) Medicare.-Section 1866(j)(1) of the Social Se20 curity Act (42 U.S.C. $1395 \mathrm{cc}(\mathrm{j})(1)$ ) is amended by adding 21 at the end the following new subparagraph:

"(D) Billing agents AND ClearingHOUSES REQUIRED TO BE REGISTERED UNDER MEDICARE.-Any agent, clearinghouse, or other 25 alternate payee that submits claims on behalf of 
1 a health care provider must be registered with

2 the Secretary in a form and manner specified

$3 \quad$ by the Secretary.'.

4 (b) MedicaId.-For a similar provision with respect

5 to the Medicaid program under title XIX of the Social Se6 curity Act, see section 1759.

7 (c) EfFective Date.-The amendment made by 8 subsection (a) shall apply to claims submitted on or after 9 January 1, 2012.

10 SEC. 1645. CONFORMING CIVIL MONETARY PENALTIES TO FALSE CLAIMS ACT AMENDMENTS.

12 Section 1128 A of the Social Security Act, as amended 13 by sections 1611, 1612, 1613, and 1615, is further 14 amended-

(1) in subsection (a)-

(A) in paragraph (1), by striking "to an officer, employee, or agent of the United States, or of any department or agency thereof, or of any State agency (as defined in subsection (i) (1))";

(B) in paragraph (4)-

(i) in the matter preceding subparagraph (A), by striking "participating in a program under title XVIII or a State 25 health care program" and inserting "par- 
ticipating in a Federal health care program (as defined in section $1128 \mathrm{~B}(\mathrm{f})$ )"; and

(ii) in subparagraph (A), by striking "title XVIII or a State health care program" and inserting "a Federal health care program (as defined in section $1128 \mathrm{~B}(\mathrm{f})) "$

(C) by striking "or" at the end of paragraph (10);

(D) by inserting after paragraph (11) the following new paragraphs:

"(12) conspires to commit a violation of this section; or

“(13) knowingly makes, uses, or causes to be made or used, a false record or statement material to an obligation to pay or transmit money or property to a Federal health care program, or knowingly conceals or knowingly and improperly avoids or decreases an obligation to pay or transmit money or property to a Federal health care program;"; and

(E) in the matter following paragraph (13), as inserted by subparagraph (D)—

(i) by striking "or" before "in cases under paragraph (11)"; and 
(ii) by inserting ", in cases under paragraph (12), $\$ 50,000$ for any violation described in this section committed in furtherance of the conspiracy involved; or in cases under paragraph (13), $\$ 50,000$ for each false record or statement, or concealment, avoidance, or decrease" after "by an excluded individual"; and (F) in the second sentence, by striking "such false statement, omission, or misrepresentation)" and inserting "such false statement or misrepresentation, in cases under paragraph (12), an assessment of not more than 3 times the total amount that would otherwise apply for any violation described in this section committed in furtherance of the conspiracy involved, or in cases under paragraph (13), an assessment of not more than 3 times the total amount of the obligation to which the false record or statement was material or that was avoided or decreased)".

(2) in subsection (c)(1), by striking "six years" and inserting "10 years"; and (3) in subsection (i)- 
(A) by amending paragraph (2) to read as follows:

“(2) The term 'claim' means any application,

4 request, or demand, whether under contract, or oth-

5 erwise, for money or property for items and services

6 under a Federal health care program (as defined in

7 section $1128 \mathrm{~B}(\mathrm{f}))$, whether or not the United States

8 or a State agency has title to the money or property,

9 that-

10 "(A) is presented or caused to be pre11 sented to an officer, employee, or agent of the 12 United States, or of any department or agency 13 thereof, or of any State agency (as defined in 14 subsection (i)(1)); or

"(B) is made to a contractor, grantee, or other recipient if the money or property is to be spent or used on the Federal health care program's behalf or to advance a Federal health care program interest, and if the Federal health care program-

“(i) provides or has provided any portion of the money or property requested or demanded; or

“(ii) will reimburse such contractor, 25 grantee, or other recipient for any portion 
of the money or property which is requested or demanded.";

(B) by amending paragraph (3) to read as follows:

“(3) The term 'item or service' means, without 6 limitation, any medical, social, management, admin7 istrative, or other item or service used in connection 8 with or directly or indirectly related to a Federal 9 health care program."; (C) in paragraph (6) the end "or";

(i) in subparagraph (C), by striking at

(ii) in the first subparagraph (D), by striking at the end the period and inserting "; or"; and

(iii) by redesignating the second subparagraph (D) as a subparagraph (E);

(D) by amending paragraph (7) to read as follows:

“(7) The terms 'knowing', 'knowingly', and 'should know' mean that a person, with respect to 24 information-

"(A) has actual knowledge of the information; 
"(B) acts in deliberate ignorance of the truth or falsity of the information; or

"(C) acts in reckless disregard of the truth or falsity of the information;

5 and require no proof of specific intent to defraud."; 6 and paragraphs:

“(8) The term 'obligation' means an established

10 duty, whether or not fixed, arising from an express

11 or implied contractual, grantor-grantee, or licensor12 licensee relationship, from a fee-based or similar re13 lationship, from statute or regulation, or from the 14 retention of any overpayment.

15 “(9) The term 'material' means having a nat16 ural tendency to influence, or be capable of influ17 encing, the payment or receipt of money or prop18 erty.". 
999

1 SEC. 1646. REQUIRING PROVIDER AND SUPPLIER PAYMENTS UNDER MEDICARE TO BE MADE THROUGH DIRECT DEPOSIT OR ELECTRONIC FUNDS TRANSFER (EFT) AT INSURED DEPOSITORY INSTITUTIONS.

6 (a) MediCARE.-Section 1874 of the Social Security 7 Act (42 U.S.C. $1395 \mathrm{kk}$ ) is amended by adding at the end 8 the following new subsection:

“(e) Limitation on Payment to Providers of

10 Services And SuppliERs.-No payment shall be made

11 under this title for items and services furnished by a pro-

12 vider of services or supplier unless each payment to the 13 provider of services or supplier is in the form of direct 14 deposit or electronic funds transfer to the provider of serv15 ices' or supplier's account, as applicable, at a depository 16 institution (as defined in section 19(b)(1)(A) of the Fed17 eral Reserve Act.'.

18 (b) EFFECTIVE DATE.-The amendments made by 19 this section shall apply to each payment made to a pro20 vider of services, provider, or supplier on or after such 21 date (not later than July 1, 2012) as the Secretary of 22 Health and Human Services shall specify, regardless of 23 when the items and services for which such payment is 24 made were furnished. 
1 SEC. 1647. INSPECTOR GENERAL FOR THE HEALTH

3 (a) Establishment; Appointment.-There is

4 hereby established an Office of Inspector General for the

5 Health Choices Administration, to be headed by the In-

6 spector General for the Health Choices Administration to

7 be appointed by the President, by and with the advice and

8 consent of the Senate.

9 (b) Amendments to the Inspector General ACT

10 OF 1978.-

11

12

(1) Application to health choices adminISTRATION.-Section 12 of the Inspector General Act of 1978 (5 U.S.C. App.) is amended-

(A) in paragraph (1), by striking "or the Federal Cochairpersons of the Commissions established under section 15301 of title 40, United States Code" and inserting "the Federal Cochairpersons of the Commissions established under section 15301 of title 40, United States Code; or the Commissioner of the Health Choices Administration established under section 241 of the Affordable Health Care for America Act"; and

(B) in paragraph (2), by striking "or the Commissions established under section 15301 of title 40, United States Code" and inserting 
1001

18 and coordinate audits, evaluations, and investiga-

19 tions of the programs and operations of the Health

20 Choices Administration established under section

21241 of the Affordable Health Care for America Act,

22 including matters relating to fraud, abuse, and mis-

23 conduct in connection with the admission and con24 tinued participation of any health benefits plan par- 
1002

1 ticipating in the Health Insurance Exchange estab-

2 lished under section 301 of such Act;

3 "(2) have the authority to conduct audits, eval-

4 uations, and investigations relating to any private

5 Exchange-participating health benefits plan, as de-

6 fined in section 201(c) of such Act;

7 "(3) have the authority, in consultation with

8 the Office of Inspector General for the Department

9 of Health and Human Services and subject to sub-

10 section (b), to conduct audits, evaluations, and in-

11 vestigations relating to the public health insurance

12 option established under section 321 of such Act;

13 and

14 “(4) have access to all relevant records nec-

15 essary to carry out this section, including records re-

16 lating to claims paid by Exchange-participating

17 health benefits plans.

18 "(b) Authority granted to the Health Choices Admin-

19 istration and the Inspector General of the Health Choices

20 Administration by the Affordable Health Care for America

21 Act does not limit the duties, authorities, and responsibil-

22 ities of the Office of Inspector General for the Department

23 of Health and Human Services, as in existence as of the

24 date of the enactment of the Affordable Health Care for

25 America Act, to oversee programs and operations of such 
1 department. The Office of Inspector General for the De-

2 partment of Health and Human Services retains primary

3 jurisdiction over fraud and abuse in connection with pay-

4 ments made under the public health insurance option es-

5 tablished under section 321 of such Act and administered

6 by the Department of Health and Human Services.".

(3) Application of Rule of CONstruc-

8 TION.-Section 8J of the Inspector General Act of

91978 (5 U.S.C. App.) is amended by striking "or

$108 \mathrm{H}$ ” and inserting “, $8 \mathrm{H}$, or 8M".

11 (c) EFFective Date.-The provisions of and

12 amendments made by this section shall take effect on the

13 date of the enactment of this Act.

\section{Subtitle D-Access to Information 15 Needed to Prevent Fraud, 16 Waste, and Abuse}

17 SEC. 1651. ACCESS TO INFORMATION NECESSARY TO IDEN-

TIFY FRAUD, WASTE, AND ABUSE.

19 (a) GAO ACCESS.-Subchapter II of chapter 7 of

20 title 31, United States Code, is amended by adding at the

21 end the following:

22 “ 721 . Access to certain information

23 "No provision of the Social Security Act shall be con24 strued to limit, amend, or supersede the authority of the 25 Comptroller General to obtain any information, to inspect 
1 any record, or to interview any officer or employee under

2 section 716 of this title, including with respect to any in-

3 formation disclosed to or obtained by the Secretary of

4 Health and Human Services under part C or D of title

5 XVIII of the Social Security Act.".

6 (b) Access to Medicare Part D Data Program

7 Integrity Purposes.-

8

9

10

11

12
(1) Provision of information as condition OF PAYMenT.-Section 1860D-15(d)(2)(B) of the Social Security Act (42 U.S.C. $1395 \mathrm{w}-$ $115(\mathrm{~d})(2)(\mathrm{B}))$ is amended-

(A) by striking "may be used by officers" and all that follows through the period and inserting "may be used by_-"; and

(B) by adding at the end the following clauses:

"(i) officers, employees, and contractors of the Department of Health and Human Services only for the purposes of, and to the extent necessary in, carrying out this section; and

"(ii) the Inspector General of the Department of Health and Human Services, the Administrator of the Centers for Medicare \& Medicaid Services, and the Attorney 
1005

General only for the purposes of protecting the integrity of the programs under this title and title XIX; conducting the activities described in section 1893 and subparagraphs (A) through (E) of section 1128C(a)(1); and for investigation, audit, evaluation, oversight, and law enforcement purposes to the extent consistent with applicable law.’.

(2) General disclosure of information.Section 1860D-15(f)(2) of the Social Security Act (42 U.S.C. $1395 \mathrm{w}-115(\mathrm{f})(2)$ ) is amended-

(A) by striking "may be used by officers" and all that follows through the period and inserting "may be used by_-"; and

(B) by adding at the end the following subparagraphs:

"(A) officers, employees, and contractors of the Department of Health and Human Services only for the purposes of, and to the extent necessary in, carrying out this section; and "(B) the Inspector General of the Department of Health and Human Services, the Administrator of the Centers for Medicare \& Medicaid Services, and the Attorney General only 
1 for the purposes of protecting the integrity of

2 the programs under this title and title XIX; conducting the activities described in section 1893 and subparagraphs (A) through (E) of section $1128 \mathrm{C}(\mathrm{a})(1)$; and for investigation, audit, evaluation, oversight, and law enforcement purposes to the extent consistent with applicable law.".

9 SEC. 1652. ELIMINATION OF DUPLICATION BETWEEN THE HEALTHCARE INTEGRITY AND PROTECTION DATA BANK AND THE NATIONAL PRACTITIONER DATA BANK.

13 (a) In GENERAL.-To eliminate duplication between 14 the Healthcare Integrity and Protection Data Bank 15 (HIPDB) established under section $1128 \mathrm{E}$ of the Social 16 Security Act and the National Practitioner Data Bank 17 (NPBD) established under the Health Care Quality Im18 provement Act of 1986 , section $1128 \mathrm{E}$ of the Social Secu19 rity Act (42 U.S.C. 1320a-7e) is amended-

(1) in subsection (a), by striking "Not later 21 than" and inserting "Subject to subsection (h), not 22 later than";

23 (2) in the first sentence of subsection (d)(2), by 24 striking "(other than with respect to requests by 25 Federal agencies)"; and 
(3) by adding at the end the following new sub-

2 section:

3 “(h) Sunset of the Healthcare Integrity and

4 Protection Data Bank; Transition Process.-Ef-

5 fective upon the enactment of this subsection, the Sec-

6 retary shall implement a process to eliminate duplication

7 between the Healthcare Integrity and Protection Data

8 Bank (in this subsection referred to as the 'HIPDB' es-

9 tablished pursuant to subsection (a) and the National

10 Practitioner Data Bank (in this subsection referred to as

11 the 'NPDB') as implemented under the Health Care Qual-

12 ity Improvement Act of 1986 and section 1921 of this Act,

13 including systems testing necessary to ensure that infor-

14 mation formerly collected in the HIPDB will be accessible

15 through the NPDB, and other activities necessary to

16 eliminate duplication between the two data banks. Upon

17 the completion of such process, notwithstanding any other

18 provision of law, the Secretary shall cease the operation

19 of the HIPDB and shall collect information required to

20 be reported under the preceding provisions of this section

21 in the NPDB. Except as otherwise provided in this sub-

22 section, the provisions of subsections (a) through $(\mathrm{g})$ shall

23 continue to apply with respect to the reporting of (or fail-

24 ure to report), access to, and other treatment of the infor-

25 mation specified in this section.". 
1008

1 (b) Elimination of the Responsibility of the

2 HHS OfFice of the Inspector General.- Section

3 1128C(a)(1) of the Social Security Act (42 U.S.C. 1320a-

$47 \mathrm{e}(\mathrm{a})(1))$ is amended-

5 (1) in subparagraph (C), by adding at the end 6 "and";

(2) in subparagraph (D), by striking at the end

8 ", and" and inserting a period; and

9

(3) by striking subparagraph (E).

10 (c) Special Provision for Access to the Na-

11 tional Practitioner Data Bank by the Depart-

12 Ment of Veterans AfFatrs.-

13 (1) In GENERAL.-Notwithstanding any other 14 provision of law, during the one year period that be15 gins on the effective date specified in subsection 16 (e)(1), the information described in paragraph (2) 17 shall be available from the National Practitioner 18 Data Bank (described in section 1921 of the Social 19 Security Act) to the Secretary of Veterans Affairs 20 without charge.

21 (2) INFORMATION DESCRIBED.-For purposes 22 of paragraph (1), the information described in this 23 paragraph is the information that would, but for the 24 amendments made by this section, have been avail- 
1 able to the Secretary of Veterans Affairs from the

2 Healthcare Integrity and Protection Data Bank.

3 (d) Funding.-Notwithstanding any provisions of 4 this Act, sections $1128 \mathrm{E}(\mathrm{d})(2)$ and $1817(\mathrm{k})(3)$ of the So5 cial Security Act, or any other provision of law, there shall 6 be available for carrying out the transition process under 7 section $1128 \mathrm{E}(\mathrm{h})$ of the Social Security Act over the pe8 riod required to complete such process, and for operation 9 of the National Practitioner Data Bank until such process 10 is completed, without fiscal year limitation-

11 (1) any fees collected pursuant to section $12 \quad 1128 \mathrm{E}(\mathrm{d})(2)$ of such Act; and

13 (2) such additional amounts as necessary, from 14 appropriations available to the Secretary and to the 15 Office of the Inspector General of the Department of 16 Health and Human Services under clauses (i) and 17 (ii), respectively, of section $1817(\mathrm{k})(3)(\mathrm{A})$ of such 18 Act, for costs of such activities during the first 12 19 months following the date of the enactment of this 20 Act.

21 (e) EFFEctive Date.-The amendments made-

22 (1) by subsection (a)(2) shall take effect on the 23 first day after the Secretary of Health and Human 24 Services certifies that the process implemented pur- 
1010

1 suant to section $1128 \mathrm{E}(\mathrm{h})$ of the Social Security Act

2 (as added by subsection (a)(3)) is complete; and

3 (2) by subsection (b) shall take effect on the

4 earlier of the date specified in paragraph (1) or the

5 first day of the second succeeding fiscal year after

6 the fiscal year during which this Act is enacted.

7 SEC. 1653. COMPLIANCE WITH HIPAA PRIVACY AND SECU-

RITY STANDARDS.

9 The provisions of sections 262(a) and 264 of the

10 Health Insurance Portability and Accountability Act of

111996 (and standards promulgated pursuant to such sec-

12 tions) and the Privacy Act of 1974 shall apply with respect

13 to the provisions of this subtitle and amendments made

14 by this subtitle.

\section{TITLE VII-MEDICAID AND CHIP}

\section{SEC. 1. TABLE OF CONTENTS [TEMPORARY].}

Sec. 1. Table of contents 【Temporary】.

Subtitle A-Medicaid and Health Reform

Sec. 1701. Eligibility for individuals with income below 150 percent of the Federal poverty level.

Sec. 1702. Requirements and special rules for certain Medicaid eligible individuals.

Sec. 1703. CHIP and Medicaid maintenance of eligibility.

Sec. 1704. Reduction in Medicaid DSH.

Sec. 1705. Expanded outstationing.

Subtitle B-Prevention

Sec. 1711. Required coverage of preventive services.

Sec. 1712. Tobacco cessation.

Sec. 1713. Optional coverage of nurse home visitation services.

Sec. 1714. State eligibility option for family planning services.

Subtitle C-Access 


\section{1}

Sec. 1721. Payments to primary care practitioners.

Sec. 1722. Medical home pilot program.

Sec. 1723. Translation or interpretation services.

Sec. 1724. Optional coverage for freestanding birth center services.

See. 1725. Inclusion of public health clinies under the vaceines for children program.

Sec. 1726. Requiring coverage of services of podiatrists.

Sec. 1726A. Requiring coverage of services of optometrists.

Sec. 1727. Therapeutic foster care.

Sec. 1728. Assuring adequate payment levels for services.

Sec. 1729. Preserving Medicaid coverage for youths upon release from public institutions.

Sec. 1730. Quality measures for maternity and adult health services under Medicaid and CHIP.

Sec. 1730A. Accountable care organization pilot program.

Sec. 1730B. FQHC coverage.

\section{Subtitle D—Coverage}

Sec. 1731. Optional Medicaid coverage of low-income HIV-infected individuals.

Sec. 1732. Extending transitional Medicaid Assistance (TMA).

Sec. 1733. Requirement of 12-month continuous coverage under certain CHIP programs.

Sec. 1734. Preventing the application under CHIP of coverage waiting periods for certain children.

Sec. 1735. Adult day health eare services.

Sec. 1736. Medicaid coverage for citizens of Freely Associated States.

Sec. 1737. Continuing requirement of Medicaid coverage of nonemergency transportation to medically necessary services.

Sec. 1738. State option to disregard certain income in providing continued Medicaid coverage for certain individuals with extremely high prescription costs.

Sec. 1739. Provisions relating to community living assistance services and supports (CLASS).

\section{Subtitle E-Financing}

Sec. 1741. Payments to pharmacists.

Sec. 1742. Prescription drug rebates.

Sec. 1743. Extension of prescription drug discounts to enrollees of Medicaid managed care organizations.

Sec. 1744. Payments for graduate medical education.

Sec. 1745. Nursing Facility Supplemental Payment Program.

Sec. 1746. Report on Medicaid payments.

Sec. 1747. Reviews of Medicaid.

Sec. 1748. Extension of delay in managed care organization provider tax elimination.

Sec. 1749. Extension of ARRA increase in FMAP.

Subtitle F-Waste, Fraud, and Abuse

Sec. 1751. Health care aequired conditions.

Sec. 1752. Evaluations and reports required under Medicaid Integrity Program.

Sec. 1753. Require providers and suppliers to adopt programs to reduce waste, fraud, and abuse.

Sec. 1754. Overpayments. 
Sec. 1755. Managed eare organizations.

Sec. 1756. Termination of provider participation under Medicaid and CHIP if terminated under Medicare or other State plan or child health plan.

See. 1757. Medicaid and CHIP exclusion from participation relating to certain ownership, control, and management affiliations.

Sec. 1758. Requirement to report expanded set of data elements under MMIS to detect fraud and abuse.

Sec. 1759. Billing agents, clearinghouses, or other alternate payees required to register under Medicaid.

Sec. 1760. Denial of payments for litigation-related misconduct.

Sec. 1761. Mandatory State use of national correct coding initiative.

Subtitle G-Payments to the Territories

Sec. 1771. Payment to territories.

Subtitle H-Miscellaneous

Sec. 1781. Technical corrections.

Sec. 1782. Extension of QI program.

Sec. 1783. Assuring transparency of information.

Sec. 1784. Medicaid and CHIP Payment and Access Commission.

Sec. 1785. Outreach and enrollment of Medicaid and CHIP eligible individuals.

Sec. 1786. Prohibitions on Federal Medicaid and CHIP payment for undocumented aliens.

Sec. 1787. Demonstration project for stabilization of emergency medical conditions by institutions for mental diseases.

Sec. 1788. Application of Medicaid Improvement Fund.

Sec. 1789. Treatment of certain Medicaid brokers.

Sec. 1790. Rule for changes requiring State legislation.

1 Subtitle A-Medicaid and Health

Reform

3 SEC. 1701. ELIGIBILITY FOR INDIVIDUALS WITH INCOME

BELOW 150 PERCENT OF THE FEDERAL POV-

ERTY LEVEL.

(a) Eligibility fOR NON-TRAditional INDIVID-

7 uals With Income Below 150 Percent of the Fed-

8 eral Poverty Level.-

(1) Full Medicaid Benefits fOR NON-Medi-

10 CARE

ELIGIBLE

INDIVIDUALS.—Section 
1013

1902(a)(10)(A)(i) of the Social Security Act (42 U.S.C. 1396b(a)(10)(A)(i)) is amended-

(A) by striking "or" at the end of subclause (VI);

(B) by adding "or" at the end of subclause (VII); and

(C) by adding at the end the following new subclause:

“(VIII) who are under 65 years of age, who are not described in a previous subclause of this clause, who are not entitled to hospital insurance benefits under part A of title XVIII, and whose family income (determined using methodologies and procedures specified by the Secretary in consultation with the Health Choices Commissioner) does not exceed 150 percent of the income official poverty line (as defined by the Office of Management and Budget, and revised annually in accordance with section $673(2)$ of the Omnibus Budget Reconciliation Act of 1981) applicable to a family of the size involved;". 
(2) Medicare cost sharing assistance for

INDIVIDUALS.- -Section

3 1902(a)(10)(E) of such Act (42 U.S.C.

$4 \quad 1396 \mathrm{~b}(\mathrm{a})(10)(\mathrm{E}))$ is amended-

(A) in clause (iii), by striking "and" at the

end; clause:

(B) in clause (iv), by adding "and" at the end; and

(C) by adding at the end the following new "(v) for making medical assistance available for medicare cost-sharing described in subparagraphs (B) and (C) of section 1905(p)(3), for individuals under 65 years of age who would be qualified medicare beneficiaries described in section 1905(p)(1) but for the fact that their income exceeds the income level established by the State under section 1905(p)(2) but is less than 150 percent of the official poverty line (referred to in such section) for a family of the size involved; and".

241905 of such Act (42 U.S.C. 1396d) is amended- 
1015

11 CREASED FMAP.-For purposes of section 1905(b)(5),

12 the amounts described in this subsection are the following:

17 section shall be construed as not providing for cov18 erage under subparagraph (A)(i)(VIII) or (E)(v) of 19 section 1902(a)(10) of the Social Security Act, as 20 added by paragraphs (1) and (2), or an increased 21 FMAP under the amendments made by paragraph 22 (3), for an individual who has been provided medical 23 assistance under title XIX of the Act under a dem24 onstration waiver approved under section 1115 of 25 such Act or with State funds. 
1016

(5) Conforming Amendients.-

(A) Section 1903(f)(4) of the Social Security Act (42 U.S.C. $1396 \mathrm{~b}(\mathrm{f})(4)$ ) is amendedby inserting “1902(a)(10)(A)(i)(VIII)," after “1902(a)(10)(A)(i)(VII),"; and

(ii) by inserting "1902(a)(10)(E)(v),” before "1905(p)(1)".

(B) Section 1905(a) of such Act (42 U.S.C. $1396 \mathrm{~d}(\mathrm{a}))$, as amended by sections 1714(a)(4) and 1731(c), is further amended, in the matter preceding paragraph (1)—

(i) by striking "or" at the end of clause (xiv);

(ii) by adding "or" at the end of clause (xv); and

(iii) by inserting after clause (xv) the following:

"(xvi) individuals described in section 1902(a)(10)(A)(i)(VIII),".

(b) Eligibility for Traditional Medicaid Eligible Individuals With Income Not Exceeding 150 3 Percent of the Federal Poverty Level .-

(1) In GENERAL.—Section 1902(a)(10)(A)(i) of the Social Security Act (42 U.S.C. 
$11396 \mathrm{~b}(\mathrm{a})(10)(\mathrm{A})(\mathrm{i}))$, as amended by subsection (a),

2 is amended-

(A) by striking "or" at the end of subclause (VII); and (B) by adding at the end the following new subclause:

"(IX) who are over 18, and under 65 years of age, who would be eligible for medical assistance under the State plan under subclause (I) or section 1931 (based on the income standards, methodologies, and procedures in effect as of June 16, 2009) but for income, who are in families whose income does not exceed 150 percent of the income official poverty line (as defined by the Office of Management and Budget, and revised annually in accordance with section 673(2) of the Omnibus Budget Reconciliation Act of 1981) applicable to a family of the size involved; or "(X) beginning with 2014, who are over 5, and under 19, years of age, who would be eligible for medical 
1018

assistance under the State plan under subclause (I) or (VII) (based on the income standards, methodologies, and procedures in effect as of June 16 , 2009) but for income, who are in families whose income does not exceed 150 percent of the income official poverty line (as defined by the Office of Management and Budget, and revised annually in accordance with section $673(2)$ of the Omnibus Budget Reconciliation Act of 1981) applicable to a family of the size involved; or "(XI) beginning with 2014, who are under 19 years of age, who are not described in subclause (X), and who would be eligible for child health assistance under a State child health plan insofar as such plan provides benefits under this title (as described in section 2101(a)(2)) based on such plan as in effect as of June 16, 2009; or".

(2) InCREASED FMAP FOR CERTAIN TRADITIONAL MEDICAID ELIGIBLE INDIVIDUALS.- 
1019

(A) INCREASED FMAP FOR ADULTS.-Section 1905(y) of such Act (42 U.S.C. $1396 \mathrm{~d}(\mathrm{y})$ ), as added by subsection (a)(2)(B), is amended by inserting "or (IX)" after "(VIII)".

(B) Enhanced fMap For Childoren.Section 1905(b)(4) of such Act is amended by inserting “1902(a)(10)(A)(i)(X), $1902(\mathrm{a})(10)(\mathrm{A})(\mathrm{i})(\mathrm{XI})$, or" after "on the basis of section".

(3) Construction.-Nothing in this subsection shall be construed as not providing for coverage under subclause (IX), (X), or (XI) of section 1902(a)(10)(A)(i) of the Social Security Act, as added by paragraph (1), or an increased or enhanced FMAP under the amendments made by paragraph (2), for an individual who has been provided medical assistance under title XIX of the Act under a demonstration waiver approved under section 1115 of such Act or with State funds.

(4) Conforming Amendment.-Section 1903(f)(4) of the Social Security Act (42 U.S.C. $1396 \mathrm{~b}(\mathrm{f})(4))$, as amended by subsection (a)(4), is amended by inserting "1902(a)(10)(A)(i)(IX), 1902(a)(10)(A)(i)(X), $1902(\mathrm{a})(10)(\mathrm{A})(\mathrm{i})(\mathrm{XI}), "$ after “1902(a)(10)(A)(i)(VIII),". 
1020

1 (c) Increased Matching Rate for Temporary

2 Coverage of Certain Newborns.-Section 1905(y) of

3 such Act, as added by subsection $(\mathrm{a})(3)(\mathrm{B})$, is amended

4 by adding at the end the following:

“(2) Amounts expended for medical assistance

6 for children described in section 305(d)(1) of the Af-

7 fordable Health Care for America Act during the

8 time period specified in such section.".

9 (d) Network Adequacy.-Section 1932(a)(2) of

10 the Social Security Act (42 U.S.C. 1396u-2(a)(2)) is

11 amended by adding at the end the following new subpara-

12 graph:

“(D) ENROLLMENT OF NON-TRADitional MEDICAID ELIGIBLES.-A State may not require under paragraph (1) the enrollment in a managed care entity of an individual described in section 1902(a)(10)(A)(i)(VIII) unless the State demonstrates, to the satisfaction of the 19 Secretary, that the entity, through its provider network and other arrangements, has the capacity to meet the health, mental health, and substance abuse needs of such individuals.".

23 (e) EFFEctive Date.-The amendments made by 24 this section shall take effect on the first day of Y1, and 
1021

1 shall apply with respect to items and services furnished

2 on or after such date.

3 SEC. 1702. REQUIREMENTS AND SPECIAL RULES FOR CERTAIN MEDICAID ELIGIBLE INDIVIDUALS.

5 (a) In General.-Title XIX of the Social Security 6 Act is amended by adding at the end the following new 7 section:

8 " REQUIREMENTS AND SPECLAL RULES FOR CERTAIN

9 MEDICAID ELIGIBLE INDIVIDUALS

10 "Sec. 1943. (a) Coordination With NHI Ex11 change Through Memorandum of Under12 STANDING.-

13 “(1) IN GENERAL.-The State shall enter into 14 a Medicaid memorandum of understanding described 15 in section 305(e)(2) of the Affordable Health Care 16 for America Act with the Health Choices Commis17 sioner, acting in consultation with the Secretary, 18 with respect to coordinating the implementation of 19 the provisions of division A of such Act with the 20 State plan under this title in order to ensure the en21 rollment of Medicaid eligible individuals in accept22 able coverage. Nothing in this section shall be con23 strued as permitting such memorandum to modify or 24 vitiate any requirement of a State plan under this 25 title. 
“(2) Enrolliment of EXChange-REFERRED

INDIVIDUALS.-

“(A) Non-Traditional IndVIDUALs.Pursuant to such memorandum the State shall accept without further determination the enrollment under this title of an individual determined by the Commissioner to be a non-traditional Medicaid eligible individual. The State shall not do any redeterminations of eligibility for such individuals unless the periodicity of such redeterminations is consistent with the periodicity for redeterminations by the Commissioner of eligibility for affordability credits under subtitle $\mathrm{C}$ of title II of division $\mathrm{A}$ of the Affordable Health Care for America Act, as specified under such memorandum.

“(B) Traditional individuals.-Pursuant to such memorandum, the State shall accept without further determination the enrollment under this title of an individual determined by the Commissioner to be a traditional Medicaid eligible individual. The State may do redeterminations of eligibility of such individual consistent with such section and the memorandum. 
1023

“(3) Determinations OF ELIGIBILITy FOR AFFORDABILITY CREDITS.-If the Commissioner de-

3 termines that a State Medicaid agency has the ca-

4 pacity to make determinations of eligibility for af-

5 fordability credits under subtitle $\mathrm{C}$ of title II of divi-

6 sion A of the Affordable Health Care for America

$7 \quad$ Act, under such memorandum-

"(A) the State Medicaid agency shall conduct such determinations for any Exchange-eligible individual who requests such a determination;

"(B) in the case that a State Medicaid agency determines that an Exchange-eligible individual is not eligible for affordability credits, the agency shall forward the information on the basis of which such determination was made to the Commissioner; and

"(C) the Commissioner shall reimburse the State Medicaid agency for the costs of conducting such determinations.

“(4) Referrals under memorandum.-Pur22 suant to such memorandum, if an individual applies 23 to the State for assistance in obtaining health cov24 erage and the State determines that the individual 25 is not eligible for medical assistance under this title 
1 and is not authorized under such memorandum to

2 make an determination with respect to eligibility for 3 coverage and affordability credits through the

4 Health Insurance Exchange, the State shall refer

5 the individual to the Commissioner for a determina-

6 tion of such eligibility and, with the individual's au-

7 thorization, provide to the Commissioner information

8 obtained by the State as part of the application 9 process.

10 “(5) AdDitionaL TERMs.- Such memorandum 11 shall include such additional provisions as are nec12 essary to implement efficiently the provisions of this 13 section and title II of division $\mathrm{A}$ of the Affordable 14 Health Care for America Act.

15 “(b) Treatment of Certain Newborns.-

16 "(1) In GEneraL.-In the case of a child who 17 is deemed under section $305(\mathrm{~d})$ of the Affordable 18 Health Care for America Act to be a Medicaid eligi19 ble individual and enrolled under this title pursuant 20 to such section, the State shall provide for a deter21 mination, by not later than the end of the period re22 ferred to in paragraph (2) of such section, of the 23 child's eligibility for medical assistance under this 24 title. 
1025

“(2) EXTENDED TREatment as TRADitionaL MEDICAID ELIGIBLE INDIVIDUAL.-In accordance

3 with paragraph (2) of section 305(d) of the Afford-

4 able Health Care for America Act, in the case of a

5 child described in paragraph (1) of such section who

6 at the end of the period referred to in such para-

7 graph is not otherwise covered under acceptable cov-

8 erage, the child shall be deemed (until such time as

9 the child obtains such coverage or the State other-

10 wise makes a determination of the child's eligibility

11 for medical assistance under its plan under this title

12 pursuant to paragraph (1)) to be a Medicaid eligible

13 individual described in section 1902(l)(1)(B).

14 “(c) Definitions.-In this section:

15 “(1) Medicaid Eligible individuaL.-The

16 term 'Medicaid eligible individual' means an indi-

17 vidual who is eligible for medical assistance under 18 Medicaid.

19 “(2) Traditional MEDICAID ELIGIBLE INDI20 VIDUAL.-The term 'traditional Medicaid eligible in21 dividual' means a Medicaid eligible individual other 22 than an individual who is-

23 “(A) a Medicaid eligible individual by rea24 son of the application of subclause (VIII) of 
section 1902(a)(10)(A)(i) of the Social Security Act; or

"(B) a childless adult not described in section 1902(a)(10)(A) or (C) of such Act (as in effect as of the day before the date of the enactment of this Act).

“(3) Non-Traditional MEDiCAID ELIGIBLE INDIVIDUAL._The term 'non-traditional Medicaid eligible individual' means a Medicaid eligible indi-

10 vidual who is not a traditional Medicaid eligible indi11 vidual.

“(4) Memorandum.-The term 'memorandum'

13 means a Medicaid memorandum of understanding 14 under section $305(\mathrm{e})(2)$ of the Affordable Health 15 Care for America Act.

16 "(5) Y1. - The term 'Y1' has the meaning given 17 such term in section $100(\mathrm{c})$ of the Affordable Health 18 Care for America Act.".

19 (b) Conforming Amendments to Error Rate.20 (1) Section 1903(u)(1)(D) of the Social Secu21 rity Act (42 U.S.C. $1396 \mathrm{~b}(\mathrm{u})(1)(\mathrm{D}))$ is amended by 22 adding at the end the following new clause:

23 "(vi) In determining the amount of erroneous excess 24 payments, there shall not be included any erroneous pay25 ments made that are attributable to an error in an eligi- 
1027

1 bility determination under subtitle $\mathrm{C}$ of title II of division

2 A of the Affordable Health Care for America Act.".

121902 of the Social Security Act (42 U.S.C. 1396a) is

$1397 \mathrm{ee}(\mathrm{c})(11))$ is amended by adding at the end the following new sentence: "Clause (vi) of section 1903(u)(1)(D) shall apply with respect to the application of such requirements under this title and title XIX.".

SEC. 1703. CHIP AND MEDICAID MAINTENANCE OF ELIGIBILITY.

(a) CHIP Maintenance of Eligibility.-Section

(1) in subsection (a), as amended by section 1631(b)(1)(D)graph (73);

(B) by striking the period at the end of paragraph (74) and inserting "; and"; and

(C) by inserting after paragraph (74) the following new paragraph: “(75) provide for maintenance of effort under 23 the State child health plan under title XXI in ac24 cordance with subsection (gg)."; and 
(2) by adding at the end the following new sub-

2 section:

3 "(gg) ChiP Maintenance of Eligibility Re4 QUIREMENT.-

6 as a condition of its State plan under this title under

7 subsection (a)(75) and receipt of any Federal finan-

8 cial assistance under section 1903(a) for calendar

9 quarters beginning after the date of the enactment

10 of this subsection and before CHIP MOE termi-

11 nation date specified in paragraph (3), a State shall

12 not have in effect eligibility standards, methodolo-

13 gies, or procedures under its State child health plan

14 under title XXI (including any waiver under such

15 title or demonstration project under section 1115)

16 that are more restrictive than the eligibility stand-

17 ards, methodologies, or procedures, respectively,

18 under such plan (or waiver) as in effect on June 16, 192009.

“(2) Limitation.-Paragraph (1) shall not be 21 construed as preventing a State from imposing a 22 limitation described in section 2110(b)(5)(C)(i)(II) 23 for a fiscal year in order to limit expenditures under 24 its State child health plan under title XXI to those 
1029

1 for which Federal financial participation is available

2 under section 2105 for the fiscal year.

“(3) CHIP moe termination Date.-In paragraph (1), the 'CHIP MOE termination date' for a State is the date that is the last day of Y1 (as defined in section $100(\mathrm{c})$ of the Affordable Health Care for America Act).

“(4) CHIP TRANSITION REPORT.-Not later than December 31, 2011, the Secretary shall submit to Congress a report-

"(A) that compares the benefits packages offered under an average State child health plan under title XXI in 2011 and to the benefit standards initially adopted under section 224(b) of the Affordable Health Care for America Act and for affordability credits under subtitle $\mathrm{C}$ of title II of division $\mathrm{C}$ of such Act; and

"(B) that includes such recommendations as may be necessary to ensure that-

"(i) such coverage is at least comparable to the coverage provided to children under such an average State child health plan; and

"(ii) there are procedures in effect for the enrollment of CHIP enrollees (includ- 
1030

.

ing CHIP-eligible pregnant women) at the end of Y1 under this title, into a qualified health benefits plan offered through the Health Insurance Exchange, or into other acceptable coverage (as defined for purposes of such Act) without interruption of coverage or a written plan of treatment.".

(b) Medicaid Maintenance of Effort; SimpliFying and Coordinating Eligibility Rules BeTween Exchange and Medicaid.-

(1) In GENERAL.-Section 1903 of such Act (42 U.S.C. 1396b) is amended by adding at the end the following new subsection:

“(aa) Maintenance of Medicaid Effort; Simplifying and Coordinating Eligibility Rules Between Health Insurance Exchange and Med-

“(1) Maintenance of EFForT.-

"(A) IN GENERAL.—Subject to subparagraph (B), a State is not eligible for payment under subsection (a) for a calendar quarter beginning after the date of the enactment of this subsection if eligibility standards, methodologies, or procedures under its plan under this title (including any waiver under this title or 
1031

demonstration project under section 1115) that are more restrictive than the eligibility standards, methodologies, or procedures, respectively, under such plan (or waiver) as in effect on June 16, 2009. The Secretary shall extend such a waiver (including the availability of Federal financial participation under such waiver) for such period as may be required for a State to meet the requirement of the previous sentence.

"(B) EXCEPTION FOR CERTAIN DEMONSTRATION PROJECTS.-In the case of a State demonstration project under section 1115 in effect on June 16, 2009, that permits individuals to be eligible solely to receive a premium or cost-sharing subsidy for individual or group health insurance coverage, effective for coverage provided in $\mathrm{Y} 1-$

"(i) the Secretary shall permit the State to amend such waiver to apply more restrictive eligibility standards, methodologies, or procedures with respect to such individuals under such waiver; and "(ii) the application of such more restrictive, standards, methodologies, or procedures under such an amendment shall 
1032

not be considered in violation of the requirement of subparagraph (A).

"(2) REMoval OF ASSET TEST FOR CERTAIN ELIGIBILITY CATEGORIES.-

"(A) IN GENERAL.-A State is not eligible for payment under subsection (a) for a calendar quarter beginning on or after the first day of Y1 (as defined in section 100(c) of the Affordable Health Care for America Act), if the State applies any asset or resource test in determining (or redetermining) eligibility of any individual on or after such first day under any of the following:

“(i) Subclause (I), (III), (IV), (VI), (VIII), (IX), (X), or (XI) of section $1902(\mathrm{a})(10)(\mathrm{A})(\mathrm{i})$.

“(ii) Subclause (II), (IX), (XIV) or (XVII) of section 1902(a)(10)(A)(ii). “(iii) Section 1931(b).

“(B) OvERRIDING CONTRARY PROVISIONS; REFERENCES.-The provisions of this title that prevent the waiver of an asset or resource test described in subparagraph (A) are hereby waived. 
1033

15 tion 1937(b) of such Act (42 U.S.C. 1396u-7(b)) is 16 amended-

"(C) References.-Any reference to a provision described in a provision in subparagraph (A) shall be deemed to be a reference to such provision as modified through the application of subparagraphs (A) and (B).'.

(2) Conforming amendments.-(A) Section 1902(a)(10)(A) of such Act (42 U.S.C. 1396a(a)(10)(A)) is amended, in the matter before clause (i), by inserting "subject to section 1903(aa)(2)," after “(A)”.

(B) Section 1931(b)(1) of such Act (42 U.S.C. $1396 \mathrm{u}-1(\mathrm{~b})(1))$ is amended by inserting "and section 1903(aa)(2)" after "and (3)".

(c) Standards for Benchmark Packages.-Sec-

(1) in each of paragraphs (1) and (2), by inserting "subject to paragraph (5)," after "subsection (a)(1),"; and

(2) by adding at the end the following new paragraph:

“(5) Minimum Standards.-Effective January 1, 2013, any benchmark benefit package (or benchmark equivalent coverage under paragraph (2)) must meet the minimum benefits and cost-sharing 
1034

1 standards of a basic plan offered through the Health

2 Insurance Exchange.".

3 (d) Repeal of CHIP.-Section 2104(a) of the So-

4 cial Security Act is amended by inserting at the end the

5 following:

6 "No funds shall be appropriated or authorized to be

7 appropriated under this section for fiscal year 2014

8 and subsequent years.".

9 SEC. 1704. REDUCTION IN MEDICAID DSH.

10 (a) REPORT.-

11 (1) In GENERAL.-Not later than January 1, 122016 , the Secretary of Health and Human Services

13 (in this title referred to as the "Secretary") shall 14 submit to Congress a report concerning the extent to 15 which, based upon the impact of the health care re16 forms carried out under division $\mathrm{A}$ in reducing the 17 number of uninsured individuals, there is a contin18 ued role for Medicaid DSH. In preparing the report, 19 the Secretary shall consult with community-based 20 health care networks serving low-income bene21 ficiaries.

(2) Matters to Be inCluded.-The report 23 shall include the following:

(A) Recommendations.-Recommenda25 tions regarding- 
1035

(i) the appropriate targeting of Medicaid DSH within States; and

(ii) the distribution of Medicaid DSH among the States, taking into account the ratio of the amount of DSH funds allocated to a State to the number of uninsured individuals in such State.

(B) Specification of DSh health REFORM METHODOLOGY.-The DSH Health Reform methodology described in paragraph (2) of subsection (b) for purposes of implementing the requirements of such subsection.

(3) Coordination with Medicare DSH REPORT.-The Secretary shall coordinate the report under this subsection with the report on Medicare DSH under section 1112.

(4) Medicaid DsH.-In this section, the term "Medicaid DSH" means adjustments in payments under section 1923 of the Social Security Act for inpatient hospital services furnished by disproportionate share hospitals.

(b) Medicaid Dsh Reductions.-

(1) Reductions.- 
1036

(A) In GENERAL.-For each of fiscal years 2017 through 2019 the Secretary shall effect the following reductions:

(i) Reduction DSH ALLotments.The Secretary shall reduce DSH allotments to States in the amount specified under the DSH health reform methodology under paragraph (2) for the State for the fiscal year.

(ii) Reductions in Payments.-The Secretary shall reduce payments to States under section 1903(a) of the Social Security Act (42 U.S.C. 1396b(a)) for each calendar quarter in the fiscal year, in the manner specified in subparagraph $(\mathrm{C})$, in an amount equal to $1 / 4$ of the DSH allotment reduction under clause (i) for the State for the fiscal year.

(B) Aggregate Reductions.-The aggregate reductions in DSH allotments for all States under subparagraph (A)(i) shall be equal to-

(i) $\$ 1,500,000,000$ for fiscal year 2017 ; 
(ii) $\$ 2,500,000,000$ for fiscal year

2018; and

2019.

The Secretary shall distribute such aggregate reduction among States in accordance with paragraph (2).

(C) Manner of Payment Reduction.The amount of the payment reduction under subparagraph (A)(ii) for a State for a quarter shall be deemed an overpayment to the State under title XIX of the Social Security Act to be disallowed against the State's regular quarterly draw for all Medicaid spending under section 1903(d)(2) of such Act (42 U.S.C. $1396 \mathrm{~b}(\mathrm{~d})(2))$. Such a disallowance is not subject to a reconsideration under $1116(\mathrm{~d})$ of such Act (42 U.S.C. 1316(d)).

(D) Definitions.-In this section:

(i) State.-The term "State" means the 50 States and the District of Columbia.

\section{(ii) DSH ALLoTMENT.-The term} "DSH allotment" means, with respect to a State for a fiscal year, the allotment made 
1038

under section 1923(f) of the Social Security Act (42 U.S.C. 1396r-4(f)) to the State for the fiscal year.

(2) DSH heAlTh REFORM METHODOLOGY.The Secretary shall carry out paragraph (1) through use of a DSH Health Reform methodology issued by the Secretary that imposes the largest percentage reductions on the States that-

(A) have the lowest percentages of uninsured individuals (determined on the basis of audited hospital cost reports) during the most recent year for which such data are available; or

(B) do not target their DSH payments on-

(i) hospitals with high volumes of Medicaid inpatients (as defined in section 1923(b)(1)(A) of the Social Security Act (42 U.S.C. 1396r-4(b)(1)(A)); and

(ii) hospitals that have high levels of uncompensated care (excluding bad debt).

(3) DSH allotment PUblications.-

(A) In general.-Not later than the publication deadline specified in subparagraph (B), the Secretary shall publish in the Federal Reg- 
1039

ister a notice specifying the DSH allotment to each State under 1923(f) of the Social Security Act for the respective fiscal year specified in such subparagraph, consistent with the application of the DSH Health Reform methodology described in paragraph (2).

(B) Publication deadline.-The publication deadline specified in this subparagraph is-

(i) January 1, 2016, with respect to DSH allotments described in subparagraph (A) for fiscal year 2017;

(ii) January 1, 2017, with respect to DSH allotments described in subparagraph (A) for fiscal year 2018; and

(iii) January 1, 2018, with respect to DSH allotments described in subparagraph (A) for fiscal year 2019 .

(c) Conforming Amendments.-

(1) Section 1923(f) of the Social Security Act (42 U.S.C. 1396r-4(f)) is amended-

(A) by redesignating paragraph (7) as paragraph (8); and

(B) by inserting after paragraph (6) the following new paragraph: 
1040

“(7) SPECIAL RULE FOR FISCAL YEARS 2017,

2 2018, AND 2019.-For each of fiscal years 2017,

32018 , and 2018, the DSH allotments under this

4 subsection are subject to reduction under section

5 1704(b) of the Affordable Health Care for America

6 Act.'.

7 (2) The second sentence of section 1923(b)(4)

8 of such Act (42 U.S.C. 1396r-4(b)(4)) is amended

9 by inserting before the period the following: "or to

10 affect the authority of the Secretary to issue and im-

11 plement the DSH Health Reform methodology under

12 section $1704(\mathrm{~b})(2)$ of the Affordable Health Care for

13 America Act'.

14 (d) Disproportionate Share Hospitals (DSH)

15 And Essential Access Hospital (EAH) Non-Dis-

16 CRIMINATION.-

17 (1) IN GENERAL.-Section 1923(d) of the So-

18 cial Security Act (42 U.S.C. 1396r-4) is amended by

19 adding at the end the following new paragraph:

20 "(4) No hospital may be defined or deemed as

21 a disproportionate share hospital, or as an essential

22 access hospital (for purposes of subsection

$23(\mathrm{f})(6)(\mathrm{A})(\mathrm{iv}))$, under a State plan under this title or

24 subsection (b) of this section (including any dem- 
1041

1 onstration project under section 1115) unless the

2 hospital-

"(A) provides services to beneficiaries

under this title without discrimination on the ground of race, color, national origin, creed, source of payment, status as a beneficiary under this title, or any other ground unrelated to such beneficiary's need for the services or the availability of the needed services in the hospital; and

“(B) makes arrangements for, and accepts, reimbursement under this title for services provided to eligible beneficiaries under this title.". (2) Effective Date.-The amendment made

15 by paragraph (1) shall apply to expenditures made 16 on or after July 1, 2010.

\section{SEC. 1705. EXPANDED OUTSTATIONING.}

18 (a) IN GENERAL.—Section 1902 (a)(55) of the Social 19 Security Act (42 U.S.C. 1396a(a)(55)) is amended by 20 striking "under subsection (a)(10)(A)(i)(IV), 21 (a) $(10)(\mathrm{A})(\mathrm{i})(\mathrm{VI}), \quad$ (a)(10)(A)(i)(VII), $\quad$ or 22 (a)(10)(A)(ii)(IX)" and inserting "(including receipt and 23 processing of applications of individuals for affordability 24 credits under subtitle $\mathrm{C}$ of title II of division A of the Af25 fordable Health Care for America Act pursuant to a Med- 
1 icaid memorandum of understanding under section 2 1943(a)(1))".

3 (b) EFFEctive Date.-Except as provided in sec4 tion 1790, the amendment made by subsection (a) shall 5 apply to services furnished on or after July 1, 2010, with6 out regard to whether or not final regulations to carry out 7 such amendment have been promulgated by such date.

9 SEC. 1711. REQUIRED COVERAGE OF PREVENTIVE SERVICES.

11 (a) Coverage.-Section 1905 of the Social Security 12 Act (42 U.S.C. 1396d), as amended by section 13 1701(a)(3)(B), is amended-

(1) in subsection (a)(4)(B) by inserting before the semicolon at the end the following: "; and (D) preventive services described in subsection (z)"; and

21 "(z) Preventive Services.-The preventive serv22 ices described in this subsection are services not otherwise 23 described in subsection (a) or ( $r$ ) that the Secretary deter24 mines are- 
1043

“(1)(A) recommended with a grade of A or B

2 by the Task Force for Clinical Preventive Services;

3 or

“(B) vaccines recommended for use as appro-

5 priate by the Director of the Centers for Disease

6 Control and Prevention; and

"(2) appropriate for individuals entitled to med-

$8 \quad$ ical assistance under this title.".

9 (b) Elimination of Cost-SHARING.-

10 (1) Subsections (a)(2)(D) and (b)(2)(D) of sec-

11 tion 1916 of such Act (42 U.S.C. 1396o) are each

12 amended by inserting "preventive services described

13 in section 1905(z)," after "emergency services (as

14 defined by the Secretary),".

15 (2) Section $1916 \mathrm{~A}(\mathrm{a})(1)$ of such Act (42 U.S.C.

16 1396o-1 (a)(1)) is amended by inserting ", preven-

17 tive services described in section 1905(z)," after 18 "subsection (c)".

19 (c) Conforming Amendment.-Section 1928 of 20 such Act (42 U.S.C. 1396s) is amended-

(1) in subsection $(\mathrm{c})(2)(\mathrm{B})(\mathrm{i})$, by striking "the 22 advisory committee referred to in subsection (e)" 23 and inserting "the Director of the Centers for Dis24 ease Control and Prevention"; 
(2) in subsection (e), by striking "Advisory

2 Committee" and all that follows and inserting "Di-

3 rector of the Centers for Disease Control and Pre-

4 vention."; and

$5 \quad$ (3) by striking subsection $(\mathrm{g})$.

6 (d) EfFective Date.-Except as provided in sec7 tion 1790, the amendments made by this section shall 8 apply to services furnished on or after July 1, 2010, with9 out regard to whether or not final regulations to carry out 10 such amendments have been promulgated by such date.

11 SEC. 1712. TOBACCO CESSATION.

12 (a) Dropping Tobacco Cessation Exclusion 13 From Covered Outpatient Drugs.-Section 14 1927(d)(2) of the Social Security Act (42 U.S.C. 1396r$158(\mathrm{~d})(2))$ is amended-

16 (1) by striking subparagraph (E);

17 (2) in subparagraph $(G)$, by inserting before the 18 period at the end the following: ", except agents ap19 proved by the Food and Drug Administration for 20 purposes of promoting, and when used to promote, 21 tobaceo cessation"; and

22 (3) by redesignating subparagraphs (F) 23 through (K) as subparagraphs (E) through (J), re24 spectively. 
1045

1 (b) EFFEctive Date.-The amendments made by

2 this section shall apply to drugs and services furnished

3 on or after January 1, 2010.

4 SEC. 1713. OPTIONAL COVERAGE OF NURSE HOME VISITATION SERVICES.

6 (a) In GeneraL.-Section 1905 of the Social Secu7 rity Act (42 U.S.C. 1396d), as amended by sections 8 1701(a)(3)(B) and 1711(a), is amended-

(1) in subsection (a)-

10

(A) in paragraph (27), by striking "and" at the end;

(B) by redesignating paragraph (28) as paragraph (29); and

(C) by inserting after paragraph (27) the following new paragraph: "(28) nurse home visitation services (as defined

17 in subsection (aa)); and"; and (2) by adding at the end the following new sub-

19 section:

20 “(aа) The term 'nurse home visitation services' 21 means home visits by trained nurses to families with a 22 first-time pregnant woman, or a child (under 2 years of 23 age), who is eligible for medical assistance under this title, 24 but only, to the extent determined by the Secretary based 
1 upon evidence, that such services are effective in one or

2 more of the following:

“(1) Improving maternal or child health and

4 pregnancy outcomes or increasing birth intervals be-

5 tween pregnancies.

6 "(2) Reducing the incidence of child abuse, ne-

7 glect, and injury, improving family stability (includ-

8 ing reduction in the incidence of intimate partner vi-

9 olence), or reducing maternal and child involvement

10 in the criminal justice system.

11 “(3) Increasing economic self-sufficiency, em-

12 ployment advancement, school-readiness, and edu-

13 cational achievement, or reducing dependence on 14 public assistance.".

15 (b) EfFective Date.-The amendments made by

16 this section shall apply to services furnished on or after 17 January 1, 2010.

18 (c) Construction.-Nothing in the amendments 19 made by this section shall be construed as affecting the 20 ability of a State under title XIX or XXI of the Social 21 Security Act to provide nurse home visitation services as 22 part of another class of items and services falling within 23 the definition of medical assistance or child health assist24 ance under the respective title, or as an administrative ex25 penditure for which payment is made under section 
1047

1 1903(a) or 2105(a) of such Act, respectively, on or after

2 the date of the enactment of this Act.

3 SEC. 1714. STATE ELIGIBILITY OPTION FOR FAMILY PLANNING SERVICES.

5 (a) Coverage as Optional Categorically 6 Needy Group.-

7

(1) IN GENERAL.-Section 1902(a)(10)(A)(ii)

8 of the Social Security Act (42 U.S.C.

$9 \quad 1396 \mathrm{a}(\mathrm{a})(10)(\mathrm{A})(\mathrm{ii}))$ is amended-

10

(A) in subclause (XVIII), by striking "or" at the end;

(B) in subclause (XIX), by adding "or" at the end; and

(C) by adding at the end the following new subclause:

"(XX) who are described in subsection (hh) (relating to individuals who meet certain income standards);".

(2) Group DEscribed.- Section 1902 of such

22 subsection:

23 "(hh)(1) Individuals described in this subsection are 24 individuals- 
1048

9 in this subsection may include individuals who, had indi-

10 viduals applied on or before January 1, 2007, would have

11 been made eligible pursuant to the standards and proc-

12 esses imposed by that State for benefits described in

13 clause $(\mathrm{XV})$ of the matter following subparagraph $(\mathrm{G})$ of

14 section subsection (a)(10) pursuant to a demonstration

15 project waiver granted under section 1115.

16 "(3) At the option of a State, for purposes of sub17 section (a)(17)(B), in determining eligibility for services 18 under this subsection, the State may consider only the in19 come of the applicant or recipient.".
(3) Limitation on Benefits.-Section 1902(a)(10) of such Act (42 U.S.C. 1396a(a)(10)) is amended in the matter following subparagraph $(\mathrm{G})$ -

(A) by striking "and (XIV)" and inserting "(XIV)"; and 
1049

(B) by inserting ", and (XV) the medical assistance made available to an individual described in subsection (hh) shall be limited to family planning services and supplies described in section 1905(a)(4)(C) including medical diagnosis and treatment services that are provided pursuant to a family planning service in a family planning setting" after "cervical cancer".

(4) Conforming Amendments.-Section 1905(a) of such Act (42 U.S.C. 1396d(a)), as amended by section $1731(\mathrm{c})$, is amended in the matter preceding paragraph (1)—

(A) in clause (xiii), by striking "or" at the end;

(B) in clause (xiv), by adding "or" at the end; and

(C) by inserting after clause (xiv) the following:

"(xv) individuals described in section 1902(hh),".

(b) Presumptive Eligibility.-

(1) In GENERAL.-Title XIX of the Social Security Act (42 U.S.C. 1396 et seq.) is amended by inserting after section 1920B the following: 
1050

"PRESUMPTIVE ELIGIBILITY FOR FAMILY PLANNING

SERVICES

3 "Sec. 1920C. (a) State Option.-State plan ap-

4 proved under section 1902 may provide for making med-

5 ical assistance available to an individual described in sec-

6 tion 1902(hh) (relating to individuals who meet certain

7 income eligibility standard) during a presumptive eligi-

8 bility period. In the case of an individual described in sec-

9 tion 1902(hh), such medical assistance shall be limited to

10 family planning services and supplies described in

11 1905(a)(4)(C) and, at the State's option, medical diag-

12 nosis and treatment services that are provided in conjunc-

13 tion with a family planning service in a family planning

14 setting.

15 “(b) Definitions.-For purposes of this section:

16 “(1) Presumptive ELIGIBILITy Period.-The

17 term 'presumptive eligibility period' means, with re-

18 spect to an individual described in subsection (a),

19 the period that-

"(A) begins with the date on which a qualified entity determines, on the basis of preliminary information, that the individual is described in section 1902(hh); and

"(B) ends with (and includes) the earlier of- 
1051

"(i) the day on which a determination is made with respect to the eligibility of such individual for services under the State plan; or

"(ii) in the case of such an individual who does not file an application by the last day of the month following the month during which the entity makes the determination referred to in subparagraph (A), such last day.

“(2) Qualified entity.-

"(A) IN GENERAL.—Subject to subparagraph (B), the term 'qualified entity' means any entity that-

"(i) is eligible for payments under a State plan approved under this title; and "(ii) is determined by the State agency to be capable of making determinations of the type described in paragraph $(1)(\mathrm{A})$. "(B) Rule of construction.-Nothing in this paragraph shall be construed as preventing a State from limiting the classes of entities that may become qualified entities in order to prevent fraud and abuse. “(c) Administration.- 
“(1) In generaL.- The State agency shall pro-

2 vide qualified entities with-

"(A) such forms as are necessary for an application to be made by an individual described in subsection (a) for medical assistance under the State plan; and

"(B) information on how to assist such individuals in completing and filing such forms.

“(2) Notification Requirements.-A quali-

10 fied entity that determines under subsection

11 (b)(1)(A) that an individual described in subsection

12 (a) is presumptively eligible for medical assistance

13 under a State plan shall-

"(A) notify the State agency of the determination within 5 working days after the date on which determination is made; and

"(B) inform such individual at the time the determination is made that an application for medical assistance is required to be made by not later than the last day of the month following the month during which the determination is made.

“(3) APPLICATION FOR MEDICAL ASSISTANCE.-In the case of an individual described in 25 subsection (a) who is determined by a qualified enti- 
1053

1 ty to be presumptively eligible for medical assistance

2 under a State plan, the individual shall apply for

3 medical assistance by not later than the last day of

4 the month following the month during which the de-

5 termination is made.

6 “(d) Payment.-Notwithstanding any other provi-

7 sion of law, medical assistance that-

8 "(1) is furnished to an individual described in

9 subsection (a)-

10 "(A) during a presumptive eligibility pe-

11 riod;

12 "(B) by a entity that is eligible for pay-

13 ments under the State plan; and

14 "(2) is included in the care and services covered

15 by the State plan,

16 shall be treated as medical assistance provided by such

17 plan for purposes of clause (4) of the first sentence of 18 section $1905(b) . "$.

(2) Conforming Amendments.-

(A) Section 1902(a)(47) of the Social Security Act (42 U.S.C. 1396a(a)(47)) is amended by inserting before the semicolon at the end the following: "and provide for making medical assistance available to individuals described in subsection (a) of section $1920 \mathrm{C}$ during a pre- 
1054

14 Ning Services AND Supplies.-Section 1937(b) of the 15 Social Security Act (42 U.S.C. 1396u-7(b)), as amended

16 by section $1703(\mathrm{c})(2)$, is amended by adding at the end 17 the following:

“(6) Coverage of Family Planning SERV-

sumptive eligibility period in accordance with such section".

(B) Section 1903(u)(1)(D)(v) of such Act (42 U.S.C. $1396 \mathrm{~b}(\mathrm{u})(1)(\mathrm{D})(\mathrm{v}))$ is amended-

(i) by striking "or for" and inserting "for"; and

(ii) by inserting before the period the following: ", or for medical assistance provided to an individual described in subsection (a) of section $1920 \mathrm{C}$ during a presumptive eligibility period under such section".

(c) Clarification of Coverage of Family Plan- 
1055

1 ning services and supplies in accordance with such

2 section.".

3 (d) EfFective Date.-The amendments made by

4 this section take effect on the date of the enactment of

5 this Act and shall apply to items and services furnished 6 on or after such date.

\section{Subtitle C-Access}

8 SEC. 1721. PAYMENTS TO PRIMARY CARE PRACTITIONERS.

(a) In General.-

(1) FeE-FOR-SERVICE PAYMents.-Section 1902 of the Social Security Act (42 U.S.C. 1396b)as amended by sections 1703(a), 1714(a), 1731(a), and 1746 , is amended-

(A) in subsection (a)(13)-

(i) by striking "and" at the end of subparagraph (A);

(ii) by adding "and" at the end of subparagraph (B); and

(iii) by adding at the end the following new subparagraph: defined in subsection $(\mathrm{kk})(1))$ furnished by physicians (or for services furnished by other health care professionals that would be primary care services under such section if furnished by 
1056

a physician) at a rate not less than 80 percent of the payment rate that would be applicable if the adjustment described in subsection $(\mathrm{kk})(2)$ were to apply to such services and physicians or professionals (as the case may be) under part B of title XVIII for services furnished in 2010, 90 percent of such adjusted payment rate for services and physicians (or professionals) furnished in 2011, or 100 percent of such adjusted payment rate for services and physicians (or professionals) furnished in 2012 and each subsequent year;"; and

(B) by adding at the end the following new subsection:

“(kk) Increased Payment for Primary Care SERvices.-For purposes of subsection $(\mathrm{a})(13)(\mathrm{C})$ :

“(1) Primary care services defined.-The term 'primary care services' means evaluation and management services, without regard to the specialty of the physician furnishing the services, that are procedure codes (for services covered under title XVIII) for services in the category designated Evaluation and Management in the Health Care Common Procedure Coding System (established by the Secretary under section 1848(c)(5) as of December 
1057

131,2009 , and as subsequently modified by the Sec-

2 retary).

“(2) Adjustment.-The adjustment described

4 in this paragraph is the substitution of 1.25 percent

5 for the update otherwise provided under section $6 \quad$ 1848(d)(4) for each year beginning with 2010.”.

(2) Under MEDiCAID MANAGED CARE

8 PLANS.-Section 1932(f) of such Act (42 U.S.C.

$9 \quad 1396 \mathrm{u}-2(\mathrm{f}))$ is amended-

10 (A) in the heading, by adding at the end 11 the following: "; ADEQUaCy OF PAYMent FOR 12 Primary Care Services"; and

13 (B) by inserting before the period at the 14 end the following: "and, in the case of primary 15 care services described in section $161902(\mathrm{a})(13)(\mathrm{C})$, consistent with the minimum 17 payment rates specified in such section (regard18 less of the manner in which such payments are 19 made, including in the form of capitation or 20 partial capitation)".

21 (b) Increase in Payment Using Increased 22 FMAP.-Section 1905(y) of the Social Security Act, as 23 added by section 1701(a)(3)(B) and as amended by sec24 tion 1701(c)(2), is amended by adding at the end the fol25 lowing: 
1058

1 "(3)(A) The portion of the amounts expended

2 for medical assistance for services described in sec-

3 tion 1902(a)(13)(C) furnished on or after January

41,2010 , that is attributable to the amount by which

5 the minimum payment rate required under such sec-

6 tion (or, by application, section 1932(f)) exceeds the

7 payment rate applicable to such services under the

$8 \quad$ State plan as of June 16, 2009.

$9 \quad$ “(B) Subparagraph (A) shall not be construed

10 as preventing the payment of Federal financial par-

11 ticipation based on the Federal medical assistance

12 percentage for amounts in excess of those specified

13 under such subparagraph.”.

14 (c) EFfective Date.-The amendments made by

15 this section shall apply to services furnished on or after

16 January 1, 2010.

17 SEC. 1722. MEDICAL HOME PILOT PROGRAM.

18 (a) In GEnERAL.-The Secretary of Health and

19 Human Services shall establish under this section a med-

20 ical home pilot program under which a State may apply

21 to the Secretary for approval of a medical home pilot

22 project described in subsection (b) (in this section referred

23 to as a "pilot project") for the application of the medical

24 home concept under title XIX of the Social Security Act. 
1059

1 The pilot program shall operate for a period of up to 5 2 years.

3

4

5

6 described in section $1866 \mathrm{~F}(\mathrm{a})(3)$ of the Social Secu-

7 rity Act (as inserted by section 1302(a)) or such

8 other model as the Secretary may approve, to indi-

9 viduals (including medically fragile children and

10 high-risk pregnant women) who are eligible for med-

11 ical assistance under title XIX of the Social Security

12 Act. The Secretary shall provide for appropriate co-

13 ordination of the pilot program under this section

14 with the medical home pilot program under section

$15 \quad 1866 \mathrm{~F}$ of such Act.

16

17 duration of not more than 5 years.
(2) Limitation.-A pilot project shall be for a (3) Consideration For certain techNOLOGIES.-In considering applications for pilots projects under this section, the Secretary may approve a project which tests the effectiveness of applications and devices, such as wireless patient management technologies, that are approved by the Food and Drug Administration and enable providers and 
1060

1 practitioners to communicate directly with their pa-

2 tients in managing chronic illness.

3 (c) Additional Incentives.-In the case of a pilot 4 project, the Secretary may-

5

6

7

8

9

10

11

12

13

14

15 a model involving medically fragile children, the model

16 shall ensure that the patient-centered medical home serv-

17 ices received by each child, in addition to fulfilling the re-

18 quirements under $1866 \mathrm{~F}(\mathrm{~b})(1)$ of the Social Security Act,

19 provide for continuous involvement and education of the

20 parent or caregiver and for assistance to the child in ob-

21 taining necessary transitional care if a child's enrollment

22 ceases for any reason.

23 (e) Evaluation; Report.-

24

25 criteria described in section $1866 \mathrm{~F}(\mathrm{e})(1)$ of the So- 
1061

1 cial Security Act (as inserted by section 1123), shall

2 conduct an evaluation of the pilot program under

3 this section.

4 (2) REPORT.-Not later than 60 days after the

5 date of completion of the evaluation under para-

6 graph (1), the Secretary shall submit to Congress

7 and make available to the public a report on the

8 findings of the evaluation under such paragraph.

9 (f) Funding.-The additional Federal financial par-

10 ticipation resulting from the implementation of the pilot

11 program under this section may not exceed in the aggre-

12 gate $\$ 1,235,000,000$ over the 5 -year period of the pro-

13 gram.

14 SEC. 1723. TRANSLATION OR INTERPRETATION SERVICES.

15 (a) In GeneraL.-Section 1903(a)(2)(E) of the So16 cial Security Act (42 U.S.C. 1396b(a)(2)), as added by 17 section 201(b)(2)(A) of the Children's Health Insurance 18 Program Reauthorization Act of 2009 (Public Law 11119 3), is amended by inserting "and other individuals" after 20 "children of families".

21 (b) EFFective Date.-The amendment made by 22 subsection (a) shall apply to payment for translation or 23 interpretation services furnished on or after January 1, 242010. 
1062

1 SEC. 1724. OPTIONAL COVERAGE FOR FREESTANDING

BIRTH CENTER SERVICES.

3 (a) In General.-Section 1905 of the Social Secu4 rity Act (42 U.S.C. 1396d), as amended by section 5 1713(a), is amended-

(1) in subsection (a)-

(A) by redesignating paragraph (29) as paragraph (30);

(B) in paragraph (28), by striking at the end "and"; and

(C) by inserting after paragraph (28) the following new paragraph: “(29) freestanding birth center services (as de-

14 fined in subsection (l)(3)(A)) and other ambulatory

15 services that are offered by a freestanding birth cen16 ter (as defined in subsection $(\mathrm{l})(3)(\mathrm{B}))$ and that are 17 otherwise included in the plan; and"; and

(2) in subsection (l), by adding at the end the 19 following new paragraph:

20 “(3)(A) The term 'freestanding birth center services' 21 means services furnished to an individual at a freestanding 22 birth center (as defined in subparagraph (B)), including 23 by a licensed birth attendant (as defined in subparagraph 24 (C)) at such center.

25 "(B) The term 'freestanding birth center' means a 26 health facility- 
1063

"(i) that is not a hospital; and

"(ii) where childbirth is planned to occur away

3 from the pregnant woman's residence.

4 “(C) The term 'licensed birth attendant' means an

5 individual who is licensed or registered by the State in-

6 volved to provide health care at childbirth and who pro-

7 vides such care within the scope of practice under which

8 the individual is legally authorized to perform such care

9 under State law (or the State regulatory mechanism pro-

10 vided by State law), regardless of whether the individual

11 is under the supervision of, or associated with, a physician

12 or other health care provider. Nothing in this subpara-

13 graph shall be construed as changing State law require-

14 ments applicable to a licensed birth attendant.".

15 (b) EFFECTIVE Date.-The amendments made by

16 this section shall apply to items and services furnished on

17 or after the date of the enactment of this Act.

18 SEC. 1725. INCLUSION OF PUBLIC HEALTH CLINICS UNDER

THE VACCINES FOR CHILDREN PROGRAM.

20 Section 1928(b)(2)(A)(iii)(I) of the Social Security

21 Act (42 U.S.C. $1396 \mathrm{~s}(\mathrm{~b})(2)(\mathrm{A})(\mathrm{iii})(\mathrm{I}))$ is amended-

22 (1) by striking "or a rural health clinic" and in-

23 serting ", a rural health clinic"; and

24 (2) by inserting "or a public health clinic," 25 after '“1905(l)(1)),". 
1 SEC. 1726. REQUIRING COVERAGE OF SERVICES OF PODIATRISTS.

3 (a) In GeneraL.-Section 1905(a)(5)(A) of the So4 cial Security Act (42 U.S.C. $1396 d(a)(5)(A)$ ) is amended 5 by striking "section 1861(r)(1)" and inserting "para6 graphs (1) and (3) of section 1861(r)".

7 (b) EfFective Date.-Except as provided in sec8 tion 1790, the amendment made by subsection (a) shall 9 apply to services furnished on or after January 1, 2010.

10 SEC. 1726A. REQUIRING COVERAGE OF SERVICES OF OPTOMETRISTS.

12 (a) In GeneraL.-Section 1905(a)(5) of the Social

13 Security Act (42 U.S.C. 1396d(a)(5)) is amended-

(1) by striking "and" before "(B)"; and

(2) by inserting before the semicolon at the end 16 the following: ", and (C) medical and other health 17 services (as defined in section 1861(s)) as authorized 18 by State law, furnished by an optometrist (described 19 in section $1861(\mathrm{r})(4))$ to the extent such services 20 may be performed under State law".

21 (b) EFfective Date.-Except as provided in sec22 tion 1790, the amendments made by subsection (a) shall 23 take effect 90 days after the date of the enactment of this 24 Act and shall apply to services furnished or other actions 25 required on or after such date. 
1065

1 SEC. 1727. THERAPEUTIC FOSTER CARE.

2 (a) Rule of Construction.-Nothing in this title

3 shall prevent or limit a State from covering therapeutic

4 foster care for eligible children in out-of-home placements

5 under section 1905(a) of the Social Security Act (42

6 U.S.C. $1396 \mathrm{~d}(\mathrm{a}))$.

7 (b) Therapeutic Foster Care Defined.-For

8 purposes of this section, the term "therapeutic foster

9 care" means a foster care program that provides-

10

11

12

13

14

15

16

17

18

19

20 and consultation with the foster parent on the man-

21 agement of children with mental illnesses and re-

22 lated health and developmental conditions. 
1 SEC. 1728. ASSURING ADEQUATE PAYMENT LEVELS FOR SERVICES.

3 (a) In GeneraL.-Title XIX of the Social Security 4 Act is amended by inserting after section 1925 the fol5 lowing new section:

6 "ASSURING ADEQUATE PAYMENT LEVELS FOR SERVICES

7 "Sec. 1926. (a) In General.-A State plan under

8 this title shall not be considered to meet the requirement 9 of section 1902(a)(30)(A) for a year (beginning with 10 2011) unless, by not later than April 1 before the begin-

11 ning of such year, the State submits to the Secretary an

12 amendment to the plan that specifies the payment rates

13 to be used for such services under the plan in such year

14 and includes in such submission such additional data as

15 will assist the Secretary in evaluating the State's compli-

16 ance with such requirement, including data relating to how

17 rates established for payments to medicaid managed care

18 organizations under sections $1903(\mathrm{~m})$ and 1932 take into

19 account such payment rates.

20 “(b) Secretarial Review.-The Secretary, by not 21 later than 90 days after the date of submission of a plan 22 amendment under subsection (a), shall-

23 "(1) review each such amendment for compli24 ance with the requirement of section $25 \quad 1902(\mathrm{a})(30)(\mathrm{A})$; and 
1067

"(2) approve or disapprove each such amend-

2 ment.

3 If the Secretary disapproves such an amendment, the

4 State shall immediately submit a revised amendment that

5 meets such requirement.".

6 (b) EFFective Date.-The amendment made by

7 subsection (a) shall take effect on the date of the enact-

8 ment of this Act.

9 SEC. 1729. PRESERVING MEDICAID COVERAGE FOR YOUTHS UPON RELEASE FROM PUBLIC INSTITUTIONS.

12 Section 1902(a) of the Social Security Act (42 U.S.C.

13 1396a), as amended by section 1631(b) and 1703(a), is

14 amended-

(1) by striking "and" at the end of paragraph

$16 \quad(74)$;

17 (2) by striking the period at the end of para18 graph (75) and inserting "; and"; and

19 (3) by inserting after paragraph (75) the fol20 lowing new paragraph:

21 "(76) provide that in the case of any youth who 22 is 18 years of age or younger, was enrolled for med23 ical assistance under the State plan immediately be24 fore becoming an inmate of a public institution, is 2518 years of age or younger upon release from such 
1068

1 institution, and is eligible for such medical assist-

2 ance under the State plan at the time of release

3 from such institution-

"(A) during the period such youth is incar-

5

6

7

8

9

10

11

12

13

14

15

16

17

18

19

20

21

22

23

24 cerated in a public institution, the State shall not terminate eligibility for medical assistance under the State plan for such youth;

"(B) during the period such youth is incarcerated in a public institution, the State shall establish a process that ensures-

"(i) that the State does not claim federal financial participation for services that are provided to such youth and that are excluded under subsection 1905(a)(28)(A); and

"(ii) that the youth receives medical assistance for which federal participation is available under this title; "(C) on or before the date such youth is released from such institution, the State shall ensure that such youth is enrolled for medical assistance under this title, unless and until there is a determination that the individual is no longer eligible to be so enrolled; and 
"(D) the State shall ensure that enrollment under subparagraph (C) will be completed before such date so that the youth can access medical assistance under this title immediately upon leaving the institution."

6 SEC. 1730. QUALITY MEASURES FOR MATERNITY AND

ADULT HEALTH SERVICES UNDER MEDICAID AND CHIP.

10 et seq.) is amended by inserting after section $1139 \mathrm{~A}$ the

11 following new section:

12 “SEC. 1139B. QUALITY MEASURES FOR MATERNITY AND ADULT HEALTH SERVICES UNDER MEDICAID AND CHIP. “(a) Maternity Care Quality Measures Under 16 Medicaid AND CHIP.-

"(1) Development of Measures.-No later 18 than January 1, 2011, the Secretary shall develop 19 and publish for comment a proposed set of measures 20 that accurately describe the quality of maternity 21 care provided under State plans under titles XIX 22 and XXI. The Secretary shall publish a final rec23 ommended set of such measures no later than July $24 \quad 1,2011$. 
2 later than January 1, 2012, the Secretary shall de-

3 velop and publish a standardized reporting format

4 for maternity care quality measures for use by State

5 programs under titles XIX and XXI to collect data

6 from managed care entities and providers and prac-

7 titioners that participate in such programs and to

8 report maternity care quality measures to the Sec9 retary.

10 “(b) Other Adult Health Quality Measures

\section{Under Medicaid.-}

“(1) Development of Measures.-The Sec-

13 retary shall develop quality measures that are not

14 otherwise developed under section 1192 for services

15 received under State plans under title XIX by indi-

16 viduals who are 21 years of age or older but have

17 not attained age 65. The Secretary shall publish

18 such quality measures through notice and comment

19 rulemaking.

“(2) StandardizED REPORTING FORMAT.-

21 The Secretary shall develop and publish a standard-

22 ized reporting format for quality measures developed

23 under paragraph (1) and section 1192 for services

24 furnished under State plans under title XIX to indi-

25 viduals who are 21 years of age or older but have 
1 not attained age 65 for use under such plans and

2 State plans under title XXI. The format shall enable

3 State agencies administering such plans to collect

4 data from managed care entities and providers and

5 practitioners that participate in such plans and to

6 report quality measures to the Secretary.

7 “(c) Development Process.-With respect to the

8 development of quality measures under subsections (a)

9 and (b)-

10 "(1) Use OF QUALIFIED ENTITIES.-The Sec-

11 retary may enter into agreements with public, non-

12 profit, or academic institutions with technical exper-

13 tise in the area of health quality measurement to as-

14 sist in such development. The Secretary may carry

15 out these agreements by contract, grant, or other-

16 wise.

17 “(2) MULTI-STAKEHOLDER PRE-RULEMAKING

18 INPUT.-The Secretary shall obtain the input of

19 stakeholders with respect to such quality measures

20 using a process similar to that described in section $21 \quad 1808(d)$.

22 "(3) Coordination.-The Secretary shall co23 ordinate the development of such measures under 24 such subsections and with the development of child 25 health quality measures under section 1139A. 
1 “(d) Annual Report to Congress.-No later than

2 January 1, 2013, and annually thereafter, the Secretary

3 shall report to the Committee on Energy and Commerce

4 of the House of Representatives the Committee on Fi-

5 nance of the Senate regarding-

6 "(1) the availability of reliable data relating to

7 the quality of maternity care furnished under State

8 plans under titles XIX and XXI;

9 "(2) the availability of reliable data relating to

10 the quality of services furnished under State plans

11 under title XIX to adults who are 21 years of age

12 or older but have not attained age 65 ; and

13 "(3) recommendations for improving the quality

14 of such care and services furnished under such State 15 plans.

16 “(e) Rule OF Construction.-Notwithstanding 17 any other provision in this section, no quality measure de18 veloped, published, or used as a basis of measurement or 19 reporting under this section may be used to establish an 20 irrebuttable presumption regarding either the medical ne21 cessity of care or the maximum permissible coverage for 22 any individual who receives medical assistance under title 23 XIX or child health assistance under title XXI.

24 "(f) Appropriation.-For purposes of carrying out 25 this section, in addition to funds otherwise available, out 
1 of any funds in the Treasury not otherwise appropriated,

2 there are appropriated $\$ 40,000,000$ for the 5-fiscal-year

3 period beginning with fiscal year 2010. Funds appro-

4 priated under this subsection shall remain available until 5 expended.".

6 SEC. 1730A. ACCOUNTABLE CARE ORGANIZATION PILOT PROGRAM.

8 (a) In GeneraL.-The Secretary of Health and

9 Human Services shall establish under this section an ac-

10 countable care program under which a State may apply

11 to the Secretary for approval of an accountable care orga-

12 nization pilot program described in subsection (b) (in this

13 section referred to as a "pilot program") for the applica-

14 tion of the accountable care organization concept under

15 title XIX of the Social Security Act.

16 (b) Pilot Program Described.-

17 (1) In GENERAL.-The pilot program described

18 in this subsection is a program that applies one or

19 more of the accountable care organization models

20 described in section $1866 \mathrm{E}$ of the Social Security

21 Act, as added by section 1301 of this Act.

22 (2) Limitation.-The pilot program shall op-

23 erate for a period of not more than 5 years.

24 (c) Additional Incentives.-In the case of the

25 pilot program under this section, the Secretary may- 
(1) waive the requirements of-

(A) section 1902(a)(1) of the Social Security Act (relating to statewideness);

(B) section 1902(a)(10)(B) of such Act (relating to comparability); and (2) increase the matching percentage for administrative expenditures up to-

(A) 90 percent (for the first 2 years of the pilot program); and

(B) 75 percent (for the next 3 years).

\section{(d) Evaluation; Report.-}

(1) Evaluation.-The Secretary shall conduct an evaluation of the pilot program under this section. In conducting such evaluation, the Secretary shall use the criteria used under subsection $(\mathrm{g})(1)$ of section 1866E of the Social Security Act (as inserted by section 1301 of this Act) to evaluate pilot programs under such section.

(2) RePORT.-Not later than 60 days after the date of completion of the evaluation under paragraph (1), the Secretary shall submit to Congress and make available to the public a report on the findings of the evaluation under such paragraph. 
1 SEC. 1730B. FQHC COVERAGE.

2 Section 1905(1)(2)(B) of the Social Security Act (42

3 U.S.C. $1396 \mathrm{~d}(\mathrm{l})(2)(\mathrm{B}))$ is amended-

4 (1) by striking "or" at the end of clause (iii);

5 (2) by striking the semicolon at the end of

6 clause (iv) and inserting “, and"; and

7 (3) by inserting after clause (iv) the following

8 new clause:

$9 \quad$ " $(\mathrm{v})$ is receiving a grant under section 399Z-1

10 of the Public Health Service Act;".

\section{Subtitle D-Coverage}

12 SEC. 1731. OPTIONAL MEDICAID COVERAGE OF LOW-INCOME HIV-INFECTED INDIVIDUALS.

14 (a) In GeneraL. - Section 1902 of the Social Secu15 rity Act (42 U.S.C. 1396a), as amended by section $161714(\mathrm{a})(1)$, is amended-

(1) in subsection (a)(10)(A)(ii)—

(A) by striking "or" at the end of subclause (XIX);

(B) by adding "or" at the end of subclause $(\mathrm{XX})$; and

(C) by adding at the end the following: "(XXI) who are described in subindividuals);"; and 
1 (2) by adding at the end, as amended by sec2 tions 1703 and 1714(a), the following:

3 “(ii) Individuals described in this subsection are indi4 viduals not described in subsection (a)(10)(A)(i)-

19 tion 1905(b) of such Act (42 U.S.C. 1396d(b)) is amended 20 by striking "section 1902(a)(10)(A)(ii)(XVIII)" and in21 serting "subclause (XVIII) or (XXI) of section 22 1902(a)(10)(A)(ii)".

23 (c) Conforming Amendments.-Section 1905(a) of 24 such Act (42 U.S.C. 1396d(a)) is amended, in the matter 25 preceding paragraph (1) — 
(1) by striking "or" at the end of clause (xii);

(2) by adding "or" at the end of clause (xiii);

3 and

4 (3) by inserting after clause (xiii) the following:

5 "(xiv) individuals described in section $6 \quad 1902($ ii),,.

7 (d) Exemption From Funding Limitation for 8 Territories.-Section 1108(g) of the Social Security 9 Act (42 U.S.C. $1308(\mathrm{~g})$ ) is amended by adding at the end 10 the following:

“(5) Disregarding medical assistance for OPTIONAL LOW-INCOME HIV-INFECTED INDIVID-

13 UALS.-The limitations under subsection (f) and the 14 previous provisions of this subsection shall not apply 15 to amounts expended for medical assistance for indi16 viduals described in section 1902(ii) who are only el17 igible for such assistance on the basis of section 18 1902(a)(10)(A)(ii)(XXI).’.

19 (e) Effective Date; Sunset.-The amendments 20 made by this section shall apply to expenditures for cal21 endar quarters beginning on or after the date of the enact22 ment of this Act, and before January 1, 2013, without 23 regard to whether or not final regulations to carry out 24 such amendments have been promulgated by such date. 
1 SEC. 1732. EXTENDING TRANSITIONAL MEDICAID ASSIST-

3 Sections $1902(\mathrm{e})(1)(\mathrm{B})$ and $1925(\mathrm{f})$ of the Social Se4 curity Act (42 U.S.C. 1396a(e)(1)(B), 1396r-6(f)), as

5 amended by section 5004(a)(1) of the American Recovery

6 and Reinvestment Act of 2009 (Public Law 111-5), are

7 each amended by striking "December 31, 2010" and in8 serting "December 31, 2012".

9 SEC. 1733. REQUIREMENT OF 12-MONTH CONTINUOUS COVERAGE UNDER CERTAIN CHIP PROGRAMS.

11 (a) In GenERAL.-Section 2102(b) of the Social Se12 curity Act (42 U.S.C. $1397 \mathrm{bb}(\mathrm{b})$ ) is amended by adding 13 at the end the following new paragraph: “(6) REQUIREMENT FOR 12-MONTH CONTIN15 UOus ELIGIBILITY.-In the case of a State child 16 health plan that provides child health assistance 17 under this title through a means other than de18 scribed in section 2101(a)(2), the plan shall provide 19 for implementation under this title of the 12-month 20 continuous eligibility option described in section $21 \quad 1902(\mathrm{e})(12)$ for targeted low-income children whose 22 family income is below 200 percent of the poverty 23 line.'.

24 (b) EFFEcTive DATE.-The amendment made by 25 subsection (a) shall apply to determinations (and redeter26 minations) of eligibility made on or after January 1, 2010. 
1079

1 SEC. 1734. PREVENTING THE APPLICATION UNDER CHIP OF COVERAGE WAITING PERIODS FOR CERTAIN CHILDREN.

(a) In GeneraL.-Section 2102(b)(1) of the Social

5 Security Act (42 U.S.C. $1397 \mathrm{bb}(\mathrm{b})(1))$ is amended-

(1) in subparagraph (B)-

(A) in clause (iii), by striking "and" at the end;

(B) in clause (iv), by striking the period at the end and inserting "; and"; and

(C) by adding at the end the following new clause:

“(v) may not apply a waiting period (including a waiting period to carry out paragraph $(3)(C))$ in the case of a child described in subparagraph (C)."; and (2) by adding at the end the following new subparagraph:

“(C) DESCRIPTION OF CHILDREN NOT SUBJECT TO WAITING PERIOD.-For purposes of this paragraph, a child described in this subparagraph is a child who, on the date an application is submitted for such child for child health assistance under this title, meets any of the following requirements: 
1080

“(i) INFANTS AND TODDLERS.-The child is under two years of age.

“(ii) Loss of group health PLAN COVERAGE.-The child previously had private health insurance coverage through a group health plan or health insurance coverage offered through an employer and lost such coverage due to-

"(I) termination of an individual's employment;

"(II) a reduction in hours that an individual works for an employer;

"(III) elimination of an individual's retiree health benefits; or "(IV) termination of an individual's group health plan or health insurance coverage offered through an employer.

"(iii) UNAFFoRDABle PRIVATE COVERAGE.-

"(I) IN GENERAL.-The family of the child demonstrates that the cost of health insurance coverage (including the cost of premiums, co-payments, deductibles, and other cost 
1081

11 this section shall take effect as of the date that is 90 days

12 after the date of the enactment of this Act.

\section{SEC. 1735. ADULT DAY HEALTH CARE SERVICES.}

(a) In GeneraL.-The Secretary of Health and

\section{Human Services shall not-}

(1) withhold, suspend, disallow, or otherwise 17 deny Federal financial participation under section 181903 (a) of the Social Security Act (42 U.S.C.

$191396 \mathrm{~b}(\mathrm{a}))$ for the provision of adult day health care 20 services, day activity and health services, or adult 21 medical day care services, as defined under a State 22 Medicaid plan approved during or before 1994, dur23 ing such period if such services are provided con24 sistent with such definition and the requirements of 25 such plan; or 
1082

(2) withdraw Federal approval of any such

2 State plan or part thereof regarding the provision of

3 such services (by regulation or otherwise).

4 (b) EFFECTIVE DATE.-Subsection (a) shall apply

5 with respect to services provided on or after October 1 , 62008.

7 SEC. 1736. MEDICAID COVERAGE FOR CITIZENS OF FREELY ASSOCIATED STATES.

9 (a) In General.- Section 402(b)(2) of the Personal

10 Responsibility and Work Opportunity Reconciliation Act 11 of 1996 (8 U.S.C. 1612(b)(2)) is amended by adding at 12 the end the following:

"(G) MEDICAID EXCEPTION FOR CITIZENS OF FREELY ASSOCIATED STATES.-With respect to eligibility for benefits for the designated Federal program defined in paragraph $(3)(\mathrm{C})$ (relating to the Medicaid program), section 401(a) and paragraph (1) shall not apply to any individual who lawfully resides in 1 of the 50 States or the District of Columbia in accordance with the Compacts of Free Association between the Government of the United States and the Gov25 ernments of the Federated States of Micronesia, the Republic of the Marshall Islands, and the Republic of Palau.". 
1083

(b) Exception to 5-year Limited Eligibility.-

2 Section 403(d) of such Act (8 U.S.C. 1613(d)) is amend3 ed-

(1) in paragraph (1), by striking "or" at the

5 end;

6 (2) in paragraph (2), by striking the period at

7 the end and inserting "; or"; and

8 (3) by adding at the end the following:

9 “(3) an individual described in section $10402(b)(2)(G)$, but only with respect to the des11 ignated Federal program defined in section $12402(b)(3)(C) . ”$.

13 (c) Definition of Qualified Alien.- Section 14 431(b) of such Act (8 U.S.C. 1641(b)) is amended-

15 (1) in paragraph (6), by striking "; or" at the 16 end and inserting a comma;

17 (2) in paragraph (7), by striking the period at 18 the end and inserting ", or"; and

19 (3) by adding at the end the following:

20 "(8) an individual who lawfully resides in the 21 United States in accordance with a Compact of Free 22 Association referred to in section 402(b)(2)(G), but 23 only with respect to the designated Federal program 24 defined in section 402(b)(3)(C) (relating to the Med25 icaid program).". 
1084

1 SEC. 1737. CONTINUING REQUIREMENT OF MEDICAID COV-

ERAGE OF NONEMERGENCY TRANSPORTATION TO MEDICALLY NECESSARY SERVICES.

5 (a) REQUiREMEnT.-Section 1902(a)(10) of the So6 cial Security Act (42 U.S.C. 1396a(a)(10)) is amended-

(1) in subparagraph (A), in the matter pre8 ceding clause (i), by striking "and (21)" and insert$9 \quad \operatorname{ing}$ " $9,(21)$, and (30)'; and

(2) in subparagraph (C)(iv), by striking "and (17)' and inserting ", (17), and (30)'.

(b) Description of SERVICES.-Section 1905(a) of

13 such Act (42 U.S.C. 1395d(a)), as amended by sections $141713(\mathrm{a})(1)$ and 1724(a)(1), is amended-

(2) by redesignating paragraph (30) as para18 graph (31) and by striking the comma at the end 19 and inserting a semicolon; and

20 (3) by inserting after paragraph (29) the fol21 lowing new paragraph:

"(30) nonemergency transportation to medically 23 necessary services, consistent with the requirement 24 of section 431.53 of title 42 , Code of Federal Regu25 lations, as in effect as of June 1, 2008; and". 
1085

1 (c) EFFECTIVE Date.-The amendments made by

2 this section shall take effect on the date of the enactment

3 of this Act and shall apply to transportation on or after

4 such date.

5 SEC. 1738. STATE OPTION TO DISREGARD CERTAIN INCOME

6 IN PROVIDING CONTINUED MEDICAID COVERAGE FOR CERTAIN INDIVIDUALS WITH EXTREMELY HIGH PRESCRIPTION COSTS.

9 Section $1902(\mathrm{e})$ of the Social Security Act (42 U.S.C.

$101396 \mathrm{~b}(\mathrm{e}))$, as amended by section 203(a) of the Children's

11 Health Insurance Program Reauthorization Act of 2009

12 (Public Law 111-3), is amended by adding at the end the

13 following new paragraph:

14 "(14)(A) At the option of the State, in the case of

15 an individual with extremely high prescription drug costs

16 described in subparagraph (B) who has been determined

17 (without the application of this paragraph) to be eligible

18 for medical assistance under this title, the State may, in

19 redetermining the individual's eligibility for medical assist-

20 ance under this title, disregard any family income of the

21 individual to the extent such income is less than an

22 amount that is specified by the State and does not exceed

23 the amount specified in subparagraph (C), or, if greater, 24 income equal to the cost of the orphan drugs described 25 in subparagraph (B)(iii). 
1086

1 “(B) An individual with extremely high prescription

2 drug costs described in this subparagraph for a 12-month 3 period is an individual-

$4 \quad$ "(i) who is covered under health insurance or a 5 health benefits plan that has a maximum lifetime 6 limit of not less than $\$ 1,000,000$ which includes all 7 prescription drug coverage;

8 "(ii) who has exhausted all available prescrip9 tion drug coverage under the plan as of the begin10 ning of such period;

11 "(iii) who incurs (or is reasonably expected to 12 incur) on an annual basis during the period costs for 13 orphan drugs in excess of the amount specified in 14 subparagraph (C) for the period; and

15 "(iv) whose annual family income (determined 16 without regard to this paragraph) as of the begin17 ning of the period does not exceed 75 percent of the 18 amount incurred for such drugs (as described in 19 clause (iii)).

20 "(C) The amount specified in this subparagraph for 21 a 12-month period beginning in“(i) 2009 or 2010 , is $\$ 200,000$; or 24 in clause (i) (or this subparagraph) for the previous 25 year increased by the annual rate of increase in the 
1 medical care component of the consumer price index

2 (U.S. city average) for the 12-month period ending 3 in August of the previous year.

4 Any amount computed under clause (ii) that is not a mul5 tiple of $\$ 1,000$ shall be rounded to the nearest multiple 6 of $\$ 1,000$.

7 “(D) In applying this paragraph, amounts incurred 8 for prescription drugs for cosmetic purposes shall not be 9 taken into account.

10 "(E) With respect to an individual described in sub11 paragraph (A), notwithstanding section 1916, the State 12 plan-

13 "(i) shall provide for the application of cost14 sharing that is at least nominal as determined under 15 section 1916 ; and

16 "(ii) may provide, consistent with section $17 \quad 1916 \mathrm{~A}$, for such additional cost-sharing as does not 18 exceed a maximum level of cost-sharing that is speci19 fied by the Secretary and is adjusted by the Sec20 retary on an annual basis.

21 "(F) A State electing the option under this para22 graph shall provide for a determination on an individual's 23 application for continued medical assistance under this 24 title within 30 days of the date the application if filed with 25 the State. 
1 " $(\mathrm{G})$ In this paragraph:

“(i) The term 'orphan drugs' means prescrip-

3 tion drugs designated under section 526 of the Fed-

4 eral Food, Drug, and Cosmetic Act (21 U.S.C.

$5360 \mathrm{bb}$ ) as a drug for a rare disease or condition.

6 “(ii) The term 'health benefits plan' includes

7 coverage under a plan offered under a State high

8 risk pool.".

9 SEC. 1739. PROVISIONS RELATING TO COMMUNITY LIVING

\section{ASSISTANCE SERVICES AND SUPPORTS} (CLASS).

13 Section 1902(a) of the Social Security Act (42 U.S.C.

14 1396a(a)), as amended by sections 1631(b), 1703(a), 15 1729, 1753, 1757(a), 1759(a), 1783(a), and 1907(b), is 16 amended-

17 (1) in paragraph (80), by striking "and" at the 18 end;

19 (2) in paragraph (81), by striking the period 20 and inserting "; and"; and

21 (3) by inserting after paragraph (81) the fol22 lowing:

23 "(82) provide that the State will comply with 24 such regulations regarding the application of pri25 mary and secondary payor rules with respect to indi- 
1 viduals who are eligible for medical assistance under

2 this title and are eligible beneficiaries under the

3 CLASS program established under title XXXII of

4 the Public Health Service Act as the Secretary shall 5 establish.".

6 (b) Assurance OF Adequate InFrastructure

7 for the Provision of Personal Care Attendant

8 WORKERS.- Section 1902(a) of such Act (42 U.S.C.

9 1396a(a)), as amended by subsection (a), is amended-

10 (1) in paragraph (81), by striking "and" at the

11 end;

12 (2) in paragraph (82), by striking the period at

13 the end and inserting "; and"; and

14 (3) by inserting after paragraph (82), the fol-

15 lowing:

16 "(83) provide that, not later than 2 years after

17 the date of enactment of this paragraph, each State 18 shall-

19 "(A) assess the extent to which entities 20 such as providers of home care, home health 21 services, home and community service providers, 22 public authorities created to provide personal 23 care services to individuals eligible for medical 24 assistance under the State plan, and nonprofit 25 organizations, are serving or have the capacity 
to serve as fiscal agents for, employers of, and providers of employment-related benefits for, personal care attendant workers who provide personal care services to individuals receiving benefits under the CLASS program established under title XXXII of the Public Health Service Act, including in rural and underserved areas; "(B) designate or create such entities to

serve as fiscal agents for, employers of, and providers of employment-related benefits for, such workers to ensure an adequate supply of the workers for individuals receiving benefits under the CLASS program, including in rural and underserved areas; and "(C) ensure that the designation or creation of such entities will not negatively alter or impede existing programs, models, methods, or administration of service delivery that provide for consumer controlled or self-directed home and community services and further ensure that such entities will not impede the ability of individuals to direct and control their home and community services, including the ability to select, manage, dismiss, co-employ, or employ such workers or inhibit such individuals from 
1091

1 relying on family members for the provision of 2 personal care services.".

3 (c) InClusion OF INFORMATION ON SUPPLEMENTAL 4 Coverage in the National Clearinghouse for 5 Long-term Care Information; Extension of Fund6 ING.- Section 6021(d) of the Deficit Reduction Act of 72005 (42 U.S.C. 1396 p note) is amended-

8

9

10

11

12

13

14

15

16

17

18

19

20

21

22

23

24
(1) in paragraph $(2)(\mathrm{A})$ -

(A) in clause (ii), by striking "and" at the end;

(B) in clause (iii), by striking the period at the end and inserting "; and"; and

(C) by adding at the end the following: "(iv) include information regarding the CLASS program established under title XXXII of the Public Health Service Act.'; and (2) in paragraph (3)-

(A) by striking "2010" and inserting "2015"; and

(B) by adding at the end the following: "In addition to the amount appropriated under the previous sentence, there are authorized to be appropriated to carry out this subsection, 
1092

$\$ 7,000,000$ for each of fiscal years 2011,2012 , and 2013.".

(d) Effective Date.- The amendments made by

4 this section take effect on January 1, 2011.

\section{Subtitle E-Financing}

6 SEC. 1741. PAYMENTS TO PHARMACISTS.

(a) Pharmacy Reimbursement Limits.-

(1) In GENERAL.-Section 1927(e) of the Social Security Act (42 U.S.C. 1396r-8(e)) is amended-

(A) by striking paragraph (5) and inserting the following:

“(5) UsE OF AMP IN UPPER PAYMENT LIMITS.-The Secretary shall calculate the Federal upper reimbursement limit established under paragraph (4) as 130 percent of the weighted average (determined on the basis of manufacturer utilization) of monthly average manufacturer prices. Nothing in the previous sentence shall be construed as preventing the Secretary from performing such calculation using a smoothing process in order to reduce significant variations from month to month as a result of rebates, discounts, and other pricing practices, such as in the manner such a process is used by the Secretary in determining the average 
1093

1 sales price of a drug or biological under section $2 \quad 1847$ A." $8(\mathrm{k})(1)(\mathrm{B}))$ is amended-

(B) in the heading, by striking "EXTENDED TO WHOLESALERS" and inserting "AND OTHER PAYMENTS"; and follows through the period and inserting the following: "regard to-

"(i) customary prompt pay discounts

extended to wholesalers;

"(ii) bona fide service fees paid by manufacturers;

“(iii) reimbursement by manufacturers for recalled, damaged, expired, or otherwise unsalable returned goods, including reimbursement for the cost of the goods and any reimbursement of costs associated with return goods handling and processing, reverse logistics, and drug destruction; "(iv) sales directly to, or rebates, discounts, or other price concessions provided to, pharmacy benefit managers, managed 
care organizations, health maintenance organizations, insurers, mail order pharmacies that are not open to all members of the public, or long term care providers, provided that these rebates, discounts, or price concessions are not passed through to retail pharmacies; "(v) sales directly to, or rebates, discounts, or other price concessions provided to, hospitals, clinics, and physicians, unless the drug is an inhalation, infusion, or injectable drug, or unless the Secretary determines, as allowed for in Agency administrative procedures, that it is necessary to include such sales, rebates, discounts, and price concessions in order to obtain an accurate AMP for the drug. Such a determination shall not be subject to judicial review; or

"(vi) rebates, discounts, and other price concessions required to be provided under agreements under subsections (f) and (g) of section 1860D-2(f)..". 
1095

(3) Manufacturer Reporting RequireMENTS.-Section 1927(b)(3)(A) of such Act (42 U.S.C. 1396r-8(b)(3)(A)) is amended-

(A) in clause (ii), by striking "and" at the end;

(B) by striking the period at the end of clause (iii) and inserting "; and"; and

(C) by inserting after clause (iii) the following new clause:

"(iv) not later than 30 days after the last day of each month of a rebate period under the agreement, on the manufacturer's total number of units that are used to calculate the monthly average manufacturer price for each covered outpatient drug.".

(4) Authority to Promulgate REgulaTION.-The Secretary of Health and Human Services may promulgate regulations to clarify the requirements for upper payment limits and for the determination of the average manufacturer price in an expedited manner. Such regulations may become effective on an interim final basis, pending opportunity for public comment. 
1096

(5) Pharmacy reimbursements through DECEMBER 31, 2010.-The specific upper limit under section 447.332 of title 42, Code of Federal Regula-

4 tions (as in effect on December 31, 2006) applicable

5 to payments made by a State for multiple source

6 drugs under a State Medicaid plan shall continue to

7 apply through December 31, 2010, for purposes of

8 the availability of Federal financial participation for

9 such payments.

10 (b) Disclosure of Price Information to the

11 Pubuic.-Section 1927(b)(3) of such Act (42 U.S.C.

$121396 \mathrm{r}-8(\mathrm{~b})(3))$ is amended-

(1) in subparagraph (A)-

(A) in clause (i), in the matter preceding subclause (I), by inserting "month of a" after "each"; and

(B) in the last sentence, by striking "and shall," and all that follows up to the period; and

(2) in subparagraph (D)(v), by inserting 21 "weighted" before "average manufacturer prices".

22 SEC. 1742. PRESCRIPTION DRUG REBATES.

23 (a) Additional Rebate for New Formulations 24 of Existing Drugs.- 
(1) In GENERAL.-Section $1927(\mathrm{c})(2)$ of the Social Security Act (42 U.S.C. 1396r-8(c)(2)) is amended by adding at the end the following new subparagraph:

"(C) Treatment OF New Formula-

TIONS.-In the case of a drug that is a line extension of a single source drug or an innovator multiple source drug that is an oral solid dosage form, the rebate obligation with respect to such drug under this section shall be the amount computed under this section for such new drug or, if greater, the product of-

"(i) the average manufacturer price of the line extension of a single source drug or an innovator multiple source drug that is an oral solid dosage form;

"(ii) the highest additional rebate (calculated as a percentage of average manufacturer price) under this section for any strength of the original single source drug or innovator multiple source drug; and

"(iii) the total number of units of each dosage form and strength of the line extension product paid for under the State 
1098

8 by paragraph (1) shall apply to drugs dispensed $9 \quad$ after December 31, 2009.

10

\section{Single Source Drugs.-}

plan in the rebate period (as reported by the State).

In this subparagraph, the term 'line extension' means, with respect to a drug, a new formulation of the drug, such as an extended release formulation.'.

(2) EFFECTIVE DATE.-The amendment made (b) Increase Minimum Rebate Percentage for

(1) IN GENERAL.-Section 1927(c)(1)(B)(i) of the Social Security Act (42 U.S.C. 1396r$8(\mathrm{c})(1)(\mathrm{B})(\mathrm{i}))$ is amended-

(A) in subclause (IV), by striking "and" at the end;

(B) in subclause (V)-

(i) by inserting "and before January 1, 2010" after "December 31, 1995,"; and

(ii) by striking the period at the end and inserting "; and"; and

(C) by adding at the end the following new subclause:

“(VI) after December 31, 2009, is 23.1 percent.". 
(2) Recapture of total savings due to inCREASE.-Section 1927(b)(1) of such Act is amended by adding at the end the following new subparagraph:

“(C) Special Rule FOR INCREased MiNIMUM REBATE PERCENTAGE.-

"(i) IN GENERAL.-In addition to the amounts applied as a reduction under subparagraph (B), for rebate periods beginning on or after January 1, 2010, during a fiscal year, the Secretary shall reduce payments to a State under section 1903(a) in the manner specified in clause (ii), in an amount equal to the product of-

"(I) 100 percent minus the Federal medical assistance percentage applicable to the rebate period for the State; and

"(II) the amounts received by the State under such subparagraph that are attributable (as estimated by the Secretary based on utilization and other data) to the increase in the minimum rebate percentage effected by the amendments made by section 
1742(b)(1) of the Affordable Health

Care for America Act, taking into account the additional drugs included under the amendments made by section 1743 of such Act.

The Secretary shall adjust such payment reduction for a calendar quarter to the extent the Secretary determines, based upon subsequent utilization and other data, that the reduction for such quarter was greater or less than the amount of payment reduction that should have been made.

“(ii) Manner OF PAYMent ReduCTION.- The amount of the payment reduction under clause (i) for a State for a quarter shall be deemed an overpayment to the State under this title to be disallowed against the State's regular quarterly draw for all Medicaid spending under section 1903(d)(2). Such a disallowance is not subject to a reconsideration under 1116(d).”. 
1101

1 SEC. 1743. EXTENSION OF PRESCRIPTION DRUG DISCOUNTS TO ENROLLEES OF MEDICAID MANAGED CARE ORGANIZATIONS.

(a) In GENERAL.-Section 1903(m)(2)(A) of the So-

5 cial Security Act (42 U.S.C. $1396 \mathrm{~b}(\mathrm{~m})(2)(\mathrm{A})$ ) is amend6 ed-

7

(1) in clause (xi), by striking "and" at the end;

(2) in clause (xii), by striking the period at the end and inserting "; and"; and

(3) by adding at the end the following:

"(xiii) such contract provides that the entity shall report to the State such information, on such timely and periodic basis as specified by the Secretary, as the State may require in order to include, in the information submitted by the State to a manufacturer under section 1927(b)(2)(A) and to the Secretary under section 1927(b)(2)(C), information on covered outpatient drugs dispensed to individuals eligible for medical assistance who are enrolled with the entity and for which the entity is responsible for coverage of such drugs under this subsection.".

(b) Conforming Amendments.-Section 1927 of such Act (42 U.S.C. 1396r-8) is amended-

(1) in the first sentence of subsection $(b)(1)(A)$, by inserting before the period at the end the following: ", including such drugs dispensed to individ- 
1 uals enrolled with a medicaid managed care organi-

2 zation if the organization is responsible for coverage 3 of such drugs";

$4 \quad$ (2) in subsection (b)(2), by adding at the end 5 the following new subparagraph:

6 “(C) Reporting on mico DRugs.-On a 7 quarterly basis, each State shall report to the 8 Secretary the total amount of rebates in dollars 9 received from pharmacy manufacturers for 10 drugs provided to individuals enrolled with 11 Medicaid managed care organizations that con12 tract under section $1903(\mathrm{~m})$ and such other in13 formation as the Secretary may require to carry 14 out paragraph $(1)(\mathrm{C})$ with respect to such re15 bates."; and

$16 \quad(3)$ in subsection $(\mathrm{j})$

17 (A) in the heading by striking "ExEMP18 TION" and inserting "SPECIAL RULES"; and 19 (B) in paragraph (1), by striking "are not 20 subject to the requirements of this section" and 21 inserting "are subject to the requirements of 22 this section unless such drugs are subject to 23 discounts under section $340 \mathrm{~B}$ of the Public 24 Health Service Act". 
1 (c) EFFective Date.-The amendments made by 2 this section take effect on January 1, 2010, and shall 3 apply to drugs dispensed on or after such date, without 4 regard to whether or not final regulations to carry out 5 such amendments have been promulgated by such date. 6 SEC. 1744. PAYMENTS FOR GRADUATE MEDICAL EDUCATION.

8 (a) In General.-Section 1905 of the Social Secu9 rity Act (42 U.S.C. 1396d), as amended by sections 10 1701(a)(3)(B), 1711(a), and 1713(a), is amended by add11 ing at the end the following new subsection:

12 “(bb) Payment For Graduate Medical Edu13 CATION.-

“(1) In GENERAL.-The term "medical assist15 ance' includes payment for costs of graduate medical 16 education consistent with this subsection, whether 17 provided in or outside of a hospital.

“(2) Submission of information.-For purposes of paragraph

(1) and section 1902(a)(13)(A)(v), payment for such costs is not consistent with this subsection unlessa timely manner and on an annual basis specified by the Secretary, information on total payments for graduate medical education and how 
such payments are being used for graduate medical education, including-

"(i) the institutions and programs eli-

“(3) Review of information.-The Secretary

20 shall make the information submitted under para21 graph (2) available to the Advisory Committee on 22 Health Workforce Evaluation and Assessment (es23 tablished under section 2261 of the Public Health 24 Service Act). The Secretary and the Advisory Com25 mittee shall independently review the information 
1 submitted under paragraph (2), taking into account

$2 \quad$ State and local workforce needs.

“(4) SPecification of goals and Require-

4 MENTS.-The Secretary shall specify by rule, ini5 tially published by not later than December 31, $6 \quad 2011-$ described in paragraph (1), taking into account recommendations of the such Advisory Committee and the goals for approved medical residency training programs described in section 1886(h)(1)(B); and

"(B) requirements for use of such funds consistent with such goals.

15 Such rule may be effective on an interim basis pend16 ing revision after an opportunity for public com17 ment.".

18 (b) Conforming Amendment.-Section 19 1902(a)(13)(A) of such Act (42 U.S.C. 1396a(a)(13)(A)), 20 as amended by section 1721(a)(1)(A), is amended-

(1) by striking "and" at the end of clause (iii); 23 inserting ", and”; and

(3) by adding at the end the following new 25 clause: 
"(v) in the case of hospitals and at the option of a State, such rates may include, to the extent consistent with section 1905(bb), payment for graduate medical education; and".

6 (c) EFFEctive Date.-The amendments made by 7 this section shall take effect on the date of the enactment 8 of this Act. Nothing in this section shall be construed as 9 affecting payments made before such date under a State 10 plan under title XIX of the Social Security Act for grad11 uate medical education.

12 SEC. 1745. NURSING FACILITY SUPPLEMENTAL PAYMENT PROGRAM. (a) Total Amount Available for Payments.(1) In GENERAL.—Out of any funds in the 16 Treasury not otherwise appropriated, there are ap17 propriated to the Secretary of Health and Human 18 Services (in this section referred to as the "Sec19 retary") to carry out this section $\$ 6,000,000,000$, of 20 which the following amounts shall be available for 21 obligation in the following years: ginning in 2010.

(B) $\$ 1,500,000,000$ shall be available beginning in 2011. 
(C) $\$ 1,500,000,000$ shall be available beginning in 2012.

(D) $\$ 1,500,000,000$ shall be available beginning in 2013.

(2) Availability.-Funds appropriated under

6 paragraph (1) shall remain available until all eligible 7 dually-certified facilities (as defined in subsection 8 (b)(3)) have been reimbursed for underpayments 9 under this section during cost reporting periods end$10 \quad$ ing during calendar years 2010 through 2013.

(3) Limitation of authority.-The Sec12 retary may not may payments under this section 13 that exceed the funds appropriated under paragraph $14 \quad(1)$.

(4) Disposition of Remaining Funds into 16 MIF.-Any funds appropriated under paragraph (1) 17 which remain available after the application of para18 graph (2) shall be deposited into the Medicaid Im19 provement Fund under section 1941 of the Social 20 Security Act.

21 (b) UsE OF Funds.-

22 (1) AUthority TO Make PAYMENTS.-From 23 the amounts available for obligation in a year under 24 subsection (a), the Secretary, acting through the Ad25 ministrator of the Centers for Medicare \& Medicaid 
1 Services, shall pay the amount determined under

2 paragraph (2) directly to an eligible dually-certified

3 facility for the purpose of providing funding to reim-

4 burse such facility for furnishing quality care to

$5 \quad$ Medicaid-eligible individuals.

(2) Determination of Payment amounts.-

(A) IN GENERAL.-Subject to subparagraphs (B) and (C), the payment amount determined under this paragraph for a year for an eligible dually-certified facility shall be an amount determined by the Secretary as reported on the facility's latest available Medicare cost report.

(B) Limitation on payment amount.In no case shall the payment amount for an eligible dually-certified facility for a year under subparagraph (A) be more than the payment deficit described in paragraph (3)(D) for such facility as reported on the facility's latest available Medicare cost report.

(C) Pro-rata Reduction.-If the amount available for obligation under subsection (a) for a year (as reduced by allowable administrative costs under this section) is insufficient to ensure that each eligible dually-cer- 
tified facility receives the amount of payment calculated under subparagraph (A), the Secretary shall reduce that amount of payment with respect to each such facility in a pro-rata manner to ensure that the entire amount avail-

able for such payments for the year be paid.

(D) No Required Match.-The Secretary may not require that a State provide matching funds for any payment made under this subsection.

(3) Eligible Dually-Certified Facility DeFINED.-For purposes of this section, the term "eligible dually-certified facility" means, for a cost reporting period ending during a year (beginning no earlier than 2010) that is covered by the latest available Medicare cost report, a nursing facility that meets all of the following requirements:

(A) The facility is participating as a nursing facility under title XIX of the Social Security Act and as a skilled nursing facility under title XVIII of such Act during the entire year. (B) The base Medicaid payment rate (excluding any supplemental payments) to the facility is not less than the base Medicaid pay- 
1110

ment rate (excluding any supplemental payments) to such facility as of June 16, 2009.

(C) As reported on the facility's latest Medicare cost report-

(i) the Medicaid share of patient days for such facility is not less than 60 percent of the combined Medicare and Medicaid share of resident days for such facility; and (ii) the combined Medicare and Medicaid share of resident days for such facility, as reported on the facility's latest available Medicare cost report, is not less than 75 percent of the total resident days for such facility.

(D) The facility has received Medicaid reimbursement (including any supplemental payments) for the provision of covered services to Medicaid eligible individuals, as reported on the facility's latest available Medicare cost report, that is significantly less (as determined by the Secretary) than the allowable costs (as determined by the Secretary) incurred by the facility in providing such services.

(E) The facility is not in the highest quartile of costs costs per day, as determined by the 
Secretary and as adjusted for case mix, wages, and type of facility.

(F) The facility provides quality care, as determined by the Secretary, to-

(i) Medicaid eligible individuals; and

(ii) individuals who are entitled to items and services under part A of title XVIII of the Social Security Act.

(G) In the most recent standard survey available, the facility was not cited for any immediate jeopardy deficiencies as defined by the Secretary.

(H) In the most recent standard survey available, the facility maintains an appropriate staffing level to attain or maintain the highest practicable well-being of each resident as defined by the Secretary

(I) The facility complies with all the requirements, as determined by the Secretary, contained in sections 1411 through 1416 and the amendments made by such sections.

(J) The facility was not listed as a Centers for Medicare \& Medicaid Services Special Focus Facility (SFF) nor as a SFF on a State-based list. 
(4) Frequency of payment.-Payment of an amount under this subsection to an eligible dually3 certified facility shall be made for a year in a lump 4 sum or in such periodic payments in such frequency 5 as the Secretary determines appropriate.

(A) shall be made directly by the Secretary to an eligible dually-certified facility or a contractor designated by such facility; and (B) shall not be made through a State.

15 basis to qualify as eligible dually-certified facilities 16 for payment under subsection (b).

17 (2) Contracting AUthority.-The Secretary 18 may enter into one or more contracts with entities 19 for the purpose of implementation of this section.

(3) Limitation.-The Secretary may not 21 spend more than 0.75 percent of the amount made 22 available under subsection (a) in any year on the 23 costs of administering the program of payments 24 under this section for the year. 
(4) Implementation.-Notwithstanding any

2 other provision of law, the Secretary may implement,

3 by program instruction or otherwise, the provisions

4 of this section.

(5) Limitations on Review.-There shall be 6 no administrative or judicial review of-

(A) the determination of the eligibility of a facility for payments under subsection (b); or (B) the determination of the amount of any payment made to a facility under such subsection.

12 (d) Annual Reports.-The Secretary shall submit 13 an annual report to the committees with jurisdiction in 14 the Congress on payments made under subsection (b). 15 Each such report shall include information on(1) the facilities receiving such payments; (2) the amount of such payments to such facili18 ties; and

(3) the basis for selecting such facilities and the 20 amount of such payments.

21 (e) Reference to Report.-For report by the 22 Medicaid and CHIP Payment and Access Commission on 23 the adequacy of payments to nursing facilities under the 24 Medicaid program, see section 1900(b)(2)(B) of the Social 25 Security Act, as amended by section 1784 . 
1 (f) Definitions.-For purposes of this section:

(1) Dually-certified Facility.-The term

3 "dually-certified facility" means a facility that is

4 participating as a nursing facility under title XIX of

5 the Social Security Act and as a skilled nursing fa-

6 cility under title XVIII of such Act.

(2) Medicaid eligible individual.-The

8 term "Medicaid eligible individual" means an indi-

9 vidual who is eligible for medical assistance, with re-

10 spect to nursing facility services (as defined in sec-

11 tion 1905(f) of the Social Security Act), under title

12 XIX of the such Act.

13 (3) STATE.-The term "State" means the 50

14 States and the District of Columbia.

15 SEC. 1746. REPORT ON MEDICAID PAYMENTS.

16 Section 1902 of the Social Security Act (42 U.S.C.

17 1396), as amended by sections 1703(a), 1714(a), and 18 1731(a), is amended by adding at the end the following 19 new subsection:

20 “(jj) Report on Medicaid Payments.-Each year, 21 on or before a date determined by the Secretary, a State 22 participating in the Medicaid program under this title 23 shall submit to the Administrator of the Centers for Medi24 care \& Medicaid Services- 
"(1) information on the determination of rates

2 of payment to providers for covered services under

3 the State plan, including-

"(A) the final rates;

"(B) the methodologies used to determine

such rates; and

"(C) justifications for the rates; and

"(2) an explanation of the process used by the

9 State to allow providers, beneficiaries and their rep-

10 resentatives, and other concerned State residents a

11 reasonable opportunity to review and comment on

12 such rates, methodologies, and justifications before

13 the State made such rates final.".

14 SEC. 1747. REVIEWS OF MEDICAID.

(a) GAO STUDY ON FMAP.—.

(1) STudy.-The Comptroller General of the

17 United States shall conduct a study regarding fed-

18 eral payments made to the State Medicaid programs

19 under title XIX of the Social Security Act for the

20 purposes of making recommendations to Congress.

(2) REPoRT.-Not later than February 15, 22 2011, the Comptroller General shall submit to the 23 appropriate committees of Congress a report on the 24 study conducted under paragraph (1) and the effect 
1 on the federal government, States, providers, and

2 beneficiaries of-

(A) removing the 50 percent floor, or 83 percent ceiling, or both, in the Federal medical assistance percentage under section 1905(b)(1) of the Social Security Act; and

(B) revising the current formula for such Federal medical assistance percentage to better reflect State fiscal capacity and State effort to pay for health and long-term care services and to better adjust for national or regional economic downturns.

(b) GaO Study on Medicaid Administrative

\section{Costs..-}

(1) STudy.-The Comptroller General of the

16 United States shall conduct a study of the adminis17 tration of the Medicaid program by the Department 18 of Health and Human Services, State Medicaid 19 agencies, and local government agencies. The report 20 shall address the following issues:

(A) The extent to which federal funds for each administrative function, such as survey and certification and claims processing, are 24 being used effectively and efficiently. 
(B) The administrative functions on which federal Medicaid funds are expended and the amounts of such expenditures (whether spent directly or by contract).

(2) REPORT.-Not later than February 15, 6 2011, the Comptroller General shall submit to the 7 appropriate committees of Congress a report on the $8 \quad$ study conducted under paragraph (1).

9 SEC. 1748. EXTENSION OF DELAY IN MANAGED CARE ORGANIZATION PROVIDER TAX ELIMINATION.

11 Effective as if included in the enactment of section 126051 of the Deficit Reduction Act of 2005 (Public Law 13 109-171), subsection (b)(2)(A) of such section is amended 14 by striking "October 1, 2009" and inserting "October 1, 15 2010".

16 SEC. 1749. EXTENSION OF ARRA INCREASE IN FMAP.

17 Section 5001 of the American Recovery and Reinvest18 ment Act of 2009 (Public Law 111-5) is amended-

(1) in subsection (a)(3), by striking "first cal20 endar quarter" and inserting "first 3 calendar quar21 ters";

(2) in subsection (b)(2), by inserting before the 23 period at the end the following: "and such para24 graph shall not apply to calendar quarters beginning 25 on or after October 1, 2010"; 
(3) in subsection (c)(4)(C)(ii), by striking "December 2009" and "January 2010" and inserting "June 2010" and "July 2010", respectively;

(4) in subsection (d), by inserting "ending before October 1, 2010" after "entire fiscal years" and 6 after "with respect to fiscal years";

(5) in subsection $(\mathrm{g})(1)$, by striking "September 30, 2011" and inserting "December 31, 2011"; and

(6) in subsection (h)(3), by striking "'December 31, 2010" and inserting "June 30, 2011".

\section{SEC. 1751. HEALTH CARE ACQUIRED CONDITIONS.}

(a) Medicaid Non-Payment for Certain Health

15 Care-ACquired Conditions.-Section 1903(i) of the 16 Social Security Act (42 U.S.C. 1396b(i)) is amended17 (1) by striking "or" at the end of paragraph $18 \quad(23)$;

19 (2) by striking the period at the end of para20 graph (24) and inserting "; or"; and

21 (3) by inserting after paragraph (24) the fol22 lowing new paragraph:

"(25) with respect to amounts expended for 24 services related to the presence of a condition that 25 could be identified by a secondary diagnostic code 
1 described in section 1886(d)(4)(D)(iv) and for any

2 health care acquired condition determined as a non$3 \quad$ covered service under title XVIII.".

4 (b) Application to CHIP.—Section 2107(e)(1)(G)

5 of such Act (42 U.S.C. $1397 \mathrm{gg}(\mathrm{e})(1)(\mathrm{G})$ ) is amended by 6 striking "and (17)" and inserting "(17), and (25)".

7 (c) Permission to Include Additional Health 8 Care-acquired Conditions.-Nothing in this section 9 shall prevent a State from including additional health 10 care-acquired conditions for non-payment in its Medicaid 11 program under title XIX of the Social Security Act.

12 (d) EFFECTive Date.-The amendments made by 13 this section shall apply to discharges occurring on or after 14 January 1, 2010.

15 SEC. 1752. EVALUATIONS AND REPORTS REQUIRED UNDER MEDICAID INTEGRITY PROGRAM.

17 Section $1936(\mathrm{c})(2)$ ) of the Social Security Act (42 18 U.S.C. $1396 \mathrm{u}-7(\mathrm{c})(2))$ is amended-

19 (1) by redesignating subparagraph (D) as sub20 paragraph $(\mathrm{E})$; and

21 (2) by inserting after subparagraph (C) the fol22 lowing new subparagraph:

"(D) For the contract year beginning in 2011 and each subsequent contract year, the 25 entity provides assurances to the satisfaction of 
the Secretary that the entity will conduct periodic evaluations of the effectiveness of the activities carried out by such entity under the Program and will submit to the Secretary an annual report on such activities.".

6 SEC. 1753. REQUIRE PROVIDERS AND SUPPLIERS TO ADOPT PROGRAMS TO REDUCE WASTE, FRAUD, AND ABUSE.

9 Section $1902(\mathrm{a})$ of such Act (42 U.S.C. 42 U.S.C.

10 1396a(a)), as amended by sections 1631(b)(1), 1703, and 11 1729, is further amended-

(2) in paragraph (76), by striking at the end 15 the period and inserting "; and"; and

16 (3) by inserting after paragraph (76) the fol17 lowing new paragraph: "(77) provide that any provider or supplier 19 (other than a physician or nursing facility) providing 20 services under such plan shall, subject to paragraph 21 (5) of section 1874(d), establish a compliance pro22 gram described in paragraph (1) of such section in 23 accordance with such section.". 
1 SEC. 1754. OVERPAYMENTS.

2 (a) In General.-Section 1903(d)(2)(C) of the So3 cial Security Act (42 U.S.C. $1396 \mathrm{~b}(\mathrm{~d})(2)(\mathrm{C})$ ) is amend4 ed-

5

6

7

8

9

10

11 subsection (a) shall apply in the case of overpayments dis-

12 covered on or after the date of the enactment of this Act.

13 SEC. 1755. MANAGED CARE ORGANIZATIONS.

14

15

16

17

18

19

20

21

22

23

24

25 (a) Minimum Medical Loss Ratio.-

(1) Medicaid.-Section 1903(m)(2)(A) of the Social Security Act (42 U.S.C. 1396b(m)(2)(A)), as amended by section $1743(\mathrm{a})(3)$, is amended-

(A) by striking "and" at the end of clause (xii);

(B) by striking the period at the end of clause (xiii) and inserting "; and"; and

(C) by adding at the end the following new clause:

"(xiv) such contract has a medical loss ratio, as determined in accordance with a methodology speci- 
1 fied by the Secretary that is a percentage (not less

2 than 85 percent) as specified by the Secretary.".

(2) CHIP.—Section 2107(e)(1) of such Act (42

$4 \quad$ U.S.C. $1397 \mathrm{gg}(\mathrm{e})(1))$ is amended-

(A) by redesignating subparagraphs $(\mathrm{H})$ through (L) as subparagraphs (I) through (M); and

(B) by inserting after subparagraph (G) the following new subparagraph:

“(H) Section 1903(m)(2)(A)(xiv) (relating to application of minimum loss ratios), with respect to comparable contracts under this title.". (3) EFfective DaTE.-The amendments made by this subsection shall apply to contracts entered into or renewed on or after July 1, 2010.

(b) Patient Encounter Data.-

(1) In GENERAL.—Section 1903(m)(2)(A)(xi) of the Social Security Act (42 U.S.C. $1396 \mathrm{~b}(\mathrm{~m})(2)(\mathrm{A})(\mathrm{xi}))$ is amended by inserting "and for the provision of such data to the State at a frequency and level of detail to be specified by the Secretary" after "patients".

(2) Effective Date.-The amendment made by paragraph (1) shall apply with respect to contract years beginning on or after January 1, 2010. 
1123

1 SEC. 1756. TERMINATION OF PROVIDER PARTICIPATION UNDER MEDICAID AND CHIP IF TERMINATED UNDER MEDICARE OR OTHER STATE PLAN OR CHILD HEALTH PLAN.

(a) State Plan Requirement.-Section

6 1902(a)(39) of the Social Security Act (42 U.S.C. 42

7 U.S.C. $1396 \mathrm{a}(\mathrm{a}))$ is amended by inserting after "1128A,"

8 the following: "terminate the participation of any indi-

9 vidual or entity in such program if (subject to such excep-

10 tions are permitted with respect to exclusion under sec-

11 tions 1128(b)(3)(C) and 1128(d)(3)(B)) participation of

12 such individual or entity is terminated under title XVIII,

13 any other State plan under this title, or any child health

14 plan under title XXI,".

15 (b) Application to CHIP.-Section 2107(e)(1)(A)

16 of such Act (42 U.S.C. $1397 \mathrm{gg}(\mathrm{e})(1)(\mathrm{A})$ ) is amended by

17 inserting before the period at the end the following: "and

18 section 1902(a)(39) (relating to exclusion and termination

19 of participation)".

20 (c) EFFECTIVE Date.-Except as provided in section

21 1790, the amendments made by this section shall apply

22 to services furnished on or after January 1, 2011, without

23 regard to whether or not final regulations to carry out

24 such amendments have been promulgated by such date. 
1 SEC. 1757. MEDICAID AND CHIP EXCLUSION FROM PARTICIPATION RELATING TO CERTAIN OWNERSHIP, CONTROL, AND MANAGEMENT AFFILIATIONS.

4 (a) State Plan Requirement.-Section 1902(a)

5 of the Social Security Act (42 U.S.C. 1396a(a)), as

6 amended by sections 1631(b)(1), 1703(a), 1729, and

7 1753, is further amended-

(1) in paragraph (76), by striking at the end $9 \quad$ "and";

(2) in paragraph (77), by striking at the end

11 the period and inserting "; and"; and

(3) by inserting after paragraph (77) the fol-

13 lowing new paragraph:

“(78) provide that the State agency described

15 in paragraph (9) exclude, with respect to a period,

16 any individual or entity from participation in the

17 program under the State plan if such individual or

18 entity owns, controls, or manages an entity that (or

19 if such entity is owned, controlled, or managed by an

20 individual or entity that)-

"(A) has unpaid overpayments under this title during such period determined by the Secretary or the State agency to be delinquent;

"(B) is suspended or excluded from participation under or whose participation is terminated under this title during such period; or 
"(C) is affiliated with an individual or entity that has been suspended or excluded from participation under this title or whose participation is terminated under this title during such period.".

6 (b) Child Health Plan Requirement.-Section $72107(\mathrm{e})(1)(\mathrm{A})$ of such Act (42 U.S.C. $1397 \mathrm{gg}(\mathrm{e})(1)(\mathrm{A})$ ), 8 as amended by section $1756(\mathrm{~b})$, is amended by striking 9 "section 1902(a)(39)" and inserting "sections 10 1902(a)(39) and 1902(a)(78)".

11 (c) EfFective Date.-Except as provided in section 12 1790, the amendments made by this section shall apply 13 to services furnished on or after January 1, 2011, without 14 regard to whether or not final regulations to carry out 15 such amendments have been promulgated by such date. 16 SEC. 1758. REQUIREMENT TO REPORT EXPANDED SET OF DATA ELEMENTS UNDER MMIS TO DETECT FRAUD AND ABUSE.

19 Section 1903(r)(1)(F) of the Social Security Act (42 20 U.S.C. 1396b(r)(1)(F)) is amended by inserting after 21 "necessary" the following: "and including, for data sub22 mitted to the Secretary on or after July 1, 2010, data 23 elements from the automated data system that the Sec24 retary determines to be necessary for detection of waste, 25 fraud, and abuse". 
1126

1 SEC. 1759. BILLING AGENTS, CLEARINGHOUSES, OR OTHER

ALTERNATE PAYEES REQUIRED TO REGISTER UNDER MEDICAID.

4 (a) In GeneraL.-Section 1902(a) of the Social Se5 curity Act (42 U.S.C. 42 U.S.C. 1396a(a)), as amended 6 by sections 1631(b), 1703(a), 1729, 1753, and 1757(a), 7 is further amended-

(1) in paragraph (77); by striking at the end 9 "and";

10 (2) in paragraph (78), by striking the period at

11 the end and inserting "and"; and

12

(3) by inserting after paragraph (78) the fol-

13 lowing new paragraph:

“(79) provide that any agent, clearinghouse, or

15 other alternate payee that submits claims on behalf 16 of a health care provider must register with the 17 State and the Secretary in a form and manner speci18 fied by the Secretary under section 1866(j)(1)(D).'.

19 (b) Denial of Payment.-Section 1903(i) of such 20 Act (42 U.S.C. 1396b(i)), as amended by section 1751, 21 is amended-

22 (1) by striking "or" at the end of paragraph $23 \quad(24)$;

(2) by striking the period at the end of para25 graph (25) and inserting "; or"; and 
(3) by inserting after paragraph (25) the fol-

2 lowing new paragraph:

"(26) with respect to any amount paid to a bill-

4 ing agent, clearinghouse, or other alternate payee

5 that is not registered with the State and the Sec-

6 retary as required under section 1902(a)(79).".

7 (c) EFFective Date._Except as provided in section

8 1790, the amendments made by this section shall apply

9 to claims submitted on or after January 1, 2012, without

10 regard to whether or not final regulations to carry out

11 such amendments have been promulgated by such date.

12 SEC. 1760. DENIAL OF PAYMENTS FOR LITIGATION-RE-

LATED MISCONDUCT.

14 (a) In GENERAL.-Section 1903(i) of the Social Se-

15 curity Act (42 U.S.C. 1396b(i)), as amended by sections

$161751(\mathrm{a})$ and $1759(\mathrm{~b})$, is amended-

17 (1) by striking "or" at the end of paragraph $18 \quad(25)$;

19 (2) by striking the period at the end of para20 graph (26) and inserting "; or"; and

21 (3) by inserting after paragraph (26) the fol22 lowing new paragraph:

23 "(27) with respect to any amount expended- 
"(A) on litigation in which a court imposes sanctions on the State, its employees, or its counsel for litigation-related misconduct; or "(B) to reimburse (or otherwise compensate) a managed care entity for payment of legal expenses associated with any action in which a court imposes sanctions on the managed care entity for litigation-related misconduct.".

10 (b) EFFECTIVE Date.-The amendments made by 11 subsection (a) shall apply to amounts expended on or after 12 January 1, 2010.

13 SEC. 1761. MANDATORY STATE USE OF NATIONAL CORRECT CODING INITIATIVE.

15 Section $1903(\mathrm{r})$ of the Social Security Act (42 U.S.C.

$161396 \mathrm{~b}(\mathrm{r}))$ is amended-

(1) in paragraph $(1)(B)-$

(A) in clause (ii), by striking "and" at the end;

(B) in clause (iii), by adding "and" at the end; and clause: 
14 shall do the following:

"(A) Identify those methodologies of the Na-

16 tional Correct Coding Initiative administered by the 17 Secretary (or any successor initiative to promote cor18 rect coding and to control improper coding leading 19 to inappropriate payment) which are compatible to 20 claims filed under this title.

ible methodologies of the National Correct Coding Initiative administered by the Secretary (or any successor initiative to promote correct coding and to control improper coding leading to inappropriate payment) and such other methodologies of that Initiative (or such other national correct coding methodologies) as the Secretary identifies in accordance with paragraph (4);"; and

(2) by adding at the end the following new paragraph:

“(4) Not later than September 1, 2010, the Secretary “(B) Identify those methodologies of such Initiative (or such other national correct coding methodologies) that should be incorporated into claims filed under this title with respect to items or services for which States provide medical assistance under 
1 this title and no national correct coding methodolo-

2 gies have been established under such Initiative with

3 respect to title XVIII.

"(C) Notify States of-

"(i) the methodologies identified under

subparagraphs (A) and (B) (and of any other

national correct coding methodologies identified

under subparagraph (B)); and

"(ii) how States are to incorporate such methodologies into claims filed under this title.

"(D) Submit a report to Congress that includes

12 the notice to States under subparagraph (C) and an

13 analysis supporting the identification of the meth14 odologies made under subparagraphs (A) and (B).".

15 Subtitle G-Payments to the

17 SEC. 1771. PAYMENT TO TERRITORIES.

18 (a) INCREASE IN CAP.-Section 1108 of the Social 19 Security Act (42 U.S.C. 1308) is amended-

(1) in subsection (f), by striking "subsection

21 (g)" and inserting "subsections (g) and (h)";

22 (2) in subsection $(\mathrm{g})(1)$, by striking "With re23 spect to" and inserting "Subject to subsection (h), 24 with respect to"; and 
1131

(3) by adding at the end the following new sub-

2 section:

3 “(h) AdDitional Increase for Fiscal Years

42011 Through 2019. - Subject to section 347(b)(1) of

5 the Affordable Health Care for America Act, with respect

6 to fiscal years 2011 through 2019, the amounts otherwise

7 determined under subsections (f) and (g) for Puerto Rico,

8 the Virgin Islands, Guam, the Northern Mariana Islands

9 and American Samoa shall be increased by the following

10 amounts:

11 “(1) For Puerto Rico, for fiscal year 2011,

$12 \$ 727,600,000$; for fiscal year 2012, $\$ 775,000,000$;

13 for fiscal year 2013, \$850,000,000; for fiscal year

$142014, \$ 925,000,000$; for fiscal year 2015,

$15 \$ 1,000,000,000 ;$ for fiscal year 2016,

$16 \$ 1,075,000,000 ;$ for fiscal year 2017,

$17 \$ 1,150,000,000 ;$ for fiscal year 2018,

$18 \$ 1,225,000,000$; and for fiscal year 2019,

$19 \$ 1,396,400,000$.

20 "(2) For the Virgin Islands, for fiscal year

$212011, \$ 34,000,000$; for fiscal year 2012,

$22 \$ 37,000,000$; for fiscal year $2013, \$ 40,000,000$; for

23 fiscal year 2014, $\$ 43,000,000$; for fiscal year 2015 ,

$24 \$ 46,000,000$; for fiscal year 2016, $\$ 49,000,000$; for 
1 fiscal year 2017, $\$ 52,000,000$; for fiscal year 2018, $2 \$ 55,000,000$; and for fiscal year $2019, \$ 58,000,000$. “(3) For Guam, for fiscal year 2011, $4 \$ 34,000,000$; for fiscal year 2012, $\$ 37,000,000$; for 5 fiscal year 2013, $\$ 40,000,000$; for fiscal year 2014 , $6 \$ 43,000,000$; for fiscal year $2015, \$ 46,000,000$; for 7 fiscal year 2016, $\$ 49,000,000$; for fiscal year 2017, $8 \$ 52,000,000$; for fiscal year 2018, $\$ 55,000,000$; and 9 for fiscal year $2019, \$ 58,000,000$.

10 “(4) For the Northern Mariana Islands, for fis11 cal year 2011, $\$ 13,500,000$; fiscal year 2012, $12 \$ 14,500,000$; for fiscal year $2013, \$ 15,500,000$; for 13 fiscal year 2014, \$16,500,000; for fiscal year 2015, $14 \$ 17,500,000$; for fiscal year $2016, \$ 18,500,000$; for 15 fiscal year 2017, $\$ 19,500,000$; for fiscal year 2018, $16 \$ 21,000,000$; and for fiscal year 2019, $\$ 22,000,000$. 17 “(5) For American Samoa, fiscal year 2011, $18 \$ 22,000,000$; fiscal year $2012, \$ 23,687,500$; for fis19 cal year 2013, $\$ 24,687,500$; for fiscal year 2014, $20 \$ 25,687,500$; for fiscal year $2015, \$ 26,687,500$; for 21 fiscal year 2016, $\$ 27,687,500$; for fiscal year 2017, $22 \$ 28,687,500$; for fiscal year $2018, \$ 29,687,500$; and 23 for fiscal year $2019, \$ 30,687,500 . ”$.

24 (b) Report on Achieving Medicaid Parity Pay25 ments Beginning With Fiscal Year 2020.- 
(1) In GENERAL.-Not later than October 1, 2 2013, the Secretary of Health and Human Services 3 shall submit to Congress a report that details a plan 4 for the transition of each territory to full parity in 5 Medicaid with the 50 States and the District of Co6 lumbia in fiscal year 2020 by modifying their exist7 ing Medicaid programs and outlining actions the 8 Secretary and the governments of each territory 9 must take by fiscal year 2020 to ensure parity in fi10 nancing. Such report shall include what the Federal 11 medical assistance percentages would be for each 12 territory if the formula applicable to the 50 States 13 were applied. Such report shall also include any rec14 ommendations that the Secretary may have as to 15 whether the mandatory ceiling amounts for each ter16 ritory provided for in section 1108 of the Social Se17 curity Act (42 U.S.C. 1308) should be increased any 18 time before fiscal year 2020 due to any factors that 19 the Secretary deems relevant.

20 (2) Per CAPITA DATA.-As part of such report 21 the Secretary shall include information about per 22 capita income data that could be used to calculate 23 Federal medical assistance percentages under section $24 \quad 1905(b)$ of the Social Security Act, under section $251108(\mathrm{a})(8)(\mathrm{B})$ of such Act, for each territory on how 
1 such data differ from the per capita income data

2 used to promulgate Federal medical assistance per-

3 centages for the 50 States. The report under this

4 subsection shall include recommendations on how

5 the Federal medical assistance percentages can be

6 calculated for the territories beginning in fiscal year

72020 to ensure parity with the 50 States.

8 (3) Subsequent REPorts.-The Secretary

9 shall submit subsequent reports to Congress in

102015,2017 , and 2019 detailing the progress that

11 the Secretary and the governments of each territory

12 have made in fulfilling the actions outlined in the

13 plan submitted under paragraph (1).

14 (c) Application OF FMAP FOR ADDitional 15 Funds.-Section 1905(b) of such Act (42 U.S.C.

$161396 \mathrm{~d}(\mathrm{~b}))$ is amended by adding at the end the following

17 sentence: "Notwithstanding the first sentence of this sub-

18 section and any other provision of law, for fiscal years

192011 through 2019, the Federal medical assistance per-

20 centage for Puerto Rico, the Virgin Islands, Guam, the

21 Northern Mariana Islands, and American Samoa shall be

22 the highest Federal medical assistance percentage applica-

23 ble to any of the 50 States or the District of Columbia

24 for the fiscal year involved, taking into account the appli-

25 cation of subsections (a) and (b)(1) of section 5001 of di- 
1 vision $\mathrm{B}$ of the American Recovery and Reinvestment Act 2 of 2009 (Public Law 111-5) to such States and the Dis3 trict for calendar quarters during such fiscal years for 4 which such subsections apply.".

5 (d) WAIVERS.-

6 (1) IN GENERAL.-Section 1902(j) of the Social 7 Security Act (42 U.S.C. 1396a(j)) is amended-

8 (A) by striking "American Samoa and the 9 Northern Mariana Islands" and inserting 10 "Puerto Rico, the Virgin Islands, Guam, the 11 Northern Mariana Islands, and American 12 Samoa"; and

(B) by striking "American Samoa or the Northern Mariana Islands" and inserting "Puerto Rico, the Virgin Islands, Guam, the 16 Northern Mariana Islands, or American 17 Samoa".

18 (2) EFFECTIVE DATE.-The amendments made 19 by paragraph (1) shall apply beginning with fiscal 20 year 2011.

21 (e) Technical Assistance.-The Secretary shall 22 provide nonmonetary technical assistance to the govern23 ments of Puerto Rico, the Virgin Islands, Guam, the 24 Northern Mariana Islands, and American Samoa in up25 grading their existing computer systems in order to antici- 
1 pate meeting reporting requirements necessary to imple-

2 ment the plan contained in the report under subsection 3 (b)(1).

\section{$4 \quad$ Subtitle $\mathbf{H}$-Miscellaneous}

5 SEC. 1781. TECHNICAL CORRECTIONS.

6 (a) Technical Correction to Section 1144 of

7 The Social SEcurity ACT.-The first sentence of sec-

8 tion 1144(c)(3) of the Social Security Act (42 U.S.C.

$91320 \mathrm{~b}-14(\mathrm{c})(3))$ is amended-

10 (1) by striking "transmittal”; and

11 (2) by inserting before the period the following:

12 "as specified in section 1935(a)(4)".

13 (b) Cluarifying Amendment to Section 1935 of

14 The Soctal Security ACT.-Section 1935(a)(4) of the

15 Social Security Act (42 U.S.C. 1396u-5(a)(4)), as

16 amended by section 113(b) of Public Law 110-275, is 17 amended-

(1) by striking the second sentence;

(2) by redesignating the first sentence as a sub-

20 paragraph (A) with appropriate indentation and 21 with the following heading: "IN GENERAL._-";

22 (3) by adding at the end the following subpara23 graphs:

“(B) Furnishing medical assistance 25 WITH REASONABLE PROMPTNESS.-For the 
purpose of a State's obligation under section $1902(\mathrm{a})(8)$ to furnish medical assistance with reasonable promptness, the date of the electronic transmission of low-income subsidy program data, as described in section 1144(c), from the Commissioner of Social Security to the State Medicaid Agency, shall constitute the date of filing of such application for benefits under the Medicare Savings Program.

“(C) Determining availability OF MEDICAL ASSISTANCE.-For the purpose of determining when medical assistance will be made available, the State shall consider the date of the individual's application for the low income subsidy program to constitute the date of filing for benefits under the Medicare Savings Pro17 gram.”.

18 (c) EfFective Date Relating to Medicaid 19 Agency Consideration of Low-income Subsidy Ap20 plication and Data Transmittal.-The amendments 21 made by subsections (a) and (b) shall be effective as if 22 included in the enactment of section 113(b) of Public Law $23 \quad 110-275$.

24 (d) Technical Correction to Section 605 of 25 CHIPRA.-Section 605 of the Children's Health Insur- 
1 ance Program Reauthorization Act of 2009 (Public Law

2 111-3) is amended by striking "legal residents" and in3 serting "lawfully residing in the United States".

4 (e) Technical Correction to Section 1905 of

5 The Social Security Act.-Section 1905(a) of the So6 cial Security Act (42 U.S.C. 1396d(a)) is amended by in7 serting "or the care and services themselves, or both" be8 fore "(if provided in or after".

9 (f) Clarifying Amendment to Section 1115 of 10 The Social Security Act.-Section 1115(a) of the So11 cial Security Act (42 U.S.C. 1315(a)) is amended by add12 ing at the end the following: "If an experimental, pilot, 13 or demonstration project that relates to title XIX is ap14 proved pursuant to any part of this subsection, such 15 project shall be treated as part of the State plan, all med16 ical assistance provided on behalf of any individuals af17 fected by such project shall be medical assistance provided 18 under the State plan, and all provisions of this Act not 19 explicitly waived in approving such project shall remain 20 fully applicable to all individuals receiving benefits under 21 the State plan.".

22 SEC. 1782. EXTENSION OF QI PROGRAM.

23 (a) In GeneraL.-Section 1902(a)(10)(E)(iv) of the 24 Social Security Act (42 U.S.C. 1396b(a)(10)(E)(iv)) is 25 amended- 
1139

1 (1) by striking "sections 1933 and" and by in$2 \quad$ serting "section"; and

(2) by striking "December 2010" and inserting 4 "December 2012".

5 (b) Elimination of Funding Limitation.-

6 (1) In GENERAL.-Section 1933 of such Act 7 (42 U.S.C. $1396 u-3)$ is amended-

23 by paragraph (1) shall take effect on January 1, 242011. and $(\mathrm{g})$;

(C) in subsection (d), by striking "furnished in a State" and all that follows and inserting "the Federal medical assistance percentage shall be equal to 100 percent."; and

(D) by redesignating subsections (d) and (f) as subsections (b) and (c), respectively.

(2) Conforming amendment.-Section 1905(b) of such Act (42 U.S.C. 1396d(b)) is amended by striking "1933(d)" and inserting "1933(b)". (3) Effective Date.-The amendments made 
1 SEC. 1783. ASSURING TRANSPARENCY OF INFORMATION.

2 (a) In General.- Section 1902(a) of the Social Se3 curity Act (42 U.S.C. 1396a(a)), as amended by sections 4 1631(b), 1703(a), 1729, 1753, 1757(a), 1759(a), and 5 1907(b), is amended-

(1) by striking "and" at the end of paragraph

7

11 lowing new paragraph:

12

22 referred to in section 1902(a)(81) are that the laws of a 23 State must-

"(1) require reporting to the State (or its

"(81) provide that the State will establish and maintain laws, in accordance with the requirements of section 1921A, to require disclosure of information on hospital charges and quality and to make such information available to the public and the Secretary."; and

(4) by inserting after section 1921 the following new section:

"HOSPITAL PRICE TRANSPARENCY

"SEC. 1921A. (a) In GENERAL.—The requirements agent) by each hospital located therein, of information on,- - 


\section{1}

"(A) the charges for the most common inpatient and outpatient hospital services;

"(B) the Medicare and Medicaid reimbursement amount for such services; and

"(C) if the hospitals allows for or provides reduced charges for individuals based on financial need, the factors considered in making determinations for reductions in charges, including any formula for such determination and the contact information for the specific department of a hospital that responds to such inquiries;

“(2) provide for notice to individuals seeking or requiring such services of the availability of information on charges described in paragraph (1);

“(3) provide for timely access to such information, including at least through an Internet website, by individuals seeking or requiring such services; and

“(4) provide for timely access to information regarding the quality of care at each hospital made publicly available in accordance with section 501 of the Medicare Prescription Drug, Improvement, and Modernization Act of 2003 (Public Law 108-173), section 1139A, or section 1139B. 
1 The Secretary shall consult with stakeholders (including

2 those entities in section 1808(d)(6) and the National Gov-

3 ernors Association) through a formal process to obtain

4 guidance prior to issuing implementing policies under this

5 section.

6 “(b) Hospital Defined.-For purposes of this sec-

7 tion, the term 'hospital' means an institution that meets

8 the requirements of paragraphs (1) and (7) of section

9 1861(e) and includes those to which section 1820(c) ap10 plies.".

11 (b) Effective Date; Administration.-

12 (1) In GENERAL.-Except as provided in para13 graphs (2)(B) and section 1790, the amendments 14 made by subsection (a) shall take effect on October $15 \quad 1,2010$.

(2) Existing PRograms.-

(A) In GENERAL.-The Secretary of Health and Human Services shall establish a process by which a State with an existing program may certify to the Secretary that its program satisfies the requirements of section 1921A of the Social Security Act, as inserted by subsection (a).

(B) 2-YEAR PERIOD TO BECOME IN COMPLIANCE.- States that, as of the date of the en- 
1143

actment of this Act, administer hospital price transparency policies that do not meet such requirements shall have 2 years from such date to make necessary modifications to come into compliance and shall not be regarded as failing to comply with such requirements during such 2year period.

8 SEC. 1784. MEDICAID AND CHIP PAYMENT AND ACCESS COMMISSION.

12 U.S.C. $1396(\mathrm{~b}))$ is amended by adding at the end the fol-

13 lowing new paragraph:

“(10) Reports ON SPECIAL topics ON PAYMENT POLICIES.CIES.-Not later than January 1, 2012, the Commission shall submit to Congress a report on nursing facility payment policies under Medicaid that includes-

"(i) information on the difference between the amount paid by each State to nursing facilities in such State under the Medicaid program under this title and the cost to such facilities of providing efficient 
quality care to Medicaid eligible individuals;

“(ii) an evaluation of patient outcomes and quality as a result of the supplemental payments under section 1745(b) of the Affordable Health Care for America Act; and

"(iii) whether adjustments should be made under the Medicaid program to the rates that States pay skilled nursing facilities to ensure that such rates are sufficient to provide efficient quality care to Medicaid eligible individuals.".

(b) Pediatric Subspeclalist Payment Poli15 CIES.-Section 1900(b)(10) of the Social Security Act, as 16 added by subsection (a) is amended by adding at the end 17 the following new subparagraph: POLICIES.-Not later than January 1, 2011, the Commission shall submit to Congress a report on payment policies for pediatric subspecialist services under Medicaid that in25

"(i) a comprehensive review of each State's Medicaid payment rates for inpa- 
tient and outpatient pediatric speciality services;

“(ii) a comparison, on a State-byState basis, of the rates under clause (i) to "(v) recommendations to ameliorate
any problems found with such payment "(v) recommendations to ameliorate
any problems found with such payment rates or with access to such services.". Medicare payments for similar services;

"(iii) information on any limitations in patient access to pediatric speciality care, such as delays in receiving care or wait times for receiving care;

"(iv) an analysis of the extent to which low Medicaid payment rates in any State contributes to limits in access to pediatric subspecialty services in such State; and

\section{(c) Additional Amendments.-}

(1) Commission status.-Section 1900(a) of the Social Security Act is amended by inserting "as an agency of Congress" after "established".

24 by striking "children's access" and inserting "access 
1 by low-income children and other eligible individ2 uals".

(3) Change in Report deadlines.--Subpara4 graphs (C) and (D) of section 1900(b)(1) of such 5 Act are amended by striking "2010" and inserting $6 \quad$ "2011" each place it appears.

(4) Report in health REFORM.-Section 1900(b)(2) of such Act is amended"skilled";

(A) in subparagraph (A)(i), by striking (B) by striking subparagraph (B);

(C) by redesignating subparagraph (C) as subparagraph (B); and

(D) by adding at the end the following new subparagraph:

"(C) Implementation OF health REFORM.-The implementation of the provisions of the Affordable Health Care for America Act that relate to Medicaid or CHIP by the Secretary, the Health Choices Commissioner, and the States, including the effect of such implementation on the access to needed health care items and services by low-income individuals and families.'. 
(5) Clanification of Membership.-Section 1900(c)(2)(B) of such Act is amended by striking

3 "consumers" and inserting "individuals".

(6) Authorization of appropriations.-

SEC. 1785. OUTREACH AND ENROLLMENT OF MEDICAID AND CHIP ELIGIBLE INDIVIDUALS.

25 date of enactment of this Act, the Secretary of Health and 
1 Human Services shall issue guidance regarding standards

2 and best practices for conducting outreach to inform eligi-

3 ble individuals about healthcare coverage under Medicaid

4 under title XIX of the Social Security Act or for child

5 health assistance under CHIP under title XXI of such

6 Act, providing assistance to such individuals for enroll-

7 ment in applicable programs, and establishing methods or

8 procedures for eliminating application and enrollment bar-

9 riers. Such guidance shall include provisions to ensure

10 that outreach, enrollment assistance, and administrative

11 simplification efforts are targeted specifically to vulnerable

12 populations such as children, unaccompanied homeless

13 youth, victims of abuse or trauma, individuals with mental

14 health or substance related disorders, and individuals with

15 HIV/AIDS. Guidance issued pursuant to this section re-

16 lating to methods to increase outreach and enrollment pro-

17 vided for under titles XIX and XXI of the Social Security

18 Act shall specifically target such vulnerable and under-

19 served populations and shall include, but not be limited

20 to, guidance on outstationing of eligibility workers, express

21 lane eligibility, residence requirements, documentation of

22 income and assets, presumptive eligibility, continuous eli-

23 gibility, and automatic renewal.

24 (b) Implementation.-In implementing the re25 quirements under subsection (a), the Secretary may use 
1 such authorities as are available under law and may work

2 with such entities as the Secretary deems appropriate to

3 facilitate effective implementation of such programs. Not

4 later than 2 years after the enactment of this Act and

5 annually thereafter, the Secretary shall review and report

6 to Congress on progress in implementing targeted out-

7 reach, application and enrollment assistance, and adminis-

8 trative simplification methods for such vulnerable and un-

9 derserved populations as are specified in subsection (a).

10 SEC. 1786. PROHIBITIONS ON FEDERAL MEDICAID AND

11 CHIP PAYMENT FOR UNDOCUMENTED

12 ALIENS.

13 Nothing in this title shall change current prohibitions

14 against Federal Medicaid and CHIP payments under titles

15 XIX and XXI of the Social Security Act on behalf of indi-

16 viduals who are not lawfully present in the United States.

17 SEC. 1787. DEMONSTRATION PROJECT FOR STABILIZATION

18 OF EMERGENCY MEDICAL CONDITIONS BY INSTITUTIONS FOR MENTAL DISEASES.

20 (a) Authority To COnduct Demonstration

21 Project.-The Secretary of Health and Human Services

22 (in this section referred to as the "Secretary") shall estab-

23 lish a demonstration project under which an eligible State

24 (as described in subsection (c)) shall provide reimburse25 ment under the State Medicaid plan under title XIX of 
1 the Social Security Act to an institution for mental dis2 eases that is subject to the requirements of section 1867 3 of the Social Security Act (42 U.S.C. 1395dd) for the pro4 vision of medical assistance available under such plan to 5 an individual who-

6 (1) has attained age 21, but has not attained $7 \quad$ age 65 ;

8 (2) is eligible for medical assistance under such 9 plan; and

10 (3) requires such medical assistance to stabilize 11 an emergency medical condition.

12 (b) IN-STAY Review.-The Secretary shall establish 13 a mechanism for in-stay review to determine whether or 14 not the patient has been stabilized (as defined in sub15 section (h)(5)). This mechanism shall commence before 16 the third day of the inpatient stay. States participating 17 in the demonstration project may manage the provision 18 of these benefits under the project through utilization re19 view, authorization, or management practices, or the ap20 plication of medical necessity and appropriateness criteria 21 applicable to behavioral health.

22 (c) Eligible State Defined.-

23 (1) Application.-Upon approval of an appli24 cation submitted by a State described in paragraph 25 (2), the State shall be an eligible State for purposes 
1 of conducting a demonstration project under this

2 section.

3 (2) State Described.- States shall be se-

4 lected by the Secretary in a manner so as to provide

5 geographic diversity on the basis of the application

6 to conduct a demonstration project under this sec-

$7 \quad$ tion submitted by such States.

8 (d) Length of Demonstration Project.-The

9 demonstration project established under this section shall

10 be conducted for a period of 3 consecutive years.

11 (e) Limitations on Federal Funding.-

(1) Appropriation.-

(A) In GENERAL.-Out of any funds in the Treasury not otherwise appropriated, there is appropriated to carry out this section, $\$ 75,000,000$ for fiscal year 2010 .

(B) Budget AUTHORITY.-Subparagraph (A) constitutes budget authority in advance of appropriations Act and represents the obligation of the Federal Government to provide for the payment of the amounts appropriated under that subparagraph.

(2) 3-Year availability.-Funds appro24 priated under paragraph (1) shall remain available 25 for obligation through December 31, 2012. 
(3) Limitation on Payments.-In no case

(A) the aggregate amount of payments made by the Secretary to eligible States under this section exceed $\$ 75,000,000$; or

(B) payments be provided by the Secretary under this section after December 31, 2012.

8

(4) Funds allocated to states.-The Secretary shall allocate funds to eligible States based on their applications and the availability of funds.

15 penditures in the quarter for medical assistance de16 scribed in subsection (a).

17 (f) REPORTS.-

(1) Annual Progress Reports.-The Sec19 retary shall submit annual reports to Congress on 20 the progress of the demonstration project conducted 21 under this section.

(2) Final Report and Recommendation.-

23 An evaluation shall be conducted of the demonstra24 tion project's impact on the functioning of the health 25 and mental health service system and on individuals 
1 enrolled in the Medicaid program. This evaluation

2 shall include collection of baseline data for one-year

3 prior to the initiation of the demonstration project

4 as well as collection of data from matched compari-

5 son states not participating in the demonstration.

6 The evaluation measures shall include the following:

(A) A determination, by State, as to

whether the demonstration project resulted in increased access to inpatient mental health services under the Medicaid program and whether average length of stays were longer (or shorter) for individuals admitted under the demonstration project compared with individuals otherwise admitted in comparison sites.

(B) An analysis, by State, regarding whether the demonstration project produced a significant reduction in emergency room visits for individuals eligible for assistance under the Medicaid program or in the duration of emergency room lengths of stay.

(C) An assessment of discharge planning by participating hospitals that ensures access to further (non-emergency) inpatient or residential care as well as continuity of care for those dis25 charged to outpatient care. 
(D) An assessment of the impact of the demonstration project on the costs of the full range of mental health services (including inpatient, emergency and ambulatory care) under the plan as contrasted with the comparison areas.

(1) In GENERAL.-The Secretary shall waive 19 (28) of section 1905(a) of the Social Security Act 20 (42 U.S.C. $1396 \mathrm{~d}(\mathrm{a})$ ) (relating to limitations on pay21 ments for care or services for individuals under 65 22 years of age who are patients in an institution for 23 mental diseases) for purposes of carrying out the 24 demonstration project under this section. 
(2) Limited OTHER WAIVER AUTHORITY.-The

2 Secretary may waive other requirements of title XIX

3 of the Social Security Act (including the require-

4 ments of sections 1902(a)(1) (relating to

5 statewideness) and 1902(1)(10)(B) (relating to com-

6 parability)) only to extent necessary to carry out the

7 demonstration project under this section.

8 (h) Definitions.-In this section:

9 (1) EMergency Medical CONdition.-The

10 term "emergency medical condition" means, with re-

11 spect to an individual, an individual who expresses

12 suicidal or homicidal thoughts or gestures, if deter-

13 mined dangerous to self or others.

14 (2) Federal medical assistance percent15 AGE.-The term "Federal medical assistance per16 centage" has the meaning given that term with re17 spect to a State under section 1905 (b) of the Social 18 Security Act (42 U.S.C. 1396d(b)).

19 (3) Institution fOR Mental Diseases.-The 20 term "institution for mental diseases" has the mean21 ing given to that term in section 1905(i) of the So22 cial Security Act (42 U.S.C. 1396d(i)).

23 (4) Medical assistance.-The term "medical 24 assistance" has the meaning given to that term in 
1 section 1905 (a) of the Social Security Act (42

2 U.S.C. $1396 \mathrm{~d}(\mathrm{a}))$.

(5) Stabilized.-The term "stabilized"

4 means, with respect to an individual, that the emer-

5 gency medical condition no longer exists with respect

6 to the individual and the individual is no longer dan-

7 gerous to self or others.

8 (6) State.-The term "State" has the mean-

9 ing given that term for purposes of title XIX of the

10 Social Security Act (42 U.S.C. 1396 et seq.).

11 SEC. 1788. APPLICATION OF MEDICAID IMPROVEMENT

FUND.

13 Section 1941(b)(1) of the Social Security Act (42

14 U.S.C. $1396 \mathrm{w}-1(\mathrm{~b})(1))$ is amended by striking "from the

15 Fund" and all that follows and inserting "from the Fund,

16 only such amounts as may be appropriated or otherwise

17 made available by law.".

18 SEC. 1789. TREATMENT OF CERTAIN MEDICAID BROKERS.

19 Section 1903(b)(4) of the Social Security Act (42

20 U.S.C. $1396 b(b)(4))$ is amended-

21 (1) in the matter before subparagraph (A), by

22 inserting after "respect to the broker" the following:

23 "(or, in the case of subparagraph (A) and subpara-

24 graph (B)(i), if the Inspector General of Department

25 of Health and Human Services finds that the broker 
1 has established and maintains procedures to ensure

2 the independence of its enrollment activities from

3 the interests of any managed care entity or pro-

4 vider)"; and

5

6

7

8

9 SEC. 1790. RULE FOR CHANGES REQUIRING STATE LEGIS-

11 In the case of a State plan for medical assistance

12 under title XIX of the Social Security Act which the Sec-

13 retary of Health and Human Services determines requires

14 State legislation (other than legislation appropriating

15 funds) in order for the plan to meet an additional require-

16 ment imposed by an amendment made by this title, the

17 State plan shall not be regarded as failing to comply with

18 the requirements of such title XIX solely on the basis of

19 its failure to meet this additional requirement before the

20 first day of the first calendar quarter beginning after the

21 close of the first regular session of the State legislature

22 that begins after the date of the enactment of this Act.

23 For purposes of the previous sentence, in the case of a

24 State that has a 2-year legislative session, each year of 
1 such session shall be deemed to be a separate regular ses-

2 sion of the State legislature.

3 TITLE VIII-REVENUE-RELATED PROVISIONS

5 SEC. 1801. DISCLOSURES TO FACILITATE IDENTIFICATION

OF INDIVIDUALS LIKELY TO BE INELIGIBLE

FOR THE LOW-INCOME ASSISTANCE UNDER

THE MEDICARE PRESCRIPTION DRUG PRO-

GRAM TO ASSIST SOCIAL SECURITY ADMINISUALS.

(a) In GeneraL.-Paragraph (19) of section 6103(l)

13 of the Internal Revenue Code of 1986 is amended to read 14 as follows:

“(19) Disclosures to Facilitate iDEnti-

16 FICATION OF INDIVIDUALS LIKELY TO BE INELI17 GIBLE FOR LOW-INCOME SUBSIDIES UNDER MEDI18 CARE PRESCRIPTION DRUG PROGRAM TO ASSIST SO19 CLAL SECURITY ADMINISTRATION'S OUTREACH TO 20 ELIGIBLE INDIVIDUALS.-

“(A) In GENERAL.-Upon written request from the Commissioner of Social Security, the following return information (including such information disclosed to the Social Security Administration under paragraph (1) or (5)) shall 
1159

1 be disclosed to officers and employees of the Social Security Administration, with respect to any taxpayer identified by the Commissioner of Social Security-

"(i) return information for the appli-

cable year from returns with respect to wages (as defined in section 3121(a) or 3401(a)) and payments of retirement income (as described in paragraph (1) of this subsection),

"(ii) unearned income information and income information of the taxpayer from partnerships, trusts, estates, and subchapter $\mathrm{S}$ corporations for the applicable year,

"(iii) if the individual filed an income tax return for the applicable year, the filing status, number of dependents, income from farming, and income from self-employment, on such return, "(iv) if the individual is a married individual filing a separate return for the applicable year, the social security number (if reasonably available) of the spouse on such return, 
"(v) if the individual files a joint re-

turn for the applicable year, the social se-

curity number, unearned income informa-

tion, and income information from partner-

ships, trusts, estates, and subchapter S

corporations of the individual's spouse on

such return, and

"(vi) such other return information relating to the individual (or the individual's spouse in the case of a joint return) as is prescribed by the Secretary by regulation as might indicate that the individual is likely to be ineligible for a low-income prescription drug subsidy under section 1860D-14 of the Social Security Act.

"(B) APPlicable Year.-For the purposes of this paragraph, the term 'applicable year' means the most recent taxable year for which information is available in the Internal Revenue Service's taxpayer information records. “(C) Restriction ON Individuals FOR WHOM DISCLOSURE MAY BE REQUESTED.-The Commissioner of Social Security shall request information under this paragraph only with respect to- 
1161

22 of such Code is amended-

(1) by striking “(19),” each place it appears, 24 and

"(i) individuals the Social Security Administration has identified, using all other reasonably available information, as likely to be eligible for a low-income prescription drug subsidy under section 1860D-14 of the Social Security Act and who have not applied for such subsidy, and "(ii) any individual the Social Security Administration has identified as a spouse of an individual described in clause (i).

“(D) Restriction on use of Disclosed INFORMATION.-Return information disclosed under this paragraph may be used only by officers and employees of the Social Security Administration solely for purposes of identifying individuals likely to be ineligible for a low-income prescription drug subsidy under section 1860D-14 of the Social Security Act for use in outreach efforts under section 1144 of the Social Security Act.”.

(b) Safeguards.-Paragraph (4) of section 6103(p) 
1 (2) by striking "or (17)" each place it appears 2 and inserting "(17), or (19)".

3 (c) Conforming Amendment.-Paragraph (3) of 4 section 6103(a) of such Code is amended by striking 5 “(19),".

6 (d) EFFective Date.-The amendments made by 7 this section shall apply to disclosures made after the date 8 which is 12 months after the date of the enactment of 9 this Act.

10 SEC. 1802. COMPARATIVE EFFECTIVENESS RESEARCH TRUST FUND; FINANCING FOR TRUST FUND.

12 (a) Establishment of Trust Fund.-

13 (1) IN GENERAL.—Subchapter A of chapter 98 14 of the Internal Revenue Code of 1986 (relating to 15 trust fund code) is amended by adding at the end 16 the following new section:

17 “SEC. 9511. HEALTH CARE COMPARATIVE EFFECTIVENESS 18 RESEARCH TRUST FUND.

19 "(a) Creation of Trust Fund.-There is estab20 lished in the Treasury of the United States a trust fund 21 to be known as the 'Health Care Comparative Effective22 ness Research Trust Fund' (hereinafter in this section re23 ferred to as the 'CERTF'), consisting of such amounts 24 as may be appropriated or credited to such Trust Fund 25 as provided in this section and section 9602(b). 
1163

“(b) Transfers to Fund.-

"(1) In GeneraL.-There are hereby appropriated to the Trust Fund the following:

“(A) For fiscal year 2010, $\$ 90,000,000$.

“(B) For fiscal year 2011, $\$ 100,000,000$.

“(C) For fiscal year 2012, $\$ 110,000,000$.

"(D) For each fiscal year beginning with

"(i) an amount equivalent to the net revenues received in the Treasury from the

fees imposed under subchapter B of chapter 34 (relating to fees on health insurance and self-insured plans) for such fiscal year; and

“(ii) subject to subsection (c)(2), amounts determined by the Secretary of Health and Human Services to be equivalent to the fair share per capita amount computed under subsection (c)(1) for the fiscal year multiplied by the average number of individuals entitled to benefits under part $A$, or enrolled under part $B$, of title XVIII of the Social Security Act during such fiscal year.

“(2) Administrative PRovisions.- 


\section{4}

“(A) Transfers FROM OTHER TRUST FUNDS.-The amounts appropriated by subparagraphs (A), (B), (C), and (D)(ii) of paragraph (1) shall be transferred from the Federal Hospital Insurance Trust Fund and from the Federal Supplementary Medical Insurance Trust Fund (established under section 1841 of such Act), and from the Medicare Prescription Drug Account within such Trust Fund, in proportion (as estimated by the Secretary) to the total expenditures during such fiscal year that are made under title XVIII of such Act from the respective trust fund or account.

“(B) ApPRopriations nOT SUBJECT TO FISCAL YEAR LIMITATION.-The amounts appropriated by paragraph (1) shall not be subject to any fiscal year limitation.

“(C) Periodic transfers, estimates, AND ADJUSTMENTS.-Except as provided in subparagraph (A), the provisions of section 9601 shall apply to the amounts appropriated by paragraph (1).

“(c) Fair Share Per Capita Amount.“(1) Computation.- 
1165

"(A) IN GENERAL.—Subject to subparagraph (B), the fair share per capita amount under this paragraph for a fiscal year (beginning with fiscal year 2013) is an amount computed by the Secretary of Health and Human Services for such fiscal year that, when applied under this section and subchapter B of chapter 34 of the Internal Revenue Code of 1986, will result in revenues to the CERTF of $\$ 375,000,000$ for the fiscal year.

“(B) Alternative computation.-

"(i) In GENERAL.-If the Secretary is unable to compute the fair share per capita amount under subparagraph (A) for a fiscal year, the fair share per capita amount under this paragraph for the fiscal year shall be the default amount determined under clause (ii) for the fiscal year.

“(ii) Default amount.-The default amount under this clause for-

"(I) fiscal year 2013 is equal to $\$ 2$; or

"(II) a subsequent year is equal to the default amount under this clause for the preceding fiscal year in- 
1166

creased by the annual percentage increase in the medical care component of the consumer price index (United States city average) for the 12-month period ending with April of the preceding fiscal year.

Any amount determined under subclause (II) shall be rounded to the nearest penny. “(2) Limitation on Medicare FUNDing.-In no case shall the amount transferred under subsection (b)(4)(B) for any fiscal year exceed $\$ 90,000,000$.

\section{“(d) Expenditures From Fund.-}

“(1) In GENERAL._-Subject to paragraph (2), amounts in the CERTF are available, without the need for further appropriations and without fiscal year limitation, to the Secretary of Health and Human Services to carry out section 1181 of the Social Security Act.

“(2) Allocation for commission.-The following amounts in the CERTF shall be available, without the need for further appropriations and without fiscal year limitation, to the Commission to carry out the activities of the Comparative Effective- 
1167

1 ness Research Commission established under section

$21181(b)$ of the Social Security Act:

11 the Secretary based on the excess of-

“Sec. 9511. Health Care Comparative Effectiveness Research Trust Fund.".

\section{1 and Self-Insured Health Plans.-}

“(A) For fiscal year 2010, $\$ 7,000,000$.

“(B) For fiscal year 2011, \$9,000,000.

"(C) For each fiscal year beginning with 2012, 2.6 percent of the total amount appropriated to the CERTF under subsection (b) for the fiscal year.

“(e) Net Revenues.-For purposes of this section, "(1) the fees received in the Treasury under subchapter B of chapter 34, over

"(2) the decrease in the tax imposed by chapter 1 resulting from the fees imposed by such subchapter.'.

(2) Clerical amendment.-The table of sections for such subchapter $\mathrm{A}$ is amended by adding at the end thereof the following new item:

(b) Financing for Fund From Fees on Insured

(1) General Rule.-Chapter 34 of the Internal Revenue Code of 1986 is amended by adding at the end the following new subchapter: 
1 “Subchapter B-Insured and Self-Insured

"Sec. 4375. Health insurance.

"Sec. 4376. Self-insured health plans.

"Sec. 4377. Definitions and special rules.

3 “SEC. 4375. HEALTH INSURANCE.

4 "(a) Imposition OF FEE.-There is hereby imposed

5 on each specified health insurance policy for each policy

6 year a fee equal to the fair share per capita amount deter-

7 mined under section 9511(c)(1) multiplied by the average

8 number of lives covered under the policy.

9 "(b) Liability FOR FEe.-The fee imposed by sub-

10 section (a) shall be paid by the issuer of the policy.

12 purposes of this section:

"(1) In GENERAL.-Except as otherwise pro-

14 vided in this section, the term 'specified health in-

15 surance policy' means any accident or health insur-

16 ance policy issued with respect to individuals resid-

17 ing in the United States.

“(2) ExEMPTION FOR CERTAIN POLICIES.-The

19 term 'specified health insurance policy' does not in-

20 clude any insurance if substantially all of its cov-

21 erage is of excepted benefits described in section $229832(\mathrm{c})$.

23 "(3) TREATMENT OF PREPAID HEALTH COV- 
1169

\section{7 "SEC. 4376. SELF-INSURED HEALTH PLANS.}

"(a) Imposition of Fee.-In the case of any appli19 cable self-insured health plan for each plan year, there is 20 hereby imposed a fee equal to the fair share per capita 21 amount determined under section 9511(c)(1) multiplied by 22 the average number of lives covered under the plan. “(b) Liability for Fee.-

25 section (a) shall be paid by the plan sponsor. 
“(2) Plan sponsor.-For purposes of para-

graph (1) the term 'plan sponsor' means-

"(A) the employer in the case of a plan established or maintained by a single employer, "(B) the employee organization in the case of a plan established or maintained by an employee organization, "(C) in the case of-

“(i) a plan established or maintained by 2 or more employers or jointly by 1 or more employers and 1 or more employee organizations, "(ii) a multiple employer welfare arrangement, or

“(iii) a voluntary employees' beneficiary association described in section $501(\mathrm{c})(9)$, the association, committee, joint board of trustees, or other similar group of representatives of the parties who establish or maintain the plan, or

"(D) the cooperative or association described in subsection $(c)(2)(\mathrm{F})$ in the case of a plan established or maintained by such a cooperative or association. 
1 “(c) Applicable Self-Insured Health Plan.-

2 For purposes of this section, the term 'applicable self-in-

3 sured health plan' means any plan for providing accident

4 or health coverage if-

5

6 other than through an insurance policy, and
"(1) any portion of such coverage is provided "(2) such plan is established or maintained"(A) by one or more employers for the benefit of their employees or former employees, "(B) by one or more employee organizations for the benefit of their members or former members,

"(C) jointly by 1 or more employers and 1 or more employee organizations for the benefit of employees or former employees,

“(D) by a voluntary employees' beneficiary association described in section 501(c)(9), "(E) by any organization described in section 501(c)(6), or

"(F) in the case of a plan not described in the preceding subparagraphs, by a multiple employer welfare arrangement (as defined in section 3(40) of Employee Retirement Income Security Act of 1974), a rural electric cooperative (as defined in section 3(40)(B)(iv) of such Act), 
or a rural telephone cooperative association (as

3 “SEC. 4377. DEFINITIONS AND SPECIAL RULES.

4 “(a) Definitions.-For purposes of this sub-

5 chapter-

“(1) Accident and health coverage.-The

7 term 'accident and health coverage' means any cov-

8 erage which, if provided by an insurance policy,

9 would cause such policy to be a specified health in-

10 surance policy (as defined in section $4375(\mathrm{c})$ ).

11 "(2) Insurance POLICY.-The term 'insurance

12 policy' means any policy or other instrument where-

13 by a contract of insurance is issued, renewed, or ex14 tended.

"(3) United States.-The term 'United

16 States' includes any possession of the United States.

17 “(b) Treatment of Governmental Entities.-

18 “(1) IN GENERAL.-For purposes of this sub19 chapter-

"(A) the term 'person' includes any governmental entity, and

“(B) notwithstanding any other law or rule of law, governmental entities shall not be exempt from the fees imposed by this subchapter except as provided in paragraph (2). 

PROGRAMS.-In the case of an exempt governmental 3 program, no fee shall be imposed under section 4375

4 or section 4376 on any covered life under such pro5 gram.

“(3) EXEMPt GOVERNMENTAL PROGRAM DEFINED.-For purposes of this subchapter, the term 'exempt governmental program' means-

"(A) any insurance program established under title XVIII of the Social Security Act, "(B) the medical assistance program established by title XIX or XXI of the Social Security Act,

“(C) any program established by Federal law for providing medical care (other than through insurance policies) to individuals (or the spouses and dependents thereof) by reason of such individuals being-

"(i) members of the Armed Forces of the United States, or

"(ii) veterans, and

“(D) any program established by Federal law for providing medical care (other than through insurance policies) to members of In- 
dian tribes (as defined in section $4(\mathrm{~d})$ of the Indian Health Care Improvement Act).

“(c) Treatment as Tax.-For purposes of subtitle

$4 \mathrm{~F}$, the fees imposed by this subchapter shall be treated 5 as if they were taxes.

6 “(d) No Cover Over to Possessions.-Notwith-

7 standing any other provision of law, no amount collected

8 under this subchapter shall be covered over to any posses-

9 sion of the United States.".

10

11

23 by this subsection shall apply with respect to policies

(A) Chapter 34 of such Code is amended by striking the chapter heading and inserting the following:

\section{“CHAPTER 34-TAXES ON CERTAIN} INSURANCE POLICIES

"SUBCHAPTER A. POLICIES ISSUED BY FOREIGN INSURERS

"SUBCHAPTER B. INSURED AND SELF-INSURED HEALTH PLANS

\section{“Subchapter A-Policies Issued By Foreign} Insurers".

(B) The table of chapters for subtitle D of such Code is amended by striking the item relating to chapter 34 and inserting the following new item:

“Chapter 34-Taxes on Certain Insurance Policies".

(3) EFFective Date.- The amendments made 
1 and plans for portions of policy or plan years begin-

2 ning on or after October 1, 2012.

3 TITLE IX-MISCELLANEOUS

4 PROVISIONS

5 SEC. 1901. REPEAL OF TRIGGER PROVISION.

6 Subtitle A of title VIII of the Medicare Prescription

7 Drug, Improvement, and Modernization Act of 2003 (Pub-

8 lic Law 108-173) is repealed and the provisions of law

9 amended by such subtitle are restored as if such subtitle

10 had never been enacted.

11 SEC. 1902. REPEAL OF COMPARATIVE COST ADJUSTMENT (CCA) PROGRAM.

13 Section $1860 \mathrm{C}-1$ of the Social Security Act (42 14 U.S.C. $1395 \mathrm{w}-29$ ), as added by section 241(a) of the 15 Medicare Prescription Drug, Improvement, and Mod16 ernization Act of 2003 (Public Law 108-173), is repealed. 17 SEC. 1903. EXTENSION OF GAINSHARING DEMONSTRATION. 18 (a) IN GENERAL.—Subsection (d)(3) of section 5007 19 of the Deficit Reduction Act of 2005 (Public Law 10920 171) is amended by inserting "(or September 30, 2011, 21 in the case of a demonstration project in operation as of 22 October 1, 2008)" after "December 31, 2009".

23 (b) Funding.- 
(1) IN GENERAL.-Subsection (f)(1) of such

2 section is amended by inserting "and for fiscal year 32 2010, $\$ 1,600,000$," after “ $\$ 6,000,000$, ,".

(2) Availability.-Subsection (f)(2) of such

5 section is amended by striking " 2010 " and inserting $6 \quad$ "2014 or until expended".

$7 \quad$ (c) REPORTS.-

(1) Quality Improvement and SAvings.9 Subsection (e)(3) of such section is amended by 10 striking "December 1, 2008" and inserting "March $1131,2011 ”$.

(2) Final REPORT.--Subsection (e)(4) of such 13 section is amended by striking "May 1, 2010" and 14 inserting "March 31, 2013”.

15 SEC. 1904. GRANTS TO STATES FOR QUALITY HOME VISITATION PROGRAMS FOR FAMILIES WITH YOUNG CHILDREN AND FAMILIES EXPECTING CHILDREN.

19 Part B of title IV of the Social Security Act (42 20 U.S.C. 621-629i) is amended by adding at the end the 21 following: 
“Subpart 3-Support for Quality Home Visitation

3 "SEC. 440. HOME VISITATION PROGRAMS FOR FAMILIES WITH YOUNG CHILDREN AND FAMILIES EXPECTING CHILDREN.

6 “(a) Purpose.-The purpose of this section is to im7 prove the well-being, health, and development of children

8 by enabling the establishment and expansion of high qual9 ity programs providing voluntary home visitation for fami-

10 lies with young children and families expecting children.

11 "(b) Grant Application.-A State that desires to 12 receive a grant under this section shall submit to the Sec13 retary for approval, at such time and in such manner as 14 the Secretary may require, an application for the grant 15 that includes the following:

“(1) Description of home visitation PRo-

17 GRAMS. - A description of the high quality programs

18 of home visitation for families with young children 19 and families expecting children that will be sup20 ported by a grant made to the State under this sec21 tion, the outcomes the programs are intended to 22 achieve, and the evidence supporting the effective23 ness of the programs. “(2) Results of needs assessment.-The 25 results of a statewide needs assessment that de26 scribes- 
"(A) the number, quality, and capacity of home visitation programs for families with young children and families expecting children in the State;

"(B) the number and types of families who

"(A) in supporting home visitation programs using funds provided under this section, the State shall identify and prioritize serving communities that are in high need of such services, especially communities with a high proportion of low-income families or a high incidence of child maltreatment; grant funds for training and technical assist- 
ance to the home visitation programs using such funds;

"(C) in supporting home visitation programs using funds provided under this section, the State will promote coordination and collaboration with other home visitation programs (in-

23 Secretary shall allot to each Indian tribe that meets 24 the requirement of subsection (d), if applicable, for 25 the fiscal year the amount that bears the same ratio 
1 to the amount so reserved as the number of children

2 in the Indian tribe whose families have income that

3 does not exceed 200 percent of the poverty line bears

4 to the total number of children in such Indian tribes

5 whose families have income that does not exceed 200

6 percent of the poverty line.

7 “(2) STATES AND TERRITORIES.-From the

8 amount appropriated under subsection (m) for a fis-

9 cal year that remains after making the reservations

10 required by subsection (1), the Secretary shall allot

11 to each State that is not an Indian tribe and that

12 meets the requirement of subsection (d), if applica-

13 ble, for the fiscal year the amount that bears the

14 same ratio to the remainder of the amount so appro-

15 priated as the number of children in the State whose

16 families have income that does not exceed 200 per-

17 cent of the poverty line bears to the total number of

18 children in such States whose families have income

19 that does not exceed 200 percent of the poverty line.

20 “(3) Reallotments.-The amount of any al-

21 lotment to a State under a paragraph of this sub-

22 section for any fiscal year that the State certifies to

23 the Secretary will not be expended by the State pur-

24 suant to this section shall be available for reallot-

25 ment using the allotment methodology specified in 


\section{1}

1 that paragraph. Any amount so reallotted to a State

2 is deemed part of the allotment of the State under

3 this subsection.

4 “(d) Maintenance of Effort.-Beginning with

5 fiscal year 2011, a State meets the requirement of this 6 subsection for a fiscal year if the Secretary finds that the 7 aggregate expenditures by the State from State and local 8 sources for programs of home visitation for families with 9 young children and families expecting children for the then 10 preceding fiscal year was not less than 100 percent of such 11 aggregate expenditures for the then 2nd preceding fiscal 12 year

13 “(e) Payment of Grant.-

14 “(1) IN GENERAL.—The Secretary shall make a 15 grant to each State that meets the requirements of 16 subsections (b) and (d), if applicable, for a fiscal 17 year for which funds are appropriated under sub18 section $(m)$, in an amount equal to the reimbursable 19 percentage of the eligible expenditures of the State 20 for the fiscal year, but not more than the amount 21 allotted to the State under subsection (c) for the fis22 cal year.

23 “(2) Reimbursable Percentage Defined.24 In paragraph (1), the term 'reimbursable percent25 age' means, with respect to a fiscal year- 
1182

“(A) 85 percent, in the case of fiscal year 2010;

"(B) 80 percent, in the case of fiscal year 2011; or

"(C) 75 percent, in the case of fiscal year 2012 and any succeeding fiscal year.

“(f) Eligible Expenditures.-

"(1) In GENERAL.-In this section, the term 'eligible expenditures'-

"(A) means expenditures to provide voluntary home visitation for as many families with young children (under the age of school entry) and families expecting children as practicable, through the implementation or expansion of high quality home visitation programs that-

“(i) adhere to clear evidence-based models of home visitation that have demonstrated positive effects on important program-determined child and parenting outcomes, such as reducing abuse and neglect and improving child health and development;

“(ii) employ well-trained and competent staff, maintain high quality super- 
vision, provide for ongoing training and professional development, and show strong organizational capacity to implement such a program;

“(iii) establish appropriate linkages and referrals to other community resources and supports;

"(iv) monitor fidelity of program implementation to ensure that services are delivered according to the specified model; and

“(v) provide parents with—

"(I) knowledge of age-appropriate child development in cognitive, language, social, emotional, and motor domains (including knowledge of second language acquisition, in the case of English language learners);

"(II) knowledge of realistic expectations of age-appropriate child behaviors;

"(III) knowledge of health and wellness issues for children and parents; 
"(IV) modeling, consulting, and coaching on parenting practices;

"(V) skills to interact with their

child to enhance age-appropriate development;

"(VI) skills to recognize and seek help for issues related to health, developmental delays, and social, emotional, and behavioral skills; and

"(VII) activities designed to help

parents become full partners in the education of their children;

"(B) includes expenditures for training, technical assistance, and evaluations related to the programs; and

"(C) does not include any expenditure with respect to which a State has submitted a claim for payment under any other provision of Federal law.

“(2) PRiority Funding FoR PRograms With STRONGEST EVIDENCE.-

“(A) In GENERAL.-The expenditures, described in paragraph (1), of a State for a fiscal year that are attributable to the cost of programs that do not adhere to a model of home 
visitation with the strongest evidence of effectiveness shall not be considered eligible expenditures for the fiscal year to the extent that the total of the expenditures exceeds the applicable percentage for the fiscal year of the allotment of the State under subsection (c) for the fiscal year. FINED.- In subparagraph (A), the term 'applicable percentage' means, with respect to a fiscal year-

“(B) Applicable Percentage DE16 “(v) 40 percent for fiscal year 2014. 18 “(g) No Use of Other Federal Funds for 19 State Match.-A State to which a grant is made under 20 this section may not expend any Federal funds to meet 21 the State share of the cost of an eligible expenditure for 22 which the State receives a payment under this section. “(h) WAiver Authority.—

“(1) IN GENERAL.—The Secretary may waive or modify the application of any provision of this 
1186

1 section, other than subsection (b) or (f), to an In-

2 dian tribe if the failure to do so would impose an

3 undue burden on the Indian tribe.

4 “(2) Spectal RULe.-An Indian tribe is

5 deemed to meet the requirement of subsection (d)

6 for purposes of subsections (c) and (e) if-

"(A) the Secretary waives the requirement;

8

or

"(B) the Secretary modifies the requirement, and the Indian tribe meets the modified requirement.

12 “(i) State RePORTS.-Each State to which a grant

13 is made under this section shall submit to the Secretary

14 an annual report on the progress made by the State in

15 addressing the purposes of this section. Each such report

16 shall include a description of-

17 "(1) the services delivered by the programs that 18 received funds from the grant;

19 "(2) the characteristics of each such program, 20 including information on the service model used by 21 the program and the performance of the program;

22 "(3) the characteristies of the providers of serv23 ices through the program, including staff qualifica24 tions, work experience, and demographic characteris25 tics; 
"(4) the characteristics of the recipients of serv-

2 ices provided through the program, including the

3 number of the recipients, the demographic charac-

4 teristics of the recipients, and family retention;

5 "(5) the annual cost of implementing the pro6 gram, including the cost per family served under the $7 \quad$ program;

8 "(6) the outcomes experienced by recipients of 9 services through the program;

10 "(7) the training and technical assistance pro11 vided to aid implementation of the program, and 12 how the training and technical assistance contrib13 uted to the outcomes achieved through the program; 14 "(8) the indicators and methods used to mon15 itor whether the program is being implemented as 16 designed; and

17 “(9) other information as determined necessary 18 by the Secretary.

19 "(j) Evaluation.-

20 "(1) IN GENERAL.-The Secretary shall, by 21 grant or contract, provide for the conduct of an 22 independent evaluation of the effectiveness of home 23 visitation programs receiving funds provided under 24 this section, which shall examine the following: 
"(A) The effect of home visitation programs on child and parent outcomes, including child maltreatment, child health and development, school readiness, and links to community services. ant to paragraph (1).

22 “(k) Annual Reports to the Congress.-The

23 Secretary shall submit annually to the Congress a report 24 on the activities carried out using funds made available 
1 under this section, which shall include a description of the

2 following:

"(1) The high need communities targeted by States for programs carried out under this section. "(2) The service delivery models used in the programs receiving funds provided under this section.

"(3) The characteristics of the programs, including-

"(A) the qualifications and demographic characteristics of program staff; and "(B) recipient characteristics including the number of families served, the demographic characteristics of the families served, and family retention and duration of services.

“(4) The outcomes reported by the programs.

“(5) The research-based instruction, materials, and activities being used in the activities funded under the grant.

"(6) The training and technical activities, including on-going professional development, provided to the programs.

"(7) The annual costs of implementing the programs, including the cost per family served under the programs. 
1 “(8) The indicators and methods used by States

2 to monitor whether the programs are being been im3 plemented as designed.

4 “(l) Reservations of Funds.-From the amounts 5 appropriated for a fiscal year under subsection (m), the 6 Secretary shall reserve-

"(1) an amount equal to 5 percent of the 8 amounts to pay the cost of the evaluation provided 9 for in subsection (j), and the provision to States of 10 training and technical assistance, including the dis11 semination of best practices in early childhood home 12 visitation; and

13 "(2) after making the reservation required by 14 paragraph (1), an amount equal to 3 percent of the 15 amount so appropriated, to pay for grants to Indian 16 tribes under this section.

17 “(m) Appropriations.-Out of any money in the 18 Treasury of the United States not otherwise appropriated, 19 there is appropriated to the Secretary to carry out this 20 section-

“(1) $\$ 50,000,000$ for fiscal year 2010;

“(2) $\$ 100,000,000$ for fiscal year 2011;

“(3) $\$ 150,000,000$ for fiscal year 2012; 
1191

1 “(n) Indian Tribes Treated as States.-In this

2 section, paragraphs (4), (5), and (6) of section 431(a)

3 shall apply.".

4 SEC. 1905. IMPROVED COORDINATION AND PROTECTION FOR DUAL ELIGIBLES.

6 Title XI of the Social Security Act is amended by

7 inserting after section 1150 the following new section:

8 "IMPROVED COORDINATION AND PROTECTION FOR DUAL

ELIGIBLES

10 "Sec. 1150A. (a) In General.-The Secretary shall

11 provide, through an identifiable office or program within

12 the Centers for Medicare \& Medicaid Services, for a fo-

13 cused effort to provide for improved coordination between

14 Medicare and Medicaid and protection in the case of dual

15 eligibles (as defined in subsection $(\mathrm{g})$ ). The office or pro16 gram shall-

“(1) review Medicare and Medicaid policies re-

18 lated to enrollment, benefits, service delivery, pay-

19 ment, and grievance and appeals processes under

20 parts $\mathrm{A}$ and $\mathrm{B}$ of title XVIII, under the Medicare

21 Advantage program under part $\mathrm{C}$ of such title, and

22 under title XIX;

23 "(2) identify areas of such policies where better

24 coordination and protection could improve care and 25 costs; and 
1 “(3) issue guidance to States regarding improv2 ing such coordination and protection.

3 "(b) Elements.-The improved coordination and 4 protection under this section shall include efforts"(1) to simplify access of dual eligibles to bene6 fits and services under Medicare and Medicaid; "(2) to improve care continuity for dual eligi8 bles and ensure safe and effective care transitions; "(3) to harmonize regulatory conflicts between

10 Medicare and Medicaid rules with regard to dual eli11 gibles; and “(4) to improve total cost and quality performance under Medicare and Medicaid for dual eligibles. 15 tion, the Secretary shall provide for the following:

17 payment systems to develop strategies to foster more 18 integrated and higher quality care.

19 “(2) Development of methods to facilitate ac20 cess to post-acute and community-based services and 21 to identify actions that could lead to better coordina22 tion of community-based care.

23 "(3) A study of enrollment of dual eligibles in 24 the Medicare Savings Program (as defined in section $251144(\mathrm{c})(7))$, under Medicaid, and in the low-income 
1 subsidy program under section 1860D-14 to identify

2 methods to more efficiently and effectively reach and 3 enroll dual eligibles.

4 “(4) An assessment of communication strate5 gies for dual eligibles to determine whether addi6 tional informational materials or outreach is needed, 7 including an assessment of the Medicare website, 18 800-MEDICARE, and the Medicare handbook. "(5) Research and evaluation of areas where 10 service utilization, quality, and access to cost sharing 11 protection could be improved and an assessment of 12 factors related to enrollee satisfaction with services 13 and care delivery.

14 "(6) Collection (and making available to the 15 public) of data and a database that describe the eli16 gibility, benefit and cost-sharing assistance available 17 to dual eligibles by State.

18 “(7) Support for coordination of State and Fed19 eral contracting and oversight for dual coordination 20 programs supportive of the goals described in sub21 section (b).

22 “(8) Support for State Medicaid agencies 23 through the provision of technical assistance for 24 Medicare and Medicaid coordination initiatives de- 
1 signed to improve acute and long-term care for dual 2 eligibles.

“(9) Monitoring total combined Medicare and

$4 \quad$ Medicaid program costs in serving dual eligibles and

5 making recommendations for optimizing total quality

6 and cost performance across both programs.

"(10) Coordination of activities relating to

$8 \quad$ Medicare Advantage plans under 1859(b)(6)(B)(ii)

9 and Medicaid.

10 “(d) REPORTING.-The Office or program shall work

11 with relevant State agencies and any appropriate quality

12 measurement entities to improve and coordinate reporting

13 requirements for Medicare and Medicaid. In addition, the

14 Office or program shall seek to minimize duplication in

15 reporting requirements, where appropriate, and to identify

16 opportunities to combine assessment requirements, where

17 appropriate. The Office or program shall seek to identify

18 quality metrics and assessment requirements that facili-

19 tate comparisons of the quality of care received by bene-

20 ficiaries enrolled in or entitled to benefits under fee-for-

21 service Medicare, the Medicare Advantage program, fee-

22 for-service Medicaid, and Medicaid managed care, and

23 combinations thereof (including integrated Medicare-Med-

24 icaid programs for dual eligibles). 
1 “(e) Endorsement.-The Secretary shall seek en2 dorsement by the entity with a contract under section 3 1890(a) of quality measures and benchmarks developed 4 under this section.

5 “(f) Consultation With Stakeholders.-The 6 Office or program shall consult with relevant stakeholders, 7 including dual eligible beneficiaries representatives for 8 dual eligible beneficiaries, health plans, providers, and rel9 evant State agencies, in the development of policies related 10 to integrated Medicare-Medicaid programs for dual eligi11 bles.

12 "(g) Periodic Reports.-Not later than 1 year 13 after the date of the enactment of this section and every 143 years thereafter the Secretary shall submit to Congress 15 a report on progress in activities conducted under this sec16 tion.

17 “(h) Definitions.-In this section:

18 “(1) Dual Eligible.-The term 'dual eligible' 19 means an individual who is dually eligible for bene20 fits under title XVIII, and medical assistance under 21 title XIX, including such individuals who are eligible 22 for benefits under the Medicare Savings Program 23 (as defined in section 1144(c)(7)). 
“(2) Medicare; Medicaid.-The terms 'Medicare' and 'Medicaid' mean the programs under titles 3 XVIII and XIX, respectively.".

4 SEC. 1906. ASSESSMENT OF MEDICARE COST-INTENSIVE DISEASES AND CONDITIONS.

6 (a) Initial Assessment.-

(1) In GENERAL.- The Secretary of Health and

8 Human Services shall conduct an assessment of the

9 diseases and conditions that are the most cost-inten-

10 sive for the Medicare program and, to the extent

11 possible, assess the diseases and conditions that

12 could become cost-intensive for Medicare in the fu-

13 ture. In conducting the assessment, the Secretary

14 shall include the input of relevant research agencies,

15 including the National Institutes of Health, the

16 Agency for Healthcare Research and Quality, the

17 Food and Drug Administration, and the Centers for

18 Medicare \& Medicaid Services.

19 (2) REPoRT.-Not later than January 1, 2011, 20 the Secretary shall transmit a report to the Commit21 tees on Energy and Commerce, Ways and Means, 22 and Appropriations of the House of Representatives 23 and the Committees on Health, Education, Labor 24 and Pensions, Finance, and Appropriations of the 
1 Senate on the assessment conducted under para2 graph (1). Such report shall-

(A) include the assessment of current and future trends of cost-intensive diseases and conditions described in such paragraph;

(B) address whether current research priorities are appropriately addressing current and future cost-intensive conditions so identified; and

(C) include recommendations concerning research in the Department of Health and Human Services that should be funded to improve the prevention, treatment, or cure of such cost-intensive diseases and conditions.

16 uary 1, 2013, and biennially thereafter, the Secretary 17 shall-

18 (1) review and update the assessment and rec19 ommendations described in subsection (a)(1); and

20 (2) submit a report described in subsection 21 (a)(2) to the Committees specified in subsection 22 (a)(2) on such updated assessment and rec23 ommendations. 
1 SEC. 1907. ESTABLISHMENT OF CENTER FOR MEDICARE AND MEDICAID INNOVATION WITHIN CMS.

4 is amended by inserting after section 1115 the following

5 new section:

6 "CENTER FOR MEDICARE AND MEDICAID INNOVATION

7 "Sec. 1115A. (a) Center For Medicare AND

8 Medicaid Innovation Established.-

"(1) IN GENERAL.-There is created within the

10 Centers for Medicare \& Medicaid Services a Center

11 for Medicare and Medicaid Innovation (in this sec-

12 tion referred to as the 'CMI') to carry out the duties

13 described in this section. The purpose of the CMI is

14 to test innovative payment and service delivery mod-

15 els to improve the coordination, quality, and effi-

16 ciency of health care services provided to applicable

17 individuals defined in paragraph (4)(A).

18 “(2) Deaduine.-The Secretary shall ensure

19 that the CMI is carrying out the duties described in

20 this section by not later than January 1, 2011.

21 “(3) Consultation.-In carrying out the du-

22 ties under this section, the CMI shall consult rep23 resentatives of relevant Federal agencies, clinical 24 and analytical experts with expertise in medicine and 25 health care management, and States. The CMI shall 
1 use open door forums or other mechanisms to seek 2 input from interested parties.

“(4) Definitions.-In this section:

"(A) Applicable individual.-The term 'applicable individual' means-

19 selection criteria under paragraph (2) to determine 20 the effect of applying such models under the applica21 ble title (as defined in subsection (a)(4)(B)) on pro22 gram expenditures under such titles and the quality 23 of care received by individuals receiving benefits 24 under such title. 
"(A) IN GENERAL.-The Secretary shall give preference to testing models for which, as determined by the Administrator of the Centers for Medicare \& Medicaid Services and using such input from outside the Centers as the Ad-

ministrator determines appropriate, there is evidence that the model addresses a defined population for which there are deficits in care leading to poor clinical outcomes or potentially avoidable expenditures. The Administrator shall focus on models expected to reduce program costs under the applicable title while preserving or enhancing the quality of care received by individuals receiving benefits under such title.

“(B) Application to OTHER DEMONSTRATIONS.-The Secretary shall operate the demonstration programs under sections 1222 and 1236 of the Affordable Health Care for America Act through the CMI in accordance with the rules applicable under this section, including those relating to evaluations, terminations, and expansions.

“(3) Budget neutrality.-

“(A) InITIAL PERIOD.-The Secretary shall not require, as a condition for testing a 
model under paragraph (1), that the design of such model ensure that such model is budget neutral initially with respect to expenditures under the applicable title.

"(B) Termination.-The Secretary shall terminate or modify the design and implementation of a model unless the Secretary determines (and the Chief Actuary of the Centers for Medicare \& Medicaid Services, with respect to spending under the applicable title, certifies), pected to-

"(i) improve the quality of care (as determined by the Administrator of the Centers for Medicare \& Medicaid Services) without increasing spending under such title;

“(ii) reduce spending under such titles without reducing the quality of care; or "(iii) do both. Such termination may occur at any time after such testing has begun and before completion of the testing. 

conduct an evaluation of each model tested under this subsection. Such evaluation shall include an analysis of-

"(i) the quality of care furnished

under the model, including through the use of patient-level outcomes measures; and "(ii) the changes in spending under the applicable titles by reason of the model.

The Secretary shall make the results of each evaluation under this paragraph available to the public in a timely fashion.

"(B) Measure selection.-To the extent feasible, the Secretary shall select measures under this paragraph that reflect national priorities for quality improvement and patientcentered care consistent with the measures developed under section 1192(c)(1).

“(5) Testing PERIOD.-In no case shall a 21 model be tested under this subsection for more than 22 a 7-year period.

23 “(c) Expansion of Modelis (Phase II).-The Sec24 retary may expand the duration and the scope of a model 
1 that is being tested under subsection (b) (including imple-

2 mentation on a nationwide basis), to the extent deter-

3 mined appropriate by the Secretary, if-

4 "(1) the Secretary determines that such expan-

5 sion is expected-

"(A) to improve the quality of patient care

without increasing spending under the applicable titles;

"(B) to reduce spending under applicable titles without reducing the quality of care; or "(C) to do both;

13 care \& Medicaid Services certifies that such expan14 sion would reduce (or not result in any increase in) 15 net program spending under applicable titles; and

16 "(3) the Secretary determines that such expan17 sion would not deny or limit the coverage or provi18 sion of benefits under the applicable title for applica19 ble individuals.

20 “(d) Implementation.-

21 “(1) WAIVER AUTHORITY.-The Secretary may 22 waive such requirements of titles XI and XVIII and 23 of sections 1902 and 1903(m) as may be necessary 24 solely for purposes of carrying out this section with 25 respect to testing models described in subsection (b). 
“(2) Limitations on Review.-There shall be no administrative or judicial review under section 1869 , section 1878 , or otherwise of-

"(A) the selection of models for testing or expansion under this section; duration of such models for testing or dissemination;

"(C) the termination or modification of the design and implementation of a model under subsection $(b)(3)(B)$; and

"(D) determinations about expansion of the duration and scope of a model under subsection $(\mathrm{c})$ including the determination that a model is not expected to meet criteria described in paragraphs (1) or (2) of such subsection.

“(3) Administration.-Chapter 35 of title 44, United States Code shall not apply to the testing and evaluation of models or expansion of such models under this section.

“(4) Funding For testing items And SERvICES AND ADMINISTRATIVE COSTS.-

"(A) Additional Benefits.-There shall be available until expended, equally divided from the Federal Supplementary Hospital In- 
surance Trust Fund and Federal Supplementary Medical Insurance Trust Fund for payments for additional benefits for items and services under models tested under subsection (b) not otherwise covered under this title and applicable to benefits under this title, and for researching, designing, implementing, and evaluating such models, $\$ 350,000,000$ for fiscal year 2010, \$440,000,000 for fiscal year 2011, $\$ 550,000,000$ for fiscal year 2012, and, for a subsequent fiscal year, the amount determined under this subparagraph for the preceding fiscal year increased by the annual percentage rate of increase in total expenditures under this title for the subsequent fiscal year as estimated in the latest available Annual Report of the Board of Trustees as described in section 1841(b)(2).

"(B) MEDICAID._For administrative costs of the Centers for Medicare \& Medicaid Services for administering this section with respect to title XIX, from any amounts in the Treasury not otherwise appropriated there are appropriated to the Secretary for the Centers for 25 
1206

agement Account $\$ 25,000,000$ for each fiscal year beginning with fiscal year 2010. Amounts appropriated under this subparagraph for a fiscal year shall be available until expended.

“(e) Report to Congress.-Beginning in 2012, 6 and not less than once every other year thereafter, the 7 Secretary shall submit to Congress a report on activities 8 under this section. Each such report shall describe the 9 payment models tested under subsection (b), including the 10 number of individuals described in subsection (a)(4)(A)(i) 11 and of individuals described in subsection (a)(4)(A)(ii) 12 participating in such models and payments made under 13 applicable titles for services on behalf of such individuals, 14 any models chosen for expansion under subsection (c), and 15 the results from evaluations under subsection (b)(4). In 16 addition, each such report shall provide such recommenda17 tions as the Secretary believes are appropriate for legisla18 tive action to facilitate the development and expansion of 19 successful payment models.".

20 (b) Medicaid Conforming Amendment.- Section 21 1902(a) of the Social Security Act (42 U.S.C. 1396a(a)), 22 as amended by sections 1631(b), 1703(a), 1729, 1753, $231757(\mathrm{a})$, and 1759(a), is amended-

24 (1) in paragraph (78), by striking "and" at the 25 end; 
(2) in paragraph (79), by striking the period at

2 the end and inserting "; and"; and

(3) by inserting after paragraph (79) the fol-

4 lowing new paragraph:

"(80) provide for implementation of the pay-

6 ment models specified by the Secretary under section

$7 \quad 1115 \mathrm{~A}(\mathrm{c})$ for implementation on a nationwide basis

8 unless the State demonstrates to the satisfaction of

9 the Secretary that implementation would not be ad-

10 ministratively feasible or appropriate to the health

11 care delivery system of the State.".

12 SEC. 1908. APPLICATION OF EMERGENCY SERVICES LAWS.

13 Nothing in this Act shall be construed to relieve any

14 health care provider from providing emergency services as

15 required by State or Federal law, including section 1867

16 of the Social Security Act (popularly known as 17 "EMTALA").

18 SEC. 1909. DISREGARD UNDER THE SUPPLEMENTAL SECU-

RITY INCOME PROGRAM OF COMPENSATION

FOR PARTICIPATION IN CLINICAL TRIALS FOR RARE DISEASES OR CONDITIONS.

22 (a) Income DisRegard.-Section 1612(b) of the So23 cial Security Act (42 U.S.C. 1382a(b)) is amended-

(1) by striking "and" at the end of paragraph $25 \quad(24)$; 
(2) by striking the period at the end of para-

2 graph (25) and inserting "; and"; and

(3) by adding at the end the following:

“(26) The first $\$ 2,000$ per year received by

5 such individual (or such spouse) for participation in

6 a clinical trial to test a treatment for a rare disease

7 or condition (within the meaning of section $5(\mathrm{~b})(2)$

8 of the Orphan Drug Act (Public Law 97-414)),

9 that-

10 "(A) has been reviewed and approved by 11 an institutional review board that-

"(i) is established to protect the rights and welfare of human subjects participating in research; and "(ii) meet the standards for such bodies set forth in part 46 of title 45 , Code of Federal Regulations; and "(B) meets the standards for protection of

(b) Resource DisRegard.- -Section 1613(a) of 22 such Act (42 U.S.C. 1382b(a)) is amendedhuman subjects for clinical research (as set forth in such part).".

$24 \quad(15)$; 
(2) by striking the period at the end of paragraph (16) and inserting "; and"; and

(3) by inserting after paragraph (16) the fol-

4 lowing:

"(17) the first $\$ 2,000$ per year received by such

6 individual (or such spouse) for participation in a

7 clinical trial, as described in section 1612(b)(26).".

8 (c) EFFECTIVE Date.-The amendments made by

9 this section shall apply to benefits payable for calendar

10 months beginning after the earlier of-

(1) the date the Commissioner of Social Secu-

12 rity promulgates regulations to carry out the amend-

13 ments; or

(2) the 180-day period that begins with the 15 date of the enactment of this Act.

\section{DIVISION C-PUBLIC HEALTH AND WORKFORCE DEVELOP- 18 MENT}

19 SEC. 2001. TABLE OF CONTENTS; REFERENCES.

20 (a) TABle of Contents.-The table of contents of 21 this division is as follows:

Sec. 2001. Table of contents; references.

Sec. 2002. Public Health Investment Fund.

Sec. 2003. Deficit neutrality.

TITLE I-COMMUNITY HEALTH CENTERS

Sec. 2101. Increased funding.

TITLE II-WORKFORCE 
Subtitle A-Primary Care Workforce

Part 1-National Health Service Corps

Sec. 2201. National Health Service Corps.

Sec. 2202. Authorizations of appropriations.

\section{Part 2-Promotion of Primary Care and Dentistry}

Sec. 2211. Frontline health providers.

"SUBPART XI-HEALTH PROFESSIONAL NEEDS AREAS

"Sec. 340H. In general.

"Sec. 340I. Loan repayments.

"Sec. 340J. Report.

"Sec. 340K. Allocation.

Sec. 2212. Primary care student loan funds.

Sec. 2213. Training in family medicine, general internal medicine, general pediatrics, geriatrics, and physician assistants.

Sec. 2214. Training of medical residents in community-based settings.

Sec. 2215. Training for general, pediatric, and public health dentists and dental hygienists.

Sec. 2216. Authorization of appropriations.

Sec. 2217. Study on effectiveness of scholarships and loan repayments.

Subtitle B-Nursing Workforce

Sec. 2221. Amendments to Public Health Service Act.

Subtitle C-Public Health Workforce

Sec. 2231. Public Health Workforce Corps.

"SUBPART XII-PUBLIC HEALTH WORKFORCE

"Sec. 340L. Public Health Workforce Corps.

"Sec. 340M. Public Health Workforce Scholarship Program.

"Sec. 340N. Public Health Workforce Loan Repayment Program.

Sec. 2232. Enhancing the public health workforce.

Sec. 2233. Public health training centers.

Sec. 2234. Preventive medicine and public health training grant program.

Sec. 2235. Authorization of appropriations.

Subtitle D-Adapting Workforce to Evolving Health System Needs

Part 1-Health Professions Training for Diversity

Sec. 2241. Scholarships for disadvantaged students, loan repayments and fellowships regarding faculty positions, and educational assistance in the health professions regarding individuals from disadvantaged backgrounds.

Sec. 2242. Nursing workforce diversity grants.

Sec. 2243. Coordination of diversity and cultural competency programs.

Part 2-Interdisciplinary Training Programs

Sec. 2251. Cultural and linguistic competency training for health professionals. Sec. 2252. Innovations in interdisciplinary care training. 


\section{1}

Part 3-Advisory Committee on Health Workforce Evaluation and Assessuent

Sec. 2261. Health workforce evaluation and assessment.

Part 4-Health Workforce Assessment

Sec. 2271. Health workforce assessment.

Part 5-Authorization of Appropriations

Sec. 2281. Authorization of appropriations.

TITLE III-PREVENTION AND WELLNESS

Sec. 2301. Prevention and wellness.

"TITLE XXXI-PREVENTION AND WELLNESS

"Subtitle A-Prevention and Wellness Trust

"Sec. 3111. Prevention and Wellness Trust.

"Subtitle B-National Prevention and Wellness Strategy

"Sec. 3121. National Prevention and Wellness Strategy.

"Subtitle C-Prevention Task Forces

"Sec. 3131. Task Force on Clinical Preventive Services.

"Sec. 3132. Task Force on Community Preventive Services.

"Subtitle D-Prevention and Wellness Research

"Sec. 3141. Prevention and wellness research activity coordination.

"Sec. 3142. Community prevention and wellness research grants.

"Sec. 3143. Research on subsidies and rewards to encourage wellness and healthy behaviors.

"Subtitle E-Delivery of Community Prevention and Wellness Services

"Sec. 3151. Community prevention and wellness services grants.

"Subtitle F-Core Public Health Infrastructure

"Sec. 3161. Core public health infrastructure for State, local, and tribal health departments.

"Sec. 3162. Core public health infrastructure and activities for CDC.

"Subtitle G-General Provisions

"Sec. 3171. Definitions.

TITLE IV—QUALITY AND SURVEILLANCE

Sec. 2401. Implementation of best practices in the delivery of health care.

Sec. 2402. Assistant Secretary for Health Information.

Sec. 2403. Authorization of appropriations.

TITLE V-OTHER PROVISIONS 


\section{2}

Subtitle A-Drug Discount for Rural and Other Hospitals; 340B Program Integrity

Sec. 2501. Expanded participation in 340B program.

Sec. 2502. Improvements to $340 \mathrm{~B}$ program integrity.

Sec. 2503. Effective date.

\section{Subtitle B-Programs \\ Part 1-Grants for Clinics and Centers}

Sec. 2511. School-based health clinics.

Sec. 2512. Nurse-Managed health centers.

Sec. 2513. Federally qualified behavioral health centers.

\section{Part 2-Other Grant Programs}

Sec. 2521. Comprehensive programs to provide education to nurses and create a pipeline to nursing.

Sec. 2522. Mental and behavioral health training.

Sec. 2523. Reauthorization of telehealth and telemedicine grant programs.

Sec. 2524. No child left unimmunized against influenza: demonstration program using elementary and secondary schools as influenza vaccination centers.

Sec. 2525. Extension of Wisewoman Program.

Sec. 2526. Healthy teen initiative to prevent teen pregnancy.

Sec. 2527. National training initiatives on autism spectrum disorders.

Sec. 2528. Implementation of medication management services in treatment of chronic diseases.

Sec. 2529. Postpartum depression.

Sec. 2530. Grants to promote positive health behaviors and outcomes.

Sec. 2531. Medical liability alternatives.

Sec. 2532. Infant mortality pilot programs.

Sec. 2533. Secondary school health sciences training program.

Sec. 2534. Community-based collaborative care networks.

Sec. 2535. Community-based overweight and obesity prevention program.

Sec. 2536. Reducing student-to-school nurse ratios.

Sec. 2537. Medical-legal partnerships.

\section{Part 3-Emergency Care-Related Programs}

Sec. 2551. Trauma care centers.

Sec. 2552. Emergency care coordination.

Sec. 2553. Pilot programs to improve emergency medical care.

Sec. 2554. Assisting veterans with military emergency medical training to become State-licensed or certified emergency medical technicians (EMTs).

Sec. 2555. Dental emergency responders: public health and medical response. Sec. 2556. Dental emergency responders: homeland security.

\section{Part 4-Pain Care and Management Programs}

Sec. 2561. Institute of Medicine Conference on Pain.

Sec. 2562. Pain research at National Institutes of Health.

Sec. 2563. Public awareness campaign on pain management.

Subtitle C-Food and Drug Administration 


\title{
Part 1-In General
}

Sec. 2571. National medical device registry.

Sec. 2572. Nutrition labeling of standard menu items at chain restaurants and of articles of food sold from vending machines.

Sec. 2573. Protecting consumer access to generic drugs.

\section{PART 2-Biosimilars}

Sec. 2575. Licensure pathway for biosimilar biological products.

Sec. 2576. Fees relating to biosimilar biological products.

Sec. 2577. Amendments to certain patent provisions.

Subtitle D—Community Living Assistance Services and Supports

Sec. 2581. Establishment of national voluntary insurance program for purchasing community living assistance services and support (CLASS program).

\section{"TITLE XXXII-COMMUNITY LIVING ASSISTANCE SERVICES AND SUPPORTS}

\author{
"Sec. 3201. Purpose. \\ "Sec. 3202. Definitions. \\ "Sec. 3203. CLASS Independence Benefit Plan. \\ "Sec. 3204. Enrollment and disenrollment requirements. \\ "Sec. 3205. Benefits. \\ "Sec. 3206. CLASS Independence Fund. \\ "Sec. 3207. CLASS Independence Advisory Council. \\ "Sec. 3208. Regulations; annual report. \\ "Sec. 3209. Inspector General's report.
}

Subtitle E-Miscellaneous

Sec. 2585. States failing to adhere to certain employment obligations.

Sec. 2586. Health centers under Public Health Service Act; liability protections for volunteer practitioners.

Sec. 2587. Report to Congress on the current state of parasitic diseases that have been overlooked among the poorest Americans.

Sec. 2588. Office of Women's Health.

Sec. 2589. Long-Term Care and Family Caregiver Support.

Sec. 2590. Web site on health care labor market and related educational and training opportunities.

Sec. 2591. Online health workforce training programs.

Sec. 2592. Access for individuals with disabilities.

1 (b) REFERENCES.-Except as otherwise specified,

2 whenever in this division an amendment is expressed in

3 terms of an amendment to a section or other provision,

4 the reference shall be considered to be made to a section 
1 or other provision of the Public Health Service Act (42

2 U.S.C. 201 et seq.).

3 SEC. 2002. PUBLIC HEALTH INVESTMENT FUND.

4

5

6 there is hereby established in the Treasury a sepa-

(a) Establishment of Funds.-

(1) In GENERAL.-Subject to section 2003, rate account to be known as the "Public Health Investment Fund" (referred to in this section and section 2003 as the "Fund").

(2) Funding.-

(A) There shall be deposited into the Fund-

(i) for fiscal year 2011, $\$ 4,600,000,000$;

(ii) for fiscal year 2012, $\$ 5,600,000,000$;

(iii) for fiscal year 2013, $\$ 6,900,000,000$;

(iv) for fiscal year 2014, $\$ 7,800,000,000$; and

(v) for fiscal year 2015, $\$ 9,000,000,000$.

(B) Amounts deposited into the Fund shall be derived from general revenues of the Treasury only for the fiscal years set forth in this 
section, and amounts appropriated from the

Fund shall remain available until expended.

(b) Authorization of Appropriations From the

4 FUND.-

5

6

7

8

9

10

11

12

13

14

15

16

17

18

19

20

21

22

23

24

25

\section{(1) New Funding.-}

(A) IN GENERAL.—Subject to section 2003, amounts in the Fund are authorized to be appropriated for carrying out activities under designated public health provisions.

(B) Designated PRovisions.-For purposes of this paragraph, the term "designated public health provisions" means the provisions for which amounts are authorized to be appropriated under section 330(s), 338(c), 338H-1, 799C, 872, or 3111 of the Public Health Service Act, as added by this division.

(2) Baseline Funding.-

(A) In General.-Amounts in the Fund are authorized to be appropriated (as described in paragraph (1)) for a fiscal year only if (excluding any amounts in or appropriated from the Fund)—

(i) the amounts specified in subparagraph (B) for the fiscal year involved are equal to or greater than the amounts spec- 
ified in subparagraph (B) for fiscal year 2008; and

(ii) the amounts appropriated, out of the general fund of the Treasury, to the Prevention and Wellness Trust under section 3111(a)(1) of the Public Health Service Act, as added by this division, for the fiscal year involved are equal to or greater than the funds-

(I) appropriated under the heading "Prevention and Wellness Fund" in title VIII of division A of the American Recovery and Reinvestment Act of 2009 (Public Law 111-5); and (II) allocated by the second proviso under such heading for evidencebased clinical and community-based prevention and wellness strategies.

(B) Amounts specified.-The amounts specified in this subparagraph, with respect to a fiscal year, are the amounts appropriated for the following:

(i) Community health centers (including funds appropriated under the authority 
of section 330 of the Public Health Service Act (42 U.S.C. 254b)).

(ii) The National Health Service Corps Program (including funds appropriated under the authority of section 338 of such Act (42 U.S.C. 254k)).

(iii) The National Health Service Corps Scholarship and Loan Repayment Programs (including funds appropriated under the authority of section $338 \mathrm{H}$ of such Act (42 U.S.C. 254q)).

(iv) Primary care education programs (including funds appropriated under the authority of sections 736, 740, 741, and 747 of such Act (42 U.S.C. 293, 293d, and $293 \mathrm{k}))$.

(v) Sections 761 and 770 of such Act (42 U.S.C. $294 \mathrm{n}$ and $295 \mathrm{e}$ ).

(vi) Nursing workforce development (including funds appropriated under the authority of title VIII of such Act (42 U.S.C. 296 et seq.)).

(vii) The National Center for Health Statisties (including funds appropriated under the authority of sections 304, 306, 

search and Quality (including funds appropriated under the authority of title IX of such Act (42 U.S.C. 299 et seq.)).

\section{SEC. 2003. DEFICIT NEUTRALITY.}

8 (a) Availability.-Funds appropriated or made 9 available pursuant to sections $330(\mathrm{~s}), 338(\mathrm{c}), 338 \mathrm{H}-1$, 10 799C, 872, or 3111 of the Public Health Service Act, as 11 added by this division, are only available for the purposes 12 set forth in this Act. Appropriations shall not be available 13 and are precluded from obligation for any other purpose.

(b) Estimation of Budgetary Impact.-For the 15 purposes of estimating the spending effects of this Act, 16 the authorization of appropriations from the Fund, to the 17 extent amounts in the Fund are derived from the general 18 revenues of the Treasury, shall be treated as new direct 19 spending and attributed to this Act.

(c) Budgetary Treatment.-For the purposes of 21 section 257 of the Balanced Budget and Emergency Def22 icit Control Act of 1985, the Fund, to the extent amounts 23 in the Fund are derived from the general revenues of the 24 Treasury, and not in excess of amounts subsequently ap25 propriated from the Fund, shall be deemed to be included 
1 on the list of appropriations referenced under section $2250(\mathrm{c})(17)$ of that Act.

3 TITLE I-COMMUNITY HEALTH

\section{CENTERS}

5 SEC. 2101. INCREASED FUNDING.

6 Section 330 of the Public Health Service Act (42

7 U.S.C. 254b) is amended-

(1) in subsection $(r)(1)-$

(A) in subparagraph (D), by striking "and" at the end;

(B) in subparagraph (E), by striking the period at the end and inserting "; and"; and

(C) by inserting at the end the following: "(F) such sums as may be necessary for each of fiscal years 2013 through 2015."; and

17 lowing:

18 “(s) AdDitional Funding.-For the purpose of 19 carrying out this section, in addition to any other amounts 20 authorized to be appropriated for such purpose, there are 21 authorized to be appropriated, out of any monies in the 22 Public Health Investment Fund, the following:

“(1) For fiscal year 2011, \$1,000,000,000. 
“(4) For fiscal year 2014, $\$ 3,000,000,000$.

“(5) For fiscal year 2015, \$4,000,000,000.”.

\section{TITLE II-WORKFORCE} Subtitle A-Primary Care Workforce

\section{PART 1-NATIONAL HEALTH SERVICE CORPS}

SEC. 2201. NATIONAL HEALTH SERVICE CORPS.

(a) Fulfillment of Obligated Service ReQuirement Through Half-Time Service.-

(1) WaIvers.-Wubsection (i) of section 331 (42 U.S.C. 254d) is amended-

(A) in paragraph (1), by striking "In carrying out subpart III" and all that follows through the period and inserting "In carrying out subpart III, the Secretary may, in accordance with this subsection, issue waivers to individuals who have entered into a contract for obligated service under the Scholarship Program or the Loan Repayment Program under which the individuals are authorized to satisfy the requirement of obligated service through providing clinical practice that is half-time.";

(B) in paragraph (2)- 
(i) in subparagraphs (A)(ii) and (B), by striking "less than full time" each place it appears and inserting "half time";

(ii) in subparagraphs (C) and (F), by striking "less than full-time service" each place it appears and inserting "half-time service"; and

(iii) by amending subparagraphs (D) and (E) to read as follows:

"(D) the entity and the Corps member agree in writing that the Corps member will perform halftime clinical practice;

"(E) the Corps member agrees in writing to fulfill all of the service obligations under section 338C through half-time clinical practice and either-

"(i) double the period of obligated service that would otherwise be required; or "(ii) in the case of contracts entered into under section $338 \mathrm{~B}$, accept a minimum service obligation of 2 years with an award amount equal to 50 percent of the amount that would otherwise be payable for full-time service; and"; and 
(C) in paragraph (3), by striking "In evaluating a demonstration project described in paragraph (1)" and inserting "In evaluating waivers issued under paragraph (1)".

(2) Definitions.-Subsection (j) of section

6331 (42 U.S.C. 254d) is amended by adding at the 7 end the following:

“(5) The terms 'full time' and 'full-time' mean

9 a minimum of 40 hours per week in a clinical prac10 tice, for a minimum of 45 weeks per year. “(6) The terms 'half time' and 'half-time' mean 12 a minimum of 20 hours per week (not to exceed 39 13 hours per week) in a clinical practice, for a min14 imum of 45 weeks per year.".

15 (b) Reappointment to National Advisory Coun16 CIL.-Section 337(b)(1) (42 U.S.C. 254j(b)(1)) is amend17 ed by striking "Members may not be reappointed to the 18 Council.".

19 (c) Loan Repayment Amount.-Section $20338 \mathrm{~B}(\mathrm{~g})(2)(\mathrm{A})$ (42 U.S.C. $254 \mathrm{l}-1(\mathrm{~g})(2)(\mathrm{A}))$ is amended 21 by striking “ $\$ 35,000$ ” and inserting “ $\$ 50,000$, plus, be22 ginning with fiscal year 2012, an amount determined by 23 the Secretary on an annual basis to reflect inflation,". 24 (d) Treatment of Teaching as Obligated Serv25 ICE.-Subsection (a) of section 338C (42 U.S.C. 254m) 
1223

1 is amended by adding at the end the following: "The Sec-

2 retary may treat teaching as clinical practice for up to

320 percent of such period of obligated service.".

4 SEC. 2202. AUTHORIZATIONS OF APPROPRIATIONS.

5 (a) National Health Service Corps Pro-

6 GRAM.-Section 338 (42 U.S.C. 254k) is amended-

(1) in subsection (a), by striking " 2012 " and

$8 \quad$ inserting " 2015 ”; and

(2) by adding at the end the following:

10 “(c) For the purpose of carrying out this subpart,

11 in addition to any other amounts authorized to be appro-

12 priated for such purpose, there are authorized to be appro-

13 priated, out of any monies in the Public Health Invest-

14 ment Fund, the following:

15

16

17

18

19

20

21 GRAMS.-Subpart III of part D of title III of the Public

22 Health Service Act (42 U.S.C. 2541 et seq.) is amended-

“(1) $\$ 63,000,000$ for fiscal year 2011.

“(2) $\$ 66,000,000$ for fiscal year 2012.

“(3) $\$ 70,000,000$ for fiscal year 2013.

“(4) $\$ 73,000,000$ for fiscal year 2014.

“(5) $\$ 77,000,000$ for fiscal year 2015.”.

(b) Scholarship and Loan Repayment Pro-

(1) in section $338 \mathrm{H}(\mathrm{a})-$

25

(A) in paragraph (4), by striking "and" at the end; 
(B) in paragraph (5), by striking the period at the end and inserting "; and"; and

(C) by adding at the end the following:

"(6) for each of fiscal years 2013 through

$5 \quad 2015$, such sums as may be necessary."; and

6 (2) by inserting after section $338 \mathrm{H}$ the fol-

7 lowing:

8 “SEC. 338H-1. ADDITIONAL FUNDING.

9 "For the purpose of carrying out this subpart, in ad-

10 dition to any other amounts authorized to be appropriated

11 for such purpose, there are authorized to be appropriated,

12 out of any monies in the Public Health Investment Fund,

13 the following:

“(1) $\$ 254,000,000$ for fiscal year 2011.

“(2) $\$ 266,000,000$ for fiscal year 2012.

16

“(3) $\$ 278,000,000$ for fiscal year 2013.

“(4) \$292,000,000 for fiscal year 2014.

“(5) $\$ 306,000,000$ for fiscal year 2015.”.

19 PART 2-PROMOTION OF PRIMARY CARE AND

DENTISTRY

\section{SEC. 2211. FRONTLINE HEALTH PROVIDERS.}

22 Part D of title III (42 U.S.C. $254 \mathrm{~b}$ et seq.) is amend23 ed by adding at the end the following: 


\section{1 "Subpart XI-Health Professional Needs Areas}

2 "SEC. 340H. IN GENERAL.

3 "(a) Program.-The Secretary, acting through the

4 Administrator of the Health Resources and Services Ad-

5 ministration, shall establish a program, to be known as

6 the Frontline Health Providers Loan Repayment Pro-

7 gram, to address unmet health care needs in health profes-

8 sional needs areas through loan repayments under section

$9340 \mathrm{I}$.

10 “(b) Designation of Health Professional

11 Needs Areas.-

12 "(1) In GENERAL.-In this subpart, the term

13 'health professional needs area' means an area, pop-

14 ulation, or facility that is designated by the Sec-

15 retary in accordance with paragraph (2).

16 "(2) Designation.-To be designated by the

17 Secretary as a health professional needs area under

18 this subpart:

"(A) In the case of an area, the area must be a rational area for the delivery of health services.

"(B) The area, population, or facility must have, in one or more health disciplines, specialties, or subspecialties for the population served, as determined by the Secretary- 
"(i) insufficient capacity of health

professionals; or

"(ii) high needs for health services, including services to address health disparities.

"(C) With respect to the delivery of primary health services, the area, population, or facility must not include a health professional shortage area (as designated under section 332 ), except that the area, population, or facility may include such a health professional shortage area in which there is an unmet need for such services.

15 the Program, an individual shall-

"(1) hold a degree in a course of study or pro17 gram (approved by the Secretary) from a school de18 fined in section $799 \mathrm{~B}(1)(\mathrm{A})$ (other than a school of 19 public health); "(2) hold a degree in a course of study or pro21 gram (approved by the Secretary) from a school or 22 program defined in subparagraph (C), (D), or 23 (E)(4) of section 799B(1), as designated by the Sec24 retary;

25 "(3) be enrolled as a full-time student- 
"(A) in a school or program defined in subparagraph (C), (D), or (E)(4) of section 799B(1), as designated by the Secretary, or a school described in paragraph (1); and

"(B) in the final year of a course of study or program, offered by such school or program and approved by the Secretary, leading to a degree in a discipline referred to in subparagraph (A) (other than a graduate degree in public health), (C), (D), or (E)(4) of section 799B(1); "(4) be a practitioner described in section $1842(\mathrm{~b})(18)(\mathrm{C})$ or $1848(\mathrm{k})(3)(\mathrm{B})(\mathrm{iii})$ or (iv) of the

13 Social Security Act; or

"(5) be a practitioner in the field of respiratory 15 therapy, medical technology, or radiologic tech16 nology.

17 “(d) Definitions.-In this subpart: "(1) The term 'health disparities' has the 19 meaning given to the term in section 3171. "(2) The term 'primary health services' has the 21 meaning given to such term in section 331(a)(3)(D).

\section{2 “SEC. 340I. LOAN REPAYMENTS.}

23 "(a) LoAN REPayments.-The Secretary, acting 24 through the Administrator of the Health Resources and 
1 Services Administration, shall enter into contracts with in-

2 dividuals under which-

"(1) the individual agrees-

"(A) to serve as a full-time primary health services provider or as a full-time or part-time provider of other health services for a period of time equal to 2 years or such longer period as the individual may agree to;

"(B) to serve in a health professional needs area in a health discipline, specialty, or a subspecialty for which the area, population, or facility is designated as a health professional needs area under section $340 \mathrm{H}$; and

"(C) in the case of an individual described in section $340 \mathrm{H}(\mathrm{c})(3)$ who is in the final year of study and who has accepted employment as a primary health services provider or provider of other health services in accordance with subparagraphs (A) and (B), to complete the education or training and maintain an acceptable level of academic standing (as determined by the educational institution offering the course of study or training); and

"(2) the Secretary agrees to pay, for each year of such service, an amount on the principal and in- 
1 terest of the undergraduate or graduate educational

2 loans (or both) of the individual that is not more

3 than 50 percent of the average award made under

4 the National Health Service Corps Loan Repayment

5 Program under subpart III in that year.

6 “(b) Practice Setting.-A contract entered into

7 under this section shall allow the individual receiving the

8 loan repayment to satisfy the service requirement de-

9 scribed in subsection (a)(1) through employment in a solo

10 or group practice, a clinic, an accredited public or private

11 nonprofit hospital, or any other health care entity, as

12 deemed appropriate by the Secretary.

13 “(c) Application of Certain Provisions.-The

14 provisions of subpart III of part D shall, except as incon-

15 sistent with this section, apply to the loan repayment pro-

16 gram under this subpart in the same manner and to the

17 same extent as such provisions apply to the National

18 Health Service Corps Loan Repayment Program estab-

19 lished under section 338B.

20 “(d) Insufficient Number of Applicants.-If

21 there are an insufficient number of applicants for loan re-

22 payments under this section to obligate all appropriated

23 funds, the Secretary shall transfer the unobligated funds

24 to the National Health Service Corps for the purpose of

25 recruiting applicants and entering into contracts with indi- 
1 viduals so as to ensure a sufficient number of participants

2 in the National Health Service Corps for the following 3 year.

4 “SEC. 340J. REPORT.

5 "The Secretary shall submit to the Congress an an6 nual report on the program carried out under this subpart.

7 “SEC. 340K. ALLOCATION.

8 "Of the amount of funds obligated under this subpart

9 each fiscal year for loan repayments-

10 “(1) 90 percent shall be for physicians and 11 other health professionals providing primary health 12 services; and

13 "(2) 10 percent shall be for health professionals 14 not described in paragraph (1).".

15 SEC. 2212. PRIMARY CARE STUDENT LOAN FUNDS.

16 (a) In GENERAL.-Section 735 (42 U.S.C. 292y) is 17 amended-

18 (1) by redesignating subsection (f) as sub19 section $(\mathrm{g})$; and

20 (2) by inserting after subsection (e) the fol21 lowing:

22 “(f) Determination of Financial Need.-The 23 Secretary-

24 "(1) may require, or authorize a school or other 25 entity to require, the submission of financial infor- 
1 mation to determine the financial resources available

2 to any individual seeking assistance under this sub-

3 part; and

$4 \quad$ "(2) shall take into account the extent to which

5 such individual is financially independent in deter-

6 mining whether to require or authorize the submis-

7 sion of such information regarding such individual's

8 family members.".

9 (b) Revised Guidelines.-The Secretary of Health 10 and Human Services shall—

11 (1) strike the second sentence of section $1257.206(\mathrm{~b})(1)$ of title 42, Code of Federal Regula13 tions; and

14 (2) make such other revisions to guidelines and 15 regulations in effect as of the date of the enactment 16 of this Act as may be necessary for consistency with 17 the amendments made by paragraph (1).

18 SEC. 2213. TRAINING IN FAMILY MEDICINE, GENERAL IN-

TERNAL MEDICINE, GENERAL PEDIATRICS, GERIATRICS, AND PHYSICIAN ASSISTANTS.

21 Section 747 (42 U.S.C. 293k) is amended-

22 (1) by amending the section heading to read as

23 follows: "PRIMARY CARE TRAINING AND EN24 HANCEMENT"; 
(2) by redesignating subsection (e) as sub-

2 section $(\mathrm{g})$; and

(3) by striking subsections (a) through (d) and

4 inserting the following:

5 “(a) Program.-The Secretary shall establish a pri6 mary care training and capacity building program con-

7 sisting of awarding grants and contracts under sub8 sections (b) and (c).

9 “(b) Support and Development of Primary 10 Care Training Programs.-

"(1) In GENERAL.-The Secretary shall make

12 grants to, or enter into contracts with, eligible enti13 tiespate in an accredited professional training program, including an accredited residency or internship program, in the field of family medicine, general internal medicine, general pediatries, or geriatrics for medical students, interns, residents, or practicing physicians;

"(B) to provide financial assistance in the form of traineeships and fellowships to medical students, interns, residents, or practicing physicians, who are participants in any such program, and who plan to specialize or work in 
1 family medicine, general internal medicine, gen-

eral pediatrics, or geriatries;

"(C) to plan, develop, operate, or participate in an accredited program for the training of physicians who plan to teach in family medicine, general internal medicine, general pediatries, or geriatrics training programs including in community-based settings;

"(D) to provide financial assistance in the form of traineeships and fellowships to practicing physicians who are participants in any such programs and who plan to teach in a family medicine, general internal medicine, general pediatrics, or geriatrics training program; and "(E) to plan, develop, operate, or participate in an accredited program for physician assistant education, and for the training of individuals who plan to teach in programs to provide such training.

“(2) Eligibility.-To be eligible for a grant or contract under paragraph (1), an entity shall be-

"(A) an accredited school of medicine or osteopathic medicine, public or nonprofit private 
23 under this section, the Secretary shall give preference to 24 entities that have a demonstrated record of at least one 25 of the following:

"(B) a public or private nonprofit entity;

$\mathrm{Or}$

"(C) a consortium of 2 or more entities described in subparagraphs (A) and (B).

“(c) Capacity Building in Primary Care."(1) IN GENERAL.—The Secretary shall make grants to or enter into contracts with eligible entities to establish, maintain, or improve-

"(A) academic administrative units (including departments, divisions, or other appropriate units) in the specialties of family medicine, general internal medicine, general pediatries, or geriatrics; or

"(B) programs that improve clinical teaching in such specialties.

“(2) Eligibility.-To be eligible for a grant or contract under paragraph (1), an entity shall be an accredited school of medicine or osteopathic medicine.

“(d) Preference.-In awarding grants or contracts 
2 percentage of health professionals who provide pri3 mary care.

"(2) Training individuals who are from dis-

5 advantaged backgrounds (including racial and ethnic

6 minorities underrepresented among primary care

7 professionals).

8 "(3) A high rate of placing graduates in prac-

9 tice settings having the principal focus of serving in

10 underserved areas or populations experiencing health

11 disparities (including serving patients eligible for

12 medical assistance under title XIX of the Social Se-

13 curity Act or for child health assistance under title

14 XXI of such Act or those with special health care 15 needs).

16 “(4) Supporting teaching programs that ad17 dress the health care needs of vulnerable popu18 lations.

19 “(e) REPORT.-The Secretary shall submit to the 20 Congress an annual report on the program carried out 21 under this section.

22 “(f) Definition.-In this section, the term 'health 23 disparities' has the meaning given the term in section 24 3171.". 
1 SEC. 2214. TRAINING OF MEDICAL RESIDENTS IN COMMUNITY-BASED SETTINGS.

3 Title VII (42 U.S.C. 292 et seq.) is amended-

4 (1) by redesignating section 748 as $749 \mathrm{~A}$; and

5 (2) by inserting after section 747 the following:

6 “SEC. 748. TRAINING OF MEDICAL RESIDENTS IN COMMUNITY-BASED SETTINGS.

8 "(a) Program._-The Secretary shall establish a pro-

9 gram for the training of medical residents in community-

10 based settings consisting of awarding grants and contracts

11 under this section.

"(b) Development And Operation of Commu-

13 Nity-Based Programs.-The Secretary shall make

14 grants to, or enter into contracts with, eligible entities-

15 "(1) to plan and develop a new primary care

16 residency training program, which may include-

"(A) planning and developing curricula;

"(B) recruiting and training residents and faculty; and

"(C) other activities designated to result in accreditation of such a program; or "(2) to operate or participate in an established 23 primary care residency training program, which may 24 include-

"(A) planning and developing curricula; 
"(B) recruitment and training of residents;

2

17 ited teaching hospital to carry out the inpatient re18 sponsibilities associated with a primary care resi19 dency training program; or

and

"(C) retention of faculty.

“(c) Eligible Entity.-To be eligible to receive a “(1) be designated as a recipient of payment for the direct costs of medical education under section $1886(\mathrm{k})$ of the Social Security Act;

“(2) be designated as an approved teaching health center under section $1502(\mathrm{~d})$ of the Affordable Health Care for America Act and continuing to participate in the demonstration project under such section;

“(3) be an applicant for designation described in paragraph (1) or (2) and have demonstrated to the Secretary appropriate involvement of an accred"(4) be eligible to be designated as described in paragraph (1) or (2), not be an applicant as described in paragraph (3), and have demonstrated appropriate involvement of an accredited teaching hospital to carry out the inpatient responsibilities asso- 
1 ciated with a primary care residency training pro-

2 gram.

3 “(d) Preferences.-In awarding grants and con4 tracts under paragraph (1) or (2) of subsection (b), the 5 Secretary shall give preference to entities that-

$6 \quad$ "(1) support teaching programs that address 7 the health care needs of vulnerable populations; or "(2) are a Federally qualified health center (as 9 defined in section 1861(aa)(4) of the Social Security 10 Act) or a rural health clinic (as defined in section 11 1861(aa)(2) of such Act).

12 “(e) Additional Preferences for Established

13 Programs. - In awarding grants and contracts under 14 subsection (b)(2), the Secretary shall give preference to 15 entities that have a demonstrated record of training“(1) a high or significantly improved percentage 17 of health professionals who provide primary care;

18 "(2) individuals who are from disadvantaged 19 backgrounds (including racial and ethnic minorities 20 underrepresented among primary care professionals); $21 \quad$ or

22 "(3) individuals who practice in settings having 23 the principal focus of serving underserved areas or 24 populations experiencing health disparities (including 25 serving patients eligible for medical assistance under 
1239

1 title XIX of the Social Security Act or for child

2 health assistance under title XXI of such Act or

3 those with special health care needs).

4 “(f) Period of Awards.- -

5 "(1) In GENERAL.—The period of a grant or 6 contract under this section-

"(A) shall not exceed 3 years for awards

8

9

10

11

12

13

14

15

16

17

18

19

20 Congress an annual report on the program carried out 21 under this section.

22 “(h) Definitions.-In this section:

23

24 disparities' has the meaning given the term in sec25 tion 3171.

"(B) shall not exceed 5 years for awards under subsection $(b)(2)$.

“(2) Special Rules.-

"(A) An award of a grant or contract under subsection (b)(1) shall not be renewed.

"(B) The period of a grant or contract awarded to an entity under subsection (b)(2) shall not overlap with the period of any grant or contact awarded to the same entity under subsection $(b)(1)$.

"(g) REPORT.-The Secretary shall submit to the "(1) Health Disparities.-The term 'health 
“(2) Primary care Resident.-The term 'primary care resident' has the meaning given the term 3 in section $1886(\mathrm{~h})(5)(\mathrm{H})$ of the Social Security Act.

“(3) Primary care residency training ProGRAM.-The term 'primary care residency training 6 program' means an approved medical residency 7 training program described in section $1886(\mathrm{~h})(5)(\mathrm{A})$ 8 of the Social Security Act for primary care residents 9 that is"(A) in the case of entities seeking awards under subsection (b)(1), actively applying to be accredited by the Accreditation Council for Graduate Medical Education or the American under subsection (b)(2), so accredited.

17 "(i) Allocation of Funds.—Of the amount appro18 priated pursuant to section $799 \mathrm{C}$ (a) for a fiscal year, not 19 more than 17 percent of such amount shall be made avail20 able to carry out this section.".

21 SEC. 2215. TRAINING FOR GENERAL, PEDIATRIC, AND PUBLIC HEALTH DENTISTS AND DENTAL HYGIEN-

24 Title VII (42 U.S.C. 292 et seq.) is amended- 
(1) in section 791(a)(1), by striking "747 and 750" and inserting " 747,749 , and 750"; and

(2) by inserting after section 748, as added, the

4 following:

5 “SEC. 749. TRAINING FOR GENERAL, PEDIATRIC, AND PUBLIC HEALTH DENTISTS AND DENTAL HYGIENISTS.

8 "(a) Program.-The Secretary shall establish a 9 training program for oral health professionals consisting 10 of awarding grants and contracts under this section.

12 Health Training Programs.-The Secretary shall

13 make grants to, or enter into contracts with, eligible enti-

14 ties-

“(1) to plan, develop, operate, or participate in

16 an accredited professional training program for oral 17 health professionals;

“(2) to provide financial assistance to oral

19 health professionals who are in need thereof, who 20 are participants in any such program, and who plan 21 to work in general, pediatric, or public health den22 tistry, or dental hygiene;

23 "(3) to plan, develop, operate, or participate in 24 a program for the training of oral health profes- 
1 sionals who plan to teach in general, pediatric, or

2 public health dentistry, or dental hygiene;

"(4) to provide financial assistance in the form

4 of traineeships and fellowships to oral health profes-

5 sionals who plan to teach in general, pediatric, or

6 public health dentistry or dental hygiene;

"(5) to establish, maintain, or improve-

"(A) academic administrative units (including departments, divisions, or other appropriate units) in the specialties of general, pediatric, or public health dentistry; or

"(B) programs that improve clinical teaching in such specialties;

“(6) to plan, develop, operate, or participate in 15 predoctoral and postdoctoral training in general, pe16 diatric, or public health dentistry programs;

17 “(7) to plan, develop, operate, or participate in 18 a loan repayment program for full-time faculty in a 19 program of general, pediatric, or public health den20 tistry; and

21 "(8) to provide technical assistance to pediatric 22 dental training programs in developing and imple23 menting instruction regarding the oral health status, 24 dental care needs, and risk-based clinical disease 
1 management of all pediatric populations with an em2 phasis on underserved children.

3 “(c) Eligibility.-To be eligible for a grant or con4 tract under this section, an entity shall be-

16 under this section, the Secretary shall give preference to 17 entities that have a demonstrated record of at least one 18 of the following:

20 percentage of oral health professionals who practice 21 general, pediatric, or public health dentistry.

23 advantaged backgrounds (including racial and ethnic 24 minorities underrepresented among oral health pro25 fessionals). 
“(3) A high rate of placing graduates in prac-

2 tice settings having the principal focus of serving in

3 underserved areas or populations experiencing health

4 disparities (including serving patients eligible for

5 medical assistance under title XIX of the Social Se-

6 curity Act or for child health assistance under title

7 XXI of such Act or those with special health care

8 needs).

9 “(4) Supporting teaching programs that ad-

10 dress the oral health needs of vulnerable popu11 lations.

12 "(5) Providing instruction regarding the oral 13 health status, oral health care needs, and risk-based 14 clinical disease management of all pediatric popu15 lations with an emphasis on underserved children.

16 “(e) REPORT.-The Secretary shall submit to the 17 Congress an annual report on the program carried out 18 under this section.

19 “(f) Definitions.-In this section:

20 “(1) The term 'health disparities' has the 21 meaning given the term in section 3171.

22 “(2) The term 'oral health professional' means 23 an individual training or practicing- 
"(A) in general dentistry, pediatric dentistry, public health dentistry, or dental hygiene; or

"(B) another oral health specialty, as deemed appropriate by the Secretary.".

6 SEC. 2216. AUTHORIZATION OF APPROPRIATIONS.

(a) In General.-Part F of title VII (42 U.S.C.

$8295 \mathrm{j}$ et seq.) is amended by adding at the end the fol-

9 lowing:

10 "SEC. 799C. FUNDING THROUGH PUBLIC HEALTH INVESTMENT FUND. “(a) Promotion of Primary Care and Den-

13 TISTRY.-For the purpose of carrying out subpart XI of 14 part D of title III and sections 747,748 , and 749 , in addi15 tion to any other amounts authorized to be appropriated 16 for such purpose, there are authorized to be appropriated, 17 out of any monies in the Public Health Investment Fund, 18 the following: “(1) $\$ 240,000,000$ for fiscal year 2011. “(2) \$253,000,000 for fiscal year 2012. “(3) $\$ 265,000,000$ for fiscal year 2013. “(4) $\$ 278,000,000$ for fiscal year 2014. “(5) $\$ 292,000,000$ for fiscal year 2015.”. 
1747 (42 U.S.C. 293k) is amended by striking "2002” and

2 inserting " 2015 ".

3 SEC. 2217. STUDY ON EFFECTIVENESS OF SCHOLARSHIPS AND LOAN REPAYMENTS.

5 (a) STUDY.-The Comptroller General of the United

6 States shall conduct a study to determine the effectiveness

7 of scholarship and loan repayment programs under sub-

8 parts III and XI of part D of title III of the Public Health

9 Service Act, as amended or added by sections 2201 and

10 2211, including whether scholarships or loan repayments

11 are more effective in-

12 (1) incentivizing physicians, and other pro-

13 viders, to pursue careers in primary care specialties;

14 (2) retaining such primary care providers; and

15 (3) encouraging such primary care providers to

16 practice in underserved areas.

17 (b) REPORT.-Not later than 12 months after the 18 date of the enactment of this Act, the Comptroller General 19 shall submit to the Congress a report on the results of 20 the study under subsection (a).

\section{Subtitle B-Nursing Workforce}

22 SEC. 2221. AMENDMENTS TO PUBLIC HEALTH SERVICE ACT.

23 (a) Definitions.-Section 801 (42 U.S.C. 296 et 24 seq.) is amended- 
(1) in paragraph (1), by inserting "nurse-managed health centers," after "nursing centers,"; and

(2) by adding at the end the following:

“(16) Nurse-managed health Center.-

5 The term 'nurse-managed health center'"(A) means a nurse-practice arrangement, managed by one or more advanced practice nurses, that provides primary care or wellness services to underserved or vulnerable populations and is associated with an accredited school of nursing, Federally qualified health center, or independent nonprofit health or social services agency; and "(B) shall not be construed as changing State law requirements applicable to an advanced practice nurse or the authorized scope of 17 practice of such a nurse.".

18 (b) Grants for Health Professions Edu19 CATION.-Title VIII (42 U.S.C. 296 et seq.) is amended 20 by striking section 807 .

21 (c) REPORTS.-Part A of title VIII (42 U.S.C. 296 22 et seq.) is amended by adding at the end the following: 
1 “SEC. 809. REPORTS.

2 "The Secretary shall submit to the Congress a sepa3 rate annual report on the activities carried out under each 4 of sections $811,821,836,846 \mathrm{~A}$, and 861.'.

5 (d) Advanced Education Nursing Grants.-Sec6 tion $811(\mathrm{f})$ (42 U.S.C. $296 \mathrm{j}(\mathrm{f})$ ) is amended-

7

8

$9 \quad$ graph $(2)$; and

10 11 striking "that agrees" and all that follows through

12 the end and inserting: "that agrees to expend the 13 award-

"(A) to train advanced education nurses

(1) by striking paragraph (2);

(2) by redesignating paragraph (3) as para(3) in paragraph (2), as so redesignated, by who will practice in health professional shortage areas designated under section 332; or "(B) to increase diversity among advanced education nurses.".

(e) Nurse Education, Practice, and Retention Grants.-Section 831 (42 U.S.C. 296p) is amended-

1 (1) in subsection (b), by amending paragraph 2 (3) to read as follows: "(3) providing coordinated care, quality care, and other skills needed to practice nursing; or"; and 
1 (2) by striking subsection (e) and redesignating

2 subsections (f) through (h) as subsections (e)

3 through $(\mathrm{g})$, respectively.

4 (f) Student Lonns.-Subsection (a) of section 836

5 (42 U.S.C. 297b) is amended-

6 (1) by striking " $\$ 2,500 "$ and inserting $7 \quad$ “\$3,300”;

8 (2) by striking " $\$ 4,000 "$ and inserting $9 \quad " \$ 5,200 " ;$

10 (3) by striking “\$13,000" and inserting 11 "\$17,000"; and

12 (4) by adding at the end the following: "Begin13 ning with fiscal year 2012, the dollar amounts speci14 fied in this subsection shall be adjusted by an 15 amount determined by the Secretary on an annual 16 basis to reflect inflation.".

17 (g) LoAn Repayment.-Section 846 (42 U.S.C. 18 297n) is amended-

19 (1) in subsection (a), by amending paragraph 20 (3) to read as follows:

21 "(3) who enters into an agreement with the 22 Secretary to serve for a period of not less than 2 23 years-

24 "(A) as a nurse at a health care facility 25 with a critical shortage of nurses; or 
"(B) as a faculty member at an accredited school of nursing;"; and

(2) in subsection $(\mathrm{g})(1)$, by striking "to provide

4 health services" each place it appears and inserting

5 "to provide health services or serve as a faculty 6 member".

7 (h) Nurse Faculty Loan Program.-Paragraph 8 (2) of section $846 \mathrm{~A}(\mathrm{c})$ (42 U.S.C. $297 \mathrm{n}-1(\mathrm{c})$ ) is amended 9 by striking " $\$ 30,000 "$ and all that follows through the 10 semicolon and inserting " $\$ 35,000$, plus, beginning with 11 fiscal year 2012, an amount determined by the Secretary 12 on an annual basis to reflect inflation;".

13 (i) Public Service Announcements.-Title VIII 14 (42 U.S.C. 296 et seq.) is amended by striking part H. 15 (j) Technical and Conforming Amendments.16 Title VIII (42 U.S.C. 296 et seq.) is amended-

17 (1) by moving section 810 (relating to prohibi18 tion against discrimination by schools on the basis of 19 sex) so that it follows section 809, as added by sub20 section $(\mathrm{c})$;

21 (2) in sections $835,836,838,840$, and 842 , by 22 striking the term "this subpart" each place it ap23 pears and inserting "this part";

24 (3) in section $836(\mathrm{~h})$, by striking the last sen25 tence; 
1 (4) in section 836, by redesignating subsection

$2 \quad(\mathrm{l})$ as subsection $(\mathrm{k})$;

3 (5) in section 839, by striking " 839 " and all 4 that follows through "(a)" and inserting "839. (a)";

$5 \quad$ (6) in section 835(b), by striking "841" each 6 place it appears and inserting " 871 ";

$7 \quad$ (7) by redesignating section 841 as section 871 , 8 moving part $\mathrm{F}$ to the end of the title, and redesig$9 \quad$ nating such part as part $\mathrm{H}$;

10 (8) in part $\mathrm{G}-$

11 (A) by redesignating section 845 as section 12 851; and

13 (B) by redesignating part $\mathrm{G}$ as part $\mathrm{F}$; and 14 (9) in part I-

15 (A) by redesignating section 855 as section 16 861; and

17 (B) by redesignating part I as part G.

18 (k) FUNDING.-

19 (1) In GENERAL.-Part $\mathrm{H}$, as redesignated, of 20 title VIII is amended by adding at the end the fol21 lowing:

22 "SEC. 872. FUNDING THROUGH PUBLIC HEALTH INVEST23 MENT FUND.

24 "For the purpose of carrying out this title, in addi25 tion to any other amounts authorized to be appropriated 
1 for such purpose, there are authorized to be appropriated,

2 out of any monies in the Public Health Investment Fund, 3 the following:

4

5

6

7

8

9

10

11

12

13

14

15

16

17

18

19

“(1) $\$ 115,000,000$ for fiscal year 2011.

“(2) \$122,000,000 for fiscal year 2012.

“(3) $\$ 127,000,000$ for fiscal year 2013.

“(4) \$134,000,000 for fiscal year 2014.

“(5) $\$ 140,000,000$ for fiscal year 2015.”.

(2) Existing authorizations of APPROPRIATIONS.-

(A) SECTIONs 831, 846, 846A, AND 861.Sections 831(g) (as so redesignated), 846(i)(1) (42 U.S.C. $297 \mathrm{n}(\mathrm{i})(1)), 846 \mathrm{~A}(\mathrm{f})$ (42 U.S.C. 297n-1(f)), and 861(e) (as so redesignated) are amended by striking " 2007 ” each place it appears and inserting " 2015 ”.

(B) Section 871.-Section 871, as so redesignated by subsection $(\mathrm{j})$, is amended to read as follows:

20 "SEC. 871. FUNDING.

21 "For the purpose of carrying out parts B, C, and D

22 (subject to section $851(\mathrm{~g})$ ), there are authorized to be ap23 propriated such sums as may be necessary for each fiscal 24 year through fiscal year 2015.". 
3 SEC. 2231. PUBLIC HEALTH WORKFORCE CORPS.

4 Part D of title III (42 U.S.C. 254b et seq.), as

5 amended by section 2211, is amended by adding at the

6 end the following:

8 “SEC. 340L. PUBLIC HEALTH WORKFORCE CORPS.

9 “(a) Establishment.-There is established, within

10 the Service, the Public Health Workforce Corps (in this

11 subpart referred to as the 'Corps'), for the purpose of en-

12 suring an adequate supply of public health professionals

13 throughout the Nation. The Corps shall consist of-

"(1) such officers of the Regular and Reserve

15 Corps of the Service as the Secretary may designate; "(2) such civilian employees of the United

$17 \quad$ States as the Secretary may appoint; and "(3) such other individuals who are not employ-

19 ees of the United States.

20 “(b) Administration.-Except as provided in sub21 section (c), the Secretary shall carry out this subpart act22 ing through the Administrator of the Health Resources 23 and Services Administration.

24 “(c) Placement and Assignment.-The Secretary, 25 acting through the Director of the Centers for Disease 
1 Control and Prevention, shall develop a methodology for

2 placing and assigning Corps participants as public health 3 professionals. Such methodology may allow for placing and 4 assigning such participants in State, local, and tribal

5 health departments and Federally qualified health centers 6 (as defined in section 1861(aa)(4) of the Social Security 7 Act).

8 “(d) Application of Certain Provisions.-The 9 provisions of subpart II shall, except as inconsistent with 10 this subpart, apply to the Public Health Workforce Corps 11 in the same manner and to the same extent as such provi12 sions apply to the National Health Service Corps estab13 lished under section 331.

14 “(e) REPORT.-The Secretary shall submit to the 15 Congress an annual report on the programs carried out 16 under this subpart.

17 "SEC. 340M. PUBLIC HEALTH WORKFORCE SCHOLARSHIP 18 PROGRAM.

19 “(a) Establishment.-The Secretary shall estab20 lish the Public Health Workforce Scholarship Program 21 (referred to in this section as the 'Program') for the pur22 pose described in section $340 \mathrm{~L}(\mathrm{a})$.

23 “(b) Eligibility.-To be eligible to participate in 24 the Program, an individual shall- 
"(1)(A) be accepted for enrollment, or be en-

2 rolled, as a full-time or part-time student in a course

3 of study or program (approved by the Secretary) at

4 an accredited graduate school or program of public

5 health; or

6 "(B) have demonstrated expertise in public

7 health and be accepted for enrollment, or be en-

8 rolled, as a full-time or part-time student in a course

9 of study or program (approved by the Secretary)

10 at-

“(i) an accredited graduate school or program of nursing; health administration, management, or policy; preventive medicine; laboratory science; veterinary medicine; or dental medicine; or

"(ii) another accredited graduate school or program, as deemed appropriate by the Secretary; "(2) be eligible for, or hold, an appointment as 20 a commissioned officer in the Regular or Reserve 21 Corps of the Service or be eligible for selection for 22 civilian service in the Corps; and

23 "(3) sign and submit to the Secretary a written 24 contract (described in subsection (c)) to serve full25 time as a public health professional, upon the com- 
1 pletion of the course of study or program involved,

2 for the period of obligated service described in sub3 section $(\mathrm{c})(2)(\mathrm{E})$.

4 “(c) CONTRACT.-The written contract between the 5 Secretary and an individual under subsection (b)(3) shall 6 contain-

7

8

9

10

11

12

13

14

15

16

17

18
"(1) an agreement on the part of the Secretary that the Secretary will-

"(A) provide the individual with a scholarship for a period of years (not to exceed 4 academic years) during which the individual shall pursue an approved course of study or program to prepare the individual to serve in the public health workforce; and

"(B) accept (subject to the availability of appropriated funds) the individual into the Corps;

"(2) an agreement on the part of the individual that the individual will-

"(A) accept provision of such scholarship to the individual;

“(B) maintain full-time or part-time enrollment in the approved course of study or program described in subsection (b)(1) until the in- 
dividual completes that course of study or program;

"(C) while enrolled in the approved course of study or program, maintain an acceptable

"(i) 1 year for each academic year for which the individual was provided a scholarship under the Program; or

"(ii) 2 years; and

"(3) an agreement by both parties as to the nature and extent of the scholarship assistance, which may include-

"(A) payment of reasonable educational expenses of the individual, including tuition, fees, books, equipment, and laboratory expenses; and "(B) payment of a stipend of not more than $\$ 1,269$ (plus, beginning with fiscal year 2012, an amount determined by the Secretary 
on an annual basis to reflect inflation) per month for each month of the academic year involved, with the dollar amount of such a stipend determined by the Secretary taking into consideration whether the individual is enrolled fulltime or part-time.

8 provisions of subpart III shall, except as inconsistent with

9 this subpart, apply to the scholarship program under this

10 section in the same manner and to the same extent as

11 such provisions apply to the National Health Service

12 Corps Scholarship Program established under section

$13338 \mathrm{~A}$.

14 "SEC. 340N. PUBLIC HEALTH WORKFORCE LOAN REPAYMENT PROGRAM.

16 “(a) Establishment.-The Secretary shall estab17 lish the Public Health Workforce Loan Repayment Pro18 gram (referred to in this section as the 'Program') for the 19 purpose described in section 340L(a).

20 “(b) Eligibility.-To be eligible to participate in 21 the Program, an individual shall"(1)(A) have a graduate degree from an accred23 ited school or program of public health; "(B) have demonstrated expertise in public 25 health and have a graduate degree in a course of 
1 study or program (approved by the Secretary)

2 from-

"(i) an accredited school or program of nursing; health administration, management, or policy; preventive medicine; laboratory science; veterinary medicine; or dental medicine; or

“(ii) another accredited school or program approved by the Secretary; or

“(C) be enrolled as a full-time or part-time student in the final year of a course of study or program (approved by the Secretary) offered by a school or program described in subparagraph (A) or (B), leading to a graduate degree;

"(2) be eligible for, or hold, an appointment as a commissioned officer in the Regular or Reserve Corps of the Service or be eligible for selection for civilian service in the Corps;

“(3) if applicable, complete a residency or internship; and

"(4) sign and submit to the Secretary a written contract (described in subsection (c)) to serve fulltime as a public health professional for the period of obligated service described in subsection $(c)(2)$. 
1 “(c) CONTRACT.-The written contract between the

2 Secretary and an individual under subsection (b)(4) shall 3 contain-

“(1) an agreement by the Secretary to repay on

5 behalf of the individual loans incurred by the indi6 vidual in the pursuit of the relevant public health

7 workforce educational degree in accordance with the 8 terms of the contract;

"(2) an agreement by the individual to serve 10 full-time as a public health professional for a period 11 of time equal to 2 years or such longer period as the 12 individual may agree to; and

13 "(3) in the case of an individual described in 14 subsection $(b)(1)(C)$ who is in the final year of study 15 and who has accepted employment as a public health 16 professional, in accordance with section $340 \mathrm{~L}(\mathrm{c})$, an 17 agreement on the part of the individual to complete 18 the education or training, maintain an acceptable 19 level of academic standing (as determined by the 20 educational institution offering the course of study 21 or training), and serve the period of obligated service 22 described in paragraph (2).

23 “(d) Payments.-

24 “(1) In GENERAL.—A loan repayment provided 25 for an individual under a written contract under the 
1 Program shall consist of payment, in accordance 2 with paragraph (2), on behalf of the individual of 3 the principal, interest, and related expenses on gov4 ernment and commercial loans received by the indi5 vidual regarding the undergraduate or graduate edu6 cation of the individual (or both), which loans were 7 made for reasonable educational expenses, including 8 tuition, fees, books, equipment, and laboratory ex9 penses, incurred by the individual.

“(A) In GENERAL.—For each year of obligated service that an individual contracts to serve under subsection (c), the Secretary may pay up to $\$ 35,000$ (plus, beginning with fiscal year 2012, an amount determined by the Secretary on an annual basis to reflect inflation) on behalf of the individual for loans described in paragraph (1).

"(B) Repayment schedule.-Any arrangement made by the Secretary for the making of loan repayments in accordance with this subsection shall provide that any repayments for a year of obligated service shall be made no later than the end of the fiscal year in which 25 the individual completes such year of service. 
1 “(e) Application of Certain Provisions.-The

2 provisions of subpart III shall, except as inconsistent with

3 this subpart, apply to the loan repayment program under

4 this section in the same manner and to the same extent

5 as such provisions apply to the National Health Service

6 Corps Loan Repayment Program established under sec-

7 tion 338B.".

8 SEC. 2232. ENHANCING THE PUBLIC HEALTH WORKFORCE.

9 Section 765 (42 U.S.C. 295) is amended to read as

10 follows:

11 “SEC. 765. ENHANCING THE PUBLIC HEALTH WORKFORCE.

12 "(a) Program. - The Secretary, acting through the

13 Administrator of the Health Resources and Services Ad-

14 ministration and in consultation with the Director of the

15 Centers for Disease Control and Prevention, shall estab-

16 lish a public health workforce training and enhancement

17 program consisting of awarding grants and contracts

18 under subsection (b).

19 “(b) Grants And CONTRACTS.-The Secretary shall

20 award grants to, or enter into contracts with, eligible enti21 ties-

22 "(1) to plan, develop, operate, or participate in, 23 an accredited professional training program in the 24 field of public health (including such a program in 25 nursing; health administration, management, or pol- 
1 icy; preventive medicine; laboratory science; veteri-

2 nary medicine; or dental medicine) for members of

3 the public health workforce, including midcareer pro-

4 fessionals;

$5 \quad$ "(2) to provide financial assistance in the form

6 of traineeships and fellowships to students who are

7 participants in any such program and who plan to

8 specialize or work in the field of public health;

9 “(3) to plan, develop, operate, or participate in

10 a program for the training of public health profes-

11 sionals who plan to teach in any program described

12 in paragraph (1); and

13 "(4) to provide financial assistance in the form

14 of traineeships and fellowships to public health pro-

15 fessionals who are participants in any program de-

16 scribed in paragraph (1) and who plan to teach in

17 the field of public health, including nursing; health

18 administration, management, or policy; preventive

19 medicine; laboratory science; veterinary medicine; or 20 dental medicine.

21 “(c) Eligibility.-To be eligible for a grant or con22 tract under this section, an entity shall be-

23 "(1) an accredited health professions school, in24 cluding an accredited school or program of public 25 health; nursing; health administration, management, 
1 or policy; preventive medicine; laboratory science;

2 veterinary medicine; or dental medicine;

“(2) a State, local, or tribal health department;

“(3) a public or private nonprofit entity; or

"(4) a consortium of 2 or more entities de-

6 scribed in paragraphs (1) through (3).

7 “(d) Preference.-In awarding grants or contracts

8 under this section, the Secretary shall give preference to

9 entities that have a demonstrated record of at least one

10 of the following:

11 “(1) Training a high or significantly improved

12 percentage of public health professionals who serve

13 in underserved communities.

14 “(2) Training individuals who are from dis-

15 advantaged backgrounds (including racial and ethnic

16 minorities underrepresented among public health

17 professionals).

18 “(3) Training individuals in public health spe-

19 cialties experiencing a significant shortage of public

20 health professionals (as determined by the Sec-

21 retary).

22 “(4) Training a high or significantly improved

23 percentage of public health professionals serving in

24 the Federal Government or a State, local, or tribal 25 government. 
1 “(e) REPORT.-The Secretary shall submit to the

2 Congress an annual report on the program carried out

3 under this section.".

4 SEC. 2233. PUBLIC HEALTH TRAINING CENTERS.

5 Section 766 (42 U.S.C. 295a) is amended-

6 (1) in subsection (b)(1), by striking "in further-

7 ance of the goals established by the Secretary for

8 the year 2000" and inserting "in furtherance of the

9 goals established by the Secretary in the national

10 prevention and wellness strategy under section

$113121 " ;$ and

12 (2) by adding at the end the following:

13 "(d) REPORT.-The Secretary shall submit to the

14 Congress an annual report on the program carried out

15 under this section.".

16 SEC. 2234. PREVENTIVE MEDICINE AND PUBLIC HEALTH TRAINING GRANT PROGRAM.

18 Section 768 (42 U.S.C. 295c) is amended to read as

19 follows:

20 “SEC. 768. PREVENTIVE MEDICINE AND PUBLIC HEALTH TRAINING GRANT PROGRAM.

22 "(a) Grants.-The Secretary, acting through the 23 Administrator of the Health Resources and Services Ad24 ministration and in consultation with the Director of the 25 Centers for Disease Control and Prevention, shall award 
1 grants to, or enter into contracts with, eligible entities to

2 provide training to graduate medical residents in preven3 tive medicine specialties.

4 “(b) EligibilitY.-To be eligible for a grant or con5 tract under subsection (a), an entity shall be-

6 "(1) an accredited school of public health or 7 school of medicine or osteopathic medicine;

$8 \quad$ “(2) an accredited public or private nonprofit 9 hospital;

10 "(3) a State, local, or tribal health department; 11 or

12 “(4) a consortium of 2 or more entities de13 scribed in paragraphs (1) through (3).

14 “(c) UsE OF Funds.-Amounts received under a 15 grant or contract under this section shall be used to16 "(1) plan, develop (including the development of 17 curricula), operate, or participate in an accredited 18 residency or internship program in preventive medi19 cine or public health;

20 "(2) defray the costs of practicum experiences, 21 as required in such a program; and "(3) establish, maintain, or improve-

24 cluding departments, divisions, or other appro- 
priate units) in preventive medicine and public health; or

"(B) programs that improve clinical teaching in preventive medicine and public health.

5 “(d) REPORT.-The Secretary shall submit to the 6 Congress an annual report on the program carried out 7 under this section.".

8 SEC. 2235. AUTHORIZATION OF APPROPRIATIONS.

9 (a) IN GENERAL.—Section 799C, as added by section 102216 of this Act, is amended by adding at the end the 11 following:

12 “(b) Public Health Workforce.-For the pur13 pose of carrying out subpart XII of part D of title III 14 and sections 765, 766, and 768, in addition to any other 15 amounts authorized to be appropriated for such purpose, 16 there are authorized to be appropriated, out of any monies 17 in the Public Health Investment Fund, the following: “(1) $\$ 51,000,000$ for fiscal year 2011. “(2) $\$ 54,000,000$ for fiscal year 2012. “(3) $\$ 57,000,000$ for fiscal year 2013. “(4) $\$ 59,000,000$ for fiscal year 2014. “(5) $\$ 62,000,000$ for fiscal year 2015.”.

23 (b) Existing Authorization OF APPRopria24 TIONS.-Subsection (a) of section 770 (42 U.S.C. 295e) 25 is amended by striking "2002" and inserting " 2015 ". 


\section{Subtitle D-Adapting Workforce to}

2 Evolving Health System Needs

3 PART 1-HEALTH PROFESSIONS TRAINING FOR DIVERSITY

5 SEC. 2241. SCHOLARSHIPS FOR DISADVANTAGED STUDENTS, LOAN REPAYMENTS AND FELLOWSHIPS REGARDING FACULTY POSITIONS, AND EDUCATIONAL ASSISTANCE IN THE HEALTH PROFESSIONS REGARDING INDIVIDUALS FROM DISADVANTAGED BACKGROUNDS.

12 is amended by striking "not more than $\$ 20,000 "$ and all

13 that follows through the end of the paragraph and insert14 ing: "not more than $\$ 35,000$ (plus, beginning with fiscal 15 year 2012, an amount determined by the Secretary on an 16 annual basis to reflect inflation) of the principal and inter17 est of the educational loans of such individuals.".

18 SEC. 2242. NURSING WORKFORCE DIVERSITY GRANTS.

19 Subsection (b) of section 821 (42 U.S.C. 296m) is 20 amended-

(1) in the heading, by striking "GuIDANCE" and inserting "Consultation"; and

(2) by striking "shall take into consideration" 24 and all that follows through "consult with nursing 
1269

1 associations" and inserting "shall, as appropriate, 2 consult with nursing associations".

3 SEC. 2243. COORDINATION OF DIVERSITY AND CULTURAL 4 COMPETENCY PROGRAMS.

5 (a) In General.-Title VII (42 U.S.C. 292 et seq.) 6 is amended by inserting after section 739 the following:

7 "SEC. 739A. COORDINATION OF DIVERSITY AND CULTURAL COMPETENCY PROGRAMS.

9 "The Secretary shall, to the extent practicable, co10 ordinate the activities carried out under this part and sec11 tion 821 in order to enhance the effectiveness of such ac12 tivities and avoid duplication of effort.".

13 (b) REPORT.-Section 736 (42 U.S.C. 293) is 14 amended-

(1) by redesignating subsection (h) as sub16 section (i); and (2) by inserting after subsection (g) the fol18 lowing:

19 “(h) REPORT.-The Secretary shall submit to the 20 Congress an annual report on the activities carried out 21 under this section.". 
3 SEC. 2251. CULTURAL AND LINGUISTIC COMPETENCY TRAINING FOR HEALTH PROFESSIONALS.

5 Section 741 (42 U.S.C. 293e) is amended-

(1) in the section heading, by striking

"GRANTS FOR HEALTH PROFESSIONS EDU-

CATION" and inserting "CULTURAL AND LIN-

GUISTIC COMPETENCY TRAINING FOR HEALTH

12 section $(\mathrm{h})$; and

13 (3) by striking subsection (a) and inserting the

14 following:

15 “(a) Program.- The Secretary shall establish a cul16 tural and linguistic competency training program for

17 health professionals, including nurse professionals, con-

18 sisting of awarding grants and contracts under subsection 19 (b).

20 “(b) Cultural and Linguistic Competency

21 Training.- The Secretary shall award grants to, or enter

22 into contracts with, eligible entities-

"(1) to test, develop, and evaluate models of

24 cultural and linguistic competency training (includ-

25 ing continuing education) for health professionals;

26 and 
"(2) to implement cultural and linguistic com-

2 petency training programs for health professionals

3 developed under paragraph (1) or otherwise.

4 “(c) Eligibility.-To be eligible for a grant or con-

5 tract under subsection (b), an entity shall be-

6 "(1) an accredited health professions school or

$7 \quad$ program;

8 “(2) an academic health center;

9 "(3) a public or private nonprofit entity; or

10 "(4) a consortium of 2 or more entities de-

11 scribed in paragraphs (1) through (3).

12 “(d) Preference.-In awarding grants and con-

13 tracts under this section, the Secretary shall give pref-

14 erence to entities that have a demonstrated record of at

15 least one of the following:

“(1) Addressing, or partnering with an entity

17 with experience addressing, the cultural and lin18 guistic competency needs of the population to be

19 served through the grant or contract.

20 “(2) Addressing health disparities.

21 "(3) Placing health professionals in regions ex-

22 periencing significant changes in the cultural and

23 linguistic demographics of populations, including

24 communities along the United States-Mexico border. 
"(4) Carrying out activities described in sub-

2 section (b) with respect to more than one health pro-

3 fession discipline, specialty, or subspecialty.

4 “(e) Consultation.-The Secretary shall carry out

5 this section in consultation with the heads of appropriate

6 health agencies and offices in the Department of Health

7 and Human Services, including the Office of Minority

8 Health and the National Center on Minority Health and

9 Health Disparities.

10 “(f) Definition.-In this section, the term 'health

11 disparities' has the meaning given to the term in section 123171.

13 "(g) REPORT.-The Secretary shall submit to the 14 Congress an annual report on the program carried out 15 under this section.".

16 SEC. 2252. INNOVATIONS IN INTERDISCIPLINARY CARE TRAINING.

18 Part D of title VII (42 U.S.C. 294 et seq.) is amend19 ed by adding at the end the following:

20 "SEC. 759. INNOVATIONS IN INTERDISCIPLINARY CARE 21 TRAINING.

22 “(a) Program.-The Secretary shall establish an in23 novations in interdisciplinary care training program con24 sisting of awarding grants and contracts under subsection 25 (b). 
1 “(b) Training Programs.-The Secretary shall

2 award grants to, or enter into contracts with, eligible enti3 ties-

4 “(1) to test, develop, and evaluate health pro5 fessional training programs (including continuing 6 education) designed to promote"(A) the delivery of health services through interdisciplinary and team-based models, which may include patient-centered medical home models, medication therapy management mod11 els, and models integrating physical, mental, or oral health services; and "(B) coordination of the delivery of health care within and across settings, including health care institutions, community-based settings, and the patient's home; and "(2) to implement such training programs de18 veloped under paragraph (1) or otherwise.

19 “(c) Eligibility.—To be eligible for a grant or con20 tract under subsection (b), an entity shall be22 program;

23 “(2) an academic health center; 
“(3) a public or private nonprofit entity (includ-

2 ing an area health education center or a geriatric

3 education center); or

"(4) a consortium of 2 or more entities de-

5 scribed in paragraphs (1) through (3).

6 “(d) Preferences.-In awarding grants and con-

7 tracts under this section, the Secretary shall give pref-

8 erence to entities that have a demonstrated record of at

9 least one of the following:

10 “(1) Training a high or significantly improved

11 percentage of health professionals who serve in un12 derserved communities.

13 “(2) Broad interdisciplinary team-based collabo14 rations.

15 “(3) Addressing health disparities.

16 “(e) REPORT.-The Secretary shall submit to the 17 Congress an annual report on the program carried out 18 under this section.

19 “(f) Definitions.-In this section:

20 “(1) The term 'health disparities' has the 21 meaning given the term in section 3171.

22 “(2) The term 'interdisciplinary' means collabo23 ration across health professions and specialties, 24 which may include public health, nursing, allied 
1 health, dietetics or nutrition, and appropriate health

2 specialties.'.

3 PART 3-ADVISORY COMMITTEE ON HEALTH

4 WORKFORCE EVALUATION AND ASSESSMENT

5 SEC. 2261. HEALTH WORKFORCE EVALUATION AND ASSESS-

6 MENT.

7 Subpart 1 of part E of title VII (42 U.S.C. $294 \mathrm{n}$

8 et seq.) is amended by adding at the end the following:

9 "SEC. 764. HEALTH WORKFORCE EVALUATION AND ASSESS-

10 MENT.

11 “(a) Advisory CommitTee.-The Secretary, acting

12 through the Assistant Secretary for Health, shall establish

13 a permanent advisory committee to be known as the Advi-

14 sory Committee on Health Workforce Evaluation and As-

15 sessment (referred to in this section as the 'Advisory Com-

16 mittee') to develop and implement an integrated, coordi-

17 nated, and strategic national health workforce policy re-

18 flective of current and evolving health workforce needs.

19 “(b) Responsibilities.-The Advisory Committee

20 shall-

"(1) not later than 1 year after the date of the

22 establishment of the Advisory Committee, submit

23 recommendations to the Secretary on- 
"(A) classifications of the health workforce to ensure consistency of data collection on the health workforce; and

"(B) based on such classifications, standardized methodologies and procedures to enumerate the health workforce; "(2) not later than 2 years after the date of the 8 establishment of the Advisory Committee, submit 9 recommendations to the Secretary on-

"(A) the supply, diversity, and geographic distribution of the health workforce;

"(B) the retention and expansion of the health workforce (on a short- and long-term basis) to ensure quality and adequacy of such workforce; and

"(C) policies to carry out the recommendations made pursuant to subparagraphs (A) and (B); and

"(3) not later than 4 years after the date of the 20 establishment of the Advisory Committee, and every 212 years thereafter, submit updated recommendations 22 to the Secretary under paragraphs (1) and (2).

23 "(c) RoLe OF AGENCY.-The Secretary shall provide 24 ongoing administrative, research, and technical support 25 for the operations of the Advisory Committee, including 
1 coordinating and supporting the dissemination of the rec-

2 ommendations of the Advisory Committee.

“(d) Membership.-

“(1) Number; APpointment.-The Secretary shall appoint 15 members to serve on the Advisory Committee.

“(2) Terms.-

"(A) IN GENERAL.-The Secretary shall appoint members of the Advisory Committee for a term of 3 years and may reappoint such members, but the Secretary may not appoint any member to serve more than a total of 6 years.

"(B) STAGGERED TERMS.-Notwithstanding subparagraph (A), of the members first appointed to the Advisory Committee under paragraph (1)—

"(i) 5 shall be appointed for a term of 1 year;

"(ii) 5 shall be appointed for a term of 2 years; and “(iii) 5 shall be appointed for a term of 3 years.

“(3) Qualifications.-Members of the Advisory Committee shall be appointed from among indi- 
1 viduals who possess expertise in at least one of the

2 following areas:

"(A) Conducting and interpreting health workforce market analysis, including health care labor workforce analysis.

"(B) Conducting and interpreting health finance and economics research.

“(C) Delivering and administering health care services.

"(D) Delivering and administering health workforce education and training.

“(4) Representation.-In appointing members of the Advisory Committee, the Secretary shall-

"(A) include no less than one representative of each of-

"(i) health professionals within the health workforce; "(ii) health care patients and consumers;

"(iii) employers;

"(iv) labor unions; and

"(v) third-party health payors; and

"(B) ensure that- 
"(i) all areas of expertise described in

paragraph (3) are represented;

"(ii) the members of the Advisory Committee include members who, collectively, have significant experience working with-

“(I) populations in urban and federally designated rural and nonmetropolitan areas; and

"(II) populations who are underrepresented in the health professions, including underrepresented minority groups; and

"(iii) individuals who are directly involved in health professions education or practice do not constitute a majority of the members of the Advisory Committee.

“(5) Disclosure AND CONFlicts OF INTEREST.-Members of the Advisory Committee shall not be considered employees of the Federal Government by reason of service on the Advisory Committee, except members of the Advisory Committee shall be considered to be special Government employees within the meaning of section 107 of the Ethics in Government Act of 1978 (5 U.S.C. App.) and section 
1208 of title 18, United States Code, for the purposes

2 of disclosure and management of conflicts of interest

3 under those sections.

4 “(6) NO PAY; RECEIPT OF TRAVEL EX-

5 Penses.-Members of the Advisory Committee shall

6 not receive any pay for service on the Committee,

7 but may receive travel expenses, including a per

8 diem, in accordance with applicable provisions of

9 subchapter I of chapter 57 of title 5, United States

10 Code.

11 “(e) Consultation.-In carrying out this section, 12 the Secretary shall consult with the Secretary of Edu13 cation and the Secretary of Labor.

14 “(f) Collaboration.-The Advisory Committee 15 shall collaborate with the advisory bodies at the Health 16 Resources and Services Administration, the National Ad17 visory Council (as authorized in section 337), the Advisory 18 Committee on Training in Primary Care Medicine and 19 Dentistry (as authorized in section 749A), the Advisory 20 Committee on Interdisciplinary, Community-Based Link21 ages (as authorized in section 756), the Advisory Council 22 on Graduate Medical Education (as authorized in section 23 762), and the National Advisory Council on Nurse Edu24 cation and Practice (as authorized in section 851). 
1281

1 "(g) FACA.—The Federal Advisory Committee Act

2 (5 U.S.C. App.) except for section 14 of such Act shall

3 apply to the Advisory Committee under this section only

4 to the extent that the provisions of such Act do not conflict

5 with the requirements of this section.

6 "(h) REPORT.-The Secretary shall submit to the

7 Congress an annual report on the activities of the Advisory

8 Committee.

9 “(i) Definition.-In this section, the term 'health

10 workforce' includes all health care providers with direct

11 patient care and support responsibilities, including physi-

12 cians, nurses, physician assistants, pharmacists, oral

13 health professionals (as defined in section 749(f)(2)), al-

14 lied health professionals, mental and behavioral health

15 professionals (as defined in section $775(\mathrm{f})(2)$ ), and public

16 health professionals (including veterinarians engaged in 17 public health practice).".

18 PART 4-HEALTH WORKFORCE ASSESSMENT

19 SEC. 2271. HEALTH WORKFORCE ASSESSMENT.

20 (a) In GeneraL.-Section 761 (42 U.S.C. 294n) is

21 amended-

22 (1) by redesignating subsection (c) as sub23 section (e); and

24 (2) by striking subsections (a) and (b) and in25 serting the following: 
1 “(a) In GeneraL.-The Secretary shall, based upon

2 the classifications and standardized methodologies and

3 procedures developed by the Advisory Committee on

4 Health Workforce Evaluation and Assessment under sec-

5 tion $764(b)-$

6 "(1) collect data on the health workforce (as

7 defined in section 764(i)), disaggregated by field,

8 discipline, and specialty, with respect to-

9 “(A) the supply (including retention) of

10 health professionals relative to the demand for

11 such professionals;

12 "(B) the diversity of health professionals

13 (including with respect to race, ethnic back-

14 ground, and sex); and

15 "(C) the geographic distribution of health

16 professionals; and

17 "(2) collect such data on individuals partici-

18 pating in the programs authorized by subtitles $\mathrm{A}, \mathrm{B}$,

19 and $\mathrm{C}$ and part 1 of subtitle D of title II of division

20 C of the Affordable Health Care for America Act.

21 “(b) Grants and Contracts for Health Work-

22 FORCE ANALysis.-

23 “(1) IN GENERAL.-The Secretary may award

24 grants to, or enter into contracts with, eligible enti-

25 ties to carry out subsection (a). 
"(2) Eligibility.-To be eligible for a grant

2 or contract under this subsection, an entity shall 3 be-

“(A) an accredited health professions school or program;

"(B) an academic health center;

“(C) a State, local, or tribal government;

“(D) a public or private entity; or

"(E) a consortium of 2 or more entities described in subparagraphs (A) through (D).

12 Secretary shall collaborate with Federal departments and 13 agencies, health professions organizations (including

14 health professions education organizations), and profes15 sional medical societies for the purpose of carrying out 16 subsection (a).

17 “(d) REPORT.-The Secretary shall submit to the 18 Congress an annual report on the data collected under 19 subsection (a).”.

(b) Period Before Completion of National 21 Strategr.-Pending completion of the classifications and 22 standardized methodologies and procedures developed by 23 the Advisory Committee on Health Workforce Evaluation 24 and Assessment under section 764(b) of the Public Health 25 Service Act, as added by section 2261, the Secretary of 
1 Health and Human Services, acting through the Adminis-

2 trator of the Health Resources and Services Administra-

3 tion and in consultation with such Advisory Committee,

4 may make a judgment about the classifications, meth-

5 odologies, and procedures to be used for collection of data

6 under section 761(a) of the Public Health Service Act, as

7 amended by this section.

8 PART 5-AUTHORIZATION OF APPROPRIATIONS

9 SEC. 2281. AUTHORIZATION OF APPROPRIATIONS.

10 (a) In General.-Section 799C, as added and

11 amended, is further amended by adding at the end the

12 following:

13 “(c) Health Professions Training for Diver-

14 SITY.-For the purpose of carrying out sections 736, 737,

15738,739 , and 739A, in addition to any other amounts

16 authorized to be appropriated for such purpose, there are

17 authorized to be appropriated, out of any monies in the

18 Public Health Investment Fund, the following:

“(1) $\$ 90,000,000$ for fiscal year 2011.

“(2) $\$ 97,000,000$ for fiscal year 2012.

“(3) \$100,000,000 for fiscal year 2013.

“(4) $\$ 104,000,000$ for fiscal year 2014.

“(5) $\$ 110,000,000$ for fiscal year 2015. 
1 Tion and Assessment, and Health Workforce As-

2 SEssment.-For the purpose of carrying out sections $3741,759,761$, and 764, in addition to any other amounts

4 authorized to be appropriated for such purpose, there are 5 authorized to be appropriated, out of any monies in the 6 Public Health Investment Fund, the following: “(1) $\$ 87,000,000$ for fiscal year 2011. “(2) $\$ 97,000,000$ for fiscal year 2012. “(3) \$103,000,000 for fiscal year 2013. “(4) $\$ 105,000,000$ for fiscal year 2014. “(5) $\$ 113,000,000$ for fiscal year 2015.”.

(1) Section 736.-Paragraph (1) of section $15736(\mathrm{i})$ (42 U.S.C. 293(h)), as redesignated, is 16 amended by striking "2002" and inserting "2015".

17 (2) SECTIONS 737, 738, AND 739.-Subsections 18 (a), (b), and (c) of section 740 are amended by 19 striking "2002" each place it appears and inserting 20 "2015”.

(3) Section 741.-Subsection (h), as so redes22 ignated, of section 741 is amended2003,"; and 
(B) by inserting ", and such sums as may be necessary for each subsequent fiscal year through the end of fiscal year 2015" before the period at the end.

(4) Section 761.--Subsection (e)(1), as so re6 designated, of section 761 is amended by striking "2002" and inserting "2015".

\section{TITLE III-PREVENTION AND WELLNESS}

10 SEC. 2301. PREVENTION AND WELLNESS.

(a) In General.-The Public Health Service Act 12 (42 U.S.C. 201 et seq.) is amended by inserting after title

13 XXX the following:

${ }^{6 T I T L E ~ X X X I-P R E V E N T I O N ~ A N D ~}$ WELLNESS Wellness Trust

18 “SEC. 3111. PREVENTION AND WELLNESS TRUST.

“(a) Deposits Into Trust.-There is established

20 a Prevention and Wellness Trust. There are authorized 21 to be appropriated to the Trust-

"(1) out of the general fund of the Treasury, 23 amounts described in section 2002(b)(2)(A)(ii) of 24 the Affordable Health Care for America Act for each 25 fiscal year; and 
"(2) in addition, out of any monies in the Pub-

2 lic Health Investment Fund-

“(A) for fiscal year 2011, $\$ 2,400,000,000$;

“(B) for fiscal year 2012, $\$ 2,845,000,000$;

“(C) for fiscal year 2013, \$3,100,000,000;

"(D) for fiscal year 2014, \$3,455,000,000;

and

"(E) for fiscal year 2015, \$3,600,000,000.

“(b) Availability of Funds.-Amounts in the Pre-

10 vention and Wellness Trust shall be available, as provided

11 in advance in appropriation Acts, for carrying out this 12 title.

13 "(c) Allocation.-Of the amounts authorized to be 14 appropriated in subsection (a)(2), there are authorized to 15 be appropriated-

“(1) for carrying out subtitle C (Prevention 17 Task Forces), $\$ 30,000,000$ for each of fiscal years 182011 through 2015; "(2) for carrying out subtitle D (Prevention 20 and Wellness Research)—

“(A) for fiscal year 2011, $\$ 155,000,000$;

“(B) for fiscal year 2012, $\$ 205,000,000$;

“(C) for fiscal year 2013, $\$ 255,000,000$;

"(D) for fiscal year 2014, $\$ 305,000,000$;

and 
1288

“(E) for fiscal year 2015, \$355,000,000;

“(3) for carrying out subtitle E (Delivery of Community Preventive and Wellness Services)—

“(A) for fiscal year 2011, $\$ 1,065,000,000$;

“(B) for fiscal year 2012, \$1,260,000,000;

“(C) for fiscal year 2013, \$1,365,000,000;

“(D) for fiscal year 2014, \$1,570,000,000;

and

“(E) for fiscal year 2015, \$1,600,000,000;

“(4) for carrying out section 3161 (Core Public Health Infrastructure for State, Local, and Tribal Health Departments)_-

“(A) for fiscal year 2011, $\$ 800,000,000$;

“(B) for fiscal year 2012, \$1,000,000,000;

“(C) for fiscal year 2013, \$1,100,000,000;

“(D) for fiscal year 2014, \$1,200,000,000;

and

“(E) for fiscal year 2015, \$1,265,000,000;

and

“(5) for carrying out section 3162 (Core Public Health Infrastructure and Activities for CDC), $\$ 350,000,000$ for each of fiscal years 2011 through 2015. 

and Wellness Strategy

3 "SEC. 3121. NATIONAL PREVENTION AND WELLNESS STRAT-

EGY.

"(a) In GEnERAL.—The Secretary shall submit to

6 the Congress within one year after the date of the enact7 ment of this section, and at least every 2 years thereafter, 8 a national strategy that is designed to improve the $\mathrm{Na}$ 9 tion's health through evidence-based clinical and commu-

10 nity prevention and wellness activities (in this section re-

11 ferred to as 'prevention and wellness activities'), including

12 core public health infrastructure improvement activities.

13 "(b) CONTENTs.-The strategy under subsection (a)

14 shall include each of the following:

15 "(1) Identification of specific national goals and 16 objectives in prevention and wellness activities that 17 take into account appropriate public health measures 18 and standards, including departmental measures and 19 standards (including Healthy People and National 20 Public Health Performance Standards). “(2) Establishment of national priorities for 22 prevention and wellness, taking into account unmet 23 prevention and wellness needs.

“(3) Establishment of national priorities for re25 search on prevention and wellness, taking into ac- 
1 count unanswered research questions on prevention 2 and wellness.

"(4) Identification of health disparities in pre4 vention and wellness.

“(5) Review of prevention payment incentives, 6 the prevention workforce, and prevention delivery 7 system capacity.

“(6) A plan for addressing and implementing 9 paragraphs (1) through (5).

10 “(c) Consultation.-In developing or revising the 11 strategy under subsection (a), the Secretary shall consult 12 with the following:

13 "(1) The heads of appropriate health agencies 14 and offices in the Department, including the Office 15 of the Surgeon General of the Public Health Service, 16 the Office of Minority Health, the Office on Wom17 en's Health, and the Substance Abuse and Mental 18 Health Services Administration.

19 "(2) As appropriate, the heads of other Federal 20 departments and agencies whose programs have a 21 significant impact upon health (as determined by the 22 Secretary).

23 "(3) As appropriate, nonprofit and for-profit 24 entities. 
"(4) The Association of State and Territorial

2 Health Officials and the National Association of

3 County and City Health Officials.

“(5) The Task Force on Community Preventive

5 Services and the Task Force on Clinical Preventive 6 Services. Forces

9 "SEC. 3131. TASK FORCE ON CLINICAL PREVENTIVE SERVICES.

11 “(a) In GeneRAL.-The Secretary, acting through 12 the Director of the Agency for Healthcare Research and 13 Quality, shall establish a permanent task force to be 14 known as the Task Force on Clinical Preventive Services 15 (in this section referred to as the 'Task Force').

16 “(b) Responsibilities.—The Task Force shall—

17 “(1) identify clinical preventive services for re18 view;

19 "(2) review the scientific evidence related to the 20 benefits, effectiveness, appropriateness, and costs of 21 clinical preventive services identified under para22 graph (1) for the purpose of developing, updating, 23 publishing, and disseminating evidence-based rec24 ommendations on the use of such services; 
"(3) as appropriate, take into account health

2 disparities in developing, updating, publishing, and

3 disseminating evidence-based recommendations on

4 the use of such services;

$5 \quad$ "(4) identify gaps in clinical preventive services

6 research and evaluation and recommend priority

$7 \quad$ areas for such research and evaluation;

$8 \quad$ “(5) pursuant to section 3143(c), determine

9 whether subsidies and rewards meet the Task

10 Force's standards for a grade of A or B;

11 "(6) as appropriate, consult with the clinical

12 prevention stakeholders board in accordance with

13 subsection (f);

14 "(7) consult with the Task Force on Commu-

15 nity Preventive Services established under section

$16 \quad 3132 ;$ and

17 “(8) as appropriate, in carrying out this sec-

18 tion, consider the national strategy under section 193121.

20 “(c) Role of AgEncy.—The Secretary shall provide 21 ongoing administrative, research, and technical support

22 for the operations of the Task Force, including coordi23 nating and supporting the dissemination of the rec24 ommendations of the Task Force.

25 “(d) Membership.- 
“(1) Number; APpointment.-The Task

2 Force shall be composed of 30 members, appointed

3 by the Secretary.

4

5

"(2) Terms.-

"(A) In GENERAL.-The Secretary shall appoint members of the Task Force for a term of 6 years and may reappoint such members, but the Secretary may not appoint any member to serve more than a total of 12 years.

"(B) StAGGERED TERMS.-Notwithstanding subparagraph (A), of the members first appointed to serve on the Task Force after the enactment of this title-

"(i) 10 shall be appointed for a term of 2 years;

"(ii) 10 shall be appointed for a term of 4 years; and

"(iii) 10 shall be appointed for a term of 6 years.

“(3) Qualifications.-Members of the Task Force shall be appointed from among individuals who possess expertise in at least one of the following areas:

“(A) Health promotion and disease prevention. 
"(B) Evaluation of research and systematic evidence reviews.

"(C) Application of systematic evidence reviews to clinical decisionmaking or health policy.

"(D) Clinical primary care in child and adolescent health.

"(E) Clinical primary care in adult health, including women's health.

"(F) Clinical primary care in geriatrics.

"(G) Clinical counseling and behavioral services for primary care patients.

“(4) Representation.-In appointing mem-

14 bers of the Task Force, the Secretary shall ensure 15 that-

"(A) all areas of expertise described in paragraph (3) are represented; and

"(B) the members of the Task Force include individuals with expertise in health disparities.

21 “(e) Subgroups.-As appropriate to maximize effi22 ciency, the Task Force may delegate authority for con23 ducting reviews and making recommendations to sub24 groups consisting of Task Force members, subject to final 25 approval by the Task Force. 
1 “(f) Clinical Prevention Stakeholders

2 BOARD.-

"(1) In General.-The Task Force shall con-

4 vene a clinical prevention stakeholders board com-

5 posed of representatives of appropriate public and

6 private entities with an interest in clinical preventive

7 services to advise the Task Force on developing, up-

8 dating, publishing, and disseminating evidence-based

9 recommendations on the use of clinical preventive

10 services.

11 "(2) Membership.-The members of the clin-

12 ical prevention stakeholders board shall include rep-

13 resentatives of the following:

“(A) Health care consumers and patient groups.

"(B) Providers of clinical preventive serv17 ices, including community-based providers.

"(C) Federal departments and agencies, including-

“(i) appropriate health agencies and

offices in the Department, including the Office of the Surgeon General of the Public Health Service, the Office of Minority Health, the National Center on Minority 
23 Members of the Task Force or the clinical prevention 24 stakeholders board shall not be considered employees of 25 the Federal Government by reason of service on the Task 
1 Force or the clinical prevention stakeholders board, except

2 members of the Task Force or the clinical prevention

3 stakeholders board shall be considered to be special Gov-

4 ernment employees within the meaning of section 107 of

5 the Ethics in Government Act of 1978 (5 U.S.C. App.)

6 and section 208 of title 18, United States Code, for the

7 purposes of disclosure and management of conflicts of in-

8 terest under those sections.

9 “(h) No Pay; Receipt of Travel Expenses.-

10 Members of the Task Force or the clinical prevention

11 stakeholders board shall not receive any pay for service

12 on the Task Force, but may receive travel expenses, in-

13 cluding a per diem, in accordance with applicable provi-

14 sions of subchapter I of chapter 57 of title 5, United

15 States Code.

16 "(i) Application of FACA.-The Federal Advisory

17 Committee Act (5 U.S.C. App.) except for section 14 of

18 such Act shall apply to the Task Force to the extent that

19 the provisions of such Act do not conflict with the provi-

20 sions of this title.

21 "(j) REPORT.-The Secretary shall submit to the

22 Congress an annual report on the Task Force, including

23 with respect to gaps identified and recommendations made

24 under subsection (b)(4). 
1 “SEC. 3132. TASK FORCE ON COMMUNITY PREVENTIVE

3 “(a) In GENERAL.-The Secretary, acting through 4 the Director of the Centers for Disease Control and Pre5 vention, shall establish a permanent task force to be 6 known as the Task Force on Community Preventive Serv7 ices (in this section referred to as the 'Task Force'). “(b) Responsibilities.- The Task Force shall— “(1) identify community preventive services for 10 review;

11 "(2) review the scientific evidence related to the 12 benefits, effectiveness, appropriateness, and costs of 13 community preventive services identified under para14 graph (1) for the purpose of developing, updating, 15 publishing, and disseminating evidence-based rec16 ommendations on the use of such services;

17 "(3) as appropriate, take into account health 18 disparities in developing, updating, publishing, and 19 disseminating evidence-based recommendations on 20 the use of such services;

21 “(4) identify gaps in community preventive 22 services research and evaluation and recommend pri23 ority areas for such research and evaluation; “(5) pursuant to section $3143(\mathrm{~d})$, determine 25 whether subsidies and rewards are effective; 
"(6) as appropriate, consult with the commu-

2 nity prevention stakeholders board in accordance

3 with subsection (f);

"(7) consult with the Task Force on Clinical

$5 \quad$ Preventive Services established under section 3131;

6 and

"(8) as appropriate, in carrying out this sec-

8 tion, consider the national strategy under section 93121.

10 “(c) Role OF AGENCY.-The Secretary shall provide 11 ongoing administrative, research, and technical support 12 for the operations of the Task Force, including coordi13 nating and supporting the dissemination of the rec14 ommendations of the Task Force.

15 “(d) Membership.-

16 “(1) Number; APPOINTMENT.-The Task 17 Force shall be composed of 30 members, appointed 18 by the Secretary. "(2) Terms."(A) IN GENERAL.-The Secretary shall appoint members of the Task Force for a term of 6 years and may reappoint such members, 23 but the Secretary may not appoint any member 24 to serve more than a total of 12 years. 
1300

"(B) STAGGERED TERMS.-Notwithstanding subparagraph (A), of the members first appointed to serve on the Task Force after the enactment of this section-

"(i) 10 shall be appointed for a term of 2 years;

"(ii) 10 shall be appointed for a term of 4 years; and

“(iii) 10 shall be appointed for a term of 6 years.

“(3) Qualifications.-Members of the Task Force shall be appointed from among individuals who possess expertise in at least one of the following areas:

"(A) Public health.

"(B) Evaluation of research and systematic evidence reviews.

“(C) Disciplines relevant to community preventive services, including health promotion; disease prevention; chronic disease; worksite health; school-site health; qualitative and quantitative analysis; and health economics, policy, law, and statistics.

“(4) Representation.-In appointing members of the Task Force, the Secretary- 
1301

12 ciency, the Task Force may delegate authority for con-

13 ducting reviews and making recommendations to sub-

14 groups consisting of Task Force members, subject to final 15 approval by the Task Force.

\section{STAKEHOLDERS}

\section{BOARD.-}

“(1) In General.- The Task Force shall con19 vene a community prevention stakeholders board 20 composed of representatives of appropriate public 21 and private entities with an interest in community 22 preventive services to advise the Task Force on de23 veloping, updating, publishing, and disseminating 24 evidence-based recommendations on the use of com25 munity preventive services. 
"(2) Membership.-The members of the com-

2 munity prevention stakeholders board shall include 3 representatives of the following:

"(A) Health care consumers and patient

groups.

"(i) appropriate health agencies and

24 holders board shall- 
“(A) recommend community preventive services for review by the Task Force;

"(B) suggest scientific evidence for consideration by the Task Force related to reviews undertaken by the Task Force;

"(C) provide feedback regarding draft recommendations by the Task Force; and “(D) assist with efforts regarding dissemination of recommendations by the Director of the Centers for Disease Control and Prevention.

12 Members of the Task Force or the community prevention

13 stakeholders board shall not be considered employees of 14 the Federal Government by reason of service on the Task 15 Force or the community prevention stakeholders board, 16 except members of the Task Force or the community pre17 vention stakeholders board shall be considered to be spe18 cial Government employees within the meaning of section 19107 of the Ethics in Government Act of 1978 (5 U.S.C. 20 App.) and section 208 of title 18, United States Code, for 21 the purposes of disclosure and management of conflicts 22 of interest under those sections.

23 "(h) No Pay; Receipt of Travel Expenses.24 Members of the Task Force or the community prevention 25 stakeholders board shall not receive any pay for service 
1 on the Task Force, but may receive travel expenses, in-

2 cluding a per diem, in accordance with applicable provi-

3 sions of subchapter I of chapter 57 of title 5, United

4 States Code.

5 “(i) Application of FACA.—The Federal Advisory

6 Committee Act (5 U.S.C. App.) except for section 14 of

7 such Act shall apply to the Task Force to the extent that

8 the provisions of such Act do not conflict with the provi-

9 sions of this title.

10 “(j) REPORT.-The Secretary shall submit to the

11 Congress an annual report on the Task Force, including

12 with respect to gaps identified and recommendations made

13 under subsection (b)(4).

"Subtitle D-Prevention and Wellness Research

16 “SEC. 3141. PREVENTION AND WELLNESS RESEARCH ACTIVITY COORDINATION.

18 "In conducting or supporting research on prevention

19 and wellness, the Director of the Centers for Disease Con-

20 trol and Prevention, the Director of the National Insti-

21 tutes of Health, and the heads of other agencies within

22 the Department of Health and Human Services con-

23 ducting or supporting such research, shall take into con-

24 sideration the national strategy under section 3121 and

25 the recommendations of the Task Force on Clinical Pre- 
1305

1 ventive Services under section 3131 and the Task Force

2 on Community Preventive Services under section 3132.

3 “SEC. 3142. COMMUNITY PREVENTION AND WELLNESS RESEARCH GRANTS.

5 “(a) In GENERAL.-The Secretary, acting through 6 the Director of the Centers for Disease Control and Pre-

7 vention, shall conduct, or award grants to eligible entities

8 to conduct, research in priority areas identified by the Sec-

9 retary in the national strategy under section 3121 or by

10 the Task Force on Community Preventive Services as re-

11 quired by section 3132 .

12 “(b) Eligibility.-To be eligible for a grant under

13 this section, an entity shall be“(1) a State, local, or tribal department of 15 health; “(2) a public or private nonprofit entity; or "(3) a consortium of 2 or more entities de18 scribed in paragraphs (1) and (2).

19 “(c) REPORT.-The Secretary shall submit to the 20 Congress an annual report on the program of research 21 under this section.

22 “SEC. 3143. RESEARCH ON SUBSIDIES AND REWARDS TO ENCOURAGE WELLNESS AND HEALTHY BEHAVIORS.

25 “(a) Research and Demonstration Projects.- 
"(1) IN GENERAL.-The Secretary shall con-

2 duct, or award grants to public or nonprofit private

3 entities to conduct, research and demonstration

4 projects on the use of financial and in-kind subsidies

5 and rewards to encourage individuals and commu-

6 nities to promote wellness, adopt healthy behaviors,

7 and use evidence-based preventive health services.

“(2) Focus.-Research and demonstration

9 projects under paragraph (1) shall focus on-

10

"(A) tobacco use, obesity, and other prevention and wellness priorities identified by the Secretary in the national strategy under section 3121 ;

"(B) the initiation, maintenance, and longterm sustainability of wellness promotion; adoption of healthy behaviors; and use of evidencebased preventive health services; and

"(C) populations at high risk of preventable diseases and conditions.

22 shall submit the findings of research and demonstra23 tion projects under subsection (a) to-

"(A) the Task Force on Clinical Preventive 25 
Task Force on Community Preventive Services established under section 3132, as appropriate; and

"(B) the Health Benefits Advisory Committee established by section 223 of the Affordable Health Care for America Act.

“(2) Report To CONGRess.-Not later than

818 months after the initiation of research and dem-

9 onstration projects under subsection (a), the Sec-

10 retary shall submit a report to the Congress on the

11 progress of such research and projects, including 12 any preliminary findings.

13 “(c) Inclusion in Essential Benefits Pack14 AGE.- - If, on the basis of the findings of research and dem15 onstration projects under subsection (a) or other sources 16 consistent with section 3131, the Task Force on Clinical 17 Preventive Services determines that a subsidy or reward 18 meets the Task Force's standards for a grade A or B, 19 the Secretary shall ensure that the subsidy or reward is 20 included in the essential benefits package under section 21222.

22 “(d) Inclusion as Allowable Use of Community 23 Prevention and Wellness Services Grants.-If, on 24 the basis of the findings of research and demonstration 25 projects under subsection (a) or other sources consistent 
1 with section 3132, the Task Force on Community Preven-

2 tive Services determines that a subsidy or reward is effec-

3 tive, the Secretary shall ensure that the subsidy or reward

4 becomes an allowable use of grant funds under section 53151.

6 “(e) Nondiscrimination; No Tie to Premium or

7 Cost Sharing.-In carrying out this section, the Sec-

8 retary shall ensure that any subsidy or reward-

9 "(1) does not have a discriminatory effect on

10 the basis of any personal characteristic extraneous

11 to the provision of high-quality health care or related

12 services; and

13 "(2) is not tied to the premium or cost sharing

14 of an individual under any qualified health benefits 15 plan (as defined in section $100(\mathrm{c})$ ).

\section{6 "Subtitle E-Delivery of Commu- 17 nity Prevention and Wellness 18 Services}

19 “SEC. 3151. COMMUNITY PREVENTION AND WELLNESS SERVICES GRANTS.

21 "(a) In GenerAL.- The Secretary, acting through

22 the Director of the Centers for Disease Control and Pre-

23 vention, shall establish a program for the delivery of com24 munity prevention and wellness services consisting of 25 awarding grants to eligible entities- 
“(1) to provide evidence-based, community pre-

2 vention and wellness services in priority areas identi-

3 fied by the Secretary in the national strategy under

4 section 3121 ; or

$5 \quad$ "(2) to plan such services.

6 “(b) Eligibility.-

7 “(1) Definition.-To be eligible for a grant

8 under this section, an entity shall be-

"(A) a State, local, or tribal department of health;

“(B) a public or private entity; or "(C) a consortium that"(i) consists of 2 or more entities described in subparagraph (A) or (B); and "(ii) may be a community partnership representing a Health Empowerment Zone. “(2) Health Empowerment ZONE.-In this subsection, the term 'Health Empowerment Zone' means an area-

"(A) in which multiple community prevention and wellness services are implemented in order to address one or more health disparities, including those identified by the Secretary in the national strategy under section 3121 ; and 
1310

12 section, the Secretary shall give preference to entities 13 that-

“(1) will address one or more goals or objec15 tives identified by the Secretary in the national $16 \quad$ strategy under section 3121 ;

17 “(2) will address significant health disparities, 18 including those identified by the Secretary in the na19 tional strategy under section 3121;

20 "(3) will address unmet community prevention 21 and wellness needs and avoid duplication of effort; 22 "(4) have been demonstrated to be effective in 23 communities comparable to the proposed target com24 munity; 
1311

"(5) will contribute to the evidence base for

2 community prevention and wellness services;

"(6) demonstrate that the community preven-

4 tion and wellness services to be funded will be sus-

5 tainable; and

6 “(7) demonstrate coordination or collaboration

7 across governmental and nongovernmental partners.

8 “(d) Health Disparities.—Of the funds awarded

9 under this section for a fiscal year, the Secretary shall

10 award not less than 50 percent for planning or imple-

11 menting community prevention and wellness services

12 whose primary purpose is to achieve a measurable reduc-

13 tion in one or more health disparities, including those

14 identified by the Secretary in the national strategy under

15 section 3121.

16 “(e) Emphasis on Recommended Services.-For

17 fiscal year 2014 and subsequent fiscal years, the Secretary

18 shall award grants under this section only for planning

19 or implementing services recommended by the Task Force

20 on Community Preventive Services under section 3132 or

21 deemed effective based on a review of comparable rigor

22 (as determined by the Director of the Centers for Disease

23 Control and Prevention). 
1 “(f) Prohibited Uses of Funds.-An entity that

2 receives a grant under this section may not use funds pro3 vided through the grant-

4 "(1) to build or acquire real property or for 5 construction; or

$6 \quad$ "(2) for services or planning to the extent that

7 payment has been made, or can reasonably be ex8 pected to be made-

9 “(A) under any insurance policy;

10 "(B) under any Federal or State health 11 benefits program (including titles XIX and XXI 12 of the Social Security Act); or

13 "(C) by an entity which provides health 14 services on a prepaid basis.

15 "(g) REPORT.-The Secretary shall submit to the 16 Congress an annual report on the program of grants 17 awarded under this section.

18 "(h) Definitions.-In this section, the term 'evi19 dence-based' means that methodologically sound research 20 has demonstrated a beneficial health effect, in the judg21 ment of the Director of the Centers for Disease Control 22 and Prevention. 


\section{1 "Subtitle F-Core Public Health}

3 "SEC. 3161. CORE PUBLIC HEALTH INFRASTRUCTURE FOR MENTS.

"(a) Program.-The Secretary, acting through the

7 Director of the Centers for Disease Control and Preven8 tion, shall establish a core public health infrastructure

9 program consisting of awarding grants under subsection 10 (b).

"(1) AWARD.-For the purpose of addressing

13 core public health infrastructure needs, the Sec14 retary-

"(A) shall award a grant to each State health department; and

"(B) may award grants on a competitive basis to State, local, or tribal health departments.

"(2) Allocation.-Of the total amount of

21 funds awarded as grants under this subsection for a 22 fiscal year-

"(A) not less than 50 percent shall be for grants to State health departments under paragraph (1)(A); and 
1314

5 grant to an entity under subsection (b)(1) only if the enti-

6 ty agrees to use the grant to address core public health

7 infrastructure needs, including those identified in the ac-

8 creditation process under subsection $(\mathrm{g})$.

9

10

11 the Secretary shall award funds to each State health de-

12 partment in accordance with"(1) a formula based on population size; burden

14 of preventable disease and disability; and core public 15 health infrastructure gaps, including those identified 16 in the accreditation process under subsection $(\mathrm{g})$; 17 and

19 Secretary, including a requirement that the State 20 submit a plan that demonstrates to the satisfaction 21 of the Secretary that the State's health department 22 will-
“(A) address its highest priority core public health infrastructure needs; and 
1315

"(B) as appropriate, allocate funds to local health departments within the State.

3 “(e) Competitive Grants to State, Local, and 4 Tribal Health Departments.-In making grants 5 under subsection $(b)(1)(B)$, the Secretary shall give pri6 ority to applicants demonstrating core public health infra7 structure needs identified in the accreditation process 8 under subsection $(\mathrm{g})$.

9 “(f) Maintenance of Effort.-The Secretary 10 may award a grant to an entity under subsection (b) only 11 if the entity demonstrates to the satisfaction of the Sec12 retary that-

"(1) funds received through the grant will be 14 expended only to supplement, and not supplant, non15 Federal and Federal funds otherwise available to the 16 entity for the purpose of addressing core public 17 health infrastructure needs; and

18 "(2) with respect to activities for which the 19 grant is awarded, the entity will maintain expendi20 tures of non-Federal amounts for such activities at 21 a level not less than the level of such expenditures 22 maintained by the entity for the fiscal year pre23 ceding the fiscal year for which the entity receives 24 the grant. 
1316

“(g) Establishment of a Public Health AC-

2 CReditation Program.-

“(1) In GENERAL.-The Secretary, acting through the Director of the Centers for Disease Control and Prevention, shall-

"(A) develop, and periodically review and update, standards for voluntary accreditation of State, local, or tribal health departments and public health laboratories for the purpose of advancing the quality and performance of such departments and laboratories; and

"(B) implement a program to accredit such health departments and laboratories in accordance with such standards.

“(2) Cooperative agrenment.-The Secretary may enter into a cooperative agreement with a private nonprofit entity to carry out paragraph (1).

"(h) REPORT.-The Secretary shall submit to the Congress an annual report on progress being made to accredit entities under subsection $(\mathrm{g})$, including-

"(1) a strategy, including goals and objectives, for accrediting entities under subsection (g) and achieving the purpose described in subsection $(\mathrm{g})(1)$; and 
“(2) identification of gaps in research related to

2 core public health infrastructure and recommenda-

3 tions of priority areas for such research.

4 “SEC. 3162. CORE PUBLIC HEALTH INFRASTRUCTURE AND

5 ACTIVITIES FOR CDC.

6 “(a) In GenerAL.-The Secretary, acting through

7 the Director of the Centers for Disease Control and Pre-

8 vention, shall expand and improve the core public health

9 infrastructure and activities of the Centers for Disease

10 Control and Prevention to address unmet and emerging

11 public health needs.

12 "(b) REPORT.-The Secretary shall submit to the

13 Congress an annual report on the activities funded

14 through this section.

\section{5 "Subtitle G-General Provisions}

16 "SEC. 3171. DEFINITIONS.

17 "In this title:

18 "(1) The term 'core public health infrastruc-

19 ture' includes workforce capacity and competency;

20 laboratory systems; health information, health infor-

21 mation systems, and health information analysis;

22 communications; financing; other relevant compo-

23 nents of organizational capacity; and other related

24 activities. 
“(2) The terms 'Department' and 'depart-

2 mental' refer to the Department of Health and

3 Human Services.

“(3) The term 'health disparities' includes

5 health and health care disparities and means popu-

6 lation-specific differences in the presence of disease,

7 health outcomes, or access to health care. For pur-

8 poses of the preceding sentence, a population may be

9 delineated by race, ethnicity, primary language, sex,

10 sexual orientation, gender identity, disability, socio-

11 economic status, or rural, urban, or other geographic

12 setting, and any other population or subpopulation

13 determined by the Secretary to experience significant

14 gaps in disease, health outcomes, or access to health 15 care.

16 “(4) The term 'tribal' refers to an Indian tribe, 17 a Tribal organization, or an Urban Indian organiza18 tion, as such terms are defined in section 4 of the 19 Indian Health Care Improvement Act.”.

20 (b) Transition Provisions applicable to Task 21 FORCES.-

22 (1) Functions, personnel, assets, Liabil23 ities, AND ADMinistrative aCtions.-All func24 tions, personnel, assets, and liabilities of, and ad25 ministrative actions applicable to, the Preventive 
1319

1 Services Task Force convened under section 915(a)

2 of the Public Health Service Act and the Task Force

3 on Community Preventive Services (as such section

4 and Task Forces were in existence on the day before

5 the date of the enactment of this Act) shall be trans-

6 ferred to the Task Force on Clinical Preventive

7 Services and the Task Force on Community Preven-

8 tive Services, respectively, established under sections

93131 and 3132 of the Public Health Service Act, as

10 added by subsection (a).

11 (2) ReCOMMENDATIONS.-All recommendations

12 of the Preventive Services Task Force and the Task

13 Force on Community Preventive Services, as in ex-

14 istence on the day before the date of the enactment

15 of this Act, shall be considered to be recommenda-

16 tions of the Task Force on Clinical Preventive Serv-

17 ices and the Task Force on Community Preventive

18 Services, respectively, established under sections

193131 and 3132 of the Public Health Service Act, as

20 added by subsection (a).

21 (3) Members already serving.-

22 (A) Initial Members.-The Secretary of

23 Health and Human Services may select those

24 individuals already serving on the Preventive

25 Services Task Force and the Task Force on 
21 STRATEGY.-Pending completion of the national strategy

22 under section 3121 of the Public Health Service Act, as 23 added by subsection (a), the Secretary of Health and 24 Human Services, acting through the relevant agency head, 25 may make a judgment about how the strategy will address 
1 an issue and rely on such judgment in carrying out any

2 provision of subtitle $\mathrm{C}, \mathrm{D}, \mathrm{E}$, or $\mathrm{F}$ of title XXXI of such

3 Act, as added by subsection (a), that requires the Sec-

4 retary-

5 (1) to take into consideration such strategy;

6 (2) to conduct or support research or provide

7 services in priority areas identified in such strategy;

8 or

9 (3) to take any other action in reliance on such

10 strategy.

11 (d) Conforming Amendments.-

12 (1) Paragraph (61) of section $3(b)$ of the In-

13 dian Health Care Improvement Act (25 U.S.C.

14 1602) is amended by striking "United States Pre-

15 ventive Services Task Force" and inserting "Task

16 Force on Clinical Preventive Services".

17 (2) Section 126 of the Medicare, Medicaid, and

18 SCHIP Benefits Improvement and Protection Act of

192000 (Appendix F of Public Law 106-554) is

20 amended by striking "United States Preventive

21 Services Task Force" each place it appears and in-

22 serting "Task Force on Clinical Preventive Serv23 ices".

24 (3) Paragraph (7) of section $317 \mathrm{D}$ (a) of the 25 Public Health Service Act (42 U.S.C. $247 \mathrm{~b}-5(\mathrm{a})$ ) is 
1322

1 amended by striking "United States Preventive

2 Services Task Force" and inserting "Task Force on

3 Clinical Preventive Services".

4 (4) Section 915 of the Public Health Service

5 Act (42 U.S.C. 299b-4) is amended by striking sub6 section (a).

(5) Subsections (s)(2)(AA)(iii)(II), (xx)(1), and 8 (ddd)(1)(B) of section 1861 of the Social Security 9 Act (42 U.S.C. 1395x) are amended by striking 10 "United States Preventive Services Task Force" 11 each place it appears and inserting "Task Force on 12 Clinical Preventive Services". SURVEILLANCE

15 SEC. 2401. IMPLEMENTATION OF BEST PRACTICES IN THE DELIVERY OF HEALTH CARE.

17 (a) In General.-Title IX of the Public Health 18 Service Act (42 U.S.C. 299 et seq.) is amended-

(1) by redesignating part D as part E;

(2) by redesignating sections 931 through 938

21 as sections 941 through 948, respectively;

(3) in section 948(1), as redesignated, by strik23 ing "931" and inserting "941”; and

(4) by inserting after part $\mathrm{C}$ the following: 
1323

2 PRACTICES IN THE DELIVERY OF HEALTH CARE

3 “SEC. 931. CENTER FOR QUALITY IMPROVEMENT.

"(a) In General.- There is established the Center

5 for Quality Improvement (referred to in this part as the

6 'Center'), to be headed by the Director.

7 “(b) Prioritization.-

8 "(1) IN GENERAL.-The Director shall

9 prioritize areas for the identification, development,

10 evaluation, and implementation of best practices (in-

11 cluding innovative methodologies and strategies) for

12 quality improvement activities in the delivery of

13 health care services (in this section referred to as 14 'best practices').

“(2) Considerations.-In prioritizing areas

16 under paragraph (1), the Director shall consider-

"(A) the priorities established under sec-

tion 1191 of the Social Security Act; and

"(B) the key health indicators identified by the Assistant Secretary for Health Information under section 1709 .

“(3) Limitations.-In conducting its duties 23 under this subsection, the Center for Quality Im24 provement shall not develop quality-adjusted life 25 year measures or any other methodologies that can 26 be used to deny benefits to a beneficiary against the 
1 beneficiary's wishes on the basis of the beneficiary's

2 age, life expectancy, present or predicted disability,

3 or expected quality of life.

4 “(c) Other ResponsibiLities.-The Director, act5 ing directly or by awarding a grant or contract to an eligi6 ble entity, shall-

"(1) identify existing best practices under sub-

$8 \quad$ section $(\mathrm{e})$;

“(2) develop new best practices under sub$10 \quad$ section $(\mathrm{f})$;

11 “(3) evaluate best practices under subsection $12 \quad(\mathrm{~g})$;

13 "(4) implement best practices under subsection $14 \quad(h) ;$

15 “(5) ensure that best practices are identified, 16 developed, evaluated, and implemented under this 17 section consistent with standards adopted by the 18 Secretary under section 3004 for health information 19 technology used in the collection and reporting of 20 quality information (including for purposes of the 21 demonstration of meaningful use of certified elec22 tronic health record (EHR) technology by physicians 23 and hospitals under the Medicare program (under 24 sections $1848(0)(2)$ and 1886(n)(3), respectively, of 25 the Social Security Act)); and 
1325

"(6) provide for dissemination of information

2 and reporting under subsections (i) and (j).

3 “(d) Eligibility.-To be eligible for a grant or con-

4 tract under subsection (c), an entity shall-

5

6

7

8

9

10

11 Act for the area to be served, agree to cooperate

12 with and avoid duplication of the activities of such

13 organization.

14

15 Director shall identify best practices that are-

16

17 (including hospitals, physician and other clinician

18 practices, community cooperatives, and other health

19 care entities) that deliver consistently high-quality,

20 efficient health care services; and

"(2) easily adapted for use by other health care

22 providers and for use across a variety of health care

23 settings.

24 "(f) Developing New Best Practices.-The Di25 rector shall develop best practices that are- 
"(1) based on a review of existing scientific evi-

2 dence;

“(2) sufficiently detailed for implementation

4 and incorporation into the workflow of health care

5 providers; and

6 "(3) designed to be easily adapted for use by

7 health care providers across a variety of health care

8 settings.

9 “(g) Evaluation of Best Practices.-The Direc-

10 tor shall evaluate best practices identified or developed

11 under this section. Such evaluation-

"(1) shall include determinations of which best

13 practices-

"(A) most reliably and effectively achieve significant progress in improving the quality of patient care; and

"(B) are easily adapted for use by health care providers across a variety of health care settings;

"(2) shall include regular review, updating, and improvement of such best practices; and

23 pirical assessments of health care providers (includ24 ing hospitals, physician and other clinician practices, 25 community cooperatives, and other health care enti- 
1 ties) and simulations of such best practices for de-

2 terminations under paragraph (1).

3 “(h) Inplementation of Best Practices.-

"(1) IN GENERAL.-The Director shall enter

5 into arrangements with entities in a State or region

6 to implement best practices identified or developed

7 under this section. Such implementation-

8 "(A) may include forming collaborative

9 multi-institutional teams; and

10 "(B) shall include an evaluation of the best

11 practices being implemented, including the

12 measurement of patient outcomes before, dur-

13 ing, and after implementation of such best

14 practices.

15 “(2) Preferences.-In carrying out this sub16 section, the Director shall give priority to health 17 care providers implementing best practices that-

18 "(A) have the greatest impact on patient 19 outcomes and satisfaction;

20 "(B) are the most easily adapted for use 21 by health care providers across a variety of 22 health care settings;

23 "(C) promote coordination of health care 24 practitioners across the continuum of care; and 
1328

"(D) engage patients and their families in improving patient care and outcomes.

4 The Director shall provide for the public dissemination of 5 information with respect to best practices and activities 6 under this section. Such information shall be made avail7 able in appropriate formats and languages to reflect the 8 varying needs of consumers and diverse levels of health 9 literacy. “(j) REPORT.-

11 "(1) IN GENERAL.-The Director shall submit 12 an annual report to the Congress and the Secretary 13 on activities under this section.

14 “(2) ConTENT.—Each report under paragraph

15 (1) shall include-

16 "(A) information on activities conducted 17 pursuant to grants and contracts awarded;

18 "(B) summary data on patient outeomes 19 before, during, and after implementation of best 20 practices; and

21 "(C) recommendations on the adaptability 22 of best practices for use by health providers.". 23 (b) Initial Quality Improvement ACtivities and 24 Initiatives To Be Implemented.-Until the Director 25 of the Agency for Healthcare Research and Quality has 
1 established initial priorities under section 931(b) of the

2 Public Health Service Act, as added by subsection (a), the

3 Director shall, for purposes of such section, prioritize the

4 following:

(1) Health care-associated infections.-

6 Reducing health care-associated infections, including

7 infections in nursing homes and outpatient settings.

8 (2) Surgery.-Increasing hospital and out-

9 patient perioperative patient safety, including reduc-

10 ing surgical-site infections and surgical errors (such

11 as wrong-site surgery and retained foreign bodies).

12 (3) Emergency RoOM.-Improving care in

13 hospital emergency rooms, including through the use

14 of principles of efficiency of design and delivery to

15 improve patient flow.

16 (4) OBSTETRICS.-Improving the provision of

17 obstetrical and neonatal care, including the identi-

18 fication of interventions that are effective in reduc-

19 ing the risk of preterm and premature labor and the

20 implementation of best practices for labor and deliv-

21 ery care.

22 (5) Pediatrics.-Improving the provision of

23 preventive and developmental child health services, 24 including interventions that can reduce child health 25 disparities (as defined in section 3171 of the Public 
$1 \quad$ Health Service Act, as added by section 2301) and

2 reduce the risk of developing chronic health-threat-

3 ening conditions that affect an individual's life

4 course development.

5 (c) REPORT.-Not later than 18 months after the 6 date of the enactment of this Act, the Director of the

7 Agency for Healtheare Research and Quality shall submit

8 a report to the Congress on the impact of the nurse-to-

9 patient ratio on the quality of care and patient outcomes,

10 including recommendations for further integration into

11 quality measurement and quality improvement activities.

12 SEC. 2402. ASSISTANT SECRETARY FOR HEALTH INFORMATION.

14 (a) Establishment.-Title XVII (42 U.S.C. 300u 15 et seq.) is amended-

16 (1) by redesignating sections 1709 and 1710 as 17 sections 1710 and 1711 , respectively; and

18 (2) by inserting after section 1708 the fol19 lowing:

20 "SEC. 1709. ASSISTANT SECRETARY FOR HEALTH INFORMATION.

22 "(a) In GENERAL.-There is established within the 23 Department an Assistant Secretary for Health Informa24 tion (in this section referred to as the 'Assistant Sec25 retary'), to be appointed by the Secretary. 
1 “(b) Responsibilities.-The Assistant Secretary

2 shall-

3 "(1) ensure the collection, collation, reporting,

4 and publishing of information (including full and

5 complete statistics) on key health indicators regard-

6 ing the Nation's health and the performance of the

$7 \quad$ Nation's health care;

8 "(2) facilitate and coordinate the collection, col-

9 lation, reporting, and publishing of information re-

10 garding the Nation's health and the performance of

11 the Nation's health care (other than information de-

12 scribed in paragraph (1));

13 "(3)(A) develop standards for the collection of

14 data regarding the Nation's health and the perform-

15 ance of the Nation's health care; and

16 "(B) in carrying out subparagraph (A)—

17 “(i) ensure appropriate specificity and

18 standardization for data collection at the na-

19 tional, regional, State, and local levels;

20 "(ii) include standards, as appropriate, for

21 the collection of accurate data on health dis-

22 parities;

23 "(iii) ensure, with respect to data on race 24 and ethnicity, consistency with the 1997 Office 25 of Management and Budget Standards for 
1332

Maintaining, Collecting and Presenting Federal Data on Race and Ethnicity (or any successor standards); and

"(iv) in consultation with the Director of the Office of Minority Health, and the Director of the Office of Civil Rights of the Department, develop standards for the collection of data on health and health care with respect to primary language;

“(4) provide support to Federal departments and agencies whose programs have a significant impact upon health (as determined by the Secretary) for the collection and collation of information described in paragraphs (1) and (2);

"(5) ensure the sharing of information described in paragraphs (1) and (2) among the agencies of the Department;

"(6) facilitate the sharing of information described in paragraphs (1) and (2) by Federal departments and agencies whose programs have a significant impact upon health (as determined by the Secretary);

"(7) identify gaps in information described in paragraphs (1) and (2) and the appropriate agency or entity to address such gaps; 
1333

1 “(8) facilitate and coordinate identification and 2 monitoring of health disparities by the agencies of 3 the Department to inform program and policy ef4 forts to reduce such disparities, including facilitating 5 and funding analyses conducted in cooperation with 6 the Social Security Administration, the Bureau of 7 the Census, and other appropriate agencies and enti8 ties;

$9 \quad$ “(9) consistent with privacy, proprietary, and 10 other appropriate safeguards, facilitate public acces11 sibility of datasets (such as de-identified Medicare 12 datasets or publicly available data on key health in13 dicators) by means of the Internet; and 14 "(10) award grants or contracts for the collec15 tion and collation of information described in para16 graphs (1) and (2) (including through statewide sur17 veys that provide standardized information).

18 “(c) Key Health Indicators.-

19 "(1) In GENERAL.-In carrying out subsection 20 (b)(1), the Assistant Secretary shall21 "(A) identify, and reassess at least once 22 every 3 years, key health indicators described in 23 such subsection;

24 "(B) publish statistics on such key health 25 indicators for the public- 
1334

17 the Office of Management and Budget governing the 18 review, release, and dissemination of key health indi19 cators shall be the same as the regulations, rules, 20 processes, and procedures of the Office of Manage21 ment and Budget governing the review, release, and 22 dissemination of Principal Federal Economic Indica23 tors (or equivalent statistical data) by the Bureau of 24 Labor Statistics.

"(I) the rate of change for a key health indicator; or "(II) the need to inform policy regarding the Nation's health and the performance of the Nation's health care; and

"(C) ensure consistency with the national strategy developed by the Secretary under section 3121 and consideration of the indicators specified in the reports under sections 308, 903(a)(6), and 913(b)(2).

“(2) Release of Key health indicators.The regulations, rules, processes, and procedures of 
1 “(d) Coordination.-In carrying out this section,

2 the Assistant Secretary shall coordinate with-

“(1) public and private entities that collect and

4 disseminate information on health and health care,

$5 \quad$ including foundations; and

6 "(2) the head of the Office of the National Co-

7 ordinator for Health Information Technology to en-

8 sure optimal use of health information technology.

9 “(e) Request for Information From Depart-

10 ments And Agencies.-Consistent with applicable law,

11 the Assistant Secretary may secure directly from any Fed-

12 eral department or agency information necessary to enable

13 the Assistant Secretary to carry out this section.

14

15

16

17 "(f) REPORT.-

“(1) Submission.-The Assistant Secretary shall submit to the Secretary and the Congress an annual report containing-

"(A) a description of national, regional, or State changes in health or health care, as reflected by the key health indicators identified under subsection $(\mathrm{c})(1)$;

"(B) a description of gaps in the collection, collation, reporting, and publishing of information regarding the Nation's health and the performance of the Nation's health care; 
1336

18 Nothing in this section shall be construed to affect appli19 cable proprietary or privacy protections. "(h) Consultation.-In carrying out this section, 21 the Assistant Secretary shall consult with-

"(C) recommendations for addressing such gaps and identification of the appropriate agency within the Department or other entity to address such gaps;

"(D) a description of analyses of health disparities, including the results of completed analyses, the status of ongoing longitudinal studies, and proposed or planned research; and "(E) a plan for actions to be taken by the Assistant Secretary to address gaps described in subparagraph (B).

“(2) Consideration.-In preparing a report under paragraph (1), the Assistant Secretary shall take into consideration the findings and conclusions in the reports under sections 308, 903(a)(6), and 913(b)(2).

“(g) Proprietary and Privacy Protections."(1) the heads of appropriate health agencies and offices in the Department, including the Office of the Surgeon General of the Public Health Service, 
1337

1 the Office of Minority Health, and the Office on

2 Women's Health; and

“(2) as appropriate, the heads of other Federal

4 departments and agencies whose programs have a

5 significant impact upon health (as determined by the 6 Secretary).

7 “(i) DeFinition.- - In this section:

8 “(1) The terms 'agency' and 'agencies' include 9 an epidemiology center established under section 214 10 of the Indian Health Care Improvement Act.

11 “(2) The term 'Department' means the Depart12 ment of Health and Human Services.

13 "(3) The term 'health disparities' has the 14 meaning given to such term in section 3171.”.

15 (b) Other COORdination Responsibilities.-

16 Title III (42 U.S.C. 241 et seq.) is amended-

17 (1) in paragraphs (1) and (2) of section 304(c)

18 (42 U.S.C. $242 \mathrm{~b}(\mathrm{c})$ ), by inserting “, acting through

19 the Assistant Secretary for Health Information," 20 after "The Secretary" each place it appears; and 21 (2) in section 306(j) (42 U.S.C. $242 \mathrm{k}(\mathrm{j})$ ), by in22 serting ", acting through the Assistant Secretary for 23 Health Information," after "of this section, the Sec24 retary". 


\section{8}

1 SEC. 2403. AUTHORIZATION OF APPROPRIATIONS.

2 Section 799C, as added and amended, is further

3 amended by adding at the end the following:

4 “(e) Quality and Surveillance.-For the pur5 pose of carrying out part D of title IX and section 1709, 6 in addition to any other amounts authorized to be appro-

7 priated for such purpose, there are authorized to be appro8 priated, out of any monies in the Public Health Invest9 ment Fund, $\$ 300,000,000$ for each of fiscal years 2011 10 through 2015.".

11 TITLE V-OTHER PROVISIONS

12 Subtitle A-Drug Discount for 13 Rural and Other Hospitals; 340B 14 Program Integrity

15 SEC. 2501. EXPANDED PARTICIPATION IN 340B PROGRAM.

(a) Expansion of Covered Entities Receiving

17 Discounted Prices.-Wection 340B(a)(4) (42 U.S.C.

18 256b(a)(4)) is amended by adding at the end the fol19 lowing:

"(M) A children's hospital excluded from the Medicare prospective payment system pursuant to section 1886(d)(1)(B)(iii) of the Social Security Act, or a free-standing cancer hospital excluded from the Medicare prospective payment system pursuant to section $1886(\mathrm{~d})(1)(\mathrm{B})(\mathrm{v})$ of the Social Security Act 
1 that would meet the requirements of subparagraph (L), including the disproportionate share adjustment percentage requirement under clause (ii) of such subparagraph, if the hospital were a subsection (d) hospital as defined by sec"(N) An entity that is a critical access hospital (as determined under section 1820(c)(2) of the Social Security Act).

“(O) An entity receiving funds under title $\mathrm{V}$ of the Social Security Act (relating to maternal and child health) for the provision of health services.

“(P) An entity receiving funds under subpart I of part B of title XIX of the Public Health Service Act (relating to comprehensive mental health services) for the provision of community mental health services. “(Q) An entity receiving funds under subpart II of such part B (relating to the prevention and treatment of substance abuse) for the provision of treatment services for substance abuse. 
"(R) An entity that is a Medicare-dependent, small rural hospital (as defined in section 1886(d)(5)(G)(iv) of the Social Security Act).

"(S) An entity that is a sole community hospital (as defined in section 1886(d)(5)(D)(iii) of the Social Security Act).

"(T) An entity that is classified as a rural referral center under section 1886(d)(5)(C) of the Social Security Act.”.

11 MENTS.-Section 340B(a) (42 U.S.C. 256b(a)) is amend$12 \mathrm{ed}-$

(A) by adding "and" at the end of clause (i);

(B) by striking "; and" at the end of clause (ii) and inserting a period; and

(C) by striking clause (iii); and

(2) in paragraph (5), by redesignating subpara20 graphs (C) and (D) as subparagraphs (D) and (E), 21 respectively, and by inserting after subparagraph 22 (B) the following:

"(C) Prohibiting use of Group PuRCHASING ARRANGEMENTS.-A hospital de25 scribed in subparagraph (L), (M), (N), (R), 
1341

(S), or (T) of paragraph (4) shall not obtain covered outpatient drugs through a group purchasing organization or other group purchasing arrangement.".

5 SEC. 2502. IMPROVEMENTS TO 340B PROGRAM INTEGRITY.

(a) Integrity Improvements.-Section 340B (42

7 U.S.C. 256b) is amended-

8

9

10 lowing:

11

12
(1) by striking subsections (c) and (d); and (2) by inserting after subsection (b) the fol“(c) Improvements in Program Integrity.“(1) Manufacturer compliance.“(A) In GENERAL.-From amounts appropriated under paragraph (4), the Secretary shall provide for improvements in compliance by manufacturers with the requirements of this section in order to prevent overcharges and other violations of the discounted pricing requirements specified in this section.

"(B) Improvements.-The improvements described in subparagraph (A) shall include the following:

"(i) The establishment of a process to enable the Secretary to verify the accuracy of ceiling prices calculated by manufactur- 
1342

ers under subsection (a)(1) and charged to covered entities, which shall include the following:

"(I) Developing and publishing, through an appropriate policy or regulatory issuance, standards and methodology for the calculation of ceiling prices under such subsection.

"(II) Comparing regularly the ceiling prices calculated by the Secretary with the quarterly pricing data that is reported by manufacturers to the Secretary.

“(III) Conducting periodic monitoring of sales transactions to covered entities.

"(IV) Inquiring into any discrepancies between ceiling prices and manufacturer pricing data that may be identified and taking, or requiring manufacturers to take, corrective action in response to such discrepancies, including the issuance of refunds pursuant to the procedures set forth in clause (ii). 
1343

“(ii) The establishment of procedures for the issuance of refunds to covered entities by manufacturers in the event that the Secretary finds there has been an overcharge, including the following:

"(I) Submission to the Secretary by manufacturers of an explanation of why and how the overcharge occurred, how the refunds will be calculated, and to whom the refunds will be issued.

"(II) Oversight by the Secretary to ensure that the refunds are issued accurately and within a reasonable period of time.

“(iii) Notwithstanding any other provision of law prohibiting the disclosure of ceiling prices or data used to calculate the ceiling price, the provision of access to covered entities and State Medicaid agencies through an Internet website of the Department of Health and Human Services or contractor to the applicable ceiling prices for covered drugs as calculated and verified by the Secretary in a manner that ensures 
1344

protection of privileged pricing data from unauthorized disclosure.

"(iv) The development of a mechanism by which-

"(I) rebates, discounts, or other price concessions provided by manufacturers to other purchasers subsequent to the sale of covered drugs to covered entities are reported to the Secretary; and

“(II) appropriate credits and refunds are issued to covered entities if such rebates, discounts, or other price concessions have the effect of lowering the applicable ceiling price for the relevant quarter for the drugs involved. "(v) In addition to authorities under section 1927(b)(3) of the Social Security Act, the Secretary may conduct audits of manufacturers and wholesalers to ensure the integrity of the program under this section, including audits on the market price of covered drugs.

"(vi) The establishment of a requirement that manufacturers and wholesalers 
1345

use the identification system developed by the Secretary for purposes of facilitating the ordering, purchasing, and delivery of covered drugs under this section, including the processing of chargebacks for such drugs.

"(vii) The imposition of sanctions in the form of civil monetary penalties, which-

“(I) shall be assessed according to standards and procedures established in regulations to be promulgated by the Secretary within one year of the date of the enactment of the Affordable Health Care for America Act; and

“(II) shall apply to any manufacturer with an agreement under this section and shall not exceed $\$ 100,000$ for each instance where a manufacturer knowingly charges a covered entity a price for purchase of a drug that exceeds the maximum applicable price under subsection (a)(1) or that knowingly violates any other provision 
1346

of this section, or withholds or provides false information to the Secretary or to covered entities under this section.

“(2) Covered entity Compliance.-

"(A) In GENERAL.-From amounts appropriated under paragraph (4), the Secretary shall provide for improvements in compliance by covered entities with the requirements of this section in order to prevent diversion and violations of the duplicate discount provision and other requirements under subsection (a)(5).

"(B) Improvements.-The improvements described in subparagraph (A) shall include the following:

“(i) The development of procedures to enable and require covered entities to update at least annually the information on the Internet Web site of the Department of Health and Human Services relating to this section.

"(ii) The development of procedures for the Secretary to verify the accuracy of information regarding covered entities that 


\section{7}

is listed on the Web site described in clause (i).

"(iii) The development of more detailed guidance describing methodologies and options available to covered entities for billing covered drugs to State Medicaid agencies in a manner that avoids duplicate discounts pursuant to subsection (a)(5)(A). "(iv) The establishment of a single, universal, and standardized identification system by which each covered entity site can be identified by manufacturers, distributors, covered entities, and the Secretary for purposes of facilitating the ordering, purchasing, and delivery of covered drugs under this section, including the processing of chargebacks for such drugs. "(v) The imposition of sanctions in the form of civil monetary penalties, which-

"(I) shall be assessed according to standards and procedures established in regulations promulgated by the Secretary; 
1348

"(II) shall not exceed $\$ 5,000$ for each violation; and

“(III) shall apply to any covered entity that knowingly violates subparagraph (a)(5)(B) or knowingly violates any other provision of this section.

"(vi) The exclusion of a covered entity from participation in the program under this section, for a period of time to be determined by the Secretary, in cases in which the Secretary determines, in accordance with standards and procedures established in regulations, that-

"(I) a violation of a requirement of this section was repeated and knowing; and

"(II) imposition of a monetary penalty would be insufficient to reasonably ensure compliance.

"(vii) The referral of matters as appropriate to the Food and Drug Administration, the Office of Inspector General of Department of Health and Human Services, or other Federal agencies. 

PROCESS.-From amounts appropriated under paragraph (4), the Secretary may establish and imple-

4 ment an administrative process for the resolution of 5 the following:

"(A) Claims by covered entities that manufacturers have violated the terms of their agreement with the Secretary under subsection (a)(1).

"(B) Claims by manufacturers that covered entities have violated subsection (a)(5)(A) or $(\mathrm{a})(5)(\mathrm{B})$.

“(4) Authorization of appropriations.-

There are authorized to be appropriated to carry out fiscal year 2011 and each succeeding fiscal year.". (b) Conforming Amendments.-

(1) Section $340 B(a)$ (42 U.S.C. $256 b(a)$ ) is amended-

(A) by adding at the end of paragraph (1) the following: "Such agreement shall require that the manufacturer offer each covered entity covered drugs for purchase at or below the applicable ceiling price if such drug is made available to any other purchaser at any price. Such 
agreement shall require that, if the supply of a covered drug is insufficient to meet demand, then the manufacturer may utilize an allocation method that is reported in writing to the Secretary and does not discriminate on the basis of the price paid by covered entities or on any other basis related to an entity's participation in the program under this section. Notwithstanding any other provision of law, if the Secretary requests a manufacturer to enter into a new or amended agreement under this section that complies with current law and if the manufacturer opts not to sign the new or amended agreement, then any existing agreement between the manufacturer and the Secretary under this section is deemed to no longer meet the requirements of this section for purposes of this section and section 1927 of the Social Security Act."; and

(B) by adding at the end the following paragraph:

“(11) QUARTERLY REPORTS.-An agreement described in paragraph (1) shall require that the manufacturer furnish the Secretary with reports on 
1351

1 a quarterly basis that include the following informa-

2 tion:

"(A) The price for each covered drug subject to the agreement that, according to the manufacturer, represents the maximum price that covered entities may permissibly be required to pay for the drug (referred to in this section as the 'ceiling price').

"(B) The component information used to calculate the ceiling price as determined necessary to administer the requirements of the program under this section.

"(C) Rebates, discounts, and other price concessions provided by manufacturers to other purchasers subsequent to the sale of covered drugs to covered entities.'.

(2) Section 1927(a)(5) of the Social Security 18 Act (42 U.S.C. 1396r-8(a)(5)) is amended by strik19 ing subparagraph (D).

\section{SEC. 2503. EFFECTIVE DATE.}

(a) In GeneraL.- The amendments made by this 22 subtitle shall take effect on the date of the enactment of 23 this Act, and sections 2501, 2502(a)(1), and 2502(b)(2) 24 shall apply to drugs dispensed on or after such date. 
1 (b) EFFEctiveness.-The amendments made by 2 this subtitle shall be effective, and shall be taken into ac3 count in determining whether a manufacturer is deemed

4 to meet the requirements of section $340 \mathrm{~B}(\mathrm{a})$ of the Public

5 Health Service Act (42 U.S.C. 256b(a)), and of section $61927(\mathrm{a})(5)$ of the Social Security Act (42 U.S.C. 1396r7 8(a)(5)), notwithstanding any other provision of law.

9 PART 1-GRANTS FOR CLINICS AND CENTERS

10 SEC. 2511. SCHOOL-BASED HEALTH CLINICS.

11 (a) In GeneraL.-Part Q of title III (42 U.S.C.

$12280 \mathrm{~h}$ et seq.) is amended by adding at the end the fol-

13 lowing:

14 “SEC. 399Z-1. SCHOOL-BASED HEALTH CLINICS.

15 “(a) Program.-The Secretary shall establish a

16 school-based health clinic program consisting of awarding

17 grants to eligible entities to support the operation of 18 school-based health clinics (referred to in this section as 19 'SBHCs').

20 "(b) EligibiLity.-To be eligible for a grant under 21 this section, an entity shall-

"(1) be an SBHC (as defined in subsection

$23 \quad(\mathrm{l})(3))$; and

"(2) submit an application at such time, in 25 such manner, and containing such information as 


\section{3}

1 the Secretary may require, including at a min2 imum-

"(A) evidence that the applicant meets all criteria necessary to be designated as an SBHC;

"(B) evidence of local need for the services to be provided by the SBHC; "(C) an assurance that-

"(i) SBHC services will be provided in accordance with Federal, State, and local laws; maintains collaborative relationships with other health care providers in the catchment area of the SBHC;

"(iii) the SBHC will provide onsite access during the academic day when school is in session and has an established network of support and access to services with backup health providers when the school or SBHC is closed; "(iv) the SBHC will be integrated into the school environment and will coordinate health services with appropriate school per- 
10 under this section-

23 amount of a grant under this section, the Secretary shall 24 take into consideration-

sonnel and other community providers colocated at the school; and "(v) the SBHC sponsoring facility assumes all responsibility for the SBHC administration, operations, and oversight; and

"(D) such other information as the Secretary may require.

“(c) UsE OF Funds.-Funds awarded under a grant "(1) may be used for-

"(A) providing training related to the provision of comprehensive primary health services and additional health services;

"(B) the management and operation of SBHC programs, including through subcontracts; and

"(C) the payment of salaries for health professionals and other appropriate SBHC personnel; and “(2) may not be used to provide abortions.

“(d) Consideration of Need.-In determining the "(1) the financial need of the SBHC; 
1355

"(2) State, local, or other sources of funding

2 provided to the SBHC; and

"(3) other factors as determined appropriate by

4 the Secretary.

$5 \quad$ “(e) Preferences.-In awarding grants under this 6 section, the Secretary shall give preference to SBHCs that

7 have a demonstrated record of service to at least one of 8 the following:

9

10 served children and adolescents.

11

12

\section{3}

14

15

16

17

18

19

20

21 SBHC agrees to provide, from non-Federal sources, an

22 amount equal to 20 percent of the amount of the grant

23 (which may be provided in eash or in kind) to carry out

24 the activities supported by the grant. 
1356

1 “(g) Supplement, Not Supplant.-The Secretary

2 may award a grant to an SBHC under this section only

3 if the SBHC demonstrates to the satisfaction of the Sec-

4 retary that funds received through the grant will be ex-

5 pended only to supplement, and not supplant, non-Federal

6 and Federal funds otherwise available to the SBHC for

7 operation of the SBHC (including each activity described

8 in paragraph (1) or (2) of subsection (c)).

9 “(h) Payor of Last Resort.-The Secretary may

10 award a grant to an SBHC under this section only if the

11 SBHC demonstrates to the satisfaction of the Secretary

12 that funds received through the grant will not be expended

13 for any activity to the extent that payment has been made,

14 or can reasonably be expected to be made-

15

“(1) under any insurance policy;

16

"(2) under any Federal or State health benefits

17 program (including titles XIX and XXI of the Social

18 Security Act); or

19

"(3) by an entity which provides health services

20 on a prepaid basis.

21 "(i) Regulations Regarding Reimbursement

22 for Health Services.- The Secretary shall issue regu-

23 lations regarding the reimbursement for health services

24 provided by SBHCs to individuals eligible to receive such

25 services through the program under this section, including 
1 reimbursement under any insurance policy or any Federal

2 or State health benefits program (including titles XIX and

3 XXI of the Social Security Act).

4 “(j) Technical Assistance.-The Secretary shall

5 provide (either directly or by grant or contract) technical

6 and other assistance to SBHCs to assist such SBHCs to

7 meet the requirements of this section. Such assistance

8 may include fiscal and program management assistance,

9 training in fiscal and program management, operational

10 and administrative support, and the provision of informa-

11 tion to the SBHCs of the variety of resources available

12 under this title and how those resources can be best used

13 to meet the health needs of the communities served by

14 the SBHCs.

15 “(k) Evaluation; Report.-The Secretary shall-

16 "(1) develop and implement a plan for evalu-

17 ating SBHCs and monitoring quality performances

18 under the awards made under this section; and

19 "(2) submit to the Congress on an annual basis

20 a report on the program under this section.

21 “(l) Definitions.-In this section:

22 “(1) COMPREhensive PRIMary health SERV-

23 ICES.-The term 'comprehensive primary health

24 services' means the core services offered by SBHCs, 25 which- 
1358

"(A) shall include-

“(i) comprehensive health assessments, diagnosis, and treatment of minor, acute, and chronic medical conditions and referrals to, and followup for, specialty care; and

“(ii) mental health assessments, crisis intervention, counseling, treatment, and referral to a continuum of services including emergency psychiatric care, community support programs, inpatient care, and outpatient programs; and “(B) may include additional services, such as oral health, social, and age-appropriate health education services, including nutritional counseling.

\section{“(2) Medically UNDERSERVED CHILDREN} AND ADOLESCENTS.-The term 'medically underserved children and adolescents' means a population of children and adolescents who are residents of an area designated by the Secretary as an area with a shortage of personal health services and health infrastructure for such children and adolescents. 
“(3) School-Based health CLINIC.-The term 'school-based health clinic' means a health clin3 ic that-

"(A) is located in, or is adjacent to, a school facility of a local educational agency;

"(D) provides comprehensive primary

"(B) is organized through school, community, and health provider relationships;

"(C) is administered by a sponsoring facility; health services during school hours to children and adolescents by health professionals in accordance with State and local laws and regulations, established standards, and community practice; and

"(E) does not perform abortion services.

“(4) Sponsoring Facility.-The term 'sponsoring facility' is-

"(A) a hospital;

“(B) a public health department;

"(C) a community health center;

"(D) a nonprofit health care entity whose mission is to provide access to comprehensive primary health care services;

"(E) a local educational agency; or 
1360

"(F) a program administered by the Indian Health Service or the Bureau of Indian Affairs or operated by an Indian tribe or a tribal organization under the Indian Self-Determination and Education Assistance Act, a Native Hawaiian entity, or an urban Indian program under title $\mathrm{V}$ of the Indian Health Care Improvement Act.

“(m) Authorization of Appropriations.-For

10 purposes of carrying out this section, there are authorized

11 to be appropriated $\$ 50,000,000$ for fiscal year 2011 and 12 such sums as may be necessary for each of fiscal years 132012 through 2015.".

14 (b) EfFective Date.-The Secretary of Health and 15 Human Services shall begin awarding grants under section 16 399Z-1 of the Public Health Service Act, as added by sub17 section (a), not later than July 1, 2010, without regard 18 to whether or not final regulations have been issued under 19 section 399Z-1(i) of such Act.

(c) Termination of Study.-Section 2(b) of the 21 Health Care Safety Net Act of 2008 (42 U.S.C. 254b 22 note) is amended by striking paragraph (2) (relating to 23 a school-based health center study). 
1 SEC. 2512. NURSE-MANAGED HEALTH CENTERS.

2 Title III (42 U.S.C. 241 et seq.) is amended by add3 ing at the end the following:

4 “PART S-NURSE-MANAGED HEALTH CENTERS

5 “SEC. 399FF. NURSE-MANAGED HEALTH CENTERS.

6 "(a) PRogram.-The Secretary, acting through the

7 Administrator of the Health Resources and Services Ad-

8 ministration, shall establish a nurse-managed health cen-

9 ter program consisting of awarding grants to entities

10 under subsection (b).

11 "(b) GRANT.-The Secretary shall award grants to

12 entities-

“(1) to plan and develop a nurse-managed

14 health center; or

“(2) to operate a nurse-managed health center.

16 "(c) UsE OF Funds.-Amounts received as a grant

17 under subsection (b) may be used for activities including

18 the following:

“(1) Purchasing or leasing equipment.

“(2) Training and technical assistance related

21 to the provision of comprehensive primary care serv-

22 ices and wellness services.

"(3) Other activities for planning, developing, 24 or operating, as applicable, a nurse-managed health 25 center. 
1 “(d) Assurances Applicable to Both Planning

2 AND Operation Grants.-

“(1) In GENERAL.—The Secretary may award a grant under this section to an entity only if the entity demonstrates to the Secretary's satisfaction that-

"(A) nurses, in addition to managing the center, will be adequately represented as providers at the center; and

"(B) not later than 90 days after receiving the grant, the entity will establish a community advisory committee composed of individuals, a majority of whom are being served by the center, to provide input into the nurse-managed health center's operations.

"(2) Matching Requirement.-The Secretary may award a grant under this section to an entity only if the entity agrees to provide, from nonFederal sources, an amount equal to 20 percent of the amount of the grant (which may be provided in cash or in kind) to carry out the activities supported by the grant.

“(3) PAYOR OF LAST RESORT.-The Secretary may award a grant under this section to an entity only if the entity demonstrates to the satisfaction of 
1363

1 the Secretary that funds received through the grant

2 will not be expended for any activity to the extent

3 that payment has been made, or can reasonably be

4 expected to be made-

5

6

7

8

9

10

11

12

13

14

15

16

17

18

19

20

21

22

23

24
"(A) under any insurance policy;

"(B) under any Federal or State health benefits program (including titles XIX and XXI of the Social Security Act); or

"(C) by an entity which provides health services on a prepaid basis.

“(4) Maintenance OF EFFORT.-The Secretary may award a grant under this section to an entity only if the entity demonstrates to the satisfaction of the Secretary that-

"(A) funds received through the grant will be expended only to supplement, and not supplant, non-Federal and Federal funds otherwise available to the entity for the activities to be funded through the grant; and

"(B) with respect to such activities, the entity will maintain expenditures of non-Federal amounts for such activities at a level not less than the lesser of such expenditures maintained by the entity for the fiscal year preceding the 
fiscal year for which the entity receives the grant.

3 “(e) Additional Assurance For Planning

4 GRANTS.-The Secretary may award a grant under sub5 section (b)(1) to an entity only if the entity agrees-

6 "(1) to assess the needs of the medically under7 served populations proposed to be served by the 8 nurse-managed health center; and

9 “(2) to design services and operations of the 10 nurse-managed health center for such populations 11 based on such assessment.

12 "(f) AdDitional Assurance FOR Operation 13 Grants.-The Secretary may award a grant under sub14 section $(b)(2)$ to an entity only if the entity assures that 15 the nurse-managed health center will provide"(1) comprehensive primary care services, 17 wellness services, and other health care services 18 deemed appropriate by the Secretary;

19 "(2) care without respect to insurance status or 20 income of the patient; and

21 "(3) direct access to client-centered services of22 fered by advanced practice nurses, other nurses, 23 physicians, physician assistants, or other qualified 24 health professionals. 
1365

1 “(g) Technical Assistance.-The Secretary shall 2 provide (either directly or by grant or contract) technical 3 and other assistance to nurse-managed health centers to 4 assist such centers in meeting the requirements of this 5 section. Such assistance may include fiscal and program 6 management assistance, training in fiscal and program 7 management, operational and administrative support, and 8 the provision of information to nurse-managed health cen9 ters regarding the various resources available under this 10 section and how those resources can best be used to meet 11 the health needs of the communities served by nurse-man12 aged health centers.

13 "(h) REPORT.-The Secretary shall submit to the 14 Congress an annual report on the program under this sec15 tion.

16 “(i) Definitions.-In this section:

17 “(1) Comprehensive PRIMARY CARE SERV18 ICES.-The term 'comprehensive primary care serv19 ices' has the meaning given to the term 'required 20 primary health services' in section $330(b)(1)$.

21 “(2) Medically UNDERSERVED POPU22 LATION.-The term 'medically underserved popu23 lation' has the meaning given to such term in section $24330(b)(3)$. 
1366

“(3) Nurse-Managed Health CEnTER.-The term 'nurse-managed health center' has the meaning' given to such term in section 801 .

“(4) WELLnESS SERVICES.—The term 'wellness

5 services' means any health-related service or inter-

6 vention, not including primary care, which is de-

7 signed to reduce identifiable health risks and in-

8 crease healthy behaviors intended to prevent the

9 onset of disease or lessen the impact of existing

10 chronic conditions by teaching more effective man-

11 agement techniques that focus on individual self-care

12 and patient-driven decisionmaking.

13 "(j) Authorization of Appropriations.-To

14 carry out this section, there are authorized to be appro-

15 priated such sums as may be necessary for each of fiscal

16 years 2011 through 2015.".

17 SEC. 2513. FEDERALLY QUALIFIED BEHAVIORAL HEALTH 18 CENTERS.

19 Section 1913 (42 U.S.C. 300x-3) is amended-

20 (1) in subsection $(\mathrm{a})(2)(\mathrm{A})$, by striking "com-

21 munity mental health services" and inserting "be-

22 havioral health services (of the type offered by feder-

23 ally qualified behavioral health centers consistent

24 with subsection (c)(3))';

$25 \quad(2)$ in subsection (b)- 
(A) by striking paragraph (1) and inserting the following:

"(1) services under the plan will be provided

4 only through appropriate, qualified community pro-

5 grams (which may include federally qualified behav-

6 ioral health centers, child mental health programs,

7 psychosocial rehabilitation programs, mental health

8 peer-support programs, and mental health primary

9 consumer-directed programs); and"; and

10 (B) in paragraph (2), by striking "commu-

11 nity mental health centers" and inserting "fed-

12 erally qualified behavioral health centers"; and

13 (3) by striking subsection (c) and inserting the

14 following:

15 “(c) Criteria for Federally Qualified Behav-

16 ioral Health Centers.-

17 "(1) IN GENERAL.-The Administrator shall 18 certify, and recertify at least every 5 years, federally 19 qualified behavioral health centers as meeting the 20 criteria specified in this subsection.

21 "(2) Regulations. - Not later than 18 months

22 after the date of the enactment of the Affordable

23 Health Care for America Act, the Administrator 24 shall issue final regulations for certifying centers 25 under paragraph (1). 
“(3) CRITERIA.-The criteria referred to in subsection (b)(2) are that the center performs each 3 of the following:

"(A) Provide services in locations that ensure services will be available and accessible human dignity and assures continuity of care. "(B) Provide services in a mode of service delivery appropriate for the target population. "(C) Provide individuals with a choice of service options where there is more than one efficacious treatment.

“(D) Employ a core staff of clinical staff that is multidisciplinary and culturally and linguistically competent.

"(E) Provide services, within the limits of the capacities of the center, to any individual residing or employed in the service area of the center.

"(F) Provide, directly or through contract, to the extent covered for adults in the State Medicaid plan and for children in accordance with section $1905(\mathrm{r})$ of the Social Security Act regarding early and periodic screening, diag- 
nosis, and treatment, each of the following services:

"(i) Screening, assessment, and diagnosis, including risk assessment.

“(ii) Person-centered treatment plan-

ning or similar processes, including risk assessment and crisis planning.

"(iii) Outpatient clinic mental health services, including screening, assessment, diagnosis, psychotherapy, substance abuse counseling, medication management, and integrated treatment for mental illness and substance abuse which shall be evidencebased (including cognitive behavioral therapy, dialectical behavioral therapy, motivational interviewing, and other such therapies which are evidence-based).

"(iv) Outpatient clinic primary care services, including screening and monitoring of key health indicators and health risk (including screening for diabetes, hypertension, and cardiovascular disease and monitoring of weight, height, body mass index (BMI), blood pressure, blood glucose or $\mathrm{HbA} 1 \mathrm{C}$, and lipid profile). 
"(v) Crisis mental health services, in-

cluding 24-hour mobile crisis teams, emergency crisis intervention services, and crisis stabilization.

“(vi) Targeted case management (services to assist individuals gaining access to needed medical, social, educational, and other services and applying for income security and other benefits to which they may be entitled).

"(vii) Psychiatric rehabilitation services including skills training, assertive community treatment, family psychoeducation, disability self-management, supported employment, supported housing services, therapeutic foster care services, multisystemic therapy, and such other evidencebased practices as the Secretary may require.

"(viii) Peer support and counselor services and family supports.

"(G) Maintain linkages, and where possible enter into formal contracts with, inpatient psychiatric facilities and substance abuse detoxification and residential programs. 
1371

"(H) Make available to individuals served by the center, directly, through contract, or through linkages with other programs, each of the following:

"(i) Adult and youth peer support and

counselor services.

“(ii) Family support services for families of children with serious mental disorders.

"(iii) Other community or regional services, supports, and providers, including schools, child welfare agencies, juvenile and criminal justice agencies and facilities, housing agencies and programs, employers, and other social services.

"(iv) Onsite or offsite access to primary care services.

“(v) Enabling services, including outreach, transportation, and translation. "(vi) Health and wellness services, including services for tobaceo cessation.". 
2 SEC. 2521. COMPREHENSIVE PROGRAMS TO PROVIDE EDUTO NURSING.

(a) Purposes.-It is the purpose of this section to 6 authorize grants to-

(1) address the projected shortage of nurses by

8 funding comprehensive programs to create a career

9 ladder to nursing (including certified nurse assist-

10 ants, licensed practical nurses, licensed vocational

11 nurses, and registered nurses) for incumbent ancil-

12 lary health care workers;

13 (2) increase the capacity for educating nurses

14 by increasing both nurse faculty and clinical oppor15 tunities through collaborative programs between 16 staff nurse organizations, health care providers, and 17 accredited schools of nursing; and

18 (3) provide training programs through edu19 cation and training organizations jointly adminis20 tered by health care providers and health care labor 21 organizations or other organizations representing 22 staff nurses and frontline health care workers, work23 ing in collaboration with accredited schools of nurs24 ing and academic institutions.

25 (b) GRANTs.-Not later than 6 months after the date 26 of the enactment of this Act, the Secretary of Labor (re- 
1 ferred to in this section as the "Secretary") shall establish

2 a partnership grant program to award grants to eligible 3 entities to carry out comprehensive programs to provide 4 education to nurses and create a pipeline to nursing for 5 incumbent ancillary health care workers who wish to ad6 vance their careers, and to otherwise carry out the pur7 poses of this section.

8 (c) Eligibility.-To be eligible for a grant under 9 this section, an entity shall be-

10 (1) a health care entity that is jointly adminis11 tered by a health care employer and a labor union 12 representing the health care employees of the em13 ployer and that carries out activities using labor14 management training funds as provided for under 15 section $302(\mathrm{c})(6)$ of the Labor Management Rela16 tions Act, 1947 (29 U.S.C. 186(c)(6));

17 (2) an entity that operates a training program 18 that is jointly administered by-

19 (A) one or more health care providers or 20 facilities, or a trade association of health care 21 providers; and

22 (B) one or more organizations which rep23 resent the interests of direct care health care 24 workers or staff nurses and in which the direct 25 care health care workers or staff nurses have 
1 direct input as to the leadership of the organi-

2 zation;

3 (3) a State training partnership program that

4 consists of nonprofit organizations that include equal

5 participation from industry, including public or pri-

6 vate employers, and labor organizations including

7 joint labor-management training programs, and

8 which may include representatives from local govern-

9 ments, worker investment agency one-stop career

10 centers, community-based organizations, community

11 colleges, and accredited schools of nursing; or

12 (4) a school of nursing (as defined in section

13801 of the Public Health Service Act (42 U.S.C.

$14296))$.

15 (d) Additional Requirements for Health Care

16 Employer Described in Subsection (c).-To be eligi-

17 ble for a grant under this section, a health care employer

18 described in subsection (c) shall demonstrate that it-

19 (1) has an established program within its facil-

20 ity to encourage the retention of existing nurses;

21 (2) provides wages and benefits to its nurses

22 that are competitive for its market or that have been

23 collectively bargained with a labor organization; and

24 (3) supports programs funded under this sec-

25 tion through 1 or more of the following: 
(A) The provision of paid leave time and continued health coverage to incumbent health care workers to allow their participation in nursing career ladder programs, including certified nurse assistants, licensed practical nurses, licensed vocational nurses, and registered nurses.

(B) Contributions to a joint labor-management training fund which administers the program involved.

(C) The provision of paid release time, incentive compensation, or continued health coverage to staff nurses who desire to work full- or part-time in a faculty position.

(D) The provision of paid release time for staff nurses to enable them to obtain a bachelor of science in nursing degree, other advanced nursing degrees, specialty training, or certification program.

(E) The payment of tuition assistance which is managed by a joint labor-management training fund or other jointly administered program.

(e) Other Requirements.-

(1) Matching ReQuirement.- 
(A) In gENERAL.-The Secretary may not make a grant under this section unless the applicant involved agrees, with respect to the costs to be incurred by the applicant in carrying out the program under the grant, to make available non-Federal contributions (in cash or in kind

under subparagraph (B)) toward such costs in an amount equal to not less than $\$ 1$ for each $\$ 1$ of Federal funds provided in the grant. Such contributions may be made directly or through donations from public or private entities, or may be provided through the cash equivalent of paid release time provided to incumbent worker students.

(B) Determination of amount of NONFEDERAL CONTRIBUTION.-Non-Federal contributions required in subparagraph (A) may be in eash or in kind (including paid release time), fairly evaluated, including equipment or services (and excluding indirect or overhead costs). Amounts provided by the Federal Government, or services assisted or subsidized to any significant extent by the Federal Government, may not be included in determining the amount of such non-Federal contributions. 
(2) Required collaboration.-Entities car-

2 rying out or overseeing programs carried out with

3 assistance provided under this section shall dem-

4 onstrate collaboration with accredited schools of

5 nursing which may include community colleges and

6 other academic institutions providing associate's,

7 bachelor's, or advanced nursing degree programs or

8 specialty training or certification programs.

9 (f) UsE OF Funds.-Amounts awarded to an entity

10 under a grant under this section shall be used for the fol-

11 lowing:

12 (1) To carry out programs that provide edu13 cation and training to establish nursing career lad14 ders to educate incumbent health care workers to be15 come nurses (including certified nurse assistants, li16 censed practical nurses, licensed vocational nurses, 17 and registered nurses). Such programs shall include 18 one or more of the following:

19 (A) Preparing incumbent workers to return 20 to the classroom through English-as-a-second21 language education, GED education, precollege 22 counseling, college preparation classes, and sup23 port with entry level college classes that are a 24 prerequisite to nursing. 
(B) Providing tuition assistance with preference for dedicated cohort classes in community colleges, universities, and accredited schools of nursing with supportive services including tutoring and counseling.

(D) Carrying out orientation and mentorship programs that assist newly graduated nurses in adjusting to working at the bedside to ensure their retention postgraduation, and ongoing programs to support nurse retention.

(E) Providing stipends for release time and continued health care coverage to enable incumbent health care workers to participate in these programs.

20 obtaining advanced degrees and completing specialty 21 training or certification programs and to establish 22 incentives for nurses to assume nurse faculty posi23 tions on a part-time or full-time basis. Such pro24 grams shall include one or more of the following: 
(A) Increasing the pool of nurses with advanced degrees who are interested in teaching by funding programs that enable incumbent nurses to return to school.

(B) Establishing incentives for advanced degree bedside nurses who wish to teach in nursing programs so they can obtain a leave from their bedside position to assume a full- or part-time position as adjunct or full-time faculty without the loss of salary or benefits.

(C) Collaboration with accredited schools of nursing which may include community colleges and other academic institutions providing associate's, bachelor's, or advanced nursing degree programs, or specialty training or certification programs, for nurses to carry out innovative nursing programs which meet the needs of bedside nursing and health care providers.

20 section the Secretary shall give preference to programs 21 that-

(1) provide for improving nurse retention;

(2) provide for improving the diversity of the 24 new nurse graduates to reflect changes in the demo25 graphics of the patient population; 
1 (3) provide for improving the quality of nursing 2 education to improve patient care and safety;

3 (4) have demonstrated success in upgrading in4 cumbent health care workers to become nurses or 5 which have established effective programs or pilots 6 to increase nurse faculty; or

7 (5) are modeled after or affiliated with such 8 programs described in paragraph (4).

9 (h) Evaluation.-

10 (1) Program evaluations.-An entity that 11 receives a grant under this section shall annually 12 evaluate, and submit to the Secretary a report on, 13 the activities carried out under the grant and the 14 outcomes of such activities. Such outcomes may in15 clude-

16 (A) an increased number of incumbent 17 workers entering an accredited school of nurs18 ing and in the pipeline for nursing programs;

19 (B) an increasing number of graduating 20 nurses and improved nurse graduation and li$21 \quad$ censure rates; (C) improved nurse retention; (D) an increase in the number of staff nurses at the health care facility involved; 
1381

222011 through 2015.

\section{SEC. 2522. MENTAL AND BEHAVIORAL HEALTH TRAINING.}

24 Part E of title VII (42 U.S.C. $294 \mathrm{n}$ et seq.) is amend25 ed by adding at the end the following: 
1382

1 “Subpart 3-Mental and Behavioral Health Training

2 "SEC. 775. MENTAL AND BEHAVIORAL HEALTH TRAINING

PROGRAM.

4 "(a) Program.-The Secretary, acting through the

5 Administrator of the Health Resources and Services Ad-

6 ministration and in consultation with the Administrator

7 of the Substance Abuse and Mental Health Services Ad-

8 ministration, shall establish an interdisciplinary mental

9 and behavioral health training program consisting of

10 awarding grants and contracts under subsection (b).

11 “(b) Support and Development of Mental and

12 Behavioral Health Training Programs.-The Sec-

13 retary shall make grants to, or enter into contracts with,

14 eligible entities-

"(1) to plan, develop, operate, or participate in

16 an accredited professional training program for men-

17 tal and behavioral health professionals to promote-

"(A) interdisciplinary training; and

"(B) coordination of the delivery of health care within and across settings, including health care institutions, community-based settings, and the patient's home;

"(2) to provide financial assistance to mental

24 and behavioral health professionals, who are partici-

25 pants in any such program, and who plan to work

26 in the field of mental and behavioral health; 
1383

1 “(3) to plan, develop, operate, or participate in

2 an accredited program for the training of mental

3 and behavioral health professionals who plan to

4 teach in the field of mental and behavioral health;

5 and

6 "(4) to provide financial assistance in the form

7 of traineeships and fellowships to mental and behav-

8 ioral health professionals who are participants in any

9 such program and who plan to teach in the field of

10 mental and behavioral health.

11 “(c) Eligibility.-To be eligible for a grant or con-

12 tract under subsection (b), an entity shall be-

13 "(1) an accredited health professions school, in-

14 cluding an accredited school or program of psy-

15 chology, psychiatry, social work, marriage and family

16 therapy, professional mental health or substance

17 abuse counseling, or addiction medicine;

18 “(2) an accredited public or nonprofit private

19 hospital;

"(3) a public or private nonprofit entity; or

“(4) a consortium of 2 or more entities de-

22 scribed in paragraphs (1) through (3).

23 “(d) Preference.-In awarding grants or contracts

24 under this section, the Secretary shall give preference to 
1 entities that have a demonstrated record of at least one

2 of the following:

“(1) Training a high or significantly improved

4 percentage of health professionals who serve in un-

5 derserved communities.

6 “(2) Supporting teaching programs that ad-

7 dress the health care needs of vulnerable popu-

8 lations.

“(3) Training individuals who are from dis-

10 advantaged backgrounds (including racial and ethnic

11 minorities underrepresented among mental and be-

12 havioral health professionals).

13 "(4) Training individuals who serve geriatric

14 populations with an emphasis on underserved elder15 ly.

16 "(5) Training individuals who serve pediatric 17 populations with an emphasis on underserved chil18 dren.

19 “(e) REPORT.-The Secretary shall submit to the 20 Congress an annual report on the program under this sec21 tion.

22 “(f) Definition.-In this section:

23 “(1) The term 'interdisciplinary' means collabo24 ration across health professions, specialties, and sub25 specialties, which may include public health, nursing, 
1 allied health, dieteties or nutrition, and appropriate

2 health specialties.

“(2) The term 'mental and behavioral health

4 professional' means an individual training or prac-

$5 \quad$ ticing-

"(A) in psychology; general, geriatric, child or adolescent psychiatry; social work; marriage and family therapy; professional mental health or substance abuse counseling; or addiction medicine; or

"(B) another mental and behavioral health specialty, as deemed appropriate by the Secretary.

“(g) Authorization of Appropriations.-To 15 carry out this section, there is authorized to be appro16 priated $\$ 60,000,000$ for each of fiscal years 2011 through 17 2015. Of the amounts appropriated to carry out this sec18 tion for a fiscal year, not less than 15 percent shall be 19 used for training programs in psychology.".

20 SEC. 2523. REAUTHORIZATION OF TELEHEALTH AND TELEMEDICINE GRANT PROGRAMS.

(a) Telehealth Network and Telehealth Re-

23 source Centers Grant Programs.-Section 330I (42

24 U.S.C. 254c-14) is amended-

25 (1) in subsection (a)- 
1386

(A) by striking paragraph (3) (relating to frontier communities); and

(B) by inserting after paragraph (2) the following:

“(3) Health disparities.-The term 'health disparities' has the meaning given such term in section 3171.”;

(2) in subsection $(d)(1)-$

(A) in subparagraph (B), by striking "and" at the end;

(B) in subparagraph (C), by striking the period at the end and inserting "; and"; and

(C) by adding at the end the following:

“(D) reduce health disparities.”;

(3) in subsection (f)(1)(B)(iii) -

(A) in subclause (VII), by inserting ", including skilled nursing facilities" before the period at the end;

(B) in subclause (IX), by inserting ", including county mental health and public mental health facilities" before the period at the end; and

(C) by adding at the end the following:

“(XIII) Renal dialysis facilities.”; 
(4) by amending subsection (i) to read as fol-

2 lows:

"(i) Preferences.-

“(1) Telehealth NeTwORKs.-In awarding

5 grants under subsection (d)(1) for projects involving

6 telehealth networks, the Secretary shall give pref-

7 erence to eligible entities meeting at least one of the

8 following:

"(A) NeTwork.-The eligible entity is a health care provider in, or proposing to form, a medically underserved area or a health professional shortage area.

"(B) Broad GeOgraphic COVERAGE.The eligible entity demonstrates broad geographic coverage in the rural or medically underserved areas of the State or States in which the entity is located.

"(C) Health disparities.-The eligible entity demonstrates how the project to be funded through the grant will address health disparities.

“(D) Linkages.-The eligible entity agrees to use the grant to establish or develop plans for telehealth systems that will link rural 
1388

hospitals and rural health care providers to other hospitals, health care providers, and patients.

"(E) EFFICIEnCY.-The eligible entity agrees to use the grant to promote greater efficiency in the use of health care resources.

"(F) Viability.-The eligible entity demonstrates the long-term viability of projects through-

“(i) availability of non-Federal funding sources; or

"(ii) institutional and community support for the telehealth network. "(G) SERviCES.-The eligible entity provides a plan for coordinating system use by eligible entities and prioritizes use of grant funds for health care services over nonclinical uses.

“(2) Telehealth Resource Centers.-In awarding grants under subsection (d)(2) for projects involving telehealth resource centers, the Secretary shall give preference to eligible entities meeting at least one of the following:

“(A) Provision of a Broad RANge of SERVICES.-The eligible entity has a record of success in the provision of a broad range of 
telehealth services to medically underserved areas or populations.

“(B) Provision of telehealth techNICAL ASSISTANCE.-The eligible entity has a record of success in the provision of technical

(5) in subsection $(\mathrm{j})(2)(\mathrm{B})$, by striking "such

16 projects for fiscal year 2001" and all that follows 17 through the period and inserting "such projects for 18 fiscal year 2010.”;

(6) in subsection $(\mathrm{k})(1)-$

(A) in subparagraph (E)(i), by striking "transmission of medical data" and inserting "transmission and electronic archival of medical 25 data"; and

(B) by amending subparagraph (F) to read as follows: 
“(F) developing projects to use telehealth

technology to-

"(i) facilitate collaboration between health care providers;

"(ii) promote telenursing services; or

"(iii) promote patient understanding and adherence to national guidelines for chronic disease and self-management of such conditions;";

(7) in subsection (q), by striking "Not later than September 30, 2005" and inserting "Not later than 1 year after the date of the enactment of the Affordable Health Care for America Act, and annually thereafter";

(8) by striking subsection (r);

(9) by redesignating subsection ( $\mathrm{s}$ ) as subsection $(\mathrm{r})$; and

(10) in subsection (r) (as so redesignated) -

(A) in paragraph (1) -

(i) by striking "and" before "such sums"; and

(ii) by inserting “, $\$ 10,000,000$ for fiscal year 2011, and such sums as may be necessary for each of fiscal years 2012 through 2015" before the semicolon; and 
(B) in paragraph (2) -

(i) by striking "and" before "such sums"; and

(ii) by inserting “, $\$ 10,000,000$ for fiscal year 2011, and such sums as may be necessary for each of fiscal years 2012 through 2015" before the period.

(b) Telemedicine; Incentive Grants Regarding

9 Coordination Among States.-Subsection (b) of sec-

10 tion 330L (42 U.S.C. 254c-18) is amended by inserting 11 “, $\$ 10,000,000$ for fiscal year 2011, and such sums as 12 may be necessary for each of fiscal years 2012 through 13 2015" before the period at the end.

14 SEC. 2524. NO CHILD LEFT UNIMMUNIZED AGAINST INFLUENZA: DEMONSTRATION PROGRAM USING ELEMENTARY AND SECONDARY SCHOOLS AS INFLUENZA VACCINATION CENTERS.

(a) Purpose.-The Secretary of Health and Human

19 Services in consultation with the Secretary of Education, 20 shall award grants to eligible partnerships to carry out 21 demonstration programs designed to test the feasibility of 22 using the Nation's elementary schools and secondary 23 schools as influenza vaccination centers.

24 (b) In GENERAL.-The Secretary shall coordinate 25 with the Secretary of Labor, the Secretary of Education, 
1 State Medicaid agencies, State insurance agencies, and

2 private insurers to carry out a program consisting of

3 awarding grants under subsection (c) to ensure that chil-

4 dren have coverage for all reasonable and customary ex-

5 penses related to influenza vaccinations, including the 6 costs of purchasing and administering the vaccine in-

7 curred when influenza vaccine is administered outside of

8 the physician's office in a school or other related setting.

9 (c) Program Description.-

10 (1) Grants.-From amounts appropriated pur-

11 suant to subsection (l), the Secretary shall award

12 grants to eligible partnerships to be used to provide

13 influenza vaccinations to children in elementary and

14 secondary schools, in coordination with school

15 nurses, school health care programs, community

16 health care providers, State insurance agencies, or 17 private insurers.

18 (2) ACIP RECOMMENDATIONs.-The program 19 under this section shall be designed to administer 20 vaccines consistent with the recommendations of the 21 Centers for Disease Control and Prevention's Advi22 sory Committee on Immunization Practices (ACIP) 23 for the annual vaccination of all children 5 through $24 \quad 19$ years of age. 
(3) Participation voluntary.-Participation

2 by a school or an individual shall be voluntary.

3 (d) UsE OF Funds.-Eligible partnerships receiving 4 a grant under this section shall ensure the maximum num5 ber of children access influenza vaccinations as follows:

(1) Covered CHILdRen.-To the extent to

7 which payment of the costs of purchasing or admin8 istering the influenza vaccine for children is not cov9 ered through other federally funded programs or 10 through private insurance, eligible partnerships re11 ceiving a grant shall use funds to purchase and ad12 minister influenza vaccinations.

(2) Children covered By other federal 14 PROGRAMS.-For children who are eligible under 15 other federally funded programs for payment of the 16 costs of purchasing or administering the influenza 17 vaccine, eligible partnerships receiving a grant shall 18 not use funds provided under this section for such 19 costs.

(3) Children covered By pRIVATe health 21 INSURANCE.-For children who have private insur22 ance, eligible partnerships receiving a grant shall 23 offer assistance in accessing coverage for vaccina24 tions administered through the program under this 25 section. 
1 (e) PRIVACY.-The Secretary shall ensure that the 2 program under this section adheres to confidentiality and 3 privacy requirements of section 264 of the Health Insur4 ance Portability and Accountability Act of 1996 (42 5 U.S.C. $1320 \mathrm{~d}-2$ note) and section 444 of the General 6 Education Provisions Act (20 U.S.C. 1232g; commonly re7 ferred to as the "Family Educational Rights and Privacy 8 Act of $1974 ")$.

9 (f) Application.-An eligible partnership desiring a 10 grant under this section shall submit an application to the 11 Secretary at such time, in such manner, and containing 12 such information as the Secretary may require.

13 (g) Duration.-Eligible partnerships receiving a 14 grant shall administer a demonstration program funded 15 through this section over a period of 2 consecutive school 16 years.

17 (h) Choice of Vaccine.-The program under this 18 section shall not restrict the discretion of a health care 19 provider to administer any influenza vaccine approved by 20 the Food and Drug Administration for use in pediatric 21 populations.

22 (i) AWARDS. - The Secretary shall award-

23 (1) a minimum of 10 grants in 10 different 24 States to eligible partnerships that each include one 
1 or more public schools serving primarily low-income

2 students; and

3 (2) a minimum of 5 grants in 5 different States

4 to eligible partnerships that each include one or

5 more public schools located in a rural local edu6 cational agency.

7 (j) REPORT.-Not later than 90 days following the 8 completion of the program under this section, the Sec9 retary shall submit to the Committees on Education and

10 Labor, Energy and Commerce, and Appropriations of the 11 House of Representatives and to the Committees on 12 Health, Education, Labor, and Pensions and Appropria13 tions of the Senate a report on the results of the program. 14 The report shall include-

15 (1) an assessment of the influenza vaccination 16 rates of school-age children in localities where the 17 program is implemented, compared to the national 18 average influenza vaccination rates for school-aged 19 children, including whether school-based vaccination 20 assists in achieving the recommendations of the Ad21 visory Committee on Immunization Practices;

22 (2) an assessment of the utility of employing el23 ementary schools and secondary schools as a part of 24 a multistate, community-based pandemic response 
1 program that is consistent with existing Federal and

2 State pandemic response plans;

3 (3) an assessment of the feasibility of using ex-

4 isting Federal and private insurance funding in es-

5 tablishing a multistate, school-based vaccination pro-

6 gram for seasonal influenza vaccination;

7 (4) an assessment of the number of education

8 days gained by students as a result of seasonal vac-

9 cinations based on absenteeism rates;

10 (5) a determination of whether the program 11 under this section-

(A) increased vaccination rates in the participating localities; and

17 should be continued, expanded, or terminated.

18 (k) DeFinitions.-In this section:

19 (1) Eligible Partnership.-The term "eligi20 ble partnership" means a local public health depart21 ment, or another health organization defined by the 22 Secretary as eligible to submit an application, and 23 one or more elementary and secondary schools.

24 (2) Elementary school.-The terms "ele25 mentary school" and "secondary school" have the 
1 meanings given such terms in section 9101 of the

2 Elementary and Secondary Education Act of 1965

$3 \quad$ (20 U.S.C. 7801).

(3) Low-INCOME.-The term "low-income"

5 means a student, age 5 through 19, eligible for free

6 or reduced-price lunch under the National School

$7 \quad$ Lunch Act (42 U.S.C. 1751 et seq.).

8 (4) RURAL LOCAL EDUCATIONAL AGENCY.-

9 The term "rural local educational agency" means an

10 eligible local educational agency described in section

$116211(b)(1)$ of the Elementary and Secondary Edu-

12 cation Act of 1965 (20 U.S.C. 7345(b)(1)).

13 (5) SECRETARY.-Except as otherwise speci14 fied, the term "Secretary" means the Secretary of $15 \quad$ Health and Human Services.

16 (l) Authorization of Appropriations.-To carry 17 out this section, there are authorized to be appropriated 18 such sums as may be necessary for each of fiscal years 192011 through 2015.

20 SEC. 2525. EXTENSION OF WISEWOMAN PROGRAM.

21 Section 1509 of the Public Health Service Act (42

22 U.S.C. $300 n-4 a)$ is amended-

23 (1) in subsection (a)-

24 (A) by striking the heading and inserting 25 "In General._-"; and 
(B) in the matter preceding paragraph (1), by striking "may make grants" and all that follows through "purpose" and inserting the following: "may make grants to such States for the purpose"; and

(2) in subsection $(d)(1)$, by striking "there are authorized" and all that follows through the period and inserting "there are authorized to be appropriated $\$ 70,000,000$ for fiscal year 2011,

11 fiscal year 2013, $\$ 81,000,000$ for fiscal year 2014, 12 and $\$ 85,000,000$ for fiscal year 2015.”.

\section{SEC. 2526. HEALTHY TEEN INITIATIVE TO PREVENT TEEN}

15 Part B of title III (42 U.S.C. 243 et seq.) is amended

16 by inserting after section $317 \mathrm{~T}$ the following:

17 "SEC. 317U. HEALTHY TEEN INITIATIVE TO PREVENT TEEN PREGNANCY.

19 “(a) Program.-To the extent and in the amount 20 of appropriations made in advance in appropriations Acts, 21 the Secretary, acting through the Director of the Centers 22 for Disease Control and Prevention, shall establish a pro23 gram consisting of making grants, in amounts determined 24 under subsection (c), to each State that submits an appli- 
1 cation in accordance with subsection (d) for an evidence-

2 based education program described in subsection (b).

3 “(b) Use of Funds.-Amounts received by a State

4 under this section shall be used to conduct or support evi-

5 dence-based education programs (directly or through

6 grants or contracts to public or private nonprofit entities,

7 including schools and community-based and faith-based

8 organizations) to reduce teen pregnancy or sexually trans-

9 mitted diseases.

10 “(c) Distribution of Funds.-The Director shall,

11 for fiscal year 2011 and each subsequent fiscal year, make

12 a grant to each State described in subsection (a) in an

13 amount equal to the product of-

"(1) the amount appropriated to carry out this

15 section for the fiscal year; and

16 "(2) the percentage determined for the State

17 under section 502(c)(1)(B)(ii) of the Social Security

18 Act.

19 “(d) Application.-To seek a grant under this sec-

20 tion, a State shall submit an application at such time, in

21 such manner, and containing such information and assur-

22 ance of compliance with this section as the Secretary may

23 require. At a minimum, an application shall to the satis-

24 faction of the Secretary- 
"(1) describe how the State's proposal will ad-

2 dress the needs of at-risk teens in the State;

“(2) identify the evidence-based education pro-

4 gram or programs selected from the registry devel-

5 oped under subsection $(\mathrm{g})$ that will be used to ad-

6 dress risks in priority populations;

7 "(3) describe how the program or programs will

8 be implemented and any adaptations to the evidence-

9 based model that will be made;

10 "(4) list any private and public entities with

11 whom the State proposes to work, including schools

12 and community-based and faith-based organizations,

13 and demonstrate their capacity to implement the

14 proposed program or programs; and

15 "(5) identify an independent entity that will

16 evaluate the impact of the program or programs.

17 “(e) Evaluation.-

18 “(1) REQUIREMENT.-As a condition on receipt 19 of a grant under this section, a State shall agree-

20 "(A) to arrange for an independent evalua-

21 tion of the impact of the programs to be con-

22 ducted or supported through the grant; and

23 "(B) submit reports to the Secretary on

24 such programs and the results of evaluation of 25 such programs. 
"(2) Funding Limitation.—Of the amounts

2 made available to a State through a grant under this

3 section for any fiscal year, not more than 10 percent

$4 \quad$ may be used for such evaluation.

5 “(f) Rule of Construction.-This section shall 6 not be construed to preempt or limit any State law regard-

7 ing parental involvement and decisionmaking in children's 8 education.

9 “(g) Registry of Eligible Programs.-The Sec10 retary shall develop not later than 180 days after the date 11 of the enactment of the Affordable Health Care for Amer12 ica Act, and periodically update thereafter, a publicly 13 available registry of programs described in subsection (b) 14 that, as determined by the Secretary-

"(1) meet the definition of the term 'evidence16 based' in subsection (i); "(2) are medically and scientifically accurate; 18 and “(3) provide age-appropriate information.

20 "(h) Matching Funds.—The Secretary may award 21 a grant to a State under this section for a fiscal year only 22 if the State agrees to provide, from non-Federal sources, 23 an amount equal to $\$ 1$ (in cash or in kind) for each $\$ 4$ 24 provided through the grant to carry out the activities sup25 ported by the grant. 
1 “(i) Definition.-In this section, the term 'evi-

2 dence-based' means based on a model that has been found,

3 in methodologically sound research-

4

5

6

$8 \quad$ rates; or

11 carry out this section, there is authorized to be appro-

12 priated $\$ 50,000,000$ for each of fiscal years 2011 through 13 2015.".

14 SEC. 2527. NATIONAL TRAINING INITIATIVES ON AUTISM

17 and Bill of Rights Act of 2000 (42 U.S.C. 15001 et seq.)

18 is amended by adding at the end the following:

\section{SPECTRUM DISORDERS.}

Title I of the Developmental Disabilities Assistance "Subtitle F-National Training Initiative on Autism Spectrum Disorders

"SEC. 171. NATIONAL TRAINING INITIATIVE.

“(a) Grants and Technical Assistance.-

“(1) Grants.- 
"(A) IN GENERAL._The Secretary, in consultation with the Interagency Autism Coordinating Committee, shall award multiyear grants to eligible entities to provide individuals (including parents and health, allied health, vocational, and educational professionals) with interdiscipli-

“(i) a University Center for Excellence in Developmental Disabilities Education, Research, and Service; or “(ii) a comparable interdisciplinary education, research, and service entity. “(C) Application Requirements.-An entity that desires to receive a grant for a program under this paragraph shall submit to the Secretary an applicationcapacity to- 
“(I) provide training and tech-

nical assistance in evidence-based practices to evaluate, and provide effective interventions, services, treatments, and supports to, children and adults with autism and their families; "(II) include individuals with autism and their families as part of the program to ensure that an individualand family-centered approach is used; "(III) share and disseminate materials and practices that are developed for, and evaluated to be effective

in, the provision of training and technical assistance; and

"(IV) provide training, technical assistance, interventions, services, treatments, and supports under this subsection statewide.

“(ii) providing assurances that the entity will-

"(I) provide trainees under this subsection with an appropriate balance of interdisciplinary academic and community-based experiences; and 
"(II) provide to the Secretary, in the manner prescribed by the Secretary, data regarding the number of individuals who have benefitted from, and outcomes of, the provision of training and technical assistance under this subsection; "(iii) providing assurances that training, technical assistance, dissemination of information, and services under this subsection will be-

"(I) consistent with the goals of this Act, the Americans with Disabilities Act of 1990, the Individuals with Disabilities Education Act, and the Elementary and Secondary Education Act of 1965; and

"(II) conducted in coordination with relevant State agencies, institutions of higher education, and service providers; and "(iv) containing such other information and assurances as the Secretary may require. 
“(D) UsE OF FUNDS.-A grant received under this subsection shall be used to provide individuals (including parents and health, allied health, vocational, and educational professionals) with interdisciplinary training, continuing education, technical assistance, and information for the purpose of improving services rendered to children and adults with autism, and their families, to address unmet needs related to autism. Such training, education, assistance, and information shall include each of the following:

"(i) Training health, allied health, vocational, and educational professionals to identify, evaluate the needs of, and develop interventions, services, treatments, and supports for, children and adults with autism.

“(ii) Developing model services and supports that demonstrate evidence-based practices.

“(iii) Developing systems and products that allow for the interventions, services, treatments, and supports to be evaluated for fidelity of implementation. 
"(iv) Working to expand the avail-

ability of evidence-based, lifelong interventions; educational, employment, and transition services; and community supports.

"(v) Providing statewide technical as-

sistance in collaboration with relevant

State agencies, institutions of higher edu-

cation, autism advocacy groups, and com-

munity-based service providers.

“(vi) Working to develop comprehensive systems of supports and services for individuals with autism and their families, including seamless transitions between education and health systems across the lifespan.

"(vii) Promoting training, technical assistance, dissemination of information, supports, and services.

“(viii) Developing mechanisms to provide training and technical assistance, including for-credit courses, intensive summer institutes, continuing education programs, distance based programs, and Webbased information dissemination strategies. 
"(ix) Promoting activities that support community-based family and individual services and enable individuals with autism and related developmental disabilities to fully participate in society and

“(2) Technical assistance.-The Secretary

16 shall reserve 2 percent of the amount appropriated

17 to carry out this subsection for a fiscal year to make 18 a grant to a national organization with dem19 onstrated capacity for providing training and tech20 nical assistance to-

"(A) assist in national dissemination of specific information, including evidence-based best practices, from interdisciplinary training programs, and when appropriate, other entities 
whose findings would inform the work performed by entities awarded grants;

"(B) compile and disseminate strategies and materials that prove to be effective in the provision of training and technical assistance so that the entire network can benefit from the models, materials, and practices developed in individual centers;

"(C) assist in the coordination of activities of grantees under this subsection;

“(D) develop a Web portal that will provide linkages to each of the individual training initiatives and provide access to training modules, promising training, and technical assistance practices and other materials developed by grantees;

"(E) serve as a research-based resource for Federal and State policymakers on information concerning the provision of training and technical assistance for the assessment, and provision of supports and services for, children and adults with autism;

"(F) convene experts from multiple interdisciplinary training programs, individuals with autism, and the families of such individuals to 
discuss and make recommendations with regard to training issues related to assessment, interventions, services, treatment, and supports for children and adults with autism; and

"(H) undertake any other functions that the Secretary determines to be appropriate. “(3) Authorization of appropriations.-

8 To carry out this subsection, there are authorized to

9 be appropriated $\$ 17,000,000$ for fiscal year 2011

10 and such sums as may be necessary for each of fis11 cal years 2012 through 2015 .

12 “(b) Expansion of the Number of University

13 Centers for Excellence in Developmental Dis14 abilities Education, Research, and Service.-

“(1) Grants.-To provide for the establish16 ment of up to 4 new University Centers for Excel17 lence in Developmental Disabilities Education, Re18 search, and Service, the Secretary shall award up to 194 grants to institutions of higher education.

"(2) ApPlicable PROvisions.-Except for 21 subsection (a)(3), the provisions of subsection (a) 22 shall apply with respect to grants under this sub23 section to the same extent and in the same manner 24 as such provisions apply with respect to grants 25 under subsection (a). 
“(3) PrIORITY.-In awarding grants under this

2 subsection, the Secretary shall give priority to appli-

3 cants that-

"(A) are minority institutions that have demonstrated capacity to meet the requirements of this section and provide services to individuals with autism and their families; or "(B) are located in a State with one or more underserved populations.

11 To carry out this subsection, there is authorized to 12 be appropriated $\$ 2,000,000$ for each of fiscal years 132011 through 2015.

14 “(c) Definitions.-In this section:

15 “(1) The term 'autism' means an autism spec16 trum disorder or a related developmental disability. 17 “(2) The term 'interventions' means edu18 cational methods and positive behavioral support 19 strategies designed to improve or ameliorate symp20 toms associated with autism.

“(3) The term 'minority institution' has the 22 meaning given to such term in section 365 of the 23 Higher Education Act of 1965. 
“(4) The term 'services' means services to as-

2 sist individuals with autism to live more independ-

3 ently in their communities.

“(5) The term 'treatments' means health serv-

5 ices, including mental health services, designed to

6 improve or ameliorate symptoms associated with au7 tism.

“(6) The term 'University Center for Excellence

9 in Developmental Disabilities Education, Research,

10 and Service' means a University Center for Excel-

11 lence in Development Disabilities Education, Re-

12 search, and Service that has been or is funded

13 through subtitle D or subsection (b).”.

14 SEC. 2528. IMPLEMENTATION OF MEDICATION MANAGEMENT SERVICES IN TREATMENT OF CHRONIC DISEASES.

17 (a) In GEnERAL.-The Secretary of Health and 18 Human Services (referred to in this section as the "Sec19 retary"), acting through the Director of the Agency for 20 Health Care Research and Quality, shall establish a pro21 gram to provide grants to eligible entities to implement 22 medication management services (referred to in this sec23 tion as "MTM services") provided by licensed phar24 macists, as a part of a collaborative, multidisciplinary, 25 interprofessional approach to the treatment of chronic dis- 
1 eases for targeted individuals, to improve the quality of

2 care and reduce overall cost in the treatment of such dis-

3 eases. The Secretary shall commence the grant program

4 not later than May 1, 2011.

5 (b) Eligible Entities.-To be eligible to receive a 6 grant under subsection (a), an entity shall-

(1) provide a setting appropriate for MTM serv-

8 ices, as recommended by the experts described in $9 \quad$ subsection (e);

10 (2) submit to the Secretary a plan for achieving 11 long-term financial sustainability;

12 (3) where applicable, submit a plan for coordi13 nating MTM services with other local providers and 14 where applicable, through or in collaboration with 15 the Medicare Medical Home Pilot program as estab16 lished by section $1866 \mathrm{~F}$ of the Social Security Act, 17 as added by section 1302(a) of this Act;

18 (4) submit a plan for meeting the requirements 19 under subsection (c); and

20 (5) submit to the Secretary such other informa21 tion as the Secretary may require.

22 (c) MTM Services to Targeted Individuals.23 The MTM services provided with the assistance of a grant 24 awarded under subsection (a) shall, as allowed by State 
1 law (including applicable collaborative pharmacy practice

2 agreements), include-

3

4

5

6

7

8

9

10

11

12

13

14

15

16

17

18

23 scriber; therapy;

(1) performing or obtaining necessary assessments of the health and functional status of each patient receiving such MTM services;

(2) formulating a medication treatment plan according to therapeutic goals agreed upon by the prescriber and the patient or caregiver or authorized representative of the patient;

(3) selecting, initiating, modifying, recommending changes to, or administering medication

(4) monitoring, which may include access to, ordering, or performing laboratory assessments, and evaluating the response of the patient to therapy, including safety and effectiveness;

(5) performing an initial comprehensive medication review to identify, resolve, and prevent medication-related problems, including adverse drug events, quarterly targeted medication reviews for ongoing monitoring, and additional followup interventions on a schedule developed collaboratively with the pre-

(6) documenting the care delivered and commu25 nicating essential information about such care (in- 


\section{5}

1 cluding a summary of the medication review) and

2 the recommendations of the pharmacist to other ap3 propriate health care providers of the patient in a 4 timely fashion;

$5 \quad$ (7) providing education and training designed 6 to enhance the understanding and appropriate use of 7 the medications by the patient, caregiver, and other 8 authorized representative;

9 (8) providing information, support services, and 10 resources and strategies designed to enhance patient 11 adherence with therapeutic regimens;

12 (9) coordinating and integrating MTM services 13 within the broader health care management services 14 provided to the patient; and

15 (10) such other patient care services as are al16 lowed under the scopes of practice for pharmacists 17 for purposes of other Federal programs.

18 (d) TARgETED Individuals.-MTM services pro19 vided by licensed pharmacists under a grant awarded 20 under subsection (a) shall be offered to targeted individ21 uals who-

(1) take 4 or more prescribed medications (in23 cluding over-the-counter and dietary supplements);

$24 \quad$ (2) take any high-risk medications; 
1 (3) have 2 or more chronic diseases, as identi-

2 fied by the Secretary; or

3 (4) have undergone a transition of care, or

4 other factors, as determined by the Secretary, that

5 are likely to create a high risk of medication-related 6 problems.

7 (e) Consultation With Experts.-In designing 8 and implementing MTM services provided under grants 9 awarded under subsection (a), the Secretary shall consult 10 with Federal, State, private, public-private, and academic 11 entities, pharmacy and pharmacist organizations, health 12 care organizations, consumer advocates, chronic disease 13 groups, and other stakeholders involved with the research, 14 dissemination, and implementation of pharmacist-deliv15 ered MTM services, as the Secretary determines appro16 priate. The Secretary, in collaboration with this group, 17 shall determine whether it is possible to incorporate rapid 18 cycle process improvement concepts in use in other Fed19 eral programs that have implemented MTM services.

20 (f) Reporting to the Secretary.-An entity that 21 receives a grant under subsection (a) shall submit to the 22 Secretary a report that describes and evaluates, as re23 quested by the Secretary, the activities carried out under 24 subsection (c), including quality measures, as determined 25 by the Secretary. 
1 (g) Evaluation and Report.-The Secretary shall

2 submit to the relevant committees of Congress a report 3 which shall-

4 (1) assess the clinical effectiveness of phar5 macist-provided services under the MTM services 6 program, as compared to usual care, including an 7 evaluation of whether enrollees maintained better 8 health with fewer hospitalizations and emergency 9 room visits than similar patients not enrolled in the 10 program;

11 (2) assess changes in overall health care re12 source of targeted individuals;

13 (3) assess patient and prescriber satisfaction 14 with MTM services;

15 (4) assess the impact of patient-cost-sharing re16 quirements on medication adherence and rec17 ommendations for modifications;

18 (5) identify and evaluate other factors that may 19 impact clinical and economic outcomes, including de20 mographic characteristics, clinical characteristics, 21 and health services use of the patient, as well as 22 characteristics of the regimen, pharmacy benefit, 23 and MTM services provided; and

24 (6) evaluate the extent to which participating 25 pharmacists who maintain a dispensing role have a 
1 conflict of interest in the provision of MTM services, 2 and if such conflict is found, provide recommenda3 tions on how such a conflict might be appropriately 4 addressed.

5 (h) Grant To Fund Development of Perform6 ance Measures.-The Secretary may award grants or 7 contracts to eligible entities for the purpose of funding the 8 development of performance measures that assess the use 9 and effectiveness of medication therapy management serv10 ices.

\section{SEC. 2529. POSTPARTUM DEPRESSION.}

12 (a) Expansion AND Intensification OF ACTIVI13 TIES.-

(1) Continuation of activities.-The Sec-

15 retary is encouraged to expand and intensify activi16 ties on postpartum conditions.

17 (2) Programs For Postpartum CONDI18 TIONs.-In carrying out paragraph (1), the Sec19 retary is encouraged to continue research to expand 20 the understanding of the causes of, and treatments 21 for, postpartum conditions, including conducting and 22 supporting the following:

23 (A) Basic research concerning the etiology 24 and causes of the conditions. 
(B) Epidemiological studies to address the frequency and natural history of the conditions and the differences among racial and ethnic groups with respect to the conditions.

(C) The development of improved screening and diagnostic techniques.

(D) Clinical research for the development and evaluation of new treatments.

(E) Information and education programs for health professionals and the public, which may include a coordinated national campaign that-

(i) is designed to increase the awareness and knowledge of postpartum conditions;

(ii) may include public service announcements through television, radio, and other means; and

(iii) may focus on-

(I) raising awareness about screening;

(II) educating new mothers and their families about postpartum conditions to promote earlier diagnosis and treatment; and 
(III) ensuring that such education includes complete information concerning postpartum conditions, including its symptoms, methods of coping with the illness, and treatment resources.

10 conditions.

(2) REPORT.-Not later than 2 years after the (b) Report by the SECRetary.-

(1) STUDY.-The Secretary shall conduct a study on the benefits of screening for postpartum .

1

2
date of the enactment of this Act, the Secretary shall complete the study required by paragraph (1) and submit a report to the Congress on the results

17 dinal Study of Relative Mental Health Con18 sequences for Women of Resolving a Preg19 NANCY.-

(1) Sense of COngress.-It is the sense of 21 the Congress that the Director of the National Insti22 tute of Mental Health may conduct a nationally rep23 resentative longitudinal study (during the period of 24 fiscal years 2011 through 2020) on the relative men25 tal health consequences for women of resolving a 
1 pregnancy (intended and unintended) in various

2 ways, including carrying the pregnancy to term and

3 parenting the child, carrying the pregnancy to term

4 and placing the child for adoption, miscarriage, and

5 having an abortion. This study may assess the inci-

6 dence, timing, magnitude, and duration of the imme-

7 diate and long-term mental health consequences

8 (positive or negative) of these pregnancy outcomes.

9 (2) REPORT.-Beginning not later than 3 years

10 after the date of the enactment of this Act, and peri-

11 odically thereafter for the duration of the study,

12 such Director may prepare and submit to the Con-

13 gress reports on the findings of the study.

14 (d) Definitions.-In this section:

15 (1) The term "postpartum condition" means

16 postpartum depression or postpartum psychosis.

17 (2) The term "Secretary" means the Secretary

18 of Health and Human Services.

19 (e) Authorization of Appropriations.-For the 20 purpose of carrying out this section, in addition to any 21 other amounts authorized to be appropriated for such pur22 pose, there are authorized to be appropriated such sums 23 as may be necessary for each of fiscal years 2011 through 242013. 
1 SEC. 2530. GRANTS TO PROMOTE POSITIVE HEALTH BEHAVIORS AND OUTCOMES.

3 Part P of title III (42 U.S.C. $280 \mathrm{~g}$ et seq.) is amend4 ed by adding at the end the following:

5 “SEC. 399V. GRANTS TO PROMOTE POSITIVE HEALTH BEHAVIORS AND OUTCOMES.

8 laboration with the Director of the Centers for Disease

9 Control and Prevention and other Federal officials deter-

10 mined appropriate by the Secretary, is authorized to

11 award grants to eligible entities to promote positive health

12 behaviors for populations in medically underserved com13 munities through the use of community health workers. 14 "(b) UsE of Funds.-Grants awarded under sub15 section (a) shall be used to support community health 16 workers-

"(1) to educate, guide, and provide outreach in

18 a community setting regarding health problems prev-

19 alent in medically underserved communities, espe20 cially racial and ethnic minority populations;

“(2) to educate, guide, and provide experiential

22 learning opportunities that target behavioral risk 23 factors including-

"(A) poor nutrition;

"(B) physical inactivity;

"(C) being overweight or obese; 

23 duplicative care; or

lems; and iors within the family; such Act;

"(D) tobacco use;

"(E) alcohol and substance use;

"(F) injury and violence;

"(G) risky sexual behavior;

“(H) untreated mental health problems;

“(I) untreated dental and oral health prob-

“(J) understanding informed consent;

“(3) to educate and provide guidance regarding. effective strategies to promote positive health behav-

“(4) to educate and provide outreach regarding enrollment in health insurance including the State Children's Health Insurance Program under title XXI of the Social Security Act, Medicare under title XVIII of such Act, and Medicaid under title XIX of

"(5) to educate and refer underserved populations to appropriate health care agencies and community-based programs and organizations in order to increase access to quality health care services, including preventive health services, and to eliminate 
“(6) to educate, guide, and provide home visita-

2 tion services regarding maternal health and prenatal

3 care.

4 “(c) Application.-

5 “(1) IN GENERAL.—Each eligible entity that 6 desires to receive a grant under subsection (a) shall 7 submit an application to the Secretary, at such time, 8 in such manner, and accompanied by such informa9 tion as the Secretary may require.

10 “(2) ConTENTs.-Each application submitted 11 pursuant to paragraph (1) shall-

"(A) describe the activities for which assistance is sought under this section; "(B) contain an assurance that, with respect to each community health worker program receiving funds under the grant, such program will provide training and supervision to community health workers to enable such workers to provide authorized program services; "(C) contain an assurance that the applicant will evaluate the effectiveness of community health worker programs receiving funds under the grant;

"(D) contain an assurance that each community health worker program receiving funds 
under the grant will provide services in the cultural context most appropriate for the individuals served by the program;

"(E) contain a plan to document and disseminate project descriptions and results to other States and organizations as identified by the Secretary; and

"(F) describe plans to enhance the capacity of individuals to utilize health services and health-related social services under Federal, State, and local programs by-

"(i) assisting individuals in establishing eligibility under the programs and in receiving the services or other benefits of the programs; and "(ii) providing other services as the Secretary determines to be appropriate, that may include transportation and translation services.

20 "(d) PRIORITY.-In awarding grants under sub21 section (a), the Secretary shall give priority to applicants 22 that- 
"(A) with a high percentage of residents who are eligible for health insurance but are uninsured or underinsured;

"(B) with a high percentage of residents who suffer from chronic diseases including pulmonary conditions, hypertension, heart disease, mental disorders, diabetes, and asthma; and "(C) with a high infant mortality rate;

10 health-related social services to individuals who are 11 underserved with respect to such services; and “(3) have documented community activity and 13 experience with community health workers. “(e) Collaboration With Academic Institu-

15 TIONS.-The Secretary shall encourage community health

16 worker programs receiving funds under this section to col-

17 laborate with academic institutions, especially those that 18 graduate a disproportionate number of health and health 19 care students from underrepresented racial and ethnic mi20 nority backgrounds. Nothing in this section shall be con21 strued to require such collaboration.

22 “(f) Evidence-Based Interventions.-The Sec23 retary shall encourage community health worker programs 24 receiving funding under this section to implement an out25 come-based payment system that rewards community 
1 health workers for connecting underserved populations

2 with the most appropriate services at the most appropriate

3 time. Nothing in this section shall be construed to require

4 such payment.

5 “(g) Quality Assurance and Cost Effective-

6 NESS.-The Secretary shall establish guidelines for assur-

7 ing the quality of the training and supervision of commu-

8 nity health workers under the programs funded under this

9 section and for assuring the cost-effectiveness of such pro-

10 grams.

11 “(h) Monitoring.-The Secretary shall monitor

12 community health worker programs identified in approved

13 applications under this section and shall determine wheth-

14 er such programs are in compliance with the guidelines

15 established under subsection (g).

16 “(i) Technical Assistance.-The Secretary may

17 provide technical assistance to community health worker

18 programs identified in approved applications under this

19 section with respect to planning, developing, and operating

20 programs under the grant.

21 “(j) Report to Congress.-

22 “(1) IN GENERAL.-Not later than 4 years

23 after the date on which the Secretary first awards

24 grants under subsection (a), the Secretary shall sub- 
1 mit to Congress a report regarding the grant

2 project.

“(2) Contents.-The report required under

4 paragraph (1) shall include the following:

"(A) A description of the programs for which grant funds were used.

"(B) The number of individuals served under such programs.

“(C) An evaluation of-

"(i) the effectiveness of such programs;

"(ii) the cost of such programs; and "(iii) the impact of the programs on the health outcomes of the community residents.

"(D) Recommendations for sustaining the community health worker programs developed or assisted under this section.

"(E) Recommendations regarding training to enhance career opportunities for community health workers.

“(k) Definitions.-In this section:

24 'community health worker' means an individual who 
1 promotes health or nutrition within the community

2 in which the individual resides-

"(A) by serving as a liaison between communities and health care agencies;

"(B) by providing guidance and social as-

23 The term 'medically underserved community' means 24 a community identified by a State, United States 
1 territory or possession, or federally recognized In-

2 dian tribe-

"(A) that has a substantial number of individuals who are members of a medically underserved population, as defined by section $330(b)(3)$; and

"(B) a significant portion of which is a health professional shortage area as designated under section 332 .

“(4) SupporT.-The term 'support' means the 11 provision of training, supervision, and materials 12 needed to effectively deliver the services described in 13 subsection (b), reimbursement for services, and 14 other benefits.

“(5) Eligible entity.-The term 'eligible en16 tity' means a public or private nonprofit entity (in17 cluding a State or public subdivision of a State, a 18 public health department, or a federally qualified 19 health center), or a consortium of any of such enti20 ties, located in the United States or territory there21 of.

22 "(l) Authorization of Appropriations.-There is 23 authorized to be appropriated to carry out this section $24 \$ 30,000,000$ for each of fiscal years 2011 through 2015.". 
1 SEC. 2531. MEDICAL LIABILITY ALTERNATIVES.

2 (a) Incentive Payments for Medical Liability

3 REFORM.-

(1) In GENERAL.-To the extent and in the amounts made available in advance in appropriations Acts, the Secretary shall make an incentive payment, in an amount determined by the Secretary, to each State that has an alternative medical liability law in compliance with this section.

(2) Determination By secretary.-The Secretary shall determine that a State has an alternative medical liability law in compliance with this section if the Secretary is satisfied that-

(A) the State enacted the law after the date of the enactment of this Act and is implementing the law;

(B) the law is effective; and

(C) the contents of the law are in accordance with paragraph (4).

(3) Considerations FOR DEtermining EFFECTIVENESS.-In determining whether an alternative medical liability law is effective under paragraph (2)(B), the Secretary shall consider whether the law- 
(A) makes the medical liability system more reliable through prevention of, or prompt and fair resolution of, disputes;

(B) encourages the disclosure of health care errors; and

(C) maintains access to affordable liability insurance.

(4) Contents of alternative medical LiABILITY LAW.- The contents of an alternative liabil10 ity law are in accordance with this paragraph ifthe law consist of certificate of merit, early offer, or both; and

(B) the law does not limit attorneys' fees or impose caps on damages.

16 (b) Use of Incentive Payments.-Amounts re17 ceived by a State as an incentive payment under this sec18 tion shall be used to improve health care in that State. 19 (c) Technical Assistance.-The Secretary may 20 provide technical assistance to the States applying for or 21 receiving an incentive payment under this section.

22 (d) REPORTS.-Beginning not later than one year 23 after the date of the enactment of this Act, the Secretary 24 shall submit to the Congress an annual report on the 25 progress States have made in enacting and implementing 
1 alternative medical liability laws in compliance with this

2 section. Such reports shall contain sufficient documenta-

3 tion regarding the effectiveness of such laws to enable an

4 objective comparative analysis of such laws.

5 (e) DeFINITION.-In this section-

6 (1) the term "Secretary" means the Secretary

7 of Health and Human Services; and

8 (2) the term "State" includes the several

9 States, District of Columbia, the Commonwealth of

10 Puerto Rico, and each other territory or possession

11 of the United States.

12 (f) Authorization of Appropriations.-There

13 are authorized to be appropriated to carry out this section

14 such sums as may be necessary, to remain available until 15 expended.

16 SEC. 2532. INFANT MORTALITY PILOT PROGRAMS.

17 (a) In GeneraL.-The Secretary of Health and

18 Human Services (in this section referred to as the "Sec-

19 retary"), acting through the Director, shall award grants

20 to eligible entities to create, implement, and oversee infant

21 mortality pilot programs.

22 (b) PERIOD OF a GRANT.-The period of a grant

23 under this section shall be 5 consecutive fiscal years.

24 (c) Preference.-In awarding grants under this 25 section, the Secretary shall give preference to eligible enti- 
1 ties proposing to serve any of the 15 counties or groups

2 of counties with the highest rates of infant mortality in

3 the United States in the past 3 years.

4 (d) Use of Funds.-Any infant mortality pilot pro-

5 gram funded under this section may-

6 (1) include the development of a plan that iden-

7 tifies the individual needs of each community to be

8 served and strategies to address those needs;

9 (2) provide outreach to at-risk mothers through

10 programs deemed appropriate by the Director;

11 (3) develop and implement standardized sys-

12 tems for improved access, utilization, and quality of

13 social, educational, and clinical services to promote

14 healthy pregnancies, full term births, and healthy in-

15 fancies delivered to women and their infants, such

16 as-

17 (A) counseling on infant care, feeding, and 18 parenting;

(B) postpartum care;

(C) prevention of premature delivery; and

(D) additional counseling for at-risk mothers, including smoking cessation programs, drug treatment programs, alcohol treatment 25 programs, nutrition and physical activity programs, postpartum depression and domestic vio- 
lence programs, social and psychological services, dental care, and parenting programs;

(4) establish a rural outreach program to pro-

4 vide care to at-risk mothers in rural areas;

(5) establish a regional public education cam6 paign, including a campaign totality; and

(6) provide for any other activities, programs, 11 or strategies as identified by the community plan.

(e) Limitation.-Of the funds received through a

13 grant under this section for a fiscal year, an eligible entity

14 shall not use more than 10 percent for program evalua15 tion.

17 (1) In GENERAL.-Not later than 1 year after 18 receiving a grant, and annually thereafter for the 19 duration of the grant period, each entity that re20 ceives a grant under subsection (a) shall submit a 21 report to the Secretary detailing its infant mortality 22 pilot program.

(2) Contents of RePonT.-The reports re24 quired under paragraph (1) shall include informa25 tion such as the methodology of, and outcomes and 
1 statisties from, the grantee's infant mortality pilot

2 program.

3 (3) Evaluation.-The Secretary shall use the 4 reports required under paragraph (1) to evaluate, 5 and conduct statistical research on, infant mortality 6 pilot programs funded through this section.

7 (g) Definitions.-For the purposes of this section:

8 (1) DIRECTOR.-The term "Director" means 9 the Director of the Centers for Disease Control and 10 Prevention.

11 (2) Eligible EnTity.-The term "eligible enti12 ty" means a State, county, city, territorial, or tribal 13 health department that has submitted a proposal to 14 the Secretary that the Secretary deems likely to re15 duce infant mortality rates within the standard met16 ropolitan statistical area involved.

17 (3) TRIBAL.-The term "tribal" refers to an 18 Indian tribe, a Tribal organization, or an Urban In19 dian organization, as such terms are defined in sec20 tion 4 of the Indian Health Care Improvement Act. 21 (h) Authorization of Appropriations.-To carry 22 out this section, there are authorized to be appropriated $23 \$ 10,000,000$ for each of fiscal years 2011 through 2015 . 
1 SEC. 2533. SECONDARY SCHOOL HEALTH SCIENCES TRAINING PROGRAM.

3 (a) Program.-The Secretary of Health and Human

4 Services, acting through the Administrator of the Health

5 Resources and Services Administration, and in consulta-

6 tion with the Secretary of Education, may establish a

7 health sciences training program consisting of awarding

8 grants and contracts under subsection (b) to prepare sec-

9 ondary school students for careers in health professions.

10 (b) Development and Implementation OF

11 Health Sciences Curricula.-The Secretary may

12 make grants to, or enter into contracts with, eligible enti-

13 ties-

14 (1) to plan, develop, or implement secondary

15 school health sciences curricula, including curricula

16 in biology, chemistry, physiology, mathematics, nu-

17 trition, and other courses deemed appropriate by the

18 Secretary to prepare students for associate's or

19 bachelor's degree programs in health professions or

20 bachelor's degree programs in health professions-re-

21 lated majors; and

22 (2) to increase the interest of secondary school 23 students in applying to, and enrolling in, accredited 24 associate's or bachelor's degree programs in health 25 professions or bachelor's degree programs in health 26 professions-related majors, including through- 
(A) work-study programs;

(B) programs to increase awareness of careers in health professions; and est.

6 (c) EligibiLitr.-To be eligible for a grant or con7 tract under subsection (b), an entity shall-

(1) be a local educational agency; and

10 grant or contract will be carried out in partnership

11 with an accredited health professions school or pro-

12 gram, public or private nonprofit hospital, or public

13 or private nonprofit entity.

14 (d) Preference.-In awarding grants and con15 tracts under subsection (b), the Secretary shall give pref16 erence to entities that have a demonstrated record of at 17 least one of the following:

18 (1) Graduating a high or significantly improved 19 percentage of students who have exhibited mastery 20 in secondary school State science standards.

(2) Graduating students from disadvantaged

22 backgrounds, including racial and ethnic minorities 23 who are underrepresented in-

(A) associate's or bachelor's degree pro25 grams in health professions or bachelor's degree 
programs in health professions-related majors;

or

(B) health professions.

4 (e) REPORT.-The Secretary shall submit to the Con5 gress an annual report on the program carried out under 6 this section.

7 (f) DeFINITIONs.-In this section:

8 (1) The term "health profession" means the 9 profession of any member of the health workforce, 10 as defined in section 764(i) of the Public Health 11 Service Act, as added by section 2261.

12 (2) The term "local educational agency" has 13 the meaning given to the term in section 9101 of the 14 Elementary and Secondary Education Act of 1965 15 (20 U.S.C. 7801). (3) The term "secondary school"-

(A) means a secondary school, as defined in section 9101 of the Elementary and Secondary Education Act of 1965 (20 U.S.C. 7801); and 25 specified. 
1 (g) Authorization of Appropriations.-To carry

2 out this section, there are authorized to be appropriated

3 such sums as may be necessary for each of fiscal years

42011 through 2015.

5 SEC. 2534. COMMUNITY-BASED COLLABORATIVE CARE NET6 WORKs.

7 (a) Purpose.-The purpose of this subtitle is to es8 tablish and provide assistance to community-based col9 laborative care networks-

10 (1) to develop or strengthen coordination of 11 services to allow all individuals, including the unin12 sured and low-income, to receive efficient and higher 13 quality care and to gain entry into and receive serv14 ices from a comprehensive system of care;

15 (2) to develop efficient and sustainable infra16 structure for a health care delivery system charac17 terized by effective collaboration, information shar18 ing, and clinical and financial coordination among 19 providers of care in the community;

20 (3) to develop or strengthen activities related to 21 providing coordinated care for individuals with 22 chronic conditions; and

23 (4) to reduce the use of emergency depart24 ments, inpatient and other expensive resources of 25 hospitals and other providers. 
(b) Creation of the Community-Based Col-

2 laborative Care Network Program.-Part D of title

3 III (42 U.S.C. 254b et seq.), as amended, is further

4 amended by inserting after subpart XII the following new

5 subpart:

6 "Subpart XIII-Community-Based Collaborative Care

\section{Network Program}

8 "SEC. 3400. COMMUNITY-BASED COLLABORATIVE CARE NETWORK PROGRAM.

10 “(a) In GeneRAL.—The Secretary may award grants

11 to eligible entities for the purpose of establishing model

12 projects to accomplish the following goals:

"(1) To reduce unnecessary use of items and

14 services furnished in emergency departments of hos-

15 pitals (especially to ensure that individuals without

16 health insurance coverage or with inadequate health

17 insurance coverage do not use the services of such

18 department instead of the services of a primary care

19 provider) through methods such as-

"(A) screening individuals who seek emergency department services for possible eligibility under relevant governmental health programs or for subsidies under such programs; and

"(B) providing such individuals referrals 25 for followup care and chronic condition care. 
1 “(2) To manage chronic conditions to reduce 2 their severity, negative health outcomes, and ex3 pense.

“(3) To encourage health care providers to co5 ordinate their efforts so that the most vulnerable pa6 tient populations seek and obtain primary care. “(4) To provide more comprehensive and co8 ordinated care to vulnerable low-income individuals 9 and individuals without health insurance coverage or 10 with inadequate coverage.

11 “(5) To provide mechanisms for improving both 12 quality and efficiency of care for low-income individ13 uals and families, with an emphasis on those most 14 likely to remain uninsured despite the existence of 15 government programs to make health insurance 16 more affordable.

17 “(6) To increase preventive services, including 18 screening and counseling, to those who would other19 wise not receive such screening, in order to improve 20 health status and reduce long-term complications 21 and costs.

"(7) To ensure the availability of community23 wide safety net services, including emergency and 24 trauma care.

25 “(b) Eligibility and Grantee Selection.- 
“(1) Application.-A community-based col-

2 laborative care network described in subsection (d)

3 shall submit to the Secretary an application in such

4 form and manner and containing such information

5 as specified by the Secretary. Such information shall

6 at least-

7

8

9

10

11

12

13

14

15

16

17

18

19

20

21

22

23

24
"(A) identify the health care providers participating in the community-based collaborative care network proposed by the applicant and, if a provider designated in paragraph $(\mathrm{d})(1)(\mathrm{B})$ is not included, the reason such provider is not so included;

"(B) include a description of how the providers plan to collaborate to provide comprehensive and integrated care for low-income individuals, including uninsured and underinsured individuals;

"(C) include a description of the organizational and joint governance structure of the community-based collaborative care network in a manner so that it is clear how decisions will be made, and how the decisionmaking process of the network will include appropriate representation of the participating entities; 
"(D) define the geographic areas and populations that the network intends to serve;

"(E) define the scope of services that the

network intends to provide and identify any reasons why such services would not include a suggested core service identified by the Secretary under paragraph (3);

“(F) demonstrate the network's ability to meet the requirements of this section; and "(G) provide assurances that grant funds received shall be used to support the entire community-based collaborative care network.

“(2) SeleCtion of GRANTEes.-

"(A) In GENERAL.-The Secretary shall select community-based collaborative care networks to receive grants from applications submitted under paragraph (1) on the basis of quality of the proposal involved, geographic diversity (including different States and regions served and urban and rural diversity), and the number of low-income and uninsured individuals that the proposal intends to serve.

“(B) PRIORITY.-The Secretary shall give priority to proposals from community-based collaborative care networks that- 
"(i) include the capability to provide the broadest range of services to low-income individuals; and

“(ii) include providers that currently serve a high volume of low-income individ-

15 collaborative care network. The Secretary may select

16 a community-based collaborative care network under

17 paragraph (2), the application of which does not in-

18 clude all such services, if such application provides

19 a reasonable explanation why such services are not 20 proposed to be included, and the Secretary deter21 mines that the application is otherwise high quality. “(4) Termination authority.-The Sec24 based collaborative care network under this section 
1 for good cause. Such good cause shall include a de2 termination that the network-

"(A) has failed to provide a comprehensive range of coordinated and integrated health care services as required under subsection $(d)(2)$;

"(B) has failed to meet reasonable quality

standards;

"(C) has misappropriated funds provided under this section; or

"(D) has failed to make progress toward accomplishing goals set out in subsection (a).

"(c) UsE OF Funds.-

“(1) UsE BY GRANTEES.-Grant funds are provided to community-based collaborative care networks to carry out the following activities:

"(A) Assist low-income individuals without adequate health care coverage to-

"(i) access and appropriately use health services;

"(ii) enroll in applicable public or private health insurance programs;

"(iii) obtain referrals to and see a primary care provider in case such an individual does not have a primary care provider; and 
"(iv) obtain appropriate care for

chronic conditions.

"(B) Improve heath care by providing case management, application assistance, and appropriate referrals such as through methods to"(i) create and meaningfully use a health information technology network to track patients across collaborative providers;

"(ii) perform health outreach, such as by using neighborhood health workers who may inform individuals about the availability of safety net and primary care providers available through the communitybased collaborative care network;

"(iii) provide for followup outreach to remind patients of appointments or followup care instructions;

"(iv) provide transportation to individuals to and from the site of care;

"(v) expand the capacity to provide care at any provider participating in the community-based collaborative care network, including telehealth, hiring new clinical or administrative staff, providing ac- 
cess to services after-hours, on weekends, or otherwise providing an urgent care al-

10 Secretary may limit the percent of grant funding

11 that may be spent on direct care services provided

12 by grantees of programs administered by the Health

13 Resources and Services Administration (in this sec14 tion referred to as 'HRSA') or impose other require15 ments on HRSA grantees participating in a commu16 nity-based collaborative care network as may be nec17 essary for consistency with the requirements of such 18 programs.

“(3) Reservation OF FUnds FOR NATIONAL 20 PROGRAM PURPOSES.-The Secretary may use not 21 more than 7 percent of funds appropriated to carry 22 out this section for providing technical assistance to 23 grantees, obtaining assistance of experts and con24 sultants, holding meetings, developing of tools, dis25 seminating of information, and evaluation. 
1 “(d) Community-Based Collaborative Care

2 NETWORKs.-

“(1) IN GENERAL.-

"(A) Description.-A community-based collaborative care network described in this subsection is a consortium of health care providers with a joint governance structure that provides a comprehensive range of coordinated and integrated health care services for low-income patient populations or medically underserved communities (whether or not such individuals receive benefits under title XVIII, XIX, or XXI of the Social Security Act, private or other health insurance or are uninsured or underinsured) and that complies with any applicable minimum eligibility requirements that the Secretary may determine appropriate.

“(B) REQUiRED INCLUSION.—Each such network shall include the following providers that serve the community (unless such provider does not exist within the community, declines or refuses to participate, or places unreasonable conditions on their participation) -

"(i) A safety net hospital that provides services to a high volume of low-in- 
come patients, as demonstrated by meeting the criteria in section 1923(b)(1) of the Social Security Act, or other similar criteria determined by the Secretary; and "(ii) All Federally qualified health centers (as defined in section 1861(aa) of the Social Security Act (42 U.S.C. $1395 \mathrm{x}(\mathrm{aa})))$ located in the geographic area served by the Coordinated Care Network;

"(C) Additional inclusions.-Each such network may include any of the following additional providers:

"(i) A hospital, including a critical access hospital (as defined in section 1820(c)(2) of the Social Security Act (42 U.S.C. 1395i-4(c)(2))).

“(ii) A county or municipal department of health. "(iii) A rural health clinic or a rural health network (as defined in sections 1861(aa) and 1820(d) of the Social Security Act, respectively (42 U.S.C. $1395 x($ aa), $1395 i-4(d)))$. 
1451

"(iv) A community clinic, including a mental health clinic, substance abuse clinic, or a reproductive health clinic.

"(v) A health center controlled network as defined by section $330(\mathrm{e})(1)(\mathrm{C})$ of the Public Health Service Act

“(vi) A private practice physician or group practice.

"(vii) A nurse or physician assistant or group practice.

"(viii) An adult day care center.

“(ix) A home health provider.

“(x) Any other type of provider specified by the Secretary, which has a desire to serve low-income and uninsured patients.

"(D) Construction.-

"(i) Nothing in this section shall prohibit a single entity from qualifying as community-based collaborative care network so long as such single entity meets the criteria of a community-based collaborative care network. If the network does not include the providers referenced in clauses (i) and (ii) of subparagraph (B) of this paragraph, the application must ex- 
plain the reason pursuant to subsection 23 Secretary shall define criteria for evaluating whether 24 the services offered by a community-based collabo25 rative care network qualify as a comprehensive range

"(ii) Participation in a communitybased collaborative care network shall not affect Federally qualified health centers' obligation to comply with the governance requirements under section 330 of the Public Health Service Act (42 U.S.C. 254b).

“(iii) Federally qualified health centers participating in a community-based collaborative care network may not be required to provide services beyond their Federal Health Center scope of project approved by HRSA.

"(iv) Nothing in this section shall be construed to expand medical malpractice liability protection under the Federal Tort Claims Act for Section 330-funded Federally qualified health centers.

“(2) Comprehensive Range of CoOrdinated AND INTEGRATED HEALTH CARE SERVICES.-The 
1 of coordinated and integrated health care services.

2 Such criteria may vary based on the needs of the ge3 ographic areas and populations to be served by the 4 network and may include the following:

"(A) Requiring community-based collaborative care networks to include at least the suggested core services identified under subsection (b)(3), or whichever subset of the suggested core services is applicable to a particular network.

"(C) Requiring the services provided by a community-based collaborative care network to include support services appropriate to meet the health needs of low-income populations in the network's community, which may include chronic care management, nutritional counseling, transportation, language services, enrollment counselors, social services and other services as proposed by the network.

"(D) Providing that the services provided by a community-based collaborative care net- 
work may also include long-term care services and other services not specified in this subsection.

"(E) Providing for the approval by the Secretary of a scope of community-based collaborative care network services for each network that addresses an appropriate minimum scope of work consistent with the setting of the network and the health professionals available in the community the network serves.

12 munity-based collaborative care network shall not 13 disqualify a health care provider from reimburse14 ment under title XVIII, XIX, or XXI of the Social 15 Security Act with respect to services otherwise reim16 bursable under such title. Nothing in this section 17 shall prevent a community-based collaborative care 18 network that is otherwise eligible to contract with 19 Medicare, a private health insurer, or any other ap20 propriate entity to provide care under Medicare, 21 under health insurance coverage offered by the in22 surer, or otherwise.

23 "(e) Evaluations.-

24 "(1) GranteE REPORTs.-Beginning in the 25 third year following an initial grant, each commu- 
1 nity-based collaborative care network shall submit to

2 the Secretary, with respect to each year the grantee

3 has received a grant, an evaluation on the activities

4 carried out by the community-based collaborative

5 care network under the community-based collabo-

6 rative care network program and shall include-

"(A) the number of people served;

"(B) the most common health problems treated;

"(C) any reductions in emergency department use;

"(D) any improvements in access to primary care;

"(E) an accounting of how amounts received were used, including identification of amounts used for patient care services as may be required for HRSA grantees; and

"(F) to the extent requested by the Secretary, any quality measures or any other measures specified by the Secretary.

“(2) Program REPorTs.-The Secretary shall 22 submit to Congress an annual evaluation (beginning 23 not later than 6 months after the first reports under 24 paragraph (1) are submitted) on the extent to which 25 emergency department use was reduced as a result 
1 of the activities carried out by the community-based

2 collaborative care network under the program. Each

3 such evaluation shall also include information on-

"(A) the prevalence of certain chronic conditions in various populations, including a comparison of such prevalence in the general population versus in the population of individuals with inadequate health insurance coverage;

"(B) demographic characteristies of the population of uninsured and underinsured individuals served by the community-based collaborative care network involved; and

"(C) the conditions of such individuals for whom services were requested at such emergency departments of participating hospitals.

"(3) Audit Authority.-The Secretary may

17 conduct periodic audits and request periodic spend18 ing reports of community-based collaborative care 19 networks under the community-based collaborative 20 care network program.

21 "(f) Clarification.-Nothing in this section re22 quires a provider to report individually identifiable infor23 mation of an individual to government agencies, unless the 24 individual consents, consistent with HIPAA privacy and 25 security law, as defined in section 3009 (a)(2). 
1 “(g) Authorization of Appropriations.-There

2 are authorized to be appropriated to carry out this section

3 such sums as may be necessary for each of fiscal years

42011 through 2015.”.

5 SEC. 2535. COMMUNITY-BASED OVERWEIGHT AND OBESITY 6 PREVENTION PROGRAM.

7 Part Q of title III (42 U.S.C. 280h et seq.) is amend-

8 ed by inserting after section $399 \mathrm{~W}$ the following:

9 “SEC. 399W-1. COMMUNITY-BASED OVERWEIGHT AND OBESITY PREVENTION PROGRAM.

11 “(a) Program.-The Secretary shall establish a

12 community-based overweight and obesity prevention pro-

13 gram consisting of awarding grants and contracts under

14 subsection (b).

15 “(b) Grants.-The Secretary shall award grants to,

16 or enter into contracts with, eligible entities-

17 "(1) to plan evidence-based programs for the

18 prevention of overweight and obesity among children

19 and their families through improved nutrition and

20 increased physical activity; or

"(2) to implement such programs.

22 “(c) Eligibinity.-To be eligible for a grant or con-

23 tract under subsection (b), an entity shall be a community

24 partnership that demonstrates community support and in25 cludes- 
“(1) a broad cross section of stakeholders, such

2 as-

"(A) hospitals, health care systems, community health centers, or other health care providers;

‘(B) universities, local educational agenments;

"(D) State, local, and tribal park and recreation departments;

"(E) employers; and

“(F) health insurance companies; 17 ing the community. "(1) IN GENERAL.-The period of a grant or 20 contract under this section shall be 5 years, subject 21 to renewal under paragraph (2).

"(2) RENEWAL.-At the end of each fiscal year,

23 the Secretary may renew a grant or contract award 24 under this section only if the grant or contract re25 cipient demonstrates to the Secretary's satisfaction 
1 that the recipient has made appropriate, measurable

2 progress in preventing overweight and obesity.

3 “(e) REQUIREMENTS.-

4 “(1) In GENERAL.-The Secretary may award

5 a grant or contract under this section to an entity 6 only if the entity demonstrates to the Secretary's 7 satisfaction that-

"(A) not later than 90 days after receiving the grant or contract, the entity will establish a steering committee to provide input on the assessment of, and recommendations on improvements to, the entity's program funded through the grant or contract; and

"(B) the entity has conducted or will conduct an assessment of the overweight and obesity problem in its community, including the extent of the problem and factors contributing to the problem.

“(2) Matching Requirement.-The Secretary may award a grant or contract to an eligible 21 entity under this section only if the entity agrees to 22 provide, from non-Federal sources, an amount equal 23 to $\$ 1$ (in cash or in kind) for each $\$ 9$ provided 24 through the grant or contract to carry out the activi25 ties supported by the grant or contract. 
“(3) PAYOR OF LAST RESORT.-The Secretary

2 may award a grant or contract under this section to

3 an entity only if the entity demonstrates to the satis-

4 faction of the Secretary that funds received through

5 the grant or contract will not be expended for any

6 activity to the extent that payment has been made,

7 or can reasonably be expected to be made-

8

9

10

11

12

13

14

15

16

17

18

19
“(A) under any insurance policy;

“(B) under any Federal or State health benefits program (including titles XIX and XXI of the Social Security Act); or

"(C) by an entity which provides health services on a prepaid basis.

“(4) Maintenance OF EFfort.-The Secretary may award a grant or contract under this section to an entity only if the entity demonstrates to the satisfaction of the Secretary that-

"(A) funds received through the grant or contract will be expended only to supplement, and not supplant, non-Federal and Federal funds otherwise available to the entity for the activities to be funded through the grant or contract; and

"(B) with respect to such activities, the entity will maintain expenditures of non-Federal 
1461

amounts for such activities at a level not less than the lesser of such expenditures maintained by the entity for the fiscal year preceding the fiscal year for which the entity receives the grant or contract.

“(f) Preferences.-In awarding grants and con-

7 tracts under this section, the Secretary shall give pref8 erence to eligible entities that-

10 overweight and obesity and related chronic diseases;

11 or

“(2) will plan or implement activities for the 13 prevention of overweight and obesity in school or 14 workplace settings.

15 "(g) REPORT.-The Secretary shall submit to the

16 Congress an annual report on the program of grants and 17 contracts awarded under this section.

18 "(h) DeFInitions.-In this section:

19 “(1) The term 'evidence-based' means that 20 methodologically sound research has demonstrated a 21 beneficial health effect in the judgment of the Sec22 retary and includes the Ways to Enhance Children's 23 Activity and Nutrition (We Can) program and cur24 riculum of the National Institutes of Health. 
“(2) The term 'local educational agency' has

2 the meaning given to the term in section 9101 of the

3 Elementary and Secondary Education Act of 1965.

4 “(i) Authorization of Appropriations.-To

5 carry out this section, there are authorized to be appro-

6 priated \$10,000,000 for fiscal year 2011 and such sums

7 as may be necessary for each of fiscal years 2012 through

8 2015.".

9 SEC. 2536. REDUCING STUDENT-TO-SCHOOL NURSE RATIOS.

10 (a) Demonstration Grants.-

11 (1) In GENERAL.-The Secretary of Education,

12 in consultation with the Secretary of Health and

13 Human Services and the Director of the Centers for

14 Disease Control and Prevention, may make dem-

15 onstration grants to eligible local educational agen-

16 cies for the purpose of reducing the student-to-

17 school nurse ratio in public elementary and sec-

18 ondary schools.

19 (2) SPECIAL CONSIDERATION.-In awarding 20 grants under this section, the Secretary of Edu21 cation shall give special consideration to applications 22 submitted by high-need local educational agencies 23 that demonstrate the greatest need for new or addi24 tional nursing services among children in the public 25 elementary and secondary schools served by the 
1 agency, in part by providing information on current

2 ratios of students to school nurses.

(3) Matching Funds.-The Secretary of Edu4 cation may require recipients of grants under this 5 subsection to provide matching funds from non-Fed6 eral sources, and shall permit the recipients to 7 match funds in whole or in part with in-kind con8 tributions.

9 (b) REPORT.-Not later than 24 months after the 10 date on which assistance is first made available to local 11 educational agencies under this section, the Secretary of 12 Education shall submit to the Congress a report on the 13 results of the demonstration grant program carried out 14 under this section, including an evaluation of the effective15 ness of the program in improving the student-to-school 16 nurse ratios described in subsection (a) and an evaluation 17 of the impact of any resulting enhanced health of students 18 on learning.

19 (c) Definitions.-For purposes of this section:

20 (1) The terms "elementary school", "local edu21 cational agency", and "secondary school" have the 22 meanings given to those terms in section 9101 of the 23 Elementary and Secondary Education Act of 1965 24 (20 U.S.C. 7801). 
1464

(2) The term "eligible local educational agency"

2 means a local educational agency in which the stu-

3 dent-to-school nurse ratio in the public elementary

4 and secondary schools served by the agency is 750

5 or more students to every school nurse.

6 (3) The term "high-need local educational agen-

$7 \quad$ cy" means a local educational agency-

8 (A) that serves not fewer than 10,000 chil-

9 dren from families with incomes below the pov-

10 erty line; or

11 (B) for which not less than 20 percent of

12 the children served by the agency are from fam-

13 ilies with incomes below the poverty line.

14 (4) The term "nurse" means a licensed nurse, 15 as defined under State law.

16 (d) Authorization of Appropriations.-To carry

17 out this section, there are authorized to be appropriated

18 such sums as may be necessary for each of fiscal years

192011 through 2015.

20 SEC. 2537. MEDICAL-LEGAL PARTNERSHIPS.

21 (a) In GeneraL.-The Secretary shall establish a 22 nationwide demonstration project consisting of-

23 (1) awarding grants to, and entering into con24 tracts with, medical-legal partnerships to assist pa- 
1 tients and their families to navigate health-related

2 programs and activities; and

3 (2) evaluating the effectiveness of such partner4 ships.

5 (b) UsE OF Funds.-Amounts received as a grant 6 or contract under this section shall be used to assist pa7 tients and their families to navigate health care-related 8 programs and activities and thereby achieve one or more 9 of the following goals:

10 (1) Enhancing access to health care services.

11 (2) Improving health outcomes for low-income 12 individuals.

13 (3) Reducing health disparities.

14 (4) Enhancing wellness and prevention of 15 chronic conditions.

16 (c) Promibition.-No funds under this section may 17 be used-

18 (1) for any medical malpractice or other civil 19 action or proceeding; or

20 (2) to assist individuals who are not lawfully 21 present in the United States.

22 (d) REPORT.-Not later than 5 years after the date 23 of the enactment of this Act, the Secretary shall submit 24 a report to the Congress on the results of the demonstra- 
1 tion project under this section. Such report shall include

2 the following:

3

4 ical-legal partnerships funded through this section

5 achieved the goals described in subsection (b).

6 (2) Recommendations on the possibility of ex-

7 tending or expanding the demonstration project.

8 (e) Definitions.-In this section:

9

10

11 Public Health Service Act, as added by section 122301.
(1) The term "health disparities" has the meaning given to the term in section 3171 of the (2) The term "medical-legal partnership" means an entity-

(A) that is a collaboration between-

(i) a community health center, public hospital, children's hospital, or other provider of health care services to a significant number of low-income beneficiaries; and

(ii) one or more attorneys; and (B) whose primary mission is to assist patients and their families navigate health care-related programs and activities. 
(3) The term "Secretary" means the Secretary

2 of Health and Human Services.

3 (f) Authorization of Appropriations.-To carry

4 out this section, there are authorized to be appropriated

5 such sums as may be necessary for each of fiscal years 62011 through 2015.

PROGRAMS

9 SEC. 2551. TRAUMA CARE CENTERS.

10 (a) Grants for Trauma Care Centers.-Section

111241 (42 U.S.C. 300d-41) is amended to read as follows:

12 “SEC. 1241. GRANTS FOR CERTAIN TRAUMA CENTERS.

13 “(a) In GeneraL.-The Secretary shall establish a 14 trauma center program consisting of awarding grants 15 under section (b).

16 “(b) GRANTS.-The Secretary shall award grants as 17 follows:

“(1) Existing Centers.-Grants to public, 19 private nonprofit, Indian Health Service, Indian 20 tribal, and urban Indian trauma centers"(A) to further the core missions of such centers; or "(B) to provide emergency relief to ensure 25 the continued and future availability of trauma services by trauma centers- 
"(i) at risk of closing or operating in an area where a closing has occurred within their primary service area; or

"(ii) in need of financial assistance following a natural disaster or other catastrophic event, such as a terrorist attack. "(2) New Centers.-Grants to local govern-

8 ments and public or private nonprofit entities to es9 tablish new trauma centers in urban areas with a 10 substantial degree of trauma resulting from violent 11 crimes. LINES.-

“(A) Limitation.-Subject to subparagraph (B), the Secretary may not award a grant to an existing trauma center under this section unless the center is a participant in a trauma care system that substantially complies with section 1213 . 
cated in States with no existing trauma care system.

“(2) Designation.-The Secretary may not

4 award a grant under this section to an existing trau5 ma center unless the center is-

"(A) verified as a trauma center by the American College of Surgeons; or

"(B) designated as a trauma center by the applicable State health or emergency medical services authority.".

121242 (42 U.S.C. 300d-42) is amended to read as follows:

13 “SEC. 1242. CONSIDERATIONS IN MAKING GRANTS.

“(1) In GENERAL.-In awarding grants under section 1241(b)(1)(A), the Secretary shall-

“(A) reserve a minimum of 25 percent of

"(B) reserve a minimum of 25 percent of the amount allocated for such grants for level III and level IV trauma centers in rural or underserved areas; the amount allocated for such grants for level I and level II trauma centers in urban areas; and 
"(C) give preference to any application made by a trauma center-

"(i) in a geographic area where growth in demand for trauma services exceeds capacity;

23 coordination activities, Medicaid funding designated

24 for trauma services, or other governmental funding).

25 State funding derived from Federal support shall 
1 not constitute State or local financial support for

2 purposes of preferential treatment under this sub3 section.

“(3) USE OF FUNDS.-The recipient of a grant 5 under section 1241(b)(1)(A) shall carry out, con6 sistent with furthering the core missions of the cen7 ter, one or more of the following activities: week trauma care availability. throughput of trauma patients.

"(D) Ensuring physician and essential personnel availability. trauma care systems.

“(E) Trauma education and outreach.

"(F) Coordination with local and regional

"(G) Such other activities as the Secretary may deem appropriate.

21 awarding grants under paragraphs (1)(B) and (2) of sec22 tion 1241(b), the Secretary shall"(1) give preference to any application sub24 mitted by an applicant that demonstrates the finan25 cial support (in accordance with subsection (a)(2)) 
1 of the State or political subdivision involved for the

2 activities to be funded through the grant for each

3 fiscal year during which payments are made to the

$4 \quad$ center under the grant; and

5 “(2) give preference to any application sub-

6 mitted for a trauma center that-

"(A) is providing or will provide trauma

8

9

10

11

12

13

14

15

16

17

18

19

20

21

22

23

24 care in a geographic area in which the availability of trauma care has either significantly decreased as a result of a trauma center in the area permanently ceasing participation in a system described in section 1241(c)(1) as of a date occurring during the 2-year period preceding the fiscal year for which the trauma center is applying to receive a grant, or in geographic areas where growth in demand for trauma services exceeds capacity;

"(B) will, in providing trauma care during the 1-year period beginning on the date on which the application for the grant is submitted, incur substantial uncompensated care costs in an amount that renders the center unable to continue participation in such system and results in a significant decrease in the 
availability of trauma care in the geographic area;

"(C) operates or will operate in rural areas

where trauma care availability will significantly

decrease if the center is forced to close or downgrade service and substantial costs are contributing to a likelihood of such closure or downgradation;

"(D) is in a geographic location substantially affected by a natural disaster or other catastrophic event such as a terrorist attack; or "(E) will establish a new trauma service in an urban area with a substantial degree of trauma resulting from violent crimes.

16 TERs IN CERTAIN States.-In the case of a State which 17 has not designated 4 levels of trauma centers, any ref18 erence in this section to“(1) a level I or level II trauma center is 20 deemed to be a reference to a trauma center within 21 the highest 2 levels of trauma centers designated 22 under State guidelines; and

23 "(2) a level III or IV trauma center is deemed 24 to be a reference to a trauma center not within such 25 highest 2 levels.". 
1 (c) Certain Agremments.-Section $1243 \quad$ (42

2 U.S.C. $300 \mathrm{~d}-43$ ) is amended to read as follows:

3 “SEC. 1243. CERTAIN AGREEMENTS.

4 “(a) Commitment Regarding Continued Par-

5 ticipation in Trauma Care System.-The Secretary

6 may not award a grant to an applicant under section

7 1241(b) unless the applicant agrees that-

8 "(1) the trauma center involved will continue

9 participation, or in the case of a new center will par-

10 ticipate, in the system described in section

11 1241(c)(1), except as provided in section

12 1241(c)(1)(B), throughout the grant period begin-

13 ning on the date that the center first receives pay-

14 ments under the grant; and

15 "(2) if the agreement made pursuant to para-

16 graph (1) is violated by the center, the center will

17 be liable to the United States for an amount equal 18 to the sum of-

"(A) the amount of assistance provided to

20 the center under section 1241; and

"(B) an amount representing interest on

22 the amount specified in subparagraph (A).

23 “(b) Maintenance of Financial Support.-With

24 respect to activities for which funds awarded through a 25 grant under section 1241 are authorized to be expended, 
1 the Secretary may not award such a grant unless the ap-

2 plicant agrees that, during the period in which the trauma 3 center involved is receiving payments under the grant, the 4 center will maintain access to trauma services at levels not 5 less than the levels for the prior year, taking into ac6 count-

"(1) reasonable volume fluctuation that is not

8 caused by intentional trauma boundary reduction;

"(2) downgrading of the level of services; and

10 "(3) whether such center diverts its incoming

11 patients away from such center 5 percent or more

12 of the time during which the center is in operation

13 over the course of the year.

14 “(c) Trauma Care Registry.-The Secretary may 15 not award a grant to a trauma center under section 16 1241(b)(1) unless the center agrees that-

17 "(1) not later than 6 months after the date on 18 which the center submits a grant application to the 19 Secretary, the center will establish and operate a 20 registry of trauma cases in accordance with guide21 lines developed by the American College of Surgeons; 22 and

23 "(2) in carrying out paragraph (1), the center 24 will maintain information on the number of trauma 25 cases treated by the center and, for each such case, 
1 the extent to which the center incurs uncompensated

$2 \quad$ costs in providing trauma care.".

3 (d) General Provisions.-Section $1244 \quad$ (42

4 U.S.C. 300d-44) is amended to read as follows:

5 “SEC. 1244. GENERAL PROVISIONS.

6 "(a) Limitation on Duration of Support.-The

7 period during which a trauma center receives payments

8 under a grant under section 1241(b)(1) shall be for 3 fis-

9 cal years, except that the Secretary may waive such re-

10 quirement for the center and authorize the center to re-

11 ceive such payments for 1 additional fiscal year.

12 “(b) EligibiLitr.-The acquisition of, or eligibility

13 for, a grant under section 1241(b) shall not preclude a

14 trauma center's eligibility for another grant described in 15 such section.

16 “(c) Funding Distribution.-Of the total amount

17 appropriated for a fiscal year under section 1245 -

18 "(1) 90 percent shall be used for grants under

19 paragraph $(1)(A)$ of section $1241(b)$; and

20 "(2) 10 percent shall be used for grants under

21 paragraphs (1)(B) and (2) of section 1241(b).

22 “(d) REPORT.-Beginning 2 years after the date of

23 the enactment of the Affordable Health Care for America

24 Act, and every 2 years thereafter, the Secretary shall bien25 nially- 
“(1) report to Congress on the status of the

2 grants made pursuant to section 1241 ;

"(2) evaluate and report to Congress on the

4 overall financial stability of trauma centers in the

$5 \quad$ United States;

6 "(3) report on the populations using trauma

7 care centers and include aggregate patient data on

8 income, race, ethnicity, and geography; and

9 “(4) evaluate the effectiveness and efficiency of

10 trauma care center activities using standard public

11 health measures and evaluation methodologies.".

12 (e) Authorization of Appropriations.-Section

131245 (42 U.S.C. 300d-45) is amended to read as follows:

14 “SEC. 1245. AUTHORIZATION OF APPROPRIATIONS.

15 "(a) IN GENERAL.-For the purpose of carrying out

16 this part, there are authorized to be appropriated

$17 \$ 100,000,000$ for fiscal year 2011, and such sums as may

18 be necessary for each of fiscal years 2012 through 2015.

19 Such authorization of appropriations is in addition to any

20 other authorization of appropriations or amounts that are

21 available for such purpose.

22 "(b) ReAllocation.-The Secretary shall reallocate

23 for grants under section 1241(b)(1)(A) any funds appro-

24 priated for grants under paragraph (1)(B) or (2) of sec- 
1 tion 1241(b), but not obligated due to insufficient applica-

2 tions eligible for funding.".

3 SEC. 2552. EMERGENCY CARE COORDINATION.

4 (a) In General.-Subtitle B of title XXVIII (42

5 U.S.C. $300 \mathrm{hh}-10$ et seq.) is amended by adding at the

6 end the following:

7 “SEC. 2816. EMERGENCY CARE COORDINATION.

8 “(a) Emergency Care Coordination Center.-

9 “(1) Establishment.-The Secretary shall es-

10 tablish, within the Office of the Assistant Secretary

11 for Preparedness and Response, an Emergency Care

12 Coordination Center (in this section referred to as

13 the 'Center'), to be headed by a director.

14 “(2) DutiEs.-The Secretary, acting through

15 the Director of the Center, in coordination with the

16 Federal Interagency Committee on Emergency Med-

17 ical Services, shall-

18 "(A) promote and fund research in emer-

19 gency medicine and trauma health care;

20 "(B) promote regional partnerships and

21 more effective emergency medical systems in

22 order to enhance appropriate triage, distribu-

23 tion, and care of routine community patients;

24 and 
"(C) promote local, regional, and State emergency medical systems' preparedness for and response to public health events.

“(b) Council of Emergency Care.-

“(1) Establishment.-The Secretary, acting through the Director of the Center, shall establish a Council of Emergency Care to provide advice and recommendations to the Director on carrying out this section.

"(2) Composition.-The Council shall be comprised of employees of the departments and agencies of the Federal Government who are experts in emergency care and management.

"(c) REPORT.-

"(1) Submission.-Not later than 12 months after the date of the enactment of the Affordable Health Care for America Act, the Secretary shall submit to the Congress an annual report on the activities carried out under this section.

“(2) Considerations.-In preparing a report under paragraph (1), the Secretary shall consider factors including-

“(A) emergency department crowding and boarding; and

"(B) delays in care following presentation. 
1 “(d) AUthorization OF Appropriations.-To

2 carry out this section, there are authorized to be appro-

3 priated such sums as may be necessary for each of fiscal 4 years 2011 through 2015.".

5 (b) Functions, Personnel, Assets, Liabilities,

6 And Administrative ACTions.-All functions, per-

7 sonnel, assets, and liabilities of, and administrative actions

8 applicable to, the Emergency Care Coordination Center,

9 as in existence on the day before the date of the enactment

10 of this Act, shall be transferred to the Emergency Care

11 Coordination Center established under section 2816(a) of

12 the Public Health Service Act, as added by subsection (a).

13 SEC. 2553. PILOT PROGRAMS TO IMPROVE EMERGENCY MEDICAL CARE.

15 Part B of title III (42 U.S.C. 243 et seq.) is amended

16 by inserting after section 314 the following:

17 “SEC. 315. REGIONALIZED COMIMUNICATION SYSTEMS FOR EMERGENCY CARE RESPONSE.

19 “(a) In GeneraL.—The Secretary, acting through

20 the Assistant Secretary for Preparedness and Response,

21 shall award not fewer than 4 multiyear contracts or com-

22 petitive grants to eligible entities to support demonstration

23 programs that design, implement, and evaluate innovative

24 models of regionalized, comprehensive, and accountable 25 emergency care systems. 


\section{1}

11 shall award a contract or grant under subsection (a) to

12 an eligible entity that proposes a demonstration program

13 to design, implement, and evaluate an emergency medical 14 system that-

“(1) coordinates with public safety services, 16 public health services, emergency medical services, 17 medical facilities, and other entities within a region;

“(1) Eligible EnTity.-In this section, the term 'eligible entity' means a State or a partnership of 1 or more States and 1 or more local governments.

"(2) Region.-In this section, the term 'region' means an area within a State, an area that lies within multiple States, or a similar area (such as a multicounty area), as determined by the Secretary. “(c) Demonstration Program.-The Secretary "(2) coordinates an approach to emergency medical system access throughout the region, including 9-1-1 public safety answering points and emergency medical dispatch;

“(3) includes a mechanism, such as a regional medical direction or transport communications system, that operates throughout the region to ensure that the correct patient is taken to the medically ap- 
1 propriate facility (whether an initial facility or a

2 higher level facility) in a timely fashion;

"(4) allows for the tracking of prehospital and

4 hospital resources, including inpatient bed capacity,

5 emergency department capacity, on-call specialist

6 coverage, ambulance diversion status, and the co-

7 ordination of such tracking with regional commu-

8 nications and hospital destination decisions; and

$9 \quad$ “(5) includes a consistent regionwide

10 prehospital, hospital, and interfacility data manage-

11 ment system that-

"(A) complies with the National EMS In-

formation System, the National Trauma Data Bank, and others;

"(B) reports data to appropriate Federal and State databanks and registries; and

"(C) contains information sufficient to evaluate key elements of prehospital care, hospital destination decisions, including initial hospital and interfacility decisions, and relevant outcomes of hospital care.

"(1) IN GENERAL.-An eligible entity that 25 shall submit to the Secretary an application at such 
1 time and in such manner as the Secretary may re-

2 quire.

“(2) Application information.-Each appli4 cation shall include-

"(A) an assurance from the eligible entity that the proposed system-

"(i) has been coordinated with the applicable State office of emergency medical services (or equivalent State office); "(ii) is compatible with the applicable

"(iii) includes consistent indirect and direct medical oversight of prehospital, hospital, and interfacility transport throughout the region;

"(iv) coordinates prehospital treatment and triage, hospital destination, and interfacility transport throughout the region;

"(v) includes a categorization or designation system for special medical facilities throughout the region that is-

"(I) consistent with State laws and regulations; and 
"(II) integrated with the protocols for transport and destination throughout the region; and "(vi) includes a regional medical direction system, a patient tracking system, and a resource allocation system that-

"(I) support day-to-day emergency care system operation;

"(II) can manage surge capacity during a major event or disaster; and "(III) are integrated with other components of the national and State emergency preparedness system;

“(B) an agreement to make available nonFederal contributions in accordance with subsection (e); and

"(C) such other information as the Secretary may require.

\section{“(e) Matching Funds.-}

"(1) IN GENERAL.-With respect to the costs of the activities to be carried out each year with a contract or grant under subsection (a), a condition for the receipt of the contract or grant is that the eligible entity involved agrees to make available (directly or through donations from public or private entities) 
1 non-Federal contributions toward such costs in an

2 amount that is not less than 25 percent of such

3 costs.

“(2) Determination of amount CONTRIB-

5 UTED.-Non-Federal contributions required in para-

6 graph (1) may be in cash or in kind, fairly evalu-

7 ated, including plant, equipment, or services.

8 Amounts provided by the Federal Government, or

9 services assisted or subsidized to any significant ex-

10 tent by the Federal Government, may not be in-

11 cluded in determining the amount of such non-Fed-

12 eral contributions.

13 “(f) PRIORITY.-The Secretary shall give priority for

14 the award of the contracts or grants described in sub15 section (a) to any eligible entity that serves a medically

16 underserved population (as defined in section 330(b)(3)).

17 “(g) REPORT.-Not later than 90 days after the com-

18 pletion of a demonstration program under subsection (a),

19 the recipient of such contract or grant described in such

20 subsection shall submit to the Secretary a report con-

21 taining the results of an evaluation of the program, includ-

22 ing an identification of-

23 "(1) the impact of the regional, accountable

24 emergency care system on patient outcomes for var- 
1 ious critical care categories, such as trauma, stroke,

2 cardiac emergencies, and pediatric emergencies;

3 "(2) the system characteristics that contribute

4 to the effectiveness and efficiency of the program (or

5 lack thereof);

6 "(3) methods of assuring the long-term finan-

$7 \quad$ cial sustainability of the emergency care system;

8 "(4) the State and local legislation necessary to

9 implement and to maintain the system; and

10 "(5) the barriers to developing regionalized, ac-

11 countable emergency care systems, as well as the

12 methods to overcome such barriers.

13 “(h) Evaluation.-The Secretary, acting through

14 the Assistant Secretary for Preparedness and Response,

15 shall enter into a contract with an academic institution

16 or other entity to conduct an independent evaluation of

17 the demonstration programs funded under subsection (a), 18 including an evaluation of-

19 "(1) the performance of the eligible entities re20 ceiving the funds; and

21 "(2) the impact of the demonstration programs.

22 “(i) Dissemination of Findings.-The Secretary

23 shall, as appropriate, disseminate to the public and to the

24 appropriate committees of the Congress, the information 25 contained in a report made under subsection (h). 
“(j) Authorization of Appropriations.-

"(1) IN GENERAL.-There is authorized to be appropriated to carry out this section $\$ 12,000,000$

4 for each of fiscal years 2011 through 2015.

“(2) Reservation.-Of the amount appro-

6 priated to carry out this section for a fiscal year, the

$7 \quad$ Secretary shall reserve 3 percent of such amount to

8 carry out subsection (h) (relating to an independent

9 evaluation).”.

10 SEC. 2554. ASSISTING VETERANS WITH MILITARY EMERGENCY MEDICAL TRAINING TO BECOME STATE-LICENSED OR CERTIFIED EMERGENCY MEDICAL TECHNICIANS (EMTS).

(a) In General.-Part B of title III (42 U.S.C. 243

15 et seq.), as amended, is amended by inserting after section 16315 the following:

17 "SEC. 315A. ASSISTING VETERANS WITH MILITARY EMERGENCY MEDICAL TRAINING TO BECOME STATE-LICENSED OR CERTIFIED EMERGENCY MEDICAL TECHNICIANS (EMTS). “(a) Program.-The Secretary shall establish a pro-

22 gram consisting of awarding grants to States to assist vet23 erans who received and completed military emergency 24 medical training while serving in the Armed Forces of the 25 United States to become, upon their discharge or release 
1 from active duty service, State-licensed or certified emer2 gency medical technicians.

3 “(b) Use of Funds.-Amounts received as a grant

4 under this section may be used to assist veterans described

5 in subsection (a) to become State-licensed or certified 6 emergency medical technicians as follows:

7

8

9 ated with-

10

11

12

13 process.

14 “(c) Eligibinity.-To be eligible for a grant under

15 this section, a State shall demonstrate to the Secretary's

16 satisfaction that the State has a shortage of emergency

17 medical technicians.

18 “(d) REPORT.-The Secretary shall submit to the

19 Congress an annual report on the program under this sec20 tion.

21 “(e) Authorization OF Appropriations.-To 22 carry out this section, there are authorized to be appro23 priated such sums as may be necessary for each of fiscal 24 years 2011 through 2015.". 
1 (b) GAO STUdY AND REPORT.-The Comptroller

2 General of the United States shall-

(1) conduct a study on the barriers experienced

4 by veterans who received training as medical per5 sonnel while serving in the Armed Forces of the 6 United States and, upon their discharge or release 7 from active duty service, seek to become licensed or 8 certified in a State as civilian health professionals; 9 and

10 (2) not later than 2 years after the date of the 11 enactment of this Act, submit to the Congress a re12 port on the results of such study, including rec13 ommendations on whether the program established 14 under section 315A of the Public Health Service 15 Act, as added by subsection (a), should be expanded 16 to assist veterans seeking to become licensed or cer17 tified in a State as health providers other than emer18 gency medical technicians.

19 SEC. 2555. DENTAL EMERGENCY RESPONDERS: PUBLIC HEALTH AND MEDICAL RESPONSE.

(a) National Health Security Strategy.-Sec22 tion 2802(b)(3) (42 U.S.C. 300hh-1(b)(3)) is amended23 (1) in the matter preceding subparagraph (A), 24 by inserting "dental and" before "mental health fa25 cilities"; and 
(2) in subparagraph (D), by inserting "and

2 dental" after "medical".

3 (b) All-Hazards Public Health and Medical 4 Response Curricula and Training.- Section $5319 \mathrm{~F}(\mathrm{a})(5)(\mathrm{B})(42$ U.S.C. $247 \mathrm{~d}-6(\mathrm{a})(5)(\mathrm{B}))$ is amended 6 by striking "public health or medical" and inserting "pub7 lic health, medical, or dental".

8 SEC. 2556. DENTAL EMERGENCY RESPONDERS: HOMELAND SECURITY.

10 (a) National Response Framework.-Paragraph

11 (6) of section 2 of the Homeland Security Act of 2002 12 (6 U.S.C. 101) is amended by inserting "and dental" after 13 "emergency medical".

14 (b) National Preparedness System.-Subpara15 graph (B) of section 653(b)(4) of the Post-Katrina Emer16 gency Management Reform Act of 2006 (6 U.S.C. 17 753(b)(4)) is amended by striking "public health and med18 ical" and inserting "public health, medical, and dental". 19 (c) Chief Medical Officer.-Paragraph (5) of 20 section 516(c) of the Homeland Security Act of 2002 (6 21 U.S.C. 321e(c)) is amended by striking "medical commu22 nity" and inserting "medical and dental communities". 
3 SEC. 2561. INSTITUTE OF MEDICINE CONFERENCE ON PAIN.

(a) Convening.-Not later than June 30, 2011, the

5 Secretary of Health and Human Services shall seek to

6 enter into an agreement with the Institute of Medicine of

7 the National Academies to convene a Conference on Pain

8 (in this section referred to as "the Conference").

9 (b) Purposes.- The purposes of the Conference

10 shall be to-

(1) increase the recognition of pain as a signifi-

12 cant public health problem in the United States;

13 (2) evaluate the adequacy of assessment, diag14 nosis, treatment, and management of acute and 15 chronic pain in the general population, and in identi16 fied racial, ethnic, gender, age, and other demo17 graphic groups that may be disproportionately af18 fected by inadequacies in the assessment, diagnosis, 19 treatment, and management of pain;

20 (3) identify barriers to appropriate pain care, 21 including-

(A) lack of understanding and education among employers, patients, health care providers, regulators, and third-party payors; 
(B) barriers to access to care at the primary, specialty, and tertiary care levels, including barriers-

(i) specific to those populations that are disproportionately undertreated for pain;

18 public and private sectors that will reduce such bar-

19 riers and significantly improve the state of pain care 20 research, education, and clinical care in the United 21 States.

22 (c) Other Appropriate Entity.-If the Institute 23 of Medicine declines to enter into an agreement under sub24 section (a), the Secretary of Health and Human Services 
1 may enter into such agreement with another appropriate

2 entity.

3 (d) REPORT.-A report summarizing the Con4 ference's findings and recommendations shall be sub5 mitted to the Congress not later than June 30, 2012.

6 (e) Authorization of Appropriations.-For the 7 purpose of carrying out this section, there is authorized 8 to be appropriated $\$ 500,000$ for each of fiscal years 2011 9 and 2012 .

10 SEC. 2562. PAIN RESEARCH AT NATIONAL INSTITUTES OF HEALTH.

12 Part B of title IV (42 U.S.C. 284 et seq.) is amended

13 by adding at the end the following:

14 “SEC. 409J. PAIN RESEARCH.

“(a) Research Initiatives.-

“(1) In GENERAL.—The Director of NIH is en-

17 couraged to continue and expand, through the Pain

18 Consortium, an aggressive program of basic and

19 clinical research on the causes of and potential treat20 ments for pain.

21 “(2) Annual Recommendations.-Not less 22 than annually, the Pain Consortium, in consultation 23 with the Division of Program Coordination, Plan24 ning, and Strategic Initiatives, shall develop and 25 submit to the Director of NIH recommendations on 
1 appropriate pain research initiatives that could be

2 undertaken with funds reserved under section

$3402 \mathrm{~A}(\mathrm{c})(1)$ for the Common Fund or otherwise

4 available for such initiatives.

5 “(3) Definition.-In this subsection, the term

6 'Pain Consortium' means the Pain Consortium of

7 the National Institutes of Health or a similar trans-

8 National Institutes of Health coordinating entity

9 designated by the Secretary for purposes of this sub-

10 section.

11 “(b) Interagency Pain Research Coordinating

12 Committee.-

13 "(1) Establishment.-The Secretary shall es-

14 tablish not later than 1 year after the date of the

15 enactment of this section and as necessary maintain

16 a committee, to be known as the Interagency Pain

17 Research Coordinating Committee (in this section

18 referred to as the 'Committee'), to coordinate all ef-

19 forts within the Department of Health and Human

20 Services and other Federal agencies that relate to 21 pain research.

“(2) Membership.-

24 be composed of the following voting members: 
1495

“(i) Not more than 7 voting Federal

representatives as follows:

"(I) The Director of the Centers for Disease Control and Prevention.

"(II) The Director of the Narectors of such national research institutes and national centers as the Secretary determines appropriate.

"(III) The heads of such other agencies of the Department of Health and Human Services as the Secretary determines appropriate.

“(IV) Representatives of other Federal agencies that conduct or support pain care research and treatment, including the Department of Defense and the Department of Veterans Affairs.

"(ii) Twelve additional voting members appointed under subparagraph (B). "(B) Additional Members. - The Committee shall include additional voting members appointed by the Secretary as follows: 
"(i) Six members shall be appointed

from among scientists, physicians, and

other health professionals, who-

“(I) are not officers or employees of the United States;

"(II) represent multiple disciplines, including clinical, basic, and public health sciences;

“(III) represent different geographical regions of the United States; and

"(IV) are from practice settings, academia, manufacturers, or other research settings.

“(ii) Six members shall be appointed from members of the general public, who are representatives of leading research, advocacy, and service organizations for individuals with pain-related conditions.

"(C) Nonvoting members.-The Committee shall include such nonvoting members as the Secretary determines to be appropriate.

“(3) Chatrperson.-The voting members of the Committee shall select a chairperson from among such members. The selection of a chairperson 
1 shall be subject to the approval of the Director of

2 NIH.

“(4) Mentings.-The Committee shall meet at

4 the call of the chairperson of the Committee or upon

5 the request of the Director of NIH, but in no case

6 less often than once each year.

“(5) Duties.-The Committee shall-

"(A) develop a summary of advances in pain care research supported or conducted by the Federal agencies relevant to the diagnosis, prevention, and treatment of pain and diseases and disorders associated with pain;

"(B) identify critical gaps in basic and clinical research on the symptoms and causes of pain;

"(C) make recommendations to ensure that the activities of the National Institutes of Health and other Federal agencies, including the Department of Defense and the Department of Veteran Affairs, are free of unnecessary duplication of effort;

“(D) make recommendations on how best to disseminate information on pain care; and "(E) make recommendations on how to ex25 pand partnerships between public entities, in- 
cluding Federal agencies, and private entities to expand collaborative, crosscutting research.

4 necessity of the Committee at least once every 2 5 years.".

6 SEC. 2563. PUBLIC AWARENESS CAMPAIGN ON PAIN MANAGEMENT.

8 Part B of title II (42 U.S.C. 238 et seq.) is amended 9 by adding at the end the following:

10 “SEC. 249. NATIONAL EDUCATION OUTREACH AND AWARENESS CAMPAIGN ON PAIN MANAGEMENT.

12 “(a) Establishment.-Not later than 12 months 13 after the date of the enactment of this section, the Sec14 retary shall establish and implement a national pain care 15 education outreach and awareness campaign described in 16 subsection (b).

17 “(b) REQuirements.-The Secretary shall design 18 the public awareness campaign under this section to edu19 cate consumers, patients, their families, and other care20 givers with respect to-

"(1) the incidence and importance of pain as a 22 national public health problem;

23 "(2) the adverse physical, psychological, emo24 tional, societal, and financial consequences that can 
1 result if pain is not appropriately assessed, diag-

2 nosed, treated, or managed;

3 "(3) the availability, benefits, and risks of all

4 pain treatment and management options;

5 “(4) having pain promptly assessed, appro6 priately diagnosed, treated, and managed, and regu-

7 larly reassessed with treatment adjusted as needed;

8 “(5) the role of credentialed pain management

9 specialists and subspecialists, and of comprehensive

10 interdisciplinary centers of treatment expertise;

11 "(6) the availability in the public, nonprofit, 12 and private sectors of pain management-related in13 formation, services, and resources for consumers, 14 employers, third-party payors, patients, their fami15 lies, and caregivers, including information on-

16 "(A) appropriate assessment, diagnosis, 17 treatment, and management options for all 18 types of pain and pain-related symptoms; and

19 "(B) conditions for which no treatment op20 tions are yet recognized; and 21 "(7) other issues the Secretary deems appro22 priate.

23 “(c) Consultation.-In designing and imple24 menting the public awareness campaign required by this 25 section, the Secretary shall consult with organizations rep- 
1 resenting patients in pain and other consumers, employ-

2 ers, physicians including physicians specializing in pain

3 care, other pain management professionals, medical device

4 manufacturers, and pharmaceutical companies.

5 “(d) CoOrdination.-

6 “(1) LeAD OFFICLAL.-The Secretary shall des-

7 ignate one official in the Department of Health and

8 Human Services to oversee the campaign established

9 under this section.

10 “(2) AGEncy COORdination.-The Secretary

11 shall ensure the involvement in the public awareness

12 campaign under this section of the Surgeon General

13 of the Public Health Service, the Director of the

14 Centers for Disease Control and Prevention, and

15 such other representatives of offices and agencies of

16 the Department of Health and Human Services as

17 the Secretary determines appropriate.

18 “(e) Underserved Areas and Populations.-In

19 designing the public awareness campaign under this sec-

20 tion, the Secretary shall-

"(1) take into account the special needs of geo-

22 graphic areas and racial, ethnic, gender, age, and

23 other demographic groups that are currently under-

24 served; and 
"(2) provide resources that will reduce dispari-

2 ties in access to appropriate diagnosis, assessment,

3 and treatment.

4 “(f) Grants and CONTRACTS.-The Secretary may

5 make awards of grants, cooperative agreements, and con-

6 tracts to public agencies and private nonprofit organiza-

7 tions to assist with the development and implementation

8 of the public awareness campaign under this section.

9 “(g) Evaluation and Report.-Not later than the

10 end of fiscal year 2012, the Secretary shall prepare and

11 submit to the Congress a report evaluating the effective-

12 ness of the public awareness campaign under this section

13 in educating the general public with respect to the matters

14 described in subsection (b).

15 “(h) AUthorization OF APPROPRIATIONS.-For

16 purposes of carrying out this section, there are authorized

17 to be appropriated $\$ 2,000,000$ for fiscal year 2011 and

$18 \$ 4,000,000$ for each of fiscal years 2012 and 2015.".

22 SEC. 2571. NATIONAL MEDICAL DEVICE REGISTRY.

23 (a) REGISTRY.- 
1502

1

2

10 medical device registry (in this subsection referred to as

11 the 'registry') to facilitate analysis of postmarket safety

12 and outcomes data on each covered device. "(B) In this subsection, the term 'covered device'"(i) shall include each class III device; and “(ii) may include, as the Secretary determines appropriate and specifies in regulation, a class II de19 retary may by order exempt a class III device from the 20 provisions of this subsection if the Secretary concludes 21 that inclusion of information on the device in the registry 22 will not provide useful information on safety or effective23 ness.

24 "(2) In developing the registry, the Secretary shall, 25 in consultation with the Commissioner of Food and Drugs, 
1 the Administrator of the Centers for Medicare \& Medicaid

2 Services, the Administrator of the Agency for Healthcare

3 Research and Quality, the head of the Office of the Na-

4 tional Coordinator for Health Information Technology,

5 and the Secretary of Veterans Affairs, determine the best

6 methods for-

7

8 sistent with subsection (f), appropriate information

9 to identify each covered device by type, model, and

10 serial number or other unique identifier;

11

12 safety and outcomes data from multiple sources and

13 for linking such data with the information included

14 in the registry as described in subparagraph (A), in-

15 cluding, to the extent feasible, use of-

16

17

18

19 "(i) data provided to the Secretary under other provisions of this chapter; and

"(ii) information from public and private sources identified under paragraph (3);

"(C) integrating the activities described in this subsection (so as to avoid duplication) with-

"(i) activities under paragraph (3) of section $505(\mathrm{k})$ (relating to active postmarket risk identification); 
17 and patient outcomes for covered devices, the Secretary 18 shall, in collaboration with public, academic, and private 19 entities, develop methods to-

"(ii) activities under paragraph (4) of section $505(\mathrm{k})$ (relating to advanced analysis of drug safety data);

"(iii) other postmarket device surveillance activities of the Secretary authorized by this chapter; and

"(iv) registries carried out by or for the Agency for Healthcare Research and Quality; and

"(D) providing public access to the data and analysis collected or developed through the registry in a manner and form that protects patient privacy and proprietary information and is comprehensive, useful, and not misleading to patients, physicians, and scientists.

"(3)(A) To facilitate analyses of postmarket safety "(i) obtain access to disparate sources of patient safety and outcomes data, including-

“(I) Federal health-related electronic data (such as data from the Medicare program under title XVIII of the Social Secu- 
14 formation respecting a covered device, including claims

15 data, patient survey data, standardized analytic files that

16 allow for the pooling and analysis of data from disparate 17 data environments, electronic health records, and any 18 other data deemed appropriate by the Secretary.

19 “(4) The Secretary shall promulgate regulations for 20 establishment and operation of the registry under para21 graph (1). Such regulations-

23 sold on or after the date of the enactment of this 24 subsection, shall require manufacturers of such de25 vices to submit information to the registry, includ- 
1 ing, for each such device, the type, model, and serial

2 number or, if required under subsection (f), other

3 unique device identifier; and

$4 \quad$ "(ii) in the case of covered devices that are sold 5 before such date, may require manufacturers of such 6 devices to submit such information to the registry, 7 if deemed necessary by the Secretary to protect the 8 public health; "(B) shall establish procedures-

"(i) to permit linkage of information submitted pursuant to subparagraph (A) with patient safety and outcomes data obtained under paragraph (3); and

"(ii) to permit analyses of linked data;

16 to submit such other information as is necessary to 17 facilitate postmarket assessments of device safety 18 and effectiveness and notification of device risks;

19 "(D) shall establish requirements for regular 20 and timely reports to the Secretary, which shall be 21 included in the registry, concerning adverse event 22 trends, adverse event patterns, incidence and preva23 lence of adverse events, and other information the 24 Secretary determines appropriate, which may include 
1 data on comparative safety and outcomes trends;

2 and

"(E) shall establish procedures to permit public

4 access to the information in the registry in a manner

5 and form that protects patient privacy and propri-

6 etary information and is comprehensive, useful, and

7 not misleading to patients, physicians, and sci-

8 entists.

9 “(5)(A) The Secretary shall promulgate final regula-

10 tions under paragraph (4) not later than 36 months after

11 the date of the enactment of this subsection.

12 "(B) Before issuing the notice of proposed rule-

13 making preceding the final regulations described in sub-

14 paragraph (A), the Secretary shall hold a public hearing

15 before an advisory committee on the issue of which class

16 II devices to include in the definition of covered devices.

17 "(C) The Secretary shall include in any regulation

18 under this subsection an explanation demonstrating that

19 the requirements of such regulation-

"(i) do not duplicate other Federal require-

21 ments; and

22 "(ii) do not impose an undue burden on device 23 manufacturers.

24 "(6) With respect to any entity that submits or is 25 required to submit a safety report or other information 
1 in connection with the safety of a device under this section

2 (and any release by the Secretary of that report or infor-

3 mation), such report or information shall not be construed

4 to reflect necessarily a conclusion by the entity or the Sec-

5 retary that the report or information constitutes an admis-

6 sion that the product involved malfunctioned, caused or

7 contributed to an adverse experience, or otherwise caused

8 or contributed to a death, serious injury, or serious illness.

9 Such an entity need not admit, and may deny, that the

10 report or information submitted by the entity constitutes

11 an admission that the product involved malfunctioned,

12 caused or contributed to an adverse experience, or caused

13 or contributed to a death, serious injury, or serious illness.

14 “(7) To carry out this subsection, there are author-

15 ized to be appropriated such sums as may be necessary

16 for each of fiscal years 2011 and 2012.'.

17 (2) EFFEctive DaTE.-The Secretary of

18 Health and Human Services shall establish and

19 begin implementation of the registry under section

$20519(\mathrm{~g})$ of the Federal Food, Drug, and Cosmetic

21 Act, as added by paragraph (1), by not later than

22 the date that is 36 months after the date of the en-

23 actment of this Act, without regard to whether or

24 not final regulations to establish and operate the

25 registry have been promulgated by such date. 

303(f)(1)(B)(ii) of the Federal Food, Drug, and

3 Cosmetic Act (21 U.S.C. 333(f)(1)(B)(ii)) is amend$4 \quad$ ed by striking " $519(\mathrm{~g})$ " and inserting " $519(\mathrm{~h})$ ".

5 (b) Electronic Exchange and Use in Certified 6 Electronic Health Records of Unique Device 7 IDENTIFIERS.-

(1) Recommendations.-The HIT Policy 9 Committee established under section 3002 of the 10 Public Health Service Act (42 U.S.C. 300jj-12) 11 shall recommend to the head of the Office of the Na12 tional Coordinator for Health Information Tech13 nology standards, implementation specifications, and 14 certification criteria for the electronic exchange and 15 use in certified electronic health records of a unique 16 device identifier for each covered device (as defined 17 under section $519(\mathrm{~g})(1)(\mathrm{B})$ of the Federal Food, 18 Drug, and Cosmetic Act, as added by subsection 19 (a)).

(2) Standards, implementation CRITERIA, 21 AND CERTIFICATION CRITERIA.-The Secretary of 22 Health and Human Services, acting through the 23 head of the Office of the National Coordinator for 24 Health Information Technology, shall adopt stand25 ards, implementation specifications, and certification 
1 criteria for the electronic exchange and use in cer-

2 tified electronic health records of a unique device

3 identifier for each covered device referred to in para-

4 graph (1), if such an identifier is required by section

$5 \quad 519(\mathrm{f})$ of the Federal Food, Drug, and Cosmetic Act

6 (21 U.S.C. $360 \mathrm{i}(\mathrm{f}))$ for the device.

7 (c) Unique Device Identification System.-The

8 Secretary of Health and Human Services, acting through

9 the Commissioner of Food and Drugs, shall issue proposed

10 regulations to implement section 519(f) of the Federal

11 Food, Drug, and Cosmetic Act (21 U.S.C. 360i(f)) not

12 later than 6 months after the date of the enactment of

13 this Act.

14 SEC. 2572. NUTRITION LABELING OF STANDARD MENU ITEMS AT CHAIN RESTAURANTS AND OF ARTICLES OF FOOD SOLD FROM VENDING MACHINES.

19 403(q)(5)(A) of the Federal Food, Drug, and Cosmetic 20 Act (21 U.S.C. $343(q)(5)(\mathrm{A}))$ is amended-

22 vided in clause (H)(ii)(III)," after “(i)" ; and

24 provided in clause (H)(ii)(III)," after “(ii)". 
1511

1 (b) Labeling Requirements.-Section 403(q)(5)

2 of the Federal Food, Drug, and Cosmetic Act (21 U.S.C.

$3343(q)(5))$ is amended by adding at the end the following:

4 “(H) Restaurants, Retail Food Establish5 ments, and Vending Machines.-

6

7

8

9

10

11 lar retail food establishment that is part of a chain

12 with 20 or more locations doing business under the

13 same name (regardless of the type of ownership of

14 the locations) and offering for sale substantially the

15 same menu items, the restaurant or similar retail

16 food establishment shall disclose the information de-

17 scribed in subclauses (ii) and (iii).

“(i) General REQUIREMENTS FOR RESTAURANTS AND SIMILAR RETAIL FOOD ESTABLISHMENTS.-Except for food described in subclause (vii), in the case of food that is a standard menu item that is offered for sale in a restaurant or simi"(ii)

“(ii) INFORMATION REQUIRED TO BE DISCLOSED BY RESTAURANTS AND RETAIL FOOD ESTABLISHMENTS.-Except as provided in subclause (vii), the restaurant or similar retail food establishment shall disclose in a clear and conspicuous manner-

"(I)(aa) in a nutrient content disclosure statement adjacent to the name of the standard 
menu item, so as to be clearly associated with the standard menu item, on the menu listing the item for sale, the number of calories contained in the standard menu item, as usually prepared and offered for sale; and

"(bb) a succinct statement concerning suggested daily caloric intake, as specified by the Secretary by regulation and posted prominently on the menu and designed to enable the public to understand, in the context of a total daily diet, the significance of the caloric information that is provided on the menu; "(II)(aa) in a nutrient content disclosure statement adjacent to the name of the standard menu item, so as to be clearly associated with the standard menu item, on the menu board, including a drive-through menu board, the number of calories contained in the standard menu item, as usually prepared and offered for sale; and

"(bb) a succinct statement concerning suggested daily caloric intake, as specified by the Secretary by regulation and posted prominently on the menu board, designed to enable the public to understand, in the context of a total daily 
diet, the significance of the nutrition information that is provided on the menu board;

"(III) in a written form, available on the premises of the restaurant or similar retail establishment and to the consumer upon request,

18 food establishment shall place adjacent to each food 19 offered a sign that lists calories per displayed food 20 item or per serving.

"(iv) Reasonable Basis.-For the purposes of 22 this clause, a restaurant or similar retail food estab23 lishment shall have a reasonable basis for its nutri24 ent content disclosures, including nutrient databases, 25 cookbooks, laboratory analyses, and other reasonable 
1 means, as described in section 101.10 of title 21,

2 Code of Federal Regulations (or any successor regu3 lation) or in a related guidance of the Food and 4 Drug Administration. “(v) Menu Variability AND COMbination 6 MEALS.- The Secretary shall establish by regulation 7 standards for determining and disclosing the nutri8 ent content for standard menu items that come in 9 different flavors, varieties, or combinations, but 10 which are listed as a single menu item, such as soft 11 drinks, ice cream, pizza, doughnuts, or children's 12 combination meals, through means determined by 13 the Secretary, including ranges, averages, or other 14 methods.

"(vi) Additional information.-If the Sec16 retary determines that a nutrient, other than a nu17 trient required under subclause (ii)(III), should be 18 disclosed for the purpose of providing information to 19 assist consumers in maintaining healthy dietary 20 practices, the Secretary may require, by regulation, 21 disclosure of such nutrient in the written form re22 quired under subclause (ii)(III). "(vii) Nonapplicability to Certain FoOd.“(I) IN GENERAL.—Subclauses (i) through 25 (vi) do not apply to- 
1515

"(aa) items that are not listed on a menu or menu board (such as condiments and other items placed on the table or counter for general use);

"(bb) daily specials, temporary menu items appearing on the menu for less than 60 days per calendar year, or custom orders; or

"(ce) such other food that is part of a customary market test appearing on the menu for less than 90 days, under terms and conditions established by the Secretary.

"(II) WritTEN FORMs._Clause (C) shall apply to any regulations promulgated under subclauses (ii)(III) and (vi).

"(viii) Vending Machines.-In the case of an article of food sold from a vending machine that"(I) does not permit a prospective purchaser to examine the Nutrition Facts Panel before purchasing the article or does not otherwise provide visible nutrition information at the point of purchase; and 
"(II) is operated by a person who is engaged in the business of owning or operating 20 or more vending machines,

4 the vending machine operator shall provide a sign in

5 close proximity to each article of food or the selec6 tion button that includes a clear and conspicuous 7 statement disclosing the number of calories con8 tained in the article.

“(ix) VOLUNTARY PROVISION OF NUTRITION IN10 FORMATION.-

"(I) IN GENERAL.-An authorized official of any restaurant or similar retail food establishment or vending machine operator not subject to the requirements of this clause may elect to be subject to the requirements of such clause, by registering biannually the name and address of such restaurant or similar retail food establishment or vending machine operator with the Secretary, as specified by the Secretary by regulation.

"(II) Registration.-Within 120 days of the enactment of this clause, the Secretary shall publish a notice in the Federal Register speci24 fying the terms and conditions for implementa- 
tion of item (I), pending promulgation of regulations.

“(III) Rule OF CONSTRUCTION.-Nothing in this subclause shall be construed to authorize the Secretary to require an application, review, or licensing process for any entity to register with the Secretary, as described in such item. "(x) Regulations.-

"(I) Proposed Regulation.-Not later than 1 year after the date of the enactment of this clause, the Secretary shall promulgate proposed regulations to carry out this clause.

"(II) CONTENTS.-In promulgating regulations, the Secretary shall-

"(aa) consider standardization of recipes and methods of preparation, reasonable variation in serving size and formulation of menu items, space on menus and menu boards, inadvertent human error, training of food service workers, variations in ingredients, and other factors, as the Secretary determines; and

"(bb) specify the format and manner of the nutrient content disclosure requirements under this subclause. 
“(III) REPORTING.-The Secretary shall submit to the Committee on Health, Education, Labor, and Pensions of the Senate and the Committee on Energy and Commerce of the House of Representatives a quarterly report that describes the Secretary's progress toward promulgating final regulations under this subparagraph.

"(xi) Definition.-In this clause, the term

10 'menu' or 'menu board' means the primary writing. 11 of the restaurant or other similar retail food estab12 lishment from which a consumer makes an order se13 lection.".

14 (c) National Uniformity.-Section 403A(a)(4) of 15 the Federal Food, Drug, and Cosmetic Act (21 U.S.C. $16343-1(\mathrm{a})(4))$ is amended by striking "except a require17 ment for nutrition labeling of food which is exempt under 18 subclause (i) or (ii) of section 403(q)(5)(A)" and inserting 19 "except that this paragraph does not apply to food that 20 is offered for sale in a restaurant or similar retail food 21 establishment that is not part of a chain with 20 or more 22 locations doing business under the same name (regardless 23 of the type of ownership of the locations) and offering for 24 sale substantially the same menu items unless such res25 taurant or similar retail food establishment complies with 
1 the voluntary provision of nutrition information require-

2 ments under section 403(q)(5)(H)(ix)".

3 (d) Rule of Construction.-Nothing in the

4 amendments made by this section shall be construed-

(1) to preempt any provision of State or local

6 law, unless such provision establishes or continues

7 into effect nutrient content disclosures of the type

8 required under section $403(q)(5)(\mathrm{H})$ of the Federal

9 Food, Drug, and Cosmetic Act (as added by sub-

10 section (b)) and is expressly preempted under sec-

11 tion $403 \mathrm{~A}(\mathrm{a})(4)$ of such Act;

12 (2) to apply to any State or local requirement

13 respecting a statement in the labeling of food that

14 provides for a warning concerning the safety of the

15 food or component of the food; or

16 (3) except as provided in section $17403(\mathrm{q})(5)(\mathrm{H})(\mathrm{ix})$ of the Federal Food, Drug, and

18 Cosmetic Act (as added by subsection (b)), to apply 19 to any restaurant or similar retail food establish20 ment other than a restaurant or similar retail food 21 establishment described in section 403(q)(5)(H)(i) of 22 such Act.

23 SEC. 2573. PROTECTING CONSUMER ACCESS TO GENERIC DRUGS.

25 (a) Findings; Purpose.- 
(1) Findings. - The Congress finds the fol-

2 lowing:

(A) In 1984, the Drug Price Competition and Patent Term Restoration Act (Pub. L. 98417 ; in this subsection referred to as the "1984 Act") was enacted with the intent of facilitating the early entry of generic drugs while preserving incentives for innovation.

(B) Prescription drugs make up 10 percent of national health care spending, but for the past decade have been one of the fastest growing segments of health care expenditures.

(C) Until recently, the 1984 Act was successful in facilitating generic competition to the benefit of consumers and health care payersalthough 67 percent of all prescriptions dispensed in the United States are generic drugs, they account for only 20 percent of all expenditures.

(D) In recent years, the intent of the 1984 Act has been subverted by certain settlement agreements between brand companies and their potential generic competitors that make reverse payments, i.e., payments by the brand company to the generic company. 
15 Drug, and Cosmetic Act (21 U.S.C. 355) is amended by 16 adding at the end the following: “(w) Protecting Consumer Access to Generic

18 Drugs.-

“(1) UNFAIR AND DECEPTIVE ACTS AND PRAC-

(E) These settlement agreements have unduly delayed the marketing of low-cost generic drugs contrary to free competition and the interests of consumers.

(F) The state of antitrust law relating to such settlement agreements is unsettled.

(2) Purpose.-The purpose of this section is to provide an additional means to effectuate the intent of the 1984 Act by enhancing competition in the pharmaceutical market by stopping agreements between brand name and generic drug manufacturers that limit, delay, or otherwise prevent competition from generic drugs.

(b) In General.-Section 505 of the Federal Food, 
"(i) an ANDA filer receives anything

of value; and

“(ii) the ANDA filer agrees to limit or forego research, development, manufacturing, marketing, or sales, for any period of time, of the drug that is to be manufactured under the ANDA involved and is the subject of the patent infringement claim.

"(B) ExCEPTIONs.-Notwithstanding subparagraph (A)(i), subparagraph (A) does not prohibit a resolution or settlement of a patent infringement claim in which the value received by the ANDA filer includes no more thanis to be manufactured under the ANDA in-

"(I) the patent that is the basis volved and is the subject of the patent infringement claim, before the expiration offor the patent infringement claim; or "(II) any other statutory exclusivity that would prevent the marketing of such drug; and 
1523

"(ii) the waiver of a patent infringement claim for damages based on prior marketing of such drug.

"(C) Enforcement.-

"(i) IN GENERAL.-A violation of subparagraph (A) shall be treated as an unfair and deceptive act or practice and an unfair method of competition in or affecting interstate commerce prohibited under section 5 of the Federal Trade Commission Act and shall be enforced by the Federal Trade Commission in the same manner, by the same means, and with the same jurisdiction as though all applicable terms and provisions of the Federal Trade Commission Act were incorporated into and made a part of this subsection.

“(ii) InAPPLICABILITY.-Subchapter A of chapter VII shall not apply with respect to this subsection.

“(D) Definitions.-In this subsection:

“(i) Agrennent.-The term 'agreement' means anything that would constitute an agreement under section 5 of the Federal Trade Commission Act. 
TLING.-The term 'agreement resolving or settling', in reference to a patent infringe-

ment claim, includes any agreement that is contingent upon, provides a contingent condition for, or is otherwise related to the resolution or settlement of the claim.

“(iii) ANDA.-The term 'ANDA' means an abbreviated new drug application for the approval of a new drug under section (j).

"(iv) ANDA FILER.-The term 'ANDA filer' means a party that has filed an ANDA with the Food and Drug Administration.

"(v) Patent Infringement.-The term 'patent infringement' means infringement of any patent or of any filed patent application, extension, reissuance, renewal, division, continuation, continuation in part, reexamination, patent term restoration, patent of addition, or extension thereof.

$$
\text { "(vi) PATENT INFRINGEMENT }
$$

CLAIM.-The term 'patent infringement claim' means any allegation made to an 
ANDA filer, whether or not included in a complaint filed with a court of law, that its ANDA or drug to be manufactured under such ANDA may infringe any patent.

“(2) FTC Rulemaking.- The Federal Trade

6 Commission may, by rule promulgated under section

7553 of title 5, United States Code, exempt certain

8 agreements described in paragraph (1) from the re9 quirements of this subsection if the Commission 10 finds such agreements to be in furtherance of mar11 ket competition and for the benefit of consumers. 12 Consistent with the authority of the Commission, 13 such rules may include interpretive rules and general 14 statements of policy with respect to the practices 15 prohibited under paragraph (1).”.

16 (c) Notice and Certification of Agremments.17 (1) Notice OF ALL AGREements.-Section $181112(\mathrm{c})(2)$ of the Medicare Prescription Drug, Im19 provement, and Modernization Act of 2003 (21 20 U.S.C. 3155 note) is amended byserting the following: "the Commission"(A) the";

(B) striking the period at the end and inserting "; and"; and 
(C) adding at the end the following:

"(B) any other agreement the parties enter into within 30 days of entering into an agreement covered by subsection (a) or (b).”.

61112 of such Act is amended by adding at the end 7 the following:

8 “(d) Certification.-The chief executive officer or 9 the company official responsible for negotiating any agree10 ment required to be filed under subsection (a), (b), or (c)

11 shall execute and file with the Assistant Attorney General 12 and the Commission a certification as follows: 'I declare 13 under penalty of perjury that the following is true and 14 correct: The materials filed with the Federal Trade Com15 mission and the Department of Justice under section 1112 16 of subtitle B of title XI of the Medicare Prescription Drug, 17 Improvement, and Modernization Act of 2003, with re18 spect to the agreement referenced in this certification: (1) 19 represent the complete, final, and exclusive agreement be20 tween the parties; (2) include any ancillary agreements 21 that are contingent upon, provide a contingent condition 22 for, or are otherwise related to, the referenced agreement; 23 and (3) include written descriptions of any oral agree24 ments, representations, commitments, or promises be25 tween the parties that are responsive to subsection (a) or 
1 (b) of such section 1112 and have not been reduced to

2 writing.'.".

\section{(d) GAO STUDY.-}

(1) STUdy.-Beginning 2 years after the date of enactment of this Act, and each year for a period of 4 years thereafter, the Comptroller General shall conduct a study on the litigation in United States courts during the period beginning 5 years prior to the date of enactment of this Act relating to patent infringement claims involving generic drugs, the number of patent challenges initiated by manufacturers of generic drugs, and the number of settlements of such litigation. The Comptroller General shall transmit to Congress a report of the findings of such a study and an analysis of the effect of the amendments made by subsections (b) and (c) on such litigation, whether such amendments have had an effect on the number and frequency of claims settled, and whether such amendments resulted in earlier or delayed entry of generic drugs to market, including whether any harm or benefit to consumers has resulted.

(2) Disclosure of AGRenments.-Notwithstanding any other law, agreements filed under section 1112 of the Medicare Prescription Drug, Im- 
1 provement, and Modernization Act of 2003 (21

2 U.S.C. 355 note), or unaggregated information from

3 such agreements, shall be disclosed to the Comp-

4 troller General for purposes of the study under para-

5 graph (1) within 30 days of a request by the Comp6 troller General.

PART 2-BIOSIMILARS

8 SEC. 2575. LICENSURE PATHWAY FOR BIOSIMILAR BIOLOGICAL PRODUCTS.

10 (a) Licensure of Biological Products as Bio-

11 SIMILAR OR INTERCHANGEABLE.-Section 351 of the 12 Public Health Service Act (42 U.S.C. 262) is amended-

(1) in subsection (a)(1)(A), by inserting "under this subsection or subsection (k)" after "biologics li15 cense"; and

(2) by adding at the end the following:

18 SIMILAR OR INTERCHANGEABLE.-

“(1) IN GENERAL.-Any person may submit an 20 application for licensure of a biological product 21 under this subsection.

“(2) Content.-

“(A) IN GENERAL.- 
shall include information demonstrating

"(I) the biological product is biosimilar to a reference product based upon data derived from-

"(aa) analytical studies that

demonstrate that the biological

product is highly similar to the reference product notwithstanding minor differences in clinically inactive components;

"(bb) animal studies (includ-

and

$$
\text { “(ce) a clinical study or }
$$
studies (including the assessment of immunogenicity and pharmacokinetics or pharmacodynamics) that are sufficient to demonstrate safety, purity, and potency in 1 or more appropriate conditions of use for which the reference product is licensed and intended to be used 
and for which licensure is sought for the biological product;

"(II) the biological product and reference product utilize the same mechanism or mechanisms of action for the condition or conditions of use prescribed, recommended, or suggested in the proposed labeling, but only to the extent the mechanism or mechanisms of action are known for the reference product;

"(III) the condition or conditions of use prescribed, recommended, or suggested in the labeling proposed for the biological product have been previously approved for the reference product;

"(IV) the route of administration, the dosage form, and the strength of the biological product are the same as those of the reference product; and

"(V) the facility in which the biological product is manufactured, processed, packed, or held meets stand- 
ards designed to assure that the biological product continues to be safe, pure, and potent.

“(ii) Determination By SECRETARY.-The Secretary may determine,

in the Secretary's discretion, that an element described in clause (i)(I) is unnecessary in an application submitted under this subsection.

“(iii) AdDitional INFORMATION.An application submitted under this subsection-

"(I) shall include publicly available information regarding the Secretary's previous determination that the reference product is safe, pure, and potent; and

“(II) may include any additional information in support of the application, including publicly available information with respect to the reference product or another biological product. “(B) InterchangeabiLity.-An application (or a supplement to an application) submitted under this subsection may include infor- 
mation demonstrating that the biological product meets the standards described in paragraph $(4)$.

“(3) Evaluation By secretary.-Upon re-

5 view of an application (or a supplement to an appli6 cation) submitted under this subsection, the Sec$7 \quad$ retary shall license the biological product under this 8 subsection if"(A) the Secretary determines that the information submitted in the application (or the supplement) is sufficient to show that the biological product-

"(i) is biosimilar to the reference product; or

"(ii) meets the standards described in paragraph (4), and therefore is interchangeable with the reference product; and "(B) the applicant (or other appropriate person) consents to the inspection of the facility that is the subject of the application, in accordance with subsection $(\mathrm{c})$.

“(4) SAFETy STANDARDS FOR DETERMINING INTERCHANGEABILITY.-Upon review of an application submitted under this subsection or any supplement to such application, the Secretary shall deter- 
1533

1 mine the biological product to be interchangeable

2 with the reference product if the Secretary deter-

3 mines that the information submitted in the applica-

4 tion (or a supplement to such application) is suffi-

5 cient to show that-

6

7

8

9

10

11

12

13

14

15

16

17

18

19

20

21

22

23

24
"(A) the biological product-

"(i) is biosimilar to the reference product; and

"(ii) can be expected to produce the same clinical result as the reference product in any given patient; and

"(B) for a biological product that is administered more than once to an individual, the risk in terms of safety or diminished efficacy of alternating or switching between use of the biological product and the reference product is not greater than the risk of using the reference product without such alternation or switch.

“(5) General Rules.-

"(A) One Reference PRoduct PER APPLICATION.-A biological product, in an application submitted under this subsection, may not be evaluated against more than 1 reference product. 

under this subsection shall be reviewed by the division within the Food and Drug Administra-

tion that is responsible for the review and approval of the application under which the reference product is licensed.

“(C) Risk evaluation and mitigation STRATEGIES.-The authority of the Secretary with respect to risk evaluation and mitigation strategies under the Federal Food, Drug, and Cosmetic Act shall apply to biological products licensed under this subsection in the same manner as such authority applies to biological products licensed under subsection (a).

“(D) Restrictions on BiOLOGICAL PRODUCTS CONTAINING DANGEROUS INGREDIENTS.-If information in an application submitted under this subsection, in a supplement to such an application, or otherwise available to the Secretary shows that a biological product"(i) is, bears, or contains a select agent or toxin listed in section 73.3 or 73.4 of title 42 , section 121.3 or 121.4 of title 9 , or section 331.3 of title 7 , Code of 
Federal Regulations (or any successor reg-

ulations); or

"(ii) is, bears, or contains a controlled substance in schedule I or II of section 202 of the Controlled Substances Act, as

23 shall not make a determination under paragraph (4)

24 that the second or subsequent biological product is 
1 interchangeable for any condition of use until the

2 earlier of-

"(A) 1 year after the first commercial marketing of the first interchangeable biosimilar biological product to be approved as interchangeable for that reference product;

"(B) 18 months after-

"(i) a final court decision on all patents in suit in an action instituted under subsection (1)(5) against the applicant that submitted the application for the first approved interchangeable biosimilar biological product; or

"(ii) the dismissal with or without prejudice of an action instituted under subsection (l)(5) against the applicant that submitted the application for the first approved interchangeable biosimilar biological product; or "(C)(i) 42 months after approval of the first interchangeable biosimilar biological product if the applicant that submitted such application has been sued under subsection (1)(5) and such litigation is still ongoing within such 42-month period; or 
1537

"(ii) 18 months after approval of the first interchangeable biosimilar biological product if the applicant that submitted such application has not been sued under subsection (l)(5).

For purposes of this paragraph, the term 'final court decision' means a final decision of a court from which no appeal (other than a petition to the United States Supreme Court for a writ of certiorari) has been or can be taken.

“(7) ExClusivity FOR REFERENCE PRODUCT.-

"(A) EFFective Date OF BIOSIMILAR APPLICATION APPROVAL.-Approval of an application under this subsection may not be made effective by the Secretary until the date that is 12 years after the date on which the reference product was first licensed under subsection (a). “(B) FILING PERIOD.-An application under this subsection may not be submitted to the Secretary until the date that is 4 years after the date on which the reference product was first licensed under subsection (a).

“(C) First LiCensure.-Subparagraphs (A) and (B) shall not apply to a license for or approval of- 
"(i) a supplement for the biological product that is the reference product; or

“(ii) a subsequent application filed by

the same sponsor or manufacturer of the biological product that is the reference

product (or a licensor, predecessor in interest, or other related entity) for-

"(I) a change (not including a modification to the structure of the biological product) that results in a new indication, route of administration, dosing schedule, dosage form, delivery system, delivery device, or strength; or "(II) a modification to the structure of the biological product that does not result in a change in safety, purity, or potency.

“(8) Pediatric studies.-

“(A) Exclusivity.-If, before or after licensure of the reference product under subsection (a) of this section, the Secretary determines that information relating to the use of such product in the pediatric population may produce health benefits in that population, the Secretary makes a written request for pediatric 
1539

studies (which shall include a timeframe for completing such studies), the applicant or holder of the approved application agrees to the request, such studies are completed using appropriate formulations for each age group for which the study is requested within any such timeframe, and the reports thereof are submitted and accepted in accordance with section $505 \mathrm{~A}(\mathrm{~d})(3)$ of the Federal Food, Drug, and Cosmetic Act the period referred to in paragraph $(7)(\mathrm{A})$ of this subsection is deemed to be 12 years and 6 months rather than 12 years. "(B) EXCEPTION.-The Secretary shall not extend the period referred to in subparagraph (A) of this paragraph if the determination under section $505 \mathrm{~A}(\mathrm{~d})(3)$ of the Federal Food, Drug, and Cosmetic Act is made later than 9 months prior to the expiration of such period.

"(C) Application OF CERTAin PROVISIONS.-The provisions of subsections (a), (d), (e), (f), (h), (j), (k), and (l) of section 505A of the Federal Food, Drug, and Cosmetic Act shall apply with respect to the extension of a period under subparagraph (A) of this para- 
graph to the same extent and in the same man-

ner as such provisions apply with respect to the extension of a period under subsection (b) or (c) of section 505A of the Federal Food, Drug, and Cosmetic Act.

"(A) In GENERAL.- The Secretary may, after opportunity for public comment, issue guidance in accordance, except as provided in subparagraph (B)(i), with section 701(h) of the Federal Food, Drug, and Cosmetic Act with respect to the licensure of a biological product under this subsection. Any such guidance may be general or specific.

"(B) Public comment.-

“(i) In GENERAL.-The Secretary shall provide the public an opportunity to comment on any proposed guidance issued under subparagraph (A) before issuing final guidance.

“(ii) InPUT REgarding MOST VALUABLE GUIDANCE.-The Secretary shall establish a process through which the public may provide the Secretary with input regarding priorities for issuing guidance. 
1541

"(C) NO REQUIREMENT FOR APPLICATION CONSIDERATION.-The issuance (or nonissuance) of guidance under subparagraph (A) shall not preclude the review of, or action on, an application submitted under this subsection.

"(D) REQUIREMENT FOR PRODUCT ClassSPECIFIC GUIDANCE.-If the Secretary issues product class-specific guidance under subparagraph (A), such guidance shall include a description of-

"(i) the criteria that the Secretary will use to determine whether a biological product is highly similar to a reference product in such product class; and

"(ii) the criteria, if available, that the Secretary will use to determine whether a biological product meets the standards described in paragraph (4).

“(E) Certain product classes.-

"(i) Guidance.-The Secretary may indicate in a guidance document that the science and experience, as of the date of such guidance, with respect to a product or product class (not including any recombinant protein) does not allow approval of 
an application for a license as provided under this subsection for such product or product class.

“(ii) Modification or Reversal.24 product.

The Secretary may issue a subsequent guidance document under subparagraph (A) to modify or reverse a guidance document under clause (i).

“(iii) No EFFECT ON ABILITY TO DENY LICENSE.-Clause (i) shall not be construed to require the Secretary to approve a product with respect to which the Secretary has not indicated in a guidance document that the science and experience, as described in clause (i), does not allow approval of such an application.

“(10) Naming.- - The Secretary shall ensure that the labeling and packaging of each biological product licensed under this subsection bears a name that uniquely identifies the biological product and distinguishes it from the reference product and any other biological products licensed under this subsection following evaluation against such reference 
1 “(l) Patent Notices; Relationship to Final Ap-

2 PROVAL.-

"(1) Definitions.-For the purposes of this subsection, the term-

“(A) 'biosimilar product' means the biological product that is the subject of the application under subsection $(\mathrm{k})$;

“(B) 'relevant patent' means a patent that-

"(i) expires after the date specified in subsection $(\mathrm{k})(7)(\mathrm{A})$ that applies to the reference product; and

"(ii) could reasonably be asserted against the applicant due to the unauthorized making, use, sale, or offer for sale within the United States, or the importation into the United States of the biosimilar product, or materials used in the manufacture of the biosimilar product, or due to a use of the biosimilar product in a method of treatment that is indicated in the application;

“(C) 'reference product sponsor' means the holder of an approved application or license for the reference product; and 
“(D) 'interested third party' means a person other than the reference product sponsor

11 in accordance with regulations promulgated by the

12 Secretary. The regulations shall require each such

13 individual to take reasonable steps to maintain the 14 confidentiality of information received pursuant to 15 this subsection and use the information solely for 16 purposes authorized by this subsection. The obliga17 tions imposed on an individual who has received con18 fidential information pursuant to this subsection 19 shall continue until the individual returns or de20 stroys the confidential information, a court imposes 21 a protective order that governs the use or handling 22 of the confidential information, or the party pro23 viding the confidential information agrees to other 24 terms or conditions regarding the handling or use of 25 the confidential information. 
“(3) Public NOTiCE BY SECRETARY.-Within

30 days of acceptance by the Secretary of an application filed under subsection $(\mathrm{k})$, the Secretary shall publish a notice identifying-

"(A) the reference product identified in the application; and

"(B) the name and address of an agent designated by the applicant to receive notices pursuant to paragraph (4)(B).

“(4) Exchanges concerning Patents.“(A) Exchanges With REFEREnCE PRODUCT SPONSOR.-

"(i) Within 30 days of the date of acceptance of the application by the Secretary, the applicant shall provide the reference product sponsor with a copy of the application and information concerning the biosimilar product and its production. This information shall include a detailed description of the biosimilar product, its method of manufacture, and the materials used in the manufacture of the product.

"(ii) Within 60 days of the date of receipt of the information required to be provided under clause (i), the reference prod- 
uct sponsor shall provide to the applicant a list of relevant patents owned by the reference product sponsor, or in respect of which the reference product sponsor has the right to commence an action of infringement or otherwise has an interest in the patent as such patent concerns the biosimilar product.

"(iii) If the reference product sponsor is issued or acquires an interest in a relevant patent after the date on which the reference product sponsor provides the list required by clause (ii) to the applicant, the reference product sponsor shall identify that patent to the applicant within 30 days of the date of issue of the patent, or the date of acquisition of the interest in the patent, as applicable.

“(B) EXCHANGES WITH INTERESTED THIRD PARTIES.-

"(i) At any time after the date on which the Secretary publishes a notice for an application under paragraph (3), any interested third party may provide notice to the designated agent of the applicant 
1547

that the interested third party owns or has rights under 1 or more patents that may be relevant patents. The notice shall identify at least 1 patent and shall designate an individual who has executed an agreement in accordance with paragraph (2) to receive confidential information from the applicant.

"(ii) Within 30 days of the date of receiving notice pursuant to clause (i), the applicant shall send to the individual designated by the interested third party the information specified in subparagraph (A)(i), unless the applicant and interested third party otherwise agree.

"(iii) Within 90 days of the date of receiving information pursuant to clause (ii), the interested third party shall provide to the applicant a list of relevant patents which the interested third party owns, or in respect of which the interested third party has the right to commence or participate in an action for infringement.

"(iv) If the interested third party is issued or acquires an interest in a relevant 
patent after the date on which the interested third party provides the list required by clause (iii), the interested third party shall identify that patent within 30 days of the date of issue of the patent, or the date of acquisition of the interest in the patent, as applicable.

"(C) Identification OF BASIS FOR INFRINGEMENT.-For any patent identified under clause (ii) or (iii) of subparagraph (A) or under clause (iii) or (iv) of subparagraph (B), the reference product sponsor or the interested third party, as applicable-

"(i) shall explain in writing why the sponsor or the interested third party believes the relevant patent would be infringed by the making, use, sale, or offer for sale within the United States, or importation into the United States, of the biosimilar product or by a use of the biosimilar product in treatment that is indicated in the application;

"(ii) may specify whether the relevant patent is available for licensing; and 
1549

"(iii) shall specify the number and date of expiration of the relevant patent. “(D) Certification by applicant conCERNING IDENTIFIED RELEVANT PATENTS.Not later than 45 days after the date on which a patent is identified under clause (ii) or (iii) of subparagraph (A) or under clause (iii) or (iv) of subparagraph (B), the applicant shall send a written statement regarding each identified patent to the party that identified the patent. Such statement shall either-

"(i) state that the applicant will not commence marketing of the biosimilar product and has requested the Secretary to not grant final approval of the application before the date of expiration of the noticed patent; or

"(ii) provide a detailed written explanation setting forth the reasons why the applicant believes-

"(I) the making, use, sale, or offer for sale within the United States, or the importation into the United States, of the biosimilar product, or the use of the biosimilar prod- 
1550

uct in a treatment indicated in the application, would not infringe the patent; or

"(II) the patent is invalid or unenforceable.

\section{“(5) ACTION FOR INFRINGEMENT INVOLVING} REFERENCE PRODUCT SPONSOR.-If an action for infringement concerning a relevant patent identified by the reference product sponsor under clause (ii) or (iii) of paragraph (4)(A), or by an interested third party under clause (iii) or (iv) of paragraph (4)(B), is brought within 60 days of the date of receipt of a statement under paragraph (4)(D)(ii), and the court in which such action has been commenced determines the patent is infringed prior to the date applicable under subsection $(\mathrm{k})(7)(\mathrm{A})$ or $(\mathrm{k})(8)$, the Secretary shall make approval of the application effective on the day after the date of expiration of the patent that has been found to be infringed. If more than one such patent is found to be infringed by the court, the approval of the application shall be made effective on the day after the date that the last such patent expires.

"(6) Notification of agreements.-

$$
\text { “(A) Requirements.- }
$$




\section{1}

"(i) Agreement Between BIOSIMILAR PRODUCT APPLICANT AND REFERENCE PRODUCT SPONSOR.-If a biosimilar product applicant under subsection (k) and the reference product sponsor enter into an agreement described in subparagraph (B), the applicant and sponsor shall each file the agreement in accordance with subparagraph (C).

"(ii) Agreement Between BIOSIMILAR PRODUCT APPLICANTS.-If 2 or more biosimilar product applicants submit an application under subsection (k) for biosimilar products with the same reference product and enter into an agreement described in subparagraph (B), the applicants shall each file the agreement in accordance with subparagraph (C).

"(B) Subject Matter of Agreement.An agreement described in this subparagraph"(i) is an agreement between the biosimilar product applicant under subsection (k) and the reference product sponsor or between 2 or more biosimilar product ap- 
1552

plicants under subsection $(\mathrm{k})$ regarding the manufacture, marketing, or sale of-

"(I) the biosimilar product (or biosimilar products) for which an application was submitted; or

"(II) the reference product;

“(ii) includes any agreement between the biosimilar product applicant under subsection $(\mathrm{k})$ and the reference product sponsor or between 2 or more biosimilar product applicants under subsection $(\mathrm{k})$ that is contingent upon, provides a contingent condition for, or otherwise relates to an agreement described in clause (i); and "(iii) excludes any agreement that solely concerns-

“(I) purchase orders for raw material supplies;

"(II) equipment and facility contracts;

“(III) employment or consulting contracts; or “(IV) packaging and labeling contracts. "(C) Filing.- - 
1553

"(i) In GENERAL.-The text of an agreement required to be filed by subparagraph (A) shall be filed with the Assistant Attorney General and the Federal Trade Commission not later than-

"(I) 10 business days after the date on which the agreement is executed; and

"(II) prior to the date of the first commercial marketing of, for agreements described in subparagraph (A)(i), the biosimilar product that is the subject of the application or, for agreements described in subparagraph (A)(ii), any biosimilar product that is the subject of an application described in such subparagraph.

“(ii) IF AGREEMENT NOT REDUCED TO TEXT.-If an agreement required to be filed by subparagraph (A) has not been reduced to text, the persons required to file the agreement shall each file written descriptions of the agreement that are sufficient to disclose all the terms and conditions of the agreement. 
1554

"(iii) Certification.-The chief executive officer or the company official responsible for negotiating any agreement required to be filed by subparagraph (A) shall include in any filing under this paragraph a certification as follows: 'I declare under penalty of perjury that the following is true and correct: The materials filed with the Federal Trade Commission and the Department of Justice under section 351(1)(6) of the Public Health Service Act, with respect to the agreement referenced in this certification: (1) represent the complete, final, and exclusive agreement between the parties; (2) include any ancillary agreements that are contingent upon, provide a contingent condition for, or are otherwise related to, the referenced agreement; and (3) include written descriptions of any oral agreements, representations, commitments, or promises between the parties that are responsive to such section and have not been reduced to writing.'.

“(D) Disclosure Exemption.-Any information or documentary material filed with 
the Assistant Attorney General or the Federal Trade Commission pursuant to this paragraph shall be exempt from disclosure under section 552 of title 5, United States Code, and no such information or documentary material may be

made public, except as may be relevant to any administrative or judicial action or proceeding. Nothing in this subparagraph prevents disclosure of information or documentary material to either body of the Congress or to any duly authorized committee or subcommittee of the Congress.

\section{"(E) EnForcement.-}

“(i) Civil Penalty.-Any person that violates a provision of this paragraph shall be liable for a civil penalty of not more than $\$ 11,000$ for each day on which the violation occurs. Such penalty may be recovered in a civil action-

"(I) brought by the United States; or "(II) brought by the Federal Trade Commission in accordance with the procedures established in section 
16(a)(1) of the Federal Trade Com-

mission Act.

"(ii) Compliance And Equitable RELIEF.-If any person violates any provision of this paragraph, the United States

"(i) may define the terms used in this paragraph;

“(ii) may exempt classes of persons or agreements from the requirements of this paragraph; and

"(iii) may prescribe such other rules as may be necessary and appropriate to carry out the purposes of this paragraph. 
"(G) Savings Clause.-Any action taken by the Assistant Attorney General or the Federal Trade Commission, or any failure of the Assistant Attorney General or the Commission to take action, under this paragraph shall not

(b) Definitions.-Section 351(i) of the Public

16 Health Service Act (42 U.S.C. 262(i)) is amended-

18 logical product' means" and inserting the following:

19 "In this section:

“(1) The term 'biological product' means";

(2) in paragraph (1), as so designated, by inserting "protein (except any chemically synthesized polypeptide)," after "allergenic product,"; and

(3) by adding at the end the following: 
“(2) The term 'biosimilar' or 'biosimilarity', in reference to a biological product that is the subject of an application under subsection $(\mathrm{k})$, means-

17 the intervention of the health care provider who pre18 scribed the reference product.

“(4) The term 'reference product' means the 20 single biological product licensed under subsection 21 (a) against which a biological product is evaluated in 22 an application submitted under subsection (k).".

23 (c) Products Previously Approved Under Sec24 TION 505.- 
(1) Requirement to FOLLOW SECTION 351.-

2 Except as provided in paragraph (2), an application 3 for a biological product shall be submitted under 4 section 351 of the Public Health Service Act (42 5 U.S.C. 262) (as amended by this Act).

6 (2) EXCEPTION.-An application for a biologi7 cal product may be submitted under section 505 of 8 the Federal Food, Drug, and Cosmetic Act (21 9 U.S.C. 355) if-

(ii) is submitted to the Secretary not later than the date that is 10 years after the date of enactment of this Act.

25 (2), an application for a biological product may not 
1 be submitted under section 505 of the Federal Food, 2 Drug, and Cosmetic Act (21 U.S.C. 355) if there is 3 another biological product approved under sub4 section (a) of section 351 of the Public Health Serv5 ice Act that could be a reference product with re6 spect to such application (within the meaning of 7 such section 351) if such application were submitted 8 under subsection (k) of such section 351.

(4) Deemed approved Under Section 351.-

10 An approved application for a biological product 11 under section 505 of the Federal Food, Drug, and 12 Cosmetic Act (21 U.S.C. 355) shall be deemed to be 13 a license for the biological product under such sec14 tion 351 on the date that is 10 years after the date 15 of enactment of this Act.

16 (5) Definitions.-For purposes of this sub17 section, the term "biological product" has the mean18 ing given such term under section 351 of the Public 19 Health Service Act (42 U.S.C. 262) (as amended by 20 this Act).

21 SEC. 2576. FEES RELATING TO BIOSIMILAR BIOLOGICAL 22 PRODUCTS.

23 Subparagraph (B) of section 735(1) of the Federal 24 Food, Drug, and Cosmetic Act (21 U.S.C. 379g(1)) is 25 amended by inserting “, including licensure of a biological 
1 product under section $351(\mathrm{k})$ of such Act" before the pe2 riod at the end.

3 SEC. 2577. AMENDMENTS TO CERTAIN PATENT PROVISIONS.

5 (a) Section 271(e)(2) of title 35, United States Code 6 is amended-

7

8 "patent,";

9

10 the comma at the end;

11

$12 \operatorname{graph}(\mathrm{B})$ :

13

14

15

16

17 (as added by paragraph (3)), by inserting before the

18 period the following: ", or if the statement described

19 in subparagraph (C) is provided in connection with

20 an application to obtain a license to engage in the 21 commercial manufacture, use, or sale of a biological

22 product claimed in a patent or the use of which is

23 claimed in a patent before the expiration of such 24 patent". 
1 (b) Section 271(e)(4) of title 35, United States Code,

2 is amended by striking "in paragraph (2)" in both places

3 it appears and inserting "in paragraph $(2)(\mathrm{A})$ or $(2)(\mathrm{B})$ ".

4 Subtitle D-Community Living

5 Assistance Services and Supports

6 SEC. 2581. ESTABLISHMENT OF NATIONAL VOLUNTARY IN-

SURANCE PROGRAM FOR PURCHASING COM-

MUNITY LIVING ASSISTANCE SERVICES AND

SUPPORT (CLASS PROGRAM).

10 (a) Establishment of CLass Program.-The

11 Public Health Service Act (42 U.S.C. 201 et seq.), as

12 amended by section 2301, is amended by adding at the

13 end the following:

“TITLE XXXII-COMMUNITY LIVING ASSISTANCE SERVICES AND SUPPORTS

17 "SEC. 3201. PURPOSE.

18 "The purpose of this title is to establish a national

19 voluntary insurance program for purchasing community

20 living assistance services and supports in order to-

“(1) provide individuals with functional limita-

22 tions with tools that will allow them to maintain

23 their personal and financial independence and live in

24 the community through a new financing strategy for

25 community living assistance services and supports; 
1563

"(2) establish an infrastructure that will help

2 address the Nation's community living assistance

3 services and supports needs;

4 “(3) alleviate burdens on family caregivers; and

5 “(4) address institutional bias by providing a fi-

6 nancing mechanism that supports personal choice

7 and independence to live in the community.

8 “SEC. 3202. DEFINITIONS.

$9 \quad$ "In this title:

10 “(1) Active EnRolleE.-The term 'active en11 rollee' means an individual who is enrolled in the 12 CLASS program in accordance with section 3204 13 and who has paid any premiums due to maintain 14 such enrollment.

15 “(2) Actively Employed.-The term 'actively 16 employed' means an individual who-

17 "(A) is reporting for work at the individ18 ual's usual place of employment or at another 19 location to which the individual is required to 20 travel because of the individual's employment 21 (or in the case of an individual who is a mem22 ber of the uniformed services, is on active duty 23 and is physically able to perform the duties of 24 the individual's position); and 
"(B) is able to perform all the usual and customary duties of the individual's employment on the individual's regular work schedule. “(3) Activities of Daily Living.-The term

5 'activities of daily living' has the meaning given the 6 term in section $7702 \mathrm{~B}(\mathrm{c})(2)(\mathrm{B})$ of the Internal Rev7 enue Code of 1986.

"(4) CLASS PROGRAM.-The term 'CLASS

9 program' means the program established under this 10 title.

“(5) Eligibility assessment system.-The 12 term 'Eligibility Assessment System' means the enti13 ty designated by the Secretary under section $14 \quad 3205(\mathrm{a})(2)(\mathrm{A})(\mathrm{i})$. “(6) Eligible Beneficiary.-

"(A) In GENERAL.—The term 'eligible beneficiary' means any individual who is an active enrollee in the CLASS program and, as of the date described in subparagraph (B) -

“(i) has paid premiums for enrollment in such program for at least 60 months; “(ii) has earned, for each calendar year that occurs during the first 60 months for which the individual has paid 25 premiums for enrollment in the program, 
1565

at least an amount equal to the amount of wages and self-employment income which an individual must have in order to be credited with a quarter of coverage under section 213(d) of the Social Security Act for that year; and "(iii) has paid premiums for enrollment in such program for at least 24 consecutive months, if a lapse in premium payments of more than 3 months has occurred during the period that begins on the date of the individual's enrollment and ends on the date of such determination.

“(B) DATE DESCRIBED.-For purposes of subparagraph (A), the date described in this subparagraph is the date on which the individual is determined to have a functional limitation described in section $3203(\mathrm{a})(1)(\mathrm{C})$ that is expected to last for a continuous period of more than 90 days.

“(C) Regulations.-The Secretary shall promulgate regulations specifying exceptions to the minimum earnings requirements under subparagraph (A)(ii) for purposes of being consid- 
1566

ered an eligible beneficiary for certain populations.

“(7) Hospital; NURsing FACILITY; INTERMEDLATE CARE FACILITY FOR THE MENTALLY RETARDED; INSTITUTION FOR MENTAL DISEASES.-

6 The terms 'hospital', 'nursing facility', 'intermediate 7 care facility for the mentally retarded', and 'institu8 tion for mental diseases' have the meanings given 9 such terms for purposes of Medicaid.

“(8) CLASS INDEPENDENCE ADVISORY COUN12 Council' or 'Council' means the Advisory Council es13 tablished under section 3207 to advise the Secretary. “(9) Cliass independence Benefit Plan.15 The term 'CLASS Independence Benefit Plan' 16 means the benefit plan developed and designated by 17 the Secretary in accordance with section 3203.

“(10) CLASS INDEPENDENCE FUND.-The 19 term 'CLASS Independence Fund' or 'Fund' means 20 the fund established under section 3206.

“(11) MedicaId.—The term 'Medicaid' means 22 the program established under title XIX of the So23 cial Security Act. “(12) Protection AND ADVOCACy system.25 The term 'Protection and Advocacy System' means 
1 the system for each State established under section

2143 of the Developmental Disabilities Assistance

3 and Bill of Rights Act of 2000.

4 “SEC. 3203. CLASS INDEPENDENCE BENEFIT PLAN.

5 “(a) Process for Development.-

6 “(1) IN GENERAL.-The Secretary, in consulta-

7 tion with appropriate actuaries and other experts,

8 shall develop at least 3 actuarially sound benefit

9 plans as alternatives for consideration for designa-

10 tion by the Secretary as the CLASS Independence

11 Benefit Plan under which eligible beneficiaries shall

12 receive benefits under this title. Each of the plan al-

13 ternatives developed shall be designed to provide eli-

14 gible beneficiaries with the benefits described in sec-

15 tion 3205 consistent with the following require-

16 ments:

17 "(A) Premiums.-Beginning with the first 18 year of the CLASS program, and for each year 19 thereafter, the Secretary shall establish all pre20 miums to be paid by enrollees for the year 21 based on an actuarial analysis of the 75-year 22 costs of the program that ensures solvency 23 throughout such 75-year period.

24 "(B) Vesting PERIOD.-A 5-year vesting 25 period for eligibility for benefits. 
"(C) Benefit Triggers. - A benefit trigger for provision of benefits that requires a determination that an individual has a functional limitation, as certified by a licensed health care practitioner, described in any of the following clauses that is expected to last for a continuous period of more than 90 days:

"(i) The individual is determined to be unable to perform at least the minimum number (which may be 2 or 3 ) of activities of daily living as are required under the plan for the provision of benefits without substantial assistance (as defined by the Secretary) from another individual.

"(ii) The individual requires substantial supervision to protect the individual from threats to health and safety due to substantial cognitive impairment. "(iii) The individual has a level of functional limitation similar (as determined under regulations prescribed by the Secretary) to the level of functional limitation described in clause (i) or (ii).

"(D) Cash Benefit.-Payment of a cash benefit that satisfies the following requirements: 
"(i) Minimum Required Amount.The benefit amount provides an eligible beneficiary with not less than an average of $\$ 50$ per day (as determined based on the reasonably expected distribution of beneficiaries receiving benefits at various benefit levels).

“(ii) Amount ScAled TO FUnCTIONAL ABILITY.- The benefit amount is varied based on a scale of functional ability, with not less than 2, and not more than 6 , benefit level amounts.

"(iii) DAILY OR WEEKLY.-The benefit is paid on a daily or weekly basis.

“(iv) No Lifetime OR AgGregate LIMIT.- The benefit is not subject to any lifetime or aggregate limit.

“(2) Review AND Recommendation By THE CLASS INDEPENDENCE ADVISORY COUNCIL.-The CLASS Independence Advisory Council shall-

"(A) evaluate the alternative benefit plans developed under paragraph (1); and "(B) recommend for designation as the CLASS Independence Benefit Plan for offering to the public the plan that the Council deter- 
mines best balances price and benefits to meet enrollees' needs in an actuarially sound manner, while optimizing the probability of the longterm sustainability of the CLASS program.

“(3) Designation by the secretary.-Not

6 later than October 1, 2012, the Secretary, taking 7 into consideration the recommendation of the 8 CLASS Independence Advisory Council under para9 graph (2)(B), shall designate a benefit plan as the 10 CLASS Independence Benefit Plan. The Secretary 11 shall publish such designation, along with details of 12 the plan and the reasons for the selection by the 13 Secretary, in a final rule that allows for a period of 14 public comment.

15 “(b) Additional Premium Requirements.-

"(A) In GENERAL.-Except as provided in subparagraphs (B), (C), (D), and (E), the amount of the monthly premium determined for an individual upon such individual's enrollment in the CLASS program shall remain the same for as long as the individual is an active enrollee in the program.

“(B) Recalculated PREmium IF REQUIRED FOR PROGRAM SOLVENCY.- 
"(i) In GENERAL.-Subject to clause (ii), if the Secretary determines, based on the most recent report of the Board of Trustees of the CLASS Independence Fund, the advice of the CLASS Independence Advisory Council, and the annual report of the Inspector General of the Department of Health and Human Services, and waste, fraud, and abuse, or such other information as the Secretary determines appropriate, that the monthly premiums and income to the CLASS Independence Fund for a year are projected to be insufficient with respect to the 20-year period that begins with that year, the Secretary shall adjust the monthly premiums for individuals enrolled in the CLASS program as necessary.

\section{"(ii) EXEMPTION FROM INCREASE.-} Any increase in a monthly premium imposed as result of a determination described in clause (i) shall not apply with respect to the monthly premium of any active enrollee who-

"(I) has attained age 65; 
"(II) has paid premiums for enrollment in the program for at least 20 years; and

"(III) is not actively employed.

\section{“(C) Recalculated PREmium IF RE-} ENROLLMENT AFTER MORE THAN A 3-MONTH LAPSE.-

"(i) IN GENERAL.-The reenrollment of an individual after a 90-day period during which the individual failed to pay the monthly premium required to maintain the individual's enrollment in the CLASS program shall be treated as an initial enrollment for purposes of age-adjusting the premium for enrollment in the program.

"(ii) CREDIT FOR PRIOR MONTHS IF REENROLLED WITHIN 5 YEARS.-An individual who reenrolls in the CLASS program after such a 90-day period and before the end of the 5-year period that begins with the first month for which the individual failed to pay the monthly premium required to maintain the individual's enrollment in the program shall be- 
"(I) credited with any months of paid premiums that accrued prior to the individual's lapse in enrollment; and

"(II) notwithstanding the total

“(D) Penalty For Reenrolliment amount of any such credited months, required to satisfy section 3202(6)(A)(ii) before being eligible to receive benefits.

AFTER 5-YEAR LAPSE.-In the case of an individual who reenrolls in the CLASS program after the end of the 5-year period described in subparagraph (C)(ii), the monthly premium required for the individual shall be the age-adjusted premium that would be applicable to an initially enrolling individual who is the same age as the reenrolling individual, increased by the greater of-

"(i) an amount that the Secretary determines is actuarially sound for each month that occurs during the period that begins with the first month for which the individual failed to pay the monthly premium required to maintain the individual's 
enrollment in the CLASS program and ends with the month preceding the month in which the reenrollment is effective; or

"(ii) 1 percent of the applicable ageadjusted premium for each such month occurring in such period.

“(2) Administrative EXPEnses.-In determining the monthly premiums for the CLASS program, the Secretary may factor in costs for administering the program, not to exceed-

"(A) in the case of the first 5 years in which the program is in effect under this title, an amount equal to 3 percent of all premiums paid during each such year; and

"(B) in the case of subsequent years, an amount equal to 5 percent of the total amount of all expenditures (including benefits paid) under this title with respect to that year.

“(3) No UNDERWRITING REQUIREMENTS.-No underwriting (other than on the basis of age in accordance with paragraph (2)) shall be used to-

"(A) determine the monthly premium for enrollment in the CLASS program; or “(B) prevent an individual from enrolling. in the program. 
1 “SEC. 3204. ENROLLMENT AND DISENROLLMENT REQUIRE-

2
MENTS. "(a) Automatic Enrolliment.“(1) IN GENERAL.—Subject to paragraph (2), the Secretary shall establish procedures under which each individual described in subsection (c) shall be automatically enrolled in the CLASS program by an employer of such individual under rules similar to the rules of sections $401(\mathrm{k})(13)$ and $414(\mathrm{w})$ of the Internal Revenue Code of 1986.

“(2) Alternative EnRolliment PROCEDURES._-The procedures established under paragraph (1) shall provide for an alternative enrollment process for an individual described in subsection (c) in the case of such an individual-

"(A) who is self-employed;

"(B) who has more than 1 employer;

"(C) whose employer does not elect to participate in the automatic enrollment process established by the Secretary; or

"(D) who is a spouse described in subsection $(c)(2)$ of who is not subject to automatic enrollment.

"(3) Administration.-

“(A) In GENERAL.—The Secretary shall, by regulation, establish procedures to- 
13 scribed in subsection (c) may elect to waive enrollment in

14 the CLASS program at any time in such form and manner 15 as the Secretary shall prescribe.

“(c) Individual Described.-For purposes of en17 rolling in the CLASS program, an individual described in 18 this paragraph is-

"(i) ensure that an individual is not "(ii) allow for an individual's employer to deduct a premium for a spouse described in subsection (c)(1)(B) who is not subject to automatic enrollment. "(B) ForM.-Enrollment in the CLASS program shall be made in such manner as the Secretary may prescribe in order to ensure ease of administration.

"(b) Election To Opt-Out.-An individual de"(1) an individual"(A) who has attained age 18; "(B) who receives wages on which there is imposed a tax under section 3101(a) or 3201(a) of the Internal Revenue Code of 1986;

"(C) who is actively employed; and

"(D) who is not- 
"(i) a patient in a hospital or nursing. facility, an intermediate care facility for the mentally retarded, or an institution for mental diseases and receiving medical assistance under Medicaid; or

“(ii) confined in a jail, prison, other

"(2) the spouse of an individual described in paragraph (1) and who would be an individual so de15 scribed but for subparagraph (B) or (C) of that 16 paragraph.

17 “(d) Rule of Construction.-Nothing in this title 18 shall be construed as requiring an active enrollee to con19 tinue to satisfy subparagraph (B) or (C) of subsection 20 (c)(1) in order to maintain enrollment in the CLASS pro21 gram. “(e) Payment.-

24 to the monthly premium for the enrollment in the 25 CLASS program of an individual shall be deducted 
1 from the wages of such individual in accordance with

2 such procedures as the Secretary shall establish for 3 employers who elect to deduct and withhold such

$4 \quad$ premiums on behalf of enrolled employees.

6 The Secretary shall establish alternative procedures

7 for the payment of monthly premiums by an indi-

8 vidual enrolled in the CLASS program who does not

9 have an employer who elects to deduct and withhold

10 premiums in accordance with subparagraph (A).

11 “(f) Transfer of Premiums Collected.-

12 “(1) In GENERAL._-During each calendar year 13 the Secretary of the Treasury shall deposit into the 14 CLASS Independence Fund a total amount equal, in 15 the aggregate, to 100 percent of the premiums col16 lected during that year.

17 “(2) Transfers Based on estimates.-The 18 amount deposited pursuant to paragraph (1) shall be 19 transferred in at least monthly payments to the 20 CLASS Independence Fund on the basis of esti21 mates by the Secretary and certified to the Sec22 retary of the Treasury of the amounts collected in 23 accordance with this section. Proper adjustments 24 shall be made in amounts subsequently transferred 
1 to the Fund to the extent prior estimates were in ex-

2 cess of, or were less than, actual amounts collected.

3 “ $(\mathrm{g})$ OTher EnRollment and Disenrollment

4 OppoRTunities.-The Secretary shall establish proce-

5 dures under which-

6 "(1) an individual who, in the year of the indi-

7 vidual's initial eligibility to enroll in the CLASS pro-

8 gram, has elected to waive enrollment in the pro-

9 gram, is eligible to elect to enroll in the program, in

10 such form and manner as the Secretary shall estab-

11 lish, only during an open enrollment period estab-

12 lished by the Secretary that is specific to the indi-

13 vidual and that may not occur more frequently than

14 biennially after the date on which the individual first

15 elected to waive enrollment in the program; and

16 "(2) an individual shall only be permitted to

17 disenroll from the program during an annual

18 disenrollment period established by the Secretary

19 and in such form and manner as the Secretary shall 20 establish.

21 "SEC. 3205. BENEFITS.

22 “(a) Determination of Eligibility.-

23 “(1) APPLICATION FOR RECEIPT OF BENE24 FITS.-The Secretary shall establish procedures 25 under which an active enrollee shall apply for receipt 
1 of benefits under the CLASS Independence Benefit 2 Plan.

“(2) Eligibility assessments.-

"(A) In GENERAL.-Not later than January 1, 2012, the Secretary shall-

"(i) designate an entity (other than a service with which the Commissioner of Social Security has entered into an agreement, with respect to any State, to make disability determinations for purposes of title II or XVI of the Social Security Act) to serve as an Eligibility Assessment System by providing for eligibility assessments of active enrollees who apply for receipt of benefits;

"(ii) enter into an agreement with the Protection and Advocacy System for each State to provide advocacy services in accordance with subsection (d); and

"(iii) enter into an agreement with public and private entities to provide advice and assistance counseling in accordance with subsection (e).

"(B) Regulations.-The Secretary shall promulgate regulations to develop an expedited 
nationally equitable eligibility determination process, as certified by a licensed health care practitioner, an appeals process, and a redetermination process, as certified by a licensed health care practitioner, including whether an applicant is eligible for a cash benefit under the

"(i) has applied for, and attests is eligible for, the maximum cash benefit available under the sliding scale established under the CLASS Independence Benefit Plan;

"(ii) is a patient in a hospital (but only if the hospitalization is for long-term care), nursing facility, intermediate care facility for the mentally retarded, or an institution for mental diseases; and 
1582

12 the following benefits under the CLASS Independence

13 Benefit Plan:

“(1) Cash Benefit.-A cash benefit estab-

15 lished by the Secretary in accordance with the re16 quirements of section 3203(a)(1)(D) that-

"(iii) is in the process of, or about to being the process of, planning to discharge from the hospital, facility, or institution, or within 60 days from the date of discharge from the hospital, facility, or institution.

"(D) APPEALs.- The Secretary shall establish procedures under which an applicant for benefits under the CLASS Independence Benefit Plan shall be guaranteed the right to appeal an adverse determination.

“(b) Benefits.-An eligible beneficiary shall receive "(A) the first year in which beneficiaries receive the benefits under the plan, is not less than the average dollar amount specified in clause (i) of such section; and

"(B) for any subsequent year, is not less than the average per day dollar limit applicable under this subparagraph for the preceding year, increased by the percentage increase in the con- 
sumer price index for all urban consumers

(U.S. city average) over the previous year.

“(2) Advocacy SERVICES.-Advocacy services

4 in accordance with subsection (d).

6 Advice and assistance counseling in accordance with

7 subsection (e).

“(4) Administrative expenses.-Advocacy

9 services and advise and assistance counseling serv-

10 ices under paragraphs (2) and (3) of this subsection

11 shall be included as administrative expenses under

12 section $3203(b)(2)$.

13 “(c) Payment of Benefits.-

“(1) Life IndePENDENCE ACCOUNT.-

"(A) IN GENERAL.-The Secretary shall establish procedures for administering the provision of benefits to eligible beneficiaries under the CLASS Independence Benefit Plan, including the payment of the cash benefit for the beneficiary into a Life Independence Account established by the Secretary on behalf of each eligible beneficiary.

"(B) Use of CASH Benefits.-Cash benefits paid into a Life Independence Account of an eligible beneficiary shall be used to purchase 
nonmedical services and supports that the beneficiary needs to maintain his or her independence at home or in another residential setting of their choice in the community, including (but not limited to) home modifications, assistive technology, accessible transportation, homemaker services, respite care, personal assistance services, home care aides, and nursing support. Nothing in the preceding sentence shall prevent an eligible beneficiary from using cash benefits paid into a Life Independence Account for obtaining assistance with decisionmaking concerning medical care, including the right to accept or refuse medical or surgical treatment and the right to formulate advance directives or other written instructions recognized under State law, such as a living will or durable power of attorney for health care, in the case that an injury or illness causes the individual to be unable to make health care decisions.

“(C) Electronic management of FUNDS.-The Secretary shall establish procedures for- 
"(i) crediting an account established

on behalf of a beneficiary with the bene-

ficiary's cash daily benefit;

“(ii) allowing the beneficiary to access

such account through debit cards; and

“(iii) accounting for withdrawals by the beneficiary from such account.

“(D) Primary payor Rules for BeneFICIARIES WHO ARE ENROLLED IN MEDICAID.In the case of an eligible beneficiary who is en-

rolled in Medicaid, the following payment rules shall apply:

"(i) Institutionalized BenEFICLARY.-If the beneficiary is a patient in a hospital, nursing facility, intermediate care facility for the mentally retarded, or an institution for mental diseases, the beneficiary shall retain an amount equal to 5 percent of the beneficiary's daily or weekly cash benefit (as applicable) (which shall be in addition to the amount of the beneficiary's personal needs allowance provided under Medicaid), and the remainder of such benefit shall be applied toward the facility's cost of providing the beneficiary's 
care, and Medicaid shall provide secondary

coverage for such care.

“(ii) Benefictaries RECEIVING

HOME AND COMMUNITY-BASED SERV-

\section{“(I) 50 PERCENT OF BENEFIT} RETAINED BY BENEFICIARY.- Subject to subclause (II), if a beneficiary is receiving medical assistance under Medicaid for home and communitybased services, the beneficiary shall retain an amount equal to 50 percent of the beneficiary's daily or weekly cash benefit (as applicable), and the remainder of the daily or weekly cash benefit shall be applied toward the cost to the State of providing such assistance (and shall not be used to claim Federal matching funds under Medicaid), and Medicaid shall provide secondary coverage for the remainder of any costs incurred in providing such assistance.

“(II) Requirement FOR state OFFSET.-A State shall be paid the 
remainder of a beneficiary's daily or weekly cash benefit under subclause (I) only if the State home and community-based waiver under section 1115 of the Social Security Act or subsection (c) or (d) of section 1915 of such Act, or the State plan amendment under subsection (i) of such section does not include a waiver of the requirements of section 1902(a)(1) of the Social Security Act (relating to statewideness) or of section 1902(a)(10)(B) of such Act (relating to comparability) and the State offers at a minimum case management services, personal care services, habilitation services, and respite care under such a waiver or State plan amendment.

“(III) Definition of home AND COMMUNITY-BASED SERVICES.-In this clause, the term 'home and community-based services' means any services which may be offered under a home and community-based waiver 
1588

authorized for a State under section 1115 of the Social Security Act or subsection (c) or (d) of section 1915 of such Act or under a State plan amendment under subsection (i) of such section.

“(iii) BenEFICLARIES ENROLLED IN PROGRAMS OF ALL-INCLUSIVE CARE FOR THE ELDERLY (PACE).-

“(I) IN GENERAL.-Subject to subclause (II), if a beneficiary is receiving medical assistance under Medicaid for PACE program services under section 1934 of the Social Security Act, the beneficiary shall retain an amount equal to 50 percent of the beneficiary's daily or weekly cash benefit (as applicable), and the remainder of the daily or weekly cash benefit shall be applied toward the cost to the State of providing such assistance (and shall not be used to claim Federal matching funds under Medicaid), and Medicaid shall provide secondary coverage for the remainder of any 
costs incurred in providing such assistance.

“(II) Institutionalized RECIPIENTS OF PACE PROGRAM SERVICES.-If a beneficiary receiving assistance under Medicaid for PACE program services is a patient in a hospital, nursing facility, intermediate care facility for the mentally retarded, or an institution for mental diseases, the beneficiary shall be treated as in institutionalized beneficiary under clause (i).

“(2) Authorized Representatives.-

"(A) IN GENERAL.-The Secretary shall establish procedures to allow access to a beneficiary's cash benefits by an authorized representative of the eligible beneficiary on whose behalf such benefits are paid.

“(B) Quality assurance AND PROTECTION AGAINST FRAUD AND ABUSE.-The procedures established under subparagraph (A) shall ensure that authorized representatives of eligible beneficiaries comply with standards of conduct established by the Secretary, including 
standards requiring that such representatives provide quality services on behalf of such beneficiaries, do not have conflicts of interest, and do not misuse benefits paid on behalf of such beneficiaries or otherwise engage in fraud or abuse.

“(3) Commencement of Benefits.-Benefits

8 shall be paid to, or on behalf of, an eligible bene9 ficiary beginning with the first month in which an 10 application for such benefits is approved. MENT.-An eligible beneficiary may elect to"(A) defer payment of their daily or weekly benefit and to rollover any such deferred benefits from month-to-month, but not from year-toyear; and

"(B) receive a lump-sum payment of such deferred benefits in an amount that may not exceed the lesser of-

"(i) the total amount of the accrued deferred benefits; or 24 BENEFITS.- 
“(A) In GENERAL.-The applicable period for determining with respect to an eligible beneficiary the applicable annual benefit and the amount of any accrued deferred benefits is the 12-month period that commences with the first

month in which the beneficiary began to receive such benefits, and each 12-month period thereafter.

"(B) Inclusion OF INCREASED BENEFITS.-The Secretary shall establish procedures under which cash benefits paid to an eligible beneficiary that increase or decrease as a result of a change in the functional status of the beneficiary before the end of a 12 -month benefit period shall be included in the determination of the applicable annual benefit paid to the eligible beneficiary.

“(C) Recoupment of UnPaid, ACCRued BENEFITS.-

"(i) In GENERAL.-The Secretary, in coordination with the Secretary of the Treasury, shall recoup any accrued benefits in the event of-

"(I) the death of a beneficiary; or 
"(II) the failure of a beneficiary

to elect under paragraph $(4)(B)$ to receive such benefits as a lump-sum payment before the end of the 12 month period in which such benefits accrued.

“(ii) Payment Into Class INDEPENDENCE FUND.-Any benefits recouped in accordance with clause (i) shall be paid into the CLASS Independence Fund and used in accordance with section 3206.

“(6) REQUiREMENT TO RECERTIFY ELIGIBILITY FOR RECEIPT OF BENEFITS.-An eligible beneficiary shall periodically, as determined by the Secretary"(A) recertify by submission of medical evidence the beneficiary's continued eligibility for receipt of benefits; and

"(B) submit records of expenditures attributable to the aggregate cash benefit received by the beneficiary during the preceding year. “(7) SupPlement, NOT SUPPlant OTHER HeALTH CARE BENEFits.-Subject to the Medicaid payment rules under paragraph (1)(D), benefits received by an eligible beneficiary shall supplement, but not supplant, other health care benefits for 
1 which the beneficiary is eligible under Medicaid or

2 any other Federally funded program that provides

3 health care benefits or assistance.

4 “(d) Advocacy SERvices.-An agreement entered 5 into under subsection (a)(2)(A)(ii) shall require the Pro6 tection and Advocacy System for the State to"(1) assign, as needed, an advocacy counselor

8 to each eligible beneficiary that is covered by such 9 agreement and who shall provide an eligible bene10 ficiary with-

"(A) information regarding how to access the appeals process established for the program; "(B) assistance with respect to the annual recertification and notification required under subsection $(c)(6)$; and "(C) such other assistance with obtaining 17 services as the Secretary, by regulation, shall 18 require; and "(2) ensure that the System and such coun20 selors comply with the requirements of subsection $21 \quad(h)$.

22 “(e) Advice and Assistance Counseling.-An 23 agreement entered into under subsection (a)(2)(A)(iii) 24 shall require the entity to assign, as requested by an eligi25 ble beneficiary that is covered by such agreement, an ad- 
1 vice and assistance counselor who shall provide an eligible

2 beneficiary with information regarding-

3

$4 \quad$ ices and supports in the most integrated setting;

6 services;

23 FITS.-Benefits paid to an eligible beneficiary under the 24 CLASS program shall be disregarded for purposes of de25 termining or continuing the beneficiary's eligibility for re- 
1 ceipt of benefits under any other Federal, State, or locally

2 funded assistance program, including benefits paid under

3 titles II, XVI, XVIII, XIX, or XXI of the Social Security

4 Act, under the laws administered by the Secretary of Vet-

5 erans Affairs, under low-income housing assistance pro-

6 grams, or under the supplemental nutrition assistance

7 program established under the Food and Nutrition Act of

82008.

9 “(g) Rule of Construction.-Nothing in this title

10 shall be construed as prohibiting benefits paid under the

11 CLASS Independence Benefit Plan from being used to

12 compensate a family caregiver for providing community

13 living assistance services and supports to an eligible bene-

14 ficiary.

15 “(h) Protection Against Conflicts of Inter-

16 EST.-The Secretary shall establish procedures to ensure

17 that the Eligibility Assessment System, the Protection and

18 Advocacy System for a State, advocacy counselors for eli-

19 gible beneficiaries, and any other entities that provide

20 services to active enrollees and eligible beneficiaries under

21 the CLASS program comply with the following:

22 "(1) If the entity provides counseling or plan-

23 ning services, such services are provided in a manner

24 that fosters the best interests of the active enrollee

25 or beneficiary. 
“(2) The entity has established operating proce-

2 dures that are designed to avoid or minimize con-

3 flicts of interest between the entity and an active en4 rollee or beneficiary.

5 “(3) The entity provides information about all 6 services and options available to the active enrollee 7 or beneficiary, to the best of its knowledge, including 8 services available through other entities or providers. 9 "(4) The entity assists the active enrollee or 10 beneficiary to access desired services, regardless of 11 the provider.

12 "(5) The entity reports the number of active 13 enrollees and beneficiaries provided with assistance 14 by age, disability, and whether such enrollees and 15 beneficiaries received services from the entity or an16 other entity.

17 "(6) If the entity provides counseling or plan18 ning services, the entity ensures that an active en19 rollee or beneficiary is informed of any financial in20 terest that the entity has in a service provider.

21 "(7) The entity provides an active enrollee or 22 beneficiary with a list of available service providers 23 that can meet the needs of the active enrollee or 24 beneficiary. 
1 “SEC. 3206. CLASS INDEPENDENCE FUND.

2 “(a) Establishment of CLASS Independence

3 Fund.-There is established in the Treasury of the

4 United States a trust fund to be known as the 'CLASS

5 Independence Fund'. The Secretary of the Treasury shall

6 serve as Managing Trustee of such Fund. The Fund shall

7 consist of all amounts derived from payments into the

8 Fund under sections 3204(f) and 3205(c)(5)(C)(ii), and

9 remaining after investment of such amounts under sub-

10 section (b), including additional amounts derived as in-

11 come from such investments. The amounts held in the

12 Fund are appropriated and shall remain available without

13 fiscal year limitation-

14 "(1) to be held for investment on behalf of indi-

15 viduals enrolled in the CLASS program;

16 "(2) to pay the administrative expenses related

17 to the Fund and to investment under subsection (b);

18 and

19 “(3) to pay cash benefits to eligible bene20 ficiaries under the CLASS Independence Benefit $21 \quad$ Plan.

22 "(b) Investment of Fund Balance.-The Sec23 retary of the Treasury shall invest and manage the 24 CLASS Independence Fund in the same manner, and to 25 the same extent, as the Federal Supplementary Medical 26 Insurance Trust Fund may be invested and managed 
1 under subsections (c), (d), and (e) of section 1841(d) of

2 the Social Security Act.

3 “(c) BoARd of Trustees.-

4 "(1) IN GENERAL.-With respect to the CLASS

5 Independence Fund, there is hereby created a body

6 to be known as the Board of Trustees of the CLASS

7 Independence Fund (hereinafter in this section re-

8 ferred to as the 'Board of Trustees') composed of

9 the Secretary of the Treasury, the Secretary of

10 Labor, and the Secretary of Health and Human

11 Services, all ex officio, and of two members of the

12 public (both of whom may not be from the same po-

13 litical party), who shall be nominated by the Presi-

14 dent for a term of 4 years and subject to confirma-

15 tion by the Senate. A member of the Board of

16 Trustees serving as a member of the public and

17 nominated and confirmed to fill a vacancy occurring

18 during a term shall be nominated and confirmed

19 only for the remainder of such term. An individual

20 nominated and confirmed as a member of the public

21 may serve in such position after the expiration of

22 such member's term until the earlier of the time at

23 which the member's successor takes office or the

24 time at which a report of the Board is first issued

25 under paragraph (2) after the expiration of the 
1599

1 member's term. The Secretary of the Treasury shall

2 be the Managing Trustee of the Board of Trustees.

3 The Board of Trustees shall meet not less frequently

4 than once each calendar year. A person serving on

5 the Board of Trustees shall not be considered to be

6 a fiduciary and shall not be personally liable for ac-

7 tions taken in such capacity with respect to the

8 Trust Fund.

9

10

11

12

13

14

15

16

17

18

19

20

21

22

23

24
“(2) Duties.-

"(A) IN GENERAL.- It shall be the duty of the Board of Trustees to do the following:

"(i) Hold the CLASS Independence Fund.

"(ii) Report to the Congress not later than the first day of April of each year on the operation and status of the CLASS Independence Fund during the preceding fiscal year and on its expected operation and status during the current fiscal year and the next 2 fiscal years.

"(iii) Report immediately to the Congress whenever the Board is of the opinion that the amount of the CLASS Independence Fund is not actuarially sound in re- 
gards to the projections under section $3203(b)(1)(B)(i)$.

"(iv) Review the general policies followed in managing the CLASS Independence Fund, and recommend changes in such policies, including necessary changes in the provisions of law which govern the way in which the CLASS Independence Fund is to be managed.

"(B) REPORT.-The report provided for in subparagraph (A)(ii) shall"(i) include"(I) a statement of the assets of, and the disbursements made from, the CLAASS Independence Fund during the preceding fiscal year;

"(II) an estimate of the expected income to, and disbursements to be made from, the CLASS Independence Fund during the current fiscal year and each of the next 2 fiscal years; "(III) a statement of the actuarial status of the CLASS Independence Fund for the current fiscal year, each of the next 2 fiscal years, and as 
1601

projected over the 75-year period beginning with the current fiscal year; and

"(IV) an actuarial opinion certifying that the techniques and methodologies used are generally accepted within the actuarial profession and that the assumptions and cost estimates used are reasonable; and “(ii) be printed as a House document of the session of the Congress to which the report is made.

"(C) Recommendations.-If the Board of Trustees determines that enrollment trends and expected future benefit claims on the CLASS Independence Fund are not actuarially sound in regards to the projections under section 3203(b)(1)(B)(i) and are unlikely to be resolved with reasonable premium increases or through other means, the Board of Trustees shall include in the report provided for in subparagraph (A)(ii) recommendations for such legislative action as the Board of Trustees determine to be appropriate, including whether to 
adjust monthly premiums or impose a temporary moratorium on new enrollments.

3 "SEC. 3207. CLASS INDEPENDENCE ADVISORY COUNCIL.

4 “(a) Establishment.-There is hereby created an

5 Advisory Committee to be known as the 'CLASS Inde6 pendence Advisory Council'.

“(1) In GENERAL.-The CLASS Independence Advisory Council shall be composed of not more

10 than 15 individuals, not otherwise in the employ of 11 the United Statesdent without regard to the civil service laws and regulations; and

"(B) a majority of whom shall be representatives of individuals who participate or are likely to participate in the CLASS program, and shall include representatives of older and younger workers, individuals with disabilities, family caregivers of individuals who require services and supports to maintain their independence at home or in another residential setting of their choice in the community, individuals with expertise in long-term care or disability insurance, actuarial science, economics, 
1603

19 Council shall advise the Secretary on matters of general 20 policy in the administration of the CLASS program estab21 lished under this title and in the formulation of regula22 tions under this title including with respect to"(1) the development of the CLASS Independ24 ence Benefit Plan under section 3203; and 
"(2) the determination of monthly premiums

2 under such plan.

3 “(d) Application of FACA.-The Federal Advisory

4 Committee Act, other than section 14 of that Act, shall

5 apply to the CLASS Independence Advisory Council.

6 “(e) Authorization of Appropriations.-

7 "(1) In GENERAL.-There are authorized to be

8 appropriated to the CLASS Independence Advisory

9 Council to carry out its duties under this section,

10 such sums as may be necessary for fiscal year 2011

11 and for each fiscal year thereafter.

12 “(2) Availability.-Any sums appropriated

13 under the authorization contained in this section

14 shall remain available, without fiscal year limitation,

15 until expended.

16 "SEC. 3208. REGULATIONS; ANNUAL REPORT.

17 “(a) Regulations.-The Secretary shall promulgate

18 such regulations as are necessary to carry out the CLASS

19 program in accordance with this title. Such regulations

20 shall include provisions to prevent fraud and abuse under

21 the program.

22 “(b) Annual Report.—Beginning January 1, 2014,

23 the Secretary shall submit an annual report to Congress

24 on the CLASS program. Each report shall include the fol25 lowing: 
1605

“(1) The total number of enrollees in the pro-

2 gram.

"(2) The total number of eligible beneficiaries

4 during the fiscal year.

“(3) The total amount of cash benefits provided

6 during the fiscal year.

"(4) A description of instances of fraud or

8 abuse identified during the fiscal year.

"(5) Recommendations for such administrative

10 or legislative action as the Secretary determines is

11 necessary to improve the program or to prevent the

12 occurrence of fraud or abuse.

\section{3 “SEC. 3209. INSPECTOR GENERAL'S REPORT.}

14 "The Inspector General of the Department of Health

15 and Human Services shall submit an annual report to the

16 Secretary and Congress relating to the overall progress of

17 the CLASS program and of the existence of waste, fraud,

18 and abuse in the CLASS program. Each such report shall

19 include findings in the following areas:

"(1) The eligibility determination process.

“(2) The provision of cash benefits.

"(3) Quality assurance and protection against

23 waste, fraud, and abuse. 
1606

1 (b) Conforming Amendments to Medicaid.-For

2 conforming provisions amending the Medicaid program, 3 see section 1739 .

$4 \quad$ Subtitle E-Miscellaneous

5 SEC. 2585. STATES FAILING TO ADHERE TO CERTAIN EMPLOYMENT OBLIGATIONS.

7 A State is eligible for Federal funds under the provi8 sions of the Public Health Service Act (42 U.S.C. 201 et 9 seq.) only if the State-

10 (1) agrees to be subject in its capacity as an 11 employer to each obligation under division $\mathrm{A}$ of this 12 Act and the amendments made by such division ap13 plicable to persons in their capacity as an employer; 14 and

15 (2) assures that all political subdivisions in the 16 State will do the same.

17 SEC. 2586. HEALTH CENTERS UNDER PUBLIC HEALTH 18 SERVICE ACT; LIABILITY PROTECTIONS FOR VOLUNTEER PRACTITIONERS.

20 (a) In General.-Section 224 (42 U.S.C. 233) is 21 amended-

(1) in subsection $(\mathrm{g})(1)(\mathrm{A})-$

(A) in the first sentence, by striking "or employee" and inserting "employee, or (subject 
to subsection $(\mathrm{k})(4)$ ) volunteer practitioner";

and

(B) in the second sentence, by inserting "and subsection (k)(4)" after "subject to paragraph (5)"; and

(2) in each of subsections $(\mathrm{g}),(\mathrm{i}),(\mathrm{j}),(\mathrm{l})$, and (m), by striking the term "employee, or contractor"

8 each place such term appears and inserting "em9 ployee, volunteer practitioner, or contractor';

10 (3) in subsection $(\mathrm{g})(1)(\mathrm{H})$, by striking the 11 term "employee, and contractor" each place such 12 term appears and inserting "employee, volunteer 13 practitioner, and contractor';

(4) in subsection (1), by striking the term "em15 ployee, or any contractor" and inserting "employee, 16 volunteer practitioner, or contractor'; and

17 (5) in subsections $(\mathrm{h})(3)$ and (k), by striking 18 the term "employees, or contractors" each place 19 such term appears and inserting "employees, volun20 teer practitioners, or contractors".

21 (b) Applicability; Definition.-Section 224(k) 22 (42 U.S.C. $233(\mathrm{k})$ ) is amended by adding at the end the 23 following paragraph:

24 "(4)(A) Subsections (g) through (m) apply with re25 spect to volunteer practitioners beginning with the first 
1 fiscal year for which an appropriations Act provides that

2 amounts in the fund under paragraph (2) are available 3 with respect to such practitioners.

4 “(B) For purposes of subsections (g) through (m),

5 the term 'volunteer practitioner' means a practitioner who,

6 with respect to an entity described in subsection $(\mathrm{g})(4)$,

7 meets the following conditions:

8 “(i) The practitioner is a licensed physician, a

9 licensed clinical psychologist, or other licensed or

10 certified health care practitioner.

11 "(ii) At the request of such entity, the practi-

12 tioner provides services to patients of the entity, at

13 a site at which the entity operates or at a site des-

14 ignated by the entity. The weekly number of hours

15 of services provided to the patients by the practi-

16 tioner is not a factor with respect to meeting condi-

17 tions under this subparagraph.

18 "(iii) The practitioner does not for the provision

19 of such services receive any compensation from such

20 patients, from the entity, or from third-party payors

21 (including reimbursement under any insurance pol-

22 icy or health plan, or under any Federal or State

23 health benefits program).". 
1 SEC. 2587. REPORT TO CONGRESS ON THE CURRENT STATE

\section{OF PARASITIC DISEASES THAT HAVE BEEN} OVERLOOKED AMONG THE POOREST AMERICANS.

$5 \quad$ Not later than 12 months after the date of the enact6 ment of this Act, the Secretary of Health and Human 7 Services shall report to Congress on the epidemiology of, 8 impact of, and appropriate funding required to address ne9 glected diseases of poverty, including neglected parasitic 10 diseases identified as Chagas disease, cysticercosis, 11 toxocariasis, toxoplasmosis, trichomoniasis, the soil-trans-

12 mitted helminths, and others. The report should provide 13 the information necessary to enhance health policy to ac14 curately evaluate and address the threat of these diseases.

15 SEC. 2588. OFFICE OF WOMEN'S HEALTH.

16 (a) Health and Human Services Office on

17 Women's Health.-

(1) Establishment.-Part A of title II (42

19 U.S.C. 202 et seq.) is amended by adding at the end 20 the following:

21 "SEC. 229. HEALTH AND HUMAN SERVICES OFFICE ON WOMEN'S HEALTH.

23 “(a) Establishment of OfFice.-There is estab24 lished within the Office of the Secretary, an Office on 25 Women's Health (referred to in this section as the 'Of26 fice'). The Office shall be headed by a Deputy Assistant 
1 Secretary for Women's Health who may report to the Sec-

2 retary.

3 "(b) DutiEs.-The Secretary, acting through the Of-

4 fice, with respect to the health concerns of women, shall-

$5 \quad$ "(1) establish short-range and long-range goals

6 and objectives within the Department of Health and

7 Human Services and, as relevant and appropriate,

8 coordinate with other appropriate offices on activi-

9 ties within the Department that relate to disease

10 prevention, health promotion, service delivery, re-

11 search, and public and health care professional edu-

12 cation, for issues of particular concern to women

13 throughout their lifespan;

14 "(2) provide expert advice and consultation to

15 the Secretary concerning scientific, legal, ethical,

16 and policy issues relating to women's health;

17 "(3) monitor the Department of Health and

18 Human Services' offices, agencies, and regional ac-

19 tivities regarding women's health and identify needs

20 regarding the coordination of activities, including in-

21 tramural and extramural multidisciplinary activities;

22 “(4) establish a Department of Health and

23 Human Services Coordinating Committee on Wom-

24 en's Health, which shall be chaired by the Deputy

25 Assistant Secretary for Women's Health and com- 
1 posed of senior level representatives from each of the

2 agencies and offices of the Department of Health

3 and Human Services;

4 “(5) establish a National Women's Health In-

5 formation Center to-

6 "(A) facilitate the exchange of information

7 regarding matters relating to health informa-

8 tion, health promotion, preventive health serv-

9 ices, research advances, and education in the

10 appropriate use of health care;

11 "(B) facilitate access to such information;

12 "(C) assist in the analysis of issues and

13 problems relating to the matters described in

14 this paragraph; and

15 "(D) provide technical assistance with re-

16 spect to the exchange of information (including

17 facilitating the development of materials for

18 such technical assistance);

19 “(6) coordinate efforts to promote women's

20 health programs and policies with the private sector;

21 and

22 “(7) through publications and any other means

23 appropriate, provide for the exchange of information

24 between the Office and recipients of grants, con-

25 tracts, and agreements under subsection (c), and be- 
1612

1 tween the Office and health professionals and the 2 general public.

3 “(c) Grants and Contracts Regarding Du4 TIES.-

5 “(1) AUTHORITY.-In carrying out subsection 6 (b), the Secretary may make grants to, and enter 7 into cooperative agreements, contracts, and inter8 agency agreements with, public and private entities, 9 agencies, and organizations.

10 “(2) Evaluation and Dissemination.-The 11 Secretary shall directly or through contracts with 12 public and private entities, agencies, and organiza13 tions, provide for evaluations of projects carried out 14 with financial assistance provided under paragraph 15 (1) and for the dissemination of information devel16 oped as a result of such projects.

17 “(d) REPORTS.-Not later than 1 year after the date 18 of enactment of this section, and every second year there19 after, the Secretary shall prepare and submit to the appro20 priate committees of Congress a report describing the ac21 tivities carried out under this section during the period 22 for which the report is being prepared.".

23 (2) Transfer OF FunCtions.-There are 24 transferred to the Office on Women's Health (estab25 lished under section 229 of the Public Health Serv- 
1 ice Act, as added by this section), all functions exer-

2 cised by the Office on Women's Health of the Public

3 Health Service prior to the date of enactment of this

4 section, including all personnel and compensation

5 authority, all delegation and assignment authority,

6 and all remaining appropriations. All orders, deter-

7 minations, rules, regulations, permits, agreements,

8 grants, contracts, certificates, licenses, registrations,

9 privileges, and other administrative actions that-

10 (A) have been issued, made, granted, or al-

11 lowed to become effective by the President, any

12 Federal agency or official thereof, or by a court

13 of competent jurisdiction, in the performance of

14 functions transferred under this paragraph; and

15 (B) are in effect at the time this section

16 takes effect, or were final before the date of en-

17 actment of this section and are to become effec-

18 tive on or after such date;

19 shall continue in effect according to their terms until

20 modified, terminated, superseded, set aside, or re-

21 voked in accordance with law by the President, the

22 Secretary, or other authorized official, a court of

23 competent jurisdiction, or by operation of law.

24 (b) Centers for Disease Control and Preven-

25 tion Office of Women's Health.-Part A of title III 
1 (42 U.S.C. 241 et seq.) is amended by adding at the end

2 the following:

3 "SEC. 310A. CENTERS FOR DISEASE CONTROL AND PREVENTION OFFICE OF WOMEN'S HEALTH.

5 “(a) Establishment.-There is established within 6 the Office of the Director of the Centers for Disease Con-

7 trol and Prevention, an office to be known as the Office

8 of Women's Health (referred to in this section as the 'Of-

9 fice'). The Office shall be headed by a director who shall

10 be appointed by the Director of such Centers.

11 "(b) Purpose.-The Director of the Office shall-

12 "(1) report to the Director of the Centers for

13 Disease Control and Prevention on the current level

14 of the Centers' activity regarding women's health

15 conditions across, where appropriate, age, biological,

16 and sociocultural contexts, in all aspects of the Cen-

17 ters' work, including prevention programs, public

18 and professional education, services, and treatment;

19 "(2) establish short-range and long-range goals

20 and objectives within the Centers for women's health

21 and, as relevant and appropriate, coordinate with

22 other appropriate offices on activities within the

23 Centers that relate to prevention, research, edu-

24 cation and training, service delivery, and policy de- 
1 velopment, for issues of particular concern to

2 women;

“(3) identify projects in women's health that

$4 \quad$ should be conducted or supported by the Centers;

5 “(4) consult with health professionals, non-

6 governmental organizations, consumer organizations,

7 women's health professionals, and other individuals

8 and groups, as appropriate, on the policy of the Cen-

9 ters with regard to women; and

10 "(5) serve as a member of the Department of

11 Health and Human Services Coordinating Com-

12 mittee on Women's Health (established under sec-

13 tion $229(b)(4))$.

14 “(c) Definition.-As used in this section, the term

15 'women's health conditions', with respect to women of all

16 age, ethnic, and racial groups, means diseases, disorders,

17 and conditions-

18 "(1) unique to, significantly more serious for,

19 or significantly more prevalent in women; and

20 "(2) for which the factors of medical risk or

21 type of medical intervention are different for women,

22 or for which there is reasonable evidence that indi-

23 cates that such factors or types may be different for 24 women.". 
1616

1 (c) Office of Women's Health Research.-Sec-

2 tion 486(a) (42 U.S.C. $287 \mathrm{~d}(\mathrm{a})$ ) is amended by inserting

3 "and who shall report directly to the Director" before the

4 period at the end thereof.

5 (d) Substance Abuse and Mental Health

6 Services Administration.-Section 501(f) (42 U.S.C.

7 290aa(f)) is amended-

8 (1) in paragraph (1), by inserting "who shall

9 report directly to the Administrator" before the pe-

10 riod;

11 (2) by redesignating paragraph (4) as para-

12 graph (5); and

13 (3) by inserting after paragraph (3), the fol-

14 lowing:

15 "(4) OFFICE.-Nothing in this subsection shall

16 be construed to preclude the Secretary from estab-

17 lishing within the Substance Abuse and Mental

18 Health Administration an Office of Women's 19 Health.”.

20 (e) Agency for Healthcare Research and 21 Quality Activities Regarding Women's Health.22 Part C of title IX (42 U.S.C. 299c et seq.) is amended23 (1) by redesignating sections 927 and 928 as $24 \quad$ sections 928 and 929 , respectively;

25 (2) by inserting after section 926 the following: 
1 “SEC. 927. ACTIVITIES REGARDING WOMEN'S HEALTH.

2 "(a) EstablishmEnT.-There is established within

3 the Office of the Director, an Office of Women's Health

4 and Gender-Based Research (referred to in this section

5 as the 'Office'). The Office shall be headed by a director

6 who shall be appointed by the Director of Healthcare and

7 Research Quality.

8 "(b) PurPose.-The official designated under sub-

9 section (a) shall-

10 "(1) report to the Director on the current

11 Agency level of activity regarding women's health,

12 across, where appropriate, age, biological, and

13 sociocultural contexts, in all aspects of Agency work,

14 including the development of evidence reports and

15 clinical practice protocols and the conduct of re-

16 search into patient outcomes, delivery of health care

17 services, quality of care, and access to health care;

18 "(2) establish short-range and long-range goals

19 and objectives within the Agency for research impor-

20 tant to women's health and, as relevant and appro-

21 priate, coordinate with other appropriate offices on

22 activities within the Agency that relate to health

23 services and medical effectiveness research, for

24 issues of particular concern to women;

25 "(3) identify projects in women's health that

26 should be conducted or supported by the Agency; 
1618

“(4) consult with health professionals, non-

2 governmental organizations, consumer organizations,

3 women's health professionals, and other individuals

4 and groups, as appropriate, on Agency policy with

5 regard to women; and

6 “(5) serve as a member of the Department of

7 Health and Human Services Coordinating Com-

8 mittee on Women's Health (established under sec-

$9 \quad \operatorname{tion} 229(\mathrm{~b})(4)) . '$; and

10 (3) by adding at the end of section 928 (as re-

11 designated by paragraph (1)) the following:

12 “(e) Women's HeALTH.-For the purpose of car-

13 rying out section 927 regarding women's health, there are

14 authorized to be appropriated such sums as may be nec-

15 essary for each of fiscal years 2011 through 2015.'.

16 (f) Health Resources And Services Adminis-

17 Tration OfFice of Women's Health.-Title VII of

18 the Social Security Act (42 U.S.C. 901 et seq.) is amended

19 by adding at the end the following:

20 “SEC. 713. OFFICE OF WOMEN'S HEALTH.

21 "(a) Establishment.-The Secretary shall estab-

22 lish within the Office of the Administrator of the Health

23 Resources and Services Administration, an office to be

24 known as the Office of Women's Health. The Office shall 
1 be headed by a director who shall be appointed by the Ad-

2 ministrator.

3 "(b) Purpose.-The Director of the Office shall-

4 "(1) report to the Administrator on the current

5 Administration level of activity regarding women's

6 health across, where appropriate, age, biological, and

$7 \quad$ sociocultural contexts;

$8 \quad$ “(2) establish short-range and long-range goals

9 and objectives within the Health Resources and

10 Services Administration for women's health and, as

11 relevant and appropriate, coordinate with other ap-

12 propriate offices on activities within the Administra-

13 tion that relate to health care provider training,

14 health service delivery, research, and demonstration

15 projects, for issues of particular eoncern to women;

16 “(3) identify projects in women's health that

17 should be conducted or supported by the bureaus of

18 the Administration;

19 "(4) consult with health professionals, non20 governmental organizations, consumer organizations, 21 women's health professionals, and other individuals 22 and groups, as appropriate, on Administration policy 23 with regard to women; and

24 "(5) serve as a member of the Department of 25 Health and Human Services Coordinating Com- 
1620

1 mittee on Women's Health (established under sec-

2 tion 229(b)(4) of the Public Health Service Act).

3 “(c) Continued Administration of Existing

4 Programs.- The Director of the Office shall assume the

5 authority for the development, implementation, adminis-

6 tration, and evaluation of any projects carried out through

7 the Health Resources and Services Administration relat-

8 ing to women's health on the date of enactment of this

9 section.

10 “(d) Definitions.-For purposes of this section:

11 “(1) Administration.-The term 'Administra-

12 tion' means the Health Resources and Services Ad-

13 ministration.

14 “(2) Administrator.-The term 'Adminis-

15 trator' means the Administrator of the Health Re-

16 sources and Services Administration.

17 “(3) OfFicE.-The term 'Office' means the Of-

18 fice of Women's Health established under this sec-

19 tion in the Administration.".

20 (g) Food and Drug Administration Office of 21 Women's Health.-Chapter IX of the Federal Food, 22 Drug, and Cosmetic Act (21 U.S.C. 391 et seq.) is amend23 ed by adding at the end the following: 
1 “SEC. 911. OFFICE OF WOMEN'S HEALTH.

2 "(a) EstABLISHMENT.-There is established within

3 the Office of the Commissioner, an office to be known as

4 the Office of Women's Health (referred to in this section

5 as the 'Office'). The Office shall be headed by a director

6 who shall be appointed by the Commissioner of Food and

7 Drugs.

8 "(b) Purpose._The Director of the Office shall-

9 "(1) report to the Commissioner of Food and

10 Drugs on current Food and Drug Administration

11 (referred to in this section as the 'Administration')

12 levels of activity regarding women's participation in

13 clinical trials and the analysis of data by sex in the

14 testing of drugs, medical devices, and biological

15 products across, where appropriate, age, biological,

16 and sociocultural contexts;

17 "(2) establish short-range and long-range goals

18 and objectives within the Administration for issues

19 of particular concern to women's health within the

20 jurisdiction of the Administration, including, where

21 relevant and appropriate, adequate inclusion of

22 women and analysis of data by sex in Administration

23 protocols and policies;

24 "(3) provide information to women and health

25 care providers on those areas in which differences

26 between men and women exist; 
1 "(4) consult with pharmaceutical, biologies, and

2 device manufacturers, health professionals with ex-

3 pertise in women's issues, consumer organizations,

4 and women's health professionals on Administration

5 policy with regard to women;

6 "(5) make annual estimates of funds needed to

7 monitor clinical trials and analysis of data by sex in

8 accordance with needs that are identified; and

9 “(6) serve as a member of the Department of

10 Health and Human Services Coordinating Com-

11 mittee on Women's Health (established under sec-

12 tion 229(b)(4) of the Public Health Service Act).".

13 (h) No New Regulatory Authority.-Nothing in

14 this section and the amendments made by this section may

15 be construed as establishing regulatory authority or modi-

16 fying any existing regulatory authority.

17 (i) Limitation on Termination.-Notwithstanding

18 any other provision of law, a Federal office of women's

19 health (including the Office of Research on Women's

20 Health of the National Institutes of Health) or Federal

21 appointive position with primary responsibility over wom-

22 en's health issues (including the Associate Administrator

23 for Women's Services under the Substance Abuse and

24 Mental Health Services Administration) that is in exist-

25 ence on the date of enactment of this section shall not 
1 be terminated, reorganized, or have any of its powers or

2 duties transferred unless such termination, reorganization, 3 or transfer is approved by an Act of Congress.

4 (j) Rule of Construction.-Nothing in this sec5 tion (or the amendments made by this section) shall be 6 construed to limit the authority of the Secretary of Health 7 and Human Services with respect to women's health, or 8 with respect to activities carried out through the Depart9 ment of Health and Human Services on the date of enact10 ment of this section.

11 SEC. 2589. LONG-TERM CARE AND FAMILY CAREGIVER SUPPORT.

13 (a) Amendments to the Older Americans ACt 14 OF $1965 .-$

(1) Promotion of Direct care WORK16 FORCE.-Section 202(b)(1) of the Older Americans 17 Act of 1965 (42 U.S.C. 3012(b)(1)) is amended by 18 inserting before the semicolon the following: ", and, 19 in carrying out the purposes of this paragraph, shall 20 make recommendations to other Federal entities re21 garding appropriate and effective means of identi22 fying, promoting, and implementing investments in 23 the direct care workforce necessary to meet the 24 growing demand for long-term health services and 25 supports and of assisting States in developing a 
1 comprehensive State workforce development plan

2 with respect to such workforce, including assisting

3 efforts to systematically assess, track, and report on

$4 \quad$ workforce adequacy and capacity".

5 (2) Personal care attendant workforce

6 ADVISORY PANEL.-Section 202 of such Act (42

7 U.S.C. 3012) is amended by adding at the end the

8 following:

9 " $(\mathrm{g})(1)$ Not later than 90 days after the date of the

10 enactment of this subsection, the Assistant Secretary shall

11 establish a Personal Care Attendant Workforce Advisory

12 Panel to examine and formulate recommendations on-

13 "(A) working conditions and training for work-

14 ers providing long-term services and supports, in-

15 cluding home health aides, certified nurse aides, and

16 personal care attendants; and

17 "(B) other workforce issues related to such

18 workers, including with respect to the adequacy of

19 the number of such workers; the salaries, wages, and

20 benefits of such workers; and access to the services

21 provided by such workers.

22 “(2) The Panel shall include representatives of-

23 “(A) relevant home- and community-based serv-

24 ice providers, health care agencies, and facilities (in-

25 cluding personal or home care agencies, home health 
1 care agencies, nursing homes, assisted living facili-

2 ties, and residential care facilities);

"(B) the disability community, including indi-

4 viduals with disabilities and family caregivers;

$5 \quad$ "(C) the nursing community;

6 "(D) direct care workers (which may include

7 unions and national organizations);

8 "(E) older individuals, including senior individ-

9 uals and family caregivers;

10 "(F) State and Federal health care entities;

11 and

12 " $(\mathrm{G})$ experts in workforce development and 13 adult learning.

14 “(3) Within one year after the establishment of the 15 Panel, the Panel shall submit a report to the Assistant 16 Secretary and the Congress on workforce issues related 17 to providing long-term services and supports, including in18 formation on core competencies for eligible personal or 19 home care aides necessary to successfully provide long20 term services and supports to eligible consumers, as well 21 as recommended training curricula and resources.

22 "(4) Within 180 days after receipt by the Assistant 23 Secretary of the report under paragraph (3), the Assistant 24 Secretary shall establish a 3-year demonstration program 25 in 4 States to pilot and evaluate the effectiveness of the 
1 competencies articulated by the Panel and the training

2 curricula and training methods recommended by the

3 Panel.

4 "(5) Not later than 1 year after the completion of

5 the demonstration program under paragraph (4), the As-

6 sistant Secretary shall submit to the Congress a report

7 containing the results of the evaluations by the Assistant

8 Secretary pursuant to paragraph (4), together with such

9 recommendations for legislation or administrative action

10 as the Assistant Secretary determines appropriate.".

11 (b) Authorization of AdDitional Appropria-

12 tions for the Family Caregiver Support Program

13 Under the Older Americans ACt of 1965.- Section

$14303(\mathrm{e})(2)$ of the Older Americans Act of 1965 (42 U.S.C.

$153023(\mathrm{e})(2))$ is amended by striking “, $\$ 173,000,000$ ” and

16 all that follows through "2011", and inserting "and

$17 \$ 250,000,000$ for each of fiscal years 2011, 2012, and 18 2013".

19 SEC. 2590. WEB SITE ON HEALTH CARE LABOR MARKET AND RELATED EDUCATIONAL AND TRAINING OPPORTUNITIES.

22 (a) In GEnERAL.-The Secretary of Labor, in con23 sultation with the National Center for Health Workforce 24 Analysis, shall establish and maintain a Web site to serve 25 as a comprehensive source of information, searchable by 
1627

1 workforce region, on the health care labor market and re-

2 lated educational and training opportunities.

3 (b) Contents.-The Web site maintained under this

4 section shall include the following:

5

6 currently or are projected to be in high demand in

7 the health care field, including-

8

9

10

11

12

13

14

15

16

17

18

19

20

21

22

23

24

25

(A) salary information; and

(B) training requirements, such as requirements for educational credentials, licensure, or certification.

(2) Information on training and educational opportunities within each region for the type of jobs described in paragraph (1), including by-

(A) type of provider or program (such as public, private nonprofit, or private for-profit);

(B) duration;

(C) cost (such as tuition, fees, books, laboratory expenses, and other mandatory costs);

(D) performance outcomes (such as graduation rates, job placement, average salary, job retention, and wage progression);

(E) Federal financial aid participation;

(F) average graduate loan debt;

(G) student loan default rates; 
(H) average institutional grant aid provided;

(I) Federal and State accreditation information; and

(J) other information determined by the Secretary.

8 training and educational options for specific health 9 care occupations to facilitate informed career and 10 education choices.

11 (4) Financial aid information, including with 12 respect to loan forgiveness, loan cancellation, loan 13 repayment, stipends, scholarships, and grants or 14 other assistance authorized by this Act or other Fed15 eral or State programs.

16 (c) Public Accessibility.-The Web site main17 tained under this section shall-

$18 \quad$ (1) be publicly accessible;

19 (2) be user friendly and convey information in 20 a manner that is easily understandable; and

21 (3) be in English and the second most prevalent 22 language spoken based on the latest Census informa23 tion. 
1 SEC. 2591. ONLINE HEALTH WORKFORCE TRAINING PRO-

3 Section 171 of the Workforce Investment Act of 1998

4 (29 U.S.C. 2916) is amended by adding at the end the 5 following:
"(1) Grant PROGRAM.-

"(A) In GENERAL. - The Secretary in consultation with the Secretary of Health and Human Services, shall award National Health Workforce Online Training Grants on a competitive basis to eligible entities to enable such entities to carry out training for individuals to attain or advance in health care occupations. An entity may leverage such grant with other Federal, State, local, and private resources, in order to expand the participation of businesses, employees, and individuals in such training programs.

"(B) Eligibility.-In order to receive a grant under the program established under this paragraph-

"(i) an entity shall be an educational institution, community-based organization, nonprofit organization, workforce invest- 
ment board, or local or county government;

and

"(ii) an entity shall provide online

workforce training for individuals seeking

to attain or advance in health care occupations, including nursing, nursing assistants, dentistry, pharmacy, health care management and administration, public health, health information systems analysis, medical assistants, and other health care practitioner and support occupations. "(C) PrIORITY.-Priority in awarding grants under this paragraph shall be given to entities that-

"(i) have demonstrated experience in implementing and operating online worker skills training and education programs;

"(ii) have demonstrated experience coordinating activities, where appropriate, with the workforce investment system; and "(iii) conduct training for occupations with national or local shortages.

“(D) Data collection.-Grantees under this paragraph shall collect and report information on- 
1631

"(i) the number of participants;

"(ii) the services received by the participants;

“(iii) program completion rates;

"(iv) factors determined as significantly interfering with program participation or completion;

"(v) the rate of job placement; and

"(vi) other information as determined as needed by the Secretary.

"(E) OUTREACH._-Grantees under this paragraph shall conduct outreach activities to disseminate information about their program and results to workforce investment boards, local governments, educational institutions, and other workforce training organizations.

"(F) Performance Levels.-The Secretary shall establish indicators of performance that will be used to evaluate the performance of grantees under this paragraph in carrying out the activities described in this paragraph. The Secretary shall negotiate and reach agreement with each grantee regarding the levels of performance expected to be achieved by the grantee on the indicators of performance. 
1632

\section{"(G) AUthorization OF APPROPRIA-} TIONS.-There are authorized to be appropriated to the Secretary to carry out this subsection $\$ 50,000,000$ for fiscal years 2011 through 2020.

"(2) Online health PROFEssions training PROGRAM CLEARINGHOUSE.-

"(A) Description of GRANT.-The Secretary may award one or more grants to eligible postsecondary educational institutions to provide the services described in this paragraph.

"(B) Eligibility.-To be eligible to receive a grant under this paragraph, a postsecondary educational institution shall-

"(i) have demonstrated the ability to disseminate research on best practices for implementing workforce investment programs; and "(ii) be a national leader in producing cutting-edge research on technology related to workforce investment systems under subtitle B.

"(C) Services.-The postsecondary educational institution that receives a grant under this paragraph shall use such grant- 
1633

18791 et seq.) is amended by adding at the end of the fol19 lowing:

20 "SEC. 510. STANDARDS FOR ACCESSIBILITY OF MEDICAL 21

22 “(a) STANDARDS.-Not later than 9 months after the 23 date of enactment of the Affordable Health Care for 24 America Act, the Architectural and Transportation Bar25 riers Compliance Board (Access Board) shall issue guide- 
1 lines setting forth the minimum technical criteria for new

2 medical diagnostic equipment to be purchased for use in

3 (or in conjunction with) physician's offices, clinics, emer-

4 gency rooms, hospitals, and other medical settings. The

5 guidelines shall ensure that such equipment is accessible

6 to, and usable by, individuals with disabilities, including

7 provisions to ensure independent entry to, use of, and exit

8 from the equipment by such individuals to the maximum

9 extent possible.

10 “(b) Medical Diagnostic Equipment Cov-

11 ERED.-The guidelines issued under subsection (a) for

12 medical diagnostic equipment shall apply to new purchases

13 of equipment that includes examination tables, examina-

14 tion chairs (including chairs used for eye examinations or

15 procedures, and dental examinations or procedures),

16 weight scales, mammography equipment, x-ray machines,

17 and other equipment commonly used for diagnostic or ex-

18 amination purposes by health professionals.

19 "(c) Regulations.-Not later than 6 months after

20 the date of the issuance of the guidelines under subsection

21 (a), each appropriate Federal agency authorized to pro-

22 mulgate regulations under this Act or under the Ameri-

23 cans with Disabilities Act shall-

24 “(1) prescribe regulations in an accessible for25 mat as necessary to carry out the provisions of such 
1635

1 Act and section 504 of this Act that include accessi-

2 bility standards that are consistent with the guide-

3 lines issued under subsection (a); and

4 “(2) ensure that health care providers and

5 health care plans covered by the Affordable Health

6 Care for America Act meet the requirements of the

7 Americans with Disabilities Act and section 504, in-

8 cluding provisions ensuring that individuals with dis-

9 abilities receive equal access to all aspects of the

10 health care delivery system.

11 “(d) Review AND Amend.-The Architectural and

12 Transportation Barriers Compliance Board (Access

13 Board) shall periodically review and, as appropriate,

14 amend the guidelines as prescribed under subsection (a).

15 Not later than 6 months after the date of the issuance

16 of such revised guidelines, revised regulations consistent

17 with such guidelines shall be promulgated in an accessible

18 format by the appropriate Federal agencies described in

19 subsection (c).".

20 DIVISION D-INDIAN HEALTH

21 CARE IMPROVEMENT

22 SEC. 3001. SHORT TITLE; TABLE OF CONTENTS.

23 (a) SHort Tithe.-This division may be cited as the

24 "Indian Health Care Improvement Act Amendments of 25 2009". 
2 this division is as follows:

DIVISION D-INDIAN HEALTH CARE IMPROVEMENT

Sec. 3001. Short title; table of contents.

TITLE I-AMENDMENTS TO INDLAN LAWS

Sec. 3101. Indian Health Care Improvement At amended.

Sec. 3102. Soboba sanitation facilities.

Sec. 3103. Native American Health and Wellness Foundation.

Sec. 3104. GAO study and report on payments for contract health services.

TITLE II-IMPROVEMENT OF INDIAN HEALTH CARE PROVIDED UNDER THE SOCIAL SECURITY ACT

Sec. 3201. Expansion of payments under Medicare, Medicaid, and SCHIP for all covered services furnished by Indian Health Programs.

Sec. 3202. Additional provisions to increase outreach to, and enrollment of, Indians in SCHIP and Medicaid.

Sec. 3203. Solicitation of proposals for safe harbors under the Social Security Act for facilities of Indian Health Programs and urban Indian organizations.

Sec. 3204. Annual report on Indians served by Social Security Act health benefit programs.

Sec. 3205. Development of recommendations to improve interstate coordination of Medicaid and SCHIP coverage of Indian children and other children who are outside of their State of residency because of educational or other needs. INDIAN LAWS

5 SEC. 3101. INDIAN HEALTH CARE IMPROVEMENT AMEND-

ED.

(a) In GeneraL.-The Indian Health Care Improve-

8 ment Act (25 U.S.C. 1601 et seq.) is amended to read 9 as follows:

10 “SECTION 1. SHORT TITLE; TABLE OF CONTENTS.

11 “(a) Short Title.-This Act may be cited as the 12 'Indian Health Care Improvement Act'. 


\section{7}

\section{1 “(b) Table of Contents.-The table of contents}

\section{2 for this Act is as follows:}

"Sec. 1. Short title; table of contents.

"Sec. 2. Findings.

"Sec. 3. Declaration of national Indian health policy.

"Sec. 4. Definitions.

\section{“TITLE I-INDLAN HEALTH, HUMAN RESOURCES, AND DEVELOPMEN'T}

"Sec. 101. Purpose.

"Sec. 102. Health professions recruitment program for Indians.

"Sec. 103. Health professions preparatory scholarship program for Indians.

"Sec. 104. Indian health professions scholarships.

"Sec. 105. American Indians Into Psychology Program.

"Sec. 106. Scholarship programs for Indian Tribes.

"Sec. 107. Indian Health Service extern programs.

"Sec. 108. Continuing education allowances.

"Sec. 109. Community Health Representative Program.

"Sec. 110. Indian Health Service Loan Repayment Program.

"Sec. 111. Scholarship and Loan Repayment Recovery Fund.

"Sec. 112. Recruitment activities.

"Sec. 113. Indian recruitment and retention program.

"Sec. 114. Advanced training and research.

"Sec. 115. Quentin N. Burdick American Indians Into Nursing Program.

"Sec. 116. Tribal cultural orientation.

"Sec. 117. INMED Program.

"Sec. 118. Health training programs of community colleges.

"Sec. 119. Retention bonus.

"Sec. 120. Nursing residency program.

"Sec. 121. Community Health Aide Program.

"Sec. 122. Tribal Health Program administration.

"Sec. 123. Health professional chronic shortage demonstration programs.

"Sec. 124. National Health Service Corps.

"Sec. 125. Substance abuse counselor educational curricula demonstration programs.

"Sec. 126. Behavioral health training and community education programs.

"Sec. 127. Exemption from payment of certain fees.

"Sec. 128. Authorization of appropriations.

\section{"TITLE II-HEALTH SERVICES}

"Sec. 201. Indian Health Care Improvement Fund.

"Sec. 202. Health promotion and disease prevention services.

"Sec. 203. Diabetes prevention, treatment, and control.

"Sec. 204. Shared services for long-term care.

"Sec. 205. Health services research.

"Sec. 206. Mammography and other cancer screening.

"Sec. 207. Patient travel costs.

"Sec. 208. Epidemiology centers.

"Sec. 209. Comprehensive school health education programs.

"Sec. 210. Indian youth program.

"Sec. 211. Prevention, control, and elimination of communicable and infectious diseases. 


\section{8}

"Sec. 212. Other authority for provision of services.

"Sec. 213. Indian women's health care.

"Sec. 214. Environmental and nuclear health hazards.

"Sec. 215. Arizona as a contract health service delivery area.

"Sec. 216. North Dakota and South Dakota as contract health service delivery area.

"Sec. 217. California contract health services program.

"Sec. 218. California as a contract health service delivery area.

"Sec. 219. Contract health services for the Trenton Service Area.

"Sec. 220. Programs operated by Indian Tribes and tribal organizations.

"Sec. 221. Licensing.

"Sec. 222. Notification of provision of emergency contract health services.

"Sec. 223. Prompt action on payment of claims.

"Sec. 224. Liability for payment.

"Sec. 225. Office of Indian Men's Health.

"Sec. 226. Catastrophic health emergency fund.

"Sec. 227. Authorization of appropriations.

\section{"TITLE III-FACILITIES}

"Sec. 301. Consultation; construction and renovation of facilities; reports.

"Sec. 302. Sanitation facilities.

"Sec. 303. Preference to Indians and Indian firms.

"Sec. 304. Expenditure of non-Service funds for renovation.

"Sec. 305. Funding for the construction, expansion, and modernization of small ambulatory care facilities.

"Sec. 306. Indian health care delivery demonstration project.

"Sec. 307. Land transfer.

"Sec. 308. Leases, contracts, and other agreements.

"Sec. 309. Study on loans, loan guarantees, and loan repayment.

"Sec. 310. Tribal leasing.

"Sec. 311. Indian Health Service/tribal facilities joint venture program.

"Sec. 312. Location of facilities.

"Sec. 313. Maintenance and improvement of health care facilities.

"Sec. 314. Tribal management of federally owned quarters.

"Sec. 315. Applicability of Buy American Act requirement.

"Sec. 316. Other funding for facilities.

"Sec. 317. Authorization of appropriations.

\section{"TITLE IV-ACCESS TO HEALTH SERVICES}

"Sec. 401. Treatment of payments under Social Security Act health benefits programs.

"Sec. 402. Grants to and contracts with the Service, Indian Tribes, Tribal Organizations, and urban Indian organizations to facilitate outreach, enrollment, and coverage of Indians under Social Security Act health benefit programs.

"Sec. 403. Reimbursement from certain third parties of costs of health services.

"Sec. 404. Crediting of reimbursements.

"Sec. 405. Purchasing health care coverage.

"Sec. 406. Sharing arrangements with Federal agencies.

"Sec. 407. Eligible indian veteran services.

"Sec. 408. Payor of last resort.

"Sec. 409. Consultation.

"Sec. 410. State Children's Health Insurance Program (SCHIP). 


\section{9}

"Sec. 411. Premium and cost sharing protections and eligibility determinations under Medicaid and SCHIP and protection of certain Indian property from Medicaid estate recovery.

"Sec. 412. Treatment under Medicaid and SCHIP managed care.

"Sec. 413. Navajo Nation Medicaid Agency feasibility study.

"Sec. 414. Exception for excepted benefits.

"Sec. 415. Authorization of appropriations.

“TITLE V-HEALTH SERVICES FOR URBAN INDIANS

"Sec. 501. Purpose.

"Sec. 502. Contracts with, and grants to, urban Indian organizations.

"Sec. 503. Contracts and grants for the provision of health care and referral services.

"Sec. 504. Use of Federal Government Facilities and Sources of Supply.

"Sec. 505. Contracts and grants for the determination of unmet health care needs.

"Sec. 506. Evaluations; renewals.

"Sec. 507. Other contract and grant requirements.

"Sec. 508. Reports and records.

"Sec. 509. Limitation on contract authority.

"Sec. 510. Facilities.

"Sec. 511. Division of Urban Indian Health.

"Sec. 512. Grants for alcohol and substance abuse-related services.

"Sec. 513. Treatment of certain demonstration projects.

"Sec. 514. Urban NIAAA transferred programs.

"Sec. 515. Conferring with urban Indian organizations.

"Sec. 516. Urban youth treatment center demonstration.

"Sec. 517. Grants for diabetes prevention, treatment, and control.

"Sec. 518. Community health representatives.

"Sec. 519. Effective date.

"Sec. 520. Eligibility for services.

"Sec. 521. Authorization of appropriations.

"Sec. 522. Health information technology.

"TITLE VI-ORGANIZATIONAL IMPROVEMENTS

"Sec. 601. Establishment of the Indian Health Service as an agency of the Public Health Service.

"Sec. 602. Automated management information system.

"Sec. 603. Authorization of appropriations.

\section{"TITLE VII-BEHAVIORAL HEALTH PROGRAMS}

"Sec. 701. Behavioral health prevention and treatment services.

"Sec. 702. Memoranda of agreement with the Department of the Interior.

"Sec. 703. Comprehensive behavioral health prevention and treatment program.

"Sec. 704. Mental health technician program.

"Sec. 705. Licensing requirement for mental health care workers.

"Sec. 706. Indian women treatment programs.

"Sec. 707. Indian youth program.

"Sec. 708. Indian youth telemental health demonstration project.

"Sec. 709. Inpatient and community-based mental health facilities design, construction, and staffing.

"Sec. 710. Training and community education.

"Sec. 711. Behavioral health program. 
"Sec. 712. Fetal alcohol disorder programs.

"Sec. 713. Child sexual abuse and prevention treatment programs.

"Sec. 714. Domestic and sexual violence prevention and treatment.

"Sec. 715. Behavioral health research.

"Sec. 716. Definitions.

"Sec. 717. Authorization of appropriations.

$$
\text { “TITLE VIII-MISCELLANEOUS }
$$

"Sec. 801. Reports.

"Sec. 802. Regulations.

"Sec. 803. Plan of implementation.

"Sec. 804. Limitation on use of funds appropriated to Indian Health Service.

"Sec. 805. Eligibility of California Indians.

"Sec. 806. Health services for ineligible persons.

"Sec. 807. Reallocation of base resources.

"Sec. 808. Results of demonstration projects.

"Sec. 809. Provision of services in Montana.

"Sec. 810. Moratorium.

"Sec. 811. Severability provisions.

"Sec. 812. Use of patient safety organizations.

"Sec. 813. Confidentiality of medical quality assurance records; qualified immunity for participants.

"Sec. 814. Claremore Indian Hospital.

"Sec. 815. Sense of Congress regarding law enforcement and methamphetamine issues in Indian country.

"Sec. 816. Permitting implementation through contracts with Tribal Health Programs.

"Sec. 817. Authorization of appropriations; availability.

\section{1 "SEC. 2. FINDINGS.}

2 "Congress makes the following findings:

3 “(1) Federal health services to maintain and

4 improve the health of the Indians are consonant

5 with and required by the Federal Government's his-

6 torical and unique legal relationship with, and re-

7 sulting responsibility to, the American Indian people.

8 “(2) A major national goal of the United States

9 is to provide the resources, processes, and structure

10 that will enable Indian tribes and tribal members to

11 obtain the quantity and quality of health care serv- 
1641

1 ices and opportunities that will eradicate the health

2 disparities between Indians the general population.

“(3) A major national goal of the United States

4 is to provide the quantity and quality of health serv-

5 ices which will permit the health status of Indians

6 to be raised to the highest possible level and to en-

7 courage the maximum participation of Indians in the

8 planning and management of those services.

9 “(4) Federal health services to Indians have re-

10 sulted in a reduction in the prevalence and incidence

11 of preventable illnesses among, and unnecessary and

12 premature deaths of, Indians.

13 "(5) Despite such services, the unmet health

14 needs of the American Indian people are severe and

15 the health status of the Indians is far below that of

16 the general population of the United States.

17 “SEC. 3. DECLARATION OF NATIONAL INDIAN HEALTH POL18 ICY.

19 "Congress declares that it is the policy of this Nation, 20 in fulfillment of its special trust responsibilities and legal 21 obligations to Indians-

22 "(1) to assure the highest possible health status

23 for Indians and Urban Indians and to provide all re24 sources necessary to effect that policy; 
1642

"(2) to raise the health status of Indians and

2 Urban Indians to at least the levels set forth in the

3 goals contained within the Health People 2010 or

4 successor objectives;

5 "(3) to the greatest extent possible, to allow In-

6 dians to set their own health care priorities and es-

7 tablish goals that reflect their unmet needs;

8 "(4) to increase the proportion of all degrees in

9 the health professions and allied and associated

10 health professions awarded to Indians so that the

11 proportion of Indian health professionals in each

12 Service Area is raised to at least the level of that of

13 the general population;

14 "(5) to require meaningful consultation with In-

15 dian Tribes, Tribal Organizations, and urban Indian

16 organizations to implement this Act and the national

17 policy of Indian self-determination; and

18 "(6) to provide funding for programs and facili-

19 ties operated by Indian Tribes, Tribal Organizations,

20 and Urban Indian Organizations in amounts that

21 are not less than the amounts provided to programs

22 and facilities operated directly by the Service.

23 “SEC. 4. DEFINITIONS.

24 "For purposes of this Act: 
1643

“(1) The term 'accredited and accessible' means

2 on or near a reservation and accredited by a na-

3 tional or regional organization with accrediting au-

4 thority.

5 “(2) The term 'Area Office' means an adminis-

6 trative entity, including a program office, within the

7 Service through which services and funds are pro-

8 vided to the Service Units within a defined geo-

9 graphic area.

10 “(3) The term 'Assistant Secretary' means the

11 Assistant Secretary of Indian Health.

12 “(4)(A) The term 'behavioral health' means the

13 blending of substance (including alcohol, drugs,

14 inhalants, and tobacco) abuse and mental health

15 prevention and treatment, for the purpose of pro-

16 viding comprehensive services.

17 “(B) The term 'behavioral health' includes the

18 joint development of substance abuse and mental

19 health treatment planning and coordinated case

20 management using a multidisciplinary approach.

21 “(5) The term 'California Indians' means those

22 Indians who are eligible for health services of the

23 Service pursuant to section 805 .

24 “(6) The term 'community college' means-

25 "(A) a tribal college or university, or 
1644

“(B) a junior or community college.

“(7) The term 'contract health service' means

3 health services provided at the expense of the Serv-

4 ice or a Tribal Health Program by public or private

5 medical providers or hospitals, other than the Serv-

6 ice Unit or the Tribal Health Program at whose ex-

7 pense the services are provided.

“(8) The term 'Department' means, unless oth-

9 erwise designated, the Department of Health and

10 Human Services.

11 “(9) The term 'disease prevention' means the

12 reduction, limitation, and prevention of disease and

13 its complications and reduction in the consequences

14 of disease, including-

15

16

17

18

19
"(A) controlling-

"(i) the development of diabetes;

"(ii) high blood pressure;

"(iii) infectious agents;

"(iv) injuries;

"(v) occupational hazards and disabilities;

“(vi) sexually transmittable diseases; and

"(vii) toxic agents; and

“(B) providing- 
1645

"(i) fluoridation of water; and

"(ii) immunizations.

“(10) The term 'health profession' means allopathic medicine, family medicine, internal medicine, pediatrics, geriatric medicine, obstetrics and gynecology, podiatric medicine, nursing, public health nursing, dentistry, psychiatry, osteopathy, optometry, pharmacy, psychology, public health, social work, marriage and family therapy, chiropractic medicine, environmental health and engineering, allied health professions, naturopathic medicine, and any other health profession.

“(11) The term 'health promotion' means-

"(A) fostering social, economic, environmental, and personal factors conducive to health, including raising public awareness about health matters and enabling the people to cope with health problems by increasing their knowledge and providing them with valid information; "(B) encouraging adequate and appropriate diet, exercise, and sleep;

"(C) promoting education and work in conformity with physical and mental capacity;

"(D) making available safe water and sanitary facilities; 
1646

"(E) improving the physical, economic, cul-

tural, psychological, and social environment;

"(F) promoting culturally competent care;

and

"(G) providing adequate and appropriate programs, which may include-

"(i) abuse prevention (mental and physical);

"(ii) community health;

“(iii) community safety;

"(iv) consumer health education;

"(v) diet and nutrition;

"(vi) immunization and other prevention of communicable diseases, including HIV/AIDS;

"(vii) environmental health;

"(viii) exercise and physical fitness;

"(ix) avoidance of fetal alcohol disorders;

"(x) first aid and CPR education;

"(xi) human growth and development;

"(xii) injury prevention and personal safety;

"(xiii) behavioral health; 
1647

"(xiv) monitoring of disease indicators between health care provider visits, through appropriate means, including Internet-based health care management systems;

"(xv) personal health and wellness practices;

"(xvi) personal capacity building;

"(xvii) prenatal, pregnancy, and infant care;

“(xviii) psychological well-being;

"(xix) reproductive health and family planning;

"(xx) safe and adequate water;

"(xxi) healthy work environments;

"(xxii) elimination, reduction, and prevention of contaminants that create unhealthy household conditions (including mold and other allergens);

"(xxiii) stress control;

"(xxiv) substance abuse;

"(xxv) sanitary facilities;

"(xxvi) sudden infant death syndrome prevention; 
1648

"(xxvii) tobaceo use cessation and re-

duction;

"(xxviii) violence prevention; and

"(xxix) activities to promote achievement of any of the objectives described in section $3(2)$.

“(12) The term 'Indian', unless otherwise des-

8 ignated, means any person who is a member of an

9 Indian Tribe or is eligible for health services under

10 section 805 , except that, for the purpose of sections

$11 \quad 102$ and 103, the term also means any individual

12 who-

"(A)(i) irrespective of whether the individual lives on or near a reservation, is a member of a tribe, band, or other organized group of Indians, including those tribes, bands, or groups terminated since 1940 and those recognized now or in the future by the State in which they reside; or

"(ii) is a descendant, in the first or second degree, of any such member; "(B) is an Eskimo or Aleut or other Alaska Native; "(C) is considered by the Secretary of the 25 Interior to be an Indian for any purpose; or 
1649

"(D) is determined to be an Indian under regulations promulgated by the Secretary.

“(13) The term 'Indian Health Program' means-

“(A) any health program administered directly by the Service;

“(B) any Tribal Health Program; or

"(C) any Indian Tribe or Tribal Organization to which the Secretary provides funding pursuant to section 23 of the Act of June 25, 1910 (25 U.S.C. 47) (commonly known as the 'Buy Indian Act').

"(14) The term 'Indian Tribe' has the meaning given the term in the Indian Self-Determination and Education Assistance Act (25 U.S.C. 450 et seq.). “(15) The term 'junior or community college' has the meaning given the term by section 312 (f) of the Higher Education Act of 1965 (20 U.S.C. 1058(f)).

“(16) The term 'reservation' means any federally recognized Indian Tribe's reservation, Pueblo, or colony, including former reservations in Oklahoma, Indian allotments, and Alaska Native Regions established pursuant to the Alaska Native Claims Settlement Act (43 U.S.C. 1601 et seq.). 
1650

“(17) The term 'Secretary', unless otherwise

2 designated, means the Secretary of Health and

3 Human Services.

"(18) The term 'Service' means the Indian

$5 \quad$ Health Service.

6 “(19) The term 'Service Area' means the geo-

7 graphical area served by each Area Office.

8 “(20) The term 'Service Unit' means an admin-

9 istrative entity of the Service, or a Tribal Health

10 Program through which services are provided, di-

11 rectly or by contract, to eligible Indians within a de-

12 fined geographic area.

13 "(21) The term 'telehealth' has the meaning

14 given the term in section $330 \mathrm{~K}(\mathrm{a})$ of the Public

15 Health Service Act (42 U.S.C. 254c-16(a)).

16 “(22) The term 'telemedicine' means a tele-

17 communications link to an end user through the use

18 of eligible equipment that electronically links health

19 professionals or patients and health professionals at

20 separate sites in order to exchange health care infor-

21 mation in audio, video, graphic, or other format for

22 the purpose of providing improved health care serv23 ices. 
1651

"(23) The term 'tribal college or university' has

2 the meaning given the term in section $316(\mathrm{~b})(3)$ of

3 the Higher Education Act (20 U.S.C. 1059c(b)(3)).

4 “(24) The term 'Tribal Health Program' means

5 an Indian Tribe or Tribal Organization that oper-

6 ates any health program, service, function, activity,

7 or facility funded, in whole or part, by the Service

8 through, or provided for in, a contract or compact

9 with the Service under the Indian Self-Determina-

10 tion and Education Assistance Act (25 U.S.C. 450

11 et seq.).

12 “(25) The term 'Tribal Organization' has the

13 meaning given the term in the Indian Self-Deter-

14 mination and Education Assistance Act (25 U.S.C.

15450 et seq.).

16 “(26) The term 'Urban Center' means any com-

17 munity which has a sufficient Urban Indian popu-

18 lation with unmet health needs to warrant assistance

19 under title $\mathrm{V}$ of this Act, as determined by the Sec20 retary.

21 “(27) The term 'Urban Indian' means any indi22 vidual who resides in an Urban Center and who 23 meets 1 or more of the following criteria:

24 "(A) Irrespective of whether the individual 25 lives on or near a reservation, the individual is 
1652

a member of a tribe, band, or other organized group of Indians, including those tribes, bands, or groups terminated since 1940 and those tribes, bands, or groups that are recognized by the States in which they reside, or who is a descendant in the first or second degree of any such member.

"(B) The individual is an Eskimo, Aleut, or other Alaska Native.

"(C) The individual is considered by the Secretary of the Interior to be an Indian for any purpose.

"(D) The individual is determined to be an Indian under regulations promulgated by the Secretary.

“(28) The term 'urban Indian organization' means a nonprofit corporate body that (A) is situated in an Urban Center; (B) is governed by an Urban Indian-controlled board of directors; (C) provides for the participation of all interested Indian groups and individuals; and (D) is capable of legally cooperating with other public and private entities for the purpose of performing the activities described in section 503(a). 


\section{1 “TITLE I-INDIAN HEALTH, 2 HUMAN RESOURCES, AND DE- 3 VELOPMENT}

4 “SEC. 101. PURPOSE.

5 "The purpose of this title is to increase, to the max-

6 imum extent feasible, the number of Indians entering the

7 health professions and providing health services, and to

8 assure an optimum supply of health professionals to the

9 Indian Health Programs and urban Indian organizations

10 involved in the provision of health services to Indians.

11 “SEC. 102. HEALTH PROFESSIONS RECRUITMENT PROGRAM FOR INDIANS.

13 "(a) IN GENERAL._The Secretary, acting through

14 the Service, shall make grants to public or nonprofit pri-

15 vate health or educational entities, Tribal Health Pro-

16 grams, or urban Indian organizations to assist such enti-

17 ties in meeting the costs of-

“(1) identifying Indians with a potential for

19 education or training in the health professions and 20 encouraging and assisting themhealth professions; or any such courses of study, to undertake such 
postsecondary education or training as may be required to qualify them for enrollment;

“(2) publicizing existing sources of financial aid

4 available to Indians enrolled in any course of study

5 referred to in paragraph (1) or who are undertaking

6 training necessary to qualify them to enroll in any

$7 \quad$ such course of study; or

8 "(3) establishing other programs which the Sec-

9 retary determines will enhance and facilitate the en-

10 rollment of Indians in, and the subsequent pursuit

11 and completion by them of, courses of study referred

12 to in paragraph (1).

13 "(b) GRANTS.-

14 "(1) Application.-No grant may be made 15 under this section unless an application has been 16 submitted to, and approved by, the Secretary. Such 17 application shall be in such form, submitted in such 18 manner, and contain such information, as the Sec19 retary shall by regulation prescribe pursuant to this 20 Act. The Secretary shall give a preference to appli21 cations submitted by Tribal Health Programs or 22 urban Indian organizations.

23 “(2) Amount of Grants; PAYMent.-The 24 amount of a grant under this section shall be deter25 mined by the Secretary. Payments pursuant to this 
1655

1 section may be made in advance or by way of reim-

2 bursement, and at such intervals and on such condi-

3 tions as provided for in regulations issued pursuant

4 to this Act. To the extent not otherwise prohibited

5 by law, grants shall be for 3 years, as provided in

6 regulations issued pursuant to this Act.

7 "SEC. 103. HEALTH PROFESSIONS PREPARATORY SCHOL-

ARSHIP PROGRAM FOR INDIANS.

9 “(a) SCHOLARships AUTHORIZED.-The Secretary,

10 acting through the Service, shall provide scholarship

11 grants to Indians who-

"(1) have successfully completed their high

13 school education or high school equivalency; and

"(2) have demonstrated the potential to suc-

15 cessfully complete courses of study in the health pro-

16 fessions.

17 “(b) Purposes.—Scholarship grants provided pursu-

18 ant to this section shall be for the following purposes:

“(1) Compensatory preprofessional education of

20 any recipient, such scholarship not to exceed 2 years

21 on a full-time basis (or the part-time equivalent

22 thereof, as determined by the Secretary pursuant to

23 regulations issued under this Act).

24 "(2) Pregraduate education of any recipient

25 leading to a baccalaureate degree in an approved 
1 course of study preparatory to a field of study in a

2 health profession, such scholarship not to exceed 4

3 years. An extension of up to 2 years (or the part-

4 time equivalent thereof, as determined by the Sec-

5 retary pursuant to regulations issued pursuant to

6 this Act) may be approved.

7 “(c) OTHER CONDitions.-Scholarships under this

8 section-

9

10

11

23 to Indians who are enrolled full or part time in ac24 credited schools pursuing courses of study in the 25 health professions. Such scholarships shall be des- 
1 ignated Indian Health Scholarships and shall be

2 made in accordance with section 338A of the Public

3 Health Services Act (42 U.S.C. 254l), except as pro-

$4 \quad$ vided in subsection (b) of this section.

5 “(2) Determinations By secretary.-The

6 Secretary, acting through the Service, shall deter-

7 mine-

8 "(A) who shall receive scholarship grants

$9 \quad$ under subsection (a); and

10 "(B) the distribution of the scholarships

11 among health professions on the basis of the

12 relative needs of Indians for additional service

13 in the health professions.

14 “(3) Certain Delegation not allowed.-

15 The administration of this section shall be a respon-

16 sibility of the Assistant Secretary and shall not be

17 delegated in a contract or compact under the Indian

18 Self-Determination and Education Assistance Act

19 (25 U.S.C. 450 et seq.).

20 “(b) Active Duty Service Obligation.-

21 "(1) OBLigation Met.-The active duty serv-

22 ice obligation under a written contract with the Sec-

23 retary under this section that an Indian has entered

24 into shall, if that individual is a recipient of an In-

25 dian Health Scholarship, be met in full-time practice 
1658

1 equal to 1 year for each school year for which the 2 participant receives a scholarship award under this 3 part, or 2 years, whichever is greater, by service in 41 or more of the following:

“(A) In an Indian Health Program.

"(B) In a program assisted under title $\mathrm{V}$ of this Act.

"(C) In the private practice of the applicable profession if, as determined by the Secretary, in accordance with guidelines promulgated by the Secretary, such practice is situated in a physician or other health professional shortage area and addresses the health care needs of a substantial number of Indians.

"(D) In a teaching capacity in a tribal college or university nursing program (or a related health profession program) if, as determined by the Secretary, the health service provided to Indians would not decrease.

“(2) Obligation DefERRED.-At the request of any individual who has entered into a contract referred to in paragraph (1) and who receives a health professions degree requiring postgraduate training for licensure or to improve clinical skills, the Secretary shall defer the active duty service obligation 
1659

1 of that individual under that contract, in order that

2 such individual may complete any internship, resi-

3 dency, or other advanced clinical training that is re-

4 quired for the practice of that health profession, for

5 an appropriate period (in years, as determined by

6 the Secretary), subject to the following conditions:

7 "(A) No period of internship, residency, or

8 other advanced clinical training shall be counted

9 as satisfying any period of obligated service

$10 \quad$ under this subsection.

11 "(B) The active duty service obligation of

12 that individual shall commence not later than

1390 days after the completion of that advanced

14 clinical training (or by a date specified by the $15 \quad$ Secretary).

16 "(C) The active duty service obligation will

17 be served in the health profession of that indi18 vidual in a manner consistent with paragraph $19 \quad(1)$.

“(D) A recipient of a scholarship under this section may, at the election of the recipient, meet the active duty service obligation described 23 in paragraph (1) by service in a program speci24 fied under that paragraph that- 
1660

17 vidual receiving a scholarship under this section who is 18 enrolled part time in an approved course of study-

"(i) is located on the reservation of the Indian Tribe in which the recipient is enrolled; or

"(ii) serves the Indian Tribe in which the recipient is enrolled.

“(3) Priority when making assignments.Subject to paragraph (2), the Secretary, in making assignments of Indian Health Scholarship recipients required to meet the active duty service obligation described in paragraph (1), shall give priority to assigning individuals to service in those programs specified in paragraph (1) that have a need for health professionals to provide health care services as a result of individuals having breached contracts entered into under this section.

“(c) Part-time Students.-In the case of an indi"(1) such scholarship shall be for a period of years not to exceed the part-time equivalent of 4 years, as determined by the Secretary;

"(2) the period of obligated service described in subsection (b)(1) shall be equal to the greater of"(A) the part-time equivalent of 1 year for each year for which the individual was provided 
1661

a scholarship (as determined by the Secretary);

or

"(B) 2 years; and

"(3) the amount of the monthly stipend speci-

5 fied in section $338 \mathrm{~A}(\mathrm{~g})(1)(\mathrm{B})$ of the Public Health

6 Service Act (42 U.S.C. $254 l(\mathrm{~g})(1)(\mathrm{B})$ ) shall be re-

7 duced pro rata (as determined by the Secretary)

8 based on the number of hours such student is en-

9 rolled.

10 “(d) BREACH OF CONTRACT.-

11 "(1) SPECIFIED BREACHES.-An individual

12 shall be liable to the United States for the amount

13 which has been paid to the individual, or on behalf

14 of the individual, under a contract entered into with

15 the Secretary under this section on or after the date

16 of enactment of the Indian Health Care Improve-

17 ment Act Amendments of 2009 if that individual-

18 "(A) fails to maintain an acceptable level

19 of academic standing in the educational institu-

20 tion in which he or she is enrolled (such level

21 determined by the educational institution under

22 regulations of the Secretary);

23 "(B) is dismissed from such educational

24 institution for disciplinary reasons; 
1662

"(C) voluntarily terminates the training in such an educational institution for which he or she is provided a scholarship under such contract before the completion of such training; or "(D) fails to accept payment, or instructs the educational institution in which he or she is enrolled not to accept payment, in whole or in part, of a scholarship under such contract, in lieu of any service obligation arising under such contract.

“(2) Other BREACHES.-If for any reason not specified in paragraph (1) an individual breaches a written contract by failing either to begin such individual's service obligation required under such contract or to complete such service obligation, the United States shall be entitled to recover from the individual an amount determined in accordance with the formula specified in subsection (l) of section 110 in the manner provided for in such subsection.

“(3) Cancellation upon Death of RecipiENT.-Upon the death of an individual who receives an Indian Health Scholarship, any outstanding obligation of that individual for service or payment that relates to that scholarship shall be canceled. 
1663

“(4) Waivers And suspensions.-The Sec-

retary shall provide for the partial or total waiver or suspension of any obligation of service or payment of a recipient of an Indian Health Scholarship if the Secretary determines that-

"(A) it is not possible for the recipient to meet that obligation or make that payment;

"(B) requiring that recipient to meet that obligation or make that payment would result in extreme hardship to the recipient; or

"(C) the enforcement of the requirement to meet the obligation or make the payment would be unconscionable.

“(5) EXTREME HARDSHIP.- - Notwithstanding any other provision of law, in any case of extreme hardship or for other good cause shown, the Secretary may waive, in whole or in part, the right of the United States to recover funds made available under this section.

“(6) BANKRUPTCY.-Notwithstanding any other provision of law, with respect to a recipient of an Indian Health Scholarship, no obligation for payment may be released by a discharge in bankruptcy under title 11, United States Code, unless that discharge is granted after the expiration of the 5-year 
1664

1 period beginning on the initial date on which that

2 payment is due, and only if the bankruptcy court

3 finds that the nondischarge of the obligation would

4 be unconscionable.

5 “SEC. 105. AMERICAN INDIANS INTO PSYCHOLOGY PRO6 GRAM.

7 “(a) Grants AUTHORIZED.-The Secretary, acting

8 through the Service, shall make grants of not more than

$9 \$ 300,000$ to each of 9 colleges and universities for the pur-

10 pose of developing and maintaining Indian psychology ca-

11 reer recruitment programs as a means of encouraging In-

12 dians to enter the behavioral health field. These programs

13 shall be located at various locations throughout the coun-

14 try to maximize their availability to Indian students and

15 new programs shall be established in different locations

16 from time to time.

17 “(b) Quentin N. Burdick Program Grant.-The

18 Secretary shall provide a grant authorized under sub-

19 section (a) to develop and maintain a program at the Uni-

20 versity of North Dakota to be known as the 'Quentin N.

21 Burdick American Indians Into Psychology Program'.

22 Such program shall, to the maximum extent feasible, co-

23 ordinate with the Quentin N. Burdick Indian Health Pro-

24 grams authorized under section 117(b), the Quentin N.

25 Burdick American Indians Into Nursing Program author- 
1 ized under section 115(e), and existing university research

2 and communications networks.

3 “(c) Regulations.-The Secretary shall issue regu-

4 lations pursuant to this Act for the competitive awarding

5 of grants provided under this section.

6 “(d) CONDitions of GRANT.-Applicants under this

7 section shall agree to provide a program which, at a min-

8 imum-

9 “(1) provides outreach and recruitment for 10 health professions to Indian communities including 11 elementary, secondary, and accredited and accessible 12 community colleges that will be served by the pro13 gram;

14 “(2) incorporates a program advisory board 15 comprised of representatives from the tribes and 16 communities that will be served by the program;

17 “(3) provides summer enrichment programs to 18 expose Indian students to the various fields of psy19 chology through research, clinical, and experimental 20 activities;

21 "(4) provides stipends to undergraduate and 22 graduate students to pursue a career in psychology; 23 “(5) develops affiliation agreements with tribal 24 colleges and universities, the Service, university af25 filiated programs, and other appropriate accredited 
1 and accessible entities to enhance the education of

2 Indian students;

"(6) to the maximum extent feasible, uses exist-

$4 \quad$ ing university tutoring, counseling, and student sup-

5 port services; and

6 "(7) to the maximum extent feasible, employs

7 qualified Indians in the program.

8 “(e) Active Duty Service Requirement.-The

9 active duty service obligation prescribed under section

$10338 \mathrm{C}$ of the Public Health Service Act (42 U.S.C. 254m)

11 shall be met by each graduate who receives a stipend de-

12 scribed in subsection $(d)(4)$ that is funded under this sec-

13 tion. Such obligation shall be met by service-

"(1) in an Indian Health Program;

15

"(2) in a program assisted under title $\mathrm{V}$ of this

16 Act; or

17 "(3) in the private practice of psychology if, as

18 determined by the Secretary, in accordance with

19 guidelines promulgated by the Secretary, such prac-

20 tice is situated in a physician or other health profes-

21 sional shortage area and addresses the health care

22 needs of a substantial number of Indians.

23 "(f) Authorization of Appropriations.-There

24 is authorized to be appropriated such sums as may be nec25 essary to carry out this section. 
1 “SEC. 106. SCHOLARSHIP PROGRAMS FOR INDIAN TRIBES.

"(a) IN GENERAL.-

“(1) Grants AUTHORIZED.-The Secretary,

5 Tribal Health Programs for the purpose of providing

6 scholarships for Indians to serve as health profes-

$7 \quad$ sionals in Indian communities.

“(2) Amount. - Amounts available under para-

10 cent of the amounts available for each fiscal year for

11 Indian Health Scholarships under section 104. under paragraph (1) shall be in such form and con-

14 tain such agreements, assurances, and information 15 as consistent with this section.

16 "(b) REQUIREMENTS.receiving a grant under subsection (a) shall provide scholarships to Indians in accordance with the re20 quirements of this section.

"(2) Costs. - With respect to costs of providing any scholarship pursuant to subsection (a)"(A) 80 percent of the costs of the scholarship shall be paid from the funds made available pursuant to subsection (a)(1) provided to the Tribal Health Program; and 
1668

“(B) 20 percent of such costs may be paid from any other source of funds.

4 shall provide scholarships under this section only to Indi5 ans enrolled or accepted for enrollment in a course of 6 study (approved by the Secretary) in 1 of the health pro7 fessions contemplated by this Act.

8 “(d) CONTRACT.-

9 “(1) IN GENERAL.-In providing scholarships 10 under subsection (b), the Secretary and the Tribal 11 Health Program shall enter into a written contract 12 with each recipient of such scholarship. “(2) Requirements.-Such contract shall"(A) obligate such recipient to provide service in an Indian Health Program or urban 16 Indian organization, in the same Service Area 17 where the Tribal Health Program providing the scholarship is located, for-

"(i) a number of years for which the scholarship is provided (or the part-time equivalent thereof, as determined by the Secretary), or for a period of 2 years, whichever period is greater; or 
1669

"(ii) such greater period of time as the recipient and the Tribal Health Program may agree;

"(B) provide that the amount of the scholarship-

“(i) may only be expended for-

"(I) tuition expenses, other reasonable educational expenses, and reasonable living expenses incurred in attendance at the educational institution; and

"(II) payment to the recipient of a monthly stipend of not more than the amount authorized by section $338(\mathrm{~g})(1)(\mathrm{B})$ of the Public Health Service Act $(42$ U.S.C. $254 \mathrm{~m}(\mathrm{~g})(1)(\mathrm{B}))$, with such amount to be reduced pro rata (as determined by the Secretary) based on the number of hours such student is enrolled, and not to exceed, for any year of attendance for which the scholarship is provided, the total amount required for the year for the purposes authorized in this clause; and 
"(ii) may not exceed, for any year of

attendance for which the scholarship is provided, the total amount required for the year for the purposes authorized in clause (i);

"(C) require the recipient of such scholarship to maintain an acceptable level of academic standing as determined by the educational institution in accordance with regulations issued pursuant to this Act; and

"(D) require the recipient of such scholarship to meet the educational and licensure requirements appropriate to each health profession.

16 contract may allow the recipient to serve in another 17 Service Area, provided the Tribal Health Program 18 and Secretary approve and services are not dimin19 ished to Indians in the Service Area where the Trib20 al Health Program providing the scholarship is lo21 cated.

“(1) SPECIFIC BReaches.-An individual who 24 has entered into a written contract with the Sec25 retary and a Tribal Health Program under sub- 
1 section (d) shall be liable to the United States for

2 the Federal share of the amount which has been

3 paid to him or her, or on his or her behalf, under

4 the contract if that individual-

"(A) fails to maintain an acceptable level of academic standing in the educational institution in which he or she is enrolled (such level as determined by the educational institution under regulations of the Secretary);

"(B) is dismissed from such educational institution for disciplinary reasons;

"(C) voluntarily terminates the training in such an educational institution for which he or she is provided a scholarship under such contract before the completion of such training; or "(D) fails to accept payment, or instructs the educational institution in which he or she is enrolled not to accept payment, in whole or in part, of a scholarship under such contract, in lieu of any service obligation arising under such contract.

“(2) OTHER BREACHES.-If for any reason not specified in paragraph (1), an individual breaches a written contract by failing to either begin such individual's service obligation required under such con- 
1 tract or to complete such service obligation, the

2 United States shall be entitled to recover from the

3 individual an amount determined in accordance with

4 the formula specified in subsection (l) of section 110

5 in the manner provided for in such subsection.

6 “(3) CANCEllation UPON DEATH OF RECIPI-

7 ENT.-Upon the death of an individual who receives

8 an Indian Health Scholarship, any outstanding obli-

9 gation of that individual for service or payment that

10 relates to that scholarship shall be canceled.

11 “(4) Information.-The Secretary may carry

12 out this subsection on the basis of information re-

13 ceived from Tribal Health Programs involved or on

14 the basis of information collected through such other

15 means as the Secretary deems appropriate.

16 “(f) Relation to Soclal Security Act.-The re-

17 cipient of a scholarship under this section shall agree, in 18 providing health care pursuant to the requirements here19 in-

"(1) not to discriminate against an individual 21 seeking care on the basis of the ability of the indi22 vidual to pay for such care or on the basis that pay23 ment for such care will be made pursuant to a pro24 gram established in title XVIII of the Social Secu- 
1 rity Act or pursuant to the programs established in

2 title XIX or title XXI of such Act; and

“(2) to accept assignment under section

$4 \quad 1842(b)(3)(B)(i i)$ of the Social Security Act for all

5 services for which payment may be made under part

6 B of title XVIII of such Act, and to enter into an

7 appropriate agreement with the State agency that

8 administers the State plan for medical assistance

9 under title XIX, or the State child health plan under

10 title XXI, of such Act to provide service to individ-

11 uals entitled to medical assistance or child health as-

12 sistance, respectively, under the plan.

13 "(g) Continuance of Funding.-The Secretary

14 shall make payments under this section to a Tribal Health

15 Program for any fiscal year subsequent to the first fiscal

16 year of such payments unless the Secretary determines

17 that, for the immediately preceding fiscal year, the Tribal

18 Health Program has not complied with the requirements

19 of this section.

20 “SEC. 107. INDIAN HEALTH SERVICE EXTERN PROGRAMS.

21 “(a) Employment Preference.-Any individual

22 who receives a scholarship pursuant to section 104 or 106

23 shall be given preference for employment in the Service,

24 or may be employed by a Tribal Health Program or an

25 urban Indian organization, or other agencies of the De- 
1 partment as available, during any nonacademic period of

2 the year.

3 “(b) Not Counted Toward Active Duty Service

4 Obligation.-Periods of employment pursuant to this

5 subsection shall not be counted in determining fulfillment

6 of the service obligation incurred as a condition of the

7 scholarship.

8 “(c) Timing; Length of Employment.-Any indi-

9 vidual enrolled in a program, including a high school pro-

10 gram, authorized under section 102(a) may be employed

11 by the Service or by a Tribal Health Program or an urban

12 Indian organization during any nonacademic period of the

13 year. Any such employment shall not exceed 120 days dur-

14 ing any calendar year.

15 “(d) Nonapplicability of Competitive Per-

16 SONnel System.-Any employment pursuant to this sec-

17 tion shall be made without regard to any competitive per-

18 sonnel system or agency personnel limitation and to a po-

19 sition which will enable the individual so employed to re-

20 ceive practical experience in the health profession in which

21 he or she is engaged in study. Any individual so employed

22 shall receive payment for his or her services comparable

23 to the salary he or she would receive if he or she were

24 employed in the competitive system. Any individual so em- 
1 ployed shall not be counted against any employment ceil-

2 ing affecting the Service or the Department.

3 “SEC. 108. CONTINUING EDUCATION ALLOWANCES.

4 "In order to encourage scholarship and stipend re-

5 cipients under sections 104, 105, 106, and 115 and health

6 professionals, including community health representatives

7 and emergency medical technicians, to join or continue in

8 an Indian Health Program and to provide their services

9 in the rural and remote areas where a significant portion

10 of Indians reside, the Secretary, acting through the Serv-

11 ice, may-

12 "(1) provide programs or allowances to transi-

13 tion into an Indian Health Program, including li-

14 censing, board or certification examination assist-

15 ance, and technical assistance in fulfilling service ob-

16 ligations under sections 104, 105, 106, and 115; and

17 “(2) provide programs or allowances to health

18 professionals employed in an Indian Health Program

19 to enable them for a period of time each year pre-

20 scribed by regulation of the Secretary to take leave

21 of their duty stations for professional consultation,

22 management, leadership, and refresher training

23 courses. 
1 "SEC. 109. COMMUNITY HEALTH REPRESENTATIVE PRO-

GRAM.

3 "(a) In General.-Under the authority of the Act 4 of November 2, 1921 (25 U.S.C. 13) (commonly known

5 as the 'Snyder Act'), the Secretary, acting through the

6 Service, shall maintain a Community Health Representa-

7 tive Program under which Indian Health Programs-

"(1) provide for the training of Indians as com-

9 munity health representatives; and

10 "(2) use such community health representatives

11 in the provision of health care, health promotion,

12 and disease prevention services to Indian commu13 nities.

14 “(b) Duties.-The Community Health Representa15 tive Program of the Service, shall-

16 "(1) provide a high standard of training for 17 community health representatives to ensure that the 18 community health representatives provide quality 19 health care, health promotion, and disease preven20 tion services to the Indian communities served by 21 the Program;

22 “(2) in order to provide such training, develop 23 and maintain a curriculum that-

"(A) combines education in the theory of 25 health care with supervised practical experience 26 in the provision of health care; and 
“(B) provides instruction and practical experience in health promotion and disease prevention activities, with appropriate consideration given to lifestyle factors that have an impact on Indian health status, such as alcoholism, family dysfunction, and poverty; “(3) maintain a system which identifies the 8 needs of community health representatives for con9 tinuing education in health care, health promotion, 10 and disease prevention and develop programs that 11 meet the needs for continuing education; “(4) maintain a system that provides close supervision of Community Health Representatives;

“(5) maintain a system under which the work 15 of Community Health Representatives is reviewed 16 and evaluated; and

17 “(6) promote traditional health care practices 18 of the Indian Tribes served consistent with the Serv19 ice standards for the provision of health care, health 20 promotion, and disease prevention.

21 “SEC. 110. INDIAN HEALTH SERVICE LOAN REPAYMENT 22 PROGRAM.

23 “(a) Establishment.-The Secretary, acting 24 through the Service, shall establish and administer a pro25 gram to be known as the Service Loan Repayment Pro- 
1 gram (hereinafter referred to as the 'Loan Repayment 2 Program') in order to ensure an adequate supply of 3 trained health professionals necessary to maintain accredi4 tation of, and provide health care services to Indians 5 through, Indian Health Programs and urban Indian orga6 nizations.

7 “(b) Eligible Individuals.-To be eligible to par8 ticipate in the Loan Repayment Program, an individual 9 must-

10

11
“(1)(A) be enrolled-

"(i) in a course of study or program in an accredited educational institution (as determined by the Secretary under section 338B(b)(1)(c)(i) of the Public Health Service Act (42 U.S.C. $254 l-1(\mathrm{~b})(1)(\mathrm{c})(\mathrm{i}))$ ) and be scheduled to complete such course of study in the same year such individual applies to participate in such program; or

"(ii) in an approved graduate training program in a health profession; or "(B) have-

"(i) a degree in a health profession; and

“(ii) a license to practice a health profession; 
"(2)(A) be eligible for, or hold, an appointment

2 as a commissioned officer in the Regular or Reserve

3 Corps of the Public Health Service;

4 "(B) meet the professional standards for civil

5 service employment in the Service; or

6 "(C) be employed in an Indian Health Program

7 or urban Indian organization without a service obli-

8 gation; and

9 "(3) submit to the Secretary an application for

10 a contract described in subsection (e).

11 "(c) APPLiCATION.-

12 “(1) INFORMATION TO BE INCLUDED WITH

13 FORMS.-In disseminating application forms and

14 contract forms to individuals desiring to participate

15 in the Loan Repayment Program, the Secretary

16 shall include with such forms a fair summary of the

17 rights and liabilities of an individual whose applica-

18 tion is approved (and whose contract is accepted) by

19 the Secretary, including in the summary a clear ex-

20 planation of the damages to which the United States

21 is entitled under subsection (l) in the case of the in-

22 dividual's breach of contract. The Secretary shall

23 provide such individuals with sufficient information

24 regarding the advantages and disadvantages of serv-

25 ice as a commissioned officer in the Regular or Re- 
1680

1 serve Corps of the Public Health Service or a civil-

2 ian employee of the Service to enable the individual

3 to make a decision on an informed basis.

4 "(2) Clear language.-The application form,

5 contract form, and all other information furnished

6 by the Secretary under this section shall be written

7 in a manner calculated to be understood by the aver-

8 age individual applying to participate in the Loan

9 Repayment Program.

10 “(3) Timely availability of FORMS.-The

11 Secretary shall make such application forms, con-

12 tract forms, and other information available to indi-

13 viduals desiring to participate in the Loan Repay-

14 ment Program on a date sufficiently early to ensure

15 that such individuals have adequate time to carefully

16 review and evaluate such forms and information.

17 “(d) Priorities.-

18 “(1) LisT.—Consistent with subsection (j), the

19 Secretary shall annually-

20 "(A) identify the positions in each Indian

21 Health Program or urban Indian organization

22 for which there is a need or a vacancy; and

23 "(B) rank those positions in order of pri-

$24 \quad$ ority. 
1681

"(2) Approvals._Consistent with the priority

2 determined under paragraph (1), the Secretary, in

3 determining which applications under the Loan Re-

4 payment Program to approve (and which contracts

5 to accept), shall-

"(A) give first priority to applications made by individual Indians; and "(B) after making determinations on all applications submitted by individual Indians as required under subparagraph $(\mathrm{A})$, give priority to-

"(i) individuals recruited through the efforts of an Indian Health Program or urban Indian organization; and "(ii) other individuals based on the priority rankings under paragraph (1).

\section{“(e) Recipient Contracts.-}

“(1) Contract Required.-An individual becomes a participant in the Loan Repayment Program only upon the Secretary and the individual entering into a written contract described in paragraph (2).

“(2) Contents of COnTRaCT.-The written contract referred to in this section between the Secretary and an individual shall contain- 
1682

“(A) an agreement under which-

"(i) subject to subparagraph (C), the Secretary agrees-

"(I) to pay loans on behalf of the individual in accordance with the provisions of this section; and

"(II) to accept (subject to the availability of appropriated funds for carrying out this section) the individual into the Service or place the individual with a Tribal Health Program or urban Indian organization as provided in clause (ii)(III); and “(ii) subject to subparagraph (C), the individual agrees-

"(I) to accept loan payments on behalf of the individual;

"(II) in the case of an individual described in subsection (b)(1)"(aa) to maintain enrollment in a course of study or training described in subsection $(b)(1)(A)$ until the individual completes the course of study or training; and 
1683

"(bb) while enrolled in such course of study or training, to maintain an acceptable level of academic standing (as determined under regulations of the Secretary by the educational institution offering such course of study or training); and "(III) to serve for a time period (in this section referred to as the "period of obligated service') equal to 2 years or such longer period as the individual may agree to serve in the full-time clinical practice of such individual's profession in an Indian Health Program or urban Indian organization to which the individual may be assigned by the Secretary;

“(B) a provision permitting the Secretary to extend for such longer additional periods, as the individual may agree to, the period of obligated service agreed to by the individual under subparagraph (A)(ii)(III);

"(C) a provision that any financial obligation of the United States arising out of a con- 
1684

13 The Secretary shall provide written notice to an individual

14 within 21 days on-

17 Loan Repayment Program, including extensions re-

18 sulting in an aggregate period of obligated service in

19 excess of 4 years; or

tract entered into under this section and any obligation of the individual which is conditioned thereon is contingent upon funds being appropriated for loan repayments under this section;

"(D) a statement of the damages to which the United States is entitled under subsection (k) for the individual's breach of the contract; and

"(E) such other statements of the rights and liabilities of the Secretary and of the individual, not inconsistent with this section.

"(f) Deadline for Decision on Application.“(1) the Secretary's approving, under subsection (e)(1), of the individual's participation in the "(2) the Secretary's disapproving an individual's participation in such Program.

"(g) Payments.-

“(1) IN GENERAL.-A loan repayment provided for an individual under a written contract under the Loan Repayment Program shall consist of payment, 
1685

1 in accordance with paragraph (2), on behalf of the

2 individual of the principal, interest, and related ex-

3 penses on government and commercial loans received

4 by the individual regarding the undergraduate or

5 graduate education of the individual (or both), which

6 loans were made for-

7

8

9

10

11

12

13

14

15

16

17 tion $338 \mathrm{~B}(\mathrm{~g})(2)(\mathrm{A})$ of the Public Health Service

18 Act, whichever is more, on behalf of the individual

19 for loans described in paragraph (1). In making a

20 determination of the amount to pay for a year of

21 such service by an individual, the Secretary shall

22 consider the extent to which each such determina-

23 tion-

"(A) affects the ability of the Secretary to 25 
1686

provided under the Loan Repayment Program from the amounts appropriated for such contracts;

"(B) provides an incentive to serve in Indian Health Programs and urban Indian organizations with the greatest shortages of health professionals; and

"(C) provides an incentive with respect to the health professional involved remaining in an Indian Health Program or urban Indian organization with such a health professional shortage, and continuing to provide primary health services, after the completion of the period of obligated service under the Loan Repayment Program.

"(3) Timing.-Any arrangement made by the Secretary for the making of loan repayments in accordance with this subsection shall provide that any repayments for a year of obligated service shall be made no later than the end of the fiscal year in which the individual completes such year of service. “(4) Reimbursements FOR tax hiability.For the purpose of providing reimbursements for tax liability resulting from a payment under paragraph (2) on behalf of an individual, the Secretary- 
"(A) in addition to such payments, may make payments to the individual in an amount equal to not less than 20 percent and not more than 39 percent of the total amount of loan repayments made for the taxable year involved; and

"(B) may make such additional payments as the Secretary determines to be appropriate with respect to such purpose.

“(5) Payment schedule.-The Secretary

11 may enter into an agreement with the holder of any 12 loan for which payments are made under the Loan

13 Repayment Program to establish a schedule for the 14 making of such payments.

15 “(h) Employment Ceiling.-Notwithstanding any 16 other provision of law, individuals who have entered into 17 written contracts with the Secretary under this section 18 shall not be counted against any employment ceiling af19 fecting the Department while those individuals are under20 going academic training.

21 "(i) Recruitment.-The Secretary shall conduct re22 cruiting programs for the Loan Repayment Program and 23 other manpower programs of the Service at educational 24 institutions training health professionals or specialists 25 identified in subsection (a). 
1 “(j) Applicability of Law.-Section 214 of the

2 Public Health Service Act (42 U.S.C. 215) shall not apply

3 to individuals during their period of obligated service

4 under the Loan Repayment Program.

5 “(k) Assignment of Indviduals.-The Secretary, 6 in assigning individuals to serve in Indian Health Pro-

7 grams or urban Indian organizations pursuant to con-

8 tracts entered into under this section, shall-

$9 \quad$ "(1) ensure that the staffing needs of Tribal

10 Health Programs and urban Indian organizations

11 receive consideration on an equal basis with pro-

12 grams that are administered directly by the Service;

13 and

14 "(2) give priority to assigning individuals to In-

15 dian Health Programs and urban Indian organiza-

16 tions that have a need for health professionals to

17 provide health care services as a result of individuals

18 having breached contracts entered into under this

19 section.

20 "(l) Breach OF CONTRACT.-

21 “(1) SPECIFIC BREaches.-An individual who

22 has entered into a written contract with the Sec-

23 retary under this section and has not received a

24 waiver under subsection $(\mathrm{m})$ shall be liable, in lieu

25 of any service obligation arising under such contract, 
1 to the United States for the amount which has been

2 paid on such individual's behalf under the contract 3 if that individual-

"(A) is enrolled in the final year of a

23 written contract under this section by failing either 24 to begin, or complete, such individual's period of ob25 ligated service in accordance with subsection (e)(2), 
1690

1 the United States shall be entitled to recover from

2 such individual an amount to be determined in ac-

3 cordance with the following formula: $A=3 Z(t-s / t)$

4 in which-

5

6

7

8

9

10

11

12

13

14

15

16

17

18

19

25 Secretary.

'(A) 'A' is the amount the United States is entitled to recover;

"(B) ' $\mathrm{Z}$ ' is the sum of the amounts paid under this section to, or on behalf of, the individual and the interest on such amounts which would be payable if, at the time the amounts were paid, they were loans bearing interest at the maximum legal prevailing rate, as determined by the Secretary of the Treasury;

"(C) ' $\mathrm{t}$ ' is the total number of months in the individual's period of obligated service; and "(D) 's' is the number of months of such period served by such individual in accordance with this section.

“(3) Time PERIOD FOR RePayment.-Any amount of damages which the United States is entitled to recover under this subsection shall be paid to the United States within the 1-year period beginning on the date of the breach or such longer period beginning on such date as shall be specified by the 
2 Amounts not paid within such period shall be sub3 ject to collection through deductions in Medicare 4 payments pursuant to section 1892 of the Social Se5 curity Act.

\section{“(5) Recovery of Delinquency.-} "(A) In GENERAL.-If damages described in paragraph (4) are delinquent for 3 months, the Secretary shall, for the purpose of recovering such damages-

"(i) use collection agencies contracted with by the Administrator of General Services; or

"(ii) enter into contracts for the recovery of such damages with collection agencies selected by the Secretary.

"(B) REPORT.-Each contract for recovering damages pursuant to this subsection shall provide that the contractor will, not less than once each 6 months, submit to the Secretary a status report on the success of the contractor in collecting such damages. Section 3718 of title 31, United States Code, shall apply to any such contract to the extent not inconsistent with this subsection. 
“(1) In GENERAL.—The Secretary shall by regulation provide for the partial or total waiver or sus-

4 pension of any obligation of service or payment by

5 an individual under the Loan Repayment Program

6 whenever compliance by the individual is impossible

7 or would involve extreme hardship to the individual

8 and if enforcement of such obligation with respect to

9 any individual would be unconscionable.

10 “(2) CANCELED UPON DEath.-Any obligation

11 of an individual under the Loan Repayment Pro-

12 gram for service or payment of damages shall be

13 canceled upon the death of the individual.

14 “(3) HaRdshiP WAIVER.-The Secretary may 15 waive, in whole or in part, the rights of the United 16 States to recover amounts under this section in any 17 case of extreme hardship or other good cause shown, 18 as determined by the Secretary.

19 “(4) BANKRUPTCY.-Any obligation of an indi20 vidual under the Loan Repayment Program for pay21 ment of damages may be released by a discharge in 22 bankruptey under title 11 of the United States Code 23 only if such discharge is granted after the expiration 24 of the 5-year period beginning on the first date that 25 payment of such damages is required, and only if 
1693

1 the bankruptcy court finds that nondischarge of the

2 obligation would be unconscionable.

3 “(n) REPORT.-The Secretary shall submit to the

4 President, for inclusion in the report required to be sub-

5 mitted to Congress under section 801, a report concerning

6 the previous fiscal year which sets forth by Service Area

7 the following:

8

9 maintained by Indian Health Programs and urban

10 Indian organizations for which recruitment or reten-

11 tion is difficult.

12

13

14 profession.

15

16

17 health profession.

18

“(2) The number of Loan Repayment Program applications filed with respect to each type of health “(3) The number of contracts described in subsection (e) that are entered into with respect to each "(4) The amount of loan payments made under this section, in total and by health profession.

"(5) The number of scholarships that are provided under sections 104 and 106 with respect to each health profession.

“(6) The amount of scholarship grants provided under sections 104 and 106, in total and by health profession. 
"(7) The number of providers of health care

2 that will be needed by Indian Health Programs and

3 urban Indian organizations, by location and profes-

4 sion, during the 3 fiscal years beginning after the

5 date the report is filed.

6 "(8) The measures the Secretary plans to take

7 to fill the health professional positions maintained

8 by Indian Health Programs or urban Indian organi-

9 zations for which recruitment or retention is dif-

10 ficult.

11 "SEC. 111. SCHOLARSHIP AND LOAN REPAYMENT RECOVERY FUND.

13 “(a) Establishment.-There is established in the 14 Treasury of the United States a fund to be known as the 15 Indian Health Scholarship and Loan Repayment Recovery 16 Fund (hereafter in this section referred to as the 'LRRF'). 17 The LRRF shall consist of such amounts as may be col18 lected from individuals under section 104(d), section 19 106(e), and section 110(l) for breach of contract, such 20 funds as may be appropriated to the LRRF, and interest 21 earned on amounts in the LRRF. All amounts collected, 22 appropriated, or earned relative to the LRRF shall remain 23 available until expended.

24 "(b) Use of Funds.- 
"(1) By SECRETARY.-Amounts in the LRRF

2 may be expended by the Secretary, acting through

3 the Service, to make payments to an Indian Health

4 Program-

"(A) to which a scholarship recipient under section 104 and 106 or a loan repayment program participant under section 110 has been assigned to meet the obligated service requirements pursuant to such sections; and "(B) that has a need for a health professional to provide health care services as a result of such recipient or participant having breached the contract entered into under section 104, 106, or 110 .

"(2) By tribal health PROgRams.—A Tribal

16 Health Program receiving payments pursuant to

17 paragraph (1) may expend the payments to provide 18 scholarships or recruit and employ, directly or by 19 contract, health professionals to provide health care 20 services.

21 "(c) Investment of Funds.-The Secretary of the 22 Treasury shall invest such amounts of the LRRF as the 23 Secretary of Health and Human Services determines are 24 not required to meet current withdrawals from the LRRF. 25 Such investments may be made only in interest bearing 
1 obligations of the United States. For such purpose, such

2 obligations may be acquired on original issue at the issue 3 price, or by purchase of outstanding obligations at the 4 market price.

5 “(d) Sale of Obligations.-Any obligation ac6 quired by the LRRF may be sold by the Secretary of the

7 Treasury at the market price.

8 "SEC. 112. RECRUITMENT ACTIVITIES.

9 “(a) Reimbursement FOR Travel.-The Sec10 retary, acting through the Service, may reimburse health 11 professionals seeking positions with Indian Health Pro12 grams or urban Indian organizations, including individ13 uals considering entering into a contract under section 14110 and their spouses, for actual and reasonable expenses 15 incurred in traveling to and from their places of residence 16 to an area in which they may be assigned for the purpose 17 of evaluating such area with respect to such assignment. 18 “(b) Recruitment Personnel.-The Secretary, 19 acting through the Service, shall assign 1 individual in 20 each Area Office to be responsible on a full-time basis for 21 recruitment activities.

22 "SEC. 113. INDIAN RECRUITMENT AND RETENTION PRO23 GRAM.

24 “(a) In GENERAL.-The Secretary, acting through 25 the Service, shall fund, on a competitive basis, innovative 
1 demonstration projects for a period not to exceed 3 years

2 to enable Indian Health Programs and urban Indian orga-

3 nizations to recruit, place, and retain health professionals

4 to meet their staffing needs.

5 “(b) Eligible Entities; Application.-Any In-

6 dian Health Program or Urban Indian organization may

7 submit an application for funding of a project pursuant

8 to this section.

9 “SEC. 114. ADVANCED TRAINING AND RESEARCH.

10 “(a) Demonstration Program.-The Secretary,

11 acting through the Service, shall establish a demonstration

12 project to enable health professionals who have worked in

13 an Indian Health Program or urban Indian organization

14 for a substantial period of time to pursue advanced train-

15 ing or research areas of study for which the Secretary de-

16 termines a need exists.

17 “(b) Service Obligation.-An individual who par-

18 ticipates in a program under subsection (a), where the

19 educational costs are borne by the Service, shall incur an

20 obligation to serve in an Indian Health Program or urban

21 Indian organization for a period of obligated service equal

22 to at least the period of time during which the individual

23 participates in such program. In the event that the indi-

24 vidual fails to complete such obligated service, the indi-

25 vidual shall be liable to the United States for the period 
1 of service remaining. In such event, with respect to indi-

2 viduals entering the program after the date of enactment

3 of the Indian Health Care Improvement Act Amendments

4 of 2009, the United States shall be entitled to recover

5 from such individual an amount to be determined in ac-

6 cordance with the formula specified in subsection (l) of

7 section 110 in the manner provided for in such subsection.

8 “(c) Equal Opportunity for Participation.-

9 Health professionals from Tribal Health Programs and

10 urban Indian organizations shall be given an equal oppor-

11 tunity to participate in the program under subsection (a).

12 "SEC. 115. QUENTIN N. BURDICK AMERICAN INDIANS INTO NURSING PROGRAM.

14 “(a) Grants Authorized.-For the purpose of in-

15 creasing the number of nurses, nurse midwives, and nurse

16 practitioners who deliver health care services to Indians,

17 the Secretary, acting through the Service, shall provide

18 grants to the following:

"(1) Public or private schools of nursing.

“(2) Tribal colleges or universities.

“(3) Nurse midwife programs and advanced

22 practice nurse programs that are provided by any

23 tribal college or university accredited nursing pro-

24 gram, or in the absence of such, any other public or

25 private institutions. 
1 “(b) Use of Grants.—Grants provided under sub2 section (a) may be used for 1 or more of the following: “(1) To recruit individuals for programs which 4 train individuals to be nurses, nurse midwives, or 5 advanced practice nurses.

6 “(2) To provide scholarships to Indians enrolled 7 in such programs that may pay the tuition charged 8 for such program and other expenses incurred in 9 connection with such program, including books, fees, 10 room and board, and stipends for living expenses.

11 “(3) To provide a program that encourages 12 nurses, nurse midwives, and advanced practice 13 nurses to provide, or continue to provide, health care 14 services to Indians.

15 "(4) To provide a program that increases the 16 skills of, and provides continuing education to, 17 nurses, nurse midwives, and advanced practice 18 nurses.

19 "(5) To provide any program that is designed 20 to achieve the purpose described in subsection (a). 21 "(c) ApPLiCations.-Each application for a grant 22 under subsection (a) shall include such information as the 23 Secretary may require to establish the connection between 24 the program of the applicant and a health care facility 25 that primarily serves Indians. 
1 “(d) Preferences for Grant Recipients.-In

2 providing grants under subsection (a), the Secretary shall 3 extend a preference to the following:

4 “(1) Programs that provide a preference to In5 dians.

$6 \quad$ “(2) Programs that train nurse midwives or ad$7 \quad$ vanced practice nurses.

8 "(3) Programs that are interdisciplinary.

9 “(4) Programs that are conducted in coopera-

10 tion with a program for gifted and talented Indian 11 students.

12 “(5) Programs conducted by tribal colleges and 13 universities.

14 “(e) Quentin N. Burdick Program Grant.-The 15 Secretary shall provide 1 of the grants authorized under 16 subsection (a) to establish and maintain a program at the 17 University of North Dakota to be known as the 'Quentin 18 N. Burdick American Indians Into Nursing Program'. 19 Such program shall, to the maximum extent feasible, co20 ordinate with the Quentin N. Burdick Indian Health Pro21 grams established under section 117(b) and the Quentin 22 N. Burdick American Indians Into Psychology Program 23 established under section 105(b).

24 "(f) Active Duty Service Obligation.-The ac25 tive duty service obligation prescribed under section $338 \mathrm{C}$ 
1 of the Public Health Service Act (42 U.S.C. 254m) shall

2 be met by each individual who receives training or assist3 ance described in paragraph (1) or (2) of subsection (b)

4 that is funded by a grant provided under subsection (a).

5 Such obligation shall be met by service-

6 "(1) in the Service;

7 “(2) in a program of an Indian Tribe or Tribal

8 Organization conducted under the Indian Self-Deter-

9 mination and Education Assistance Act (25 U.S.C.

10450 et seq.) (including programs under agreements

11 with the Bureau of Indian Affairs);

12 "(3) in a program assisted under title $\mathrm{V}$ of this

13 Act;

14 "(4) in the private practice of nursing if, as de-

15 termined by the Secretary, in accordance with guide-

16 lines promulgated by the Secretary, such practice is

17 situated in a physician or other health shortage area

18 and addresses the health care needs of a substantial

19 number of Indians; or

20 "(5) in a teaching capacity in a tribal college or 21 university nursing program (or a related health pro22 fession program) if, as determined by the Secretary, 23 health services provided to Indians would not de24 crease. 
1 “SEC. 116. TRIBAL CULTURAL ORIENTATION.

2 “(a) Cultural Education of Employees.-The

3 Secretary, acting through the Service, shall require that

4 appropriate employees of the Service who serve Indian

5 Tribes in each Service Area receive educational instruction

6 in the history and culture of such Indian Tribes and their

7 relationship to the Service.

8 "(b) Program.-In carrying out subsection (a), the

9 Secretary shall establish a program which shall, to the ex-

10 tent feasible-

"(1) be developed in consultation with the af-

12 fected Indian Tribes, Tribal Organizations, and

13 urban Indian organizations;

14 "(2) be carried out through tribal colleges or

15 universities;

16 "(3) include instruction in American Indian

17 studies; and

18 "(4) describe the use and place of traditional

19 health care practices of the Indian Tribes in the 20 Service Area.

21 "SEC. 117. INMED PROGRAM.

22 “(a) Grants Authorized.-The Secretary, acting 23 through the Service, is authorized to provide grants to col24 leges and universities for the purpose of maintaining and 25 expanding the Indian health careers recruitment program 26 known as the 'Indians Into Medicine Program' (herein- 
1 after in this section referred to as 'INMED') as a means

2 of encouraging Indians to enter the health professions.

3 “(b) Quentin N. Burdick Grant.-The Secretary

4 shall provide 1 of the grants authorized under subsection

5 (a) to maintain the INMED program at the University

6 of North Dakota, to be known as the 'Quentin N. Burdick

7 Indian Health Programs', unless the Secretary makes a

8 determination, based upon program reviews, that the pro-

9 gram is not meeting the purposes of this section. Such

10 program shall, to the maximum extent feasible, coordinate

11 with the Quentin N. Burdick American Indians Into Psy-

12 chology Program established under section 105(b) and the

13 Quentin N. Burdick American Indians Into Nursing Pro-

14 gram established under section 115.

15 “(c) Regulations.-The Secretary, pursuant to this

16 Act, shall develop regulations to govern grants pursuant 17 to this section.

18 “(d) REQUIREMENTS.-Applicants for grants pro-

19 vided under this section shall agree to provide a program 20 which-

21 "(1) provides outreach and recruitment for 22 health professions to Indian communities including 23 elementary and secondary schools and community 24 colleges located on reservations which will be served 25 by the program; 
“(2) incorporates a program advisory board comprised of representatives from the Indian Tribes and Indian communities which will be served by the 4 program;

“(3) provides summer preparatory programs for

6 Indian students who need enrichment in the subjects

7 of math and science in order to pursue training in 8 the health professions;

“(4) provides tutoring, counseling, and support

10 to students who are enrolled in a health career pro11 gram of study at the respective college or university; 12 and "(5) to the maximum extent feasible, employs 15 "SEC. 118. HEALTH TRAINING PROGRAMS OF COMMUNITY COLLEGES.

17 “(a) Grants To Establish Programs.-

18 “(1) In GENERAL.-The Secretary, acting 19 through the Service, shall award grants to accredited 20 and accessible community colleges for the purpose of 21 assisting such community colleges in the establish22 ment of programs which provide education in a 23 health profession leading to a degree or diploma in 24 a health profession for individuals who desire to 
1 practice such profession on or near a reservation or

2 in an Indian Health Program.

“(2) Amount of grants.-The amount of any

4 grant awarded to a community college under para-

5 graph (1) for the first year in which such a grant

6 is provided to the community college shall not exceed

$7 \$ 250,000$.

8 “(b) Grants For Maintenance and Recruit-

9 ING.- -

10 “(1) IN GENERAL.-The Secretary, acting

11 through the Service, shall award grants to accredited

12 and accessible community colleges that have estab-

13 lished a program described in subsection (a)(1) for

14 the purpose of maintaining the program and recruit-

15 ing students for the program.

16 “(2) REQUIREMENTS.-Grants may only be 17 made under this section to a community college 18 which-

"(A) is accredited;

"(B) has a relationship with a hospital faprovide training of nurses or health profes23 sionals; 
1706

21 encourage community colleges described in subsection 22 (b)(2) to establish and maintain programs described in 23 subsection (a) (1) by-

“(1) entering into agreements with such col25 leges for the provision of qualified personnel of the 
1 Service to teach courses of study in such programs;

2 and

“(2) providing technical assistance and support

4 to such colleges.

5 “(d) Advanced Training.-

6 “(1) REQUIRED.—Any program receiving as-

7 sistance under this section that is conducted with re-

8 spect to a health profession shall also offer courses

9 of study which provide advanced training for any

10 health professional who-

11 "(A) has already received a degree or di12 ploma in such health profession; and

13 "(B) provides clinical services on or near a 14 reservation or for an Indian Health Program.

15 “(2) May Be offered at aLternate site.-

16 Such courses of study may be offered in conjunction

17 with the college or university with which the commu-

18 nity college has entered into the agreement required

19 under subsection $(b)(2)(C)$.

20 “(e) PRIORITY.-Where the requirements of sub21 section (b) are met, grant award priority shall be provided 22 to tribal colleges and universities in Service Areas where 23 they exist. 
1 “SEC. 119. RETENTION BONUS.

2 “(a) Bonus Authorized.-The Secretary may pay

3 a retention bonus to any health professional employed by,

4 or assigned to, and serving in, an Indian Health Program

5 or urban Indian organization either as a civilian employee

6 or as a commissioned officer in the Regular or Reserve

7 Corps of the Public Health Service who-

"(1) is assigned to, and serving in, a position

9 for which recruitment or retention of personnel is

10 difficult;

11 "(2) the Secretary determines is needed by In-

12 dian Health Programs and urban Indian organiza13 tions;

"(3) has-

"(A) completed 2 years of employment with an Indian Health Program or urban Indian organization; or

"(B) completed any service obligations incurred as a requirement of-

“(i) any Federal scholarship program;

or

“(ii) any Federal education loan re-

payment program; and

“(4) enters into an agreement with an Indian

25 Health Program or urban Indian organization for 
1 continued employment for a period of not less than 21 year.

3 “(b) RATES. - The Secretary may establish rates for 4 the retention bonus which shall provide for a higher an5 nual rate for multiyear agreements than for single year 6 agreements referred to in subsection (a)(4), but in no 7 event shall the annual rate be more than $\$ 25,000$ per 8 annum.

9 “(c) Default of Retention Agreement.-Any 10 health professional failing to complete the agreed upon 11 term of service, except where such failure is through no 12 fault of the individual, shall be obligated to refund to the 13 Government the full amount of the retention bonus for the 14 period covered by the agreement, plus interest as deter15 mined by the Secretary in accordance with section $16110(\mathrm{l})(2)(\mathrm{B})$.

17 “(d) Other Retention Bonus.-The Secretary 18 may pay a retention bonus to any health professional em19 ployed by a Tribal Health Program if such health profes20 sional is serving in a position which the Secretary deter21 mines is"(1) a position for which recruitment or reten23 tion is difficult; and "(2) necessary for providing health care services 25 to Indians. 
1 “SEC. 120. NURSING RESIDENCY PROGRAM.

2 “(a) Establishment of Program.-The Sec-

3 retary, acting through the Service, shall establish a pro-

4 gram to enable Indians who are licensed practical nurses,

5 licensed vocational nurses, and registered nurses who are

6 working in an Indian Health Program or urban Indian

7 organization, and have done so for a period of not less

8 than 1 year, to pursue advanced training. Such program

9 shall include a combination of education and work study

10 in an Indian Health Program or urban Indian organiza-

11 tion leading to an associate or bachelor's degree (in the

12 case of a licensed practical nurse or licensed vocational

13 nurse), a bachelor's degree (in the case of a registered

14 nurse), or advanced degrees or certifications in nursing

15 and public health.

16 “(b) Service Obligation.-An individual who par-

17 ticipates in a program under subsection (a), where the

18 educational costs are paid by the Service, shall incur an

19 obligation to serve in an Indian Health Program or urban

20 Indian organization for a period of obligated service equal

21 to 1 year for every year that nonprofessional employee (li-

22 censed practical nurses, licensed vocational nurses, nurs-

23 ing assistants, and various health care technicians), or 2

24 years for every year that professional nurse (associate de-

25 gree and bachelor-prepared registered nurses), partici-

26 pates in such program. In the event that the individual 
1 fails to complete such obligated service, the United States

2 shall be entitled to recover from such individual an amount

3 determined in accordance with the formula specified sub-

4 section (d)(1) of Section 104 for individuals failing to

5 graduate from their degree program and subsection (l) of

6 Section 110 for individuals failing to start or complete the

7 obligated service.

8 "SEC. 121. COMMUNITY HEALTH AIDE PROGRAM.

9 “(a) General Purposes of Program.-Under the

10 authority of the Act of November 2, 1921 (25 U.S.C. 13)

11 (commonly known as the 'Snyder Act'), the Secretary, act-

12 ing through the Service, shall develop and operate a Com-

13 munity Health Aide Program in Alaska under which the

14 Service-

"(1) provides for the training of Alaska Natives

16 as health aides or community health practitioners;

17 "(2) uses such aides or practitioners in the pro-

18 vision of health care, health promotion, and disease

19 prevention services to Alaska Natives living in vil-

20 lages in rural Alaska; and

"(3) provides for the establishment of tele-

22 conferencing eapacity in health clinies located in or

23 near such villages for use by community health aides

24 or community health practitioners. 
1712

1 “(b) Specific Program Requirements.-The Sec-

2 retary, acting through the Community Health Aide Pro-

3 gram of the Service, shall-

4 “(1) using trainers accredited by the Program,

5 provide a high standard of training to community

6 health aides and community health practitioners to

7 ensure that such aides and practitioners provide

8 quality health care, health promotion, and disease

9 prevention services to the villages served by the Pro-

10 gram;

11 “(2) in order to provide such training, develop

12 a curriculum that-

13 "(A) combines education in the theory of

14 health care with supervised practical experience

15 in the provision of health care;

16 "(B) provides instruction and practical ex-

17 perience in the provision of acute care, emer-

18 gency care, health promotion, disease preven-

19 tion, and the efficient and effective manage-

20 ment of clinic pharmacies, supplies, equipment,

21 and facilities; and

22 "(C) promotes the achievement of the

23 health status objectives specified in section

$24 \quad 3(2)$; 
1713

“(3) establish and maintain a Community

2 Health Aide Certification Board to certify as com-

3 munity health aides or community health practi-

4 tioners individuals who have successfully completed

5 the training described in paragraph (1) or can dem-

6 onstrate equivalent experience;

7 “(4) develop and maintain a system which iden-

8 tifies the needs of community health aides and com-

9 munity health practitioners for continuing education

10 in the provision of health care, including the areas

11 described in paragraph (2)(B), and develop pro-

12 grams that meet the needs for such continuing edu-

13 cation;

14 "(5) develop and maintain a system that pro-

15 vides close supervision of community health aides

16 and community health practitioners;

17 "(6) develop a system under which the work of 18 community health aides and community health prac-

19 titioners is reviewed and evaluated to assure the pro-

20 vision of quality health care, health promotion, and

21 disease prevention services; and

22 “(7) ensure that pulpal therapy (not including

23 pulpotomies on deciduous teeth) or extraction of

24 adult teeth can be performed by a dental health aide

25 therapist only after consultation with a licensed den- 
1 tist who determines that the procedure is a medical

2 emergency that cannot be resolved with palliative

3 treatment, and further that dental health aide thera-

4 pists are strictly prohibited from performing all

5 other oral or jaw surgeries, provided that uncompli-

6 cated extractions shall not be considered oral sur-

7 gery under this section.

$8 \quad$ “(c) Program Review.-

9

“(1) Neutral Panel.-

10 “(A) Establishment.-The Secretary, 11 acting through the Service, shall establish a 12 neutral panel to carry out the study under 13 paragraph (2).

14 "(B) Membership.-Members of the neu15 tral panel shall be appointed by the Secretary 16 from among clinicians, economists, community 17 practitioners, oral epidemiologists, and Alaska $18 \quad$ Natives. “(2) STUdY.-

“(A) IN GENERAL.-The neutral panel established under paragraph (1) shall conduct a study of the dental health aide therapist serv24 Program under this section to ensure that the 
quality of care provided through those services is adequate and appropriate.

"(B) Parameters of study.-The Secretary, in consultation with interested parties, including professional dental organizations, shall develop the parameters of the study. "(C) Inclusions.-The study shall include a determination by the neutral panel with respect to-

"(i) the ability of the dental health aide therapist services under this section to address the dental care needs of Alaska Natives;

"(ii) the quality of care provided through those services, including any training, improvement, or additional oversight required to improve the quality of care; and

"(iii) whether safer and less costly alternatives to the dental health aide therapist services exist.

“(D) Consultation.-In carrying out the study under this paragraph, the neutral panel shall consult with Alaska Tribal Organizations 
with respect to the adequacy and accuracy of the study.

"(3) REPORT.-The neutral panel shall submit

4 to the Secretary, the Committee on Indian Affairs of

5 the Senate, and the Committee on Natural Re6 sources of the House of Representatives a report de7 scribing the results of the study under paragraph 8 (2), including a description of-

"(A) any determination of the neutral panel under paragraph $(2)(\mathrm{C})$; and

"(B) any comments received from an Alaska Tribal Organization under paragraph (2)(D).

16 graph (2), the Secretary, acting through the Service, 17 may establish a national Community Health Aide 18 Program in accordance with the program under this 19 section, as the Secretary determines to be appro20 priate.

“(2) ExceptTIOn.-The national Community 22 Health Aide Program under paragraph (1) shall not 23 include dental health aide therapist services.

“(3) Requirement.-In establishing a na25 tional program under paragraph (1), the Secretary 
1 shall not reduce the amount of funds provided for

2 the Community Health Aide Program described in

3 subsections (a) and (b).

4 “SEC. 122. TRIBAL HEALTH PROGRAM ADMINISTRATION.

5 "The Secretary shall, by contract or otherwise, pro-

6 vide training for individuals in the administration and

7 planning of Tribal Health Programs, with priority to Indi-

8 ans.

9 "SEC. 123. HEALTH PROFESSIONAL CHRONIC SHORTAGE

10 DEMONSTRATION PROGRAMS.

11 “(a) Demonstration Programs Authorized.-

12 The Secretary, acting through the Service, may fund dem-

13 onstration programs for Tribal Health Programs to ad-

14 dress the chronic shortages of health professionals.

15 “(b) Purposes of Programs.-The purposes of

16 demonstration programs funded under subsection (a) shall 17 be-

"(1) to provide direct clinical and practical ex-

19 perience at a Service Unit to health profession stu-

20 dents and residents from medical schools;

21 "(2) to improve the quality of health care for

22 Indians by assuring access to qualified health care

23 professionals; and

24 "(3) to provide academic and scholarly opportu-

25 nities for health professionals serving Indians by 
1 identifying all academic and scholarly resources of

2 the region.

3 “(c) ADVISORY BOARD.-The demonstration pro4 grams established pursuant to subsection (a) shall incor5 porate a program advisory board composed of representa6 tives from the Indian Tribes and Indian communities in

7 the area which will be served by the program.

8 "SEC. 124. NATIONAL HEALTH SERVICE CORPS.

9 “(a) No Reduction in Services.-The Secretary 10 shall not-

11 "(1) remove a member of the National Health 12 Service Corps from an Indian Health Program or 13 urban Indian organization; or

14 "(2) withdraw funding used to support such 15 member, unless the Secretary, acting through the 16 Service, has ensured that the Indians receiving serv17 ices from such member will experience no reduction 18 in services.

19 “(b) Treatment of Indian Health Programs.20 At the request of an Indian Health Program, the services 21 of a member of the National Health Service Corps as22 signed to an Indian Health Program may be limited to 23 the persons who are eligible for services from such Pro24 gram. 
1 "SEC. 125. SUBSTANCE ABUSE COUNSELOR EDUCATIONAL

3 “(a) CONTRACTS AND GRANTS.-The Secretary, act-

4 ing through the Service, may enter into contracts with,

5 or make grants to, accredited tribal colleges and univer-

6 sities and eligible accredited and accessible community col-

7 leges to establish demonstration programs to develop edu-

8 cational curricula for substance abuse counseling.

9 “(b) Use of Funds.-Funds provided under this

10 section shall be used only for developing and providing

11 educational curriculum for substance abuse counseling (in-

12 cluding paying salaries for instructors). Such curricula

13 may be provided through satellite campus programs.

14 “(c) Time Period of Assistance; Renewal.-A

15 contract entered into or a grant provided under this sec-

16 tion shall be for a period of 3 years. Such contract or

17 grant may be renewed for an additional 2-year period

18 upon the approval of the Secretary.

19 “(d) Criteria For Review and Approval of Ap-

20 Plications. - Not later than 180 days after the date of

21 enactment of the Indian Health Care Improvement Act

22 Amendments of 2009, the Secretary, after consultation

23 with Indian Tribes and administrators of tribal colleges

24 and universities and eligible accredited and accessible com-

25 munity colleges, shall develop and issue criteria for the

26 review and approval of applications for funding (including 
1 applications for renewals of funding) under this section.

2 Such criteria shall ensure that demonstration programs 3 established under this section promote the development of

4 the capacity of such entities to educate substance abuse 5 counselors.

6 "(e) Assistance.-The Secretary shall provide such

7 technical and other assistance as may be necessary to en-

8 able grant recipients to comply with the provisions of this 9 section.

10 “(f) REPORT.-Each fiscal year, the Secretary shall 11 submit to the President, for inclusion in the report which 12 is required to be submitted under section 801 for that fis13 cal year, a report on the findings and conclusions derived 14 from the demonstration programs conducted under this 15 section during that fiscal year.

16 “ $(\mathrm{g})$ Definition.-For the purposes of this section, 17 the term 'educational curriculum' means 1 or more of the 18 following:

“(1) Classroom education.

“(2) Clinical work experience.

“(3) Continuing education workshops.

22 "SEC. 126. BEHAVIORAL HEALTH TRAINING AND COMMUNITY EDUCATION PROGRAMS.

24 “(a) STUDY; LisT.-The Secretary, acting through 25 the Service, and the Secretary of the Interior, in consulta- 
1 tion with Indian Tribes and Tribal Organizations, shall 2 conduct a study and compile a list of the types of staff 3 positions specified in subsection (b) whose qualifications 4 include, or should include, training in the identification, 5 prevention, education, referral, or treatment of mental ill6 ness, or dysfunctional and self-destructive behavior.

7 “(b) Positions.- The positions referred to in sub8 section (a) are-

"(1) staff positions within the Bureau of Indian 10 Affairs, including existing positions, in the fields 11 of-

"(A) elementary and secondary education; "(B) social services and family and child welfare;

“(C) law enforcement and judicial services; and "(D) alcohol and substance abuse; "(2) staff positions within the Service; and "(3) staff positions similar to those identified in 20 paragraphs (1) and (2) established and maintained 21 by Indian Tribes, Tribal Organizations (without re22 gard to the funding source), and urban Indian orga23 nizations.

24 “(c) Training Criteria.- 
"(1) In GENERAL.-The appropriate Secretary

2 shall provide training criteria appropriate to each

3 type of position identified in subsection (b)(1) and

$4 \quad(b)(2)$ and ensure that appropriate training has

5 been, or shall be provided to any individual in any

6 such position. With respect to any such individual in

7 a position identified pursuant to subsection (b)(3),

8 the respective Secretaries shall provide appropriate

9 training to, or provide funds to, an Indian Tribe,

10 Tribal Organization, or urban Indian organization

11 for training of appropriate individuals. In the case of

12 positions funded under a contract or compact under

13 the Indian Self-Determination and Education Assist-

14 ance Act (25 U.S.C. 450 et seq.), the appropriate

15 Secretary shall ensure that such training costs are

16 included in the contract or compact, as the Sec-

17 retary determines necessary.

18 “(2) POSITION SPECIFIC TRAINING CRITERIA.-

19 Position specific training criteria shall be culturally

20 relevant to Indians and Indian Tribes and shall en-

21 sure that appropriate information regarding tradi-

22 tional health care practices is provided.

23 “(d) Community Education on Mental Ill-

24 NEss.-The Service shall develop and implement, on re25 quest of an Indian Tribe, Tribal Organization, or urban 
1 Indian organization, or assist the Indian Tribe, Tribal Or-

2 ganization, or urban Indian organization to develop and

3 implement, a program of community education on mental

4 illness. In carrying out this subsection, the Service shall,

5 upon request of an Indian Tribe, Tribal Organization, or

6 urban Indian organization, provide technical assistance to

7 the Indian Tribe, Tribal Organization, or urban Indian or-

8 ganization to obtain and develop community educational

9 materials on the identification, prevention, referral, and

10 treatment of mental illness and dysfunctional and self-de-

11 structive behavior.

12 “(e) Plan.-Not later than 90 days after the date

13 of enactment of the Indian Health Care Improvement Act

14 Amendments of 2009 , the Secretary shall develop a plan

15 under which the Service will increase the health care staff

16 providing behavioral health services by at least 500 posi-

17 tions within 5 years after the date of enactment of this

18 section, with at least 200 of such positions devoted to

19 child, adolescent, and family services. The plan developed

20 under this subsection shall be implemented under the Act

21 of November 2, 1921 (25 U.S.C. 13) (commonly known

22 as the 'Snyder Act').

23 “SEC. 127. EXEMPTION FROM PAYMENT OF CERTAIN FEES.

24 "Employees of a Tribal Health Program or an Urban

25 Indian Organization shall be exempt from payment of li- 
1 censing, registration, and other fees imposed by a Federal

2 agency to the same extent that Commissioned Corps Offi-

3 cers or other employees of the Indian Health Service are

4 exempt from such fees.

5 "SEC. 128. AUTHORIZATION OF APPROPRIATIONS.

6 "There are authorized to be appropriated such sums

7 as may be necessary to carry out this title.

8 “TITLE II-HEALTH SERVICES

9 "SEC. 201. INDIAN HEALTH CARE IMPROVEMENT FUND.

10 “(a) UsE OF Funds.-The Secretary, acting through

11 the Service, is authorized to expend funds, directly or

12 under the authority of the Indian Self-Determination and

13 Education Assistance Act (25 U.S.C. 450 et seq.), which

14 are appropriated under the authority of this section, for

15 the purposes of-

16 "(1) eliminating the deficiencies in health sta-

17 tus and health resources of all Indian Tribes;

18 "(2) eliminating backlogs in the provision of

19 health care services to Indians;

20 "(3) meeting the health needs of Indians in an

21 efficient and equitable manner, including the use of

22 telehealth and telemedicine when appropriate;

23 "(4) eliminating inequities in funding for both

24 direct care and contract health service programs;

25 and 
"(5) augmenting the ability of the Service to

2 meet the following health service responsibilities with

3 respect to those Indian Tribes with the highest levels

4 of health status deficiencies and resource defi-

5 ciencies:

6 “(A) Clinical care, including inpatient care,

outpatient care (including audiology, clinical

eye, and vision care), primary care, secondary

and tertiary care, and long-term care.

"(B) Preventive health, including mammography and other cancer screening in accordance with section 207.

“(C) Dental care.

"(D) Mental health, including community mental health services, inpatient mental health services, dormitory mental health services, therapeutic and residential treatment centers, and training of traditional health care practitioners.

“(E) Emergency medical services.

"(F) Treatment and control of, and rehaIndians. 
“(G) Injury prevention programs, including data collection and evaluation, demonstration projects, training, and capacity building.

“(H) Home health care.

"(I) Community health representatives.

“(J) Maintenance and improvement.

8 priated under the authority of this section shall not be

9 used to offset or limit any other appropriations made to

10 the Service under this Act or the Act of November 2, 1921

11 (25 U.S.C. 13) (commonly known as the 'Snyder Act'), 12 or any other provision of law. “(1) IN GENERAL.-Funds appropriated under 15 the authority of this section shall be allocated to 16 Service Units, Indian Tribes, or Tribal Organiza17 tions. The funds allocated to each Indian Tribe, 18 Tribal Organization, or Service Unit under this 19 paragraph shall be used by the Indian Tribe, Tribal 20 Organization, or Service Unit under this paragraph 21 to improve the health status and reduce the resource 22 deficiency of each Indian Tribe served by such Serv23 ice Unit, Indian Tribe, or Tribal Organization. “(2) APPORTIONMENT OF ALLOCATED 25 FUNDS. - The apportionment of funds allocated to a 
1 Service Unit, Indian Tribe, or Tribal Organization

2 under paragraph (1) among the health service re3 sponsibilities described in subsection (a)(5) shall be

4 determined by the Service in consultation with, and 5 with the active participation of, the affected Indian 6 Tribes and Tribal Organizations.

7 “(d) Provisions Relating to Health Status 8 and Resource Deficiencies.-For the purposes of this 9 section, the following definitions apply:

10 “(1) Definition.-The term 'health status 11 and resource deficiency' means the extent to 12 which-

"(A) the health status objectives set forth in section 3(2) are not being achieved; and "(B) the Indian Tribe or Tribal Organization does not have available to it the health resources it needs, taking into account the actual cost of providing health care services given local geographic, climatic, rural, or other circumstances.

"(2) Available Resources.-The health re23 nization include health resources provided by the 24 Service as well as health resources used by the In25 dian Tribe or Tribal Organization, including services 
1 and financing systems provided by any Federal pro-

2 grams, private insurance, and programs of State or

3 local governments.

“(3) Process For Review OF DETERMina-

5 TIONs.-The Secretary shall establish procedures

6 which allow any Indian Tribe or Tribal Organization

7 to petition the Secretary for a review of any deter-

8 mination of the extent of the health status and re-

9 source deficiency of such Indian Tribe or Tribal Or-

10 ganization.

11 “(e) Eligibility For Funds.-Tribal Health Pro-

12 grams shall be eligible for funds appropriated under the

13 authority of this section on an equal basis with programs

14 that are administered directly by the Service.

15 "(f) REPORT.-By no later than the date that is 3

16 years after the date of enactment of the Indian Health

17 Care Improvement Act Amendments of 2009, the Sec-

18 retary shall submit to Congress the current health status

19 and resource deficiency report of the Service for each

20 Service Unit, including newly recognized or acknowledged

21 Indian Tribes. Such report shall set out-

22 "(1) the methodology then in use by the Service

23 for determining Tribal health status and resource

24 deficiencies, as well as the most recent application of

25 that methodology; 
"(2) the extent of the health status and re-

2 source deficiency of each Indian Tribe served by the

3 Service or a Tribal Health Program;

"(3) the amount of funds necessary to eliminate

5 the health status and resource deficiencies of all In-

6 dian Tribes served by the Service or a Tribal Health

$7 \quad$ Program; and

8

9

10

11

12

13

14

15

16

17

18

19
"(4) an estimate of-

"(A) the amount of health service funds appropriated under the authority of this Act, or any other Act, including the amount of any funds transferred to the Service for the preceding fiscal year which is allocated to each Service Unit, Indian Tribe, or Tribal Organization;

"(B) the number of Indians eligible for health services in each Service Unit or Indian Tribe or Tribal Organization; and "(C) the number of Indians using the Service resources made available to each Service Unit, Indian Tribe or Tribal Organization, and, to the extent available, information on the waiting lists and number of Indians turned away for services due to lack of resources. 
1 “(g) Inclusion in Base Budget.-Funds appro-

2 priated under this section for any fiscal year shall be in3 cluded in the base budget of the Service for the purpose 4 of determining appropriations under this section in subse5 quent fiscal years.

6 "(h) Clarification.-Nothing in this section is in7 tended to diminish the primary responsibility of the Serv8 ice to eliminate existing backlogs in unmet health care 9 needs, nor are the provisions of this section intended to 10 discourage the Service from undertaking additional efforts 11 to achieve equity among Indian Tribes and Tribal Organi12 zations.

13 "(i) Funding Designation.-Any funds appro14 priated under the authority of this section shall be des15 ignated as the 'Indian Health Care Improvement Fund'. 16 “SEC. 202. HEALTH PROMOTION AND DISEASE PREVENTION SERVICES.

18 “(a) Findings.-Congress finds that health pro19 motion and disease prevention activities"(1) improve the health and well-being of Indi21 ans; and "(2) reduce the expenses for health care of In23 dians.

24 "(b) Provision of Services.-The Secretary, act25 ing through the Service, shall provide health promotion 
1 and disease prevention services to Indians to achieve the

2 health status objectives set forth in section 3(2).

3 “(c) Evaluation.-The Secretary, after obtaining

4 input from the affected Tribal Health Programs, shall

5 submit to the President for inclusion in the report which

6 is required to be submitted to Congress under section 801

7 an evaluation of-

8

9 tion needs of Indians;

10 "(2) the health promotion and disease preven-

11 tion activities which would best meet such needs;

12

13 Tribal Health Programs to meet such needs; and

14

15 enable the Service and Tribal Health Programs to

16 undertake the health promotion and disease preven-

17 tion activities necessary to meet such needs.

18 "SEC. 203. DIABETES PREVENTION, TREATMENT, AND CON-

TROL.

“(a) Determinations Regarding Diabetes.-

21 The Secretary, acting through the Service, and in con-

22 sultation with Indian Tribes and Tribal Organizations, 23 shall determine- 
1732

“(1) by Indian Tribe and by Service Unit, the

2 incidence of, and the types of complications resulting

3 from, diabetes among Indians; and

"(2) based on the determinations made pursu-

5 ant to paragraph (1), the measures (including pa-

6 tient education and effective ongoing monitoring of

7 disease indicators) each Service Unit should take to

8 reduce the incidence of, and prevent, treat, and con-

9 trol the complications resulting from, diabetes

10 among Indian Tribes within that Service Unit.

11 "(b) Diabetes Screening.-To the extent medi-

12 cally indicated and with informed consent, the Secretary

13 shall screen each Indian who receives services from the

14 Service for diabetes and for conditions which indicate a

15 high risk that the individual will become diabetic and es-

16 tablish a cost-effective approach to ensure ongoing moni-

17 toring of disease indicators. Such screening and moni-

18 toring may be conducted by a Tribal Health Program and

19 may be conducted through appropriate Internet-based

20 health care management programs.

21 "(c) Diabetes Projects.-The Secretary shall con-

22 tinue to maintain each model diabetes project in existence

23 on the date of enactment of the Indian Health Care Im-

24 provement Act Amendments of 2009. 
1 “(d) Dialysis Programs.-The Secretary is author2 ized to provide, through the Service, Indian Tribes, and 3 Tribal Organizations, dialysis programs, including the 4 purchase of dialysis equipment and the provision of nec5 essary staffing.

6 “(e) OTHER Duties OF THE Secretary.“(1) IN GENERAL.-The Secretary shall, to the 8 extent funding is availabledian Tribes and Tribal Organizations regarding programs for the prevention, treatment, and control of diabetes;

"(B) establish in each Area Office a registry of patients with diabetes to track the incidence of diabetes and the complications from diabetes in that area; and

"(C) ensure that data collected in each Area Office regarding diabetes and related complications among Indians are disseminated to all other Area Offices, subject to applicable patient privacy laws.

“(2) Diabetes control OFficers.“(A) In generaL._-The Secretary may establish and maintain in each Area Office a position of diabetes control officer to coordinate and 
manage any activity of that Area Office relating to the prevention, treatment, or control of diabetes to assist the Secretary in carrying out a program under this section or section $330 \mathrm{C}$ of the Public Health Service Act (42 U.S.C. 254c$3)$.

"(B) Certain activities.-Any activity carried out by a diabetes control officer under subparagraph (A) that is the subject of a contract or compact under the Indian Self-Determination and Education Assistance Act (25 U.S.C. 450 et seq.), and any funds made available to carry out such an activity, shall not be divisible for purposes of that Act.

\section{5 “SEC. 204. SHARED SERVICES FOR LONG-TERM CARE.}

“(a) Long-Term CARE.-Notwithstanding any other

17 provision of law, the Secretary, acting through the Service,

18 is authorized to provide directly, or enter into contracts

19 or compacts under the Indian Self-Determination and

20 Education Assistance Act (25 U.S.C. 450 et seq.) with

21 Indian Tribes or Tribal Organizations for, the delivery of

22 long-term care (including health care services associated

23 with long-term care) provided in a facility to Indians. Such

24 agreements shall provide for the sharing of staff or other 25 services between the Service or a Tribal Health Program 
1 and a long-term care or related facility owned and oper-

2 ated (directly or through a contract or compact under the

3 Indian Self-Determination and Education Assistance Act

4 (25 U.S.C. 450 et seq.)) by such Indian Tribe or Tribal

5 Organization.

6 “(b) Contents of Agreements.-An agreement

7 entered into pursuant to subsection (a) -

8 "(1) may, at the request of the Indian Tribe or

9 Tribal Organization, delegate to such Indian Tribe

10 or Tribal Organization such powers of supervision

11 and control over Service employees as the Secretary

12 deems necessary to carry out the purposes of this

13 section;

14 "(2) shall provide that expenses (including sala-

15 ries) relating to services that are shared between the

16 Service and the Tribal Health Program be allocated

17 proportionately between the Service and the Indian

18 Tribe or Tribal Organization; and

19 “(3) may authorize such Indian Tribe or Tribal

20 Organization to construct, renovate, or expand a

21 long-term care or other similar facility (including the

22 construction of a facility attached to a Service facil23 ity).

24 “(c) Minimum Requirement.-Any nursing facility 25 provided for under this section shall meet the require- 
1 ments for nursing facilities under section 1919 of the So-

2 cial Security Act.

3 “(d) Other Assistance.-The Secretary shall pro-

4 vide such technical and other assistance as may be nec-

5 essary to enable applicants to comply with the provisions 6 of this section.

7 “(e) Use of Existing or Underused Facili-

8 TIES.-The Secretary shall encourage the use of existing

9 facilities that are underused or allow the use of swing beds

10 for long-term or similar care.

11 “SEC. 205. HEALTH SERVICES RESEARCH.

12 “(a) In GeneraL.- The Secretary, acting through

13 the Service, shall make funding available for research to

14 further the performance of the health service responsibil-

15 ities of Indian Health Programs.

16 “(b) Coordination of Resources and ACtivi-

17 TIES.-The Secretary shall also, to the maximum extent

18 practicable, coordinate departmental research resources

19 and activities to address relevant Indian Health Program

20 research needs.

21 “(c) Availability.-Tribal Health Programs shall

22 be given an equal opportunity to compete for, and receive,

23 research funds under this section.

24 “(d) UsE of Funds.-This funding may be used for

25 both clinical and nonclinical research. 
1 “(e) Evaluation and Dissemination.-The Sec-

2 retary shall periodically-

"(1) evaluate the impact of research conducted

$4 \quad$ under this section; and

“(2) disseminate to Tribal Health Programs in-

6 formation regarding that research as the Secretary

7 determines to be appropriate.

8 "SEC. 206. MAMMOGRAPHY AND OTHER CANCER SCREENING.

10 "The Secretary, acting through the Service, shall pro-

11 vide for screening as follows:

“(1) Screening mammography (as defined in 13 section 1861(jj) of the Social Security Act) for In14 dian women at a frequency appropriate to such 15 women under accepted and appropriate national 16 standards, and under such terms and conditions as 17 are consistent with standards established by the Sec18 retary to ensure the safety and accuracy of screen19 ing mammography under part B of title XVIII of 20 such Act.

21 "(2) Other cancer screening that receives an A 22 or B rating as recommended by the United States 23 Preventive Services Task Force established under 24 section 915(a)(1) of the Public Health Service Act 25 (42 U.S.C. 299b-4(a)(1)). The Secretary shall en- 
1 sure that screening provided for under this para2 graph complies with the recommendations of the 3 Task Force with respect to-

4

\section{1 "SEC. 207. PATIENT TRAVEL COSTS.}

“(a) Definition of Qualified Escort.-In this

13 section, the term 'qualified escort' means-

“(1) an adult escort (including a parent, guard15 ian, or other family member) who is required be16 cause of the physical or mental condition, or age, of 17 the applicable patient; 23 priate.

24 "(b) Provision of Funds.-The Secretary, acting 25 through the Service, is authorized to provide funds for the 
1 following patient travel costs, including qualified escorts,

2 associated with receiving health care services provided (ei-

3 ther through direct or contract care or through a contract

4 or compact under the Indian Self-Determination and Edu-

5 cation Assistance Act (25 U.S.C. 450 et seq.)) under this 6 Act-

"(1) emergency air transportation and non-

8 emergency air transportation where ground trans-

9 portation is infeasible;

10 "(2) transportation by private vehicle (where no

11 other means of transportation is available), specially

12 equipped vehicle, and ambulance; and

13 "(3) transportation by such other means as

14 may be available and required when air or motor ve-

15 hicle transportation is not available.

16 "SEC. 208. EPIDEMIOLOGY CENTERS.

17 “(a) Establishment of Centers.-The Secretary

18 shall establish an epidemiology center in each Service Area

19 to carry out the functions described in subsection (b). Any

20 new center established after the date of enactment of the

21 Indian Health Care Improvement Act Amendments of

222008 may be operated under a grant authorized by sub-

23 section (d), but funding under such a grant shall not be 24 divisible. 
1 “(b) FunCtions of CEnTERs.-In consultation with

2 and upon the request of Indian Tribes, Tribal Organiza-

3 tions, and Urban Indian communities, each Service Area

4 epidemiology center established under this section shall,

5 with respect to such Service Area-

6 "(1) collect data relating to, and monitor

7 progress made toward meeting, each of the health

8 status objectives of the Service, the Indian Tribes,

9 Tribal Organizations, and Urban Indian commu-

10 nities in the Service Area;

11 “(2) evaluate existing delivery systems, data

12 systems, and other systems that impact the improve-

13 ment of Indian health;

14 “(3) assist Indian Tribes, Tribal Organizations, 15 and Urban Indian Organizations in identifying their 16 highest priority health status objectives and the 17 services needed to achieve such objectives, based on 18 epidemiological data;

19 "(4) make recommendations for the targeting 20 of services needed by the populations served;

21 “(5) make recommendations to improve health 22 care delivery systems for Indians and Urban Indi23 ans;

24 “(6) provide requested technical assistance to 25 Indian Tribes, Tribal Organizations, and Urban In- 
1 dian Organizations in the development of local

2 health service priorities and incidence and prevalence

3 rates of disease and other illness in the community;

4 and

$5 \quad$ “(7) provide disease surveillance and assist In6 dian Tribes, Tribal Organizations, and Urban Indian 7 communities to promote public health.

8 “(c) Technical Assistance.-The Director of the 9 Centers for Disease Control and Prevention shall provide 10 technical assistance to the centers in carrying out the re11 quirements of this section.

12 “(d) Grants For Studies.-

13 "(1) In GeneraL.-The Secretary may make 14 grants to Indian Tribes, Tribal Organizations, In15 dian organizations, and eligible intertribal consortia 16 to conduct epidemiological studies of Indian commu17 nities.

“(2) Eligible intertribal CONsortia.-An

19 intertribal consortium or Indian organization is eligi20 ble to receive a grant under this subsection if"(A) the intertribal consortium is incor-

23 Indian health; and

"(B) the intertribal consortium is rep25 resentative of the Indian Tribes or urban In- 
dian communities in which the intertribal consortium is located.

"(3) ApPlications.-An application for a 4 grant under this subsection shall be submitted in 5 such manner and at such time as the Secretary shall 6 prescribe.

“(4) Requirements.-An applicant for a 8 grant under this subsection shall-

"(A) demonstrate the technical, administrative, and financial expertise necessary to carry out the functions described in paragraph $(5)$;

"(B) consult and cooperate with providers of related health and social services in order to avoid duplication of existing services; and

"(C) demonstrate cooperation from Indian Tribes or Urban Indian Organizations in the area to be served.

“(5) UsE OF FUNDS. - A grant awarded under paragraph (1) may be used-

"(A) to carry out the functions described in subsection (b); "(B) to provide information to and consult with tribal leaders, urban Indian community 
leaders, and related health staff on health care

and health service management issues; and

"(C) in collaboration with Indian Tribes, Tribal Organizations, and urban Indian communities, to provide the Service with information regarding ways to improve the health status of Indians.

“(e) Access to Information.-

“(1) An epidemiology center operated by a grantee pursuant to a grant awarded under subsection (d) shall be treated as a public health authority for purposes of the Health Insurance Portability and Accountability Act of 1996, as such entities are defined in part 164.501 of title 45 , Code of Federal Regulations.

“(2) The Secretary shall grant to such epidemiology center access to use of the data, data sets, monitoring systems, delivery systems, and other protected health information in the possession of the Secretary.

"(3) The activities of such an epidemiology center shall be for the purposes of research and for preventing and controlling disease, injury, or disability for purposes of the Health Insurance Portability and Accountability Act of 1996 (Public Law 104-191; 
1110 Stat. 2033), as such activities are described in

2 part 164.512 of title 45, Code of Federal Regula-

3 tions (or a successor regulation).

4 “(f) Funds Not Divisible.-An epidemiology cen-

5 ter established under this section shall be subject to the 6 provisions of the Indian Self-Determination and Edu7 cation Assistance Act (25 U.S.C. 450 et seq.), but the

8 funds for such center shall not be divisible.

9 "SEC. 209. COMPREHENSIVE SCHOOL HEALTH EDUCATION PROGRAMS.

11 “(a) Funding for Development of Programs.-

12 In addition to carrying out any other program for health

13 promotion or disease prevention, the Secretary, acting

14 through the Service, is authorized to award grants to In15 dian Tribes and Tribal Organizations to develop com16 prehensive school health education programs for children

17 from pre-school through grade 12 in schools for the benefit 18 of Indian children.

19 “(b) Use OF Grant Funds.-A grant awarded 20 under this section may be used for purposes which may 21 include, but are not limited to, the following:

22 “(1) Developing health education materials both 23 for regular school programs and afterschool pro24 grams. 
“(2) Training teachers in comprehensive school

2 health education materials.

"(3) Integrating school-based, community-

4 based, and other public and private health promotion 5 efforts.

6 “(4) Encouraging healthy, tobacco-free school 7 environments.

“(5) Coordinating school-based health programs

9 with existing services and programs available in the 10 community.

11 “(6) Developing school programs on nutrition 12 education, personal health, oral health, and fitness.

13 “(7) Developing behavioral health wellness pro14 grams.

15 “(8) Developing chronic disease prevention pro16 grams.

17 “(9) Developing substance abuse prevention 18 programs.

19 “(10) Developing injury prevention and safety 20 education programs.

21 "(11) Developing activities for the prevention 22 and control of communicable diseases.

23 “(12) Developing community and environmental 24 health education programs that include traditional 25 health care practitioners. 
“(13) Violence prevention.

"(14) Such other health issues as are appro-

3 priate.

4 “(c) Technical Assistance.-Upon request, the

5 Secretary, acting through the Service, shall provide tech-

6 nical assistance to Indian Tribes and Tribal Organizations

7 in the development of comprehensive health education

8 plans and the dissemination of comprehensive health edu-

9 cation materials and information on existing health pro-

10 grams and resources.

11 “(d) Criteria For Review and Approval of Ap-

12 Plications.- The Secretary, acting through the Service,

13 and in consultation with Indian Tribes and Tribal Organi-

14 zations, shall establish criteria for the review and approval

15 of applications for grants awarded under this section.

16 “(e) Development of Program for BLA-Funded

17 Schools.-

18 "(1) In GeneraL.-The Secretary of the Inte19 rior, acting through the Bureau of Indian Affairs 20 and in cooperation with the Secretary, acting 21 through the Service, shall develop a comprehensive 22 school health education program for children from 23 preschool through grade 12 in schools for which sup24 port is provided by the Bureau of Indian Affairs. 
“(2) Requirements FOR PROGRAMS.-Such

2 programs shall include-

"(A) school programs on nutrition education, personal health, oral health, and fitness; "(B) behavioral health wellness programs;

"(C) chronic disease prevention programs;

“(D) substance abuse prevention programs;

"(E) injury prevention and safety education programs; and

"(F) activities for the prevention and control of communicable diseases. “(3) Duties of the secretary.-The Sec14 retary of the Interior shall-

"(A) provide training to teachers in comprehensive school health education materials;

"(B) ensure the integration and coordination of school-based programs with existing services and health programs available in the community; and

\section{3 "SEC. 210. INDIAN YOUTH PROGRAM.}

24 "(a) Program Authorized.-The Secretary, acting 25 through the Service, is authorized to establish and admin- 
1748

1 ister a program to provide grants to Indian Tribes, Tribal

2 Organizations, and urban Indian organizations for innova-

3 tive mental and physical disease prevention and health

4 promotion and treatment programs for Indian and urban

5 Indian preadolescent and adolescent youths.

6 “(b) Use of Funds.-

7 “(1) Allowable uses.-Funds made available

8 under this section may be used to-

9 “(A) develop prevention and treatment

10 programs for Indian youth which promote men-

11 tal and physical health and incorporate cultural

12 values, community and family involvement, and

13 traditional health care practitioners; and

14 "(B) develop and provide community train-

15 ing and education.

16 “(2) Prohibited Use.-Funds made available

17 under this section may not be used to provide serv-

18 ices described in section 707(c).

19 “(c) Duties of the Secretary.-The Secretary

20 shall-

"(1) disseminate to Indian Tribes, Tribal Orga-

22 nizations, and urban Indian organizations informa-

23 tion regarding models for the delivery of comprehen-

24 sive health care services to Indian and urban Indian 25 adolescents; 
"(2) encourage the implementation of such

2 models; and

"(3) at the request of an Indian Tribe, Tribal

4 Organization, or urban Indian organization, provide

5 technical assistance in the implementation of such

6 models.

7 “(d) Criteria for Review and Approval of Ap-

8 PLications._- The Secretary, in consultation with Indian

9 Tribes, Tribal Organizations, and urban Indian organiza-

10 tions, shall establish criteria for the review and approval

11 of applications or proposals under this section.

12 “SEC. 211. PREVENTION, CONTROL, AND ELIMINATION OF COMMUNICABLE AND INFECTIOUS DISEASES.

14 "(a) GRANTs AuthorIzED.—The Secretary, acting 15 through the Service, and after consultation with the Cen16 ters for Disease Control and Prevention, may make grants 17 available to Indian Tribes, Tribal Organizations, and 18 urban Indian organizations for the following: 23 eases, and H. Pylori. 
1750

“(2) Public information and education pro-

2 grams for the prevention, control, and elimination of

3 communicable and infectious diseases.

“(3) Education, training, and clinical skills im-

5 provement activities in the prevention, control, and

6 elimination of communicable and infectious diseases

7 for health professionals, including allied health pro-

8 fessionals.

9 “(4) Demonstration projects for the screening, 10 treatment, and prevention of hepatitis $\mathrm{C}$ virus 11 (HCV).

12 “(b) Application Required.-The Secretary may 13 provide funding under subsection (a) only if an application 14 or proposal for funding is submitted to the Secretary.

15 “(c) Coordination With Health Agencies.-In16 dian Tribes, Tribal Organizations, and urban Indian orga17 nizations receiving funding under this section are encour18 aged to coordinate their activities with the Centers for 19 Disease Control and Prevention and State and local health 20 agencies.

21 “(d) Technical Assistance; Report.-In carrying 22 out this section, the Secretary-

23 "(1) may, at the request of an Indian Tribe, 24 Tribal Organization, or urban Indian organization, 25 provide technical assistance; and 
1751

"(2) shall prepare and submit a report to Con-

2 gress biennially on the use of funds under this sec-

3 tion and on the progress made toward the preven-

4 tion, control, and elimination of communicable and

5 infectious diseases among Indians and Urban Indi6 ans.

7 "SEC. 212. OTHER AUTHORITY FOR PROVISION OF SERV-

ICES.

9 “(a) Funding Authorized.-The Secretary may

10 provide funding under this Act to meet the objectives set

11 forth in section 3 of this Act through health care-related

12 services and programs of the Service, Indian Tribes, and

13 Tribal Organizations not otherwise described in this Act

14 for the following services:

15

16

17

20 eligible to receive long-term care under this section:

“(1) Hospice care.

"(2) Assisted living services.

“(3) Long-term care services.

“(4) Home- and community-based services.

"(b) EligibiLity.-The following individuals shall be

“(1) Individuals who are unable to perform a certain number of activities of daily living without assistance.

“(2) Individuals with a mental impairment, such as dementia, Alzheimer's disease, or another 
1 disabling mental illness, who may be able to perform

2 activities of daily living under supervision.

3 “(3) Such other individuals as an applicable In-

4 dian Health Program determines to be appropriate.

5 “(c) Definitions.-For the purposes of this section, 6 the following definitions shall apply:

“(1) The term 'assisted living services' means

8 any service provided by an assisted living facility (as

9 defined in section 232(b) of the National Housing

10 Act (12 U.S.C. $1715 \mathrm{w}(\mathrm{b}))$ ), except that such an as-

11 sisted living facility-

12 "(A) shall not be required to obtain a li-

13 cense; but

14 "(B) shall meet all applicable standards

15 for licensure.

16 "(2) The term 'home- and community-based 17 services' means 1 or more of the services specified 18 in paragraphs (1) through (9) of section 1929(a) of

19 the Social Security Act (42 U.S.C. 1396t(a))

20 (whether provided by the Service or by an Indian 21 Tribe or Tribal Organization pursuant to the Indian 22 Self-Determination and Education Assistance Act 23 (25 U.S.C. 450 et seq.)) that are or will be provided 24 in accordance with applicable standards. 
"(3) The term 'hospice care' means the items

2 and services specified in subparagraphs (A) through

3 (H) of section 1861(dd)(1) of the Social Security

4 Act (42 U.S.C. $1395 x(d d)(1))$, and such other serv-

5 ices which an Indian Tribe or Tribal Organization

6 determines are necessary and appropriate to provide

7 in furtherance of this care.

8 “(4) The term 'long-term care services' has the

9 meaning given the term 'qualified long-term care

10 services' in section $7702 \mathrm{~B}(\mathrm{c})$ of the Internal Rev-

11 enue Code of 1986.

12 “(d) Authorization of Convenient Care Serv-

13 ICES.-The Secretary, acting through the Service, Indian

14 Tribes, and Tribal Organizations, may also provide fund-

15 ing under this Act to meet the objectives set forth in sec-

16 tion 3 of this Act for convenient care services programs

17 pursuant to section 306(c)(2)(A).

18 “SEC. 213. INDIAN WOMEN'S HEALTH CARE.

19 "The Secretary, acting through the Service and In20 dian Tribes, Tribal Organizations, and Urban Indian Or21 ganizations, shall monitor and improve the quality of 22 health care for Indian women of all ages through the plan23 ning and delivery of programs administered by the Service, 24 in order to improve and enhance the treatment models of 25 care for Indian women. 
1 “SEC. 214. ENVIRONMENTAL AND NUCLEAR HEALTH HAZARDS.

3 “(a) STUDIES AND Monitoring.-The Secretary 4 and the Service shall conduct, in conjunction with other 5 appropriate Federal agencies and in consultation with con6 cerned Indian Tribes and Tribal Organizations, studies 7 and ongoing monitoring programs to determine trends in 8 the health hazards to Indian miners and to Indians on 9 or near reservations and Indian communities as a result 10 of environmental hazards which may result in chronic or 11 life threatening health problems, such as nuclear resource

12 development, petroleum contamination, and contamination 13 of water source and of the food chain. Such studies shall 14 include-

"(1) an evaluation of the nature and extent of 16 health problems caused by environmental hazards 17 currently exhibited among Indians and the causes of 18 such health problems;

19 "(2) an analysis of the potential effect of ongo20 ing and future environmental resource development 21 on or near reservations and Indian communities, in22 cluding the cumulative effect over time on health;

23 "(3) an evaluation of the types and nature of 24 activities, practices, and conditions causing or affect25 ing such health problems, including uranium mining 26 and milling, uranium mine tailing deposits, nuclear 
1 power plant operation and construction, and nuclear

2 waste disposal; oil and gas production or transpor-

3 tation on or near reservations or Indian commu-

4 nities; and other development that could affect the

5 health of Indians and their water supply and food 6 chain;

7 "(4) a summary of any findings and rec-

8 ommendations provided in Federal and State stud-

9 ies, reports, investigations, and inspections during

10 the 5 years prior to the date of enactment of the In-

11 dian Health Care Improvement Act Amendments of

122009 that directly or indirectly relate to the activi-

13 ties, practices, and conditions affecting the health or

14 safety of such Indians; and

15 "(5) the efforts that have been made by Federal

16 and State agencies and resource and economic devel-

17 opment companies to effectively carry out an edu-

18 cation program for such Indians regarding the

19 health and safety hazards of such development.

20 "(b) Health Care Plans.-Upon completion of

21 such studies, the Secretary and the Service shall take into

22 account the results of such studies and develop health care

23 plans to address the health problems studied under sub-

24 section (a). The plans shall include- 
“(1) methods for diagnosing and treating Indi-

2 ans currently exhibiting such health problems;

"(2) preventive care and testing for Indians

4 who may be exposed to such health hazards, includ-

5 ing the monitoring of the health of individuals who

6 have or may have been exposed to excessive amounts

7 of radiation or affected by other activities that have

8 had or could have a serious impact upon the health

9 of such individuals; and

10 “(3) a program of education for Indians who,

11 by reason of their work or geographic proximity to

12 such nuclear or other development activities, may ex-

13 perience health problems.

14 “(c) Submission of Report and Plan to Con-

15 GRESS.-The Secretary and the Service shall submit to

16 Congress the study prepared under subsection (a) no later

17 than 18 months after the date of enactment of the Indian

18 Health Care Improvement Act Amendments of 2009. The

19 health care plan prepared under subsection (b) shall be

20 submitted in a report no later than 1 year after the study

21 prepared under subsection (a) is submitted to Congress.

22 Such report shall include recommended activities for the

23 implementation of the plan, as well as an evaluation of

24 any activities previously undertaken by the Service to ad-

25 dress such health problems. 


\section{“(d) Intergovernmental Task Force.-}

“(1) Establishment; members.-There is established an Intergovernmental Task Force to be composed of the following individuals (or their designees):

"(A) The Secretary of Energy.

"(B) The Secretary of the Environmental Protection Agency.

"(C) The Director of the Bureau of Mines.

“(D) The Assistant Secretary for Occupational Safety and Health.

"(E) The Secretary of the Interior.

"(F) The Secretary of Health and Human Services.

"(G) The Director of the Indian Health Service.

“(2) Duties.—The Task Force shall—

“(A) identify existing and potential operations related to nuclear resource development or other environmental hazards that affect or may affect the health of Indians on or near a reservation or in an Indian community; and

"(B) enter into activities to correct existing health hazards and ensure that current and future health problems resulting from nuclear 
1 resource or other development activities are

2 minimized or reduced.

“(3) Chairman; meetings.-The Secretary of

4 Health and Human Services shall be the Chairman

5 of the Task Force. The Task Force shall meet at 6 least twice each year.

7 “(e) Health Services to Certain Employees.8 In the case of any Indian who-

“(1) as a result of employment in or near a 10 uranium mine or mill or near any other environ11 mental hazard, suffers from a work-related illness or 12 condition;

13 "(2) is eligible to receive diagnosis and treat14 ment services from an Indian Health Program; and 15 “(3) by reason of such Indian's employment, is 16 entitled to medical care at the expense of such mine 17 or mill operator or entity responsible for the environ18 mental hazard, the Indian Health Program shall, at 19 the request of such Indian, render appropriate med20 ical care to such Indian for such illness or condition 21 and may be reimbursed for any medical care so ren22 dered to which such Indian is entitled at the expense 23 of such operator or entity from such operator or en24 tity. Nothing in this subsection shall affect the 25 rights of such Indian to recover damages other than 
1759

1 such amounts paid to the Indian Health Program

2 from the employer for providing medical care for 3 such illness or condition.

4 “SEC. 215. ARIZONA AS A CONTRACT HEALTH SERVICE DE-

\section{LIVERY AREA.}

6 “(a) In GeneraL._For fiscal years beginning with

7 the fiscal year ending September 30, 1983, and ending

8 with the fiscal year ending September 30, 2025, the State

9 of Arizona shall be designated as a contract health service

10 delivery area by the Service for the purpose of providing

11 contract health care services to members of federally rec-

12 ognized Indian Tribes of Arizona.

13 “(b) Maintenance of Services.-The Service

14 shall not curtail any health care services provided to Indi15 ans residing on reservations in the State of Arizona if such

16 curtailment is due to the provision of contract services in 17 such State pursuant to the designation of such State as 18 a contract health service delivery area pursuant to sub19 section (a).

20 "SEC. 216. NORTH DAKOTA AND SOUTH DAKOTA AS CONTRACT HEALTH SERVICE DELIVERY AREA.

22 “(a) In GeneraL.-Beginning in fiscal year 2003, 23 the States of North Dakota and South Dakota shall be 24 designated as a contract health service delivery area by 25 the Service for the purpose of providing contract health 
1 care services to members of federally recognized Indian

2 Tribes of North Dakota and South Dakota.

3 “(b) Limitation.-The Service shall not curtail any

4 health care services provided to Indians residing on any

5 reservation, or in any county that has a common boundary

6 with any reservation, in the State of North Dakota or

7 South Dakota if such curtailment is due to the provision

8 of contract services in such States pursuant to the des-

9 ignation of such States as a contract health service deliv-

10 ery area pursuant to subsection (a).

11 "SEC. 217. CALIFORNIA CONTRACT HEALTH SERVICES PROGRAM.

13 “(a) Funding Authorized.-The Secretary is au-

14 thorized to fund a program using the California Rural In-

15 dian Health Board (hereafter in this section referred to

16 as the 'CRIHB') as a contract care intermediary to im-

17 prove the accessibility of health services to California Indi18 ans.

19 "(b) Reimbursement Contract.-The Secretary 20 shall enter into an agreement with the CRIHB to reim21 burse the CRIHB for costs (including reasonable adminis22 trative costs) incurred pursuant to this section, in pro23 viding medical treatment under contract to California In24 dians described in section 805(a) throughout the Cali- 
1 fornia contract health services delivery area described in

2 section 219 with respect to high cost contract care cases.

3 “(c) Administrative Expenses.-Not more than 5

4 percent of the amounts provided to the CRIHB under this

5 section for any fiscal year may be for reimbursement for

6 administrative expenses incurred by the CRIHB during

7 such fiscal year.

8 “(d) Limitation on Payment.-No payment may

9 be made for treatment provided hereunder to the extent

10 payment may be made for such treatment under the In-

11 dian Catastrophic Health Emergency Fund described in

12 section 202 or from amounts appropriated or otherwise

13 made available to the California contract health service de-

14 livery area for a fiscal year.

15 “(e) ADVISORY BOARD.-There is established an ad-

16 visory board which shall advise the CRIHB in carrying

17 out this section. The advisory board shall be composed of

18 representatives, selected by the CRIHB, from not less

19 than 8 Tribal Health Programs serving California Indians

20 covered under this section at least $1 / 2$ of whom of whom

21 are not affiliated with the CRIHB.

22 “SEC. 218. CALIFORNIA AS A CONTRACT HEALTH SERVICE

23 DELIVERY AREA.

24 "The State of California, excluding the counties of 25 Alameda, Contra Costa, Los Angeles, Marin, Orange, Sac- 
1 ramento, San Francisco, San Mateo, Santa Clara, Kern,

2 Merced, Monterey, Napa, San Benito, San Joaquin, San

3 Luis Obispo, Santa Cruz, Solano, Stanislaus, and Ven-

4 tura, shall be designated as a contract health service deliv-

5 ery area by the Service for the purpose of providing con-

6 tract health services to California Indians. However, any

7 of the counties listed herein may only be included in the

8 contract health services delivery area if funding is specifi-

9 cally provided by the Service for such services in those

10 counties.

11 “SEC. 219. CONTRACT HEALTH SERVICES FOR THE TREN12 TON SERVICE AREA.

13 “(a) Authorization FOR Services.-The Sec-

14 retary, acting through the Service, is directed to provide

15 contract health services to members of the Turtle Moun-

16 tain Band of Chippewa Indians that reside in the Trenton

17 Service Area of Divide, McKenzie, and Williams counties

18 in the State of North Dakota and the adjoining counties

19 of Richland, Roosevelt, and Sheridan in the State of Mon-

20 tana.

21 "(b) No Expansion of EligibiLity.-Nothing in

22 this section may be construed as expanding the eligibility

23 of members of the Turtle Mountain Band of Chippewa In-

24 dians for health services provided by the Service beyond 
1 the scope of eligibility for such health services that applied

2 on May 1, 1986.

3 "SEC. 220. PROGRAMS OPERATED BY INDIAN TRIBES AND TRIBAL ORGANIZATIONS.

5 "The Service shall provide funds for health care pro6 grams, functions, services, activities, information tech-

7 nology, and facilities operated by Tribal Health Programs

8 on the same basis as such funds are provided to programs,

9 functions, services, activities, information technology, and

10 facilities operated directly by the Service.

11 “SEC. 221. LICENSING.

12 "Licensed health care professionals employed by a

13 Tribal Health Program shall, if licensed in any State, be 14 exempt from the licensing requirements of the State in 15 which the Tribal Health Program performs the services

16 described in its contract or compact under the Indian Self17 Determination and Education Assistance Act (25 U.S.C. 18450 et seq.) while performing such services.

19 "SEC. 222. NOTIFICATION OF PROVISION OF EMERGENCY CONTRACT HEALTH SERVICES.

21 "With respect to an elderly Indian or an Indian with 22 a disability receiving emergency medical care or services 23 from a non-Service provider or in a non-Service facility 24 under the authority of this Act, the time limitation (as 
1 a condition of payment) for notifying the Service of such

2 treatment or admission shall be 30 days.

3 “SEC. 223. PROMPT ACTION ON PAYMENT OF CLAIMS.

4 “(a) DEADline FOR Response.-The Service shall

5 respond to a notification of a claim by a provider of a

6 contract care service with either an individual purchase

7 order or a denial of the claim within 5 working days after

8 the receipt of such notification.

9 “(b) EfFect of Untimely Response.-If the

10 Service fails to respond to a notification of a claim in ac-

11 cordance with subsection (a), the Service shall accept as

12 valid the claim submitted by the provider of a contract

13 care service.

14 “(c) Deadline for Payment of Valid Clatim.-

15 The Service shall pay a valid contract care service claim

16 within 30 days after the completion of the claim.

17 “SEC. 224. LIABILITY FOR PAYMENT.

18 “(a) No Patient Liability.-A patient who re-

19 ceives contract health care services that are authorized by

20 the Service shall not be liable for the payment of any

21 charges or costs associated with the provision of such serv-

22 ices.

23 “(b) Notification.-The Secretary shall notify a 24 contract care provider and any patient who receives con25 tract health care services authorized by the Service that 
1 such patient is not liable for the payment of any charges

2 or costs associated with the provision of such services not

3 later than 5 business days after receipt of a notification

4 of a claim by a provider of contract care services.

5 “(c) No Recourse.-Following receipt of the notice

6 provided under subsection (b), or, if a claim has been

7 deemed accepted under section 224(b), the provider shall

8 have no further recourse against the patient who received

9 the services.

10 “SEC. 225. OFFICE OF INDIAN MEN'S HEALTH.

11 “(a) Establishment.—The Secretary may establish

12 within the Service an office to be known as the 'Office

13 of Indian Men's Health' (referred to in this section as the

14 'Office').

15 “(b) DiRECTOR.-

16 "(1) In GENERAL.-The Office shall be headed

17 by a director, to be appointed by the Secretary.

18 "(2) DuTIEs.-The director shall coordinate

19 and promote the status of the health of Indian men

20 in the United States.

21 "(c) Report.-Not later than 2 years after the date

22 of enactment of the Indian Health Care Improvement Act

23 Amendments of 2009, the Secretary, acting through the

24 director of the Office, shall submit to Congress a report

25 describing- 
1766

1 “(1) any activity carried out by the director as

2 of the date on which the report is prepared; and

3 "(2) any finding of the director with respect to

4 the health of Indian men.

5 “SEC. 226. CATASTROPHIC HEALTH EMERGENCY FUND.

6 "(a) Establishment.-There is established an In-

7 dian Catastrophic Health Emergency Fund (hereafter in

8 this section referred to as the 'CHEF') consisting of-

9 "(1) the amounts deposited under subsection

$10 \quad(\mathrm{f})$; and

11 "(2) the amounts appropriated to CHEF under

12 this section.

13 "(b) Administration.-CHEF shall be adminis14 tered by the Secretary, acting through the headquarters 15 of the Service, solely for the purpose of meeting the ex16 traordinary medical costs associated with the treatment of 17 victims of disasters or catastrophic illnesses who are with18 in the responsibility of the Service.

19 "(c) Conditions on Use of Fund.-No part of 20 CHEF or its administration shall be subject to contract 21 or grant under any law, including the Indian Self-Deter22 mination and Education Assistance Act (25 U.S.C. 450 23 et seq.), nor shall CHEF funds be allocated, apportioned, 24 or delegated on an Area Office, Service Unit, or other 25 similar basis. 
1 “(d) Regulations.-The Secretary shall promul-

2 gate regulations consistent with the provisions of this sec3 tion to-

4 “(1) establish a definition of disasters and cata5 strophic illnesses for which the cost of the treatment 6 provided under contract would qualify for payment 7 from CHEF;

8 "(2) provide that a Service Unit shall not be el9 igible for reimbursement for the cost of treatment 10 from CHEF until its cost of treating any victim of 11 such catastrophic illness or disaster has reached a 12 certain threshold cost which the Secretary shall es13 tablish at"(A) the 2000 level of $\$ 19,000$; and "(B) for any subsequent year, not less

23 ment of the portion of the costs that exceeds such 24 threshold cost incurred by- 
"(B) whenever otherwise authorized by the Service, non-Service facilities or providers;

“(4) establish a procedure for payment from

4 CHEF in cases in which the exigencies of the med-

5 ical circumstances warrant treatment prior to the

6 authorization of such treatment by the Service; and

7 "(5) establish a procedure that will ensure that

8 no payment shall be made from CHEF to any pro-

9 vider of treatment to the extent that such provider

10 is eligible to receive payment for the treatment from

11 any other Federal, State, local, or private source of

12 reimbursement for which the patient is eligible.

13 “(e) No Offset or Limitation.-Amounts appro-

14 priated to CHEF under this section shall not be used to

15 offset or limit appropriations made to the Service under

16 the authority of the Act of November 2, 1921 (25 U.S.C.

17 13) (commonly known as the 'Snyder Act'), or any other 18 law.

19 “(f) Deposit of Reimbursement Funds.-There 20 shall be deposited into CHEF all reimbursements to which 21 the Service is entitled from any Federal, State, local, or 22 private source (including third party insurance) by reason 23 of treatment rendered to any victim of a disaster or cata24 strophic illness the cost of which was paid from CHEF. 
1 “SEC. 227. AUTHORIZATION OF APPROPRIATIONS.

2 "There are authorized to be appropriated such sums

3 as may be necessary to carry out this title.

\section{“TITLE III-FACILITIES}

5 "SEC. 301. CONSULTATION; CONSTRUCTION AND RENOVA-

“(a) Prerequisites FOR Expenditure OF

8 Funds.-Prior to the expenditure of, or the making of 9 any binding commitment to expend, any funds appro-

10 priated for the planning, design, construction, or renova-

11 tion of facilities pursuant to the Act of November 2, 1921

12 (25 U.S.C. 13) (commonly known as the 'Snyder Act'),

13 the Secretary, acting through the Service, shall-

14 "(1) consult with any Indian Tribe that would

15 be significantly affected by such expenditure for the

16 purpose of determining and, whenever practicable,

17 honoring tribal preferences concerning size, location,

18 type, and other characteristics of any facility on

19 which such expenditure is to be made; and

20 “(2) ensure, whenever practicable and applica-

21 ble, that such facility meets the construction stand-

22 ards of any accrediting body recognized by the Sec-

23 retary for the purposes of the Medicare, Medicaid, 24 and SCHIP programs under titles XVIII, XIX, and 25 XXI of the Social Security Act by not later than 1 
1 year after the date on which the construction or ren-

2 ovation of such facility is completed.

3 “(b) Closures.-

“(1) Evaluation Required.-Notwith-

5 standing any other provision of law, no facility oper-

6 ated by the Service may be closed if the Secretary

7 has not submitted to Congress, not less than 1 year

8 and not more than 2 years before the date of the

9 proposed closure, an evaluation, completed not more

10 than 2 years before such submission, of the impact

11 of the proposed closure that specifies, in addition to

12 other considerations-

13 "(A) the accessibility of alternative health

14 care resources for the population served by such 15 facility;

16 "(B) the cost-effectiveness of such closure;

17 "(C) the quality of health care to be pro-

18 vided to the population served by such facility

19 after such closure;

20 "(D) the availability of contract health 21 care funds to maintain existing levels of service;

22 "(E) the views of the Indian Tribes served

23 by such facility concerning such closure;

24 "(F) the level of use of such facility by all 25 eligible Indians; and 
1771

"(G) the distance between such facility and the nearest operating Service hospital. “(2) ExCEPTION FOR CERTAIN TEMPORARY CLOSURES.-Paragraph (1) shall not apply to any temporary closure of a facility or any portion of a 6 facility if such closure is necessary for medical, envi-

7 ronmental, or construction safety reasons.

8 “(c) Health Care Facility Priority System."(1) IN GENERAL."(A) Prionity system.-The Secretary, acting through the Service, shall maintain a health care facility priority system, which-

"(i) shall be developed in consultation

“(ii) shall give Indian Tribes' needs tions; the highest priority;

“(iii)(I) may include the lists required in paragraph (2)(B)(ii); and “(II) shall include the methodology required in paragraph $(2)(\mathrm{B})(\mathrm{v})$; and "(III) may include such other facilities, and such renovation or expansion needs of any health care facility, as the 
Service, Indian Tribes, and Tribal Organizations may identify; and "(iv) shall provide an opportunity for the nomination of planning, design, and construction projects by the Service, Indian Tribes, and Tribal Organizations for consideration under the priority system at least once every 3 years, or more frequently as the Secretary determines to be appropriate.

“(B) Needs OF FACILITIES UNDER ISDEAA AGREEMENTS.-The Secretary shall ensure that the planning, design, construction, renovation, and expansion needs of Service and non-Service facilities operated under contracts or compacts in accordance with the Indian SelfDetermination and Education Assistance Act (25 U.S.C. 450 et seq.) are fully and equitably integrated into the health care facility priority system.

"(C) Criterla FOR Evaluating NEEDS.-For purposes of this subsection, the Secretary, in evaluating the needs of facilities operated under a contract or compact under the Indian Self-Determination and Education As- 
sistance Act (25 U.S.C. 450 et seq.), shall use the criteria used by the Secretary in evaluating the needs of facilities operated directly by the Service.

“(D) PRIORITY OF CERTAIN PROJECTS PROTECTED.-The priority of any project estab-

lished under the construction priority system in effect on the date of enactment of the Indian Health Care Improvement Act Amendments of 2009 shall not be affected by any change in the construction priority system taking place after that date if the project-

"(i) was identified in the fiscal year 2008 Service budget justification as-

"(I) 1 of the 10 top-priority inpatient projects;

"(II) 1 of the 10 top-priority outpatient projects;

"(III) 1 of the 10 top-priority staff quarters developments; or

"(IV) 1 of the 10 top-priority Youth Regional Treatment Centers; "(ii) had completed both Phase I and Phase II of the construction priority sys- 
tem in effect on the date of enactment of

such Act; or

"(iii) is not included in clause (i) or (ii) and is selected, as determined by the Secretary-

"(I) on the initiative of the Secretary; or "(II) pursuant to a request of an Indian Tribe or Tribal Organization. “(2) Report; COnTEnts.“(A) Initial COMPREHENSIVE REPORT.“(i) Definitions.-In this subparagraph:

“(I) Facilities appropriation ADVISORY BOARD.—The term 'Facilities Appropriation Advisory Board' means the advisory board, comprised of 12 members representing Indian tribes and 2 members representing the Service, established at the discretion of the Assistant Secretary"(aa) to provide advice and recommendations for policies and procedures of the programs fund- 
ed pursuant to facilities appropriations; and

"(bb) to address other facilities issues.

“(II) Facilities needs assessMENT WORKGROUP.-The term 'Facilities Needs Assessment Workgroup' means the workgroup established at the discretion of the Assistant Secretary-

"(aa) to review the health care facilities construction priority system; and

"(bb) to make recommendations to the Facilities Appropriation Advisory Board for revising the priority system.

“(ii) INITLAL REPORT.-

"(I) In GENERAL.-Not later than 1 year after the date of enactment of the Indian Health Care Improvement Act Amendments of 2009, the Secretary shall submit to the Committee on Indian Affairs of the Senate and the Committee on Natural 
Resources of the House of Representatives a report that describes the comprehensive, national, ranked list of all health care facilities needs for the Service, Indian Tribes, and Tribal Organizations (including inpatient health care facilities, outpatient health care facilities, specialized health care facilities (such as for long-term care and alcohol and drug abuse treatment), wellness centers, staff quarters and hostels associated with health care facilities, and the renovation and expansion needs, if any, of such facilities) developed by the Service, Indian Tribes, and Tribal Organizations for the Facilities Needs Assessment Workgroup and the Facilities Appropriation Advisory Board.

"(II) InCLusions.-The initial report shall include-

"(aa) the methodology and criteria used by the Service in determining the needs and estab- 
lishing the ranking of the facili-

ties needs; and

"(bb) such other information

as the Secretary determines to be appropriate.

"(I) update the report under clause (ii) not less frequently that once every 5 years; and

"(II) include the updated report in the appropriate annual report under subparagraph (B) for submission to Congress under section 801 .

“(B) Annual Reports.-The Secretary shall submit to the President, for inclusion in the report required to be transmitted to Congress under section 801, a report which sets forth the following:

"(i) A description of the health care facility priority system of the Service established under paragraph (1).

"(ii) Health care facilities lists, which may include- 
"(I) the 10 top-priority inpatient

health care facilities;

"(II) the 10 top-priority out-

patient health care facilities;

"(III) the 10 top-priority special-

"(IV) the 10 top-priority staff quarters developments associated with health care facilities; and

“(3) Requirements For PREPARATiOn OF RE-

"(V) the 10 top-priority hostels associated with health care facilities. "(iii) The justification for such order of priority.

"(iv) The projected cost of such projects.

"(v) The methodology adopted by the Service in establishing priorities under its health care facility priority system. 
Tribes, Tribal Organizations, and urban Indian

organizations; and

"(B) review the total unmet needs of all Indian Tribes, Tribal Organizations, and urban Indian organizations for health care facilities (including hostels and staff quarters), including needs for renovation and expansion of existing facilities.

“(d) Review of Methodology Used for Health

10 Facilities Construction Priority System.-

"(1) IN GENERAL.-Not later than 1 year after

12 the establishment of the priority system under sub-

13 section $(\mathrm{c})(1)(\mathrm{A})$, the Comptroller General of the

14 United States shall prepare and finalize a report re-

15 viewing the methodologies applied, and the processes

16 followed, by the Service in making each assessment

17 of needs for the list under subsection (c)(2)(A)(ii)

18 and developing the priority system under subsection

19 (c)(1), including a review of-

"(A) the recommendations of the Facilities Appropriation Advisory Board and the Facilities Needs Assessment Workgroup (as those 24 terms are defined in subsection $(\mathrm{c})(2)(\mathrm{A})(\mathrm{i}))$; and 
"(B) the relevant criteria used in ranking. or prioritizing facilities other than hospitals or clinics.

“(2) Submission to congress.-The Comp-

5 troller General of the United States shall submit the 6 report under paragraph (1) to-

"(A) the Committees on Indian Affairs and Appropriations of the Senate;

"(B) the Committees on Natural Resources and Appropriations of the House of Representatives; and "(C) the Secretary.

13 “(e) Funding Condition.-All funds appropriated 14 under the Act of November 2, 1921 (25 U.S.C. 13) (com15 monly known as the 'Snyder Act'), for the planning, de16 sign, construction, or renovation of health facilities for the 17 benefit of 1 or more Indian Tribes shall be subject to the 18 provisions of the Indian Self-Determination and Edu19 cation Assistance Act (25 U.S.C. 450 et seq.). “(f) Development of Innovative Approaches.-

21 The Secretary shall consult and cooperate with Indian 22 Tribes, Tribal Organizations, and urban Indian organiza23 tions in developing innovative approaches to address all 24 or part of the total unmet need for construction of health 
1 facilities, including those provided for in other sections of

2 this title and other approaches.

3 “SEC. 302. SANITATION FACILITIES.

4 “(a) Findings.-Congress finds the following:

5 "(1) The provision of sanitation facilities is pri-

6 marily a health consideration and function.

“(2) Indian people suffer an inordinately high

8 incidence of disease, injury, and illness directly at-

9 tributable to the absence or inadequacy of sanitation 10 facilities.

11 "(3) The long-term cost to the United States of 12 treating and curing such disease, injury, and illness 13 is substantially greater than the short-term cost of 14 providing sanitation facilities and other preventive 15 health measures.

16 “(4) Many Indian homes and Indian commu17 nities still lack sanitation facilities.

18 "(5) It is in the interest of the United States, 19 and it is the policy of the United States, that all In20 dian communities and Indian homes, new and exist21 ing, be provided with sanitation facilities.

22 “(b) Facilities and Services.-In furtherance of 23 the findings made in subsection (a), Congress reaffirms 24 the primary responsibility and authority of the Service to 25 provide the necessary sanitation facilities and services as 
1 provided in section 7 of the Act of August 5, 1954 (42

2 U.S.C. 2004a). Under such authority, the Secretary, act-

3 ing through the Service, is authorized to provide the fol-

4 lowing:

5 “(1) Financial and technical assistance to In6 dian Tribes, Tribal Organizations, and Indian com-

7 munities in the establishment, training, and equip-

8 ping of utility organizations to operate and maintain

9 sanitation facilities, including the provision of exist-

10 ing plans, standard details, and specifications avail-

11 able in the Department, to be used at the option of

12 the Indian Tribe, Tribal Organization, or Indian

13 community.

14 “(2) Ongoing technical assistance and training

15 to Indian Tribes, Tribal Organizations, and Indian

16 communities in the management of utility organiza-

17 tions which operate and maintain sanitation facili18 ties.

19 "(3) Priority funding for operation and mainte20 nance assistance for, and emergency repairs to, sani21 tation facilities operated by an Indian Tribe, Tribal 22 Organization or Indian community when necessary 23 to avoid an imminent health threat or to protect the 24 investment in sanitation facilities and the investment 
1 in the health benefits gained through the provision

2 of sanitation facilities.

3 “(c) Funding.-Notwithstanding any other provi4 sion of law-

"(1) the Secretary of Housing and Urban De-

6 velopment is authorized to transfer funds appro-

7 priated under the Native American Housing Assist-

8 ance and Self-Determination Act of 1996 (25 U.S.C.

94101 et seq.) to the Secretary of Health and Human

10 Services;

11 "(2) the Secretary of Health and Human Serv-

12 ices is authorized to accept and use such funds for

13 the purpose of providing sanitation facilities and

14 services for Indians under section 7 of the Act of

15 August 5, 1954 (42 U.S.C. 2004a);

16 "(3) unless specifically authorized when funds

17 are appropriated, the Secretary shall not use funds

18 appropriated under section 7 of the Act of August

195,1954 (42 U.S.C. 2004a), to provide sanitation fa-

20 cilities to new homes constructed using funds pro-

21 vided by the Department of Housing and Urban De-

22 velopment;

23 "(4) the Secretary of Health and Human Serv-

24 ices is authorized to accept from any source, includ-

25 ing Federal and State agencies, funds for the pur- 
1 pose of providing sanitation facilities and services

2 and place these funds into contracts or compacts

3 under the Indian Self-Determination and Education

4 Assistance Act (25 U.S.C. 450 et seq.);

$5 \quad$ "(5) except as otherwise prohibited by this sec-

6 tion, the Secretary may use funds appropriated

7 under the authority of section 7 of the Act of Au-

8 gust 5, 1954 (42 U.S.C. 2004a), to fund up to 100

9 percent of the amount of an Indian Tribe's loan ob-

10 tained under any Federal program for new projects

11 to construct eligible sanitation facilities to serve In-

12 dian homes;

13 "(6) except as otherwise prohibited by this sec-

14 tion, the Secretary may use funds appropriated

15 under the authority of section 7 of the Act of Au-

16 gust 5, 1954 (42 U.S.C. 2004a), to meet matching

17 or cost participation requirements under other Fed-

18 eral and non-Federal programs for new projects to

19 construct eligible sanitation facilities;

20 “(7) all Federal agencies are authorized to 21 transfer to the Secretary funds identified, granted, 22 loaned, or appropriated whereby the Department's 23 applicable policies, rules, and regulations shall apply 24 in the implementation of such projects; 
1 "(8) the Secretary of Health and Human Serv-

2 ices shall enter into interagency agreements with

3 Federal and State agencies for the purpose of pro-

4 viding financial assistance for sanitation facilities

5 and services under this Act;

6 "(9) the Secretary of Health and Human Serv-

7 ices shall, by regulation, establish standards applica-

8 ble to the planning, design, and construction of sani-

9 tation facilities funded under this Act; and

10 "(10) the Secretary of Health and Human

11 Services is authorized to accept payments for goods

12 and services furnished by the Service from appro-

13 priate public authorities, nonprofit organizations or

14 agencies, or Indian Tribes, as contributions by that

15 authority, organization, agency, or tribe to agree-

16 ments made under section 7 of the Act of August 5,

171954 (42 U.S.C. 2004a), and such payments shall

18 be credited to the same or subsequent appropriation

19 account as funds appropriated under the authority

20 of section 7 of the Act of August 5, 1954 (42 U.S.C.

$212004 a)$.

22 “(d) Certain Capabilities Not Prerequisite.-

23 The financial and technical capability of an Indian Tribe,

24 Tribal Organization, or Indian community to safely oper-

25 ate, manage, and maintain a sanitation facility shall not 
1 be a prerequisite to the provision or construction of sanita-

2 tion facilities by the Secretary.

3 “(e) Financial Assistance.-The Secretary is au-

4 thorized to provide financial assistance to Indian Tribes,

5 Tribal Organizations, and Indian communities in an

6 amount equal to the Federal share of the costs of oper-

7 ating, managing, and maintaining the facilities provided

8 under the plan described in subsection $(\mathrm{h})(1)(\mathrm{F})$.

9 “(f) Operation, Management, and Maintenance

10 of Facilities. - The Indian Tribe has the primary re-

11 sponsibility to establish, collect, and use reasonable user

12 fees, or otherwise set aside funding, for the purpose of

13 operating, managing, and maintaining sanitation facilities.

14 If a sanitation facility serving a community that is oper-

15 ated by an Indian Tribe or Tribal Organization is threat-

16 ened with imminent failure and such operator lacks capac-

17 ity to maintain the integrity or the health benefits of the

18 sanitation facility, then the Secretary is authorized to as-

19 sist the Indian Tribe, Tribal Organization, or Indian com-

20 munity in the resolution of the problem on a short-term

21 basis through cooperation with the emergency coordinator

22 or by providing operation, management, and maintenance

23 service.

24 “(g) ISDEAA Program Funded on Equal

25 Basis.-Tribal Health Programs shall be eligible (on an 
1 equal basis with programs that are administered directly

2 by the Service) for-

"(1) any funds appropriated pursuant to this

4 section; and

"(2) any funds appropriated for the purpose of

6 providing sanitation facilities.

7 "(h) REPORT.-

8

“(1) Required; CONTENTs.-The Secretary, in

9 consultation with the Secretary of Housing and

10 Urban Development, Indian Tribes, Tribal Organiza-

11 tions, and tribally designated housing entities (as de-

12 fined in section 4 of the Native American Housing

13 Assistance and Self-Determination Act of 1996 (25

14 U.S.C. 4103)) shall submit to the President, for in-

15 clusion in the report required to be transmitted to

16 Congress under section 801, a report which sets

17 forth-

"(A) the current Indian sanitation facility

priority system of the Service;

"(B) the methodology for determining sanitation deficiencies and needs;

"(C) the criteria on which the deficiencies and needs will be evaluated;

"(D) the level of initial and final sanitation 
each project of each Indian Tribe or Indian community;

"(E) the amount and most effective use of funds, derived from whatever source, necessary to accommodate the sanitation facilities needs Native American Housing Assistance and SelfDetermination Act (25 U.S.C. 4101 et seq.), and to reduce the identified sanitation deficiency levels of all Indian Tribes and Indian communities to level I sanitation deficiency as defined in paragraph $(3)(\mathrm{A})$; and

"(F) a 10-year plan to provide sanitation facilities to serve existing Indian homes and Indian communities and new and renovated Indian homes.

"(2) UNIFORM METHODOLOGY.-The methodology used by the Secretary in determining, preparing cost estimates for, and reporting sanitation deficiencies for purposes of paragraph (1) shall be applied uniformly to all Indian Tribes and Indian communities.

“(3) Sanitation Deficiency Levels.-For purposes of this subsection, the sanitation deficiency levels for an individual, Indian Tribe, or Indian com- 
1 munity sanitation facility to serve Indian homes are 2 determined as follows:

"(A) A level I deficiency exists if a sanitation facility serving an individual, Indian Tribe, or Indian community-

"(i) complies with all applicable water supply, pollution control, and solid waste disposal laws; and "(ii) deficiencies relate to routine replacement, repair, or maintenance needs.

“(B) A level II deficiency exists if a sanitation facility serving an individual, Indian Tribe, or Indian community substantially or recently complied with all applicable water supply, pollution control, and solid waste laws and any deficiencies relate to-

"(i) small or minor capital improvements needed to bring the facility back into compliance;

"(ii) capital improvements that are necessary to enlarge or improve the facilities in order to meet the current needs for domestic sanitation facilities; or

"(iii) the lack of equipment or training by an Indian Tribe, Tribal Organiza- 
tion, or an Indian community to properly

operate and maintain the sanitation facilities.

"(C) A level III deficiency exists if a sanitation facility serving an individual, Indian Tribe or Indian community meets 1 or more of the following conditions-

"(i) water or sewer service in the home is provided by a haul system with holding tanks and interior plumbing; "(ii) major significant interruptions to water supply or sewage disposal occur frequently, requiring major capital improvements to correct the deficiencies; or "(iii) there is no access to or no approved or permitted solid waste facility available.

“(D) A level IV deficiency exists— "(i) if a sanitation facility for an individual home, an Indian Tribe, or an Indian community exists but-

"(I) lacks“(aa) a safe water supply system; or 
"(bb) a waste disposal sys-

tem;

"(II) contains no piped water or

sewer facilities; or homes do not have access to safe drinking water or adequate wastewater (including sewage) disposal.

"(III) has become inoperable due to a major component failure; or "(ii) if only a washeteria or central facility exists in the community.

"(E) A level $\mathrm{V}$ deficiency exists in the ab15 following terms apply:

17 community' means a geographic area, a significant 18 proportion of whose inhabitants are Indians and 19 which is served by or capable of being served by a 20 facility described in this section.

"(2) SANITATION FACILITIES.-The terms

22 'sanitation facility' and 'sanitation facilities' mean 23 safe and adequate water supply systems, sanitary 24 sewage disposal systems, and sanitary solid waste 
1 systems (and all related equipment and support in2 frastructure).

3 “SEC. 303. PREFERENCE TO INDIANS AND INDIAN FIRMS.

4 “(a) Buy Indian ACT.-The Secretary, acting

5 through the Service, may use the negotiating authority of 6 section 23 of the Act of June 25, 1910 (25 U.S.C. 47,

7 commonly known as the 'Buy Indian Act'), to give pref-

8 erence to any Indian or any enterprise, partnership, cor-

9 poration, or other type of business organization owned and

10 controlled by an Indian or Indians including former or

11 currently federally recognized Indian Tribes in the State

12 of New York (hereinafter referred to as an 'Indian firm')

13 in the construction and renovation of Service facilities pur-

14 suant to section 301 and in the construction of sanitation

15 facilities pursuant to section 302. Such preference may be

16 accorded by the Secretary unless the Secretary finds, pur-

17 suant to regulations, that the project or function to be

18 contracted for will not be satisfactory or such project or

19 function cannot be properly completed or maintained

20 under the proposed contract. The Secretary, in arriving

21 at such a finding, shall consider whether the Indian or

22 Indian firm will be deficient with respect to-

23 “(1) ownership and control by Indians;

24 "(2) equipment;

25 “(3) bookkeeping and accounting procedures; 
1793

"(4) substantive knowledge of the project or

2 function to be contracted for;

“(5) adequately trained personnel; or

“(6) other necessary components of contract

5 performance.

6 "(b) PAY RATES.-For the purposes of implementing

7 the provisions of this title, the Secretary shall assure that

8 the rates of pay for personnel engaged in the construction

9 or renovation of facilities constructed or renovated in

10 whole or in part by funds made available pursuant to this

11 title are not less than the prevailing local wage rates for

12 similar work as determined in accordance with the Act of

13 March 3, 1931 (40 U.S.C. 276a-276a-5, known as the

14 Davis-Bacon Act).

15 “(c) Labor Standards.-For the purposes of im-

16 plementing the provisions of this title, contracts for the

17 construction or renovation of health care facilities, staff

18 quarters, and sanitation facilities, and related support in-

19 frastructure, funded in whole or in part with funds made

20 available pursuant to this title, shall contain a provision

21 requiring compliance with subchapter IV of chapter 31 of

22 title 40, United States Code (commonly known as the

23 'Davis-Bacon Act'). 
1 "SEC. 304. EXPENDITURE OF NON-SERVICE FUNDS FOR RENOVATION.

3 “(a) In GENERAL.-Notwithstanding any other pro-

4 vision of law, if the requirements of subsection (c) are met,

5 the Secretary, acting through the Service, is authorized

6 to accept any major expansion, renovation, or moderniza-

7 tion by any Indian Tribe or Tribal Organization of any

8 Service facility or of any other Indian health facility oper-

9 ated pursuant to a contract or compact under the Indian

10 Self-Determination and Education Assistance Act (25

11 U.S.C. 450 et seq.), including-

12 "(1) any plans or designs for such expansion,

13 renovation, or modernization; and

14 “(2) any expansion, renovation, or moderniza-

15 tion for which funds appropriated under any Federal

16 law were lawfully expended.

17 “(b) Priority List.-

18 “(1) IN GENERAL.—The Secretary shall main-

19 tain a separate priority list to address the needs for

20 increased operating expenses, personnel, or equip-

21 ment for such facilities. The methodology for estab-

22 lishing priorities shall be developed through regula-

23 tions. The list of priority facilities will be revised an-

24 nually in consultation with Indian Tribes and Tribal

25 Organizations. 
“(2) REPORT._The Secretary shall submit to

2 the President, for inclusion in the report required to

3 be transmitted to Congress under section 801, the

4 priority list maintained pursuant to paragraph (1).

5 "(c) REQUIREMENTs.-The requirements of this sub-

6 section are met with respect to any expansion, renovation,

7 or modernization if-

8

9

10

11

12

13

14

15

16 tion-

17

"(1) the Indian Tribe or Tribal Organization"(A) provides notice to the Secretary of its intent to expand, renovate, or modernize; and "(B) applies to the Secretary to be placed on a separate priority list to address the needs of such new facilities for increased operating expenses, personnel, or equipment; and “(2) the expansion, renovation, or moderniza"(A) is approved by the appropriate area director of the Service for Federal facilities; and "(B) is administered by the Indian Tribe or Tribal Organization in accordance with any applicable regulations prescribed by the Secretary with respect to construction or renovation of Service facilities.

“(d) Additional Requirement for Expansion.25 In addition to the requirements under subsection (c), for 
1 any expansion, the Indian Tribe or Tribal Organization

2 shall provide to the Secretary additional information pur-

3 suant to regulations, including additional staffing, equip-

4 ment, and other costs associated with the expansion.

5 “(e) Closure or Conversion of Facilities.-If

6 any Service facility which has been expanded, renovated,

7 or modernized by an Indian Tribe or Tribal Organization

8 under this section ceases to be used as a Service facility

9 during the 20-year period beginning on the date such ex-

10 pansion, renovation, or modernization is completed, such

11 Indian Tribe or Tribal Organization shall be entitled to

12 recover from the United States an amount which bears

13 the same ratio to the value of such facility at the time

14 of such cessation as the value of such expansion, renova-

15 tion, or modernization (less the total amount of any funds

16 provided specifically for such facility under any Federal

17 program that were expended for such expansion, renova-

18 tion, or modernization) bore to the value of such facility

19 at the time of the completion of such expansion, renova-

20 tion, or modernization.

21 "SEC. 305. FUNDING FOR THE CONSTRUCTION, EXPANSION,

AND MODERNIZATION OF SMALL AMBULATORY CARE FACILITIES.

24 “(a) GRANTS.- 
"(1) IN GENERAL.-The Secretary, acting

2 through the Service, shall make grants to Indian

3 Tribes and Tribal Organizations for the construc-

4 tion, expansion, or modernization of facilities for the

5 provision of ambulatory care services to eligible Indi-

6 ans (and noneligible persons pursuant to subsections

$7 \quad(b)(2)$ and $(c)(1)(C))$. A grant made under this sec-

8 tion may cover up to 100 percent of the costs of

9 such construction, expansion, or modernization. For

10 the purposes of this section, the term 'construction'

11 includes the replacement of an existing facility.

12 "(2) GRANT AGREEMENT REQUIRED.-A grant

13 under paragraph (1) may only be made available to

14 a Tribal Health Program operating an Indian health

15 facility (other than a facility owned or constructed

16 by the Service, including a facility originally owned

17 or constructed by the Service and transferred to an

18 Indian Tribe or Tribal Organization).

19 "(b) UsE OF Grant Funds.-

20 "(1) Allowable UsEs.-A grant awarded 21 under this section may be used for the construction, 22 expansion, or modernization (including the planning 23 and design of such construction, expansion, or mod24 ernization) of an ambulatory care facility-

25 "(A) located apart from a hospital; 
"(B) not funded under section 301 or sec-

tion 306; and

"(C) which, upon completion of such construction or modernization will-

“(i) have a total capacity appropriate to its projected service population; "(ii) provide annually no fewer than 150 patient visits by eligible Indians and other users who are eligible for services in such facility in accordance with section $806(\mathrm{c})(2) ;$ and

"(iii) provide ambulatory care in a Service Area (specified in the contract or compact under the Indian Self-Determination and Education Assistance Act (25 U.S.C. 450 et seq.)) with a population of no fewer than 1,500 eligible Indians and other users who are eligible for services in such facility in accordance with section $806(\mathrm{c})(2)$.

“(2) Additional allowable use.-The Secretary may also reserve a portion of the funding provided under this section and use those reserved funds to reduce an outstanding debt incurred by Indian Tribes or Tribal Organizations for the con- 
1 struction, expansion, or modernization of an ambula-

2 tory care facility that meets the requirements under 3 paragraph (1). The provisions of this section shall 4 apply, except that such applications for funding

5 under this paragraph shall be considered separately

6 from applications for funding under paragraph (1). “(3) Use ONLY FOR CERTAIN PORTION OF 8 Costs.-A grant provided under this section may be 9 used only for the cost of that portion of a construc10 tion, expansion, or modernization project that bene11 fits the Service population identified above in sub12 section $(b)(1)(C)$ (ii) and (iii). The requirements of 13 clauses (ii) and (iii) of paragraph (1)(C) shall not 14 apply to an Indian Tribe or Tribal Organization ap15 plying for a grant under this section for a health 16 care facility located or to be constructed on an is17 land or when such facility is not located on a road 18 system providing direct access to an inpatient hos19 pital where care is available to the Service popu20 lation.

21 “(c) GRANTS.-

22 "(1) ApPLication.-No grant may be made 23 under this section unless an application or proposal 24 for the grant has been approved by the Secretary in 25 accordance with applicable regulations and has set 
1800

1 forth reasonable assurance by the applicant that, at

2 all times after the construction, expansion, or mod-

3 ernization of a facility carried out using a grant re-

4 ceived under this section-

5

6

7

8

9

10

11

12

13

14

15

16

17

18

19

20

"(A) adequate financial support will be available for the provision of services at such facility;

"(B) such facility will be available to eligible Indians without regard to ability to pay or source of payment; and

"(C) such facility will, as feasible without diminishing the quality or quantity of services provided to eligible Indians, serve noneligible persons on a cost basis.

“(2) PRIORITY.-In awarding grants under this section, the Secretary shall give priority to Indian Tribes and Tribal Organizations that demonstrate“(A) a need for increased ambulatory care services; and

"(B) insufficient capacity to deliver such services.

“(3) Peer Review PANelis.-The Secretary may provide for the establishment of peer review panels, as necessary, to review and evaluate applications and proposals and to advise the Secretary re- 
1801

1 garding such applications using the criteria devel-

2 oped pursuant to subsection (a)(1).

3 “(d) Reversion of Facilities.-If any facility (or

4 portion thereof) with respect to which funds have been

5 paid under this section, ceases, at any time after comple-

6 tion of the construction, expansion, or modernization car-

7 ried out with such funds, to be used for the purposes of

8 providing health care services to eligible Indians, all of the

9 right, title, and interest in and to such facility (or portion

10 thereof) shall transfer to the United States unless other-

11 wise negotiated by the Service and the Indian Tribe or

12 Tribal Organization.

13 “(e) Funding Nonrecurring.-Funding provided

14 under this section shall be nonrecurring and shall not be

15 available for inclusion in any individual Indian Tribe's

16 tribal share for an award under the Indian Self-Deter-

17 mination and Education Assistance Act (25 U.S.C. 450

18 et seq.) or for reallocation or redesign thereunder.

19 “SEC. 306. INDIAN HEALTH CARE DELIVERY DEMONSTRATION PROJECT.

21 “(a) Health Care Demonstration Projects.-

22 The Secretary, acting through the Service, is authorized 23 to make grants to, and enter into construction contracts 24 or construction project agreements with, Indian Tribes or 25 Tribal Organizations under the Indian Self-Determination 
1802

1 and Education Assistance Act (25 U.S.C. 450 et seq.) for

2 the purpose of carrying out a health care delivery dem-

3 onstration project to test alternative means of delivering

4 health care and services to Indians through facilities.

5 “(b) UsE OF Funds.-The Secretary, in approving

6 projects pursuant to this section, may authorize such con-

7 tracts for the construction and renovation of hospitals,

8 health centers, health stations, and other facilities to de-

9 liver health care services and is authorized to-

10 “(1) waive any leasing prohibition;

11 "(2) permit carryover of funds appropriated for

12 the provision of health care services;

13 "(3) permit the use of other available funds;

14 "(4) permit the use of funds or property do-

15 nated from any source for project purposes;

16 "(5) provide for the reversion of donated real or

17 personal property to the donor; and

18 "(6) permit the use of Service funds to match

19 other funds, including Federal funds.

20 "(c) Regulations.-The Secretary shall develop

21 and promulgate regulations, not later than 1 year after

22 the date of enactment of the Indian Health Care Improve-

23 ment Act Amendments of 2009, for the review and ap-

24 proval of applications submitted under this section. 
1803

1 “(d) Criteria.-The Secretary may approve projects

2 that meet the following criteria:

"(1) There is a need for a new facility or pro-

4 gram or the reorientation of an existing facility or 5 program.

6 “(2) A significant number of Indians, including

7 those with low health status, will be served by the 8 project.

9 “(3) The project has the potential to deliver

10 services in an efficient and effective manner.

11 “(4) The project is economically viable.

12 “(5) The Indian Tribe or Tribal Organization

13 has the administrative and financial capability to ad-

14 minister the project.

15 "(6) The project is integrated with providers of

16 related health and social services and is coordinated

17 with, and avoids duplication of, existing services.

18 “(e) Peer Review Panels.-The Secretary may

19 provide for the establishment of peer review panels, as nec-

20 essary, to review and evaluate applications using the cri-

21 teria developed pursuant to subsection (d).

22 “(f) PRIORITY.—The Secretary shall give priority to

23 applications for demonstration projects in each of the fol24 lowing Service Units to the extent that such applications 
1 are timely filed and meet the criteria specified in sub2 section $(d)$ :

3

4

5

6

7

8

9

10 essary to enable applicants to comply with the provisions

11 of this section.

12

“(h) Service to Ineligible Persons.-Subject to

13 section 806, the authority to provide services to persons

14 otherwise ineligible for the health care benefits of the

15 Service and the authority to extend hospital privileges in

16 Service facilities to non-Service health practitioners as

17 provided in section 806 may be included, subject to the 18 terms of such section, in any demonstration project ap19 proved pursuant to this section.

20 “(i) Equitable Treatment.-For purposes of sub21 section (d)(1), the Secretary shall, in evaluating facilities 22 operated under any contract or compact under the Indian 23 Self-Determination and Education Assistance Act (25 24 U.S.C. 450 et seq.), use the same criteria that the Sec- 
1 retary uses in evaluating facilities operated directly by the

2 Service.

4 Secretary shall ensure that the planning, design, construc-

5 tion, renovation, and expansion needs of Service and non-

6 Service facilities which are the subject of a contract or

7 compact under the Indian Self-Determination and Edu-

8 cation Assistance Act (25 U.S.C. 450 et seq.) for health

9 services are fully and equitably integrated into the imple-

10 mentation of the health care delivery demonstration

11 projects under this section.

12 "SEC. 307. LAND TRANSFER.

13 "Notwithstanding any other provision of law, the Bu-

14 reau of Indian Affairs and all other agencies and depart-

15 ments of the United States are authorized to transfer, at

16 no cost, land and improvements to the Service for the pro-

17 vision of health care services. The Secretary is authorized

18 to accept such land and improvements for such purposes.

19 "SEC. 308. LEASES, CONTRACTS, AND OTHER AGREEMENTS.

20 "The Secretary, acting through the Service, may

21 enter into leases, contracts, and other agreements with In-

22 dian Tribes and Tribal Organizations which hold (1) title

23 to, (2) a leasehold interest in, or (3) a beneficial interest

24 in (when title is held by the United States in trust for

25 the benefit of an Indian Tribe) facilities used or to be used 
1 for the administration and delivery of health services by

2 an Indian Health Program. Such leases, contracts, or

3 agreements may include provisions for construction or ren-

4 ovation and provide for compensation to the Indian Tribe

5 or Tribal Organization of rental and other costs consistent

6 with section 105(l) of the Indian Self-Determination and

7 Education Assistance Act (25 U.S.C. 450j(1)) and regula-

8 tions thereunder.

9 "SEC. 309. STUDY ON LOANS, LOAN GUARANTEES, AND LOAN REPAYMENT.

11 “(a) In GEnERAL.-The Secretary, in consultation

12 with the Secretary of the Treasury, Indian Tribes, and

13 Tribal Organizations, shall carry out a study to determine

14 the feasibility of establishing a loan fund to provide to In-

15 dian Tribes and Tribal Organizations direct loans or guar-

16 antees for loans for the construction of health care facili-

17 ties, including-

“(1) inpatient facilities;

“(2) outpatient facilities;

"(3) staff quarters;

"(4) hostels; and

“(5) specialized care facilities, such as behav-

23 ioral health and elder care facilities.

24 “(b) Determinations.-In carrying out the study 25 under subsection (a), the Secretary shall determine- 
"(1) the maximum principal amount of a loan

2 or loan guarantee that should be offered to a recipi3 ent from the loan fund;

4 “(2) the percentage of eligible costs, not to ex-

5 ceed 100 percent, that may be covered by a loan or 6 loan guarantee from the loan fund (including costs 7 relating to planning, design, financing, site land de8 velopment, construction, rehabilitation, renovation, 9 conversion, improvements, medical equipment and 10 furnishings, and other facility-related costs and cap11 ital purchase (but excluding staffing));

12 "(3) the cumulative total of the principal of di13 rect loans and loan guarantees, respectively, that 14 may be outstanding at any 1 time;

15 "(4) the maximum term of a loan or loan guar16 antee that may be made for a facility from the loan 17 fund;

18 "(5) the maximum percentage of funds from 19 the loan fund that should be allocated for payment 20 of costs associated with planning and applying for a 21 loan or loan guarantee;

22 “(6) whether acceptance by the Secretary of an 23 assignment of the revenue of an Indian Tribe or 24 Tribal Organization as security for any direct loan 
1 or loan guarantee from the loan fund would be ap-

2 propriate;

3 "(7) whether, in the planning and design of

4 health facilities under this section, users eligible

5 under section 806(c) may be included in any projec-

6 tion of patient population;

$7 \quad$ "(8) whether funds of the Service provided

8 through loans or loan guarantees from the loan fund

9 should be eligible for use in matching other Federal

10 funds under other programs;

11 "(9) the appropriateness of, and best methods

12 for, coordinating the loan fund with the health care

13 priority system of the Service under section 301; and

14 "(10) any legislative or regulatory changes re-

15 quired to implement recommendations of the Sec-

16 retary based on results of the study.

17 “(c) REPORT.-Not later than September 30, 2010,

18 the Secretary shall submit to the Committee on Indian Af-

19 fairs of the Senate and the Committee on Natural Re-

20 sources and the Committee on Energy and Commerce of

21 the House of Representatives a report that describes-

22 "(1) the manner of consultation made as re-

23 quired by subsection (a); and 
1809

"(2) the results of the study, including any rec-

2 ommendations of the Secretary based on results of

3 the study.

4 “SEC. 310. TRIBAL LEASING.

5 "A Tribal Health Program may lease permanent

6 structures for the purpose of providing health care services

7 without obtaining advance approval in appropriation Acts.

8 "SEC. 311. INDIAN HEALTH SERVICE/TRIBAL FACILITIES JOINT VENTURE PROGRAM.

10 "(a) IN GENERAL.-The Secretary, acting through

11 the Service, shall make arrangements with Indian Tribes

12 and Tribal Organizations to establish joint venture dem-

13 onstration projects under which an Indian Tribe or Tribal

14 Organization shall expend tribal, private, or other avail-

15 able funds, for the acquisition or construction of a health

16 facility for a minimum of 10 years, under a no-cost lease,

17 in exchange for agreement by the Service to provide the

18 equipment, supplies, and staffing for the operation and

19 maintenance of such a health facility. An Indian Tribe or

20 Tribal Organization may use tribal funds, private sector,

21 or other available resources, including loan guarantees, to

22 fulfill its commitment under a joint venture entered into

23 under this subsection. An Indian Tribe or Tribal Organi-

24 zation shall be eligible to establish a joint venture project

25 if, when it submits a letter of intent, it- 
"(1) has begun but not completed the process

2 of acquisition or construction of a health facility to

3 be used in the joint venture project;

"(2) has not begun the process of acquisition or

5 construction of a health facility for use in the joint

6 venture project; or

"(3) in its application for a joint venture agree-

8 ment, agrees-

"(A) to construct a facility for the joint venture which complies with the size and space criteria established by the Service; or

"(B) if the facility it proposes for the joint venture is already in existence or under construction, that only the portion of such facility which complies with the size and space criteria of the Service will be eligible for the joint venture agreement.

18 “(b) Requirements.-The Secretary shall make 19 such an arrangement with an Indian Tribe or Tribal Orga20 nization only if23 trative and financial capabilities necessary to com24 plete the timely acquisition or construction of the 25 relevant health facility; and 
1811

"(2) the Indian Tribe or Tribal Organization

2 meets the need criteria determined using the criteria

3 developed under the health care facility priority sys-

4 tem under section 301, unless the Secretary deter-

5 mines, pursuant to regulations, that other criteria

6 will result in a more cost-effective and efficient

7 method of facilitating and completing construction of

8 health care facilities.

9 “(c) Continued Operation.-The Secretary shall

10 negotiate an agreement with the Indian Tribe or Tribal

11 Organization regarding the continued operation of the fa-

12 cility at the end of the initial 10 year no-cost lease period.

13 “(d) Breach of Agreement.-An Indian Tribe or

14 Tribal Organization that has entered into a written agree-

15 ment with the Secretary under this section, and that

16 breaches or terminates without cause such agreement,

17 shall be liable to the United States for the amount that

18 has been paid to the Indian Tribe or Tribal Organization,

19 or paid to a third party on the Indian Tribe's or Tribal

20 Organization's behalf, under the agreement. The Sec-

21 retary has the right to recover tangible property (including

22 supplies) and equipment, less depreciation, and any funds

23 expended for operations and maintenance under this sec-

24 tion. The preceding sentence does not apply to any funds 
1 expended for the delivery of health care services, per-

2 sonnel, or staffing.

3 “(e) Recovery for Nonuse.-An Indian Tribe or

4 Tribal Organization that has entered into a written agree-

5 ment with the Secretary under this subsection shall be en-

6 titled to recover from the United States an amount that

7 is proportional to the value of such facility if, at any time

8 within the 10-year term of the agreement, the Service

9 ceases to use the facility or otherwise breaches the agree-

10 ment.

11 "(f) Definition.-For the purposes of this section,

12 the term 'health facility' or 'health facilities' includes

13 quarters needed to provide housing for staff of the rel-

14 evant Tribal Health Program.

15 "SEC. 312. LOCATION OF FACILITIES.

16 “(a) In GeneRAL.-In all matters involving the reor-

17 ganization or development of Service facilities or in the

18 establishment of related employment projects to address

19 unemployment conditions in economically depressed areas,

20 the Bureau of Indian Affairs and the Service shall give

21 priority to locating such facilities and projects on Indian

22 lands, or lands in Alaska owned by any Alaska Native vil-

23 lage, or village or regional corporation under the Alaska

24 Native Claims Settlement Act (43 U.S.C. 1601 et seq.), 25 or any land allotted to any Alaska Native, if requested 
1813

1 by the Indian owner and the Indian Tribe with jurisdiction

2 over such lands or other lands owned or leased by the In-

3 dian Tribe or Tribal Organization. Top priority shall be

4 given to Indian land owned by 1 or more Indian Tribes.

5 "(b) Definition.-For purposes of this section, the

6 term 'Indian lands' means-

$7 \quad$ "(1) all lands within the exterior boundaries of

8 any reservation; and

9 "(2) any lands title to which is held in trust by

10 the United States for the benefit of any Indian

11 Tribe or individual Indian or held by any Indian

12 Tribe or individual Indian subject to restriction by

13 the United States against alienation.

14 "SEC. 313. MAINTENANCE AND IMPROVEMENT OF HEALTH CARE FACILITIES.

16 “(a) REPORT.-The Secretary shall submit to the

17 President, for inclusion in the report required to be trans-

18 mitted to Congress under section 801, a report which iden-

19 tifies the backlog of maintenance and repair work required

20 at both Service and tribal health care facilities, including

21 new health care facilities expected to be in operation in

22 the next fiscal year. The report shall also identify the need

23 for renovation and expansion of existing facilities to sup-

24 port the growth of health care programs. 
1 “(b) Maintenance of Newly Constructed

2 SPACE.-The Secretary, acting through the Service, is au-

3 thorized to expend maintenance and improvement funds

4 to support maintenance of newly constructed space only

5 if such space falls within the approved supportable space

6 allocation for the Indian Tribe or Tribal Organization.

7 Supportable space allocation shall be defined through the

8 health care facility priority system under section 301(c).

9 “(c) Replacement Facilities.-In addition to

10 using maintenance and improvement funds for renovation,

11 modernization, and expansion of facilities, an Indian Tribe

12 or Tribal Organization may use maintenance and improve-

13 ment funds for construction of a replacement facility if

14 the costs of renovation of such facility would exceed a

15 maximum renovation cost threshold. The Secretary shall

16 consult with Indian Tribes and Tribal Organizations in de-

17 termining the maximum renovation cost threshold.

18 "SEC. 314. TRIBAL MANAGEMENT OF FEDERALLY OWNED QUARTERS.

“(a) Rental Rates.-

“(1) Establishment.-Notwithstanding any

22 other provision of law, a Tribal Health Program

23 which operates a hospital or other health facility and

24 the federally owned quarters associated therewith

25 pursuant to a contract or compact under the Indian 
1 Self-Determination and Education Assistance Act

2 (25 U.S.C. 450 et seq.) shall have the authority to 3 establish the rental rates charged to the occupants

4 of such quarters by providing notice to the Secretary

5 of its election to exercise such authority.

6 “(2) OBJECTIVES.-In establishing rental rates 7 pursuant to authority of this subsection, a Tribal 8 Health Program shall endeavor to achieve the fol9 lowing objectives:

"(A) To base such rental rates on the reasonable value of the quarters to the occupants thereof.

"(B) To generate sufficient funds to prudently provide for the operation and maintenance of the quarters, and subject to the discretion of the Tribal Health Program, to supply reserve funds for capital repairs and replacement of the quarters.

“(3) Equitable Funding.-Any quarters 20 whose rental rates are established by a Tribal 21 Health Program pursuant to this subsection shall 22 remain eligible for quarters improvement and repair 23 funds to the same extent as all federally owned 24 quarters used to house personnel in Services-sup25 ported programs. 
“(4) Notice OF Rate Change.-A Tribal Health Program which exercises the authority pro-

3 vided under this subsection shall provide occupants

4 with no less than 60 days notice of any change in 5 rental rates.

6 “(b) Direct Collection of Rent.-

"(1) IN GENERAL.-Notwithstanding any other

8 provision of law, and subject to paragraph (2), a

9 Tribal Health Program shall have the authority to

10 collect rents directly from Federal employees who oc-

11 cupy such quarters in accordance with the following:

“(A) The Tribal Health Program shall notify the Secretary and the subject Federal employees of its election to exercise its authority to collect rents directly from such Federal employees.

"(B) Upon receipt of a notice described in subparagraph (A), the Federal employees shall pay rents for occupancy of such quarters directly to the Tribal Health Program and the Secretary shall have no further authority to collect rents from such employees through payroll deduction or otherwise.

"(C) Such rent payments shall be retained 25 
made payable to or otherwise be deposited with the United States.

"(D) Such rent payments shall be deposited into a separate account which shall be used by the Tribal Health Program for the maintenance (including capital repairs and replacement) and operation of the quarters and facilities as the Tribal Health Program shall determine.

11 Tribal Health Program which has made an election 12 under paragraph (1) requests retrocession of its au13 thority to directly collect rents from Federal employ14 ees occupying federally owned quarters, such ret15 rocession shall become effective on the earlier of"(A) the first day of the month that begins no less than 180 days after the Tribal Health Program notifies the Secretary of its desire to retrocede; or

23 "(c) Rates in Alaska.- To the extent that a Tribal 24 Health Program, pursuant to authority granted in sub25 section (a), establishes rental rates for federally owned 
1818

1 quarters provided to a Federal employee in Alaska, such

2 rents may be based on the cost of comparable private rent-

3 al housing in the nearest established community with a

4 year-round population of 1,500 or more individuals.

5 “SEC. 315. APPLICABILITY OF BUY AMERICAN ACT RE6 QUIREMENT.

7 “(a) APPLICABILITY.-The Secretary shall ensure 8 that the requirements of the Buy American Act apply to 9 all procurements made with funds provided pursuant to 10 section 317. Indian Tribes and Tribal Organizations shall 11 be exempt from these requirements.

12 “(b) EfFect of Violation.-If it has been finally

13 determined by a court or Federal agency that any person 14 intentionally affixed a label bearing a 'Made in America' 15 inscription or any inscription with the same meaning, to 16 any product sold in or shipped to the United States that 17 is not made in the United States, such person shall be 18 ineligible to receive any contract or subcontract made with

19 funds provided pursuant to section 317, pursuant to the 20 debarment, suspension, and ineligibility procedures de21 scribed in sections 9.400 through 9.409 of title 48, Code 22 of Federal Regulations.

23 "(c) Definitions.-For purposes of this section, the 24 term 'Buy American Act' means title III of the Act enti25 tled 'An Act making appropriations for the Treasury and 
1 Post Office Departments for the fiscal year ending June

2 30, 1934, and for other purposes', approved March 3,

31933 (41 U.S.C. 10a et seq.).

4 “SEC. 316. OTHER FUNDING FOR FACILITIES.

5 “(a) Authority To ACcept Funds.-The Sec-

6 retary is authorized to accept from any source, including

7 Federal and State agencies, funds that are available for

8 the construction of health care facilities and use such

9 funds to plan, design, and construct health care facilities

10 for Indians and to place such funds into a contract or com-

11 pact under the Indian Self-Determination and Education

12 Assistance Act (25 U.S.C. 450 et seq.). Receipt of such

13 funds shall have no effect on the priorities established pur-

14 suant to section 301.

15 “(b) Interagency Agreements.-The Secretary is

16 authorized to enter into interagency agreements with

17 other Federal agencies or State agencies and other entities

18 and to accept funds from such Federal or State agencies

19 or other sources to provide for the planning, design, and

20 construction of health care facilities to be administered by

21 Indian Health Programs in order to carry out the pur-

22 poses of this Act and the purposes for which the funds

23 were appropriated or for which the funds were otherwise

24 provided. 
1 “(c) Transferred Funds.-Any Federal agency to

2 which funds for the construction of health care facilities

3 are appropriated is authorized to transfer such funds to

4 the Secretary for the construction of health care facilities

5 to carry out the purposes of this Act as well as the pur-

6 poses for which such funds are appropriated to such other

7 Federal agency.

8 “(d) Establishment of Standards.-The Sec-

9 retary, through the Service, shall establish standards by

10 regulation for the planning, design, and construction of

11 health care facilities serving Indians under this Act.

12 “SEC. 317. AUTHORIZATION OF APPROPRIATIONS.

13 "There are authorized to be appropriated such sums

14 as may be necessary to carry out this title.

15 “TITLE IV-ACCESS TO HEALTH SERVICES

17 "SEC. 401. TREATMENT OF PAYMENTS UNDER SOCIAL SECURITY ACT HEALTH BENEFITS PROGRAMS. “(a) Disregard of Medicare, Medicaid, and

20 SChiP Payments in Determining Appropriations.-

21 Any payments received by an Indian Health Program or

22 by an urban Indian organization under title XVIII, XIX, 23 or XXI of the Social Security Act for services provided 24 to Indians eligible for benefits under such respective titles 
1821

1 shall not be considered in determining appropriations for

2 the provision of health care and services to Indians.

3 “(b) Nonpreferential Treatment.-Nothing in

4 this Act authorizes the Secretary to provide services to an

5 Indian with coverage under title XVIII, XIX, or XXI of

6 the Social Security Act in preference to an Indian without

7 such coverage.

8 “(c) UsE OF Funds.-

9

“(1) Speclat FUnd.-

10

"(A) 100 PERCENT PASS-THROUgh OF PAYMENTS DUE TO FACILITIES.-Notwithstanding any other provision of law, but subject to paragraph (2), payments to which a facility of the Service is entitled by reason of a provision of title XVIII or XIX of the Social Security Act shall be placed in a special fund to be held by the Secretary. In making payments from such fund, the Secretary shall ensure that each Service Unit of the Service receives 100 percent of the amount to which the facilities of the Service, for which such Service Unit makes collections, are entitled by reason of a provision of either such title.

"(B) UsE OF FUNDS.-Amounts received 25 by a facility of the Service under subparagraph 
(A) by reason of a provision of title XVIII or XIX of the Social Security Act shall first be

23 provided by such Program during the period of such 24 election.

25 “(d) Direct Billing.- 
“(1) In GENERAL.—Subject to complying with

2 the requirements of paragraph (2), a Tribal Health

3 Program may elect to directly bill for, and receive

4 payment for, health care items and services provided

5 by such Program for which payment is made under

6 title XVIII, XIX, or XXI of the Social Security Act.

“(2) Direct Reimbursement.-

“(A) Use OF Funds.-Each Tribal Health

Program making the election described in paragraph (1) with respect to a program under title XVIII, XIX, or XXI of the Social Security Act shall be reimbursed directly by that program for items and services furnished without regard to subsection (c)(1), but all amounts so reimbursed shall be used by the Tribal Health Program for the same purposes with respect to such Program for which payment under subparagraph (A) of subsection (c)(1) to a facility of the Service may be used pursuant to subparagraph (B) of such subsection with respect to the Service.

"(B) Audits.-The amounts paid to a Tribal Health Program making the election described in paragraph (1) with respect to a pro25 gram under title XVIII, XIX, or XXI of the So- 
1824

cial Security Act shall be subject to all auditing requirements applicable to the program under such title, as well as all auditing requirements applicable to programs administered by an Indian Health Program. Nothing in the preceding sentence shall be construed as limiting the application of auditing requirements applicable to amounts paid under title XVIII, XIX, or XXI of the Social Security Act.

"(C) Identification of source of PaYMENTs.-Any Tribal Health Program that receives reimbursements or payments under title XVIII, XIX, or XXI of the Social Security Act shall provide to the Service a list of each provider enrollment number (or other identifier) under which such Program receives such reimbursements or payments.

“(3) Examination and implementation OF CHANGES.-

"(A) In GENERAL.—The Secretary, acting through the Service and with the assistance of the Administrator of the Centers for Medicare \& Medicaid Services, shall examine on an ongoing basis and implement any administrative changes that may be necessary to facilitate di- 
rect billing and reimbursement under the program established under this subsection, including any agreements with States that may be necessary to provide for direct billing under a program under title XIX or XXI of the Social Security Act.

"(B) Coordination OF information.The Service shall provide the Administrator of the Centers for Medicare \& Medicaid Services with copies of the lists submitted to the Service under paragraph $(2)(\mathrm{C})$, enrollment data regarding patients served by the Service (and by Tribal Health Programs, to the extent such data is available to the Service), and such other information as the Administrator may require 16 for purposes of administering title XVIII, XIX, 17 or XXI of the Social Security Act.

18 “(4) WithdraWal From Program.-A Tribal 19 Health Program that bills directly under the pro20 gram established under this subsection may with21 draw from participation in the same manner and 22 under the same conditions that an Indian Tribe or 23 Tribal Organization may retrocede a contracted pro24 gram to the Secretary under the authority of the In25 dian Self-Determination and Education Assistance 
1826

1 Act (25 U.S.C. 450 et seq.). All cost accounting and

2 billing authority under the program established

3 under this subsection shall be returned to the Sec-

4 retary upon the Secretary's acceptance of the with-

5 drawal of participation in this program.

6 “(5) Termination FOR FAILURE TO COMPLY

7 WiTh REQUIREMENTS.- The Secretary may termi-

8 nate the participation of a Tribal Health Program or

9 in the direct billing program established under this

10 subsection if the Secretary determines that the Pro-

11 gram has failed to comply with the requirements of

12 paragraph (2). The Secretary shall provide a Tribal

13 Health Program with notice of a determination that

14 the Program has failed to comply with any such re-

15 quirement and a reasonable opportunity to correct

16 such noncompliance prior to terminating the Pro-

17 gram's participation in the direct billing program es-

18 tablished under this subsection.

19 “(e) Related Provisions Under the Soclal Se-

20 CURITY ACT.-For provisions related to subsections (c)

21 and (d), see sections 1880, 1911, and 2107(e)(1)(D) of

22 the Social Security Act. 
1827

1 "SEC. 402. GRANTS TO AND CONTRACTS WITH THE SERV-

ICE, INDIAN TRIBES, TRIBAL ORGANIZATIONS, AND URBAN INDIAN ORGANIZATIONS TO FACILITATE OUTREACH, ENROLLMENT, AND COVERAGE OF INDIANS UNDER SOCIAL SECURITY ACT HEALTH BENEFIT PROGRAMS.

"(a) INDIAN TRIBES AND TRIBAL ORganizA-

8 TIONS.-The Secretary, acting through the Service, shall

9 make grants to or enter into contracts with Indian Tribes

10 and Tribal Organizations to assist such Tribes and Tribal

11 Organizations in establishing and administering programs

12 on or near reservations, trust lands, and Alaska Native

13 Villages, including programs to provide outreach and en-

14 rollment through video, electronic delivery methods, or

15 telecommunication devices that allow real-time or time-de-

16 layed communication between individual Indians and the

17 benefit program, to assist individual Indians-

"(1) to enroll for benefits under a program es-

19 tablished under title XVIII, XIX, or XXI of the So-

20 cial Security Act; and

21 "(2) with respect to such programs for which

22 the charging of premiums and cost sharing is not

23 prohibited under such programs, to pay premiums or

24 cost sharing for coverage for such benefits, which

25 may be based on financial need (as determined by

26 the Indian Tribe or Tribes or Tribal Organizations 
1828

1 being served based on a schedule of income levels de-

2 veloped or implemented by such Tribe, Tribes, or

3 Tribal Organizations).

4 “(b) Conditions.-The Secretary, acting through

5 the Service, shall place conditions as deemed necessary to

6 effect the purpose of this section in any grant or contract

7 which the Secretary makes with any Indian Tribe or Trib-

8 al Organization pursuant to this section. Such conditions

9 shall include requirements that the Indian Tribe or Tribal

10 Organization successfully undertake-

11 "(1) to determine the population of Indians eli-

12 gible for the benefits described in subsection (a);

13 "(2) to educate Indians with respect to the ben-

14 efits available under the respective programs;

15 "(3) to provide transportation for such indi-

16 vidual Indians to the appropriate offices for enroll-

17 ment or applications for such benefits; and

18 "(4) to develop and implement methods of im-

19 proving the participation of Indians in receiving ben-

20 efits under such programs.

21 "(c) Application to Urban Indian Organiza-

22 TIONS.-

23 “(1) In GENERAL.-The provisions of sub24 section (a) shall apply with respect to grants and 25 other funding to urban Indian organizations with re- 
1 spect to populations served by such organizations in

2 the same manner they apply to grants and contracts

3 with Indian Tribes and Tribal Organizations with

4 respect to programs on or near reservations.

5 “(2) REQUIREMENTS.-The Secretary shall in-

6 clude in the grants or contracts made or provided

7 under paragraph (1) requirements that are-

"(A) consistent with the requirements imposed by the Secretary under subsection (b);

"(B) appropriate to urban Indian organizations and urban Indians; and "(C) necessary to effect the purposes of this section. “(d) Facilitating Cooperation in Enrollment 15 And Retention.-The Secretary, acting through the 16 Centers for Medicare \& Medicaid Services, shall consult 17 with States, the Service, Indian Tribes, Tribal Organiza18 tions, and urban Indian organizations to develop and dis19 seminate best practices with respect to facilitating agree20 ments between the States and Indian Tribes, Tribal Orga21 nizations, and urban Indian organizations relating to en22 rollment and retention of Indians in programs established 23 under titles XVIII, XIX, and XXI of the Social Security 24 Act. 
1830

1 “(e) Agreements To Improve Enrollment of

2 Indians Under Social Security Act Health Bene-

3 FITS Programs.-For provisions relating to agreements

4 between the Secretary and the Service, Indian Tribes,

5 Tribal Organizations, and urban Indian organizations for

6 the collection, preparation, and submission of applications

7 by Indians for assistance under the Medicaid and chil-

8 dren's health insurance programs established under titles

9 XIX and XXI of the Social Security Act, and benefits

10 under the Medicare program established under title XVIII

11 of such Act, see subsections (a) and (b) of section 1139

12 of the Social Security Act.

13 “(f) DeFINITIONS.-In this section:

14 “(1) Premium.-The term 'premium' includes 15 any enrollment fee or similar charge.

16 "(2) Cost sharing.-The term 'cost sharing'

17 includes any deduction, deductible, copayment, coin18 surance, or similar charge.

19 “(3) Benefits.—The term 'benefits' means, 20 with respect to-

"(A) title XVIII of the Social Security Act, 22 benefits under such title;

23 "(B) title XIX of such Act, medical assist$24 \quad$ ance under such title; and 
1831

"(C) title XXI of such Act, assistance under such title.

3 "SEC. 403. REIMBURSEMENT FROM CERTAIN THIRD PARTIES OF COSTS OF HEALTH SERVICES.

“(a) Right of Recovery.-Except as provided in 6 subsection (f), the United States, an Indian Tribe, or

7 Tribal Organization shall have the right to recover from 8 an insurance company, health maintenance organization, 9 employee benefit plan, third-party tortfeasor, or any other 10 responsible or liable third party (including a political sub11 division or local governmental entity of a State) the rea12 sonable charges incurred by the Secretary, an Indian 13 Tribe, or Tribal Organization, or, if higher, the highest 14 amount the third party would pay for care and services 15 furnished by providers other than governmental entities, 16 in providing health services through the Service, an Indian 17 Tribe, or Tribal Organization to any individual to the 18 same extent that such individual, or any nongovernmental 19 provider of such services, would be eligible to receive dam20 ages, reimbursement, or indemnification for such charges 21 if23 governmental provider; and 
1832

"(2) such individual had been required to pay

2 such charges or expenses and did pay such charges

3 or expenses.

4 “(b) Limitations on Recoveries From States.-

5 Subsection (a) shall provide a right of recovery against

6 any State, only if the injury, illness, or disability for which

7 health services were provided is covered under-

“(1) workers' compensation laws; or

9

“(2) a no-fault automobile accident insurance

10 plan or program.

11 “(c) Nonapplication of Other Laws.-No law of

12 any State, or of any political subdivision of a State and

13 no provision of any contract, insurance or health mainte-

14 nance organization policy, employee benefit plan, self-in-

15 surance plan, managed care plan, or other health care plan

16 or program entered into or renewed after the date of the

17 enactment of the Indian Health Care Amendments of

181988 , shall prevent or hinder the right of recovery of the

19 United States, an Indian Tribe, or Tribal Organization

20 under subsection (a).

21 “(d) No Effect on Private Rights of Action.-

22 No action taken by the United States, an Indian Tribe,

23 or Tribal Organization to enforce the right of recovery

24 provided under this section shall operate to deny to the 
1 injured person the recovery for that portion of the person's

2 damage not covered hereunder.

“(e) Enforcement.-

"(1) In GENERAL.- The United States, an Indian Tribe, or Tribal Organization may enforce the right of recovery provided under subsection (a) by"(A) intervening or joining in any civil action or proceeding brought-

"(i) by the individual for whom health services were provided by the Secretary, an Indian Tribe, or Tribal Organization; or "(ii) by any representative or heirs of such individual, or "(B) instituting a civil action, including a civil action for injunctive relief and other relief and including, with respect to a political subdivision or local governmental entity of a State, such an action against an official thereof.

“(2) Notice.-All reasonable efforts shall be made to provide notice of action instituted under paragraph (1)(B) to the individual to whom health services were provided, either before or during the pendency of such action.

“(3) ReCOVERY From tortFeasors.- 
1834

"(A) IN GENERAL.-In any case in which an Indian Tribe or Tribal Organization that is authorized or required under a compact or contract issued pursuant to the Indian Self-Determination and Education Assistance Act (25 U.S.C. 450 et seq.) to furnish or pay for health services to a person who is injured or suffers a disease on or after the date of enactment of the Indian Health Care Improvement Act Amendments of 2009 under circumstances that establish grounds for a claim of liability against the tortfeasor with respect to the injury or disease, the Indian Tribe or Tribal Organization shall have a right to recover from the tortfeasor (or an insurer of the tortfeasor) the reasonable value of the health services so furnished, paid for, or to be paid for, in accordance with the Federal Medical Care Recovery Act (42 U.S.C. 2651 et seq.), to the same extent and under the same circumstances as the United States may recover under that Act.

"(B) Treatment.-The right of an Indian Tribe or Tribal Organization to recover under subparagraph (A) shall be independent of the rights of the injured or diseased person 
1835

served by the Indian Tribe or Tribal Organization.

3 “(f) Limitation.-Absent specific written authoriza-

4 tion by the governing body of an Indian Tribe for the pe-

5 riod of such authorization (which may not be for a period

6 of more than 1 year and which may be revoked at any

7 time upon written notice by the governing body to the

8 Service), the United States shall not have a right of recov-

9 ery under this section if the injury, illness, or disability

10 for which health services were provided is covered under

11 a self-insurance plan funded by an Indian Tribe, Tribal

12 Organization, or urban Indian organization. Where such

13 authorization is provided, the Service may receive and ex-

14 pend such amounts for the provision of additional health

15 services consistent with such authorization.

16 “(g) Costs And Attorneys' Fees.-In any action

17 brought to enforce the provisions of this section, a pre-

18 vailing plaintiff shall be awarded its reasonable attorneys'

19 fees and costs of litigation.

20 "(h) Nonapplication of Clatms Filing Require-

21 MENTS.-An insurance company, health maintenance or-

22 ganization, self-insurance plan, managed care plan, or

23 other health care plan or program (under the Social Secu-

24 rity Act or otherwise) may not deny a claim for benefits

25 submitted by the Service or by an Indian Tribe or Tribal 
1836

1 Organization based on the format in which the claim is

2 submitted if such format complies with the format re3 quired for submission of claims under title XVIII of the

4 Social Security Act or recognized under section 1175 of 5 such Act.

6 "(i) APPLICATION TO URBAN INDIAN ORGANIZA-

7 TIONS.-The previous provisions of this section shall apply

8 to urban Indian organizations with respect to populations

9 served by such Organizations in the same manner they

10 apply to Indian Tribes and Tribal Organizations with re-

11 spect to populations served by such Indian Tribes and

12 Tribal Organizations.

13 “(j) Statute of Limitations.-The provisions of 14 section 2415 of title 28, United States Code, shall apply 15 to all actions commenced under this section, and the ref16 erences therein to the United States are deemed to include 17 Indian Tribes, Tribal Organizations, and urban Indian or18 ganizations.

19 "(k) SAVINGS.-Nothing in this section shall be con20 strued to limit any right of recovery available to the 21 United States, an Indian Tribe, or Tribal Organization 22 under the provisions of any applicable, Federal, State, or 23 Tribal law, including medical lien laws. 
1 “SEC. 404. CREDITING OF REIMBURSEMENTS.

2 “(a) Retention of Amounts for Use by Pro-

3 GRAM.-Except as provided in section 202(f) (relating to

4 the Catastrophic Health Emergency Fund) and section

5806 (relating to health services for ineligible persons), all

6 reimbursements received or recovered, including under

7 section 806, by reason of the provision of health services

8 by the Service, by an Indian Tribe or Tribal Organization,

9 or by an urban Indian organization, shall be credited to

10 the Service, such Indian Tribe or Tribal Organization, or

11 such urban Indian organization, respectively, and may be

12 used as provided in section 401. In the case of such a

13 service provided by or through a Service Unit, such

14 amounts shall be credited to such unit and used for such

15 purposes.

16 “(b) No Offset of Amounts.-The Service may

17 not offset or limit any amount obligated to any Service

18 Unit or entity receiving funding from the Service because

19 of the receipt of reimbursements under subsection (a).

20 “SEC. 405. PURCHASING HEALTH CARE COVERAGE.

21 “(a) Purchasing Coverage.-

22 “(1) IN GENERAL.-Insofar as amounts are

23 made available under law (including a provision of

24 the Social Security Act, the Indian Self-Determina-

25 tion and Education Assistance Act (25 U.S.C. 450

26 et seq.), or other law, other than under section 402) 
1838

1 to Indian Tribes, Tribal Organizations, and urban

2 Indian organizations for health benefits for Service

3 beneficiaries, Indian Tribes, Tribal Organizations, 4 and urban Indian organizations may use such

5 amounts to purchase health benefits coverage that 6 qualifies as creditable coverage under section $72701(\mathrm{c})(1)$ of the Public Health Service Act for such 8 beneficiaries, including, subject to paragraph (2), 9 throughcare plan;

"(A) a tribally owned and operated health "(B) a State or locally authorized or licensed health care plan;

"(C) a health insurance provider or managed care organization; or

“(D) a self-insured plan.

“(2) ExceptTon.-The coverage provided under paragraph (1) may not include coverage consisting of-

"(A) benefits provided under a health flexible spending arrangement (as defined in section 106(c)(2) of the Internal Revenue Code of 1986); or

"(B) a high deductible health plan (as defined in section 223(c)(2) of such Code), with- 
1839

14 case of a self-insured plan under subsection (a)(4), the 15 amounts may be used for expenses of operating the plan,

16 including administration and insurance to limit the finan17 cial risks to the entity offering the plan.

18 “(c) CONstruCtion.-Nothing in this section shall 19 be construed as affecting the use of any amounts not re20 ferred to in subsection (a).

21 "SEC. 406. SHARING ARRANGEMENTS WITH FEDERAL AGEN-

out regard to whether the plan is purchased in conjunction with a health savings account (as defined under section 223(d) of such Code).

“(3) Permitting PURchase of COVERAge BASED ON FINANCIAL NEED.-The purchase of coverage by an Indian Tribe, Tribal Organization, or urban Indian organization under this subsection may be based on the financial needs of beneficiaries (as determined by the Indian Tribe or Tribes being served based on a schedule of income levels developed or implemented by such Indian Tribe or Tribes).

"(b) Expenses For Self-insured Plan.-In the 
1 medical facilities and services between the Service,

2 Indian Tribes, and Tribal Organizations and the De-

3 partment of Veterans Affairs and the Department of

4 Defense.

5

6 QUIRED.-The Secretary may not finalize any ar-

7 rangement between the Service and a Department

8 described in paragraph (1) without first consulting

9 with the Indian Tribes which will be significantly af-

10 fected by the arrangement.

11 “(b) Limitations.-The Secretary shall not take

12 any action under this section or under subchapter IV of

13 chapter 81 of title 38, United States Code, which would

14 impair-

15 "(1) the priority access of any Indian to health

16 care services provided through the Service and the

17 eligibility of any Indian to receive health services

18 through the Service;

19 "(2) the quality of health care services provided

20 to any Indian through the Service;

21 "(3) the priority access of any veteran to health

22 care services provided by the Department of Vet23 erans Affairs; 
1841

1 “(4) the quality of health care services provided

2 by the Department of Veterans Affairs or the De3 partment of Defense; or

4 "(5) the eligibility of any Indian who is a vet5 eran to receive health services through the Depart6 ment of Veterans Affairs.

7 “(c) Remmbursement.-The Service, Indian Tribe, 8 or Tribal Organization shall be reimbursed by the Depart9 ment of Veterans Affairs or the Department of Defense 10 (as the case may be) where services are provided through 11 the Service, an Indian Tribe, or a Tribal Organization to 12 beneficiaries eligible for services from either such Depart13 ment, notwithstanding any other provision of law.

14 “(d) Construction.-Nothing in this section may 15 be construed as creating any right of a non-Indian veteran 16 to obtain health services from the Service.

17 “SEC. 407. ELIGIBLE INDIAN VETERAN SERVICES.

18 “(a) Findings; Purpose."(1) Findings.-Congress finds that"(A) collaborations between the Secretary and the Secretary of Veterans Affairs regarding the treatment of Indian veterans at facilities of 24 imum extent practicable; and 
1842

"(B) increased enrollment for services of the Department of Veterans Affairs by veterans who are members of Indian tribes should be encouraged to the maximum extent practicable.

"(2) Purpose.-The purpose of this section is to reaffirm the goals stated in the document entitled 'Memorandum of Understanding Between the VA/ Veterans Health Administration And HHS/Indian Health Service' and dated February 25, 2003 (relating to cooperation and resource sharing between the Veterans Health Administration and Service).

“(b) Definitions.-In this section: “(1) Eligible indian veteran.-The term 'eligible Indian veteran' means an Indian or Alaska Native veteran who receives any medical service that is-

"(A) authorized under the laws administered by the Secretary of Veterans Affairs; and "(B) administered at a facility of the Service (including a facility operated by an Indian tribe or tribal organization through a contract or compact with the Service under the Indian Self-Determination and Education Assistance Act (25 U.S.C. 450 et seq.)) pursuant to a local memorandum of understanding. 
1843

“(2) LOCAL MEMORANDUM OF UNDERSTANDING._-The term 'local memorandum of under-

3 standing' means a memorandum of understanding

4 between the Secretary (or a designee, including the

5 director of any Area Office of the Service) and the

6 Secretary of Veterans Affairs (or a designee) to im-

7 plement the document entitled 'Memorandum of Un-

8 derstanding Between the VA/Veterans Health Ad-

9 ministration And HHS/Indian Health Service' and

10 dated February 25, 2003 (relating to cooperation

11 and resource sharing between the Veterans Health

12 Administration and Indian Health Service).

13 “(c) Eligible Indian Veterans' Expenses.-

14 "(1) IN GENERAL._Notwithstanding any other

15 provision of law, the Secretary shall provide for vet-

16 eran-related expenses incurred by eligible Indian vet-

17 erans as described in subsection $(b)(1)(B)$.

18 “(2) METHOD OF PAYMENT.-The Secretary

19 shall establish such guidelines as the Secretary de-

20 termines to be appropriate regarding the method of

21 payments to the Secretary of Veterans Affairs under

22 paragraph (1).

23 "(d) Tribal Approval of Memoranda.-In nego24 tiating a local memorandum of understanding with the 25 Secretary of Veterans Affairs regarding the provision of 
1 services to eligible Indian veterans, the Secretary shall

2 consult with each Indian tribe that would be affected by

3 the local memorandum of understanding.

4 “(e) Funding.-

5 “(1) Treatment.-Expenses incurred by the

$6 \quad$ Secretary in carrying out subsection (c)(1) shall not

7 be considered to be Contract Health Service ex8 penses.

9 “(2) UsE OF FUNDS.—Of funds made available

10 to the Secretary in appropriations Acts for the Serv-

11 ice (excluding funds made available for facilities,

12 Contract Health Services, or contract support costs),

13 the Secretary shall use such sums as are necessary

14 to carry out this section.

15 “SEC. 408. PAYOR OF LAST RESORT.

16 "Indian Health Programs and health care programs 17 operated by Urban Indian Organizations shall be the 18 payor of last resort for services provided to persons eligible 19 for services from Indian Health Programs and Urban In20 dian Organizations, notwithstanding any Federal, State, 21 or local law to the contrary.

22 “SEC. 409. CONSULTATION.

23 "For provisions related to consultation with rep24 resentatives of Indian Health Programs and urban Indian 25 organizations with respect to the health care programs es- 
1845

1 tablished under titles XVIII, XIX, and XXI of the Social

2 Security Act, see section 1139(d) of the Social Security

3 Act (42 U.S.C. $1320 b-9(d))$.

4 "SEC. 410. STATE CHILDREN'S HEALTH INSURANCE PRO-

5

6 "For provisions relating to"(1) outreach to families of Indian children

8 likely to be eligible for child health assistance under

9 the State children's health insurance program estab-

10 lished under title XXI of the Social Security Act, see

11 sections 2105(c)(2)(C) and 1139(a) of such Act (42

12 U.S.C. $1397 \mathrm{ee}(\mathrm{c})(2), 1320 \mathrm{~b}-9)$; and

13 "(2) ensuring that child health assistance is

14 provided under such program to targeted low-income

15 children who are Indians and that payments are

16 made under such program to Indian Health Pro-

17 grams and urban Indian organizations operating in

18 the State that provide such assistance, see sections

$192102(\mathrm{~b})(3)(\mathrm{D})$ and 2105(c)(6)(B) of such Act (42

20 U.S.C. $1397 \mathrm{bb}(\mathrm{b})(3)(\mathrm{D}), 1397 \mathrm{ee}(\mathrm{c})(6)(\mathrm{B}))$. 
1846

1 "SEC. 411. PREMIUM AND COST SHARING PROTECTIONS AND ELIGIBILITY DETERMINATIONS UNDER MEDICAID AND SCHIP AND PROTECTION OF CERTAIN INDIAN PROPERTY FROM MEDICAID ESTATE RECOVERY.

6 "For provisions relating to-

“(1) premiums or cost sharing protections for

8 Indians furnished items or services directly by In-

9 dian Health Programs or through referral under the

10 contract health service under the Medicaid program

11 established under title XIX of the Social Security

12 Act, see sections 1916(j) and 1916A(a)(1) of the So-

13 cial Security Act (42 U.S.C. 1396o(j), 1396o$14 \quad 1(\mathrm{a})(1))$;

15 "(2) rules regarding the treatment of certain 16 property for purposes of determining eligibility 17 under such programs, see sections 1902(e)(13) and $182107(\mathrm{e})(1)(\mathrm{B})$ of such Act (42 U.S.C. 1396a(e)(13), $19 \quad 1397 \mathrm{gg}(\mathrm{e})(1)(\mathrm{B}))$; and

20 "(3) the protection of certain property from es21 tate recovery provisions under the Medicaid pro22 gram, see section $1917(\mathrm{~b})(3)(\mathrm{B})$ of such Act (42 $23 \quad$ U.S.C. $1396 p(b)(3)(B))$. 
1 “SEC. 412. TREATMENT UNDER MEDICAID AND SCHIP MANAGED CARE.

3 "For provisions relating to the treatment of Indians

4 enrolled in a managed care entity under the Medicaid pro-

5 gram under title XIX of the Social Security Act and In-

6 dian Health Programs and urban Indian organizations

7 that are providers of items or services to such Indian en-

8 rollees, see sections $1932(\mathrm{~h})$ and $2107(\mathrm{e})(1)(\mathrm{H})$ of the So-

9 cial Security Act (42 U.S.C. 1396u-2(h),

$101397 \mathrm{gg}(\mathrm{e})(1)(\mathrm{H}))$.

11 “SEC. 413. NAVAJO NATION MEDICAID AGENCY FEASIBILITY STUDY.

13 "(a) STUDY.-The Secretary shall conduct a study

14 to determine the feasibility of treating the Navajo Nation

15 as a State for the purposes of title XIX of the Social Secu-

16 rity Act, to provide services to Indians living within the

17 boundaries of the Navajo Nation through an entity estab-

18 lished having the same authority and performing the same

19 functions as single-State Medicaid agencies responsible for

20 the administration of the State plan under title XIX of 21 the Social Security Act.

22 "(b) CONsiderations.-In conducting the study, 23 the Secretary shall consider the feasibility of-

"(1) assigning and paying all expenditures for 25 the provision of services and related administration 26 funds, under title XIX of the Social Security Act, to 
1 Indians living within the boundaries of the Navajo

2 Nation that are currently paid to or would otherwise

3 be paid to the State of Arizona, New Mexico, or

$4 \quad$ Utah;

$5 \quad$ "(2) providing assistance to the Navajo Nation

6 in the development and implementation of such enti-

7 ty for the administration, eligibility, payment, and

8 delivery of medical assistance under title XIX of the

9 Social Security Act;

10 "(3) providing an appropriate level of matching

11 funds for Federal medical assistance with respect to

12 amounts such entity expends for medical assistance

13 for services and related administrative costs; and

14 "(4) authorizing the Secretary, at the option of

15 the Navajo Nation, to treat the Navajo Nation as a

16 State for the purposes of title XIX of the Social Se-

17 curity Act (relating to the State children's health in-

18 surance program) under terms equivalent to those

19 described in paragraphs (2) through (4).

20 “(c) REPORT.-Not later than 3 years after the date

21 of enactment of the Indian Health Care Improvement Act

22 Amendments of 2009, the Secretary shall submit to the

23 Committee on Indian Affairs and Committee on Finance

24 of the Senate and the Committee on Natural Resources 
1 and Committee on Energy and Commerce of the House

2 of Representatives a report that includes-

"(1) the results of the study under this section;

"(2) a summary of any consultation that oc-

5 curred between the Secretary and the Navajo Na-

6 tion, other Indian Tribes, the States of Arizona,

7 New Mexico, and Utah, counties which include Nav-

8 ajo Lands, and other interested parties, in con-

9 ducting this study;

10 "(3) projected costs or savings associated with

11 establishment of such entity, and any estimated im-

12 pact on services provided as described in this section

13 in relation to probable costs or savings; and

14 "(4) legislative actions that would be required

15 to authorize the establishment of such entity if such

16 entity is determined by the Secretary to be feasible.

17 “SEC. 414. EXCEPTION FOR EXCEPTED BENEFITS.

18 "The previous provisions of this title shall not apply

19 to the provision of excepted benefits described in para-

20 graph $(1)(\mathrm{A})$ or (3) of section 2791(c) of the Public

21 Health Service Act (42 U.S.C. 300gg-91(c)).

22 "SEC. 415. AUTHORIZATION OF APPROPRIATIONS.

23 "There are authorized to be appropriated such sums

24 as may be necessary to carry out this title. 


\section{1}

10 (25 U.S.C. 13) (commonly known as the 'Snyder Act'),

11 the Secretary, acting through the Service, shall enter into

12 contracts with, or make grants to, urban Indian organiza-

13 tions to assist such organizations in the establishment and 14 administration, within Urban Centers, of programs which 15 meet the requirements set forth in this title. Subject to 16 section 506, the Secretary, acting through the Service, 17 shall include such conditions as the Secretary considers 18 necessary to effect the purpose of this title in any contract 19 into which the Secretary enters with, or in any grant the 20 Secretary makes to, any urban Indian organization pursu21 ant to this title.

22 "SEC. 503. CONTRACTS AND GRANTS FOR THE PROVISION 23

25 TRACTS.-Under authority of the Act of November 2, 
1851

11921 (25 U.S.C. 13) (commonly known as the "Snyder 2 Act'), the Secretary, acting through the Service, shall 3 enter into contracts with, and make grants to, urban In4 dian organizations for the provision of health care and re5 ferral services for Urban Indians. Any such contract or 6 grant shall include requirements that the urban Indian or7 ganization successfully undertake to-

"(1) estimate the population of Urban Indians

9 residing in the Urban Center or centers that the or10 ganization proposes to serve who are or could be re11 cipients of health care or referral services;

12 "(2) estimate the current health status of 13 Urban Indians residing in such Urban Center or 14 centers;

15 "(3) estimate the current health care needs of 16 Urban Indians residing in such Urban Center or 17 centers;

18 "(4) provide basic health education, including 19 health promotion and disease prevention education, 20 to Urban Indians;

21 "(5) make recommendations to the Secretary 22 and Federal, State, local, and other resource agen23 cies on methods of improving health service pro24 grams to meet the needs of Urban Indians; and 
1852

“(6) where necessary, provide, or enter into

2 contracts for the provision of, health care services

3 for Urban Indians.

4 "(b) Criteria.-The Secretary, acting through the

5 Service, shall, by regulation, prescribe the criteria for se-

6 lecting urban Indian organizations to enter into contracts

7 or receive grants under this section. Such criteria shall,

8 among other factors, include-

9 "(1) the extent of unmet health care needs of

10 Urban Indians in the Urban Center or centers in-

11 volved;

12 "(2) the size of the urban Indian population in

13 the Urban Center or centers involved;

14 "(3) the extent, if any, to which the activities

15 set forth in subsection (a) would duplicate any

16 project funded under this title, or under any current

17 public health service project funded in a manner

18 other than pursuant to this title;

19 "(4) the capability of an urban Indian organiza-

20 tion to perform the activities set forth in subsection

21 (a) and to enter into a contract with the Secretary

22 or to meet the requirements for receiving a grant

23 under this section; 
1853

1 “(5) the satisfactory performance and success-

2 ful completion by an urban Indian organization of 3 other contracts with the Secretary under this title;

4 “(6) the appropriateness and likely effectiveness

5 of conducting the activities set forth in subsection

6 (a) in an Urban Center or centers; and

7 “(7) the extent of existing or likely future par-

8 ticipation in the activities set forth in subsection (a)

9 by appropriate health and health-related Federal,

10 State, local, and other agencies.

11 “(c) Access to Health Promotion and Disease

12 Prevention Programs.- The Secretary, acting through

13 the Service, shall facilitate access to or provide health pro-

14 motion and disease prevention services for Urban Indians

15 through grants made to urban Indian organizations ad-

16 ministering contracts entered into or receiving grants

17 under subsection (a).

18 “(d) Immunization Services.-

19 “(1) ACCESS OR SERVICES PROVIDED.-The

20 Secretary, acting through the Service, shall facilitate

21 access to, or provide, immunization services for

22 Urban Indians through grants made to urban Indian

23 organizations administering contracts entered into or

24 receiving grants under this section. 
“(2) Definition.-For purposes of this sub-

2 section, the term 'immunization services' means

3 services to provide without charge immunizations

4 against vaccine-preventable diseases.

5 “(e) Behavioral Health Services.-

6 "(1) ACCESS OR SERVICES PROVIDED.-The

$7 \quad$ Secretary, acting through the Service, shall facilitate

8 access to, or provide, behavioral health services for

9 Urban Indians through grants made to urban Indian

10 organizations administering contracts entered into or

11 receiving grants under subsection (a).

“(2) Assessment Required.-Except as pro-

13 vided by paragraph (3)(A), a grant may not be made

14 under this subsection to an urban Indian organiza-

15 tion until that organization has prepared, and the

16 Service has approved, an assessment of the fol17 lowing:

"(A) The behavioral health needs of the urban Indian population concerned.

"(B) The behavioral health services and other related resources available to that population.

"(C) The barriers to obtaining those serv24 ices and resources. 
"(D) The needs that are unmet by such services and resources.

“(3) Purposes of Grants.-Grants may be

4 made under this subsection for the following:

“(A) To prepare assessments required under paragraph (2).

"(B) To provide outreach, educational, and referral services to Urban Indians regarding the availability of direct behavioral health services, to educate Urban Indians about behavioral health issues and services, and effect coordination with existing behavioral health providers in order to improve services to Urban Indians.

"(C) To provide outpatient behavioral health services to Urban Indians, including the identification and assessment of illness, therapeutic treatments, case management, support groups, family treatment, and other treatment. “(D) To develop innovative behavioral health service delivery models which incorporate Indian cultural support systems and resources. “(f) Prevention of Child Abuse."(1) ACCESS OR SERVICES PROVIDED.-The Secretary, acting through the Service, shall facilitate access to or provide services for Urban Indians 
1856

1 through grants to urban Indian organizations ad2 ministering contracts entered into or receiving 3 grants under subsection (a) to prevent and treat 4 child abuse (including sexual abuse) among Urban $5 \quad$ Indians.

6 “(2) Evaluation Required.-Except as pro7 vided by paragraph (3)(A), a grant may not be made 8 under this subsection to an urban Indian organiza9 tion until that organization has prepared, and the 10 Service has approved, an assessment that documents 11 the prevalence of child abuse in the urban Indian 12 population concerned and specifies the services and 13 programs (which may not duplicate existing services 14 and programs) for which the grant is requested. “(3) Purposes of Grants.-Grants may be 16 made under this subsection for the following:

17 "(A) To prepare assessments required 18 under paragraph (2).

19 "(B) For the development of prevention, 20 training, and education programs for Urban In21 dians, including child education, parent edu22 cation, provider training on identification and 23 intervention, education on reporting require24 ments, prevention campaigns, and establishing 
service networks of all those involved in Indian child protection.

"(C) To provide direct outpatient treatment services (including individual treatment, family treatment, group therapy, and support groups) to Urban Indians who are child victims of abuse (including sexual abuse) or adult survivors of child sexual abuse, to the families of such child victims, and to urban Indian perpetrators of child abuse (including sexual

13 GRANTS.-In making grants to carry out this sub14 section, the Secretary shall take into considerationganization demonstrated by the child protection authorities in the area, including committees or other services funded under the Indian Child Welfare Act of 1978 (25 U.S.C. 1901 et seq.), if any;

"(B) the capability and expertise demonstrated by the urban Indian organization to address the complex problem of child sexual 24 abuse in the community; and 
1858

"(C) the assessment required under paragraph (2).

3 "(g) OTHER Grants.-The Secretary, acting 4 through the Service, may enter into a contract with or 5 make grants to an urban Indian organization that pro6 vides or arranges for the provision of health care services 7 (through satellite facilities, provider networks, or other8 wise) to Urban Indians in more than 1 Urban Center.

9 “SEC. 504. USE OF FEDERAL GOVERNMENT FACILITIES AND SOURCES OF SUPPLY.

11 “(a) In GENERAL.-The Secretary may permit an 12 urban Indian organization that has entered into a contract 13 or received a grant pursuant to this title, in carrying out 14 such contract or grant, to use existing facilities and all 15 equipment therein or pertaining thereto and other per16 sonal property owned by the Federal Government within 17 the Secretary's jurisdiction under such terms and condi18 tions as may be agreed upon for their use and mainte19 nance.

20 "(b) Donations.-Subject to subsection (d), the 21 Secretary may donate to an urban Indian organization 22 that has entered into a contract or received a grant pursu23 ant to this title any personal or real property determined 24 to be excess to the needs of the Indian Health Service or 
1 the General Services Administration for the purposes of

2 carrying out the contract or grant.

3 “(c) ACquisition of Property.-The Secretary

4 may acquire excess or surplus government personal or real

5 property for donation, subject to subsection (d) to an

6 urban Indian organization that has entered into a contract

7 or received a grant pursuant to this title if the Secretary

8 determines that the property is appropriate for use by the

9 urban Indian organization for a purpose for which a con-

10 tract or grant is authorized under this title.

11 “(d) PRIORITY.-In the event that the Secretary re-

12 ceives a request for a specific item of personal or real

13 property described in subsections (b) or (c) from an urban

14 Indian organization and from an Indian Tribe or Tribal

15 Organization, the Secretary shall give priority to the re-

16 quest for donation to the Indian Tribe or Tribal Organiza-

17 tion if the Secretary receives the request from the Indian

18 Tribe or Tribal Organization before the date the Secretary

19 transfers title to the property or, if earlier, the date the

20 Secretary transfers the property physically, to the urban

21 Indian organization.

22 “(e) Executive Agency Status.-For purposes of

23 section 201(a) of the Federal Property and Administrative

24 Services Act of 1949 (40 U.S.C. 481(a)) (relating to Fed-

25 eral sources of supply), an urban Indian organization that 
1860

1 has entered into a contract or received a grant pursuant

2 to this title may be deemed to be an executive agency when

3 carrying out such contract or grant.

4 “SEC. 505. CONTRACTS AND GRANTS FOR THE DETERMINATION OF UNMET HEALTH CARE NEEDS.

6 “(a) Grants AND CONTRACTS AUthorized.-

7 Under authority of the Act of November 2, 1921 (25

8 U.S.C. 13) (commonly known as the 'Snyder Act'), the

9 Secretary, acting through the Service, may enter into con-

10 tracts with or make grants to urban Indian organizations

11 situated in Urban Centers for which contracts have not

12 been entered into or grants have not been made under sec-

13 tion 503.

14 “(b) PURPose.-The purpose of a contract or grant 15 made under this section shall be the determination of the 16 matters described in subsection $(c)(1)$ in order to assist 17 the Secretary in assessing the health status and health 18 care needs of Urban Indians in the Urban Center involved 19 and determining whether the Secretary should enter into 20 a contract or make a grant under section 503 with respect 21 to the urban Indian organization which the Secretary has 22 entered into a contract with, or made a grant to, under 23 this section. 
1861

“(c) Grant and Contract Requirements.-Any

2 contract entered into, or grant made, by the Secretary

3 under this section shall include requirements that-

“(1) the urban Indian organization successfully

5 undertakes to-

"(A) document the health care status and unmet health care needs of urban Indians in the Urban Center involved; and

"(B) with respect to urban Indians in the Urban Center involved, determine the matters described in paragraphs (2), (3), (4), and (7) of section 503(b); and

“(2) the urban Indian organization complete performance of the contract, or carry out the re-

15 quirements of the grant, within 1 year after the date 16 on which the Secretary and such organization enter 17 into such contract, or within 1 year after such orga18 nization receives such grant, whichever is applicable. 19 “(d) No Renewals.-The Secretary may not renew 20 any contract entered into or grant made under this sec21 tion.

22 “SEC. 506. EVALUATIONS; RENEWALS.

23 “(a) Procedures For Evaluations.-The Sec24 retary, acting through the Service, shall develop proce25 dures to evaluate compliance with grant requirements and 
1862

1 compliance with and performance of contracts entered into

2 by urban Indian organizations under this title. Such pro-

3 cedures shall include provisions for carrying out the re4 quirements of this section.

5 “(b) Evaluations.-The Secretary, acting through 6 the Service, shall evaluate the compliance of each Urban

7 Indian Organization which has entered into a contract or 8 received a grant under section 503 with the terms of such 9 contract or grant. For purposes of this evaluation, the 10 Secretary shall-

"(1) acting through the Service, conduct an an-

12 nual onsite evaluation of the organization; or "(2) accept in lieu of such onsite evaluation evi-

14 dence of the organization's provisional or full accred-

15 itation by a private independent entity recognized by

16 the Secretary for purposes of conducting quality re17 views of providers participating in the Medicare pro18 gram under title XVIII of the Social Security Act. 19 “(c) Noncompliance; Unsatisfactory Perform20 ANCE.-If, as a result of the evaluations conducted under 21 this section, the Secretary determines that an urban In22 dian organization has not complied with the requirements 23 of a grant or complied with or satisfactorily performed a 24 contract under section 503, the Secretary shall, prior to 25 renewing such contract or grant, attempt to resolve with 
1863

1 the organization the areas of noncompliance or unsatisfac-

2 tory performance and modify the contract or grant to pre-

3 vent future occurrences of noncompliance or unsatisfac-

4 tory performance. If the Secretary determines that the

5 noncompliance or unsatisfactory performance cannot be

6 resolved and prevented in the future, the Secretary shall

7 not renew the contract or grant with the organization and

8 is authorized to enter into a contract or make a grant

9 under section 503 with another urban Indian organization

10 which is situated in the same Urban Center as the urban

11 Indian organization whose contract or grant is not re-

12 newed under this section.

13 “(d) Considerations For Renewals.-In deter-

14 mining whether to renew a contract or grant with an

15 urban Indian organization under section 503 which has

16 completed performance of a contract or grant under sec-

17 tion 504, the Secretary shall review the records of the

18 urban Indian organization, the reports submitted under

19 section 507, and shall consider the results of the onsite

20 evaluations or accreditations under subsection (b).

21 “SEC. 507. OTHER CONTRACT AND GRANT REQUIREMENTS.

22 “(a) Procurement.-Contracts with urban Indian

23 organizations entered into pursuant to this title shall be

24 in accordance with all Federal contracting laws and regu-

25 lations relating to procurement except that in the discre- 
1864

1 tion of the Secretary, such contracts may be negotiated

2 without advertising and need not conform to the provisions

3 of sections 1304 and 3131 through 3133 of title 40,

4 United States Code.

5 “(b) Payments Under Contracts or Grants.-

6 “(1) In GENERAL.-Payments under any con-

7 tracts or grants pursuant to this title, notwith-

8 standing any term or condition of such contract or

9 grant-

10 "(A) may be made in a single advance pay11 ment by the Secretary to the urban Indian or12 ganization by no later than the end of the first 1330 days of the funding period with respect to 14 which the payments apply, unless the Secretary 15 determines through an evaluation under section 16505 that the organization is not capable of ad17 ministering such a single advance payment; and 18 "(B) if any portion thereof is unexpended 19 by the urban Indian organization during the 20 funding period with respect to which the pay21 ments initially apply, shall be carried forward 22 for expenditure with respect to allowable or re23 imbursable costs incurred by the organization 24 during 1 or more subsequent funding periods 25 without additional justification or documenta- 


\section{5}

16 Notwithstanding any provision of law to the contrary, the 17 Secretary may, at the request and consent of an urban 18 Indian organization, revise or amend any contract entered 19 into by the Secretary with such organization under this 20 title as necessary to carry out the purposes of this title. “(d) Fair and Uniform Services and Assist22 ANCE.-Contracts with or grants to urban Indian organi23 zations and regulations adopted pursuant to this title shall 24 include provisions to assure the fair and uniform provision 
1866

1 to urban Indians of services and assistance under such

2 contracts or grants by such organizations.

3 “SEC. 508. REPORTS AND RECORDS.

"(a) REPORTS.-

“(1) IN GENERAL._For each fiscal year during

6 which an urban Indian organization receives or ex-

7 pends funds pursuant to a contract entered into or

8 a grant received pursuant to this title, such urban

9 Indian organization shall submit to the Secretary

10 not more frequently than every 6 months, a report

11 that includes the following:

"(A) In the case of a contract or grant under section 503, recommendations pursuant to section 503(a)(5).

"(B) Information on activities conducted by the organization pursuant to the contract or grant.

"(C) An accounting of the amounts and purpose for which Federal funds were expended.

"(D) A minimum set of data, using uniformly defined elements, as specified by the Secretary after consultation with urban Indian organizations.

“(2) Health status and services.- 
1867

23 Indian organization with respect to a contract or grant 24 under this title shall be subject to audit by the Secretary 25 and the Comptroller General of the United States. 
1 “(c) Costs of Audits.-The Secretary shall allow

2 as a cost of any contract or grant entered into or awarded 3 under section 502 or 503 the cost of an annual inde4 pendent financial audit conducted by-

5 "(1) a certified public accountant; or

$6 \quad$ "(2) a certified public accounting firm qualified

7 to conduct Federal compliance audits.

8 “SEC. 509. LIMITATION ON CONTRACT AUTHORITY.

9 "The authority of the Secretary to enter into con-

10 tracts or to award grants under this title shall be to the

11 extent, and in an amount, provided for in appropriation 12 Acts.

\section{3 "SEC. 510. FACILITIES.}

14 “(a) Grants.-The Secretary, acting through the

15 Service, may make grants to contractors or grant recipi16 ents under this title for the lease, purchase, renovation, 17 construction, or expansion of facilities, including leased fa18 cilities, in order to assist such contractors or grant recipi19 ents in complying with applicable licensure or certification 20 requirements.

21 "(b) LoAn Fund Study.-The Secretary, acting 22 through the Service, may carry out a study to determine 23 the feasibility of establishing a loan fund to provide to 24 urban Indian organizations direct loans or guarantees for 25 loans for the construction of health care facilities in a 
1869

1 manner consistent with section 309, including by submit-

2 ting a report in accordance with subsection (c) of that sec3 tion.

4 “SEC. 511. DIVISION OF URBAN INDIAN HEALTH.

5 "There is established within the Service a Division 6 of Urban Indian Health, which shall be responsible for-

7

8

9

10

11 dian organizations.

12 "SEC. 512. GRANTS FOR ALCOHOL AND SUBSTANCE ABUSE13

14 “(a) Grants Authorized.-The Secretary, acting 15 through the Service, may make grants for the provision 16 of health-related services in prevention of, treatment of, 17 rehabilitation of, or school- and community-based edu18 cation regarding, alcohol and substance abuse in Urban 19 Centers to those urban Indian organizations with which 20 the Secretary has entered into a contract under this title 21 or under section 201.

22 "(b) GoALs._Each grant made pursuant to sub23 section (a) shall set forth the goals to be accomplished 24 pursuant to the grant. The goals shall be specific to each 25 grant as agreed to between the Secretary and the grantee. 
1 “(c) Criteria.-The Secretary shall establish cri-

2 teria for the grants made under subsection (a), including 3 criteria relating to the following:

4 “(1) The size of the urban Indian population. 5 "(2) Capability of the organization to ade6 quately perform the activities required under the 7 grant.

8 "(3) Satisfactory performance standards for the 9 organization in meeting the goals set forth in such 10 grant. The standards shall be negotiated and agreed 11 to between the Secretary and the grantee on a 12 grant-by-grant basis.

13 “(4) Identification of the need for services.

14 “(d) Allocation of Grants.-The Secretary shall 15 develop a methodology for allocating grants made pursu16 ant to this section based on the criteria established pursu17 ant to subsection (c).

18 “(e) Grants Subject to Criteria.-Any grant re19 ceived by an urban Indian organization under this Act for 20 substance abuse prevention, treatment, and rehabilitation 21 shall be subject to the criteria set forth in subsection (c). 
1 "SEC. 513. TREATMENT OF CERTAIN DEMONSTRATION

PROJECTS.

3 "Notwithstanding any other provision of law, the

4 Tulsa Clinic and Oklahoma City Clinic demonstration

5 projects shall-

"(1) be permanent programs within the Serv-

7 ice's direct care program;

"(2) continue to be treated as Service Units

9 and Operating Units in the allocation of resources

10 and coordination of care; and

11 "(3) continue to meet the requirements and

12 definitions of an urban Indian organization in this

13 Act, and shall not be subject to the provisions of the

14 Indian Self-Determination and Education Assistance

15 Act (25 U.S.C. 450 et seq.).

16 “SEC. 514. URBAN NIAAA TRANSFERRED PROGRAMS.

17 "(a) GRANTs AND CONTRACTs.-The Secretary,

18 through the Division of Urban Indian Health, shall make

19 grants or enter into contracts with urban Indian organiza-

20 tions, to take effect not later than September 30, 2010,

21 for the administration of urban Indian alcohol programs

22 that were originally established under the National Insti-

23 tute on Alcoholism and Alcohol Abuse (hereafter in this

24 section referred to as 'NIAAA') and transferred to the

25 Service. 
1 “(b) Use of Funds.—Grants provided or contracts 2 entered into under this section shall be used to provide 3 support for the continuation of alcohol prevention and 4 treatment services for urban Indian populations and such 5 other objectives as are agreed upon between the Service 6 and a recipient of a grant or contract under this section. 7 “(c) Eligibility.-Urban Indian organizations that 8 operate Indian alcohol programs originally funded under 9 the NIAAA and subsequently transferred to the Service 10 are eligible for grants or contracts under this section.

11 “(d) REPORT.-The Secretary shall evaluate and re12 port to Congress on the activities of programs funded 13 under this section not less than every 5 years.

14 "SEC. 515. CONFERRING WITH URBAN INDIAN ORGANIZA15 TIONS.

16 “(a) In GenERAL.-The Secretary shall ensure that 17 the Service confers or conferences, to the greatest extent 18 practicable, with Urban Indian Organizations.

19 “(b) Definition of Confer; Conference.-In 20 this section, the terms 'confer' and 'conference' mean an 21 open and free exchange of information and opinions 22 that-

23 "(1) leads to mutual understanding and com24 prehension; and 
2 sponsibility.

3 "SEC. 516. URBAN YOUTH TREATMENT CENTER DEM“(a) Construction and Operation.ONSTRATION. “(1) IN GENERAL.-The Secretary, acting 8 fund the construction and operation of at least 1 9 residential treatment center in each Service Area 10 that meets the eligibility requirements set forth in 11 subsection (b) to demonstrate the provision of alco12 hol and substance abuse treatment services to Urban 13 Indian youth in a culturally competent residential 14 setting. “(2) Treatment.-Each residential treatment 16 center described in paragraph (1) shall be in addi17 tion to any facilities constructed under section $18 \quad 707(b)$.

19 “(b) Eligibility Requirements.-To be eligible to 20 obtain a facility under subsection (a)(1), a Service Area 21 shall meet the following requirements:

23 the Service Area. 
"(2) There reside in the Service Area Urban Indian youth with need for alcohol and substance abuse treatment services in a residential setting.

"(3) There is a significant shortage of cul5 turally competent residential treatment services for 6 Urban Indian youth in the Service Area.

7 “SEC. 517. GRANTS FOR DIABETES PREVENTION, TREATMENT, AND CONTROL. “(a) Grants Authorized.- - The Secretary may 10 make grants to those urban Indian organizations that 11 have entered into a contract or have received a grant 12 under this title for the provision of services for the preven13 tion and treatment of, and control of the complications 14 resulting from, diabetes among urban Indians.

15 "(b) GOALS.-Each grant made pursuant to sub16 section (a) shall set forth the goals to be accomplished 17 under the grant. The goals shall be specific to each grant 18 as agreed to between the Secretary and the grantee.

19 “(c) Establishment of Criteria.-The Secretary 20 shall establish criteria for the grants made under sub21 section (a) relating to-

"(1) the size and location of the urban Indian 23 population to be served; "(2) the need for prevention of and treatment 25 of, and control of the complications resulting from, 
1 diabetes among the urban Indian population to be

2 served;

"(3) performance standards for the organiza-

4 tion in meeting the goals set forth in such grant

5 that are negotiated and agreed to by the Secretary

6 and the grantee;

7 "(4) the capability of the organization to ade-

8 quately perform the activities required under the

9 grant; and

10 "(5) the willingness of the organization to col-

11 laborate with the registry, if any, established by the

12 Secretary under section 203(e)(1)(B) in the Area

13 Office of the Service in which the organization is lo14 cated.

15 “(d) Funds Subject to Criteria.-Any funds re-

16 ceived by an urban Indian organization under this Act for

17 the prevention, treatment, and control of diabetes among

18 urban Indians shall be subject to the criteria developed

19 by the Secretary under subsection (c).

20 “SEC. 518. COMMUNITY HEALTH REPRESENTATIVES.

21 "The Secretary, acting through the Service, may

22 enter into contracts with, and make grants to, urban In-

23 dian organizations for the employment of Indians trained

24 as health service providers through the Community Health

25 Representatives Program under section 109 in the provi- 
1 sion of health care, health promotion, and disease preven-

2 tion services to urban Indians.

3 "SEC. 519. EFFECTIVE DATE.

4 "The amendments made by the Indian Health Care

5 Improvement Act Amendments of 2009 to this title shall

6 take effect beginning on the date of enactment of that Act,

7 regardless of whether the Secretary has promulgated regu-

8 lations implementing such amendments.

9 “SEC. 520. ELIGIBILITY FOR SERVICES.

10 "Urban Indians shall be eligible for, and the ultimate

11 beneficiaries of, health care or referral services provided

12 pursuant to this title.

13 “SEC. 521. AUTHORIZATION OF APPROPRIATIONS.

14 “(a) In GenERAL.—There are authorized to be ap-

15 propriated such sums as may be necessary to carry out

16 this title.

17 “(b) Urban Indian Organizations.-The Sec-

18 retary, acting through the Service, is authorized to estab-

19 lish programs, including programs for the awarding of

20 grants, for urban Indian organizations that are identical

21 to any programs established pursuant to section 126 (be-

22 havioral health training), section 209 (school health edu-

23 cation), section 211 (prevention of communicable dis-

24 eases), section 701 (behavioral health prevention and 
1 treatment services), and section $707(\mathrm{~g})$ (multidrug abuse

2 program).

3 “SEC. 522. HEALTH INFORMATION TECHNOLOGY.

4 "The Secretary, acting through the Service, may

5 make grants to urban Indian organizations under this title

6 for the development, adoption, and implementation of

7 health information technology (as defined in section

$83000(5)$ of the American Recovery and Reinvestment Act),

9 telemedicine services development, and related infrastruc-

10 ture.

“TITLE VI-ORGANIZATIONAL IMPROVEMENTS

13 "SEC. 601. ESTABLISHMENT OF THE INDIAN HEALTH SERVICE AS AN AGENCY OF THE PUBLIC HEALTH SERVICE.

“(a) Establishment.-

“(1) IN GENERAL.-In order to more effectively

18 and efficiently carry out the responsibilities, authori-

19 ties, and functions of the United States to provide

20 health care services to Indians and Indian Tribes, as

21 are or may be hereafter provided by Federal statute

22 or treaties, there is established within the Public

23 Health Service of the Department the Indian Health 24 Service. 
“(2) Assistant SECRETARY OF INDIAN HEALTH.-The Service shall be administered by an Assistant Secretary of Indian Health, who shall be

4 appointed by the President, by and with the advice 5 and consent of the Senate. The Assistant Secretary 6 shall report to the Secretary. Effective with respect 7 to an individual appointed by the President, by and 8 with the advice and consent of the Senate, after 9 January 1, 2010, the term of service of the Assist10 ant Secretary shall be 4 years. An Assistant Sec11 retary may serve more than 1 term.

"(3) Incumbent.-The individual serving in 13 the position of Director of the Service on the day be14 fore the date of enactment of the Indian Health 15 Care Improvement Act Amendments of 2009 shall 16 serve as Assistant Secretary.

17 “(4) Advocacy and consultation.-The po18 sition of Assistant Secretary is established to, in a 19 manner consistent with the government-to-govern20 ment relationship between the United States and In21 dian Tribes-

"(A) facilitate advocacy for the develop24 ment of appropriate Indian health policy; and 25 lating to Indian health. 
1 “(b) AGEnCY.—The Service shall be an agency within

2 the Public Health Service of the Department, and shall

3 not be an office, component, or unit of any other agency

4 of the Department.

$5 \quad$ “(c) Duties.—The Assistant Secretary shall-

6 "(1) perform all functions that were, on the day

7 before the date of enactment of the Indian Health

8 Care Improvement Act Amendments of 2009, car-

9 ried out by or under the direction of the individual

10 serving as Director of the Service on that day;

11 “(2) perform all functions of the Secretary re-

12 lating to the maintenance and operation of hospital

13 and health facilities for Indians and the planning

14 for, and provision and utilization of, health services

15 for Indians;

16 “(3) administer all health programs under

17 which health care is provided to Indians based upon

18 their status as Indians which are administered by

19 the Secretary, including programs under-

"(A) this Act;

"(B) the Act of November 2, 1921 (25 U.S.C. 13); 
1880

"(D) the Act of August 16, 1957 (42 U.S.C. 2005 et seq.); and "(E) the Indian Self-Determination and Education Assistance Act (25 U.S.C. 450 et seq.);

“(4) administer all scholarship and loan functions carried out under title I;

"(5) report directly to the Secretary concerning all policy- and budget-related matters affecting Indian health;

“(6) collaborate with the Assistant Secretary for Health concerning appropriate matters of Indian health that affect the agencies of the Public Health Service;

“(7) advise each Assistant Secretary of the Department concerning matters of Indian health with respect to which that Assistant Secretary has authority and responsibility; "(8) advise the heads of other agencies and programs of the Department concerning matters of Indian health with respect to which those heads have authority and responsibility;

"(9) coordinate the activities of the Department concerning matters of Indian health; and 
1881

"(10) perform such other functions as the Sec-

2 retary may designate.

3 “(d) AUTHORITY.-

4 "(1) IN GENERAL.-The Secretary, acting

5 through the Assistant Secretary, shall have the au6 thority-

"(A) except to the extent provided for in paragraph (2), to appoint and compensate employees for the Service in accordance with title 5, United States Code;

"(B) to enter into contracts for the procurement of goods and services to carry out the functions of the Service; and "(C) to manage, expend, and obligate all funds appropriated for the Service. “(2) Personnel ACTIOns.-Notwithstanding 17 any other provision of law, the provisions of section 1812 of the Act of June 18, 1934 (48 Stat. 986; 25 19 U.S.C. 472), shall apply to all personnel actions 20 taken with respect to new positions created within 21 the Service as a result of its establishment under 22 subsection (a).

23 "(e) References.-Any reference to the Director of 24 the Indian Health Service in any other Federal law, Exec25 utive order, rule, regulation, or delegation of authority, or 
1882

1 in any document of or relating to the Director of the In-

2 dian Health Service, shall be deemed to refer to the Assist3 ant Secretary.

4 "SEC. 602. AUTOMATED MANAGEMENT INFORMATION SYS-

5

6

7

8

9 for the Service.

10

11

12

13

14

15

16

17

18

19

20

21

22

23

24

25

TEM. includeagency; “(a) Establishiment.-

“(1) IN GENERAL.-The Secretary shall establish an automated management information system "(2) ReQUiReMents of system.-The information system established under paragraph (1) shall

"(A) a financial management system;

“(B) a patient care information system for each area served by the Service;

"(C) privacy protections consistent with the regulations promulgated under section 264(c) of the Health Insurance Portability and Accountability Act of 1996 or, to the extent consistent with such regulations, other Federal rules applicable to privacy of automated management information systems of a Federal

“(D) a services-based cost accounting component that provides estimates of the costs as- 
1883

sociated with the provision of specific medical treatments or services in each Area office of the Service;

"(E) an interface mechanism for patient billing and accounts receivable system; and "(F) a training component.

8 nizations.-The Secretary shall provide each Tribal

9 Health Program automated management information sys10 tems which-

"(1) meet the management information needs 12 of such Tribal Health Program with respect to the 13 treatment by the Tribal Health Program of patients 14 of the Service; and “(2) meet the management information needs 16 of the Service.

17 "(c) Access to Records.-The Service shall pro18 vide access of patients to their medical or health records 19 which are held by, or on behalf of, the Service in accord20 ance with the regulations promulgated under section $21264(\mathrm{c})$ of the Health Insurance Portability and Account22 ability Act of 1996 or, to the extent consistent with such 23 regulations, other Federal rules applicable to access to 24 health care records. 
1884

1 “(d) Authority To Enhance Information Tech-

2 NOLOGY.-The Secretary, acting through the Assistant

3 Secretary, shall have the authority to enter into contracts,

4 agreements, or joint ventures with other Federal agencies,

5 States, private and nonprofit organizations, for the pur-

6 pose of enhancing information technology in Indian

7 Health Programs and facilities.

8 "SEC. 603. AUTHORIZATION OF APPROPRIATIONS.

9 "There is authorized to be appropriated such sums

10 as may be necessary to carry out this title.

11

12

\section{3}

14

15

16 follows:

\section{“TITLE VII-BEHAVIORAL} HEALTH PROGRAMS

"SEC. 701. BEHAVIORAL HEALTH PREVENTION AND TREATMENT SERVICES.

“(a) Purposes.-The purposes of this section are as

"(1) To authorize and direct the Secretary, act-

18 ing through the Service, to develop a comprehensive

19 behavioral health prevention and treatment program

20 which emphasizes collaboration among alcohol and

21 substance abuse, social services, and mental health

22 programs.

“(2) To provide information, direction, and

24 guidance relating to mental illness and dysfunction

25 and self-destructive behavior, including child abuse 


\section{5}

1 and family violence, to those Federal, tribal, State,

2 and local agencies responsible for programs in In-

3 dian communities in areas of health care, education,

4 social services, child and family welfare, alcohol and

5 substance abuse, law enforcement, and judicial serv6 ices.

“(3) To assist Indian Tribes to identify services

8 and resources available to address mental illness and

9 dysfunctional and self-destructive behavior.

10 “(4) To provide authority and opportunities for

11 Indian Tribes and Tribal Organizations to develop,

12 implement, and coordinate with community-based

13 programs which include identification, prevention,

14 education, referral, and treatment services, including

15 through multidisciplinary resource teams.

16 "(5) To ensure that Indians, as citizens of the

17 United States and of the States in which they re-

18 side, have the same access to behavioral health serv-

19 ices to which all citizens have access.

20 “(6) To modify or supplement existing pro-

21 grams and authorities in the areas identified in

22 paragraph (2).

23 "(b) Plans.-

24 “(1) Development.-The Secretary, acting 25 through the Service, shall encourage Indian Tribes 
1886

1 and Tribal Organizations to develop tribal plans, 2 and urban Indian organizations to develop local 3 plans, and for all such groups to participate in de4 veloping areawide plans for Indian Behavioral 5 Health Services. The plans shall include, to the ex6 tent feasible, the following components: or other substance abuse, mental illness, and dysfunctional and self-destructive behavior, including suicide, child abuse, and family vio11 lence, among Indians, includingare directly or indirectly affected by such illness or behavior; or

"(ii) an estimate of the financial and human cost attributable to such illness or behavior.

"(B) An assessment of the existing and additional resources necessary for the prevention and treatment of such illness and behavior, including an assessment of the progress toward achieving the availability of the full continuum of care described in subsection (c).

"(C) An estimate of the additional funding needed by the Service, Indian Tribes, Tribal 
1 Organizations, and urban Indian organizations

2 to meet their responsibilities under the plans.

3 “(2) National Clearinghouse.-The Sec-

4 retary, acting through the Service, shall coordinate

5 with existing national clearinghouses and informa-

6 tion centers to include at the clearinghouses and

7 centers plans and reports on the outcomes of such

8 plans developed by Indian Tribes, Tribal Organiza-

9 tions, urban Indian organizations, and Service Areas

10 relating to behavioral health. The Secretary shall en-

11 sure access to these plans and outcomes by any In-

12 dian Tribe, Tribal Organization, urban Indian orga-

13 nization, or the Service.

14 “(3) Technical assistance.-The Secretary

15 shall provide technical assistance to Indian Tribes,

16 Tribal Organizations, and urban Indian organiza-

17 tions in preparation of plans under this section and

18 in developing standards of care that may be used

19 and adopted locally.

20 "(c) Programs.-The Secretary, acting through the

21 Service, shall provide, to the extent feasible and if funding

22 is available, programs including the following:

23 “(1) Comprehensive CARE.-A comprehensive 24 continuum of behavioral health care which pro25 vides- 
1888

"(A) community-based prevention, intervention, outpatient, and behavioral health aftercare;

"(B) detoxification (social and medical);

"(C) acute hospitalization;

“(D) intensive outpatient/day treatment;

"(E) residential treatment;

"(F) transitional living for those needing a temporary, stable living environment that is supportive of treatment and recovery goals;

"(G) emergency shelter;

"(H) intensive case management; and

"(I) diagnostic services.

“(2) CHILd CARE.-Behavioral health services for Indians from birth through age 17, including"(A) preschool and school age fetal alcohol disorder services, including assessment and behavioral intervention;

"(B) mental health and substance abuse services (emotional, organic, alcohol, drug, inhalant, and tobaceo);

"(C) identification and treatment of co-occurring disorders and comorbidity;

“(D) prevention of alcohol, drug, inhalant, and tobacco use; 
"(E) early intervention, treatment, and

aftercare;

"(F) promotion of healthy approaches to risk and safety issues; and

"(G) identification and treatment of ne-

"(D) promotion of healthy approaches for risk-related behavior;

"(E) treatment services for women at risk of giving birth to a child with a fetal alcohol disorder; and

"(F) sex specific treatment for sexual assault and domestic violence.

“(4) Family CARE.-Behavioral health services 25 for families, including- 
“(A) early intervention, treatment, and aftercare for affected families;

"(B) treatment for sexual assault and domestic violence; and

"(C) promotion of healthy approaches reaftercare;

"(B) mental health and substance abuse services (emotional, alcohol, drug, inhalant, and tobacco), including sex specific services;

"(C) identification and treatment of co-occurring disorders (dual diagnosis) and comorbidity;

“(D) promotion of healthy approaches to managing conditions related to aging;

"(E) sex specific treatment for sexual assault, domestic violence, neglect, physical and mental abuse and exploitation; and "(F) identification and treatment of dementias regardless of cause. “(d) Community Behavioral Health Plan.- 
“(1) Establishment.-The governing body of

2 any Indian Tribe, Tribal Organization, or urban In-

3 dian organization may adopt a resolution for the es-

4 tablishment of a community behavioral health plan

5 providing for the identification and coordination of

6 available resources and programs to identify, pre-

7 vent, or treat substance abuse, mental illness, or

8 dysfunctional and self-destructive behavior, including

9 child abuse and family violence, among its members

10 or its service population. This plan should include

11 behavioral health services, social services, intensive

12 outpatient services, and continuing aftercare.

13 "(2) Technical assistance.-At the request

14 of an Indian Tribe, Tribal Organization, or urban

15 Indian organization, the Bureau of Indian Affairs

16 and the Service shall cooperate with and provide

17 technical assistance to the Indian Tribe, Tribal Or-

18 ganization, or urban Indian organization in the de-

19 velopment and implementation of such plan.

20 “(3) Funding.- - The Secretary, acting through

21 the Service, may make funding available to Indian

22 Tribes and Tribal Organizations which adopt a reso-

23 lution pursuant to paragraph (1) to obtain technical

24 assistance for the development of a community be- 
1 havioral health plan and to provide administrative

2 support in the implementation of such plan.

3 “(e) Coordination for Availability of Serv-

4 ICES.-The Secretary, acting through the Service, shall

5 coordinate behavioral health planning, to the extent fea-

6 sible, with other Federal agencies and with State agencies,

7 to encourage comprehensive behavioral health services for

8 Indians regardless of their place of residence.

9 “(f) Mental Health Care Need Assessment.-

10 Not later than 1 year after the date of enactment of the

11 Indian Health Care Improvement Act Amendments of

12 2009, the Secretary, acting through the Service, shall

13 make an assessment of the need for inpatient mental

14 health care among Indians and the availability and cost

15 of inpatient mental health facilities which can meet such

16 need. In making such assessment, the Secretary shall con-

17 sider the possible conversion of existing, underused Service

18 hospital beds into psychiatric units to meet such need.

19 "SEC. 702. MEMORANDA OF AGREEMENT WITH THE DEPARTMENT OF THE INTERIOR.

21 "(a) Contents. - Not later than 12 months after the

22 date of enactment of the Indian Health Care Improvement

23 Act Amendments of 2009, the Secretary, acting through

24 the Service, and the Secretary of the Interior shall develop

25 and enter into a memoranda of agreement, or review and 
1 update any existing memoranda of agreement, as required

2 by section 4205 of the Indian Alcohol and Substance 3 Abuse Prevention and Treatment Act of 1986 (25 U.S.C.

4 2411) under which the Secretaries address the following:

"(1) The scope and nature of mental illness and

6 dysfunctional and self-destructive behavior, including

7 child abuse and family violence, among Indians.

8 "(2) The existing Federal, tribal, State, local,

9 and private services, resources, and programs avail-

10 able to provide behavioral health services for Indi11 ans.

12 "(3) The unmet need for additional services, re13 sources, and programs necessary to meet the needs 14 identified pursuant to paragraph (1).

15 "(4)(A) The right of Indians, as citizens of the 16 United States and of the States in which they re17 side, to have access to behavioral health services to 18 which all citizens have access.

19 "(B) The right of Indians to participate in, and 20 receive the benefit of, such services.

21 "(C) The actions necessary to protect the exer22 cise of such right.

23 "(5) The responsibilities of the Bureau of In24 dian Affairs and the Service, including mental illness 25 identification, prevention, education, referral, and 
1 treatment services (including services through multi-

2 disciplinary resource teams), at the central, area,

3 and agency and Service Unit, Service Area, and

4 headquarters levels to address the problems identi-

5 fied in paragraph (1).

6 “(6) A strategy for the comprehensive coordina-

7 tion of the behavioral health services provided by the

8 Bureau of Indian Affairs and the Service to meet

9 the problems identified pursuant to paragraph (1), 10 including-

"(A) the coordination of alcohol and substance abuse programs of the Service, the $\mathrm{Bu}-$ reau of Indian Affairs, and Indian Tribes and Tribal Organizations (developed under the Indian Alcohol and Substance Abuse Prevention and Treatment Act of 1986 (25 U.S.C. 2401 et seq.)) with behavioral health initiatives pursuant to this Act, particularly with respect to the referral and treatment of dually diagnosed individuals requiring behavioral health and substance abuse treatment; and Affairs and Service programs and services (including multidisciplinary resource teams) ad25 dressing child abuse and family violence are co- 
ordinated with such non-Federal programs and services.

"(7) Directing appropriate officials of the $\mathrm{Bu}$ -

4 reau of Indian Affairs and the Service, particularly

5 at the agency and Service Unit levels, to cooperate

6 fully with tribal requests made pursuant to commu-

7 nity behavioral health plans adopted under section

$8701(\mathrm{c})$ and section 4206 of the Indian Alcohol and

9 Substance Abuse Prevention and Treatment Act of

101986 (25 U.S.C. 2412).

“(8) Providing for an annual review of such

12 agreement by the Secretaries which shall be provided

13 to Congress and Indian Tribes and Tribal Organiza-

14 tions.

15 “(b) Specific Provisions Required.-The memo-

16 randa of agreement updated or entered into pursuant to

17 subsection (a) shall include specific provisions pursuant to

18 which the Service shall assume responsibility for-

19 "(1) the determination of the scope of the prob-

20 lem of alcohol and substance abuse among Indians,

21 including the number of Indians within the jurisdic-

22 tion of the Service who are directly or indirectly af-

23 fected by alcohol and substance abuse and the finan24 cial and human cost; 
1896

$1 \quad$ "(2) an assessment of the existing and needed

2 resources necessary for the prevention of alcohol and

3 substance abuse and the treatment of Indians af-

$4 \quad$ fected by alcohol and substance abuse; and

$5 \quad$ "(3) an estimate of the funding necessary to

6 adequately support a program of prevention of alco-

7 hol and substance abuse and treatment of Indians

8 affected by alcohol and substance abuse.

9 “(c) Publication.-Each memorandum of agree-

10 ment entered into or renewed (and amendments or modi-

11 fications thereto) under subsection (a) shall be published

12 in the Federal Register. At the same time as publication

13 in the Federal Register, the Secretary shall provide a copy

14 of such memoranda, amendment, or modification to each

15 Indian Tribe, Tribal Organization, and urban Indian orga-

16 nization.

17 “SEC. 703. COMPREHENSIVE BEHAVIORAL HEALTH PRE18 VENTION AND TREATMENT PROGRAM.

19 “(a) Establishment.-

20 "(1) IN GENERAL.-The Secretary, acting

21 through the Service, shall provide a program of com-

22 prehensive behavioral health, prevention, treatment, 23 and aftercare, including Systems of Care, which 24 shall include- 
"(A) prevention, through educational intervention, in Indian communities;

"(B) acute detoxification, psychiatric hos-

18 lation of such programs shall be members of Indian

19 Tribes. Efforts to train and educate key members of 20 the Indian community shall also target employees of 21 health, education, judicial, law enforcement, legal, 22 and social service programs.

23 “(b) Contract Health Services.“(1) In GENERAL.-The Secretary, acting 25 through the Service, may enter into contracts with 
1898

1 public or private providers of behavioral health treat-

2 ment services for the purpose of carrying out the

3 program required under subsection (a).

4 “(2) Provision of assistance.-In carrying

5 out this subsection, the Secretary shall provide as-

6 sistance to Indian Tribes and Tribal Organizations

7 to develop criteria for the certification of behavioral

8 health service providers and accreditation of service

9 facilities which meet minimum standards for such

10 services and facilities.

11 "SEC. 704. MENTAL HEALTH TECHNICIAN PROGRAM.

12 "(a) In General.-Under the authority of the Act

13 of November 2, 1921 (25 U.S.C. 13) (commonly known

14 as the 'Snyder Act'), the Secretary shall establish and

15 maintain a mental health technician program within the

16 Service which-

17 "(1) provides for the training of Indians as

18 mental health technicians; and

19 "(2) employs such technicians in the provision

20 of community-based mental health care that includes

21 identification, prevention, education, referral, and

22 treatment services.

23 “(b) Paraprofessional Training.-In carrying

24 out subsection (a), the Secretary, acting through the Serv-

25 ice, shall provide high-standard paraprofessional training 
1 in mental health care necessary to provide quality care to

2 the Indian communities to be served. Such training shall

3 be based upon a curriculum developed or approved by the

4 Secretary which combines education in the theory of men-

5 tal health care with supervised practical experience in the 6 provision of such care.

7 “(c) Supervision and Evaluation of Techni8 CIANS.-The Secretary, acting through the Service, shall 9 supervise and evaluate the mental health technicians in 10 the training program.

11 “(d) Traditional Health Care Practices.-The

12 Secretary, acting through the Service, shall ensure that

13 the program established pursuant to this subsection in-

14 volves the use and promotion of the traditional health care

15 practices of the Indian Tribes to be served.

16 “SEC. 705. LICENSING REQUIREMENT FOR MENTAL HEALTH CARE WORKERS.

18 “(a) IN GENERAL.—Subject to the provisions of sec-

19 tion 221, and except as provided in subsection (b), any 20 individual employed as a psychologist, social worker, or 21 marriage and family therapist for the purpose of providing 22 mental health care services to Indians in a clinical setting 23 under this Act is required to be licensed as a psychologist, 24 social worker, or marriage and family therapist, respec25 tively. 
1 “(b) Trainees.-An individual may be employed as

2 a trainee in psychology, social work, or marriage and fam-

3 ily therapy to provide mental health care services de-

4 scribed in subsection (a) if such individual-

$5 \quad$ "(1) works under the direct supervision of a li-

6 censed psychologist, social worker, or marriage and

7 family therapist, respectively;

$8 \quad$ "(2) is enrolled in or has completed at least 2

9 years of course work at a post-secondary, accredited

10 education program for psychology, social work, mar-

11 riage and family therapy, or counseling; and

12 “(3) meets such other training, supervision, and

13 quality review requirements as the Secretary may es-

14 tablish.

15 “SEC. 706. INDIAN WOMEN TREATMENT PROGRAMS.

16 “(a) GRants.-The Secretary, consistent with sec-

17 tion 701, may make grants to Indian Tribes, Tribal Orga-

18 nizations, and urban Indian organizations to develop and

19 implement a comprehensive behavioral health program of

20 prevention, intervention, treatment, and relapse preven-

21 tion services that specifically addresses the cultural, his-

22 torical, social, and child care needs of Indian women, re-

23 gardless of age.

24 "(b) Use of Grant Funds.-A grant made pursu25 ant to this section may be used to- 
1901

“(1) develop and provide community training,

2 education, and prevention programs for Indian

3 women relating to behavioral health issues, including

4 fetal alcohol disorders;

$5 \quad$ “(2) identify and provide psychological services,

6 counseling, advocacy, support, and relapse preven-

7 tion to Indian women and their families; and

8 “(3) develop prevention and intervention models

9 for Indian women which incorporate traditional

10 health care practices, cultural values, and commu-

11 nity and family involvement.

12 "(c) CRITERIA.-The Secretary, in consultation with

13 Indian Tribes and Tribal Organizations, shall establish

14 criteria for the review and approval of applications and

15 proposals for funding under this section.

16 “(d) Allocation of Funds for Urban Indan

17 Organizations.- Twenty percent of the funds appro-

18 priated pursuant to this section shall be used to make

19 grants to urban Indian organizations.

20 “SEC. 707. INDIAN YOUTH PROGRAM.

21 “(a) Detoxification and Rehabilitation.-The

22 Secretary, acting through the Service, consistent with sec-

23 tion 701, shall develop and implement a program for acute

24 detoxification and treatment for Indian youths, including

25 behavioral health services. The program shall include re- 
1902

1 gional treatment centers designed to include detoxification

2 and rehabilitation for both sexes on a referral basis and

3 programs developed and implemented by Indian Tribes or

4 Tribal Organizations at the local level under the Indian

5 Self-Determination and Education Assistance Act (25

6 U.S.C. 450 et seq.). Regional centers shall be integrated

7 with the intake and rehabilitation programs based in the

8 referring Indian community.

9 “(b) Alcohol and Substance Abuse Treatment

10 Centers or Facilities.-

11

12

13

14

15

16

17

18

19
“(1) Establishment.-

"(A) IN GENERAL.—The Secretary, acting through the Service, shall construct, renovate, or, as necessary, purchase, and appropriately staff and operate, at least 1 youth regional treatment center or treatment network in each area under the jurisdiction of an Area Office.

"(B) Area OFFICE In CALIFornia.-For the purposes of this subsection, the Area Office in California shall be considered to be 2 Area Offices, 1 office whose jurisdiction shall be considered to encompass the northern area of the State of California, and 1 office whose jurisdiction shall be considered to encompass the remainder of the State of California for the pur- 
pose of implementing California treatment networks.

"(2) Funding.-For the purpose of staffing 4 and operating such centers or facilities, funding

5 shall be pursuant to the Act of November 2, 1921 6 (25 U.S.C. 13).

“(3) Location.-A youth treatment center 8 constructed or purchased under this subsection shall 9 be constructed or purchased at a location within the 10 area described in paragraph (1) agreed upon (by ap11 propriate tribal resolution) by a majority of the In12 dian Tribes to be served by such center. “(4) SPECIFIC PROVISION OF FUNDS."(A) In GENERAL.—Notwithstanding any other provision of this title, the Secretary may, from amounts authorized to be appropriated for the purposes of carrying out this section, make funds available to-

"(i) the Tanana Chiefs Conference, Incorporated, for the purpose of leasing, constructing, renovating, operating, and maintaining a residential youth treatment facility in Fairbanks, Alaska; and

"(ii) the Southeast Alaska Regional Health Corporation to staff and operate a 
1904

17 havioral health services, which may incorporate Sys-

18 tems of Care, to Indian children and adolescents, in-

19 cluding-

residential youth treatment facility without regard to the proviso set forth in section 4(l) of the Indian Self-Determination and Education Assistance Act (25 U.S.C. $450 \mathrm{~b}(\mathrm{l}))$.

"(B) Provision of services to EligiBLE YOUTHS.-Until additional residential youth treatment facilities are established in Alaska pursuant to this section, the facilities specified in subparagraph (A) shall make every effort to provide services to all eligible Indian youths residing in Alaska.

“(c) Intermediate Adolescent Behavioral Health Services.-

“(1) In GENERAL.-The Secretary, acting through the Service, may provide intermediate be“(A) pretreatment assistance;

"(B) inpatient, outpatient, and aftercare services;

“(C) emergency care;

"(D) suicide prevention and crisis intervention; and 
1905

"(E) prevention and treatment of mental illness and dysfunctional and self-destructive behavior, including child abuse and family violence.

“(2) UsE OF FUNDs.-Funds provided under this subsection may be used-

"(A) to construct or renovate an existing health facility to provide intermediate behavioral health services;

"(B) to hire behavioral health professionals;

"(C) to staff, operate, and maintain an intermediate mental health facility, group home, sober housing, transitional housing or similar facilities, or youth shelter where intermediate behavioral health services are being provided;

“(D) to make renovations and hire appropriate staff to convert existing hospital beds into adolescent psychiatric units; and

"(E) for intensive home- and communitybased services.

“(3) CRITERIA.- - The Secretary, acting through the Service, shall, in consultation with Indian Tribes and Tribal Organizations, establish criteria for the 
1 review and approval of applications or proposals for

2 funding made available pursuant to this subsection.

3 “(d) Federaliy Owned Structures.-

4 “(1) In GENERAL.-The Secretary, in consulta5 tion with Indian Tribes and Tribal Organizations, 6 shall"(A) identify and use, where appropriate, federally owned structures suitable for local residential or regional behavioral health treatment for Indian youths; and

"(B) establish guidelines for determining the suitability of any such federally owned structure to be used for local residential or regional behavioral health treatment for Indian youths.

19 may be agreed upon by the Secretary and the agency 20 having responsibility for the structure and any In21 dian Tribe or Tribal Organization operating the pro22 gram.

23 “(e) Rehabilitation and Aftercare Services."(1) In GENERAL.-The Secretary, Indian 25 Tribes, or Tribal Organizations, in cooperation with 
1 the Secretary of the Interior, shall develop and im-

2 plement within each Service Unit, community-based

3 rehabilitation and follow-up services for Indian

4 youths who are having significant behavioral health

5 problems, and require long-term treatment, commu-

6 nity reintegration, and monitoring to support the In-

7 dian youths after their return to their home commu-

8 nity.

“(2) Administration.-Services under para-

10 graph (1) shall be provided by trained staff within

11 the community who can assist the Indian youths in

12 their continuing development of self-image, positive

13 problem-solving skills, and nonalcohol or substance

14 abusing behaviors. Such staff may include alcohol

15 and substance abuse counselors, mental health pro-

16 fessionals, and other health professionals and para-

17 professionals, including community health represent18 atives.

19 “(f) Inclusion of Family in Youth Treatment

20 Program.-In providing the treatment and other services 21 to Indian youths authorized by this section, the Secretary, 22 acting through the Service, shall provide for the inclusion 23 of family members of such youths in the treatment pro24 grams or other services as may be appropriate. Not less 25 than 10 percent of the funds appropriated for the pur- 
1 poses of carrying out subsection (e) shall be used for out-

2 patient care of adult family members related to the treat3 ment of an Indian youth under that subsection.

4 “(g) Multidrug Abuse Program.-The Secretary, 5 acting through the Service, shall provide, consistent with 6 section 701, programs and services to prevent and treat 7 the abuse of multiple forms of substances, including alco8 hol, drugs, inhalants, and tobacco, among Indian youths 9 residing in Indian communities, on or near reservations, 10 and in urban areas and provide appropriate mental health 11 services to address the incidence of mental illness among 12 such youths.

13 “(h) Indian Youth Mental Health.-The Sec14 retary, acting through the Service, shall collect data for 15 the report under section 801 with respect to-

16 "(1) the number of Indian youth who are being 17 provided mental health services through the Service 18 and Tribal Health Programs;

19 "(2) a description of, and costs associated with, 20 the mental health services provided for Indian youth 21 through the Service and Tribal Health Programs;

22 "(3) the number of youth referred to the Serv23 ice or Tribal Health Programs for mental health 24 services; 
"(4) the number of Indian youth provided resi-

2 dential treatment for mental health and behavioral

3 problems through the Service and Tribal Health

4 Programs, reported separately for on- and off-res-

5 ervation facilities; and

6 "(5) the costs of the services described in para-

$7 \quad$ graph (4).

8 "SEC. 708. INDIAN YOUTH TELEMENTAL HEALTH DEM-

10 “(a) Purpose.-The purpose of this section is to au-

11 thorize the Secretary to carry out a demonstration project

12 to test the use of telemental health services in suicide pre-

13 vention, intervention and treatment of Indian youth, in-

14 cluding through-

15 "(1) the use of psychotherapy, psychiatric as16 sessments, diagnostic interviews, therapies for men17 tal health conditions predisposing to suicide, and al18 cohol and substance abuse treatment;

19 "(2) the provision of clinical expertise to, con20 sultation services with, and medical advice and train21 ing for frontline health care providers working with 22 Indian youth;

23 "(3) training and related support for commu24 nity leaders, family members and health and edu25 cation workers who work with Indian youth; 
“(4) the development of culturally relevant edu-

2 cational materials on suicide; and

“(5) data collection and reporting.

4 "(b) Definitions.-For the purpose of this section,

5 the following definitions shall apply:

"(1) Demonstration PRoject.-The term 'demonstration project' means the Indian youth telemental health demonstration project authorized under subsection (c).

“(2) Telemental health.-The term 'telemental health' means the use of electronic information and telecommunications technologies to support long distance mental health care, patient and professional-related education, public health, and health administration.

“(c) Authorization.-

“(1) IN GENERAL.- The Secretary is authorized to award grants under the demonstration project for the provision of telemental health services to Indian youth who-

"(A) have expressed suicidal ideas;

"(B) have attempted suicide; or

"(C) have mental health conditions that increase or could increase the risk of suicide. 
"(2) EligIBILITY FOR GRANTs.-Such grants

2 shall be awarded to Indian Tribes and Tribal Orga-

3 nizations that operate 1 or more facilities-

"(A) located in Alaska and part of the

Alaska Federal Health Care Access Network;

"(B) reporting active clinical telehealth ca-

pabilities; or

"(C) offering school-based telemental health services relating to psychiatry to Indian youth.

"(3) GRANT PERIOD._The Secretary shall 12 award grants under this section for a period of up 13 to 4 years.

"(4) AWARDING OF GRANTs._-Not more than 5

15 grants shall be provided under paragraph (1), with 16 priority consideration given to Indian Tribes and 17 Tribal Organizations that-

“(A) serve a particular community or geographic area where there is a demonstrated need to address Indian youth suicide;

"(B) enter in to collaborative partnerships with Indian Health Service or Tribal Health 23 Programs or facilities to provide services under 24 this demonstration project; 
"(C) serve an isolated community or geographic area which has limited or no access to behavioral health services; or

"(D) operate a detention facility at which Indian youth are detained.

“(d) UsE OF Funds.-

"(1) In general.-An Indian Tribe or Tribal Organization shall use a grant received under subsection (c) for the following purposes:

“(A) To provide telemental health services to Indian youth, including the provision of“(i) psychotherapy; “(ii) psychiatric assessments and diagnostic interviews, therapies for mental health conditions predisposing to suicide, and treatment; and

"(iii) alcohol and substance abuse treatment. "(B) To provide clinician-interactive medical advice, guidance and training, assistance in diagnosis and interpretation, crisis counseling and intervention, and related assistance to Service, tribal, or urban clinicians and health services providers working with youth being served under this demonstration project. 
"(C) To assist, educate and train community leaders, health education professionals and paraprofessionals, tribal outreach workers, and family members who work with the youth receiving telemental health services under this

“(i) suicide prevention;

"(ii) suicide education;

"(iii) suicide screening;

"(iv) suicide intervention; and

"(v) ways to mobilize communities with respect to the identification of risk factors for suicide.

"(E) For data collection and reporting related to Indian youth suicide prevention efforts. “(2) Traditional health care PraCTICES.-In earrying out the purposes described in 
1 paragraph (1), an Indian Tribe or Tribal Organiza-

2 tion may use and promote the traditional health care 3 practices of the Indian Tribes of the youth to be 4 served.

5 “(e) ApPLications.-To be eligible to receive a grant 6 under subsection (c), an Indian Tribe or Tribal Organiza7 tion shall prepare and submit to the Secretary an applica8 tion, at such time, in such manner, and containing such 9 information as the Secretary may require, including-

10 "(1) a description of the project that the Indian 11 Tribe or Tribal Organization will carry out using the 12 funds provided under the grant;

13 "(2) a description of the manner in which the 14 project funded under the grant would-

15 "(A) meet the telemental health care needs 16 of the Indian youth population to be served by 17 the project; or

18 "(B) improve the access of the Indian 19 youth population to be served to suicide preven20 tion and treatment services;

21 "(3) evidence of support for the project from 22 the local community to be served by the project;

23 "(4) a description of how the families and lead24 ership of the communities or populations to be 
1 served by the project would be involved in the devel-

2 opment and ongoing operations of the project;

"(5) a plan to involve the tribal community of

4 the youth who are provided services by the project

5 in planning and evaluating the mental health care

6 and suicide prevention efforts provided, in order to

7 ensure the integration of community, clinical, envi-

8 ronmental, and cultural components of the treat-

9 ment; and

10 "(6) a plan for sustaining the project after Fed-

11 eral assistance for the demonstration project has ter-

12 minated.

13 “(f) Collaboration; Reporting to National

14 Clearinghouse.-

15 “(1) Collaboration.-The Secretary, acting

16 through the Service, shall encourage Indian Tribes

17 and Tribal Organizations receiving grants under this

18 section to collaborate to enable comparisons about

19 best practices across projects.

20 “(2) REPORTING TO NATIONAL CLEARING-

21 HousE.-The Secretary, acting through the Service,

22 shall also encourage Indian Tribes and Tribal Orga-

23 nizations receiving grants under this section to sub-

24 mit relevant, declassified project information to the

25 national clearinghouse authorized under section 
1916

$1701(b)(2)$ in order to better facilitate program per-

2 formance and improve suicide prevention, interven-

3 tion, and treatment services.

4 “(g) Annual Report.-Each grant recipient shall

5 submit to the Secretary an annual report that-

6 "(1) describes the number of telemental health

$7 \quad$ services provided; and

8 "(2) includes any other information that the

$9 \quad$ Secretary may require.

10 "(h) REPORT To Congress.-Not later than 270

11 days after the termination of the demonstration project,

12 the Secretary shall submit to the Committee on Indian Af-

13 fairs of the Senate and the Committee on Natural Re-

14 sources and Committee on Energy and Commerce of the

15 House of Representatives a final report, based on the an-

16 nual reports provided by grant recipients under subsection

17 (h), that-

18 "(1) describes the results of the projects funded

19 by grants awarded under this section, including any

20 data available which indicates the number of at21 tempted suicides;

22 "(2) evaluates the impact of the telemental

23 health services funded by the grants in reducing the 24 number of completed suicides among Indian youth; 
“(3) evaluates whether the demonstration

2 project should be-

"(A) expanded to provide more than 5 grants; and

“(B) designated a permanent program; and "(4) evaluates the benefits of expanding the

8 demonstration project to include urban Indian orga9 nizations.

10 "(i) Authorization of Appropriations.-There is 11 authorized to be appropriated such sums as may be nec12 essary to carry out this section.

13 “SEC. 709. INPATIENT AND COMMUNITY-BASED MENTAL HEALTH FACILITIES DESIGN, CONSTRUCTION, AND STAFFING.

16 "Not later than 1 year after the date of enactment 17 of the Indian Health Care Improvement Act Amendments 18 of 2009, the Secretary, acting through the Service, may 19 provide, in each area of the Service, not less than 1 inpa20 tient mental health care facility, or the equivalent, for In21 dians with behavioral health problems. For the purposes 22 of this subsection, California shall be considered to be 2 23 Area Offices, 1 office whose location shall be considered 24 to encompass the northern area of the State of California 25 and 1 office whose jurisdiction shall be considered to en- 
1 compass the remainder of the State of California. The Sec-

2 retary shall consider the possible conversion of existing,

3 underused Service hospital beds into psychiatric units to

4 meet such need.

5 “SEC. 710. TRAINING AND COMMUNITY EDUCATION.

6 “(a) Program.-The Secretary, in cooperation with

7 the Secretary of the Interior, shall develop and implement

8 or assist Indian Tribes and Tribal Organizations to de-

9 velop and implement, within each Service Unit or tribal

10 program, a program of community education and involve-

11 ment which shall be designed to provide concise and timely

12 information to the community leadership of each tribal

13 community. Such program shall include education about

14 behavioral health issues to political leaders, Tribal judges,

15 law enforcement personnel, members of tribal health and

16 education boards, health care providers including tradi-

17 tional practitioners, and other critical members of each

18 tribal community. Such program may also include commu-

19 nity-based training to develop local capacity and tribal

20 community provider training for prevention, intervention,

21 treatment, and aftercare.

22 “(b) Instruction.-The Secretary, acting through

23 the Service, shall provide instruction in the area of behav-

24 ioral health issues, including instruction in crisis interven-

25 tion and family relations in the context of alcohol and sub- 
1 stance abuse, child sexual abuse, youth alcohol and sub-

2 stance abuse, and the causes and effects of fetal alcohol

3 disorders to appropriate employees of the Bureau of In-

4 dian Affairs and the Service, and to personnel in schools

5 or programs operated under any contract with the Bureau

6 of Indian Affairs or the Service, including supervisors of

7 emergency shelters and halfway houses described in sec-

8 tion 4213 of the Indian Alcohol and Substance Abuse Pre-

9 vention and Treatment Act of 1986 (25 U.S.C. 2433).

10 “(c) Training Models.-In carrying out the edu-

11 cation and training programs required by this section, the

12 Secretary, in consultation with Indian Tribes, Tribal Or-

13 ganizations, Indian behavioral health experts, and Indian

14 alcohol and substance abuse prevention experts, shall de-

15 velop and provide community-based training models. Such

16 models shall address-

17 "(1) the elevated risk of alcohol and behavioral

18 health problems faced by children of alcoholics;

19 "(2) the cultural, spiritual, and

20 multigenerational aspects of behavioral health prob-

21 lem prevention and recovery; and

22 "(3) community-based and multidisciplinary

23 strategies, including Systems of Care, for preventing

24 and treating behavioral health problems. 
1 “SEC. 711. BEHAVIORAL HEALTH PROGRAM.

2 “(a) Innovative Programs. - The Secretary, acting

3 through the Service, consistent with section 701, may

4 plan, develop, implement, and carry out programs to de-

5 liver innovative community-based behavioral health serv-

6 ices to Indians.

7 “(b) AwARds; CRITERIA._-The Secretary may award

8 a grant for a project under subsection (a) to an Indian

9 Tribe or Tribal Organization and may consider the fol-

10 lowing criteria:

11 "(1) The project will address significant unmet

12 behavioral health needs among Indians.

13 “(2) The project will serve a significant number

14 of Indians.

15 "(3) The project has the potential to deliver

16 services in an efficient and effective manner.

17 "(4) The Indian Tribe or Tribal Organization

18 has the administrative and financial capability to ad-

19 minister the project.

20 “(5) The project may deliver services in a man21 ner consistent with traditional health care practices.

22 "(6) The project is coordinated with, and avoids 23 duplication of, existing services.

24 "(c) Equitable Treatment.-For purposes of this 25 subsection, the Secretary shall, in evaluating project appli26 cations or proposals, use the same criteria that the Sec- 
1 retary uses in evaluating any other application or proposal

2 for such funding.

3 “SEC. 712. FETAL ALCOHOL DISORDER PROGRAMS.

“(a) Programs. -

“(1) Establishment.-The Secretary, consistent with section 701 and acting through the Service, is authorized to establish and operate fetal alcohol disorder programs as provided in this section for the purposes of meeting the health status objectives specified in section 3 .

“(2) USE OF FUNDS.-

"(A) IN GENERAL.-Funding provided pursuant to this section shall be used for the following:

“(i) To develop and provide for Indians community and in-school training, education, and prevention programs relating to fetal alcohol disorders.

“(ii) To identify and provide behavioral health treatment to high-risk Indian women and high-risk women pregnant with an Indian's child.

“(iii) To identify and provide appropriate psychological services, educational and vocational support, counseling, advo- 
cacy, and information to fetal alcohol disorder affected Indians and their families or caretakers.

"(iv) To develop and implement coun-

seling and support programs in schools for fetal alcohol disorder affected Indian children.

“(v) To develop prevention and intervention models which incorporate practitioners of traditional health care practices, cultural values, and community involvement.

"(vi) To develop, print, and disseminate education and prevention materials on fetal alcohol disorder.

"(vii) To develop and implement, in consultation with Indian Tribes, Tribal Organizations, and urban Indian organizations, culturally sensitive assessment and diagnostic tools including dysmorphology clinics and multidisciplinary fetal alcohol disorder clinics for use in Indian communities and Urban Centers.

"(B) AdDitional Uses.-In addition to any purpose under subparagraph (A), funding 
provided pursuant to this section may be used for 1 or more of the following:

“(i) Early childhood intervention projects from birth on to mitigate the effects of fetal alcohol disorder among Indi-

“(3) Criteria For applications.-The Sec-

13 retary shall establish criteria for the review and ap14 proval of applications for funding under this section. 15 "(b) SERvices.-The Secretary, acting through the 16 Service, shall-

"(1) develop and provide services for the pre18 vention, intervention, treatment, and aftercare for 19 those affected by fetal alcohol disorder in Indian 20 communities; and

“(2) provide supportive services, including serv22 ices to meet the special educational, vocational, 23 school-to-work transition, and independent living 24 needs of adolescent and adult Indians with fetal al25 cohol disorder. 
1 “(c) TAsk FORCE.-The Secretary shall establish a 2 task force to be known as the Fetal Alcohol Disorder Task 3 Force to advise the Secretary in carrying out subsection 4 (b). Such task force shall be composed of representatives 5 from the following:

8 coholism. 24 experts. vention.

“(1) The National Institute on Drug Abuse. “(2) The National Institute on Alcohol and Al“(3) The Office of Substance Abuse Prevention. “(4) The National Institute of Mental Health. “(5) The Service. "(6) The Office of Minority Health of the Department of Health and Human Services. “(7) The Administration for Native Americans. “(8) The National Institute of Child Health and Human Development (NICHD). “(9) The Centers for Disease Control and Pre-

"(10) The Bureau of Indian Affairs.

“(11) Indian Tribes.

“(12) Tribal Organizations.

“(13) urban Indian organizations.

“(14) Indian fetal alcohol spectrum disorders 
1925

1 “(d) Applied Research Projects.-The Sec2 retary, acting through the Substance Abuse and Mental 3 Health Services Administration, shall make grants to In4 dian Tribes, Tribal Organizations, and urban Indian orga5 nizations for applied research projects which propose to 6 elevate the understanding of methods to prevent, inter7 vene, treat, or provide rehabilitation and behavioral health 8 aftercare for Indians and urban Indians affected by fetal 9 alcohol spectrum disorders.

10 “(e) Funding For Urban Indian Organiza11 TIONs.-Ten percent of the funds appropriated pursuant 12 to this section shall be used to make grants to urban In13 dian organizations funded under title $\mathrm{V}$.

14 “SEC. 713. CHILD SEXUAL ABUSE AND PREVENTION TREAT15 MENT PROGRAMS.

16 "(a) Establishment.-The Secretary, acting

17 through the Service, shall establish, consistent with section 18 701, in every Service Area, programs involving treatment 19 for-

"(1) victims of sexual abuse who are Indian

21 children or children in an Indian household; and “(2) perpetrators of child sexual abuse who are 23 Indian or members of an Indian household.

24 “(b) Use of Funds.-Funding provided pursuant to 25 this section shall be used for the following: 
“(1) To develop and provide community edu-

2 cation and prevention programs related to sexual

3 abuse of Indian children or children in an Indian

4 household.

5 “(2) To identify and provide behavioral health

6 treatment to victims of sexual abuse who are Indian

7 children or children in an Indian household, and to

8 their family members who are affected by sexual

9 abuse.

10 “(3) To develop prevention and intervention

11 models which incorporate traditional health care

12 practices, cultural values, and community involve-

13 ment.

14 “(4) To develop and implement culturally sen15 sitive assessment and diagnostic tools for use in In16 dian communities and Urban Centers.

17 “(5) To identify and provide behavioral health 18 treatment to Indian perpetrators and perpetrators 19 who are members of an Indian household-

20 "(A) making efforts to begin offender and 21 behavioral health treatment while the perpe22 trator is incarcerated or at the earliest possible 23 date if the perpetrator is not incarcerated; and 
1927

5 under subsection (a) shall be carried out in coordination

6 with programs and services authorized under the Indian

7 Child Protection and Family Violence Prevention Act (25

8 U.S.C. 3201 et seq.).

9 “SEC. 714. DOMESTIC AND SEXUAL VIOLENCE PREVENTION

11 “(a) In GeneRAL.-The Secretary, in accordance

12 with section 701, is authorized to establish in each Service

13 Area programs involving the prevention and treatment

14 of-

“(1) Indian victims of domestic violence or sex-

16 ual abuse; and

“(2) perpetrators of domestic violence or sexual

18 abuse who are Indian or members of an Indian

19 household.

20 "(b) UsE OF Funds.-Funds made available to carry 21 out this section shall be used-

"(1) to develop and implement prevention pro-

23 grams and community education programs relating 24 to domestic violence and sexual abuse; 
1 “(2) to provide behavioral health services, in2 cluding victim support services, and medical treat3 ment (including examinations performed by sexual 4 assault nurse examiners) to Indian victims of domes5 tic violence or sexual abuse;

$6 \quad$ "(3) to purchase rape kits;

7 “(4) to develop prevention and intervention 8 models, which may incorporate traditional health $9 \quad$ care practices; and

10 "(5) to identify and provide behavioral health 11 treatment to perpetrators who are Indian or mem12 bers of an Indian household.

13 “(c) Training and Certification.-

14 "(1) In GENERAL. - Not later than 1 year after 15 the date of enactment of the Indian Health Care Im16 provement Act Amendments of 2009, the Secretary 17 shall establish appropriate protocols, policies, proce18 dures, standards of practice, and, if not available 19 elsewhere, training curricula and training and cer20 tification requirements for services for victims of do21 mestic violence and sexual abuse.

22 “(2) REPORT.-Not later than 18 months after 23 the date of enactment of the Indian Health Care Im24 provement Act Amendments of 2008, the Secretary 25 shall submit to the Committee on Indian Affairs of 
1929

1 the Senate and the Committee on Natural Resources

2 of the House of Representatives a report that de-

3 scribes the means and extent to which the Secretary

4 has carried out paragraph (1).

5 “(d) CoORdination.-

6 "(1) In GENERAL.-The Secretary, in coordina-

7 tion with the Attorney General, Federal and tribal

8 law enforcement agencies, Indian Health Programs,

9 and domestic violence or sexual assault victim orga-

10 nizations, shall develop appropriate victim services

11 and victim advocate training programs-

"(A) to improve domestic violence or sexual abuse responses;

"(B) to improve forensic examinations and collection;

"(C) to identify problems or obstacles in the prosecution of domestic violence or sexual abuse; and

"(D) to meet other needs or carry out other activities required to prevent, treat, and improve prosecutions of domestic violence and sexual abuse.

24 date of enactment of the Indian Health Care Im25 provement Act Amendments of 2008, the Secretary 
1 shall submit to the Committee on Indian Affairs of

2 the Senate and the Committee on Natural Resources

3 of the House of Representatives a report that de-

4 scribes, with respect to the matters described in

5 paragraph (1), the improvements made and needed,

6 problems or obstacles identified, and costs necessary

7 to address the problems or obstacles, and any other

8 recommendations that the Secretary determines to

9 be appropriate.

10 “SEC. 715. BEHAVIORAL HEALTH RESEARCH.

11 "The Secretary, in consultation with appropriate

12 Federal agencies, shall make grants to, or enter into con-

13 tracts with, Indian Tribes, Tribal Organizations, and

14 urban Indian organizations or enter into contracts with,

15 or make grants to appropriate institutions for, the conduct

16 of research on the incidence and prevalence of behavioral

17 health problems among Indians served by the Service, In-

18 dian Tribes, or Tribal Organizations and among Indians

19 in urban areas. Research priorities under this section shall

20 include-

"(1) the multifactorial causes of Indian youth

22 suicide, including-

"(A) protective and risk factors and scientific data that identifies those factors; and 
1931

10 The effect of the interrelationships and interdependencies

11 referred to in paragraph (2) on children, and the develop-

12 ment of prevention techniques under paragraph (3) appli-

13 cable to children, shall be emphasized.

"SEC. 716. DEFINITIONS.

"For the purpose of this title, the following defini-

16 tions shall apply:

“(1) Assessment.-The term 'assessment'

18 means the systematic collection, analysis, and dis-

19 semination of information on health status, health 20 needs, and health problems.

ALCOHOL-RELATED

23 term 'alcohol-related neurodevelopmental disorders' 24 or 'ARND' means, with a history of maternal alco25 hol consumption during pregnancy, central nervous 
1932

1 system involvement such as developmental delay, in-

2 tellectual deficit, or neurologic abnormalities. Behav-

3 iorally, there can be problems with irritability, and

4 failure to thrive as infants. As children become older

5 there will likely be hyperactivity, attention deficit,

6 language dysfunction, and perceptual and judgment

7 problems.

8 “(3) Behavioral health aFtercare.-The

9 term 'behavioral health aftercare' includes those ac-

10 tivities and resources used to support recovery fol-

11 lowing inpatient, residential, intensive substance

12 abuse, or mental health outpatient or outpatient

13 treatment. The purpose is to help prevent or deal

14 with relapse by ensuring that by the time a client or

15 patient is discharged from a level of care, such as

16 outpatient treatment, an aftercare plan has been de-

17 veloped with the client. An aftercare plan may use

18 such resources as a community-based therapeutic

19 group, transitional living facilities, a 12-step spon-

20 sor, a local 12-step or other related support group,

21 and other community-based providers.

22 “(4) Dual diagnosis.-The term 'dual diag-

23 nosis' means coexisting substance abuse and mental

24 illness conditions or diagnosis. Such clients are 
1 sometimes referred to as mentally ill chemical abus2 ers (MICAs).

“(5) Fetal alcohol SPECTRUm Dis4 ORDERS.-

"(A) In genERAL.-The term 'fetal alcohol spectrum disorders' includes a range of effects that can occur in an individual whose mother drank alcohol during pregnancy, including physical, mental, behavioral, and/or learning disabilities with possible lifelong implications.

"(B) Inclusions.-The term 'fetal alcohol spectrum disorders' may include“(i) fetal alcohol syndrome (FAS); "(ii) fetal alcohol effect (FAE); "(iii) alcohol-related birth defects; and "(iv) alcohol-related neurodevelopmental disorders (ARND). “(6) Fetal alcohol syndrome or FAS.The term 'fetal alcohol syndrome' or 'FAS' means any 1 of a spectrum of effects that may occur when a woman drinks alcohol during pregnancy, the diagnosis of which involves the confirmed presence of the following 3 criteria:

"(A) Craniofacial abnormalities.

"(B) Growth deficits. 
1934

"(C) Central nervous system abnormalities. “(7) Rehabilitation.-The term 'rehabilitation' means medical and health care services that“(A) are recommended by a physician or licensed practitioner of the healing arts within the scope of their practice under applicable law; "(B) are furnished in a facility, home, or other setting in accordance with applicable standards; and

"(C) have as their purpose any of the following:

"(i) The maximum attainment of physical, mental, and developmental functioning.

"(ii) Averting deterioration in physical or mental functional status.

"(iii) The maintenance of physical or mental health functional status.

“(8) Substance abuse.-The term 'substance abuse' includes inhalant abuse.

“(9) Systems OF CARE.-The term 'Systems of Care' means a system for delivering services to children and their families that is child-centered, familyfocused and family-driven, community-based, and culturally competent and responsive to the needs of 
1 the children and families being served. The systems

2 of care approach values prevention and early identi-

3 fication, smooth transitions for children and fami-

4 lies, child and family participation and advocacy,

5 comprehensive array of services, individualized serv-

6 ice planning, services in the least restrictive environ-

7 ment, and integrated services with coordinated plan-

8 ning across the child-serving systems.

9 “SEC. 717. AUTHORIZATION OF APPROPRIATIONS.

10 "There is authorized to be appropriated such sums

11 as may be necessary to carry out the provisions of this 12 title.

\section{3 “TITLE VIII-MISCELLANEOUS}

14 “SEC. 801. REPORTS.

15 "For each fiscal year following the date of enactment

16 of the Indian Health Care Improvement Act Amendments

17 of 2009, the Secretary shall transmit to Congress a report

18 containing the following:

19 "(1) A report on the progress made in meeting.

20 the objectives of this Act, including a review of pro-

21 grams established or assisted pursuant to this Act

22 and assessments and recommendations of additional

23 programs or additional assistance necessary to, at a

24 minimum, provide health services to Indians and en-

25 sure a health status for Indians, which are at a par- 
1936

1 ity with the health services available to and the

2 health status of the general population.

“(2) A report on whether, and to what extent,

4 new national health care programs, benefits, initia-

5 tives, or financing systems have had an impact on

6 the purposes of this Act and any steps that the Sec-

7 retary may have taken to consult with Indian Tribes,

8 Tribal Organizations, and urban Indian organiza-

9 tions to address such impact, including a report on

10 proposed changes in allocation of funding pursuant

11 to section 807.

12 "(3) A report on the use of health services by

13 Indians-

"(A) on a national and area or other relevant geographical basis;

"(B) by gender and age;

"(C) by source of payment and type of service;

"(D) comparing such rates of use with rates of use among comparable non-Indian populations; and

24 Health Care Educational Loan Repayments every 6 25 months required by section 110 . 
1937

"(5) A general audit report of the Secretary on

2 the Health Care Educational Loan Repayment Pro-

3 gram as required by section $110(\mathrm{~m})$.

4 “(6) A report of the findings and conclusions of

5 demonstration programs on development of edu-

6 cational curricula for substance abuse counseling as

7 required in section $125(\mathrm{f})$.

8 "(7) A separate statement which specifies the

9 amount of funds requested to carry out the provi-

$10 \quad$ sions of section 201.

11 "(8) A report of the evaluations of health pro-

12 motion and disease prevention as required in section

$13203(\mathrm{c})$.

14 “(9) A biennial report to Congress on infectious

15 diseases as required by section 212 .

16 "(10) A report on environmental and nuclear

17 health hazards as required by section 215 .

18 "(11) An annual report on the status of all

19 health care facilities needs as required by section

$20301(\mathrm{c})(2)(\mathrm{B})$ and $301(\mathrm{~d})$.

21 "(12) Reports on safe water and sanitary waste

22 disposal facilities as required by section $302(\mathrm{~h})$.

23 "(13) An annual report on the expenditure of 24 non-Service funds for renovation as required by sec25 tions $304(\mathrm{~b})(2)$. 
1938

"(14) A report identifying the backlog of main-

2 tenance and repair required at Service and tribal fa-

3 cilities required by section 313(a).

4 “(15) A report providing an accounting of reim-

5 bursement funds made available to the Secretary

6 under titles XVIII, XIX, and XXI of the Social Se-

$7 \quad$ curity Act.

8 "(16) A report on any arrangements for the

9 sharing of medical facilities or services, as author-

$10 \quad$ ized by section 406 .

11 "(17) A report on evaluation and renewal of

12 urban Indian programs under section 505.

13 "(18) A report on the evaluation of programs

14 as required by section $513(\mathrm{~d})$.

15 "(19) A report on alcohol and substance abuse

16 as required by section 701(f).

17 “(20) A report on Indian youth mental health 18 services as required by section $707(\mathrm{~h})$.

19 "(21) A report on the reallocation of base re20 sources if required by section 807 .

21 "(22) A report on the movement of patients be22 tween Service Units, including-

23 "(A) a list of those Service Units that have 24 a net increase and those that have a net de25 crease of patients due to patients assigned to 
1939

one Service Unit voluntarily choosing to receive service at another Service Unit;

"(B) an analysis of the effect of patient movement on the quality of services for those Service Units experiencing an increase in the number of patients served; and

"(C) what funding changes are necessary to maintain a consistent quality of service at Service Units that have an increase in the number of patients served.

“(23) A report on the extent to which health care facilities of the Service, Indian Tribes, Tribal Organizations, and urban Indian organizations comply with credentialing requirements of the Service or licensure requirements of States.

"SEC. 802. REGULATIONS.

“(a) Deadines.-

"(1) Procedures.-Not later than 90 days after the date of enactment of the Indian Health Care Improvement Act Amendments of 2009, the Secretary shall initiate procedures under subchapter III of chapter 5 of title 5 , United States Code, to negotiate and promulgate such regulations or amendments thereto that are necessary to carry out this Act, except sections 105, 115, 117, 202, and 
1409 through 414 . The Secretary may promulgate

2 regulations to carry out such sections using the pro-

3 cedures required by chapter 5 of title 5, United

4 States Code (commonly known as the 'Administra5 tive Procedure Act').

6 “(2) Proposed Regulations.-Proposed reg-

7 ulations to implement this Act shall be published in

8 the Federal Register by the Secretary no later than

92 years after the date of enactment of the Indian

10 Health Care Improvement Act Amendments of 2009

11 and shall have no less than a 120-day comment pe12 riod.

13 "(3) Final Regulations.-The Secretary 14 shall publish in the Federal Register final regula15 tions to implement this Act by not later than 3 years 16 after the date of enactment of the Indian Health 17 Care Improvement Act Amendments of 2009.

18 “(b) CommitTeE.-A negotiated rulemaking com19 mittee established pursuant to section 565 of title 5, 20 United States Code, to carry out this section shall have 21 as its members only representatives of the Federal Gov22 ernment and representatives of Indian Tribes, and Tribal 23 Organizations, a majority of whom shall be nominated by 24 and be representatives of Indian Tribes and Tribal Orga25 nizations from each Service Area. 
1 “(c) Adaptation of Procedures.-The Secretary

2 shall adapt the negotiated rulemaking procedures to the 3 unique context of self-governance and the government-to4 government relationship between the United States and 5 Indian Tribes.

6 “(d) Lack of Regulations.-The lack of promul7 gated regulations shall not limit the effect of this Act.

8 "SEC. 803. PLAN OF IMPLEMENTATION.

9 “(a) In GENERAL.-Not later than 1 year after the 10 date of enactment of the Indian Health Care Improvement 11 Act Amendments of 2009, the Secretary, in consultation 12 with Indian Tribes, Tribal Organizations, and urban In13 dian organizations, shall submit to Congress a plan ex14 plaining the manner and schedule, by title and section, 15 by which the Secretary will implement the provisions of 16 this Act. This consultation may be conducted jointly with 17 the annual budget consultation pursuant to the Indian 18 Self-Determination and Education Assistance Act (25 19 U.S.C. 450 et seq.).

20 "(b) Lack of Plan.-The lack of (or failure to sub21 mit) such a plan shall not limit the effect, or prevent the 22 implementation, of this Act. 
1942

1 “SEC. 804. LIMITATION ON USE OF FUNDS APPROPRIATED TO INDIAN HEALTH SERVICE.

3 "Any limitation on the use of funds contained in an 4 Act providing appropriations for the Department for a pe5 riod with respect to the performance of abortions shall 6 apply for that period with respect to the performance of 7 abortions using funds contained in an Act providing ap8 propriations for the Service.

9 “SEC. 805. ELIGIBILITY OF CALIFORNIA INDIANS.

10 “(a) In GENERAL.- The following California Indians 11 shall be eligible for health services provided by the Service: "(1) Any member of a federally recognized In13 dian Tribe. “(2) Any descendant of an Indian who was re15 siding in California on June 1, 1852, if such de16 scendant"(A) is a member of the Indian community served by a local program of the Service; and "(B) is regarded as an Indian by the community in which such descendant lives. "(3) Any Indian who holds trust interests in 22 public domain, national forest, or reservation allot23 ments in California.

"(4) Any Indian in California who is listed on 25 the plans for distribution of the assets of rancherias 26 and reservations located within the State of Cali- 
1943

1 fornia under the Act of August 18, 1958 (72 Stat.

2 619), and any descendant of such an Indian.

3 "(b) Clarification.-Nothing in this section may

4 be construed as expanding the eligibility of California Indi-

5 ans for health services provided by the Service beyond the

6 scope of eligibility for such health services that applied on

7 May 1, 1986.

8 “SEC. 806. HEALTH SERVICES FOR INELIGIBLE PERSONS.

9 “(a) Childoren.-Any individual who-

10 “(1) has not attained 19 years of age;

11 "(2) is the natural or adopted child, stepchild,

12 foster child, legal ward, or orphan of an eligible In-

13 dian; and

14 "(3) is not otherwise eligible for health services

15 provided by the Service,

16 shall be eligible for all health services provided by the

17 Service on the same basis and subject to the same rules

18 that apply to eligible Indians until such individual attains

1919 years of age. The existing and potential health needs

20 of all such individuals shall be taken into consideration

21 by the Service in determining the need for, or the alloca-

22 tion of, the health resources of the Service. If such an indi-

23 vidual has been determined to be legally incompetent prior

24 to attaining 19 years of age, such individual shall remain 
1 eligible for such services until 1 year after the date of a

2 determination of competency.

3 “(b) Spouses.-Any spouse of an eligible Indian who

4 is not an Indian, or who is of Indian descent but is not

5 otherwise eligible for the health services provided by the

6 Service, shall be eligible for such health services if all such

7 spouses or spouses who are married to members of each

8 Indian Tribe being served are made eligible, as a class,

9 by an appropriate resolution of the governing body of the

10 Indian Tribe or Tribal Organization providing such serv-

11 ices. The health needs of persons made eligible under this

12 paragraph shall not be taken into consideration by the

13 Service in determining the need for, or allocation of, its

14 health resources.

15 “(c) Provision of Services to Other Individ-

16 UALS.-

17 “(1) IN GENERAL.—The Secretary is authorized

18 to provide health services under this subsection

19 through health programs operated directly by the

20 Service to individuals who reside within the Service

21 area of the Service Unit and who are not otherwise

22 eligible for such health services if-

23 "(A) the Indian Tribes served by such

24 Service Unit request such provision of health

25 services to such individuals; and 
"(B) the Secretary and the served Indian

Tribes have jointly determined that-

"(i) the provision of such health services will not result in a denial or diminution of health services to eligible Indians; and

"(ii) there is no reasonable alternative health facilities or services, within or without the Service Unit, available to meet the health needs of such individuals.

“(2) ISDEAA PROGRAMS.-In the case of health programs and facilities operated under a contract or compact entered into under the Indian SelfDetermination and Education Assistance Act (25 U.S.C. 450 et seq.), the governing body of the Indian Tribe or Tribal Organization providing health services under such contract or compact is authorized to determine whether health services should be provided under such contract to individuals who are not eligible for such health services under any other subsection of this section or under any other provision of law. In making such determinations, the governing body of the Indian Tribe or Tribal Organization shall take into account the considerations described in paragraph (1)(B). 


\section{“(3) Payment for services.-}

"(A) In GENERAL.-Persons receiving health services provided by the Service under this subsection shall be liable for payment of such health services under a schedule of charges prescribed by the Secretary which, in the judgment of the Secretary, results in reimbursement in an amount not less than the actual cost of providing the health services. Notwithstanding section 404 of this Act or any other provision of law, amounts collected under this subsection, including Medicare, Medicaid, or SCHIP reimbursements under titles XVIII, XIX, and XXI of the Social Security Act, shall be credited to the account of the program providing the service and shall be used for the purposes listed in section 401(d)(2) and amounts collected under this subsection shall be available for expenditure within such program.

"(B) Indigent PEOPLE.-Health services may be provided by the Secretary through the Service under this subsection to an indigent individual who would not be otherwise eligible for such health services but for the provisions of paragraph (1) only if an agreement has been 
entered into with a State or local government

under which the State or local government agrees to reimburse the Service for the expenses incurred by the Service in providing such health services to such indigent individual.

“(4) Revocation OF CONSENT FOR SERV-

"(A) Single tribe SERvice AREa.-In the case of a Service Area which serves only 1 Indian Tribe, the authority of the Secretary to provide health services under paragraph (1) shall terminate at the end of the fiscal year succeeding the fiscal year in which the governing body of the Indian Tribe revokes its concurrence to the provision of such health services.

“(B) Multitribal SERVice AREa.-In the case of a multitribal Service Area, the authority of the Secretary to provide health services under paragraph (1) shall terminate at the end of the fiscal year succeeding the fiscal year in which at least 51 percent of the number of Indian Tribes in the Service Area revoke their concurrence to the provisions of such health services. 
1 “(d) Other Services.-The Service may provide

2 health services under this subsection to individuals who

3 are not eligible for health services provided by the Service

4 under any other provision of law in order to-

5 "(1) achieve stability in a medical emergency;

$6 \quad$ “(2) prevent the spread of a communicable dis-

7 ease or otherwise deal with a public health hazard;

8 "(3) provide care to non-Indian women preg-

9 nant with an eligible Indian's child for the duration

10 of the pregnancy through postpartum; or

11 "(4) provide care to immediate family members

12 of an eligible individual if such care is directly re-

13 lated to the treatment of the eligible individual.

14 “(e) Hospital Privileges for Practitioners.-

15 “(1) IN GENERAL.-Hospital privileges in

16 health facilities operated and maintained by the

17 Service or operated under a contract or compact

18 pursuant to the Indian Self-Determination and Edu-

19 cation Assistance Act (25 U.S.C. 450 et seq.) may

20 be extended to non-Service health care practitioners

21 who provide services to individuals described in sub-

22 section (a), (b), (c), or (d). Such non-Service health

23 care practitioners may, as part of the privileging

24 process, be designated as employees of the Federal

25 Government for purposes of section $1346(\mathrm{~b})$ and 
1 chapter 171 of title 28, United States Code (relating

2 to Federal tort claims) only with respect to acts or

3 omissions which occur in the course of providing

4 services to eligible individuals as a part of the condi-

5 tions under which such hospital privileges are ex6 tended.

"(2) Definition.-For purposes of this sub-

8 section, the term 'non-Service health care practi-

9 tioner' means a practitioner who is not-

10 “(A) an employee of the Service; or

11 "(B) an employee of an Indian tribe or 12 tribal organization operating a contract or com13 pact under the Indian Self-Determination and 14 Education Assistance Act or an individual who 15 provides health care services pursuant to a per16 sonal services contract with such Indian tribe or 17 tribal organization.

18 "(f) Eligible Indian.-For purposes of this sec19 tion, the term 'eligible Indian' means any Indian who is 20 eligible for health services provided by the Service without 21 regard to the provisions of this section.

22 "SEC. 807. REALLOCATION OF BASE RESOURCES.

23 “(a) REPORT REQUIRED.-Notwithstanding any 24 other provision of law, any allocation of Service funds for 25 a fiscal year that reduces by 5 percent or more from the 
1950

1 previous fiscal year the funding for any recurring pro-

2 gram, project, or activity of a Service Unit may be imple-

3 mented only after the Secretary has submitted to Con-

4 gress, under section 801, a report on the proposed change

5 in allocation of funding, including the reasons for the

6 change and its likely effects.

7 “(b) ExCEPTION.-Subsection (a) shall not apply if

8 the total amount appropriated to the Service for a fiscal

9 year is at least 5 percent less than the amount appro-

10 priated to the Service for the previous fiscal year.

11 “SEC. 808. RESULTS OF DEMONSTRATION PROJECTS.

12 "The Secretary shall provide for the dissemination to

13 Indian Tribes, Tribal Organizations, and urban Indian or-

14 ganizations of the findings and results of demonstration

15 projects conducted under this Act.

16 “SEC. 809. PROVISION OF SERVICES IN MONTANA.

17 “(a) Consistent With Court Decision.-The

18 Secretary, acting through the Service, shall provide serv-

19 ices and benefits for Indians in Montana in a manner con-

20 sistent with the decision of the United States Court of Ap-

21 peals for the Ninth Circuit in MeNabb for MeNabb v.

22 Bowen, 829 F.2d 787 (9th Cir. 1987).

23 “(b) Clarification.-The provisions of subsection

24 (a) shall not be construed to be an expression of the sense

25 of Congress on the application of the decision described 
1 in subsection (a) with respect to the provision of services

2 or benefits for Indians living in any State other than Mon-

3 tana.

4 "SEC. 810. MORATORIUM.

5 "During the period of the moratorium imposed on 6 implementation of the final rule published in the Federal

7 Register on September 16, 1987, by the Department of

8 Health and Human Services, relating to eligibility for the

9 health care services of the Indian Health Service, the In-

10 dian Health Service shall provide services pursuant to the

11 criteria for eligibility for such services that were in effect

12 on September 15, 1987, subject to the provisions of sec-

13 tions 805 and 806, until the Service has submitted to the

14 Committees on Appropriations of the Senate and the

15 House of Representatives a budget request reflecting the

16 increased costs associated with the proposed final rule,

17 and the request has been included in an appropriations

18 Act and enacted into law.

19 "SEC. 811. SEVERABILITY PROVISIONS.

20 "If any provision of this Act, any amendment made

21 by the Act, or the application of such provision or amend-

22 ment to any person or circumstances is held to be invalid,

23 the remainder of this Act, the remaining amendments

24 made by this Act, and the application of such provisions 
1 to persons or circumstances other than those to which it

2 is held invalid, shall not be affected thereby.

3 “SEC. 812. USE OF PATIENT SAFETY ORGANIZATIONS.

4 "The Service, an Indian Tribe, Tribal Organization,

5 or urban Indian organization may provide for quality as-

6 surance activities through the use of a patient safety orga-

7 nization in accordance with title IX of the Public Health

8 Service Act.

9 "SEC. 813. CONFIDENTIALITY OF MEDICAL QUALITY ASSURANCE RECORDS; QUALIFIED IMMUNITY FOR PARTICIPANTS.

12 “(a) Confidentiality of Records.-Medical qual-

13 ity assurance records created by or for any Indian Health

14 Program or a health program of an Urban Indian Organi15 zation as part of a medical quality assurance program are 16 confidential and privileged. Such records may not be dis17 closed to any person or entity, except as provided in sub18 section (c). “(b) Prohibition on Disclosure and Testi20 MONY.-

"(1) In GENERAL.—No part of any medical 22 quality assurance record described in subsection (a) 23 may be subject to discovery or admitted into evi24 dence in any judicial or administrative proceeding, 25 except as provided in subsection (c). 
2 creates medical quality assurance records for any In3 dian Health Program or Urban Indian Organization

4 who participates in any proceeding that reviews or 5 creates such records may not be permitted or re6 quired to testify in any judicial or administrative 7 proceeding with respect to such records or with re8 spect to any finding, recommendation, evaluation, 9 opinion, or action taken by such person or body in 10 connection with such records except as provided in 11 this section.

12 “(c) Authorized Disclosure and Testimony.13 "(1) In GENERAL.—Subject to paragraph (2), a 14 medical quality assurance record described in sub15 section (a) may be disclosed, and a person referred 16 to in subsection (b) may give testimony in connec17 tion with such a record, only as follows:

18 "(A) To a Federal executive agency or pri19 vate organization, if such medical quality assur20 ance record or testimony is needed by such 21 agency or organization to perform licensing or 22 accreditation functions related to any Indian 23 Health Program or to a health program of an 24 Urban Indian Organization to perform moni- 
toring, required by law, of such program or organization.

"(B) To an administrative or judicial proceeding commenced by a present or former Indian Health Program or Urban Indian Organization provider concerning the termination, suspension, or limitation of clinical privileges of such health care provider.

"(C) To a governmental board or agency or to a professional health care society or organization, if such medical quality assurance record or testimony is needed by such board, agency, society, or organization to perform licensing, credentialing, or the monitoring of professional standards with respect to any health care provider who is or was an employee of any Indian Health Program or Urban Indian Organization.

"(D) To a hospital, medical center, or other institution that provides health care services, if such medical quality assurance record or testimony is needed by such institution to assess the professional qualifications of any health care provider who is or was an employee of any 25 
nization and who has applied for or been granted authority or employment to provide health care services in or on behalf of such program or organization.

"(E) To an officer, employee, or contractor of the Indian Health Program or Urban Indian Organization that created the records or for which the records were created. If that officer, employee, or contractor has a need for such record or testimony to perform official duties. "(F) To a criminal or civil law enforcement agency or instrumentality charged under applicable law with the protection of the public health or safety, if a qualified representative of such agency or instrumentality makes a written request that such record or testimony be provided for a purpose authorized by law.

"(G) In an administrative or judicial proceeding commenced by a criminal or civil law enforcement agency or instrumentality referred to in subparagraph $(\mathrm{F})$, but only with respect to the subject of such proceeding.

24 exception of the subject of a quality assurance ac25 tion, the identity of any person receiving health care 
1956

1 services from any Indian Health Program or Urban

2 Indian Organization or the identity of any other per-

3 son associated with such program or organization

4 for purposes of a medical quality assurance program

5 that is disclosed in a medical quality assurance

6 record described in subsection (a) shall be deleted

7 from that record or document before any disclosure

8 of such record is made outside such program or or-

9 ganization.

10 “(d) Disclosure For Certain Purposes.-

11 "(1) IN GENERAL.-Nothing in this section

12 shall be construed as authorizing or requiring the

13 withholding from any person or entity aggregate sta-

14 tistical information regarding the results of any In-

15 dian Health Program or Urban Indian

16 Organizations's medical quality assurance programs.

17 “(2) WithHOLDING FROM CONGRESS.-Noth-

18 ing in this section shall be construed as authority to

19 withhold any medical quality assurance record from

20 a committee of either House of Congress, any joint

21 committee of Congress, or the Government Account-

22 ability Office if such record pertains to any matter

23 within their respective jurisdictions.

24 “(e) Prohibition on Disclosure of Record or

25 Testimony.-A person or entity having possession of or 
1 access to a record or testimony described by this section

2 may not disclose the contents of such record or testimony

3 in any manner or for any purpose except as provided in

4 this section.

5 “(f) Exemption From Freedom of Information

6 ACT.-Medical quality assurance records described in sub-

7 section (a) may not be made available to any person under

8 section 552 of title 5, United States Code.

9 “(g) Limitation on Civil Liability.-A person

10 who participates in or provides information to a person

11 or body that reviews or creates medical quality assurance

12 records described in subsection (a) shall not be civilly lia-

13 ble for such participation or for providing such informa-

14 tion if the participation or provision of information was

15 in good faith based on prevailing professional standards

16 at the time the medical quality assurance program activity

17 took place.

18 “(h) Application to Information in Certain

19 Other Records.-Nothing in this section shall be con-

20 strued as limiting access to the information in a record

21 created and maintained outside a medical quality assur-

22 ance program, including a patient's medical records, on

23 the grounds that the information was presented during

24 meetings of a review body that are part of a medical qual-

25 ity assurance program. 
1 “(i) Regulations.-The Secretary, acting through

2 the Service, shall promulgate regulations pursuant to sec3 tion 802.

$4 \quad$ “(j) Definitions.-In this section:

5 “(1) The term 'health care provider' means any

6 health care professional, including community health

$7 \quad$ aides and practitioners certified under section 121,

8 who are granted clinical practice privileges or em-

9 ployed to provide health care services in an Indian

10 Health Program or health program of an Urban In-

11 dian Organization, who is licensed or certified to

12 perform health care services by a governmental

13 board or agency or professional health care society

14 or organization.

15 “(2) The term 'medical quality assurance pro-

16 gram' means any activity carried out before, on, or

17 after the date of enactment of this Act by or for any

18 Indian Health Program or Urban Indian Organiza-

19 tion to assess the quality of medical care, including

20 activities conducted by or on behalf of individuals,

21 Indian Health Program or Urban Indian Organiza-

22 tion medical or dental treatment review committees,

23 or other review bodies responsible for quality assur-

24 ance, credentials, infection control, patient safety,

25 patient care assessment (including treatment proce- 
1 dures, blood, drugs, and therapeutics), medical

2 records, health resources management review and

3 identification and prevention of medical or dental in$4 \quad$ cidents and risks.

5 "(3) The term 'medical quality assurance

6 record' means the proceedings, records, minutes, and

7 reports that emanate from quality assurance pro-

8 gram activities described in paragraph (2) and are

9 produced or compiled by or for an Indian Health

10 Program or Urban Indian Organization as part of a

11 medical quality assurance program.

12 “(k) Continued Protection.-Disclosure under

13 subsection (c) does not permit redisclosure except to the

14 extent such further disclosure is authorized under sub-

15 section (c) or is otherwise authorized to be disclosed under

16 this section.

17 “(l) InCONSISTENCIES.-To the extent that the pro18 tections under the Patient Safety and Quality Improve19 ment Act of 2005 and this section are inconsistent, the 20 provisions of whichever is more protective shall control. 21 "(m) Relationship to Other Law.-This section 22 shall continue in force and effect, except as otherwise spe23 cifically provided in any Federal law enacted after the date 24 of enactment of the Indian Health Care Improvement Act 25 Amendments of 2009. 
1 “SEC. 814. CLAREMORE INDIAN HOSPITAL.

2 "The Claremore Indian Hospital shall be deemed to

3 be a dependant Indian community for the purposes of sec-

4 tion 1151 of title 18, United States Code.

5 “SEC. 815. SENSE OF CONGRESS REGARDING LAW ENFORCEMENT AND METHAMPHETAMINE ISSUES IN INDIAN COUNTRY.

8 "It is the sense of Congress that Congress encourages

9 State, local, and Indian tribal law enforcement agencies

10 to enter into memoranda of agreement between and

11 among those agencies for purposes of streamlining law en-

12 forcement activities and maximizing the use of limited re-

13 sources-

14 "(1) to improve law enforcement services pro15 vided to Indian tribal communities; and

16 "(2) to increase the effectiveness of measures to 17 address problems relating to methamphetamine use 18 in Indian country (as defined in section 1151 of title 19 18, United States Code).

20 “SEC. 816. PERMITTING IMPLEMENTATION THROUGH CONTRACTS WITH TRIBAL HEALTH PROGRAMS.

22 "Nothing in this Act shall be construed as preventing" 23 the Secretary from-

"(1) carrying out any section of this Act 25 through contracts with Tribal Health Programs; and 
1961

“(2) carrying out sections through 214, 701(a)(1), 701(b)(1), 701(c), 707(g), and 712(b),

3 through contracts with urban Indian organizations.

4 The previous sentence shall not affect the authority the

5 Secretary may otherwise have to carry out other provisions

6 of this Act through such contracts.

7 "SEC. 817. AUTHORIZATION OF APPROPRIATIONS; AVAIL-

ABILITY.

“(a) Authorization of Appropriations.-There

10 are authorized to be appropriated such sums as may be

11 necessary to carry out this title.

12 “(b) Limitation on New Spending Authority.-

13 Any new spending authority (described in subparagraph

14 (A) or (B) of section 401(c)(2) of the Congressional Budg-

15 et Act of 1974 (Public Law 93-344; 88 Stat. 317)) which

16 is provided under this Act shall be effective for any fiscal

17 year only to such extent or in such amounts as are pro-

18 vided in appropriation Acts.

19 "(c) Availability.-The funds appropriated pursu20 ant to this Act shall remain available until expended.".

21 (b) Rate OF PaY.-

22 (1) Positions at LeVel IV.-Section 5315 of

23 title 5, United States Code, is amended by striking

24 "Assistant Secretaries of Health and Human Serv- 
1962

1 ices (6)." and inserting "Assistant Secretaries of $2 \quad$ Health and Human Services (7)".

(2) Positions at Level V.-Section 5316 of

4 title 5, United States Code, is amended by striking

5 "Director, Indian Health Service, Department of $6 \quad$ Health and Human Services".

7 (c) Amendments to Other Provisions of Law.-

$8 \quad(1)$ Section $3307(b)(1)(C)$ of the Children's 9 Health Act of 2000 (25 U.S.C. 1671 note; Public 10 Law 106-310) is amended by striking "Director of 11 the Indian Health Service" and inserting "Assistant 12 Secretary for Indian Health".

13 (2) The Indian Lands Open Dump Cleanup Act 14 of 1994 is amended-

(A) in section 3 (25 U.S.C. 3902)-

(i) by striking paragraph (2);

(ii) by redesignating paragraphs (1), (3), (4), (5), and (6) as paragraphs (4), (5), (2), (6), and (1), respectively, and moving those paragraphs so as to appear in numerical order; and lowing: 
1963

“(3) Assistant secretary.-The term 'Assistant Secretary' means the Assistant Secretary for $3 \quad$ Indian Health."; striking the section designation and heading and inserting the following: DIAN HEALTH.”;

"SEC. 5. AUTHORITY OF ASSISTANT SECRETARY FOR IN-

(C) in section 6(a) (25 U.S.C. 3905(a)), in the subsection heading, by striking "DIRECTOR" and inserting "Assistant SECRETARY"; (D) in section 9(a) (25 U.S.C. 3908(a)), in the subsection heading, by striking "DIRECTOR" and inserting "Assistant SECRETARY"; and

19 Hawkins-Robert T. Stafford Elementary and Sec20 ondary School Improvement Amendments of 1988 21 (25 U.S.C. 2001 note; Public Law 100-297) is 22 amended by striking "Director of the Indian Health 23 Service" and inserting "Assistant Secretary for In24 dian Health". 
(4) Section 203(a)(1) of the Rehabilitation Act of 1973 (29 U.S.C. 763(a)(1)) is amended by strik3 ing "Director of the Indian Health Service" and in4 serting "Assistant Secretary for Indian Health".

(5) Subsections (b) and (e) of section 518 of 6 the Federal Water Pollution Control Act (33 U.S.C. 7 1377) are amended by striking "Director of the In8 dian Health Service" each place it appears and in9 serting "Assistant Secretary for Indian Health".

10 (6) Section $317 \mathrm{M}(\mathrm{b})$ of the Public Health Serv11 ice Act (42 U.S.C. 247b-14(b)) is amended-

(A) by striking "Director of the Indian Health Service" each place it appears and inserting "Assistant Secretary for Indian Health"; and Directors referred to in such paragraph" and inserting "the Director of the Centers for Disease Control and Prevention and the Assistant Secretary for Indian Health”.

(7) Section $417 \mathrm{C}(\mathrm{b})$ of the Public Health Service Act (42 U.S.C. 285-9(b)) is amended by striking "Director of the Indian Health Service" and inserting "Assistant Secretary for Indian Health". 
1965

18 amended by adding at the end the following: "SEC. 9. Nothing in this Act shall preclude the 20 Soboba Band of Mission Indians and the Soboba Indian 21 Reservation from being provided with sanitation facilities 22 and services under the authority of section 7 of the Act 23 of August 5, 1954 (68 Stat. 674), as amended by the Act 24 of July 31, 1959 (73 Stat. 267).”. 
1 SEC. 3103. NATIVE AMERICAN HEALTH AND WELLNESS FOUNDATION.

3 (a) In GENERAL.-The Indian Self-Determination 4 and Education Assistance Act (25 U.S.C. 450 et seq.) is 5 amended by adding at the end the following:

6 "TITLE VIII-NATIVE AMERICAN 7 HEALTH AND WELLNESS 8 FOUNDATION

9 “SEC. 801. DEFINITIONS.

10 "In this title:

11 “(1) BOARD.-The term 'Board' means the 12 Board of Directors of the Foundation.

13 “(2) Commitree.-The term 'Committee' 14 means the Committee for the Establishment of $\mathrm{Na}$ 15 tive American Health and Wellness Foundation es16 tablished under section 802(f).

17 “(3) Foundation.-The term 'Foundation' 18 means the Native American Health and Wellness $19 \quad$ Foundation established under section 802.

20 “(4) SECRETARY.—The term 'Secretary' means 21 the Secretary of Health and Human Services.

22 “(5) Service.-The term 'Service' means the 23 Indian Health Service of the Department of Health 24 and Human Services. 
1967

1 "SEC. 802. NATIVE AMERICAN HEALTH AND WELLNESS FOUNDATION.

3 “(a) Establishment.-

"(1) In GENERAL.—As soon as practicable

5 after the date of enactment of this title, the Sec-

6 retary shall establish, under the laws of the District

7 of Columbia and in accordance with this title, the

8 Native American Health and Wellness Foundation.

“(2) Funding Determinations.-No funds,

10 gift, property, or other item of value (including any

11 interest accrued on such an item) acquired by the

12 Foundation shall-

"(A) be taken into consideration for purposes of determining Federal appropriations relating to the provision of health care and services to Indians; or

"(B) otherwise limit, diminish, or affect

the Federal responsibility for the provision of health care and services to Indians.

20 "(b) Perpetual Existence.-The Foundation 21 shall have perpetual existence.

22 “(c) Nature of Corporation.-The Foundation23 "(1) shall be a charitable and nonprofit feder24 ally chartered corporation; and 25 "(2) shall not be an agency or instrumentality 26 of the United States. 
1 “(d) Place of Incorporation and Domicile.-

2 The Foundation shall be incorporated and domiciled in the

3 District of Columbia.

4 “(e) Duties.-The Foundation shall-

$5 \quad$ "(1) encourage, accept, and administer private

6 gifts of real and personal property, and any income

7 from or interest in such gifts, for the benefit of, or

8 in support of, the mission of the Service;

$9 \quad$ "(2) undertake and conduct such other activi-

10 ties as will further the health and wellness activities

11 and opportunities of Native Americans; and

12 "(3) participate with and assist Federal, State,

13 and tribal governments, agencies, entities, and indi-

14 viduals in undertaking and conducting activities that

15 will further the health and wellness activities and op-

16 portunities of Native Americans.

17 “(f) Committee for the Establishment of NA18 tive American Health and Wellnness Founda19 TION.-

“(1) In GENERAL.-The Secretary shall estab21 lish the Committee for the Establishment of Native 22 American Health and Wellness Foundation to assist 23 the Secretary in establishing the Foundation. 
"(2) Duties.-Not later than 180 days after

2 the date of enactment of this section, the Committee

3 shall-

"(A) carry out such activities as are necessary to incorporate the Foundation under the laws of the District of Columbia, including acting as incorporators of the Foundation;

"(B) ensure that the Foundation qualifies for and maintains the status required to carry out this section, until the Board is established; "(C) establish the constitution and initial bylaws of the Foundation;

"(D) provide for the initial operation of the Foundation, including providing for temporary or interim quarters, equipment, and staff; and

"(E) appoint the initial members of the Board in accordance with the constitution and initial bylaws of the Foundation.

“(g) BoARd OF Directors.-

“(1) In General.-The Board of Directors shall be the governing body of the Foundation.

“(2) Powens.—The Board may exercise, or provide for the exercise of, the powers of the Foun- 


\section{“(3) Selection.-}

"(A) IN GENERAL.—Subject to subparagraph (B), the number of members of the Board, the manner of selection of the members (including the filling of vacancies), and the terms of office of the members shall be as provided in the constitution and bylaws of the Foundation.

"(B) Requirements.-

"(i) Number OF Members.-The Board shall have at least 11 members, who shall have staggered terms.

"(ii) Initial Voting Members.-The initial voting members of the Board-

"(I) shall be appointed by the Committee not later than 180 days after the date on which the Foundation is established; and "(II) shall have staggered terms. “(iii) Qualification.-The members of the Board shall be United States citizens who are knowledgeable or experienced in Native American health care and related matters. 
"(C) Compensation.-A member of the Board shall not receive compensation for service as a member, but shall be reimbursed for actual and necessary travel and subsistence expenses incurred in the performance of the duties of the Foundation.

"(1) In generaL.—The officers of the Foundation shall be-

"(A) a secretary, elected from among the members of the Board; and

16 of the Board, as the chief operating officer of the 17 Foundation, or the Board may appoint a chief oper18 ating officer, who shall serve at the direction of the 19 Board.

“(3) Election.-The manner of election, term 21 of office, and duties of the officers of the Founda22 tion shall be as provided in the constitution and by23 laws of the Foundation.

24 “(i) PowErs.-The Foundation- 
"(1) shall adopt a constitution and bylaws for

2 the management of the property of the Foundation

3 and the regulation of the affairs of the Foundation;

$4 \quad$ "(2) may adopt and alter a corporate seal;

$5 \quad$ “(3) may enter into contracts;

6 “(4) may acquire (through a gift or otherwise),

7 own, lease, encumber, and transfer real or personal

8 property as necessary or convenient to carry out the

9 purposes of the Foundation;

10 "(5) may sue and be sued; and

11 "(6) may perform any other act necessary and

12 proper to carry out the purposes of the Foundation.

13 “(j) Principal Office.-

14 "(1) In GENERAL.-The principal office of the

15 Foundation shall be in the District of Columbia.

16 “(2) ACTIVITIEs; OFFICES.-The activities of

17 the Foundation may be conducted, and offices may

18 be maintained, throughout the United States in ac-

19 cordance with the constitution and bylaws of the

20 Foundation.

21 “(k) SERvice of Process.-The Foundation shall

22 comply with the law on service of process of each State

23 in which the Foundation is incorporated and of each State

24 in which the Foundation carries on activities. 
2 Agents.-

"(1) In GENERAL.-The Foundation shall be

4 liable for the acts of the officers, employees, and

5 agents of the Foundation acting within the scope of 6 their authority.

“(2) Personal liability.-A member of the

8 Board shall be personally liable only for gross neg-

9 ligence in the performance of the duties of the mem10 ber.

11 “(m) REstrictions.-

12 “(1) Limitation on sPending.—Beginning

13 with the fiscal year following the first full fiscal year

14 during which the Foundation is in operation, the ad-

15 ministrative costs of the Foundation shall not exceed

16 the percentage described in paragraph (2) of the 17 sum of-

"(A) the amounts transferred to the Foundation under subsection (o) during the preceding fiscal year; and

"(B) donations received from private sources during the preceding fiscal year. 
"(A) for the first fiscal year described in that paragraph, 20 percent;

"(B) for the following fiscal year, 15 per-

cent; and

"(C) for each fiscal year thereafter, 10 percent.

“(3) Appointment And HiRIng.-The ap-

8 pointment of officers and employees of the Founda-

9 tion shall be subject to the availability of funds.

10

"(4) Status.-A member of the Board or offi-

11 cer, employee, or agent of the Foundation shall not

12 by reason of association with the Foundation be con-

13 sidered to be an officer, employee, or agent of the

$14 \quad$ United States.

15 "(n) Audits. - The Foundation shall comply with 16 section 10101 of title 36, United States Code, as if the 17 Foundation were a corporation under part B of subtitle 18 II of that title.

19 “(o) Funding.-

20 “(1) AUthorization OF APPROPRIATIONS.-

21 There is authorized to be appropriated to carry out 22 subsection (e)(1) $\$ 500,000$ for each fiscal year, as 23 adjusted to reflect changes in the Consumer Price 24 Index for all-urban consumers published by the De25 partment of Labor. 
“(2) Transfer OF DONATED Funds.-The

2 Secretary shall transfer to the Foundation funds

3 held by the Department of Health and Human Serv-

4 ices under the Act of August 5, 1954 (42 U.S.C.

52001 et seq.), if the transfer or use of the funds is

6 not prohibited by any term under which the funds

7 were donated.

8 “SEC. 803. ADMINISTRATIVE SERVICES AND SUPPORT.

9 “(a) Provision of Support by Secretary.-Sub-

10 ject to subsection (b), during the 5-year period beginning

11 on the date on which the Foundation is established, the

12 Secretary-

“(1) may provide personnel, facilities, and other

14 administrative support services to the Foundation;

15 "(2) may provide funds for initial operating

16 costs and to reimburse the travel expenses of the

17 members of the Board; and

18 "(3) shall require and accept reimbursements

19 from the Foundation for-

“(A) services provided under paragraph

(1); and

“(B) funds provided under paragraph (2).

23 “(b) Reimbursement.-Reimbursements accepted

24 under subsection (a)(3)- 
"(1) shall be deposited in the Treasury of the

2 United States to the credit of the applicable appro3 priations account; and

4 "(2) shall be chargeable for the cost of pro5 viding services described in subsection (a)(1) and 6 travel expenses described in subsection (a)(2).

7 “(c) Continuation of Certain Services.-The 8 Secretary may continue to provide facilities and necessary 9 support services to the Foundation after the termination 10 of the 5-year period specified in subsection (a) if the facili11 ties and services-

12 “(1) are available; and

13 "(2) are provided on reimbursable cost basis.". 14 (b) Technical Amendments.-The Indian Self-De15 termination and Education Assistance Act is amended16 (1) by redesignating title V (25 U.S.C. $458 \mathrm{bbb}$ 17 et seq.) as title VII;

18 (2) by redesignating sections 501, 502, and 503 19 (25 U.S.C. 458bbb, 458bbb-1, 458bbb-2) as sec20 tions 701, 702, and 703, respectively; and

21 (3) in subsection (a)(2) of section 702 and 22 paragraph (2) of section 703 (as redesignated by 23 paragraph (2)), by striking "section 501" and in24 serting "section 701". 
1 SEC. 3104. GAO STUDY AND REPORT ON PAYMENTS FOR

3 (a) STUDY.-

4 (1) In GeneraL.-The Comptroller General of 5 the United States (in this section referred to as the 6 "Comptroller General") shall conduct a study on the 7 utilization of health care furnished by health care 8 providers under the contract health services program

9 funded by the Indian Health Service and operated 10 by the Indian Health Service, an Indian Tribe, or a 11 Tribal Organization (as those terms are defined in 12 section 4 of the Indian Health Care Improvement 13 Act).

(2) AnALYsis.-The study conducted under 15 paragraph (1) shall include an analysis of-

(A) the amounts reimbursed under the contract health services program described in paragraph (1) for health care furnished by entities, individual providers, and suppliers, including a comparison of reimbursement for such health care through other public programs and in the private sector;

(B) barriers to accessing care under such contract health services program, including, but not limited to, barriers relating to travel distances, cultural differences, and public and pri- 
vate sector reluctance to furnish care to patients under such program;

(C) the adequacy of existing Federal funding for health care under such contract health services program; and

(D) any other items determined appropriate by the Comptroller General.

8 (b) REPORT.-Not later than 18 months after the 9 date of enactment of this Act, the Comptroller General 10 shall submit to Congress a report on the study conducted 11 under subsection (a), together with recommendations re12 garding-

13 (1) the appropriate level of Federal funding 14 that should be established for health care under the 15 contract health services program described in sub16 section (a)(1); and

17 (2) how to most efficiently utilize such funding. 18 (c) Consultation.-In conducting the study under 19 subsection (a) and preparing the report under subsection 20 (b), the Comptroller General shall consult with the Indian 21 Health Service, Indian Tribes, and Tribal Organizations. 
1 TITLE II-IMPROVEMENT OF IN2 DIAN HEALTH CARE PRO3 VIDED UNDER THE SOCIAL 4 SECURITY ACT

5 SEC. 3201. EXPANSION OF PAYMENTS UNDER MEDICARE, MEDICAID, AND SCHIP FOR ALL COVERED SERVICES FURNISHED BY INDIAN HEALTH PROGRAMS.

9 (a) MEDICAID.-

10 (1) EXPANSION TO ALL COVERED SERVICES.11 Section 1911 of the Social Security Act (42 U.S.C. 12 1396j) is amended-

13 (A) by amending the heading to read as 14 follows:

15 “SEC. 1911. INDIAN HEALTH PROGRAMS.”; 16 and (B) by amending subsection (a) to read as follows:

19 “(a) Eligibility for Payment for Medical As20 sistance.-An Indian Health Program shall be eligible 21 for payment for medical assistance provided under a State 22 plan or under waiver authority with respect to items and 23 services furnished by the Program if the furnishing of 24 such services meets all the conditions and requirements 25 which are applicable generally to the furnishing of items 
1 and services under this title and under such plan or waiver 2 authority.".

3

4

5

6

7

8

9 The Secretary may enter into an agreement with a State

10 for the purpose of reimbursing the State for medical as-

11 sistance provided by the Indian Health Service, an Indian

12 Tribe, Tribal Organization, or an Urban Indian Organiza-

13 tion (as so defined), directly, through referral, or under

14 contracts or other arrangements between the Indian

15 Health Service, an Indian Tribe, Tribal Organization, or

16 an Urban Indian Organization and another health care

17 provider to Indians who are eligible for medical assistance

18 under the State plan or under waiver authority. This sub-

19 section shall not be construed to impair the entitlement

20 of a State to reimbursement for such medical assistance 21 under this title.".
(4) Cross-References to special Fund FOR IMPROVEMENT OF IHS FACILITIES; DIRECT BILLING OPTION; DEFINITIONS.- Such section is further 
1981

1 amended by striking subsection (d) and adding at

2 the end the following new subsections:

3 “(c) Special Fund for Improvement of IHS Fa-

4 CILITIES.-For provisions relating to the authority of the

5 Secretary to place payments to which a facility of the In-

6 dian Health Service is eligible for payment under this title

7 into a special fund established under section 401(c)(1) of

8 the Indian Health Care Improvement Act, see subpara-

9 graphs (A) and (B) of section 401(c)(1) of such Act.

10 “(d) Direct Billing.-For provisions relating to

11 the authority of an Tribal Health Program to elect to di-

12 rectly bill for, and receive payment for, health care items

13 and services provided by such Program for which payment

14 is made under this title, see section 401(d) of the Indian

15 Health Care Improvement Act.”.

16 (5) Definitions.-Section 1101(a) of such Act

17 (42 U.S.C. 1301(a)) is amended by adding at the 18 end the following new paragraph:

19 "(11) For purposes of this title and titles 20 XVIII, XIX, and XXI, the terms 'Indian Health 21 Program', 'Indian Tribe' (and 'Indian tribe'), 'Tribal 22 Health Program', 'Tribal Organization' (and 'tribal 23 organization'), and 'urban Indian organization' (and 24 'urban Indian organization') have the meanings 
1982

1 given those terms in section 4 of the Indian Health

2 Care Improvement Act.".

3 (b) Medicare.-

4

(1) Expansion to ALl COVERED services.-

5 Section 1880 of such Act (42 U.S.C. 1395qq) is 6 amended-

(A) by amending the heading to read as follows:

9 “SEC. 1880. INDIAN HEALTH PROGRAMS.”;

10 and

11

(B) by amending subsection (a) to read as follows:

13 “(a) Eligibilitity FOR Payments.-Subject to sub14 section (e), an Indian Health Program shall be eligible for 15 payments under this title with respect to items and serv16 ices furnished by the Program if the furnishing of such 17 services meets all the conditions and requirements which 18 are applicable generally to the furnishing of items and 19 services under this title.".

(2) Repeal of obsolete PROvision.-Sub21 section (b) of such section is repealed.

(3) Cross-References to speclal Fund FOR 23 IMPROVEMENT OF IHS FACILITIES; DIRECT BILLING 24 OPTION; DEFINITIONS.- 
1983

(A) In GENERAL.- Such section is further amended by striking subsections (c) and (d) and inserting the following new subsections:

5 CILITIEs.-For provisions relating to the authority of the 6 Secretary to place payments to which a facility of the In-

7 dian Health Service is eligible for payment under this title 8 into a special fund established under section 401(c)(1) of 9 the Indian Health Care Improvement Act, and the require10 ment to use amounts paid from such fund for making im11 provements in accordance with subsection (b), see sub12 paragraphs (A) and (B) of section 401(c)(1) of such Act. 13 "(c) Direct Billing.-For provisions relating to 14 the authority of a Tribal Health Program to elect to di15 rectly bill for, and receive payment for, health care items 16 and services provided by such Program for which payment 17 is made under this title, see section 401(d) of the Indian 18 Health Care Improvement Act.”.

(B) Conforming Amendments.- Such section is further amended-

(i) in subsection (e)(3), by striking "Subsection (c)" and inserting "Subsection (b) and section 401(b)(1) of the Indian Health Care Improvement Act"; 
1984

1

2

6 lowing new subsection:

7

8 dian Health Program', 'Indian Tribe', 'Service Unit',

9 'Tribal Health Program', 'Tribal Organization', and

10 'Urban Indian Organization' have the meanings given

11 those terms in section 4 of the Indian Health Care Im12 provement Act.".

13 (c) Application to SCHIP.-Section 2107(e)(1) of 14 the Social Security Act (42 U.S.C. $1397 \mathrm{gg}(\mathrm{e})(1)$ ) is 15 amended-

16

(1) by redesignating subparagraphs (K)

17 through (M) as subparagraphs (L) through (N), re18 spectively; and

(2) by inserting after subparagraph ( $\mathrm{J})$, the fol-

20 lowing new subparagraph:

"(K) Section 1911 (relating to Indian Health Programs, other than subsection (c) of such section).". 
1985

1 SEC. 3202. ADDITIONAL PROVISIONS TO INCREASE OUTREACH TO, AND ENROLLMENT OF, INDIANS IN SCHIP AND MEDICAID.

(a) Assurance of Payments to Indian Health

5 Care Providers for Child Health Assistance.6 Section 2102(b)(3)(D) of the Social Security Act (42 7 U.S.C. $1397 \mathrm{bb}(\mathrm{b})(3)(\mathrm{D}))$ is amended by striking "(as de8 fined in section $4(\mathrm{c})$ of the Indian Health Care Improve9 ment Act, 25 U.S.C. 1603(c))" and inserting ", including 10 how the State will ensure that payments are made to In11 dian Health Programs and urban Indian organizations op12 erating in the State for the provision of such assistance".

13 (b) Inclusion of Other Indian Financed

14 Health Care Programs in Exemption From Prohi15 bition on Certain Payments.-Section 2105(c)(6)(B) 16 of such Act (42 U.S.C. 1397ee(c)(6)(B)) is amended by 17 striking "insurance program, other than an insurance pro18 gram operated or financed by the Indian Health Service" 19 and inserting "program, other than a health care program 20 operated or financed by the Indian Health Service or by 21 an Indian Tribe, Tribal Organization, or urban Indian or22 ganization".

23 (c) Definitions.-Section 2110(c) of such Act (42 24 U.S.C. 1397.j.(c)) is amended by adding at the end the 25 following new paragraph: 
1986

“(9) Indian; indan heALth PROGRAM; INDIAN TRIBE; ETC.-The terms 'Indian', 'Indian Health Program', 'Indian Tribe', 'Tribal Organiza4 tion', and 'Urban Indian Organization' have the 5 meanings given those terms in section 4 of the In6 dian Health Care Improvement Act.".

7 SEC. 3203. SOLICITATION OF PROPOSALS FOR SAFE HARBORS UNDER THE SOCIAL SECURITY ACT FOR FACILITIES OF INDIAN HEALTH PROGRAMS AND URBAN INDIAN ORGANIZATIONS.

11 The Secretary of Health and Human Services, acting 12 through the Office of the Inspector General of the Depart13 ment of Health and Human Services, shall publish a no14 tice, described in section $1128 \mathrm{D}(\mathrm{a})(1)(\mathrm{A})$ of the Social Se15 curity Act (42 U.S.C. 1320a-7d(a)(1)(A)), soliciting a 16 proposal, not later than July 1, 2010, on the development 17 of safe harbors described in such section relating to health 18 care items and services provided by facilities of Indian 19 Health Programs or an urban Indian organization (as 20 such terms are defined in section 4 of the Indian Health 21 Care Improvement Act). Such a safe harbor may relate 22 to areas such as transportation, housing, or cost-sharing, 23 assistance provided through such facilities or contract 24 health services for Indians. 
1987

1 SEC. 3204. ANNUAL REPORT ON INDIANS SERVED BY SO-

4 Section 1139 of the Social Security Act (42 U.S.C.

5 1320b-9), as amended by the sections 3203 and 3204,

6 is amended by redesignating subsection (e) as subsection

7 (f), and inserting after subsection (d) the following new

8 subsection:

9 “(e) ANNuAl Report ON INDIANs SERVED BY

10 Health Benefit Programs Funded Under This

11 ACT.-Beginning January 1, 2011, and annually there-

12 after, the Secretary, acting through the Administrator of

13 the Centers for Medicare \& Medicaid Services and the Di-

14 rector of the Indian Health Service, shall submit a report

15 to Congress regarding the enrollment and health status

16 of Indians receiving items or services under health benefit

17 programs funded under this Act during the preceding

18 year. Each such report shall include the following:

"(1) The total number of Indians enrolled in, or

20 receiving items or services under, such programs,

21 disaggregated with respect to each such program.

22 “(2) The number of Indians described in para-

23 graph (1) that also received health benefits under

24 programs funded by the Indian Health Service.

25 "(3) General information regarding the health

26 status of the Indians described in paragraph (1), 
1988

1 disaggregated with respect to specific diseases or 2 conditions and presented in a manner that is con3 sistent with protections for privacy of individually 4 identifiable health information under section 264(c) 5 of the Health Insurance Portability and Account$6 \quad$ ability Act of 1996.

7 "(4) A detailed statement of the status of facili8 ties of the Indian Health Service or an Indian Tribe, 9 Tribal Organization, or an Urban Indian Organiza10 tion with respect to such facilities' compliance with 11 the applicable conditions and requirements of titles 12 XVIII, XIX, and XXI, and, in the case of title XIX 13 or XXI, under a State plan under such title or 14 under waiver authority, and of the progress being 15 made by such facilities (under plans submitted 16 under 1911(b) or otherwise) toward the achievement 17 and maintenance of such compliance.

18 "(5) Such other information as the Secretary 19 determines is appropriate.". 
1989

1 SEC. 3205. DEVELOPMENT OF RECOMMENDATIONS TO IMPROVE INTERSTATE COORDINATION OF MEDICAID AND SCHIP COVERAGE OF INDIAN CHILDREN AND OTHER CHILDREN WHO ARE OUTSIDE OF THEIR STATE OF RESIDENCY BECAUSE OF EDUCATIONAL OR OTHER NEEDS.

(a) STUDY.-The Secretary shall conduct a study to

8 identify barriers to interstate coordination of enrollment 9 and coverage under the Medicaid program under title XIX 10 of the Social Security Act and the State Children's Health

11 Insurance Program under title XXI of such Act of chil-

12 dren who are eligible for medical assistance or child health

13 assistance under such programs and who, because of edu-

14 cational needs, migration of families, emergency evacu-

15 ations, or otherwise, frequently change their State of resi-

16 dency or otherwise are temporarily present outside of the

17 State of their residency. Such study shall include an exam-

18 ination of the enrollment and coverage coordination issues

19 faced by Indian children who are eligible for medical as-

20 sistance or child health assistance under such programs

21 in their State of residence and who temporarily reside in

22 an out-of-State boarding school or peripheral dormitory

23 funded by the Bureau of Indian Affairs.

24 (b) REPORT.-Not later than 18 months after the 25 date of enactment of this Act, the Secretary, in consulta26 tion with directors of State Medicaid programs under title 
1 XIX of the Social Security Act and directors of State Chil2 dren's Health Insurance Programs under title XXI of such 3 Act, shall submit a report to Congress that contains rec4 ommendations for such legislative and administrative ac5 tions as the Secretary determines appropriate to address 6 the enrollment and coverage coordination barriers identi7 fied through the study required under subsection (a). 